\title{
Road Safety Annual Report 2017
}

\section{Janstrup, Kira Hyldekær}

Link to article, DOI:

$10.1787 / 23124571$

Publication date:

2017

\section{Document Version}

Publisher's PDF, also known as Version of record

Link back to DTU Orbit

Citation (APA):

Janstrup, K. H. (2017). Road Safety Annual Report 2017. https://doi.org/10.1787/23124571

\section{General rights}

Copyright and moral rights for the publications made accessible in the public portal are retained by the authors and/or other copyright owners and it is a condition of accessing publications that users recognise and abide by the legal requirements associated with these rights.

- Users may download and print one copy of any publication from the public portal for the purpose of private study or research.

- You may not further distribute the material or use it for any profit-making activity or commercial gain

- You may freely distribute the URL identifying the publication in the public portal

If you believe that this document breaches copyright please contact us providing details, and we will remove access to the work immediately and investigate your claim. 


\section{Road Safety Annual Report 2017}

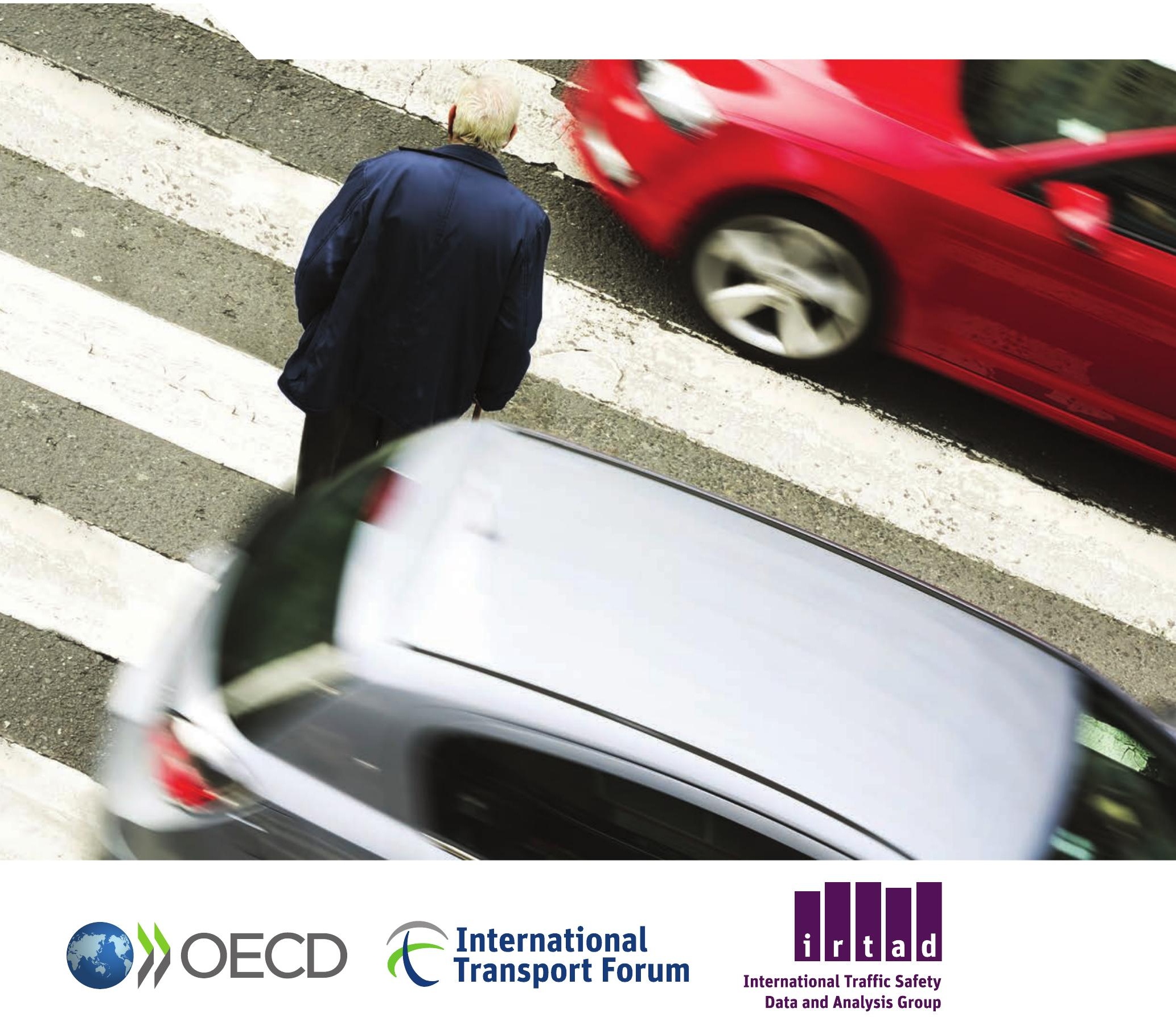





\section{Road Safety Annual Report 2017}


This work is published under the responsibility of the Secretary-General of the OECD. The opinions expressed and arguments employed herein do not necessarily reflect the official views of OECD member countries.

This document, as well as any data and map included herein, are without prejudice to the status of or sovereignty over any territory, to the delimitation of international frontiers and boundaries and to the name of any territory, city or area.

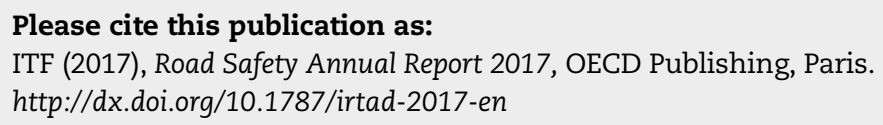

Periodical : Road Safety Annual Report

ISSN 2312-4563 (print)

ISSN 2312-4571 (online)

The statistical data for Israel are supplied by and under the responsibility of the relevant Israeli authorities. The use of such data by the OECD is without prejudice to the status of the Golan Heights, East Jerusalem and Israeli settlements in the West Bank under the terms of international law.

Photo credits: ๑ Gena Menlendrez/Shutterstock.

Corrigenda to OECD publications may be found on line at: www.oecd.org/publishing/corrigenda.htm.

(c) OECD 2017

You can copy, download or print OECD content for your own use, and you can include excerpts from OECD publications, databases and multimedia products in your own documents, presentations, blogs, websites and teaching materials, provided that suitable acknowledgement of OECD as source and copyright owner is given. All requests for public or commercial use and translation rights should be submitted to rights@oecd.org. Requests for permission to photocopy portions of this material for public or commercial use shall be addressed directly to the Copyright Clearance Center (CCC) at info@copyright.com or the Centre français d'exploitation du droit de copie (CFC) at contact@cfcopies.com. 


\section{Foreword}

$I_{t}$

t is with great pleasure that I present the 2017 edition of the Annual Report of the International Traffic Safety Data and Analysis Group (IRTAD) which contains the most recent road safety data and up-to-date information on road safety measures and strategies for 40 countries. This year's report contains information from an additional country - Uruguay - raising to four the number of Latin American countries covered by this report. The expansion of the IRTAD Group is a positive step and the intention is to continue this growth, without compromising the quality of the data. This report therefore makes a distinction between "validated" data (available for 2015 data for 31 countries) and data and information that is "under review".

Latin America is an increasingly important focus of IRTAD's work. In 2016/17, IRTAD has continued to strengthen co-operation in the region. A major report on benchmarking road safety performance in Latin America covering ten countries will be published shortly. It has been developed in co-operation with the Ibero-American Road Safety Observatory (OISEVI) and with support from the Fédération Internationale de l'Automobile (FIA) and represents a major effort in collecting and analysing road safety data in these countries with a view to highlighting paths for better road safety management.

The success of the OISEVI initiative has inspired further efforts to foster the systematic collection of data based on common definitions. In May 2017, the International Transport Forum (as the home of IRTAD), FIA and the World Bank signed an agreement to jointly work towards the creation of further regional road safety observatories around the world. In the same spirit, IRTAD is involved in the SaferAfrica project, funded by the European Commission, which aims to create a communication platform between Europe and Africa on road safety. Through both initiatives, IRTAD expects to establish co-operation in other regions and continue to assist countries in improving their national crash data systems.

The IRTAD Group has a full and ambitious programme of work. It published a report on AlcoholRelated Road Casualties in Official Crash Statistics in 2017, with another report on The Relationship Between Speed and Crash Risks under preparation. Three new sub-groups with promising deliverables were launched, to work on exposure data, safety performance indicators and a review of the IRTAD database. All these initiatives will also provide important inputs for the International Transport Forum's Annual Summit in May 2018, which will focus on topics right at the heart of IRTAD's work, under the theme "Transport Safety and Security".

Fred Wegman

Chairman of IRTAD 



\section{Table of contents}

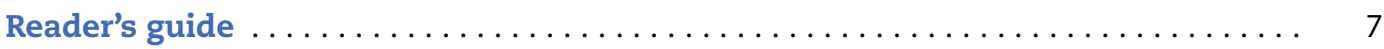

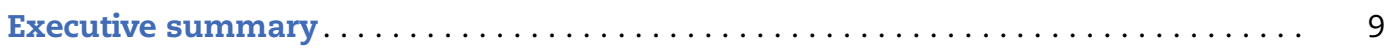

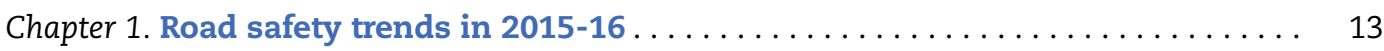

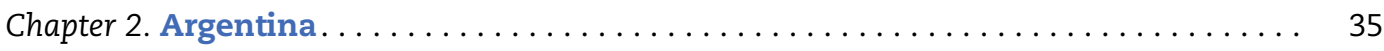

Chapter 3. Australia..................................... 47

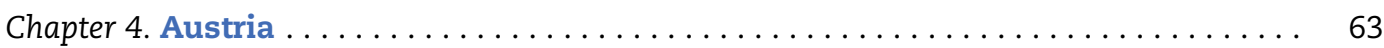

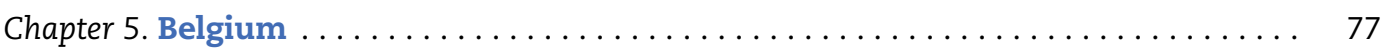

Chapter 6. Cambodia................................... 95

Chapter 7. Canada ....................................... 105

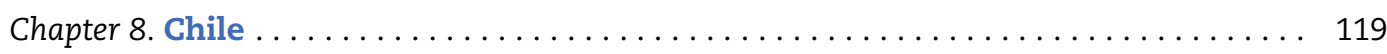

Chapter 9. Czech Republic ................................. 131

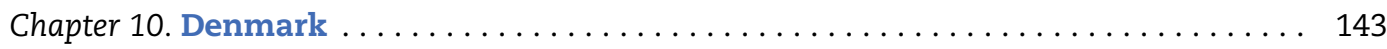

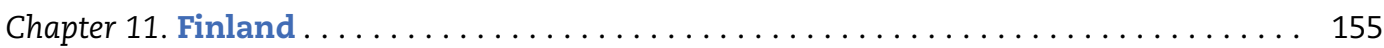

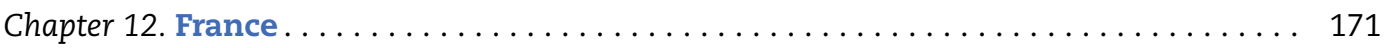

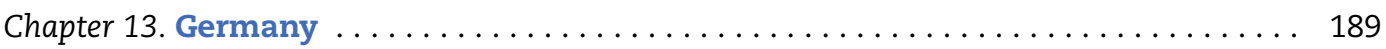

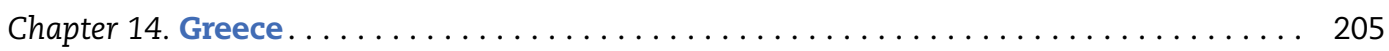

Chapter 15. Hungary .................................... 219

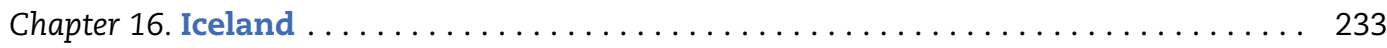

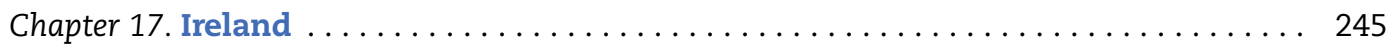

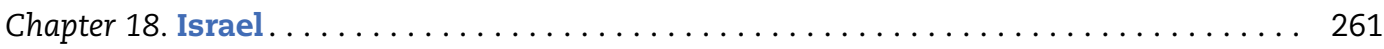

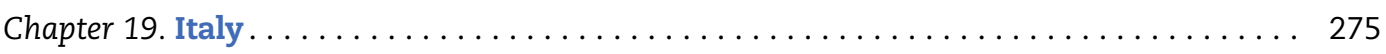

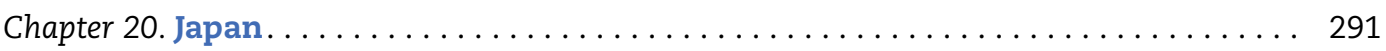

Chapter 21. Korea. .................................. 301

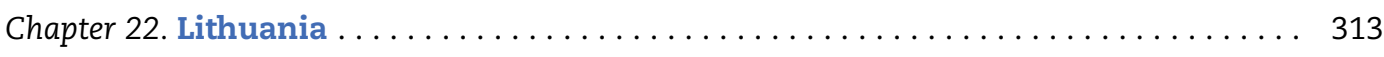

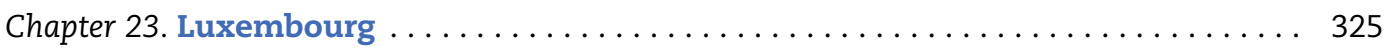

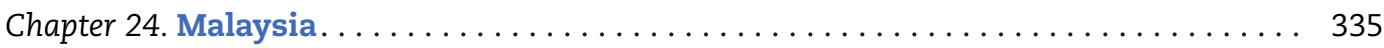

Chapter 25. Mexico ......................................... 345 


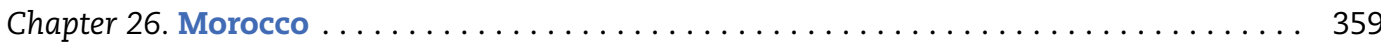

Chapter 27. The Netherlands. . . . . . . . . . . . . . . . . . . . . . . . . . . . . 369

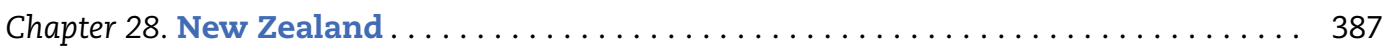

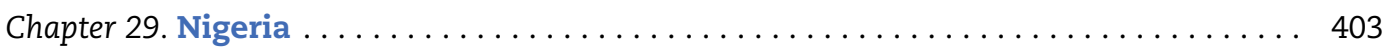

Chapter 30. Norway............................. 411

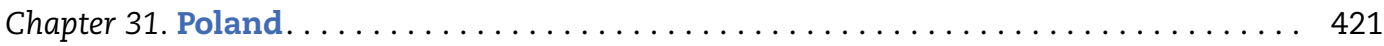

Chapter 32. Portugal ................................. 435

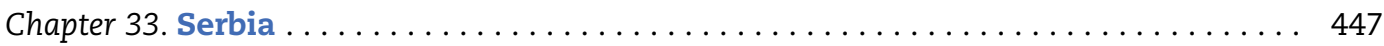

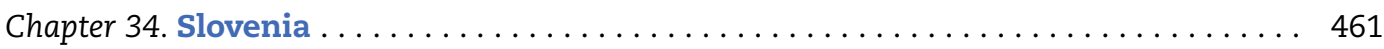

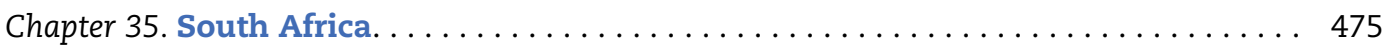

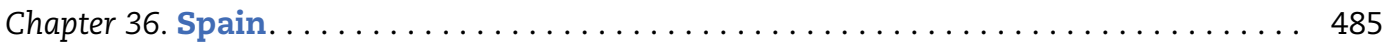

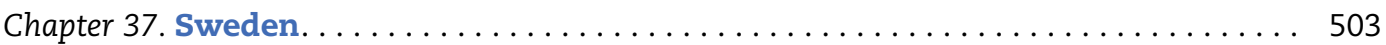

Chapter 38. Switzerland . . . . . . . . . . . . . . . . . . . . . . . . . 519

Chapter 39. United Kingdom . . . . . . . . . . . . . . . . . . . . . . 533

Chapter 40. United States. . . . . . . . . . . . . . . . . . . . . . . . . . . . . 549

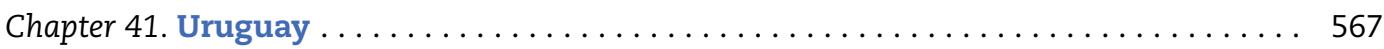

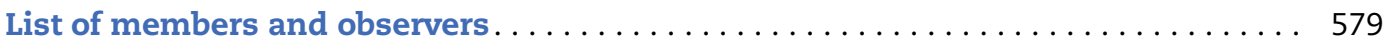

\section{Follow OECD Publications on:}

Y http://twitter.com/OECD_Pubs

f $h$ ttp://www.facebook.com/OECDPublications

in. http://www.linkedin.com/groups/OECD-Publications-4645871

You http://www.youtube.com/oecdilibrary

OECD http://www.oecd.org/oecddirect/

\section{This book has...}

StatLinks 枋L

A service that delivers Excelø files from the printed page!

Look for the StatLinks 形里 at the bottom of the tables or graphs in this book. To download the matching Excel ${ }^{\circledR}$ spreadsheet, just type the link into your Internet browser, starting with the http://dx.doi.org prefix, or click on the link from the e-book edition. 


\section{Reader's guide}

$\mathrm{T}$ he 2017 Annual Report on Road Safety has been prepared by the International Traffic Safety Data and Analysis Group (IRTAD) and is based on data included in the IRTAD Database.

\section{The IRTAD Group and the IRTAD Database}

The International Traffic Safety Data and Analysis Group (IRTAD) is a permanent working group of the Transport Research Centre of the International Transport Forum. It is composed of road safety experts and statisticians from renowned safety research institutes, national road and transport administrations, international organisations, universities, automobile associations, the automobile industry, etc.

Currently, more than 80 organisations from 40 OECD and non-OECD countries are members of IRTAD (see list of members and observers at the end of the report).

IRTAD's main objectives are to contribute to international co-operation on safety data and its analysis. Its key outputs are the IRTAD database and its annual report on road safety performance. It also conducts regular research and analysis on topics related to safety data analysis (e.g. forecasting, relationship between speed and crash risks, road safety and economic developments).

The IRTAD Database includes aggregated data on injury accidents, road fatalities, injured and hospitalised road users, as well as relevant exposure data, in relation to factors such as population, motor vehicle fleet, road network length, vehicle-kilometres and seatbelt wearing rates covering every year since 1970.

The ambition of IRTAD is to include new countries and to build and maintain a highquality database on road safety information. IRTAD offers a mechanism for the integration of prospective member countries while assisting with improvement of road safety data collection systems, where needed. The IRTAD Group co-operates with a number of partners such as the World Bank's Global Road Safety Facility, the Interamerican Development Bank, the CAF Development Bank of Latin America, the FIA and the FIA Foundation for the Automobile and Society, to involve low and middle-income countries in the work of the Group.

The IRTAD Database currently includes "validated" data from 32 countries. Nine additional countries also provide data and the validation process by the IRTAD Group is on-going.

\section{Measuring risk and comparing countries}

To measure road safety performance and compare safety level across countries, three indicators are commonly used:

- the number of fatalities per head of population (mortality rate)

- the number of fatalities per distance travelled by motorised vehicles (vehicle-kilometres) (fatality risk)

- the number of fatalities per registered motorised vehicles. 
Each indicator has pros and cons and in all cases, country comparisons should be interpreted with greatest care, especially between countries with different level of motorisation.

\section{Fatalities per 100000 inhabitants}

The number of inhabitants is the denominator most often used, as the figure is readily available in most countries. This rate expresses the mortality rate, or an overall risk of being killed in traffic, for the average citizen. It can be compared with other causes of death, like heart disease, HIV/Aids, etc. It is useful to compare risk in countries with comparable levels of motorisation. It is, however, not very meaningful to compare safety levels between highmotorised countries and countries where the level of motorisation is low.

\section{Fatalities per billion vehicle-kilometres}

This indicator describes the safety quality of road traffic and theoretically is the best indicator to assess the level of risk of the road network. This indicator does not take into account non-motorised vehicles (such as bicycles), which can in some countries represent a large part of the vehicle fleet and of the fatality figures. Only a limited number of countries collect data on distance travelled.

\section{Fatalities per 10000 registered (motorised) vehicles}

This rate can be seen as an alternative to the previous indicator, although it differs in that the annual distance travelled is unknown. This indicator can therefore only be used to compare the safety performance between countries with similar traffic and car-use characteristics. It requires reliable statistics on the number of vehicles. In some countries, scrapped vehicles are not systematically removed from the registration database, thereby undermining accuracy. This indicator does not take into account non-motorised vehicles (such as bicycles), which can in some countries represent a large part of the vehicle fleet and of the fatality figures.

\section{Content of the report}

This report contains 41 chapters.

Chapter 1 presents a synthesis of main road safety trends in IRTAD countries in 2015 and 2016. It also lists the current national road safety strategies and legislation in place regarding drinking and driving, speed limits and the use of seat belt and helmet.

Chapters 2 to 41 present detailed country reports for the 40 IRTAD member and observer countries, focusing on data collection process, most recent safety data, road safety performance by user group, age group and road type and recent trends in road safety behaviour. It also describes national road safety strategies and targets and progress towards these targets. The 2017 edition pays special attention to road safety for an ageing population. 
Road Safety Annual Report 2017

(c) OECD 2017

\section{Executive summary}

\section{Background}

Road crashes kill about 1.3 million people worldwide every year and severely injure an estimated 50 million. Out of ten lives lost in traffic, nine are lost in low- and middle- income countries. But the number of road deaths is on the rise again even in some countries with impressive road safety improvements. The increasing share of vulnerable road users such as seniors, pedestrian, cyclists and motorcyclists that become victims of road traffic raises particular concerns.

Reliable data on traffic crashes is crucial for effective action on road safety. Without hard facts about the scale of the problem, the exposure to crash risks and the effectiveness of policies the problems cannot be addressed at the core. The International Traffic Safety Data and Analysis Group (IRTAD) of the International Transport Forum (ITF) brings together transport ministries, road safety agencies, research institutes, industry and non-governmental organisations to ensure co-operation around improving the collection and analysis of data, understanding trends and shaping better road safety policies. Common reporting standards allow benchmarking of performance across IRTAD membership. The 2017 Road Safety Annual Report provides the most recent road safety data for member countries, including provisional data for 2016 and an overview of road safety strategies in each country.

The visibility of the tragedy on the world's roads and the sense of urgency to achieve significant reductions in the number of road deaths globally has been much strengthened by inclusion of road safety targets in the UN Sustainable Development Goals (SDGs). SDG 3.2 aspires to reduce global road traffic deaths and injuries by $50 \%$ by the year 2020 , compared to their 2010 levels. SDG 11.2 calls to "provide access to safe, affordable, accessible and sustainable transport systems for all, improving road safety, notably by expanding public transport, with special attention to the needs of those in vulnerable situations, women, children, persons with disabilities and older persons" by 2030. Today, most countries have national road safety strategies in place, often with ambitious targets. Still, the aspiration set out in the SDGs requires countries to further intensify efforts, and strengthening the capacity to collect and analyse road safety data will have to be among these.

\section{Findings}

The positive trend over the last few years of reduced road fatalities did not continue in 2015 and 2016. The 31 IRTAD member countries for which data are consistently available registered a 3.3\% increase in road fatalities in 2015 compared to 2014. In 2015, the number of road deaths increased in 21 countries compared to 2014. In 2016, the number of fatalities increased in 14 countries. Ten countries registered more road deaths for two consecutive years, i.e. in both 2015 and 2016. 
Looking at the longer-term developments since 2010, the number of road deaths has decreased in all but three countries with validated data. Thirteen countries form a group of relatively well-performing countries with mortality rates per 100000 inhabitants of five or less. Three of these had in 2015 mortality rate of three or less. Yet data for some IRTAD accession and observer countries suggest much higher rates, with more than 20 deaths per 100000 inhabitants. These can be taken as an indicator for the situation in the many low and middle income countries not included in this report.

Road safety for an ageing population is a growing concern in nearly all countries. Older people are the world's fastest-growing age group, and the share of people aged 60 or above is expected to reach $21 \%$ of the world population by 2050 , up from $9 \%$ in 1994 . At the same time, senior citizens have become more mobile than in the past and therefore more exposed to traffic risk. This creates significant challenges for road safety. The share of old people killed in traffic is already larger than their share in the total population, and it is growing. Seniors have not benefited from improved road safety at the same pace as the general population in past years. While the number of road deaths declined by 6.5\% overall between 2010 and 2015 across IRTAD countries, that of senior citizens killed in crashes increased by $3.4 \%$. More than half of the road fatalities among seniors above 65 falls into the vulnerable road users category, i.e. concern older pedestrians, cyclists and motorcyclists.

\section{Policy insights}

\section{Analyse the reasons for the relatively poor road safety performance in 2015 and 2016, with a view to adapt road safety policies}

The most recent data suggest that the past trend of continued reduction in the number of road fatalities may have stalled in IRTAD countries. This development merits careful investigation and monitoring to establish whether what is being observed in 2015 and 2016 is the start of a negative trend for road safety, and to take appropriate policy decisions and implement corrective measures.

\section{Strengthen efforts to improve the road safety data available for low- and middle- income countries}

Reliable and timely road safety data are essential components of sound road safety policies. Most high-income countries have functioning crash data collection systems. Huge efforts are needed in most low- and middle-income countries to ensure a minimum set of data is collected to allow a robust diagnosis of the respective road safety situation.

\section{Collect more accurate data on serious injuries from road crashes}

Road safety data collection and analysis should not be limited to fatality data. Around 50 million people are seriously injured in the world every year, but reliable data on serious injuries are very scarce even in the best performing countries. To seriously address the human suffering and economic loss associated with the current levels of serious injury from road crashes, all countries need to improve their collection and analysis of serious injury data.

\section{Enforce drink-driving laws, speed limits and the wearing of seat belts and motorcycle helmets}

Drink driving, speeding and the non-wearing of seat belts in cars and helmets on motorcycles are leading contributors to crashes resulting in serious and fatal injuries. 
These represent common safety challenges in all countries and can be tackled through established international best practices even in very different contexts.

\section{Take action to ensure a safe mobility for an ageing population}

Ensuring a safe mobility for senior citizens should be a priority in all countries. An integrated mobility strategy for an ageing population is needed. Its development should involve a wide range of stakeholders. Policy actions are needed to provide safe and easy access to public transport and to ensure urban planning reflects the needs of the most vulnerable road users, for instance through enhanced intersection design and traffic calming in urban areas. Improvements in the active and passive safety of vehicles should also be pursued. 



\section{Chapter 1}

\section{Road safety trends in $2015-16$}

This chapter presents an overview of most recent road safety trends for 31 countries, based on the latest available data for 2015 and 2016. It covers general road safety performance across countries and specifically analyses road safety trends with regard to senior citizens. It also looks at current national road safety strategies and legislation on speed limits, drinking and driving, as well as the use of seat belts and helmets. 
$\mathrm{T}_{\mathrm{r}}$ he positive trend over the last few years of reduced road fatalities did not continue in 2015 and 2016. The 31 member countries of the International Road Traffic and Accident Database (IRTAD) for which data are consistently available ${ }^{1}$ registered a 3.3\% increase in road fatalities in 2015 compared to 2014, although fatalities were still down 6.5\% compared to 2010 (Table 1.1). The number of road deaths increased in 21 countries in 2015, of which 10 registered more road deaths for 2 consecutive years, in 2015 and 2016. Only ten IRTAD countries succeeded in reducing the number of road deaths in 2015.

Provisional fatality data for 2016, available for 30 countries, show an upward trend for a large number of countries. The number of fatalities increased in a further 14 countries, while only 16 countries managed to reduce or stabilise their road death toll. This development merits careful investigation and monitoring to establish whether the latest numbers represent an incidental, one-off blip or the start of a negative trend.

It is likely that the recent economic recovery experienced in several countries, leading to higher mobility levels, has generated more exposure and crashes. Similarly, the positive results achieved in the beginning of the current decade can be partly attributed to the economic downturn following the 2008 financial crisis, which altered traffic patterns in several ways.

Road mortality in terms of fatalities per $\mathbf{1 0 0} 000$ inhabitants differs substantially between regions. The IRTAD countries with the lowest road mortality rates are located in Europe. In 2015, three countries - Norway, Sweden and the United Kingdom - recorded less than 3 fatalities per 100000 inhabitants. In other regions, however, some countries have mortality rates above 10 (Figure 1.1).

Thirteen countries form a group of relatively well-performing countries with mortality rates per 100000 inhabitants of five or less (Figure 1.2). Data for some IRTAD accession and observer countries, ${ }^{2}$ for example South Africa and Cambodia, indicate much higher rates of above 20 deaths per 100000 inhabitants. They are included in this report, although they have not been reviewed and validated by IRTAD.

While the mortality rate per capita is useful for comparing the road safety level of countries with similar levels of development and motorisation, its usefulness as a universal tool to rank all countries is limited. Analysis in terms of fatalities by distance travelled is a useful indicator for assessing the risk of travelling on the road network. However, only 22 IRTAD countries regularly collect data on vehicle-kilometres travelled (VKT). Data on risks expressed in terms of deaths per billion vehicle kilometres are summarised for these countries in Figure 1.3. In 2015, six countries - Norway, Sweden, the United Kingdom, Denmark, Ireland and Switzerland - recorded less than four deaths per billion VKT.

In the absence of data on distance travelled, the fatality rate per registered motor vehicles may be used as an approximation of exposure to risk. Figure 1.4 illustrates risk exposure expressed as the number of deaths per 10000 registered motor vehicles. The bestperforming countries in 2015 were Iceland, Norway, Switzerland, Sweden and the United Kingdom, with fatality rates below 0.5 deaths per 10000 registered motor vehicles. 
Figure 1.1. Percentage change in the number of road deaths, 2014-15

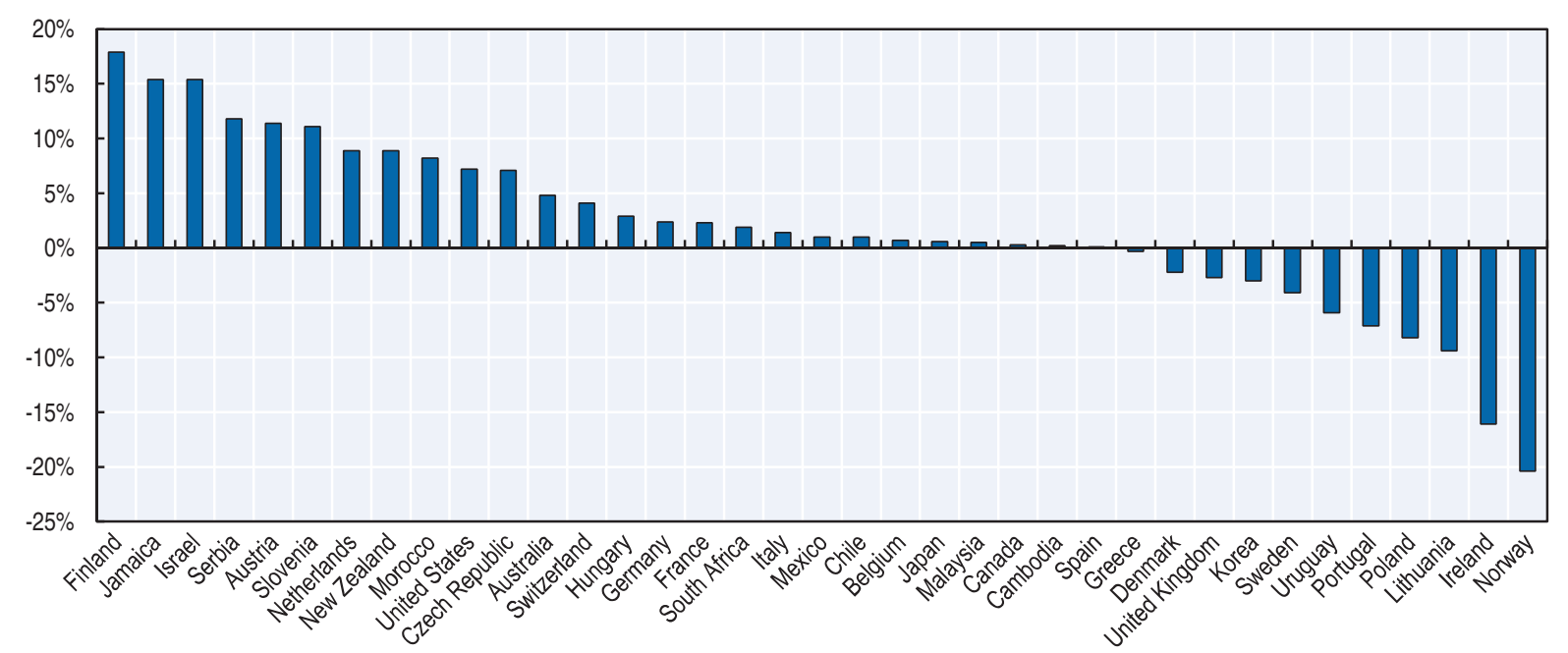

Note: Iceland and Luxembourg not included due to wide yearly fluctuations.

Figure 1.2. Road fatalities per 100000 inhabitants, 2015

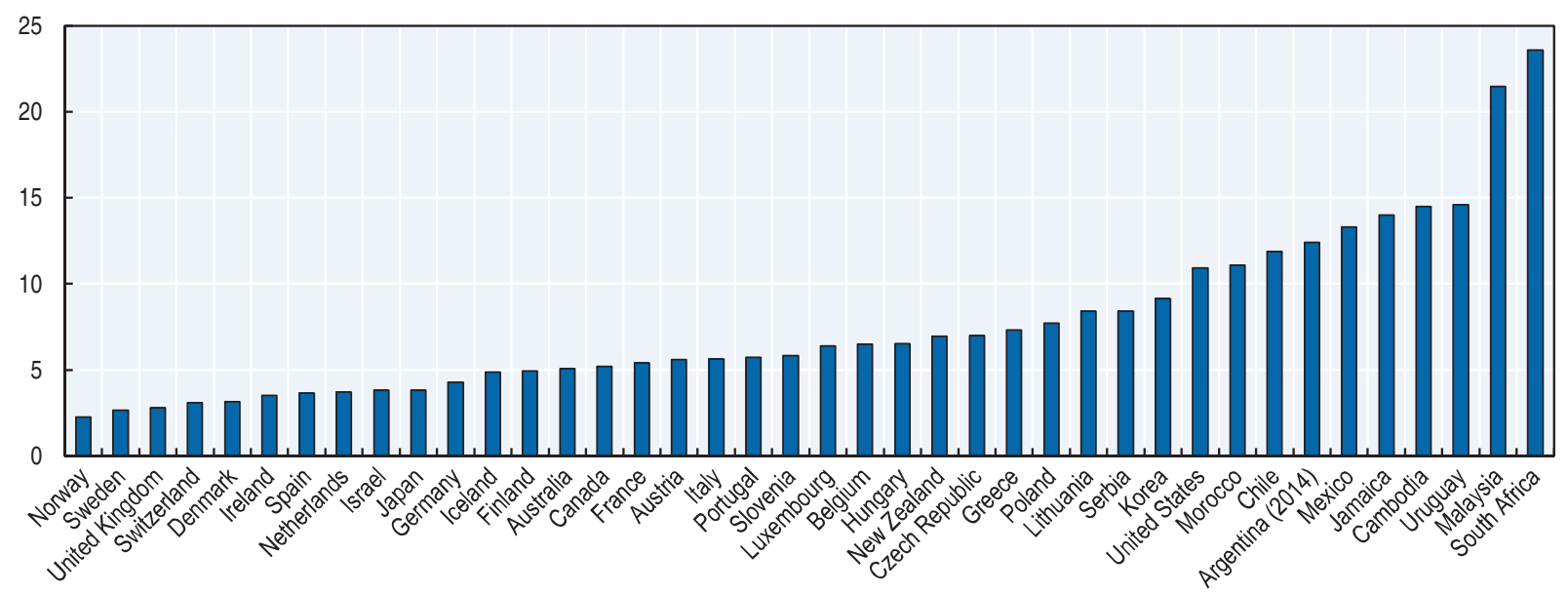

Data from Cambodia, Jamaica, Mexico, Malaysia, Morocco, Serbia, South Africa and Uruguay as provided by the countries and not validated by IRTAD.

StatLink तiाst $h t t p: / / d x . d o i . o r g / 10.1787 / 888933580080$

Looking at the longer-term developments since 2010, the number of road deaths has decreased in all countries with validated data except in the United States, Chile and Sweden. In the United States, fatalities increased by $6.3 \%$ between 2010 and 2015 and indications suggest that the situation has not improved in 2016. In Chile, the number of road fatalities increased by $4.9 \%$ between 2010 and 2016. Sweden saw four more fatalities (+1.5\%) in 2016 than in 2010. The strongest decreases were observed in Lithuania (-37\% between 2010 and 2016), Portugal (-37\% up to 2015), Greece (-36\% up to 2016), Norway (-35\% up to 2016), Switzerland (-34\% up to 2016) and Spain (-32\% up to 2015).

The rate of improvement in the past two years has been much smaller than in the previous period in many countries; most of the reductions in the number of road deaths between 2010 and 2016 were obtained in the beginning of the decade. Even in the historically 
Figure 1.3. Road fatalities per billion vehicle-kilometres, 2015

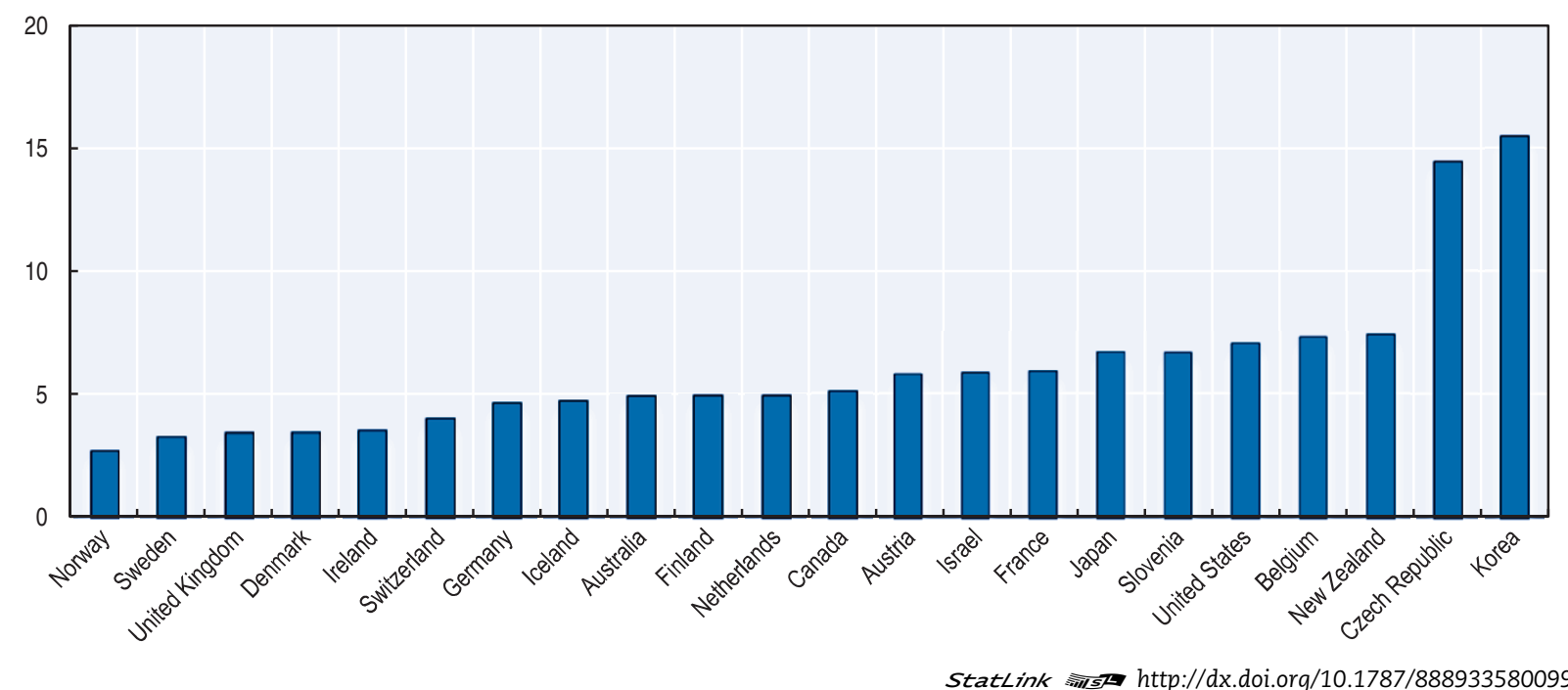

Figure 1.4. Road fatalities per 10000 registered vehicles, 2015

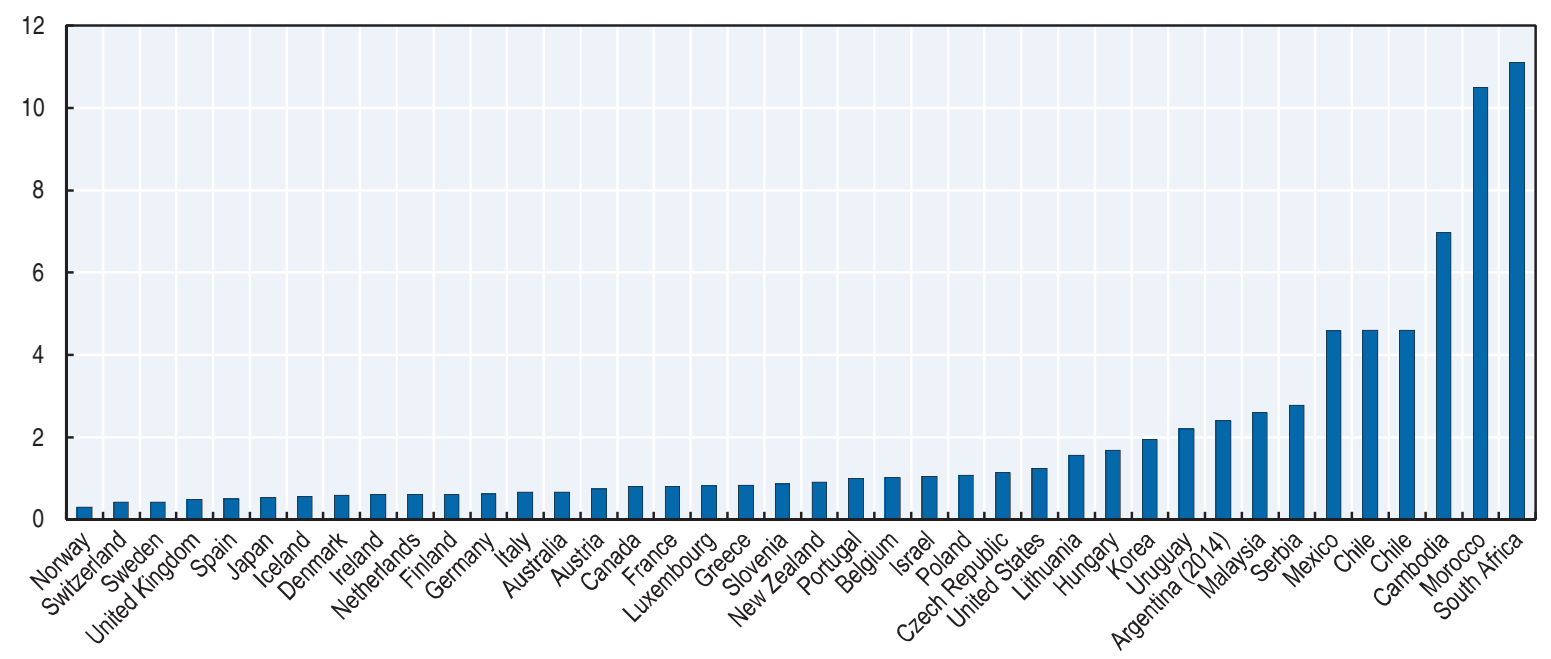

Note: Total registered motor vehicles do not include mopeds for Belgium, Denmark, Hungary and Portugal. Data from Cambodia, Jamaica, Mexico, Malaysia, Morocco, Serbia, South Africa and Uruguay as provided by the countries and not validated by IRTAD.

best-performing countries - such as the United Kingdom and the Netherlands - advances have been modest. In Sweden, traditionally a leader in road safety advances, the number of road deaths even increased. The slow-down of progress in countries that achieved notable successes during the previous decades and can boast some of the lowest fatality rates worldwide may also point to the limits of current safety measures and the need for further innovation in road safety policies. The report Zero Road Deaths and Serious Injuries: Leading a Paradigm Shift Towards a Safe System (ITF, 2016) contains a range of policy suggestions that extend beyond the approaches traditionally employed in most countries. Generally, strong and innovative policies need to be brought to bear worldwide in the remainder of the decade to reach the target of halving the number of road deaths by 2020, set in the United Nations Sustainable Development Goals. 
Table 1.1. Road fatality trends, 2010-15

\begin{tabular}{|c|c|c|c|c|c|c|c|c|c|}
\hline \multirow{2}{*}{ Country } & \multicolumn{6}{|c|}{ Road fatalities } & \multicolumn{2}{|c|}{$\begin{array}{c}2015 \% \\
\text { change from }\end{array}$} & \multirow{2}{*}{$\begin{array}{c}\text { Annual average } \\
\text { change }^{1}\end{array}$} \\
\hline & 2015 & 2014 & 2013 & 2012 & 2011 & 2010 & 2014 & 2010 & \\
\hline Argentina & & 5279 & 5209 & 5074 & 5040 & 5094 & & & \\
\hline Australia & 1205 & 1150 & 1187 & 1300 & 1277 & 1351 & 4.8 & -10.8 & -2.3 \\
\hline Austria & 479 & 430 & 455 & 531 & 523 & 552 & 11.4 & -13.2 & -2.8 \\
\hline Belgium & 732 & 727 & 724 & 770 & 861 & 840 & 0.7 & -12.9 & -2.7 \\
\hline Cambodia & 2231 & 2226 & 1950 & 1966 & 1905 & 1816 & 0.2 & 22.9 & 4.2 \\
\hline Canada & 1858 & 1852 & 1954 & 2079 & 2023 & 2238 & 0.3 & -17.0 & -3.7 \\
\hline Chile & 2140 & 2119 & 2110 & 1980 & 2045 & 2074 & 1.0 & 3.2 & 0.6 \\
\hline Czech Republic & 737 & 688 & 654 & 742 & 773 & 802 & 7.1 & -8.1 & -1.7 \\
\hline Denmark & 178 & 182 & 191 & 167 & 220 & 255 & -2.2 & -30.2 & -6.9 \\
\hline Finland & 270 & 229 & 258 & 255 & 292 & 272 & 17.9 & -0.7 & -0.1 \\
\hline France & 3461 & 3384 & 3268 & 3653 & 3963 & 3992 & 2.3 & -13.3 & -2.8 \\
\hline Germany & 3459 & 3377 & 3339 & 3600 & 4009 & 3648 & 2.4 & -5.2 & -1.1 \\
\hline Greece & 793 & 795 & 879 & 988 & 1141 & 1258 & -0.3 & -37.0 & -8.8 \\
\hline Hungary & 644 & 626 & 591 & 605 & 638 & 740 & 2.9 & -13.0 & -2.7 \\
\hline Iceland & 16 & 4 & 15 & 9 & 12 & 8 & 300.0 & 100.0 & 14.9 \\
\hline Ireland & 162 & 193 & 188 & 163 & 186 & 212 & -16.1 & -23.6 & -5.2 \\
\hline Israel & 322 & 279 & 277 & 263 & 341 & 352 & 15.4 & -8.5 & -1.8 \\
\hline Italy & 3428 & 3381 & 3401 & 3753 & 3860 & 4114 & 1.4 & -16.7 & -3.6 \\
\hline Jamaica & 382 & 331 & 307 & 260 & 308 & 319 & 15.4 & 19.7 & 3.7 \\
\hline Japan & 4867 & 4838 & 5165 & 5261 & 5535 & 5828 & 0.6 & -16.5 & -3.5 \\
\hline Korea & 4621 & 4762 & 5092 & 5392 & 5229 & 5505 & -3.0 & -16.1 & -3.4 \\
\hline Lithuania & 242 & 267 & 258 & 301 & 296 & 299 & -9.4 & -19.1 & -4.1 \\
\hline Luxembourg & 36 & 35 & 45 & 34 & 33 & 32 & 2.9 & 12.5 & 2.4 \\
\hline Malaysia & 6706 & 6674 & 6915 & 6917 & 6877 & 6872 & 0.5 & -2.4 & -0.5 \\
\hline Mexico & 16039 & 15886 & 15853 & 17102 & 16615 & 16559 & 1.0 & -3.1 & -0.6 \\
\hline Morocco & 3776 & 3489 & 3832 & 4167 & 4222 & 3778 & 8.2 & -0.1 & 0.0 \\
\hline Netherlands & 621 & 570 & 570 & 650 & 661 & 640 & 8.9 & -3.0 & -0.6 \\
\hline New Zealand & 319 & 293 & 253 & 308 & 284 & 375 & 8.9 & -14.9 & -3.2 \\
\hline Norway & 117 & 147 & 187 & 145 & 168 & 208 & -20.4 & -43.8 & -10.9 \\
\hline Poland & 2938 & 3202 & 3357 & 3571 & 4189 & 3908 & -8.2 & -24.8 & -5.5 \\
\hline Portugal & 593 & 638 & 637 & 718 & 891 & 937 & -7.1 & -36.7 & -8.7 \\
\hline Serbia & 599 & 536 & 650 & 688 & 731 & 660 & 11.8 & -9.2 & -1.9 \\
\hline Slovenia & 120 & 108 & 125 & 130 & 141 & 138 & 11.1 & -13.0 & -2.8 \\
\hline South Africa & 12944 & 12702 & 11844 & 13528 & 13954 & 13967 & 1.9 & -7.3 & -1.5 \\
\hline Spain & 1689 & 1688 & 1680 & 1903 & 2060 & 2478 & 0.1 & -31.8 & -7.4 \\
\hline Sweden & 259 & 270 & 260 & 285 & 319 & 266 & -4.1 & -2.6 & -0.5 \\
\hline Switzerland & 253 & 243 & 269 & 339 & 320 & 327 & 4.1 & -22.6 & -5.0 \\
\hline United Kingdom & 1804 & 1854 & 1770 & 1802 & 1960 & 1905 & -2.7 & -5.3 & -1.1 \\
\hline United States & 35092 & 32744 & 32893 & 33782 & 32479 & 32999 & 7.2 & 6.3 & 1.2 \\
\hline Uruguay & 506 & 538 & 567 & 510 & 572 & 556 & -5.9 & -9.0 & -1.9 \\
\hline
\end{tabular}

Data from Cambodia, Jamaica, Mexico, Morocco, Serbia, South Africa and Uruguay as provided by the countries and not validated by IRTAD.

Police-recorded fatalities (except the Netherlands for 2000 onwards: real data, see country report). Death within 30 days. 1. Geometric mean: (Fatalities EndYear $/$ Fatalities StartYear $^{1 / n}-1 ; n-$ Number of years $=5$.

StatLink Aाs http://dx.doi.org/10.1787/888933580213

Nearly all countries are facing the problem of ensuring road safety for an ageing population. Older people are the world's fastest-growing age group. The number of people aged 60 years or older has almost doubled between 1994 and 2014. The share of seniors aged $60+$ is expected to reach $21 \%$ of the world population by 2050 , up from $9 \%$ in 1994 . The number of seniors over 80 years could triple by 2050, to 392 million (UNESC 2014). At the same time, senior citizens have become more mobile than in the past and therefore more 
Table 1.2. Road fatality data for $\mathbf{2 0 1 6}$ compared to $\mathbf{2 0 1 5}$

\begin{tabular}{|c|c|c|c|c|}
\hline & 2016 road deaths & Data status & 2015 road deaths & $\%$ change (provisional) \\
\hline Argentina & 5550 & Provisional & & \\
\hline Australia & 1292 & Provisional & 1205 & 7.2 \\
\hline Austria & 432 & Final & 479 & -9.8 \\
\hline Belgium & 637 & Final & 732 & -13.0 \\
\hline Cambodia & 1852 & Final & 2231 & -17.0 \\
\hline Canada & & & 1858 & \\
\hline Chile & 2178 & Final & 2140 & 1.8 \\
\hline Czech Republic & 611 & Final & 737 & -17.1 \\
\hline Denmark & 211 & Provisional & 178 & 18.5 \\
\hline Finland & 240 & Provisional & 270 & -11.1 \\
\hline France & 3469 & Provisional & 3461 & 0.2 \\
\hline Germany & 3206 & Provisional & 3459 & -7.3 \\
\hline Greece & 807 & Provisional & 793 & 1.8 \\
\hline Hungary & 607 & Final & 644 & -5.7 \\
\hline Iceland & 18 & Final & 16 & 12.5 \\
\hline Ireland & 186 & Provisional & 162 & 14.8 \\
\hline Israel & 335 & Final & 322 & 4.0 \\
\hline Italy & 1466 & Provisional for Jan-Jun & 1539 & -4.7 \\
\hline Jamaica & 379 & Provisional & 382 & -0.8 \\
\hline Japan & 4682 & Provisional & 4867 & -3.8 \\
\hline Korea & 4292 & Provisional & 4621 & -7.1 \\
\hline Lithuania & 188 & Provisional & 242 & -22.3 \\
\hline Luxembourg & 32 & Final & 36 & -11.1 \\
\hline Malaysia & 7152 & Provisional & 6706 & 6.7 \\
\hline Mexico & & & 16039 & \\
\hline Morocco & 3593 & Provisional & 3776 & -4.8 \\
\hline Netherlands & 629 & Final & 621 & 1.3 \\
\hline New Zealand & 328 & Provisional & 319 & 2.8 \\
\hline Norway & 135 & Provisional & 117 & 15.4 \\
\hline Poland & 2946 & Provisional & 2938 & 0.3 \\
\hline Portugal & 461 & Provisional for Jan-0ct & 485 & -4.9 \\
\hline Serbia & 607 & Final & 599 & 1.3 \\
\hline Slovenia & 130 & Final & 120 & 8.3 \\
\hline South Africa & 14071 & Final & 12944 & 8.7 \\
\hline Spain & & Provisional for fatalities within 24 hours & & 3.8 \\
\hline Sweden & 270 & Final & 259 & 4.2 \\
\hline Switzerland & 216 & Final & 253 & -14.6 \\
\hline United Kingdom & 1810 & Estimate based on provisional data Jan-Sep & 1804 & 0.3 \\
\hline United States & 27875 & Estimate for Jan-Sep & 25808 & 8.0 \\
\hline Uruguay & 446 & Final & 506 & -11.9 \\
\hline
\end{tabular}

Data from Cambodia, Jamaica, Mexico, Serbia, South Africa and Uruguay as provided by the countries and not validated by IRTAD. Police-recorded fatalities (except for the Netherlands: real data).

exposed to traffic risk. More fragile and vulnerable citizens being involved in road crashes implies significant challenges for road safety.

In 2015, senior citizens aged 65 and above accounted for between $10 \%$ and $26 \%$ of the population in IRTAD countries. In all of them, the share of old people killed in traffic is larger than their share in the total population. In Japan, for instance, the elderly represent $26 \%$ of the population but more than half of all traffic fatal casualties. Also, in the majority of countries, the road mortality rate increases with age - people above 85 are more at risk than those between 65 and 74 . 
Table 1.3. Road fatalities per 100000 inhabitants, per billion vehicle-km and per 10000 registered motor vehicles

\begin{tabular}{|c|c|c|c|c|c|c|c|c|c|c|c|c|}
\hline \multirow{2}{*}{ Country } & \multicolumn{4}{|c|}{$\begin{array}{c}\text { Road fatalities per } 100000 \\
\text { inhabitants }\end{array}$} & \multicolumn{4}{|c|}{ Road fatalities per billion VKT } & \multicolumn{4}{|c|}{$\begin{array}{l}\text { Road fatalities per } 10000 \\
\text { registered vehicles }\end{array}$} \\
\hline & 1990 & 2000 & 2010 & 2015 & 1990 & 2000 & 2010 & 2015 & 1990 & 2000 & 2010 & 2015 \\
\hline Argentina & - & - & 12.6 & $12.4^{a}$ & - & - & - & - & & 2.0 & 2.9 & $2.4^{a}$ \\
\hline Australia & 13.7 & 9.5 & 6.1 & 5.1 & 14.7 & 9.1 & 5.9 & 4.9 & 2.3 & 1.5 & 0.8 & 0.7 \\
\hline Austria & 20.4 & 12.2 & 6.6 & 5.6 & 32.0 & 15.0 & 7.3 & 5.8 & 3.7 & 1.8 & 0.9 & 0.7 \\
\hline Belgium & 19.9 & 14.4 & 7.7 & 6.5 & 28.1 & 16.3 & 8.5 & 7.3 & 4.3 & 2.6 & 1.3 & 1.0 \\
\hline Cambodia & - & - & 12.7 & 14.5 & - & - & - & - & & & 11.0 & 7.0 \\
\hline Canada & 14.3 & 9.5 & 6.6 & 5.2 & - & 9.4 & 6.7 & 5.1 & 2.3 & 1.6 & 1.0 & 0.8 \\
\hline Chile & 15.7 & 14.3 & 12.1 & 11.9 & - & - & - & - & 19.2 & 10.6 & 6.3 & 4.6 \\
\hline Czech Republic & 12.5 & 14.5 & 7.7 & 7.0 & 48.3 & 36.7 & 16.2 & 14.4 & 3.3 & 3.2 & 1.3 & 1.1 \\
\hline Denmark & 12.3 & 9.3 & 4.6 & 3.1 & 17.3 & 10.7 & 5.6 & 3.4 & 3.1 & 2.1 & 0.9 & 0.6 \\
\hline Finland & 13.0 & 7.7 & 5.1 & 4.9 & 16.3 & 8.5 & 5.1 & 4.9 & 2.8 & 1.5 & 0.7 & 0.6 \\
\hline France & 19.8 & 13.7 & 6.4 & 5.4 & 25.7 & 15.1 & 7.1 & 5.9 & 3.6 & 2.3 & 1.0 & 0.8 \\
\hline Germany & $14.2^{b}$ & 9.1 & 4.5 & 4.3 & $19.7^{b}$ & 11.3 & 5.2 & 4.6 & $2.5^{b}$ & 1.4 & 0.7 & 0.6 \\
\hline Greece & 20.3 & 18.7 & 11.2 & 7.3 & - & - & - & - & & 3.1 & 1.3 & 0.8 \\
\hline Hungary & 23.4 & 11.7 & 7.4 & 6.5 & - & - & - & - & 11.2 & 4.4 & 2.0 & 1.7 \\
\hline Iceland & 9.5 & 11.5 & 2.5 & 4.9 & 14.9 & 13.8 & 2.5 & 4.7 & 1.7 & 1.8 & 0.3 & 0.6 \\
\hline Ireland & 13.6 & 11.0 & 4.7 & 3.5 & 19.2 & 11.5 & 4.9 & 3.5 & 4.5 & 2.5 & 0.9 & 0.6 \\
\hline Israel & 8.7 & 7.1 & 4.6 & 3.8 & 22.4 & 12.4 & 7.1 & 5.9 & 4.1 & 2.4 & 1.4 & 1.0 \\
\hline Italy & 12.6 & 12.4 & 7.0 & 5.6 & - & - & - & - & 2.1 & 1.6 & 0.8 & 0.7 \\
\hline Jamaica & & 12.9 & 11.8 & 14.0 & & & & & & & 9.4 & 10.3 \\
\hline Japan & 11.8 & 8.2 & 4.6 & 3.8 & 23.2 & 13.4 & 8.0 & 6.7 & 1.9 & 1.2 & 0.6 & 0.5 \\
\hline Korea & 33.1 & 21.8 & 11.3 & 9.1 & - & 49.5 & 18.7 & 15.5 & 28.9 & 6.9 & 2.6 & 2.0 \\
\hline Lithuania & 29.3 & 18.3 & 9.5 & 8.4 & - & - & - & - & 12.7 & 5.0 & 1.4 & 1.6 \\
\hline Luxembourg & 18.7 & 17.5 & 6.4 & 6.4 & - & - & - & - & 3.3 & 2.4 & 0.8 & 0.8 \\
\hline Malaysia & - & 25.9 & 24.0 & 21.5 & - & - & - & - & & 5.7 & 3.4 & 2.6 \\
\hline Mexico & 17.2 & 13.9 & 14.5 & 13.3 & - & - & - & 30.4 & 14.2 & 9.0 & 5.2 & 4.6 \\
\hline Morocco & 11.5 & 12.7 & 11.8 & 11.1 & - & - & - & - & 29.0 & 21.7 & 13.5 & 10.5 \\
\hline Netherlands ${ }^{C}$ & - & 7.3 & 3.9 & 3.7 & - & 9.2 & 5.1 & 4.9 & & 1.4 & 0.7 & 0.6 \\
\hline New Zealand & 21.4 & 12.0 & 8.6 & 6.9 & - & 13.6 & 9.4 & 7.4 & 3.3 & 1.8 & 1.2 & 0.9 \\
\hline Norway & 7.8 & 7.6 & 4.3 & 2.3 & 12.0 & 10.5 & 4.9 & 2.6 & 1.4 & 1.2 & 0.6 & 0.3 \\
\hline Poland & 19.3 & 16.4 & 10.2 & 7.7 & - & - & - & - & 8.1 & 4.5 & 1.8 & 1.1 \\
\hline Portugal & 29.3 & 20.0 & 8.9 & 5.7 & - & - & - & - & 13.4 & 4.3 & 1.6 & 1.0 \\
\hline Serbia & - & 13.9 & 9.0 & 8.4 & - & - & - & - & & 3.6 & 3.6 & 2.8 \\
\hline Slovenia & 25.9 & 15.8 & 6.7 & 5.8 & 65.1 & 26.7 & 7.7 & 6.7 & 6.9 & 3.2 & 1.1 & 0.9 \\
\hline South Africa & 30.3 & 19.0 & 27.4 & 23.6 & - & - & - & - & 24.2 & 14.0 & 15.3 & 11.1 \\
\hline Spain & 23.3 & 14.4 & 5.3 & 3.6 & - & - & - & - & 5.1 & 2.2 & 0.7 & 0.5 \\
\hline Sweden & 9.1 & 6.7 & 2.8 & 2.7 & 12.0 & 8.5 & 3.5 & 3.2 & 1.7 & 1.2 & 0.5 & 0.4 \\
\hline Switzerland & 13.9 & 8.3 & 4.2 & 3.1 & 18.6 & 10.6 & 5.2 & 4.0 & 2.2 & 1.2 & 0.6 & 0.4 \\
\hline United Kingdom & 9.4 & 6.1 & 3.0 & 2.8 & 12.8 & 7.4 & 3.8 & 3.4 & 2.1 & 1.2 & 0.5 & 0.5 \\
\hline United States & 17.9 & 14.9 & 10.7 & 10.9 & 12.9 & 9.5 & 6.9 & 7.0 & 2.4 & 1.9 & 1.3 & 1.2 \\
\hline Uruguay & - & - & 16.6 & 14.6 & - & - & - & - & & & 3.4 & 2.2 \\
\hline
\end{tabular}

Death within 30 days. Police recorded data (except for the Netherlands for 2000 onwards, see country report).

Data from Cambodia, Jamaica, Mexico, Serbia, South Africa and Uruguay as provided by the countries and not validated by IRTAD.

$a=2014$.

$b=1991$.

$c=$ "real" data for the Netherlands for 2000 onwards.

$d$ = data for Belgium, Cambodia, Denmark, Hungary, Korea, Poland, Portugal, Slovenia and Uruguay do not include mopeds.

StatLink AाIs $h t t p: / / d x . d o i . o r g / 10.1787 / 888933580232$

Seniors have not benefited from improved road safety at the same pace as the general population in past years. While the number of all road deaths declined by $6.5 \%$ between 2010 and 2015 across IRTAD countries, that of senior citizens increased by $3.4 \%$. Eighteen of 
Figure 1.5. Percentage change in the number of road deaths, 2010-16

(or 2010-15 where 2016 provisional or final data are not available)

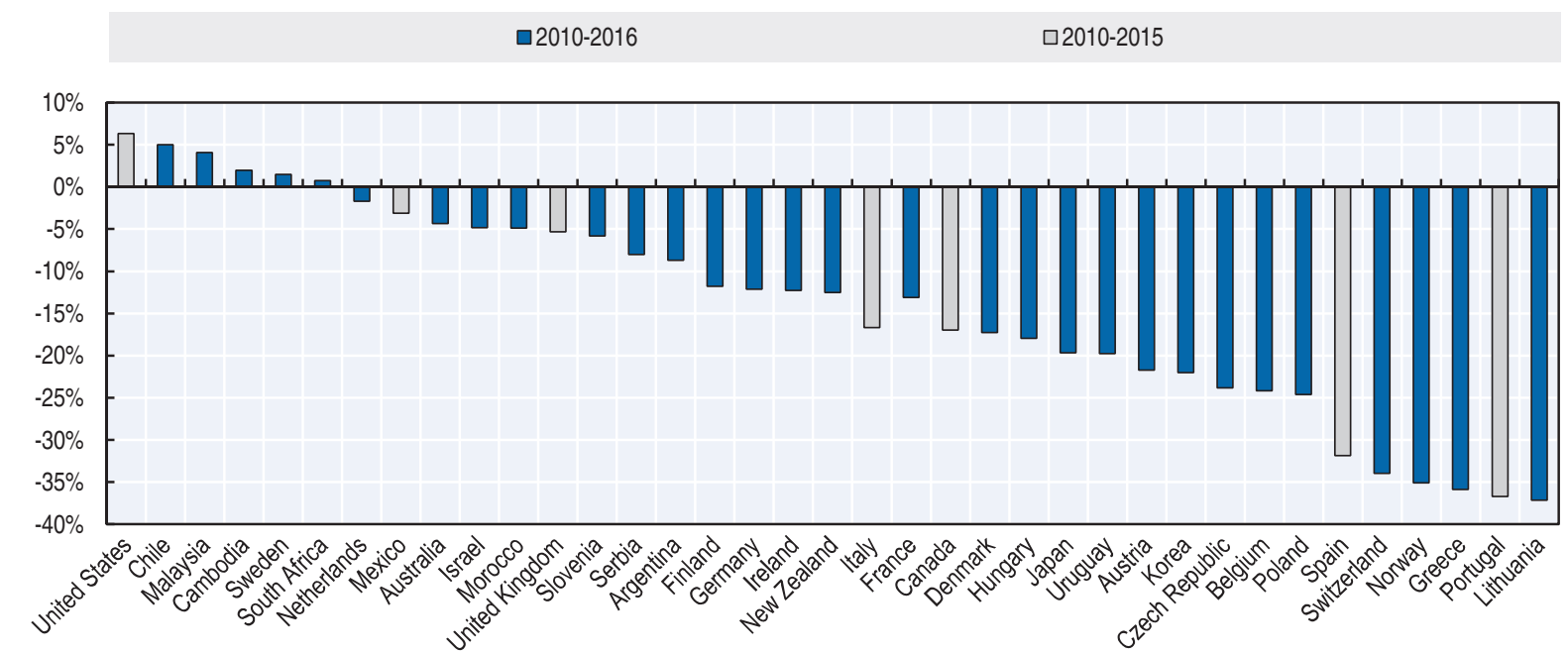

Note: Iceland and Luxembourg not included due to small numbers and wide yearly fluctuations. Data from Cambodia, Mexico, Malaysia Morocco, Serbia, South Africa and Uruguay as provided by the countries and not validated by IRTAD.

StatLink काज् $h$ ttp://dx.doi.org/10.1787/888933580137

Figure 1.6. Share of the over 65 age group in the population and in total road deaths

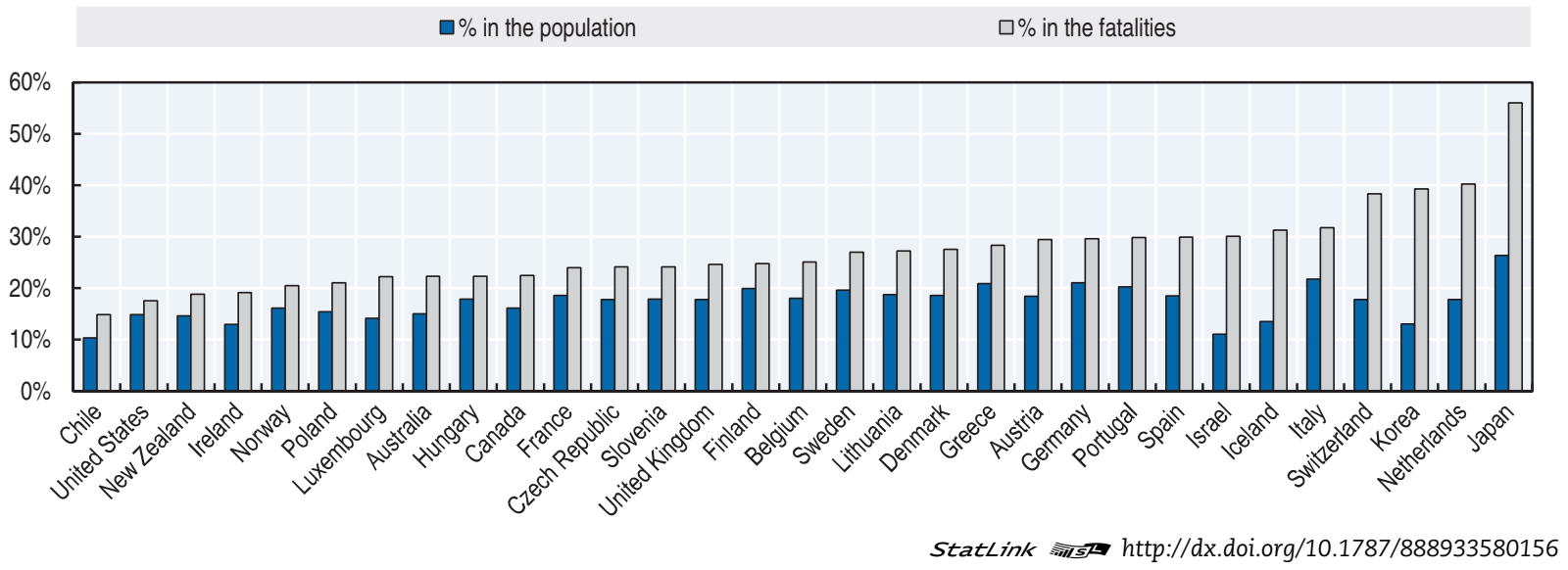

31 countries have seen a rise in the number of road deaths among the elderly, while the total number of road deaths increased in only three of these 31 countries.

In the majority of countries, more than half of road deaths among the senior population above 65 are in the vulnerable road users category (pedestrians, cyclists and motorcyclists). This share is much higher in urban areas and calls for dedicated actions to ensure a safer mobility in city environments; a task that is being tackled by the new Safer City Streets network of cities ${ }^{1}$ created by the International Transport Forum.

Countries generally recognise the growing challenge of providing safe mobility for an ageing population. Most measures to protect the elderly in traffic focus on compulsory medical exams for licence renewal, however. Yet there is no scientific evidence showing that scrutinising all older drivers from a certain age is a cost-beneficial measure, as age is a very unreliable predictor for fitness to drive (Hakamies-Blomqvist et al., 2002; Torpey, 1986; DaCoTa, 2012). While age itself does not pose a road safety problem, illnesses can be 
Figure 1.7. Change in the number of road deaths among population 65 years and over, 2010-15

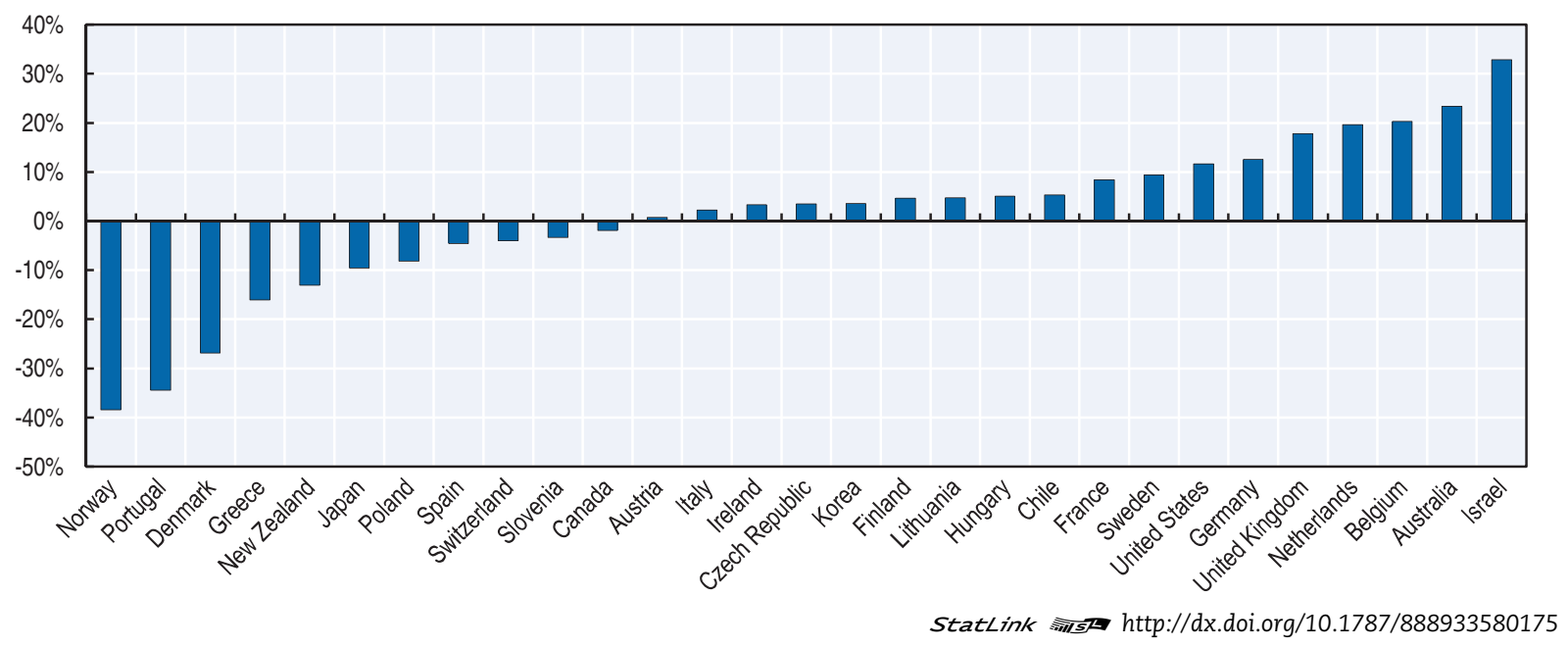

Figure 1.8. Older persons killed by user group, average 2013-15

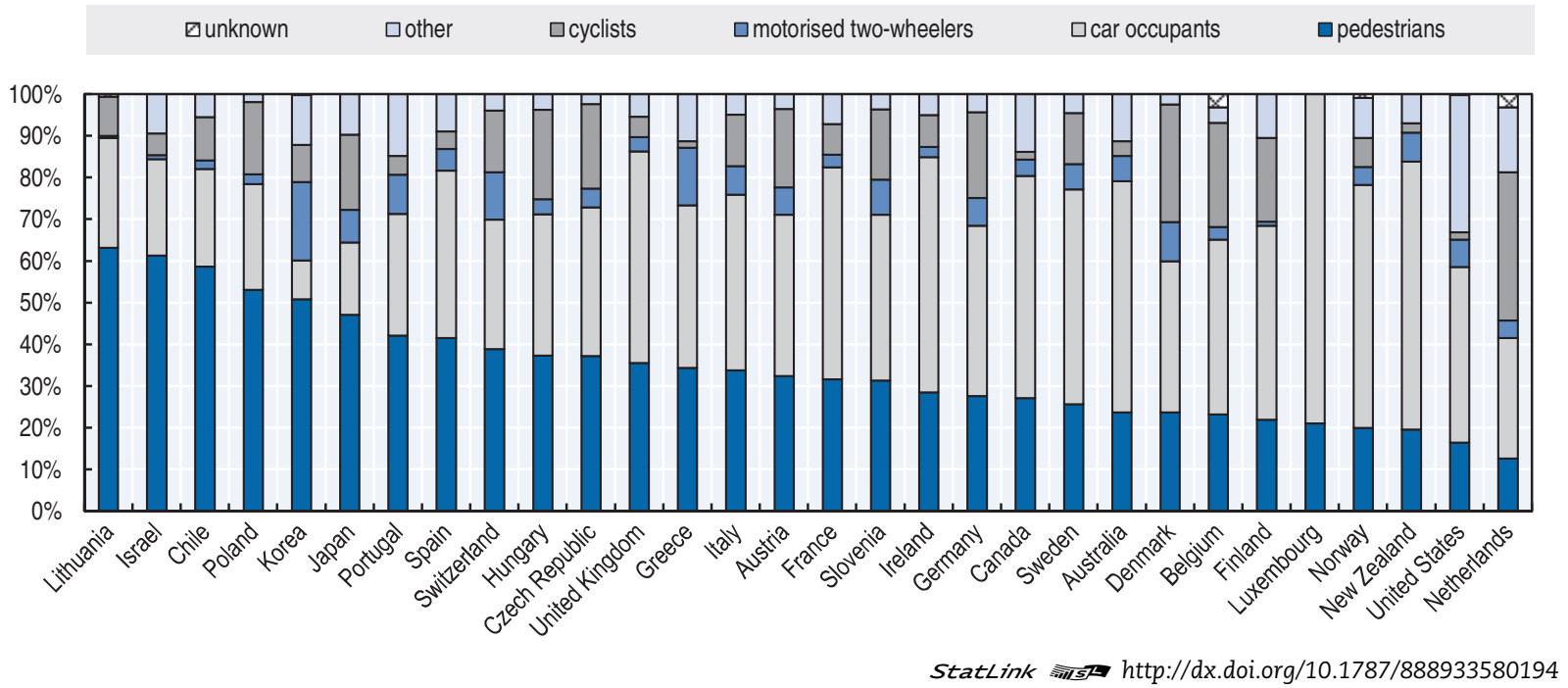

a cause of concern, as well as the fact that the senior population are more vulnerable and the consequences of injuries can be more severe than for younger road users. To ensure safer mobility for senior citizens, policy actions need to focus on awareness campaigns; improvement in active and passive safety of vehicles; safe urban design; enhanced intersection design; the promotion of $30 \mathrm{~km} / \mathrm{h}$ speed zones in areas with a high density of vulnerable road users; and safe and easy to access to public transport. 
Figure 1.9. Road fatalities among senior population per 100000 inhabitants, average 2013-15 average population, $65-74,75-84$ and 85 and above

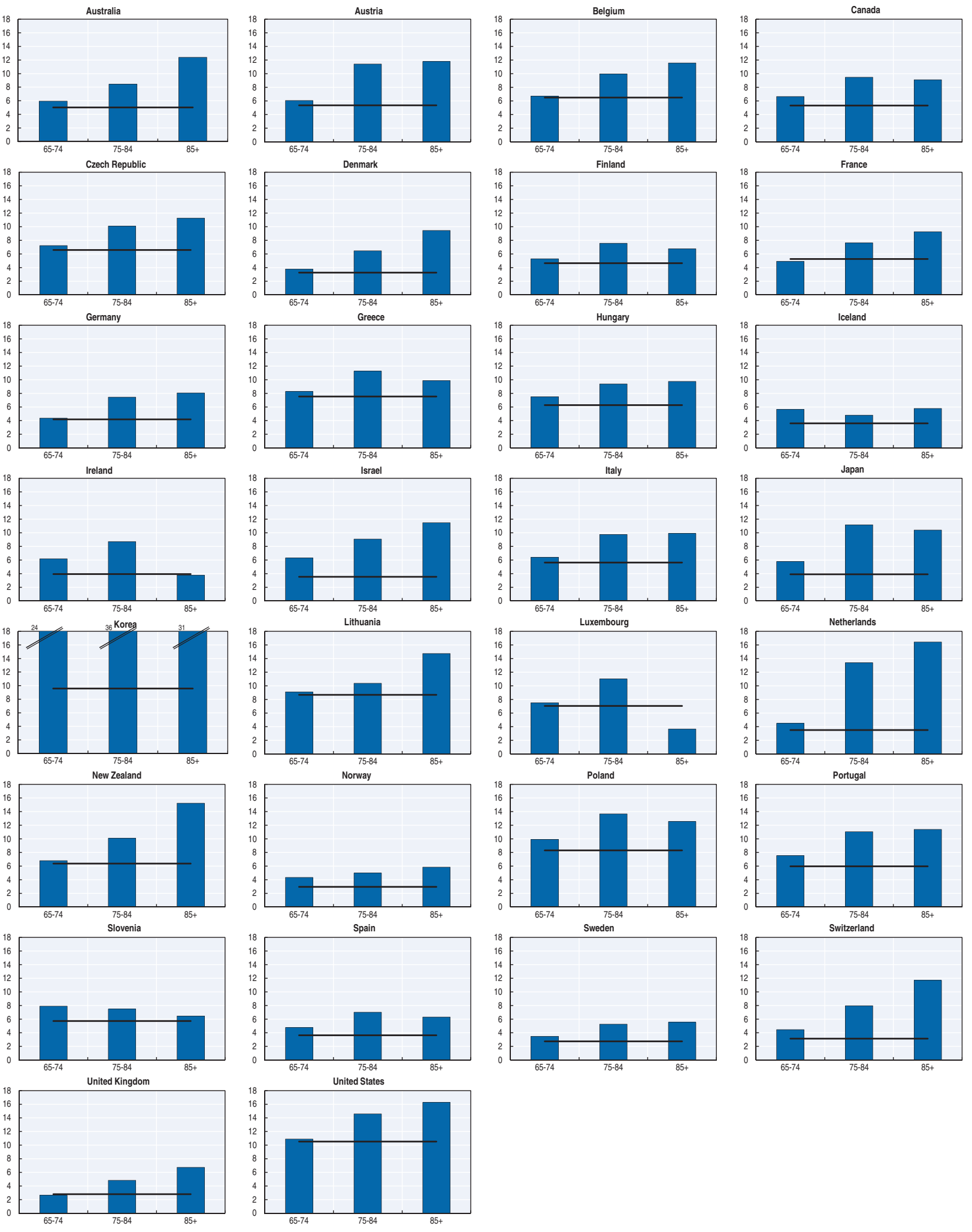


Table 1.4. Driving licence renewal rules

\begin{tabular}{|c|c|}
\hline Country & Driving licence renewal rules for non-professional car licences \\
\hline Argentina & Licence renewal after 70 . Theory and practical test and complete medical exam \\
\hline Australia & $\begin{array}{l}\text { Varies between jurisdictions. Some jurisdictions require medical tests yearly from } 75 \text { or } 80 \text { years of age; and some } \\
\text { also require driving tests every year or two years from } 85 \text { years old onward. }\end{array}$ \\
\hline Austria & No age-specific tests for drivers; only the general EU licence renewal rules apply. \\
\hline Belgium & $\begin{array}{l}\text { Since } 2013 \text {, the Belgian driver's licence is valid for ten years. Renewal of the licence is an administrative procedure } \\
\text { in which the candidates have to confirm that they are able to drive. No medical testing is required. }\end{array}$ \\
\hline Cambodia & $\begin{array}{l}\text { Licence renewal every ten years under the age of } 65 \text {, every two years from } 65 . \text { A medical test (vision, hearing } \\
\text { and fitness to drive) is required for renewal regardless of age. }\end{array}$ \\
\hline Canada & Driving licence renewal rules vary between jurisdictions. \\
\hline Chile & $\begin{array}{l}\text { Licence renewal every six years (every four years for professional licenses for truck and bus drivers). A medical } \\
\text { test including vision and hearing tests is required for renewal regardless of age. }\end{array}$ \\
\hline Czech Republic & Mandatory medical examination at 65 and 68 years of age, then every two years. \\
\hline Finland & $\begin{array}{l}\text { Licence renewal after the age of } 70 \text {. Persons over } 70 \text { must provide a medical certificate or a comprehensive medical } \\
\text { report. The licence is renewed for a period of five years; less if the medical report requires it. }\end{array}$ \\
\hline France & No licence renewal or medical checks required \\
\hline Germany & No special restrictive regulations regarding older road users \\
\hline Greece & Mandatory neurological, neuropsychological and psychiatric assessment for drivers aged 80 years or over. \\
\hline Hungary & $\begin{array}{l}\text { Licence renewal every ten years below } 40 \text { years of age, every five years between } 40 \text { and } 60 \text {, every three years between } \\
60 \text { and } 70 \text { and every two years for drivers over age } 70 \text {. All drivers must pass a vision tests and other basic medical } \\
\text { checks. }\end{array}$ \\
\hline Iceland & $\begin{array}{l}\text { Licence renewal every } 15 \text { years until age } 70 \text {, every five years between } 70 \text { and } 75 \text {, every two years between } 75 \text { and } 80 \text {, } \\
\text { and every year above the age of } 80 \text {. Medical tests are mandatory for renewals over } 70 \text { years of age. }\end{array}$ \\
\hline Ireland & Licence renewal of one or three years for drivers over 70 depending on mandatory medical report. \\
\hline Israel & Medical examination required every five years between ages of 70 and 80 , and every two years thereafter. \\
\hline Italy & $\begin{array}{l}\text { Licence renewal every five years from age } 50 \text {, every three years from age } 70 \text {, every two years from } 80 \text {, following } \\
\text { medical check. }\end{array}$ \\
\hline Japan & $\begin{array}{l}\text { Licence renewal every five years, every three years over age } 71 \text {. Cognitive impairment screening tests required } \\
\text { from age } 75 . .\end{array}$ \\
\hline Lithuania & $\begin{array}{l}\text { Licence renewal subject to a medical examination every ten years under the age of } 56 \text {, every five years for drivers } \\
\text { aged 56-69; every two years for drivers aged } 70-79 \text { and every year for those aged } 80 \text { and above. }\end{array}$ \\
\hline Luxembourg & $\begin{array}{l}\text { Mandatory medical check after the age of } 60 \text {. Licence renewal for up to five years from the age of } 70 \text { and two years } \\
\text { from age } 80 \text {, subject to a medical examination. }\end{array}$ \\
\hline Mexico & Varies between jurisdictions. \\
\hline Morocco & Licence renewal every ten years, every two years after the age of 65 subject to a medical test. \\
\hline Netherlands & $\begin{array}{l}\text { Licence renewal every ten years. Drivers aged } 75 \text { years and older have to submit a Declaration of Fitness to Drive } \\
\text { when applying for a new driving licence, which is valid for five years (until 2013, this applied to drivers } 70 \text { years } \\
\text { and older). }\end{array}$ \\
\hline New Zealand & Licence renewal at age 75,80 and every two years thereafter, subject to the presentation of a medical certificate \\
\hline Poland & No licence renewal or medical checks required \\
\hline Portugal & Licence renewal at 60, 65 and 70 years of age, then every two years subject to a medical certificate. \\
\hline Serbia & Licence renewal every ten years and every five years for persons above 65 , upon presentation of a medical certificate. \\
\hline Slovenia & Licence renewal every three years from age 70 upon presentation of a medical certificate. \\
\hline Spain & Licence renewed every ten years; every five years from age 65 subject to a medical check. \\
\hline Sweden & $\begin{array}{l}\text { No licence renewal or medical checks required (cars and motorcycles). Groups } 2 \text { and } 3 \text { licenses (C1, C1E, C, CE, D1, } \\
\text { D1E, D, DE) are renewed every five years, subject to a medical certificate after the age of } 45 .\end{array}$ \\
\hline Switzerland & Mandatory medical examination from age 70. \\
\hline United Kingdom & Licence renewal every three years after the age of 70 . \\
\hline United States & Varies between states \\
\hline
\end{tabular}

\section{National Road Safety Strategies}

An overview of national road safety strategies and targets followed by IRTAD member and observer countries is provided Table 1.5 below. The table also references current international strategies and targets. More detailed information on national policies is given in the country chapters. 


\section{Table 1.5. Road safety strategies and targets}

\begin{tabular}{|c|c|c|}
\hline International Strategies & Vision & Targets \\
\hline $\begin{array}{l}\text { United Nations } \\
\text { Decade of Action for Road Safety 2011-20 } \\
\text { Global Plan for the Decade of Action }\end{array}$ & & $\begin{array}{l}\text { Stabilise and then reduce the forecasted level of road traffic } \\
\text { fatalities around the world by increasing activities conducted } \\
\text { at the national, regional and global levels }\end{array}$ \\
\hline $\begin{array}{l}\text { United Nations } \\
\text { Sustainable Development Goals }\end{array}$ & & $\begin{array}{l}\text { SDG targets to halve road deaths by } 2020 \text { and to improve road } \\
\text { safety in cities } \\
\text { Goal } 3.6 \text { (health): By } 2020 \text {, halve the number of global deaths and } \\
\text { injuries from road traffic accidents } \\
\text { Goal } 11.2 \text { (cities): By } 2030 \text {, provide access to safe, affordable, } \\
\text { accessible and sustainable transport systems for all, improving } \\
\text { road safety, notably by expanding public transport, with special } \\
\text { attention to the needs of those in vulnerable situations, women, } \\
\text { children, persons with disabilities and older persons }\end{array}$ \\
\hline $\begin{array}{l}\text { European Union } \\
\text { Policy Orientations on Road Safety 2011-20 }\end{array}$ & Towards Zero & $-50 \%$ fatalities by 2020 (base year: 2010) \\
\hline Country/Strategy/timeframe & Vision & Targets \\
\hline $\begin{array}{l}\text { Argentina } \\
\text { National Road Safety Strategy }\end{array}$ & $\begin{array}{l}\text { Based on the UN Road Safety Plan } \\
\text { for the Decade of Action for Road Safety }\end{array}$ & $\begin{array}{l}-50 \% \text { fatalities by } 2014 \text {, base year } 2009 \\
\text { Specific targets for } 2020 \text { are being developed }\end{array}$ \\
\hline $\begin{array}{l}\text { Australia } \\
\text { National Road Safety Strategy (NRSS) } \\
2011-2020\end{array}$ & $\begin{array}{l}\text { Safe System } \\
\text { No-one should be killed or seriously } \\
\text { injured on Australia's roads }\end{array}$ & $\begin{array}{l}-30 \% \text { (at least) fatalities by } 2020 \\
-30 \% \text { (at least) severely injured by } 2020 \\
\text { Base year average } 2008-2010\end{array}$ \\
\hline $\begin{array}{l}\text { Austria } \\
\text { Austrian Road Safety Programme 2011-20 }\end{array}$ & $\begin{array}{l}\text { Safe system } \\
\text { Become one of the five safest countries } \\
\text { in Europe }\end{array}$ & $\begin{array}{l}-50 \% \text { fatalities by } 2020 \text {, based on the average for the years } \\
2008-10 \text { (Interim target: }-25 \% \text { by } 2015 \text { ) } \\
-40 \% \text { serious injuries by } 2020 \text {, based on the average for the } \\
\text { years } 2008-10 \text { (Interim target: }-20 \% \text { by } 2015 \text { ) } \\
-20 \% \text { injury accidents by } 2020 \text {, based on the average for the } \\
\text { years } 2008-10 \text { (Interim targets: }-10 \% \text { by } 2015 \text { ) }\end{array}$ \\
\hline $\begin{array}{l}\text { Belgium } \\
\text { National Road Safety Strategy 2011-20 }\end{array}$ & & $\begin{array}{l}-50 \% \text { fatalities in } 2020 \text { in comparison to } 2010 \text { ( } 420 \text { road deaths } \\
\text { in } 2020 \text { ) }\end{array}$ \\
\hline
\end{tabular}

Recommendations for 15 priority measures for a period of 2015-20

\section{Cambodia}

National Plan for Road Safety 2011 -20

(approved by the Council of Ministers in 2014)

2016 Annual Road Safety Plan (approved by the

\section{Canada}

Road Safety Strategy (RSS) 2025

(introduced in January 2016)

Chile

Road Safety Plan 2011-2014

A new National Road Safety Policy in preparation

Czech Republic

The National Strategic Road Safety Plan 2011-20

\section{Denmark}

National Traffic Safety Action Plan, 2013-20 government)

Based on the UN Road Safety Plan

for the Decade of Action for Road Safety

Based on UN Sustainable Development Goals

Towards Zero

Based on the UN Road Safety Plan for the Decade of Action for Road Safety Vision Zero

Based on Vision Zero

National Road Safety Strategy 2012-2014 ended.

A new resolution on road safety was approved by the Government on 15 December 2016
Reduce by $50 \%$ the forecasted number of fatalities by 2020 .

Several sub-targets on helmet wearing rates, speed, drink-driving

Interim target 2016: reducing the number of road deaths by $10 \%$ compared to 2015.

New interim target for 2017: reducing the number of road deaths by $9 \%$ compared to 2016

No hard numerical targets

Achieve a continual downward trend in fatalities and serious injuries throughout the ten-year duration of the strategy

$-20 \%$ road deaths by 2014 in comparison with 2011 level

Reduce fatality rate to EU 27 average

$60 \%$ reduction in fatalities by 2020 compared to 2009

$40 \%$ reduction in in the number of persons seriously injured by 2020 compared to 2009

Interim targets for the number of fatalities and persons seriously injured are set for each year until 2020

Fewer than 120 killed in 2020 , equivalent to $53 \%$ fatalities compared to 2010 (based on EU Road Safety target) $52 \%$ serious and $52 \%$ of slightly injured road users in 2020compared to 2010

Plan includes 10 focus areas and defines a performance indicators, for each of the area

Fewer than 137 fatalities (or 24 fatalities per million inhabitants) by 2020 (based on EU Road Safety target)

Fewer than 5750 injuries by 2020 (based on EU Road Safety target) Long term target: fewer than 100 fatalities by 2025 
Table 1.5. Road safety strategies and targets (cont.)

\begin{tabular}{lll}
\hline International Strategies & Vision & Targets \\
\hline $\begin{array}{l}\text { France } \\
\text { Action Plan for Road Safety, including } 26 \text { measures }\end{array}$ & $-50 \%$ fatalities by 2020 (fewer than 2000 fatalities) \\
$\begin{array}{l}\text { announced by Minister of Interior in January 2015 } \\
55 \text { measures announced during the Inter-ministerial }\end{array}$ & \\
Road Safety Committee (October 2015) & & \\
Germany & Developing a road safety culture & $-40 \%$ fatalities by 2020 (base year: 2010 ) \\
Road Safety Programme 2011-20 & & $-50 \%$ fatalities by 2020 (based on EU Road Safety target); \\
Greece & base year: 2010 \\
National Strategic Road Safety Plan 2011-20 & Interim targets: reduction by 80 road fatalities per year between \\
& $2010-15$ and 50 road fatalities per year between $2016-20$ \\
Hungary & & $-50 \%$ fatalities by 2020 compared to 2010 (based on EU \\
Road Safety Action Programme 2014-16 & Road Safety target); \\
(integrated into the National Transport Strategy) & Interim target: fewer than 518 fatalities in 2016 \\
The new road safety action programme for 2017-20 &
\end{tabular}

is under preparation

\section{Iceland}

Road Safety Plan 2011-22

Ireland

Government Road Safety Strategy 2013-20

\section{Israel}

National Road Safety Plan 2020

\section{Italy}

National Road Safety Plan Horizon 2020 (final

approval of updated version by an inter-ministerial

board expected in 2107)

Japan

10th Traffic Safety Programme 2016-20

Korea

8th National Transport Safety Plan 2017-21

\section{Lithuania}

Traffic Safety Development Programme 2011-17

\section{Luxembourg}

"National Charter for Road Safety"

Malaysia

Road Safety Plan 2014-20

Mexico

Estrategia Nacional de Seguridad Vial (National

Road Safety Strategy) 2011-2020

Morocco

New National Road Safety Strategy for 2016-25

\section{Netherlands}

Road Safety Strategic Plan

2008-20 (SPV)

Development of a new Strategic Plan for the

period of 2020-2030 started in 2017
No child should die on the road

Rate per 100000 inhabitants should not be higher than in the best countries by 2022

Average annual reduction in killed and seriously injured of $5 \%$ until 2022.

11 sub-targets defined

Reduction of fatalities to 25 per million population (i.e. 124 or fewer fatalities) or less by 2020 .

Provisional target for the reduction of serious injuries by $30 \%$ from 472 (2011) to 330 or fewer, by 2020 , or 61 per million population. Specific targets for reducing speed and to increase seat belt use. Fewer than 240 fatalities per year by 2020 (reduction of about $30 \%$ compared to the 2010 ) fatality rate less than four fatalities per billion kilometres travelled $-50 \%$ fatalities by 2020 (based on EU Road Safety target) Mid-term target (under consideration) an average annual reduction rate of fatalities of $7 \%$, corresponding to a reduction of $38 \%$ in 2017 (with reference to 2010 fatalities).

Make Japan the safest country for road traffic

Reach the average safety level of OECD countries

No one should be killed or seriously injured on Lithuania's roads

Zero fatalities and serious injuries on the Luxembourg road network Based on the UN Road Safety Plan for the Decade of Action for Road Safety Based on the UN Road Safety Plan for the Decade of Action for Road Safety

Development of responsible road behaviour and a safe road system

Sustainable Road Safety Fewer than 2500 deaths (deaths within 24 hours) by 2020 Fewer than 500000 casualties by 2020

Fewer than 2700 fatalities by 2021 , with interim targets for each year from 2017 to 2021

Reducing the rate of fatalities per 100000 inhabitants to 5.2 by 2021 ,

Less than 1.0 fatalities per 10000 vehicles (including mopeds) by 2021

Fewer than six killed per 100000 inhabitants (or 60 per million inhabitants) or,to be ranked among the 10 best performing countries in the EU

Fewer than 16 fatalities by 2020 (-50\% fatalities by 2020 compared to 2010, based on EU Road Safety target);

Reduce by $50 \%$ the forecasted number of fatalities by 2020 (corresponds to a $22 \%$ reduction compared to 2010) $-50 \%$ fatalities by 2020

Reduce the number of deaths to less than 2800 by 2020 (decrease of $20 \%$ from 2015 to 2020).

Reduce the number of deaths to less than 1900 fatalities by 2025 (decrease of 50\% from 2015 to 2025).

Fewer than 500 fatalities by 2020 (-28\% compared to 2010) Fewer than 10600 serious road injuries (MAIS2+) by 2020 (-43\% compared to 2010$)$ 
Table 1.5. Road safety strategies and targets (cont.)

\begin{tabular}{|c|c|c|}
\hline International Strategies & Vision & Targets \\
\hline $\begin{array}{l}\text { New Zealand } \\
\text { "Safer Journeys": Road Safety Strategy 2010-20 } \\
\text { 3rd Action Plan for 2016-2020 under preparation }\end{array}$ & $\begin{array}{l}\text { Safe System } \\
\text { A safe road system increasingly free } \\
\text { of death and serious injury }\end{array}$ & $\begin{array}{l}\text { No general fatality target } \\
\text { Several sub-targets and performance indicators }\end{array}$ \\
\hline $\begin{array}{l}\text { Nigeria } \\
\text { Road Safety Strategy (NRSS 2016-20) }\end{array}$ & $\begin{array}{l}\text { Based on the UN Road Safety Plan } \\
\text { for the Decade of Action for Road Safety. }\end{array}$ & $\begin{array}{l}-50 \% \text { fatalities by } 2015 \text { compared to } 2007 \text { level } \\
\text { Reduce by } 50 \% \text { the forecasted number of fatalities by } 2020 \\
\text { in comparison with } 2010 \text { level (based on UN Decade of Action } \\
\text { Plan) }\end{array}$ \\
\hline $\begin{array}{l}\text { Norway } \\
\text { Road Safety Strategy 2014-24 } \\
\text { National Plan of Action for Road Traffic Safety 2014-17 }\end{array}$ & Vision Zero & Fewer than 500 fatalities and serious injuries by 2024 . \\
\hline $\begin{array}{l}\text { Poland } \\
\text { National Road Safety Programme 2013-20 }\end{array}$ & Vision Zero & $\begin{array}{l}-50 \% \text { fatalities by } 2020 \text { (based on EU Road Safety target) } \\
-40 \% \text { severely injured by } 2020 \\
\text { Base year } 2010\end{array}$ \\
\hline $\begin{array}{l}\text { Portugal } \\
\text { National Strategic Road Safety Plan } \\
\text { (PENSE 2020) } \\
2020\end{array}$ & & $\begin{array}{l}41 \text { fatalities per million inhabitants in } 2020 \text {, representing } \\
\text { a decrease of } 56 \% \text { compared to } 2010 \\
\text { Fewer than } 178 \text { seriously injured (MAIS3+) people in } 2020 \text {, } \\
\text { representing a decrease of } 22 \% \text { compared to } 2010\end{array}$ \\
\hline $\begin{array}{l}\text { Serbia } \\
\text { National Strategy for Road Traffic Safety } \\
\text { for the period 2015-20 (adopted in June 2015) }\end{array}$ & & $\begin{array}{l}\text { No child killed in traffic by } 2020 \\
-50 \% \text { fatalities and serious injuries by } 2020 \text { compared to } 2011 \\
\text { Halving by } 2020 \text { the total annual social-economic costs of traffic } \\
\text { crashes compared to } 2011 \text { level } \\
\text { Several sub-targets on seatbelt wearing rates, child restraint } \\
\text { usage, helmet wearing rates, speed and drink-driving }\end{array}$ \\
\hline $\begin{array}{l}\text { Slovenia } \\
\text { National Road Safety Programme 2013-22 }\end{array}$ & $\begin{array}{l}\text { Vision Zero } \\
\text { No fatalities and no one seriously } \\
\text { injured on Slovenian roads }\end{array}$ & $\begin{array}{l}-50 \% \text { fatalities by } 2022 \text { or less than } 35 \text { fatalities per million } \\
\text { inhabitants } \\
-50 \% \text { seriously injured by } 2022 \text { or less than } 230 \text { seriously } \\
\text { injured per million inhabitants }\end{array}$ \\
\hline $\begin{array}{l}\text { Spain } \\
\text { Road Safety Strategy 2011-20 }\end{array}$ & $\begin{array}{l}\text { Safe system/Vision Zero. } \\
\text { Citizens have the right to a Safe Mobility } \\
\text { System in which everyone involved } \\
\text { has a responsibility }\end{array}$ & $\begin{array}{l}\text { Less than } 3.7 \text { killed per } 100000 \text { population } \\
\text { aligned with the European } 2020 \text { target } \\
\text {-35\% seriously injured compared to } 2009 \\
\text { Several targets for various performance indicators } \\
\text { (restraint systems, speed, drink-driving, etc.) }\end{array}$ \\
\hline $\begin{array}{l}\text { South Africa } \\
\text { National Road Safety Strategy 2016-30 }\end{array}$ & $\begin{array}{l}\text { Aligned with the United Nations Decade } \\
\text { of Action pillars }\end{array}$ & $\begin{array}{l}\text { Target under consideration: }-50 \% \text { fatalities by } 2030 \text { compared } \\
\text { to } 2010 \text {. }\end{array}$ \\
\hline $\begin{array}{l}\text { Sweden } \\
\text { No safety plan in a traditional sense }\end{array}$ & $\begin{array}{l}\text { Vision Zero } \\
\text { (Renewed Commitment to Vision Zero } \\
\text { in October 2016) }\end{array}$ & $\begin{array}{l}-50 \% \text { fatalities between } 2007 \text { and } 2020 \text { (the average for } 2006-08 \\
\text { is used as the base figure), i.e. max. } 220 \text { deaths by } 2020 \text {. } \\
-25 \% \text { severely injured between } 2007 \text { and } 2020 \text {. }\end{array}$ \\
\hline $\begin{array}{l}\text { Switzerland } \\
\text { Via Sicura } \\
\text { Adopted in June } 2012 \text { by Swiss Federal Council }\end{array}$ & & $\begin{array}{l}\text { No hard numerical targets } \\
\text { Range of targeted measures }\end{array}$ \\
\hline $\begin{array}{l}\text { United Kingdom (Great Britain) } \\
\text { Road safety statement: "Working together } \\
\text { to build a safer road system" }\end{array}$ & Safe System approach. & $\begin{array}{l}\text { This British Road Safety Statement sets out the context of road } \\
\text { safety in Great Britain today and the overarching scope of road } \\
\text { safety activity for the government. It will be followed } \\
\text { by consultations on specific issues as options are developed. } \\
\text { The statement covers road safety policy within Great Britain } \\
\text { as governed by the Department for Transport (DfT). } \\
\text { The governments and administrations of Scotland, Wales } \\
\text { and Northern Ireland will seek to produce their own policies } \\
\text { and strategic documents on devolved matters. }\end{array}$ \\
\hline United States & $\begin{array}{l}\text { Dedicated to achieving the highest } \\
\text { standards of excellence in motor vehicle } \\
\text { safety and reducing deaths, injuries and } \\
\text { economic losses resulting from motor } \\
\text { vehicle crashes. }\end{array}$ & $\begin{array}{l}\text { Performance targets set to end } 2016 \\
\text { Less than } 1.02 \text { fatalities per } 100 \text { million vehicle miles travelled } \\
\text { in } 2016 \\
\text { Performance targets for four sub measures: large trucks, } \\
\text { passenger vehicles, non-occupants, and motorcycles }\end{array}$ \\
\hline
\end{tabular}

The priority challenges for road safety remain drink driving, speeding and the nonwearing of seat belts and motorcycle helmets. These are common safety hazards in all countries. The sections below summarise existing regulations and practices regarding maximum authorised blood alcohol content, speed limits, seat belt and helmet use. 
One of the primary measures to prevent drink driving and the crashes, injuries and fatalities causes is to implement maximum levels for authorised blood alcohol content (BAC) for drivers. All IRTAD member and observer countries have established general BAC levels. These vary between $0.0 \mathrm{~g} / \mathrm{l}$ in the Czech Republic and in Hungary to $0.8 \mathrm{~g} / \mathrm{l}$ in Canada, Jamaica, Malaysia, the United Kingdom (excluding Scotland) and the United States. The most common maximum authorised BAC level is $0.5 \mathrm{~g} / \mathrm{l}$. Most of the countries also apply lower BAC levels for novice, young and professional drivers (see Table 1.6).

Table 1.6. Maximum authorised blood alcohol content, 2017

\begin{tabular}{|c|c|c|}
\hline Country & General BAC level $(g / l)$ & Differentiated BAC for novice drivers, professional drivers \\
\hline Argentina & 0.5 & $0.0 \mathrm{~g} / \mathrm{l}$ for professional drivers \\
\hline Australia & 0.5 & $\begin{array}{l}0.0 \mathrm{~g} / \mathrm{l} \text { for novice drivers } \\
0.2 \mathrm{~g} / \mathrm{l} \text { for professional drivers }\end{array}$ \\
\hline Austria & 0.5 & $\begin{array}{l}0.1 \mathrm{~g} / \mathrm{l} \text { for moped drivers under } 20 \text {; novice drivers (less than } 2 \text { years), truck } \\
\text { ( }>7.5 \text { tons) and bus ( }>9 \text { seats) drivers }\end{array}$ \\
\hline Belgium & 0.5 & $0.2 \mathrm{~g} / \mathrm{l}$ for professional drivers (since January 2015) \\
\hline Cambodia & 0.5 & - \\
\hline Canada & 0.8 & $\begin{array}{l}\text { administrative maximum level of } 0.5 \mathrm{~g} / \mathrm{l} \text { or } 0.4 \mathrm{~g} / \mathrm{l} \text { in most provinces } \\
0.0 \mathrm{~g} / \mathrm{l} \text { administrative maximum level for novice and young (under } 21 \text { ) drivers } \\
\text { in most provinces }\end{array}$ \\
\hline Chile & 0.3 & - \\
\hline Czech Republic & 0.0 & - \\
\hline Denmark & 0.5 & - \\
\hline Finland & 0.5 & - \\
\hline France & 0.5 & $0.2 \mathrm{~g} / \mathrm{l}$ for bus/coach drivers, novice drivers \\
\hline Germany & $\begin{array}{l}0.5 \text { (Drivers with a BAC between } 0.3-0.5 \mathrm{~g} / \mathrm{l} \text { can have their } \\
\text { licenses suspended if their driving ability is impaired) }\end{array}$ & $\begin{array}{l}0.0 \mathrm{~g} / \mathrm{l} \text { for drivers under } 21 \text { and novice drivers } \\
0.0 \mathrm{~g} / \mathrm{l} \text { for professional drivers who transport passengers or hazardous goods }\end{array}$ \\
\hline Greece & 0.5 & $0.2 \mathrm{~g} / \mathrm{l}$ for professional drivers, motorcycles and moped riders \\
\hline Hungary & 0.0 & - \\
\hline Iceland & 0.5 & - \\
\hline Ireland & 0.5 & $0.2 \mathrm{~g} / \mathrm{l}$ for novice and professional drivers \\
\hline Israel & 0.5 & $0.1 \mathrm{~g} / \mathrm{l}$ for young (under 24), novice and professional drivers \\
\hline Italy & 0.5 & $0.0 \mathrm{~g} / \mathrm{l}$ for young, novice and professional drivers \\
\hline Jamaica & 0.8 & - \\
\hline Japan & 0.3 & - \\
\hline Korea & 0.5 & - \\
\hline Lithuania & 0.4 & $0.0 \mathrm{~g} / \mathrm{l}$ for novice, professional, moped and motorcycle drivers \\
\hline Luxembourg & 0.5 & $0.2 \mathrm{~g} / \mathrm{l}$ for novice and professional drivers \\
\hline Malaysia & 0.8 & - \\
\hline Mexico & 0.8 (may vary by state on urban roads) & $0.3 \mathrm{~g} / \mathrm{l}$ for professional drivers (may vary by state) \\
\hline Morocco & 0.2 & - \\
\hline Netherlands & 0.5 (including cyclists) & $0.2 \mathrm{~g} / \mathrm{l}$ for novice drivers (first five years) \\
\hline New Zealand & 0.5 & $0.0 \mathrm{~g} / \mathrm{l}$ for drivers under 20 years \\
\hline Nigeria & 0.5 & $0.2 \mathrm{~g} / \mathrm{l}$ for novice and $0.0 \mathrm{~g} / \mathrm{l}$ for professional drivers (draft Law under approval) \\
\hline Norway & 0.2 & - \\
\hline Poland & 0.2 & - \\
\hline Portugal & 0.5 & $0.2 \mathrm{~g} / \mathrm{l}$ for novice (first three years) and professional drivers (since 1 January 2014) \\
\hline Serbia & 0.3 & $0.0 \mathrm{~g} / \mathrm{l}$ for novice and professional drivers and for PTW operators \\
\hline Slovenia & 0.5 & $0.0 \mathrm{~g} / \mathrm{l}$ for novice (first three years) and professional drivers \\
\hline South Africa & 0.5 & $0.2 \mathrm{~g} / \mathrm{l}$ for professional drivers \\
\hline Spain & 0.5 & $0.3 \mathrm{~g} / \mathrm{l}$ for novice and professional drivers \\
\hline Sweden & 0.2 & - \\
\hline Switzerland & 0.5 & $0.0 \mathrm{~g} / \mathrm{l}$ for novice (first three years) and professional drivers \\
\hline United Kingdom & $\begin{array}{l}0.8 \text { (England, Wales, Northern Ireland. Northern Ireland } \\
\text { will lower limit to } 0.5 \mathrm{~g} / \mathrm{l} \text { from 2018) } \\
0.5 \text { (Scotland) }\end{array}$ & - \\
\hline United States & 0.8 & $\begin{array}{l}0.4 \mathrm{~g} / \mathrm{l} \text { for professional drivers } \\
0.0 \text { to } 0.2 \mathrm{~g} / \mathrm{l} \text { for drivers }<21\end{array}$ \\
\hline Uruguay & 0.0 & $0.0 \mathrm{~g} / \mathrm{l}$ \\
\hline
\end{tabular}


Speed management is a critical element of any road safety strategy, and setting and enforcing adequate speed limits is essential to reducing the number of road deaths. The default speed limit for passenger cars in urban areas is $50 \mathrm{~km} / \mathrm{h}$ in most IRTAD countries. Lower speed limits - typically $30 \mathrm{~km} / \mathrm{h}$ - are often in force in residential areas or around schools. Higher default speed limits in urban areas $(60 \mathrm{~km} / \mathrm{h})$ are found in Chile, Korea and Poland (during the night).

On non-motorway roads outside built-up areas, speed limits typically vary between 80 and $100 \mathrm{~km} / \mathrm{h}$. The lowest speed limits for rural roads among IRTAD member countries and observers exist in Jamaica $(50 \mathrm{~km} / \mathrm{h}$ ) and Japan $(50$ or $60 \mathrm{~km} / \mathrm{h}$ ). The highest non-urban speed limits - up to $120 \mathrm{~km} / \mathrm{h}$ - are found in Chile and Poland. Several countries differentiate speed limits according to the type of road, weather or pavement conditions.

On motorways speed limits vary between $90 \mathrm{~km} / \mathrm{h}$ and $140 \mathrm{~km} / \mathrm{h}$. In Germany, there is no general speed limit. Instead there is a recommended speed limit of $130 \mathrm{~km} / \mathrm{h}$ and local speed limits apply on a large part of the motorway network.

Table 1.7. General speed limits for passenger cars, $2017(\mathbf{k m} / \mathbf{h})$

\begin{tabular}{|c|c|c|c|}
\hline Country & Urban areas & Rural roads & Motorways \\
\hline Argentina & $\begin{array}{l}\text { 40-60 (Buenos Aires City has a range } \\
\text { of } 20 \text { to } 70 \mathrm{~km} / \mathrm{h} \text { speed limits) }\end{array}$ & 110 & $120-130$ \\
\hline Australia & $\begin{array}{l}50 \\
60-80 \text { (arterial roads - increasing use } \\
\text { of } 40 \mathrm{~km} / \mathrm{h} \text { or lower limits in urban areas } \\
\text { with high pedestrian activities) }\end{array}$ & 100,110 & $\begin{array}{l}\text { Set by each state }(e . g .130 \mathrm{~km} / \mathrm{h} \text { in the } \\
\text { Northern Territory) }\end{array}$ \\
\hline Austria & 50 & 100 & 130 \\
\hline Belgium & $30-50$ & $70-90$ & 120 \\
\hline Cambodia & $\begin{array}{l}30-40 \text { (motorcycles, tricycles) } \\
40 \text { (passenger cars) }\end{array}$ & 90 & No motorways \\
\hline Canada & $40-70$ & $80-90$ & $100-110$ \\
\hline Chile & 60 & 100 & 120 \\
\hline Czech Republic & 50 & 90 & 130 \\
\hline Denmark & 50 & 80 & 130 (110 for certain sections) \\
\hline Finland & 50 (sections with 30,40 , or 60 ) & 100 (80 in winter) & 120 (100 near cities) \\
\hline France & 50 & 90 (80 in wet weather, for novice drivers) & 130 (110 in wet weather and for novice drivers) \\
\hline Germany & 50 & 100 & None (130 recommended) \\
\hline Greece & 50 & 90 & 130 \\
\hline Hungary & 50 & 90 & 130 (110 on "motor roads") \\
\hline Iceland & 50 & $\begin{array}{l}90 \text { (paved roads) } \\
80 \text { (gravel roads) }\end{array}$ & n.a. \\
\hline Ireland & $\begin{array}{l}<=60 \text { (can be } 60 \text { on arterial roads, } \\
30 \text { in built up areas) }\end{array}$ & 80,100 & 120 \\
\hline Israel & $50-70$ & $80,90,100$ & 110 \\
\hline Italy & 50 & $70-90$ (110 on some main dual carriageways) & $\begin{array}{l}130 \text { (110 in wet weather, } 100 \text { for novice drivers. } \\
\text { Motorway operator may increase speed limit up } \\
\text { to } 150 \text { if stringent requirements are met) }\end{array}$ \\
\hline Jamaica & 50 & 50 & 70,110 \\
\hline Japan & $40,50,60$ & 50,60 & 100 \\
\hline Korea & 60 & $60-80$ & 110 (100 in urban areas), \\
\hline Lithuania & 50 & 90 (70 on gravel roads and for novice drivers) & 120,130 (110 in winter, 90 for novice drivers) \\
\hline Luxembourg & 50 & 90 & 130 (110 in wet weather) \\
\hline Malaysia & 50 & 90 & 110 \\
\hline Mexico & $10-80$ & 50 (other roads) & 110 (100 on high-speed roads) \\
\hline Morocco & 60 & 100 & 120 \\
\hline Netherlands & $30-50$ & $60-80$ & $100-130$ \\
\hline New Zealand & 50 (sections may have higher or lower limits) & 100 (specific sections may have lower limits) & 100 \\
\hline
\end{tabular}


Table 1.7. General speed limits for passenger cars, 2017 (km/h) (cont.)

\begin{tabular}{llll}
\hline Country & Urban areas & Rural roads & Motorways \\
\hline Nigeria & 50 (45 for tankers, trailers $)$ & 80 (differentiated by vehicle type) & 100 (differentiated by vehicle type) \\
Norway & 50 (30 on residential streets) & 80 & $90,100,110$ \\
Poland & 50 (60 at nighttime) & $90,100,120$ & 140 \\
Portugal & 50 & 90 & 120 \\
Serbia & 50 & 80,100 & 120 \\
Slovenia & 50 & $90(110$ on expressways) & 130 \\
South Africa & 60 & 100 & 120 \\
Spain & 50 & 90,100 & 120 \\
Sweden & $30,40,50$ & $60,70,80,90,100$ & 110,120 \\
Switzerland & 50 & 80 & 120 \\
United Kingdom & $48(30 \mathrm{mph})$ & $96,113(60,70 \mathrm{mph})$ & $113(70$ mph) \\
United States & Set by each state & Set by each state & $88-129$ (55-80 mph, set by each state) \\
Uruguay & 45 & 90 & No motorways \\
\hline
\end{tabular}

For occupants of passenger vehicles, the use of seat belts is regarded as one of the most effective measures to save lives and reduce the severity of crash injuries. All IRTAD countries have mandatory front seat belt regulations. The use of seat belts on rear seats is still not mandatory on the whole road network in some countries.

There is no internationally agreed methodology to measure seatbelt use. Available data are based on national surveys and cannot be directly compared. Nevertheless they provide a helpful overview on the use of seatbelt. Wearing rates vary widely in IRTAD member countries. For front seats they are usually higher, typically ranging between $80 \%$ and $100 \%$. However, they can also be significantly lower, for instance 50\% for drivers in Argentina. In some observer countries they are very low indeed: The seatbelt-wearing rate in South Africa is $5 \%$; in Cambodia it is $12 \%$. For rear seats, more than $95 \%$ of car passengers use belts in Canada, the Netherlands, Australia, Czech Republic and Germany. In 19 countries the rate is between 65 and $95 \%$. In twelve countries, $40 \%$ or less use seats belts when seated in the rear of a vehicle (Figures 1.10 and 1.11).

Crash helmets for two-wheelers protect a particularly fragile and critical body part of motorcyclists, moped users and cyclists, who are already among the most vulnerable road users in a crash. In all IRTAD member and observer countries except the United States, the use of helmets on powered two-wheelers (motorcycles and mopeds) is compulsory. The helmet wearing rate is usually high with many countries reporting nearly $100 \%$ compliance for motorcyclists. In the United States, there is no federal law on helmet use, and three states do not have any helmet law. Helmet use for cyclists is not compulsory in most countries; however the compulsory use of helmets by cycling children is becoming more frequent (see Table 1.9). 
Figure 1.10. Seatbelt use by drivers, 2016 or latest available year

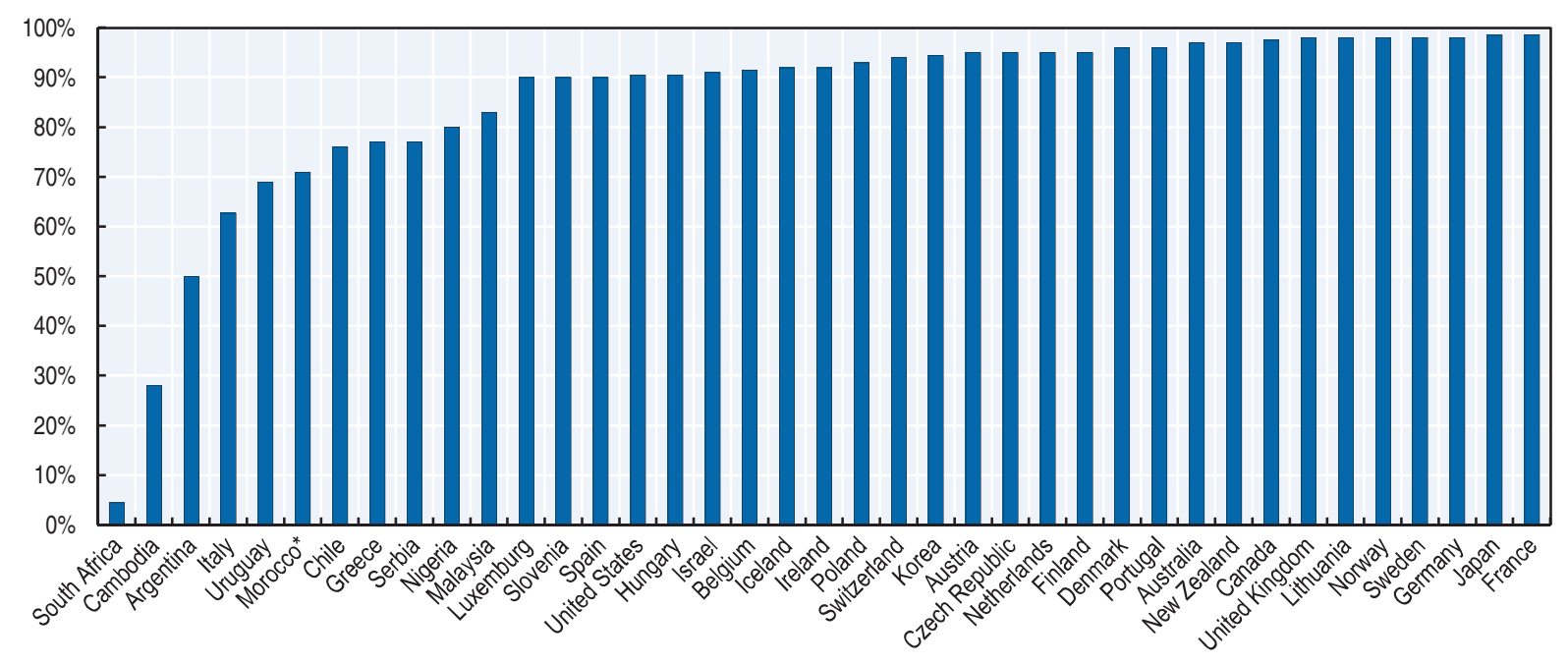

* On motorways only.

Note: Data based on national surveys and not on a common international methodology.

Figure 1.11. Seatbelt use by rear seat passengers, 2016 or latest available year

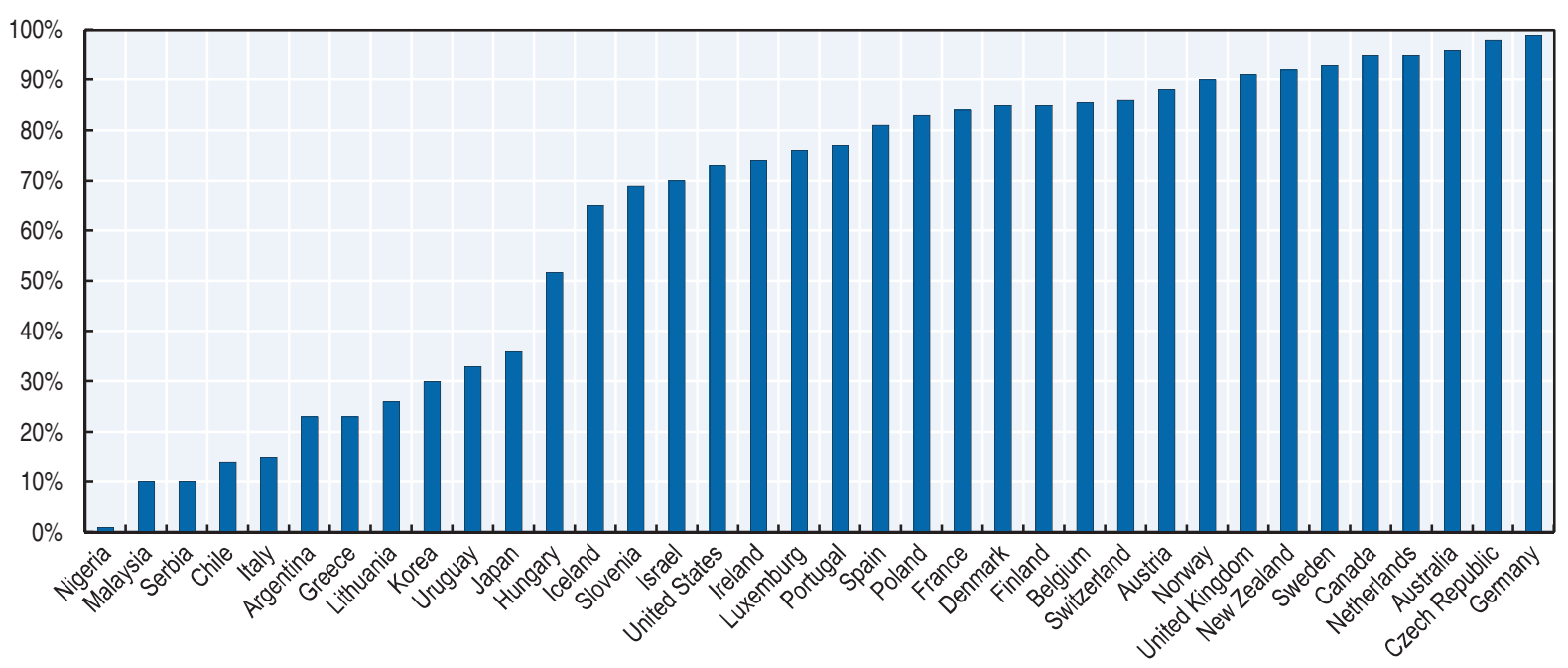

Note: Data based on national surveys and not on a common international methodology.

Table 1.8. Seatbelt wearing rates in front and rear seats of passenger cars, 2016 or the latest available year

\begin{tabular}{|c|c|c|c|c|}
\hline \multirow{2}{*}{ Country } & \multicolumn{2}{|c|}{ Front seats } & \multicolumn{2}{|c|}{ Rear seats } \\
\hline & Date of application & Wearing rate $(\%)$ & Date of application & Wearing rate $(\%)$ \\
\hline Argentina & 1995 & 50 driver & 1995 & 23 \\
\hline Australia & 1970 s & 97 (2013 data) & 1970 s & 96 (2013 data) \\
\hline Austria & 1984 & 95 driver, 96 passengers & 1990 & 88 \\
\hline Belgium & 1975 & 92 drivers and pass. (2015 data) & 1991 & 86 (2015 data) \\
\hline Cambodia & 2007 & 28 (2016 data) & Law in preparation & - \\
\hline Canada & $1976-1988$ & 97.5 & $1976-1988$ & 95 (2015 data) \\
\hline
\end{tabular}


Table 1.8. Seatbelt wearing rates in front and rear seats of passenger cars, 2016 or the latest available year (cont.)

\begin{tabular}{|c|c|c|c|c|}
\hline \multirow{2}{*}{ Country } & \multicolumn{2}{|c|}{ Front seats } & \multicolumn{2}{|c|}{ Rear seats } \\
\hline & Date of application & Wearing rate $(\%)$ & Date of application & Wearing rate $(\%)$ \\
\hline Chile & 1985 & 76 drivers, 59 pass (2015 data) & 2006 & 14 (2015 data) \\
\hline Czech Republic & 1966 & 95 (2015 data) & 1975 & 95 (2015 data) \\
\hline Denmark & 1970s & 96 (2014 data) & 1980s & 85 (2014 data) \\
\hline Finland & 1975 & 95 drivers and pass. (2015 data) & 1987 & 85 (2016 data) \\
\hline France & $\begin{array}{l}1973 \text { (rural), } 1975 \text { (urban) } \\
1979 \text { (all times) }\end{array}$ & $\begin{array}{l}95.8 \text { urban roads, } 98.6 \text { motorways } \\
\text { (2012 data) }\end{array}$ & 1991 & $\begin{array}{l}71 \text { urban roads, } \\
84 \text { motorways ( } 2012 \text { data) }\end{array}$ \\
\hline Germany & 1976 & 98 & 1984 & 99 \\
\hline Greece & 1987 & 77 drivers, 74 pass. (2009 data) & 2003 & 23 (2009 data) \\
\hline Hungary & 1976 & $\begin{array}{l}91 \text { drivers, } 89 \text { passenger } \\
\text { ( } 2017 \text { data) }\end{array}$ & $\begin{array}{l}1993 \text { outside built up areas, } \\
2001 \text { inside built up areas }\end{array}$ & 52 \\
\hline Iceland & & 79 urban roads, 92 rural roads & & 80 \\
\hline Ireland & 1971 & 92 drivers, 94 passengers & 1971 & 74 \\
\hline Israel & 1975 & 91 & 1995 & 70 \\
\hline Italy & 1988 & $63(2015-2016)$ & 1994 & $11(2015-2016)$ \\
\hline Japan & 1985 & 99 drivers, 95 passengers & 2008 & 36 \\
\hline Korea & 1990 & $\begin{array}{l}94 \text { drivers on motorways, } \\
83 \text { passengers on motorways }\end{array}$ & 2008 , on motorways only & 30 on motorways \\
\hline Lithuania & - & 98 & - & 26 \\
\hline Luxembourg & 1975 & 90 (2015 data) & 1992 & 76 (2015 data) \\
\hline Malaysia & 1978 & 83 drivers, 74 pass (2015 data) & 2009 & 10 (2015 data) \\
\hline Mexico & 2012 & 54 & 2015 & 21 \\
\hline Morocco & $\begin{array}{l}1977 \text { - rural areas } \\
2005 \text { - urban areas }\end{array}$ & $\begin{array}{l}71 \text { drivers on motorways } \\
62-65 \text { drivers urban/rural roads } \\
59-62 \text { pass. on urban/ rural roads }\end{array}$ & 2005 - rural areas & 25 \\
\hline Netherlands & 1975 & >95 (2010 data) & 1992 & > 95 (2010 data) \\
\hline New Zealand & 1972 & 97 drivers, 96 pass (2016 data) & 1979 & 92 (2014 data) \\
\hline Nigeria & 1997 (enforced from 2002) & 80 (2014 data) & 1997 (enforcement pending) & $<1 \%$ (2014 data) \\
\hline Norway & 1975 & 97 drivers & 1985 & 90 (estimated) \\
\hline Poland & 1983 & 93 drivers, 95 pass (2016 data) & 1991 & 83 (2016 data) \\
\hline Portugal & 1978 & 96 drivers and passengers & 1994 & 77 \\
\hline Serbia & 1982 & 77 drivers, 73 passengers & 2009 & 10 \\
\hline Slovenia & 1977 & 90 drivers, 92 passengers & 1998 & 69 adults (2016 data) \\
\hline South Africa & $\begin{array}{l}2005 \text {, vehicles registered } \\
\text { after } 1 \text { January } 2006\end{array}$ & 4.5 drivers, 5 passengers & $\begin{array}{l}2005 \text {, vehicles registered after } \\
1 \text { January } 2006\end{array}$ & - \\
\hline Spain & $\begin{array}{l}1974 \text { outside urban areas } \\
1992 \text { inside urban areas }\end{array}$ & 90 (2012 data) & 1992 & 81 (2012 data) \\
\hline Sweden & 1975 & 98 & 1986; child restraint since 1988 & 93 \\
\hline Switzerland & 1981 & 94 drivers, 94 passengers & 1994 & 86 \\
\hline United Kingdom & 1983 & $\begin{array}{l}98 \text { drivers, } 97 \text { passengers (2014 } \\
\text { data for England and Scotland) }\end{array}$ & 1989 (children); 1991 (adults) & $\begin{array}{l}91 \text { (2014 data for England } \\
\text { and Scotland) }\end{array}$ \\
\hline United States & $\begin{array}{l}\text { Primary law in } 34 \text { states, } \\
\text { secondary law in } 15 \text { states. } \\
\text { Not mandatory for adults } \\
\text { in one state. }\end{array}$ & 91 drivers, 89 pass. (2016 data) & Varies by State & 73 (2014 data) \\
\hline Uruguay & 2007 & 69 drivers (2016 data) & 2007 & 33 \\
\hline
\end{tabular}


Table 1.9. Helmet laws and wearing rates, 2016 or latest available year

\begin{tabular}{|c|c|c|c|c|}
\hline \multirow{2}{*}{ Country } & \multicolumn{2}{|c|}{ Powered two-wheelers } & \multicolumn{2}{|c|}{ Cyclists } \\
\hline & Helmet law & Wearing rate $(\%)$ & Helmet law & Wearing rate $(\%)$ \\
\hline Argentina & Yes & $\begin{array}{l}65 \text { drivers, } 44 \text { first pass., } \\
22 \text { additional passengers }\end{array}$ & No & \\
\hline Australia & Yes & 99 drivers (estimate) & Yes & \\
\hline Austria & Yes & 100 (approx.) & Yes, for children to age 12 & \\
\hline Belgium & Yes & $\begin{array}{l}\text { No national data } \\
99.3 \text { Brussels ( } 2013 \text { data) }\end{array}$ & No & \\
\hline Cambodia & $\begin{array}{l}\text { Yes, PTW from } 50 \mathrm{cc} \text {, motorcycles } \\
\text { with trailers, motorised tricycles } \\
\text { (drivers and passengers) }\end{array}$ & Low (no precise data) & No & \\
\hline Canada & Yes & & In some jurisdictions & \\
\hline Chile & Yes & 99 drivers, 98 passengers & Yes in urban areas. & \\
\hline Czech Republic & Yes & 100 (approx.) & Yes, for children to age 18 & \\
\hline Denmark & Yes & 97 (2014 data) & No & \\
\hline Finland & Yes & n.a & No & $\begin{array}{l}43 \text { (2015 data) } \\
<70 \text { Helsinki area }\end{array}$ \\
\hline France & Yes, since 1973 & $90-100$ & No & \\
\hline Germany & Yes & 99 & No & 17 \\
\hline Greece & Yes & $\begin{array}{l}75 \text { drivers, } 46 \text { passengers } \\
\text { (2009 data) }\end{array}$ & No & \\
\hline Hungary & $\begin{array}{l}\text { Yes since } 1965 \text { for motorcyclists, } \\
1997 \text { for moped riders outside } \\
\text { built up areas } \\
1998 \text { for moped riders in urban areas. }\end{array}$ & 100 (approx.) & No & $\begin{array}{l}23 \text { Budapest area } \\
4 \text { Rural areas (2017 data) }\end{array}$ \\
\hline Iceland & Yes & n.a & Yes, for children to age 14 & \\
\hline Ireland & Yes & 100 (approx.) & No & 38 \\
\hline Israel & Yes & 100 (approx.) & $\begin{array}{l}\text { Yes for children to age } 18 \text {, } \\
\text { for adults on rural roads }\end{array}$ & $\begin{array}{l}90 \text { Rural roads } \\
\text { (2013 data) }\end{array}$ \\
\hline Italy & Yes, for all since 2000 & $98(2015-2016)$ & No & \\
\hline Japan & Yes & 100 (approx.) & No & \\
\hline Korea & Yes & 84 & No & \\
\hline Lithuania & Yes & n.a. & Yes, for children to age 18 & \\
\hline Luxembourg & Yes, since 1976 & 100 (estimate) & & \\
\hline Malaysia & Yes, since 1973 & c. $77(2015)$ & No & \\
\hline Mexico & Yes & $\begin{array}{l}82 \text { drivers, } 57 \text { passengers } \\
\text { (2014 data) }\end{array}$ & No & \\
\hline Morocco & Yes, since 1976 & 65 drivers, 34 passengers & No & \\
\hline Netherlands & $\begin{array}{l}\text { Yes, motorcycles since 1972; } \\
\text { mopeds since 1975. Not compulsory } \\
\text { on mofas (max. } 25 \mathrm{~km} / \mathrm{h} \text { ) }\end{array}$ & $\begin{array}{l}100 \text { motorcyclists (approx.), } \\
96 \text { moped riders (2008) }\end{array}$ & No & \\
\hline New Zealand & Yes, since 1973 & 100 (approx.) & Yes, since 1994 & 92 (2012 data) \\
\hline Nigeria & Yes & 60 (estimate) & Yes & \\
\hline Norway & Yes & 100 (approx.) & No & 56 Cyclists above 12 \\
\hline Poland & Yes since 1997 & 100 (approx.) & No & \\
\hline Portugal & Yes & n.a & No & \\
\hline Serbia & Yes & $\begin{array}{l}91 \text { motorcyclists } \\
80 \text { moped riders }\end{array}$ & No & \\
\hline Slovenia & Yes & n.a & Yes for children to age 14 & \\
\hline South Africa & Yes & & Yes & \\
\hline Spain & Yes & 100 (approx.) & $\begin{array}{l}\text { Except in built-up areas. } \\
\text { Mandatory below age } 16\end{array}$ & \\
\hline Sweden & Yes & $96-99$ & Yes, for children to age 15 & $\begin{array}{l}60-70 \text { children } \\
30 \text { adults }\end{array}$ \\
\hline Switzerland & $\begin{array}{l}\text { Yes, motorcycles since 1981; } \\
\text { mopeds since } 1990\end{array}$ & 100 (approx.) & $\begin{array}{l}\text { No for regular bicycles } \\
\text { Yes for e-bikes }>25 \mathrm{~km} / \mathrm{h}\end{array}$ & $\begin{array}{l}49 \text { cyclists } \\
60 \text { e-bikes < 25km/h: } \\
86 \text { e-bikes }>25 \mathrm{~km} / \mathrm{h} \text { : }\end{array}$ \\
\hline
\end{tabular}


Table 1.9. Helmet laws and wearing rates, 2016 or latest available year (cont.)

\begin{tabular}{|c|c|c|c|c|}
\hline \multirow{2}{*}{ Country } & \multicolumn{2}{|c|}{ Powered two-wheelers } & \multicolumn{2}{|c|}{ Cyclists } \\
\hline & Helmet law & Wearing rate $(\%)$ & Helmet law & Wearing rate $(\%)$ \\
\hline United Kingdom & $\begin{array}{l}\text { Yes, motorcycles 1973; mopeds } \\
\text { since } 1977\end{array}$ & & No & \\
\hline United States & $\begin{array}{l}\text { No national law. } 19 \text { states require } \\
\text { helmet use by all, } 28 \text { by some } \\
\text { users, } 3 \text { have no helmet law. }\end{array}$ & $\begin{array}{l}65 \text { use of DOT-compliant } \\
\text { helmets ( } 2016 \text { data) }\end{array}$ & $\begin{array}{l}\text { Age-specific helmet laws } \\
\text { in } 21 \text { states and D.C. }\end{array}$ & \\
\hline Uruguay & Yes & & Yes & \\
\hline
\end{tabular}

\section{Notes}

1. The IRTAD database includes validated data for 32 countries. For 2015, it only includes 31 countries, as Argentina did not publish data for 2015.

2. Cambodia, Jamaica, Nigeria, Mexico, Malaysia, Morocco, Serbia, South Africa and Uruguay.

3. See www.itf-oecd.org/safer-city-streets.

\section{References}

DaCoTA (2012), Older Drivers, Deliverable 4.8k of the EC FP7 project “Road Safety Data, Collection, Transfer and Analysis" (DaCoTA).

Hakamies-Blomqvist, L., T. Raitanen and D. O'Neill (2002), "Driver ageing does not cause higher accident rates per km", Transportation Research Part F: Traffic Psychology and Behaviour, Vol. 5/4, pp. 271-274.

ITF (2016), Zero Road Deaths and Serious Injuries: Leading a Paradigm Shift Towards a Safe System, OECD Publishing, Paris, http://dx.doi.org/10.1787/9789282108055-en.

Torpey, S.E. (1986), Licence re-testing of older drivers, Road Traffic Authority, Hawthorn, Melbourne.

UNESC (2014), World demographic trends. Report of the Secretary General, United Nations Economic and Social Council E/CN.9/2014/3. 



\section{Chapter 2}

\section{Argentina}

This chapter presents provisional data for Argentina from 2016. As Argentina could not publish data for 2015, it looks at trends in traffic and road safety from the years 1990 to 2014 and road user behaviour patterns, with a special focus on the ageing population. Sections include data on speed, drink driving, drugs and driving, distracted driving, and seat belt and helmet use. The chapter reviews Argentina's road safety strategy, national targets, recently implemented measures and ongoing research.*

* All data stem from the National Road Safety Agency (ANSV) and IRTAD unless otherwise noted. For more information please contact Veronica Heler: vheler@seguridadvial.gov.ar. 


\begin{abstract}
According to provisional data, in 2016 there were approximately 5550 deaths on Argentinean roads. Argentina did not publish official data for 2015 due to incomplete reporting. However, estimates indicate that fatalities, as in previous years, remained at around the 5000 mark. This relative stagnation should be seen in the context of the rapid motorisation of Argentina, with a 52\% increase in registered vehicles between 2009 and 2015. Since 2016, the National Road Safety Agency has been reviewing road safety data collection methodology in all jurisdictional districts and introduced a new data collection programme in 2017.
\end{abstract}

\title{
Road safety data collection
}

\section{Definitions applied in Argentina}

- Road fatality: Person killed in a traffic crash or within 30 days of the crash.

- Serious injury: Non-fatal casualty who stayed more than 24 hours in hospital.

- Slight injury: Non-fatal casualty admitted to hospital for less than 24 hours.

\section{Data collection}

The National Road Safety Agency (ANSV) of Argentina joined the International Road Traffic and Accident Database (IRTAD) group in 2010. It benefited in 2010-12 from a twinning programme with the General Traffic Directorate of Spain to review and audit its crash data collection and analysis system. This programme has been instrumental in guiding ANSV in the improvement of the data collection process, conforming to international standards and indicators. In 2013, data from Argentina were validated for inclusion in the IRTAD database.

The 24 Argentinean jurisdictions inform aggregated monthly road crash data using a tool known as the "A Form", which is the main source of official statistics.

In order to get more detailed road crash statistics, the Argentinean road safety statistical form (FEU is its Spanish acronym) was implemented in 2010. This form was being used by 12 of the 24 Argentinean provinces by 2015 to report detailed data on road crashes. However, figures obtained from this source of information show, when compared with the aggregated source, that there is a large amount of underreporting. Therefore, more efforts are needed to improve the coverage of the detailed database.

The A Form is for the most part sent electronically to the ANSV, but a few provinces still send it by postal mail. FEU forms are sent by postal mail to the ANSV where they are digitalised, and a few provinces have implemented a digital system to locally process part of the information contained in them. The ANSV is currently implementing a computerised data collection system that is expected to improve the field work of the police, resulting in faster and more efficient procedures. Among other important features, the system will integrate several sources of information to enable cross-checking, allowing early detection of missing observations. Underreporting is quite high for crashes without injuries and those with slight injuries.

The ANSV is currently working closely with the 24 jurisdictions in order to review their crash data collection process. In 2016, the Agency visited most of the provincial agencies in 
charge of road safety statistics, to sign new information exchange agreements, provide training and create a network of local road safety observatories. Since 2017, a new software programme called SIGISVI has started to be implemented in the territory. Its main purpose is to improve the data collecting process and enhance evidence-based decision making by bringing technology to sub-national levels of government.

Since 2010, the ANSV has been working with the Ministry of Health to link hospital records and the FEU Form data. However, very modest progress has been attained so far due to the diverse complexities of the Argentinean health system.

\section{Most recent safety data}

\section{Road crashes in 2016 - provisional data}

Based on provisional data, approximately 550 road deaths were registered in 2016. To finalise their data, some provinces follow a cross-checking procedure with several sources of information that can take up to 8 months. Consequently the final figure is expected to be different.

\section{Road crashes in 2015}

About 5000 road fatalities were registered by the police in 2015. However, the ANSV has not published official data for the year 2015, as some of the 24 sources of information (from the 24 jurisdictions) on which such statistics are based did not validate or send the information in the correct way

For these reasons, there are no further road safety indicators for the year 2015 in this report. It is worth mentioning that for this same year, the Direction of Health Statistics and Information from the Health Ministry reported a total of 4566 road fatalities.

In December 2015, a bus transporting police officers plunged off a precipice in Salta province, killing more than 40 people. This event was a national tragedy.

\section{Traffic}

Motorisation is growing quickly in Argentina. Based on vehicle registration data, the number of motorised vehicles grew by more than 6 million units from 2009 to 2015, a 52\% increase; this includes an increase of 3.5 million motorcycles, more than doubling the fleet over this 5-year period. It should be noted, however, that these data includes figures for scrapped vehicles.

This extremely rapid motorisation raises important challenges in terms of traffic and infrastructure management, congestion and safety.

\section{Road safety}

\section{Crashes and casualties}

Since 2008, the number of road fatalities has fluctuated between 5000 and 5 200, even when considering different sources of information. This relative stagnation is to be analysed in relation to the explosion in the number of vehicles.

\section{Rates}

In 2014, the mortality rate was 12.4 deaths per 100000 inhabitants. The fatality risk decreased to 2.2 deaths per 10000 registered vehicles, a 22\% decrease when compared to 2010. This rapid decrease is related to the rapid increase in the vehicle fleet. 
Table 2.1. Road safety and traffic data

\begin{tabular}{|c|c|c|c|c|c|c|c|c|}
\hline & \multirow{2}{*}{2009} & \multirow{2}{*}{2010} & \multirow{2}{*}{2012} & \multirow{2}{*}{2013} & \multirow{2}{*}{2014} & \multicolumn{3}{|c|}{$2014 \%$ change from } \\
\hline & & & & & & 2013 & 2010 & 2009 \\
\hline \multicolumn{9}{|l|}{ Reported safety data } \\
\hline Fatalities & 5219 & 5094 & 5074 & 5209 & 5279 & 1.3 & 3.6 & 1.1 \\
\hline Injury crashes & 90851 & 89403 & 92240 & 89630 & 84513 & -5.7 & -5.5 & -7.0 \\
\hline Deaths per 100000 inhabitants & 13 & 12.6 & 12.3 & 12.3 & 12.4 & 0.2 & -1.6 & -4.8 \\
\hline Deaths per 10000 registered vehicles & 3.2 & 2.9 & 2.5 & 2.3 & 2.2 & -3.7 & -21.9 & -29.5 \\
\hline \multicolumn{9}{|l|}{ Traffic data } \\
\hline Registered vehicles (thousands) & 16416 & 17751 & 20684 & 22371 & 23544 & 5.2 & 32.6 & 43.4 \\
\hline Registered vehicles per 1000 inhabitants & 409 & 438 & 501 & 530 & 552 & 4.1 & 25.9 & 34.9 \\
\hline
\end{tabular}

Note: Vehicle fleet data includes figures for scrapped vehicles.

Figure 2.1. Road safety, traffic and GDP trends index $1990=100$

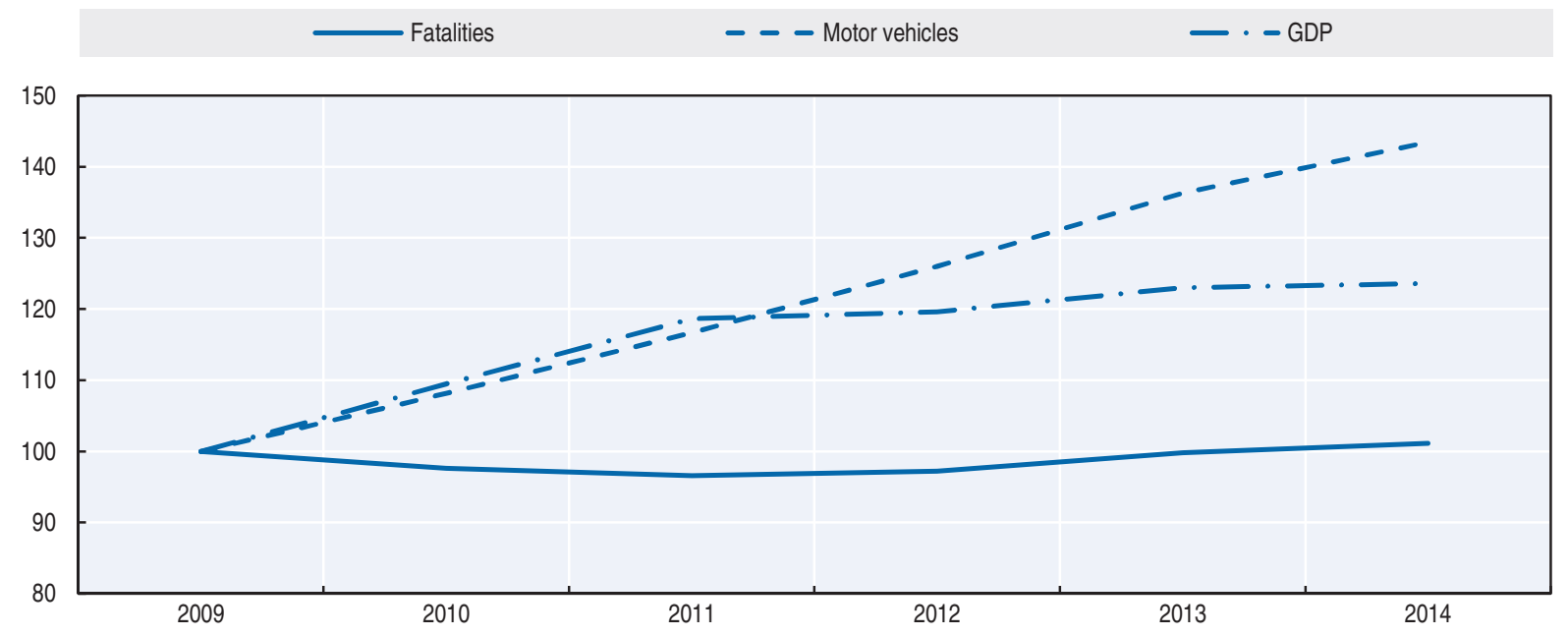

Note: Vehicle fleet data includes figures for scrapped vehicles.

Source: World Bank (2017) (GDP; constant prices).

\section{Road safety by user group}

Data collected by the ANSV showed a steady decrease in car occupant fatalities since 2010. However, the situation for all other road users deteriorated.

The number of pedestrians killed increased by more than $72 \%$ since 2010 . In 2014 , this number increased by $8 \%$ when compared with 2013. Based on reported data, pedestrians represent $11 \%$ of all road fatalities.

The number of motorcyclists killed has increased by $46 \%$ since 2010 . This increase is to be analysed in conjunction with the rapid expansion of the motorcycle fleet which has more than doubled in the last five years. The safety of powered two-wheelers is a major concern in Argentina, in particular in urban areas. Since 2012 the safe interaction between motorcycles, pedestrians and cyclists in urban areas has become a priority.

\section{Road safety by age group}

In 2014, 23\% of traffic fatalities involved road users between 15 and 24 years old, who represent $17 \%$ of the total population. Young people have a higher risk than the general 
Table 2.2. Road fatalities by road user group

\begin{tabular}{|c|c|c|c|c|c|c|}
\hline & \multirow{2}{*}{2010} & \multirow{2}{*}{2012} & \multirow{2}{*}{2013} & \multirow{2}{*}{2014} & \multicolumn{2}{|c|}{$2014 \%$ change from } \\
\hline & & & & & 2013 & 2010 \\
\hline Cyclists & 77 & 96 & 102 & 83 & -18.6 & 7.8 \\
\hline Motorcyclists & 1161 & 1344 & 1547 & 1691 & 9.3 & 45.7 \\
\hline Passenger car occupants & 2923 & 2778 & 2619 & 2363 & -9.8 & -19.2 \\
\hline Pedestrians & 329 & 382 & 524 & 568 & 8.4 & 72.6 \\
\hline Others & 604 & 474 & 417 & 574 & 37.6 & -5.0 \\
\hline Total & 5094 & 5074 & 5209 & 5279 & 1.3 & 3.6 \\
\hline
\end{tabular}

Source: Informed by recent Direction of National Road Safety Observatory (2010-15).

Figure 2.2. Road fatalities by road user group in percentage of total, 2014

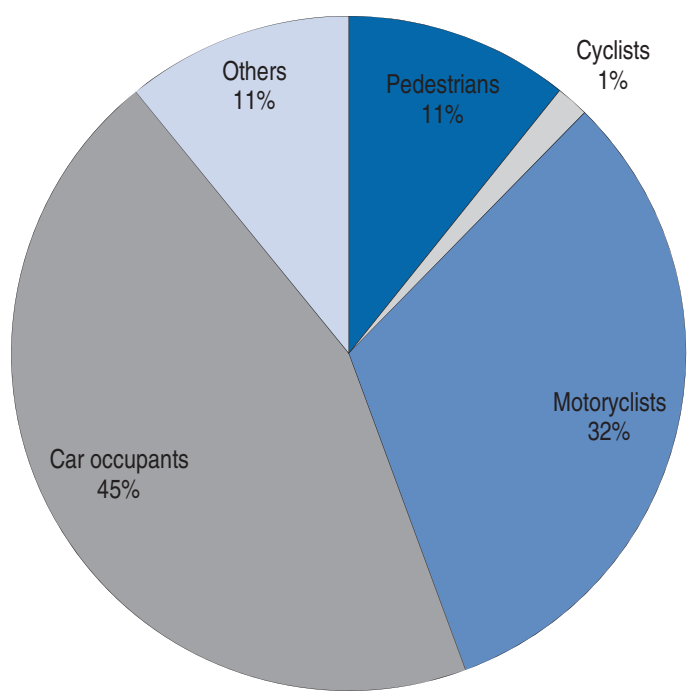

Source: Based on data from the National Road Safety Observatory (2010-15).

population, followed closely by road users aged 25 to 64 . Since 2010, the number of young people killed in this age group has increased by $10 \%$.

Since 2010, much improvement has been observed for the senior population with a $28 \%$ overall decrease in the number of fatalities, despite a 6\% increase in 2014.

Table 2.3. Road fatalities by age group

\begin{tabular}{lrrrrrr}
\hline \multirow{2}{*}{ Age } & 2010 & 2012 & 2013 & 2014 & \multicolumn{2}{c}{$2014 \%$ change from } \\
\cline { 5 - 6 } & & & & & 2013 & 2010 \\
\hline $0-5$ & 166 & 129 & 91 & 161 & 25.8 & -3.0 \\
$6-9$ & 108 & 107 & 105 & 110 & 11.1 & 1.9 \\
$10-14$ & 139 & 369 & 396 & 390 & -1.5 & -21.6 \\
$15-17$ & 358 & 367 & 385 & 379 & -1.6 & 7.1 \\
$18-20$ & 354 & 481 & 523 & 516 & -1.3 & 11.4 \\
$21-24$ & 463 & 3111 & 3224 & 2980 & -7.6 & -0.2 \\
$25-64$ & 2987 & 429 & 349 & 372 & 6.6 & -28.3 \\
65 & 519 & $\mathbf{5 0 7 4}$ & $\mathbf{5 2 0 9}$ & $\mathbf{5 2 7 9}$ & $\mathbf{1 . 3}$ & $\mathbf{3 . 6}$ \\
\hline
\end{tabular}

Note: The ANSV collects aggregate road fatalities information for the following age ranges: 0-5; 6-14; 15-24; $25-34 ; 35-44$; $45-54 ; 55-64 ; 65-74 ;+75$. The information was estimated as a weighted average, considering age distribution of the total population as published by the National Institute of Statistics and Censuses of Argentina (INDEC). 
Figure 2.3. Road fatality rates by age group Deaths per 100000 inhabitants in a given age group, 2009-14

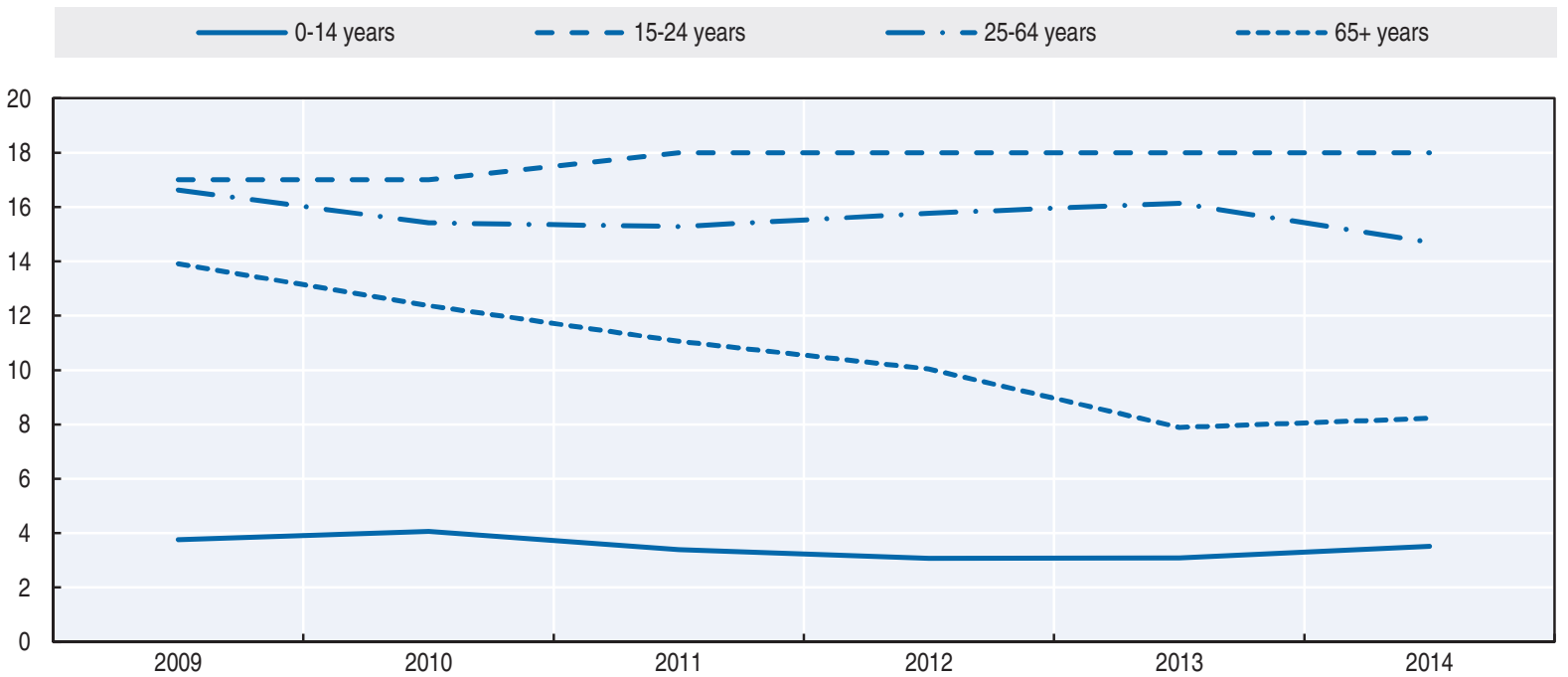

\section{Box 2.1. Road safety for an ageing population}

In 2015, there were approximately 44 million inhabitants in Argentina, of which 3.3 million (7.5\%) were aged 70 years or over. According to official projections, the elderly segment of the population is expected to have by far the largest increase in the next 20 years, with an average annual growth rate of $2.4 \%$. Ageing is not only a challenge itself for social systems but also raises significant questions for road safety policy makers.

Figure 2.4. Evolution of the number of deaths and fatality rate of the senior population. 2005-14

$\square$ Road deaths

$\diamond$ Mortality rate

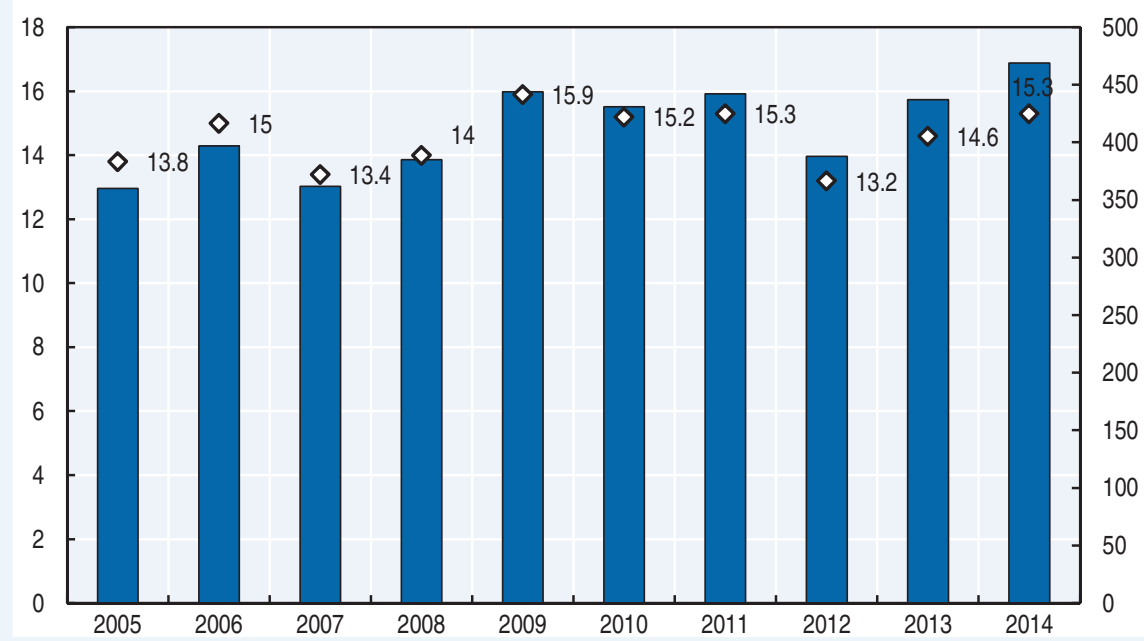




\section{Box 2.1. Road safety for an ageing population (cont.)}

According to health registers, in 2014, 470 people aged 70 and over were killed in traffic crashes, representing $9 \%$ of all road reported road deaths. With a mortality rate of 15.3 deaths per 100000 , they are the second age group (after the 15-29 year olds) most at risk in traffic.

There is no clear trend regarding the evolution in the mortality rate of the older population in the last 10 years. However, there has been a steady increase during the last 3 years for which data are available.

In Argentina, it is compulsory for people aged 70 years or more to apply annually for a renewal of their driving license. This requires taking a theoretical and a practical test, together with a complete medical exam that includes visual, hearing, physical and psychological tests. No research is available regarding the effectiveness of such medical examinations.

Source: Health Ministry.

\section{Road safety by road type}

In 2014, 93\% of all reported road crashes occurred in urban and suburban areas, accounting for $89 \%$ of injured persons and $58 \%$ of fatalities. Non-urban areas accounted for $7 \%$ of road crashes but $42 \%$ of fatalities.

The safety of pedestrians, cyclists and motorcyclists in urban areas remains a major challenge. The number of fatalities has increased by 13\% in urban areas since 2010.

\section{Figure 2.5. Reported road fatalities by location}

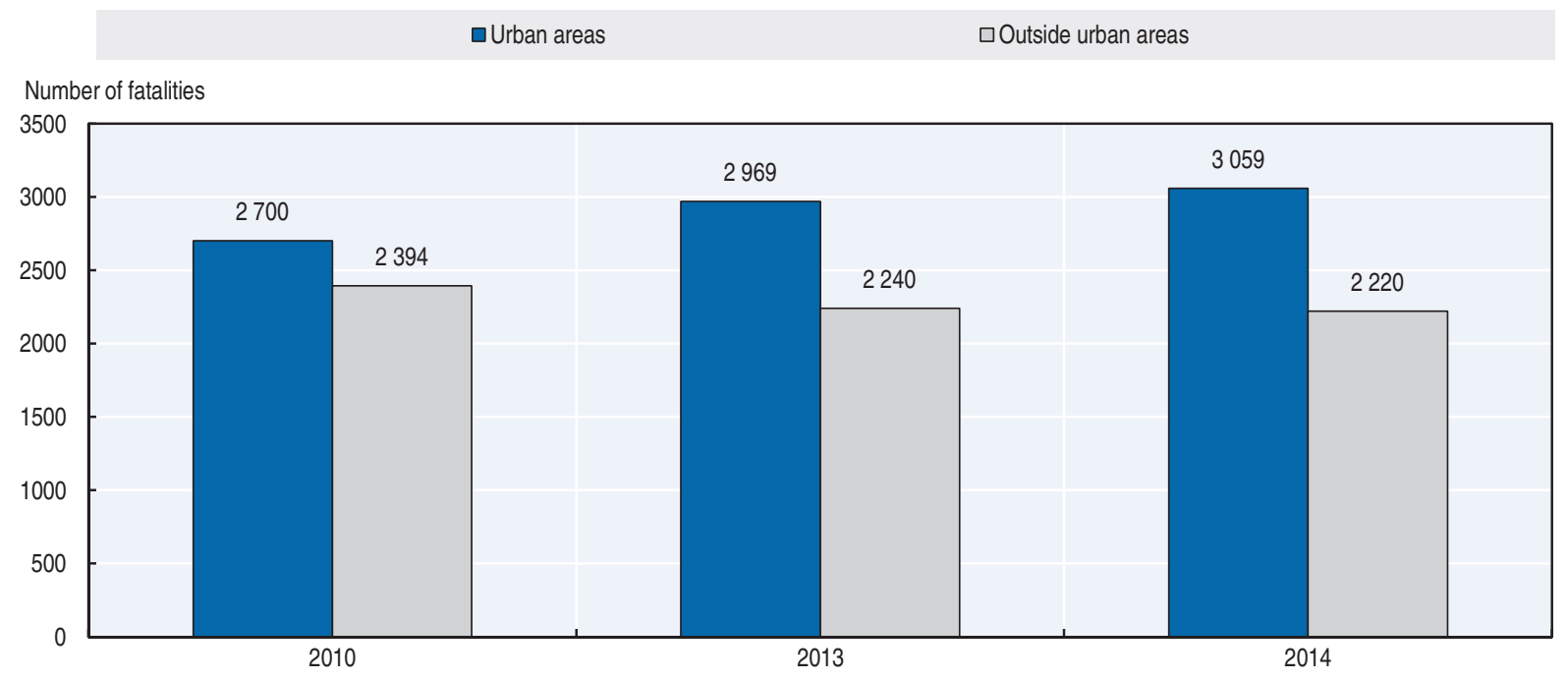

\section{Economic costs of traffic crashes}

In 2010, it was estimated that road crashes represented 1.2\% of the Argentina's GDP (PAHO and ANSV, 2012).

In 2016, the ANSV developed a preliminary methodology to estimate the social cost of road crashes. The methodology is based on the Human Capital Method. The main cost components are victim related costs (productivity loss, medical costs and other costs), and damage costs. 
In 2016, a pilot study was conducted in the province of Mendoza. The preliminary results show that the social cost for road crashes in 2015 amount to ARS 3050 million (Argentine Pesos) (approximately USD 276 million). Productivity loss and medical costs account for the majority of total cost (respectively $48 \%$ and $37 \%$ of total costs) (see Table 2.4). However, the methodology does not allow distinguishing the costs borne by the government and those borne by the private sector. Further research in this area would be useful in order to convince policy makers to invest more in prevention.

The methodology is currently under review, and a final methodology will be released in 2018.

Table 2.4. Cost of road crashes in the Province of Mendoza, 2015

\begin{tabular}{lcc}
\hline Component & ARS & Relative share \\
\hline Total & ARS $\mathbf{3} \mathbf{0 5 0} \mathbf{4 7 9} \mathbf{8 6 5}$ & $\mathbf{1 0 0 \%}$ \\
Costs associated with the victims & ARS 2 709 085 069 & $88.8 \%$ \\
Productivity loss & ARS 1 476 570 369 & $48.4 \%$ \\
Medical costs & ARS 1 137 611 929 & $37.3 \%$ \\
Other costs & ARS 94 902 770 & $3.1 \%$ \\
Material costs & ARS 341 394 796 & $11.2 \%$
\end{tabular}

\section{Recent trends in road user behaviour}

Speed

The table below summarises the main speed limits in Argentina.

Table 2.5. Passenger car speed limits by road type, 2017

\begin{tabular}{|c|c|c|c|c|}
\hline Location & Number of lanes & Median barrier & Controlled-access & Speed limit $(\mathrm{km} / \mathrm{h})$ \\
\hline Urban* & 2 & No & No & 40 \\
\hline Urban* & $2+2$ or more & No & No & 60 \\
\hline Rural & $1+1$ & No & No & 110 \\
\hline Rural & $2+2$ or more & Yes & No & 120 \\
\hline Rural & $2+2$ or more & Yes & Yes & 130 \\
\hline
\end{tabular}

* Buenos Aires City has a range of 20 to $70 \mathrm{~km} / \mathrm{h}$, divided in 5 categories.

\section{Drink driving}

A maximum legal blood alcohol content (BAC) was introduced in February 1995 of $0.5 \mathrm{~g} / \mathrm{l}$ for most road user categories and zero for professional drivers of buses, taxis and trucks.

In 2017 the ANSV and SEDRONAR will conduct a study to assess the incidence of psychoactive substances, including alcohol, in the occurrence of road crashes. Results are expected by the end of 2018 .

\section{Drugs and driving}

The national traffic law prohibits driving while "having consumed illegal or legal drugs that reduce the ability to drive".

Research undertaken by SEDRONAR estimated that out of a sample of 1777 surveyed cases in 2012 throughout the country, 22.5\% of road casualties treated in emergency rooms had consumed some type of psychoactive substance (including alcohol among them). It is worth mentioning that results were based on a declarative survey, and most probably they 
underestimate the real extent of the problem. This figure is similar to the ones obtained on previous studies. A new survey financed by the ANSV and co-ordinated with SEDRONAR will be conducted during 2017. It will be based on voluntary tests of people injured in road crashes (breath tests for alcohol and urine rapid tests for 4 different categories of drugs).

\section{Distraction}

The national traffic law prohibits the use of mobile phones, electronic hand-held devices, DVD players and similar devices while driving.

\section{Sleepiness and fatigue}

National legislation requires professional drivers to rest eight hours after eight hours of driving. Controls are heavily focused on professional drivers of long-distance public transport.

\section{Seat belts and helmets}

Seat belt wearing has been compulsory in front and rear seats since February 1995. Dedicated child restraint systems are mandatory for children under four years old. The table below summarises the evolution in the seat belt wearing rate. While there is some improvement since 2011, the wearing rate is still very low in comparison to most OECD countries. The evolution also shows that improvement has stagnated since 2014.

Table 2.6. Seat-belt wearing rate by car occupancy

\begin{tabular}{|c|c|c|c|c|c|}
\hline & 2011 & 2012 & 2013 & 2014 & 2016 \\
\hline \multicolumn{6}{|l|}{ Front seat } \\
\hline General & 33 & 38 & 38 & 45 & 41 \\
\hline Drivers & 39 & 44 & 42 & 52 & 50 \\
\hline Passengers & 29 & 34 & 37 & 45 & 43 \\
\hline \multicolumn{6}{|l|}{ Rear seats } \\
\hline Adults & 11 & 18 & 26 & 19 & 23 \\
\hline Child restraint system & 26 & 29 & 34 & 45 & 47 \\
\hline
\end{tabular}

All riders of powered two-wheelers are required to wear helmets. In 2016, it was estimated that $65 \%$ of motorcycle riders and $44 \%$ of passengers wore a helmet (considering only the first passenger). These results show stagnation for the helmet rate use, for both riders and passengers, since the last survey in 2014.

\section{National road safety strategies and targets Organisation of road safety}

The National Road Safety Agency (ANSV), created in 2008 under the Ministry of the Interior and Transport, is the leading road safety agency in Argentina. The agency has two councils and committees: a Federal Council, represented by one member of each province; and a Consultative Committee, represented mainly by relatives of road safety victims.

All road safety policies are decided within the ANSV. Since its inception, the focus has been on the creation of a national driver's licence, a national education plan, a national monitoring plan and creation of the National Road Safety Observatory. However, as Argentina is a federal country, provinces are empowered to accept or not recommendations by the government, as represented by the ANSV. 


\section{Road safety strategy for 2011-2020}

A new road safety strategy is under development. It will be based on the pillars recommended by the United Nations Road Safety Plan for the Decade of Action for Road Safety.

\section{Road safety targets}

The government set an objective of a reduction in the number of road traffic fatalities by 50\% between 2009 and 2014. Specific targets for 2020 are being developed following the pillars of the Decade-of-Action Plan.

\section{Monitoring}

The target to halve the number of fatalities between 2009 and 2014 was probably unrealistic in such a short time frame and was not achieved.

Figure 2.6. Trends in road fatalities towards national target

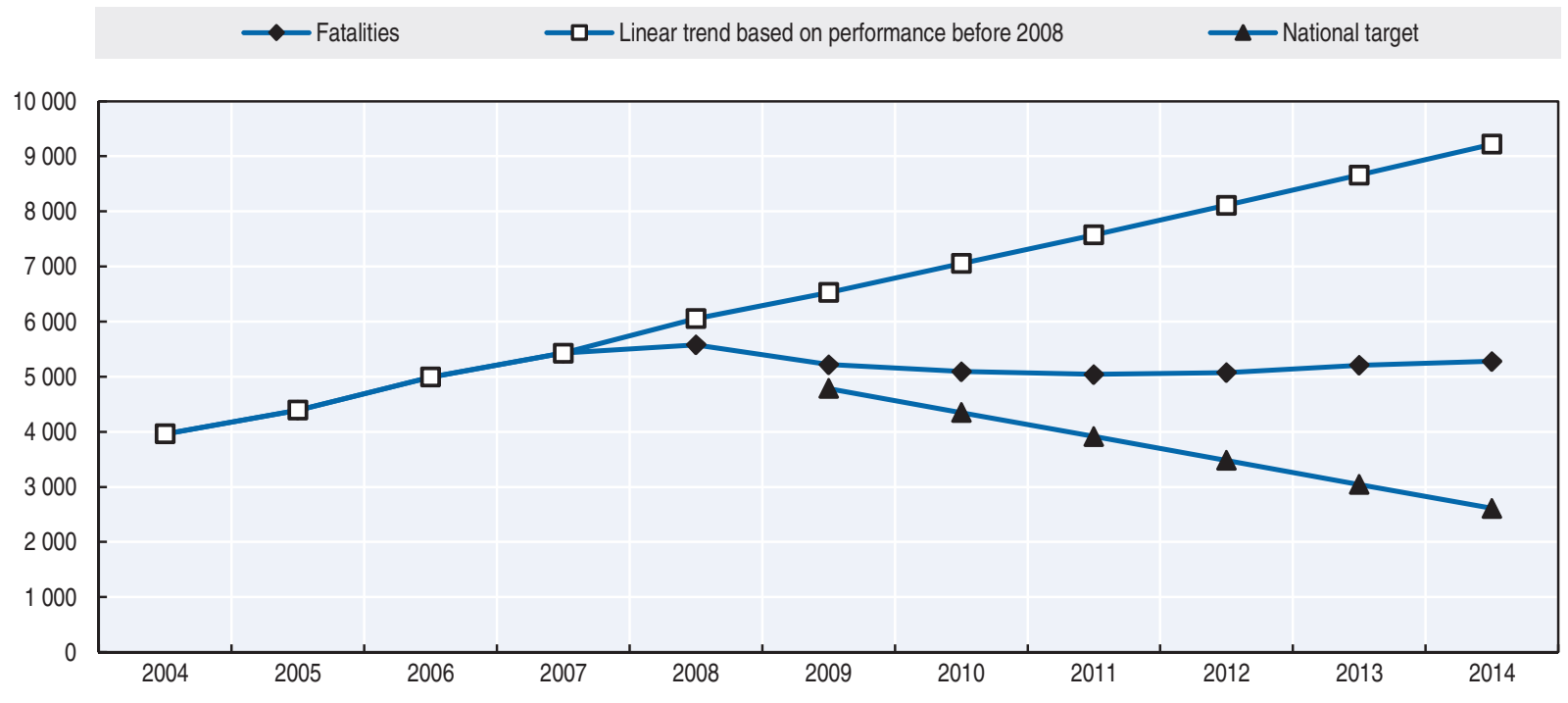

\section{Recent safety measures (2014-17)}

\section{Road safety management}

\section{National licensing system}

- In 2014, 23 of the 24 Argentinean regional authorities adopted a new National Driving Licence system. The national licensing system centralises driving documentation. This mechanism allows criminal background checks, traffic violation checks, judicial disqualifications and the scoring of the person seeking the licence. By 2016, all 24 authorities had adopted this system. However, pre-existing local systems are still in use; efforts are being made to include them in the new national system.

\section{Road users}

\section{Motorcyclist safety}

- In 2012, the ANSV, in co-operation with the Ministry of Health, motorcyclists' associations and other stakeholders, launched a National Motorcycle Plan. It has also launched several safety campaigns specially targeting this group of users since then. 


\section{Impaired driving}

- In December 2016 a new law incrementing penal punishments for crimes committed while driving under the influence of alcohol was approved (Law 27.347).

\section{Education and training}

- In 2014, the ANSV initiated the "Safe Road to School" programme. It started with surveys in schools on mobility patterns of children. This was followed by the implementation of a safe road network to access the schools. In 2016, a total of 15 schools comprising about 6300 students participated in such a programme.

- In 2016, the ANSV created a new department for the design and implementation of road safety campaigns, educational programmes and press communication, in an effort to coordinate awareness campaigns with more and better traffic controls.

- Since 2011, more than 550 conferences reaching more than 100000 people took place in high schools all over the country, to increase awareness among students about road safety measures. These conferences were aimed at promoting care and respect for others and raising awareness about behaviour in public spaces.

\section{Infrastructure}

- Since 2011 a total of 37855 kilometres of road were surveyed by the ANSV to determine their risk level in terms of road safety and to ensure intervention is assigned to the relevant authorities.

- The ANSV is working together with the National Road Direction (DNV) to carry out road safety audits and to survey road sections, which in turn will enable the implementation of road safety improvements. Such joint work became fully viable in 2016, when both governmental institutions were put under a common national ministry.

\section{Vehicles}

- Since 2011, several agreements were reached with car manufacturers and importers to implement European standards for new vehicles sold in Argentina.

- The ANSV is proposing an integral modification of the Road Traffic Bill, which includes the recognition and regulation of electric vehicles and quads.

Table 2.7. Implementation dates of vehicle safety systems

\begin{tabular}{|c|c|c|}
\hline Safety systems & New vehicle models & All vehicle models \\
\hline Anti-lock braking system & & 1 January 2014 \\
\hline Airbags & & 1 January 2014 \\
\hline Seat-back head restraints contiguous to the doors & & 1 January 2014 \\
\hline Centre head restraint & & 24 months after its compulsory application in Europe \\
\hline Seat Belt Reminder (SBR) & 1 January 2014 & $\begin{array}{l}1 \text { January } 2015 \text { (In both cases visual and acoustic } \\
\text { only for the driver) }\end{array}$ \\
\hline Daytime Running Lights (DRL) & 1 January 2014 & \\
\hline Frontal impact test according to the UNECE regulation & 30 January 2014 & 30 January 2016 \\
\hline Rear impact test according to the UNECE regulation & 24 months after its compulsory application in Europe & 24 months after its compulsory application in Europe \\
\hline Child Restraint System (ISOFIX or LATCH) & 1 January 2016 & 1 January 2018 \\
\hline Side impact test according to the UNECE regulation & 1 January 2018 & 1 January 2022 \\
\hline Electronic Stability Control & 1 January 2018 & \\
\hline Rear seat belt retractor & & 1 January 2016 \\
\hline Third stop light & & 1 January 2014 \\
\hline Mounting bracket and provision of fire extinguisher & & 1 January 2015 \\
\hline
\end{tabular}




\section{Recent and ongoing research}

Two main studies were carried out by the ANSV in 2016:

- The fifth National Survey on Road Safety Behaviour. The results of this survey are very important for policy makers at different levels of government as they set the baselines for policy planning and indicators to monitor progress.

- A socio-cultural survey on Road Safety Perceptions. The results provided valuable insights highlighting the challenges in changing user behaviour.

The analysis of the results of both surveys revealed the large gap between declarative and observed behaviours. Figure 2.7 illustrates such a gap for seat belt use by car occupants.

\section{Figure 2.7. Seat belt use by car occupants Results of the observational study and the socio-cultural study}

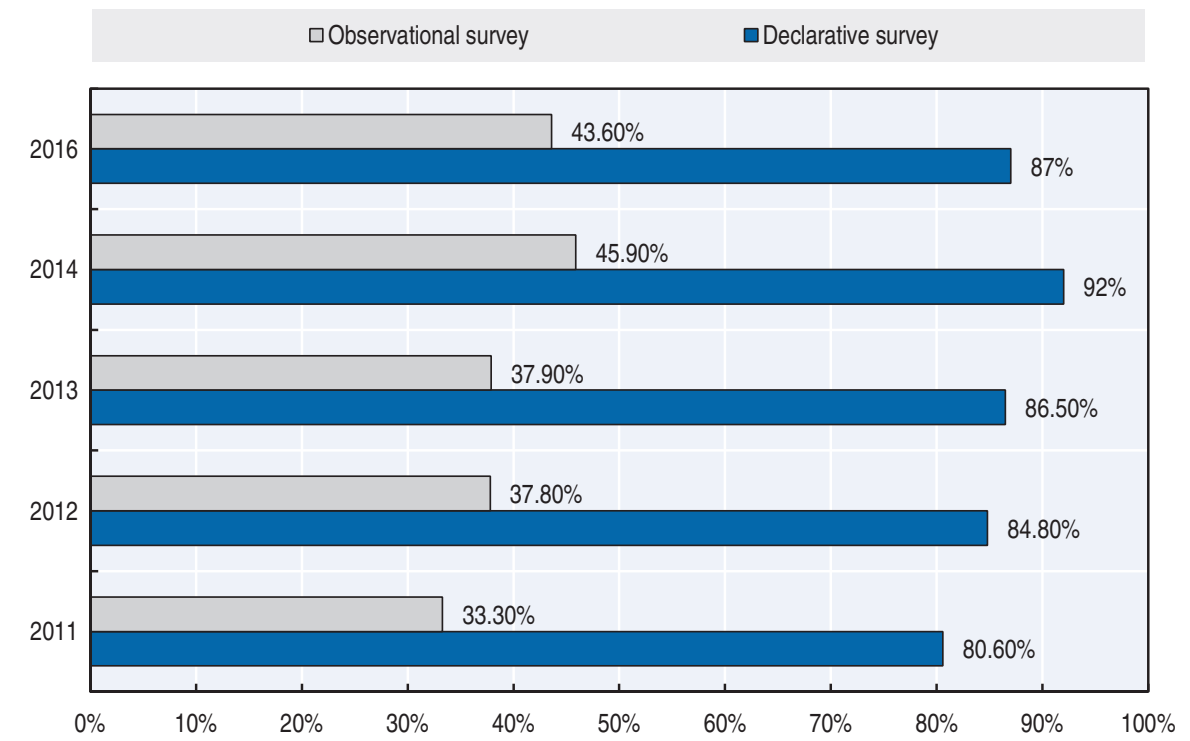

As mentioned before, a preliminary methodology to estimate the social costs of road crashes was developed and used in a pilot test in the province of Mendoza. Such methodology is currently under review and it is expected to be finalised by 2018 .

These studies were carried out by a new research unit of the Road Safety Observatory that was created in 2016.

\section{References}

ANSV (2017), Estudio Observacional del comportamiento de conductores y ocupantes de vehículos de 2 y 4 (o más) ruedas; National Road Safety Agency (ANSV), Buenos Aires.

World Bank (2017), “GDP (constant US\$)”, World Development Indicators, http://databank.worldbank.org/ data/reports.aspx?source=world-development-indicators (accessed 23 February 2017).

\section{Websites}

- National Road Safety Agency (ANSV): www.seguridadvial.gov.ar/ (accessed 19 June 2017).

- National Road Safety Observatory: http://observatoriovial.seguridadvial.gov.ar (accessed 19 June 2017). 


\section{Chapter 3}

\section{Australia}

This chapter presents 2015 road safety data for Australia along with provisional data from 2016. It looks at trends in traffic and road safety from the years 1990 to 2015 and road user behaviour patterns, with a special focus on the ageing population. Data on speed, drink driving, drugs and driving, distracted driving, fatigue and seat belt usage is also included. Australia's National Road Safety Strategy for 2011-20 is supported by an Action Plan for 2015-17. The chapter reviews these strategies, their development and implementation and the progress achieved to date. It also looks at recently adopted safety measures and improvements in infrastructure.

* All data stem from the Australia Department of Infrastructure and Regional Development and IRTAD unless otherwise noted. For more information please contact: Tim.Risbey@infrastructure.gov.au. 
Since 1990 road deaths in Australia have nearly halved, in parallel to an increase of $79 \%$ in the number of registered vehicles on the road. Road deaths reached an all-time low in 2014 of 1150 or 4.92 per 100000 inhabitants. However, since 2014 a reversal in this trend has been observed. Road deaths in 2015 increased by 4.7\% over 2014 figures to 1205 with provisional data from 2016 indicating a further increase of $7.2 \%$ to 1292 fatalities. This increase is seen in all user groups, except cyclists where the number of fatalities continues to fall. All age groups are also affected although the last ten years show the ageing population to be at increasing risk, with the over 65 age group accounting for $22 \%$ of all fatalities.

\section{Road safety data collection}

\section{Definitions applied in Australia}

- Road fatality: A person who dies within 30 days of a crash as a result of injuries received in that crash.

- Serious/slightly injured: Australia does not have systems in place to reliably measure national indicators of injuries from road crashes, in part due to jurisdictional differences in injury definitions and reporting arrangements.

A national pilot project, expected to be completed by the end of 2017, is being undertaken to link hospital and crash data sets. Pending a successful outcome, deciding an appropriate national definition of what constitutes a serious injury and the establishment of an on-going monitoring process may then become possible.

\section{Data collection}

In Australia, crash data are collected and validated by the police and transport agencies in each of the eight states and territories.

Common protocols for the collection of fatality data have enabled the establishment of a reliable national road fatality database, which is managed by the federal Department of Infrastructure and Regional Development (hereafter referred to as the Department). This database is the source of the fatality data included in this report.

With respect to the collection of serious injury road crash data, there are currently substantial differences in the approaches adopted by the Australian states and territories. The federal Department is working with state and territory agencies on options to develop a national serious injury database; however, significant issues must be resolved before this can occur.

The 2014 Review of the National Road Safety Strategy 2011-2020 found that progress in reducing serious injury numbers was difficult to determine because of the lack of reliable, nationally consistent, non-fatal crash data. Addressing this issue is a priority action. Current efforts to develop national measures of serious injury are focused on a long-term solution to link states' and territories' hospital case data with road crash data, and the adoption of common standards that will enable national aggregation and reporting. 


\section{Most recent road safety data}

\section{Road crashes in 2016 - provisional data}

Based on provisional data, the number of road deaths continued to increase in 2016 reaching 1 292, a 7.2\% increase when compared with 2015.

In particular, deaths of young adults aged between 17 and 25 increased by 17\% from 2015. Deaths of older persons aged 65 and above decreased by 1\% from 2015.

\section{Road crashes in 2015}

In 2015, there were 1205 road fatalities, representing a 5\% increase when compared with 2014.

In particular, deaths among young drivers/motorcyclists aged between 17 and 25 decreased by $2.7 \%$ from 2014 . The deaths of older drivers/motorcyclists aged 65 and above increased by $7.4 \%$ from 2014.

\section{Trends in traffic and road safety (1990-2016) Traffic}

Between 1990 and 2015, the number of motorised vehicles registered for road use increased by $79 \%$ and overall vehicle-kilometres-travelled increased by $52 \%$.

While light passenger vehicles still account for more than $71 \%$ of traffic volume in Australia, there has been a gradual increase in the presence of motorcycles and commercial vehicles. Between 1990 and 2015, the number of vehicle-kilometres-travelled by light commercial vehicles grew by $102 \%$, articulated trucks by $95 \%$, motorcycles by $66 \%$ and cars by $41 \%$.

In 2015 , the number of motorised vehicles increased by $2.1 \%$ and vehicle-kilometres travelled increased by $1.7 \%$ when compared to 2014 .

\section{Road safety \\ Crashes and casualties}

Since 1990, there has been an underlying and relatively constant downward trend in road deaths, with an overall reduction in total fatalities of nearly $50 \%$. Key measures contributing to this reduction, particularly over the last decade, have been the implementation of intensive speed compliance measures, progressive introduction of graduated licensing restrictions, targeted safety investment in road infrastructure and continuous vehicle safety improvements.

Under Australia's National Road Safety Strategy 2011-2020, key statistical indicators are benchmarked against the three-year period 2008 to 2010. Overall, fatality numbers to the end of 2015 decreased by 15\%. However, there were notable differences in trends for some road user groups and crash types:

- Deaths of young drivers and motorcyclists (aged 17-25 years) decreased by $4.6 \%$.

- Deaths of all motorcyclists decreased by $13 \%$.

- Deaths of older drivers and motorcyclists (aged $65+$ years) increased by $28 \%$.

- Deaths of bicycle riders decreased by $7 \%$ (though relatively small numbers).

Over this period there were positive changes in vehicle sales.

- The proportion of new light vehicles sold with a 5-star Australasian New Car Assessment Program (ANCAP) rating increased to $86 \%$. 
However in the past two years (since 2014) deaths have increased by $12.7 \%$. The increases occur in all ages (except for 0 to 16), and in all road user groups except passengers and bicyclists, neither of which show consistent decreases. Despite the more recent increases, total deaths in 2016 were down from the $2008-2010$ baseline period by $9 \%$.

\section{Rates}

In 2015, the number of annual deaths per 100000 population was 5.1, a 3.3\% increase compared to its lowest level of 4.9 reached in 2014. Overall, since 2010, the mortality rate has decreased by $17.5 \%$.

Fatality risk expressed in deaths per vehicle kilometres had also reached its lowest level in 2014 at 4.7 fatalities per billion vehicle-kilometres, increasing by 3.1\% in 2015 to 4.9 . There are however important variations between the different states of Australia, with the highest rate, of nearly 4 times the average level, in the Northern Territory.

\section{Analysis of seriously injured data}

Between 2000 and 2013, the number of people hospitalised due to road crashes increased from 26963 to 35 059. However, a break in series on 1 July 2012 means it is not possible to be certain about the size of recent increases. Much of this increase is attributable to vulnerable road users (especially motorcyclists and cyclists).

Table 3.1. Road safety and traffic data

\begin{tabular}{|c|c|c|c|c|c|c|c|c|c|}
\hline & \multirow{2}{*}{1990} & \multirow{2}{*}{2000} & \multirow{2}{*}{2010} & \multirow{2}{*}{2014} & \multirow{2}{*}{2015} & \multicolumn{4}{|c|}{$2015 \%$ change from } \\
\hline & & & & & & 2014 & 2010 & 2000 & 1990 \\
\hline \multicolumn{10}{|l|}{ Reported safety data } \\
\hline Fatalities & 2331 & 1817 & 1351 & 1150 & 1205 & 4.8 & -10.8 & -33.7 & -48.3 \\
\hline Injured persons hospitalised & 25008 & 26963 & 32775 & & & & & & \\
\hline Deaths per 100000 inhabitants & 13.7 & 9.5 & 6.1 & 4.9 & 5.1 & 3.3 & -17.5 & -47.0 & -62.9 \\
\hline Deaths per 10000 registered vehicles & 2.3 & 1.5 & 0.8 & 0.7 & 0.7 & 2.7 & -20.4 & -54.4 & -71.0 \\
\hline Deaths per billion vehicle kilometres & 14.7 & 9.1 & 5.9 & 4.7 & 4.9 & 3.1 & -17.4 & -46.6 & 66.8 \\
\hline \multicolumn{10}{|l|}{ Traffic data } \\
\hline Registered vehicles ${ }^{1}$ (thousands) & 10081 & 12373 & 16061 & 17633 & 18008 & 2.1 & 12.1 & 45.5 & 78.6 \\
\hline Vehicle-kilometres (millions) & 162233 & 198669 & 228768 & 242635 & 246617 & 1.6 & 7.8 & 24.1 & 52.0 \\
\hline Registered vehicles per 1000 inhabitants & 587 & 646 & 724 & 746 & 752 & 0.8 & 3.8 & & 28.1 \\
\hline
\end{tabular}

1. Including mopeds.

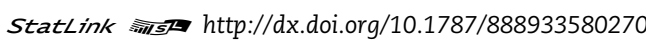

\section{Road safety by user group}

Since 1990, overall fatalities have dropped by nearly $50 \%$, with the most noticeable decreases observed among cyclists (-61\%), pedestrians (-61\%) and vehicle occupants (-49\%). During the same time span, motorcyclist fatalities decreased by only $23 \%$.

Since 2010, cyclist deaths have decreased at the fastest rate (-18\%). Between 2014 and 2015 , the number of cyclists killed decreased by $31 \%$. Despite fluctuations over recent years, cyclist deaths decreased from a high of 50 in 2013 to 45 in 2014 down to 31 in 2015.

In 2015, fatality counts increased for all road user groups except cyclists.

Changes in motorcycle fatalities have been influenced by changes in exposure (number of active riders and age profile as well as total distance travelled). There is concern that automated speed enforcement may have had less influence on motorcycle speeds than on speeds of other vehicles, partly because motorcycles have no front number plates. 
Figure 3.1. Road safety, traffic and GDP trends index $1990=100$

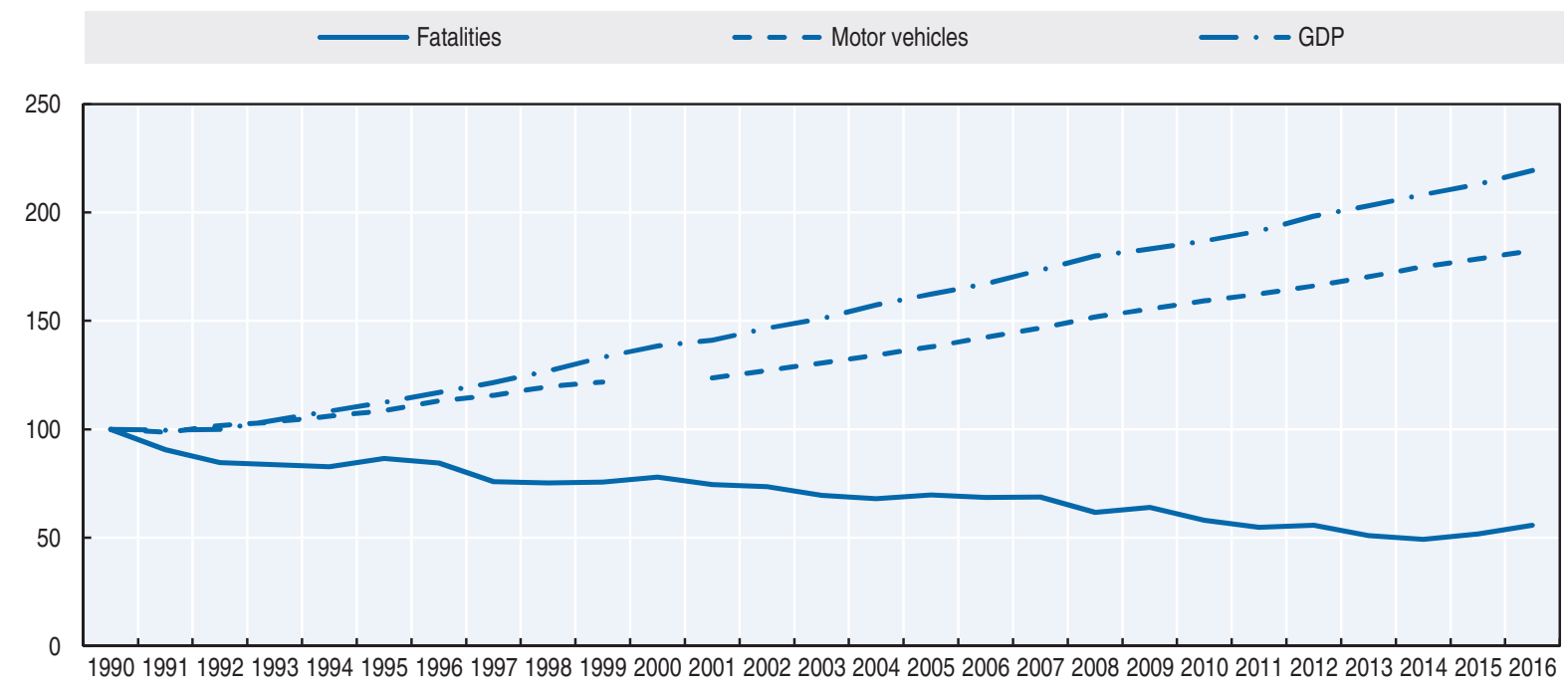
Source: BITRE for Gross Domestic Product (GDP; constant prices).

Table 3.2. Road fatalities by road user group

\begin{tabular}{|c|c|c|c|c|c|c|c|c|c|}
\hline & \multirow{2}{*}{1990} & \multirow{2}{*}{2000} & \multirow{2}{*}{2010} & \multirow{2}{*}{2014} & \multirow{2}{*}{2015} & \multicolumn{4}{|c|}{$2015 \%$ change from } \\
\hline & & & & & & 2014 & 2010 & 2000 & 1990 \\
\hline Pedestrians & 420 & 287 & 172 & 150 & 162 & 8.0 & -5.8 & -43.6 & -61.4 \\
\hline Cyclists & 80 & 31 & 38 & 44 & 31 & -31.8 & -21.1 & -3.2 & -62.5 \\
\hline Motorised two-wheelers & 262 & 191 & 224 & 191 & 203 & 5.8 & -9.8 & 5.8 & -22.9 \\
\hline Car occupants & & & 722 & 566 & 605 & 6.9 & -16.2 & & \\
\hline Others & 1569 & 1308 & 195 & 199 & 204 & 4.0 & 6.2 & & \\
\hline Total & 2331 & 1817 & 1351 & 1150 & 1205 & 4.8 & -10.8 & -33.7 & -48.3 \\
\hline
\end{tabular}

Note: Until 2010 it was not possible to make the distinction between car occupants and other motor vehicle occupants.

Figure 3.2. Road fatalities by road user group in percentage of total, 2015

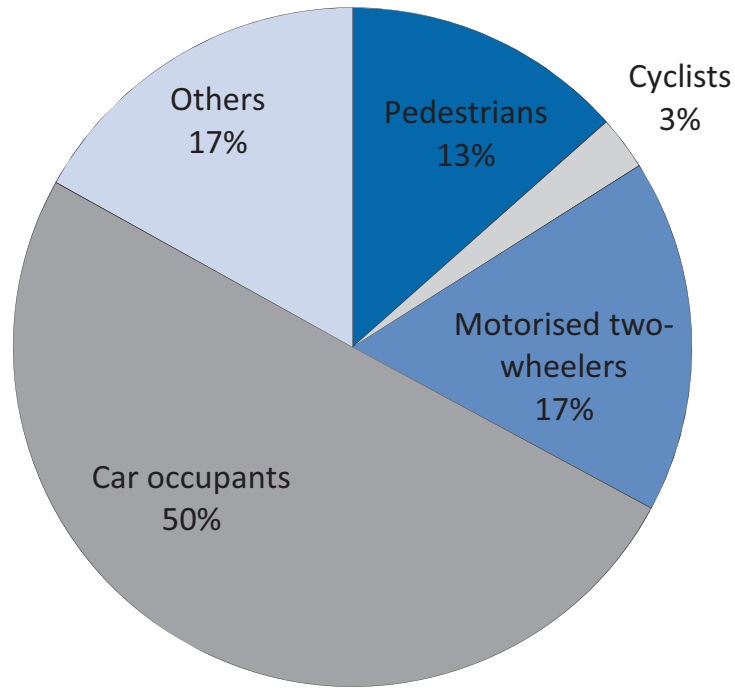




\section{Road safety by age group}

Since 1990, fatality decreases were observed among all age groups. The biggest decreases were observed for young people aged 0 to 14 .

In terms of risk, young people (18-20) are the most at risk in traffic with a mortality rate (deaths per 100000 inhabitants) twice as high as the general population. The second group most at risk is the senior population.

Table 3.3. Road fatalities by age group

\begin{tabular}{|c|c|c|c|c|c|c|c|c|c|}
\hline \multirow{2}{*}{ Age } & \multirow{2}{*}{1990} & \multirow{2}{*}{2000} & \multirow{2}{*}{2010} & \multirow{2}{*}{2014} & \multirow{2}{*}{2015} & \multicolumn{4}{|c|}{$2015 \%$ change from } \\
\hline & & & & & & 2014 & 2010 & 2000 & 1990 \\
\hline $0-14$ & 184 & 114 & 56 & 53 & 43 & -20.8 & -25.0 & -63.2 & -77.2 \\
\hline $15-17$ & 129 & 104 & 53 & 29 & 47 & 62.1 & -11.3 & -54.8 & -63.6 \\
\hline $18-20$ & 340 & 204 & 138 & 86 & 93 & 9.3 & -31.9 & -53.9 & -72.4 \\
\hline $21-24$ & 278 & 178 & 141 & 102 & 83 & -18.6 & -41.1 & -53.4 & -70.1 \\
\hline $25-64$ & 1049 & 923 & 744 & 639 & 669 & 4.9 & -9.9 & -27.4 & -36.1 \\
\hline $65-74$ & 170 & 127 & 96 & 109 & 118 & 8.3 & 22.9 & -7.1 & -30.6 \\
\hline $75-84$ & 165 & 117 & 81 & 79 & 89 & 12.7 & 9.9 & -23.9 & -46.1 \\
\hline$\geq 85$ & 16 & 50 & 41 & 52 & 62 & 19.2 & 51.2 & 24.0 & 287.5 \\
\hline Total including unknown & 2331 & 1817 & 1351 & 1150 & 1206 & 4.9 & -10.7 & -33.6 & -48.3 \\
\hline
\end{tabular}

Figure 3.3. Road fatality rates by age group Deaths per 100000 inhabitants in a given age group, 1990-2015

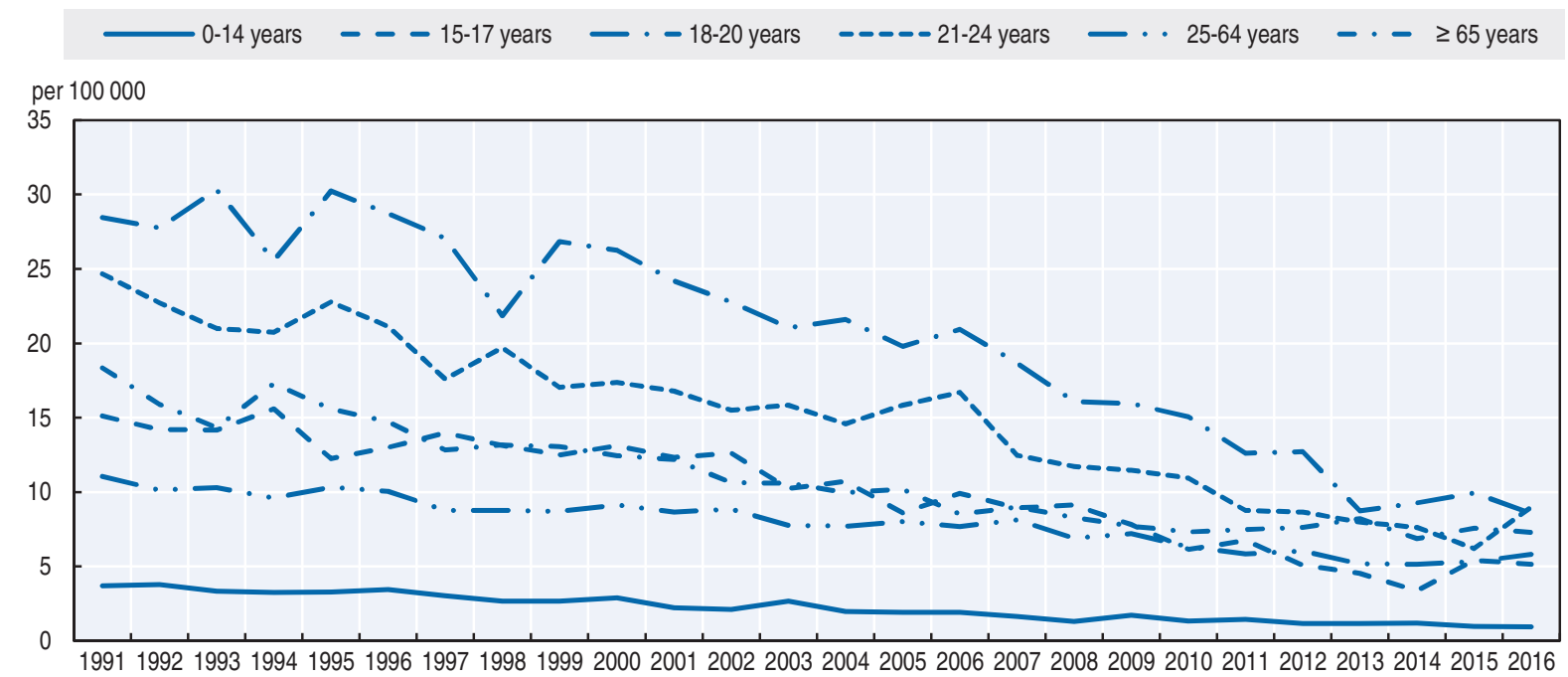

\section{Box 3.1. Road safety for an ageing population}

Today the 65 and over age group accounts for 15\% of the total population, compared to $13 \%$ ten years ago. The Australian Bureau of Statistics projects that this proportion will rise to $21 \%$ by 2050 .

Presently, this group accounts for $22 \%$ of all deaths on the road. Ten years ago this proportion was $15 \%$. The mortality rate of the elderly increases with age, with those over 85 having a mortality rate more than twice that of the 65-74 age group. Elderly people are particularly vulnerable as car occupants or pedestrians. 


\section{Box 3.1. Road safety for an ageing population (cont.)}

In the five year period to 2015, deaths of those aged 65 and over increased by $23 \%$. However, total deaths in the same period decreased by $11 \%$. Recent increasing trends appear in driver, pedestrian and motorcyclist fatalities. No clear declining trends occur for any road user group.

Driver licensing arrangements vary between the different states and territories. Some jurisdictions require medical tests yearly from 75 or 80 years of age; and some also require driving tests every year or two years from 85 years old onward.

Austroads has commissioned a research project to identify emerging trends in road trauma involving older road users, to support the development of targeted countermeasures.

Table 3.4. Road fatalities among senior citizens

\begin{tabular}{lrr|rr|rr}
\hline & \multicolumn{2}{c|}{$65-74$} & \multicolumn{2}{c|}{$75-84$} & \multicolumn{2}{c}{$85+$} \\
\cline { 2 - 7 } & 2010 & 2015 & 2010 & 2015 & 2010 & 2015 \\
\hline Pedestrians & 15 & 25 & 18 & 21 & 11 & 23 \\
Cyclists & 6 & 3 & 2 & 3 & 0 & 0 \\
Motorcyclists & 10 & 12 & 0 & 1 & 0 & 0 \\
Car occupants & 56 & 60 & 53 & 50 & 27 & 33 \\
Total & 96 & 118 & 81 & 89 & 41 & 62 \\
\hline
\end{tabular}

Figure 3.4. Road fatality rates by age group - focus on the senior population Deaths per 100000 inhabitants in a given age group, 2000-15
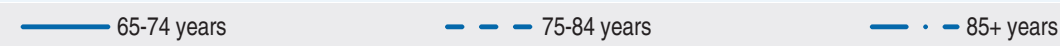

per 100000

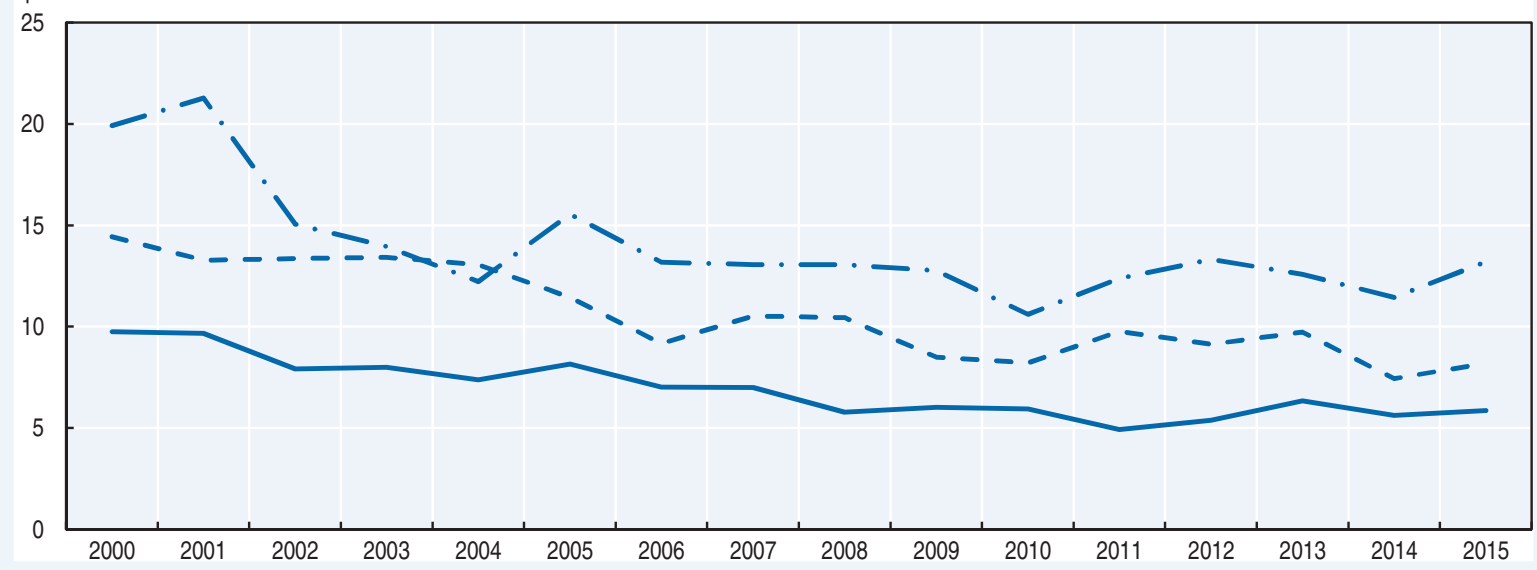

\section{Road safety by road type}

Road fatality rates are higher in rural areas (particularly remote ones) than for in major cities. People living and driving outside cities tend to do more of their driving at highway speeds, more driving on lower standard rural roads and more driving overall. Effective enforcement of speed limits, alcohol restrictions and seat belt use is more difficult in rural areas.

Only a small proportion of the rural road network in Australia is a divided road and an even smaller proportion is motorway standard. National and state road safety strategies 
Figure 3.5. Road fatality rate by age and road user group Fatalities per 100000 inhabitants, 2015

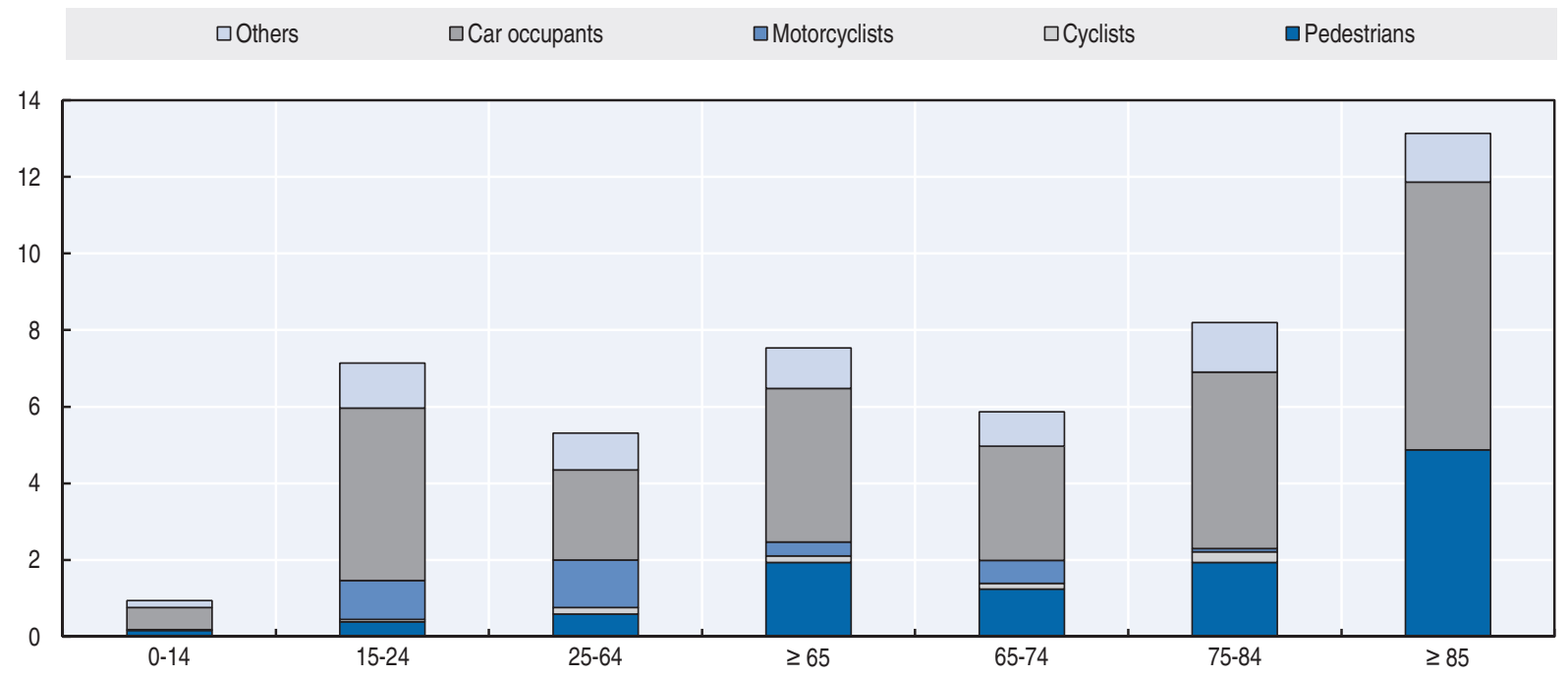

emphasise the importance of road infrastructure improvements, including relatively low-cost measures applicable to single-carriageway roads.

Approximately one-third of all fatal crashes occur in posted speed zones of $100 \mathrm{~km} / \mathrm{h}$.

\section{Economic costs of traffic crashes}

The annual economic cost of road crashes in Australia is an estimated AUD 27 billion per year, based on 2006 data. This estimate is equivalent to 1.8\% of national GDP in 2012-13. A willingness-to-pay methodology was used to value the human losses from road crashes.

The estimated cost includes non-reported crashes and injuries.

Table 3.5. Costs of road crashes, 2006

\begin{tabular}{|c|c|c|}
\hline & Unit cost [AUD] & Total [AUD] \\
\hline Fatalities & & 9.9 billion \\
\hline Injury and disability & & 10.3 billion \\
\hline Property damage and other costs & & 6.9 billion \\
\hline Total & & 27.1 billion \\
\hline Total as $\%$ of GDP & & 1.8 \\
\hline
\end{tabular}

Source: BITRE (2010); BITRE (2014).

\section{Recent trends in road user behaviour}

\section{Speed}

Australia does not have reliable national data on the contribution of speed to serious crashes. Police crash reports have suggested that excessive speed is a factor in about a third of all fatal crashes, though this is likely to be an underestimate.

Statistical series and other evaluation studies in individual jurisdictions indicate that speed management measures have made an important contribution to reducing road fatalities and injuries. For example, an authoritative evaluation of a package of Victorian speed-management initiatives in the early 2000 s found a $10 \%$ reduction in all casualty 
crashes and a $27 \%$ reduction in fatal crashes. National data on speed distributions are not available. Obtaining such data has been identified as a priority to support the effective monitoring of progress under the National Road Safety Strategy.

Under Australia's National Road Safety Strategy, there have been moves to better align posted speed limits with the objective risk profiles of roads. This has led, for example, to an expansion of lower urban speed zones (typically $40 \mathrm{~km} / \mathrm{h}$ ) in areas with high pedestrian and cycling activity.

Nationally co-ordinated work has recently been undertaken to develop guidelines for speed limits at high-risk locations and to facilitate the adoption of best practice speed limits more broadly.

Over the last 10 years, most Australian jurisdictions have taken steps to strengthen speed enforcement programmes, particularly through increased use of mobile and fixed cameras; in recent years several jurisdictions on a modest scale have introduced, or planned to introduce, point to point camera systems to measure average speed.

Most jurisdictions have reviewed their speeding sanctions and several have announced stronger penalties, mainly for high-range offences.

The table below summarises the main speed limits in Australia. It should be noted that speed limits are state-based, but there is broad consistency across jurisdictions.

Table 3.6. Passenger car speed limits by road type, $2017^{1}$

\begin{tabular}{ll}
\hline & General speed limit \\
\hline Urban roads (non-arterial) & $50 \mathrm{~km} / \mathrm{h}$ Increasing use of $40 \mathrm{~km} / \mathrm{h}$ limits in urban areas with high pedestrian activities \\
Urban roads (arterial) & $60 \mathrm{~km} / \mathrm{h}$ to $80 \mathrm{~km} / \mathrm{h}$ \\
Rural roads (undivided) & $100 \mathrm{~km} / \mathrm{h}$ \\
Rural roads (divided) & $100 \mathrm{~km} / \mathrm{h}$ or $110 \mathrm{~km} / \mathrm{h}$ \\
Motorways & $110 \mathrm{~km} / \mathrm{h}$ \\
\hline
\end{tabular}

1. Speed limits are state-based and may vary from one state to another.

\section{Drink driving}

In Australia, it is illegal to drive a motor vehicle with blood alcohol content (BAC) of $0.5 \mathrm{~g} / \mathrm{l}$ or higher. Lower BAC limits apply to truck, bus and taxi drivers (typically $0.2 \mathrm{~g} / \mathrm{l}$ ) and to novice drivers $(0.0 \mathrm{~g} / \mathrm{l})$.

All jurisdictions have had considerable success in reducing the contribution of alcohol to road trauma, largely attributable to the combination of intensive random breath-testing programmes and ongoing public education campaigns. While absolute numbers of alcoholrelated fatalities have continued to decline over the last decade, it is estimated that about $14 \%$ of all fatally injured motorists have a BAC above the maximum legal limit of $0.5 \mathrm{~g} / \mathrm{l}$.

This figure varies significantly among jurisdictions, with rural and remote areas of Australia presenting particular challenges for the implementation of effective deterrence measures.

States are expanding the use of alcohol interlock programmes, which are now in place for drink-driving offenders in all jurisdictions.

\section{Drugs and driving}

There is evidence that other drugs (both illicit and prescription) are a factor in Australian road trauma and this has been raised recently as a growing concern by police and policy makers. It is very difficult to obtain reliable data on drug involvement in serious 
crashes, though estimates from coroner information have suggested that about $7 \%$ of road deaths involve a driver who has used illicit drugs driving as a factor (excluding cases also involving alcohol).

In recent years, most jurisdictions have introduced random roadside drug-testing programmes, supported by laws that make it illegal to drive a motor vehicle with a prescribed drug present in their blood or oral fluid. These laws currently focus on selected illicit drugs, such as cannabis, methamphetamines and ecstasy.

\section{Distraction}

Distracted driving is recognised as a major and potentially growing problem in Australia. However, there is no official definition as to what constitutes "distracted driving" for national statistical collection. Mobile phone use is of particular concern, with self-report surveys consistently finding that about $60 \%$ of drivers use a mobile phone while driving. Of increasing concern is the significant minority of drivers who admit to reading $(32 \%)$ or sending $(18 \%)$ text messages while driving.

It is illegal to use a hand-held phone while driving in all jurisdictions. Learner and provisional licence holders in some jurisdictions are subject to further restrictions, including a total ban on phone use while driving. Breaches attract fines and licence demerit points.

\section{Sleepiness and fatigue}

There is no definitive measure of fatigue involvement in crashes, though various estimates suggest that fatigue may be a factor in $20-30 \%$ of fatalities.

\section{Seat belts and helmets}

Seat belt use has been compulsory in all Australian states and territories since the 1970s. In most states there are licence demerit point penalties as well as fines for unbelted drivers, and in some states demerit points apply to drivers with unbelted passengers (in addition to fines for unbelted adult passengers).

Children 7 years of age and under must be seated in a rear seat (if available) and be adequately restrained in an appropriate child restraint or booster seat, taking into account their weight and height.

Objective nationwide data on usage rates are not available, but non-national observational surveys and self-report data from national surveys indicate that usage rates for both front and rear-seat occupants are now in excess of $95 \%$.

Despite high general usage rates, the rates of non-use among fatally injured vehicle occupants are still estimated at $27 \%$. Analysis indicates that this high figure is the result of a high crash involvement rate among those who do not wear belts, as well as the fact that they are more likely to be killed if involved in a crash.

Table 3.7. Seat belt wearing rate by car occupancy and road type

\begin{tabular}{lcc} 
& $\%$ & 2013 \\
\hline $\begin{array}{l}\text { Front seat } \\
\text { General (driver + passengers) }\end{array}$ & 2000 & 97 \\
$\begin{array}{c}\text { Rear seats } \\
\text { General }\end{array}$ & 96 & 96 \\
\hline
\end{tabular}


Helmets are compulsory for motorcycle and moped riders and cyclists. Approximately 1 in 15 motorcyclists and 1 in 9 cyclists killed in road crashes were not wearing a helmet. There is no national data on general helmet usage rates.

\section{National road safety strategies and targets Organisation of road safety}

In Australia's federal system, government responsibilities for road safety vary across jurisdictions. The Australian Government is responsible for regulating safety standards for new vehicles and for allocating infrastructure resources, including for safety, across the national highway and local road networks.

State and territory governments are responsible for funding, planning, designing and operating the road network, managing vehicle registration and driver licensing systems, and regulating and enforcing road user behaviour.

Local governments have responsibility for funding, planning, designing and operating road networks in their local areas.

\section{Road safety strategy for 2011-20}

The National Road Safety Strategy 2011-20 represents the commitment of Australia's nine federal, state and territory governments to an agreed set of national road safety goals, objectives and actions. The strategy is firmly based on Safe System principles and is framed by the guiding vision that no person should be killed or seriously injured on Australia's roads.

Following a comprehensive review of Australia's National Road Safety Strategy 2011-20, a new National Safety Action Plan (for 2015-2017) was endorsed by Transport Ministers in November 2014. It outlines 19 priority action items for the three years, intended to focus national efforts on activities that will deliver or support significant long-term improvements to the safety of Australia's road transport system, especially through strategic investment in infrastructure safety, vehicle safety and capacity building work. The 19 actions are grouped into four broad areas:

- prioritising the investments in infrastructure

- improving the safety of our vehicle fleet

- encouraging safer road use

- advancing the Safe System

\section{Road safety targets and monitoring}

The strategy presents a 10-year plan to reduce the annual numbers of both deaths and serious injuries on Australian roads by at least $30 \%$ by 2020 , relative to the average numbers of fatalities and serious injuries in the baseline period 2008-10. In developing these targets, data modelling was carried out to calculate the level of serious casualty reduction that could realistically be achieved over the life of the strategy. The modelling work was informed by a review of Australian and overseas research on the effectiveness of a number of road safety interventions. A macro-modelling approach was used to estimate the reductions in people killed or seriously injured that would result from a range of possible road safety interventions, during the 10-year life of the strategy.

To help monitor the implementation of the national strategy, a range of high-level outcome indicators and more specific Safety Performance Indicators (SPIs) were adopted as 
empirical measures of progress. The indicators are mainly based on crash data, and reporting is facilitated by a national compilation of state and territory data managed by the Department's Bureau of Infrastructure, Transport and Regional Economics (BITRE).

In addition to data monitoring, the Department works with state and territory transport agencies to periodically gather and compile information on actions taken to deliver the strategy's initiatives.

In November 2016 a report on progress with the National Road Safety Strategy was submitted to the Transport and Infrastructure Council of Ministers. The report provides an assessment of overall progress towards the high-level Directions laid out in the NRSS, an assessment of progress on each of the 19 priority actions in the Action Plan, and a report of statistical progress against the NRSS performance indicators. See: http://roadsafety.gov.au/ performance/files/NRSS_Implementation_report_Nov2016.pdf (accessed 27 April 2017). It highlights categories where reduction in fatalities were lower than average.

In 2015, there were 1205 road crash deaths, a reduction of $15.4 \%$ relative to the baseline. Preliminary road fatality statistics for 2016 (1 300) indicate the number of deaths has increased for the second consecutive year.

Figure 3.6. Trends in road fatalities towards national target

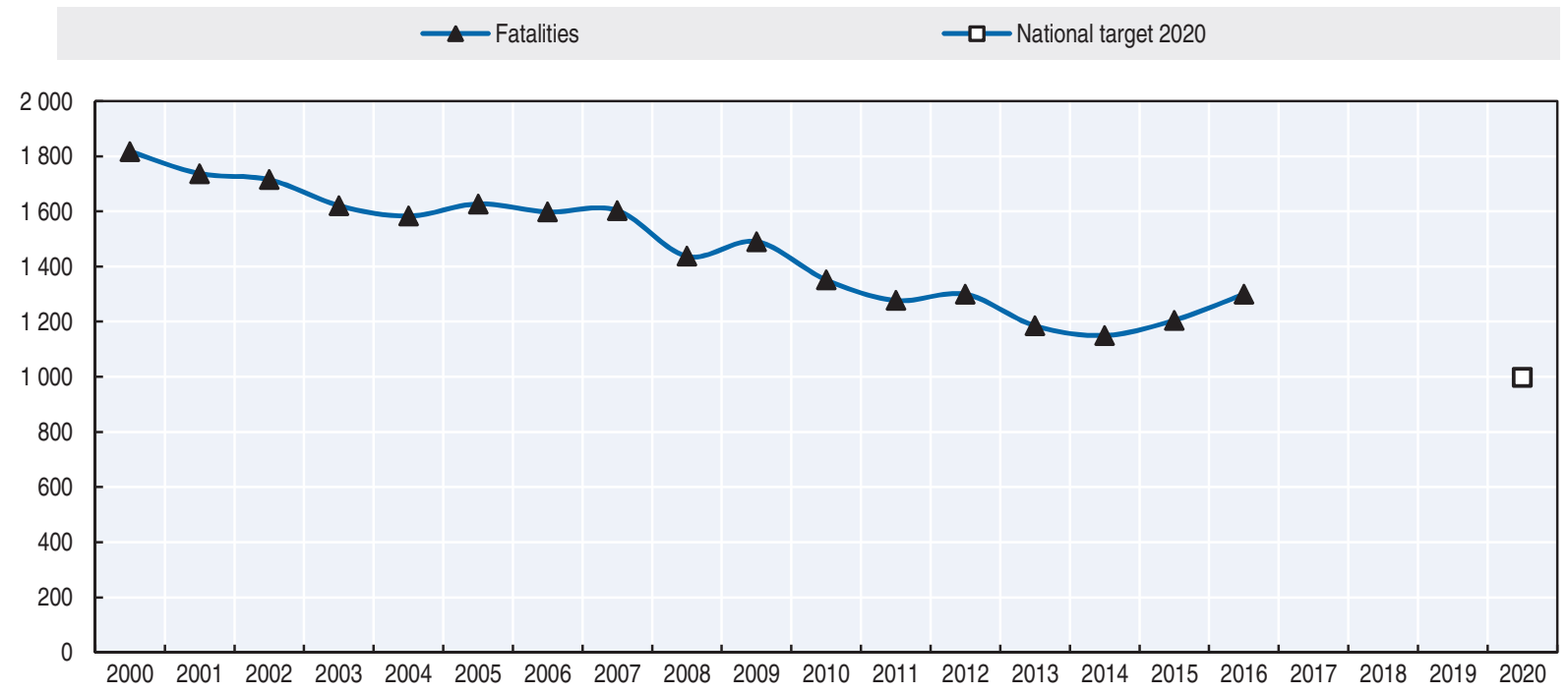

\section{Recent safety measures (2014-17)}

\section{Road safety management}

- In recent years, improved co-ordination and advisory arrangements for national road safety activities (including the National Road Safety Strategy) were put in place through Austroads. This included arrangements for better national engagement between transport and police agencies.

- The National Road Safety Partnership Program was launched in 2014 as a major industrysupported initiative encouraging private sector organisations to develop positive road safety cultures and implement effective road safety strategies within their workplaces. Participation has been strong and continues to grow. 
- A pilot project established in 2015 aims to demonstrate the strengths and limitations of adopting a national data linkage approach to improve measurement and reporting of non-fatal injury road crashes.

\section{Road users}

\section{Driving licence}

- There has been ongoing work in several Australian states to strengthen graduated licensing systems (GLS), supported by Austroads research on the safety evidence associated with different GLS elements. In 2014, New South Wales led a national project to develop a best-practice policy framework for GLS.

- Several jurisdictions have initiated licensing support programmes for people in indigenous communities. This includes the successful completion of a major two-year trial of the DriveSafe NT Remote programme in the Northern Territory, which helped 623 people in remote and very remote regions obtain a full driver's licence.

\section{Drink Driving}

- States have continued to expand the use of alcohol interlock programmes, and all jurisdictions now have these in place for drink driving offenders.

\section{Speed Management}

- Significant action was taken in some jurisdictions to adopt safer speed limits. Most notably, lower speed limits were reduced on substantial sections of the rural network in South Australia and on unsealed roads in Tasmania; while $40 \mathrm{~km} / \mathrm{h}$ limits were increasingly introduced in most capital cities, targeting areas with high pedestrian and cyclist activity.

- Efforts to facilitate the implementation of intelligent speed adaptation (ISA) have been proceeding, focused on the development of suitable speed-limit maps, exploration of the potential regulatory role of ISA in managing high-risk drivers, and integration of safety assist technologies such as ISA into the Australasian New Car Assessment Program's star rating system. In 2014, New South Wales introduced an ISA advisory app for mobile phones that is available free-of-charge to the public.

- The National Transport Commission has work underway to assess a number of enforcement approaches to reduce speeding by heavy vehicles.

\section{Infrastructure}

Federal, state and territory governments have invested significantly in a range of infrastructure improvement initiatives. These include:

The Australian Government has committed AUD 500 million over five years to the national Black Spot Programme.

Major investments in safe roads of AUD 1 billion in Victoria and AUD 100 million in South Australia.

Significant infrastructure upgrades including wide median treatments on $20 \%$ of the Bruce Highway in Queensland; and AUD 36 million from fine revenue toward addressing single vehicle run-off-road crashes in Western Australia. 
The New South Wales Community Safety Fund (fines from speed cameras) allocated more than AUD 60 million for targeted road safety infrastructure treatments and Black Spots under the Safer Roads Engineering Program.

Austroads developed the Australian National Risk Assessment Model (ANRAM) to help jurisdictions better target infrastructure safety investments using an objective risk-based approach. Austroads has also developed a training package to assist with translating Safe System knowledge and research into practice.

\section{Vehicles}

Major vehicle safety activities in recent years have included:

- Increased harmonisation of Australia's vehicle safety standards - the Australian Design Rules - with regulations of the United Nations Economic Commission for Europe (UNECE) and Global Technical Regulations.

- Given its commitment to harmonisation, Australia participates actively in the development of international vehicle regulations. A major initiative has been Australia's leadership of Global Technical Regulation 14/UN Regulation (UNR) 135 on Pole Side Impact, which will reduce fatalities and injuries in all side impacts (which account for $20 \%$ of Australian road deaths and similar figures in some other countries).

- New Australian Design Rules for pole side impact performance for light passenger and commercial vehicles, seat belt reminders, ISOFIX child seats, Brake Assist Systems for light passenger and commercial vehicles, Electronic Stability Control for light commercial vehicles and Antilock Brake Systems for heavy vehicles.

- Regulation Impact Statements are under development to consider ADRs on Antilock Brake Systems for motorcycles and Electronic Stability Control for heavy vehicles.

- Continued expansion of the Australasian New Car Assessment Program (ANCAP). Under Australia's National Road Safety Strategy 2011-2020, statistical performance indicators are benchmarked against the three-year period 2008 to 2010. Data to 2014 showed positive changes in key vehicle safety indicators, with the proportion of new light vehicles sold with a 5 -star ANCAP rating having increased by $54 \%$, to $86 \%$ of new vehicles.

- The National Transport Commission and the National Heavy Vehicle Regulator (NHVR) have worked together on a joint programme to improve heavy vehicle roadworthiness.

\section{Recent and ongoing research}

\section{Bureau of Infrastructure, Transport and Regional Economics:}

- Australian Motorcycling safety (Forthcoming).

- Heavy truck safety: crash analysis and trends

- https://bitre.gov.au/publications/2016/is_078.aspx (accessed 27 April 2017).

- Light commercial vehicle safety

- https://bitre.gov.au/publications/2017/is_087.aspx (accessed 27 April 2017).

\section{Austroads:}

- Austroads, the association of Australasian road transport and traffic agencies, manages an ongoing programme of nationally coordinated road safety research work: www.austroads. com.au/road-operations/road-safety/safety-program (accessed 27 April 2017). This has a focus 
on work that will support the development of Safe System transport networks and includes research projects on land use planning processes, infrastructure performance and the development of a Safe System assessment framework, as well as work to help translate Safe System infrastructure research and knowledge into practice.

- Some key completed pieces of research from this programme include:

- Review of the National Road Safety Strategy: www.onlinepublications.austroads.com.au/items/ AP-R477-15 (accessed 27 April 2017).

- Options for rehabilitation in interlock programmes: www.onlinepublications.austroads.com. au/items/AP-R484-15 (accessed 27 April 2017).

- Public demand for safer speeds: identification of interventions for trial: www.onlinepublications. austroads.com.au/items/AP-R507-16 (accessed 27 April 2017).

- Summary of literature of the effective components of graduated driver licensing systems: www.onlinepublications.austroads.com.au/items/AP-R476-15 (accessed 27 April 2017).

- Social costs of road crashes in Australia: the case for willingness-to-pay values for road safety: www.onlinepublications.austroads.com.au/items/AP-R438-15 (accessed 27 April 2017).

- Investigation of key crash types: rear-end crashes in urban and rural environments: www.onlinepublications.austroads.com.au/items/AP-R480-15 (accessed 27 April 2017).

- Safe System assessment framework for road infrastructure projects: www.onlinepublications. austroads.com.au/items/AP-R509-16 (accessed 27 April 2017).

- Infrastructure improvements to reduce motorcycle casualties:

- www.onlinepublications.austroads.com.au/items/AP-R515-16 (accessed 27 April 2017).

\section{References}

BITRE (2010), Cost of Road Crashes in Australia 2006, Research Report 118, Department of Infrastructure, Transport, Regional Development and Local Government, Canberra.

BITRE (2014), Impact of Road Trauma and Measures to Improve Outcomes, Research Report 140, Department of Infrastructure, Transport, Regional Development and Local Government, Canberra.

\section{Websites}

- National Road Safety Strategy 2011-2020: www.roadsafety.gov.au (accessed 27 April 2017).

- National Road Safety Action Plan 2015-2017: http://roadsafety.gov.au/action-plan/files/National_Road_ Safety_Action_Plan_2015_2017.pdf (accessed 27 April 2017).

- Department of Infrastructure and Regional Development: www.infrastructure.gov.au/roads/safety (accessed 27 April 2017).

- Bureau of Infrastructure, Transport and Regional Economics: www.bitre.gov.au/ (accessed 27 April 2017).

- Australian Road Deaths Database: https://bitre.gov.au/statistics/safety/fatal_road_crash_database.aspx (accessed 27 April 2017).

- Road Trauma Australia: Annual Summaries: https://bitre.gov.au/publications/ongoing/road_deaths_ australia_annual_summaries.aspx (accessed 27 April 2017).

- Austroads: www.austroads.com.au/ (accessed 27 April 2017).

- Review of the National Road Safety Strategy: www.onlinepublications.austroads.com.au/items/AP-R477-15 (accessed 11 March 2016).

- ARRB, Australian Road Research Board: www.arrb.com.au (accessed 27 April 2017).

- Monash University Accident Research Centre: www.monash.edu.au/miri/research/research-areas/transportsafety/ (accessed 27 April 2017). 
- Centre for Automotive Safety Research: http://casr.adelaide.edu.au/ (accessed 27 April 2017).

- Centre for Accident Research \& Road Safety - Queensland: www.carrsq.qut.edu.au/ (accessed 27 April 2017).

- Transport and Road Safety (TARS) Research: www.tars.unsw.edu.au/research/index.html (accessed 27 April 2017).

- The George Institute for Global Health: www.georgeinstitute.org.au/our-work/our-divisions/injury (accessed 27 April 2017). 


\section{Chapter 4}

\section{Austria}

This chapter presents 2015 road safety data for Austria along with provisional data from 2016. It looks at trends in traffic and road safety from the years 1990 to 2015 and road user behaviour patterns, with a special focus on the ageing population. Sections include data on speed, drink driving, drugs and driving, distracted driving, fatigue and seat belt usage. The chapter reviews Austria's road safety strategy and national targets to 2020 and the progress achieved so far. It also provides details of all recently implemented safety measures and current and ongoing research.*

* All data stem from KFV (Kuratorium für Verkehrssicherheit, based on disaggregated police data provided by Statistik Austria) and IRTAD unless otherwise noted. For more information please contact: klaus.machata@kfv.at. 
F ollowing the lowest year on record for fatalities in 2014, Austria recorded an increase of $11.4 \%$ in 2015, totalling 479 deaths, equivalent to a rate of 5.6 deaths per 100000 inhabitants. Car occupants, pedestrians and motorcyclists were most affected by the increase, as were the 18-24 year old age group and those over 65. Provisional data from 2016 indicate a new decrease of $10.9 \%$ in fatalities with a total of 427 road deaths, just under the 2014 level. Once confirmed this would mark a new record in Austrian road safety since monitoring began in 1950.

\section{Road safety data collection}

\section{Definitions applied in Austria}

Data included in this report correspond to the consolidated set of police data.

- Road fatalities refer to deaths within 30 days of the crash.

- Injury crashes are crashes resulting in at least one injured or killed person.

- Since 2012 injured persons are subdivided into seriously injured and slightly injured. (Prior to 2012, a third category, "unknown degree of severity", existed).

* Slightly injured are all other injured persons.

* Seriously injured persons are those suffering an injury resulting in an inability to work or health problems for more than 24 days.

- Since 2015, the number of people seriously injured with a Maximum Abbreviated Injury Scale of three or more (MAIS3+) injuries is being reported.

\section{Data collection}

In Austria, crash data are collected by the police. The crash data acquisition process was completely transformed in January 2012 from paper forms to integrated data input including geographic information system (GIS) support. It is believed that this has significantly reduced underreporting rates, especially for less severe road crashes (see resulting increase in the number of injury crashes in Table 4.1 from 2010 to 2013). However, due to a change in the collection method, data for injuries and crashes since 2012 cannot be directly compared with previous figures. This does not apply to the number of fatalities.

Injury severity is assessed by the police at the crash scene, with only occasional feedback from hospitals. It is not possible to link police and hospital data directly on the basis of the present data architecture.

Regular estimates for the number of serious injuries are required by the European Commission, based on a Maximum Abbreviated Injury Scale (MAIS) score of 3 or more (MAIS3+). In 2015, for the first time in Austria, this estimate was derived from the International Classification of Diseases-10 (ICD-10) hospital data on road traffic victims. The process was repeated in 2016 and will from now on be carried out on a regular annual basis. 


\section{Most recent safety data}

\section{Road crashes in 2016 - final data}

In 2016, 432 persons were killed on Austrian roads, 9.8\% less than in 2015. Therefore, 2016 marks the year with the lowest fatality count since recording started in the Austrian Home Office in 1950. Among the road deaths, 44\% were car occupants, 20\% motorcyclists, $11 \%$ cyclists (nearly one-third of which were on electric bicycles), and $17 \%$ pedestrians. The proportion of vulnerable road users has increased and now accounts for around half of all fatalities - a trend that has also been observed in many other countries over recent years.

\section{Road crashes in 2015}

The number of fatalities in 2015 was $11 \%$ higher than the previous year. This increase was predominantly seen among car occupants $(+26 \%)$ and pedestrians $(+18 \%)$, as well as powered two-wheeler (PTW) riders $(+9 \%)$.

This relatively bad performance is in part explained by the fact that 2014 had been an extraordinarily good year and had broken all-time records for months June through September. The usual summer high in fatality counts was much less pronounced in 2014 (potential contributors being cool and rainy weather and rising unemployment rates) whereas 2015 had largely returned to average seasonal values. Analysis confirmed that exposure on the high-level road network was higher in 2015 than in 2014 for the months June through September, especially on weekends.

In 2015, the police recorded 37960 injury crashes, virtually the same as in 2014.

\section{Trends in traffic and road safety (1990-2015) Traffic}

Since 1990, the number of vehicles has increased by $54 \%$ and traffic has increased by $69 \%$ (2015 data). Until 2008, the average yearly increase in kilometres driven was nearly 3\%; in 2009, the trend shifted downward and growth since then has been about $1.1 \%$ annually. However, in 2014 and 2015 an annual increase of nearly 3\% was re-established.

\section{Road safety}

\section{Crashes and casualties}

Between 1990 and 2015, the number of road fatalities decreased by 69\%. More recently (2000 to 2015), the number of fatalities has decreased by 51\%. A rise of crash figures in 2012 was artificially induced by the new data collection methodology. As a result, injury crash counts for 2012 and later cannot be compared to previous years.

The substantial decline in road mortality since 1990 was marked by the implementation of the first two integrated road safety programmes in Austria incorporating a variety of measures including:

- second phase education for novice drivers after granting the driving licence

- automatic section control of average speeds along stretches of motorways and rural roads

- awareness campaigns in such areas as seat belt and child restraint use, alcohol, child safety and choice of adequate speed on rural roads

- large-scale roadside testing for alcohol using alcohol screening devices

- penalty point system. 


\section{Rates}

The road death rate per 100000 inhabitants has decreased by 73\% since 1990, while the number of vehicles per 1000 inhabitants has increased by $38 \%$.

\section{Analysis of seriously injured data}

In 2014 and 2015, KFV carried out a feasibility study on MAIS3+ assessment on behalf of the Austrian Transport Ministry (BMVIT). The study covered two methods of estimating the number of serious road injuries:

- application of a (hospital data based) correction factor to the police reported number of serious injuries

- use of hospital data alone to arrive at an estimate for serious injuries.

The latter method was selected for further use. For 2014 and 2015 the numbers of MAIS3+ injuries were estimated at 1410 and 1309 , resulting in ratios of 3.28 and 2.73 between MAIS3+ injuries and fatalities.

The accuracy of the estimation procedure may be substantially influenced by data quality and the accuracy of the Hospital Discharge Register.

Table 4.1. Road safety and traffic data

\begin{tabular}{|c|c|c|c|c|c|c|c|c|c|}
\hline & \multirow{2}{*}{1990} & \multirow{2}{*}{2000} & \multirow{2}{*}{2010} & \multirow{2}{*}{2014} & \multirow{2}{*}{2015} & \multicolumn{4}{|c|}{$2015 \%$ change from } \\
\hline & & & & & & 2014 & 2010 & 2000 & 1990 \\
\hline \multicolumn{10}{|l|}{ Reported safety data } \\
\hline Fatalities & 1558 & 976 & 552 & 430 & 479 & 11.4 & -13.2 & -50.9 & -69.3 \\
\hline Injury crashes ${ }^{1}$ & 46338 & 42126 & 35348 & 37957 & 37960 & 0.0 & 7.4 & -9.9 & -18.1 \\
\hline Serious injuries (MAIS3+) & & & & 1410 & 1309 & -7.2 & & & \\
\hline Deaths per 100,000 population & 20.4 & 12.2 & 6.6 & 5.1 & 5.6 & 10.5 & -15.5 & -54.2 & -72.6 \\
\hline Deaths per 10,000 registered vehicles & 3.7 & 1.8 & 0.9 & 0.7 & 0.7 & 10.0 & -19.7 & -58.5 & -80.1 \\
\hline Deaths per billion vehicle kilometres & 32.0 & 15.0 & 7.3 & 5.4 & 5.8 & 8.1 & -20.3 & -61.3 & -81.9 \\
\hline \multicolumn{10}{|l|}{ Traffic data } \\
\hline Registered vehicles ${ }^{2}$ (thousands) & 4186 & 5471 & 5981 & 6385 & 6466 & 1.3 & 8.1 & 18.2 & 54.5 \\
\hline Vehicle kilometres ${ }^{2}$ (millions) & 48687 & 65143 & 75894 & 80150 & 82176 & 2.5 & 8.3 & 26.1 & 68.8 \\
\hline Registered vehicles per 1,000 population & 548 & 684 & 716 & 751 & 754 & 0.4 & 5.3 & 10.3 & 37.7 \\
\hline
\end{tabular}

1. Due to a change in crash data collection methods a direct comparison of data on injury crashes, or injured road users, with data recorded before 2012 is not possible.

2. Including mopeds.

StatLink काISL http://dx.doi.org/10.1787/888933580289

\section{Road safety by user group}

Since 1990, all road users in Austria have benefited from improvements in road safety. By 2015 , there was a $74 \%$ reduction in fatalities among the largest group, car occupants. Among the second largest group, pedestrians, fatalities were reduced by $68 \%$ since 1990 . This positive development is contrasted by an increase since 2010 in motorcycle fatalities (22\%). Motorcyclists now represent $17 \%$ of road fatalities in Austria.

Cycling popularity is increasing in Austria and municipalities are providing additional and safer cycling infrastructures. Cyclists accounted for 8\% of all fatalities in 2015.

\section{Road safety by age group}

Since 1990 , a reduction in fatality rates of more than $60 \%$ has been observed in all age groups, except the older population of 65 years of age and over (-49.3\%). Historically, young 
Figure 4.1. Road safety, traffic and GDP trends index $1990=100$

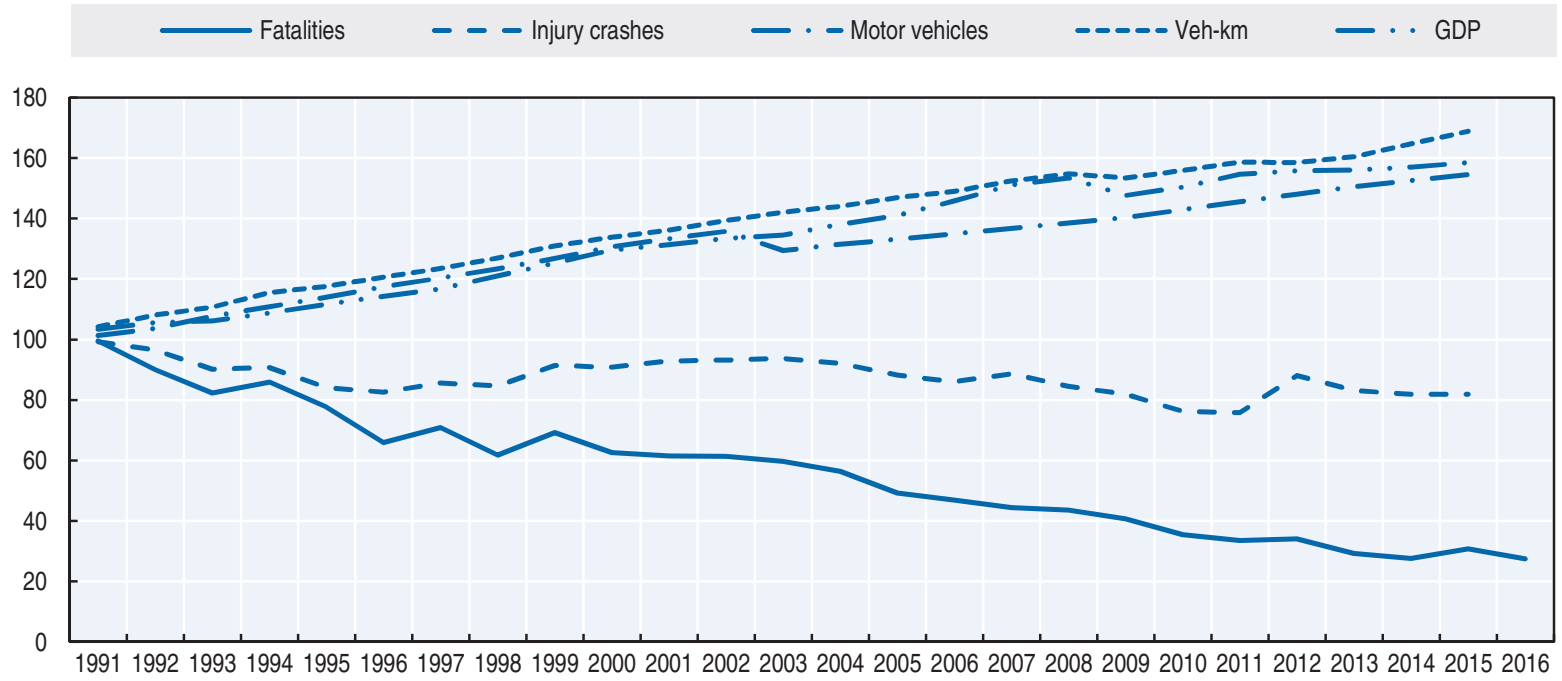

Note: A direct comparison of data on injury crashes, or injured road users, with data recorded before 2012 is not possible. Source: World Bank (2017) (GDP; constant prices).

Table 4.2. Road fatalities by road user group

\begin{tabular}{lrrrrr|rrrr}
\hline \multirow{2}{*}{ Road users } & 1990 & 2000 & 2010 & 2014 & 2015 & \multicolumn{4}{|c}{$2015 \%$ change from } \\
\cline { 7 - 10 } & & & & & & 2014 & 2010 & 2000 & 1990 \\
\hline Pedestrians & 260 & 140 & 98 & 71 & 84 & 18.3 & -14.3 & -40.0 & -67.7 \\
Cyclists & 106 & 62 & 32 & 45 & 39 & -13.3 & 21.9 & -37.1 & -63.2 \\
Moped riders & 88 & 44 & 18 & 14 & 7 & -50.0 & -61.1 & -84.1 & -92.0 \\
Motorcyclists & 112 & 112 & 68 & 75 & 83 & 10.7 & 22.1 & -25.9 & -25.9 \\
Car occupants & 913 & 549 & 292 & 189 & 238 & 25.9 & -18.5 & -56.6 & -73.9 \\
Others & 78 & 69 & 44 & 36 & 28 & -22.2 & -36.4 & -59.4 & -64.1 \\
Total & $\mathbf{1 5 5 8}$ & $\mathbf{9 7 6}$ & $\mathbf{5 5 2}$ & $\mathbf{4 3 0}$ & $\mathbf{4 7 9}$ & $\mathbf{1 1 . 4}$ & $\mathbf{- 1 3 . 2}$ & $\mathbf{- 5 0 . 9}$ & $\mathbf{- 6 9 . 3}$ \\
\hline
\end{tabular}

Figure 4.2. Road fatalities by road user group in percentage of total, 2015

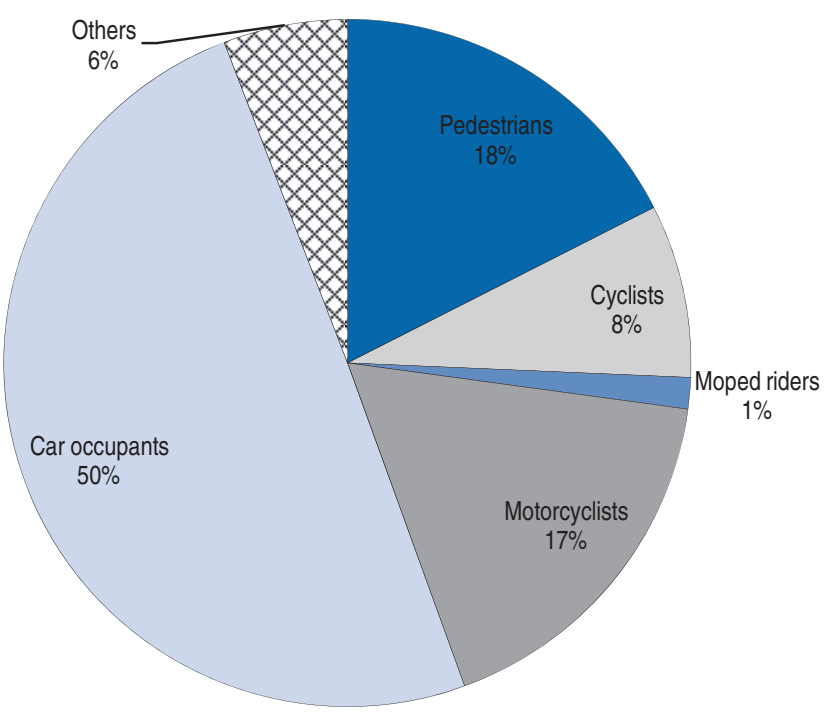


people represent a high-risk group in road safety. In 1990, the highest number of fatalities per 100000 inhabitants was recorded for persons 18-20 years old (59), followed by the 21-24 year old group (35). In 2015, this rate decreased to 11 and 9, respectively.

Table 4.3. Road fatalities by age group

\begin{tabular}{|c|c|c|c|c|c|c|c|c|c|}
\hline \multirow{2}{*}{ Age } & \multirow{2}{*}{1990} & \multirow{2}{*}{2000} & \multirow{2}{*}{2010} & \multirow{2}{*}{2014} & \multirow{2}{*}{2015} & \multicolumn{4}{|c|}{$2015 \%$ change from } \\
\hline & & & & & & 2014 & 2010 & 2000 & 1990 \\
\hline $0-14$ & 67 & 26 & 10 & 8 & 11 & 37.5 & 10.0 & -57.7 & -83.6 \\
\hline $15-17$ & 55 & 37 & 27 & 16 & 17 & 6.3 & -37.0 & -54.1 & -69.1 \\
\hline $18-20$ & 205 & 105 & 45 & 26 & 32 & 23.1 & -28.9 & -69.5 & -84.4 \\
\hline $21-24$ & 186 & 99 & 57 & 33 & 40 & 21.2 & -29.8 & -59.6 & -78.5 \\
\hline $25-64$ & 764 & 518 & 273 & 232 & 238 & 2.6 & -12.8 & -54.1 & -68.8 \\
\hline $65-74$ & 123 & 86 & 57 & 51 & 53 & 3.9 & -7.0 & -38.4 & $-56,9$ \\
\hline $75-84$ & 133 & 74 & 59 & 46 & 60 & 30.4 & 1.7 & -18.9 & $-54,9$ \\
\hline$\geq 85$ & 19 & 30 & 24 & 18 & 28 & 55.6 & 16.7 & -6.7 & 47,4 \\
\hline Total incl. unknown & 1558 & 976 & 552 & 430 & 479 & 11.4 & -13.2 & -50.9 & -69.3 \\
\hline
\end{tabular}

Figure 4.3. Road fatality rates by age group Deaths per 100000 inhabitants in a given age group, 1990-2015

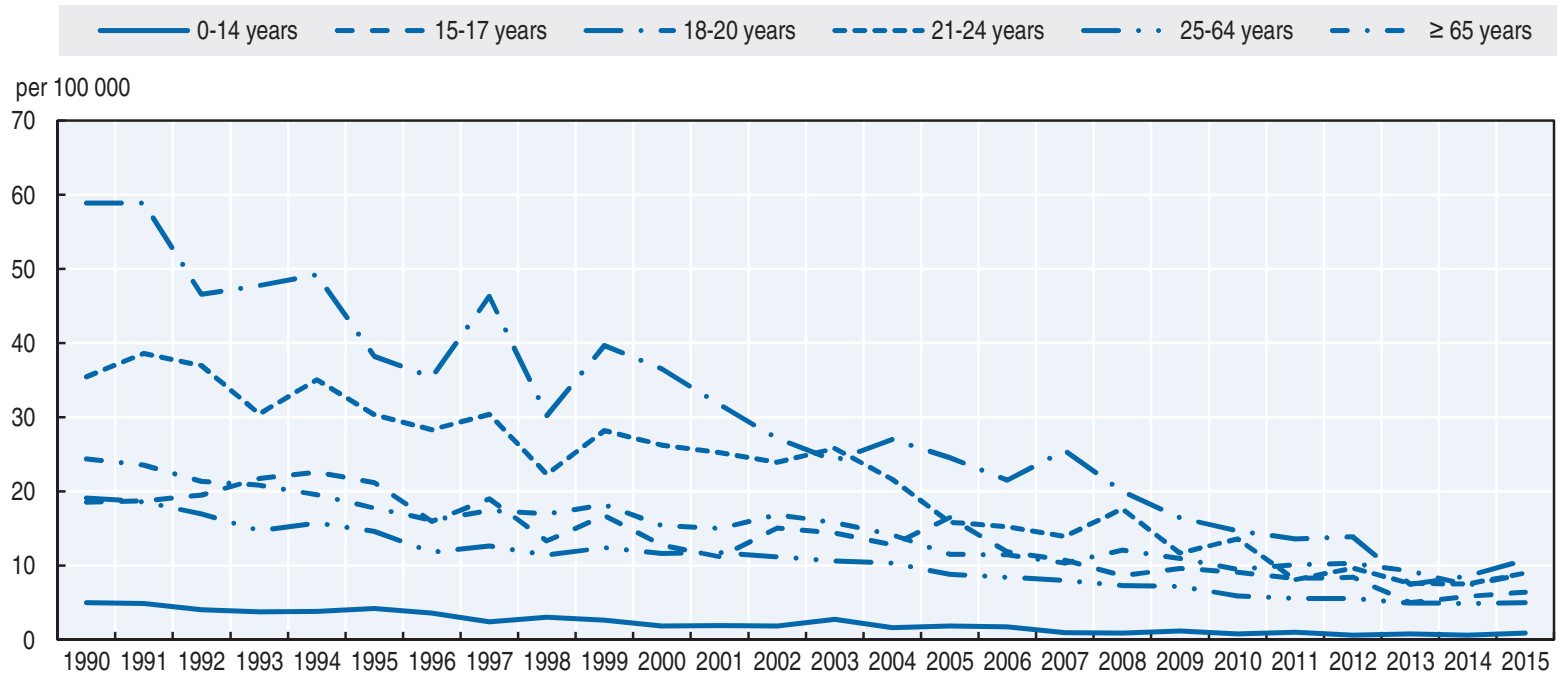

\section{Road safety by road type}

In $2015,64 \%$ of fatalities occurred on rural roads, nearly $27 \%$ in urban areas and about $9 \%$ on motorways. While the overall fatalities have been reduced by $69 \%$ since 1990 , fatalities on motorways decreased by the highest rate (73\%) followed by rural roads $(69 \%)$ and urban areas (68\%). In 2015, compared with the previous year, the number of fatalities has increased on all road types. 


\section{Box 4.1. Road safety for an ageing population}

In 2015, people aged 65 and above represented 19\% of the total population. This share is estimated to reach almost 30\% in 2050 (Statistik Austria, Bevölkerungsprognose, 2016). This has important consequences for road safety policy.

Compared to other age groups, since 1990, the mortality rates decreased the least for the 65+ age group, and increased in 2015, after the marked decrease in 2014. Consequently, the share of fatalities of the 65+ age group of all road fatalities has been steadily increasing, from $19 \%$ in 2000 to $29 \%$ in 2015 . An increasing share of older people are also killed as car occupants: $31 \%$ in 1990, 36\% in 2000 and $44 \%$ in 2015. In 2015, almost $80 \%$ of these car occupants were drivers, as compared to only 51\% in 1990, and $62 \%$ in 2010 (for women, the ratio of car drivers among car occupant fatalities was $20 \%$ in 2000 and 50\% in 2015).

In Austria, there are no age-specific tests for drivers; only the general EU licence renewal rules apply.

In 2012, KfV piloted voluntary risk competence training for senior motorists as a promising alternative to performance tests and health checks. The common perception from research results is that scrutinising all older drivers from a certain age is not a cost-beneficial measure, as age is a very unreliable predictor for fitness to drive.

Table 4.4. Road fatalities among senior citizens

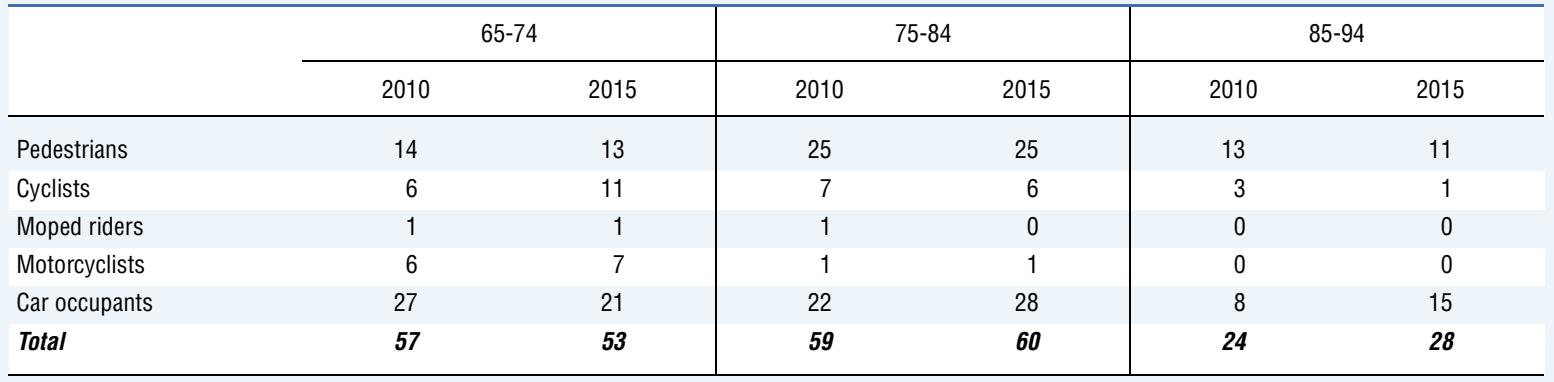

Figure 4.4. Road fatality rates by age group - Focus on the senior population Deaths per 100000 inhabitants in a given age group, 2000-15
$65-74$ years
$-075-84$ years
$-\cdot-85+$ years

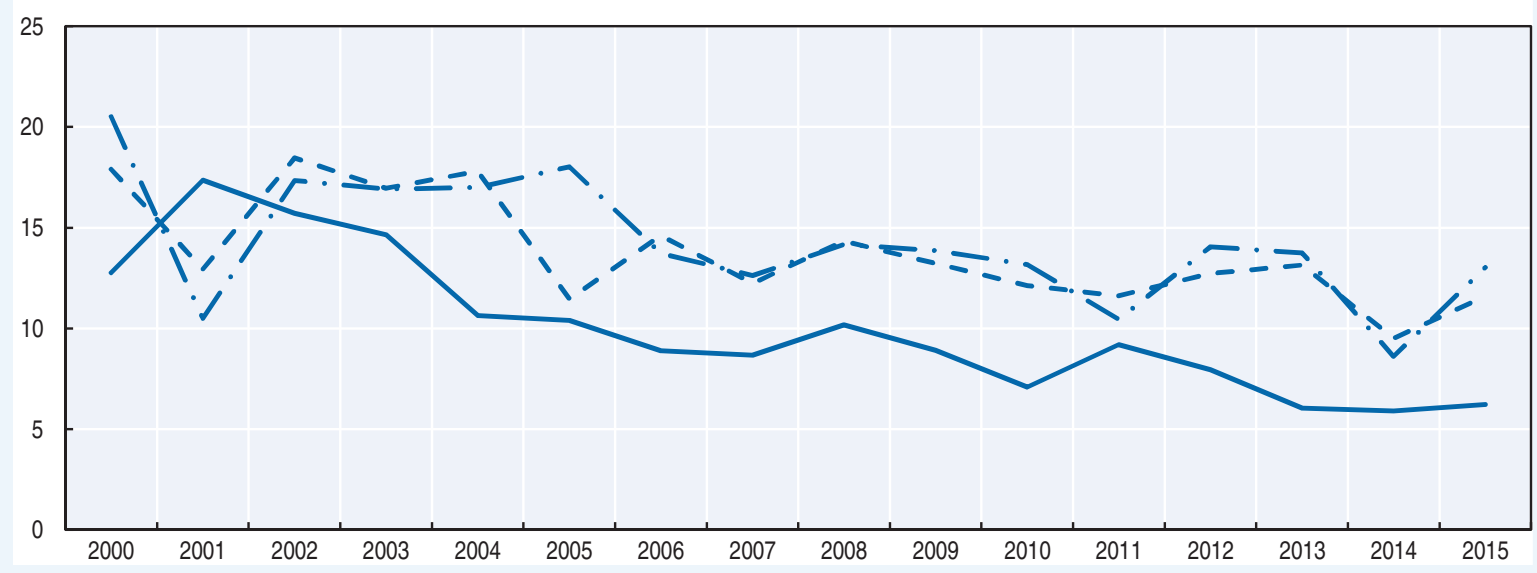


Figure 4.5. Road fatality rate by age and road user group Fatalities per 100000 inhabitants, 2015

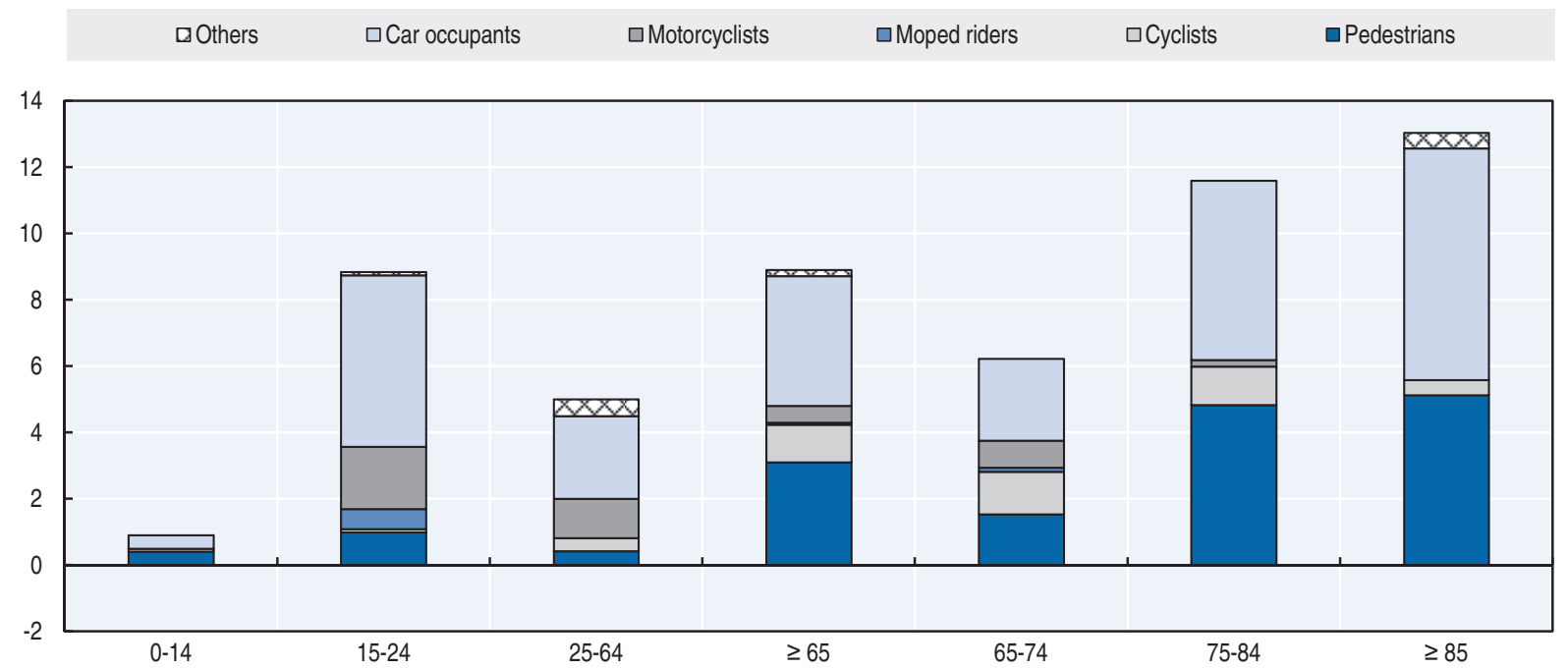

Figure 4.6. Road fatalities by road type

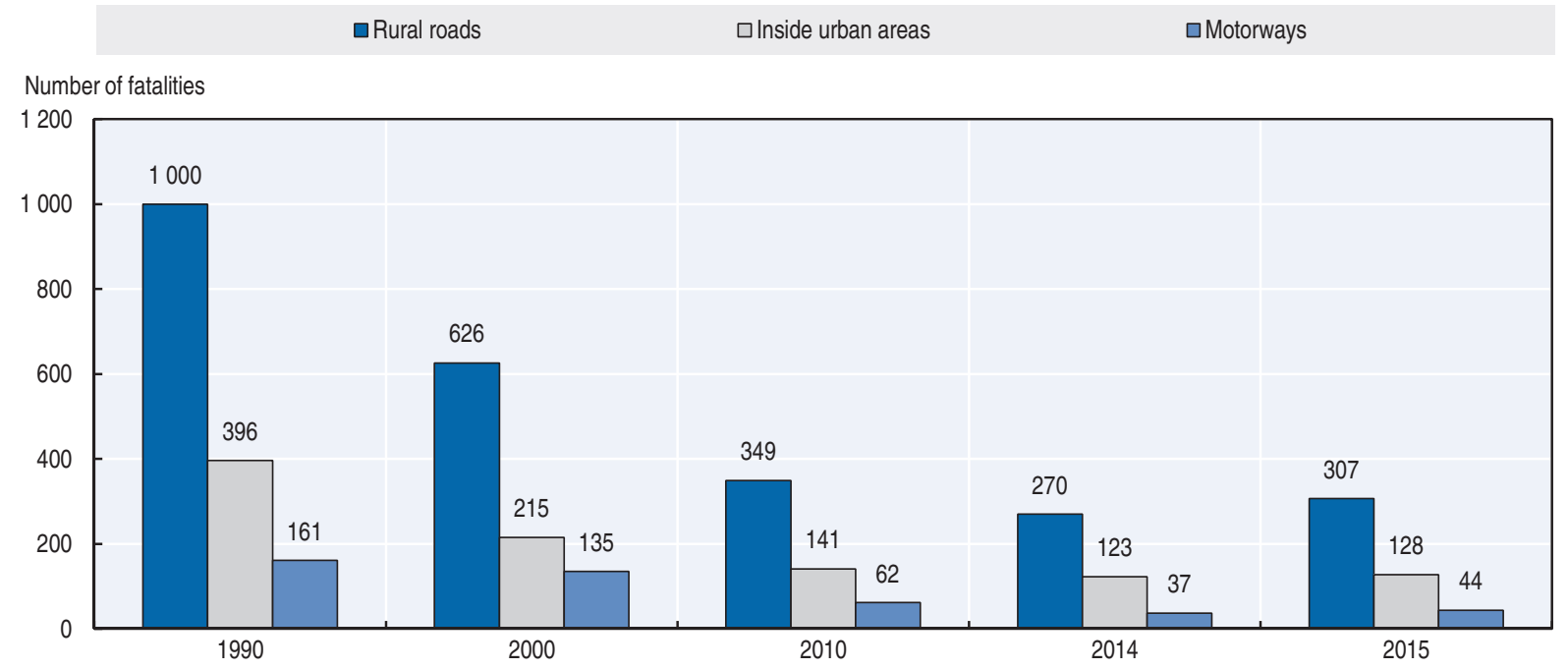

\section{Economic costs of traffic crashes}

Traffic crashes represent a very significant cost for the Austrian society, estimated at around EUR 10 billion (about 3.4\% of GDP).

There are no regular updates of the economic costs of traffic crashes in Austria. According to the most recent study (Herry et al., 2013), the costs of human suffering make up almost half of the crash costs (48\% using the "willingness to pay" approach), while the most important other costs are material damage (25\%), loss in achievement potential (15\% using human capital approach), insurance administration (7\%) and legal costs (2\%). 
Table 4.5. Costs of road crashes, 2011

\begin{tabular}{lcc}
\hline & Unit cost & Total \\
\hline Fatalities & EUR 3016194 & EUR 1.58 billion \\
Severe injuries & EUR 381480 & EUR 4.01 billion \\
Slight injuries & EUR 26894 & EUR 0.93 billion \\
Property damage costs & EUR 8245 & EUR 3.58 billion \\
Total & & EUR 10.09 billion \\
Total as \% of GDP & & $3.4 \%$ \\
\hline
\end{tabular}

Source: Herry et al. (2013).

\section{Recent trends in road user behaviour}

\section{Speed}

Speed, and especially inappropriate speed, is one of the main causes of crashes in Austria. According to a police assessment in $2015,14 \%$ of all injury crashes and $24 \%$ of all road fatalities were caused by speeding.

Due to restrictions in manpower, increases in speed surveillance by traffic police cannot be expected in the future, but automatic speed enforcement including section controls will be further developed. The table below summarises the main speed limits in Austria.

Table 4.6. Passenger car speed limits by road type, 2017

\begin{tabular}{lc}
\hline & General speed limit \\
\hline Urban roads & $50 \mathrm{~km} / \mathrm{h}$ \\
Rural roads & $100 \mathrm{~km} / \mathrm{h}$ \\
Motorways & $130 \mathrm{~km} / \mathrm{h}$ \\
\hline
\end{tabular}

In 2016, the Austrian Ministry of Transport launched a nation-wide campaign on adequate speed choice on rural roads that has been continued into 2017. $\mathrm{KfV}$ will evaluate the impact of the campaign once it is finalised.

\section{Drink driving}

To define drink-driving crashes, Austria uses the definition recommended by the European Union project SafetyNet: any crash in which any active participant had a blood alcohol content level (BAC) above the legal limit.

The maximum permissible blood alcohol level for drivers in Austria has been $0.5 \mathrm{~g} / \mathrm{l}$ since 1998. The level is $0.1 \mathrm{~g} / \mathrm{l}$ for moped drivers under 20 years' old, novice drivers (holding a licence for less than two years), drivers of trucks over 7.5 tonnes and drivers of buses with more than nine seats.

Since 2002, every driver involved in an injury crash is tested for alcohol. However, it is not permitted in Austria to test a dead or an unconscious person (unless the prosecutor requires it). Therefore, the number of unreported cases is believed to be substantial.

In 2015 there were 2226 recorded drink-driving crashes (+0.6\% compared to 2014) with 2834 injured persons (-2\%) and 27 fatalities $(-15.6 \%)$. The share of fatalities in crashes involving an alcohol-intoxicated person decreased from $7.4 \%$ in 2014 to 5.6\% in 2015. However the actual share is probably much higher, as deceased persons are not tested. 
Drink driving remains a predominantly male problem. However, the share of drunk females in alcohol-related crashes has been on a steady increase since 2000 (8\%), reaching 13\% in 2015.

An alcohol interlock rehabilitation programme for offenders was introduced in 2017.

\section{Drugs and driving}

Austrian regulations provide no specific thresholds for drug concentrations. It is forbidden to drive or ride a motor vehicle while under the influence of drugs.

Little is currently known about the prevalence of drugs as a causal factor in accidents. According to a subjective assessment of the Austrian police, in 2015, $4.2 \%$ of all injury crashes and $3.8 \%$ of all road fatalities were caused by impairment due to alcohol and illicit or pharmaceutical drugs.

In 2017, the Austrian police started trialling roadside drug testing devices (saliva tests) in all of the nine Austrian regions.

\section{Distraction}

In 2015 , about $38 \%$ of all road traffic crashes and $31 \%$ of all road fatalities were attributed to inattentiveness or distraction as the main cause of the crash.

In Austria, it is not permitted to drive while using a hand-held mobile phone. However, the use of hands-free devices is tolerated. The use of hand-held mobile phones while cycling was prohibited in 2013.

Since 2016, the prohibition of hand-held mobile phone use during driving also includes texting, dialling, social media etc., with the exception of navigation. KFV has developed "distraction workshops" for Austrian schools, of which the first pilot projects were successfully deployed in all Austrian provinces in 2016.

\section{Sleepiness and fatigue}

The share of fatigue as a causal factor in crashes is especially challenging to detect. According to the Austrian Statistics Bureau (Statistik Austria) and based on police assessment, in $2015,1.5 \%$ of all injury crashes and $4.6 \%$ of all road fatalities were caused by drowsiness in drivers. The real figures may be significantly higher.

\section{Seat belts and helmets}

Seat belt wearing has been compulsory in Austria since 1984 in front seats and from 1990 for rear seats. The seat belt wearing rate on front seats has been steadily increasing and was around $95 \%$ in 2016, whereas rear seat belts are used by only $88 \%$ of adult car occupants.

The use of dedicated child restraint devices has been mandatory in Austria since 1994 for children under 14 years of age or less than $150 \mathrm{~cm}$ tall.

The share of fatally injured car occupants not using a seat belt has dropped from about $50 \%$ in 2000 to $34 \%$ in 2015 .

Helmets are compulsory on all powered two-wheelers. The helmet-wearing rate of riders of powered two-wheelers is not surveyed regularly, but it is believed to be at practically $100 \%$.

Since June 2011, bicycle helmets have been compulsory for children up to 12 years of age. 
Table 4.7. Seat belt wearing rate by car occupancy and road type

\begin{tabular}{|c|c|c|c|c|c|c|c|}
\hline & 1990 & 2000 & 2012 & 2013 & 2014 & 2015 & 2016 \\
\hline \multicolumn{8}{|l|}{ Front seat } \\
\hline General (driver + passenger) & & 76 & 89 & 91 & 95 & 93 & 95 \\
\hline Driver & & 74 & 89 & 91 & 95 & 93 & 95 \\
\hline Passenger & & 79 & 90 & 93 & 96 & 94 & 96 \\
\hline Urban roads (driver) & 63 & 71 & 89 & 92 & 95 & 92 & 94 \\
\hline Rural roads (driver) & 74 & 77 & 88 & 90 & 95 & 95 & 97 \\
\hline Motorways (driver) & 75 & 79 & 91 & 92 & 95 & 95 & 97 \\
\hline \multicolumn{8}{|l|}{ Rear seats } \\
\hline Adults & & 45 & 75 & 76 & 77 & 78 & 88 \\
\hline Children (use of child restraint) & & 71 & 94 & 95 & 99 & 97 & 98 \\
\hline
\end{tabular}

\section{National road safety strategies and targets \\ Organisation of road safety}

Primary responsibility for road safety in Austria lies with the Federal Ministry for Transport, Innovation and Technology (BMVIT). BMVIT co-operates with the Federal Ministry of the Interior (BM.I) and other government ministries, regional and local authorities, interest groups, chambers of commerce and industry, trade and labour associations and road safety organisations through the Road Safety Programme.

The Road Safety Advisory Council, established at BMVIT, serves as the institutional platform for partners in the Road Safety Programme. It was established in 2006 as the forum for decision makers in matters relating to road safety and, in particular, for the preparation, ongoing evaluation and development of road safety programmes for all modes of transport. Members are transport spokespersons for the parliamentary political parties, representatives of government ministries, local and regional authorities, automobile clubs, chambers of commerce and industry, trade and labour associations, interest groups and research institutions.

The Austrian Road Safety Fund, also established at BMVIT, was set up with the aim of promoting and furthering road safety. The Road Safety Fund is funded with revenues from personalised vehicle number plates. The Road Safety Fund plays a key role in financing road safety related research and activities relating to the Road Safety Programme. Funding priorities are aligned to Road Safety Programme targets.

\section{Road safety strategy for 2011-2020}

Despite significant progress in the last decade, Austrian road safety figures are still only average compared to the European Union as whole and below average for the EU15 countries. The Road Safety Programme 2011-2020 aims at "making Austria one of the five safest countries in Europe". It is based on the Safe System approach and has an increased focus on reducing the number of serious injuries on Austrian roads. The Programme features 17 main fields of action.

\section{Road safety targets}

- $50 \%$ reduction in fatalities by 2020 , based on the average for the years 2008-10 (Interim target: $-25 \%$ by 2015 ) 
- $40 \%$ reduction in serious injuries by 2020 , based on the average for the years $2008-10$ (Interim target: $-20 \%$ by 2015 )

- $20 \%$ reduction in injury crashes by 2020 , based on the average for the years $2008-10$ (Interim targets: $-10 \%$ by 2015 ).

The targets are based on the EU fatality reduction target as well as the European Transport Safety Council's proposal for a serious injury reduction target.

To ensure the Road Safety Programme is successfully implemented, the Road Safety Advisory Council provides support in all 17 fields of action throughout the duration of the programme. It gathers and analyses available annual crash statistics, behaviour parameters and safety indicators. Based on this information, measures are adjusted as required to accommodate changes in road behaviour and crashes.

The Annual Report 2015 by the Federal Ministry for Transport, Innovation and Technology (BMVIT, 2015) provides the most recent overview of the implementation status of the Road Safety Programme and therefore serves as an ongoing programme evaluation tool.

Figure 4.7. Trends in road fatalities towards national target

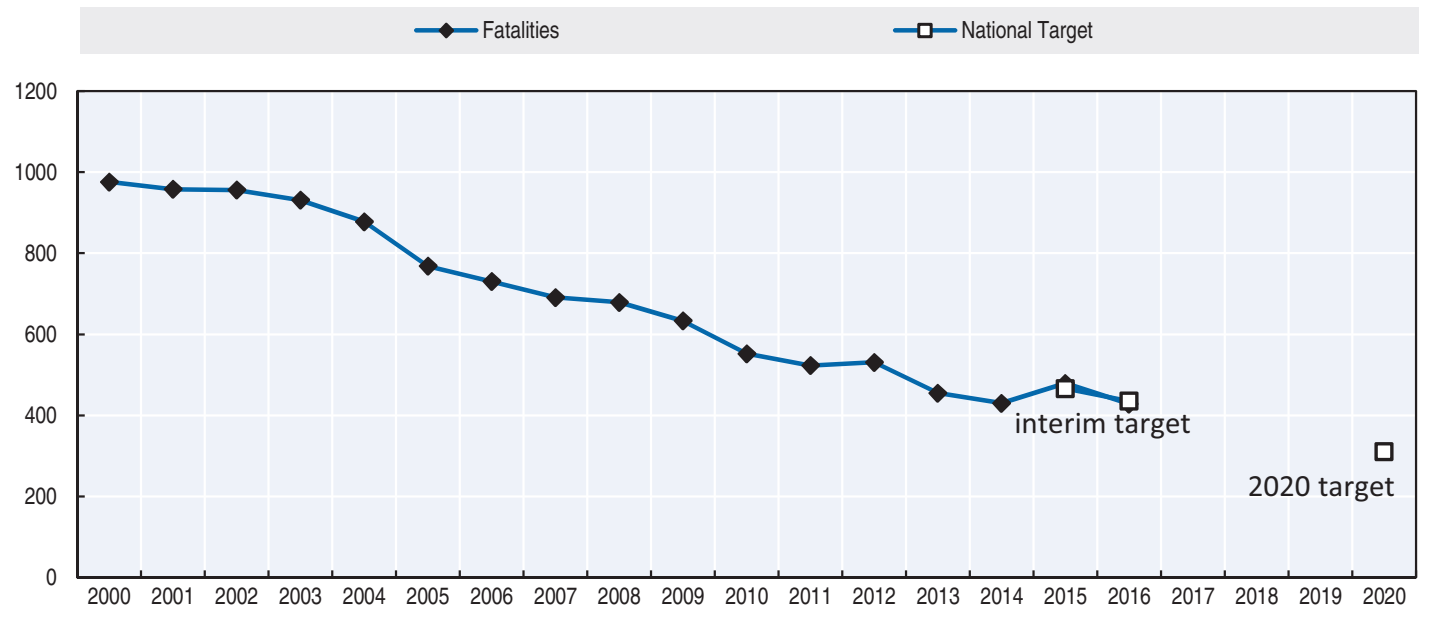

Figure 4.8. Trends in injury crashes ${ }^{1}$ towards national target

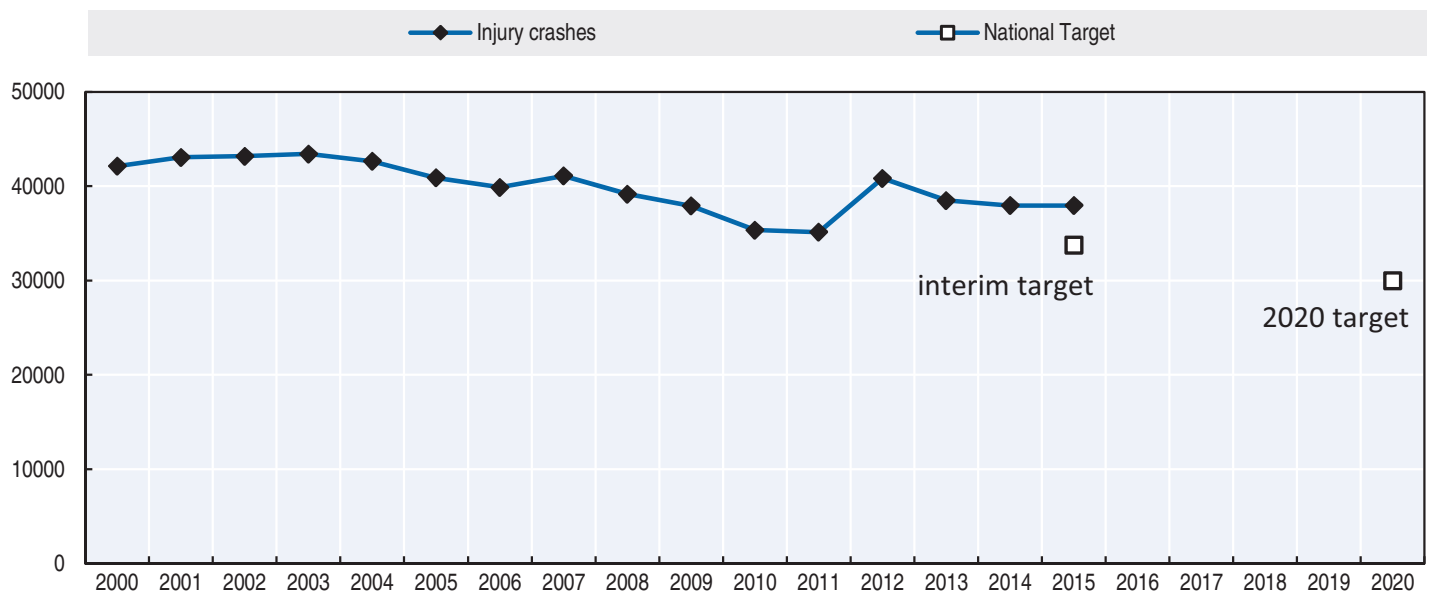

1. Crash data acquisition process changed in 2012. 


\section{Recent safety measures (2014-17)}

\section{Road safety management}

- An updated version of the Austrian Road Safety Programme 2011-2020 was published in 2016 (BMVIT 2016) www.bmuit.gu.at/en/service/publications/transport/downloads/rsp2020_ 2016.pdf.

\section{Road users}

\section{Driving licence}

- A "late starter" motorcycle driving licence (for age group 39+) was introduced in 2014, featuring new modules on risk competence and practical handling of heavy bikes.

- A risk competence course for all driving instructors of A-category licences was introduced in 2015.

- Second phase (post-licence) driving licence education: all involved bodies (incl. driving schools) now to take part in a quality assurance process.

\section{Distraction}

- Since 2016, the prohibition of hand-held mobile phone use during driving also includes texting, dialling, social media etc., with the exception of navigation.

\section{Driving under the influence}

- A maximum BAC level of $0.1 \mathrm{~g} / \mathrm{l}$ for non-commercial school transport was introduced in 2016.

- Implementation of the EU Directive requiring expert certificates and regular monitoring of sleep apnoea patients

- An alcohol interlock rehabilitation programme for offenders was introduced in 2017.

- In 2017, the Austrian police started testing of roadside drug test devices (saliva tests) in all of the nine Austrian regions.

\section{Protective equipment for motorcyclists}

- The Supreme Court ruled that motorcycle riders not wearing appropriate protective clothing (in addition to a safety helmet) will not receive full compensation in case of an accident.

\section{Speed Management/Education and Awareness}

- In 2016, the Austrian Ministry of Transport launched a nation-wide campaign on adequate speed choice on rural roads, which continues into 2017. KFV will evaluate the impact of the campaign once it is finalised. https://infothek.bmuit.gu.at/verkehrssicherheitskampagnelenken-sie-ihr-schicksal-selbst/ (accessed 11 May 2017)

\section{Infrastructure}

- In 2014, trucks above 7.5 tons were prohibited from using fast lanes on motorways with three or more lanes.

- Since 2016, automated driving pilot projects in real traffic are possible in Austria (but require decree by the transport ministry). 


\section{Recent and ongoing research}

The Austrian Road Safety Fund (RSF) has been issuing thematic calls for tenders since 2010. The respective themes are defined by BMVIT in line with Road Safety Programme goals and current accident trends. For all RSF projects, reports are available on the BMVIT website at www.bmuit.gu.at/verkehr/strasse/sicherheit/fonds/vsf/index.html (in German, with English abstracts; accessed 11 May 2017). Some examples are listed here:

- Co-driver: Reduction of children car passenger injuries" (in German with English abstract): www.bmuit.gu.at/bmuit/verkehr/strasse/sicherheit/fonds/vsf/downloads/49_codriver.pdf.

- Cognitive training for older cyclists to improve vigilance and multitasking performance (in German with English abstract): www.bmuit.gu.at/bmuit/verkehr/strasse/sicherheit/fonds/ usf/downloads/50_spielerischestraining.pdf.

- Role Model: reducing accidents through role models and by considerate driving (in German with English abstract): www.bmuit.gu.at/bmuit/verkehr/strasse/sicherheit/fonds/vsf/downloads/ 51_rolemodel.pdf.

- The KFV has published the following recent studies on its website:

- 100-Car Study Austria: Naturalistic observation of driving behaviour (German with English abstract): http://www.kfu.at/fileadmin/content/Taetigkeitsbereich/Publikationen/100-CarStudy_ web.pdf.

- Strategic goals in European road transport policies (German with English abstract): http://www.kfu.at/fileadmin/content/Taetigkeitsbereich/Publikationen/KFV_Publikation_ Strategische_Themen_EU_Final.pdf.

\section{References}

BMVIT (2015), Road Safety in Austria? Annual Report 2015, Federal Ministry for Transport, Innovation and Technology, Vienna, www.bmuit.gu.at/en/service/publications/transport/downloads/roadsafety_ report2015.pdf (accessed 11 May 2017).

BMVIT (2016), “Austrian Road Safety Programme 2011-2020”, 2nd edition for 2016-2020, Federal Ministry for Transport, Innovation and Technology, Vienna, www.bmuit.gu.at/bmvit/en/verkehr/ roads/safety/publications/index.html (accessed 11 May 2017).

Herry, M. et al., (2013), Studie im Auftrag des VSF/bmvit: Unfallkostenrechnung Straße 2012 unter Berücksichtigung des menschlichen Leids, Federal Ministry for Transport, Innovation and Technology, Vienna.

World Bank (2017), “GDP (constant US\$)”, World Development Indicators, http://databank.worldbank. org/data/reports.aspx? source=world-development-indicators (accessed 23 February 2017).

\section{Websites (all accessed 11 May 2017)}

- Austrian Ministry for Transport, Innovation and Technology : www.bmuit.gu.at.

- Austrian Road Safety Board (KFV): www.kfu.at.

- Statistik Austria: www.statistik.at/web_en/statistics/transport/road/road_traffic_accidents/index.html.

- Information site on child safety in cars: www.autokindersitz.at/content/index.php.

- Automobile, Motorcycle and Bicyclists Club Austria: www.arboe.at.

- Austrian Automobile, Motorcycle and Touring Club: www.oeamtc.at. 


\section{Chapter 5}

\section{Belgium}

This chapter presents 2015 road safety data for Belgium along with provisional data from 2016. It looks at trends in traffic and road safety from the years 1990 to 2015 and road user behaviour patterns, with a special focus on the ageing population. Sections include data on speed, drink driving, drugs and driving, distracted driving, fatigue and seat belt and helmet use. The chapter reviews Belgium's road safety strategy and national targets to 2020 and the progress achieved thus far. It also highlights the most recently implemented safety measuress and current and ongoing research.*

* All data stem from the Belgian Road Safety Institute (BRSI) and IRTAD unless otherwise noted. For more information please contact: heike.martensen@bivv.be. 
I In 2015, for the first time in 5 years, Belgium recorded a slight increase of $0.7 \%$ in the number of fatalities, rising from 727 to 732 . However, provisional data from 2016 show a substantial decrease of $13 \%$. Pedestrians and car occupants benefited the most with a reduction in the number of fatalities in 2015 in these user groups, whereas deaths amongst motorcyclists increased substantially by $17.6 \%$. Belgium has a road traffic mortality rate of 6.5 per 100000 inhabitants.

\section{Road safety data collection}

\section{Definitions applied in Belgium}

- Road fatality: A person who died immediately or within 30 days of a crash

- Seriously injured: A person who stays for treatment for more than 24 hours in a hospital following the crash, as reported by police.

- Slightly injury: A person who claims to be in need of medical treatment, as reported by police.

The differentiation between slight and seriously injured persons is not reliable as it is determined by the police at the crash scene. Most Belgian reports therefore treat slightly and seriously injured jointly.

A methodology to collect and estimate the number of people injured based on the Maximum Abbreviated Injury Score of 3 or more (MAIS3+) from hospital data is still under development.

\section{Data collection}

Road safety data are electronically collected and centralised by the police force. After some validation procedures, data are transferred to the National Statistics Office. The National Statistics Office carries out some corrections and adds the fatalities occurring within 30 days to the database. This latter operation is done by linking the notification of death (a paper form with very basic information) that is sent by the Department of Justice to the National Statistical Office.

The number of slightly and seriously injured persons is the most likely to be underreported, as many crashes, especially with cyclists and motorcyclists, are not reported to the police. Since 2015 a new procedure has been under development to take hospital data into account. This will result in correction for underreporting and an estimation of the numbers of victims with injuries of a Medical Abbreviated Injury Score of 3 and above (MAIS3+). The results are, however, still too preliminary and the data in this report are not corrected for underreporting in police records.

In 2014 the road safety database in Belgium was modified. The database now contains both injury crashes recorded by the police at the scene of the accident and injury crashes self-reported at a police station. The quality of the database has also improved thanks to changes in the data processing method, which notably allow for better identification of 
user types and of characteristics of individuals and vehicles. The database is therefore more comprehensive. However, it also means that statistics from 2014 onwards are not fully comparable with those of previous years. Also, due to the registration of cases that would earlier not have been registered, there is an increase in the number of the "unknown" category in many variables. Comparisons with previous years should therefore be made with caution.

\section{Road crashes in 2016 - final data}

In 2016, there were 637 road deaths, a 13\% decrease when compared to 2015. The decrease in the number of fatalities occurred in all regions. The strongest decrease is observed among motorcyclists and pedestrians, and also car occupants. There are smaller decreases among moped riders and among cyclists. The number of fatalities in crashes involving heavy good vehicles increased compared to 2015.

The number of injury crashes in 2016 overall remained similar to that of $2015(-0.5 \%)$ with regional differences: it stagnated in the Flemish region, it decreased in the Walloon region and increased in the Brussels region.

\section{Road crashes in 2015}

Following the increase seen in 2014, the number of injury crashes in Belgium decreased in 2015 resulting in a slightly better result than that of 2013.

For fatalities however, the continuous decrease recorded over the previous four years was interrupted by a slight increase between 2014 and 2015. An increase in fatalities was observed for powered two-wheelers, cyclists and crashes involving light-goods vehicles, as well as for victims with an "unknown" road user type. Decreases were observed for car occupants and pedestrians. The evolution in the number of fatalities is different among the regions: there was a small decrease in the Flemish region, stagnation in the Brussels region and an increase in the Walloon region.

\section{Trends in traffic and road safety (1990-2016) Traffic}

Since 1990, the distance travelled by motorised road users has increased by more than $43 \%$. In the same period, the number of vehicles has increased by $56 \%$. After a stagnation in vehicle-kilometres between 2007 and 2010, and a 2\% reduction in 2013 compared to 2012, vehicle-kilometres began increasing annually again during 2014-15.

\section{Road safety}

\section{Crashes and casualties}

Between 1990 and 2015, the number of fatalities decreased by 63\%, the number of seriously injured persons (as registered by the police) by $76 \%$ and the number of injury crashes by more than $35 \%$. The biggest share of these improvements, however, fell to the period following 2000.

Around the time of the millennium change, road safety became an issue of great public interest in Belgium. While the number of fatalities had been stagnating or had even increased in the late 1990s, this number has steadily declined since 2001, the year in which 
the first national assembly on road safety (Etats Généraux de la Sécurité Routière/Staten-Generaal van de Verkeersueiligheid) initiated many improvements in infrastructure, enforcement and education. The reduction in the number of fatalities in the years following this event is even more striking when considering that between 2001 and 2004 the registration of crashes was revised and strongly improved, which would normally lead to an increase in registered fatalities. The decline has been relatively steady since, with small variations that are probably due to the economic situation (decrease in 2008) or meteorological variations (2010-11, 2014).

The most important measures to have contributed to the decline of mortality in Belgium are:

- reduction of speed limit on many rural roads

- stricter control of speed limits

- black-spot treatment and adjustment of the infrastructure

- improved safety systems in cars and trucks

- better road safety awareness through campaigns and educational measures

\section{Rates}

Between 1990 and 2015, the road traffic mortality rate, expressed in terms of deaths per 100000 inhabitants decreased by more than $67 \%$, and risks expressed in deaths per number of vehicles decreased by almost $80 \%$.

\section{Analysis of seriously injured data}

While the number of fatalities decreased markedly between 1990 and 2010, this was much less the case for injury crashes. Recently, however, while the reduction in the number of fatalities slowed down, the decrease of injury crashes was similar or even larger than for fatalities.

Table 5.1. Road safety and traffic data

\begin{tabular}{|c|c|c|c|c|c|c|c|c|c|}
\hline & \multirow{2}{*}{1990} & \multirow{2}{*}{2000} & \multirow{2}{*}{2010} & \multirow{2}{*}{2014} & \multirow{2}{*}{2015} & \multicolumn{4}{|c|}{$2015 \%$ change from } \\
\hline & & & & & & 2014 & 2010 & 2000 & 1990 \\
\hline \multicolumn{10}{|l|}{ Reported safety data* } \\
\hline Fatalities & 1976 & 1470 & 840 & 727 & 732 & 0.7 & -12.9 & -50.2 & -63.0 \\
\hline Injury crashes & 62446 & 49065 & 45927 & 41481 & 40303 & -2.8 & -12.2 & -17.9 & -35.5 \\
\hline Injured persons hospitalised ${ }^{1}$ & 17479 & 9847 & 5984 & 4502 & 4201 & -6.7 & -29.8 & -57.3 & -76.0 \\
\hline Deaths per 100000 inhabitants & 19.9 & 14.4 & 7.7 & 6.5 & 6.5 & 0.2 & -16.1 & -54.7 & -67.3 \\
\hline Deaths per 10000 registered vehicles & 4.3 & 2.6 & 1.3 & 1.0 & 1.0 & -0.7 & -18.8 & -60.2 & -76.3 \\
\hline Deaths per billion vehicle kilometres & 28.1 & 16.3 & 8.5 & 7.3 & 7.3 & -0.4 & -14.3 & -55.3 & -74.0 \\
\hline \multicolumn{10}{|l|}{ Traffic data } \\
\hline Registered vehicles ${ }^{2}$ (thousands) & 4594 & 5735 & 6689 & 7076 & 7175 & 1.4 & 7.3 & 25.1 & 56.2 \\
\hline Vehicle-kilometres (millions) & 70276 & 90036 & 98678 & 99194 & 100306 & 1.1 & 1.6 & 11.4 & 42.7 \\
\hline Registered vehicles per 1000 inhabitants & 462 & 560 & 617 & 632 & 637 & 0.9 & 3.3 & 13.8 & 38.0 \\
\hline
\end{tabular}

* The data collection system changed in 2014; statistics from 2014 onwards are not fully comparable with those of previous years.

1. The number of injured persons hospitalised is subject to underreporting.

2. Registered vehicles excluding mopeds. 
Figure 5.1. Road safety, traffic and GDP trends index $1990=100$

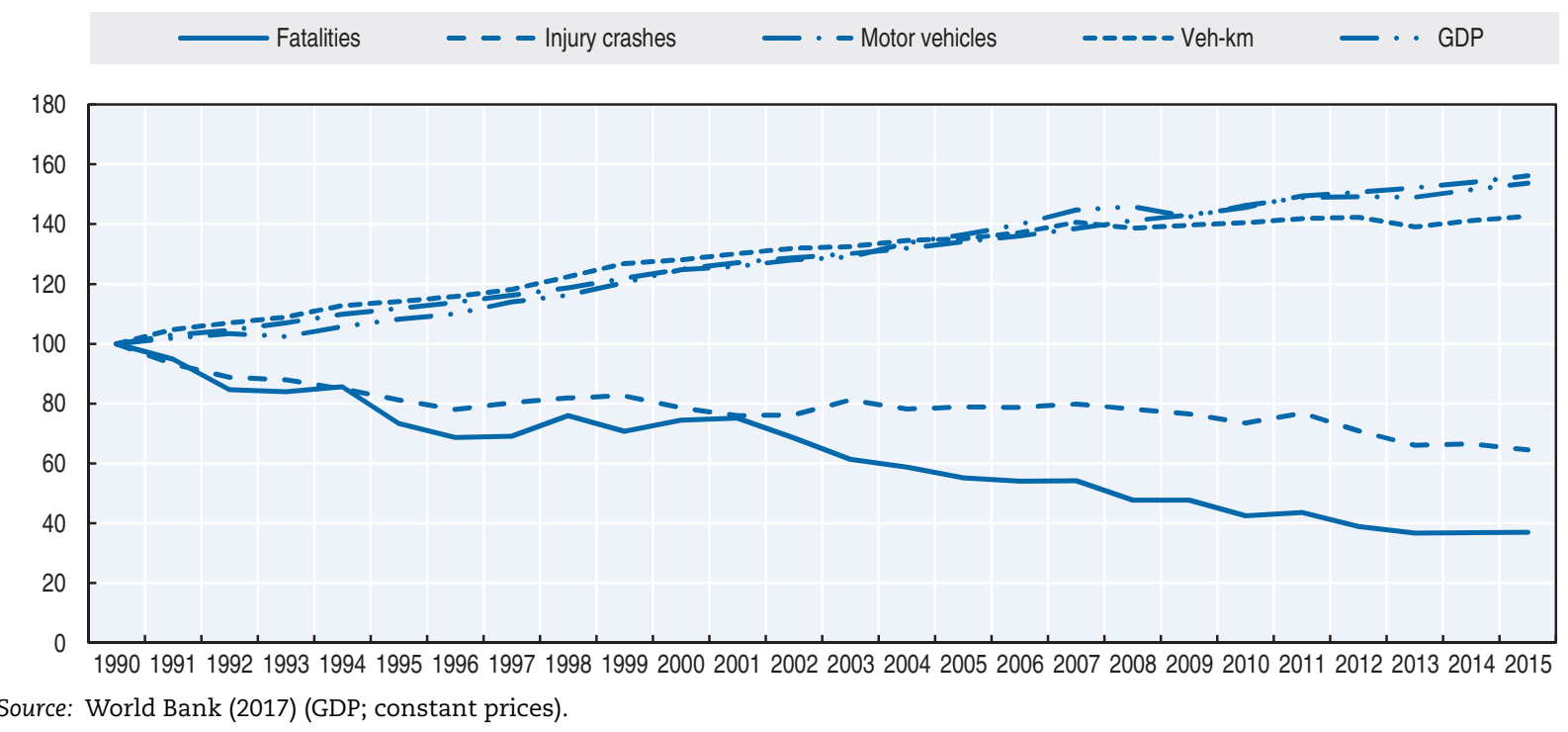

\section{Road safety by user group}

All user groups, in particular pedestrians, cyclists, moped users and passenger car occupants have benefited from safety improvements since 1990.

While the number of fatalities for car occupants, pedestrians, moped riders and cyclists have shown a more or less regular decline in the last two decades (from $58 \%$ to $83 \%$ ), fatalities among motorcyclists, and truck and van occupants have shown only a relatively small decrease $(20 \%)$.

In the last five years (from 2010) there was an average decrease of $13 \%$ in road fatalities. However, while fatalities for pedestrians, passenger cars, motorcycles and mopeds show improvements of various degrees, the number of cyclists killed has increased. This has probably resulted from an increase in cycling. The ageing of the population may also play a role.

In 2015 fatalities increased compared to 2014 for cyclists, moped riders and motorcycles, as well as for the "other" category. It should be noted, at the same time, that the collection process changed in 2014 and there is a break in the data. This should not be interpreted in terms of road safety developments.

Table 5.2. Road fatalities by road user group

\begin{tabular}{lrrrrr|rrrr}
\hline & 1990 & 2000 & 2010 & 2014 & 2015 & \multicolumn{4}{|c}{$2015 \%$ change from } \\
\cline { 7 - 10 } & & & & & & 2014 & 2010 & 2000 & 1990 \\
\hline Pedestrians & 301 & 142 & 106 & 106 & 92 & -13.2 & -13.2 & -35.2 & -69.4 \\
Cyclists & 196 & 134 & 70 & 76 & 83 & 9.2 & 18.6 & -38.1 & -57.7 \\
Moped riders & 110 & 64 & 22 & 17 & 19 & 11.8 & -13.6 & -70.3 & -82.7 \\
Motorcyclists & 106 & 118 & 102 & 85 & 100 & 17.6 & -2.0 & -15.3 & -5.7 \\
Car occupants & 1181 & 922 & 444 & 381 & 362 & -5.0 & -18.5 & -60.7 & -69.3 \\
Others & 82 & 90 & 96 & 62 & 76 & 22.6 & -20.8 & -15.6 & -7.3 \\
Total & $\mathbf{1 9 7 6}$ & $\mathbf{1 4 7 0}$ & $\mathbf{8 4 0}$ & $\mathbf{7 2 7}$ & $\mathbf{7 3 2}$ & $\mathbf{0 . 7}$ & $\mathbf{- 1 2 . 9}$ & $\mathbf{- 5 0 . 2}$ & $\mathbf{- 6 3 . 0}$ \\
\hline
\end{tabular}


Figure 5.2. Road fatalities by road user group in percentage of total, 2015

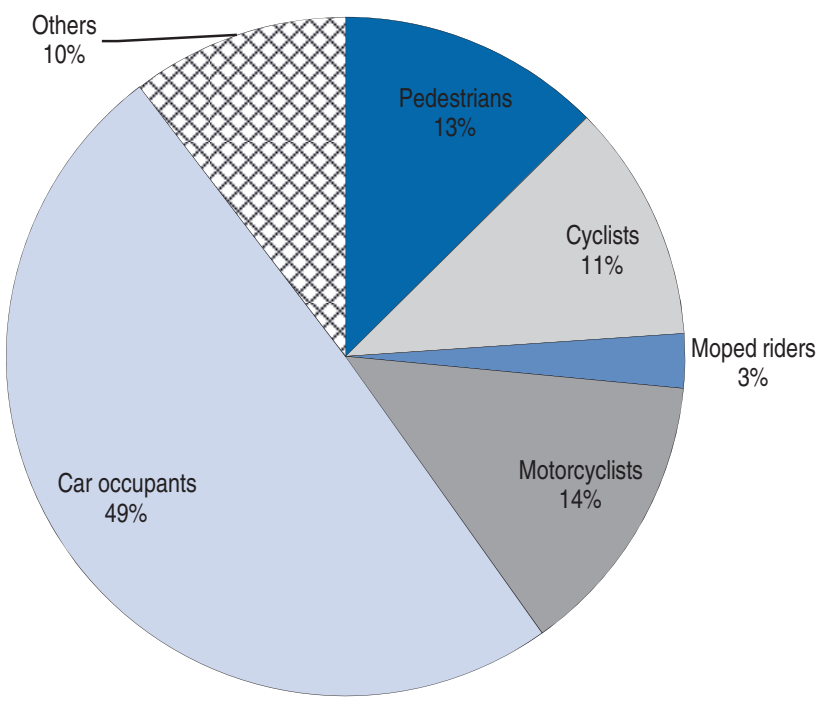

\section{Road safety by age group}

Since 1990, the reduction in fatalities has benefited all age groups, but the most impressive reduction concerns children aged 0 to 14 years (by almost $83 \%$ ), as well as the groups of young people aged $15-17$ and $18-20$ (more than $76 \%$ and $83 \%$, respectively). Despite substantial reductions, young people aged 18-24 are still a high-risk group, with a fatality rate nearly twice as high as that of the general population. Improvements were weaker for the senior population of those 65 years and older, with a reduction of only $45 \%$ when compared to 1990.

Since 2000, the situation has improved for all age groups, except for those 85 and over. However, since 2010 the situation has deteriorated for the over 65s (except a small decrease for the 75-84).

The analysis of developments since 2010 shows an improvement in youth mortality.

Table 5.3. Road fatalities by age group

\begin{tabular}{|c|c|c|c|c|c|c|c|c|c|}
\hline \multirow{2}{*}{ Age } & \multirow{2}{*}{1990} & \multirow{2}{*}{2000} & \multirow{2}{*}{2010} & \multirow{2}{*}{2014} & \multirow{2}{*}{2015} & \multicolumn{4}{|c|}{$2015 \%$ change from } \\
\hline & & & & & & 2014 & 2010 & 2000 & 1990 \\
\hline $0-14$ & 108 & 52 & 23 & 10 & 19 & 90.0 & -17.4 & -63.5 & -82.4 \\
\hline $15-17$ & 72 & 55 & 21 & 22 & 17 & -22.7 & -19.0 & -69.1 & -76.4 \\
\hline $18-20$ & 202 & 130 & 64 & 37 & 34 & -8.1 & -46.9 & -73.8 & -83.2 \\
\hline $21-24$ & 245 & 198 & 107 & 80 & 67 & -16.3 & -37.4 & -66.2 & -72.7 \\
\hline $25-64$ & 992 & 784 & 467 & 392 & 408 & 4.1 & -12.6 & -48.0 & -58.9 \\
\hline $65-74$ & & 114 & 65 & 72 & 73 & 1.4 & 12.3 & -36.0 & \\
\hline $75-84$ & & 98 & 68 & 80 & 66 & -17.5 & -2.9 & -32.7 & \\
\hline$\geq 85$ & & 26 & 20 & 26 & 45 & 73.1 & 125.0 & 73.1 & \\
\hline Total & 1976 & 1470 & 840 & 727 & 732 & 0.7 & -12.9 & -50.2 & -63.0 \\
\hline
\end{tabular}


Figure 5.3. Road fatality rates by age group

Deaths per 100000 inhabitants in a given age group, 1990-2015

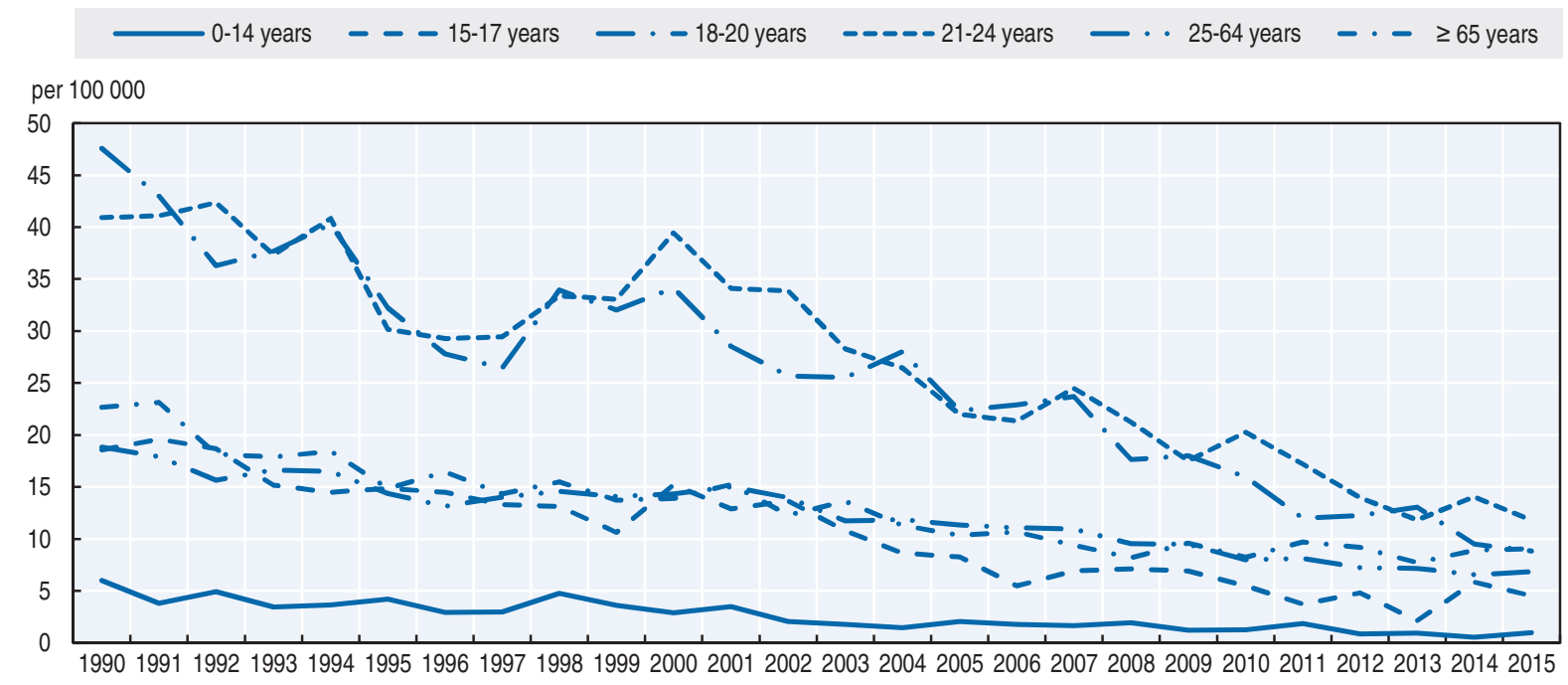

\section{Box 5.1. Road safety for an ageing population}

Although the phenomenon of an ageing society is less strong in Belgium than in some of its neighbouring countries, the percentage of senior citizens is rising steadily. The share of over $65 \mathrm{~s}$ in the total population increased from 15\% in 1991 to $19 \%$ in 2016. It is projected that it will reach $26 \%$ by 2050 .

The growing share of the older population is also reflected in road crash statistics. While in $1992,17 \%$ of road fatalities were in the 65+ age group, this figure was $25 \%$ in 2015.

Figure 5.4. Evolution in number of fatalities in the over 65 age group 1991-2016

$\square$ Number of fatalities among senior

Share of seniors among fatatalities

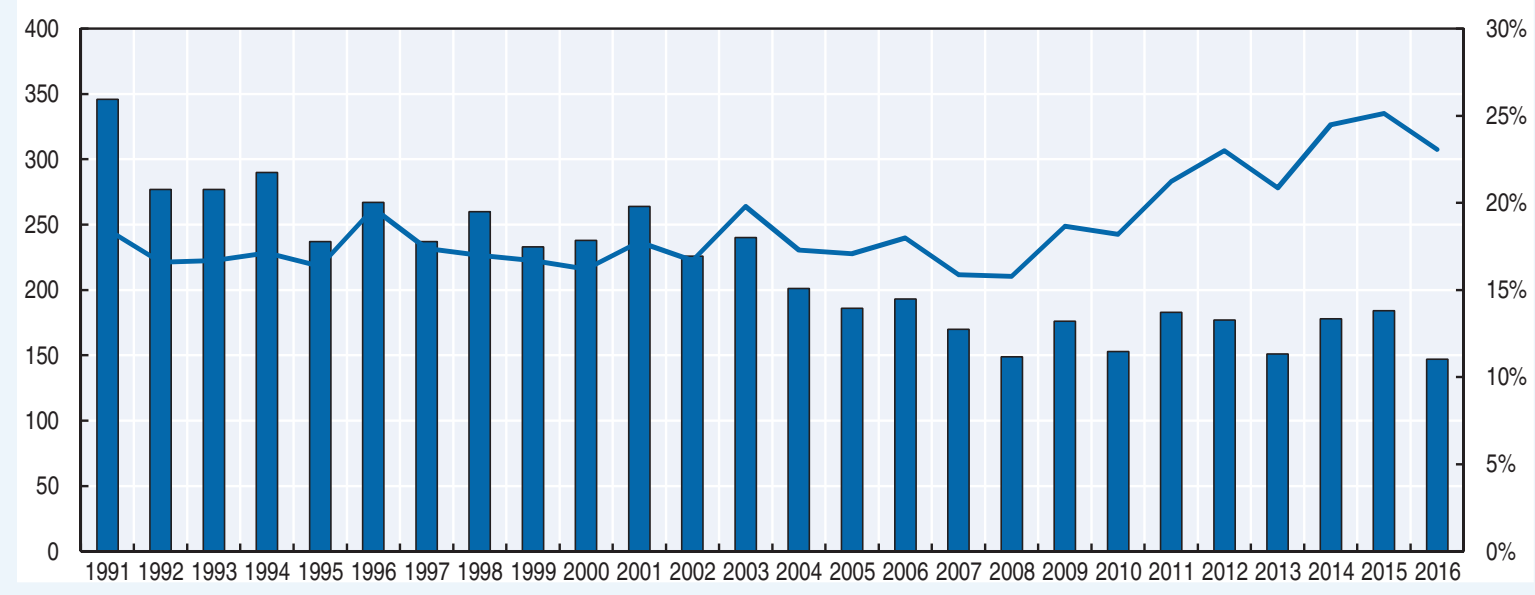

The ageing population is particularly vulnerable when cycling and walking. In 2015, more than half of the over 65 age group killed were pedestrians or cyclists. For middle-aged road users the ratio is 1 in 5 . To the contrary, the share of car driver fatalities in the older population is lower than among middle-aged victims. 


\section{Box 5.1. Road safety for an ageing population (cont.)}

In the over-75 age group, the risk of being fatally injured per kilometre travelled increases in all modes of transport when compared to the average risk calculated across all age groups. For car passengers the risk is doubled, for pedestrians it is four times as high and as cyclists the risk is 6 times higher than the average. Road users aged 65-74 also have an elevated risk, but the increase is much smaller. Only as cyclists do they have a substantially higher risk (4 times the all-age average).

For older road users complex traffic situations can become even more challenging than for younger ones, for example, junctions and crossroads. Crashes occurring while pedestrians are crossing the road or while drivers/cyclists are turning left are more frequent among older road users compared to middle-aged ones (Martensen, 2014).

Since 2013, the Belgian driver's licence is valid for ten years. Renewal of the licence is an administrative procedure in which the candidates have to confirm that they are able to drive. No medical testing is required. However, this new law only concerns newly issued licences; in practice, the large majority of the adult population still has a licence with unlimited validity.

Table 5.4. Road fatalities among senior citizens

\begin{tabular}{lcc|rr|rr}
\hline & \multicolumn{2}{c|}{$65-74$} & \multicolumn{2}{c|}{$75-84$} & \multicolumn{2}{c}{$85+$} \\
\cline { 2 - 7 } & 2010 & 2015 & 2010 & 2015 & 2010 & 2015 \\
\hline Pedestrians & 10 & 14 & 24 & 7 & 6 & 13 \\
Cyclists & 15 & 12 & 14 & 20 & 6 & 14 \\
Moped riders & 1 & 1 & 1 & 0 & 0 & 0 \\
Motorcyclists & 1 & 3 & 0 & 2 & 0 & 1 \\
Car occupants & 27 & 34 & 26 & 35 & 8 & 16 \\
Total & $\mathbf{6 5}$ & $\mathbf{7 3}$ & $\mathbf{6 8}$ & $\mathbf{6 6}$ & $\mathbf{2 0}$ & $\mathbf{4 5}$ \\
\hline
\end{tabular}

Figure 5.5. Road fatality rates by age group - Focus on the senior population Deaths per 100000 inhabitants in a given age group, 2000-15

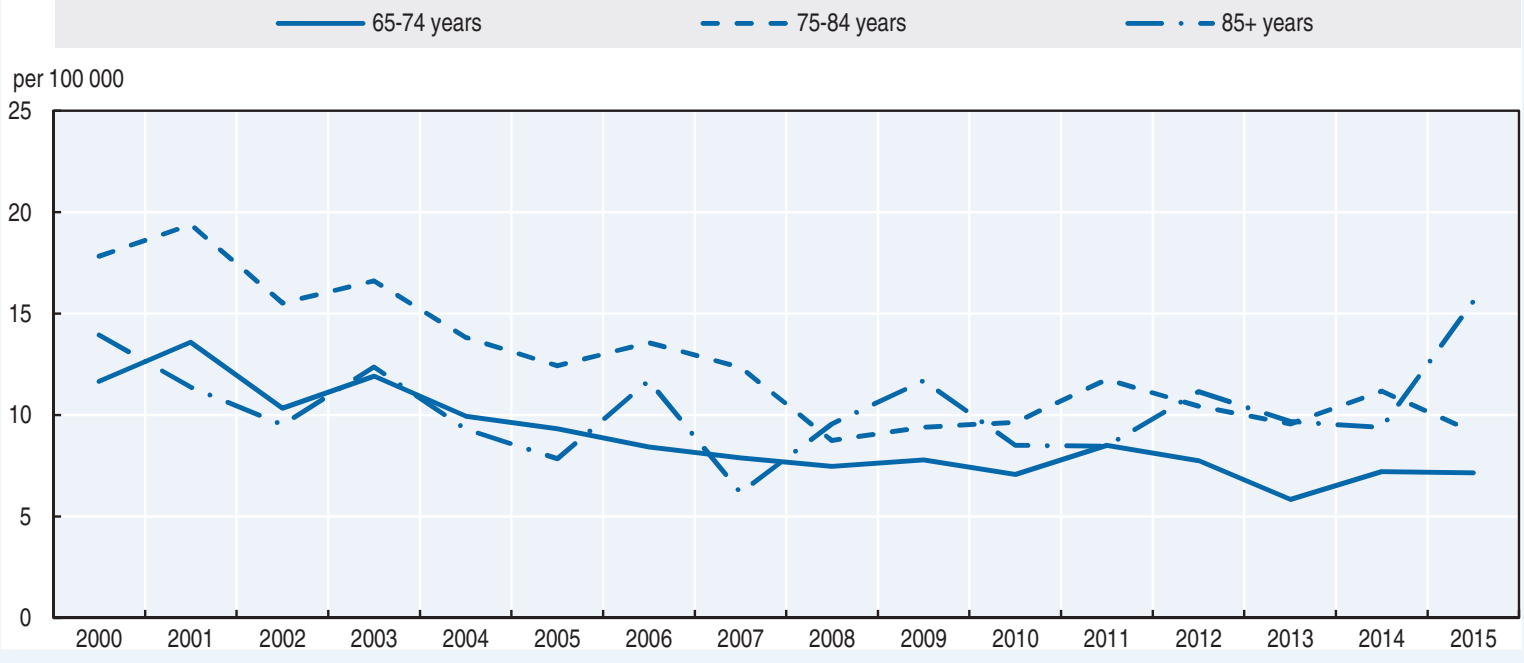




\section{Box 5.1. Road safety for an ageing population (cont.)}

Doctors are legally obliged to check fitness to drive in the case of a number of illnesses (neurological, mental, etc.) on the basis of a list of given criteria. In practice, cases of doubt are often referred to the Centre for Fitness to Drive and Vehicle Adjustments (CARA), where an in-depth testing programme is tailored to the referral diagnosis. The tests usually include a practical exam, and sometimes result in a limited driver's licence (e.g. only on known routes) to guarantee an optimal balance between road safety and the need to remain mobile.

Figure 5.6. Road fatality rate by age and road user group Fatalities per 100000 inhabitants, 2015

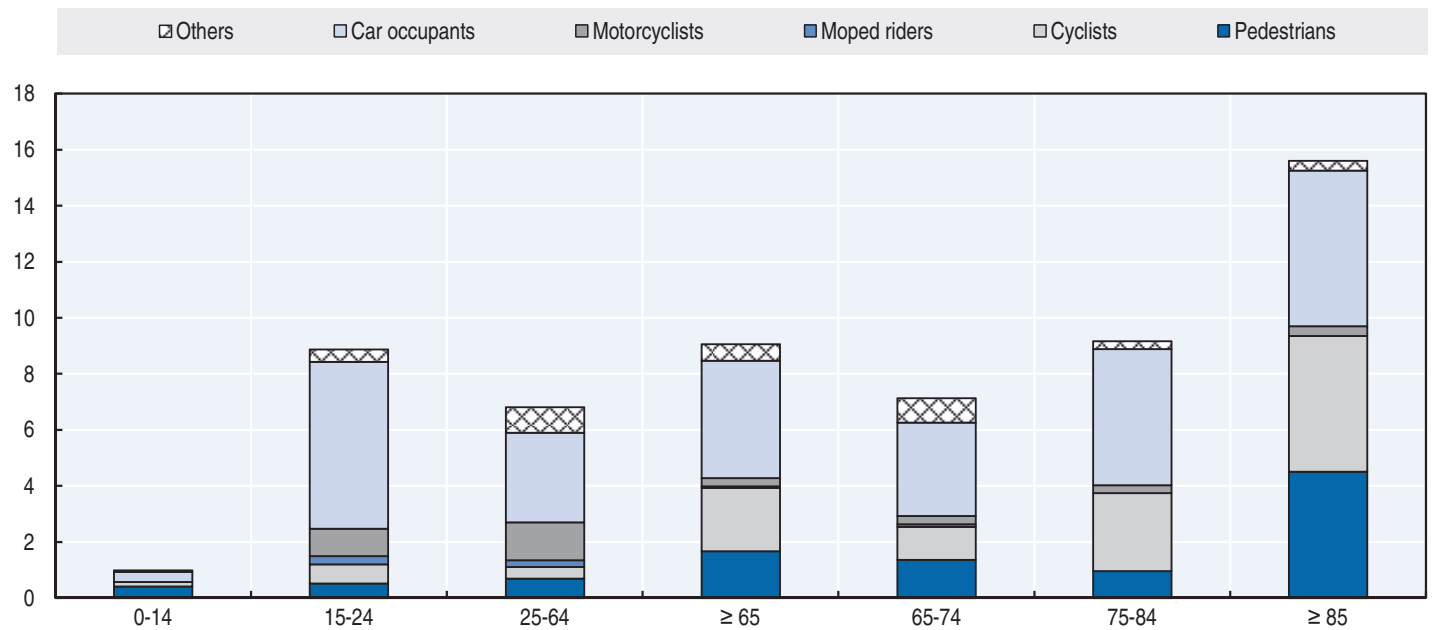

\section{Road safety by road type}

In 2015 , more than half (51\%) of fatalities occurred on rural roads, $31 \%$ in urban areas and $14 \%$ on motorways. For $5 \%$ of the fatalities the road type is unknown. Since 1991, the greatest reduction in fatalities occurred on rural roads (-64.4\%) and inside urban areas (-64.1\%). Improvement on motorways was more moderate (- $49.5 \%)$.

\section{Figure 5.7. Road fatalities by road type*}

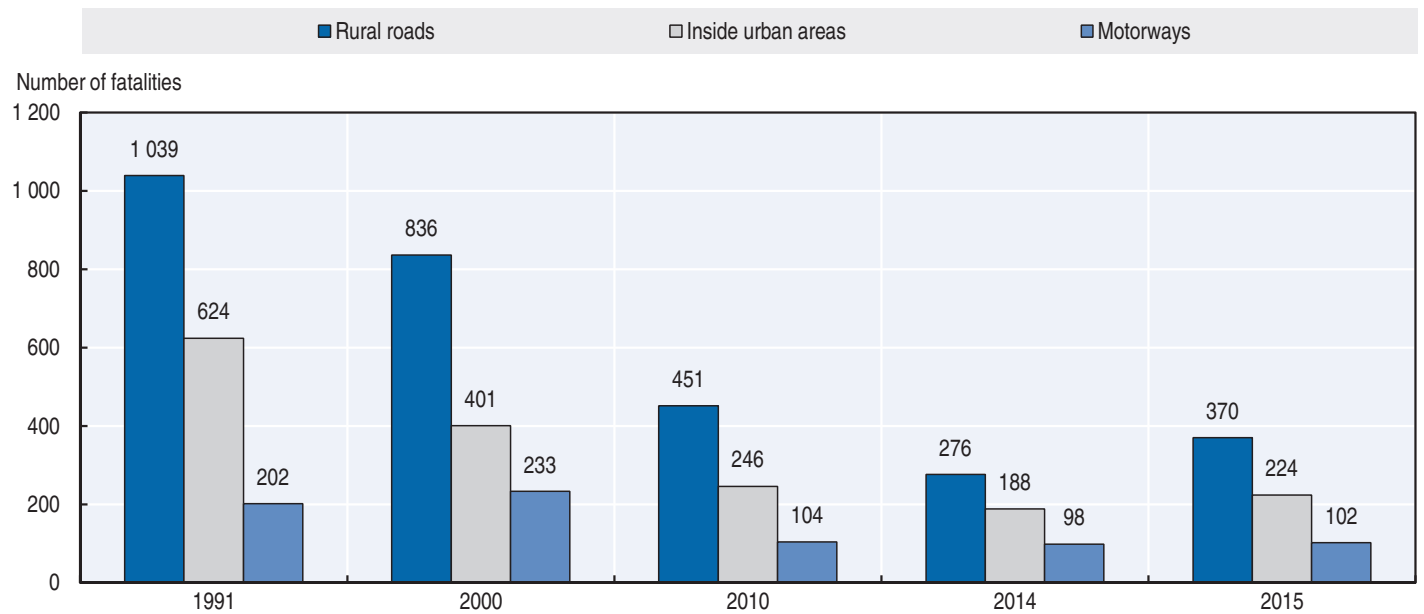

* Due to registration problems in 2014 (that were only partly resolved in 2015) and a large share of "unknown" locations, the figures from 2014 and 2015 are not comparable to the figures of the earlier years. 


\section{Economic costs of traffic crashes}

In Belgium there is no recent information on the costs of crashes. The unit costs in Table 5.5 are based on value transfer from European medians (SafetyCube D3.2, Wijnen et al., 2017). Based on this methodology, road crash costs would amount to EUR 5.9 billion or $1.4 \%$ of Belgian GDP.

Table 5.5. Costs of road crashes, 2015

\begin{tabular}{lrc}
\hline Cost (EUR) & Unit cost & Total \\
\hline Fatalities & 2519610 & 1844354830 \\
Serious & 311916 & 1310359986 \\
Slight injuries & 30203 & 1438803178 \\
Property damage costs & 3960 & 1312227188 \\
Total (EUR) & & $\mathbf{5 9 0 5 7 4 5 \mathbf { 1 8 1 }}$ \\
Total as\% of GDP (at constant prices) & & $\mathbf{1 . 4 \%}$ \\
\hline
\end{tabular}

Source: Wijnen et al. (2017).

\section{Recent trends in road user behaviour}

Speed

The table below summarises the main speed limits in Belgium.

Table 5.6. Passenger car speed limits by road type, 2017

\begin{tabular}{lc}
\hline & General speed limit \\
\hline Urban roads & $30 / 50 \mathrm{~km} / \mathrm{h}$ \\
Rural roads & $70 / 90 \mathrm{~km} / \mathrm{h}$ \\
Motorways & $120 \mathrm{~km} / \mathrm{h}$ \\
\hline
\end{tabular}

Since 2003, the Belgian Road Safety Institute (BRSI) has regularly measured the average speed on Belgian roads. Until 2012, speeds were measured with radar systems. Since 2015, speed is also measured through floating car data (recorded by GPS or mobile phones). Results with the two methodologies cannot be directly compared

In 2015, speed was measured with the old methodology (radar systems) but only in urban areas. Speed was measured in $50 \mathrm{~km} / \mathrm{h}$ zones and in school zones with $30 \mathrm{~km} / \mathrm{h}$. The $30 \mathrm{~km} / \mathrm{h}$ zones around schools where there are no speed deterrents show the most dramatic picture. When the infrastructure is not at all designed to ensure that people respect the speed limit, average driven speed is still almost $15 \mathrm{~km} / \mathrm{h}$ above the limit. There had been a clear decrease between 2007 and 2012 but since then there was not much improvement (-2\%). In $50 \mathrm{~km} / \mathrm{h}$ zones there was initially less improvement but from 2012 to 2015 there has been a decrease by $8 \%$.

Table 5.7. Average speed in urban areas (measured through radar systems)

\begin{tabular}{lllllll}
\hline & 2007 & 2008 & 2009 & 2010 & 2012 & 2015 \\
\hline Zone $50 \mathrm{~km} / \mathrm{h}$ & 54.7 & 55.6 & 53.4 & 53.6 & 52.5 & 48.5 \\
School zone $30 \mathrm{~km} / \mathrm{h}$ & 51.9 & 51.0 & 48.6 & 46.3 & 44.3 & 43.4 \\
\hline
\end{tabular}

Source: Temmerman (2016). 
Outside urban areas, the speed measurements in 2015 were based on floating car data from a panel of 200000 vehicles circulating in Belgium (not necessarily representative of the fleet in Belgium). The resulting indicators identified motorways and two-lane roads $(90 \mathrm{~km} / \mathrm{h})$ as most problematic. These speed regimes present high hourly mean speeds and an alarming share of speeding violations of more than $10 \mathrm{~km} / \mathrm{h}$ (more than $30 \%$ of the observations). Note however, that the results might be influenced by sampling problems and that they are not comparable to the speed measurements between 2003 and 2012.

Table 5.8. Average speed in non-urban areas (measured by floating car data non-representative sample) 2015

\begin{tabular}{lccccc}
\hline & $70 \mathrm{~km} / \mathrm{h}-$ one lane & $70 \mathrm{~km} / \mathrm{h}-$ two lanes & $90 \mathrm{~km} / \mathrm{h}$ two lanes & $120 \mathrm{~km} / \mathrm{h}$ two lanes & $120 \mathrm{~km} / \mathrm{h}$ motorways \\
\hline Light traffic (passenger cars and vans) & 71.8 & 88.0 & 97.3 & 116.3 & 123.0 \\
Heavy vehicles (trucks) & 76.2 & 87.2 & 91.3 & 92.1 & 90.5 \\
\hline
\end{tabular}

Source: Trotta (2016).

\section{Drink driving}

In Belgium, the maximum authorised blood alcohol content (BAC) is $0.5 \mathrm{~g} / \mathrm{l}$. Since January 2015 the limit for professional drivers is $0.2 \mathrm{~g} / 1$.

An alcohol-related crash is defined as a crash involving a driver or a pedestrian who was subjected to a test and either refused to be tested or had a blood alcohol concentration of $0.5 \mathrm{~g} / \mathrm{l}$ or higher. In $2013,65 \%$ of the drivers involved in crashes were subjected to tests, and $10.5 \%$ were either positive or refused to be tested.

In $2015,2.7 \%$ of the car drivers tested had a blood alcohol level above the legal limit (0.22 mg of alcohol per litre of exhaled alveolar air or $0.5 \mathrm{~g} / \mathrm{l}$ of alcohol per litre of blood).

This figure of $2.7 \%$ is the same as that observed in 2009 and 2012 and is significantly higher than the results obtained in 2007 (2.0\%). Furthermore, the share of highly intoxicated drivers (more than $0.35 \mathrm{mg}$ or more than $0.8 \mathrm{~g} / \mathrm{l}$ of blood) among offenders has also increased (from 55\% in 2007 to $69 \%$ in 2015) Half of the offenders had a blood alcohol level of nearly $1 \mathrm{~g} /$ litre of blood. This 6 th edition of the behavioural measurement highlights an alarming upward trend of driving under the influence of alcohol on Belgian roads (Focant, 2016).

\section{Drugs and driving}

In Belgium legislation sets limits for driving under the influence of THC or cannabis (1 ng/ml), amphetamines ( $25 \mathrm{ng} / \mathrm{ml})$, MDMA or ecstasy $(25 \mathrm{ng} / \mathrm{ml})$, morphine $(10 \mathrm{ng} / \mathrm{ml})$ and cocaine $(25 \mathrm{ng} / \mathrm{ml})$. Drivers suspected of being impaired are tested for drugs. They can also be tested if the driver transports drugs, admits having taken drugs or is involved in a crash.

The European research project, "Driving Under the Influence of Drugs, Alcohol and Medicines" (DRUID), found for the sample in Belgium that $0.5 \%$ of all drivers drove under the influence of cannabis, $0.4 \%$ under the influence of cocaine and $0.2 \%$ under the influence of heroin. No trace of amphetamines ("speed" and/or "ecstasy") was found among the population of examined Belgian drivers.

\section{Distraction}

The use of hand-held phones while driving is forbidden. The use of hands-free devices while driving is authorised. In a 2013 roadside survey, $2 \%$ of drivers were talking on the phone without a hands-free kit. Another 1.2\% held the phone in their hand. Drivers of vans 
and trucks were significantly more often observed with hand-held devices than car drivers. Overall it was estimated that at any time $4 \%$ of drivers are using a hands-free or hand-held phone (Riguelle and Roynard, 2014).

A pilot observation survey was undertaken in 2015 in three large Belgian cities on the use of mobile phones by road users waiting at traffic lights. It showed that $7 \%$ of the car drivers, $9 \%$ of the drivers of light goods vehicles, $5 \%$ of cyclists and $18 \%$ of pedestrians used their mobile phone when stopped at traffic lights (Focant, 2016).

\section{Sleepiness and fatigue}

The results of a survey study (Diependaele, 2015) show that $4.8 \%$ of journeys by car drivers in Belgium involved a driver who was showing signs of sleepiness. The analysis of contextual variables shows that various circumstances result in a prevalence that is considerably higher than the overall estimate of $4.8 \%$.

\section{Seat belts and helmets}

Seat belt use has been compulsory in front seats since 1975 and in rear seats since 1991. Children must be protected by a child restraint appropriate for their size and weight. In 2015 , the rate of seat belt use was $92 \%$ for drivers and front seat passengers in passenger cars. For rear-seat passengers it is however much lower at $86 \%$ (Lequeux, 2016). Clear progress in seat belt usage occurred between 2003 and 2015. However, the 2010 target of $95 \%$ seat belt usage has still not been met.

Table 5.9. Seat belt wearing rate by car occupancy and road type

\begin{tabular}{lccc}
\hline & 2000 & 2010 & 2015 \\
\hline Front seat & & & 91.5 \\
Driver & & 85.6 & 92.2 \\
Passenger & 50 & 85.7 & 91 \\
Urban roads (driver) & 57 & 84 & 93 \\
Rural roads (driver) & 66 & 87 & 93 \\
Motorways (driver) & & 90 & 85.5 \\
Rear seats & & & $35 / 89^{1}$ \\
General & & & \\
Children (use of child restraint) & & \\
\hline
\end{tabular}

1. In 2014, among drivers who agree to have the child seat use investigated, $89 \%$ of the children are somehow restrained, but only $35 \%$ correctly so (right system \& correct use) (Roynard, 2015).

All riders of powered two-wheelers are required to wear helmets. Motorcyclists (>50 cc) also have to wear gloves, boots that protect the ankle and long sleeved/legged jacket and trousers. The helmet-wearing rate by riders of powered two-wheelers is not systematically monitored for the whole country. In Brussels, the observed rate was 99.3\% in 2013 (Riguelle and Roynard, 2013).

There is no mandatory helmet-use law for cyclists.

\section{National road safety strategies and targets Organisation of road safety}

In 2015 , several public responsibilities in relation to road safety shifted from the federal government to the regional ones. The federal level has kept a few remaining 
competencies, in particular the traffic regulation (although speed limits on regional roads are a regional matter), vehicle safety regulation, licensing (although the drivers' training is now a regional matter) and most of the enforcement chain. All other road safety matters (infrastructure, education, campaigns, training, local police controls) are now determined at the regional level.

At the federal level, the Federal Commission for Road Safety is still responsible for setting out the road safety plan. It brings together national and regional government representatives, representatives of the different groups of road users and other non-government organisations, police and justice representatives and organises the General Assembly on Road Safety where the Belgian Road Safety Programme, including the target for 2020 was decided in 2011. The future of this commission is, however, unclear.

For the Flemish region, the Vlaams Huis voor de Verkeersueiligheid is working on a road safety plan for Flanders. For Wallonia, the Conseil Supérieur Wallon de la Sécurite Routière (CSWSR) has taken over this responsibility under the leadership of the Agence wallonne pour la Sécurité routière (AWSR). There will be a Regional General Assembly in the fall of 2017. For the Brussels region it is not yet clear which agency will take the lead in Road Safety.

\section{Road safety strategy for 2011-20}

The present road safety strategy was released in 2011. The mission from the decade before, to achieve a 50\% decrease in fatalities between 2001 and 2011, was renewed for the period 2011-20.

\section{Road safety targets}

The European target of halving fatalities by 2020 was adopted, meaning fewer than 420 road fatalities. Forecasting based on past development predicts a number higher than 500 fatalities for 2020. Therefore, additional efforts and measures will be required to achieve the target.

\section{Monitoring targets}

Regular monitoring of road safety performance is being undertaken. The results are taken into account by policy makers at the federal and regional levels, but there is no explicit structure for how these are used to define the road safety strategy.

- Representative safety performance measures are regularly conducted:

- roadside surveys every three years of driving under the influence of alcohol, speed and seat belt use

- annual survey of national opinions on road safety

- survey of road safety attitudes, acceptance of measures and self-reported behaviour.

In December 2015, during the General Assembly for Road Safety (http://egsr2015.be/ in French or http://sguv2015.be/ in Dutch [accessed 9 May 2017]) the progress midway to the 2020 target was evaluated. On the basis of the development of the fatality numbers so far, it was estimated that in 2020 the number of fatalities will lie between 475 and 780. With the present efforts Belgium will therefore not reach the 2020 target of 420 . The Federal Minister for Mobility announced the following actions:

- better coordination of road safety efforts in Belgium

- regulation of electrical bike use 
- simplifying traffic rules

- a BAC of $0 \%$ for young drivers

- introducing new (quicker) testing devices for drugs

- strategical action plan for better co-ordinated traffic controls

- legal implementation of cross border prosecution

- improving the link between registered offenses and actually paid fines

- legalising the use of APNR cameras for automatic license plate recognition

- improvement of database for offenders

- mandatory fitting of alcolocks in vehicles for person transport

- review of rules for application of alcolocks for recidivists

- alternative punishments have to be paid by offenders

- enabling in-depth accident studies in Belgium (access to accident scenes)

- mandatory installation of event data recorder

- code of practice for testing (semi) automatic vehicles on public roads

Figure 5.8. Trends in road fatalities towards national target

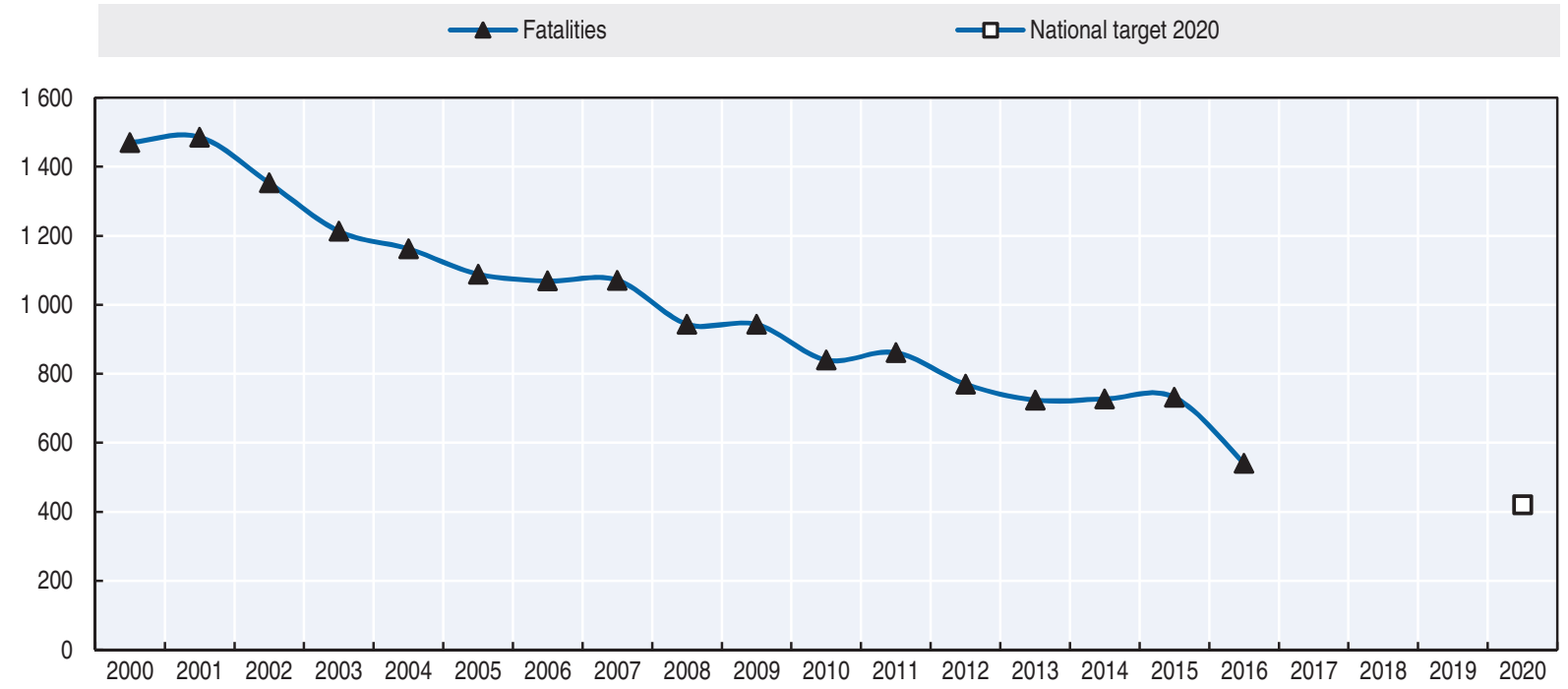

\section{Recent safety measures (2014-17)}

\section{Road safety management}

- The Sixth state reform, shifting some responsibilities from national to regional governments, was approved on 1 January 2015. These responsibilities include, amongst others, infrastructure management and driving education.

- Foundation of regional road safety funds: Federal, Flanders, Wallonia and Brussels.

- Road pricing for trucks entered into force on 1 April 2016 (not a dedicated road safety measure - for details see www.viapass.be/en/about-viapass/viapass-for-hgus/). 


\section{Speed management}

Belgium's first speed camera system to control average speed on a section of a motorway was put into operation in June 2012. Early 2017, systems were operational in 7 locations. More than 30 additional sections are planned by the Flemish and the Walloon road authorities, while the Brussels region is also testing a first project.

- Flanders has decided to lower the general speed limit outside built-up areas from 90 to $70 \mathrm{~km} / \mathrm{h}$, as of 1 January 2017. Since most of these roads are already limited to $70 \mathrm{~km} / \mathrm{h}$ by traffic signs, it will eventually lead to a reduction in the number of road signs. Moreover, as of 2017, local decision makers need to justify when they wish to allow a speed higher than $70 \mathrm{~km}$, while so far they have to give reasons for not allowing $90 \mathrm{~km} / \mathrm{h}$. This also means that the default speed limits will not be the same all over Belgium but will change at regionals border.

- Since 2015, the speed limit on roads restricted to pedestrians, cyclists, horse riders and agricultural vehicles is $30 \mathrm{~km} / \mathrm{h}$ instead of the general speed limit on that area.

\section{Driving under the influence of alcohol}

- Since January 2015, the maximum legal alcohol limit for professional drivers is $0.2 \mathrm{~g} / \mathrm{l}$, while $0.5 \mathrm{~g} / \mathrm{l}$ remains the maximum level for other drivers.

- Since December 2015, a new executive decree under the road traffic law went into force. It offers additional tools and quicker ways to determine psychoactive substances in blood and saliva.

\section{Education and awareness}

- Road safety campaigns are regularly conducted, targeting drink driving, speeding, a more respectful attitude towards the other road users, seat belt use and young drivers. There are separate campaigns for the three regions.

\section{Infrastructure}

- Since the beginning of 2016, hard shoulders on some motorways can be opened to traffic as an additional lane during rush hour.

- Since March 2014, at some intersections, cyclists are allowed to turn right on red. A survey study amongst cyclists suggests that there might be a spillover effect leading cyclists to ignore the red light at other crossings as well (De Ceuninck et al., 2016).

- Since March 2014, alternate merging is mandatory in case of congestion. This is actually not a road safety measure but a road capacity measure.

\section{Vehicles}

- A new vehicle type "speed pedelec" (1 000-4 000W; $25-45 \mathrm{~km} / \mathrm{h}$ ) was introduced and is considered equivalent to a moped. A driver's licence for mopeds is required and the minimum age to drive this vehicle is 16 . Helmet (bicycle or moped) wearing and registration are mandatory. A compulsory insurance applies if the engine can work autonomously (i.e. without pedalling).

- Registration of mopeds is now mandatory. Owners of mopeds already in use must register their moped before December 2016. 
- Testing autonomously driving cars. Belgium has been one of the countries at the origin of the modification of the Vienna convention to clarify that driving assisting systems are not contradictory to the principle of having constant control over the vehicle. To allow testing of their prototypes on Belgian roads, manufacturers need to get approval from the Federal authority responsible for transport and the Regional authority responsible for the road network. Belgian authorities are seeking to have a transparent approach with clear rules in order to encourage testing of such vehicles in Belgium. To achieve this, the Federal and Regional authorities have developed a Belgian code of practice taking the UK code of practice as starting point. The private sector was also involved with representatives of the car, ICT and road safety sectors. This code of practice was made publically available in fall 2016 (see also https://mobilit.belgium.be/sites/default/files/ resources/files/code_of_practice_en_2016_09.pdf, accessed on 9 May 2017).

- A two-yearly periodical vehicle inspection is introduced for agricultural vehicles with a maximum authorised mass (MAM) higher than 3.5 tonnes and lower than 7.5 tonnes. A yearly periodical vehicle inspection is introduced for agricultural vehicles with a MAM higher than 7.5 tonnes.

\section{Recent and ongoing research}

- Martensen, H., J. Leblud and P. Temmerman (2016), Motorcycles and traffic filtering, IFZ Forschungshefte 2017, Proceedings of the 11th International Motorcycle Conference 2016. This research showed that the legalisation of traffic filtering had no impact on crashes.

- Torfs, K., U. Meesmann, W. Van den Berghe and M. Trotta (2016), ESRA 2015: The results. Brussels, Belgium: Belgian Road Safety Institute - Knowledge Center. The ESRA project (www.esranet.eu/, accessed 9 May 2017) is a joint data collection on road safety attitudes and performance by partner organisations in a large number of European countries.

- Meunier, J.-C., L. Kluppels and S. Boets (2016), Effectiveness of graduated driving licence systems. Synthesis of results from international literature. Brussels, Belgium: Belgian Road Safety Institute - Knowledge Center Road Safety. This report provides an exploratory review of literature relating to Graduated Driving Licence (GDL) systems which are implemented in a number of countries around the world.

- Temmerman P., F. Slootmans and Q. Lequeux (2016), Accidents involving trucks - Phase 1. Problem extent, literature review, analysis of accident data and survey. Brussels, Belgium: Belgian Road Safety Institute - Knowledge Centre Road Safety. A survey among truck drivers indicated problems with seat-belt use, phone use, and accident frequency, but not in accident risk.

- Meesmann, U. and A. Schoeters (2016), How do car drivers view road safety? Results of the fifth national attitude measurement on road safety of the Belgian Road Safety Institute (2015). Brussels, Belgium: Belgian Road Safety Institute - Knowledge Center Road Safety. For a wide range of risky behaviour, this attitude survey identifies primary target groups and those approaches with the best chance to achieve behavioural change (e.g. speeding: men, social acceptability; distracted driving: young drivers, raising awareness).

\section{References}

Diependaele, K. (2015), Sleepy at the wheel. Analysis of the extent and characteristics of sleepiness among Belgian car drivers. Belgian Road Safety Institute - Knowledge Centre Road Safety, Brussels. 
Focant, N. (2016), Drinking and driving: Do we do it too much? National behavioural survey "Driving under the influence of alcohol", Belgian Road Safety Institute - Knowledge Centre Road Safety, Brussels.

Lequeux, Q. (2016), National roadside survey of seatbelt use in Belgium 2015, Belgian Road Safety Institute Knowledge Centre Road Safety, Brussels.

Martensen, H. (2014), Seniors in traffic: Mobility and road safety of elderly in Belgium, Belgian Road Safety Institute - Knowledge Centre Road Safety, Brussels.

Riguelle, F. and M. Roynard (2014), Conduire sans les mains. Utilisation du GSM et d'autres objets pendant la conduite sur le réseau routier belge, Belgian Road Safety Institute - Knowledge Centre Road Safety, Brussels.

Riguelle, F. and M. Roynard (2013), Mesure de comportement équipements individuels de protection motards en Région de Bruxelles-Capitale 2013, Belgian Road Safety Institute - Knowledge Centre Road Safety, Brussels.

Roynard, M. (2015), Are children transported safely? National behavioural survey on the use of child restraint systems 2014, Belgian Road Safety Institute - Knowledge Centre Road Safety, Brussels.

Temmerman, P. (2016), Speed(ing) in built-up areas, Results of the BRSI behavioural survey speed in built-up areas in 2015. Belgian Road Safety Institute - Knowledge Center Road Safety, Brussels.

Trotta, M. (2016), What do we learn from GPS-data on road speeds? Behavioural measurement: speed outside urban areas 2015, Belgian Road Safety Institute - Knowledge Centre Road Safety, Brussels.

Wijnen, W., W. Weijermars, W. Vanden Berghe, A. Schoeters, R. Bauer, L. Carnis, R. Elvik, A. Theofilatos, C. Perez and H. Martensen (2017), "Crash cost estimates for European countries", D3.2 of the H2020 project SafetyCube.

World Bank (2017), “GDP (constant US\$)”, World Development Indicators, http://databank.worldbank.org/ data/reports.aspx?source=world-development-indicators (accessed 23 February 2017).

\section{Websites (all accessed 9 May 2017)}

- BRSI-BIVV-IBSR (Belgian Road Safety Institute): http://ibsr.be/fr (French); http://ibsr.be/nl/ (Dutch); http://ibsr.be/en/ (English).

- BRSI-BIVV-IBSR research and statistical reports: www.ibsr.be/fr/securite-routiere/publications/ (French); http://ibsr.be/nl/verkeersveiligheid/onze-publicaties/(Dutch); http://ibsr.be/en/road-safety/notrepublications/ (English).

- Belgian Road Safety barometer: http://ibsr.be/fr/securite-routiere/barometre-de-la-securite-routiere/ (French); http://ibsr.be/nl/verkeersveiligheid/verkeersveiligheidsbarometer/ (Dutch); http://ibsr.be/en/road-safety/ road-safety-monitoring-survey/ (English).

- Vlaams Huis voor de Verkeersveiligheid: www.vlaamshuisvoorverkeersveiligheid.be.

- Conseil supérieur wallon de la sécurité routière: www.cswsr.be.

- Agence wallonne pour la Sécurité routière: www.awsr.be.

- Instituut voor Mobiliteit Universiteit Hasselt: www.uhasselt.be/IMOB-EN.

- Vlaamse stichting verkeerskunde (Flemish Foundation for Traffic Knowledge): www.usv.be/nl/home. 



\section{Chapter 6}

\section{Cambodia}

This chapter presents provisional road safety data for Cambodia for 2016. It looks at recent trends in traffic and road safety as well as road user behaviour patterns, including sections on the ageing population, speed, drink driving and seat belt and helmet use. The chapter also reviews Cambodia's road safety strategy and national targets to 2020 . $^{*}$

* All data stem from National Road Safety Committee unless otherwise noted. The National Road Safety Committee joined the International Road Traffic and Accident Database (IRTAD) group in 2010. Data presented in this report are under validation by IRTAD. Actual numbers are likely to be higher. For more information please contact: voun.chhoun@gmail.com. 
$\mathrm{P}$ Provisional data from 2016 show improvement in Cambodia's road safety, with a decrease of $17 \%$ in the number of reported fatalities to 1852 and a $13 \%$ decrease in the number of those seriously injured. However, the number of fatalities reported over the last ten years has doubled. This is largely due to the rapid motorisation of Cambodia, where the number of motorised vehicles has been multiplied by more than five since 2006, with motorcycles making up over $80 \%$ of the fleet. Annual road safety plans with interim targets have been approved to support the 2020 target of 1600 fatalities.

\section{Road safety data collection}

\section{Definitions applied in Cambodia}

- Road fatality: Person who died immediately as a result of a crash or within 30 days.

- Seriously injured person: Person injured in a traffic crash and hospitalised for at least eight days due to sustained injuries. At this stage, it is not envisaged to adopt a definition based on the Maximum Abbreviated Injury Scale.

\section{Data collection}

The Road Crash and Victim Information System (RCVIS) was initiated and developed by Handicap International, in close collaboration with the Ministry of Health, the Ministry of the Interior and the Ministry of Public Works and Transport. Data are reported by traffic police and health facilities nationwide. Currently, the Ministry of Health and the Ministry of the Interior are in charge of data collection at a provincial level and provide a soft copy to the National Road Safety Committee (NRSC).

The NRSC combines data from the Ministry of Health and the Ministry of the Interior using a data-linkage system developed with support from the Institute for Road Safety Research (SWOV) in the Netherlands, in the framework of twinning under the International Road Traffic and Accident Database. Duplicate entries are automatically identified. Work is ongoing to assess the level of underreporting.

Most data are available from 2006. Data presented in this report are data currently reported by the police and are under validation by IRTAD. Actual numbers are likely to be higher.

\section{Most recent safety data}

\section{Road crashes in 2016 - provisional data}

Based on provisional data, there were 1852 reported fatalities in 2016, a 17\% decrease when compared to 2015. On average, more than five people died and almost 13 were injured every day.

\section{Trends in traffic and road safety (2005-16) Traffic}

Cambodia's motorisation is rapidly increasing. Since 2006, the number of registered motorised vehicles has been multiplied by more than five from around 714000 units to 
3.3 million units. In 2015 alone there was a 14\% increase in the number of registered vehicles. Powered two-wheelers account for about $80 \%$ of the motor vehicle fleet and play an important role in the day to day life of people and in the transport sector.

\section{Road safety}

\section{Crashes and casualties}

Over the last 10 years (2006-16), the number of fatalities reported by the RCVIS has doubled. At the same time, the population has increased by $18 \%$ and the number of registered motorised vehicles has risen by $425 \%$. This increase is explained by the economic boom, the sharp increase in registered vehicles and the young population, as well as the reconstruction of paved roads over the last five years. Road crashes disproportionately affect the most vulnerable road users (motorcyclists, pedestrians and cyclists).

Traffic crashes have major impacts on both the social economy and welfare of Cambodia and are one of the major causes of mortality. Unless additional road safety actions are taken, the number of fatalities in Cambodia could increase to 3200 by 2020 . Therefore, the Royal Government of Cambodia has committed to developing a national road safety action plan for 2011-20 with the objective of reducing the number of road fatalities by $50 \%$ by 2020, from the estimated forecast of 3200 road deaths to 1600 .

A major concern in Cambodia is that many people do not understand the importance of road safety and have no knowledge of traffic laws. Also the vehicle fleet is very old and not equipped with safety devices and the road infrastructure is often in a poor condition.

\section{Rates}

In 2016, the reported death rate per 100000 inhabitants was 11.9, a decrease of $6 \%$ from 2010.

From 2010 to 2016, the reported fatalities rate per 10000 vehicles decreased from 11 to 4.9 as the number of registered vehicles increased rapidly (it nearly doubled during this period).

Table 6.1. Road safety and traffic data

\begin{tabular}{|c|c|c|c|c|c|c|}
\hline & \multirow{2}{*}{2010} & \multirow{2}{*}{2014} & \multirow{2}{*}{2015} & \multirow{2}{*}{2016} & \multicolumn{2}{|c|}{$2016 \%$ change from } \\
\hline & & & & & 2015 & 2010 \\
\hline \multicolumn{7}{|l|}{ Reported safety data } \\
\hline Fatalities & 1816 & 2226 & 2231 & 1852 & -17.0 & 2.0 \\
\hline Injury crashes & 18287 & 15327 & 13649 & 11899 & -12.8 & -34.9 \\
\hline Deaths per 100000 inhabitants & 12.7 & 14.7 & 14.5 & 11.9 & -17.8 & -6.3 \\
\hline Deaths per 10000 registered vehicles & 11.0 & 7.9 & 7.0 & 4.9 & -29.7 & -55.5 \\
\hline \multicolumn{7}{|l|}{ Traffic data } \\
\hline Registered vehicles (thousands) & 1650 & 2801 & 3200 & 3752 & 17.3 & 127.4 \\
\hline Registered vehicles per 1000 inhabitants & 115 & 184 & 208 & 240 & 15.5 & 108.0 \\
\hline
\end{tabular}

Source: RCVIS. Safety data are those currently reported by the police. Actual numbers are likely to be higher.

StatLink काजि http://dx.doi.org/10.1787/888933580327

\section{Road safety by user group}

Vulnerable road users (motorcyclists, pedestrians and cyclists) represent more than $80 \%$ of traffic casualties in Cambodia. Riders of powered two-wheelers are the most vulnerable road users. In 2016, they represented $88 \%$ of the motorised vehicle fleet and $73 \%$ of all fatalities. Improving the safety of motorcyclists is a key priority in Cambodia. 
Figure 6.1. Road safety, traffic and GDP trends index $2008=100$

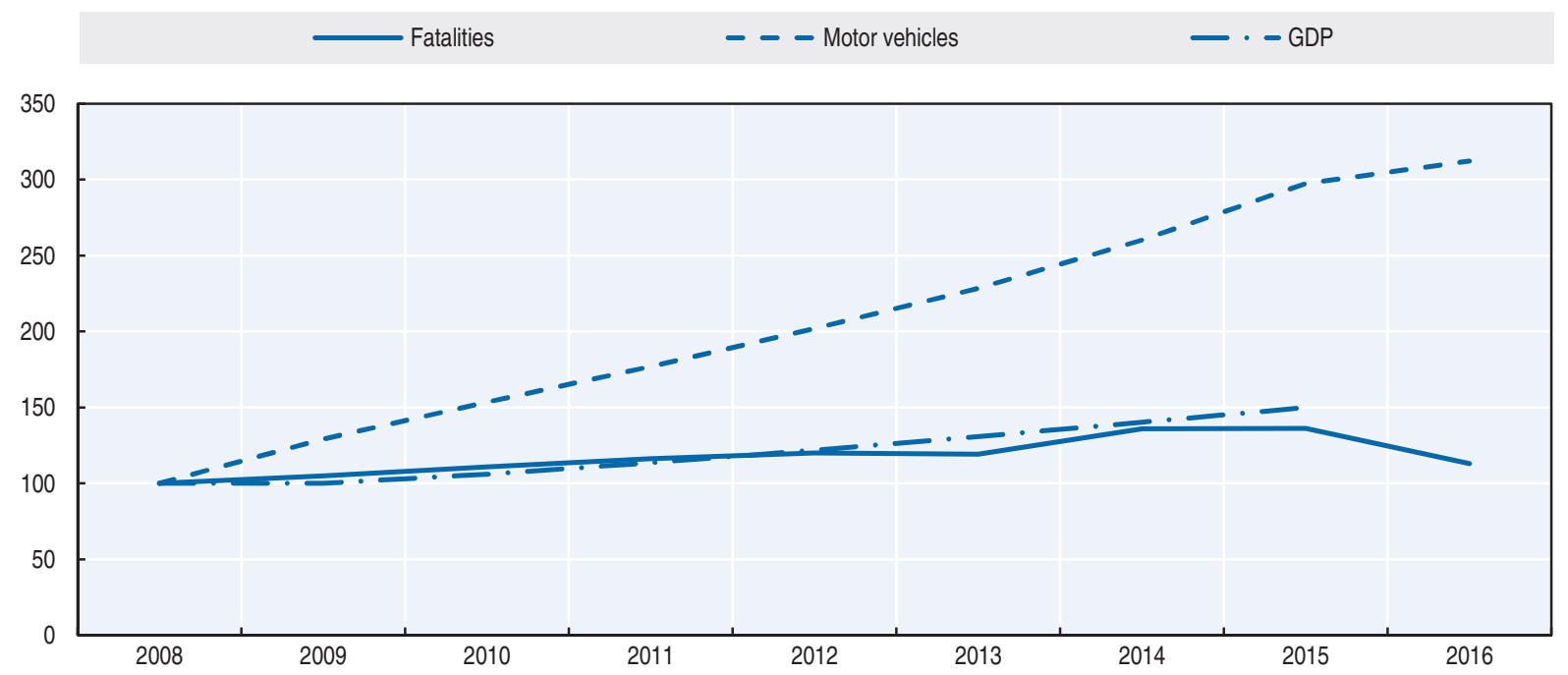

Source: RCVIS, World Bank (2017) (GDP; constant prices).

Table 6.2. Reported road fatalities by road user group

\begin{tabular}{lrrrr|rr}
\hline \multirow{2}{*}{ Road users } & 2010 & 2014 & 2015 & 2016 & \multicolumn{2}{|c}{$2016 \%$ change over } \\
\cline { 5 - 7 } & & & & 2015 & 2010 \\
\hline Pedestrians & 217 & 223 & 221 & 178 & -19.5 & -18.0 \\
Cyclists & 72 & 66 & 55 & 42 & -23.6 & -41.7 \\
Motorised two-wheelers & 1209 & 1614 & 1586 & 1361 & -14.2 & 12.6 \\
Car occupants & 140 & 172 & 202 & 260 & 28.7 & 85.7 \\
Others incl. unknown & 178 & 151 & 167 & 11 & -93.4 & -93.8 \\
Total & $\mathbf{1 8 1 6}$ & $\mathbf{2 2 2 6}$ & $\mathbf{2 2 3 1}$ & $\mathbf{1 8 5 2}$ & $\mathbf{- 1 7 . 0}$ & $\mathbf{2 . 0}$ \\
\hline
\end{tabular}

Source: RCVIS. Safety data are those reported by police. Actual numbers are likely to be higher.

Figure 6.2. Road fatalities by road user group in percentage of total, 2016

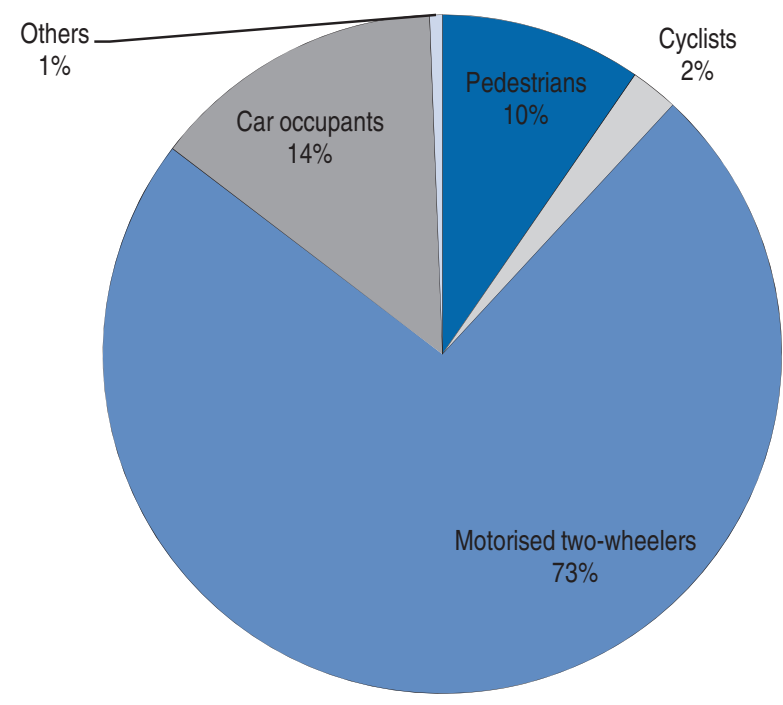

Source: RCVIS 


\section{Road safety by age group}

In 2016, about half of total fatalities were between 15 and 34 years old. The 21-24 age group had the highest fatality rate with 21 deaths for 100000 inhabitants.

Table 6.3. Reported road fatalities by age group

\begin{tabular}{lrrrr|rr}
\hline \multirow{2}{*}{ Age } & 2010 & 2014 & 2015 & 2016 & \multicolumn{2}{|c}{$2016 \%$ change from } \\
\cline { 5 - 6 } & & & & 2015 & 2010 \\
\hline $0-14$ & 148 & 175 & 160 & 150 & -6.3 & 1.4 \\
$15-17$ & 68 & 64 & 96 & 88 & -8.3 & 29.4 \\
$18-20$ & 228 & 214 & 249 & 172 & -30.9 & -24.6 \\
$21-24$ & 271 & 423 & 344 & 294 & -14.5 & 8.5 \\
$25-64$ & 1000 & 1247 & 1282 & 1066 & -16.8 & 6.6 \\
$65-74$ & 56 & 62 & 70 & 56 & -20.0 & 0.0 \\
$75-84$ & 25 & 33 & 23 & 23 & 0.0 & -8.0 \\
$\geq 85$ & 3 & 8 & 7 & 3 & -57.1 & 0.0 \\
Total & $\mathbf{1 8 1 6}$ & 2226 & 2231 & $\mathbf{1 8 5 2}$ & -17.0 & 2.0 \\
\hline
\end{tabular}

Source: RCVIS, data are those reported by police. Actual numbers are likely to be higher. 2014 data are provisional.

Figure 6.3. Reported road death rates by age group Fatalities per 100000 inhabitants in a given age group, 2008-16

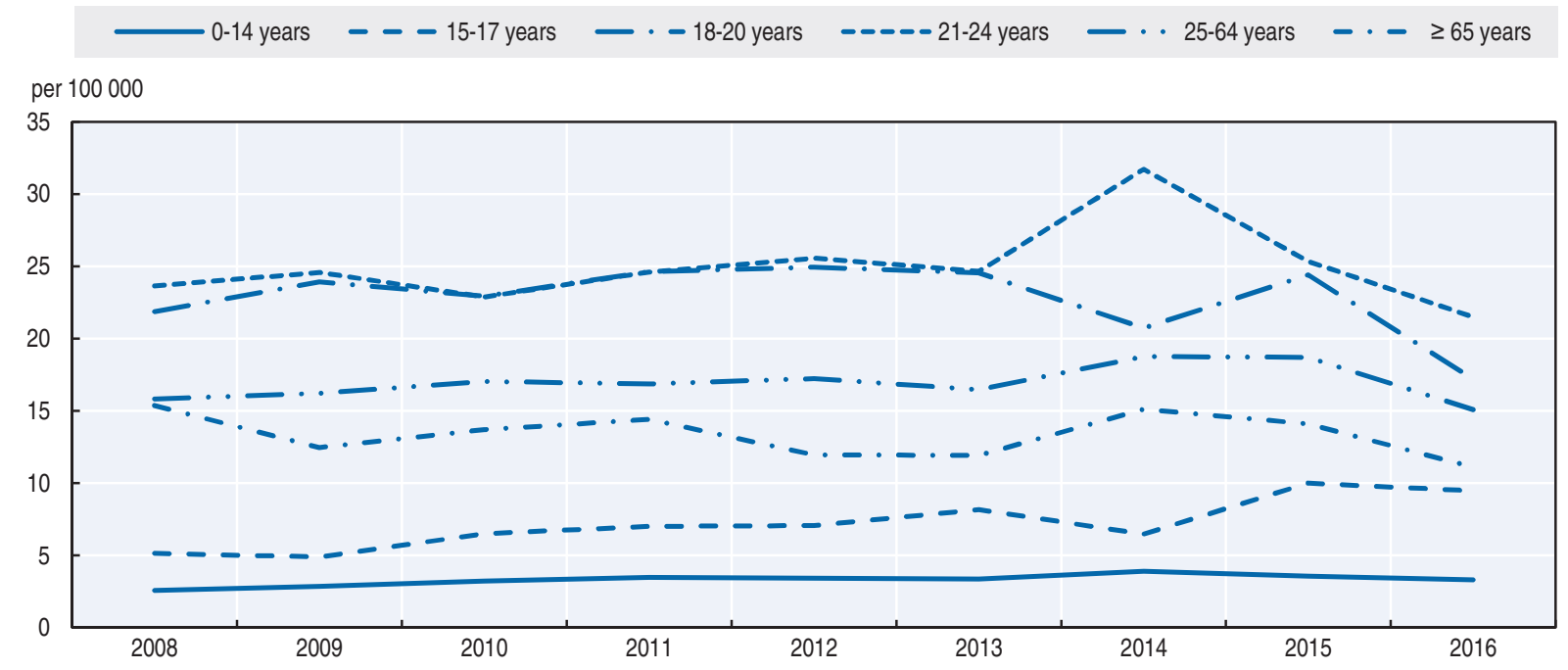

Source: RCVIS. Data are those reported by the police. Actual numbers are likely to be higher.

\section{Road safety by road type}

In Cambodia, the roads are classified as follows:

- national roads: long roads connecting provinces

- provincial roads: roads connecting districts within a province

- main and minor roads in cities and towns

- local roads and tracks: small roads in villages

There is no motorway network in Cambodia. The large majority of fatalities $(70 \%)$ occur on national roads. 


\section{Box 6.1. Road safety for an ageing population}

Over the age of 65 , drivers have to renew their driving licence every two years (as opposed to every ten years for drivers under 65).

A medical test (vision, hearing and fitness to drive) is required at each renewal process, whatever the age of the driver.

Table 6.4. Road fatalities among senior citizens

\begin{tabular}{lrr|rr|rr}
\hline & \multicolumn{2}{c|}{$65-74$} & \multicolumn{2}{c|}{$65-74$} & \multicolumn{2}{c}{$65-74$} \\
\cline { 2 - 7 } & 2010 & 2015 & 2010 & 2015 & 2010 & 2015 \\
\hline Pedestrians & 17 & 20 & 11 & 7 & 3 & 4 \\
Cyclists & 5 & 12 & 5 & 2 & 0 & 0 \\
Motorcyclists & 27 & 32 & 6 & 13 & 0 & 2 \\
Car occupants & 4 & 5 & 2 & 1 & 0 & 1 \\
Total & $\mathbf{5 6}$ & $\mathbf{7 0}$ & $\mathbf{2 5}$ & $\mathbf{2 3}$ & $\mathbf{3}$ & $\mathbf{7}$ \\
\hline
\end{tabular}

Figure 6.4. Road fatality rate by age and road user group Fatalities per 100000 inhabitants, 2016

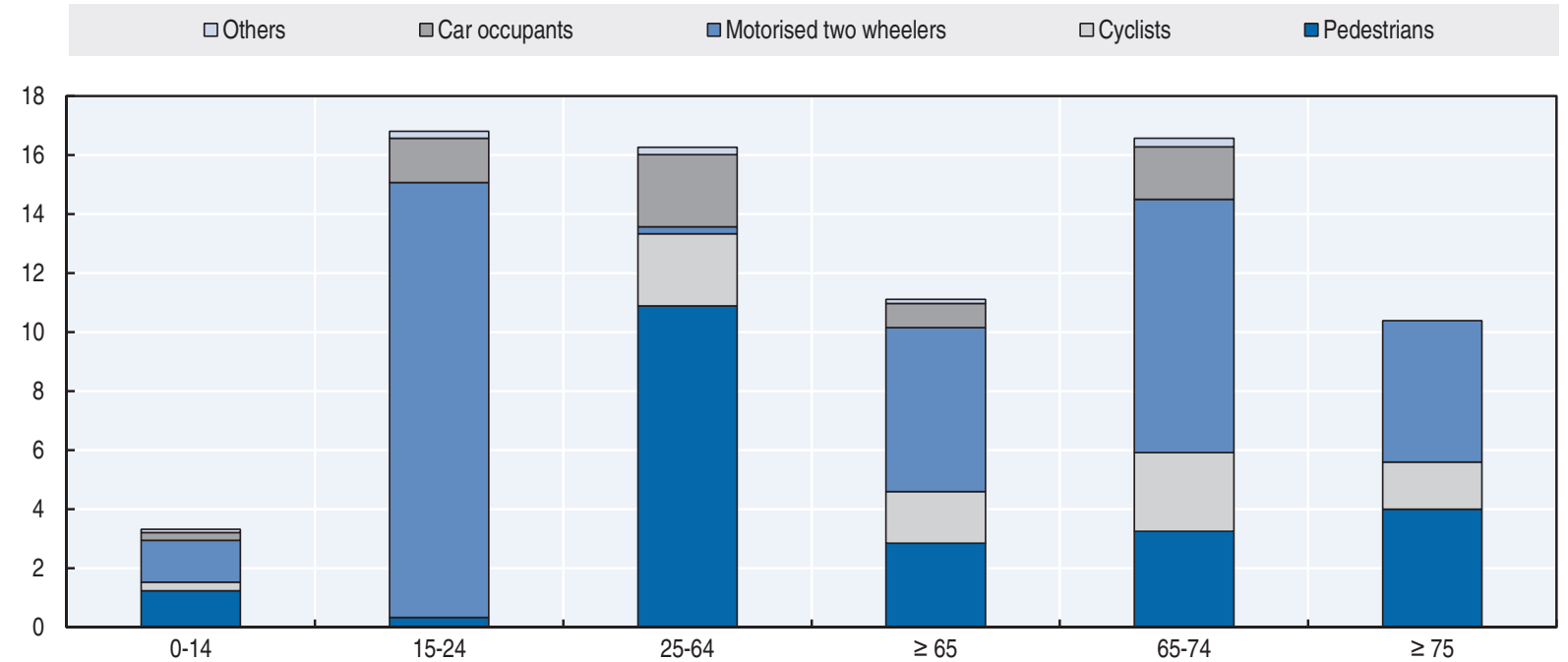

In Cambodia, the roads are shared by a wide range of road users, with high speed differentials between them which increases the risk of vulnerable road users being involved in a crash.

\section{Economic cost of traffic crashes}

It is estimated that in 2013 the economic cost of road crashes equalled approximately USD 337 million. This represents $2.3 \%$ of Cambodia's GDP. The cost was estimated by Handicap International based on a methodology developed by the Asian Development Bank and updated by Handicap International Belgium and Hasselt University (2012). 
The capital approach (human capital method) was used to calculate the cost of road crashes, which includes property damage costs, administrative costs, medical costs, lost output costs and human costs.

\section{Recent trends in road user behaviour}

Speed

Excessive speed is the leading cause of traffic crashes in Cambodia. In 2016, it was estimated that speed was a contributing factor in $38 \%$ of fatalities.

Until 2014, the number of speed-related fatalities was increasing annually due to the development of the road network and road rehabilitation throughout the country which facilitated higher driving speeds. However, the number of speed-related fatalities decreased in 2014 and 2016.

The table below summarises the main speed limits in Cambodia.

Table 6.5. Speed limits by road type and vehicle type, 2017

\begin{tabular}{lcc}
\hline & Motorcycles, tricycles & Passenger cars \\
\hline Inside built up areas & $30 \mathrm{~km} / \mathrm{h}$ & $40 \mathrm{~km} / \mathrm{h}$ \\
Outside built up areas & $40 \mathrm{~km} / \mathrm{h}$ on national roads & $90 \mathrm{~km} / \mathrm{h}$ \\
\hline
\end{tabular}

Source: RCVIS.

\section{Drink driving}

The maximum authorised blood alcohol content (BAC) is $0.5 \mathrm{~g} / \mathrm{l}$ for all drivers. A drinkdriving related crash is defined as a crash caused by a road user with a BAC over the limit.

Drink driving is the second major cause of road crashes and casualties in Cambodia after speeding. In 2016, 13\% of reported fatalities were due to drink driving.

In 2016, a peak of drink-driving fatalities was observed between 7 p.m. and 8 p.m. (15\%). The weekend (Fridays, Saturdays and Sundays) had the highest percentage of alcoholrelated fatalities: $15 \%, 19 \%$ and $17 \%$ respectively. According to RCVIS, $73 \%$ of at-fault drivers in drink-driving crashes were motorcycle riders.

\section{Drugs and driving}

Cambodia has neither a legal framework nor facilities to enforce drug-driving penalties.

\section{Distraction}

The new land traffic law bans hand-held mobile phones while driving. Hands-free phones can be used.

\section{Seat belts and helmets}

Seat belt wearing has been compulsory on front seats since 2007. Seat belt wearing is not compulsory for rear-seat passengers. Enforcement is weak and the rate of use is low.

Babies less than 10 months old must use a baby seat with the safety belt firmly attached. Children between 10 months and 4 years old must use a child seat with the safety belt attached. Children less than 10 years old in front seats must be accompanied by an adult and must wear a seat belt. The compliance rate is low. 
In $2016,65 \%$ of passenger car drivers who died in a crash were not wearing a seat belt.

Table 6.6. Seat belt wearing rate by car occupancy and road type

$\%$

\begin{tabular}{lccccc}
\hline & 2009 & 2010 & 2011 & 2012 & 2016 \\
\hline General & 23 & 30 & 27 & 16 & 28 (driver) \\
Urban roads (driver) & 52 & 41 & 44 & & \\
Rural roads (driver) & 42 & 35 & 41 & & \\
\hline
\end{tabular}

Source: RCVIS.

Helmet wearing has been compulsory since 2007 for operators of powered twowheelers over $49 \mathrm{cc}$, for motorcycles with trailers and for motorised tricycles. Helmets are not compulsory on mopeds below $49 \mathrm{cc}$. The mandatory use of helmets by passengers is approved and has been included in the latest revision to the traffic laws in 2015.

The helmet wearing rate is low: $77 \%$ of motorcycle riders killed in a road crash and $99 \%$ of child passengers killed were not wearing a helmet.

\section{National road safety strategies and targets Organisation of road safety}

The National Road Safety Committee (NRSC) was established in 2005 as the lead agency for road safety, initially under the responsibility of the Ministry of Transport and Public Works. Its role is to manage and co-ordinate all road safety activities in Cambodia. In the framework of the new traffic laws, which came into force in January 2016, the NRSC is now reporting to the Ministry of Interior, and the Chairman of the NRSC is the Minister of Interior.

\section{Road safety strategy for 2011-20}

To respond to the current road traffic crash situation, the NRSC has developed the National Plan for Road Safety 2011-20, based on the action plan developed to support the United Nations Decade of Action for Road Safety. The plan was submitted to the Prime Minister and was approved by the Council of Ministers in 2014.

The IRTAD twinning programme has allowed the NRSC to collaborate with Handicap International, the Institute for Road Safety Research of The Netherlands and Road Safety for All. Collaboration was instrumental in developing the road safety strategy and defining targets and performance indicators to monitor progress. The Action Plan consists of seven pillars: road safety management; infrastructure; safe vehicles; safe road user behaviour; post-crash care; traffic law legislation and enforcement; driver licensing, and better transport services for passengers and cargo.

Measures are chiefly focused on the main risk factors, which are the absence of helmets, speeding and drink-driving.

\section{Road safety targets}

This plan includes, for the first time, quantified national targets and safety performance indicators. The main target is to reduce the forecast number of fatalities by $50 \%$ by 2020 , as recommended by the United Nations. 
In 2010, the forecast for the number of road traffic fatalities for the period 2011-20 was estimated based on 1995 to 2009 road traffic fatalities and motor vehicle ownership. The forecasting method adapted the latent risk time series model to predict the numbers of fatalities for 2010 to 2020. It is estimated that unless additional road safety actions are taken, the number of fatalities in Cambodia will increase up to 3200 by 2020. The target is therefore to reduce the number of fatalities to less than 1600 . If the target is achieved progressively, 7350 lives will be saved.

Following the endorsement of the Sustainable Development Goals of the United Nations, the 2016 Annual Road Safety Plan was approved by the government and included the interim target of reducing the number of road deaths by 10\% in 2016 compared to 2015 . A new interim target for 2017 was approved and consists of a 9\% reduction in the number of road deaths in 2017 over 2016.

\section{Monitoring}

Monitoring tools have been developed by the co-operation between Cambodia and the Netherlands. The tools include:

- Analysis of data from the RCVIS:

- fatalities and trends (by age groups, road users, provinces, etc.)

* fatalities caused by head injuries, speeding and drink-driving.

- Observational studies:

* helmet-wearing rate during daytime and night-time

- drink driving measurement

speed measurement: average speed, percentage of drivers exceeding the limit, etc.

- Roadside surveys/interviews to improve knowledge on attitudes and practices regarding helmet wearing, drink-driving and speeding.

Figure 6.5. Trends in road fatalities towards national target

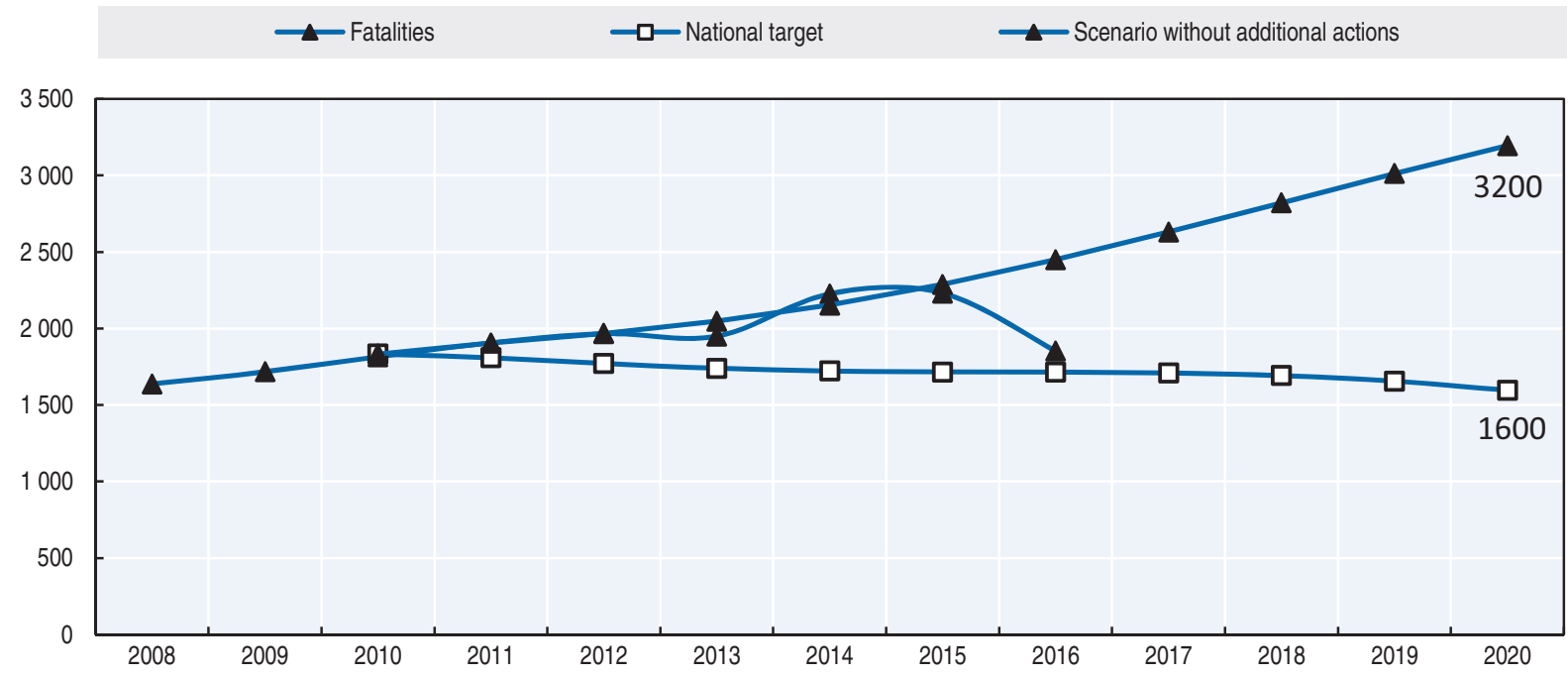

Source: RCVIS. Data are those reported by police. Actual death rates are likely to be higher. 


\section{Recent safety measures (2014-17)}

\section{Road safety management}

- Elaboration of annual action plans to support the target for 2020.

- The government has strengthened its provincial road safety committees and interventions by establishing road safety action plans in most of the provinces. At least half of the provinces in Cambodia have exercised these enforced interventions, in particular with drink driving, helmet wearing and overloading. The reports on the intervention results are not yet available.

- Improvement of the national crash data reporting system. Recoding of all road crashes for the whole country.

\section{Vehicles}

- Strengthening of the car inspection service, with the opening of new inspection centres and awareness campaigns about vehicle safety.

\section{Road users}

\section{Education and awareness}

- Media campaigns (television, newspapers) creating awareness on the importance of road safety.

\section{Infrastructure}

- Identification of black spots.

\section{References}

Handicap International Belgium and the Institute of Mobility - Hasselt University of Belgium (2012), Cost Analysis of Road Crashes in Cambodia, Phnom Penh, Handicap International Belgium, 2012.

World Bank (2017), “GDP (constant US\$)”, World Development Indicators, http://databank.worldbank.org/ data/reports.aspx?source=world-development-indicators (accessed 23 February 2017).

\section{Website}

- National Road Safety Committee: www.nrsc.gou.kh. 


\section{Chapter 7}

\section{Canada}

This chapter presents 2015 road safety data for Canada. It looks at trends in traffic and road safety from the years 1990 to 2015 and road user behaviour patterns with a special focus on the ageing population. The following sections contain data on speed, drink driving, drugs and driving, distracted driving, fatigue and seat belt usage. The chapter also reviews Canada's road safety strategy for 2015-25 along with details of all recently implemented safety measures and current and ongoing research.*

* All data stem from Transport Canada and IRTAD unless otherwise noted. For more information, please contact: michael.marth@tc.gc.ca. 


\section{C}

anada, with its population of over 36 million inhabitants and the country with the largest land area in the Western Hemisphere, recorded 1858 fatalities in 2015, 6 more than in 2014. This is the second best year on record. This translates into a rate of 5.2 deaths per 100000 inhabitants. Young people still remain most at risk, with the 15-24 year old group making up the majority of the fatalities.

\section{Road safety data collection}

\section{Definitions applied in Canada}

- Road fatality: Person who died as a result of a reportable motor vehicle crash within 30 days of its occurrence.

- Seriously injured person: Person admitted to hospital for treatment or observation.

- Slight injury: If "minimal" then no immediate medical attention was required, but would include minor abrasions, bruises and complaint of pain. If "minor" then the person went to the hospital, was treated but not admitted.

- There has been no significant progress made in relation to collecting and/or reporting injury data using the MAIS or MAIS3+ standard.

\section{Data collection}

Transport Canada has a well-established road safety data programme and has been reporting on motor vehicle crash statistics since the 1970s. Police-reported road traffic crash information is collected and processed by provinces and territories and is then sent to Transport Canada for final processing and for compilation of national crash statistics.

Transport Canada considers the motor vehicle crash data to be relevant, of good quality overall and reliable for most analytical purposes. However, there are areas for improvement, as some specific data variables are not provided by certain jurisdictions or consistently reported by all of them. In some cases, where data has not been received from all jurisdictions within Canada, methodologies are used to ensure that national estimates take into account any non-reporting.

Transport Canada is currently working with provincial and territorial road safety partners in the area of electronic data collection and other initiatives aimed at improving the timeliness and accuracy of motor vehicle crash data. A pilot project by a national police agency in Canada is being implemented and as a result, it is anticipated that approximately one-third of the national collision data will be collected electronically by the end of 2017 .

Currently, serious injury data are collected through the same reporting mechanism as for all crash data. Transport Canada is in the initial stages of trying to improve the quality of the injury data, and is currently undertaking an environmental scan and consultation process as part of its efforts.

The National Collision Database online web application is a query tool that contains national level statistics on vehicle crashes occurring on public roads in Canada. Approximately 23 of the 
data elements contained in the National Collision Database are available to users, so that they can select and extract data of interest to them. A second version created for provinces and territories allows access to more detailed information.

\section{Most recent safety data.}

\section{Road crashes in 2015}

The 2015 fatality count of 1858 was $0.3 \%$ higher than that of the previous year, and marked the second lowest number of fatalities on record since data were first collected by Transport Canada over four decades ago.

The long-term downward trend in both fatalities and serious injuries continued in 2015. Comparing 2015 fatality counts with those recorded in 2005 and in 1995, there has been a decrease of $36 \%$ and $44 \%$ respectively. The reduction in the number of serious injuries was $35 \%$ and $49 \%$ respectively.

This progress was achieved despite significant growth over this time period in the Canadian population, the number of licensed drivers, the number of registered vehicles and in vehicle kilometres travelled (VKT). Factors that helped contribute to the overall progress include national and jurisdictional road safety strategies and countermeasures as well as continuing improvement in vehicle safety features and equipment.

In terms of progress made on national road safety plans, the progress that was achieved in the closing years of the Road Safety Vision 2010 has so far kept its momentum going over the course of Road Safety Strategy 2015.

\section{Trends in traffic and road safety (1990-2015) Traffic}

Motor vehicle registrations in Canada have been steadily increasing over the last two decades, rising by 41\% since 1990. Between 2000 and 2015, light-duty vehicle registrations rose by about $31 \%$, while commercial vehicle registrations were up by about $55 \%$. Driver exposure in that period, as measured by vehicle-kilometres travelled for light-duty and commercial vehicles, increased by approximately $18 \%$.

\section{Road safety}

\section{Crashes and casualties}

In 2015 , fatalities were down more than by $53 \%$ as compared to the benchmark year of 1990, with the number of serious injuries having fallen $59 \%$. In recent years, motor vehicle casualties decreased significantly in 2013 and 2014, with fatalities and serious injuries remaining largely unchanged in 2015.

This progress was achieved despite ongoing growth in recent years in the number of licensed drivers, in the number of registered vehicles and in vehicle kilometres travelled.

It is believed that increased efforts by key stakeholders in developing and implementing road safety strategies, plans and countermeasures that focused on key areas of concern, such as speeding, impaired driving and unbelted occupants, contributed to the overall progress. Other contributors include improvements in vehicle safety features and equipment. 


\section{Rates}

In 2015, the rate of fatalities per billion vehicle kilometres travelled was 5.1, which was slightly lower than the 2014 rate of 5.2 and approximately $24 \%$ lower than the rate seen five years previously.

The rate of fatalities per 100000 inhabitants has fallen from 14.3 in 1990 to 5.2 in 2015; a decrease of $64 \%$.

A very similar decrease was seen in the rate of serious injuries per 100000 inhabitants which fell from 81.5 in 1990 to 28.7 in 2015; a decrease of 65\%.

\section{Analysis of seriously injured data}

Looking back over four decades worth of motor vehicle casualty data, the long-term trends across fatalities, serious injuries and injuries are all closely aligned and show very similar patterns. With the exception of the early 1980s, serious injuries were on the rise throughout the 1970s and 1980s. It was only starting in 1990 that there was essentially a steady decline in serious injuries.

Table 7.1. Road safety and traffic data

\begin{tabular}{|c|c|c|c|c|c|c|c|c|c|}
\hline & \multirow{2}{*}{1990} & \multirow{2}{*}{2000} & \multirow{2}{*}{2010} & \multirow{2}{*}{2014} & \multirow{2}{*}{2015} & \multicolumn{4}{|c|}{$2015 \%$ change over } \\
\hline & & & & & & 2014 & 2010 & 2000 & 1990 \\
\hline \multicolumn{10}{|l|}{ Reported safety data } \\
\hline Fatalities & 3963 & 2904 & 2238 & 1852 & 1858 & 0.3 & -17.0 & -36.0 & -53.1 \\
\hline Injury crashes & 181960 & 155838 & 125636 & 115491 & 118404 & 2.5 & -5.8 & -24.0 & -34.9 \\
\hline Injured persons hospitalised & 25020 & 13439 & 11290 & 9926 & 9800 & -1.3 & -13.2 & -27.1 & -60.8 \\
\hline Deaths per 100,000 population & 14.3 & 9.5 & 6.6 & 5.3 & 5.2 & -1.8 & -21.2 & -45.2 & -63.8 \\
\hline Deaths per 10,000 registered vehicles & 2.3 & 1.6 & 1.0 & 0.8 & 0.8 & -1.3 & -23.9 & -52.0 & -66.6 \\
\hline Deaths per billion vehicle kilometres & & 9.4 & 6.7 & 5.2 & 5.1 & -1.3 & -23.5 & -45.8 & \\
\hline \multicolumn{10}{|l|}{ Traffic data } \\
\hline Registered vehicles (thousands) & 16981 & 17882 & 21848 & 23539 & 23924 & 1.6 & 9.5 & 33.8 & 40.9 \\
\hline Vehicle kilometres (millions) & & 308631 & 335900 & 358518 & 365854 & 2.0 & 8.9 & 18.5 & \\
\hline Registered vehicles per 1,000 population & 613 & 583 & 642 & 662 & 667 & 0.8 & 3.9 & 14.5 & 8.8 \\
\hline
\end{tabular}

\section{Road safety by user group}

Since 1990, improvement in road safety benefited all user groups, though the reduction was slower for motorcyclists (-22\%; whereas the overall fatalities declined by $53 \%$ ).

Fatalities by road user class over the short term have remained fairly stable across their respective categories, though fatalities of passenger car occupants $(-27 \%)$ have declined at a greater rate than that of other groups over the 2010 to 2015 period.

With respect to vehicle types in 2015, while passenger cars continued to represent the vehicle type attributed with the most fatalities, this proportion has been decreasing in the last five years.

\section{Road safety by age group}

Since 1990, improvements in road safety have benefited all age groups, with the strongest reduction for children up to 14 .

The 15-24 year-olds continued to account for the most fatalities and injuries in 2015. Approximately $19 \%$ of fatalities in 2015 were associated with a driver or passenger in that age group, however, this representation has decreased slightly in recent years. Conversely, 
Figure 7.1. Road safety, traffic and GDP trends index $1990=100$

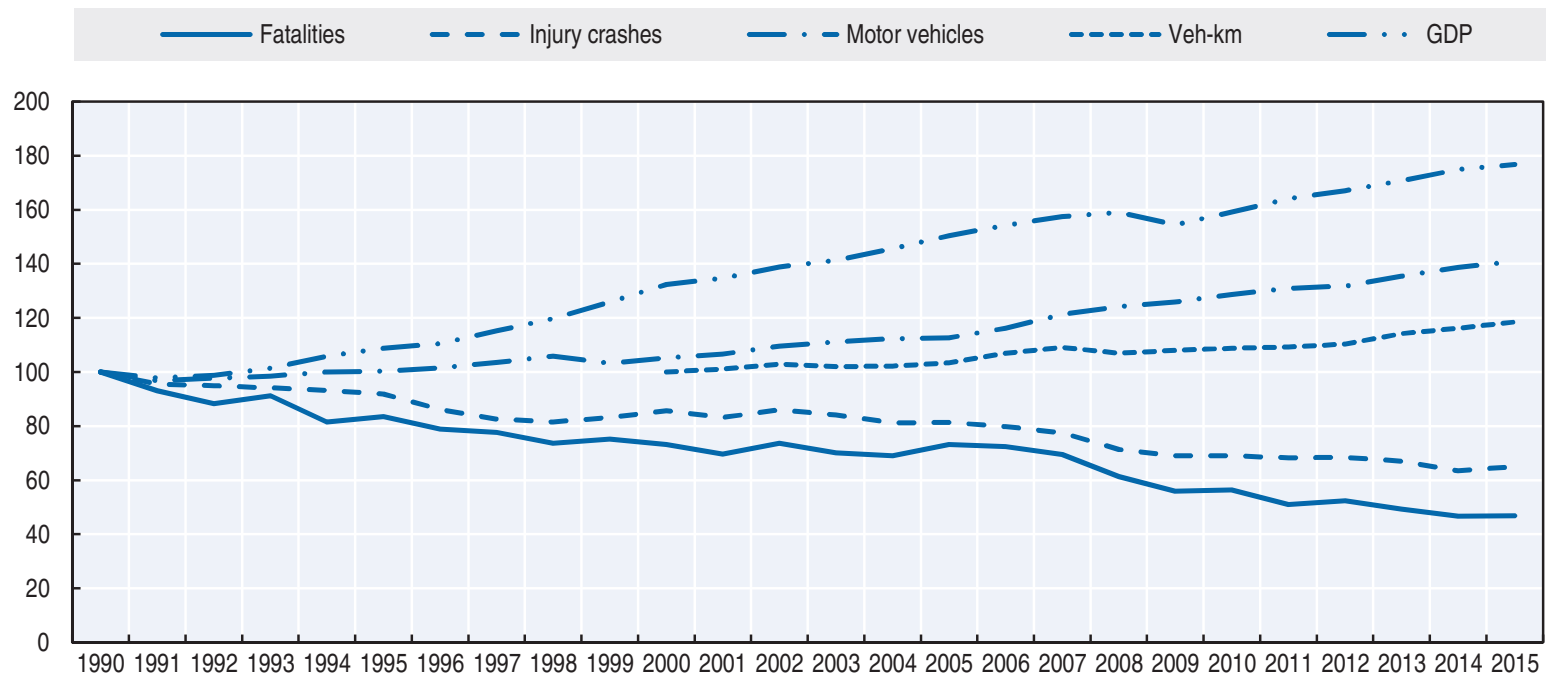
Source: World Bank (2017) (GDP; constant prices).

Table 7.2. Road fatalities by road user group

\begin{tabular}{|c|c|c|c|c|c|c|c|c|c|}
\hline \multirow{2}{*}{ Road users } & \multirow{2}{*}{1990} & \multirow{2}{*}{2000} & \multirow{2}{*}{2010} & \multirow{2}{*}{2014} & \multirow{2}{*}{2015} & \multicolumn{4}{|c|}{$2015 \%$ change over } \\
\hline & & & & & & 2014 & 2010 & 2000 & 1990 \\
\hline Pedestrians & 584 & 373 & 306 & 304 & 301 & -1.0 & -1.6 & -19.3 & -48.5 \\
\hline Cyclists & 106 & 40 & 61 & 42 & 47 & 11.9 & -23.0 & 17.5 & -55.7 \\
\hline Moped riders & 8 & 5 & 5 & 3 & 4 & 33.3 & -20.0 & -20.0 & -50.0 \\
\hline Motorcyclists & 252 & 166 & 188 & 187 & 196 & 4.8 & 4.3 & 18.1 & -22.2 \\
\hline Car occupants & 2244 & 1761 & 1270 & 927 & 922 & -0.5 & -27.4 & -47.6 & -58.9 \\
\hline Others & 769 & 559 & 408 & 389 & 388 & -0.3 & -4.9 & -30.6 & -49.5 \\
\hline Total & 3963 & 2904 & 2238 & 1852 & 1858 & 0.3 & -17.0 & -36.0 & -53.1 \\
\hline
\end{tabular}

Figure 7.2. Road fatalities by road user group in percentage of total, 2015

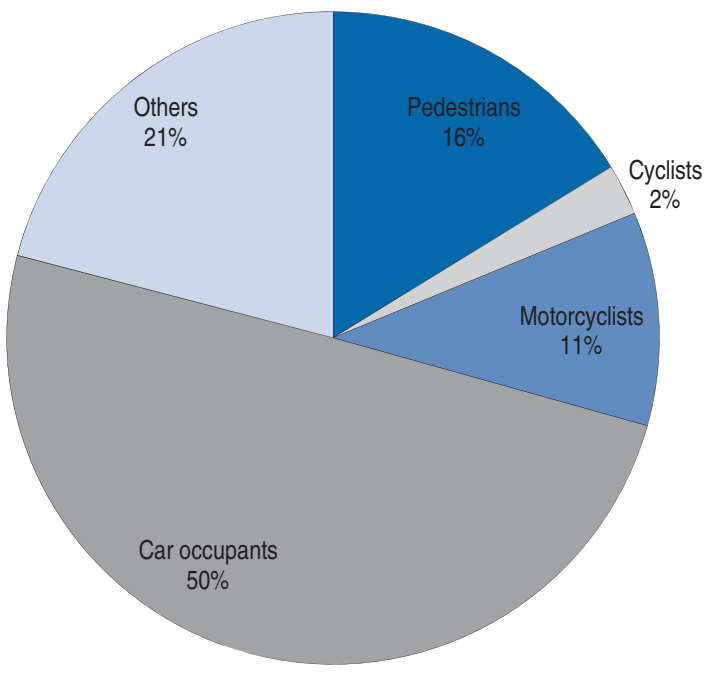


there has been a slight increase in the proportion of seniors (65+) fatally injured over the last five years, rising from $19 \%$ in 2010 to $22 \%$ in 2015 . This coincides with an increase in population share for that age grouping, which accounted for $16 \%$ of the population in 2015 compared to $14 \%$ in 2010.

Young people (18-20) are the most at risk in traffic with a fatality rate that is approximately $60 \%$ higher than that of the rest of the population.

Table 7.3. Road fatalities by age group

\begin{tabular}{|c|c|c|c|c|c|c|c|c|c|}
\hline \multirow{2}{*}{ Age } & \multirow{2}{*}{1990} & \multirow{2}{*}{2000} & \multirow{2}{*}{2010} & \multirow{2}{*}{2014} & \multirow{2}{*}{2015} & \multicolumn{4}{|c|}{$2015 \%$ change over } \\
\hline & & & & & & 2014 & 2010 & 2000 & 1990 \\
\hline $0-14$ & 305 & 144 & 63 & 47 & 51 & 8.5 & -19.0 & -64.6 & -83.3 \\
\hline $15-17$ & 223 & 183 & 114 & 56 & 74 & 32.1 & -35.1 & -59.6 & -66.8 \\
\hline $18-20$ & 382 & 293 & 193 & 139 & 108 & -22.3 & -44.0 & -63.1 & -71.7 \\
\hline $21-24$ & 444 & 294 & 211 & 153 & 161 & 5.2 & -23.7 & -45.2 & -63.7 \\
\hline $25-64$ & 2003 & 1461 & 1,220 & 1026 & 1036 & 1.0 & -15.1 & -29.1 & -48.3 \\
\hline $65-74$ & & 225 & 191 & 193 & 194 & 0.5 & 1.6 & -13.8 & \\
\hline $75-84$ & & 221 & 169 & 159 & 162 & 1.9 & -4.1 & -26.7 & \\
\hline$\geq 85$ & & 59 & 66 & 61 & 62 & 1.6 & -6.1 & 5.1 & \\
\hline Total incl. unknown & 3963 & 2904 & 2238 & 1852 & 1858 & 0.3 & -17.0 & -36.0 & -53.1 \\
\hline
\end{tabular}

Figure 7.3. Road death rates by age group Fatalities per 100000 inhabitants in a given age group, 1990-2015

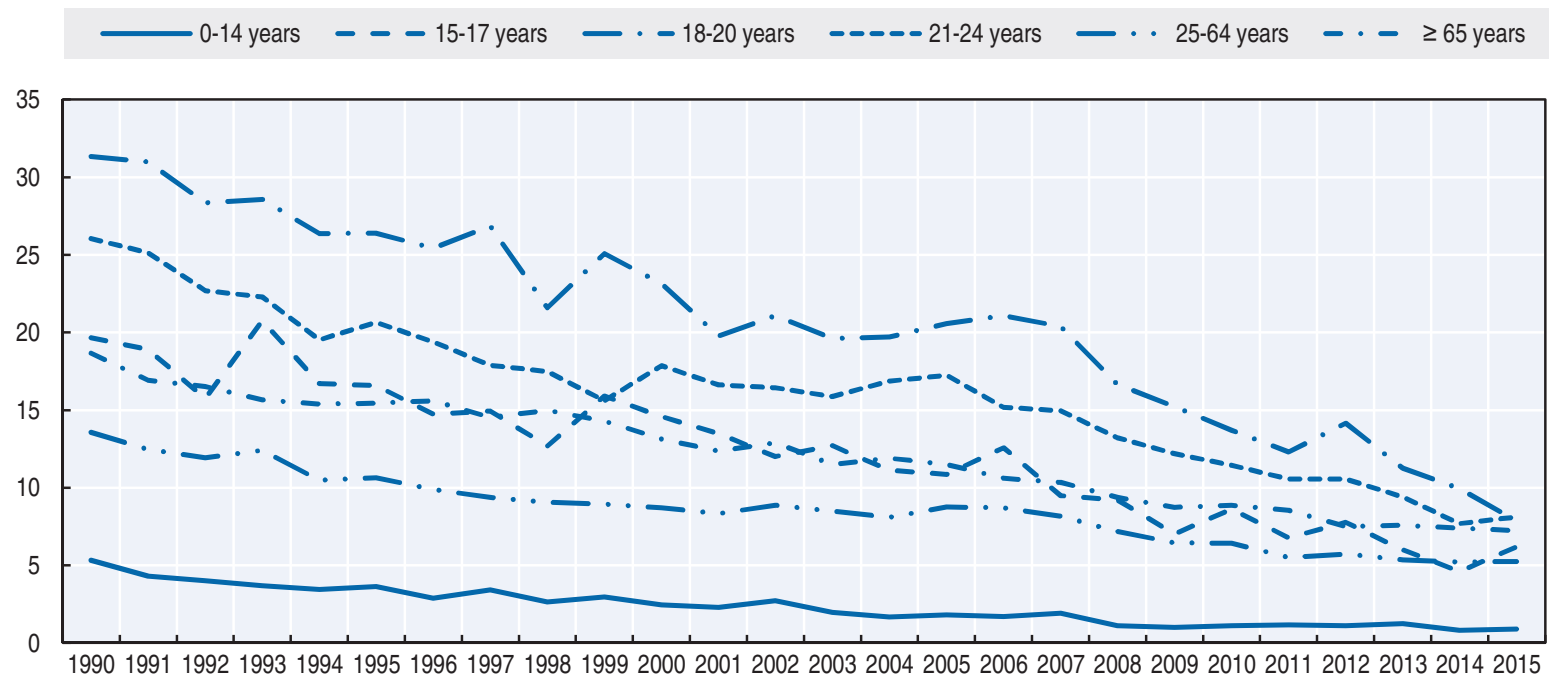

Box 7.1. Road safety for an ageing population

\section{Demographic forecast}

Based on Statistics Canada's medium growth scenario, the population in the 65-74 year age group is projected to grow to 4620600 by 2038, while the population in the 75-84 year age group is projected to grow to 4042200 and the population 85 years and older is projected to grow to 1773600 . These represent increases of $35 \%, 126 \%$ and $128 \%$ respectively. 


\section{Box 7.1. Road safety for an ageing population (cont.)}

\section{Road safety trends}

The trends for 2000 to 2014 show an overall decrease in the rate of road fatalities per 100000 population for the three age groups of 65-74, 75-84 and 85 years and older. The rate is the lowest for 65-74 year olds for each year during that time period, while the rate is the highest for the 85 and over group for most of the years during this period.

The data for 2000 to 2014 show a slight non-monotone downward trend in the rate of road fatalities per 100000 population for pedestrians 65 years and older. For cyclists and motorcyclists, an upward nonmonotone trend can be seen. The trends for 2000 to 2014 show a clearer decrease for the rate of road fatalities per 100000 population for occupants.

\section{Driving licence renewal rules}

In Canada, driving licence renewal rules for the senior population are set by the provinces and territories and thus vary across jurisdictions. As an example, in one particular province, once drivers reach 80 years of age, every two years they must: take a vision test, undergo a driver record review, participate in a 45-minute Group Education Session (GES), during the GES, complete two, brief, non-computerized in-class screening assignments and, if necessary, take a road test. Once the group session and screening components have been completed, drivers may also be asked to submit medical information from their doctor.

Table 7.4. Road fatalities among senior citizens (2014)

\begin{tabular}{|c|c|c|c|c|c|c|c|c|c|}
\hline & \multicolumn{3}{|c|}{$65-74$} & \multicolumn{3}{|c|}{$75-84$} & \multicolumn{3}{|c|}{$\geq 85$} \\
\hline & 2010 & 2014 & $\%$ change & 2010 & 2014 & $\%$ change & 2010 & 2014 & $\%$ change \\
\hline Pedestrians & 37 & 42 & 14 & 46 & 51 & 11 & 22 & 20 & -9 \\
\hline Cyclists & 7 & 5 & - & 3 & 1 & - & 0 & 0 & $=$ \\
\hline Moped riders & 1 & 0 & - & 0 & 0 & $=$ & 1 & 0 & - \\
\hline Motorcyclists & 12 & 11 & -8 & 1 & 1 & $=$ & 0 & 0 & $=$ \\
\hline Car occupants & 100 & 98 & -2 & 100 & 84 & -16 & 33 & 38 & 15 \\
\hline Total & 191 & 193 & 1 & 169 & 162 & -4 & 66 & 62 & -6 \\
\hline
\end{tabular}

Figure 7.4. Road fatality rates by age group - Focus on the senior population Deaths per 100000 inhabitants in a given age group, 2000-15
$65-74$ years
- - $75-84$ years
$-\cdot-85+$ years

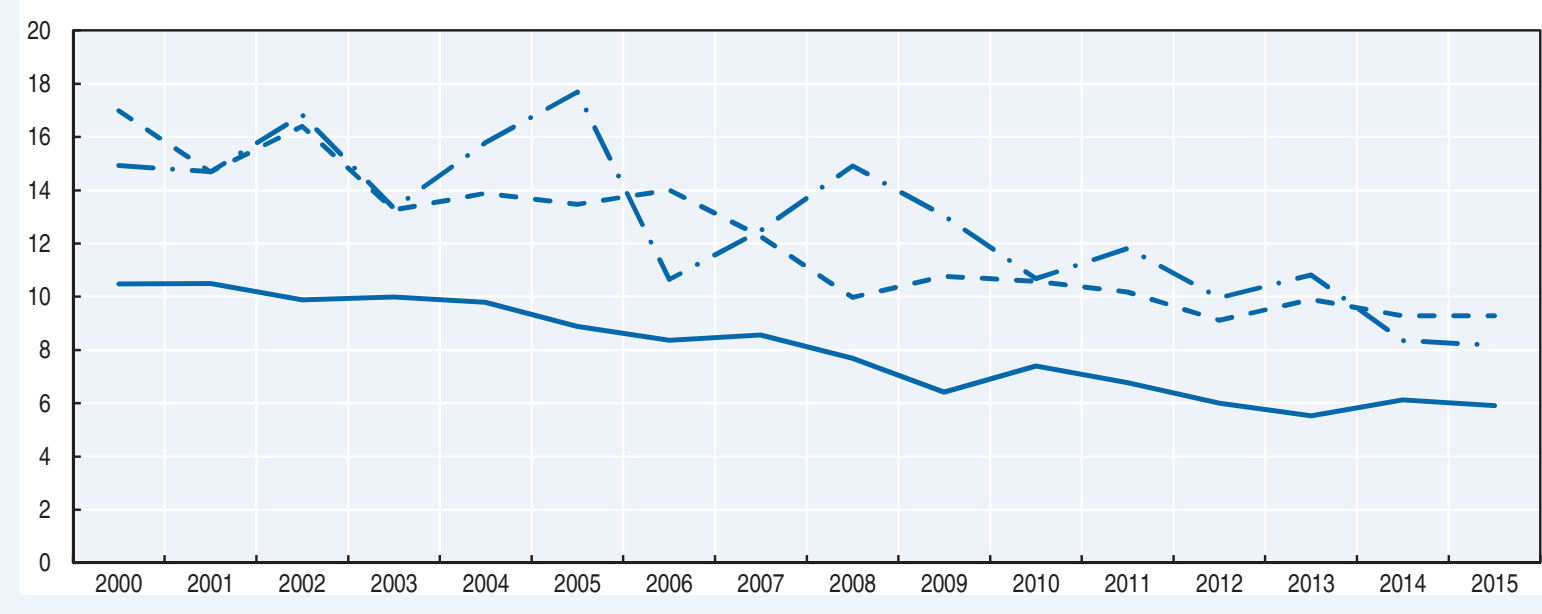




\section{Box 7.1. Road safety for an ageing population (cont.)}

\section{Important measures to improve safety of the senior population}

In addition to the license renewal processes and medical tests noted above, delivering services tailored to an ageing population by providing more of the services they require within close proximity could help reduce travel needs of seniors and therefore help limit exposure and risk associated with driving. Access to reliable and affordable public transit would also help reduce the number of senior drivers on the roads. On an individual basis, seniors who do find themselves driving regularly can consider a number of strategies to stay safer on the roads such as regular exercise, reviewing prescribed medicines with their doctor, driving in favourable environmental conditions, planning routes in advance and avoiding possible distractions.

Figure 7.5. Road fatality rate by age and road user group Fatalities per 100000 inhabitants, 2014

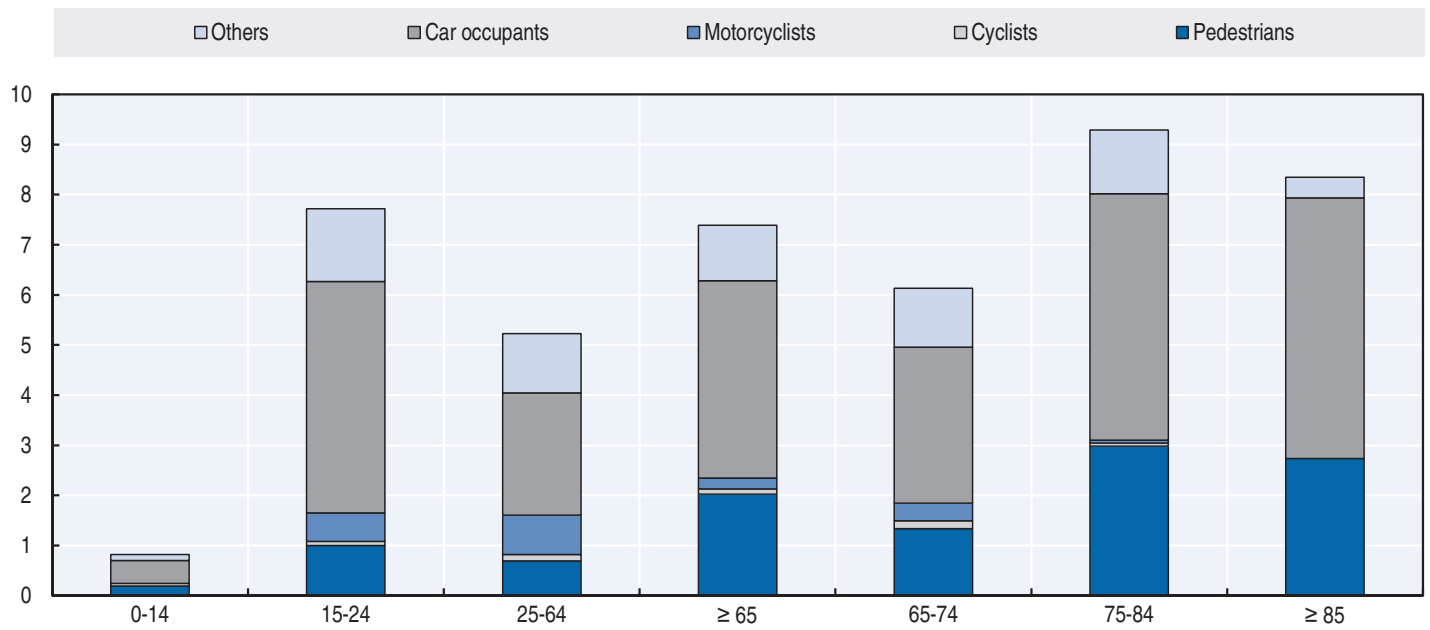

\section{Road safety by road type}

The highest number of fatalities is found on rural roads. However, the percentage of fatalities on rural roads has decreased from approximately $51.4 \%$ in 1990 to 50\% in 2015.

Figure 7.6. Road fatalities by road type (2015)

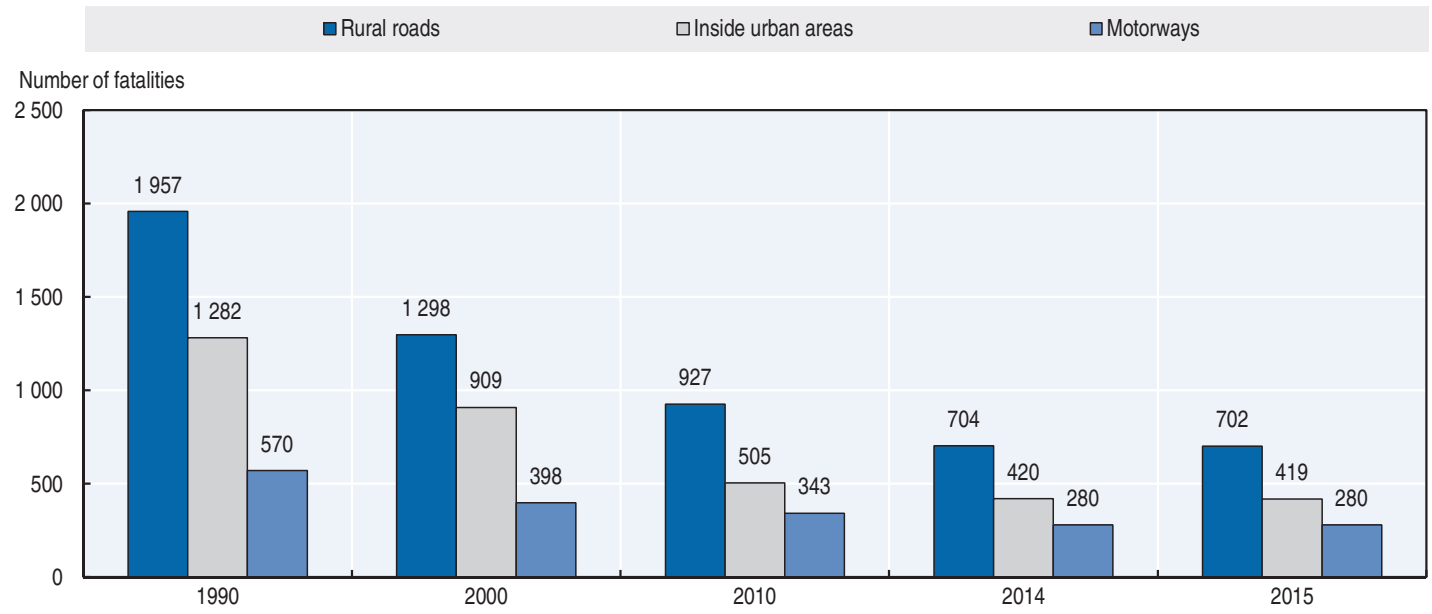




\section{Economic costs of traffic crashes}

For the purposes of this report, costs have been calculated using the willingness-topay approach. This means that the value of a statistical life (VSL) is used to value fatalities, and fractions of VSL are used to value injuries, based on quality-adjusted life years (QALYs) lost. The values noted below are still preliminary and may be subject to change.

Traffic crashes represent a very significant cost for society at CAD 35.9 billion or $1.9 \%$ of GDP in 2013.

Table 7.5. Costs of road crashes, 2013

\begin{tabular}{lcc}
\hline Costs & Unit cost (2013 CAD) & Total (2013 CAD) \\
\hline Fatalities & 8590493 & 16.8 billion \\
Hospitalised people & 1066939 & 10.9 billion \\
Slight injuries & 22727 & 3.5 billion \\
Property damage costs & 8967 & 4.8 billion \\
Total (CAD) & $\mathbf{6 7 7 0 \mathbf { 1 } ^ { \mathbf { 1 } }}$ & $\mathbf{3 5 . 9}$ billion \\
Total as \% of GDP & & $\mathbf{1 . 9 0 \%}$ \\
\hline
\end{tabular}

1. Total unit cost is per crash.

\section{Recent trends in road user behaviour}

\section{Speed}

Speeding, along with impaired and distracted driving, is a significant contributor to motor vehicle fatalities. In 2014, it is estimated that approximately one-fifth of fatal crashes involved speeding. Over the last decade, speed-related fatalities have declined about $47 \%$. Casualty data in 2014 indicated a 42\% reduction in speed related crashes compared to the 2006 to 2010 period.

The table below summarises the main speed limits in Canada.

Table 7.6. Passenger car speed limits by road type, 2017

\begin{tabular}{lc}
\hline & General speed limit \\
\hline Urban roads & $40-70 \mathrm{~km} / . \mathrm{h}$ \\
Rural roads & $80-90 \mathrm{~km} / \mathrm{h}$ \\
Motorways & $100-110 \mathrm{~km} / \mathrm{h}$ \\
\hline
\end{tabular}

\section{Drinking and driving}

Under the Criminal Code of Canada the maximum permissible blood alcohol content (BAC) when driving is $0.8 \mathrm{~g} / \mathrm{l}$. However, in most provinces and territories, there is an additional administrative maximum level of $0.5 \mathrm{~g} / \mathrm{l}$ ( $0.4 \mathrm{~g} / \mathrm{l}$ in Saskatchewan, and in Quebec the $0.5 \mathrm{~g} / \mathrm{l}$ limit only applies to commercial vehicles).

Penalties under these administrative programmes are significant but do not match the seriousness of a full Criminal Code of Canada charge. Penalties in both situations increase for repeat offenders. In addition, most provincial/territorial jurisdictions have a zero BAC limit for young (under 21) and/or novice drivers.

The 2013 preliminary data (most recent available) indicate that $32 \%$ of drivers who were fatally injured in road crashes had some level of alcohol in their blood and $24 \%$ were over the $0.8 \mathrm{~g} / \mathrm{l}$ threshold. 
Information on the presence of alcohol is collected on police crash report forms, but as the data are not always reliable, a surrogate is used for instances of deaths of drivers and pedestrians involving alcohol. The percentage of fatally injured drivers who were tested for alcohol is applied to all motor vehicle deaths to estimate the percentage of all deaths which were alcohol related. With respect to injury crashes, any police report which indicates alcohol or any crashes that fit a surrogate model are identified as alcohol related (Mayhew et al., 1997). Currently a Bill (C-46) is before the Canadian Parliament which aims to modernize the Criminal Code of Canada provisions relating to impaired driving and addressing the issue of drugged impaired driving. The changes being considered include adding Mandatory Breath Testing, increasing penalties and limiting appropriate defence strategies.

\section{Drugs and driving}

The Criminal Code of Canada sections that govern impaired driving would also include impairment by drugs. The Criminal Code was updated in 2009 to detail a police investigation of suspected drug-impaired driving situations, based on behavioural indices of unsafe driving and following the procedures set out by the Drug Recognition Evaluator (DRE) programme of the International Association of Chiefs of Police. This programme is initiated if there appears to be behavioural indications of impairment and no or little alcohol is found. The penalties are the same as for impairment by alcohol.

Canada began testing fatally injured drivers for drugs in 2000 , similar to the method used for alcohol. The table below indicates the number and percentage of drivers who were tested and found positive or negative for drugs. Not all drivers are tested and the testing rate is typically lower than that of alcohol. It should be noted that the rate of psychotropic drugs found in fatally injured drivers is similar to that of alcohol. Canada is reviewing the situation of cannabis with a view to changing its current status. The government of Canada is currently studying its options. Canada is in the process of changing the way cannabis is regulated for use through Bill C45. Cannabis would be legalised in limited quantities for people over the age of at least 18 . Bill C- 46 creates new offences regarding cannabis use and driving and combining cannabis and alcohol and driving.

\section{Seat belts and helmets}

Seat belt use was made compulsory in Canadian jurisdictions between 1976 and 1988.

In Canada, road user behaviour is a provincial/territorial responsibility and the laws around the use of seat belts and child restraints are provincial or territorial. All provinces and territories have laws in place mandating the use of child restraints since the 1980s, and they are occasionally updated. In most cases, the driver is responsible for ensuring that a child is correctly restrained.

In Canada, child restraint use is promoted in four stages: stage 1, rear facing; stage 2, forward facing; stage 3, booster sears; stage 4, three-point seat belt in the rear seat. Graduation from one stage to another is based on the seat involved and the weight and height of the child. Usage for Stage 1 and Stage 2 seats is very high but only some provinces/ territories have legislation requiring booster seats.

A 2010 observational survey of child restraint use in Canada indicates that incorrect use of child restraints increases with the age of the child. The most significant incorrect usage issue is premature graduation from one stage to another, which reduces safety for the child (Snowdon et al., 2010). 
Seat belt use in Canada over the last several years was at approximately $95 \%$. A recent 2016 urban survey of front seat occupants in Canada indicated seat belt usage rates were $97.5 \%$. However, about $28 \%$ of occupants killed in 2014 were unbelted at the time of the crash; a 20\% decrease from the rate of 35\% in 2010.

Table 7.7. Seat belt wearing rate by car occupancy and road type

$\%$

\begin{tabular}{lccc}
\hline & 2000 & 2010 & 2016 \\
\hline $\begin{array}{l}\text { Front seat } \\
\text { Driver }\end{array}$ & 91.1 & 96.2 & 97.5 \\
\hline
\end{tabular}

\section{Distraction}

Broadly speaking, distracted driving was commonly associated with activities such as eating, talking to other passengers, adjusting entertainment or climate controls and general inattention. While these types of driver distraction continue to this day, there is increasing focus on distracted driving due to electronic communication devices and electronic vehicle equipment.

The use of mobile phones or other electronic devices while driving is regulated by the individual provinces and territories.

An observational mobile phone survey was conducted at 286 urban sites during September 2012 and at 252 rural sites during September 2013. A total of 70686 drivers of light-duty vehicles were observed while they were stopped at a traffic light or a stop sign at urban sites and 33483 drivers were observed at rural sites at similar intersections. The use of a hand-held Electronic Communications Device (ECD) was recorded, as was the type of usage (i.e. speaking, typing, both), driver age and gender, number of passengers in the vehicle and type of vehicle. The data were weighted by population and number of vehicles passing through each survey site to obtain estimates of ECD use and the type of use.

Nationally, an estimated $4.4 \%( \pm 0.4)$ of the drivers used an ECD, varying by jurisdiction from 1.4 to $8.7 \%$. ECDs were used for talking by $2.3 \%$ of drivers and for typing by $1.6 \%$ of drivers. Nationally, the use of hand-held ECDs for talking was 58\% lower in the 2012-13 surveys than that observed in 2006-2007 surveys.

There was an urban national observation survey in the Fall of 2016 and there are plans to conduct the rural observation survey in the Fall of 2017. Analysis will be undertaken to measure the changes in ECD use between the survey periods (i.e. the 2012-13 and 2016-17 surveys) and the results will be reported once they are made available.

\section{Fatigue and sleepiness}

The North American Fatigue Management Program (www.nafmp.com) is a comprehensive educational website that provides Motor Carriers, their drivers, dispatchers and management, with all the necessary information to mitigate driver fatigue over and above Hours of Service Regulations. The website was launched in July 2014. 


\section{National road safety strategies and targets \\ Organisation of road safety}

In Canada, the responsibility for road safety is divided among different levels of government and other road safety and private sector partners.

Federal, provincial and territorial departments responsible for transportation and highway safety work together through various committees and associations that report to the Council of Ministers Responsible for Transportation and Highway Safety. This council is assisted by the Council of Deputy Ministers Responsible for Transportation and Highway Safety. Within this structure, three committees co-ordinate multi-jurisdictional views and efforts (Canadian Council of Motor Transport Administrators, Engineering and Research Support Committee and the Policy and Planning Support Committee). In addition, the Transportation Association of Canada, which also includes a number of municipal partners, addresses infrastructure issues.

This structure is designed to promote national consistency, provide a platform to share information and assist jurisdictions in addressing the issues within their specific mandate. Ultimately the responsibility for implementation remains with the appropriate jurisdiction.

The Federal Government is responsible for regulations and standards related to the manufacture and importation of motor vehicles, tyres and child restraints. Provincial and territorial governments are responsible for licensing drivers, registering vehicles and administering justice and jurisdictional road safety programmes. They are also responsible for policy and regulations regarding the roadways. In many cases, the road authority responsible for the operations of the road may be regional or municipal governments, which must operate within the provincial guidelines.

\section{Road safety strategy for 2015-25}

Canada's fourth national road safety plan, the Road Safety Strategy (RSS) 2025 has been launched by the Council of Ministers Responsible for Transportation and Highway Safety. The goal remains to achieve downward trends in fatalities and serious injuries throughout a five-year duration, comparing a rolling three-year average with the established baseline period

The new plan has a greater emphasis on vehicle technologies and roadway infrastructure. Canada has adopted the Vision Zero approach as an aspirational goal. A database of proven and promising road safety initiatives is maintained as a part of the strategy and each jurisdiction is encouraged to develop their own road safety plan based on regional needs and conditions. More information is available at http://crss-2025.ccmta.ca (accessed 4 May 2017).

\section{Road safety targets}

The aspirational goal of RSS 2025 is zero fatalities and serious injuries. The ongoing goal of the current programme is to achieve a continual downward trend in fatalities and serious injuries throughout the ten-year duration of the strategy.

The Canadian Council of Motor Transport Administrators with assistance from Transport Canada reports annually on progress toward the goals of fatality and injury reduction. A number of rate-based measures are used to focus on progress in specific areas such as impaired driving, speeding, and unbelted occupants. 
When comparing the 2015 figures with the baseline period of 2006-10, fatalities were down $26 \%$, while serious injuries were down by $23 \%$. The $2011-15$ average fatalities and serious injuries were respectively $22 \%$ and $20 \%$ lower than the baseline period.

A similar story unfolds using a rate-based measure, with the rate of fatalities per billion VKTs in 2015 being 33\% lower than that of the baseline period (2006-10), and the rate of serious injuries per billion VKTs was $31 \%$ lower.

\section{Recent safety measures (2014-17)}

\section{Road safety management}

- All jurisdictions are requested to develop a jurisdictional road safety plan specific to the regional challenges they face. These plans may also include hard targets. It is recommended that plans be published.

\section{Road users}

\section{Impaired driving}

- Changes to the Criminal Code of Canada have been proposed to increase the effectiveness of the law with regard to drug and alcohol impaired driving.

- This includes the authorisation of road side testing for cannabis in drivers and new offences related to cannabis and cannabis mixed with alcohol and driving.

\section{Education and awareness}

- A study on vulnerable road user safety around large and heavy vehicles has been launched and is expected to report in early April 2018.

\section{Driving licence}

- Some jurisdictions are updating their driver licensing systems to include more use of electronic systems.

- Additional driver reciprocity agreements with other countries have been secured and consideration is being given to the changes by the Global Road Safety Forum regarding International Driving Permits.

\section{Fatigue}

- The North American Fatigue Management Program information can be found at the following website www.nafmp.com (accessed 4 May 2017).

\section{Infrastructure}

- Programmes for safer communities continue to be adopted by Canadian municipalities.

- Up-to-date information on infrastructure improvements can be found at: http://tac-atc.ca/ en/bookstore-and-resources/tac-news (accessed 4 May 2017).

\section{Vehicles}

- The Motor Vehicle Safety Act has been updated to support alignment with other safety regimes in the United States and the United Nations Economic Commission for Europe (UNECE) and to increase its defect and recall powers. The department is also a member of a United Nations effort to harmonise vehicle regulations, Working Party 29. 
- The Automated Vehicle Working Group managed by CCMTA has produced a report related to on-road testing of automated and connected vehicles.

\section{Recent and ongoing research}

Updates on road safety research in Canada can be found at:

- Canadian Association of Road Safety Professionals Conference: www.carsp.ca (accessed 4 May 2017).

- Road Safety driver and vehicle policy, regulations and research: www.ccmta.ca (accessed 4 May 2017).

- Infrastructure projects: www.tac-atc.ca (accessed 4 May 2017).

\section{References}

Federal Bills C-45, the Cannabis Act and C-46, Offences related to Conveyances can be found at www.parl.gc.ca/LegisInfo/AboutLegisInfo.aspx (accessed 4 May 2017).

Mayhew, D.R., D.J. Beirness and H.M. Simpson (1997), Indicators of the Alcohol-Crash Problem, Road Safety and Motor Vehicle Regulation, Transport Canada, Ottawa, Ontario.

Snowdon, A., A. Hussein and E. Ahmed (2011), Canadian National Survey on Child Restraint Use 2010, completed for Transport Canada, in partnership with AUTO21, www.tc.gc.ca/eng/motorvehiclesafety/ resources-researchstats-child-restraint-survey-2010-1207.htm (accessed 4 May 2017).

World Bank (2017), “GDP (constant US\$)”, World Development Indicators, http://databank.worldbank.org/ data/reports.aspx?source=world-development-indicators (accessed 23 February 2017).

\section{Websites}

- Transport Canada: www.tc.gc.ca/ (accessed 4 May 2017).

- Road Safety Vision 2010: http://ccmta.ca/en/members/standing-committees/rsrp-member-page/rsrp-memberpage-committee-reports (accessed 4 May 2017).

- Road Safety Strategy 2025: http://crss-2025.ccmta.ca/en/ (accessed 4 May 2017).

- Transportation Association of Canada: www.tac-atc.ca/ (accessed 4 May 2017).

- National Collision Data Base On-Line Web application: www.tc.gc.ca/VehicleCollisions (accessed 4 May 2017). 


\section{Chapter 8}

\section{Chile}

This chapter presents 2015 road safety data for Chile along with provisional data from 2016. It looks at trends in traffic and road safety from the years 2000 to 2015 and road user behaviour patterns with a special focus on the ageing population. Data on speed, drink driving, drugs and driving, distracted driving, fatigue and seat belt and helmet use is also included. The chapter reviews Chile's road safety strategy and the most recently implemented safety measures. ${ }^{*}$

* Data included in this report are under validation by IRTAD. All data stem from National Road Safety Commission (CONASET) unless otherwise noted. For more information please contact: CMedina@mtt.gob.cl. 
B etween 2000 and 2015, fatalities in Chile fluctuated with no clear trend emerging. This can be explained in part by the exponential increase in the number of vehicles (124\%) and motorcycles (515\%) on the roads during this same period. In 2015, there were 2140 road deaths in Chile, a 1\% increase over 2014, equalling a fatality rate of 11.9 per 100000 inhabitants. Provisional data from 2016 indicate a further increase of 1.7\% to 2176 fatalities.

Despite a reduction in pedestrian fatalities in 2015 , this group still represents $34 \%$ of all fatalities, second only to car occupants, with the 25-34 year age group most affected. In 2015, motorcyclists became the focus of a new government safety plan following a dramatic increase (80\%) in fatalities since 2010 with a $24 \%$ increase seen in the year between 2014 and 2015.

\section{Road safety data collection}

\section{Definitions applied in Chile}

- Road fatality: A person who dies from injuries within 24 hours of the crash. To conform to international definitions being a death within 30 days, the National Road Safety Commission (CONASET, Comisión Nacional de Seguridad de Tránsito) applies a correction factor of 1.3. Fatality data in this report correspond to the corrected data.

- Person seriously injured: A person injured and hospitalised for more than 24 hours.

\section{Data collection}

Following a traffic crash, the police (Carabineros de Chile) attending the site of the accident are responsible for filling out a Data Collection Form of Road Traffic Accidents (SIEC 2), which is used throughout the country. The information is later entered and stored in a road traffic crash database available to the police. In cases of crashes involving deaths or serious injuries, the crash report is sent by the police to the relevant judges. The police records only include data for the first 24 hours after the crash has occurred.

The official data, on the other hand, is generated through the National Vital Statistics Agreement (CNEV, whose members are the National Statistics Institute, the Ministry of Health and the Civil Registry and Identification Service). The cause of death is coded by the Ministry of Health using the International Statistical Classification of Diseases and Related Health Problems (ICD-10). The most recent information from the National Vital Statistics Agreement is from 2014. The collection and validation process also involves cross checking with police data. This process is not yet automated, which explains the delay in reporting data on vital statistics.

Due to these challenges, to standardise the number of deaths to those occurring up to 30 days after the crash and in accordance with the criteria set by the World Health Organisation (WHO), a correction factor of 1.3 is applied to the death data received from the police. CONASET is currently working together with the police and other relevant institutions to develop an improved form and to create a new database with automated linkage between police and health data. The new system is expected to start its trial phase in 2017. 


\section{Most recent safety data}

\section{Road crashes in 2016 - provisional data}

Based on provisional data, there were 2178 road fatalities in 2016, an increase of $1.8 \%$ when compared to 2015 .

\section{Road crashes in 2015}

In 2015, there were 2140 reported road deaths in Chile, $1 \%$ more than in 2014 . The number of injury crashes also slightly increased by $0.7 \%$.

Despite a reduction in pedestrian fatalities in 2015, pedestrians are the second user group the most affected by traffic crashes and represented $34 \%$ of all road fatalities. The 25-34 year age group is the most impacted.

\section{Trends in traffic and road safety (2000-15) Traffic}

Between 2000 and 2015, the number of motorised vehicles more than doubled (124\%), with the number of motorcycles multiplied by more than five times from approximately 30000 to over 170000 (515\%).

There is a greater vehicle concentration in the main cities. As a consequence, congestion is increasing, especially during rush hours. Infrastructure is being developed and new public transportation alternatives are under construction.

\section{Road safety}

\section{Crashes and casualties}

Between 2000 and 2015, fatalities have fluctuated with no clear trend emerging. The lowest value of 1960 was observed in 2009 and the highest at 2317 was observed in 2008.

Two important measures were implemented in 2014: the reform of the driving licence procedure, with new theoretical and practical exams; and the adoption in September 2014 of "Emilia's Law" which increases the severity of punishment for drunk drivers who cause serious injuries or death.

\section{Rates}

In 2015, Chile had a fatality rate of 11.9 fatalities per 100000 inhabitants. Since 1990 the rate has decreased by $24 \%$.

Table 8.1. Road safety and traffic data

\begin{tabular}{|c|c|c|c|c|c|c|c|c|c|}
\hline & \multirow{2}{*}{1990} & \multirow{2}{*}{2000} & \multirow{2}{*}{2010} & \multirow{2}{*}{2014} & \multirow{2}{*}{2015} & \multicolumn{4}{|c|}{$2015 \%$ change from } \\
\hline & & & & & & 2014 & 2010 & 2000 & 1990 \\
\hline \multicolumn{10}{|l|}{ Reported safety data } \\
\hline Fatalities & 2063 & 2207 & 2074 & 2119 & 2140 & 1.0 & 3.2 & -3.0 & 3.7 \\
\hline Injury crashes & & 30772 & 34335 & 38483 & 38736 & 0.7 & 12.8 & 25.9 & \\
\hline Seriously injured persons & 6312 & 7581 & 6420 & 6968 & & & & & \\
\hline Deaths per 100000 inhabitants & 15.7 & & 12.1 & 11.9 & 11.9 & -0.1 & -2.0 & & -24.3 \\
\hline Deaths per 10000 registered vehicles & 19.2 & 10.6 & 6.3 & 4.7 & 4.6 & -2.9 & -26.7 & -56.6 & -76.0 \\
\hline \multicolumn{10}{|l|}{ Traffic data } \\
\hline Registered vehicles ${ }^{1}$ (thousands) & & 2079 & 3299 & 4468 & 4647 & 4.0 & 40.8 & 123.5 & \\
\hline Registered vehicles per 1000 inhabitants & & 135 & 193 & 251 & 258 & 2.9 & 33.7 & 91.2 & \\
\hline
\end{tabular}

1. With mopeds. 
Figure 8.1. Road safety, traffic and GDP trends index $2000=100$

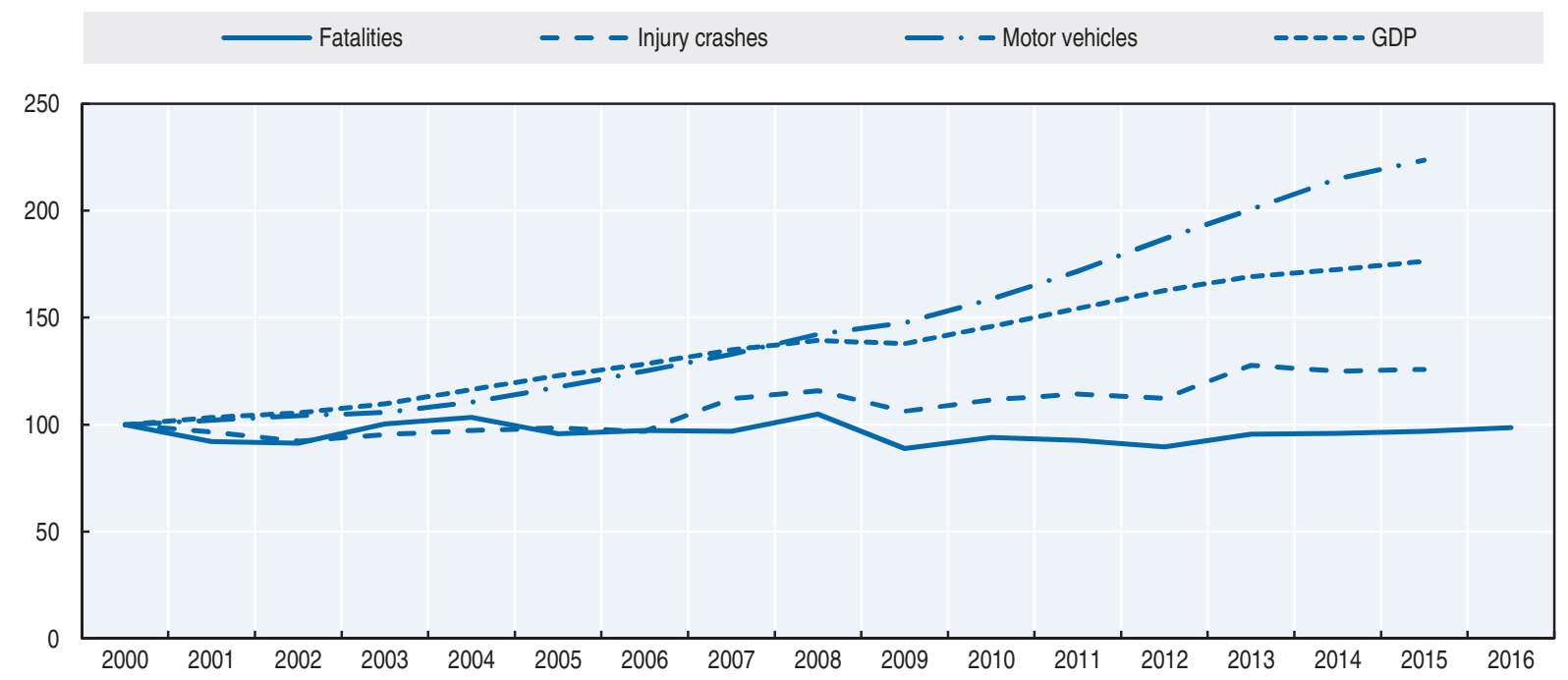

Source: World Bank (2017) (GDP; constant prices).

\section{Road safety by user group}

Pedestrians are the second user group, after car occupants, most affected by road crashes, representing in $2015,34 \%$ of all road deaths. This is a very high proportion when compared with other OECD countries. In 2015, an improvement was observed with a reduction of $8 \%$ in the number of pedestrians killed.

As in many Latin American countries, the safety of motorcyclists is a growing concern. While the motorcycle fleet is still relatively small, it is expanding rapidly. As a consequence, since 2010 the number of motorcyclists killed has increased by $80 \%$. Between 2014 and 2015, i.e. in just one year, it increased by $24 \%$. To respond to this new challenge, in 2015, the government launched a national plan to improve the safety of motorcyclists. It includes 35 targeted measures, including a graduated licensing system, a more rigorous driving exam and infrastructure improvement (see also the section on recent road safety measures).

Overall in 2015, the number of road deaths increased for all user groups, except pedestrians, the highest increase being observed for motorcyclists $(+24 \%)$ followed by cyclists $(+15 \%)$.

Table 8.2. Road fatalities by road user group

\begin{tabular}{lrrr|rr}
\hline & 2010 & 2014 & 2015 & \multicolumn{2}{|c}{$2015 \%$ change from } \\
\cline { 5 - 6 } & & & 733 & 2014 & 2010 \\
\hline Pedestrians & 815 & 800 & 163 & -8.4 & -10.1 \\
Cyclists & 189 & 142 & 199 & 14.8 & -13.8 \\
Motorcyclists & 111 & 160 & 844 & 1.4 & 79.3 \\
Car occupants & 731 & 832 & 202 & 8.6 & -11.8 \\
Others & 229 & 186 & $\mathbf{2 1 4 0}$ & $\mathbf{1 . 0}$ & $\mathbf{3 . 2}$ \\
Total & $\mathbf{2 0 7 4}$ & $\mathbf{2 1 1 9}$ & & & \\
\hline
\end{tabular}


Figure 8.2. Road fatalities by road user group in percentage of total, 2015

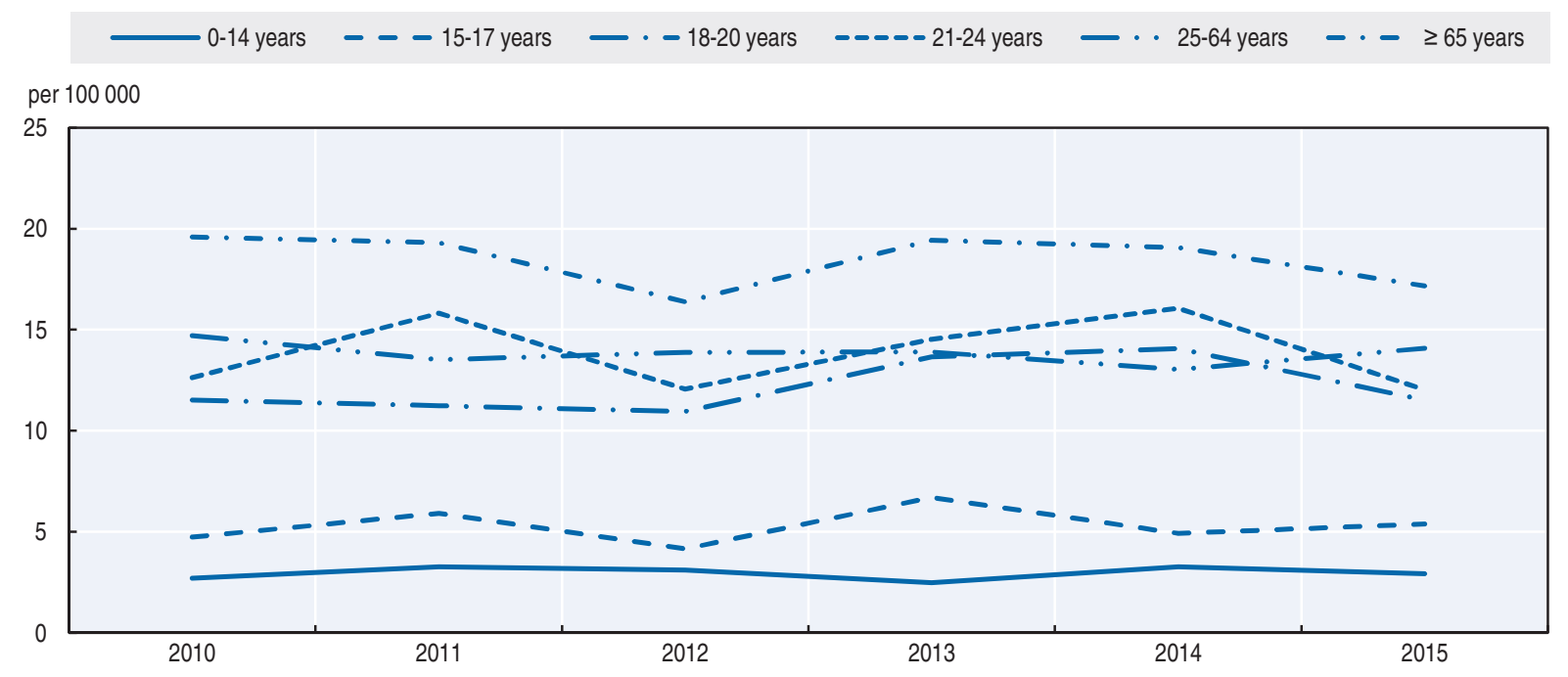

\section{Road safety by age group}

Road crashes are the primary cause of external death in children aged between 1 and 14 .

Senior citizens (65+ years old) are the most at risk in traffic, with a mortality rate of 17 deaths per 100000 inhabitants. They are particularly vulnerable as pedestrians and cyclists. Unlike many other OECD countries, young people have a relatively low mortality rate when compared to the other age groups.

In 2015, fatalities decreased markedly for young people (18-24 years old). Also since 2010, they are the only age group for which the number of fatalities decreased.

Table 8.3. Road fatalities by age group

\begin{tabular}{lrrr|rr}
\hline \multirow{2}{*}{ Age } & 2010 & 2014 & 2015 & \multicolumn{2}{|c}{$2015 \%$ change from } \\
\cline { 4 - 5 } & & & 2014 & 2010 \\
\hline $0-14$ & 103 & 119 & 107 & -10.1 & 3.9 \\
$15-17$ & 42 & 39 & 42 & 7.7 & 0.0 \\
$18-20$ & 104 & 118 & 95 & -19.5 & -8.7 \\
$21-24$ & 147 & 192 & 142 & -26.0 & -3.4 \\
$25-64$ & 1292 & 1243 & 1365 & 9.8 & 5.7 \\
$65-74$ & 177 & 216 & 187 & -13.4 & 5.6 \\
$75-84$ & 98 & 99 & 104 & 5.1 & 6.1 \\
$\geq 85$ & 27 & 26 & 27 & 3.8 & 0.0 \\
Total & $\mathbf{2 0 7 4}$ & $\mathbf{2 1 1 9}$ & $\mathbf{2 1 4 0}$ & $\mathbf{1 . 0}$ & $\mathbf{3 . 2}$ \\
\hline
\end{tabular}


Figure 8.3. Road fatality rates by age group Deaths per 100000 inhabitants in a given age group, 2000-15

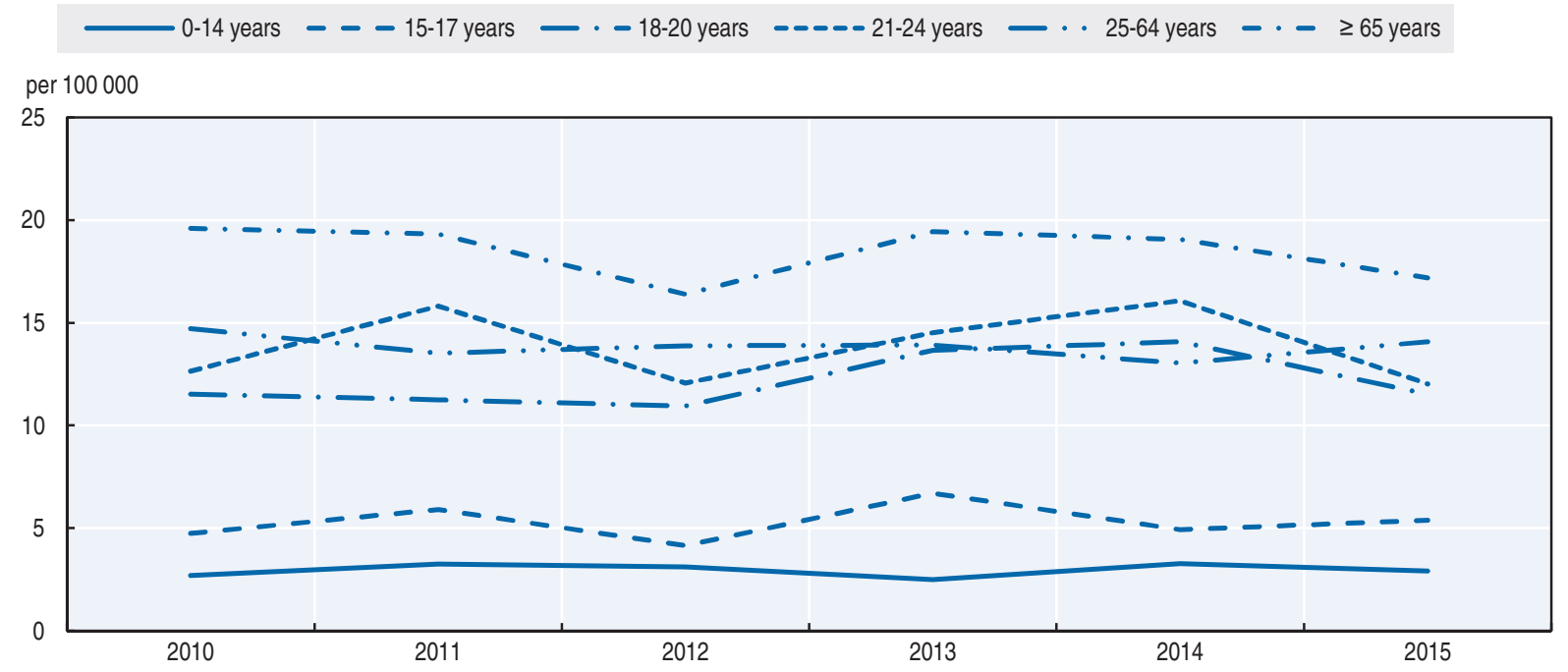

\section{Box 8.1. Road safety for an ageing population}

In 2015, the over 65 age group represented around $10 \%$ of the total population. The population growth rate was at $1.04 \%$ but is expected to drop to $0.89 \%$ by 2020. In 2015, there were 73 people over 65 for 100 people under 15. This rate is expected to grow to 88 in 2020.

Elderly people are particularly vulnerable as pedestrians. More than $60 \%$ of the over 65 s killed in traffic are pedestrians.

In Chile, the driving licence must be renewed every six years and every four years for professional licenses (trucks and buses). There is no age limit set by law to renew a driver's license and the requirements for renewal are the same regardless of age. To renew their licence, drivers must pass a medical exam, including a vision and hearing evaluation. The doctor in charge of the evaluation can recommend not renewing the licence or renewing it for a shorter period, based on the driver's fitness. The doctor can also request additional exams to evaluate the driver's mental state. Mental acuity tests were introduced in 1985 , and to date there is no evidence of their effectiveness in evaluating drivers.

Table 8.4. Road fatalities among senior citizens

\begin{tabular}{lrrr|rcc|ccc}
\hline & \multicolumn{3}{c|}{$65-74$} & \multicolumn{3}{c|}{$75-84$} & \multicolumn{3}{c}{$85+$} \\
\cline { 2 - 10 } & 2010 & 2015 & \% change & 2010 & 2015 & \% change & 2010 & 2015 & \% change \\
\hline Pedestrians & 101 & 91 & -10 & 68 & 78 & 15 & 18 & 20 & 11 \\
Cyclists & 22 & 30 & 36 & 8 & 8 & $=$ & 1 & 0 & - \\
Motorcyclists & 1 & 3 & + & 0 & 0 & $=$ & 0 & 0 & $=$ \\
Car occupants & 39 & 49 & 26 & 13 & 14 & 8 & 7 & 8 & + \\
Total & $\mathbf{1 7 7}$ & $\mathbf{1 8 7}$ & $\mathbf{6}$ & $\mathbf{9 8}$ & $\mathbf{1 0 4}$ & $\mathbf{6}$ & $\mathbf{2 7}$ & $\mathbf{2 7}$ & $\mathbf{0}$ \\
\hline
\end{tabular}


Figure 8.4. Road fatality rate by age and road user group Fatalities per 100000 inhabitants, 2015

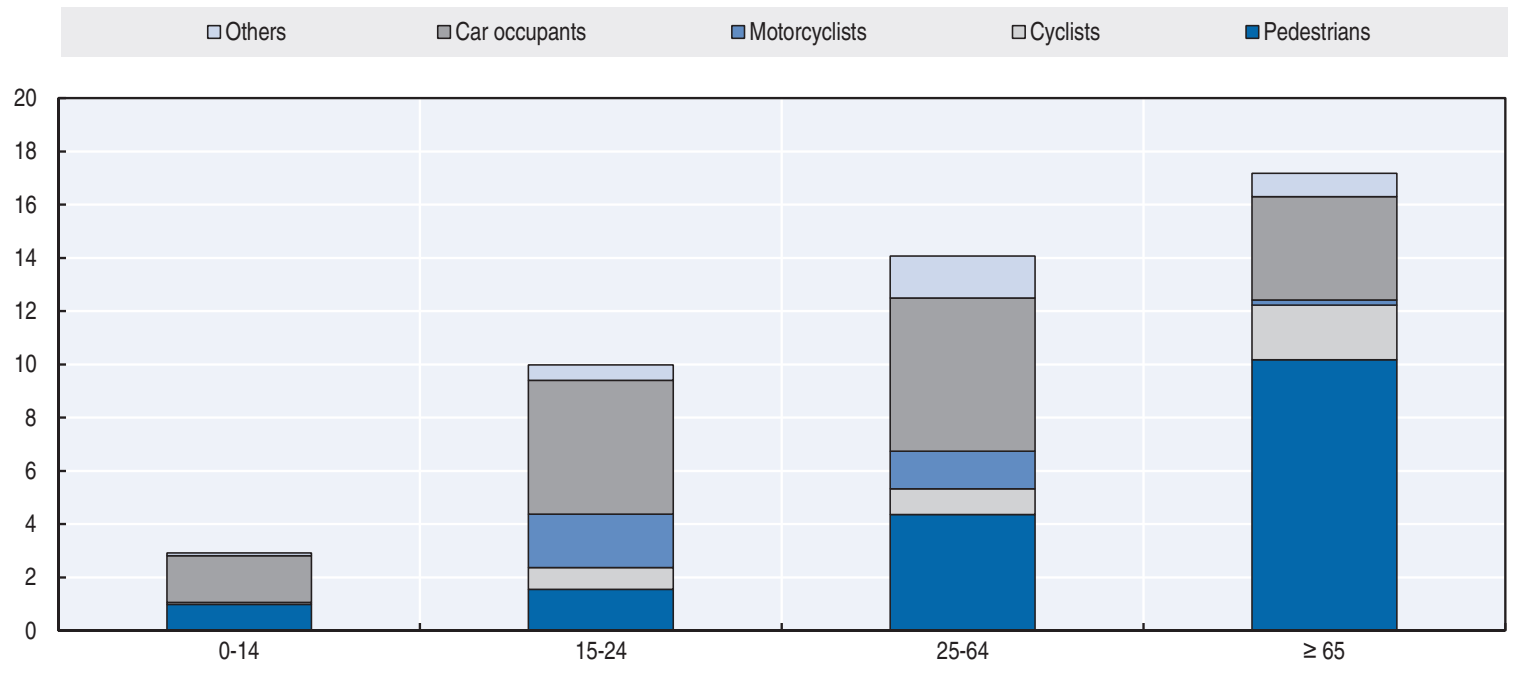

\section{Road safety by road type}

In $2015,61 \%$ of road fatalities occurred on roads outside urban areas.

Figure 8.5. Road fatalities by road type

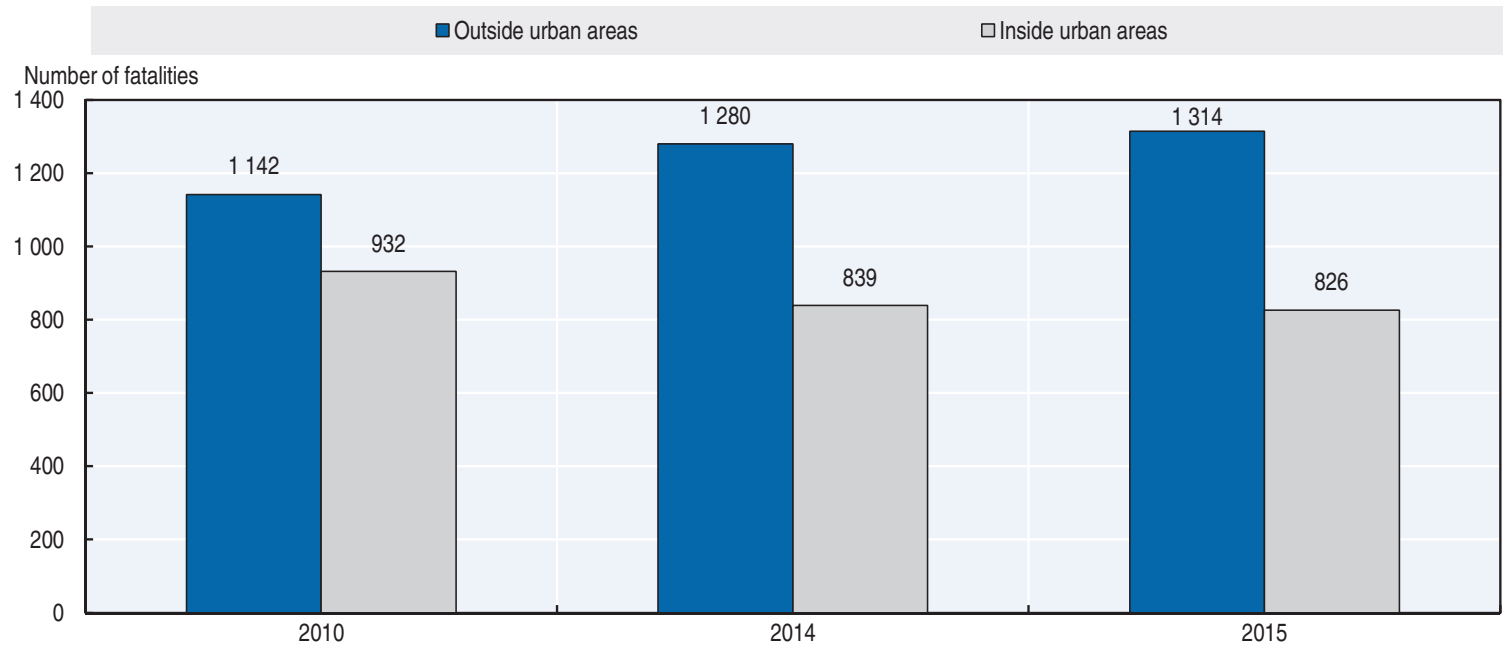

\section{Economic cost of traffic crashes}

To assess the cost of road crashes, CONASET has reviewed several methodologies. As a starting point, it uses the 2011 "simplified methodology of estimates of social benefits due to the reduction of accidents in interurban roads" from the Road and Urban Transport Program (SECTRA-MDS [2011]) of the Ministry of Transportation and the Ministry of Social Development. This methodology takes into account material damage to vehicles, treatment of injured people, administrative costs and loss of productivity (human capital approach). In addition, CONASET uses the "willingness to pay" (WTP) approach to evaluate the benefit of preventing a road death, based on a 2014 study "Estimation of the statistical value of life 
related to atmospheric pollution and traffic accidents" commissioned by the Environment Vice Ministry (GreenLabUC, 2014).

As a result, the estimated cost of traffic crashes for 2015 was USD 4.9 billion equivalent to approximately $2.5 \%$ of Chile's GDP.

\section{Recent trends in road user behaviour}

\section{Speed}

A study conducted in 2014-15 revealed that at any given time $50 \%$ of drivers exceed the speed limit on interurban roads and $40 \%$ in urban areas. The research also showed speeding was more prevalent during the night and at weekends. Another study (CONASET, 2014-15) also found that roads with a median barrier separation contributed to speeding.

It is roughly estimated that speeding is responsible for around $30 \%$ of fatal crashes.

In August 2015, the Ministry of Transportation and Telecommunications submitted a bill to congress that proposes reducing the urban speed limit from 60 to $50 \mathrm{~km} / \mathrm{h}$. This law is expected to be voted on by parliament in 2017 .

Table 8.5. Passenger car speed limits by road type, 2017

\begin{tabular}{ll}
\hline & General speed limit \\
\hline Urban roads & $60 \mathrm{~km} / \mathrm{h}$ \\
Rural roads & $100 \mathrm{~km} / \mathrm{h}$ if there is one lane in each direction \\
& $120 \mathrm{~km} / \mathrm{h}$ if there are two or more lanes in each direction \\
Motorways & $120 \mathrm{~km} / \mathrm{h}$ \\
\hline
\end{tabular}

\section{Drink driving}

In 2012, the government of Chile introduced a new law to support the zero tolerance policy for drunk driving. It sets the maximum permissible blood alcohol content (BAC) at $0.3 \mathrm{~g} / \mathrm{l}$. The law defines:

- driving under the influence of alcohol as driving with a BAC between $0.3 \mathrm{~g} / \mathrm{l}$ and $0.8 \mathrm{~g} / \mathrm{l}$

- driving while intoxicated, which entails much tougher sanctions, as driving with a BAC of $0.8 \mathrm{~g} / \mathrm{l}$ or higher.

A traffic crash is defined as alcohol-related when either a driver, or another person involved in the crash (including motorcyclists, cyclists or pedestrians), has a measurable or estimated BAC of $0.3 \mathrm{~g} / \mathrm{l}$ or above.

The number of fatalities due to drink driving declined significantly in 2012, when the zero tolerance law was implemented. This decline has stabilised and has remained at $9 \%$ of total fatalities over recent years.

In 2014, "Emilia's Law" (Ley Emilia) was implemented to more severely punish drunk drivers responsible for serious injury or fatal crashes. This new law complements the zero tolerance law enacted in 2012 and increases sanctions for drunk driving, such as disqualifying the driver for life. The driver is also subject to at least one year of actual imprisonment. In addition, fleeing the scene or refusing an alcohol test is now a criminal offence. More information can be found at www.conaset.cl/ley-emilia.html (accessed 28 April 2017).

Following the first year of the implementation of "Emilia's Law" the number of fatalities, crashes and those injured due to the influence of alcohol decreased respectively by $16 \%, 12 \%$ and $13 \%$. 


\section{Drugs and driving}

Currently there is no proper drug test process following a crash. Therefore, the attribution of only $0.1 \%$ of deaths to driving under the influence of drugs is largely underestimated. This situation can be explained because a road crash is defined as caused by drugs only when the police see the act of consuming or any physical evidence of drugs.

\section{Distraction}

Chilean traffic law considers driving while using a mobile phone a serious traffic violation, unless the person is using a hands-free device.

A large behavioural study was undertaken in 89 cities in 2015. It revealed that $4 \%$ of light vehicle drivers use their cell phone while driving (CONASET, 2015).

Police data reported that $7 \%$ of crash deaths in 2015 were related to distracted driving.

\section{Sleepiness and fatigue}

According to police data less than 1\% of traffic deaths in 2015 were related to fatigue. This figure is low because it is difficult for the police to discern the physical condition of the drivers when the crash occurred.

\section{Seat belts and helmets}

Seat belt use has been compulsory for front seats since 1985 and rear seats since 2006. A major survey in all 15 regions of the country was undertaken in 2015 and showed that the wearing rate was $76 \%$ for drivers, $59 \%$ for front seat passengers and around $15 \%$ for rear seat passengers (CONASET, 2015). The survey also revealed wide disparities between regions. As an example, the wearing rate for drivers varies from $57 \%$ (in Araucania Region) to $92 \%$ (in Los Lagos Region), showing the important progress that could be made in this area.

Until 2015, children under 8 years of age had to be seated in the rear seat and be adequately restrained. Since March 2016, this applies to children up to 12 years of age. As of 2017, the obligation to use child restraints will be applied to children from 4 to 8 years of age or those below $1.35 \mathrm{~m}$ height and lighter than $33 \mathrm{~kg}$ of weight.

Helmet use by all riders of motorised two-wheelers has been compulsory since 1985 when the transit law was published. The helmet wearing rate is high at $99 \%$ for drivers and $98 \%$ for passengers.

For cyclists, wearing helmets has been required from 2005, but only in urban areas.

Table 8.6. Seat belt wearing rate by car occupancy and road type

\begin{tabular}{lcc}
\multicolumn{2}{c}{$\%$} & 2015 \\
\hline \multicolumn{2}{l}{2014} & \\
\hline Front seat & & 76 \\
Driver & 78 & 59 \\
Passenger & 62 & \\
Rear seats & & 14 \\
General & 15 & 73 \\
Child restraint use & & \\
\hline
\end{tabular}




\section{National road safety strategies and targets \\ Organisation of road safety}

CONASET is an interministerial body created as a presidential advisory commission through Supreme Decree 223, of 27 December 1993.

CONASET has a board of 10 ministers (Ministry of Interior Affairs, Ministry of the General Secretariat of the Presidency, Ministry General Secretariat of Government, Ministry of Education, Ministry of Justice, Ministry of Public Works, Ministry of Health, Ministry of Housing and Urban Development, Ministry of Labour and Ministry of Transportation) plus the National Police Director. CONASET is led by the Minister of Transportation, and CONASET's Executive Secretary is in charge of the National Road Safety Strategy, which is agreed by the board.

In 1993, CONASET began working on a framework policy declaration, which has served as the general strategic guide.

\section{Road safety strategy}

Chile is currently updating its National Road Safety Policy, which will have a strategy and action plan that will be based on the five pillars of the Global Plan for the Decade of Action for Road Safety 2011-2020. In particular, the scope of action of the new strategy will be: enforcement, regulatory framework, research and innovation, and education and promotion.

In 2015 a special evaluation was made for the first half of the decade. Its results will guide the elaboration of the updated National Road Safety Policy and the development of new strategies and plans. In particular, the evaluation highlighted the need to develop safety plans for the most vulnerable road users, including children, teenagers and motorcyclists.

\section{Recent safety measures (2014-17)}

\section{Road safety management}

\section{Road users}

\section{Driving license}

- The new practical exam for vehicle drivers requires candidates to demonstrate their ability to drive safely and does not only evaluate a set of determined manoeuvres.

- In order to educate citizens on the benefits of eco-driving, this topic was included in the knowledge exam from 2015.

- Since 2014, the knowledge exam can be also taken in English throughout all of Chile.

- CONASET developed a handbook (Libro del Nuevo Conductor) to help candidates study for their tests.

\section{Pedestrians}

- In Chile, pedestrians account for around 35\% of all road fatalities. They remain a target for awareness campaigns which focus on respect, self-care and civic coexistence to improve people's quality of life (More information can be found at www.conaset.cl/todos-somospeatones/ [accessed 28 April 2017]).

\section{Motorcycle road safety plan}

- The Motorcycle Road Safety plan was launched in 2015. This plan contains 35 measures including short, medium and long term initiatives. (More information can be found at: www.conaset.cl/programa/motociclistas/plan-de-motos [accessed 28 April 2017]). 


\section{Children and teenagers' road safety plan}

- In Chile, road crashes are the first cause of external death for children between 1 and 14 years of age. To demonstrate the urgent need to improve road safety in this area, Chile joined the UN's \#SaveKidsLives initiative and started to develop a road safety plan for children and teenagers. The plan was based on consultation with citizens, parents and children throughout Chile and some of the measures have been implemented such as the change in Child Restraint Systems age requirement.

\section{Speed management}

- In August 2015 the Ministry of Transportation and Telecommunications submitted a bill to congress that proposes reducing urban speed limits from 60 to $50 \mathrm{~km} / \mathrm{h}$. In 2002, the speed limit was increased to $60 \mathrm{~km} / \mathrm{h}$ and the following year crashes in urban areas increased, as well as fatalities (by $25 \%$ ). The bill has priority and will be discussed during the first semester of 2017.

\section{Road safety education and campaigns}

- In the last three years CONASET in collaboration with the Ministry of Education has added road safety activities to primary school programs.

- CONASET is continuously developing road safety awareness campaigns.

- More about campaigns from CONASET can be found at: www.facebook.com/conaset/ www.youtube.com/user/Manejateporlavida (accessed 28 April 2017).

\section{Vehicles}

Recent improvements to vehicle safety include:

- Mandatory frontal airbags (for drivers and passengers) on new light vehicles sold in Chile (2015)

- ISOFIX or LATCH anchoring systems for vehicles of $2700 \mathrm{~kg}$ or less to simplify correct installation of child restraint systems without the need of seat belts (2014)

- Reflective vests in cars starting as of January 2016

- Increased safety requirements for motorcycles, including standards for motorcycle features in line with international regulations (2014)

\section{Recent and ongoing research}

- A speed survey was carried out in 2014 and 2015 on different road types of Chile. Speed data was collected by radars continuously for 24 hours a day, seven days a week at 50 control points. In short, the data showed that 5 out of 10 drivers exceed speed limits in intercity roads and 4 out of 10 exceed the limits in urban roads.

- Behavioural studies were conducted in 89 cities from 15 regions in 2015, focusing on seat belt use, helmet use and distracted driving by car or motorcycle drivers. These studies showed that $76 \%$ of drivers and $59 \%$ of the front seat passengers use their seat belt and that the use of helmets is $99 \%$ for the drivers and $98 \%$ for the passengers. The study also showed that $62 \%$ of motorcyclists wear gloves and $33 \%$ use proper shoes. Regarding distracted driving, $4 \%$ of light vehicles drivers use their cell phones while driving. More information can be found at: www.conaset.cl/programa/observatorio-datos-estadistica/ biblioteca-observatorio/estudios/ (accessed 28 April 2017). 


\section{References}

CONASET (2015), Estudio Observación de uso de sistema de retención y casco, distractores presentes en la conducción de vehículos livianos, www.conaset.cl/programa/observatorio-datos-estadistica/bibliotecaobservatorio/estudios/ (accessed 28 April 2017).

CONASET (2014-2015),“Caracterización perfil de velocidades de vehículos motorizados en rutas representativas del país".

SECTRA-MDS (2011), Metodología Simplificada de estimación de beneficios sociales por disminución de accidentes en proyectos de vialidad interurbana, www.ministeriodesarrollosocial.gob.cl/btca/txtcompleto/ mideplan/metod.benef.soc-accidentab.vialurb.pdf (accessed 28 April 2017).

GreenLabUC (2014), Estimación del valor de la vida estadística asociado a contaminación atmosférica y accidentes de tránsito, www.greenlabuc.cl/wp-content/uploads/2016/04/2014-VVE-Informe-Final-23Dic2014-1125casos.pdf (accessed 28 April 2017).

World Bank (2017), “GDP (constant US\$)”, World Development Indicators, http://databank.worldbank.org/ data/reports.aspx? source=world-development-indicators (accessed 23 February 2017).

\section{Websites}

- National Road Safety Commission? CONASET: www.conaset.cl (accessed 28 April 2017).

- Ministry of Transport and Telecommunications: www.mtt.gob.cl (accessed 28 April 2017). 


\section{Chapter 9}

\section{Czech Republic}

This chapter presents 2015 road safety data for the Czech Republic along with provisional data from 2016. It looks at trends in traffic and road safety from the years 1990 to 2016 and road user behaviour patterns, with a special focus on the ageing population. Data on speed, drink driving, drugs and driving, distracted driving, fatigue and seat belt usage are also included. The chapter reviews the Czech Republic's road safety strategy and national targets to 2020 and the progress achieved thus far. It also looks at ongoing research and recently implemented safety measures. ${ }^{*}$

* All data stem from CDV (Centrum dopravního výzkumu: Czech Transport Research Centre) and IRTAD unless otherwise noted. For more information please contact: jan.tecl@cdv.cz. 
Between 1994 and 2016, the Czech Republic, with its population of 10.5 million, saw a decline in the number of road deaths by $63 \%$. Its lowest rate to date of 6.2 deaths per 100000 inhabitants was reached in 2013. However, the years 2014 and 2015 both experienced increases in the number of fatalities reaching 737 deaths in 2015, a rate of 7.0 per 100000 inhabitants. Cyclists and pedestrians were most affected.

In contrast, data from 2016 indicate that this increasing trend was short-lived with a $17.5 \%$ decrease in fatalities to 611 , the country's lowest figure on record. Despite this positive development, meeting the 2020 national and EU targets will remain extremely challenging and to this end interim sub-targets have been developed.

\section{Road safety data collection}

\section{Definitions applied in the Czech Republic}

- Road fatality: Person who died immediately after the crash or within the next 30 days. (Note: this is fully applied for international data comparison, but for domestic purposes, a road fatality often refers to a person who died immediately or within 24 hours).

- Serious injury: Injury severity is determined through the opinion of the physician at the scene of the crash or later in hospital (within 24 hours of the crash). A serious injury is one considered to cause serious harm to health. At present, the severity value based on a score of three or more on the Maximum Abbreviated Injury Scale (MAIS3+) is not in general use in crash registration, and its future utilisation is still to be decided.

\section{Data collection}

Crash data in the Czech Republic are collected by the traffic police in 80 districts and transferred to the police headquarters. Data are checked both at district and central levels.

Crash reporting rates in the police database are relatively high due the legal obligation that all crashes with a death, injury or material damage over CZK 100000 (since 2009) have to be reported to and registered by the police.

\section{Most recent safety data}

\section{Road crashes in 2016 - final data}

There were 611 reported road fatalities in 2016, a 17.1\% decrease when compared to 2015. The number of injury crashes decreased by $0.8 \%$. Despite this considerable fatalities reduction, the main interim target of the National road safety strategy (503 killed in 2016) was not achieved for the third consecutive year.

Given the current level of road deaths, meeting the 2020 national and EU targets will be extremely challenging. The national strategy is currently being reviewed seeking for more effective measures to reduce the number of road deaths. The targets will not be changed. 


\section{Road crashes in 2015}

In 2015, there were 737 reported road fatalities, a $7.1 \%$ increase when compared to 2014. The number of injury crashes increased by $2.4 \%$. For the second consecutive year, the targets of the national road safety strategy were not achieved (with 2016 data bringing it to three consecutive years).

The number of fatalities increased significantly on rural roads ( $+13 \%$ fatalities) and on motorways (+28\%). There was an increase of $24 \%$ in the number of cyclists killed and of $15 \%$ in the number of pedestrians killed.

Due to the poor performance seen in 2014 and 2015, there is an urgent need to implement new and effective road safety measures and to bring radical changes to the current road safety management system. Based on analyses of the 2014 and 2015 data, it is particularly important to increase traffic enforcement, strengthen the driver licensing system, improve traffic education and undertake infrastructure audits and inspections, especially at railway crossings.

\section{Trends in traffic and road safety (1990-2016) Traffic}

Since 1990, the number of motor vehicles has increased by more than $75 \%$. Traffic volume (expressed in vehicle-kilometres) more than doubled between 1990 and 2009, followed by several years (2010-14) where either a stagnation or decrease was registered. Since 2015, traffic volume has once again been on the increase, as a result of the economic recovery.

Road freight traffic of heavy goods vehicles has also steadily increased since 1990 with the development of the new market economy.

\section{Road safety}

\section{Crashes and casualties}

Fatalities had reached a peak in 1969 and then steadily decreased until 1986. Between 1986 and 1994, due to a rapid deterioration in road safety, deaths again increased by $82 \%$. This was during a period of important political changes in the Czech Republic and other neighbouring Central-Eastern European countries following the fall of the Soviet bloc. During this period, the number of motorised vehicles increased sharply in a context of weak police control and low political attention to road safety.

Between 1994 and 2016, the number of road deaths declined by 63\% while the number of injury crashes declined by $22.5 \%$. These relatively positive results are the fruit of successive national strategic safety plans. However, overall the Czech Republic is still among the weakest European countries in terms of road safety.

\section{Rates}

In 2015, the road traffic mortality rate was 7.0 fatalities per 100000 inhabitants and the fatality risk was of 14.4 deaths per billion vehicle-kilometres.

\section{Analysis of seriously injured data}

Reducing the number of persons seriously injured is the second target of the national road safety strategy. Unfortunately, it is not yet possible to estimate the number of persons injured based on the MAIS3+ classification as a decision to use these criteria has not been 
agreed. Based on the current national definition, the number of persons seriously injured decreased by $8.9 \%$ to 2463 between 2014 and 2015 achieving one goal of the strategic road safety programme.

Table 9.1. Road safety and traffic data

\begin{tabular}{|c|c|c|c|c|c|c|c|c|c|}
\hline & \multirow{2}{*}{1990} & \multirow{2}{*}{2000} & \multirow{2}{*}{2010} & \multirow{2}{*}{2014} & \multirow{2}{*}{2015} & \multicolumn{4}{|c|}{$2015 \%$ change from } \\
\hline & & & & & & 2014 & 2010 & 2000 & 1990 \\
\hline \multicolumn{10}{|l|}{ Reported safety data } \\
\hline Fatalities & 1291 & 1486 & 802 & 688 & 737 & 7.1 & -8.1 & -50.4 & -42.9 \\
\hline Injury crashes & 21910 & 25445 & 19676 & 21054 & 21561 & 2.4 & 9.6 & -15.3 & -1.6 \\
\hline Serious injuries (national definition) & 4401 & 5375 & 2774 & 2703 & 2463 & -8.9 & -11.2 & -54.2 & -44.0 \\
\hline Deaths per 100000 inhabitants & 12.5 & 14.5 & 7.7 & 6.5 & 7.0 & 6.9 & -8.8 & -51.6 & -43.9 \\
\hline Deaths per 10000 registered vehicles & 3.3 & 3.2 & 1.3 & 1.1 & 1.1 & 4.8 & -14.9 & -64.6 & -65.5 \\
\hline Deaths per billion vehicle kilometres & 48.3 & 36.7 & 16.2 & 14.2 & 14.4 & 1.9 & -11.0 & -60.6 & -70.1 \\
\hline \multicolumn{10}{|l|}{ Traffic data } \\
\hline Registered vehicles ${ }^{1}$ (thousands) & 3933 & 4636 & 6021 & 6360 & 6499 & 2.2 & 7.9 & 40.2 & 65.2 \\
\hline Vehicle-kilometres (millions) & 26710 & 40480 & 49434 & 48513 & 51020 & 5.2 & 3.2 & 26.0 & 91.0 \\
\hline Registered vehicles per 1000 inhabitants & 380 & 451 & 576 & 605 & 617 & 1.9 & 7.2 & 36.7 & 62.5 \\
\hline
\end{tabular}

1. With mopeds.

Figure 9.1. Road safety, traffic and GDP trends index $1990=100$

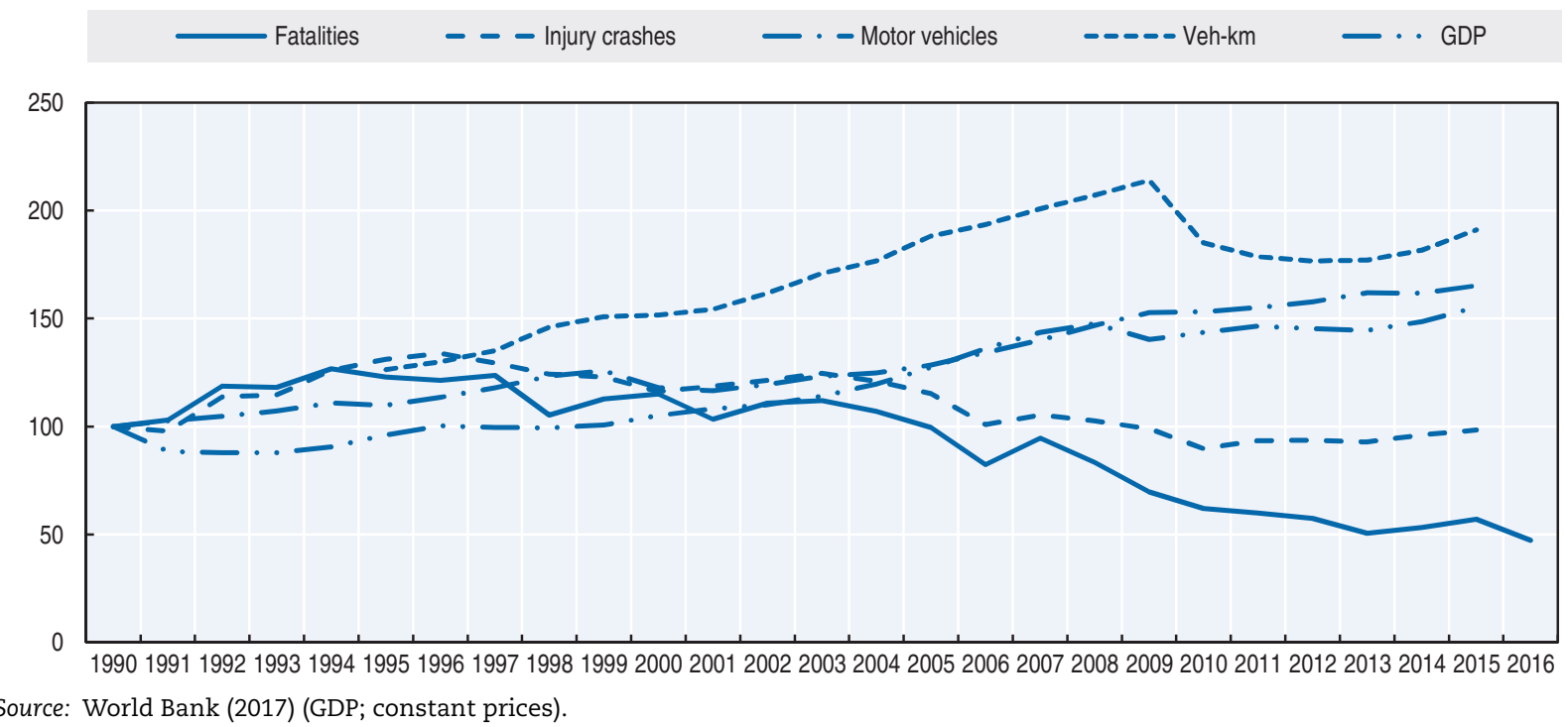

\section{Road safety by user group}

Since 2000, all user groups have benefited from safety improvements. Strengthened enforcement and education within the national strategic safety plan contributed to these good results in the first period of the safety plan.

However, in 2015, the situation has worsened for all road users (with the exception of moped riders, but their number is low). In particular, the number of cyclists killed increased by $25 \%$ and the number of pedestrians by $15 \%$. This can be partly explained by increased numbers of pedestrians and cyclists on the roads (in part due to favourable weather conditions). A lack of adherence to traffic laws was also observed amongst pedestrians and cyclists. 
Table 9.2. Road fatalities by road user group

\begin{tabular}{lrrrrr|rrrr}
\hline & 1990 & 2000 & 2010 & 2014 & 2015 & \multicolumn{4}{|c}{$2015 \%$ change from } \\
\cline { 7 - 10 } & & & & & & 2014 & 2010 & 2000 & 1990 \\
\hline Pedestrians & 359 & 362 & 168 & 130 & 150 & 15.4 & -10.7 & -58.6 & -58.2 \\
Cyclists & 135 & 151 & 80 & 68 & 85 & 25.0 & 6.3 & -43.7 & -37.0 \\
Moped riders & 47 & 16 & 4 & 8 & 6 & -25.0 & 50.0 & -62.5 & -87.2 \\
Motorcyclists & 66 & 100 & 95 & 88 & 92 & 4.5 & -3.2 & -8.0 & 39.4 \\
Car occupants & 597 & 784 & 403 & 347 & 366 & 5.5 & -9.2 & -53.3 & -38.7 \\
Others & 87 & 73 & 52 & 47 & 38 & -19.1 & -26.9 & -47.9 & -56.3 \\
Total & $\mathbf{1 2 9 1}$ & $\mathbf{1 4 8 6}$ & $\mathbf{8 0 2}$ & $\mathbf{6 8 8}$ & $\mathbf{7 3 7}$ & $\mathbf{7 . 1}$ & $\mathbf{- 8 . 1}$ & $\mathbf{- 5 0 . 4}$ & $\mathbf{- 4 2 . 9}$ \\
\hline
\end{tabular}

Figure 9.2. Road fatalities by road user group in percentage of total, 2015

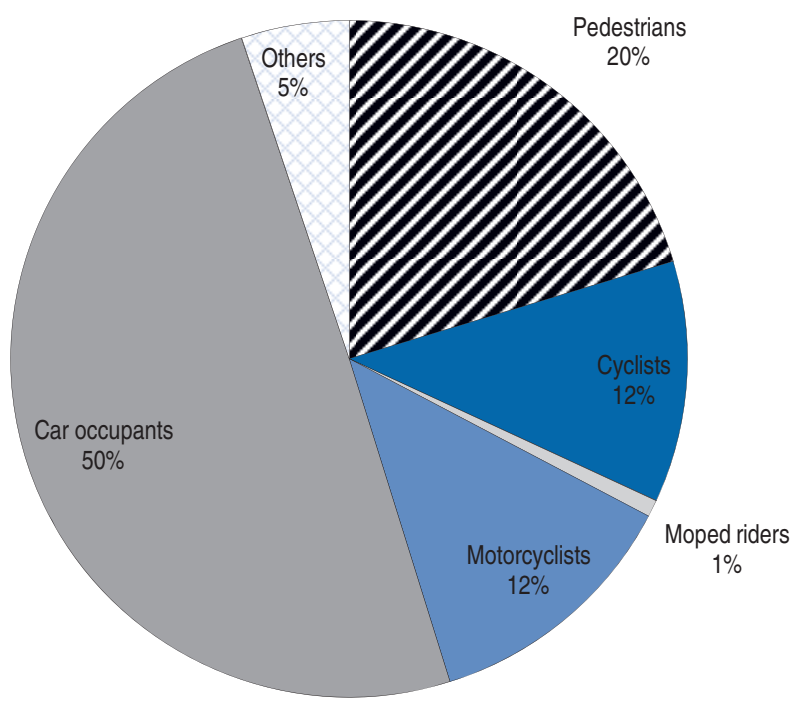

\section{Road safety by age group}

Since 2000, a gradual reduction in fatalities has benefited all age groups, with the highest reduction for children and young people and the lowest reduction for the elderly.

In 2015, the number of people killed increased markedly for the older population in the age groups $65-74(+36 \%)$ and $75-84(+59 \%)$ and for young people aged $21-24(+30 \%)$.

Young people (18-24) and the elderly have a risk well above the average of $7.0 \mathrm{road}$ deaths per 100000 inhabitants. In 2015, the death rate for the 21-24 age group was 14 per 100000 inhabitants and for the $18-20$ age group, it was 11 . The over $75 \mathrm{~s}$ had a mortality rate of 11 for the 75-84 age group and 10 for those 85 and over. 
Table 9.3. Road fatalities by age group

\begin{tabular}{|c|c|c|c|c|c|c|c|c|c|}
\hline \multirow{2}{*}{ Age } & \multirow{2}{*}{1990} & \multirow{2}{*}{2000} & \multirow{2}{*}{2010} & \multirow{2}{*}{2014} & \multirow{2}{*}{2015} & \multicolumn{4}{|c|}{$2015 \%$ change from } \\
\hline & & & & & & 2014 & 2010 & 2000 & 1990 \\
\hline $0-14$ & 59 & 54 & 17 & 14 & 18 & 28.6 & 5.9 & -66.7 & -69.5 \\
\hline $15-17$ & 57 & 44 & 17 & 11 & 4 & -63.6 & -76.5 & -90.9 & -93.0 \\
\hline $18-20$ & 107 & 103 & 51 & 46 & 34 & -26.1 & -33.3 & -67.0 & -68.2 \\
\hline $21-24$ & 123 & 155 & 74 & 54 & 70 & 29.6 & -5.4 & -54.8 & -43.1 \\
\hline $25-64$ & 668 & 881 & 471 & 430 & 431 & 0.2 & -8.5 & -51.1 & -35.5 \\
\hline $65-74$ & 124 & 123 & 79 & 72 & 98 & 36.1 & 24.1 & -20.3 & -21.0 \\
\hline $75-84$ & & 100 & 69 & 39 & 62 & 59.0 & -10.1 & -38.0 & \\
\hline$\geq 85$ & & 20 & 24 & 20 & 18 & -10.0 & -25.0 & -10.0 & \\
\hline Total & 1291 & 1486 & 802 & 688 & 737 & 7.1 & -8.1 & -50.4 & -42.9 \\
\hline
\end{tabular}

Figure 9.3. Road fatality rates by age group Deaths per 100000 inhabitants in a given age group, 2015

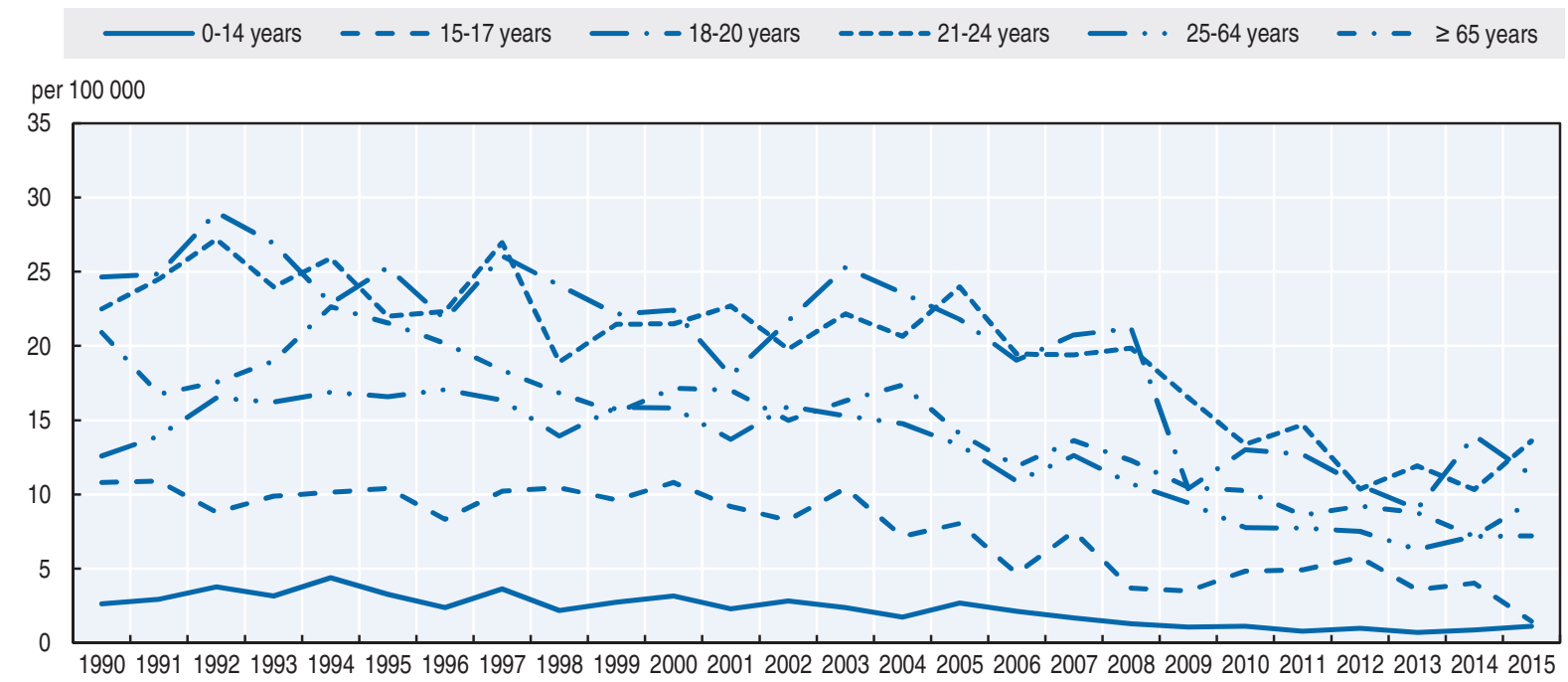

\section{Box 9.1. Road safety for an ageing population}

In 2015, more than 1.8 million Czech citizens were over 65 years of age, representing $17 \%$ of the population. This number is expected to grow and could reach 2.6 million by 2030 , around a third of the total population.

Senior citizens over 75 have a mortality rate much higher than the average population. They are particularly vulnerable as pedestrians. Nearly $80 \%$ of the road deaths in the over 85 age group are pedestrians. The number of older people killed in road traffic increased considerably in $2015(+36 \%)$, in particular for pedestrians and cyclists. This is a major challenge for the national road safety strategy. Based on provisional data, the situation improved in 2016.

Medical tests for drivers are obligatory at 65 and 68 years of age and then every two years.

Campaigns are regularly conducted for the attention of the ageing population on the risks as pedestrians, cyclists and drivers, on new traffic rules and on the importance of regular medical tests. 
Box 9.1. Road safety for an ageing population (cont.)

Table 9.4. Road fatalities among senior citizens

\begin{tabular}{lrr|rr|rr}
\hline & \multicolumn{2}{c|}{$65-74$} & \multicolumn{2}{c|}{$75-84$} & \multicolumn{2}{c}{$85+$} \\
\cline { 2 - 7 } & 2010 & 2015 & 2010 & 2015 & 2010 & 2015 \\
\hline Pedestrians & 31 & 20 & 37 & 29 & 13 & 14 \\
Cyclists & 10 & 29 & 10 & 9 & 2 & 3 \\
Moped riders & 1 & 0 & 2 & 1 & 0 & 0 \\
Motorcyclists & 1 & 6 & 0 & 1 & 0 & 0 \\
Car Occupants & 31 & 41 & 20 & 20 & 9 & 1 \\
Total & $\mathbf{7 9}$ & $\mathbf{9 8}$ & $\mathbf{6 9}$ & $\mathbf{6 2}$ & $\mathbf{2 4}$ & $\mathbf{1 8}$ \\
\hline
\end{tabular}

Figure 9.4. Road fatality rates in the $65+$ age groups Deaths per 100000 inhabitants in a given age group, 2000-15

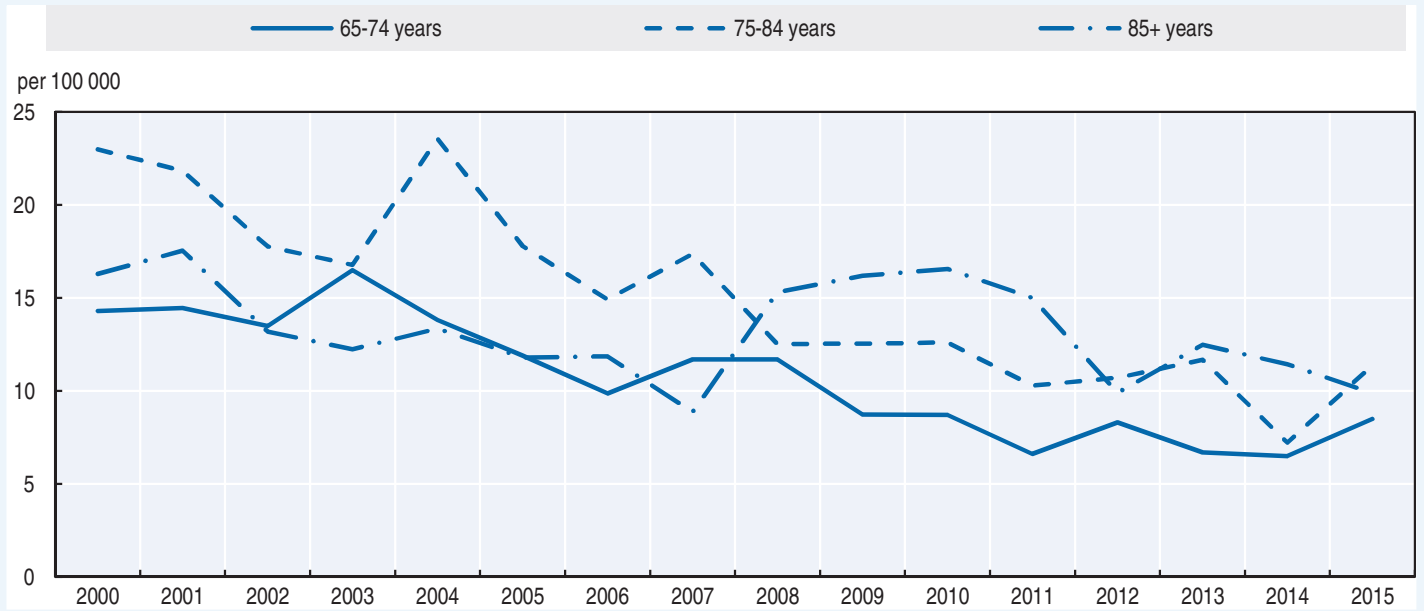

Figure 9.5. Road fatality rate by age and road user group Fatalities per 100000 inhabitants, 2015

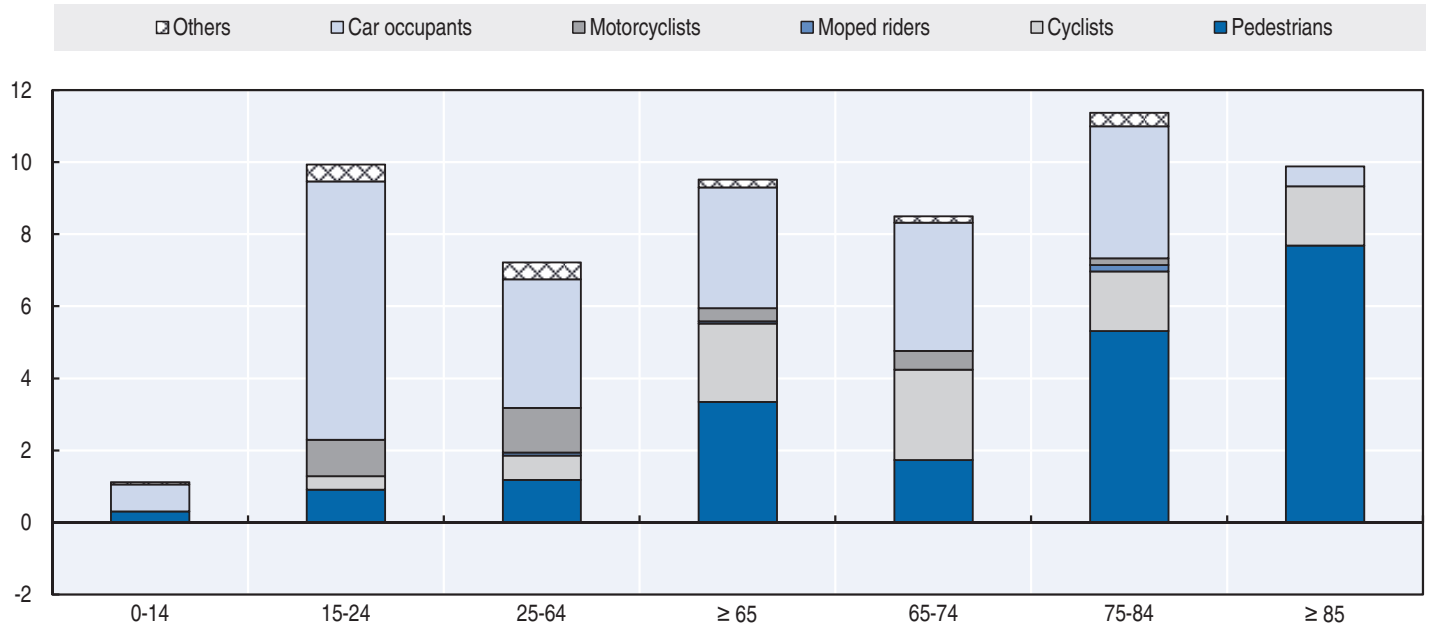




\section{Road safety by road type}

Since 1990, the greatest reduction in fatalities has occurred on urban roads (-65\%), while improvement on rural roads has been less marked (-28\%). Improvements on urban roads are related to the introduction of the $50 \mathrm{~km} / \mathrm{h}$ speed limit, the extension of $30 \mathrm{~km} / \mathrm{h}$ zones, and the widespread introduction of traffic-calming measures. Since 2000, fatalities decreased by $62 \%$ on urban roads and $48 \%$ on rural roads. In 2015 , there was a sharp increase in the number of fatalities on rural roads $(+13 \%)$ and motorways $(+28 \%)$.

Since 1 January 2016, expressways are classified as 2nd class motorways. Second class motorways have slightly lower standards. The total length of motorways is now $1210 \mathrm{~km}$ (including $776 \mathrm{~km}$ of 1st class motorways and $434 \mathrm{~km}$ of 2 nd class motorways).

Figure 9.6. Road fatalities by road type

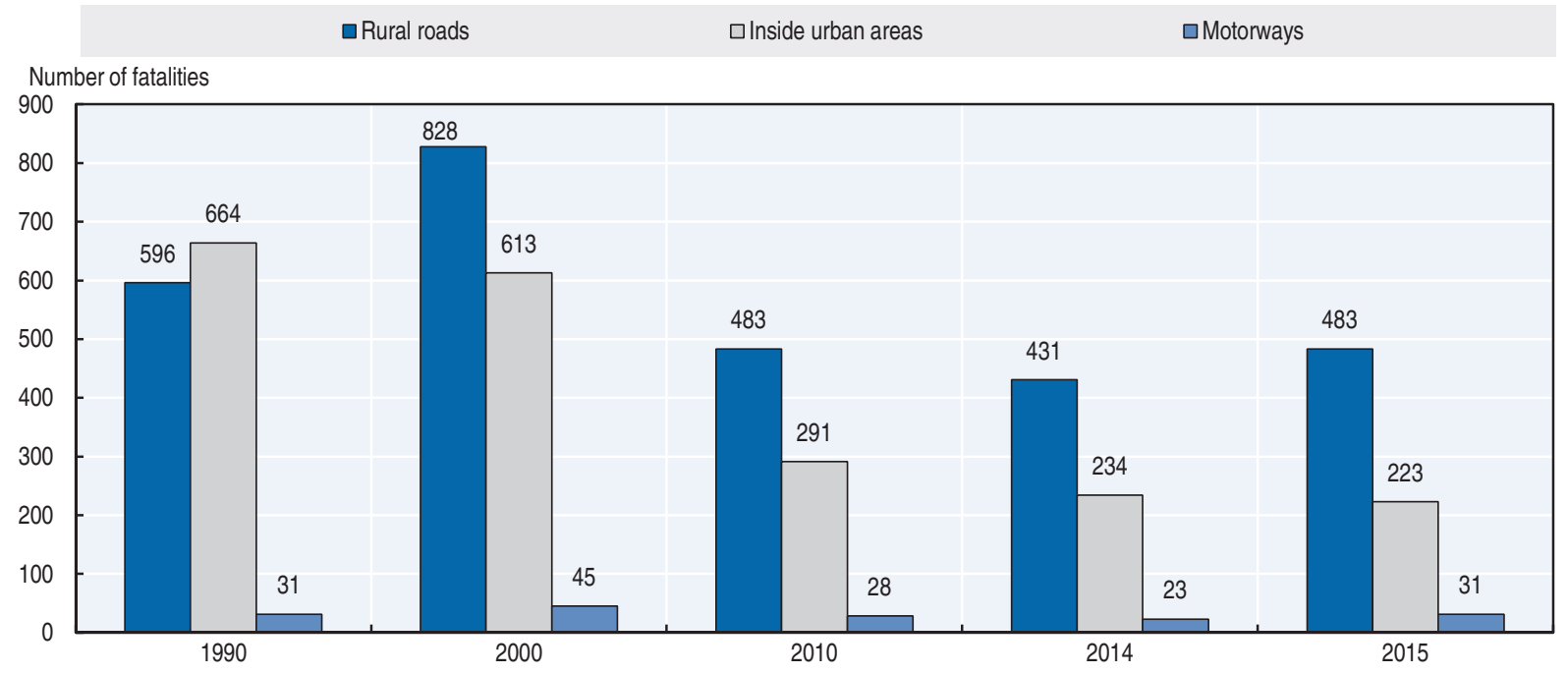

\section{Economic costs of traffic crashes}

Economic costs engendered by road crashes are evaluated by the human capital approach. They are composed of direct costs (chiefly medical care, rescue service, police and justice) and indirect costs (lost value of economic productivity due to ill health, disability, or premature mortality, and social expenses).

The economic costs of crashes for the Czech Republic are published every year. For 2015, they have been estimated at EUR 2.5 billion, or $1.6 \%$ of GDP.

Table 9.5. Costs of road crashes, 2015

\begin{tabular}{lcc}
\hline & Unit cost & Total \\
\hline Fatalities & EUR 762000 & EUR 562 million \\
Hospitalised persons & EUR 185000 & EUR 455 million \\
Slight injuries & EUR 23800 & EUR 582 million \\
Property damage costs & EUR 12600 & EUR 904 million \\
Total & & EUR 2.5 billion \\
Total as \% of GDP & & $\mathbf{1 . 6 \%}$ \\
\hline
\end{tabular}




\section{Recent trends in road user behaviour}

\section{Speed}

Speeding is the main contributing factor in fatal crashes, although the number of drivers above the legal speed limit has decreased, especially in urban areas. The share of fatal crashes due to excessive speed was 33\% in 1980, 40\% in 2000 and in 2014, and 36\% in 2015.

Average speed, 85th percentile speed and the percentage of drivers above the speed limit have been monitored regularly since 2005. The introduction of a demerit point system in 2006 resulted in a reduction in the number of drivers above the limit, but this share increased again after 2012. Overall, it is estimated that $25 \%$ of drivers speed (30\% in urban areas and $20 \%$ in rural areas).

The table below summarises the main speed limits in the Czech Republic.

Table 9.6. Passenger car speed limits by road type, 2016

\begin{tabular}{lc}
\hline & General speed limit \\
\hline Urban roads & $50 \mathrm{~km} / \mathrm{h}$ \\
Rural roads & $90 \mathrm{~km} / \mathrm{h}$ \\
Motorways & $130 \mathrm{~km} / \mathrm{h}$ \\
\hline
\end{tabular}

\section{Drink driving}

There is a zero blood alcohol content (BAC) limit in the Czech Republic. When police arrive at the scene of a crash, all persons involved are checked for BAC. If the BAC level of anyone involved is positive, the crash is classified as alcohol related.

In $2002,11 \%$ of fatalities were due to alcohol-related crashes. This proportion decreased to $3.4 \%$ in 2007 , but then increased again. In $2015,9.4 \%$ of road fatalities were alcohol-related crashes.

\section{Drugs and driving}

A crash is defined as drug related if the driver tests positive for drug consumption.

The share of fatal crashes due to a driver under the influence of drugs was estimated at $1.8 \%$ in 2015.

\section{Distraction}

In the Czech Republic, drivers are not allowed to drive while using a hand-held phone or other electronic device such as a Personal Digital Assistant (PDA). Hands-free devices are tolerated. In 2015 , it was estimated that $2.8 \%$ of drivers used a mobile phone while driving.

\section{Sleepiness and fatigue}

In 2015 , it was estimated that about $2.5 \%$ of crashes were due to fatigue.

\section{Seat belts and helmets}

Seat belt use has been compulsory in front seats since 1966 and in rear seats since 1975. However, until recently the level of enforcement was very low. The situation has significantly improved since 2004.

Dedicated child restraints are compulsory for children between 0 and 3 years old, and for children 4 and above who are less than $150 \mathrm{~cm}$ in height or $36 \mathrm{~kg}$ in weight. 
In $2015,28.5 \%$ of car occupants killed were not wearing a seat belt when the crash occurred. It is estimated that 80 lives could have been saved if all car occupants had worn seat belts.

Table 9.7. Seat belt wearing rate by car occupancy and road type

\begin{tabular}{|c|c|c|c|c|}
\hline & 2000 & 2012 & 2014 & 2015 \\
\hline \multicolumn{5}{|l|}{ Front seat } \\
\hline General (driver + passengers) & 63 & 97 & 93 & 95 \\
\hline Driver & & 97 & 93 & 95 \\
\hline Passenger & & 96 & 94 & 95 \\
\hline Urban roads (driver) & 46 & 98 & 93 & 94 \\
\hline Rural roads (driver) & 62 & 96 & 94 & 95 \\
\hline \multicolumn{5}{|l|}{ Rear seats } \\
\hline General & & 88 & 93 & 98 \\
\hline Children (use of child restraint) & & 98 & & \\
\hline
\end{tabular}

Helmet wearing is compulsory for all motorcycle and moped riders and the wearing rate is nearly $100 \%$. Safety helmets were made mandatory for cyclists up to the age of 15 in 2001 and up to 18 in 2006. The compulsory wearing of helmets for all cyclists is under discussion.

\section{National road safety strategies and targets Organisation of road safety}

BESIP (Bezpečnost silničního provozu), an independent department of the Ministry of Transport, is the main co-ordinating body for road traffic in the Czech Republic. BESIP is responsible for the National Road Safety Strategy for 2011-20. The other key player is the Government Council of Road Traffic Safety (composed of representatives of parliament, ministries, civil associations, professional organisations and the private sector). There are also 14 regional BESIP co-ordinators.

\section{Road safety strategy for 2011-20}

The main target of the National Road Safety Strategic Plan for the years 2011-20 is to decrease the fatality rate (deaths per 100000 inhabitants) to the European average. This corresponds approximately to a $60 \%$ reduction in fatalities by 2020 compared to 2009 . The second target is a reduction by $40 \%$ in the number of persons seriously injured.

Interim targets for the number of fatalities and persons seriously injured have been set for each year until 2020. Results are monitored annually by the BESIP for the Government Council of Road Traffic Safety at national and regional levels.

While the country was on track in 2013, the interim targets between 2014 and 2016 were not achieved. In view of this unfavourable development, an in-depth revision of the national strategy is being undertaken. The main targets have not been changed, however new sub targets have been introduced. There are new sub targets for right of way, overtaking and goods vehicles.

New measures are needed to get back on track towards the 2020 target, including more enforcement, traffic education, a strengthened driving license system, traffic infrastructure audit and inspection, and the penetration of safer vehicles into the fleet, etc. 
Figure 9.7. Trends in road fatalities towards national target

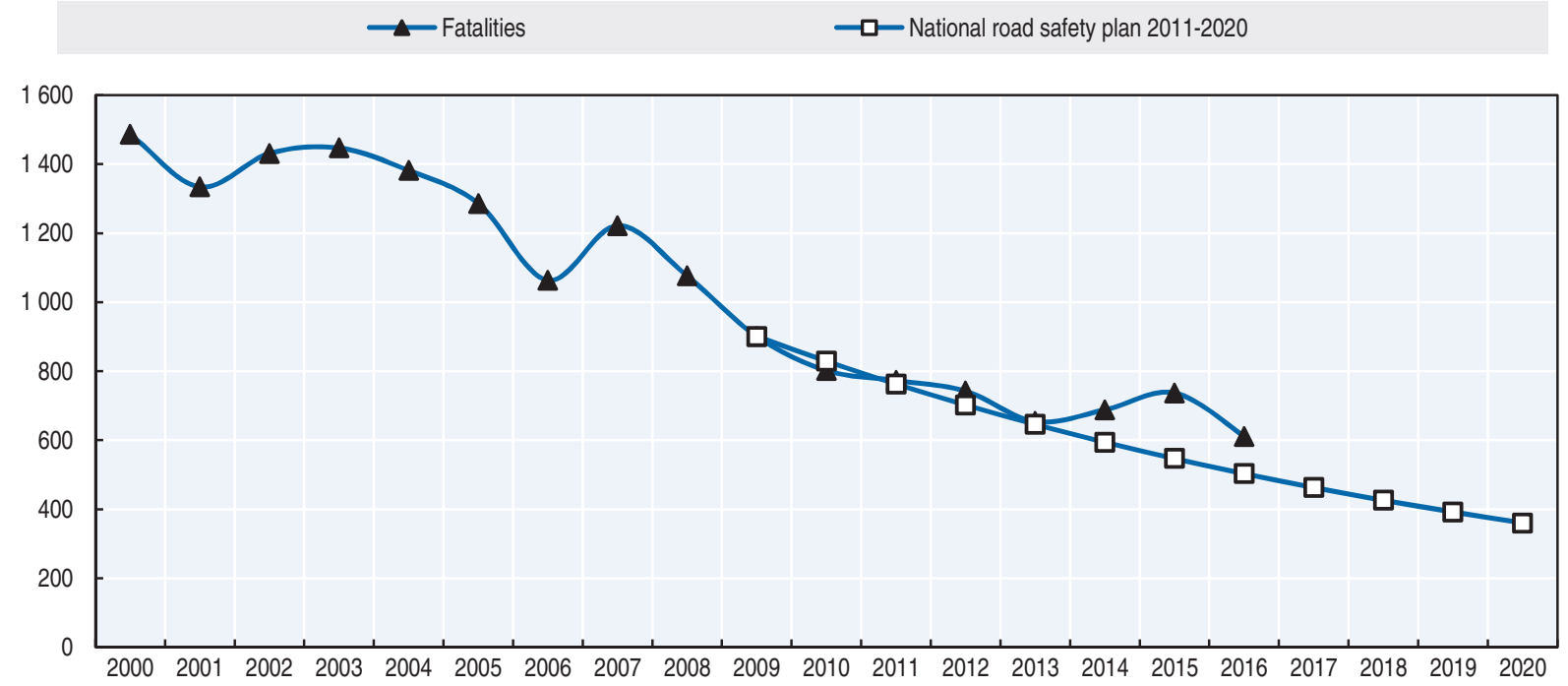

Figure 9.8. Trends in seriously injured towards national target

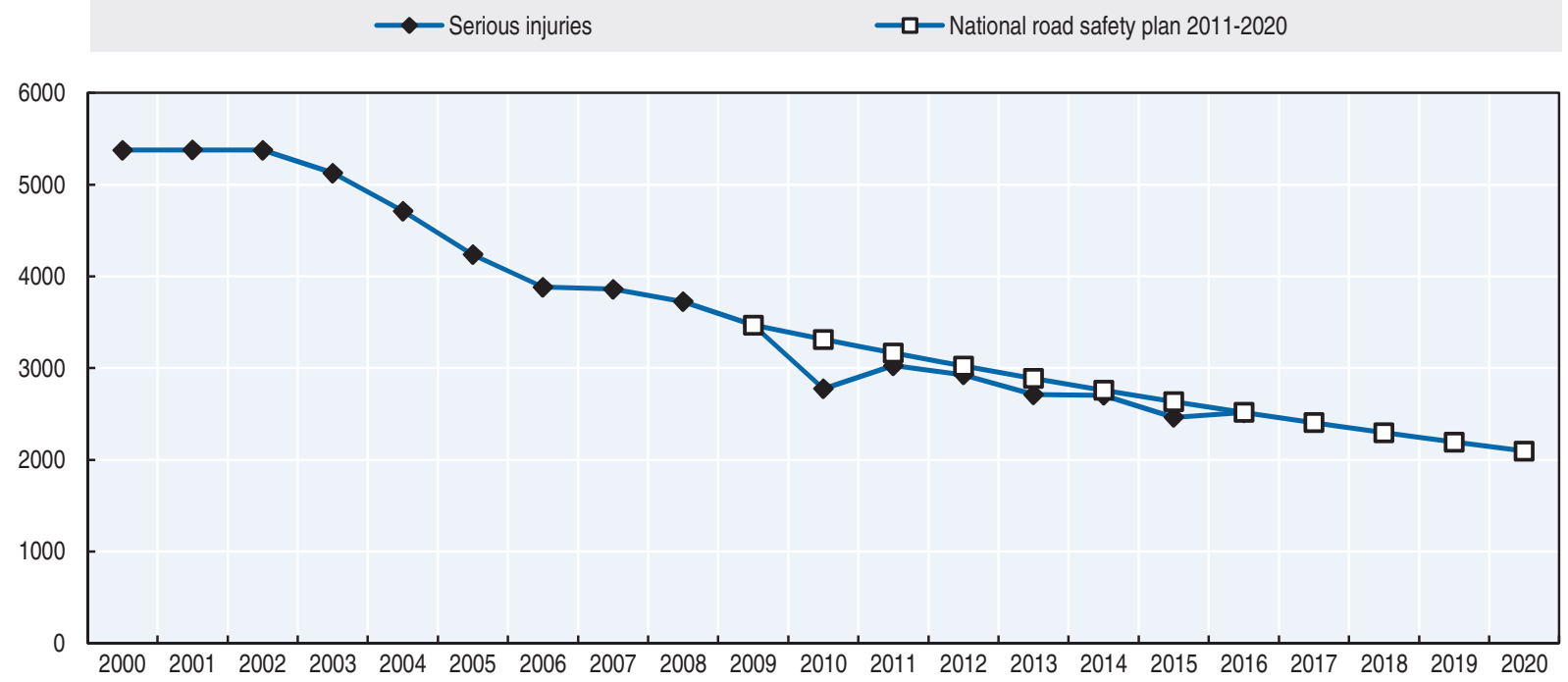

Recent safety measures (2014-17)

\section{Road safety management}

- Since 2014, the new civil code includes an article regarding higher financial compensation from the guilty drivers to the crash victim.

\section{Enforcement}

- The improvement of the penalty point system is under discussion.

- Traffic enforcement is being intensified.

- Implementation of transboundary enforcement.

- Increased penalties for driving on a railway crossing. 


\section{Speed management}

- Mobile speed cameras are being deployed.

\section{Road users}

\section{Protective equipment}

- The compulsory use of helmets by all cyclists is under discussion.

- Compulsory use of reflective jackets for pedestrians walking along rural roads.

\section{Traffic control}

- Systems to detect right-of-way violations are being implemented.

\section{Education and awareness}

- Work is underway to implement an improved curriculum in driving schools.

\section{Infrastructure}

- Since 1 January 2016, expressways are newly classified as 2nd class motorways. Second class motorways have slightly lower standards.

- Safety improvement of railway crossings has become a priority.

\section{Vehicles}

- Discussions are underway for Antilock Braking Systems (ABS) and Electronic Stability Control (ESC) to become standard equipment in new vehicles.

\section{Recent and ongoing research}

Some research projects of CDV include:

- in-depth accident analysis

- road infrastructure assessment

- safety improvement at railways crossings

- prediction models of crashes

- human factor analysis.

\section{References}

World Bank (2017), “GDP (constant US\$)”, World Development Indicators, http://databank.worldbank.org/ data/reports.aspx? source=world-development-indicators (accessed 23 February 2017).

\section{Websites}

- CDV, Transport Research Centre: www.cdv.cz (accessed 3 May 2017).

- Ministry of Transport: www.mdcr.cz (accessed 3 May 2017).

- Police of the Czech Republic: www.policie.cz (accessed 3 May 2017).

- Road safety observatory: www.czrso.cz (accessed 3 May 2017).

- In-depth accidents analysis: http://hadn.cduinfo.cz (accessed 3 May 2017).

- Road traffic infrastructure improvement: http://veobez.cdvinfo.cz (accessed 3 May 2017). 


\section{Chapter 10}

\section{Denmark}

This chapter presents 2015 road safety data for Denmark along with provisional data from 2016. It looks at trends in traffic and road safety from the years 1990 to 2015 and road user behaviour patterns including a focus on the ageing population. Sections include data on speed, drink driving, drugs and driving, distracted driving, fatigue and seat belt usage. The chapter reviews Denmark's road safety strategy and national targets to 2020 and the progress achieved thus far. It also provides details of all recently implemented safety measures and current and ongoing research.*

* All data stem from the Danish Road Directorate and IRTAD unless otherwise noted. For more information please contact: Stig R. Hemdorff, Traffic Safety Department, Road Directorate, srh@vd.dk. 
$\mathrm{D}$ enmark continued its positive trend in road safety in 2015 with 178 fatalities, a 2.2\% decrease over 2014. Injury crashes and the number of persons injured also decreased. The fatality rate in 2015 dropped to 3.1 per 100000 inhabitants. Car occupants benefited the most from the reduction in fatalities in 2015 with a $17 \%$ decrease, whereas riders of powered two-wheelers and pedestrians saw an increase in fatalities. Provisional data from 2016 indicate a substantial 19.5\% increase to 211 fatalities.

\section{Road safety data collection}

\section{Definitions applied in Denmark}

- Road fatality: Person who dies within 30 days as a result of a traffic crash.

- Seriously injured persons: Those included in the police report under bodily injury and any type of injury other than "minor injuries only".

- Slightly injured persons: Persons suffering from minor injuries only.

\section{Data collection}

Traffic crash data are collected by the police using a common national system. Data are transferred to the Road Directorate every week. These data contain preliminary and final information. Final information about a crash should be sent within six weeks following the incident. This, however, is not always the case. In particular, information about alcohol levels awaiting laboratory analysis might delay the process.

In the Danish system, there are more than 90 different parameters for crash data. Some may be subjective. For example, "speed driven before the crash" is filled in by the police officer on the basis of witness statements. More accurate speed information is obtained when investigating fatal accidents or others chosen for in-depth study.

Serious injuries data are based solely on police reports, and the severity of injuries is based upon the judgement of the police officer. A hospital may be contacted to obtain additional information, but there is no systematic linkage with hospital data. Currently, a linking procedure is not possible as the Danish hospital registration system does not include the Abbreviated Injury Scale (AIS) score of patients; only diagnosis codes are included. Denmark is working on a process to convert diagnosis codes into AIS and Maximum Abbreviated Injury Scale (MAIS) scores.

Details of traffic-related casualties are recorded in the national patient register. Information from the national patient register reveals that the real number of injury crashes is much higher than those recorded by the police. Injuries to vulnerable road users are particularly underreported in police records.

The weakness of the national patient register is that there is little information on the accident compared to police records. For example, there is little indication of the crash location and no information on vehicle occupancy. 


\section{Most recent safety data}

\section{Road crashes in 2016 - provisional data}

Preliminary data for 2016 show an increase in the number of fatalities and injured people compared to 2015 levels. Based on provisional data, there were 211 road fatalities in 2016, a 19.5\% increase over the previous year, and 3228 injured people, an increase of 5\%.

\section{Road crashes in 2015}

In 2015, all crash and casualty figures went down compared to 2014. The number of road fatalities decreased by $2 \%$, the number of injury crashes by $1 \%$ and the number of hospitalised casualties by $6 \%$.

The fall in the number of fatalities was due in large part to a $17 \%$ decrease in the number of car occupant fatalities. On the other hand, the number of pedestrians and riders of powered two-wheelers killed in traffic increased during the same time period.

The fatality rate per 100000 population decreased in 2015 by nearly $3 \%$ compared to 2014. The rates per 10000 registered vehicles, as well as per vehicle kilometres travelled decreased equally, by about $4 \%$ and $5 \%$, for the same time period.

\section{Trends in traffic and road safety (1990-2016) Traffic}

Between 1990 and 2015, the number of motorised vehicles increased by $46.5 \%$ and the overall vehicle kilometres travelled increased by around $42 \%$.

In 2015 , the number of motorised vehicles increased by $1.6 \%$ and traffic volume increased by nearly 3\% over 2014.

\section{Road safety \\ Crashes and casualties}

The year with the fewest road deaths in Denmark since registration started in the 1930s was in 2012, with 167 deaths. Between 1990 and 2012, the number of fatalities decreased by nearly 70\%. Between 2008 and 2012, the reduction in fatalities accelerated, with a nearly 60\% reduction overall. In 2009, there was a 25\% decrease in the number of road deaths over 2008. In 2007 and 2008 there had been an increase of about 100 road deaths, a phenomenon which cannot really be explained. However, the former decreasing trend continued in the following years.

Effective safety measures, tough winter conditions in 2010 and 2011, and possibly the economic downturn might explain this sharp decrease in fatalities. There are also indications that although mean speeds have decreased only slightly, the top speeds have reduced more significantly. This may be more related to saving fuel, which became more expensive. Finally, the penetration of new vehicles with advanced safety equipment into the fleet has also had a positive impact.

The year 2013 saw an increase in road deaths compared to 2012, but in 2014 the trend was downward once again and this was also sustained in 2015.

\section{Rates}

Since 2000, both the mortality rate (expressed in deaths per 100000 inhabitants) and the fatality risk (expressed in deaths per billion vehicle-kilometres) have decreased by about 
$65 \%$. In 2012, Denmark had a mortality rate of 3.0 per 100000 inhabitants, one of the lowest rates among countries in the Organisation for Economic Development and Co-operation (OECD). The rate slightly increased to 3.4 in 2013, but it decreased to 3.2 in 2014.

Table 10.1. Road safety and traffic data

\begin{tabular}{|c|c|c|c|c|c|c|c|c|c|}
\hline & \multirow{2}{*}{1990} & \multirow{2}{*}{2000} & \multirow{2}{*}{2010} & \multirow{2}{*}{2014} & \multirow{2}{*}{2015} & \multicolumn{4}{|c|}{$2015 \%$ change from } \\
\hline & & & & & & 2014 & 2010 & 2000 & 1990 \\
\hline \multicolumn{10}{|l|}{ Reported safety data } \\
\hline Fatalities & 634 & 498 & 255 & 182 & 178 & -2.2 & -30.2 & -64.3 & -71.9 \\
\hline Injury crashes & 9155 & 7346 & 3498 & 2881 & 2853 & -1.0 & -18.4 & -61.2 & -68.8 \\
\hline Injured persons hospitalised & 5347 & 4366 & 2071 & 1556 & 1465 & -5.8 & -29.3 & -66.4 & -72.6 \\
\hline Deaths per 100000 population & 12.3 & 9.3 & 4.6 & 3.2 & 3.1 & -2.8 & -31.7 & -66.3 & -74.5 \\
\hline Deaths per 10000 registered vehicles & 3.1 & 2.1 & 0.9 & 0.6 & 0.6 & -3.7 & -33.4 & -71.6 & -80.8 \\
\hline Deaths per billion vehicle kilometres & 17.3 & 10.7 & 5.6 & 3.6 & 3.4 & -4.9 & -39.6 & -68.0 & -80.3 \\
\hline \multicolumn{10}{|l|}{ Traffic data } \\
\hline Registered vehicles ${ }^{1}$ (thousands) & 2068 & 2409 & 2892 & 2982 & 3029 & 1.6 & 4.7 & 25.7 & 46.5 \\
\hline Vehicle kilometres (millions) & 36600 & 46753 & 45432 & 50692 & 52151 & 2.9 & 14.8 & 11.5 & 42.5 \\
\hline Registered vehicles per 1000 population & 403 & 452 & 523 & 530 & 535 & 1.0 & 2.4 & 18.4 & 32.9 \\
\hline
\end{tabular}

1. Registered vehicles excluding mopeds.

Figure 10.1. Road safety, traffic and GDP trends index $1990=100$

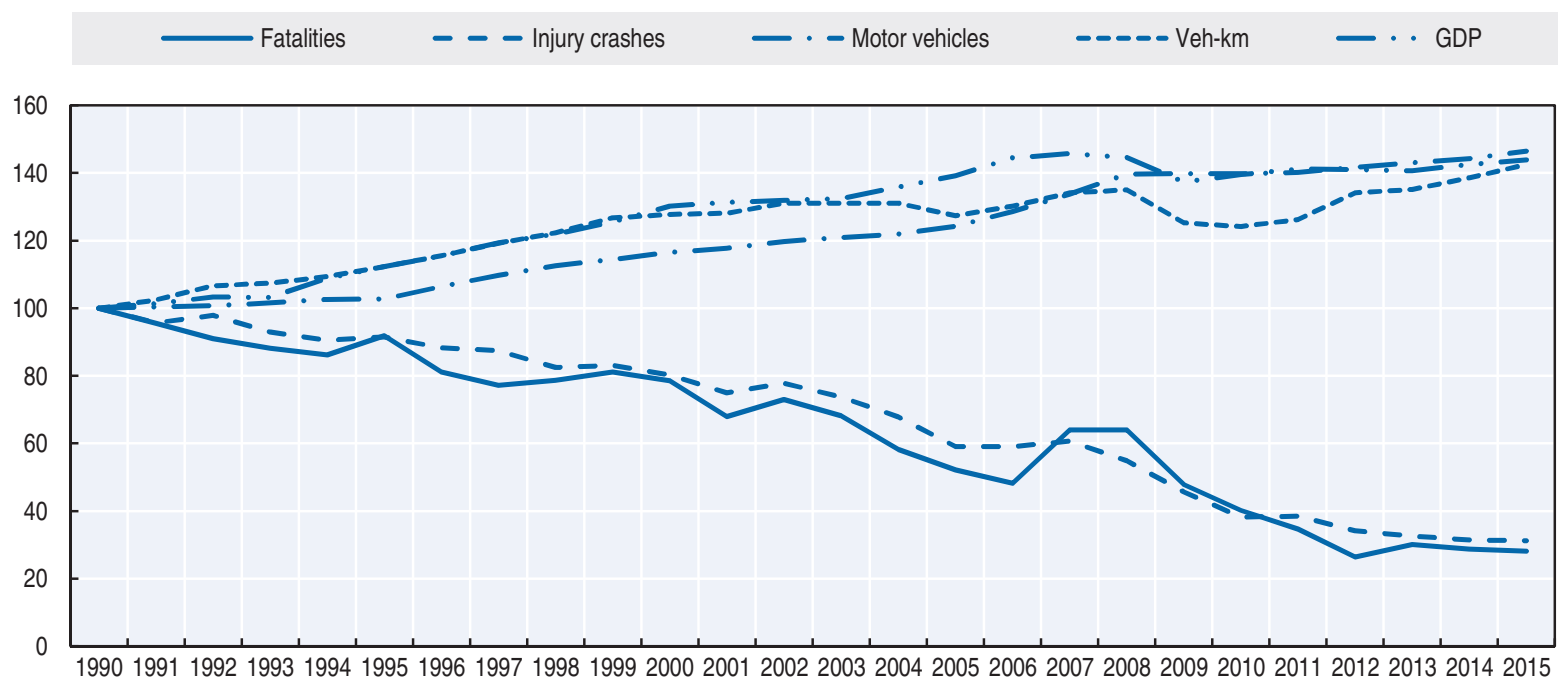

Source: World Bank (2017) (GDP; constant prices).

\section{Road safety by user group}

Looking at those killed and injured by road user group there has been a steady decrease for cars and mopeds since the end of 2004. For pedestrians and cyclists there was a decreasing trend up until the beginning of 2013 after which it levelled out. For motorcyclists there has been an increase since the end of 2012. Motorcyclists have seen the least progress since the end of 2004. The downward trend for car occupants is partly due to the renewal of the fleet, as old cars are substituted by newer cars with more safety equipment.

In 2015 , a decrease of $17 \%$ was observed for passenger car occupants and fatalities among cyclists decreased by more than $13 \%$. However, there was an increase in pedestrian 
fatalities (from 22 to 27) and moped riders (from 13 to 19). Absolute numbers are relatively low to be able to draw any conclusions.

Table 10.2. Road fatalities by road user group

\begin{tabular}{|c|c|c|c|c|c|c|c|c|c|}
\hline \multirow{2}{*}{ Road users } & \multirow{2}{*}{1990} & \multirow{2}{*}{2000} & \multirow{2}{*}{2010} & \multirow{2}{*}{2014} & \multirow{2}{*}{2015} & \multicolumn{4}{|c|}{$2015 \%$ change from } \\
\hline & & & & & & 2014 & 2010 & 2000 & 1990 \\
\hline Pedestrians & 118 & 99 & 44 & 22 & 27 & 22.7 & -38.6 & -72.7 & -77.1 \\
\hline Cyclists & 110 & 58 & 26 & 30 & 26 & -13.3 & 0.0 & -55.2 & -76.4 \\
\hline Moped riders & 44 & 47 & 11 & 13 & 19 & 46.2 & 72.7 & -59.6 & -56.8 \\
\hline Motorcyclists & 39 & 24 & 22 & 18 & 19 & 5.6 & -13.6 & -20.8 & -51.3 \\
\hline Car occupants & 284 & 239 & 137 & 89 & 74 & -16.9 & -46.0 & -69.0 & -73.9 \\
\hline Others & 39 & 31 & 15 & 10 & 13 & 30.0 & -13.3 & -58.1 & -66.7 \\
\hline Total & 634 & 498 & 255 & 182 & 178 & -2.2 & -30.2 & -64.3 & -71.9 \\
\hline
\end{tabular}

Figure 10.2. Road fatalities by road user group in percentage of total, 2015

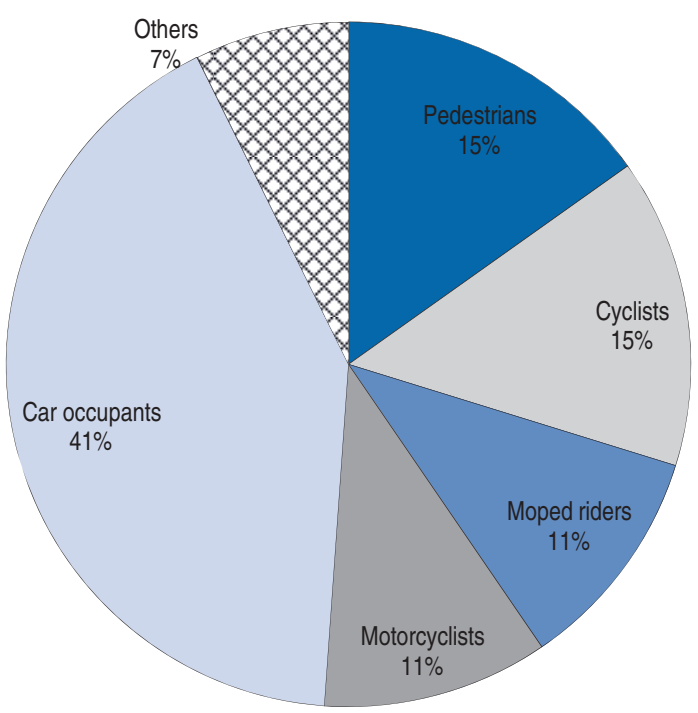

\section{Road safety by age group}

Since 1990, all age groups have shared in the reduction in fatalities, with the biggest decrease of $88 \%$ observed among 0-17 year olds. The over 65 age group benefited from safety improvements the least, with a reduction of 15\% between 1990 and 2015.

In 2015, fatalities increased among 15-24 year olds and those 85 years and older. This increase was offset, however, by fatality reductions among the 25-64 and 65-74 age groups. 
Table 10.3. Road fatalities by age group

\begin{tabular}{|c|c|c|c|c|c|c|c|c|c|}
\hline \multirow{2}{*}{ Age } & \multirow{2}{*}{1990} & \multirow{2}{*}{2000} & \multirow{2}{*}{2010} & \multirow{2}{*}{2014} & \multirow{2}{*}{2015} & \multicolumn{4}{|c|}{$2015 \%$ change from } \\
\hline & & & & & & 2014 & 2010 & 2000 & 1990 \\
\hline $0-14$ & 48 & 25 & 9 & 6 & 6 & 0.0 & -33.3 & -76.0 & -87.5 \\
\hline $15-17$ & 35 & 30 & 8 & 3 & 4 & 33.3 & -50.0 & -86.7 & -88.6 \\
\hline $18-20$ & 46 & 30 & 24 & 9 & 12 & 33.3 & -50.0 & -60.0 & -73.9 \\
\hline $21-24$ & 57 & 55 & 18 & 13 & 20 & 53.8 & 11.1 & -63.6 & -64.9 \\
\hline $25-64$ & 257 & 224 & 129 & 93 & 87 & -6.5 & -32.6 & -61.2 & -66.1 \\
\hline $65-74$ & & 48 & 24 & 29 & 15 & -48.3 & -37.5 & -68.8 & \\
\hline $75-84$ & & 60 & 29 & 18 & 19 & 5.6 & -34.5 & -68.3 & \\
\hline$\geq 85$ & & 26 & 14 & 11 & 15 & 36.4 & 7.1 & -42.3 & \\
\hline Total incl. unknown & 634 & 498 & 255 & 182 & 178 & -2.2 & -30.2 & -64.3 & -71.9 \\
\hline
\end{tabular}

Figure 10.3. Road fatality rates by age group Deaths per 100000 inhabitants in a given age group, 1990-2015

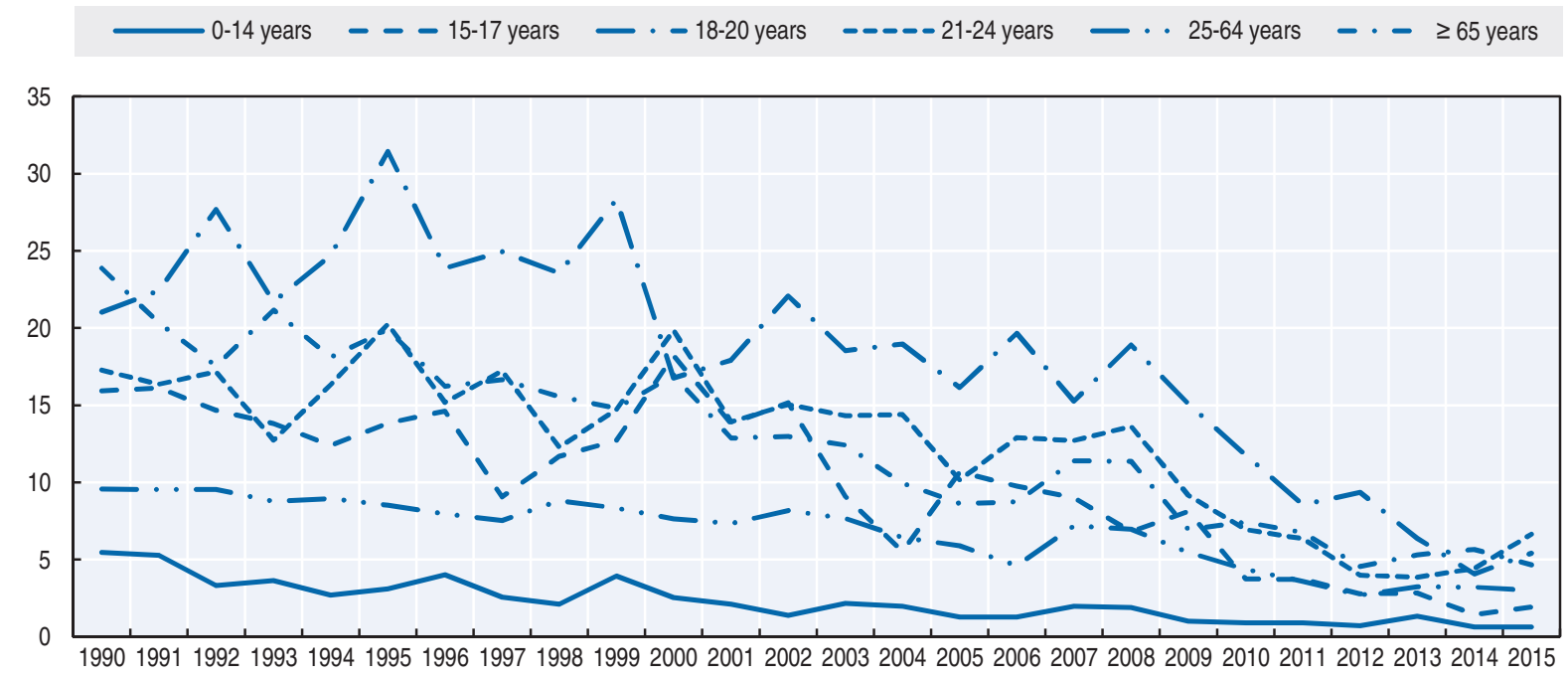

\section{Box 10.1. Road safety for an ageing population}

In 2015 , the senior population aged 65 or above represented $18.6 \%$ of the population and $27 \%$ of all road deaths.

The senior population are particularly vulnerable as pedestrians and cyclists with a relatively high mortality rate compared to other age groups, reflecting the fact that cycling is also a popular transport means among those who are 65 and over. Since 2013, Denmark has seen an increase in the use of E-bikes, in particular among the older population. As a result, the number of fatalities and injuries in the $65+$ age group is increasing. In 2015 this group comprised 18\% of all fatalities and injuries among cyclists.

Persons aged 85 and over have a marked higher risk. 
Box 10.1. Road safety for an ageing population (cont.)

Table 10.4. Road fatalities among senior citizens

\begin{tabular}{lcc|cc|cc}
\hline & \multicolumn{2}{c|}{$65-74$} & \multicolumn{2}{c|}{$75-84$} & \multicolumn{2}{c}{$85+$} \\
\cline { 2 - 7 } & 2010 & 2015 & 2010 & 2015 & 2010 & 2015 \\
\hline Pedestrians & 5 & 5 & 8 & 2 & 6 & 4 \\
Cyclists & 6 & 3 & 7 & 7 & 0 & 6 \\
Moped riders & 0 & 1 & 1 & 2 & 2 & 1 \\
Motorcyclists & 1 & 1 & 0 & 1 & 0 & 0 \\
Car occupants & 12 & 5 & 12 & 7 & 6 & 4 \\
Total & $\mathbf{2 4}$ & $\mathbf{1 5}$ & $\mathbf{2 9}$ & $\mathbf{1 9}$ & $\mathbf{1 4}$ & $\mathbf{1 5}$ \\
\hline
\end{tabular}

Figure 10.4. Road fatality rates in the $65+$ age groups Deaths per 100000 inhabitants in a given age group, 2000-15

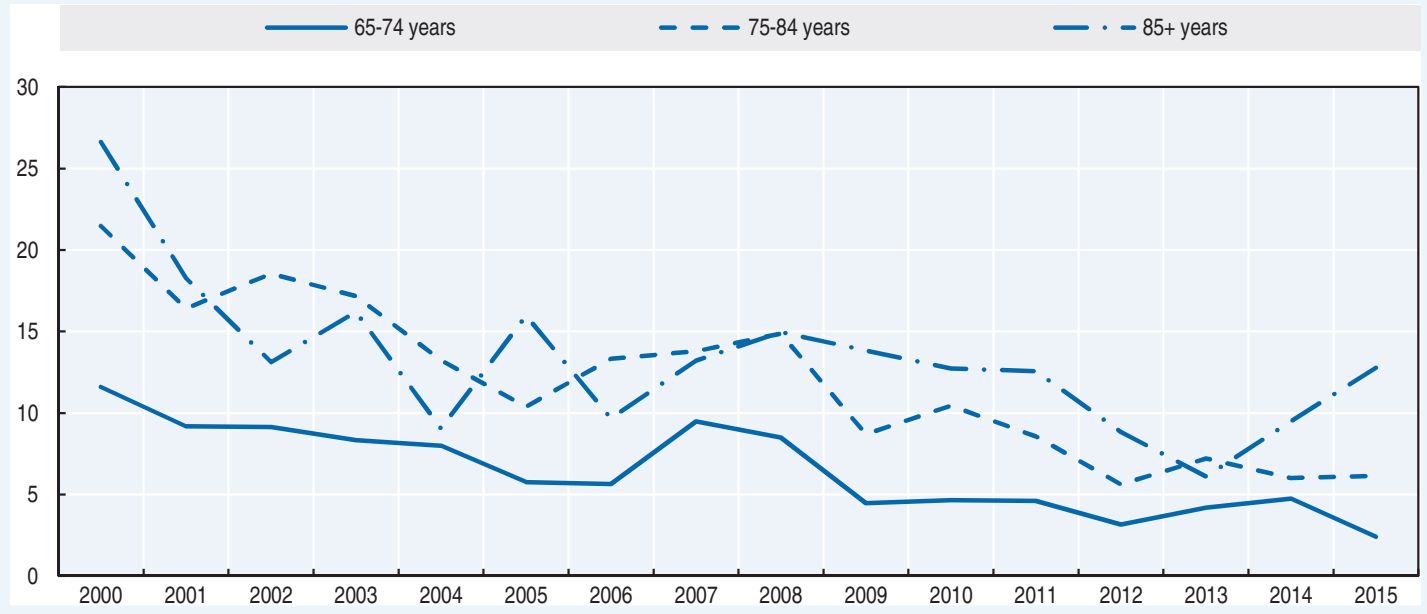

Figure 10.5. Road fatality rate by age and road user group Fatalities per 100000 inhabitants, 2015

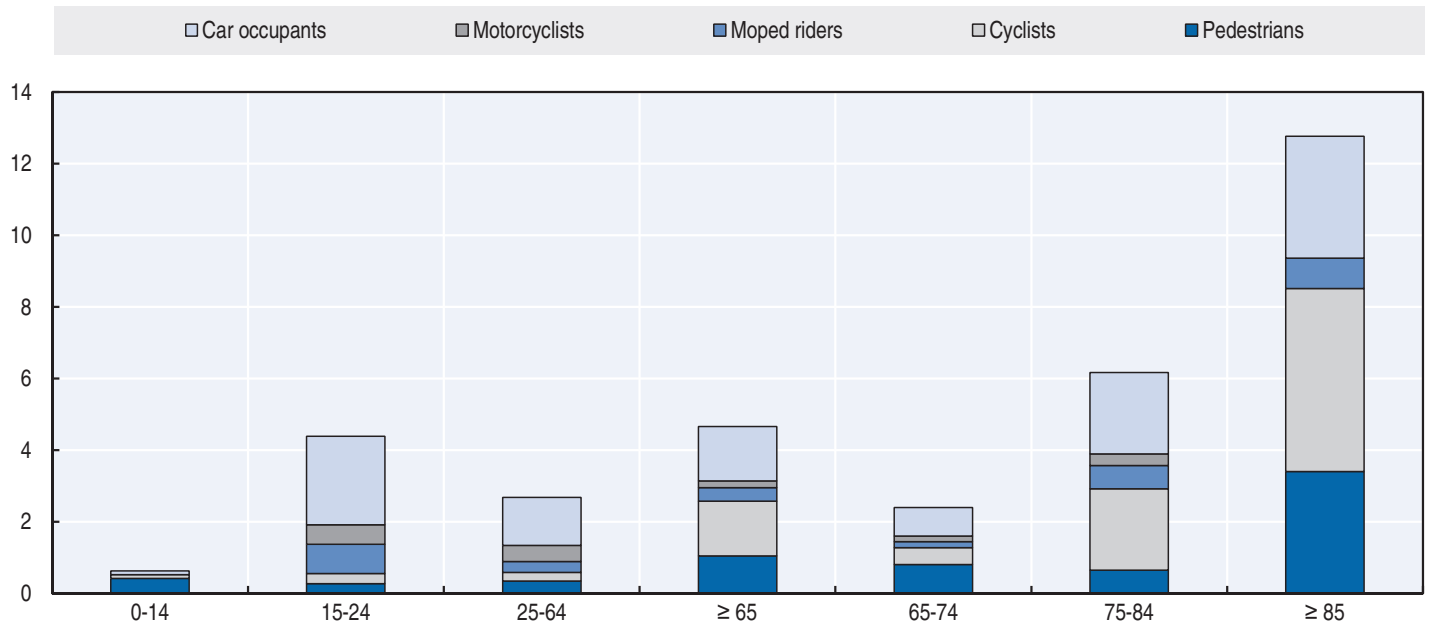




\section{Road safety by road type}

In $2015,56 \%$ of fatalities occurred on rural roads, $35 \%$ in urban areas and $9 \%$ on motorways. Since the 1990s, the greatest reduction in fatalities occurred on urban roads $(-75 \%)$, which can be partly explained by a change in traffic patterns. Another explanation is that automatic speed controls were first introduced in urban areas. In addition, speeds are higher on rural roads, resulting in more severe injuries. It should be noted, however, that the general speed level continued to decrease slightly during 2015.

Figure 10.6. Road fatalities by road type

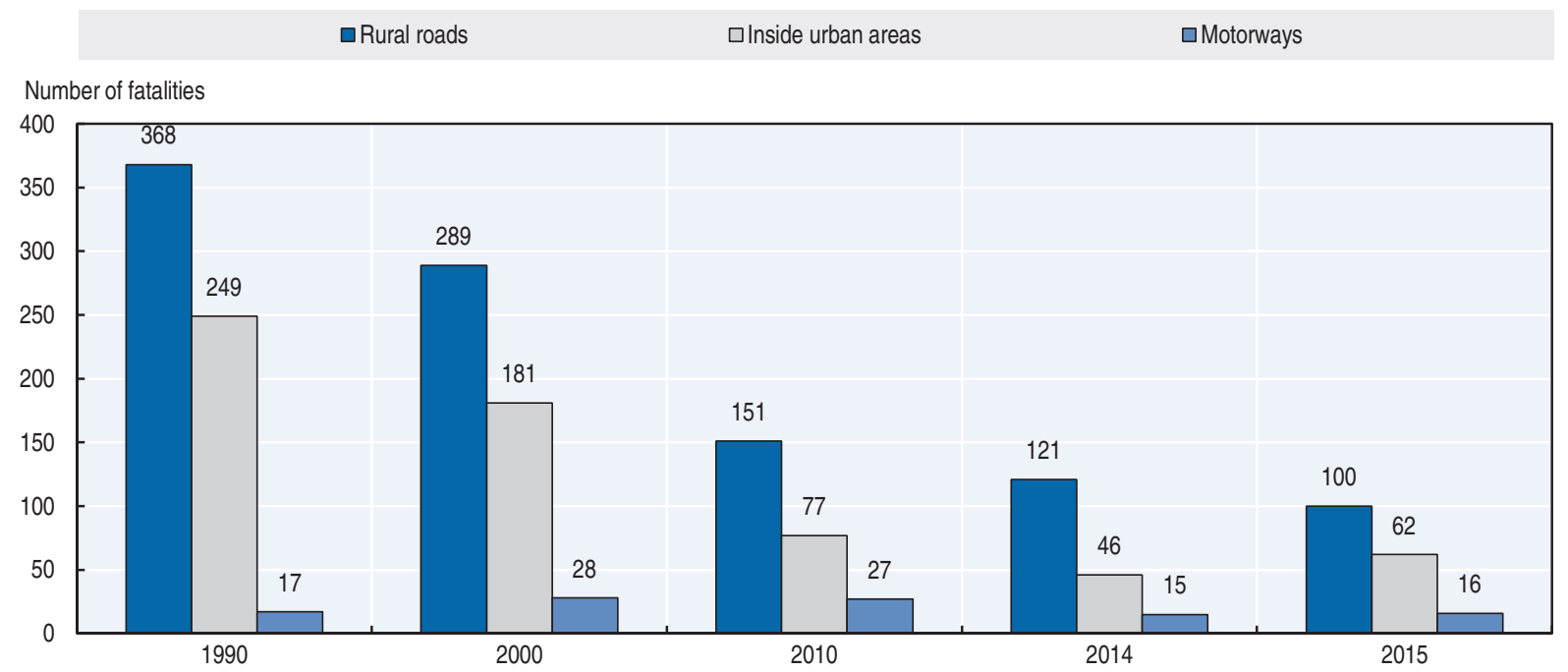

\section{Economic costs of traffic crashes}

The socio-economic costs of road crashes are calculated using so called transport economic unit prices. These are regularly calculated and updated by the Department of Transport at the Technical University of Denmark.

Unit prices for the socio-economic costs of road crashes include not only directly measurable expenses - such as hospital and health care charges, the cost of police and emergency services, lost earnings and the cost of material damage - but also the so-called welfare loss, representing a valuation for lost lives and capacity. The welfare loss can be taken as an expression of what road users think it is "worth" to prevent road crashes over and above directly measurable costs (COWI, 2010).

Traffic crashes are estimated on the basis of unit costs for deaths, severely injured persons and slightly injured persons.

In 2015, the cost of traffic crashes was around EUR 1.9 billion.

Table 10.5. Cost of road crashes, 2015

\begin{tabular}{|c|c|c|}
\hline Cost (EUR) & Unit cost & Total costs \\
\hline Fatalities & & EUR 709 million \\
\hline Seriously injured persons & & EUR 1120 million \\
\hline Slight injuries & & EUR 113 million \\
\hline Property damage costs & & Included in the above \\
\hline Total (EUR) & & EUR 1.9 billion \\
\hline
\end{tabular}




\section{Recent trends in road user behaviour}

\section{Speed}

Speeding is thought to be a contributing factor in around $40 \%$ of fatal crashes.

The table below summarises the main speed limits in Denmark. There is no reduced speed limit for young drivers.

Table 10.6. Passenger car speed limits by road type, 2017

\begin{tabular}{lrl}
\hline & General speed limit & Comments \\
\hline Urban roads & $50 \mathrm{~km} / \mathrm{h}$ & For heavy vehicles $50 \mathrm{~km} / \mathrm{h}$ is the maximum limit, even if there is a higher local limit. \\
Rural roads & $80 \mathrm{~km} / \mathrm{h}$ & \\
Motorways & $130 \mathrm{~km} / \mathrm{h}$ & About half of the motorway network has a signed speed limit of $110 \mathrm{~km} / \mathrm{h}$ especially around cities
\end{tabular}

The Road Directorate regularly publishes a speed barometer, where the speed development on different road types is monitored. Over time, there is a general decline in the mean speed. The decrease in mean speed during 2015 and 2016 might be due to the introduction of additional speed cameras.

\section{Drink driving}

The maximum authorised blood alcohol content (BAC) is $0.5 \mathrm{~g} / \mathrm{l}$ for drivers of any motorised vehicle requiring a driving licence (including professional drivers). There is no maximum authorised BAC for cyclists or pedestrians. The penalty is higher for novice drivers who have had their licence for fewer than three years.

Over the past five years alcohol-related injury crashes have decreased more than the general decrease. This can be explained to a certain extent by ongoing awareness campaigns and a low social acceptance of drunk driving. In 2015, $12 \%$ of the personal injury crashes involved alcohol.

\section{Drugs and driving}

Since 1 July 2007, the Traffic Act has included a zero tolerance level for driving under the influence of drugs. Since then, as a result of better monitoring, there has been an increase in numbers of drug-related crashes. This is because before 1 July 2007, police were responsible for proving that the use of drugs had influenced a crash. Police often did not investigate any further or register it in the statistics as drug related.

\section{Seat belts and helmets}

Seat belt use has been compulsory in front seats since the early 1970s and in rear seats since the late 1980s. Rear seat belts are not compulsory in cars made before 1990, and very old cars need not have front seat belts either. Such cars account for a very low share of the Danish car fleet.

Child restraints are also compulsory. Small children, typically up to 3-4 years old have to use special designed "baby-chairs". Children over this age can use a child seat connected to the safety belt. When they reach the height of $140 \mathrm{~cm}$, normal seat belt use is permitted.

Helmets are required to be worn by all motorcycle and moped riders. The compliance rate by motorcyclists was around 97\% in 2014. This rate has been constant as of 2006.

There is no mandatory helmet use law for cyclists. 
Table 10.7. Seat belt wearing rate by car occupancy and road type

\begin{tabular}{|c|c|c|c|}
\hline & 2010 & 2012 & 2014 \\
\hline \multicolumn{4}{|l|}{ Front seat } \\
\hline General (driver + passengers) & 92 & 94 & 96 \\
\hline \multicolumn{4}{|l|}{ Driver } \\
\hline \multicolumn{4}{|l|}{ Passenger } \\
\hline Urban roads (driver) & 90 & 94 & \\
\hline Rural roads (driver) & 95 & 95 & \\
\hline \multicolumn{4}{|l|}{ Motorways (driver) } \\
\hline \multicolumn{4}{|l|}{ Rear seats } \\
\hline General & 76 & 81 & 85 \\
\hline Children (use of child restraint) & & & \\
\hline
\end{tabular}

\section{Distraction}

Distraction is becoming an important factor to be analysed in explaining crash circumstances. In 2014, inattention is thought to have been a contributing factor in $35 \%$ of fatal crashes.

The fatal accident investigations and in-depth investigations have shown that distraction is often an issue both inside and outside the vehicle. Therefore external distraction has become a special focus of the new Danish Traffic Safety Action Plan.

Driving while using a hand-held mobile phone is not allowed. The use of hands-free devices is legal.

\section{National road safety strategies and targets Organisation of road safety}

There is no leading agency as such concerning traffic safety in Denmark. The responsibility is held by the ministries of transport, justice, interior and health, associated agencies and in the municipalities. Overall, this organisation works well because stakeholders share the same goal and work in close co-operation with each other. The Danish Road Safety Commission is an advisory body composed of politicians from each party in the parliament and technical advisors. It sets targets and areas for interaction. It does not manage a budget, so it is up to stakeholders to take up their recommendations.

Traffic safety work in Denmark is very locally based.

\section{Road safety strategy for 2011-20}

In May 2013, the new Traffic Safety Action Plan was launched with the following slogan "Every accident is one too many - a shared responsibility". The Action Plan includes ten focus areas.

\section{Road safety targets}

The Danish Road Safety Commission has set ambitious targets for 2020: no more than 120 deaths, 1000 serious injuries and 1000 minor injuries by 2020. This follows the European Union objective to halve the number of fatalities by 2020 in comparison to 2010 . This is a more ambitious target than in previous action plans, and the aim is to reach the objective in a shorter timeframe. 
For each focus area, a set of suggested measures has been proposed and a performance indicator defined. The 10 focus areas will be reviewed on a regular basis up until 2020 by establishing measurement points as a basis for necessary actions.

Table 10.8. Traffic safety action plan focus areas

\begin{tabular}{|c|c|}
\hline Focus areas & Indicators \\
\hline 1. Speeding & Proportion of journeys exceeding the speed limit \\
\hline 2. Alcohol and drugs & $\begin{array}{l}\text { Number of road users killed and injured in accidents where at least one driver of a motor vehicle } \\
\text { has a blood alcohol level over } 0.5 \mathrm{~g} / \mathrm{l}\end{array}$ \\
\hline 3. Inattention & Proportion of drivers who admit to engaging in distracting actions while driving: \\
\hline 4. Failure to wear seat belts and helmets & $\begin{array}{l}\text { Proportion of drivers and passengers who wear seat belts: } \\
\text { Proportion of adult cyclists wearing helmets }\end{array}$ \\
\hline 5. Pedestrians & Number of pedestrians killed and injured \\
\hline 6. Cyclists and moped riders & Number of cyclists and moped riders killed and injured \\
\hline 7. Young drivers under 24 & Number of deaths and injuries in accidents involving at least one car driver under 24 years old \\
\hline 8. Accidents with oncoming traffic & Number of persons killed and injured in accidents with oncoming traffic \\
\hline 9. Single-vehicle accidents & Number of persons killed and injured in single-vehicle accidents \\
\hline 10. Accidents at rural junctions & Number of persons killed and injured in accidents at rural junctions \\
\hline
\end{tabular}

Figure 10.7. Trends in road fatalities towards national target

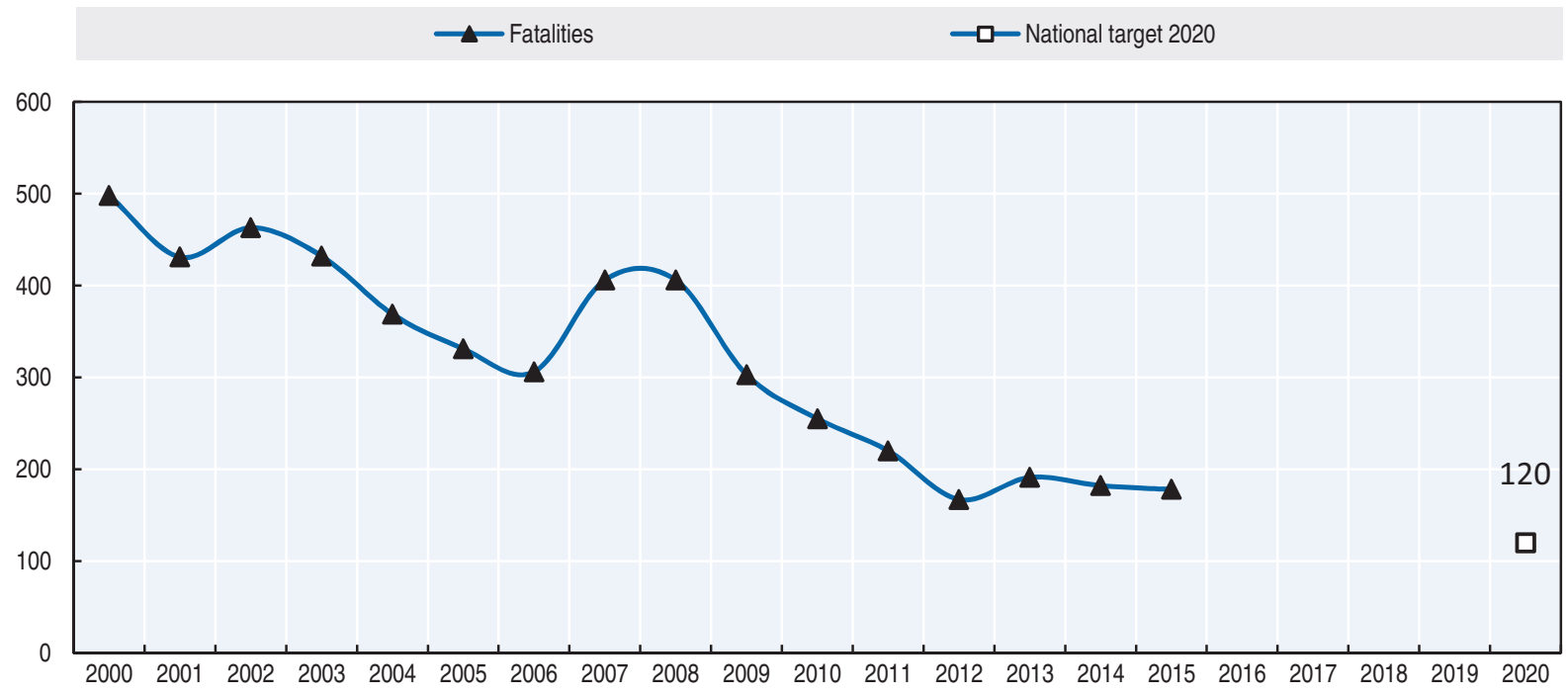

\section{Recent safety measures (2014-17)}

There have not been any major new measures implemented.

\section{Recent and ongoing research}

Some research projects are presented below.

- A New Method for Identifying Hazardous Road Locations Using GPS and Accelerometer. Reinau, Kristian Hegner; Andersen, Camilla Sloth; Agerholm, Niels, Proceedings of 23rd World Congress on Intelligent Transport Systems: Melbourne 2016, http://vbn.aau.dk/da/ publications/a-new-method-for-identifying-hazardous-road-locations-using-gps-andaccelerometer(c1bb3ed7-dec6-48b4-9c5f-d83b64dd69df).html (accessed 20 June 2017). 
- Review of current study methods for VRU safety: Appendix 7 - Systematic literature review: Self-reported accidents. Andersen, Camilla Sloth; Kamaluddin, Noor Azreena; Várhelyi, András; Madsen, Tanja Kidholm Osmann; Møller, Katrine Meltofte. Warsaw Rapport: http:// ubn.aau.dk/da/publications/review-of-current-study-methods-for-vru-safety(2b3a6a8f-cf24-43a09ee7-f4b6f853c319).html (accessed 20 June 2017).

- Comparison of five bicycle facility designs in signalized intersections using traffic conflict studies. Madsen, Tanja Kidholm Osmann; Lahrmann, Harry Spaabæk.

- Factors contributing to young moped rider accidents in Denmark: http://orbit.dtu.dk/en/ publications/factors-contributing-to-young-moped-rider-accidents-in-denmark(beb0b9c5-464d4d72-907d-b6ebe3e9a324).html (accessed 20 June 2017).

- E-bike safety: Individual-level factors and incident characteristics: http://orbit.dtu.dk/en/ publications/ebike-safety-individuallevel-factors-and-incident-characteristics(17ab9d75-ae5f4fcb-bd38-4844d725df08).html (accessed 20 June 2017).

- Understanding traffic crash under-reporting: Linking police and medical records to individual and crash characteristics: http://orbit.dtu.dk/en/publications/understanding-trafficcrash-underreporting(d2f32df1-ed01-4e54-bd5d-e7063ee32767).html (accessed 20 June 2017).

- Statistical modelling of the frequency and severity of road accidents: http://orbit.dtu.dk/en/ publications/statistical-modelling-of-the-frequency-and-severity-of-road-accidents(b1b7279327c6-4191-8651-8df9e58fb9b9).html (accessed 20 June 2017).

- Investigating the reasons behind the intention to report cycling crashes to the police and hospitals in Denmark: http://orbit.dtu.dk/en/publications/investigating-the-reasons-behindthe-intention-to-report-cycling-crashes-to-the-police-and-hospitals-in-denmark(850c1c20-40fc471d-9452-cf3feec3b2da).html (accessed 20 June 2017).

\section{References}

World Bank (2017), “GDP (constant US\$)”, World Development Indicators, http://databank.worldbank.org/ data/reports.aspx?source=world-development-indicators (accessed 23 February 2017).

\section{Websites}

- Danish Road Directorate www.vejdirektoratet.dk (accessed 20 June 2017).

- Technical University of Denmark www.transport.dtu.dk (accessed 20 June 2017).

- Aalborg University www.aau.dk/ (accessed 20 June 2017).

- The Danish Road Safety Commission National Action Plan 2013-20 www.faerdselssikkerhedskommissionen. $\mathrm{dk} /$ sites/kombelt.dev2.1508test.dk/files/filer/Danish\%20National\%20Action\%20plan\%202013-2020\%20\%E2 \%80\%9CEvery\%20Accident\%20is\%20one\%20too\%20many\%20\%E2\%80\%93\%20a\%20shared\%20responsibility.pdf (accessed 20 June 2017). 


\section{Chapter 11}

\section{Finland}

This chapter presents 2015 road safety data for Finland along with provisonal data from 2016. It looks at trends in traffic and road safety from the years 1990 to 2015 and road user behaviour patterns with a special focus on the ageing population. The following sections include data on speed, drink driving, drugs and driving, distracted driving, fatigue and seat belt use. The chapter reviews Finland's road safety strategy and national targets to 2020 and the progress achieved thus far. It also provides details of all recently implemented safety measures and current and ongoing research. ${ }^{*}$

* All data stem from the Finnish Transport Safety Agency (Trafi) and IRTAD unless otherwise noted. For more information please contact: riikka.rajamaki@trafi.fi. 
$\mathrm{T}$ he positive safety trend observed over recent years in Finland experienced a downward turn in 2015 with an increase in the number of fatalities by nearly 18\% to 270 . However, there was a decrease in the number of injury crashes $(-2.6 \%)$ and those seriously injured $(-8.1 \%)$. Decreases in fatalities were also seen amongst pedestrians and moped riders. In 2015, the mortality rate per 100000 inhabitants as well as per billion vehicle-kilometres was at 4.9. Provisional data from 2016 indicate an $11 \%$ decrease in fatalities to 240.

\section{Road safety data collection}

\section{Definitions applied in Finland}

- Road fatality: A person who died immediately in a crash or within the following 30 days. Suicides and presumed suicides are not removed from the statistics.

- Injured person (as defined in police reports): A person not fatally injured in a traffic crash, but requiring medical care or observation in hospital, treatment at home (sick leave) or surgical treatment, such as stitches. Persons who sustain bruises or scratches that do not require the aforementioned treatment are not accounted for as "injured". The classification "injured" is determined by the police officers present at the scene of the crash.

- Seriously injured person: A person who suffers injuries with a score of three or above on the Abbreviated Injury Scale (MAIS3+).

Data on serious injuries have been reported from 2014 onwards and are integrated into the Statistics Finland database. This contains crash data reported by the police, complemented by injury severity information coming from the health care database.

\section{Data collection}

Traffic crash data in Finland are collected through two different channels: the police and the insurance companies.

Statistics Finland receives data on road traffic crashes from the police. Local police districts transfer the data to a central register, from which new data are processed and transferred to Statistics Finland three times a month. Statistics Finland verifies the data, makes further enquiries to the police districts and, where necessary, supplements the data with data from other registers.

Statistics Finland supplements its annual data with data on deaths derived from statistics on causes of death. The data are also supplemented with information on crash locations from the Finnish Transport Agency's Digiroadzp information system; data from the Rescue Services' PRONTO statistics on resources and crashes; data on coercive measures from Justice Statistics; and data on fatal drink-driving crashes from the road crash investigation teams. Data on road traffic crashes are also supplemented annually by the Finnish Transport Safety Agency's data on driving licences and motor vehicles.

Statistical coverage of fatal crashes is $100 \%$. Reporting is controlled using death certificates. Coverage of injury crashes is about $20 \%$. Coverage is worst for cyclists injured in 
single crashes. Many of the injury crashes are not reported to the police because, in a number of cases, the injuries are slight and compensation is settled between the parties involved.

In addition to statistics based on police reporting, the Traffic Safety Committee of Insurance Companies (VALT) compiles and publishes statistics on crashes investigated by the road crash investigation teams and crashes for which insurance compensation has been paid. The road crash investigation teams investigate nearly all fatal road traffic crashes in Finland. It is most useful in the case of damage-only crashes, as many minor crashes are reported to the insurance company but not to the police.

Hospitals and health centres also compile statistics on cases of traffic crashes, but the data collected are mainly intended for health-care services and cannot be properly used for traffic safety purposes. These data can be used as supplementary material, as they contain information excluded from other statistics, such as injuries caused in pedestrian and bicycle traffic.

Since 2014, police and hospital data have been linked to facilitate correct estimation of the number of serious injuries (defined as MAIS3+). More information can be found at: http://tieliikenneonnettomuudet.stat.fi/tieliikenneonnettomuudet_en.html (accessed 4 May 2017).

\section{Most recent safety data}

\section{Road crashes in 2016 - provisional data}

Based on provisional data, there were 240 road fatalities in 2016, 30 less than in 2015 representing a decrease of $11 \%$. The number of reported injury crashes decreased by $9 \%$ compared to 2015 .

\section{Road crashes in 2015}

Overall, the positive safety trend observed in the past years was reversed in 2015, as the number of road deaths increased by nearly $18 \%$, compared to 2014 . However, there was a decrease in the number of injury crashes $(-2.6 \%)$ and those seriously injured (-8.1\%).

While the numbers of fatal crashes involving cyclists, motorcycles and passenger cars increased, the number of those killed amongst moped riders and pedestrians decreased.

The number of fatal moped crashes has been decreasing since 2011, when a mandatory training and driving test for moped riders was introduced, reaching a record low of 2 fatalities in 2015.

\section{Trends in traffic and road safety (1990-2016) Traffic}

In the last 25 years (1990-2015), the distance travelled has increased by almost 39\%. More recently, over the last 10 years, the distance travelled by cars and vans has increased by 7\% only. In 2012 and 2013, it decreased slightly from the 2011 level, probably as a result of the economic downturn. In 2014 and 2015, the distance travelled once again increased.

\section{Road safety}

\section{Crashes and casualties}

Between 1990 and 2015, the number of deaths decreased by 58\%. In recent years (2000-15), deaths decreased by about $32 \%$. Overall, pedestrian, cyclist and moped rider fatalities and those in urban areas decreased more than fatalities for car occupants or motorcyclists and 
those in rural areas, with slight variations in the trends for pedestrians and cyclists for some recent years.

No single measure can be identified as the main reason for this positive road safety development. Between 2000 and 2015, a number of measures were implemented, including:

- lower speed limits in most urban areas

- construction of pedestrian and bicycle paths

- construction of $260 \mathrm{~km}$ of motorways

- installation of automatic speed cameras on nearly $2000 \mathrm{~km}$ of main roads

- reform of driver education

- renewal of the car fleet, with better safety performance and occupant protection than 15 years ago.

Rates

Since 1990, the death rate per 100000 inhabitants has decreased by more than $62 \%$ and the death rate per billion vehicle-kilometres by 70\%. In 2015, the death rates per 100000 inhabitants as well as per billion vehicle-kilometres were at 4.9 .

\section{Analysis of seriously injured data}

Data on serious injuries have been reported and integrated into the Statistics Finland database since 2014. In 2015, 477 persons injured in a traffic crash reported by the police had an MAIS of 3 or above and were considered seriously injured. This is $8 \%$ less than in 2014 . In 2010, there were around 800 seriously injured persons (Trafi, 2014); however the conversion from the International Statistical Classification of Diseases (ICD10) to the Abbreviated Injury Score (AIS) was somewhat different in the 2010 estimation.

Statistics Finland have also provided unofficial figures for serious injuries found in hospital data with the reason code "traffic accident" but they do not match police data. In 2014, 434 seriously injured people were reported in hospital data and 399 in 2015. Of those seriously injured $55 \%$ were cyclists.

Table 11.1. Road safety and traffic data

\begin{tabular}{|c|c|c|c|c|c|c|c|c|c|}
\hline & \multirow{2}{*}{1990} & \multirow{2}{*}{2000} & \multirow{2}{*}{2010} & \multirow{2}{*}{2014} & \multirow{2}{*}{2015} & \multicolumn{4}{|c|}{$2015 \%$ change from } \\
\hline & & & & & & 2014 & 2010 & 2000 & 1990 \\
\hline \multicolumn{10}{|l|}{ Reported safety data } \\
\hline Fatalities & 649 & 396 & 272 & 229 & 270 & 17.9 & -0.7 & -31.8 & -58.4 \\
\hline Injury crashes & 10175 & 6633 & 6072 & 5324 & 5185 & -2.6 & -14.6 & -21.8 & -49.0 \\
\hline Serious injuries (MAIS3+) & & & & 519 & 477 & -8.1 & & & \\
\hline Deaths per 100000 inhabitants & 13.0 & 7.7 & 5.1 & 4.2 & 4.9 & 17.5 & -2.9 & -35.6 & -62.2 \\
\hline Deaths per 10000 registered vehicles & 2.8 & 1.5 & 0.7 & 0.5 & 0.6 & 15.4 & -13.6 & -60.2 & -77.9 \\
\hline Deaths per billion vehicle kilometres & 16.3 & 8.5 & 5.1 & 4.2 & 4.9 & 16.7 & -3.1 & -42.2 & -70.0 \\
\hline \multicolumn{10}{|l|}{ Traffic data } \\
\hline Registered vehicles ${ }^{1}$ (thousands) & 2350 & 2586 & 3855 & 4334 & 4428 & 2.2 & 14.9 & 71.2 & 88.4 \\
\hline Vehicle-kilometres (millions) & 39750 & 46710 & 53815 & 54580 & 55145 & 1.0 & 2.5 & 18.1 & 38.7 \\
\hline Registered vehicles per 1000 inhabitants & 472 & 500 & 720 & 795 & 809 & 1.8 & 12.3 & 61.8 & 71.3 \\
\hline
\end{tabular}


Figure 11.1. Road safety, traffic and GDP trends index $1990=100$

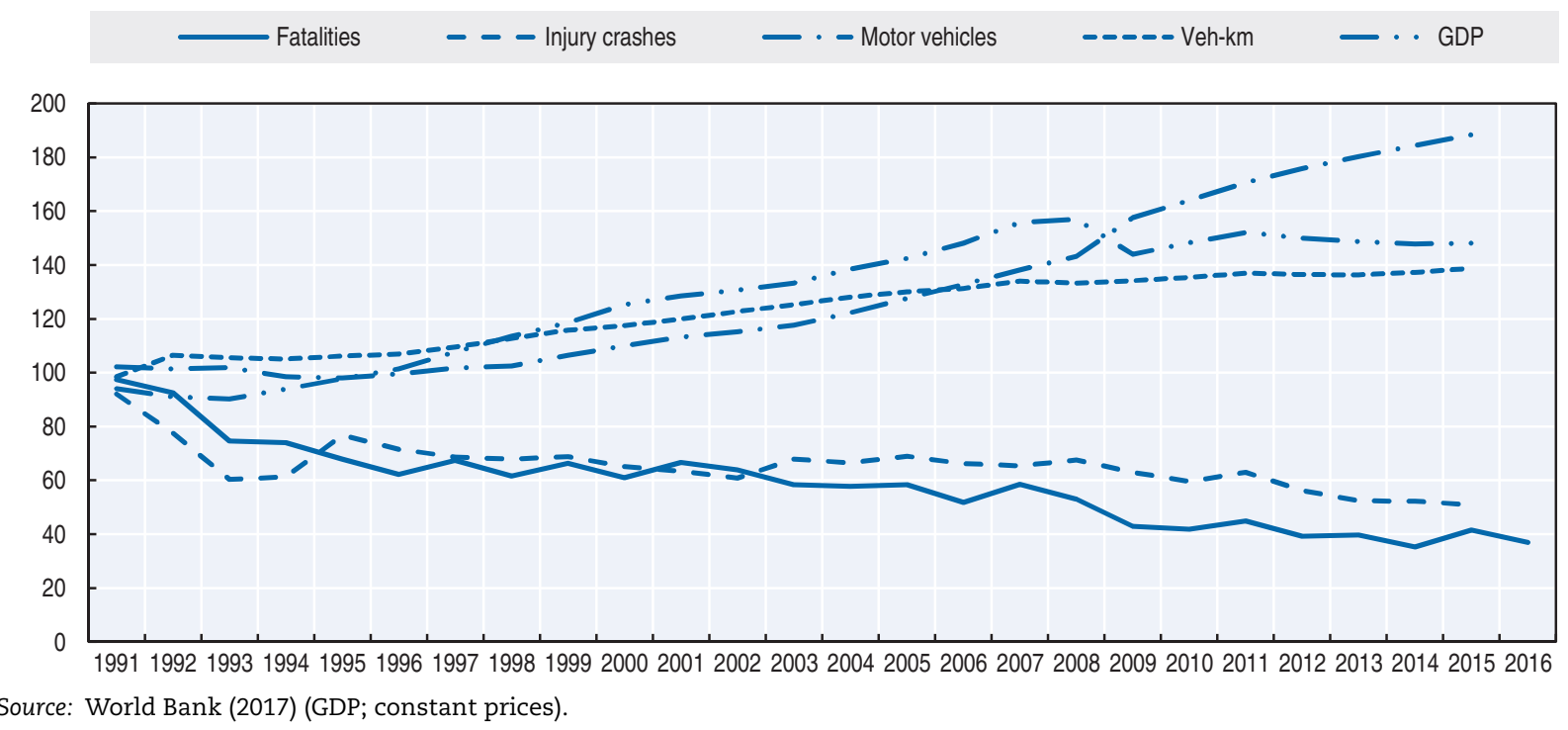

\section{Road safety by user group}

All user groups have benefited from important safety improvements since the 1990s. Cyclist and pedestrian user groups benefited the most from the progress in safety. There has also been a sharp drop in fatalities among moped riders.

However, the safety situation for motorcyclists has deteriorated since 2000. There were 10 motorcyclists killed in 2000 and 20 in 2015. Motorcycling grew rapidly in the 2000s and the number of registered motorcycles increased by 150\% between 2000 and 2010 (from 90000 to 226000 units). A positive change was observed in 2014, with 7 fewer motorcyclists killed. However, in 2015 the number of fatality crashes among motorcyclists increased again. There is no data on motorcycle traffic volume, and therefore it remains unclear whether the positive or negative trend in motorcycle fatalities and crashes is due to changes in traffic volume.

Injury crashes involving mopeds more than doubled between 2000 and 2008, probably due to the increase of the moped fleet, which increased by more than $150 \%$ between 2000 and 2010. In 2012-16 there were significantly fewer moped crashes, due to new legislation requiring mandatory driving lessons and a driving test for moped riders, along with a decrease in registration of new mopeds.

Table 11.2. Road fatalities by road user group

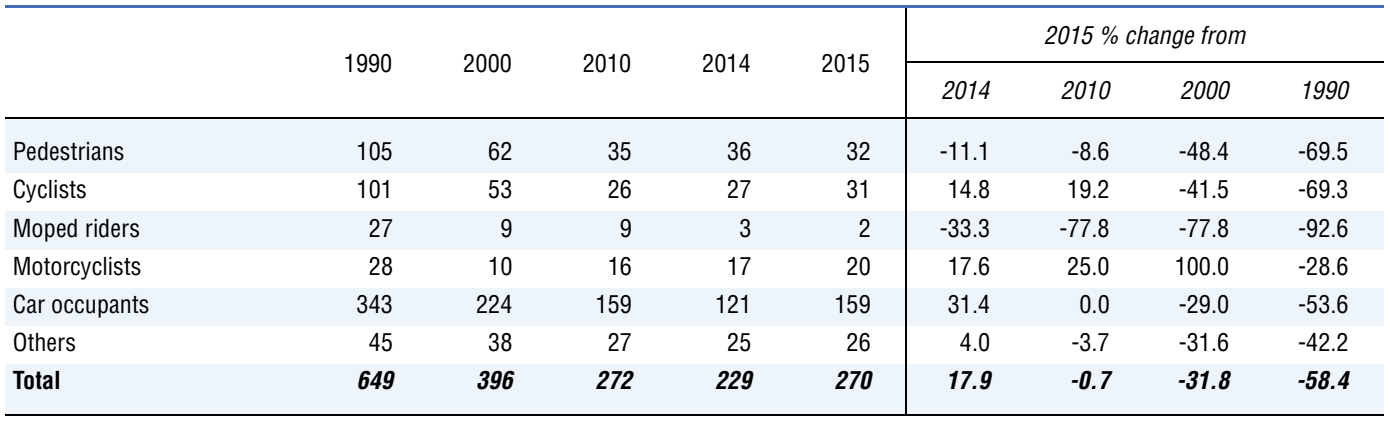


Figure 11.2. Road fatalities by road user group in percentage of total, 2015

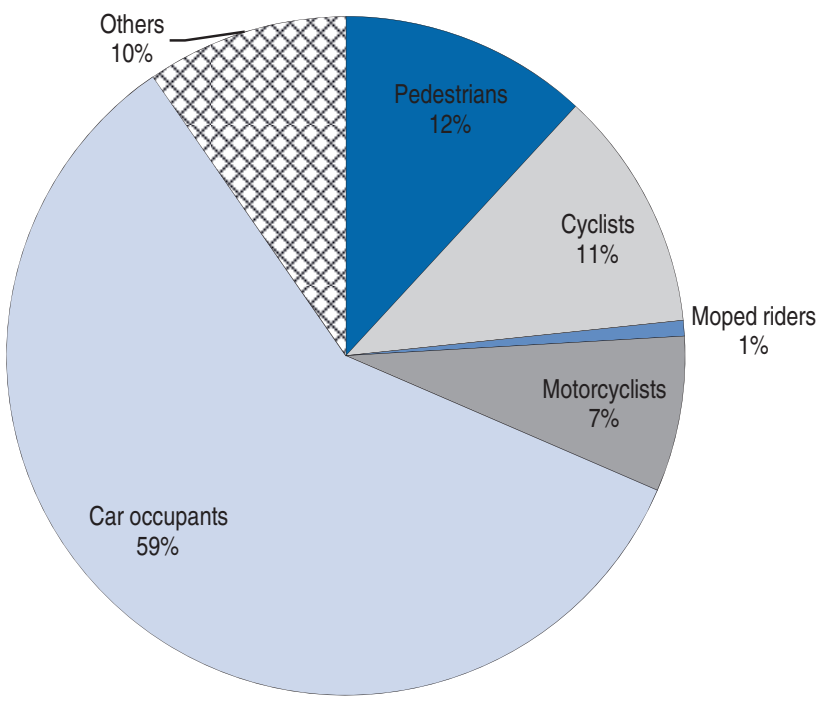

\section{Road safety by age group}

Since 1990, the reduction in fatalities has benefited all age groups, with the most impressive reduction for the youngest groups of $0-14$ and 15-17. In these groups fatalities decreased between $70 \%$ and $84 \%$ respectively.

While the 18-20 age group has a mortality rate much higher than the other age groups, it has been reduced by $50 \%$ between 2010 and 2012-13, with a fatality rate of 7 per 100000 population in 2012-13. In 2014 and 2015, however it increased again with a fatality rate of 12 per 100000 in 2015.

For the over 65 population, the mortality rate has been reduced by 3.5 times since 1990, from 24 deaths per 100000 population in 1990 to 7 in 2015.

Table 11.3. Road fatalities by age group

\begin{tabular}{|c|c|c|c|c|c|c|c|c|c|}
\hline \multirow{2}{*}{ Age } & \multirow{2}{*}{1990} & \multirow{2}{*}{2000} & \multirow{2}{*}{2010} & \multirow{2}{*}{2014} & \multirow{2}{*}{2015} & \multicolumn{4}{|c|}{$2015 \%$ change from } \\
\hline & & & & & & 2014 & 2010 & 2000 & 1990 \\
\hline $0-14$ & 45 & 20 & 7 & 10 & 14 & 40.0 & 100.0 & -30.0 & -68.9 \\
\hline $15-17$ & 43 & 16 & 13 & 12 & 7 & -41.7 & -46.2 & -56.3 & -83.7 \\
\hline $18-20$ & 66 & 32 & 28 & 18 & 23 & 27.8 & -17.9 & -28.1 & -65.2 \\
\hline $21-24$ & 63 & 19 & 20 & 14 & 25 & 78.6 & 25.0 & 31.6 & -60.3 \\
\hline $25-64$ & 274 & 203 & 140 & 119 & 130 & 9.2 & -7.1 & -36.0 & -52.6 \\
\hline $65-64$ & 159 & 53 & 36 & 32 & 33 & 3.1 & -8.3 & -37.7 & 57.9 \\
\hline $75-84$ & & 38 & 23 & 15 & 27 & 80.0 & 17.4 & -28.9 & \\
\hline$\geq 85$ & & 15 & 5 & 9 & 7 & -22.2 & 40.0 & -53.3 & \\
\hline Total & 649 & 396 & 272 & 229 & 270 & 17.9 & -0.7 & -31.8 & -58.4 \\
\hline
\end{tabular}


Figure 11.3. Road fatality rates by age group Deaths per 100000 inhabitants in a given age group, 1990-2015

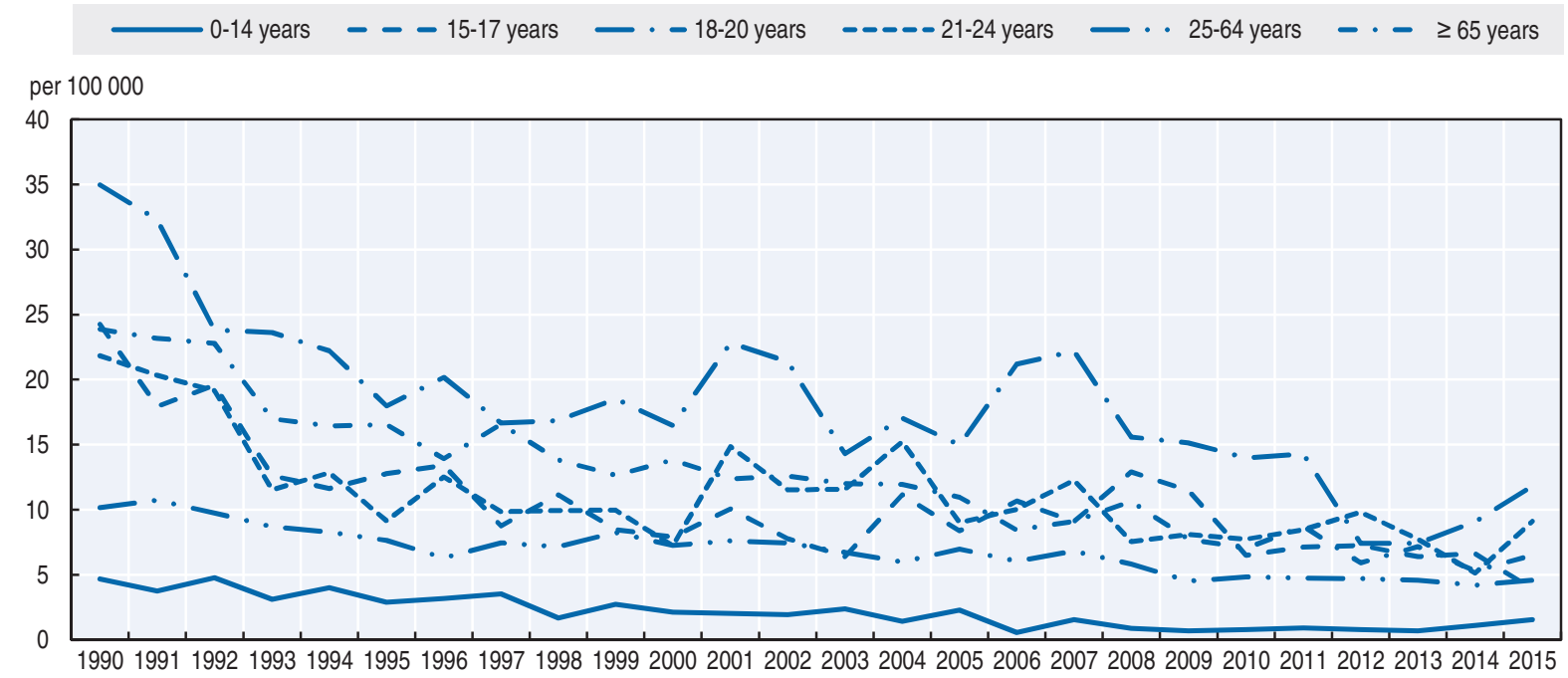

\section{Box 11.1. Road safety for an ageing population}

In 2015 , the $65+$ age group represented $20.5 \%$ of the population compared to only $15 \%$ in 2000 . The share of senior citizens in the population increased rapidly in the 2000s when the baby boomers entered this age group, and is expected to reach $27 \%$ by 2050 .

The number of driving licence holders over 65 has also increased. There were 388000 in 2005 and 705000 in 2015, and their number is expected to increase.

Traffic fatalities among the older population has declined by $38 \%$ since 2000 , while the total number of deaths declined by $32 \%$. The number of injured people has remained approximately the same. The majority (52\%) of older persons killed are car occupants.

Car driving licences are valid until the licence holder reaches the age of 70. To renew their licences, older drivers must provide a medical certificate or a comprehensive medical report. The license is then renewed for a period of 5 years, or less if the medical report requires so. If there is reason to believe that the holder of a driving license no longer meets the health requirements or that he/she is no longer able to drive safely due to his health, the police may order the driver to submit a medical report or new driving test. More information can be found at: www.trafi.fi/en/road/i_have_a_driving_licence/renewing_your_driving_licence (accessed 5 May 2017).

There has been some discussion on the effectiveness of medical tests. A study was made in 2014 which suggested that age-based medical examinations for elderly drivers are more likely to have a negative impact on traffic safety and infringement-free driving than a positive one (Trafi, 2014).

Recent important measures to improve the safety of the senior population include:

- Better intersection designs so that they are easier to perceive. In particular this concerns ramp designs at the entrance of motorways to prevent entering via the wrong direction.

- Similar infrastructure measures which are beneficial for all pedestrians and cyclists: lower speed limits in built-up areas together with infrastructure which supports lower speeds.

- Better assessment of the fitness to drive. Transport Medicine Units have been established in the largest hospitals. 
Box 11.1. Road safety for an ageing population (cont.)

Table 11.4. Road fatalities among senior citizens

\begin{tabular}{lcc|cc|cc}
\hline & \multicolumn{2}{c|}{$65-74$} & \multicolumn{2}{c|}{$75-84$} & \multicolumn{2}{c}{$85+$} \\
\cline { 2 - 7 } & 2010 & 2015 & 2010 & 2015 & 2010 & 2015 \\
\hline Pedestrians & 7 & 5 & 5 & 7 & 2 & 4 \\
Cyclists & 8 & 7 & 2 & 6 & 2 & 1 \\
Moped riders & 1 & 0 & 1 & 0 & 0 & 0 \\
Motorcyclists & 0 & 1 & 0 & 0 & 0 & 0 \\
Car occupants & 17 & 15 & 15 & 13 & 1 & 1 \\
Total & $\mathbf{3 6}$ & $\mathbf{3 3}$ & $\mathbf{2 3}$ & $\mathbf{2 7}$ & $\mathbf{5}$ & $\mathbf{7}$ \\
\hline
\end{tabular}

Figure 11.4. Road fatality rates by age group - focus on the senior population Deaths per 100000 inhabitants in a given age group, 2000-15

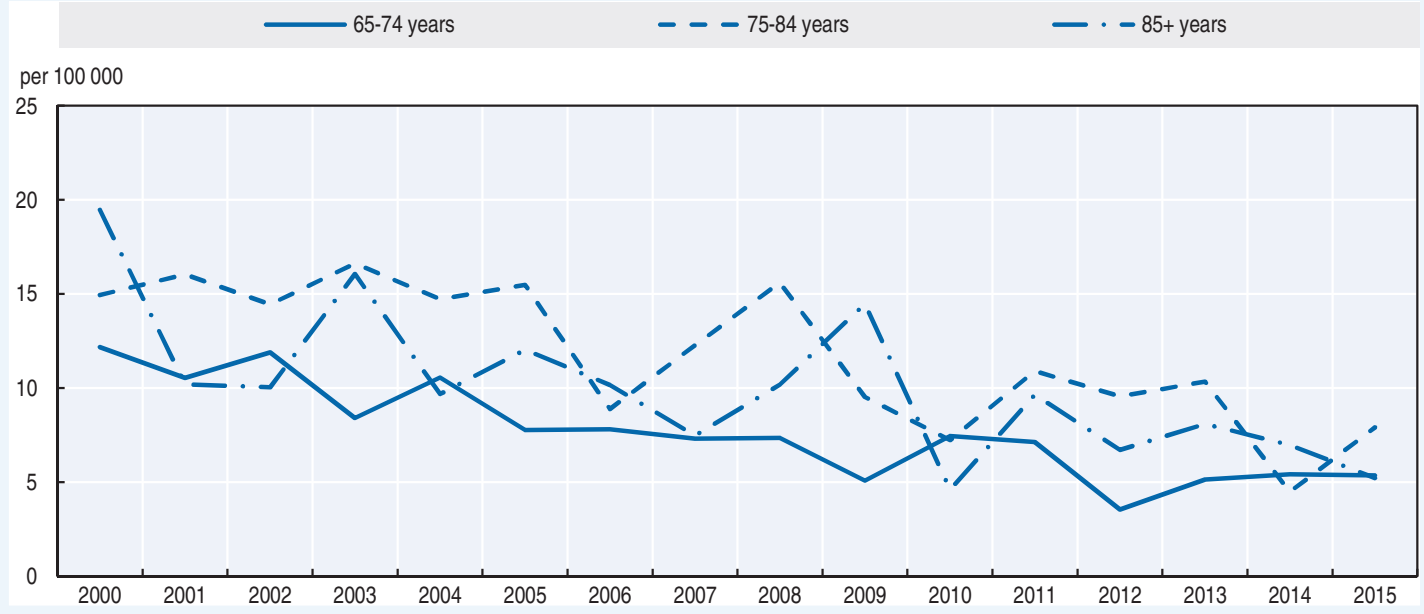

Figure 11.5. Road fatality rate by age and road user group Fatalities per 100000 inhabitants, 2015

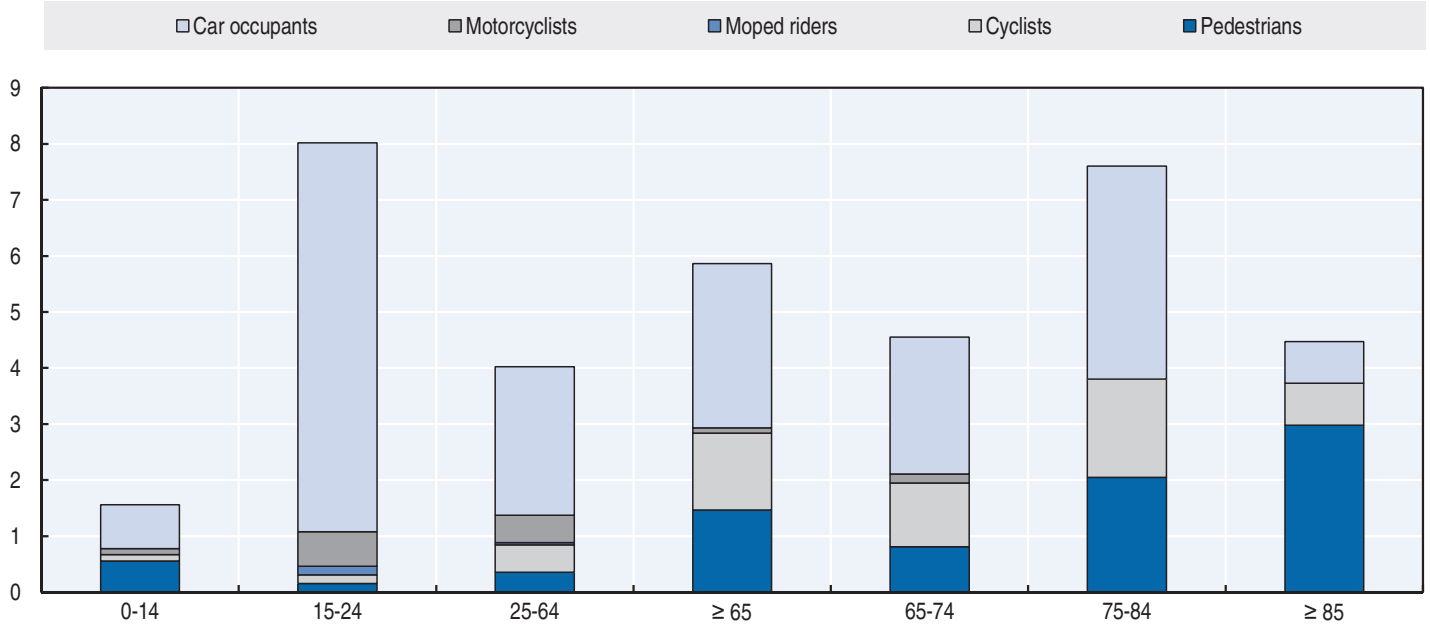




\section{Road safety by road type}

In $2015,70 \%$ of fatalities occurred on rural roads, $28 \%$ in urban areas and $2 \%$ on motorways. Since 1990, the reduction in deaths has been greater on urban roads.

Approximately one-third of fatalities are due to frontal crashes, which typically occur on main roads outside built-up areas. Another third of fatalities are run-off-road crashes, typically on small country roads. Finland only has about $890 \mathrm{kms}$ of motorway, and they account for a minor share of crashes. High-risk roads are usually those with a single carriageway, no central fencing and $80 \mathrm{~km} / \mathrm{h}$ or $100 \mathrm{~km} / \mathrm{h}$ speed limits.

\section{Figure 11.6. Road fatalities by road type}

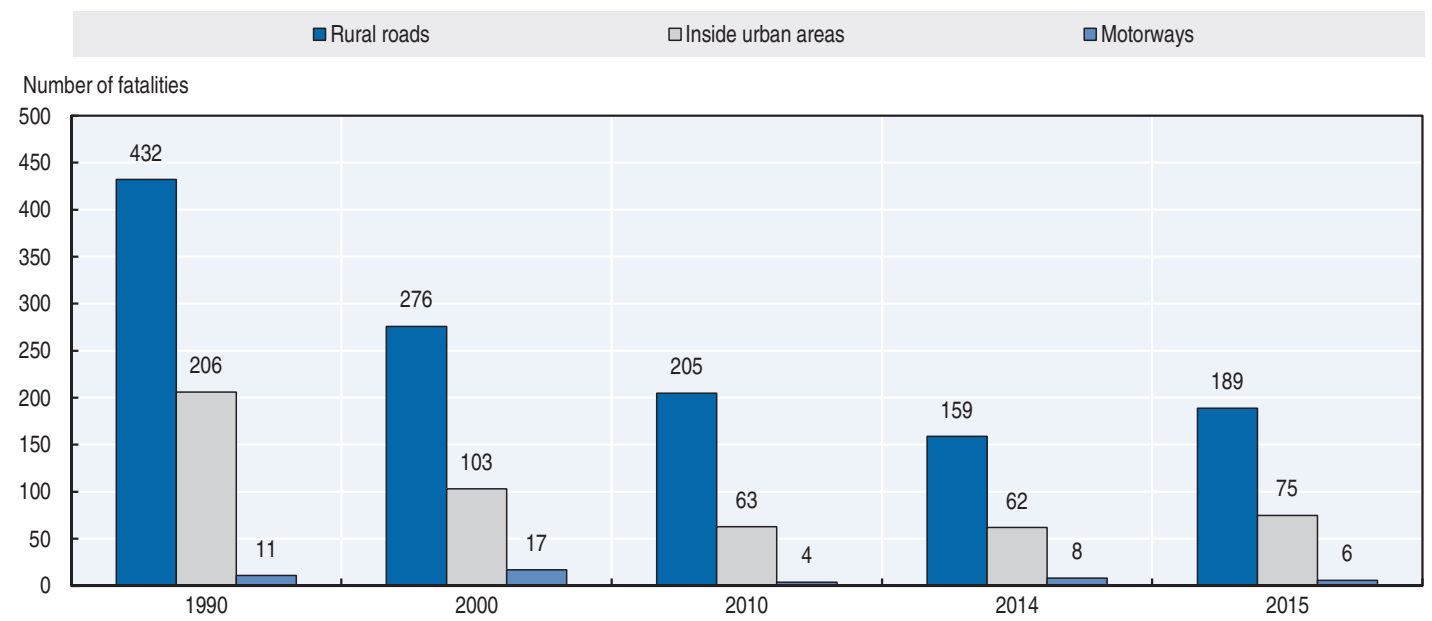

\section{Economic costs of traffic crashes}

The economic and social cost of road crashes is estimated based on actual medical and intervention costs (health care, police, fire brigade, etc.); loss of production calculated through an estimate of lost labour time; and loss of human well-being estimated on the basis of a willingness-to-pay method using values from other Nordic countries.

Cost analysis is conducted and updated every five years. In the latest update, health care information on crash severity was integrated to improve the estimates of health costs.

In 2015, the cost of road crashes based on police reported crashes was EUR 1.3 billion. This does not include costs associated with non-reported crashes.

Trafi is currently working in defining a monetary value for MAIS3+ (TRAFI, 2016).

A new estimation of road crash costs, based willingness-to-pay estimates from Sweden, will be conducted in the coming years.

Table 11.5. Costs of road crashes, 2015

\begin{tabular}{lcc}
\hline Cost (EUR) & Unit cost & Total \\
\hline Fatalities & EUR 2766677 & EUR 747 million \\
Serious & EUR 793646 & EUR 379 million \\
Slight injuries & EUR 18240 & EUR 108 million \\
Property damage costs & EUR 3200 & EUR 65 million \\
Total (EUR) & & EUR $\mathbf{1 . 3}$ billion \\
Total as \% of GDP (at constant prices) & & $\mathbf{0 . 6 \%}$ \\
\hline
\end{tabular}

Source: Finnish Transport Safety Agency (2015). 
Property damage costs are probably underestimated, as property damage only crashes, which do not require further police investigation, are not included in the crash database.

\section{Recent trends in road user behaviour}

\section{Speed}

According to reports from the road crash investigation teams, speeding or inappropriate speed is a contributing factor in $30 \%$ of all fatal crashes.

There have not been any major changes in mean speed over the past 10 years. Reduction of the mean speed by $1-3 \mathrm{~km} / \mathrm{h}$ has been observed on road sections where speed cameras have been installed. While a high proportion of drivers exceed the speed limit, especially during the winter months when speed limits are lowered, the percentage of drivers speeding $10 \mathrm{~km} / \mathrm{h}$ above the limit is relatively low. In $2015,10 \%$ of drivers exceeded the speed limits by more than $10 \mathrm{~km} / \mathrm{h}$ in summer and $14 \%$ in winter on main roads.

Speed cameras, implemented mainly during the 2000s, cover around $3000 \mathrm{~km}$ of main roads. There are less speeding offences at police speed camera sites.

The table below summarises the main speed limits in Finland.

Table 11.6. Passenger car speed limits by road type, 2017

\begin{tabular}{lcl}
\hline & General speed limit & Comments \\
\hline Urban roads & $50 \mathrm{~km} / \mathrm{h}$ & 30,40 or $60 \mathrm{~km} / \mathrm{h}$ on a large share of streets \\
Rural roads & $100 \mathrm{~km} / \mathrm{h}$ (summer) & $60-80 \mathrm{~km} / \mathrm{h}$ at intersections or where bad road geometry or high traffic volume. $80 \mathrm{~km} / \mathrm{h}$ \\
& $80 \mathrm{~km} / \mathrm{h}$ (winter) & if no speed limit signs. \\
Motorways & $120 \mathrm{~km} / \mathrm{h}$ & $100 \mathrm{~km} / \mathrm{h}$ near cities. \\
& & A large share of motorways have variable speed limits \\
\hline
\end{tabular}

\section{Drink driving}

The maximum authorised blood alcohol content (BAC) is $0.5 \mathrm{~g} / \mathrm{l}$ for all drivers. In 2015, it was estimated that $21 \%$ of fatal crashes involved a driver with a BAC above the $0.5 \mathrm{~g} / \mathrm{l}$ limit (this share was 24\% in 2010, 25\% in 2011, 17\% in 2012 and 22\% in 2013). It is typical in alcohol-related fatal crashes that the driver is strongly intoxicated. In $2015,84 \%$ of drivers responsible for a fatal crash exceeded $1.2 \mathrm{~g} / \mathrm{l}$, the limit of aggravated drunk driving.

Those who die in drunk-driving crashes are most often the drunk drivers themselves. From $2014-16,71 \%$ of killed persons were drunk drivers, $20 \%$ were their passengers and $9 \%$ were others.

The percentage of drivers under the influence of alcohol in traffic has slowly decreased from $0.25 \%$ in 1990. In 2015 and 2016, 0.13\% of drivers had a BAC above the legal limit.

\section{Drugs and driving}

In 2015, 14 drivers involved in fatal crashes were suspected of driving under the influence of drugs.

\section{Distraction}

In Finland, it is forbidden to drive with a hand-held mobile phone, while hands-free devices are tolerated. Around three fatal crashes every year are related to mobile phone use while driving (Jääskeläinen, 2014). 


\section{Seat belts and helmets}

Seat belt use has been compulsory for front seats since 1975 and for rear seats since 1987. There has been a significant increase in seat belt use by car drivers since 1980 .

Based on monitoring by Liikenneturva, in 2016, the seat belt wearing rate was $96 \%$ for front seats on rural roads, $95 \%$ for front seats on urban roads, and $85 \%$ for rear seats on urban roads.

According to the road crash investigation teams, $41 \%$ of car or van occupants killed were not wearing a seat belt. It is estimated that $100 \%$ seat belt usage would have saved 19 lives in 2015.

Under Finnish law, children under $135 \mathrm{~cm}$ in height must wear a safety device determined by their weight when in a car.

Table 11.7. Seat belt wearing rate by car occupancy and road type

\begin{tabular}{|c|c|c|c|c|}
\hline & 2000 & 2010 & 2105 & 2016 \\
\hline \multicolumn{5}{|l|}{ Front seat } \\
\hline Driver & & 92 & 95 & \\
\hline Passenger & & 92 & 95 & \\
\hline Urban roads (driver) & 80 & 91 & 93 & 95 \\
\hline Rural roads (driver) & 89 & 94 & 96 & 96 \\
\hline \multicolumn{5}{|l|}{ Rear seats } \\
\hline General & & 84 & 88 & 85 \\
\hline
\end{tabular}

Helmet wearing is compulsory for all motorcycle and moped riders.

Although, since 2003, the traffic law has strongly recommended cyclists to wear helmets, this is not enforced. The bicycle-helmet usage rate was $25 \%$ in 2004 and reached $43 \%$ in 2015. Most small children wear helmets, but teenagers and elderly people tend not to do so. The usage rate in the Helsinki area is about 70\%, but rates in northern Finland are much lower.

\section{National road safety strategies and targets Organisation of road safety}

The Ministry of Transport and Communications is responsible for drafting legislation concerning road safety.

The Ministry's main agencies involved in road safety are:

- The Finnish Transport Agency, which is responsible for road design, construction and maintenance, and for road and traffic signs.

- The Finnish Transport Safety Agency, which is responsible for vehicle registration, supervision of driving schools and driving licence operations, and organisation of matters related to vehicle inspection. The agency's responsibilities also include campaigning for road and traffic safety.

- Liikenneturva (Finnish Road Safety Council) which implements campaigns for road and traffic safety, disseminates information, contributes to road safety education for various age groups and provides further training for drivers. 


\section{Road safety strategy}

The road safety programme for the years 2012-14 ended. A new resolution on road safety was approved by the Government on 15 December 2016 (www.lum.fi/en/-/government-resolutionon-road-safety-looks-into-the-future-914474; accessed 5 May 2017). The long-term vision of the resolution is that no-one would be killed or seriously injured on the road. The resolution outlines measures that will promote road safety related to drivers, vehicles and roads alike and creates preconditions for increasing automation and the use of digital data in transport.

\section{Road safety targets}

The target for 2020 is based on the target set by the European Commission to reduce by half the number of fatalities by 2020 compared to 2010 level. In addition, there is a target to reduce by $25 \%$ the number of persons seriously injured.

Figure 11.7. Trends in road fatalities towards national target

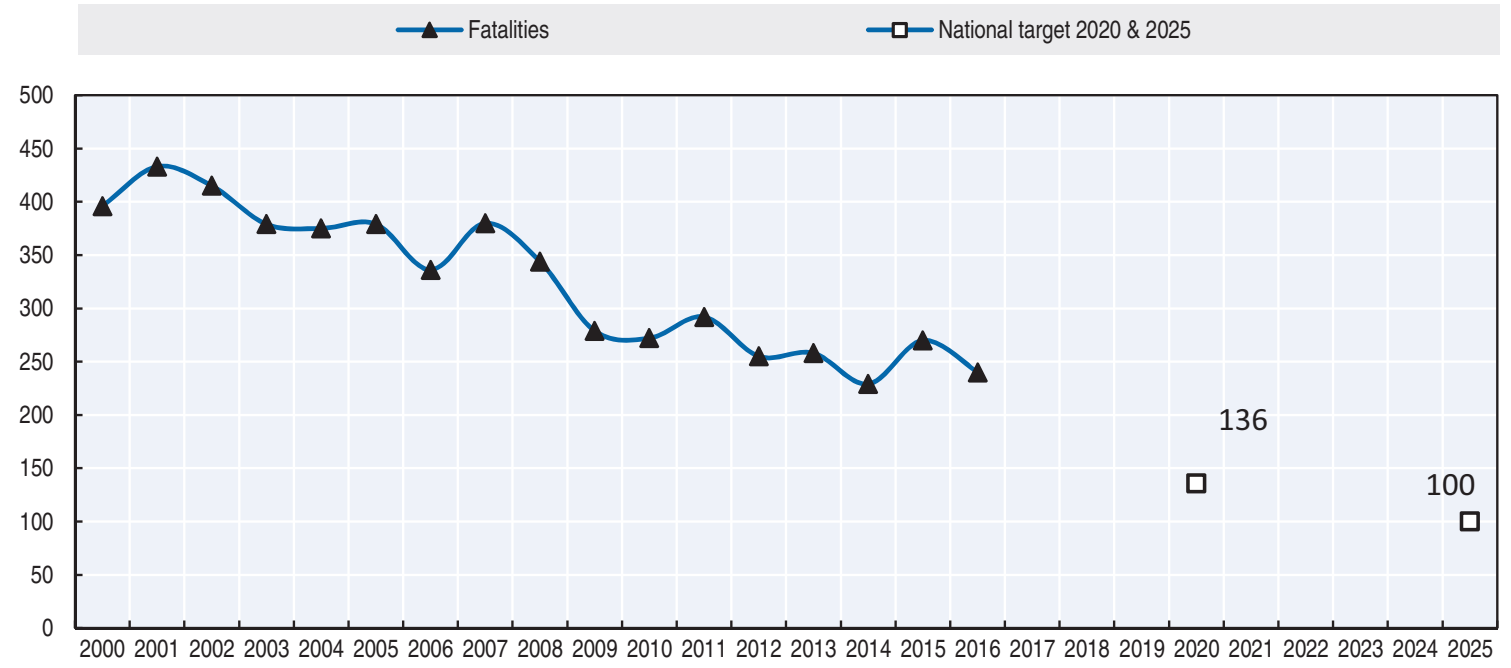

Figure 11.8. Trends in the number of people injured towards national target

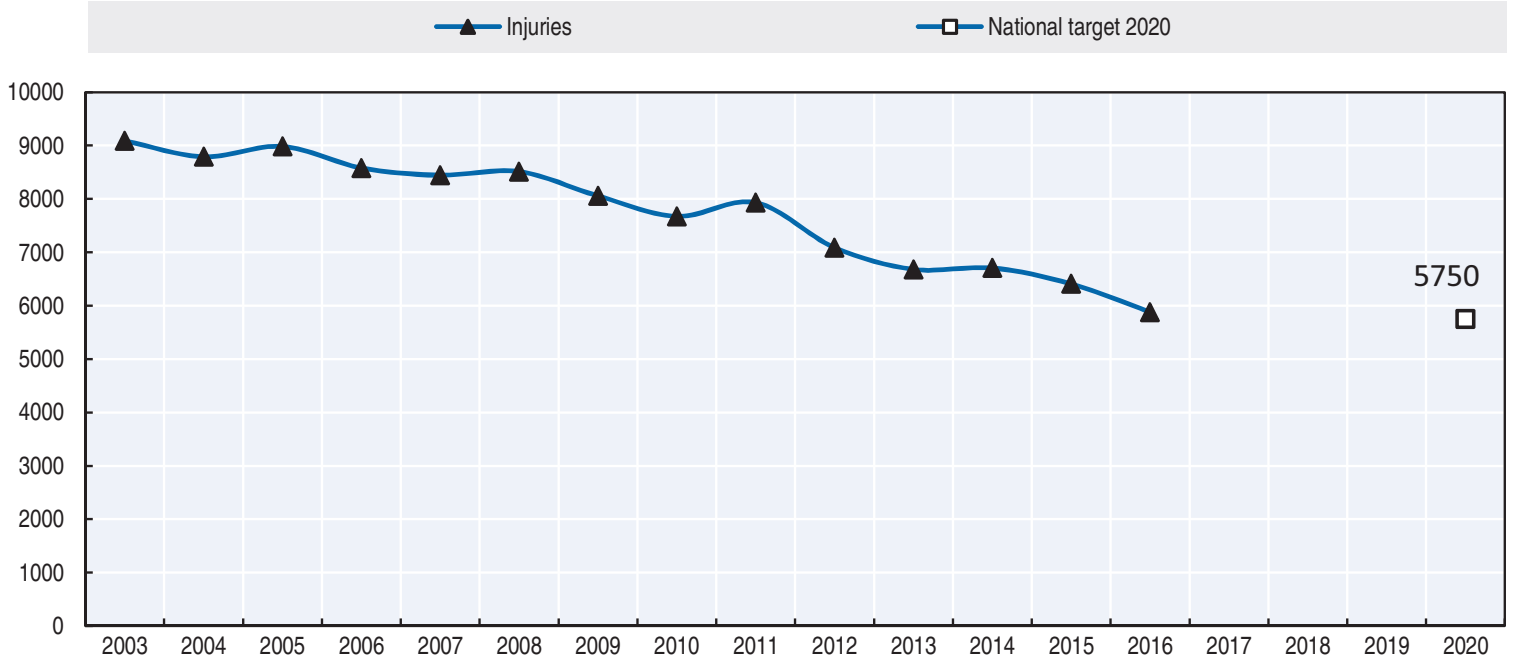


The corresponding numerical targets are:

- fewer than 137 fatalities (or 24 fatalities per million inhabitants) by 2020

- fewer than 5750 police-reported injuries by 2020

- long-term target of fewer than 100 fatalities by 2025.

At the current pace, it is estimated that the 2020 target will be reached for injuries but not for fatalities.

\section{Recent safety measures (2014-17)}

\section{Road safety management}

\section{Transport companies}

- The Transport Safety Agency has developed a voluntary management and practice model for road transport companies. It provides practical guidance for responsible, economic, safe, and high-quality operating.

\section{Driving license}

- In October 2016, the Ministry of transport published a memo on a new driver education reform which is open for comments. The memo proposes a single-phase education with less regulation on education's contents, in comparison to current graduated driving license.

- Some driving schools are now permitted to test after a lower amount of mandatory theory and driving lessons for the first phase of the passenger car driving licence. In this test the minimum number of theory lessons is 10 hours (instead of 19) and the minimum number of driving lessons is 10 hours (instead of 18).

\section{Traffic rules}

- The total overhaul of the Road Traffic Act has transitioned to the statement phase. The draft proposal contains, among other things, the traffic rules as well as the regulations affecting traffic management, vehicle behaviour and breaking the law. The current valid law dates from 1981, and it has been supplemented by innumerable statutes from various years. With this big renewal, the regulatory framework will be streamlined to replace the ambiguities and shortcomings of the old legislation as well as prepare road transport for rapid technical advancement and automation.

\section{Road users}

\section{Enforcement}

- Almost all fixed fines were doubled in September 2015. Now the lowest fine is EUR 20 and the largest EUR 200. Speeding is the most common reason for a fixed fine.

- Installation of plate-recognition devices in police cars started in 2014. As of November 2016 around 300 devices were in use.

\section{Vehicles}

- Finland's vehicle fleet is one of the oldest in the European Union. The average age of passenger cars in traffic is 11 years. A trial incentive programme for car scrappage was conducted in 2015 to promote the replacement of old vehicles with modern vehicles. Around 8000 old cars were replaced by new vehicles producing carbon dioxide emissions of $120 \mathrm{~g} / \mathrm{km}$ or less. This was not continued in 2016. 
- At the beginning of 2016, a new classification for new types of very light electric vehicles came into force. Vehicles such as senior scooters and electric skateboards with a maximum speed of $15 \mathrm{~km} / \mathrm{h}$ and a maximum power of $1 \mathrm{~kW}$ are considered as "pedestrians". These devices are allowed on the sidewalk when travelling at walking speed and on bicycle paths when travelling at higher speeds. Vehicles with a maximum speed of $25 \mathrm{~km} / \mathrm{h}$ and a maximum power of $1 \mathrm{~kW}$ power are considered as "bicycles". In 2017, the number of these vehicles remained low.

- Winter wheels became mandatory for heavy vehicles from January 2017.

- Finland is developing an Arctic Intelligent Transport System (ITS) test site for automated driving, designed for verifying and validating new ITS solutions and innovations in Arctic conditions with extreme seasonal changes. An Arctic testing ecosystem for intelligent transport and automated driving is being built in Finnish Lapland. The improvement of highway E8 is underway to meet the requirements of the public test area (see www.snowbox.fi/, accessed 5 May 2017).There are now several automated driving or other ITS tests and test sites in Finland:

* Aurora test site in Lapland, www.liikennevirasto.fi/web/en/e8-aurora\#.WN4v42_yjIU (accessed 5 May 2017).

* Nordicway Coop connected vehicle pilot project in southern Finland, www.trafi.fi/en/ about_trafi/news/3472/finland_joins_a_nordic_connected_vehicle_pilot (accessed 5 May 2017).

* Living Lab Bus - Open innovation and test platform for the development, testing and demonstration of various services and technologies in public transport, http:// livinglabbus.fi/ (accessed 5 May 2017).

* Robot bus experiment in real traffic, http://sohjoa.fi/in-english (accessed 5 May 2017).

\section{High capacity vehicles}

- Special permits for High Capacity Transport vehicle combinations have been granted since November 2013. In spring 2017, there were 26 vehicle combinations in use, transporting sea containers, timber and foodstuff.

\section{Recent and ongoing research}

- Suicides in road and rail transport: A feasibility study. www.trafi.fi/filebank/a/1474275404/ fefaba00bf78053625648cb56e0a994e/22452-Trafin_tutkimuksia_7_2016_Itsemurhat_ liikenteessa.pdf (accessed 5 May 2017).

- Calming traffic and to improving the safety of pedestrian crossings: Case Turenki. www.trafi.fi/filebank/a/1473313266/66eba0b5ec6adaceab5cf51da341f2b2/22378-Turengin_ suojatieselvitys_loppuraportti_FINAL.pdf (accessed 5 May 2017).

- Automatic speed enforcement on Ring Road I in Helsinki area: A before-after-study. www.trafi.fi/filebank/a/1484560717/4ff0370cd96a15b00e783cf4bc3e6ef7/23805-Trafi_01_ 2017_Keha_I_ennen-jalkeen-tutkimus_raportti_.pdf (accessed 5 May 2017).

- Road safety in Finland and Sweden: A comparison of associated factors. www.trafi.fi/ filebank/a/1453805909/bf0e9e4f3f9492480bc0b561d4d99217/19608-Trafin_tutkimuksia_22016_-_FINENS_report_20_01_2016.pdf (accessed 5 May 2017).

- Cost-effective middle barrier solutions. www2.liikennevirasto.fi/julkaisut/pdf8/lts_2016-02_ kustannustehokkaat_keskikaideratkaisut_web.pdf (accessed 5 May 2017). 
- Safety of road intersections: A review of accidents from 2011 to 2015. www2.liikennevirasto. fi/julkaisut/pdf8/lts_2016-57_maanteiden_tasoliittymien_web.pdf (accessed 5 May 2017).

\section{References}

Official Statistics of Finland (OSF), Statistics on road traffic accidents, www.stat.fi (accessed 5 May 2017).

Finnish Transport Safety Agency (Trafi), Finnish Road Traffic 2015: Safety and environmental impacts, http:// katsaukset.trafi.fi/media/katsaukset/tieliikenne/finnish-road-traffic-2015.pdf (accessed 5 May 2017).

Finnish Transport Safety Agency (Trafi), Finnish Road Traffic 2014: Safety and environmental impacts, http:// pinnalla.trafi.fi/e-julkaisut/finnish_road_traffic_2014/pdf/Trafi_Finnish_roadtraffic_2014_EN.pdf (accessed 5 May 2017).

Finnish Transport Safety Agency (Trafi) (2014), Ajokortin uusintaan liittyvien ikäkausitarkastusten vaikutus liikennemenestykseen (The impact of driving license revision related to road traffic offsets), www.trafi.fi/ filebank/a/1394024746/d14a9dd33fc059d7bfde272b04cd2fab/14340-Trafin_tutkimuksia_02-2014__Ikakausitarkastusten_vaikutus_liikennemenestykseen.pdf (summary in English; accessed 5 May 2017).

Finnish Transport Safety Agency (Trafi) (2014), Tieliikenteessä vakavasti loukkaantuneiden määrän arviointi VAAKKU (Evaluation of the number of people seriously injured in road traffic), www.trafi.fi/filebank/ a/1416923679/b8f9e9b07b0dca1231c3958a3c995e52/16298-Trafin_tutkimuksia_10-2014_-_Vakavasti_ loukkaantuneet.pdf (accessed 5 May 2017).

Finnish Transport Safety Agency (Trafi) (2016), Tieliikenteen onnettomuuskustannusten tarkistaminen (Validating road traffic accident costs), www.trafi.fi/filebank/a/1465820007/76d4b29cc 9424288b707133f5259494d/21751-Trafin_tutkimuksia_5_2016_Tieliikenteen_onnettomuuskustannusten_ tarkistaminen.pdf (summary in English; accessed 5 May 2017).

World Bank (2017), "GDP (constant US\$)", World Development Indicators, http://databank.worldbank.org/ data/reports.aspx?source=world-development-indicators (accessed 23 February 2017).

\section{Websites}

- Finnish Transport Safety Agency (Trafi): www.trafi.fi (accessed 5 May 2017).

- Ministry of Transport and Communications: www.lum.fi (accessed 5 May 2017).

- Finnish Transport Agency: www.liikennevirasto.fi (accessed 5 May 2017).

- Liikenneturva - Finnish Road Safety Council: www.liikenneturva.fi (accessed 5 May 2017).

- Statistics Finland: www.stat.fi/index_en.html (accessed 5 May 2017). 



\section{Chapter 12}

\section{France}

This chapter presents 2015 road safety data for France along with provisional data from 2016. It looks at trends in traffic and road safety from the years 1990 to 2015 and road user behaviour patterns, with a special focus on the ageing population. Sections include data on speed, drink driving, drugs and driving, distracted driving, fatigue and seat belt and helmet use. The chapter reviews France's road safety strategy and national targets to 2020. It also looks at the most recently implemented safety measures and ongoing research.*

* All data stem from the French Road Safety Observatory (Observatoire national interministériel de la sécurité routière ONISR) and IRTAD unless otherwise noted. Data presented in this report concern the French metropolitan area. For more information please contact: onisr-dscr@interieur.gouv.fr. 
I In 2015, road deaths increased by $2.4 \%$ over 2014, from 3384 to 3461 , the equivalent of a fatality rate of 5.4 per 100000 inhabitants. This is the second consecutive year of increases. Favourable weather and a dramatic truck and coach crash resulting in 41 fatalities in 2015 contributed to this increase. Provisional data for 2016 indicates again a slight increase with an estimated $0.5 \%$ increase in fatalities.

\section{Road safety data collection}

\section{Definitions applied in France}

- Road fatality: Person who died within 30 days of a road crash. Before 2005 , fatalities were counted within six days. For international comparisons, a correction factor of 1.069 is applied for the years before 2005 .

- Hospitalised: Non-fatal casualty who stayed longer than 24 hours in hospital. Before 2005, this category used the duration of more than 6 days for the hospital stay.

- Slightly injured: Non-fatal casualty who received medical care but did not stay in hospital longer than 24 hours (or 6 days before 2005).

- Seriously injured: Person who is injured with at least one injury ranking three or more on Maximum Abbreviated Injury Scale (MAIS3+), not including those who died within 30 days.

\section{Data collection}

French official road safety information comes from the National Road Traffic Accident (RTA) database which includes results for mainland France only, unless specified that data from overseas territories are included.

Road traffic crashes leading to injury are recorded by the police into their own software programme according to a dedicated format, the Injury Accident Analysis Bulletin (BAAC, Bulletins d'analyse d'accident corporel). These files are then gathered centrally through a web-based programme and constitute the National RTA database.

A new information system is currently under development to modernise the data collection process and the analysis of road traffic accident data. The format of the Injury Accident Analysis Bulletin (BAAC) has been revised accordingly (date of implementation January 2018) to facilitate the work of the police, improve the coherence of statistics and to introduce information about new means of transport or accident factors.

The data collection process is managed by the French Road Safety Observatory (ONISR, Observatoire national interministériel de la sécurite routière), with the assistance of technical teams from the French Research Centre on Risks, Environment, Mobility and Planning (CEREMA, Centre d'études et d'expertise sur les risques, l'environnement, la mobilité et l'aménagement) and the network of local observatories to check and complement the information as necessary.

Proven suicides and intentional murders are not registered as road traffic crashes.

Monitoring the quality of data is partially ensured by comparing it with the Rhone registry, i.e. information gathered from hospitals in the Rhone region on all road traffic crash 
victims who received medical care at a hospital. Information on the number of fatalities is considered very accurate and used as a benchmark. Serious injury crashes are usually recorded accurately too, except in the case of single vehicle crashes involving powered twowheelers and cyclists.

There are some variations across the country over the way slight injury accidents are recorded. The French Institute of Science and Technology for Transport, Development and Networks (IFSTTAR) estimates that the number of injured people is significantly underestimated and could be four times greater than the registered number.

Based on the expertise developed by using both the Rhone registry and the National RTA database, IFSTTAR has been tasked with providing a national estimate for MAIS3+ victims to provide the relevant information requested by the European Commission for their 2014 baseline.

\section{Most recent safety data}

\section{Road crashes in 2016 - provisional data}

Provisional data indicate that the number of road fatalities remained fairly stable in 2016 with less than 0.5\% increase over 2015.

The number of fatalities observed in the first half of 2016 was higher than in the previous three years, but dropped off towards the latter half of the year.

Motorcyclist fatalities appear to have remained stable in 2016, resulting in an overall decrease of $13 \%$ since 2010. Car occupant fatalities, which had increased since 2013, decreased by $2 \%$ compared to 2015 and by $17 \%$ compared to 2010 . Moped users have benefitted from significantly less fatalities than in 2015, although serious injuries in this group increased. Cyclist fatalities increased by $9 \%$ (10\% higher than in 2010). Provisional data also indicate that pedestrian fatalities have reached a very high level, with a $19 \%$ increase over 2015 and a 15\% overall increase since 2010.

\section{Road crashes in 2015}

In 2015, 3461 persons were killed on the French mainland roads, representing 77 additional fatalities and a $2.3 \%$ increase compared to 2014 . The number of injury crashes, injuries, including hospitalised victims was down slightly $(-2.7 \%,-3.1 \%$ and $-0.2 \%$ respectively). In 2015, of the 3461 road fatalities:

- $75 \%$ were male (2 604), $25 \%$ female (857)

- $63 \%$ died on roads outside built-up areas

- Nearly a quarter died in a crash involving a new driver (licence holder less than two years)

- Nearly a quarter were motorcyclists or moped users.

In 2015, the number of fatalities among users of public transport, usually less than $10 \mathrm{a}$ year, included the 41 passengers killed in the Puisseguin crash between a bus and a truck.

\section{Trends in traffic and road safety (1990-2015) Traffic}

Between 1990 and 2015, the number of motorised vehicles increased by $37.2 \%$ and the overall vehicle kilometres driven by $39.2 \%$. Light vehicle traffic increased consistently from 1990 to 2003 and then remained more or less stable until 2009 and then increased again by $5 \%$ over the next 6 years. Utility vehicle traffic increased regularly until 2005; then remained 
stable; it increased again by 11.3\% between 2009 and 2015. After the steady increase seen from 1990 to 2007, heavy goods vehicle (HGV) traffic dramatically dropped by $18.5 \%$ between 2007 and 2009 due to the economic downturn. It has remained fairly stable since 2009.

\section{Road safety}

\section{Crashes and casualties}

The number of road fatalities peaked in 1972 with about 18000 fatalities. France had a fatality rate of 35 deaths per 100000 inhabitants. Since then, the number of fatalities has followed a downward trend, with fluctuations from year to year. Between 1990 and 2015, the number of road fatalities decreased by more than $70 \%$.

Between 1990 and 2000, the following important road safety measures were introduced:

- In 1989 the publication of the White Paper on Road Safety paved the way for road safety policies on improving and enhancing enforcement that would come into effect 10 years later.

- The maximum speed limit in built-up areas was set at $50 \mathrm{~km} / \mathrm{h}$ in 1990 , and the maximum allowable blood alcohol content level (BAC) was lowered to $0.5 \mathrm{~g} / \mathrm{l}$.

- The demerit point system was introduced in 1992.

- Most motorway network construction was achieved during this period.

- Most vehicles were equipped with airbags.

- The educational continuum was implemented.

Despite these measures, fatalities only decreased by $20 \%$ in the decade, as traffic increased by $20 \%$. In 2000 , there were 15 people killed per billion vehicle kilometres driven and 14 per 100000 inhabitants. In July 2002, French President Jacques Chirac declared road safety to be one of his four main priorities. Between 2000 and 2010 important advances in road safety included:

- The first permanent automated speed cameras were introduced in 2003.

- A Road Safety National Council was established for public and private stakeholders to meet and present action proposals to the government.

- Probationary licences were introduced in 2004.

- A driver caught exceeding the maximum blood alcohol concentration level would lose six demerit points out of 12 (or 6 out of 6 for drivers in their probation period).

These changes made it possible to break through the symbolic level of 5000 fatalities per year in 2006 . Fatalities fell by $51 \%$ over the 10 -year period. Experts attribute $75 \%$ of the improvement to a reduction in average speed and $11 \%$ to improved vehicle safety. At the same time, traffic was up $7 \%$.

Between 2010 and 2012, fatalities decreased by 8.5\%, in line with the trend observed at the end of the 2000s. As a result of favourable weather conditions in particular, 2013 was marked by an accelerated decline in the number of fatalities, with a $10.5 \%$ decrease compared to 2012. In 2014, the increase in car occupant fatalities compensated the decline. The increase among car occupant fatalities continued fuelling the upward trend in 2015.

\section{Rates}

In 2015, the fatality rate expressed in terms of deaths per 100000 inhabitants was 5.4 and the fatality risks, expressed in terms of deaths per billion vehicle-kilometres was 5.9. In 
1990 the respective rates were 19.8 and 25.2, which means that the risk of dying on a French road was divided by about four between 1990 and 2015. During the same period, the number of vehicles per 1000 inhabitants increased by $22 \%$.

\section{Analysis of seriously injured data}

IFSTTAR estimates the number of people in road traffic crashes with a MAIS3+ injury. This modelling work is currently being evaluated. Based on these estimates, in 2012, 43\% of persons injured with a MAIS of 3 or above were powered two-wheelers riders, $26 \%$ were car occupants, $14 \%$ cyclists and $12 \%$ pedestrians. This means that nearly $70 \%$ of those seriously injured are vulnerable road users.

Table 12.1. Road safety and traffic data

\begin{tabular}{|c|c|c|c|c|c|c|c|c|c|}
\hline & \multirow{2}{*}{1990} & \multirow{2}{*}{2000} & \multirow{2}{*}{2010} & \multirow{2}{*}{2014} & \multirow{2}{*}{2015} & \multicolumn{4}{|c|}{$2015 \%$ change from } \\
\hline & & & & & & 2014 & 2010 & 2000 & 1990 \\
\hline \multicolumn{10}{|l|}{ Reported safety data } \\
\hline Fatalities & 10999 & 8170 & 3992 & 3384 & 3461 & 2.3 & -13.3 & -57.6 & -68.5 \\
\hline Injury crashes & 162573 & 121223 & 67288 & 58191 & 56603 & -2.7 & -15.9 & -53.3 & -65.2 \\
\hline Injured persons hospitalised & & & 30393 & 26635 & 26595 & -0.2 & -12.5 & & \\
\hline Deaths per 100000 inhabitants & 19.8 & 13.7 & 6.4 & 5.3 & 5.4 & 1.8 & -15.3 & -60.8 & -72.8 \\
\hline Deaths per 10000 registered vehicles & 3.6 & 2.3 & 1.0 & 0.8 & 0.8 & 1.7 & -18.4 & -64.0 & -77.7 \\
\hline Deaths per billion vehicle kilometres & 25.7 & 15.1 & 7.1 & 5.9 & 5.9 & 0.1 & -16.9 & -60.9 & -77.0 \\
\hline \multicolumn{10}{|l|}{ Traffic data } \\
\hline Registered vehicles ${ }^{1}$ (thousands) & 30869 & 35874 & 40181 & 42476 & 42701 & 0.5 & 6.3 & 19.0 & 38.3 \\
\hline Vehicle kilometres (millions) & 436000 & 518200 & 560400 & 572394 & 584914 & 2.2 & 4.4 & 12.9 & 34.2 \\
\hline Registered vehicles per 1000 inhabitants & 546 & 609 & 640 & 664 & 664 & 0.1 & 3.8 & 9.0 & 21.8 \\
\hline
\end{tabular}

1. With mopeds.

StatLink क्ञाड http://dx.doi.org/10.1787/888933580441

Figure 12.1. Road safety, traffic and GDP trends index $1990=100$

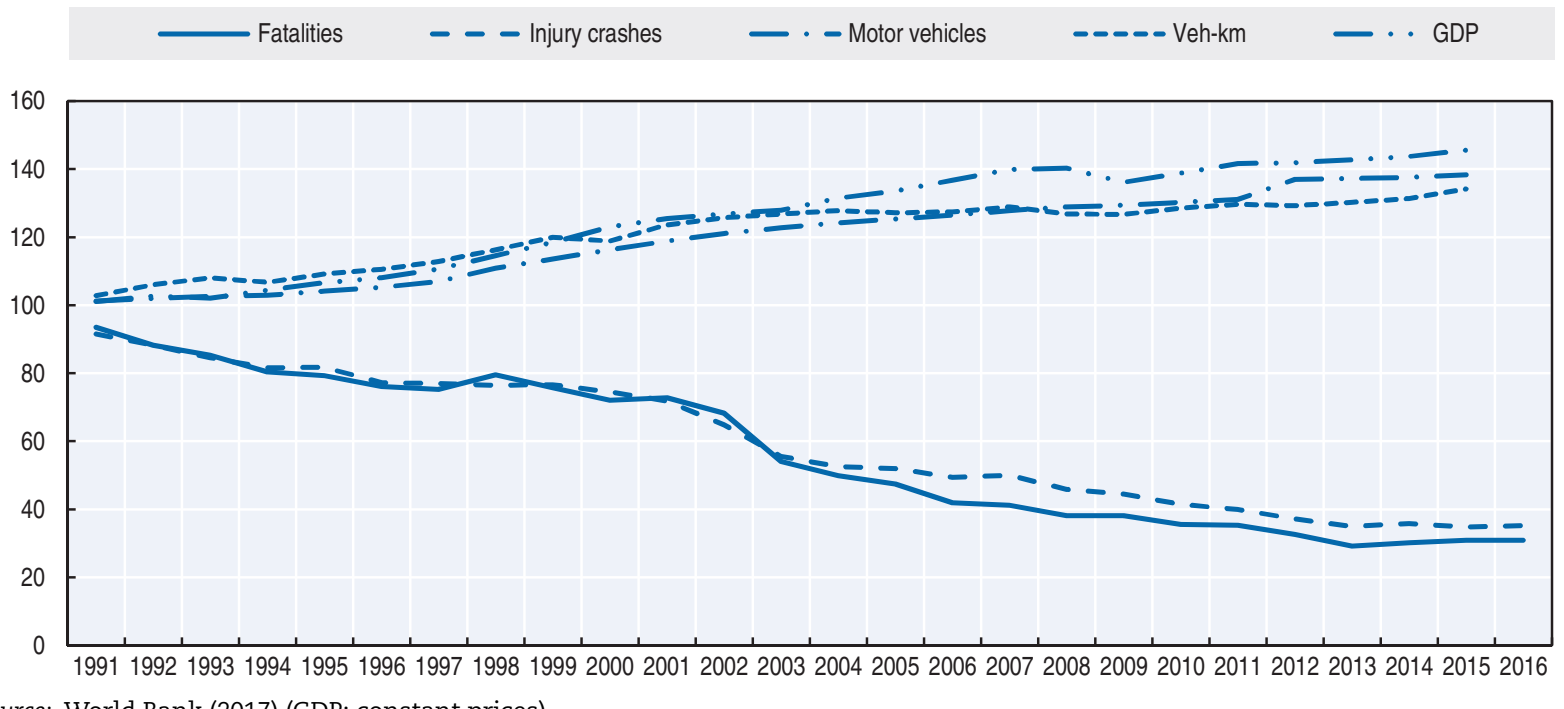

Source: World Bank (2017) (GDP; constant prices). 


\section{Road safety by user group}

The reduction in road deaths since 2000 did not benefit all categories of users in the same manner. The greatest reductions were observed for car occupants and moped riders $(-66.4 \%)$. The number of motorcyclists killed decreased by $35.2 \%$. The number of pedestrians and cyclists killed decreased by $45 \%$. These gains were achieved mainly in the first half of the period. A stagnation has been observed since 2007 for cyclists and since 2009 for pedestrians.

Powered two-wheelers (moped riders and motorcyclists) are overrepresented in road fatalities. While they account for less than $2 \%$ of distance travelled, they represent $22 \%$ of total fatalities and $30.8 \%$ of those seriously injured. The risk of fatality per kilometre driven is 23 times higher for a motorcyclist than for a car occupant. However, some progress is being observed, in part attributed to a decrease in speed of passenger cars and to a lesser extent of motorcyclists themselves. The implementation of speed cameras able to record the rear motorcycle plate has contributed to an annual average reduction of $3.5 \%$ of motorcyclists killed since 2005 (with strong annual fluctuations due to weather conditions).

In 2015, pedestrians and cyclists represented about $18 \%$ of all fatalities, and their mortality has decreased since 2014 by $6.2 \%$ and $6.3 \%$ respectively. The number of car occupant fatalities continued to increase throughout 2015. The increase in motorcyclist

Table 12.2. Road fatalities by road user group

\begin{tabular}{lrrrrr|rrrr}
\hline & 1990 & 2000 & 2010 & 2014 & 2015 & \multicolumn{4}{|c}{$2015 \%$ change from } \\
\cline { 7 - 10 } & & & & & & 2014 & 2010 & 2000 & 1990 \\
\hline Pedestrians & 1504 & 848 & 485 & 499 & 468 & -6.2 & -3.5 & -44.8 & -68.9 \\
Cyclists & 429 & 273 & 147 & 159 & 149 & -6.3 & 1.4 & -45.4 & -65.3 \\
Moped users & 702 & 461 & 248 & 165 & 155 & -6.1 & -37.5 & -66.4 & -77.9 \\
Motorcyclists & 1011 & 947 & 704 & 625 & 614 & -1.8 & -12.8 & -35.2 & -39.3 \\
Car occupants & 6729 & 5351 & 2117 & 1663 & 1796 & 8.0 & -15.2 & -66.4 & -73.3 \\
Others & $\mathbf{4 9 6}$ & 290 & 291 & 273 & 279 & 2.2 & -4.1 & -3.8 & -43.8 \\
Total & $\mathbf{1 0 9 9}$ & $\mathbf{8 1 7 0}$ & $\mathbf{3 9 9 2}$ & $\mathbf{3 3 8 4}$ & $\mathbf{3 4 6 1}$ & $\mathbf{2 . 3}$ & $\mathbf{- 1 3 . 3}$ & $\mathbf{- 5 7 . 6}$ & $\mathbf{- 6 8 . 5}$ \\
\hline
\end{tabular}

Figure 12.2. Road fatalities by road user group in percentage of total, 2015

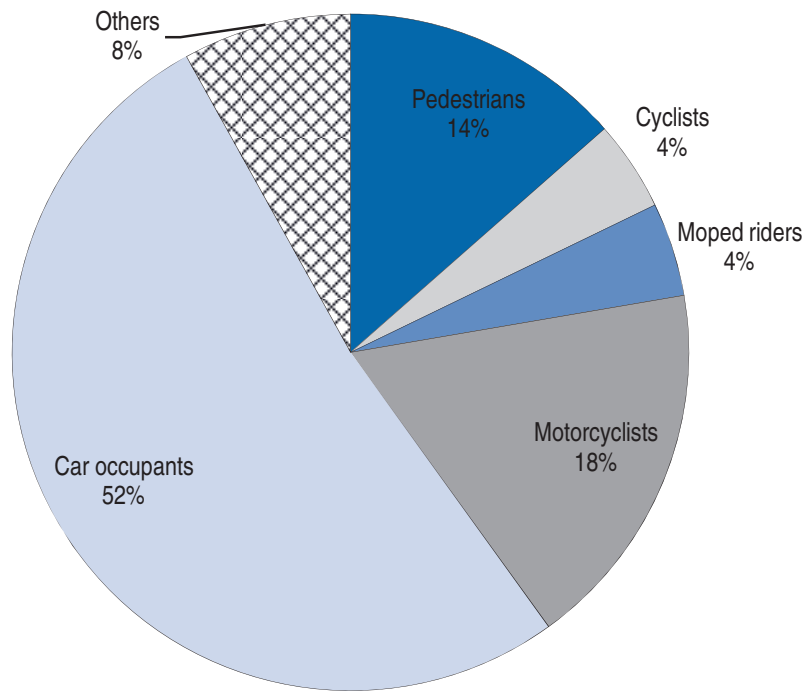


fatalities during the summer of 2015, due to favourable weather conditions, was compensated for by a strong decrease in autumn. Overall, the number of motorcyclist fatalities slightly decreased (-1.8\%) in 2015 compared to 2014.

\section{Road safety by age group}

Between 2000 and 2015, the different age groups followed different trends. This is the result of both an evolution in individual risk and demographic change.

The 18-24 year-old group are the most affected by road crashes. In 2015, they represented $18 \%$ of all fatalities but only $8 \%$ of the population. Fatalities in this group which had declined by $8.5 \%$ in 2014 ( 54 fewer people killed), increased again by $6.4 \%$ ( 27 people) in 2015. Following the significant decline in motorcyclist fatalities among young people in 2014, figures remained stable in 2015 with 107 fatalities (compared with 105 in 2014 and 148 in 2010).

The 15-17 year-old group are also associated with a high number of injured hospitalised, but their mortality is now moderate following a strong decrease in the number of moped riders in the 2000s.

Table 12.3. Road fatalities by age group

\begin{tabular}{|c|c|c|c|c|c|c|c|c|c|}
\hline \multirow{2}{*}{ Age } & \multirow{2}{*}{1990} & \multirow{2}{*}{2000} & \multirow{2}{*}{2010} & \multirow{2}{*}{2014} & \multirow{2}{*}{2015} & \multicolumn{4}{|c|}{$2015 \%$ change from } \\
\hline & & & & & & 2014 & 2010 & 2000 & 1990 \\
\hline $0-14$ & 535 & 366 & 130 & 112 & 101 & -9.8 & -22.3 & -72.4 & -81.1 \\
\hline $15-17$ & 463 & 354 & 161 & 116 & 125 & 7.8 & -22.4 & -64.7 & -73.0 \\
\hline $18-20$ & 1131 & 867 & 370 & 252 & 284 & 12.7 & -23.2 & -67.2 & -74.9 \\
\hline $21-24$ & 1563 & 879 & 461 & 330 & 335 & 1.5 & -27.3 & -61.9 & -78.6 \\
\hline $25-64$ & 5672 & 4204 & 2105 & 1802 & 1785 & -0.9 & -15.2 & -57.5 & -68.5 \\
\hline $65-74$ & & 620 & 264 & 283 & 312 & 10.2 & 18.2 & -49.7 & \\
\hline $75-84$ & & 562 & 366 & 310 & 318 & 2.6 & -13.1 & -43.4 & \\
\hline$\geq 85$ & & 187 & 135 & 179 & 199 & 11.2 & 47.4 & 6.4 & \\
\hline Total & 10999 & 8170 & 3992 & 3384 & 3461 & 2.3 & -13.3 & -57.6 & -68.5 \\
\hline
\end{tabular}

Figure 12.3. Road fatality rates by age group Deaths per 100000 inhabitants in a given age group, 1990-2015

0-14 years $\quad--15-17$ years $\_--18-20$ years $\quad----21-24$ years $\quad \cdots 25-64$ years $\quad \cdots \geq 65$ years

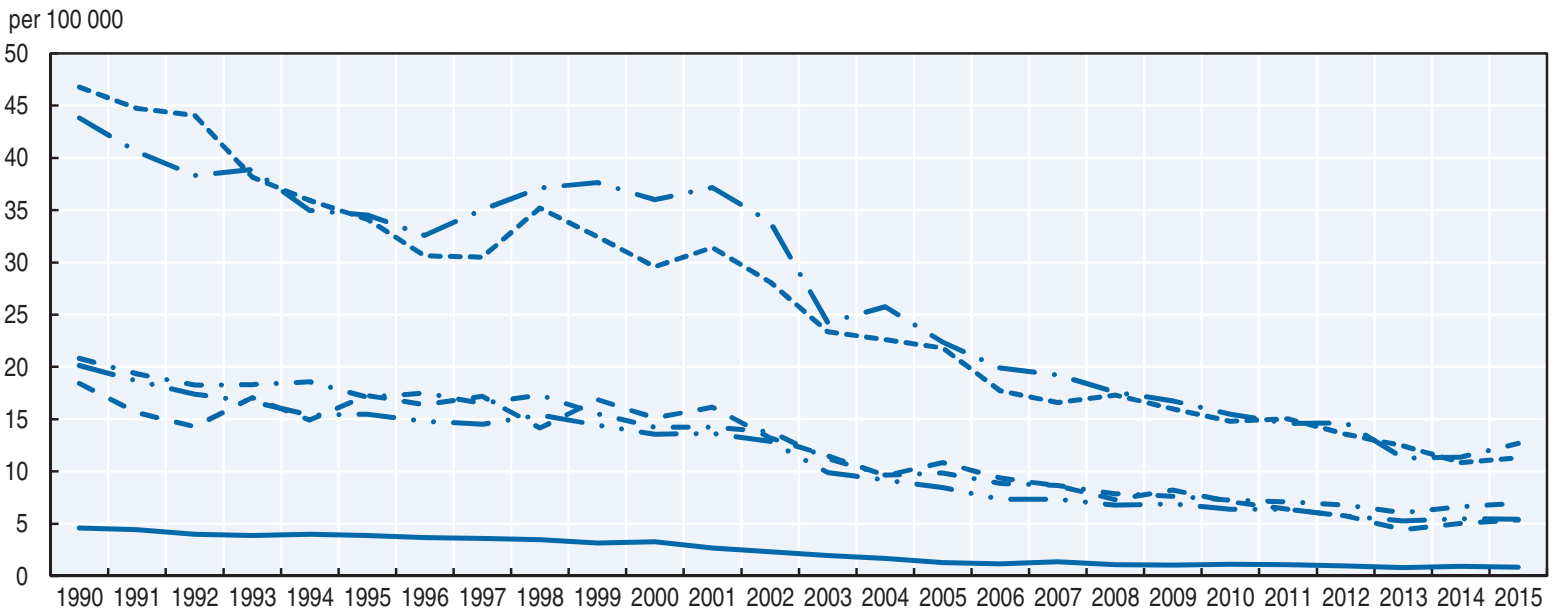




\section{Box 12.1. Road safety for an ageing population}

The population aged 65 and over is increasing, as well as the mobility of this age group. In 1990, they represented $14 \%$ of the population; in 2015 this share was $19 \%$ and it is estimated that it will reach $26 \%$ in 2060 (INSEE, 2010).

Persons aged 65 and over represented $24 \%$ of road deaths in 2015 and this share is estimated to reach $30 \%$ in 2020. In the years to come, persons aged 65 and over will be at the centre of road safety policies.

The senior population clearly has an increased risk in traffic. Their mortality rate is of 69 persons killed per million inhabitants for the 65 and over age group, and 87 for the 75 and over age group (compared to the average of 54 for the entire population).

Fatalities are linked to the user groups most specific to this age group. Fatalities among those aged 75 are mainly among pedestrians, whereas the increase of mortality of those aged 65-74 primarily concerns cyclists and motorists.

There is no mandatory renewal of the driving licence or medical examination required. However, medical tests may be required by administrative authorities. Medical tests are systematically compulsory for candidates or holders of a driving licence suffering from a physical disability or medical disease. Medical tests consist of cognitive and sensory ability checks, led by a licensed physician or the region's medical committee.

Table 12.4. Road fatalities among senior citizens

\begin{tabular}{|c|c|c|c|c|c|c|c|c|c|}
\hline & \multicolumn{3}{|c|}{$65-74$} & \multicolumn{3}{|c|}{$75-84$} & \multicolumn{3}{|c|}{$\geq 85$} \\
\hline & 2010 & 2015 & $\%$ change & 2010 & 2015 & $\%$ change & 2010 & 2015 & $\%$ change \\
\hline Pedestrians & 64 & 60 & -6 & 119 & 93 & -22 & 62 & 74 & 19 \\
\hline Cyclists & 26 & 27 & 4 & 21 & 20 & -5 & 6 & 4 & - \\
\hline Moped riders & 9 & 6 & - & 6 & 2 & - & 0 & 0 & $=$ \\
\hline Motorcyclists & 10 & 15 & 50 & 10 & 2 & - & 1 & 0 & - \\
\hline Car occupants & 143 & 178 & 24 & 199 & 167 & -16 & 59 & 105 & 78 \\
\hline Total & 264 & 312 & $18 \%$ & 366 & 318 & -13 & 135 & 199 & 47 \\
\hline
\end{tabular}

Figure 12.4. Road fatality rates by age group - Focus on the senior population Deaths per 100000 inhabitants in a given age group, 2000-15
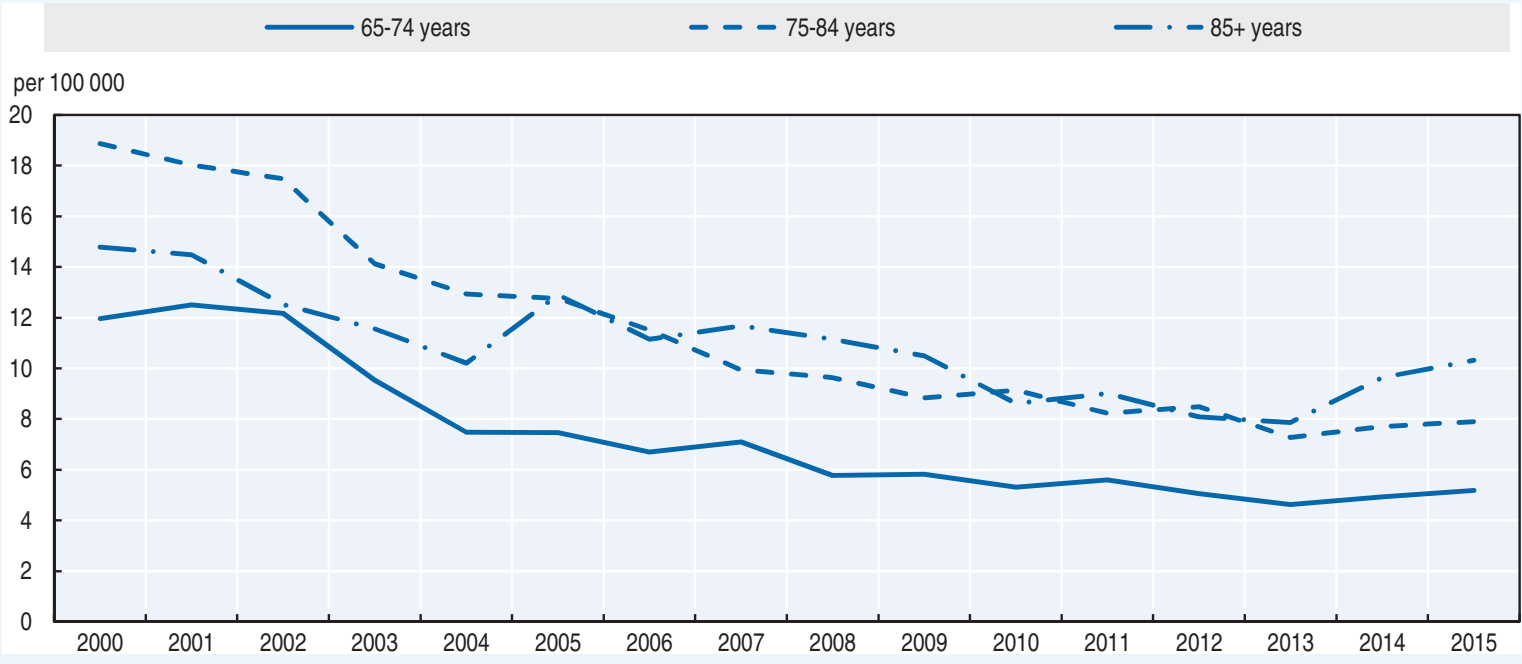
Regarding the impact of demographic changes, the population aged 65 and above has increased significantly since 2011 (see Box 12.1). To a lesser extent, the upward trend for the 45-64 age group (the baby boomers) and those 75 and over is continuing (+6.4\%). As the population ages, improvement in road safety for the older generation is becoming an important focus.

The repartition of road fatalities by travel mode is largely influenced by age, given the minimum age required to drive certain vehicles. Thus the 15-17 age group represents the largest share of fatalities among moped riders. Children under 14 and those above 65 are particularly vulnerable as pedestrians and cyclists.

Figure 12.5. Road fatality rate by age and road user group Fatalities per 100000 inhabitants, 2015

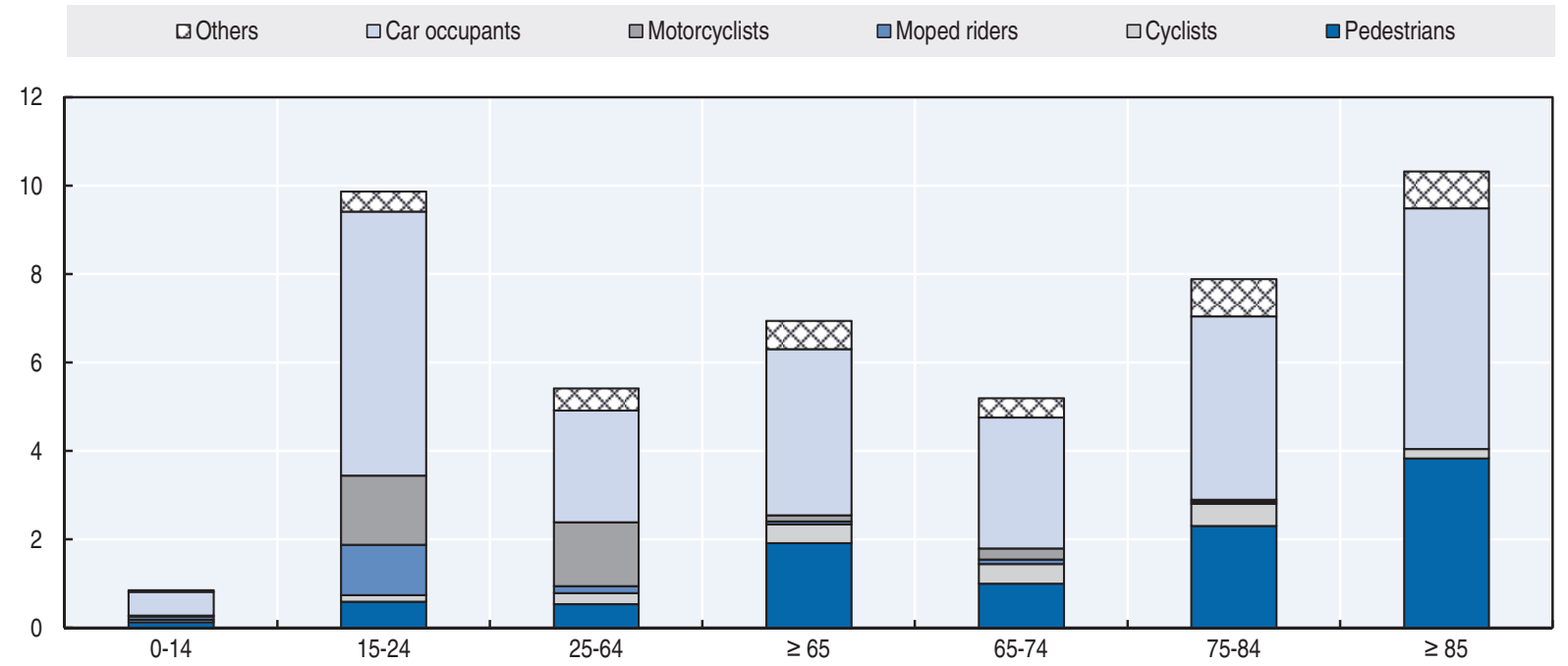

\section{Road safety by road type}

In 2015, France had more than 1 million kilometres of roads. When fatalities per billion vehicle-kilometres travelled are broken down by type of road, the risk on country roads is much higher.

Motorways are the safest network, since they absorb $25 \%$ of the traffic, in a context of growing traffic $(+3 \%)$ and account for $9 \%$ of fatalities. Fatalities on motorways rose considerably in 2015 in comparison with 2014 (56 more people killed, representing an increase of $23 \%$ ).

Since 2000, the decrease in the number of fatalities in built-up areas and rural roads has been of the same magnitude, about $60 \%$. In $2015,63 \%$ of fatalities occurred on rural roads and $29 \%$ on urban roads. More than half of all road deaths are on a $90 \mathrm{~km} / \mathrm{h}$ speed limit road, outside built-up areas. 
Figure 12.6. Road fatalities by road type

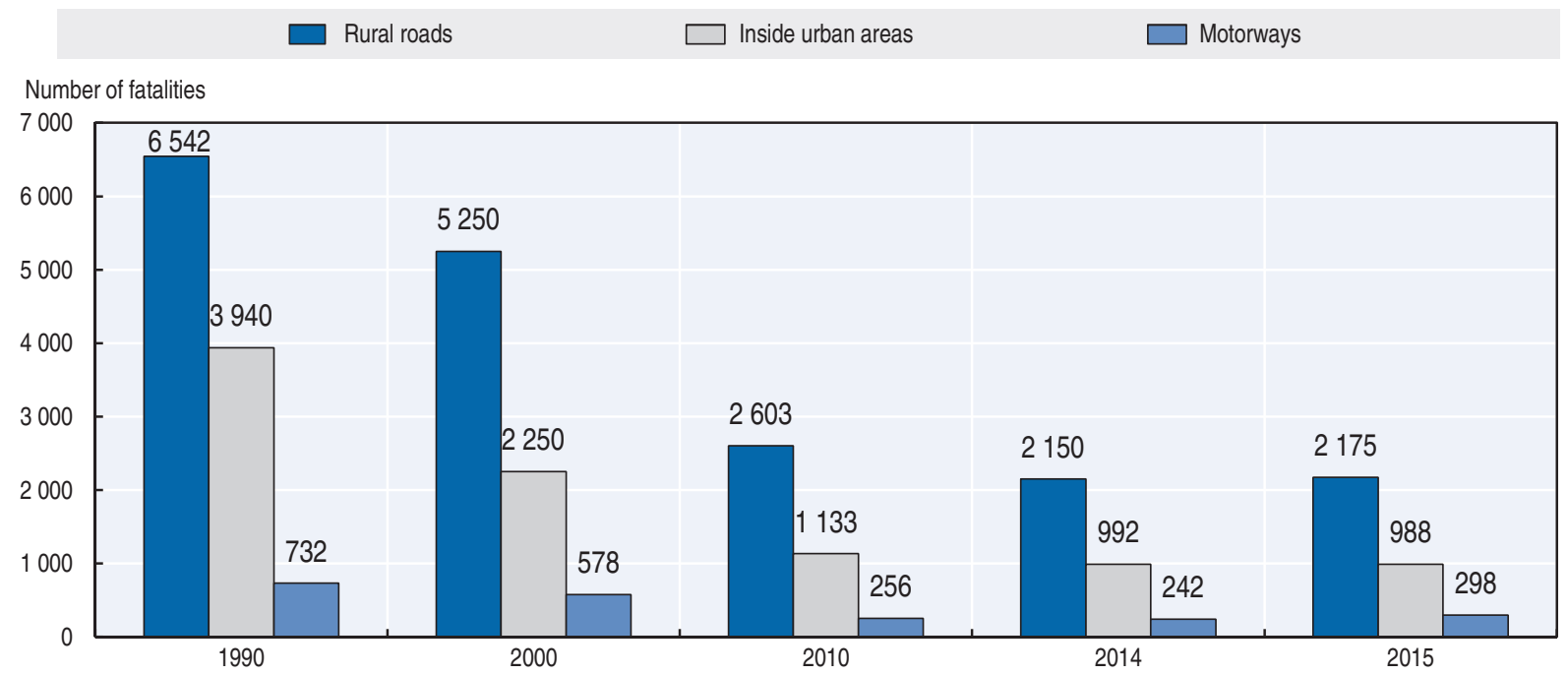

\section{Economic costs of traffic crashes}

Road traffic crashes represent a significant cost for society. Based on reported crashes, the cost was estimated in 2015 at about EUR 32.8 billion, or 1.5\% of GDP. These costs cannot be directly compared to the costs published for previous years, as unit values for a road fatality, injured person and property damage have been revised following 2014 guidelines on the socio-economic evaluation of projects following recommendations from the OECD (CGSP, 2013).

Costs of road crashes take into account production losses, affective loss for the relatives, medical costs and the loss of quality of life.

The total costs could actually be much higher, when taking into account non-reported crashes. IFSTTAR estimates that the number of injured people could be four times greater than the registered number, and the number of hospitalised nearly twice as great. This could lead to a global total of EUR 47.2 billion, representing 2.2\% of France's GDP.

Table 12.5. Costs of road crashes, 2015

\begin{tabular}{lcc}
\hline & Unit cost & Total \\
\hline Fatalities & EUR 3197 million & EUR 11.1 billion \\
Hospitalised persons & EUR 399633 & EUR 10.6 billion \\
Slight injuries & EUR 15895 & EUR 0.7 billion \\
Property damage costs of injury crashes & EUR 4902 & EUR 0.3 billion \\
Property damage costs of non-injury crashes & & EUR 10.1 billion \\
Total & & EUR $\mathbf{3 2 . 8}$ billion \\
Total as \% of GDP & & $\mathbf{1 . 5 \%}$ \\
\hline
\end{tabular}

\section{Recent trends in road user behaviour}

\section{Speed}

In 2015, inappropriate or excessive speed remained the main cause of fatal crashes (23\%) and was present in $32 \%$ of road crashes. 
Between 2000 and 2011, average speeds during daytime decreased by $10 \mathrm{~km} / \mathrm{h}$ or more on all non-urban networks. However, speed measurements undertaken in 2015 revealed that the average speed increased by $4 \mathrm{~km} / \mathrm{h}$ on the motorway network (speed limit: $130 \mathrm{~km} / \mathrm{h}$ ) compared to 2012. The average speed also increased by $2 \mathrm{~km} / \mathrm{h}$ on the dual carriageway network (speed limit: $110 \mathrm{~km} / \mathrm{h}$ ). On non-urban roads with a $90 \mathrm{~km} / \mathrm{h}$ speed limit, driving speeds remained stable in 2015 at the level reached in 2008. Driving speeds in urban areas (where the speed limit is $50 \mathrm{~km} / \mathrm{h}$ ) increased again, after a significant decrease in 2013 and 2014, by $3 \mathrm{~km} / \mathrm{h}$ compared with the level reached between 2008 and 2012.

The table below summarises the main speed limits in France.

Table 12.6. Passenger car speed limits by road type, 2017

\begin{tabular}{lrr}
\hline & General speed limit & \multicolumn{1}{l}{ Comments } \\
\hline Urban roads & $50 \mathrm{~km} / \mathrm{h}$ & \\
Rural roads & $90 \mathrm{~km} / \mathrm{h}$ & $80 \mathrm{~km} / \mathrm{h}$ in wet weather or for novice drivers \\
Dual carriageways & $110 \mathrm{~km} / \mathrm{h}$ & $100 \mathrm{~km} / \mathrm{h}$ in wet weather or for novice drivers \\
Motorways & $130 \mathrm{~km} / \mathrm{h}$ & $110 \mathrm{~km} / \mathrm{h}$ in wet weather or for novice drivers \\
\hline
\end{tabular}

\section{Drink driving}

The maximum authorised blood alcohol content (BAC) is $0.5 \mathrm{~g} / \mathrm{l}$ for all drivers (including cyclists). For bus and coach drivers the maximum authorised BAC is $0.2 \mathrm{~g} / \mathrm{l}$. Since 2009 all buses that carry children have alcohol interlocks installed. Since 1 July 2015 the maximum authorised BAC is $0.2 \mathrm{~g} / \mathrm{l}$ for novice drivers during their probation period.

It is estimated that alcohol is the main cause of $19 \%$ of fatalities and a contributing factor in $30.5 \%$ of fatal crashes. This proportion has remained stable, around $30 \%$, since 2000. Drinking and driving involves all age groups, except the older generation.

Experimentation with the use of alcohol interlocks for drink driving offenders started in December 2016 in some regions. Some drink driving offenders, subject to a mandatory review by a medical committee, will be allowed to resume driving on the condition that they install an alcohol interlock device in their vehicle.

\section{Drugs and driving}

A study among drivers estimated that $3 \%$ of crashes could be attributed to the consumption of prescription drugs. Benzodiazepines (anxiolytic or hypnotic) and antidepressants, widely used in France, are associated with a significant increase in the risk of causing a road crash.

Since 2010 between $21 \%$ and $26 \%$ of fatal crashes have involved use of illegal drugs. In 2015 , it was estimated that illegal drugs were a factor in $23 \%$ of fatalities and the main cause of more than 5\% of fatal crashes. Illegal drug use continued in 2015 with an increase of 1.5 points over 2014.

Among drivers tested with a BAC above the legal limit of $0.5 \mathrm{~g} / \mathrm{l}$, at least one-third also tested positive in a drug test.

Since 2003, driving under the influence of substances or plants classified as narcotics constitutes an offence. Testing is approved for the following categories: cannabinoids, amphetamines, cocaine and opiates. Increased random drug tests, using a saliva-testing kit, will be carried out by the police, which are less expensive than blood tests. After a trial 
period from December 2015 to June 2016 in 11 counties, saliva tests will be generalised in 2017. The short-term objective is the doubling of the number of drug tests per year.

\section{Distraction}

Some international studies show that between $25 \%$ and $50 \%$ of injury crashes are due to a lack of attention, but these incidents are difficult to report. In police files, the factor "distracted attention" was mentioned in 246 fatal cases in 2015 ( $7 \%$ of fatalities).

It is forbidden to drive with a hand-held mobile phone, but the use of hands-free mobile phones is tolerated. While phoning when driving is a growing concern, the concern is even greater over the expanding number of communication functions offered by a smartphone. Since 1 July 2015, drivers are prohibited from using any device attached to the ear while driving, whether used for phone calls or for listening to music or the radio (headphones, headsets).

\section{Sleepiness and fatigue}

According to police records, sickness and sleepiness are a contributing factor in $5 \%$ of fatal crashes. Sleepiness is more prevalent on motorways, where it is identified in $26 \%$ of fatal road crashes (AFFA, 2016).

\section{Seat belts and helmets}

Seat belt wearing has been compulsory for drivers and in front seats in rural areas since 1973, on urban areas and at night since 1975 and at all times since 1979. They have been compulsory in rear seats since 1991. Children under 10 must be seated in a rear seat and be adequately restrained, taking into account their weight and height.

The seat belt wearing rate is among the highest in OECD countries; however, there is still room for improvement, especially for rear seats. In $2015,21 \%$ of car occupants killed and $32 \%$ of utilitarian vehicle occupants killed were not wearing a seat belt or the seat belt was not well buckled when the crash occurred; $11 \%$ of front-seat passengers and $28 \%$ of rear-seat passengers were not wearing a seat belt; $43 \%$ of fatalities involving a driver under the influence of alcohol were not wearing a seat belt and $31 \%$ of road users killed at night were not wearing a seat belt. It is estimated that 150 lives could have been saved if all vehicle occupants had worn their seat belts.

Table 12.7. Seat belt wearing rate by car occupancy and road type

$\%$

\begin{tabular}{lcc}
\hline & 2005 & 2012 \\
\hline Front seat & & \\
$\quad$ Urban roads & 94.2 & 95.8 \\
$\quad$ Motorways & 98.3 & 98.6 \\
Rear seats & & 71 \\
$\quad$ Adults - Urban roads & 66 & 84 \\
Adults - Motorways & 73 & 89 \\
Children (use of child restraint) - Urban roads & 85 & 94 \\
Children (use of child restraint)- Motorways & 82 & \\
\hline
\end{tabular}

Wearing a helmet was made compulsory in 1973 for motorcyclists with engines over $125 \mathrm{cc}$ and for moped riders and motorcyclists with engines of $50 \mathrm{cc}$ to $125 \mathrm{cc}$ in rural areas. 
This obligation was extended to urban areas in 1975 . The helmet-wearing rate of powered two-wheelers (it is difficult to discriminate between mopeds and motorcycles during observations) is almost $100 \%$ during week days but only $90 \%$ during the weekend. In 2014 , 36 of the moped or motorcycle riders killed (18 motorcyclists [3\%] and 18 moped riders [12\%]) were not wearing a helmet.

Recent research by IFSTTAR has demonstrated that the risk of severe injury was considerably reduced when wearing a helmet. In particular the chance of a severe head injury (MAIS3+) was reduced by $66 \%$ in urban areas and by $97 \%$ outside urban areas.

Since March 2017, it is illegal to allow children under 12 to ride a bike without a helmet. Failure to do so results in a fine for the parents.

\section{National road safety strategies and targets}

\section{Organisation of road safety}

Since 2012, the lead agency for road safety (Road Safety Directorate) reports to the Minister of the Interior. The Minister of the Interior chairs the Inter-ministerial Road Safety Committee, an assembly of representatives of various ministries, where decisions are taken. The ONISR observatory reports to the road safety director and is in charge of managing the road traffic accident database, analysing road safety performance and organising research to prepare for new measures and evaluate.

The National Road Safety Council (CNSR) is in charge of presenting road safety action proposals to the government. Its main role is to provide guidance to the government, formulating recommendations and identifying objectives to reduce road crashes. It is assisted by an experts committee which provide appropriate technology and scientific input.

\section{Road safety strategy for 2011-20}

In order to reduce the number of road deaths by half over the period 2011-20, which would mean fewer than 2000 persons killed on French roads by the end of the decade, key priorities identified by the government are to:

- reduce fatalities among young people and novice drivers

- reduce fatalities among powered two-wheelers

- combat the main crash-contributing factors of speed and impaired (alcohol/drug) driving.

The Minister of Interior announced on 26 January 2015 an action plan with 26 road safety measures, aimed in particular at reducing injuries among vulnerable road users who currently represent $70 \%$ of those seriously injured. Nineteen measures were implemented as of 31 December 2015. The Inter-ministerial Road Safety Committee (CISR) met on 2 October 2015 for the first time since May 2011. A 22-point action plan was announced, accompanied by 33 additional measures, articulated around the following objectives:

- to increase the fight against dangerous behaviour on the roads

- to protect vulnerable road users

- to bring road safety into the digital era

- to strengthen legal equality for all road users. 


\section{Road safety targets}

The current target of the French government is to reduce the number of road fatalities to below 2000 by 2020, which is in line with the European Commission goal of halving the number of fatalities by 2020 .

\section{Monitoring}

The progress towards the 2020 target is measured using national indicators and published each year in the French Road Safety Observatory (ONISR) annual report. The projections of road fatalities produced through the simulation models of population dynamics are also considered a tool for the management of implemented policies. The assessment of the impact of road safety policies identifies issues and priorities, therefore influencing the choice of new measures to be implemented.

Figure 12.7. Trends in road fatalities towards national target

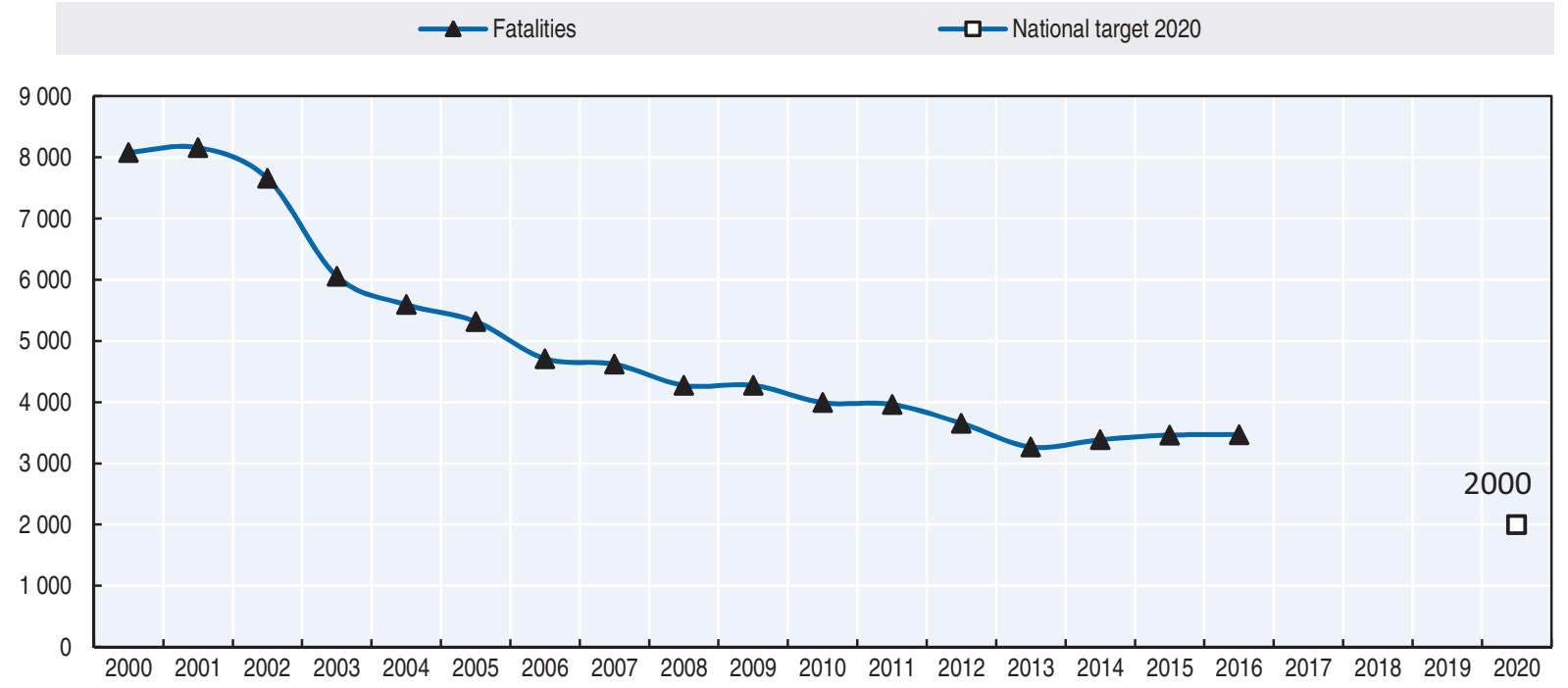

\section{Recent safety measures (2014-17)}

\section{Road safety management}

- The National Road Safety Council issued 17 recommendations to the government. Some of them have already been implemented (e.g. signs to announce fixed speed cameras, communication rather than enforcement around the use of self-alcohol testing, promoting accompanied driver education). Others were among the 26 measures announced in January 2015 by the Minister of Interior (e.g. regulations for motorcyclists driving between two lanes, forbidding the use of ear pieces and audio headsets, standardising powered two-wheeler number plates, defining auditing methods for local road networks to deal with road side obstacles, experimenting with some reduction in speed limits on single carriageways).

- The National Council for Road Safety (CNSR) will initiate its work organised around commissions focusing on vulnerable road users: education and road safety at work or on the way to work; vehicles: innovative technologies and infrastructures; medical conditions and road safety. 


\section{Driving licence}

- In a context of an overall lack of places, high charges and long waiting periods, new measures have been adopted since 2014 to improve the organisation of driver licence tests.

- Since 1 November 2014, accompanied driving practice is possible from the age of 15 (instead of 16 as previously). Young people can take the driving licence examination at 17.5 year old, although they will not be driving on their own before they turn 18 .

- In 2016, 1000 new questions were introduced in the driving theory test. They are aimed at raising awareness of the dangers on the road, with new subjects such as "eco-driving" and "first aid".

- Since June 2016, the organisation and administration of the driving theory test has been delegated to certified third-party operators. This measure aims at freeing up examiners and opening up 142000 places for practical driving tests. It also reduces cheating as the test is electronic and nearby candidates cannot see the same slides or videos.

\section{Powered two-wheelers driving licence}

- Since June 2016, to prevent immediate access for new motorcyclists to powerful powered two-wheelers, motorcyclists of all ages will start with the A2 licence (previously only applied to those under 24 years of age) and will need to wait for 2 years before getting the full A licence.

\section{Speed management}

- In 2014, the speed camera fleet was strengthened with new automated speed cameras including average speed checks. Other new automated cameras enforce stops at train crossings and traffic lights.

- In 2015, France trialled new speed management devices: fixed speed cameras that detect excess speed in both directions; speed cameras that take pictures of both the front and rear of the vehicle; traffic light radars to determine if they can be adapted to capturing excessive speed as well, and autonomous speed cameras for road work sections.

- The inter-ministerial action plan defined a strategy for 2016 for automated speed control with the objective of modernising the cameras already in place and increasing fourfold the number of controlled areas. It is planned to install within a three-year period 10000 mock speed cameras and 500 real ones, bringing the overall total to 4700 devices as compared to 4200 today.

- The "two-way" function was installed on 111 fixed-speed cameras allowing speed checks on opposing travel lanes.

- In February 2016, the first mock speed camera (by using a sign with the following message: "For safety reasons, frequent flashing zone") was installed on a route prone to accidents. The principle is to frequently and randomly move an autonomous camera on specific routes to stimulate driver vigilance and encourage compliance with speed limits. A different concept, a mock camera using a booth will be trialled in 2017. By the end of 2020, 1000 dangerous routes and zones will be equipped.

- As of 2017, on-board speed cameras will be operated by accredited private providers on pre-defined routes by administrative authorities and the police. 
- In accordance with the Safe System approach, traffic calming measures have been widely adopted in the urban space, such as "zone 30". Since 2015, the mayor has the power to lower speed limits in all or parts of urban and residential areas to $30 \mathrm{~km} / \mathrm{h}$.

\section{Enforcement}

- In order to ensure equality between road users, since 1 January 2017, employers have the obligation to name employees driving a company vehicle when detected committing a traffic offence

- According to EU Directive 2015/413 facilitating cross-border exchange information on road safety traffic offences, France is developing its exchange of information policy with more than 10, mainly neighbouring, countries.

- In 2015 the CISR decided to ensure legal equality for all road users. Offenders who do not pay their fine despite notifications are registered in a "Register of bad payers". When stopped (during a check or following an offence) by French police, payment of the fine will be requested and their vehicle will be retained as long as the fine remains unpaid.

- As of 2017, offenders will be monitored with a virtual driving licence, which will function similar to a normal French driving licence with the same amount of points (12), with the possibility of a driving ban in France for one year in the case of there being no points left.

- After trials in 2016 in several regions, drug saliva tests will be generalised in 2017.

\section{Work-related road crashes}

- The Interministerial Committee for Road Safety (CISR, 2015) plans to improve the exemplary role of State employees. Liability may be established for State employees who commit a road traffic offence with a vehicle placed at their disposal by their employer. As an example, the Charter of the Ministry of Economy and Finance commitment in favour of road safety was recently signed.

- In 2016, 21 companies agreed to respect 7 road safety commitments and joined the call to ensure appropriate road safety of their employees (http://entreprises.routeplussure.fr/, accessed 11 May 2017). In 2017, this call has already been signed by 500 companies.

\section{Road users}

\section{Protective equipment for motorcyclists}

- A guide was released in 2012 to promote the benefits of individual protective equipment. In 2014 and 2015, a partnership with insurance companies, protective equipment providers and bikers' associations set up an incentive scheme for users of powered two-wheelers to purchase personal protective equipment as a package deal (gloves, boots, clothing and possibly an airbag suit).

- In 2015, the Inter-ministerial Road Safety Committee (CISR) made it compulsory for motorcyclists to have technical checks of their powered two-wheelers when selling, and to wear certified gloves.

- Wearing the safety vest is mandatory for motorcycle users in case of an emergency stop.

- Since February 2016, trials started allowing powered two-wheeler users around Paris, Marseille, Bordeaux and Lille to legally ride between stationary lines of traffic. Riding in-between the lanes is allowed only on dual-carriageways and motorways where the speed limit is between $70 \mathrm{~km} / \mathrm{h}$ and $130 \mathrm{~km} / \mathrm{h}$, when all lanes are at a standstill. PTW rides 
should stay in the two lanes on the left and not ride faster than $50 \mathrm{~km} / \mathrm{h}$, with sufficient space.

\section{Infrastructure}

- New motorways are being equipped with rumble strips on the edges of road markings to prevent crashes due to drowsiness.

- As one of the 26 priority measures of January 2015, additional yellow "No Entry" signs can be installed on exit slip roads to prevent accessing the motorway the wrong way.

\section{Road safety campaigns}

\section{Drink driving - Drugs and driving}

- In 2015, a campaign was launched on the 10-year anniversary of "Sam", the designated driver www.securite-routiere.gouv.fr/medias/campagnes/10ansdesam (accessed 11 May 2017).

- In 2016, "Sam" became "Samvenger", a special agent of the Avengers (popular characters from comic books) responsible for preventing young people from driving while impaired www.securite-routiere.gouv.fr/medias/campagnes/sam-et-les-avengers-partent-en-mission (accessed 11 May 2017).

- The "Dare to Say No" campaign was launched to encourage passengers to refuse to ride with an alcohol-impaired driver. Media personalities and athletes committed themselves to testifying in several videos www.securite-routiere.gouv.fr/medias/campagnes/osezdirenon (accessed 11 May 2017).

- A public campaign was launched in 2016 to inform and raise awareness about the risks of driving under the influence of drugs www.securite-routiere.gouv.fr/medias/campagnes/ stupefiants-au-volant-chiffres-et-risques (accessed 11 May 2017).

\section{Consequences of road crashes}

- A new programme entitled Shockwave (“Onde de choc") was introduced in 2015 to boost awareness that road crashes impact not only the victims, but also their family, friends and colleagues. In 2016, the Shockwave campaign was reinforced with several new messages.

- In February 2017, a short movie "L'annonce" ("Breaking the news"), by the Oscar-winning documentary filmmaker Jean-Xavier de Lestrade, focuses on the precise moment when police announce the death of a loved one in a road crash www.securite-routiere.gouv.fr/ medias/campagnes/l-annonce (accessed 11 May 2017).

\section{Children Safety}

- A character "Elliot le pilot" ("Elliot the pilote") was created to guide road safety initiatives for children aged 6 to 10, with playful and amusing videos and apps www.securiteroutiere.gouv.fr/medias/campagnes/elliot-le-pilote-le-guide-securite-routiere-des-6-10-ans (accessed 11 May 2017).

\section{Recent and ongoing research}

Important ongoing research includes the following:

- Driving Licence Exam: Differences between Men and Women

- Quality of Primary Road Safety Education

- Risk Assessment of Head Trauma in Accidents Involving Cyclists and Pedestrians (TEVU) 
The results of some recent completed research projects are presented below.

\section{Drink and drug driving}

- Project "ActuSAM": The purpose of this research was to re-evaluate the relative risk of being responsible for a fatal crash while driving under the influence of illicit drugs and/or alcohol, the prevalence of such drivers within the driving population, and the corresponding numbers of people killed in France. The risk of being responsible for a fatal crash increases by a factor of 1.65 for drivers under the influence of cannabis, and by a factor of 16.8 for alcohol-impaired drivers.

\section{Powered two-wheelers}

- Project "EFFIGAM": Motorcycle air bags, efficiency, and at what speed? The objective of this study was to assess the protection provided by motorcycle air bags. The protective effect of the air bag deployment is greater than that of back protection, as it significantly reduces the probability of fatal injuries. However air bag effectiveness varies depending and the type of impact and the severity of the crash.

\section{Innovative technologies}

- The human factor, embedded and digital technologies: What role for road safety policies? www.territoires-ville.cerema.fr/facteurs-humains-technologies-embarquees-et-a2208.html (accessed 11 May 2017).

\section{References}

ASFA (2016), Key figures 2016, www.autoroutes.fr/FCKeditor/UserFiles/File/Chiffres\%20cl\%C3\%A9s\%20ASFA \%202016\%20BD.pdf (accessed 11 May 2017).

INSEE (2010), Projections de population à l'horizon 2060, www.insee.fr/fr/statistiques/1281151 (accessed 11 May 2017).

World Bank (2017), “GDP (constant US\$)”, World Development Indicators, http://databank.worldbank.org/ data/reports.aspx? source=world-development-indicators (accessed 23 February 2017).

\section{Websites (all accessed 11 May 2017)}

- ONISR - The French Road Safety Observatory: www.securite-routiere.gouv.fr/la-securite-routiere/lobservatoire-national-interministeriel-de-la-securite-routiere.

* Road Safety in France: 2015 Annual Report. www.securite-routiere.gouv.fr/content/download/35538/ 340472/version/1/file/2016-05-18+Final+2015+Road+Safety++Results+2015+-+France+-+Abstract.pdf.

* French Road Safety Results - Provisional 2016. www.securite-routiere.gouv.fr/content/download/ 36244/346638/version/1/file/2017+01+23+-+French+Road+Safety+Results+-+Provisional+2016.pdf.

- The National Council for Road Safety: www.conseil-national-securite-routiere.fr/.

- IFSTTAR - The French Institute of Science and Technology for Transport, Development and Networks: www.ifsttar.fr/.

- CEREMA - The French Research Centre on Risks, Environment, Mobility and Planning www.cerema.fr.

- Health and Driving: This website gathers information from the latest news and scientific papers driving ability. http://medecins.inserr.org/.

- Road Safety Foundation: http://fondation-securite-routiere.org/.

- European centre of studies on safety and risk analysis: www.ceesar.fr.

- UTAC CERAM (Car, Motorcycle and Bicycle Technical Union): www.utacceram.com/fr/. 


\section{Chapter 13}

\section{Germany}

This chapter presents 2015 road safety data for Germany along with provisional data from 2016. It looks at trends in traffic and road safety from the years 1990 to 2015 and road user behaviour patterns with a special focus on the ageing population. Sections include data on speed, drink driving, drugs and driving, distracted driving, fatigue and seat belt usage. The chapter reviews Germany's road safety strategy and national targets to 2020 and the progress achieved thus far. It also provides details of all recently implemented safety measures and current and ongoing research.*

* All data stem from BASt, the Federal Highway Research Institute of Germany, and IRTAD unless otherwise noted. For more information please contact: schoenebeck@bast.de. 
I In 2015, for the second consecutive year, Germany recorded an increase in road deaths to 3459 , a $2.5 \%$ increase over 2014 . This is equivalent to a mortality rate of 4.3 per 100000 inhabitants. Pedestrians, car occupants and in particular motorcyclists were most affected by this increase. However, provisional data from 2016 shows a 7\% decrease in fatalities to 3214 . Since 2000, fatalities on the roads have been reduced by $54 \%$, although injury crashes have not benefitted from the same level of improvement.

\section{Road safety data collection \\ Definitions applied in Germany}

Data in this report correspond to the consolidated set of police data.

- Road fatality: Road death which occurs within 30 days of a road crash.

- Injury crash: Road crash resulting in at least one injured or killed person.

- Seriously injured: Any person immediately taken to hospital after a road crash for inpatient treatment of at least 24 hours.

- Slightly injured: Any other person injured in a road crash.

According to directives from the European High Level Group on Road Safety all European Union member states are requested to estimate their number of critically injured persons, defined as those with injuries rated as Maximum Abbreviated Injury Scale of 3 or more (MAIS3+) from 2014 onwards. In Germany, the number of MAIS3+ is extrapolated from data from the German In-Depth Accident Study (GIDAS).

\section{Data collection}

In Germany, crash data are collected by the police agencies of the different federal states (Bundesländer) and then consolidated at a federal level.

As the crash data is collected by the police, only accidents which are known to the police are registered. For fatalities, the reporting rate is suspected to be nearly $100 \%$. No information is available on the percentage of crash injuries that are not reported.

\section{Most recent safety data}

\section{Road crashes in 2016 - provisional data}

Based on provisional data, it is estimated that 3206 people lost their lives on the roads in Germany in 2016, representing a decrease of more than 7\% over 2015. This represents a positive change after two consecutive years of increases in the number of road fatalities (by $1.1 \%$ in 2014 and $2.4 \%$ in 2015).

At the same time, the number of injury crashes increased by $0.6 \%$ and the number of injured road users increased by $0.7 \%$ following an increase in 2014 and stagnation in 2015.

Following two years of increases in the number of fatally injured motorcyclists, 2016 saw a decrease of $16 \%$ in this category. The number of fatally injured occupants of goods vehicles decreased by $9 \%$, as did fatalities amongst pedestrians. The number of severe and 
slightly injured among cyclists increased in 2016, which is to a considerable extent due to increasing numbers of injured users of pedelecs.

\section{Road crashes in 2015}

In 2015, 3459 people died on roads in Germany representing an increase of almost $2.5 \%$ compared to the previous year. The number of injury crashes increased by $1 \%$ and the number of injured road users stagnated for the same time period.

This is the second consecutive year with an increase in the number of road fatalities and injury crashes. This increase was observed more particularly in fatalities on urban roads $(6.6 \%)$ and on motorways $(10.4 \%)$. The increase in 2015 was strongly characterised by the fatality numbers for pedestrians $(+2.7 \%)$ and motorcyclists $(+8.9 \%)$ as well as car occupants, with an increase of $2.9 \%$. While the number of fatally injured cyclists decreased slightly, by $3 \%$, in 2015 , the reduction in the number of fatally injured moped riders was more significant - almost $30 \%$ over the previous year.

Although other factors play an important role in the long-term development of fatality and crash figures, once again in 2015, as in 2014, the relatively mild winter and warm and early spring is likely to have resulted in an increase in the number of road users. The good economic performance in Germany in 2015 led to a higher increase in the annual mileage than previous years.

Despite some yearly changes in different age groups, traffic modes or road types, the number of injury accidents and injured persons, especially fatally injured persons, is still decreasing over the long term. However, recent years also show that decreasing rates are stagnating and some groups have even been showing a steady increase for some years, e.g. severely and slightly injured cyclists.

Taking into account the development of the accident and fatality numbers of the last years, the Mid-Term Review of the 2011-20 Road Safety Programme identified two key areas of action for the second half of the Road Safety Programme. On rural roads the main focus will be on users of passenger cars and motorcyclists and on urban roads the priority will be on measures to protect pedestrians and cyclists in particular.

\section{Trends in traffic and road safety (1990-2016) Traffic}

Between 1991, the first year following German reunification, and 2015, the number of motorised vehicles increased by $24 \%$ and vehicle kilometres driven rose by $31 \%$.

Provisional figures for 2016 indicate that the overall traffic volume increased by $2 \%$.

\section{Road safety}

\section{Crashes and casualties}

Between 1991 and 2015, the number of fatalities decreased by $70 \%$, whereas the number of injury crashes fell by only $20.6 \%$. In recent years (2000-15), the number of fatalities decreased by $54 \%$, while the number of seriously injured decreased only by $34 \%$.

The decrease in the number of crashes and fatalities is due to various changes in all fields of road safety: traffic safety-related behaviour and education as well as infrastructure and vehicle safety. The improvements in road safety are due to several measures taken and regulations introduced in the past 10 years. Some highlights include: 
- road safety education in schools

- accompanied driving programme and alcohol prohibition for novice drivers

- road safety audits

- treatment of accident black spots

- improvements in passive and active vehicle safety

- identifying special fields of road safety and finding solutions, such as requiring child restraint systems, protecting trees on the roadside and adding underrun protection for guard rails to prevent serious motorcycle accidents.

\section{Rates}

Since 1991, the death rate per 100000 inhabitants has decreased by 70\%, while the number of vehicles registered per 1000 inhabitants has increased by $22 \%$.

\section{Analysis of seriously injured data}

The estimation of seriously injured casualties is based on an extrapolation of in-depth data collected in the regions of Hannover and Dresden (in the framework of the GIDAS

Table 13.1. Road safety and traffic data

\begin{tabular}{|c|c|c|c|c|c|c|c|c|c|}
\hline & \multirow{2}{*}{1991} & \multirow{2}{*}{2000} & \multirow{2}{*}{2010} & \multirow{2}{*}{2014} & \multirow{2}{*}{2015} & \multicolumn{4}{|c|}{$2015 \%$ change from } \\
\hline & & & & & & 2014 & 2010 & 2000 & 1991 \\
\hline \multicolumn{10}{|l|}{ Reported safety data } \\
\hline Fatalities & 11300 & 7503 & 3648 & 3377 & 3459 & 2.4 & -5.2 & -53.9 & -69.4 \\
\hline Injury crashes & 385147 & 382949 & 288297 & 302435 & 305659 & 1.1 & 6.0 & -20.2 & -20.6 \\
\hline Injured persons hospitalised & 131093 & 102416 & 62620 & 67732 & 67706 & 0.0 & 8.1 & -33.9 & -48.4 \\
\hline Deaths per 100000 inhabitants & 14.2 & 9.1 & 4.5 & 4.2 & 4.3 & 1.9 & -4.5 & -53.4 & -69.9 \\
\hline Deaths per 10000 registered vehicles & 2.5 & 1.4 & 0.7 & 0.6 & 0.6 & 1.1 & -11.1 & -56.1 & -75.3 \\
\hline Deaths per billion vehicle kilometres & 19.7 & 11.3 & 5.2 & 4.6 & 4.6 & 0.8 & -11.2 & -59.4 & -76.6 \\
\hline \multicolumn{10}{|l|}{ Traffic data } \\
\hline Registered vehicles ${ }^{1}$ (thousands) & 44925 & 53106 & 52289 & 55011 & 55752 & 1.3 & 6.6 & 5.0 & 24.1 \\
\hline Vehicle-kilometres (millions) & 574100 & 663302 & 704800 & 740500 & 752300 & 1.6 & 6.7 & 13.4 & 31.0 \\
\hline Registered vehicles per 1000 inhabitants & 563 & 646 & 639 & 681 & 687 & 0.8 & 7.4 & 6.2 & 21.9 \\
\hline
\end{tabular}

1. Registered vehicles including mopeds.

StatLink AाISL http://dx.doi.org/10.1787/888933580460

Figure 13.1. Road Safety, traffic and GDP trends index $1990=100$

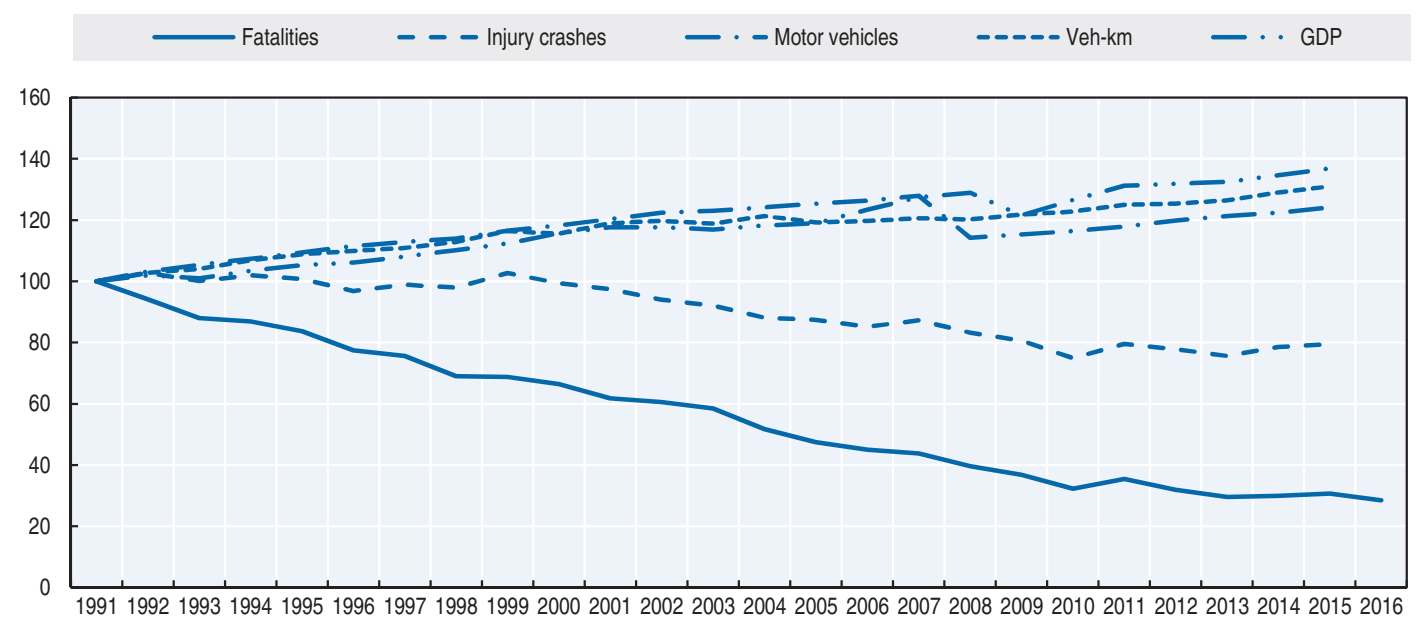

Source: World Bank (2017), (GDP; constant prices). 
project). In 2015, 15442 or $22.8 \%$ of all hospitalised road crash casualties had an MAIS of 3 or above, a number similar to 2014 .

\section{Road safety by user group}

Germany is one of the world's most highly motorised countries. Motor vehicle occupants account for the large majority of traffic fatalities that occur each year on German roads. Fatalities among motor vehicle occupants and pedestrians have gradually decreased since 1991, with the reduction being strongest for passenger car occupants $(-76 \%)$.

In 2015, an increase in the number of fatalities was observed among pedestrians $(+2.7 \%)$, car occupants $(+2.9 \%)$ and motorcyclists $(+8.9 \%)$. The strong reduction in fatalities was observed for moped riders (-28.7\%), with a more moderate improvement for cyclists $(-3.3 \%)$.

Starting from 2014, official crash statistics make a distinction between cyclists using bicycles without electronic assistance and pedelecs. In 2014, nearly $10 \%$ of cyclists killed were using a pedelec (39 of 396). In 2015 a pedelec was used in $9 \%$ of fatal accidents involving cyclists (36 of 383). The number of pedelec accidents with personal injury rose from 2245 accidents in 2014 to 2992 accidents in 2015. Preliminary data for 2016 indicate an increase to nearly 4000 pedelec accidents in the last year. The increase is strongly related to an increase of the pedelec fleet in Germany. According to the German Bicycle Association the number of pedelecs sold between 2010 and 2016 has nearly tripled.

Table 13.2. Road fatalities by road user group

\begin{tabular}{lrrrrr|rrrr}
\hline & 1991 & 2000 & 2010 & 2014 & 2015 & \multicolumn{4}{c}{$2015 \%$ change from } \\
\cline { 7 - 10 } & & & & & & 2014 & 2010 & 2000 & 1991 \\
\hline Pedestrians & 1918 & 993 & 476 & 523 & 537 & 2.7 & 12.8 & -45.9 & -72.0 \\
Cyclists & 925 & 659 & 381 & 396 & 383 & -3.3 & 0.5 & -41.9 & -58.6 \\
Moped riders & 243 & 157 & 74 & 87 & 62 & -28.7 & -16.2 & -60.5 & -74.5 \\
Motorcyclists & 992 & 945 & 635 & 587 & 639 & 8.9 & 0.6 & -32.4 & -35.6 \\
Car occupants & 6801 & 4396 & 1840 & 1575 & 1620 & 2.9 & -12.0 & -63.1 & -76.2 \\
Others & 421 & 353 & 242 & 209 & 218 & 4.3 & -9.9 & -38.2 & -48.2 \\
Total & $\mathbf{1 1 3 0 0}$ & $\mathbf{7 5 0 3}$ & $\mathbf{3 6 4 8}$ & $\mathbf{3 3 7 7}$ & $\mathbf{3 4 5 9}$ & $\mathbf{2 . 4}$ & $\mathbf{- 5 . 2}$ & $\mathbf{- 5 3 . 9}$ & $\mathbf{- 6 9 . 4}$ \\
\hline
\end{tabular}

Figure 13.2. Road fatalities by road user group in percentage of total, 2015

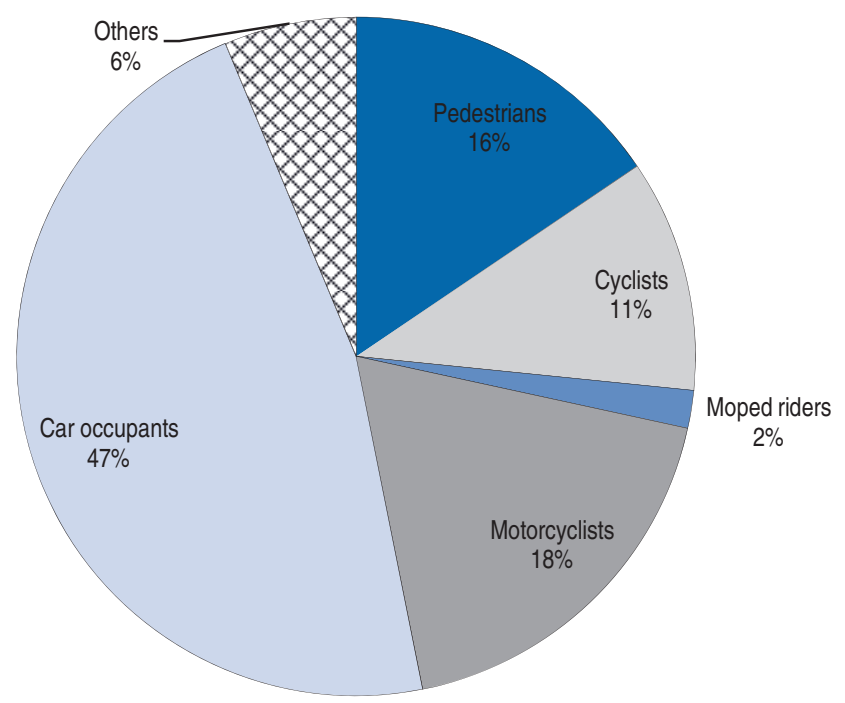




\section{Road safety by age group}

Since 2000, the number of fatalities decreased in all age groups. But while the number of fatalities decreased by $50 \%$ and more for the age groups under 65 , the $22 \%$ reduction for the over $65 \mathrm{~s}$ is the smallest. This is largely attributed to demographic change, as the older population is growing quickly.

The increase of those fatally injured can be seen in all age groups except the 15-20 year group. Despite an $11 \%$ decrease in fatality numbers for the 18-20 year group, it still has a mortality rate double that of the general population. Gradual licencing and accompanied driving programmes are important measures to counter driver inexperience, particularly among those aged 18-20.

The number of fatally injured among the senior population increased in 2015 by $3.7 \%$, following three years of more or less unchanged figures. The number of fatally injured middle-aged persons (25-64 years) also increased by $4.2 \%$.

Table 13.3. Road fatalities by age group

\begin{tabular}{|c|c|c|c|c|c|c|c|c|c|}
\hline \multirow{2}{*}{ Age } & \multirow{2}{*}{1991} & \multirow{2}{*}{2000} & \multirow{2}{*}{2010} & \multirow{2}{*}{2014} & \multirow{2}{*}{2015} & \multicolumn{4}{|c|}{2015 \% change from } \\
\hline & & & & & & 2014 & 2010 & 2000 & 1991 \\
\hline $0-14$ & 511 & 240 & 104 & 71 & 84 & 18.3 & -19.2 & -65.0 & -83.6 \\
\hline $15-17$ & 415 & 336 & 101 & 91 & 72 & -20.9 & -28.7 & -78.6 & -82.7 \\
\hline $18-20$ & 1204 & 933 & 327 & 236 & 210 & -11.0 & -35.8 & -77.5 & -82.6 \\
\hline $21-24$ & 1545 & 803 & 363 & 260 & 263 & 1.2 & -27.5 & -67.2 & -83.0 \\
\hline $25-64$ & 5754 & 3876 & 1842 & 1732 & 1804 & 4.2 & -2.1 & -53.5 & -68.6 \\
\hline $65-74$ & 712 & 629 & 395 & 364 & 357 & -1.9 & -9.6 & -43.2 & -49.9 \\
\hline $75-84$ & 904 & 490 & 402 & 458 & 481 & 5.0 & 19.7 & -1.8 & -46.8 \\
\hline$\geq 85$ & 237 & 192 & 113 & 165 & 186 & 12.7 & 64.6 & -3.1 & -21.5 \\
\hline Total & 11300 & 7503 & 3648 & 3377 & 3459 & 2.4 & -5.2 & -53.9 & -69.4 \\
\hline
\end{tabular}

Figure 13.3. Road fatality rates by age group

Deaths per 100000 inhabitants in a given age group, 2000-15

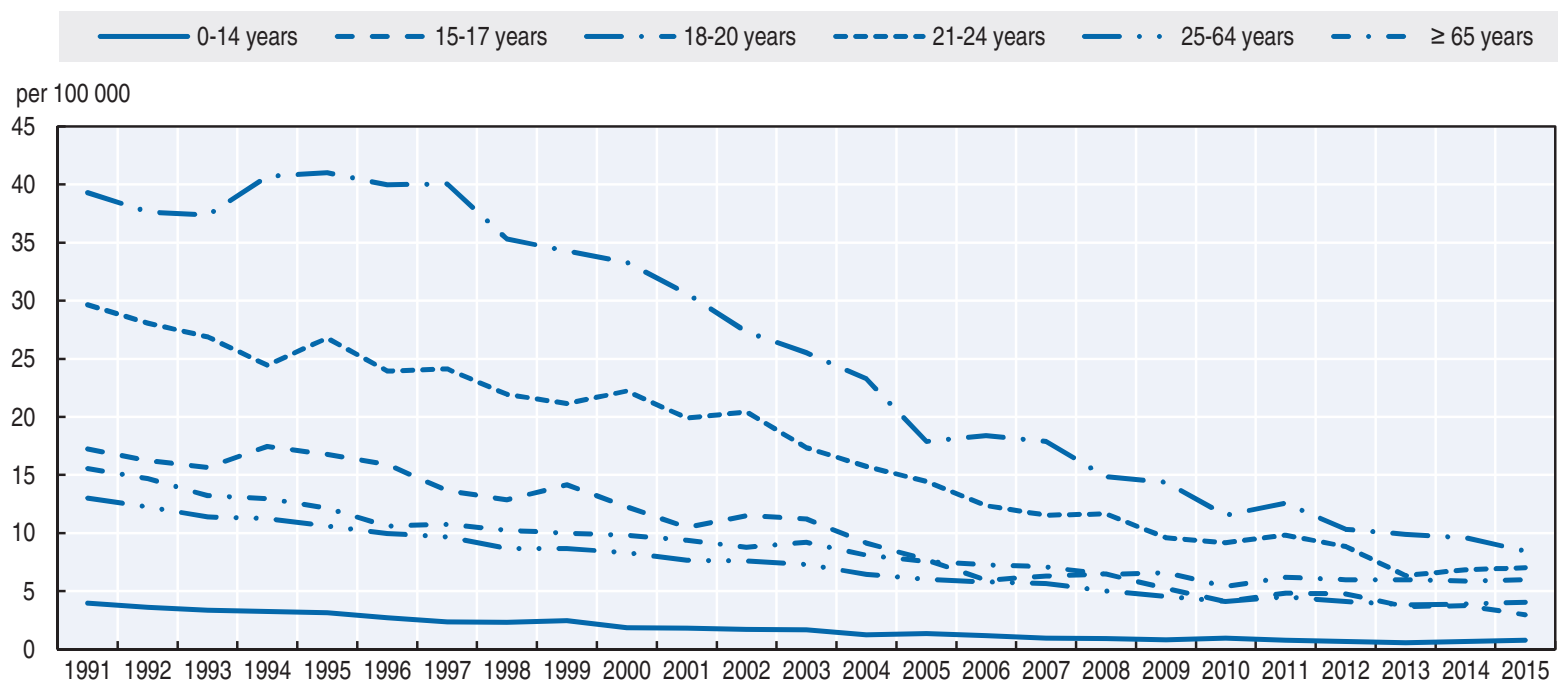




\section{Box 13.1. Road safety for an ageing population}

As in several countries the population in Germany has been decreasing over recent years. The population projection forecasts a negative trend for the coming years. Due to the age structure of the population, the number of older people in Germany will increase by $46 \%$ for the $65-74$ year age group by 2033 , by $43 \%$ for 75-84 year group by 2043 and by $147 \%$ for the $85+$ group by 2050 .

People aged 65 years and above accounted, in 2015, for around 12\% of all traffic casualties. But they are the most vulnerable road users, with a much higher mortality rate. The mortality rate for the age groups 65-74, 75-84 and 85 and over is respectively two, three and six times higher compared to the 25-64 year age group. People aged 65 and above represented, in 2015, 30\% of all road fatalities This share is increasing (it was $26 \%$ in 2011). The number of fatalities among 75-84 year olds and those over 85 has increased since 2011 by $9 \%$ and $4 \%$, while all other age groups decreased during the same period. More than $50 \%$ of all fatally injured among the over $65 \mathrm{~s}$ had an accident as a vulnerable road user, such as a pedestrian, cyclist or rider of a powered two-wheeler. In particular, there is a strong increase in the number of fatally injured pedestrians and cyclists for the higher age groups.

According to road safety experts and research, age itself does not pose a road safety problem. Nevertheless, illnesses can be a cause of concern as well as the fact that the senior population is more vulnerable and the consequences of injuries can be more severe than for younger road users. Therefore, road safety measures aiming at this age group mostly consist of measures that increase awareness of these factors within this age group. Measures are usually voluntary, there are no special restrictive regulations regarding older road users.

One major pillar of road safety measures is the improvement of self-regulation, which is mainly achieved by means of information campaigns, targeted activities and consultation services. Driving schools offer special driver training and there are educational road safety programmes by stakeholders such as the German Road Safety Council (DVR-Program "Staying Mobile - But Safely"), or the German Association for the Prevention of Road Accidents (DVW-Program "Mobile in a Safe Way").

Physicians are also involved, as they are in a favourable position to inform their patients about the risks that come with illnesses or from medication. Information events for physicians have been introduced and a handbook for physicians has been developed and made available. Physicians can also make use of a screening procedure to assess factors that are detrimental to the road safety of a senior citizen - as a basis subsequent counselling.

Figure 13.4. Road fatality rates in the $65+$ age groups Deaths per 100000 inhabitants in a given age group, 2000-15

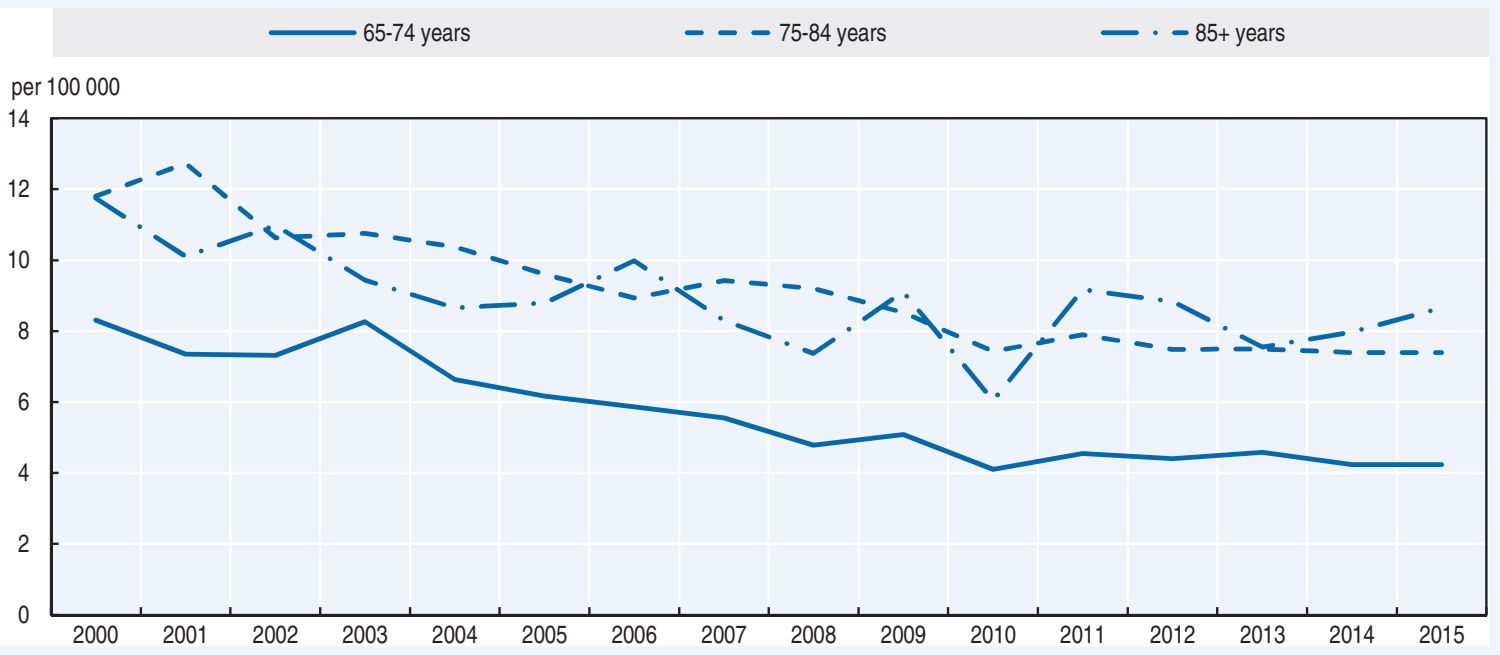




\section{Box 13.1. Road safety for an ageing population (cont.)}

Table 13.4. Road fatalities among senior citizens

\begin{tabular}{|c|c|c|c|c|c|c|c|c|c|}
\hline & \multicolumn{3}{|c|}{$65-74$} & \multicolumn{3}{|c|}{$75-84$} & \multicolumn{3}{|c|}{$85+$} \\
\hline & 2010 & 2015 & $\%$ change & 2010 & 2015 & $\%$ change & 2010 & 2015 & $\%$ change \\
\hline Pedestrians & 71 & 62 & -8 & 107 & 143 & 35 & 49 & 76 & 55 \\
\hline Cyclists & 105 & 72 & -31 & 75 & 94 & 25 & 17 & 32 & 88 \\
\hline Moped riders & 8 & 4 & - & 8 & 16 & 100 & 2 & 0 & - \\
\hline Motorcyclists & 30 & 34 & 13 & 9 & 15 & 67 & 0 & 0 & $=$ \\
\hline Car occupants & 166 & 160 & -2 & 186 & 199 & 8 & 41 & 71 & 73 \\
\hline Total & 395 & 357 & -10 & 402 & 481 & 20 & 113 & 186 & 65 \\
\hline
\end{tabular}

Figure 13.5. Road fatality rate by age and road user group Fatalities per 100000 inhabitants, 2015

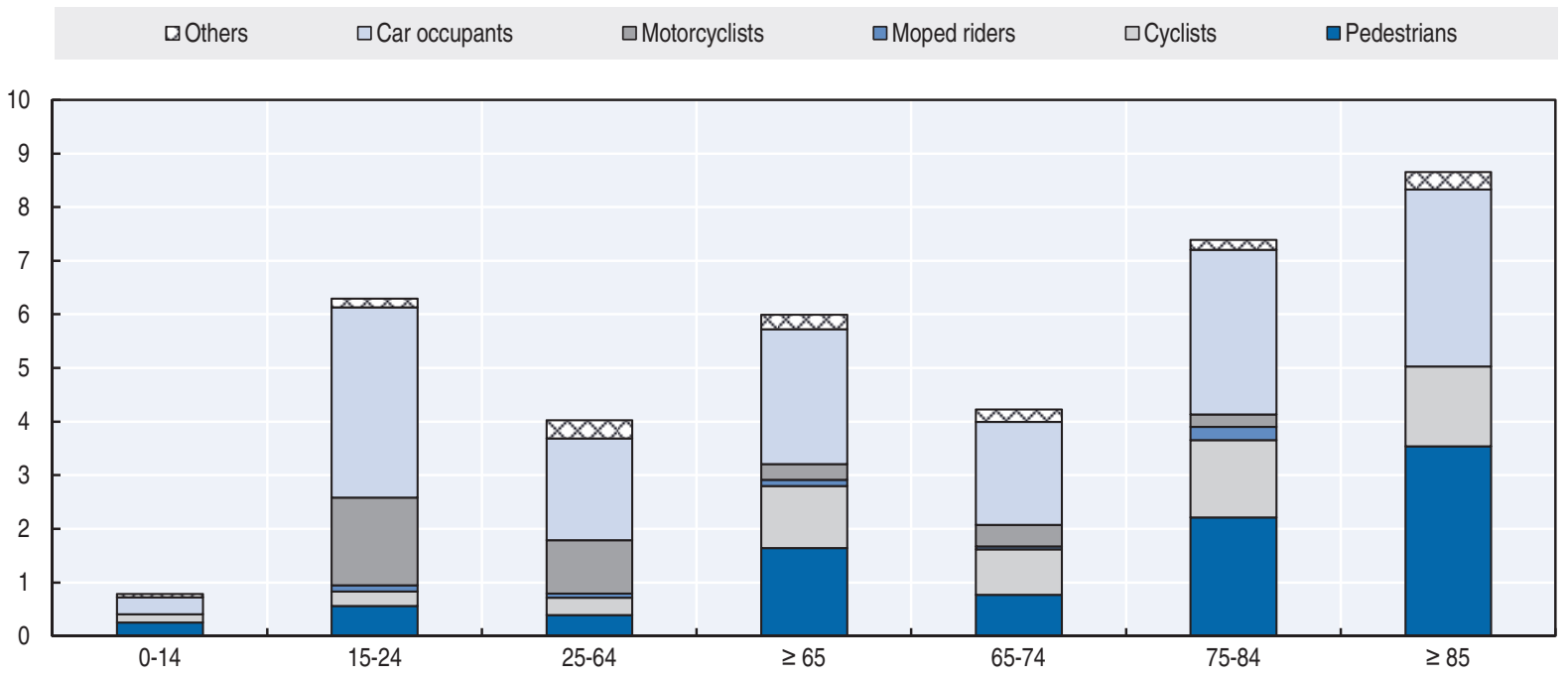

\section{Road safety by road type}

Rural roads are the most dangerous for road users, as nearly $60 \%$ of fatalities occur on this network. However, many improvements have been realised since the 1990s, such as construction of roundabouts to manage intersections and underrun protection for guard rails to prevent serious injuries to motorcyclists.

In 2015 , the increase in fatalities was registered mainly on motorways $(+10.4 \%)$ and inside urban areas $(+10.4 \%)$. The number of fatalities on rural roads slightly decreased, by $1.1 \%$, bringing the number of fatalities to the level of 2013. 
Figure 13.6. Road fatalities by road type

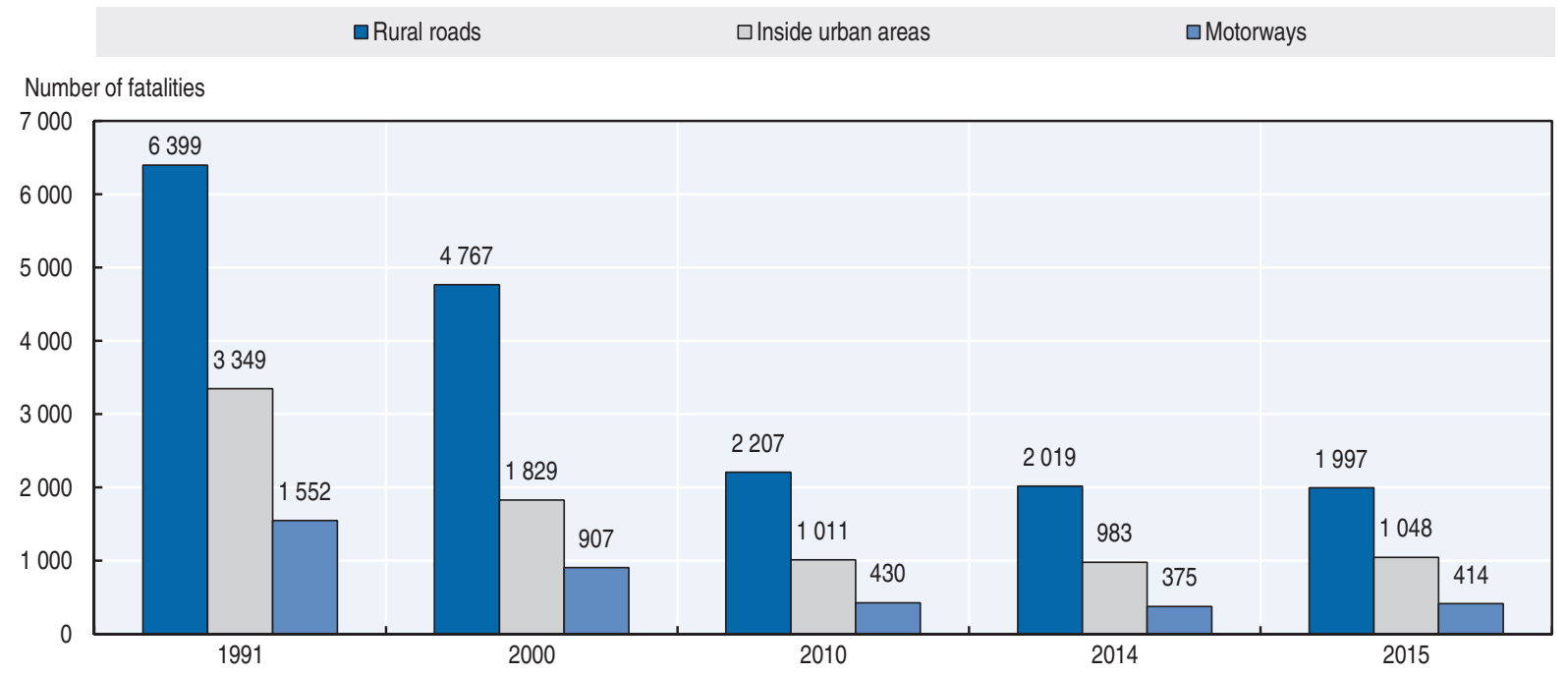

\section{Economic costs of traffic crashes}

The Federal Highway Research Institute (BASt, Bundesanstalt für Straßenwesen) calculates the cost of road crashes on an annual basis. The cost of road traffic crashes to Germany's national economy is based on the capital approach, encompassing costs for personal injuries and damage to goods. Calculated costs include:

- direct costs (medical treatment, vehicle repair/replacement)

- indirect costs (police services, legal system, insurance administration, replacement of employees)

- lost potential growth (including the shadow economy);

- lost added value of housework and voluntary work

- humanitarian costs

- costs of travel time lost due to accidents on motorways.

Traffic crashes represent a significant cost for society, estimated in 2015 at around EUR 34.4 billion, or 1.1\% of Germany's GDP. It is estimated that since 2005 crash costs have increased by $9 \%$. These figures do not include an estimation of costs of non-reported crashes.

The most recent information on costs for road accidents in Germany can be downloaded from the website of the Federal Highway Research Institute (www.bast.de).

Table 13.5. Costs of road crashes, 2015

\begin{tabular}{lcc}
\hline Cost (EUR) & Unit cost & Total \\
\hline Fatalities & EUR 1191937 & EUR 4.13 billion \\
Serious & EUR 123510 & EUR 8.40 billion \\
Slight injuries & EUR 5139 & EUR 1.79 billion \\
Property damage costs & n.a. & EUR 20.13 billion \\
Total (EUR) & & EUR 34.44 billion \\
Total as $\%$ of GDP (at constant prices) & & $\mathbf{1 . 1 \%}$ \\
\hline
\end{tabular}




\section{Recent trends in road user behaviour}

\section{Speed}

Inappropriate speed was a factor in nearly $34 \%$ of fatal crashes and about $15 \%$ of injury crashes in 2015. Speed is often cited as a factor in combination with other high-risk behaviour, such as drink driving.

The table below summarises the main speed limits in Germany.

Table 13.6. Passenger car and lorry speed limits by road type, 2017

\begin{tabular}{lcc}
\hline & General speed limit Passenger cars & General speed limit trucks $>3.5 \mathrm{t}$ \\
\hline Urban roads & $50 \mathrm{~km} / \mathrm{h}$ & $50 \mathrm{~km} / \mathrm{h}$ \\
Rural roads & $100 \mathrm{~km} / \mathrm{h}$ & $60 \mathrm{~km} / \mathrm{h}$ \\
Motorways & $130 \mathrm{~km} / \mathrm{h}$ (recommended) & $80 \mathrm{~km} / \mathrm{h}$ \\
\hline
\end{tabular}

\section{Drink driving}

In Germany, driving with blood alcohol content (BAC) over $0.5 \mathrm{~g} / 1$ is punishable by a fine, licence suspension and possibly jail. In addition, drivers with a BAC between $0.3 \mathrm{~g} / \mathrm{l}$ and $0.5 \mathrm{~g} / \mathrm{l}$ can have their licence suspended if their driving ability is impaired. Since 2007, as part of Germany's graduated licensing programme, a zero BAC is required for drivers under 21 and those in their probationary period.

In 2015, alcohol use was cited as a contributing factor in $7.2 \%$ of all fatal crashes, defined as those where a driver had any alcohol in the blood. The number of alcoholrelated crashes as well as alcohol-related fatalities has decreased continuously over recent years by $12 \%$ and $25 \%$ respectively since 2010 .

\section{Drugs and driving}

Driving under the influence of drugs is considered an offence. A driver is considered "under the influence" if drugs can be found in his blood - irrespective of the amount or concentration. This regulation refers to a selected list of drugs. Drugs used as medication and administered as intended are exempt.

In 2015, there were 1679 drug-related crashes in Germany causing 43 fatalities and 2304 injuries. The figures have risen from the 2000 level of 1 015, both from possible increased drug use as well as better education within the police agencies on detecting the influence of drugs.

\section{Seat belts and helmets}

Seat belt use has been compulsory for front seats since 1976 and rear seats since 1984 . Fines for not wearing seat belts were introduced in the mid-1980s and led to a sharp increase in seat belt use. In recent years the seat belt wearing rates of adult car occupants are consistently high at $97 \%$.

Children under the age of 12 and less than $150 \mathrm{~cm}$ tall must be restrained in motor vehicles by an approved system suitable for the child's height and weight. While the overall securing rate for children remains high at $99 \%$, the use of specific child restraint systems is decreasing slightly. 
Table 13.7. Seat belt wearing rate by car occupancy and road type

\begin{tabular}{|c|c|c|c|c|}
\hline & 2000 & 2010 & 2015 & 2016 \\
\hline \multicolumn{5}{|l|}{ Front seat } \\
\hline Driver & 94 & 98 & 98 & 99 \\
\hline Passenger & 95 & 98 & 98 & 98 \\
\hline Urban roads (driver) & 90 & 97 & 97 & 98 \\
\hline Rural roads (driver) & 95 & 98 & 97 & 99 \\
\hline Motorways (driver) & 98 & 99 & 99 & 99 \\
\hline \multicolumn{5}{|l|}{ Rear seats } \\
\hline General & 82 & 97 & 99 & 99 \\
\hline $\begin{array}{l}\text { Children (use of child restraint) } \\
\text { Children up to } 5 \text { years inside urban areas }\end{array}$ & & 92 & 91 & 91 \\
\hline
\end{tabular}

All riders of powered two-wheelers (PTWs) are required to wear helmets. Helmets are not mandatory for cyclists (including electric cycles with pedal assistance up to $25 \mathrm{~km} / \mathrm{h}$ ). The helmet wearing rate of riders of PTWs is high at 100\% (rider) and 99\% (passenger).

\section{Distraction}

Using a hand-held mobile phone is prohibited while driving a motor vehicle or riding a bicycle. Motor vehicle violators are fined EUR 60 and 1 demerit point; cyclists are fined EUR 25. In 2011, 450000 vehicle users violated this law, of whom $27 \%$ were female and $73 \%$ male.

Estimation of fatalities due to the use of mobile phones, based on the official accident statistics, is not possible, since mobile phone use is not assessed in the course of the collection of crash data by the police agencies.

\section{Sleepiness and fatigue}

According to the official accident statistics, $0.6 \%$ of injury crashes are attributed to fatigue. The number is expected to be underreported as it is difficult for police to identify fatigue as a cause of a crash.

\section{National road safety strategies and targets}

\section{Organisation of road safety}

The Federal Ministry of Transport and Digital Infrastructure is responsible for transport policy and road safety at the national level. It develops the national road safety strategy, including the national road safety action programme, and sets and monitors national targets.

Each of the 16 federal states has its own Ministry of Transport. These ministries can formulate road safety programmes independently and are usually responsible for improvements in road infrastructure in their own state. Police forces are organised at the state level, and enforcement of traffic laws is the responsibility of each federal state.

\section{Road safety strategy for 2011-20}

The 2011-2020 road safety programme was launched in the last quarter of 2011. The principal aim of the programme is to enable safe, ecologically sensitive and sustainable mobility for all road users in Germany. It has a wide range of road safety measures addressing users, vehicles and the infrastructure. 
The programme addresses new challenges, such as demographic change and the mobility of the older population, and it aims at safeguarding the efficiency of the road network. It reflects recent technological developments in vehicles such as driver assistance systems, co-operative vehicle systems and new engine concepts. In these latter areas, the main focus lies on ensuring that the development of vehicle technology does not induce safety risks. Activities also focus on rural roads and on reducing the number of serious injuries as well as fatalities.

\section{Road safety targets}

The quantitative target for 2020 is a reduction by $40 \%$ in the number of fatalities compared to the 2010 level. The target was defined on the basis of research regarding the expected development of road safety until the year 2020. This target was established taking into account the $-50 \%$ target of the European Commission and the level of road safety in Germany. There are also specific targets in individual federal German states.

A model was developed to predict the number of crashes and casualties in Germany for the years 2015-20 and for different road types (motorways, rural and urban roads). The risks of crashes and injuries were subdivided for each mode of traffic and age of road user. The time series model assumes that efforts to improve road safety continue as they have in the past. The forecast, based on the model and an estimation of future traffic conditions in Germany, shows a considerable decrease $(-30 \%)$ in the number of casualties.

\section{Monitoring targets}

Monitoring and assessment of road safety measures and progress toward the target is achieved with the Road Accident Prevention Report, which is prepared every two years and submitted to the German parliament (Bundestag). The report discusses the general development of road safety and contains a comprehensive collection of measures implemented in the two years following the last report, as well as major ongoing and concluded research, and planned projects and measures.

Figure 13.7. Trends in road fatalities towards national target

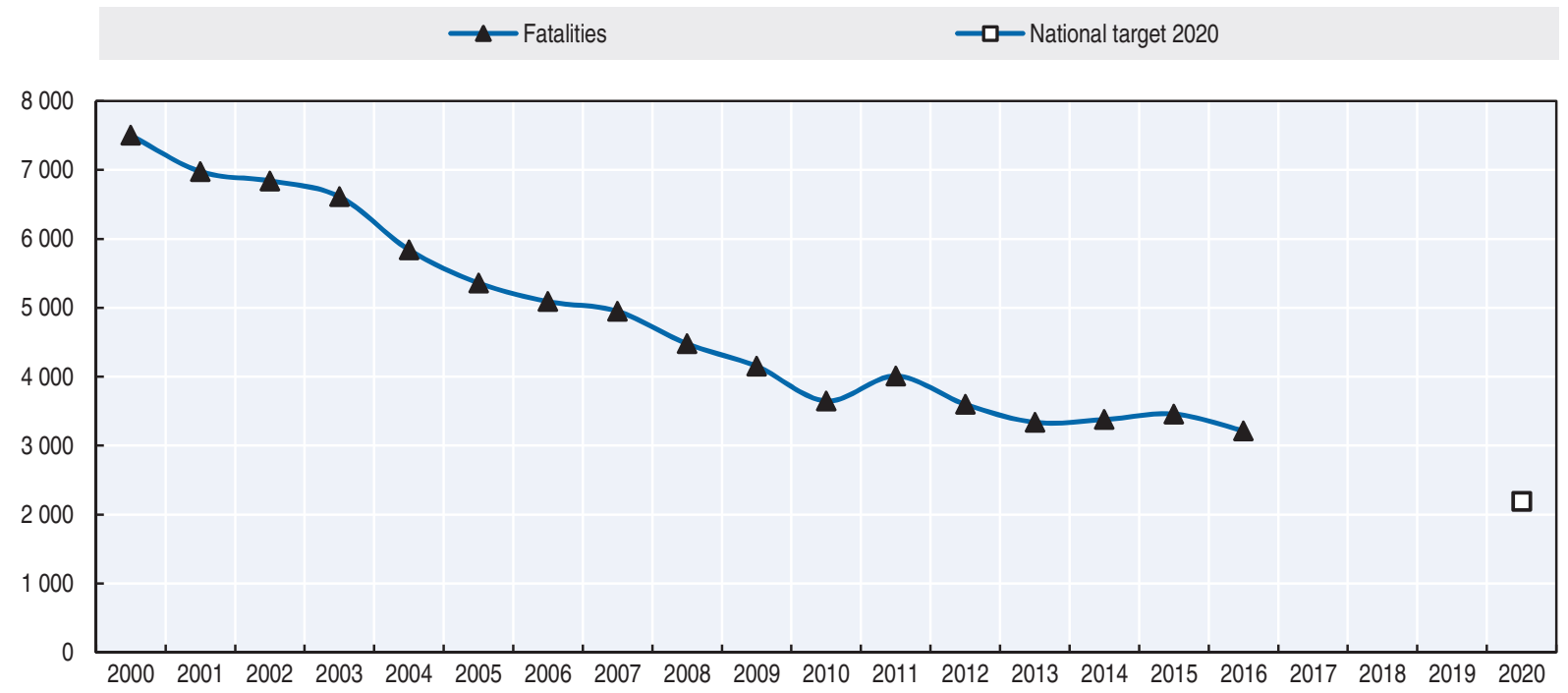


The latest "Accident Prevention Report 2014/2015", published in September 2016 gives an overview of the actual situation of road safety in Germany, progress towards targets, informs about road safety measures and major research undertaken in 2014-15 and provides an outlook of road safety measures being implemented from 2016 onwards (http:// dip21.bundestag.de/dip21/btd/18/096/1809640.pdf (accessed 20 June 2017).

\section{Recent safety measures (2014-17)}

\section{Road safety management}

- The German demerit point system for drivers has been fully restructured and modernised. The new demerit point system entered into force on 1 May 2014. It was designed to increase the acceptability of the system and decrease bureaucracy. Drivers can accumulate up to eight points at which point their driving licence is withdrawn. Under some conditions, demerit points can be reduced if the driver completes a voluntary seminar aimed at improving knowledge on road safety regulations and increasing their acceptance.

- Since 2014 training for local planners of road infrastructure has been intensified to ensure the correct implementation of existing technical regulations in the field of infrastructure with a focus on road safety.

\section{Road users}

\section{Speed management}

- Anti-speeding marathons were introduced in Germany in 2012. Since then this concentrated enforcement action focusing on speeding has been conducted yearly by the police. The action lasts for 24 hours and is widely communicated beforehand.

- Since 2014, German authorities have been enabled to follow up traffic offences of drivers with vehicles with foreign licence plates on the basis of the European directive on the cross-border exchange of information (Directive 2015/413/EU). Thus, the amount of transnational prosecution has been facilitated and increasingly used by German authorities. In 2015, information on 780000 vehicle owners was obtained, $95 \%$ of whom had committed a speeding offence.

- The conditions for motorcycle driving tests changed in May 2014. During the test candidates mandatorily wear appropriate protective clothing consisting of a well-fitting motorcycle helmet, motorcycle gloves, a tight-fitting motorcycle jacket, a back protector (if not integrated in the jacket), motorcycle trousers and motorcycle boots with sufficient ankle protection.

\section{Education and awareness}

- Since 2008 a series of awareness campaigns have been launched under the umbrella "Runter vom Gas!" (Stop speeding!). The campaigns address pressing road safety topics, such as speeding, alcohol, distraction, dangerous overtaking, tailgating and other relevant accident causes. In 2016 a new campaign with the title "Because life is beautiful..." was launched, using billboards on motorways and online information.

- Two recent online campaigns to raise awareness started in 2016:

* "Safe Motorcycle Riding" aims at informing motorcycle riders about vehicle safety systems, their effects on driving and vehicle safety. There is a high demand from driving schools who include these films in their theoretical driving lessons: www.vivalamopped. com/motorrad-aber-sicher/ 
* "Track \& Safety Days" aims at persons from tuning communities. It informs about safe tuning of vehicles and how this can affect road safety.

- A handbook for mapping safe ways to school has been introduced as a tool to support independent mobility of pupils and to reduce unsafe spots in the local area close to schools.

\section{Infrastructure}

- The toll for Heavy Goods Vehicles (HGVs) with a permissible gross weight of 12 tonnes or over has been in force on German motorways and selected national roads since 2005. On 1 July 2015, the HGV toll was expanded to an additional $1100 \mathrm{~km}$ of selected national roads. This was followed by the lowering of the permissible gross weight of HGVs under the law to 7.5 tonnes. The revenues must be used for the preservation and extension of the road infrastructure in Germany. The toll will be expanded to all national roads in 2018.

- Since January 2017 adults are allowed to ride a bicycle on the footpath if they accompany a cycling child. Before 2017, children up to the age of 8 had to use the footpath, whereas adults were prohibited from using it.

- Since January 2017 , electric bikes $(<25 \mathrm{~km} / \mathrm{h})$ are permitted to use designated cycle lanes inside urban areas and all cycle lanes outside urban areas.

- Legal pre-conditions to introduce $30 \mathrm{~km} / \mathrm{h}$ zones on main roads inside urban areas are less stringent.

- The number of overtaking lanes is increasing considerably. The construction of a third lane on previous two-lane rural roads makes it possible for vehicles to overtake safely without having to use the lane for traffic travelling in the opposite direction.

\section{Vehicles}

- Since July 2014, a high visibility vest must be available in all cars, goods vehicles and buses. Motorcycles are exempt.

- Following the introduction of mandatory ABS for new motorcycles in 2016, information campaigns have been launched by the Ministry of Transport and Digital Infrastructure to ensure the acceleration of market penetration.

- A new law on automated driving was adopted in 2017. The core of the law concerns the legal equality of the human driver and the computer. As a result highly and fully automated driving systems can autonomously take on the driving task in future.

\section{Recent and ongoing research}

Some research projects are presented below:

- Karthaus, Melanie et al. Compensatory strategies of older traffic participants after a VZRconspicuousness (Berichte der Bundesanstalt für Straßenwesen, Mensch und Sicherheit Heft M 254, Bergisch Gladbach 2016), http://bast.opus.hbz-nrw.de/volltexte/2015/1419/ (accessed 20 June 2017).

- Hoppe, Rolf, Tekaat, Anne: Alcohol consumption among children and adolescents and the impacts on traffic safety (Berichte der Bundesanstalt für Straßenwesen, Mensch und Sicherheit Heft M 259, Bergisch Gladbach 2016), http://bast.opus.hbz-nrw.de/frontdoor.php? source_opus=1402\&la=en (accessed 20 June 2017). 
- Von Below, Ariane: Road safety of cyclists: Analysis of motives relevant for security, settings and behaviour patterns (Berichte der Bundesanstalt für Straßenwesen, Mensch und Sicherheit Heft M 264, Bergisch Gladbach 2016), http://bast.opus.hbz-nrw.de/ frontdoor.php?source_opus=1663\&la=en. (accessed 20 June 2017).

- Kühne, Mike ; Hundertmark, Tobias: Legal probation of traffic offenders after licence reinstatement (Berichte der Bundesanstalt für Straßenwesen, Mensch und Sicherheit Heft M 265, Bergisch Gladbach 2016), http://bast.opus.hbz-nrw.de/frontdoor.php?source opus=1664\&la=en (accessed 20 June 2017).

- Ohm, Dirk et al.: Cycling in mixed traffic on the carriageway on urban main roads (Berichte der Bundesanstalt für Straßenwesen, Mensch und Sicherheit Heft V 257, Bergisch Gladbach 2016), http://bast.opus.hbz-nrw.de/frontdoor.php?source_opus=1401\&la=de (accessed 20 June 2017).

- Hegewald, Andreas: Motorcycle crashes - influencing factors of road infrastructure (Berichte der Bundesanstalt für Straßenwesen, Mensch und Sicherheit Heft V 268, Bergisch Gladbach 2015), http://bast.opus.hbz-nrw.de/frontdoor.php?source_opus=1622\& la=en (accessed 20 June 2017).

\section{References}

World Bank (2017), “GDP (constant US\$)”, World Development Indicators, http://databank.worldbank.org/ data/reports.aspx?source=world-development-indicators (accessed 23 February 2017).

\section{Websites}

- Federal Ministry of Transport and Digital Infrastructure: www.bmvi.de/EN/Home/home_node.html (accessed 20 June 2017).

- Road safety programme 2011-2020: https://ec.europa.eu/transport/road_safety/sites/roadsafety/files/pdf/ 20151210_2_germany_road-safety-programme-2011.pdf (accessed 20 June 2017).

- Mid-term review of road safety programme 2011: www.bmui.de/SharedDocs/EN/publications/mid-termreview-of-the-2011-2020-road-safety-programme.pdf?_blob=publicationFile (accessed 20 June 2017).

- Federal Highway Research Institute (BASt): www.bast.de/EN/Home/home_node.html; Research reports: www.bast.de/EN/Publications/Reports/Reports_node.html; Electronic BASt-archive: http://bast.opus.hbznrw.de/ (accessed 20 June 2017).

- German Federal Statistical Office's accident statistic reports: www.destatis.de/DE/ZahlenFakten/ Wirtschaftsbereiche/TransportVerkehr/Verkehrsunfaelle/Verkehrsunfaelle.html (accessed 20 June 2017).

- German Road Safety Council e.V.: www.dur.de/ (accessed 20 June 2017).

- German In-Depth Accident Study (GIDAS): www.gidas.org (accessed 20 June 2017). 



\section{Chapter 14}

\section{Greece}

This chapter presents 2015 road safety data for Greece along with provisional data from 2016. It looks at trends in traffic and road safety from the years 1990 to 2015 and road user behaviour patterns with a special focus on the ageing population. Sections include data on speed, drink driving, drugs and driving, distracted driving, fatigue and seat belt usage. The chapter reviews Greece's road safety strategy and national targets to 2020 and the progress achieved thus far. It also provides details of all recently implemented safety measures and current and ongoing research.*

* All data stem from the National Technical University of Athens (NTUA), the Hellenic Statistical Authority (ELSTAT) and IRTAD unless otherwise noted. For more information please contact: geyannis@central.ntua.gr. 


\begin{abstract}
C rash data in 2015 stagnated at the 2014 level, following five consecutive years with a significant (generally above $10 \%$ ) decrease in fatalities, resulting in an overall decrease for the period 2009-14 of 45\%. The fatality rate for Greece (7.3 deaths per 100000 inhabitants) is for the second year closer to the EU average than to the least performing EU countries. However, while the economic downturn is not yet over, Greece has probably reached the point at which the drop in road fatalities has levelled off.
\end{abstract}

\title{
Road safety data collection
}

\section{Definitions applied in Greece}

- Injury crash: Any crash involving at least one road motor vehicle in motion on a public road or square to which the public has access (excluding yards, industrial sites or vehicle depots for public transport), resulting in at least one injured or killed person. Property damage only crashes are not included.

- Road fatality: Any person killed immediately or dying within 30 days as a result of an injury crash. (This national definition has applied since 1996. For the years prior to 1996 a conversion factor is applied to the fatality data in the International Road Traffic and Accident Database.)

- Seriously injured person: Any person who sustained an injury as result of an injury crash, such as brain damage, mutilation or other injuries that may result in lack of awareness or which are life-threatening. Hospital data have not been exploited yet and the identification of serious road injuries according to the Maximum Abbreviated Injury Scale (MAIS) definition is not possible.

\section{Data collection}

From the early 1960s, the Hellenic Statistical Authority (EL.STAT) has maintained Greece's official road crash database. This contains disaggregated road crash data and detailed information concerning drivers, road crash casualties and the vehicles involved. Data is coded on the basis of the Road Accident Data Collection Form, which is filled in by traffic police for every road crash with casualties.

Traffic police respond to all crashes with casualties. Officers are responsible for filling in the Road Accident Data Collection Form and for finalising information concerning casualties within 30 days of the crash. Data are forwarded to EL.STAT and are also stored in the traffic police database. The EL.STAT database includes reliable and detailed information on road crashes, persons and vehicles as well as additional elements such as causes and conditions of the vehicles.

The Ministry of Infrastructure, Transport and Networks is responsible for vehicle registration and driver licensing. It maintains databases of registered vehicles and of licensed drivers. The registered vehicles database includes disaggregate information on vehicle characteristics, such as vehicle type and use, year of first registration, length, weight, engine size, fuel type, manufacturer, etc. This database does not include mopeds 
(data for the number of mopeds in operation come from the traffic police, who are responsible for moped registration and moped driver licensing). Scrapped vehicles are systematically removed from the database. The driver license database includes disaggregate information on driver characteristics, such as license type and year, the related vehicle type, license renewal or modification, age, gender, etc. However, deceased drivers are not systematically removed from the database.

Data on the severity of injuries are not systematically collected by hospitals; only road fatalities are properly reported. Consequently, it is not currently possible to have data on serious injuries according based on the Maximum Abbreviated Injury Scale (MAIS).

\section{Most recent safety data}

\section{Road crashes in 2016 - provisional data}

Provisional data indicate that there were 807 road fatalities in Greece in 2016, representing an increase of $1 \%$, the first increase seen since 2004. This ends the impressive drop in road fatalities experienced during the economic downturn of almost $50 \%$.

The number of injury crashes in 2016 stayed at the 2015 level, while the number of injured persons showed a slight (-2\%) decrease for the same period.

The economic downturn is not yet over, but Greece has probably reached the point at which the drop in road fatalities has levelled off. There is a need for strengthened efforts to further improve road safety, with systematic action from the authorities and serious engagement from society.

\section{Road crashes in 2015}

The crash data in 2015 stagnated at the 2014 level, following five consecutive years with a significant (generally above $10 \%$ ) decrease in fatalities, resulting in an overall decrease for the period 2009-14 of 45\%. Injury crashes in 2015 decreased by $2.1 \%$. The fatality rate for Greece (7.3 deaths per 100000 inhabitants) is for the second year closer to the EU average than to the least performing EU countries. These improvements are mainly attributed to the combined effect of:

- more systematic initiatives from the relevant authorities, including intensification of enforcement, construction and upgrade of $2500 \mathrm{~km}$ of motorways, urban mobility plans, educational campaigns, training and monitoring.

- the deep economic recession, which resulted in fewer vehicle-kilometres travelled, less speeding and less aggressive driving behaviours.

No specific studies are available yet to assess the relative contribution of these factors.

\section{Trends in traffic and road safety (1990-2016) Traffic}

Since 1990, the number of motor vehicles (including mopeds) has more than tripled in Greece. During the decade 2000-09 an annual increase of about 5\% was observed. Since 2009 , the annual increase in the vehicle fleet has been less than $1 \%$, although the number of motorcycles is increasing about $2 \%$ annually.

Between 2009 and 2014, traffic volume decreased by $20 \%$ on urban roads and $35 \%$ on toll motorways. In 2015 this trend ended as a very slight increase (1\%) was observed. 


\section{Road safety}

\section{Crashes and casualties}

The number of fatalities reached a peak in 1995 with 2411 road deaths. The 793 deaths in 2014 were $67 \%$ below the 1995 peak.

During the last decade, an important improvement was observed in road fatalities for young people, as well as in fatalities outside urban areas and in the number of people killed in crashes involving heavy goods vehicles. There was less improvement on motorways and for elderly road users, motorcyclists, foreign drivers and female drivers.

Over the last six years (2010-15), the number of fatalities decreased by $37 \%$. Since mid-2008, there have been some road safety developments such as the new Highway Code and new motorways, but the economic recession has been the most important factor bringing a further significant decrease in road fatalities.

\section{Rates}

In 2015 , Greece had a mortality rate of 7.3 road deaths per 100000 inhabitants, which is less than $40 \%$ of the rate of 2000 , but still above the EU average of 5.1 .

Table 14.1. Road safety and traffic data

\begin{tabular}{|c|c|c|c|c|c|c|c|c|c|}
\hline & \multirow{2}{*}{1990} & \multirow{2}{*}{2000} & \multirow{2}{*}{2010} & \multirow{2}{*}{2014} & \multirow{2}{*}{2015} & \multicolumn{4}{|c|}{$2015 \%$ change from } \\
\hline & & & & & & 2014 & 2010 & 2000 & 1990 \\
\hline \multicolumn{10}{|l|}{ Reported safety data } \\
\hline Fatalities & 2050 & 2037 & 1258 & 795 & 793 & -0.3 & -37.0 & -61.1 & -61.3 \\
\hline Injury crashes & 19609 & 23001 & 15032 & 11690 & 11440 & -2.1 & -23.9 & -50.3 & -41.7 \\
\hline Deaths per 100000 inhabitants & 20.3 & 18.7 & 11.2 & 7.3 & 7.3 & 0.4 & -35.1 & -60.9 & -63.9 \\
\hline Deaths per 10000 registered vehicles & 7.4 & 3.1 & 1.3 & 0.8 & 0.8 & -0.9 & -37.4 & -72.9 & -88.7 \\
\hline \multicolumn{10}{|l|}{ Deaths per billion vehicle kilometres } \\
\hline \multicolumn{10}{|l|}{ Traffic data } \\
\hline Registered vehicles ${ }^{1}$ (thousands) & 2780 & 6622 & 9451 & 9459 & 9518 & 0.6 & 0.7 & 43.7 & 242.4 \\
\hline Registered vehicles per 1000 inhabitants & 275 & 607 & 845 & 866 & 877 & 1.3 & 3.7 & 44.3 & 219.1 \\
\hline
\end{tabular}

1. Registered vehicles including mopeds.

StatLink कilsL http://dx.doi.org/10.1787/888933580479

Figure 14.1. Road safety, traffic and GDP trends index $1990=100$

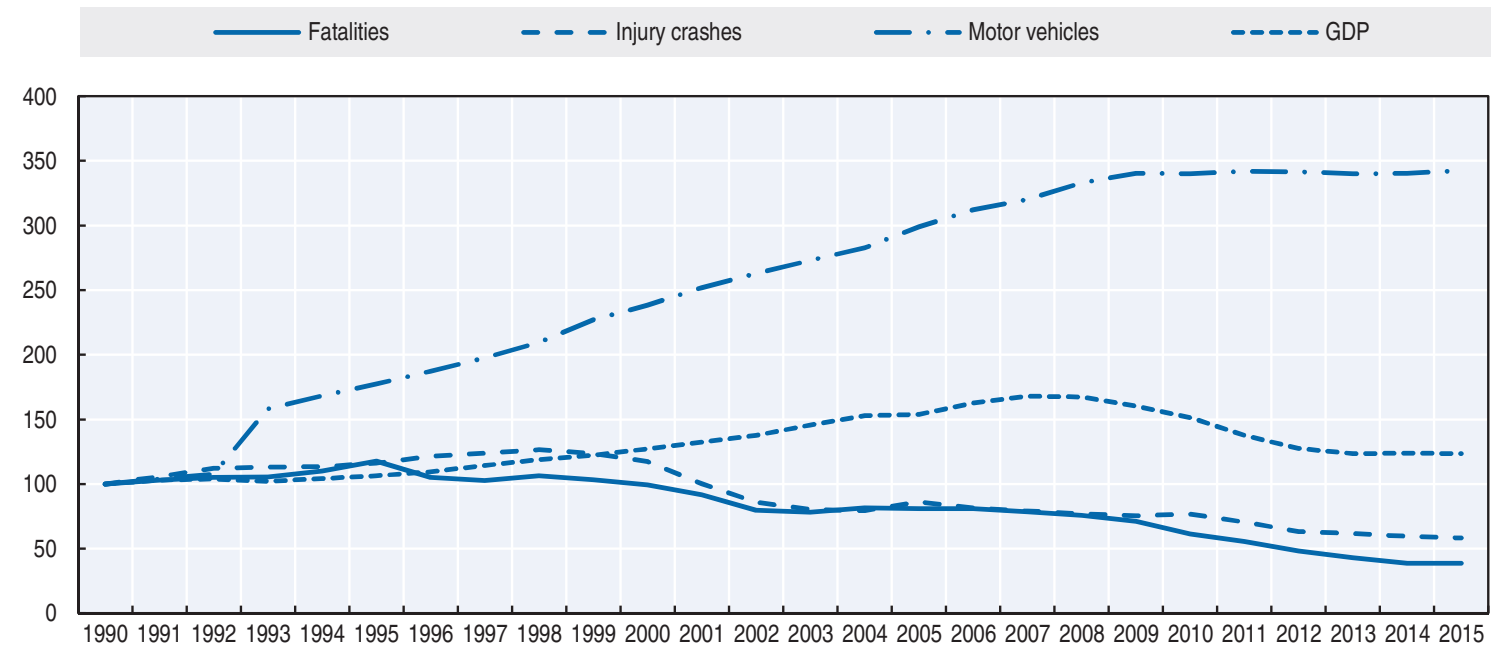

Source: World Bank (2017) (GDP; constant prices) 


\section{Analysis of seriously injured data}

Over the last six years serious injuries (as recorded by the police) have been continuously decreasing and in 2015 were half of those of 2010.

\section{Road safety by user group}

Since the peak in fatalities in 1995, all road users have benefited from the overall improvement in road safety. Between 1990 and 2015, the number of moped riders killed decreased by $83 \%$ mainly due to the lack of popularity of this form of transport, whereas the number of motorcyclists killed decreased by only $13.5 \%$. Pedestrian fatalities decreased by $76 \%$. However, during the recession period in which fatalities decreased considerably, riders of two-wheelers did not experience the same decline. Motorcyclist fatalities were reduced by $29 \%$ and cyclists were reduced only by $14 \%$ between 2008 and 2014, compared to the $49 \%$ decrease in the total number of fatalities over the same period.

Between 2014 and 2015, fatalities decreased for cyclists (-42.1\%) and motorcyclists $(-4.7 \%)$. For the other road users the number of road deaths increased, with a biggest increase for moped riders (60\%), followed by car occupants $(+8.7 \%)$ and pedestrians $(+2.4 \%)$.

Table 14.2. Road fatalities by road user group

\begin{tabular}{lrrrrr|rrrr}
\hline & 1990 & 2000 & 2010 & 2014 & 2015 & \multicolumn{4}{c}{$2015 \%$ change from } \\
\cline { 7 - 10 } & & & & & & 2014 & 2010 & 2000 & 1990 \\
\hline Pedestrians & 524 & 375 & 179 & 125 & 128 & 2.4 & -28.5 & -65.9 & -75.6 \\
Cyclists & 26 & 22 & 23 & 19 & 11 & -42.1 & -52.2 & -50.0 & -57.7 \\
Moped riders & 192 & 90 & 36 & 20 & 32 & 60.0 & -11.1 & -64.4 & -83.3 \\
Motorcyclists & 274 & 412 & 372 & 278 & 237 & -14.7 & -36.3 & -42.5 & -13.5 \\
Car occupants & 712 & 891 & 542 & 289 & 314 & 8.7 & -42.1 & -64.8 & -55.9 \\
Others & 322 & 247 & 106 & 64 & 71 & 10.9 & -33.0 & -71.3 & -78.0 \\
Total & $\mathbf{2 0 5 0}$ & $\mathbf{2 0 3 7}$ & $\mathbf{1 2 5 8}$ & $\mathbf{7 9 5}$ & $\mathbf{7 9 3}$ & $\mathbf{- 0 . 3}$ & $\mathbf{- 3 7 . 0}$ & $\mathbf{- 6 1 . 1}$ & $\mathbf{- 6 1 . 3}$ \\
\hline
\end{tabular}

Figure 14.2. Road fatalities by road user group in percentage of total, 2015

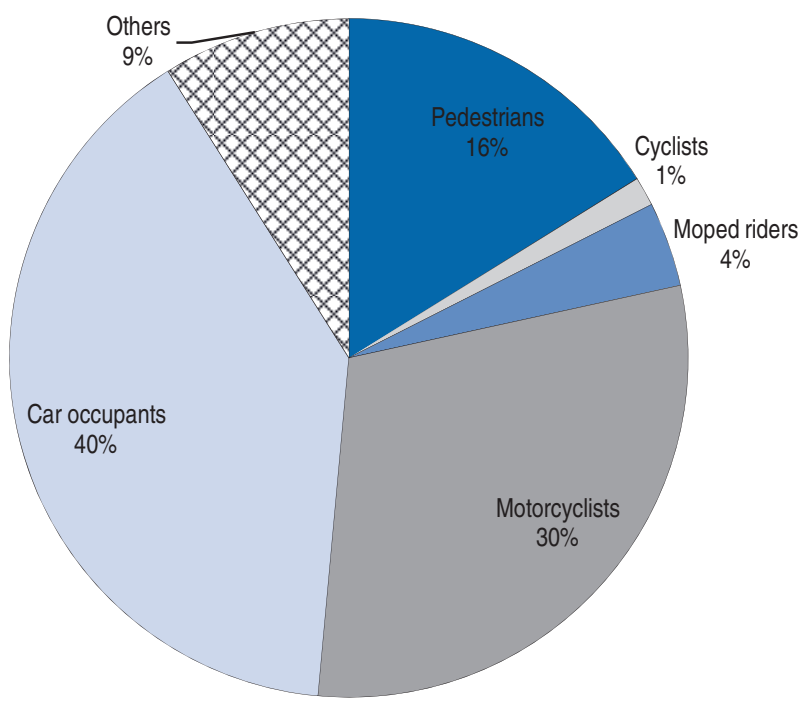




\section{Road safety by age group}

Since the peak in 1995, all age groups have benefited from a drop in fatalities, with the best performance seen for the 0-14 age group.

Between 2010 and 2015, the 0-14 age group showed the highest decrease in the number of fatalities $(-80 \%)$ followed by the $15-17$ age group (-51\%). However, with regard to the fatality rate per 100000 inhabitants, young people have a much higher risk than other age groups, with the 18-24 year old group having a rate of 17 .

Between 2014 and 2015, the number of road deaths among the youngest age group (0-14) substantially decreased again (-40\%), while there was an increase of more than $20 \%$ in the number of deaths among the senior population.

Table 14.3. Road fatalities by age group

\begin{tabular}{lrrrrr|rrrr}
\hline \multirow{2}{*}{ Age } & 1990 & 2000 & 2010 & 2014 & 2015 & \multicolumn{4}{|c}{$2015 \%$ change from } \\
\cline { 7 - 10 } & & & & & & 2014 & 2010 & 2000 & 1990 \\
\hline $0-14$ & 95 & 40 & 30 & 10 & 6 & -40.0 & -80.0 & -85.0 & -93.7 \\
$15-17$ & 76 & 60 & 39 & 19 & 19 & 0.0 & -51.3 & -68.3 & -75.0 \\
$18-20$ & 183 & 156 & 73 & 45 & 34 & -24.4 & -53.4 & -78.2 & -81.4 \\
$21-24$ & 249 & 219 & 113 & 69 & 78 & 13.0 & -31.0 & -64.4 & -68.7 \\
$25-64$ & 1051 & 1107 & 711 & 460 & 427 & -7.2 & -39.9 & -61.4 & -59.4 \\
$65-74$ & & 241 & 113 & 82 & 89 & 8.5 & -21.2 & -63.1 & \\
$75-84$ & & 147 & 124 & 80 & 112 & 40.0 & -9.7 & -23.8 & \\
$\geq 85$ & & 40 & 31 & 25 & 24 & -4.0 & -22.6 & -40.0 & \\
Total & $\mathbf{2 0 5 0}$ & $\mathbf{2 0 3 7}$ & $\mathbf{1 2 5 8}$ & $\mathbf{7 9 5}$ & $\mathbf{7 9 3}$ & $\mathbf{- 0 . 3}$ & $\mathbf{- 3 7 . 0}$ & $\mathbf{- 6 1 . 1}$ & $\mathbf{- 6 1 . 3}$ \\
\hline
\end{tabular}

Figure 14.3. Road fatality rates by age group Deaths per 100000 inhabitants in a given age group, 1990-2015

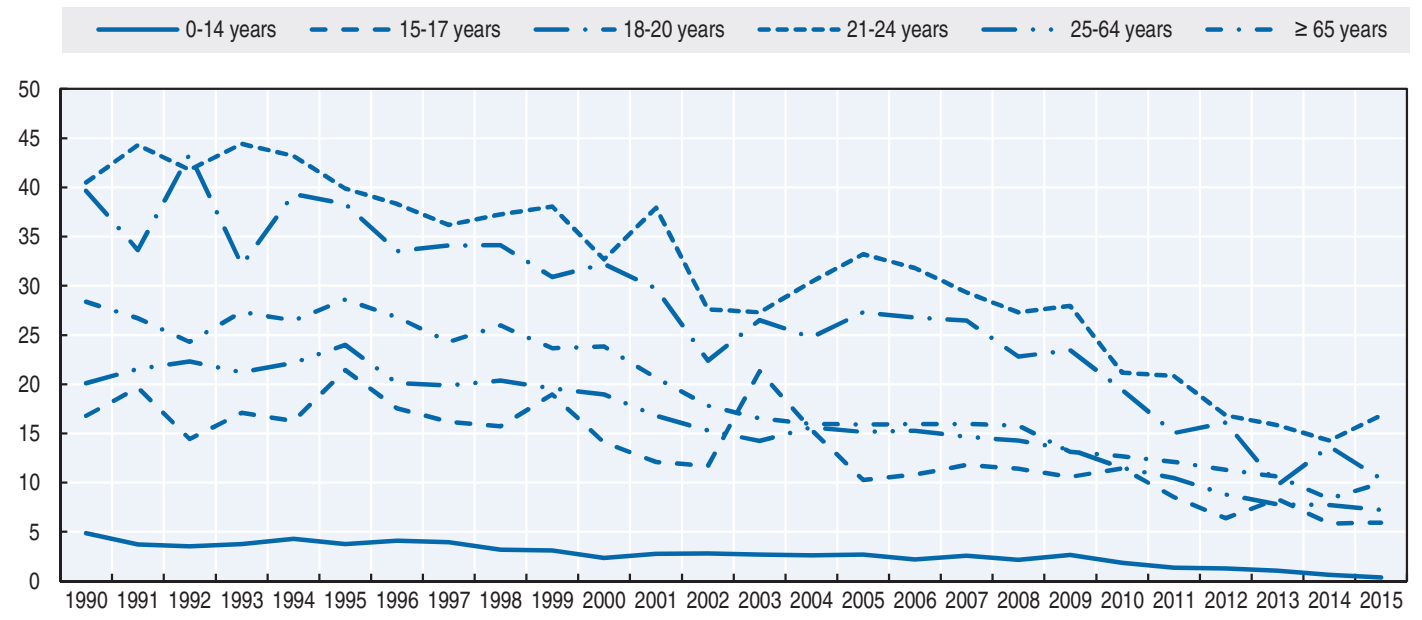

\section{Box 14.1. Road safety for an ageing population}

The share of people aged 65 and above was $14 \%$ in 1990 and 21\% in 2015. According to ELSTAT, it will reach $32 \%$ by 2050 . In addition, the over 75 population is expected to reach $17.8 \%$ in 2050 .

Between 2000 and 2015, senior citizens experienced a drop in fatalities alongside other age groups, with the 65-74 age group recording the highest reduction (63.1\%). This might be attributed to the fact that the economic crisis led to a decrease in the number of older drivers on the road and subsequently to less road fatalities. 


\section{Box 14.1. Road safety for an ageing population (cont.)}

With regard to the fatality rate per 100000 inhabitants, in 2015 those between 75 and 84 years of age had the highest risk of being killed in a road crash, while the over 85 year olds showed the highest decrease since 2010.

Between 2014 and 2015, the over 85 year old age group showed a decrease of $4 \%$, whereas there was a significant increase of $40 \%$ for road users between $75-84$ years old.

Most fatalities among the older population are as pedestrians. Since 2010 fatalities among pedestrian aged between 65 and 74 years old were reduced by $39 \%$ and motorcyclists by $40 \%$, while an increase of $2 \%$ was recorded for car occupants.

The ratio between male and female fatality rates per 100000 population is about 7 for the 65-74 age group and about 4 for the 75-84 age group. Since 2010, the highest decrease in male fatality rates per 100000 population was recorded for the over 85 year old group (39\%).

For individuals up to 80 years old, without any medical history that could potentially influence safe driving, the examination for diving license is carried out by two medical doctors, i.e. a pathologist and an ophthalmologist. Those doctors are responsible for the Primary Medical Examination. According to the updated legislative directives, after the completion of 80 years of age, the renewal of the driving license should be made by the Secondary Medical Commission with a duration of no more than two years from the date of renewal.

Table 14.4. Road fatalities among senior citizens

\begin{tabular}{lrcc|ccc|ccc}
\hline & \multicolumn{3}{c|}{$65-74$} & \multicolumn{3}{c|}{$75-84$} & \multicolumn{3}{c}{$\geq 85$} \\
\cline { 2 - 10 } & 2010 & 2015 & \% change & 2010 & 2015 & \% change & 2010 & 2015 & \% change \\
\hline Pedestrians & 31 & 19 & -39 & 52 & 49 & -6 & 17 & 13 & -24 \\
Cyclists & 3 & 1 & - & 2 & 0 & - & 1 & 0 & - \\
Moped riders & 3 & 3 & $=$ & 10 & 6 & - & 2 & 3 & + \\
Motorcyclists & 15 & 9 & -40 & 8 & 9 & + & 0 & 0 & $=$ \\
Car occupants & 43 & 44 & 2 & 36 & 36 & 0 & 9 & 7 & - \\
Total & $\mathbf{1 1 3}$ & $\mathbf{8 9}$ & $\mathbf{- 2 1}$ & $\mathbf{1 2 4}$ & $\mathbf{1 1 2}$ & $\mathbf{- 1 0}$ & $\mathbf{3 1}$ & $\mathbf{2 4}$ & $\mathbf{- 2 3}$ \\
\hline
\end{tabular}

Figure 14.4. Road fatality rates in the $65+$ age groups Deaths per 100000 inhabitants in a given age group, 2000-15

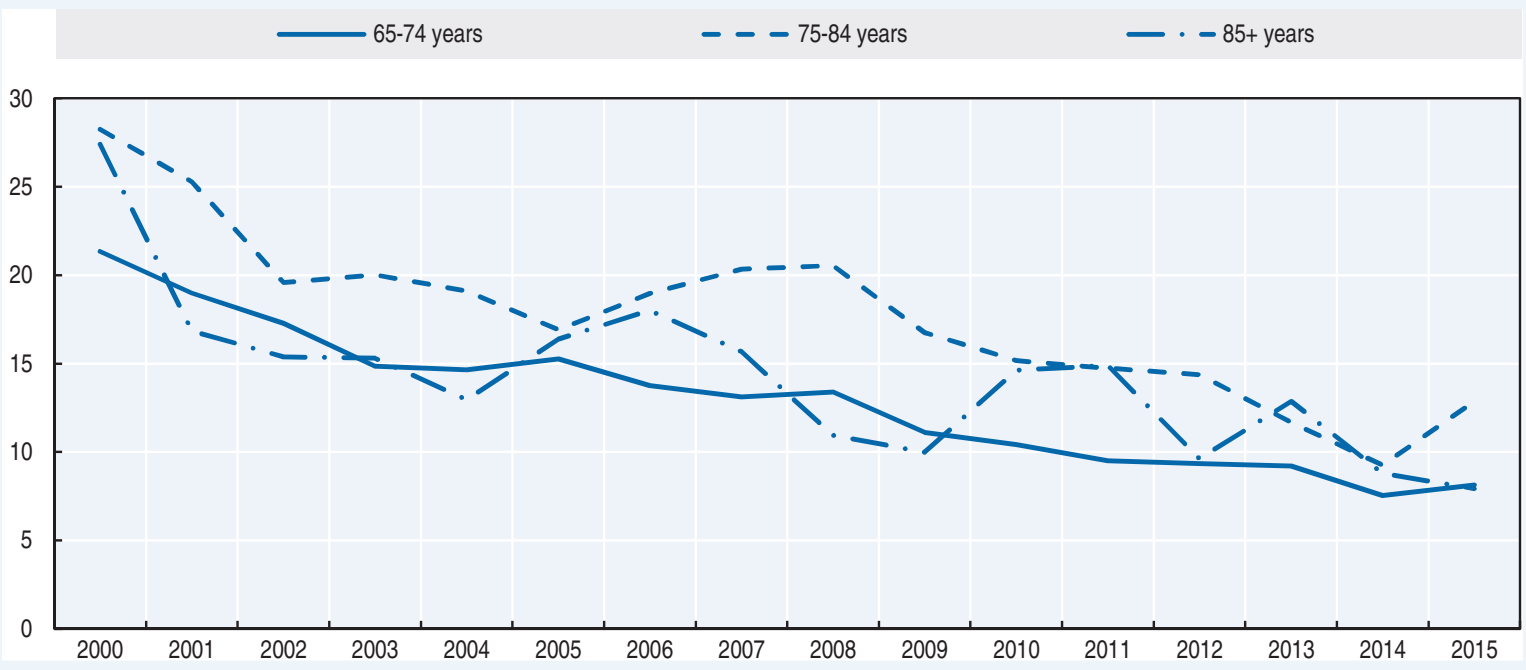




\section{Box 14.1. Road safety for an ageing population (cont.)}

A new Legislation was adopted in Greece in 2016 regarding the Medical Assessment of Drivers and Candidate Drivers. According to this new Legislation, among other provisions, the minimum requirements for physical and mental fitness to drive were revised and all drivers aged 80 years or over must complete a neurological, neuropsychological and psychiatric assessment in order to be considered as fit or not fit to drive.

The results of scientific research carried out jointly by NTUA and Attikon University Hospital have largely contributed to this new legislation.

Figure 14.5. Road fatality rate by age and road user group Fatalities per 100000 inhabitants, 2015

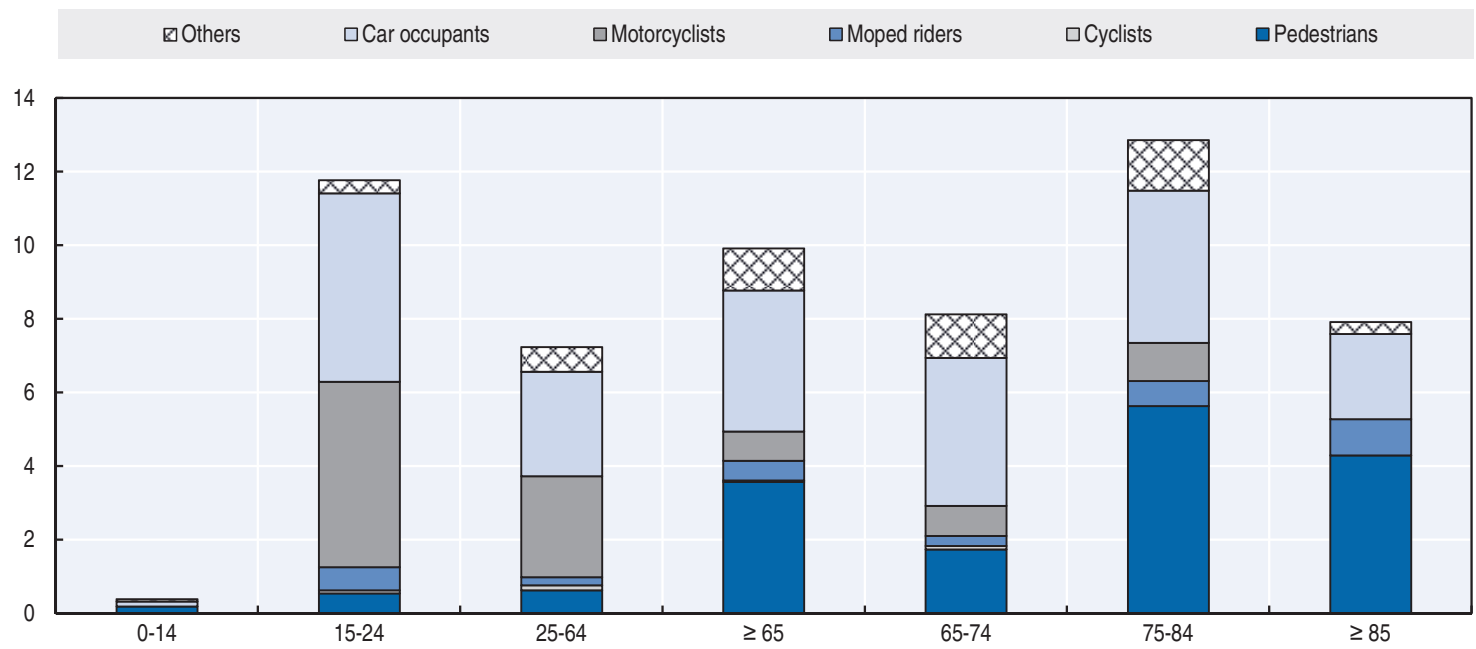

\section{Road safety by road type}

In $2015,49 \%$ of fatal crashes occurred in urban areas (mainly due to the increased motorcycle and pedestrian traffic), $44 \%$ on rural roads and $7 \%$ on motorways.

Figure 14.6. Road fatalities by road type

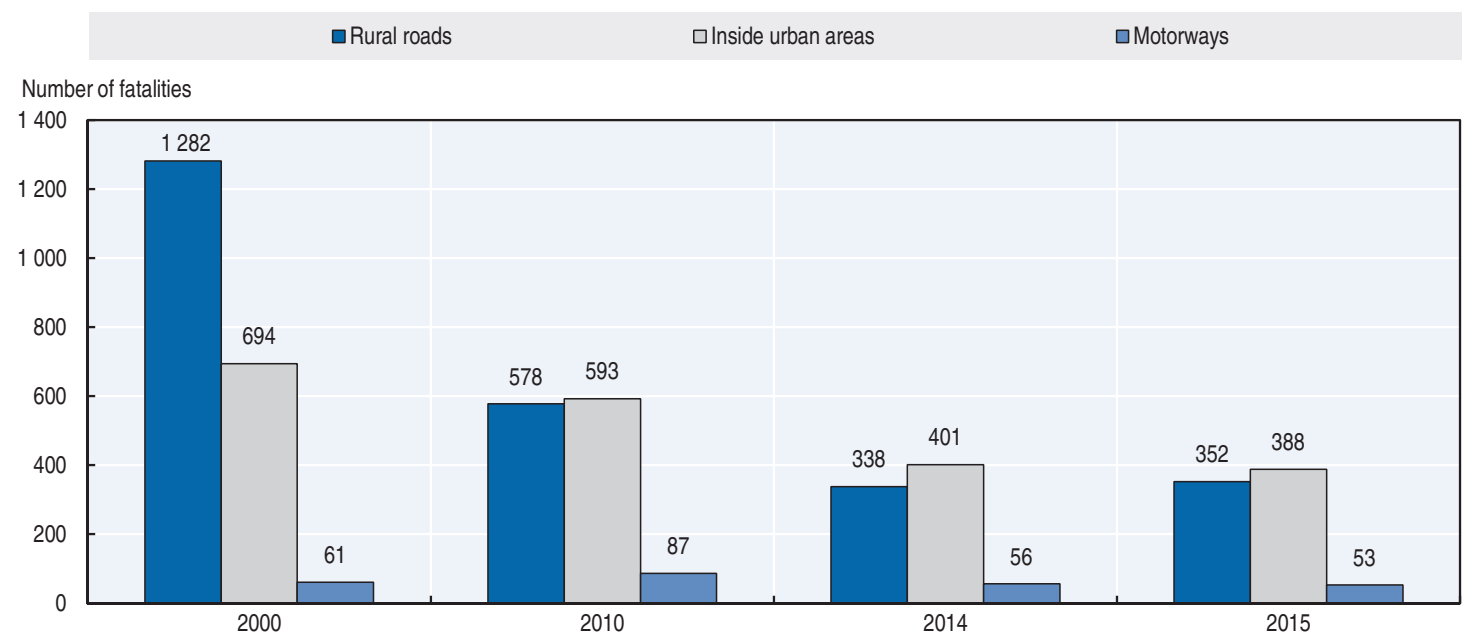


Since 2000 , there has been a $73 \%$ decrease in road deaths on the rural network, as almost $1200 \mathrm{~km}$ of the national interurban network were upgraded to motorways.

\section{Economic costs of traffic crashes}

Traffic crashes represent a significant cost for society, estimated in 2015 at around EUR 2.8 billion, representing almost 1.3\% of Greece's GDP (Wijnen et al., 2017). This calculation uses a combination of the lost production methodology and the willingness-to-pay methodology.

The cost is almost tripled if the real numbers of injuries and of "material damage only" crashes are taken into account.

Table 14.5. Costs of road crashes, 2015

\begin{tabular}{lrc}
\hline Cost (EUR) & Unit cost & Total \\
\hline Fatalities & 2171344 & EUR 1.73 billion \\
Serious injuries & 252277 & EUR 0.25 billion \\
Slight injuries & 41971 & EUR 0.57 billion \\
Property damage costs & 3044 & EUR 0.25 billion \\
Total (EUR) & & EUR $\mathbf{2 . 8}$ billion \\
Total as \% of GDP (at constant prices) & & $\mathbf{1 . 3}$ \\
\hline
\end{tabular}

\section{Recent trends in road user behaviour}

Speed

Speeding is perhaps the most critical factor for road crashes in Greece. Speeding enforcement varied during the last decade, with a direct impact on the progress of road safety trends. The recent important decline in road fatalities and speeding may be a result of the economic crisis encouraging more ecological driving.

The table below summarises the main speed limits in Greece.

Table 14.6. Passenger car speed limits by road type, 2017

\begin{tabular}{lrl}
\hline & General speed limit & \multicolumn{1}{c}{ Comments } \\
\hline Urban roads & $50 \mathrm{~km} / \mathrm{h}$ & \\
Rural roads & $90 \mathrm{~km} / \mathrm{h}$ & \\
Motorways & $130 \mathrm{~km} / \mathrm{h}$ & $\begin{array}{l}\text { Variable speed limits are implemented } \\
\text { when variable message signs are available }\end{array}$ \\
\hline
\end{tabular}

\section{Drink driving}

According to the Greek Highway Code, the maximum permissible blood alcohol content (BAC) is $0.5 \mathrm{~g} / \mathrm{l}$ when measured by blood sample, and $0.25 \mathrm{mg} / \mathrm{l}$ when measured by breath testing.

Since 2007, a lower limit $(0.2 \mathrm{~g} / \mathrm{l})$ has applied to professional drivers (heavy goods vehicles, school buses and coaches), motorcycles and moped riders.

Studies demonstrate that drivers over the legal limit are seven times more likely to be involved in a road crash. 
It is estimated that, in 2015 , almost $25 \%$ of road fatalities were attributed to drink driving. The share of alcohol-related fatalities has dropped by $25 \%$ since 2010 and a significant decrease of 36\% was recorded between 2000 and 2015.

\section{Drugs and driving}

Driving under the influence of drugs is prohibited under Greece's Road Code. No data are available for drug related crashes.

\section{Seat belts and helmets}

The use of seat belts has been compulsory since 1987 in front seats and since 2003 in rear seats.

Children under 12 must be seated in a rear seat and be adequately restrained, taking into account their weight and height.

There has been no recent seat belt user survey. According to 2009 data, the seat belt use rate was $77 \%$ for drivers, $74 \%$ for a front seat passenger and $23 \%$ in rear seats. The percentage of seat belt use by the driver was $72 \%$ in urban areas, $78 \%$ on rural roads and $95 \%$ on motorways.

All riders of powered two-wheelers (PTWs) are required to wear helmets. The helmetwearing rate is $75 \%$ for drivers and $46 \%$ for passengers. Helmet use by the driver is $73 \%$ in urban areas, $85 \%$ on rural roads and $98 \%$ on motorways.

\section{Table 14.7. Seat belt wearing rate by car occupancy and road type}

\begin{tabular}{lc}
\hline & 2009 \\
\hline Front seat & 77 \\
Driver & 74 \\
Passenger & 72 \\
Urban roads (driver) & 78 \\
Rural roads (driver) & 98 \\
Motorways (driver) & 23 \\
Rear seats & No data \\
General & \\
Children (use of child restraint) & \\
\hline
\end{tabular}

\section{Distraction}

In Greece, it is forbidden to use a hand-held phone or headphones while driving. Only wireless, hands-free devices are permitted.

There has been no recent survey on the use of mobile phones while driving. According to an observational study by the National Technical University of Athens (NTUA) in 2009, $9 \%$ of passenger-car drivers and $2 \%$ of powered two-wheeler riders use mobile phones while driving.

The mobile phone use rate increases inside built-up areas and for young drivers (16-24), especially for young female drivers of passenger cars (16\%) and powered two-wheelers (12\%).

\section{Sleepiness and fatigue}

No studies on the effect of fatigue on road safety were carried out in Greece. 


\section{National road safety strategies and targets \\ Organisation of road safety}

The co-ordination of all the ministries involved in road safety management is ensured by the Inter-Ministry Committee on Road Safety, chaired by the Minister of Citizen Protection. However, his role remains limited, as the corresponding co-ordination secretariat has never been properly operational. Some stakeholder consultation takes place at the National Road Safety Council. Regional and local authorities implement road safety activities, mainly on road infrastructure and vehicle control; however, there is no process to integrate national and regional activities and there is no reporting from the regional to the national level.

Despite the three strategic plans adopted during the last decade, mobilisation of the authorities and of society remained limited and road safety is still not a recognised policy area in practice. There is no identifiable budget for road safety.

Quite a few non-governmental organisations (NGOs) are strong advocates for road safety, with the Road Safety Institute Panos Mylonas, having a very active role. Road safety problems and solutions are well known in Greece through research studies; however, implementation of measures is limited. Furthermore, there is no official monitoring of road safety actions, no benchmarking and little evaluation of the road safety interventions.

\section{Road safety strategy for 2011-20}

The third National Road Safety Strategic Plan, developed by the NTUA, was approved by the Ministry of Infrastructure, Transport and Networks in September 2011. The aim of this strategic plan is the development of a strong road safety culture. The plan foresees a national road safety management structure comprising the Inter-Ministry Committee, the Parliamentary Committee, the National Advisory Committee as well as a framework for efficient implementation, monitoring and evaluation of road safety level and measures. The strategic plan is composed of six pillars: road safety education, road safety enforcement, safe road users, safe road infrastructure, safe vehicles and post-crash management.

\section{Road safety targets}

The strategic plan adopts the European target of reducing the number of road fatalities by $50 \%$ between 2010 and 2020. Intermediate targets include a reduction of 80 road fatalities per year between 2010 and 2015, which has been achieved partly due to the economic crisis, and a reduction of 50 road fatalities per year between 2016 and 2020.

Specific actions by the central and regional governments have been identified as necessary to reach the target. A prerequisite is a strong political will and support at the highest political level. The Inter-Ministry Committee, re-established twice (in 2010 and in 2014 under the chairmanship of the Prime Minister), is expected to play a critical role.

Even though the strategy has clearly defined the targets, the programmes and the implementation framework, some important barriers remain, such as the lack of systematic implementation of the measures and a lack of co-ordination and monitoring. The co-ordination instruments to support the Inter-Ministry Committee were never fully operational and the necessary resources were never allocated to the related road safety actions. 
Figure 14.7. Trends in road fatalities towards national target

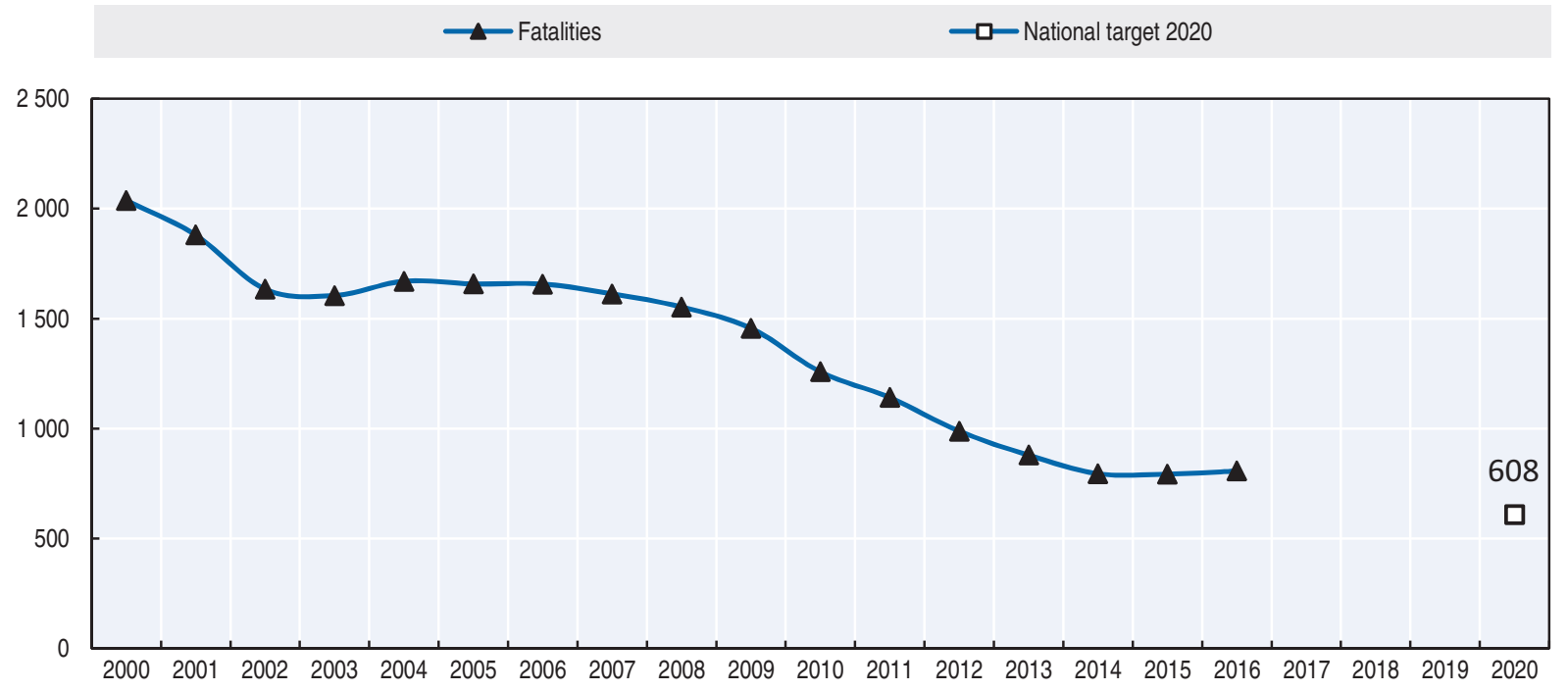

\section{Recent safety measures (2014-17)}

The unprecedented economic crisis during the last six years has resulted in a limited budget for road safety initiatives in Greece.

Some road safety measures are being implemented focusing on road safety police enforcement (for speeding, drink driving and use of seat belts and helmets) and through road safety education and information campaigns conducted mainly by private companies such as motorway concessionaires and NGOs. Greek universities and research institutes carry out many road safety research projects, thus supporting road safety actions in Greece.

\section{Road safety management}

- New legislation concerning road safety audits has been introduced, which in the future might result in more systematic audits of the road network.

- Following a new law, the Inter-Ministry Committee on Road Safety was re-established a first time in 2010 and a second time in 2014, this time under the chairmanship of the Prime Minister. However, this Inter-Ministry Committee has not met for the last three years.

- Road safety management is the responsibility of both national and regional authorities. During the last decade, more and more regional and local authorities have established and implemented regional road safety plans, sometimes within their urban mobility plans, which are starting to bring results.

\section{Road users}

\section{Speed management}

- During the last five years, Greek drivers have improved their driving behaviour, becoming less aggressive and speeding less, as a consequence of the personal budget limitations brought by the economic crisis. This has resulted in significant safety improvements. The improved driver behaviour is expected to remain following the crisis, despite potential increase in traffic volumes. 


\section{Speed management}

- The update of the Highway Code is still under discussion and includes consideration of speed limit reviews for both traffic safety and efficiency reasons. Higher gas prices due to the crisis had a direct impact on average speed reduction and consequently to traffic safety improvement.

\section{Education and awareness}

- National, regional and local authorities regularly conduct campaigns and training on user behaviours such as speeding, impaired driving, seat belt and helmet misuse, etc. However the impact of these efforts on traffic safety is unknown as no monitoring programme exists.

- The Road Safety Institute Panos Mylonas continues a massive programme of road safety campaigns and training. Other NGOs and private companies (motorways concessions) carry out some road safety campaigns.

\section{Infrastructure}

- Due to the difficult economic conditions, the budget for road maintenance and safety intervention has been significantly reduced. Nevertheless, the major motorway development programme totalling $2500 \mathrm{~km}$ of toll motorways (including the construction of $1300 \mathrm{~km}$ of new motorways) restarted in 2013 and is gradually delivering all motorway sections during 2017.

\section{Vehicles}

- All European Union regulations on vehicles are properly transposed into Greek legislation, resulting in higher safety standards for all new vehicles entering into circulation in Greece. Improved passive and active safety is one of the reasons for the significant reduction of persons killed and seriously injured in traffic crashes.

- It should be noted however, that the vehicle fleet is renewed very slowly, resulting in an increase in the age of the vehicle fleet.

\section{Recent and ongoing research}

- The National Technical University of Athens (NTUA) and the Hellenic Institute of Transport (HIT/CERTh) are the two main road safety research organisations in Greece. Current research involves road crash analysis, road safety management, vehicle safety, driver behaviour and intelligent transportation systems and lately the autonomous vehicles. Several of these research results are available at: www.nrso.ntua.gr/ (accessed 16 June 2017).

\section{References}

Hellenic Institute of Transportation Engineers (2016), HITE position on Road Safety in Greece, HITE, 2016.

Wijnen, W., W. Weijermars, W. Vanden Berghe, A. Schoeters, R. Bauer, L. Carnis, R. Elvik, A. Theofilatos, A. Filtness, S. Reed, C. Perez and H. Martensen (2017), Crash cost estimates for European countries, Deliverable 3.2 of the H2020 project SafetyCube.

World Bank (2017), “GDP (constant US\$)”, World Development Indicators, http://databank.worldbank.org/ data/reports.aspx?source=world-development-indicators (accessed 23 February 2017). 


\section{Websites}

- Hellenic Statistical Authority: www.statistics.gr (accessed 16 June 2017).

- Ministry of Infrastructure, Transport and Networks: www.yme.gr (accessed 16 June 2017).

- Road Safety Observatory of the National Technical University of Athens: www.nrso.ntua.gr (accessed 16 June 2017).

- Road Safety Institute Panos Mylonas: www.ioas.gr (accessed 16 June 2017).

- Road Safety Resources in Greece: www.nrso.ntua.gr/road-safety-links (accessed 16 June 2017). 


\section{Chapter 15}

\section{Hungary}

This chapter presents 2015 road safety data for Hungary along with provisional data from 2016. It looks at trends in traffic and road safety from the years 1990 to 2015 and road user behaviour patterns, with a focus on the ageing population. Sections include data on speed, drink driving, drugs and driving, distracted driving, fatigue and seat belt usage. The chapter reviews Hungary's road safety strategy and national targets to 2020 and the progress achieved thus far. It also provides details of all recently implemented safety measures and current and ongoing research.*

* All data stem from the Institute for Transport Sciences (KTI) and IRTAD unless otherwise noted. For more information please contact: Prof. Dr Péter Holló, hollo.peter@kti.hu. 


\section{I} there were 644 road fatalities, a $2.9 \%$ increase when compared to 2014, equalling a rate of 6.5 fatalities per 100000 inhabitants. This was the second consecutive year with an increase in the number of fatalities, following a seven-year period of continuous decrease. The increase was mainly seen among car occupants and is partly linked to the decrease in seat belt use. However, final data from 2016 indicate a reversal to this trend with 607 fatalities, a 5.7\% decrease over 2015.

\section{Road safety data collection}

\section{Definitions applied in Hungary}

- Road fatality: Person who dies within 30 days as a result of a traffic crash.

- Seriously injured person: Any person who, due to the crash, sustained an injury which meets one of the following criteria:

* necessitates hospitalisation for more than 48 hours within seven days of the accident

* caused a fracture (except for finger, toe, nose fractures)

* caused cuts that resulted in serious bleeding or nerve, muscle or tendon injuries

* caused injury of inner organs;

* caused a burn of second or third degree or a burn affecting more than $5 \%$ of body surface.

Hungary does not use the Maximum Abbreviated Injury Scale to define a serious injury. Nevertheless, to fulfil EU requirements it will report MAIS3+ data as of 2018.

\section{Data collection}

Data on personal injury crashes are collected by the police and form the basis of the official Hungarian road crash statistics.

In Hungary, the provision of road traffic crash data is governed by the government decree on the National Statistical Data Collection Programme, in line with the Act on Statistics. It takes into account Council Decision 93/704/EC, which stipulates that the member states provide their safety data to the European Commission for the elaboration of a European community database ("CARE"). The Hungarian national data collection system has been adjusted to be compatible with the Common Accident Data Set (CADaS) structure. Variables are divided into four categories: Accident, Road, Traffic Unit, and Person.

The European Commission and the International Road Traffic and Accident Database (IRTAD) have recommended that Hungary collect data on serious injuries based on the Maximum Abbreviated Injury Scale of 3 or more (MAIS3+). Hungary is expected to fulfil requirements of the data reporting method on MAIS3+ serious injuries from 2018. The preparation process related to the implementation of MAIS3+ method as well as related legal steps have started recently. The final migration is expected to happen by the end of 2017, with the first data reporting according to the new methodology expected during 2018. 
The quality and completeness of police reported data are relatively good for fatal crashes and casualties. However, based on previous research, it is estimated that only $85 \%$ of those seriously injured (based on the national definition) and $60 \%$ of those slightly injured are reported in police records.

\section{Most recent safety data}

\section{Road crashes in 2016 - final data}

In 2016 there were 607 road fatalities, a 5.7\% decrease when compared to 2015. One of the reasons that could have contributed to this improvement is the impact of the implementation of a new intelligent camera system ("VÉDA").

\section{Road crashes in 2015}

In 2015 , there were 644 road fatalities, a $2.9 \%$ increase when compared to 2014 . This was the second consecutive year with an increase in the number of fatalities, following a seven-year period of continuous decrease. The recovery of the economy is one of the main factors that explain the increase in the number of road deaths.

The biggest increase was observed among moped riders and car occupants, while fatalities among vulnerable road users - pedestrians and cyclists have decreased over the same period from $2 \%$ (pedestrians) to more than $15 \%$ (for cyclists). Fatalities also decreased among motorcyclists (-14\%).

\section{Trends in traffic and road safety (1990-2016) Traffic}

The annual distance travelled (vehicle-kilometres) on the state road network decreased by $10 \%$ between 2008 and 2012. The decrease concerned both light and heavy vehicles. In 2013 the number of vehicle-kilometres was practically the same as in 2012, and started increasing again in $2014(+7.5 \%)$ and $2015(+11 \%)$, probably as a result of the economic recovery.

\section{Road safety}

\section{Crashes and casualties}

According to Prof. Dr Péter Holló, the history of Hungarian road safety can be divided into the following periods:

- 1976-86: Relatively stable period. The 30-day definition for road accident fatalities was introduced in 1976.

- 1987-90: Strong deterioration, similar to all countries where the political, social and economic systems changed following the collapse of the socialist bloc. This political change was accompanied by negative side effects for road safety, due to weak police control, less political attention to road safety, a false interpretation of freedom, explosion in the size and changes in the structure of the vehicle fleet, etc. The worst year for Hungarian road safety was in 1990, with nearly 2500 people killed.

- 1991-2000: Important improvements and major initiatives:

* 1993: Adoption of the first Hungarian National Road Safety Programme with a quantitative target. Road safety measures were implemented such as lower speed limits in built-up areas, mandatory daytime running lights and obligatory usage of rear safety belts 
outside built-up areas, intensified police control and road safety campaigns, more severe sanctions, etc.

* 2000 was the most successful year until 2008, with a reduction of more than $50 \%$ in the number of people killed (1 200) compared to 1990. Some demographic and economic factors contributed to the positive trend: a decrease in the number of novice drivers and an increase in vehicle operating costs.

- 2001-06: Deterioration, mainly outside built-up areas. In 2001, the speed limits outside built-up areas were raised. The level of police enforcement was insufficient, as was the organisation and funding of road safety activities.

- 2007-13: After several years of increasing road fatalities, the 2007 performance was back to that of 2000. In 2008, there was a remarkable decrease in fatalities - less than 1 000. In 2013 the number of road fatalities was as low as that of 50 years earlier. The improvement in the passive safety of vehicles is considered to be an important factor contributing to these positive results. Several other factors (introduction of the owner responsibility, installation of automatic speed cameras, further development of point demerit system, etc.,) as well as the economic recession have also contributed to the reduction in the number of road deaths.

- In 2014 and 2015, the number of fatalities increased, but in 2016 the trend was reversed, with a reduction of about $6 \%$ in the number of killed on Hungarian roads.

\section{Rates}

In 2015, Hungary recorded 6.5 fatalities per 100000 inhabitants, a rate almost four times lower than the maximum in the 1990s. However this rate has increased by $3 \%$ compared to 2014 and by almost 7\% compared to 2013 .

Fatalities per 10000 registered motor vehicles (excluding mopeds) were divided by almost seven between 1990 and 2015 and by a factor of 2.5 since 2000. The rate was 1.6 fatalities in 2013 which increased slightly to 1.7 in 2014 and 2015.

Table 15.1. Road safety and traffic data

\begin{tabular}{|c|c|c|c|c|c|c|c|c|c|}
\hline & \multirow{2}{*}{1990} & \multirow{2}{*}{2000} & \multirow{2}{*}{2010} & \multirow{2}{*}{2014} & \multirow{2}{*}{2015} & \multicolumn{4}{|c|}{$2015 \%$ change from } \\
\hline & & & & & & 2014 & 2010 & 2000 & 1990 \\
\hline \multicolumn{10}{|l|}{ Reported safety data } \\
\hline Fatalities & 2432 & 1200 & 740 & 626 & 644 & 2.9 & -13.0 & -46.3 & -73.5 \\
\hline Injury crashes & 27801 & 17493 & 16308 & 15847 & 16331 & 3.1 & 0.1 & -6.6 & -41.3 \\
\hline Deaths per 100000 inhabitants & 23.4 & 11.7 & 7.4 & 6.3 & 6.5 & 3.1 & -11.6 & -44.3 & -72.1 \\
\hline Deaths per 10000 registered vehicles & 11.2 & 4.4 & 2.0 & 1.7 & 1.7 & 0.0 & -16.4 & -61.7 & -84.9 \\
\hline \multicolumn{10}{|l|}{ Traffic data } \\
\hline Registered vehicles ${ }^{1}$ (thousands) & 2163 & 2706 & 3640 & 3718 & 3822 & 2.8 & 5.0 & 41.2 & 76.7 \\
\hline Registered vehicles per 1000 inhabitants & 208 & 265 & 363 & 376 & 388 & 3.0 & 6.7 & 46.5 & 86.0 \\
\hline
\end{tabular}

1. Registered vehicles excluding mopeds. 
Figure 15.1. Road safety, traffic and GDP trends index $1990=100$

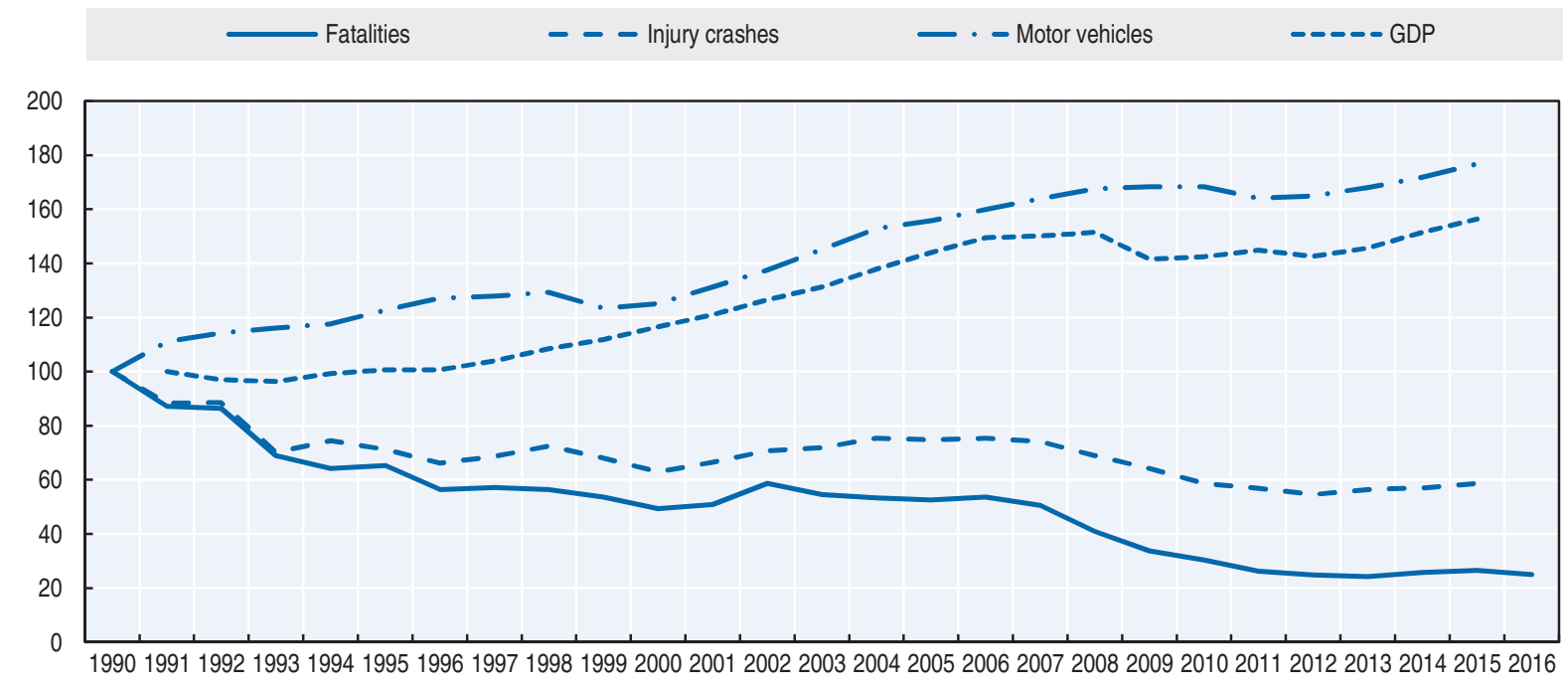

Source: World Bank (2017) (GDP; constant prices).

\section{Road safety by user group}

All user groups have benefited from important safety improvements since 1990, with the largest benefits for vulnerable road users: pedestrians (-81\%), cyclists $(-74 \%)$ and moped users $(-72 \%)$.

In 2015, safety improved for pedestrians, cyclists and motorcyclists. Fatalities for the two latter groups were reduced by almost $15 \%$, while the decrease was less significant for pedestrians (-2\%). In 2015, the number of road deaths increased among car occupants $(+19 \%)$ and moped riders $(+59 \%$ but absolute numbers are relatively small from 17 to 27$)$.

The increase in the number of killed car occupants (from 256 to 304) can be explained mainly by the decreasing use of safety belts.

Table 15.2. Road fatalities by road user group

\begin{tabular}{|c|c|c|c|c|c|c|c|c|c|}
\hline & \multirow{2}{*}{1990} & \multirow{2}{*}{2000} & \multirow{2}{*}{2010} & \multirow{2}{*}{2014} & \multirow{2}{*}{2015} & \multicolumn{4}{|c|}{$2015 \%$ change from } \\
\hline & & & & & & 2014 & 2010 & 2000 & 1990 \\
\hline Pedestrians & 803 & 346 & 192 & 152 & 149 & -2.0 & -22.4 & -56.9 & -81.4 \\
\hline Cyclists & 313 & 182 & 92 & 98 & 83 & -15.3 & -9.8 & -54.4 & -73.5 \\
\hline Moped riders & 95 & 33 & 19 & 17 & 27 & 58.8 & 42.1 & -18.2 & -71.6 \\
\hline Motorcyclists & 143 & 52 & 49 & 58 & 50 & -13.8 & 2.0 & -3.8 & -65.0 \\
\hline Car occupants & 974 & 500 & 330 & 256 & 304 & 18.8 & -7.9 & -39.2 & -68.8 \\
\hline Others & 104 & 87 & 58 & 45 & 31 & -31.1 & -46.6 & -64.4 & -70.2 \\
\hline Total & 2432 & 1200 & 740 & 626 & 644 & 2.9 & -13.0 & -46.3 & -73.5 \\
\hline
\end{tabular}


Figure 15.2. Road fatalities by road user group in percentage of total, 2015

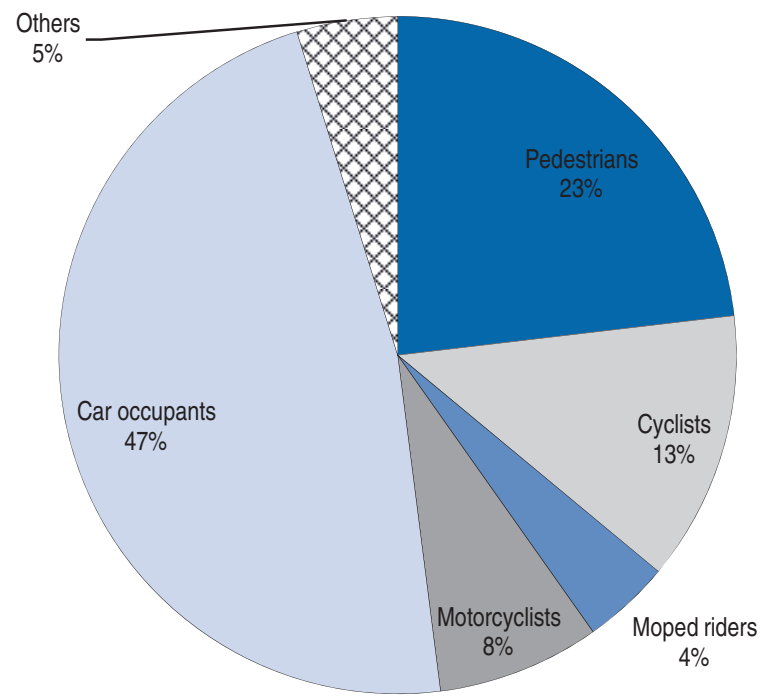

\section{Road safety by age group}

Since 1990, the reduction in fatalities has benefited all age groups, with a $90 \%$ decrease for young children of 0-17 years old. Marked improvements with reductions up to $85 \%$ were also observed among young adults aged 18-20 and 21-24.

In 2015, there was a general improvement among the senior population of 65 years and older (-7.1\%), against a background of an overall increase in fatalities by $2.9 \%$. A noticeable fatality reduction by $27.2 \%$ was observed for the $65-74$ age group, while fatalities for the older age group of 75-84 years old increased by the same percentage $(+27,1 \%)$.

In 2015, a deterioration or stagnation in fatalities was observed for all other age groups of population.

Table 15.3. Road fatalities by age group

\begin{tabular}{lrrrrr|rrrr}
\hline \multirow{2}{*}{ Age } & \multirow{2}{*}{1990} & 2000 & 2010 & 2014 & 2015 & \multicolumn{4}{|c}{$2015 \%$ change from } \\
\cline { 7 - 9 } & & & & & & 2014 & 2010 & 2000 & 1990 \\
\hline $0-14$ & 107 & 44 & 20 & 11 & 11 & 0.0 & -45.0 & -75.0 & -89.7 \\
$15-17$ & 99 & 18 & 10 & 7 & 9 & 28.6 & -10.0 & -50.0 & -90.9 \\
$18-20$ & 162 & 64 & 33 & 24 & 24 & 0.0 & -27.3 & -62.5 & -85.2 \\
$21-24$ & 191 & 114 & 40 & 35 & 37 & 5.7 & -7.5 & -67.5 & -80.6 \\
$25-64$ & 1365 & 736 & 488 & 392 & 416 & 6.1 & -14.8 & -43.5 & -69.5 \\
$65-74$ & & & 77 & 92 & 67 & -27.2 & -13.0 & & \\
$75-84$ & & & 51 & 48 & 61 & 27.1 & 19.6 & & \\
$\geq 85$ & & & 9 & 15 & 16 & 6.7 & 77.8 & & $\mathbf{- 7 3 . 5}$ \\
Total & $\mathbf{2 3 2}$ & $\mathbf{1 2 0 0}$ & $\mathbf{7 4 0}$ & $\mathbf{6 2 6}$ & $\mathbf{6 4 4}$ & $\mathbf{2 . 9}$ & $\mathbf{- 1 3 . 0}$ & $\mathbf{- 4 6 . 3}$ \\
\hline
\end{tabular}


Figure 15.3. Road fatality rates by age group Deaths per 100000 inhabitants in a given age group, 1990-2015
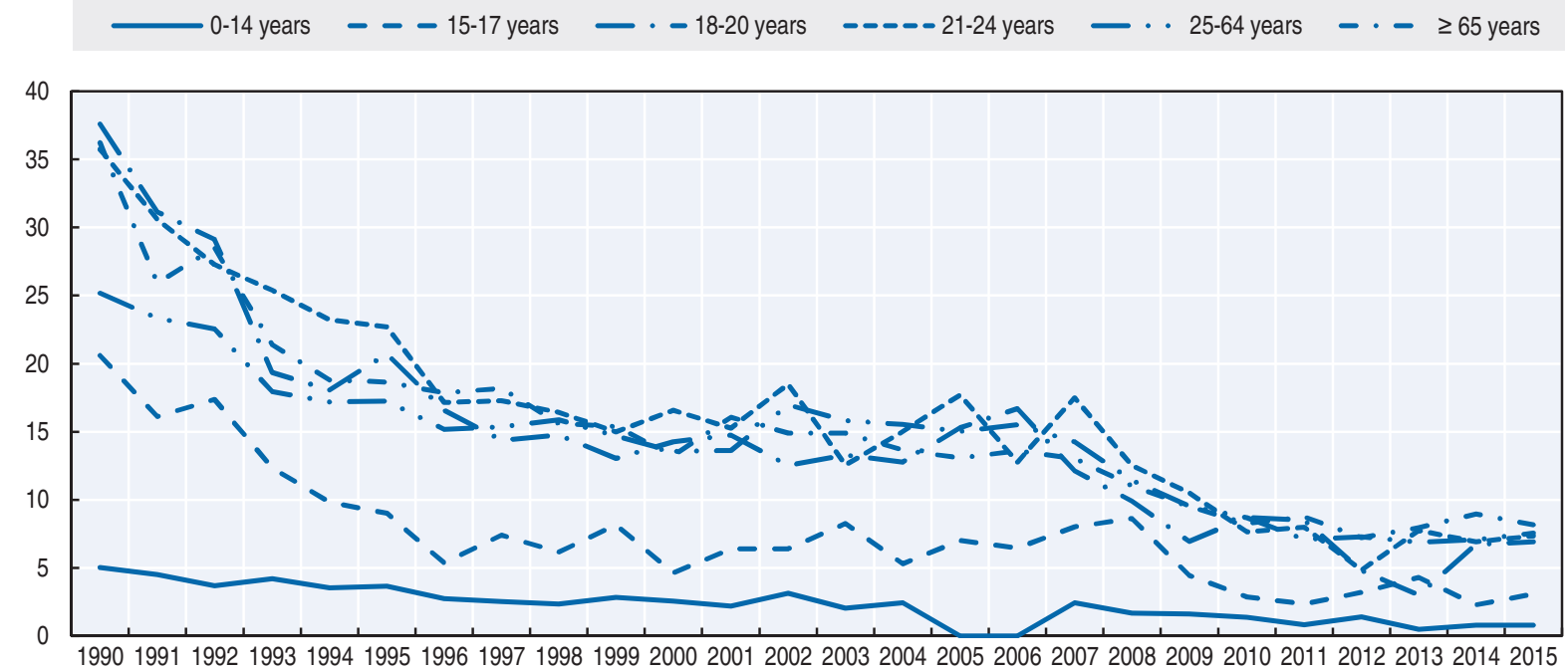

\section{Box 15.1. Road safety for an ageing population}

In $2015,18 \%$ of the population was aged 65 or above and this share is steadily increasing. By 2020 , there will be more people over the age of 65 than young people under the age of 19 .

In 2015, there were 144 persons aged 65 or over killed in road traffic (22\% of all road deaths). Of those, $37 \%$ were car occupants, $33 \%$ pedestrians, $22 \%$ cyclists and $5 \%$ powered two-wheelers.

In Hungary, all drivers must pass a medical visit to validate and renew their licence. The medical test is to be renewed every ten years for drivers below 40 years of age, every five years for drivers between 40 and 60, every three years for drivers between 60 and 70 and every two years for drivers over 70 .

The medical examination consists of vision test (including any vision deficiency such as colour blindness) and other basics medical checks (such as blood pressure). Since 2016, the driver may be tested for sleep apnoea.

Several campaigns are being undertaken to raise awareness on the safety of the older population. A recent campaign, "Make Your Grandparents Visible", focused on the need for increased conspicuity of older people.

Table 15.4. Road fatalities among senior citizens

\begin{tabular}{lccc|ccc|ccc}
\hline & \multicolumn{3}{c}{$65-74$} & \multicolumn{3}{c|}{$65-74$} & \multicolumn{3}{c}{$65-74$} \\
\cline { 2 - 10 } & 2010 & 2015 & \% change & 2010 & 2015 & \% change & 2010 & 2015 & \% change \\
\hline Pedestrians & 30 & 13 & -57 & 25 & 25 & 0 & 6 & 9 & + \\
Cyclists & 16 & 15 & -6 & 10 & 14 & 40 & 1 & 3 & + \\
Moped riders & 2 & 3 & + & 1 & 1 & $=$ & 0 & 2 & + \\
Motorcyclists & 0 & 2 & + & 0 & 0 & $=$ & 0 & 0 & $=$ \\
Car occupants & 23 & 31 & 35 & 14 & 20 & 43 & 2 & 2 & $=$ \\
Total & $\mathbf{7 7}$ & $\mathbf{6 7}$ & $\mathbf{- 1 3}$ & $\mathbf{5 1}$ & $\mathbf{6 1}$ & $\mathbf{2 0}$ & $\mathbf{9}$ & $\mathbf{1 6}$ & $\mathbf{7 8}$ \\
\hline
\end{tabular}




\section{Box 15.1. Road safety for an ageing population (cont.)}

Figure 15.4. Road fatality rates by age group - focus on the senior population Deaths per 100000 inhabitants in a given age group, 2000-15

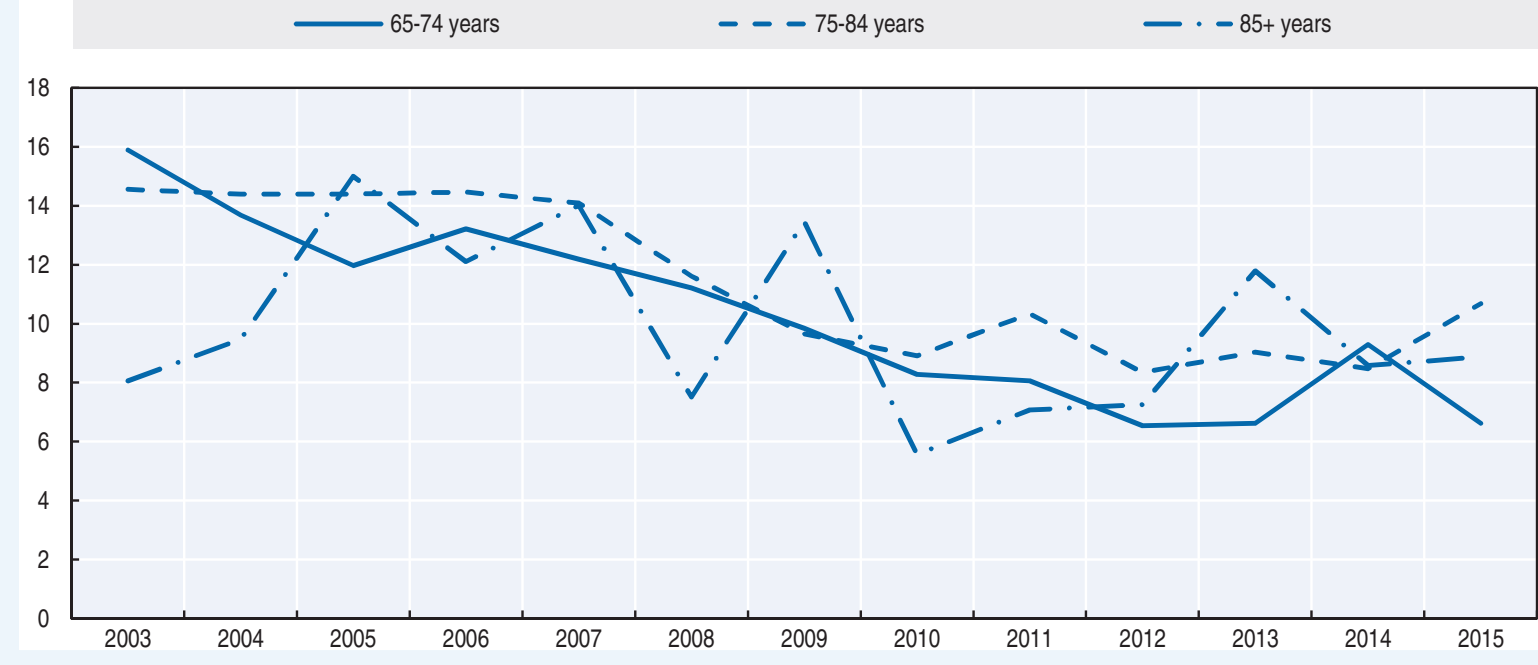

Figure 15.5. Road fatality rate by age and road user group Fatalities per 100000 inhabitants, 2015

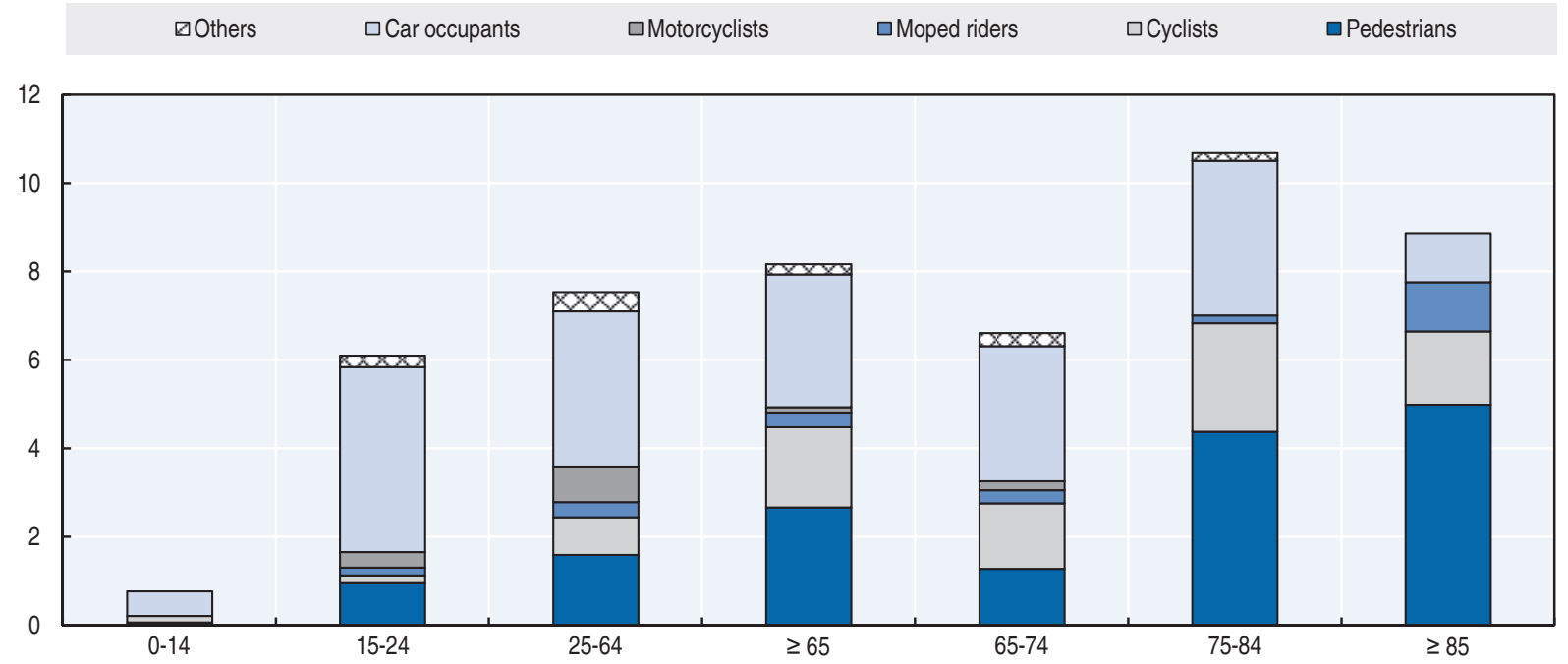

\section{Road safety by road type}

In $2015,54 \%$ of road fatalities occurred on rural roads, $41 \%$ in urban areas and $5 \%$ on motorways. In 2015, the situation deteriorated on the whole road network except rural roads, where fatalities were reduced by $3 \%$ when compared to 2014 . Since 1990 , road safety improvements have benefited all roads, with most progress seen on roads in urban areas. 
Figure 15.6. Road fatalities by road type

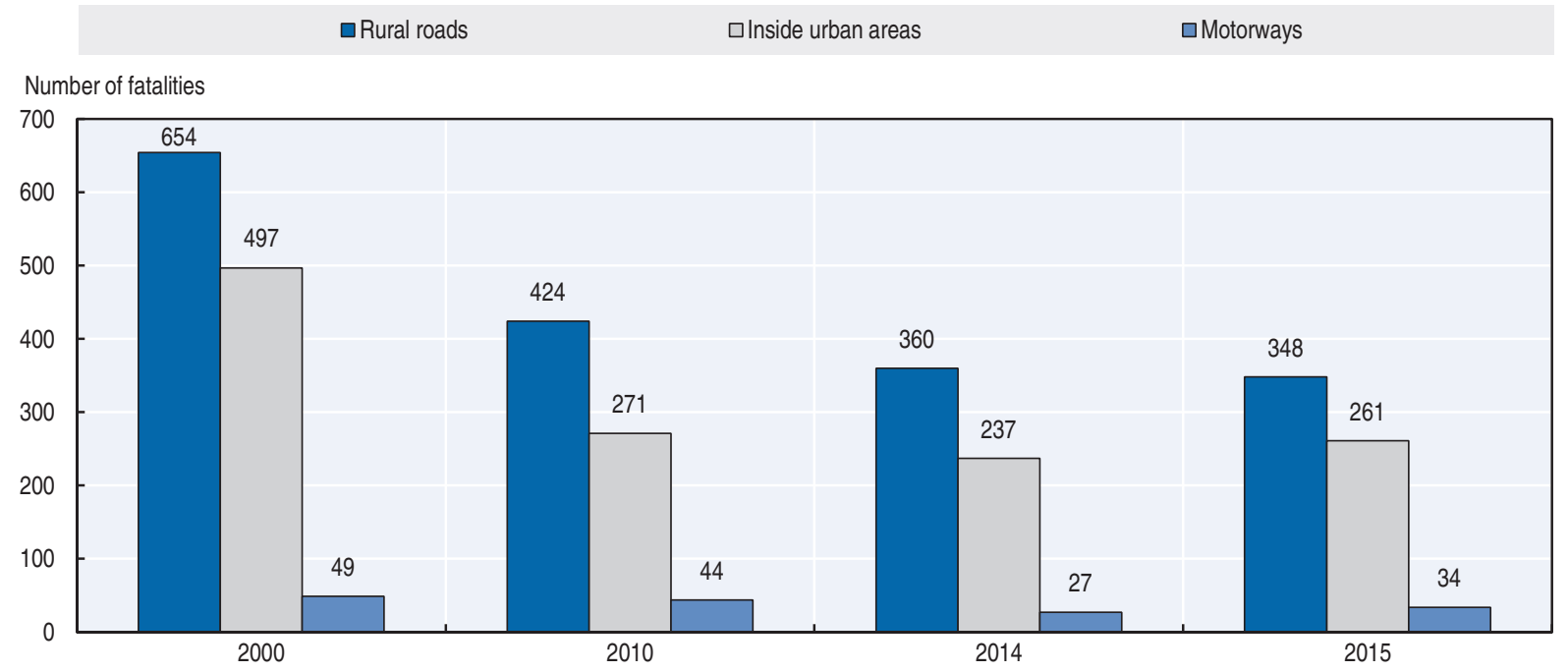

\section{Economic costs of traffic crashes}

Traffic crashes represent a significant cost for society, estimated in 2013 at around EUR 1.88 billion. This estimation is calculated using both a "willingness to pay" and a "human capital" approach, based on a methodology by McMahon and Dahdah (2008), on calculating the statistical value of a road fatality and a person seriously injured.

\section{Recent trends in road user behaviour}

\section{Speed}

According to on-site police investigations, speeding is a contributing factor in about $40 \%$ of fatal crashes.

In order to intensify speed enforcement, automatic speed cameras are being introduced. As of September 2016, 365 fixed and 160 mobile intelligent cameras ("VÉDA") have been installed. In the near future these devices will be able to monitor other offences as well (e.g. red light running, non-wearing of safety belts, use of hand held mobile phones, etc.)

The table below summarises the main speed limits in Hungary.

Table 15.5. Passenger car speed limits by road type, 2017

\begin{tabular}{lc}
\hline & General speed limit \\
\hline Urban roads & $50 \mathrm{~km} / \mathrm{h}$ \\
Rural roads & $90 \mathrm{~km} / \mathrm{h}$ \\
Motorways & $130 \mathrm{~km} / \mathrm{h} 110 \mathrm{~km} / \mathrm{h}$ on motor roads \\
\hline
\end{tabular}

\section{Drink driving}

In Hungary, drivers are forbidden to drive under the influence of alcohol. The theoretical maximum blood alcohol content (BAC) is $0.0 \mathrm{~g} / \mathrm{l}$. In practice, drivers are convicted only if their BAC is above $0.2 \mathrm{~g} / \mathrm{l}$. However, the law was softened in July 2011 and the driving licence can be withdrawn on the spot only when the driver is "seriously" under the influence of alcohol. 
In Hungary, the person responsible for a road crash is tested for their blood alcohol concentration. Crash opponents who are not at fault are usually not tested. A crash is recorded as alcohol related when the person responsible for the crash is under the influence of alcohol.

In $2015,9.7 \%$ of all injury crashes were caused by a driver under the influence of alcohol.

\section{Drugs and driving}

Driving under the influence of drugs is defined in the Act of Criminal Code and is listed among the potential crash contributing factors in accident forms. Unlike alcohol, there is no per se limit regarding drug consumption.

Saliva tests are not yet in use in Hungary, which makes drug driving enforcement very difficult. Drivers may be tested (from blood or urine samples) when they are suspected of impairment and when the alcohol test is negative. This happens very rarely and no random testing is being carried out, partly due to the costs of toxicology tests. Therefore, statistics on drug driving fatalities are not representative of the reality. In 2015, driving under the influence of drugs was reported as a contributing factor in five cases.

\section{Seat belts and helmets}

Seat belt use has been compulsory in front seats since 1976. Outside urban areas they have been compulsory in rear seats since 1993 and in urban areas since 2001. Dedicated child restraint use is compulsory for children of $150 \mathrm{~cm}$ or under.

In $2015,83 \%$ of front-seat occupants and $39 \%$ of adult rear-seat occupants wore a seat belt, which is low in comparison to best performing countries. In addition, these rates have deteriorated since the last survey in 2013 , when they were at $87 \%$ and $57 \%$ respectively.

Table 15.6. Seat belt wearing rate (\%) by car occupancy and road type

\begin{tabular}{|c|c|c|c|c|}
\hline & 2000 & 2012 & 2015 & 2017 \\
\hline \multicolumn{5}{|l|}{ Front seat } \\
\hline Driver & & 82 & 82 & 91 \\
\hline Driver and passenger & 49 & 80 & 83 & \\
\hline Urban roads (driver) & & 77 & 75 & \\
\hline Rural roads (driver) & & 83 & 80 & \\
\hline Motorways (driver) & & 86 & 90 & \\
\hline \multicolumn{5}{|l|}{ Rear seats } \\
\hline General & 8 & 58 & 39 & 52 \\
\hline Children (use of child restraint) & & 90 & 79 & $\begin{array}{c}90 \text { (76 with child seats, } \\
14 \text { with adult belts) }\end{array}$ \\
\hline
\end{tabular}

Helmet wearing has been compulsory since 1965 for motorcyclists, since 1997 for moped riders outside built-up areas, and since 1998 for moped riders inside built-up areas. The compliance rate by motorcyclists is nearly $100 \%$.

There is no mandatory helmet use law for cyclists.

\section{Distraction}

Hungary recognises distracted driving in fatal and injury crashes. Mobile phone use or texting while driving are not identified specifically in the category of distracted behaviour. 
The use of hand-held mobile phones while driving is not authorised. The penalty for using a hand-held mobile phone while driving is HUF 10000 in urban areas, HUF 15000 outside urban areas and HUF 20000 on motorways.

According to a roadside survey undertaken in 2015 , more than $5 \%$ of drivers regularly use a hand-held mobile phone while driving.

\section{Sleepiness and fatigue}

Based on expert estimations, $10-15 \%$ of all road fatalities are due to sleepiness and fatigue.

\section{National road safety strategies and targets \\ Organisation of road safety}

In Hungary, the Ministry of the Interior and the Ministry of National Development are responsible for road safety. Overall responsibility rests with the deputy state secretary of the Ministry of National Development.

\section{Road safety strategy for 2011-20}

The Road Safety Action Programme 2014-16 is integrated into the Hungarian Transport Strategy. The primary aim of the programme for 2014-16 is to improve road user behaviour, increase the level of compliance with traffic rules, develop individual responsibility and establish partnership in road traffic. Detailed road safety action plans are developed for each year.

The National Transport Strategy builds on the previous Hungarian Transport Policy 2003-15, which included targets to reduce the number of injury crashes and road fatalities by $30 \%$ from 2001 to 2010 and by $50 \%$ by 2015 .

The new road safety action programme for the period 2017-2020 is under preparation.

\section{Road safety targets}

The Hungary Transport Strategy includes a road safety target aiming at decreasing by $50 \%$ the number of road fatalities between 2010 and 2020. It also includes an interim target of fewer than 518 road deaths by 2016, which was not met.

In addition to the national target, Hungary adopted the European Commission's target to reduce by $50 \%$ the number of road fatalities by 2020, in comparison with 2011 level.

KTI continuously monitors the road safety situation and each year publishes a detailed evaluation based on outcome indicators (number of deaths and injury crashes) and also on a set of safety performance indicators (such as the use of seat belts, child restraints, daylight running lights, etc.). Based on the evaluation of the previous programme, KTI recommends dedicating further efforts to increasing the use of seat belts and child seats, installing more speed cameras and better protecting vulnerable road users. 
Figure 15.7. Trends in road fatalities towards national target

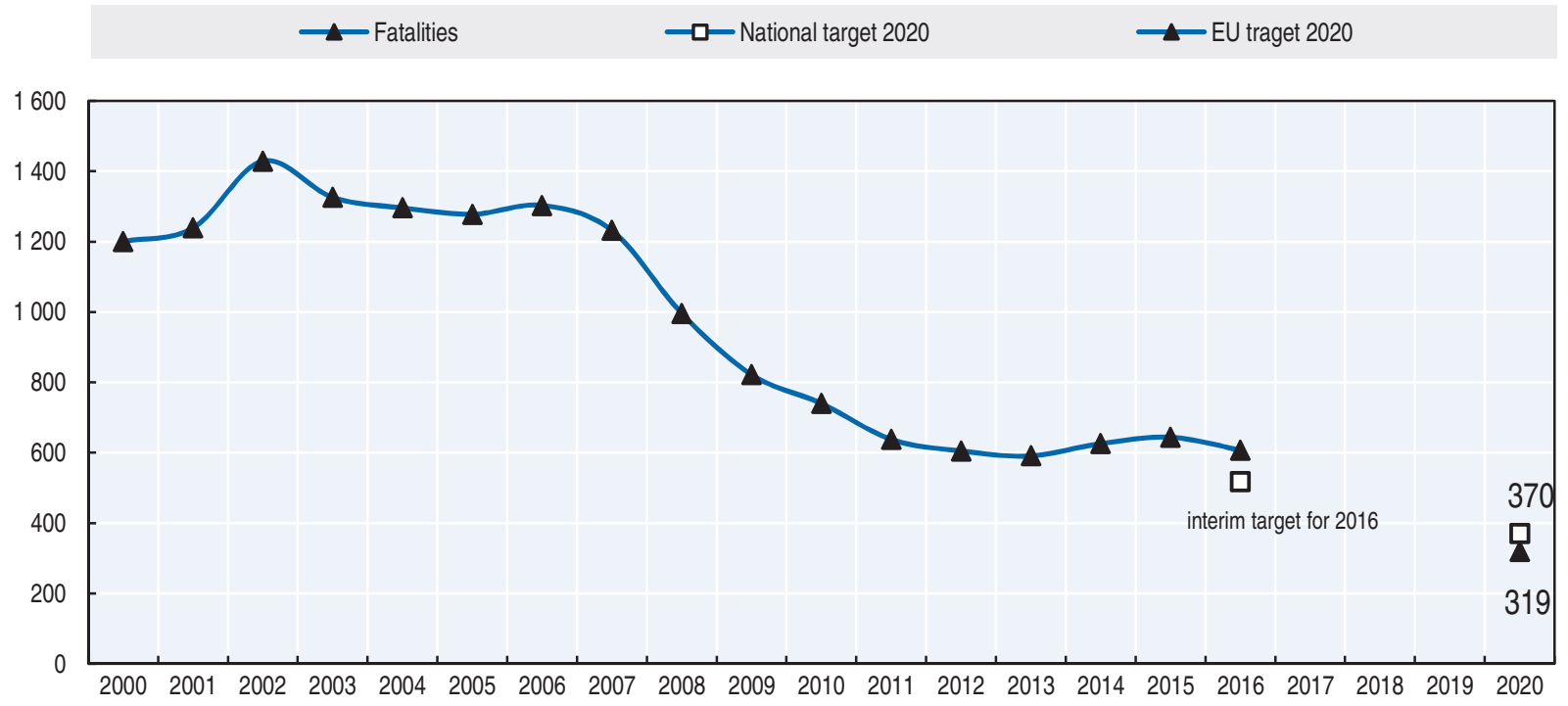

\section{Recent safety measures (2014-17)}

\section{Road safety management}

- As of 1 September 2014 the Highway Code was modified:

* Drivers are forbidden to overtake buses transporting children at stops where children get on and off.

* Application rules for child restraints in the front seats of passenger cars are more precise.

* Reduced speed limits around educational institutes only apply during school hours.

\section{Road users}

\section{Speed management}

- A new "intelligent" camera system (VÉDA) is progressively being implemented on the Hungarian road network. The cameras are currently used for speed detection but will be able to detect other offences (such as red light running or non-wearing of safety belts).

\section{Infrastructure}

- A new road category, "fast roads", has been agreed. The roads in this category have dual carriageways and a central barrier, but, unlike motorways, they allow for intersections, traffic control signals and roundabouts. The speed limit will be $110 \mathrm{~km} / \mathrm{h}$. Such roads do not yet exist.

\section{Recent and ongoing research}

KTI is conducting a number of road safety research projects. More information can be found at: www.kti.hu (accessed 11 May 2017). 


\section{References}

McMahon, K. and S. Dahdah (2008), The true cost of road crashes: Valuing life and the cost of a serious injury, International Road Assessment Programme (iRAP), Basingstoke.

World Bank (2017), “GDP (constant US\$)”, World Development Indicators, http://databank.worldbank.org/ data/reports.aspx? source=world-development-indicators (accessed 23 February 2017).

\section{Further reading}

Holló, P. and D.S. Kiss (2015), "How to Deliver the Necessary Data about Serious Injuries to the European Union", Journal of Traffic and Transport Engineering, Volume 3/7, Number 4, pp. 247-253.

Török, Á. (2015), "Case Study on the Relationship between Road Safety and Economy in Hungary", American Journal of Vehicle Design, Vol. 3/1, pp. 1-5.

Sipos, T. (2017), "Spatial Statistical Analysis of the Traffic Accidents", Periodica Polytechnica Transportation Engineering, pp.1-5, 10.3311/PPtr.9895.

\section{Websites (accessed 11 May 2017)}

- Institute for Transport Sciences (KTI): www.kti.hu.

- Road Safety in South East European Regions (ROSEE): www.rosee-project.eu.

- Safety Tunes: www.safetytunes.eu/web/. 



\section{Chapter 16}

\section{Iceland}

This chapter presents 2015 and 2016 road safety data for Iceland. It looks at trends in traffic and road safety from the years 1990 to 2016 and road user behaviour patterns. This includes data on speed, drink driving, drugs and driving, distracted driving, fatigue and seat belt usage, with a special focus on the ageing population. The chapter reviews Iceland's road safety strategy and national targets to 2022 and the progress achieved thus far. It also provides details of all recently implemented safety measures and current and ongoing research.*

* All data stem from the Icelandic Road and Coastal Administration and IRTAD unless otherwise noted. For more information please contact: audur.th.arnadottir@vegagerdin.is. 
I

Iceland, with its low population of just over 330000 inhabitants, has seen consistent improvement in its road safety record over recent years. However, the last two years have seen a large increase in the number of road deaths, due in part to a greater number of foreign tourists, many of whom use rental cars. The number of overseas visitors increased from 0.3 million in the year 2000 to almost 1.8 million in 2016. In 2015, out of the 16 fatalities, 5 were visitors to the country. In 2016, there were 18 fatalities including two tourists. The current fatality rate is 5.4 per 100000 inhabitants. Improving road safety for foreign tourists has become a priority in Iceland.

\section{Road safety data collection}

\section{Definitions applied in Iceland}

- Road fatality: Person who dies within 30 days as a result of a traffic crash.

- Serious injuries are defined by an old European definition: "Fractures, concussion, internal lesions, crushing, severe cuts and laceration, severe general shock requiring medical treatment and any other serious lesions entailing detention in hospital."

Iceland is working towards using the Maximum Abbreviated Injury Scale of three or more (MAIS3+) to define a serious injury. A central accident database including non-traffic accidents is being developed for the healthcare system in which a MAIS score for each accident will be found.

\section{Data collection}

Crash data is based on police reports. Reports are made by police at the scene and sent to the Icelandic Transport Authority. Information on the cause and type of crash is added to the files along with detailed information on location, vehicles and other factors.

All fatal crashes are recorded in the database. An in-depth study is undertaken for each fatal crash. By law, every injury crash must be reported to the police and therefore it will be included in the database. In practice, some injury crashes are not reported and others may be misreported.

From 1999, crash forms have been transferred electronically, which has led to a much better reporting rate. Comparing recent injury crash data with that from years before 2000 is not recommended.

The Icelandic Transportation Safety Board studies all fatal crashes.

As the number of fatalities in Iceland is low, fatality data is not compared between single years, but between series of five consecutive years.

\section{Most recent safety data}

\section{Road crashes in 2016}

The number of persons killed and seriously injured in 2016 was 233. In 2016, there were 18 fatalities, two more than in 2015. The number of those seriously injured also 
increased to 215, 37 more than in 2015. For the period 2007-16, the average number of those killed in road crashes was 12.6 per year and the average number of seriously injured was 180.7. Figures for 2016 were above these averages, highlighting that the year 2016 was a bad year from a traffic safety point of view.

The number of injured or killed cyclists continues to increase.

Two out of the 18 people killed in traffic in 2016 were foreign tourists. Forty-seven out of the 215 seriously injured in 2016 , or $21.9 \%$, were foreign tourists. It should be noted that the number of tourists increased by 39\% between 2015 and 2016.

In 2016, for the first time crash reports recorded whether the casualty was a foreign tourist. Until 2015 , reports only mentioned the nationality of the casualty. In $2015,75.7 \%$ of all those killed or injured were Icelandic and in 2016 this percentage was 76.3\%.

\section{Road crashes in 2015}

In 2015, 16 people were killed in road traffic, 12 more than in 2014. The five-year average for 2011-2015 was 11.2 killed per year, while 16.6 were killed per year for the previous five-year period (2006-10), thus reflecting a reduction in the number of people killed on the road. However, the high number of road deaths in 2015 is an important concern.

Among the 16 people killed five were foreign tourists. The number of foreign tourists visiting Iceland has grown rapidly in recent years. In 2015, almost 1.3 million tourists came to Iceland via the international airport in Keflavik, about half a million more than just two years previously in 2013. More people visit and drive in Iceland during winter time when the roads are icy; however, most tourists do not have experience of driving in these conditions. In addition, many foreign tourists do not wear seat belts.

The five-year annual average for injury crashes (excluding fatal crashes) for 2011-15 was 816. With 969 per year for the previous five-year period (2006-10), the number of injury crashes also decreased for the five-year period.

\section{Trends in traffic and road safety (1990-2016) Traffic}

Since 1990, the number of registered vehicles and vehicle kilometres has increased by more than $100 \%$. Road traffic measured in vehicle-kilometres slightly decreased between 2010 and 2012 but is again increasing as the economy recovers from the financial crisis and due to the expansion of tourism in Iceland.

The current transport plan promotes the use of alternatives to cars, such as public transport, cycling and walking. In recent years, Iceland has improved the infrastructure for cyclists within the capital and has provided special lanes for buses.

\section{Road safety}

\section{Crashes and casualties}

The peak in road fatalities in Iceland was 37, in 1977. Since then fatalities have been declining while motorisation has significantly increased.

Between 1990 and 2016, the number of fatalities overall followed a decreasing trend, fluctuating as high as 32 in 2000 and as low as four in 2014. The relatively high fatality numbers the last two years are of great concern. 
Between 1990 and 2016, the number of injury crashes increased by almost 75\%. The reason for this apparent sizeable increase is largely explained by better reporting. Until 1998/99, crash reports were sent by paper; since then reports have been sent electronically, leading to a much better reporting rate. Comparing injury data for the years prior to 2000 is not recommended.

\section{Rates}

In 2016, the mortality rate (expressed in terms of deaths per 100000 inhabitants) was 5.4. The average mortality rate was 4.4 for the period 2006-15 and 3.5 for the period 2011-15.

\section{Serious injury data}

In 2016, the rate of seriously injured persons per 100000 inhabitants was 64.7, compared to an average rate of 55.0 for the period 2006-15 and 50.9 for the period 2011-15. The much higher rate in 2016 is of concern.

Table 16.1. Road safety and traffic data

\begin{tabular}{|c|c|c|c|c|c|c|c|c|c|}
\hline & \multirow{2}{*}{1990} & \multirow{2}{*}{2000} & \multirow{2}{*}{2010} & \multirow{2}{*}{2015} & \multirow{2}{*}{2016} & \multicolumn{4}{|c|}{$2016 \%$ change over } \\
\hline & & & & & & 2015 & 2010 & 2000 & 1990 \\
\hline \multicolumn{10}{|l|}{ Reported safety data } \\
\hline Fatalities & 24 & 32 & 8 & 16 & 18 & & & & \\
\hline Injury crashes & 564 & 999 & 883 & 912 & 986 & 8.1 & 11.7 & -1.3 & 74.8 \\
\hline Deaths per 100,000 population & 9.5 & 11.5 & 2.5 & 4.9 & 5.4 & & & & \\
\hline Deaths per 10000 registered vehicles & 1.7 & 1.8 & 0.3 & 0.6 & 0.6 & & & & \\
\hline Deaths per billion vehicle kilometres & 14.9 & 13.8 & 2.5 & 4.7 & 4.9 & & & & \\
\hline \multicolumn{10}{|l|}{ Traffic data } \\
\hline Registered vehicles (thousands) & 138 & 173 & 260 & 285 & 304 & 6.7 & 16.9 & 75.7 & 120.3 \\
\hline Vehicle kilometres (millions) & 1612 & 2316 & 3168 & 3411 & 3693 & 8.3 & 16.6 & 59.5 & 129.1 \\
\hline Registered vehicles per 1,000 population & 544 & 620 & 819 & 866 & 914 & 5.5 & 11.7 & 47.4 & 68.1 \\
\hline
\end{tabular}

1. Registered vehicles excluding mopeds.

* Due to a change in the registration process, comparing injury crashes for the years prior to 2000 is not recommended. StatLink तiाsस $h t t p: / / d x . d o i . o r g / 10.1787 / 888933580517$

Figure 16.1. Road safety, traffic and GDP trends index $1990=100$

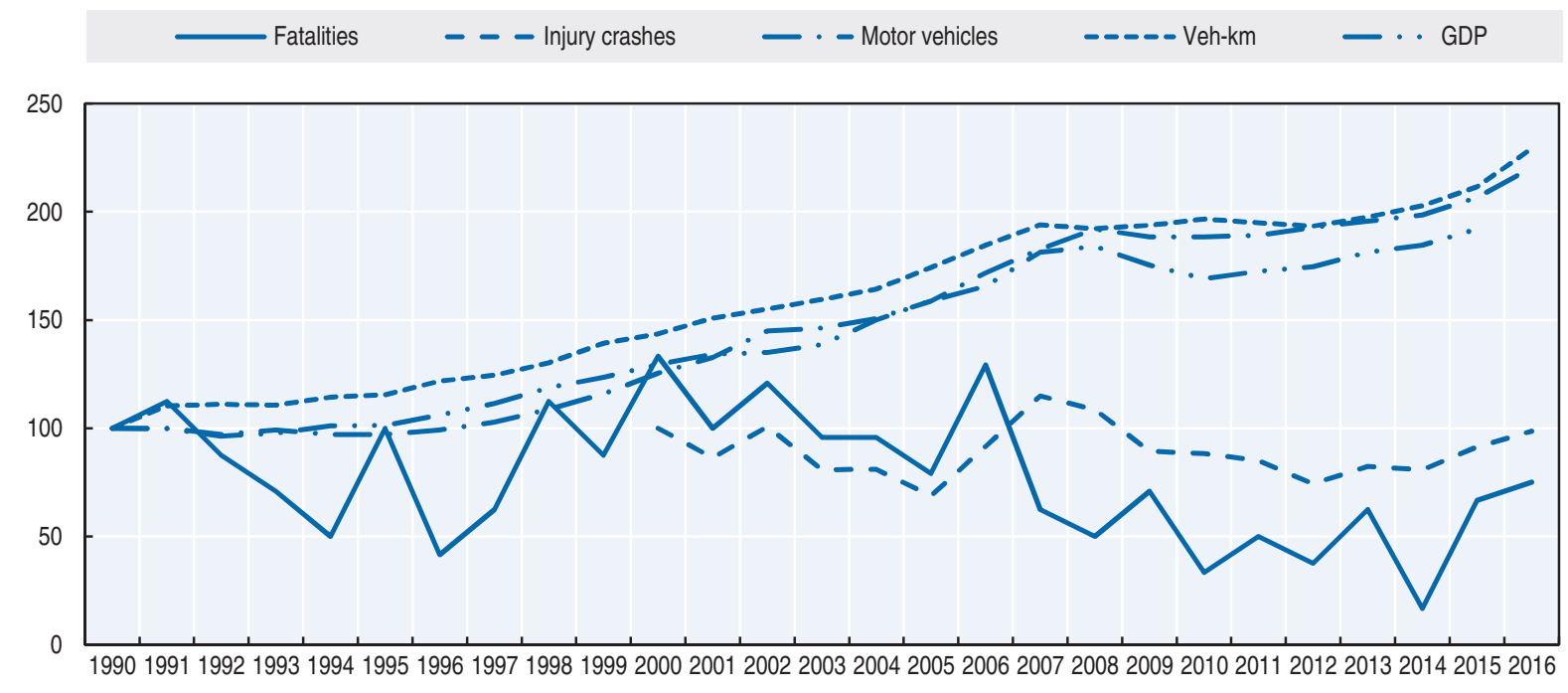

Source: World Bank (2017) (GDP; constant prices). 


\section{Road safety by user group}

In Iceland, most traffic casualties are passenger car occupants.

Table 16.2. Road fatalities by road user group

\begin{tabular}{lcccccc}
\hline & 1990 & 2000 & 2010 & 2014 & 2015 & 2016 \\
\hline Pedestrians & 6 & 1 & 2 & 0 & 1 & 2 \\
Cyclists & 0 & 0 & 0 & 0 & 1 & 0 \\
Moped riders & 0 & 0 & 0 & 0 & 0 & 0 \\
Motorcyclists & 3 & 1 & 1 & 0 & 1 & 2 \\
Car occupants & 15 & 25 & 4 & 3 & 12 & 14 \\
Others & 0 & 5 & 1 & 1 & 1 & 0 \\
Total & $\mathbf{2 4}$ & $\mathbf{3 2}$ & $\mathbf{8}$ & $\mathbf{4}$ & $\mathbf{1 6}$ & $\mathbf{1 8}$ \\
\hline
\end{tabular}

Figure 16.2. Road fatalities by road user group in percentage of total average 2014-16

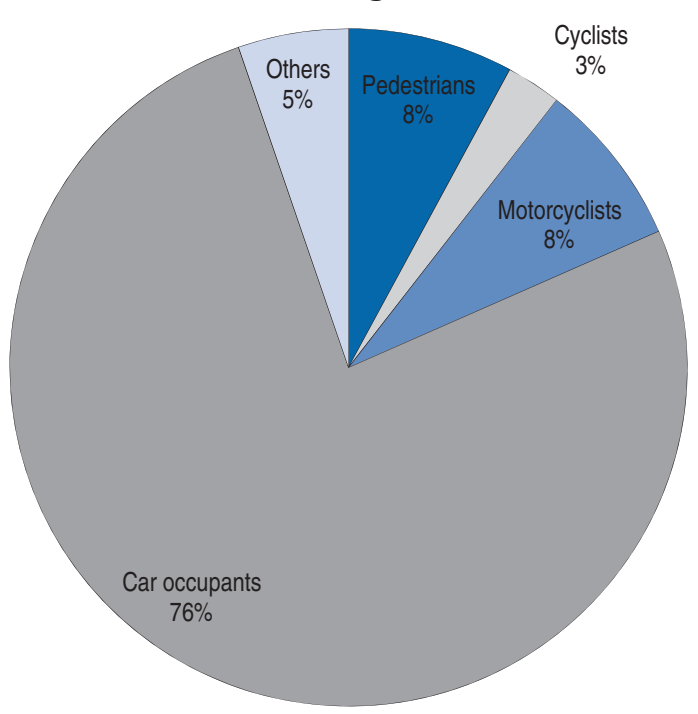

\section{Road safety by age group}

The table below shows a breakdown of fatalities by age group.

Table 16.3. Road fatalities by age group

\begin{tabular}{lccccc}
\hline Age & 1990 & 2000 & 2010 & 2014 & 2015 \\
\hline $0-14$ & 3 & 0 & 0 & 0 & 2 \\
$15-17$ & 2 & 5 & 0 & 1 & 0 \\
$18-20$ & 4 & 4 & 2 & 1 & 4 \\
$21-24$ & 3 & 1 & 1 & 0 & 1 \\
$25-64$ & 9 & 16 & 0 & 2 & 4 \\
$65-74$ & & 2 & 0 & 2 \\
$75-84$ & & & 0 & 0 & 1 \\
$\geq 85$ & & $\mathbf{3 2}$ & $\mathbf{8}$ & $\mathbf{4}$ & $\mathbf{1 6}$ \\
Total & $\mathbf{2 4}$ & & & & \\
\hline
\end{tabular}


Figure 16.3. Road fatality rates by age group

\section{Deaths per 100000 inhabitants in a given age group, 1994-2016 5-year moving average}

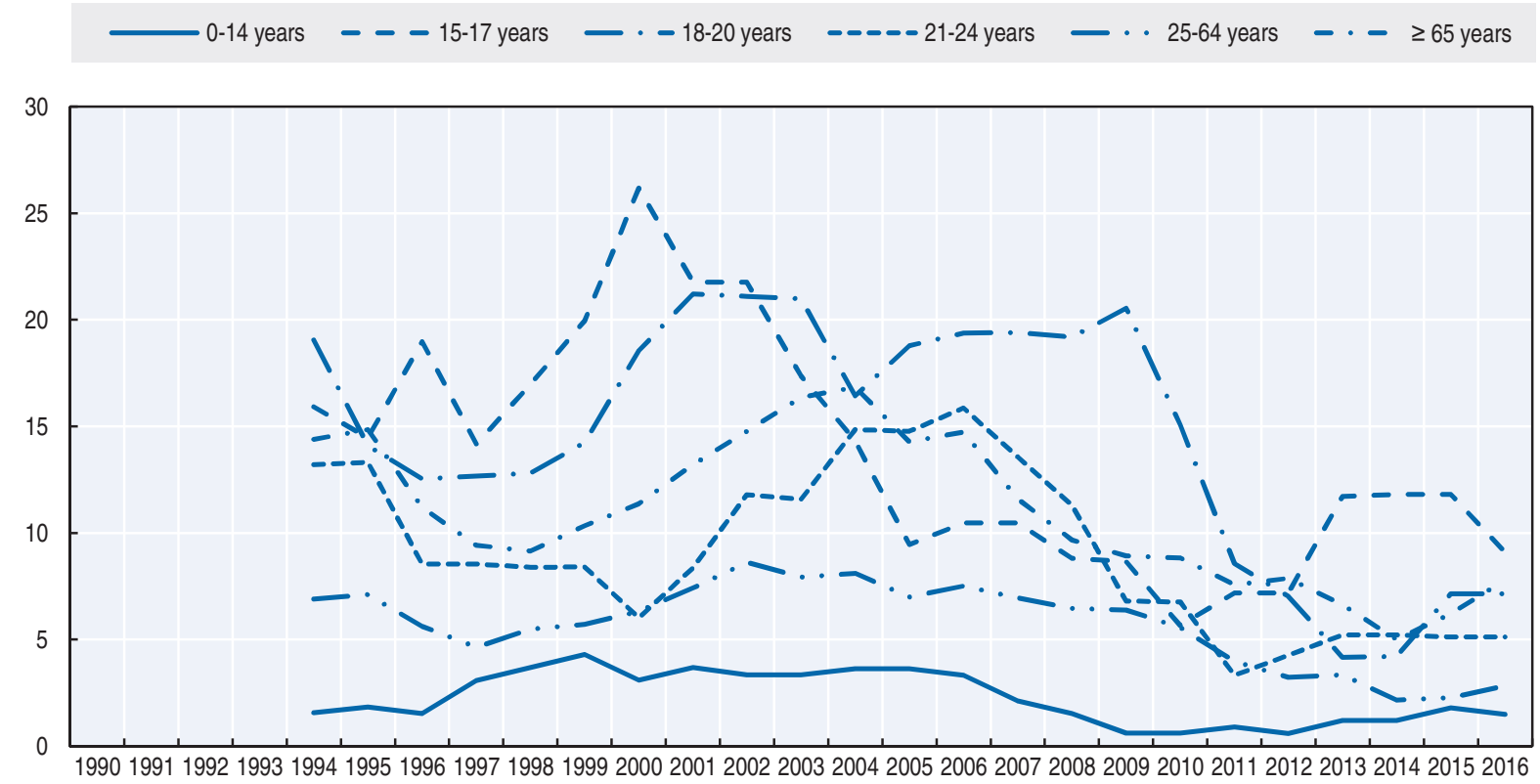

\section{Box 16.1. Road safety for an ageing population}

Persons aged 65 and older will represent more than $20 \%$ of the total population in 2035 and more than $25 \%$ in 2061. In 2049, for the first time, there will more people aged 65 and above than young people aged 20 or less (Source: Statistics Iceland, www.statice.is/).

Traffic safety for the elderly has been pretty stable for the last decade or two. However, in 2016 and to some extent also in 2015, an increase was observed in the number of crashes, serious crashes and also of incidents without injuries. Fatalities among senior road users have also increased over the last two years with one in every three fatalities being that of someone over 65 years of age in 2016. A spike in the number of road crashes caused by illness among senior drivers was observed in 2015. This number slightly decreased in 2016 but is still higher than it has been since 2008 .

Driving licence renewal rules are pretty standard in Iceland. Category A and B licences are renewed every 15 years, and professional and heavy vehicle licences are renewed every 5 years, until the age of 70 . At 70 drivers receive a five-year licence renewal and after 75 they receive a two-year renewal, until 80 when they get a one-year renewal.

Medical tests are compulsory for renewals over 70 years of age as well as for every renewal of professional and heavy vehicle licences. Their substance is in accordance with EU directives on driving licences.

In 2015 the Icelandic Transport Authority created and tested a seminar for senior citizens. It consisted of education and tips on driving, traffic rules, latest development in road traffic as well as one-on-one practical tuition where the students drove with a driving instructor, who then gave them advice on how to improve their safety in traffic. This was successful and after the first trials the seminar "package" was given to the Senior Citizens Association which then can recruit professional driving instructors to hold the seminar. 


\section{Road safety by road type}

In 2016, 5 people were killed on roads inside urban areas and 13 were killed on roads outside urban areas. Over three years, on average, $21 \%$ of fatalities were recorded inside urban areas.

Figure 16.4. Road fatalities by road type

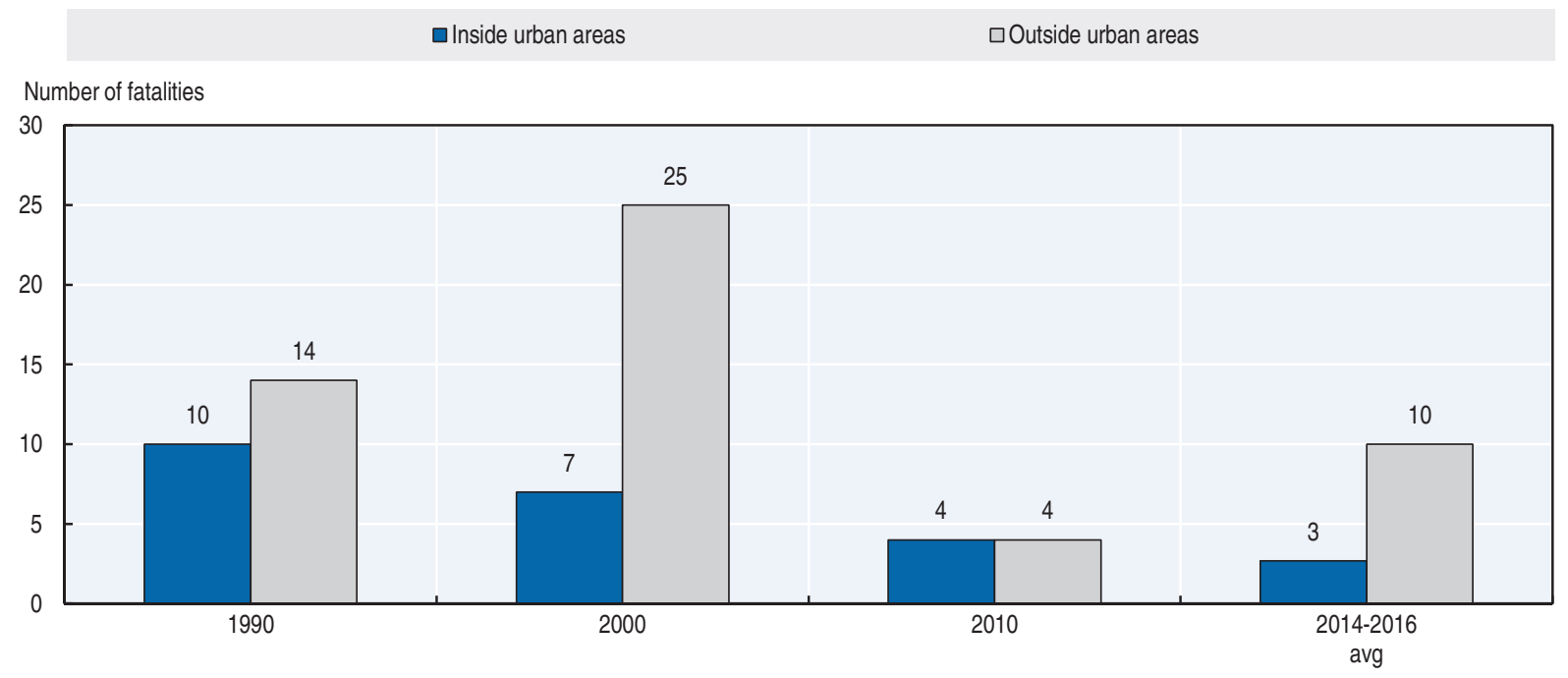

\section{Economic costs of traffic crashes}

A 2014 report (Sigthorsson and Hilmarsson, 2014) on the economic costs of traffic crashes in Iceland reviewed the history of traffic crash cost estimation and presented an overview of methodologies used in other countries.

In 2013, it was estimated that road crash costs amounted to EUR 254 million, or $2 \%$ of Iceland's GDP.

Table 16.4. Costs of road crashes, 2013

\begin{tabular}{lrc}
\hline Cost (EUR) & Unit cost & \multicolumn{1}{c}{ Total } \\
\hline Injury or fatal crashes & 252667 & 207692274 \\
Property damage only crashes & 9333 & 46767663 \\
Total (EUR) & & $\mathbf{2 5 4} \mathbf{4 5 9} \mathbf{9 3 7}$ \\
Total as \% of GDP (at constant prices) & & $\mathbf{2 \%}$
\end{tabular}

Source: Sigthorsson and Hilmarsson (2014).

\section{Recent trends in road user behaviour}

\section{Speed}

Speed has been a major problem on Icelandic roads. However, from 2004 Iceland recorded a positive trend, with a decrease and then stabilisation in the mean speed. However, data for the summer of 2016 indicate that speed is going up. The average free flow speed on the ring road increased by $0.5 \mathrm{~km} / \mathrm{h}$ between 2015 and 2016 and the v85 speed (meaning 15\% drive faster than v85) increased by $0.9 \mathrm{~km} / \mathrm{h}$ (Vegagerdin, 2017). Iceland has increased enforcement (both traditional and automatic speed controls), but budgets have limited the ability to increase the number of automatic speed cameras more rapidly. 
The table below summarises the passenger car speed limits in Iceland.

Table 16.5. Passenger car speed limits by road type, 2017

\begin{tabular}{lcc}
\hline & General speed limit & Comments \\
\hline $\begin{array}{l}50 \mathrm{~km} / \mathrm{h} \\
\text { Urban roads }\end{array}$ & \\
Rural roads & $90 \mathrm{~km} / \mathrm{h}$ paved roads & $80 \mathrm{~km} / \mathrm{h}$ gravel roads \\
\hline
\end{tabular}

\section{Drink driving}

The maximum authorised blood alcohol content (BAC) is $0.5 \mathrm{~g} / \mathrm{l}$. From 2012-16, on average, $8 \%$ of those killed and $4 \%$ of those seriously injured were involved in road crashes where one of the drivers had a BAC above the limit or had taken drugs. Drink driving has declined in Iceland although 2016 was unusually bad in this regard. In the five year period of 2012-16, there were three years when nobody died in an alcohol-related crash.

Television commercials have been run almost every year to combat drink driving. Some years there has also been special funding for the police force for drink driving enforcement.

\section{Drugs and driving}

Traffic regulations in Iceland prohibit driving a vehicle while under the influence of illegal narcotic substances. The penalties are the suspension of the driving licence for 3 to 24 months for a first offence and 2 to 5 years for a repeated offence.

During the $2012-16$ period, $8 \%$ of fatal crashes and $2.8 \%$ of serious injury crashes involved a driver under the influence of drugs. In 2015, Iceland had a very positive result in terms of drivers under the influence with zero fatalities and a record low number of accidents. In 2016, however, there were three fatal crashes caused by driving under the influence of alcohol and three caused by driving under the influence of illegal narcotics, one of which was caused by both alcohol and drugs. This means that five out of the 18 fatalities were caused by either alcohol or drugs (or both).

\section{Seat belts and helmets}

In Iceland, it is compulsory to wear seat belts in both front and rear seats. Dedicated child restraint use is compulsory for children under $135 \mathrm{~cm}$. A survey on child restraint usage is conducted every year at preschool establishments and the trend has been very positive. Since 1985 the child seat using rate of preschool children (3-6 years old) has gone up from $21 \%$ to $98 \%$.

During the period 2011-15, on average, $43 \%$ of car occupant fatalities were not wearing a seat belt.

Helmet wearing is mandatory for all powered two-wheelers, and is compulsory for cyclists up to 14 years of age.

\section{Distraction}

According to the law, it is illegal to drive with a hand-held mobile phone. The use of hands-free devices is authorised. 
Table 16.6. Seat belt wearing rate by car occupancy and road type

$\%$

\begin{tabular}{lcccc}
\hline & 2010 & 2013 & 2015 & 2016 \\
\hline Front seat & & & & \\
$\quad$ Driver & 86 & 86 & 85 & 89 \\
Passenger & 88 & 84 & 78 & 79 \\
$\quad$ Urban roads (driver) & 77 & 79 & 94 & 92 \\
$\quad$ Rural roads (driver) & 95 & 93 & 69 & 80 \\
Rear seats & 73 & 65 & & $98^{1}$ \\
$\quad$ General & & & & \\
$\quad$ Children (use of child restraint) & & & \\
\hline
\end{tabular}

Note: $93 \%$ in a child car seat, $5 \%$ in seat belt only.

\section{Sleepiness and fatigue}

During the period 2012-16, about 3-4\% of fatal and injury crashes involved a driver who was drowsy, almost falling asleep or fully asleep while driving.

\section{National road safety strategies and targets}

\section{Organisation of road safety}

Under the supervision of the Ministry of the Interior, three organisations manage road safety in Iceland. The Icelandic Road and Coastal Administration (Vegagerðin - IRCA) handles the infrastructure and the actual road improvements; the Icelandic Transport Authority (Samgöngustofa) handles the human behaviour elements through campaigns, education, etc., and the National Commissioner of the Icelandic Police monitors speed and alcohol and drug abuse.

\section{Road safety strategy for 2011-22}

In 2012, the Icelandic parliament agreed upon a new Road Safety Plan for the period 2011-22.

\section{Road safety targets}

The Plan has the following targets:

- In 2022, the number of traffic fatalities per 100000 inhabitants should not exceed the rate of countries with outstanding traffic safety records.

- The number of killed and seriously injured should decrease annually, on average, by $5 \%$ until 2022.

The target-setting process for the first indicator is self-explanatory. The second target (average annual decrease of $5 \%$ of killed and seriously injured) was selected because it is believed to be achievable with current strategies and the available funding. This is equivalent to a $46 \%$ decrease over the 12-year period (2011-22). The baseline for the second target is the average of the years 2006-10, which is 201.

To assist in achieving this target, 11 sub-targets have been set to guide the strategy and monitor progress. These sub-targets include, among others: a 5\% decrease in crashes involving young drivers (aged 17-20), elimination of fatalities due to lack of seat-belt wearing and a $5 \%$ decrease in injured foreigners. 
Crash data are monitored monthly and this short-term analysis influences decisions on safety measures. Annual reviews focus in particular on the sub-targets.

Figure 16.5. Trends in road fatalities towards EU target

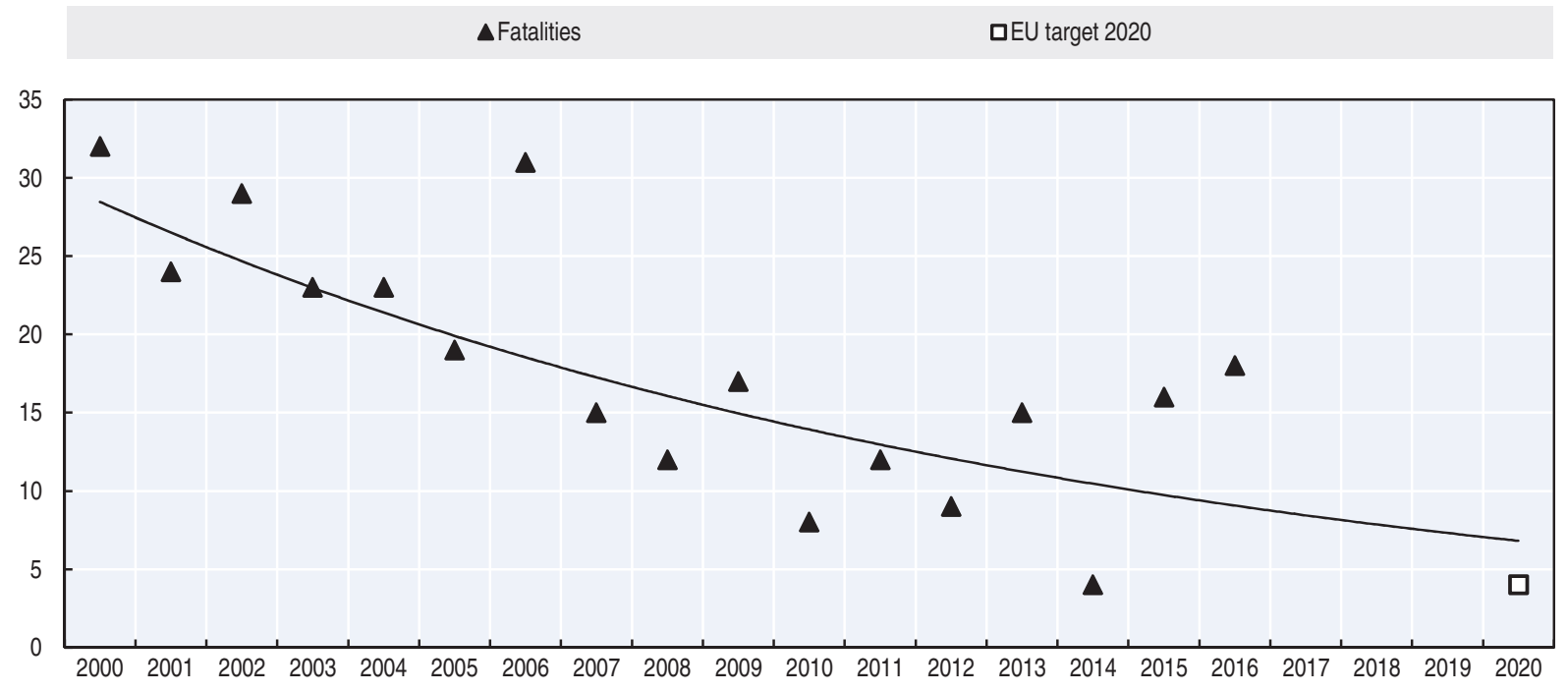

Table 16.7. Trends in road fatalities towards national target

\begin{tabular}{llcccc}
\hline Type & Targets & Base year & Target year & Base year figure & Current results (2016 figure) \\
\hline Fatalities per 100 000 inhabitants & Not higher than the best performing countries & Average 2006-10 & 2022 & 5.2 & 5.4 \\
Killed and seriously injured & $-5 \%$ per year (less than 109 by 2022) & Average 2006-10 & 2022 & 201 & 215 \\
\hline
\end{tabular}

Based on a preliminary assessment of the 2011-22 Road Safety Plan, it is now proposed to make more use of performance indicators.

\section{Recent safety measures (2014-17)}

\section{Road safety management}

- In line with the directive of the European Commission on road safety management (2008/96/EC) there is much emphasis on Road Infrastructure Safety Management. Municipalities are encouraged to make their own road safety plans.

- Traffic signs at narrow (i.e. one lane) bridges have been improved. Extra signs have been put up and the reflectivity has been increased. In addition flashing warning lights are systematically being installed at narrow bridges on main roads. In the autumn of 2016, warning lights were installed at all narrow bridges on the popular tourist section of Route 1 along the south coast and this year, warning lights will be installed at all remaining narrow bridges on Route 1 and at narrow bridges on some other major routes as well.

- A research project was launched focusing on identifying locations where it is most important to improve facilities for visitors to take pictures (photo stops). The focus is now on the design of such facilities. 


\section{Road users}

\section{Speed management}

- Automatic speed control started in 2007. In the Road Safety Plan, which is being revised, it is proposed to further deploy the system and to introduce average section speed control. Average section speed control was successfully tried out in Iceland in 2015 with the help of the Norwegian Road Administration.

\section{Education and awareness}

- Various campaigns are being conducted on such topics as not using a mobile phone when driving, speeding, driving under the influence of alcohol and/or drugs, fatigue, etc.

- Road safety education is proposed at all school levels.

- There is a dedicated information programme informing foreign drivers of the specificities of driving in Iceland, including sheep on the road, gravel roads, narrow bridges, etc. Road safety information is attached to the steering wheel of rental cars, highlighting the specificities of driving in winter time and summer time and this was redesigned in 2016.

- A video was released for the attention of foreign drivers to show specific characteristics of Icelandic traffic: www.drive.is (accessed 26 June 2017).

- Because the majority of crashes in rural areas are run-off-road crashes, there are important projects to improve roads and roadsides to make them more forgiving. Efforts include:

* elimination of black spots

* separation of driving directions

* increased use of rumble strips

* improved winter services (as many crashes occur on icy roads).

\section{Recent and ongoing research}

- In 2016, the Traffic Department of the Iceland Road and Coastal Administration (IRCA) published a report on accidents involving foreign drivers at roundabouts in Iceland.

- An ongoing research project focuses on cycle crashes. In 2016, IRCA's Traffic Department published a report showing the results of an in-depth investigation of all bicycle crashes in 2014 (Vegagerdin, 2016). The results showed that intersections of all kinds have a great accident risk. In 2017, follow-up research will be conducted, where all bicycle accidents at intersections in 2015 and 2016 will be investigated.

- In 2017, the Traffic Department of the IRCA will conduct in-depth investigations into all serious and fatal traffic crashes involving children in the period 2011-15. This research project originated from bad crash records regarding children highlighted in a previous IRTAD annual report.

- The IRCA will continue financing research projects on foreign tourists' mobility and safety.

- One employee of the IRCA is starting a Ph.D. study on the traffic safety of tourist drivers in an unfamiliar driving environment. 


\section{References}

Sigthorsson, H. and V. Hilmarsson (2014), Kostnadur umferdarslysa, A research project for the Icelandic Road and Coastal Administration, May 2014, www.vegagerdin.is/Vefur2.nsf/Files/Kostnadur umferdarslysa/\$file/Kostna\%C3\%B0ur\%20umfer\%C3\%BOarslysa.pdf (accessed 26 June 2017).

Vegagerdin (2017), Ökuhraði á bjóðvegum 2004-2016 (Driving speeds on highways 2004-2016), Icelandic Road and Coastal Administration, www.vegagerdin.is/vefur2.nsf/Files/Okuhradi_2004-2016/\$file/\%C3 \%96kuhra\%C3\%BOi_2004-2016_KaH_audur_Loka.pdf (accessed 26 June 2017).

Vegagerdin (2016), Nákvœm greining hjólreiðaslysa, Slys sem urðu árið 2014 (Detailed analysis of bicycles crashes in 2014) Icelandic Road and Coastal Administration, http://www.vegagerdin.is/vefur2.nsf/ Files/nakuaem_greining_hjolreidaslysa/\$file/N\%C3\%A1kv\%C3\%A6m_greining_hj\%C3\%B3lrei\%C3\%B0 aslysa_2014.pdf (accessed 26 June 2017).

\section{Websites}

- Safe Travel: www.safetravel.is (accessed 26 June 2017).

- Icelandic Transport Authority: www.samgongustofa.is (accessed 26 June 2017).

- Iceland Road and Coastal Administration: www.vegagerdin.is (accessed 26 June 2017).

- Icelandic Transportation Safety Board: www.rnsa.is (accessed 26 June 2017). 


\section{Chapter 17}

\section{Ireland}

This chapter presents 2015 road safety data for Ireland along with provisional data from 2016. It looks at trends in traffic and road safety from the years 1990 to 2015 and road user behaviour patterns with a special focus on the ageing population. Sections include data on speed, drink driving, drugs and driving, distracted driving, fatigue and seat belt usage. The chapter reviews Ireland's road safety strategy and national targets to 2020 and the progress achieved thus far. It also provides details of all recently implemented safety measures and current and ongoing research.*

* All data stem from the Irish Road Safety Authority and IRTAD unless otherwise noted. For more information please contact: sheffernan@rsa.ie. 
$\mathrm{F}$ F ollowing two consecutive years of increases, 2015 saw a $16 \%$ decrease in the number of fatalities on the road, to 162, Ireland's best performance in road safety since records began. This is equivalent to a fatality rate of 3.5 per 100000 inhabitants. All road user groups and age groups, apart from 18-24 year olds, benefited from this reduction. However, provisional data from 2016 indicate an increase of 16\%, bringing fatalities back up to 188. This increase was seen almost exclusively amongst car occupants (+44\% over 2015), who accounted for $64 \%$ of total fatalities in 2016.

\section{Road safety data collection}

\section{Definitions applied in Ireland}

- Road fatality: A death resulting from a road crash within 30 days.

- Serious injury: An injury for which a person is detained in hospital as an inpatient, or, whether or not detained in hospital, having any fractures, concussion, internal injuries, crushing, severe cuts and lacerations, or severe general shock requiring medical treatment.

- Slight injury: An injury of a minor character, such as a sprain or bruise.

The Road Safety Authority (RSA) is working with the Health Intelligence Unit (HIU) of the Health Services Executive to develop an appropriate methodology for reporting on serious injuries with a Maximum Abbreviated Injury Scale of 3 or more (MAIS3+). While work is ongoing on the longer term goal of data linkage, in order to comply with the EU requests in the short term, Ireland has provided the European Commission with serious injury figures in MAIS3+ format for the period 2005-12 derived from hospital data only. Serious injury figures were estimated by converting hospital data to MAIS3+ but were found to be lower than that of police data which is counterintuitive. The RSA and the HIU are working on refining the methodology. Matching hospital and police data continues to be the long-term goal. Further collaboration with the Irish Police Force, the An Garda Síochána (AGS), and the HIU is required to progress with this complex work.

\section{Data collection}

In Ireland, official road crash data is generated by two agencies. Members of the AGS complete detailed road crash reports that are subsequently forwarded to the RSA for analysis and publication. Reporting of fatalities is comprehensive in Ireland, but serious injury collisions are likely to be underreported.

From 1 January 2014 reporting and collection of road crash data moved from a paperbased system to an electronic format. This system allows a two way validation process between AGS and the RSA. This change will improve recording in terms of the number of variables collected and the accuracy of the data. 


\section{Most recent safety data}

\section{Road crashes in 2016 - provisional data}

Based on provisional data, as of 31 December 2016, there were 176 fatal collisions with 186 fatalities. This represents 24 more deaths $(+15 \%)$ compared to the same period in 2015. The key findings of the provisional review of 2016 fatalities (Road Safety Authority, 2016a) show that:

- There has been an increase in fatalities across drivers $(+12)$, passengers $(+11)$, pedestrians (+2) and cyclists (+1) compared to the same period in 2015.

- The highest risk age groups in 2016 are those aged 66 and older (24\% of all road users killed), 16-25 (21\%) and those aged 26-35 (21\%).

- Fatalities among those aged 26-35 were higher in 2016 than the same period in $2015(+12)$ but lower among those aged 16-25 (-5). Fatalities among the age group 66 and older also increased in $2016(+15)$ compared to the same period for 2015.

- July was a particularly dangerous month with 21 deaths followed by May (20) and October (20).

- The highest number of fatalities occurred from $4 \mathrm{pm}-6 \mathrm{pm}$ (29) followed by $10 \mathrm{pm}$ to midnight (19) and 6-8pm (18).

- Sunday (36) had the highest number of fatalities, followed by Thursday (33), Saturday (28) and Tuesday (28).

- Non-wearing of seat belts remains a concern for both drivers and passengers (22\%).

\section{Road crashes in 2015}

In 2015 there were 162 fatalities on Irish roads, a decrease of $16 \%$ compared to 2014 when 193 people were killed. Of those killed, 33 were pedestrians, 72 were drivers and 26 were passengers. There were 22 motorcyclists killed and 9 cyclists killed. Fatalities were highest among those aged 16-25 years (46), 27 people killed were aged 66 years and older, followed by the 26-35 years age category (26). There were three people killed under the aged of 15 .

There have been changes in trends in fatal collisions, including the following main points:

- Over a fifth fewer pedestrian fatalities, particularly among younger and older people.

- Almost a third fewer passenger fatalities.

- Significant number of motorcyclist fatalities.

- Increased incidence of fatal collisions on Sundays, but fewer fatalities observed overall at the weekend.

- $10 \mathrm{am}$ and $12 \mathrm{pm}$ was the most dangerous times on the road.

- December was the most dangerous month for 2015.

- There was a significant reduction in child fatalities (under 15) in 2015 compared to 2014.

- Compared to 2014, there were more deaths among those aged 16-25 and those aged 56-65.

- High incidence of "no seatbelt" as a factor in fatal collisions.

The reduction in fatalities seen in 2015 is welcome in light of the increases seen in the previous two years. In fact 2015 was the safest year on record. Key interventions and 
initiatives which may have contributed to this reduction took place in 2015 included the RSA International Conference on Child Safety in April 2015, transfer of the Road Safety Authority/An Garda Síochána's "Go Slow" Campaign to the high risk period of summer, a high profile launch of the July Fatality Review, increased media reporting on road safety in second half of 2015 in particular, and an extensive range of public awareness campaigns.

\section{Trends in traffic and road safety (2000-16)}

\section{Traffic and economic factors}

There was continued improvement in the economy in both 2015 and 2016. The number of new private cars licensed for the first time increased by 17\% to 141931 in 2016 compared to 2015 (CSO, 2016). The average annual unemployment rate for 2016 was $7.9 \%$, down from $9.5 \%$ in 2015 (CSO, 2016). The most recent figures show that diesel consumption grew by 5.8\% during 2015 and was recorded as the fuel used most in transport (SEAI, 2016). The latest figures show that overall traffic volume (vehicle kilometres travelled) increased by $8 \%$ in 2015. Irish licensed vehicles travelled a total of 46 billion kilometres, with each vehicle travelling an average of 17852 kilometres in 2015 (CSO, 2017).

\section{Crashes and casualties}

The number of road fatalities peaked in 1972 with 640 deaths. Since crash data was first recorded road deaths reached their lowest level in 2012 with 162 fatalities, this level was achieved again in 2015, following two consecutive years of increases in 2013 and 2014.

The first half of the current Government Road Safety Strategy, from 2013 to end 2016, has shown an increase in car user fatalities (+24\%), as well as an increase in Vulnerable Road User (VRU's) fatalities (+20\%). Vehicle occupants typically represent approximately $60 \%$ of road fatalities, while VRU's represent $30-40 \%$ of all road users killed.

\section{Rates of road fatalities}

Since 2000, the risk has been more than halved for the fatality rate per 100000 inhabitants and deaths per 10000 registered vehicles. In 2015, the death rate per 100000 inhabitants was 3.5 and the death rate per 10000 registered vehicles was 0.6.

Table 17.1. Road safety and traffic data

\begin{tabular}{|c|c|c|c|c|c|c|c|c|c|}
\hline & \multirow{2}{*}{1990} & \multirow{2}{*}{2000} & \multirow{2}{*}{2010} & \multirow{2}{*}{2014} & \multirow{2}{*}{$2015^{*}$} & \multicolumn{4}{|c|}{$2015 \%$ change from } \\
\hline & & & & & & 2014 & 2010 & 2000 & 1990 \\
\hline \multicolumn{10}{|l|}{ Reported safety data } \\
\hline Fatalities & 478 & 415 & 212 & 193 & 162 & -16.1 & -23.6 & -61.0 & -66.1 \\
\hline Injury crashes & 6067 & 7757 & 5780 & 5838 & 6048 & -2.9 & -1.9 & -26.9 & -6.5 \\
\hline Deaths per 100000 inhabitants & 13.6 & 11.0 & 4.7 & 4.2 & 3.5 & -16.5 & -24.9 & -68.1 & -74.3 \\
\hline Deaths per 10000 registered vehicles & 4.5 & 2.5 & 0.9 & 0.8 & 0.6 & -21.8 & -31.6 & -75.7 & -86.8 \\
\hline Deaths per billion vehicle kilometres & 19.2 & 11.5 & 4.9 & 4.5 & 3.5 & -23.0 & -28.6 & -69.6 & -81.8 \\
\hline \multicolumn{10}{|l|}{ Traffic data } \\
\hline Registered vehicles ${ }^{1}$ (thousands) & 1054 & 1684 & 2416 & 2515 & 2570 & 2.2 & 6.4 & 52.6 & 143.8 \\
\hline Vehicle-kilometres (millions) & 24896 & 36001 & 47414 & 42447 & 45,950 & & & & \\
\hline Registered vehicles per 1000 inhabitants & 301 & 446 & 531 & 546 & 554 & 1.4 & 4.3 & 24.3 & 84.3 \\
\hline
\end{tabular}

1. The RSA collision database does not have a vehicle class category for mopeds.

Note: Data for 2015 is provisional and subject to change. 
Figure 17.1. Road safety, traffic and GDP trends index $1990=100$

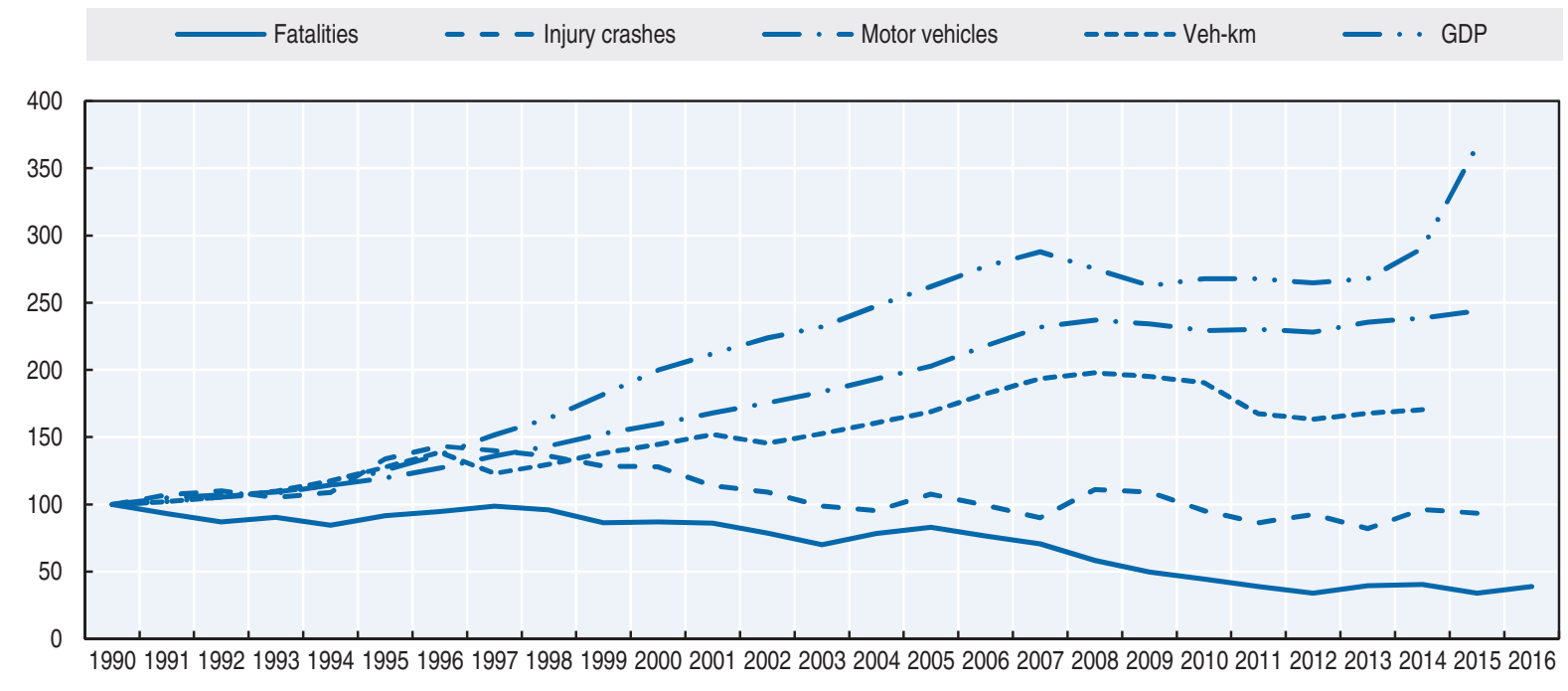

Source: World Bank (2017) (GDP; constant prices).

\section{Road safety by user group}

Fatalities for all user groups have declined since 2000, with the highest reduction for passenger car occupants (-57\%) and pedestrians (-59\%). Between 2010 and 2016, improvements in road safety benefitted pedestrians and car occupants the most. Drivers and passengers represented 59\% of fatalities in 2016 and vulnerable road users (pedestrians, motorcyclists and cyclists) represented just over one-third (36\%).

There was an increase across the driver, passenger, pedestrian and cyclist road user groups in 2016 compared to 2015. The greatest change in profile observed was a $41 \%$ increase in passenger fatalities, up from 27 to 38 . Driver $(+12)$ and passenger $(+11)$ fatalities increased in 2016 representing a net increase in vehicle occupant fatalities from 98 in 2015 to 121 in $2016(+23 \%)$.

Table 17.2. Road fatalities by road user group

\begin{tabular}{|c|c|c|c|c|c|c|c|c|c|c|}
\hline & \multirow{2}{*}{1990} & \multirow{2}{*}{2000} & \multirow{2}{*}{2010} & \multirow{2}{*}{2014} & \multirow{2}{*}{$2015^{*}$} & \multirow{2}{*}{$2016^{*}$} & \multicolumn{4}{|c|}{$2016 \%$ change from } \\
\hline & & & & & & & 2015 & 2010 & 2000 & 1990 \\
\hline Pedestrians & 150 & 85 & 44 & 42 & 33 & 35 & 6.1 & -20.5 & -58.8 & -76.7 \\
\hline Cyclists & 46 & 10 & 5 & 13 & 9 & 10 & 11.1 & 100.0 & 0.0 & -78.3 \\
\hline Motorcyclists** & 41 & 39 & 17 & 24 & 22 & 22 & 0.0 & 29.4 & -43.6 & -46.3 \\
\hline Car occupants & 206 & 260 & 130 & 96 & 77 & 111 & 44.2 & -14.6 & -57.3 & -46.1 \\
\hline Others & 35 & 21 & 16 & 18 & 21 & 10 & -52.4 & -37.5 & -52.4 & -71.4 \\
\hline Total & 478 & 415 & 212 & 193 & 162 & 188 & 16.0 & -11.3 & -54.7 & -60.7 \\
\hline
\end{tabular}

* All data for 2015 and 2016 is provisional and subject to change.

* The RSA do not have a unique category for moped drivers. 
Figure 17.2. Road fatalities by road user group in percentage of total, 2016

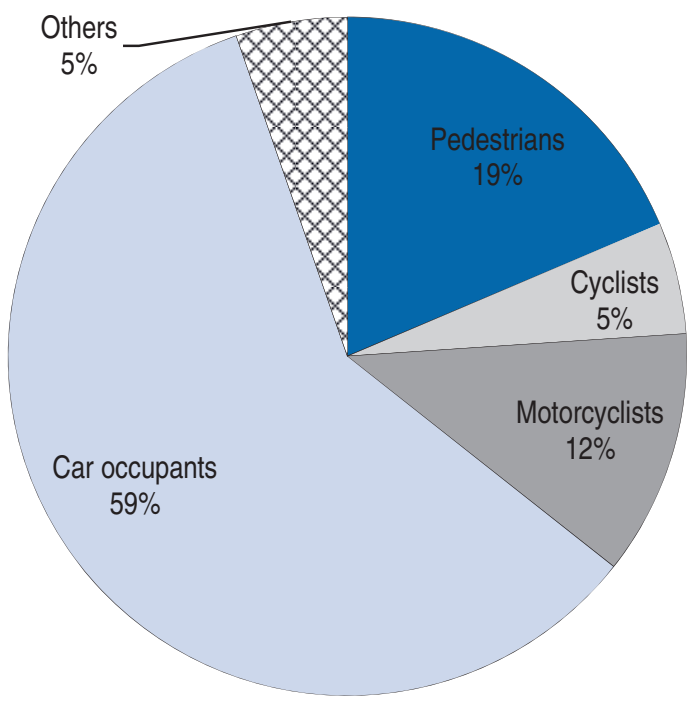

\section{Road safety by age group}

There has been a reduction in fatalities for all age groups since 1990. Between 2010 and 2016 improvements in road safety were mostly seen among 21-24 year olds (-60\%) while the number of senior citizens killed in road traffic increased $(+50 \%)$. However, it should be noted that there have been demographic changes over this period within these age groups. There has been an increase in those aged 65 and over (+19\%) in Ireland.

Overall there was an increase in fatalities between 2015 and $2016(+16 \%)$. The increase seen in 2016 was primarily among the $25-64$ year old group (+13\%) and the over $65 \mathrm{~s}(+45 \%)$. However there has been a reduction in the number of those killed aged 21-24 (-4). There was an increase in the number of children aged 0 - 14 killed in 2016 over $2015(+6)$.

Table 17.3. Road fatalities by age group

\begin{tabular}{|c|c|c|c|c|c|c|c|c|c|c|}
\hline \multirow{2}{*}{ Age } & \multirow{2}{*}{1990} & \multirow{2}{*}{2000} & \multirow{2}{*}{2010} & \multirow{2}{*}{2014} & \multirow{2}{*}{$2015^{\star}$} & \multirow{2}{*}{$2016^{*}$} & \multicolumn{4}{|c|}{2015 \% change from } \\
\hline & & & & & & & 2014 & 2010 & 2000 & 1990 \\
\hline $0-14$ & 46 & 22 & 6 & 13 & 3 & 9 & \multirow{2}{*}{\multicolumn{2}{|c|}{$\begin{array}{l}\text { Figures too small } \\
\text { for meaningful } \\
\text { comparisons }\end{array}$}} & -59.1 & -80.4 \\
\hline $15-17$ & 28 & 23 & 7 & 6 & 3 & 3 & & & -87.0 & -89.3 \\
\hline $18-20$ & 56 & 63 & 21 & 12 & 19 & 18 & -5.3 & -14.3 & -71.4 & -67.9 \\
\hline $21-24$ & 53 & 54 & 35 & 16 & 18 & 14 & -22.2 & -60.0 & -74.1 & -73.6 \\
\hline $25-64$ & 195 & 195 & 109 & 103 & 88 & 99 & 12.5 & -9.2 & -49.2 & -49.2 \\
\hline $65-74$ & & 16 & 18 & 23 & 16 & 23 & & 27.8 & 43.8 & \\
\hline $75-84$ & & 24 & 9 & 14 & 12 & 15 & & 66.7 & -37.5 & \\
\hline$\geq 85$ & & 4 & 3 & 6 & 3 & 7 & & 133.3 & 75.0 & \\
\hline Total & 478 & 415 & 212 & 193 & 162 & 188 & 16.0 & -11.3 & -54.7 & -60.7 \\
\hline
\end{tabular}

* All data for 2015 and 2016 is provisional and subject to change. 
Figure 17.3. Road fatality rates by age group Deaths per 100000 inhabitants in a given age group, 1990-2015

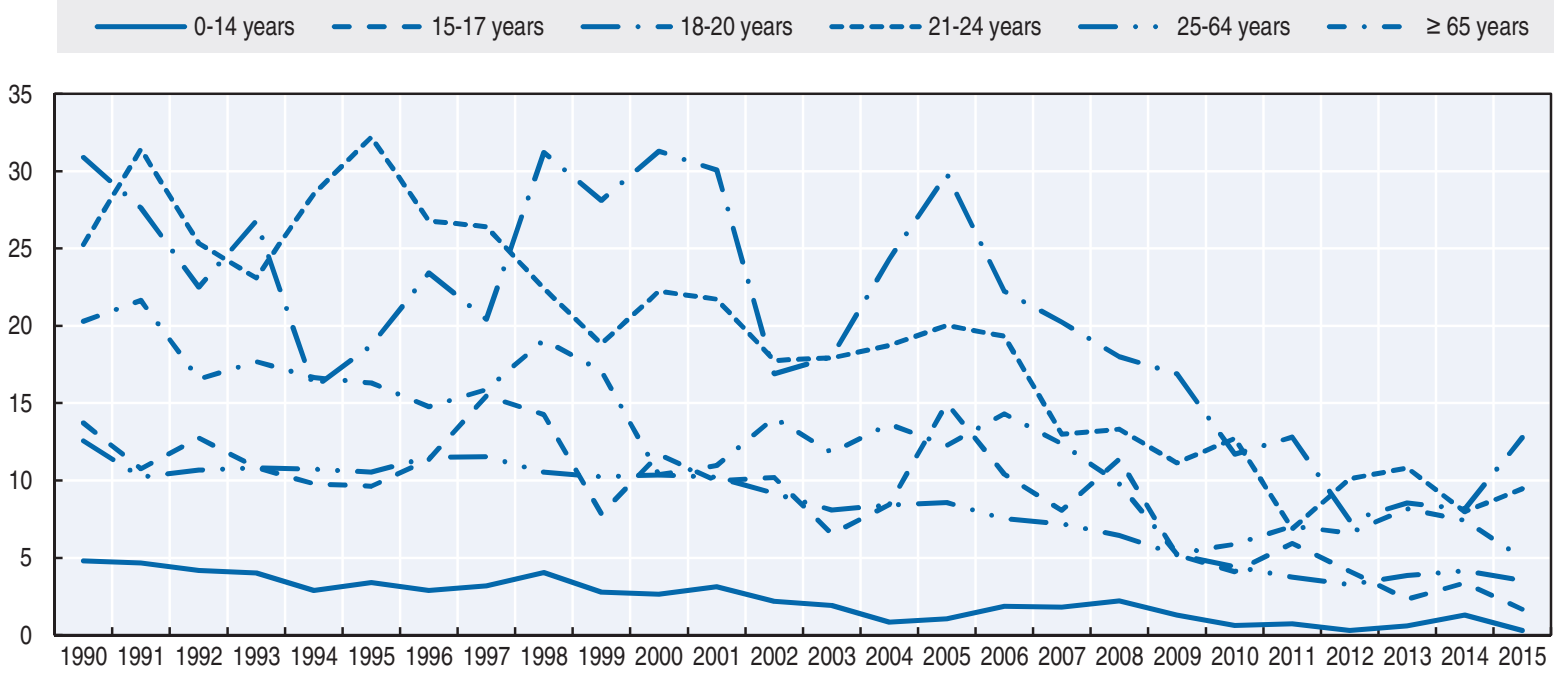

\section{Box 17.1. Road safety for an ageing population}

Road safety for the senior population has declined between 2010 and 2016 with 15 additional fatalities occurring. The RSA conducted a separate analysis on fatalities among older road users from 2013-2016. The review showed that young and older drivers are more likely to be killed. Older drivers aged 80+ are also over-represented relative to their number in the driving population.

Currently all drivers aged over 70 years old are required to present a medical report on renewing their licence. A one or three year licence can then be granted. The RSA are currently giving consideration to changing the minimum age to 75 and allowing for a one, three or five year licence to be granted on the advice of the physician.

Figure 17.4. Road fatality rates in the $65+$ age groups Deaths per 100000 inhabitants in a given age group, 2000-15

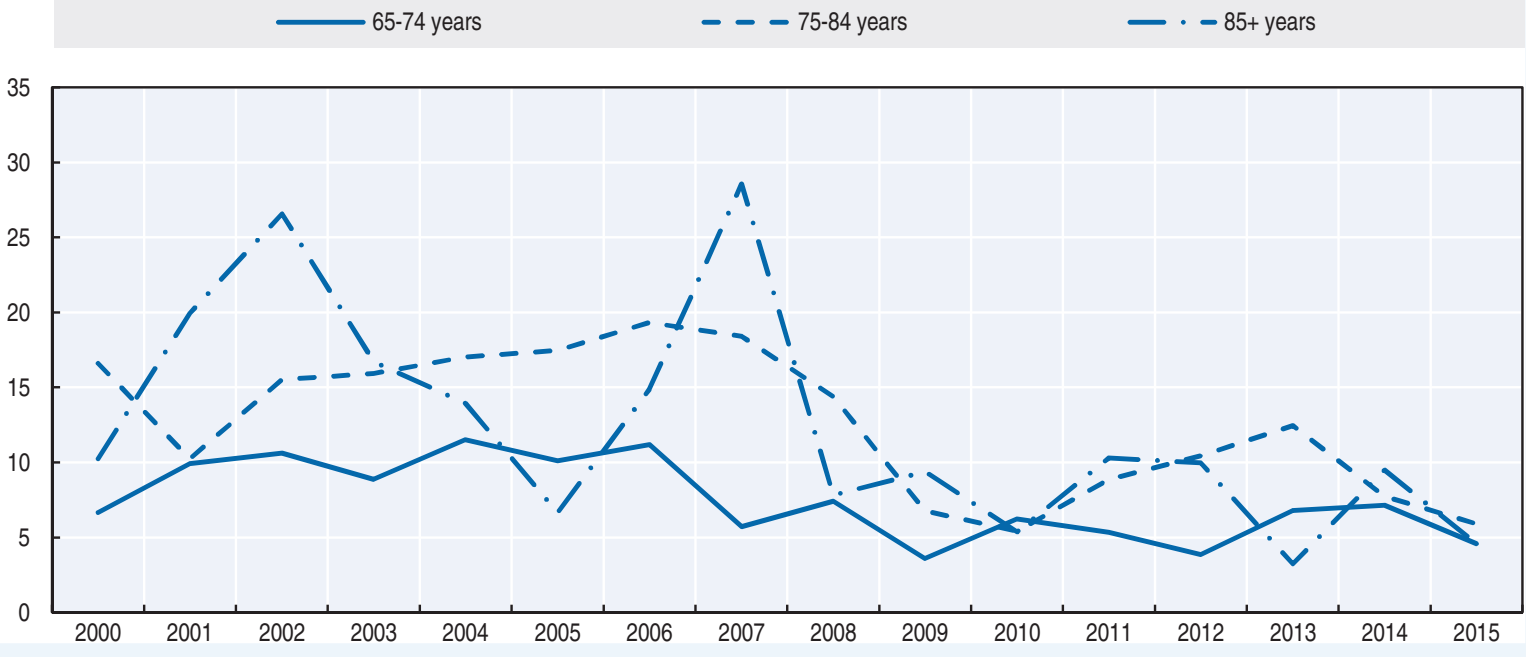




\section{Box 17.1. Road safety for an ageing population (cont.)}

Mobility Matters is an awareness programme on road safety for older people which is made up of a resource pack and an accompanying DVD. The programme deals with the following topics: buying a car, keeping your car in good condition, driving safely, bus safety, pedestrian safety, cycle safety, safety belts, child restraints and medical conditions This programme is delivered in a workshop format in a community setting. It also covers what the law says on protecting yourself and other road users. The RSA runs a free 'train the trainer' session for trainers involved in senior citizen groups such as Active Retirement Ireland, so that the Mobility Matters programme can be delivered.

Table 17.4. Road fatalities among senior citizens

\begin{tabular}{lccc|ccc|ccc}
\hline & \multicolumn{3}{c}{$65-74$} & \multicolumn{3}{c|}{$75-84$} & \multicolumn{3}{c}{$85+$} \\
\cline { 2 - 10 } & 2010 & 2015 & 2016 & 2010 & 2015 & 2016 & 2010 & 2015 & 2016 \\
\hline Pedestrians & 5 & 4 & 8 & 3 & 2 & 4 & 2 & 0 & 1 \\
Cyclists & 2 & 3 & 1 & 0 & 2 & 2 & 1 & 0 & 0 \\
Moped riders & 0 & 0 & 0 & 0 & 0 & 0 & 0 & 0 & 0 \\
Motorcyclists & 0 & 0 & 2 & 0 & 0 & 0 & 0 & 0 & 0 \\
Car occupants & 11 & 9 & 12 & 6 & 9 & 9 & 0 & 2 & 6 \\
Other & 0 & 0 & 0 & 0 & 1 & 0 & 0 & 1 & 0 \\
Total & $\mathbf{1 8}$ & $\mathbf{1 6}$ & $\mathbf{2 3}$ & $\mathbf{9}$ & $\mathbf{1 2}$ & $\mathbf{1 5}$ & $\mathbf{3}$ & $\mathbf{3}$ & $\mathbf{7}$ \\
\hline
\end{tabular}

Figure 17.5. Road fatality rate by age and road user group Fatalities per 100000 inhabitants, 2015

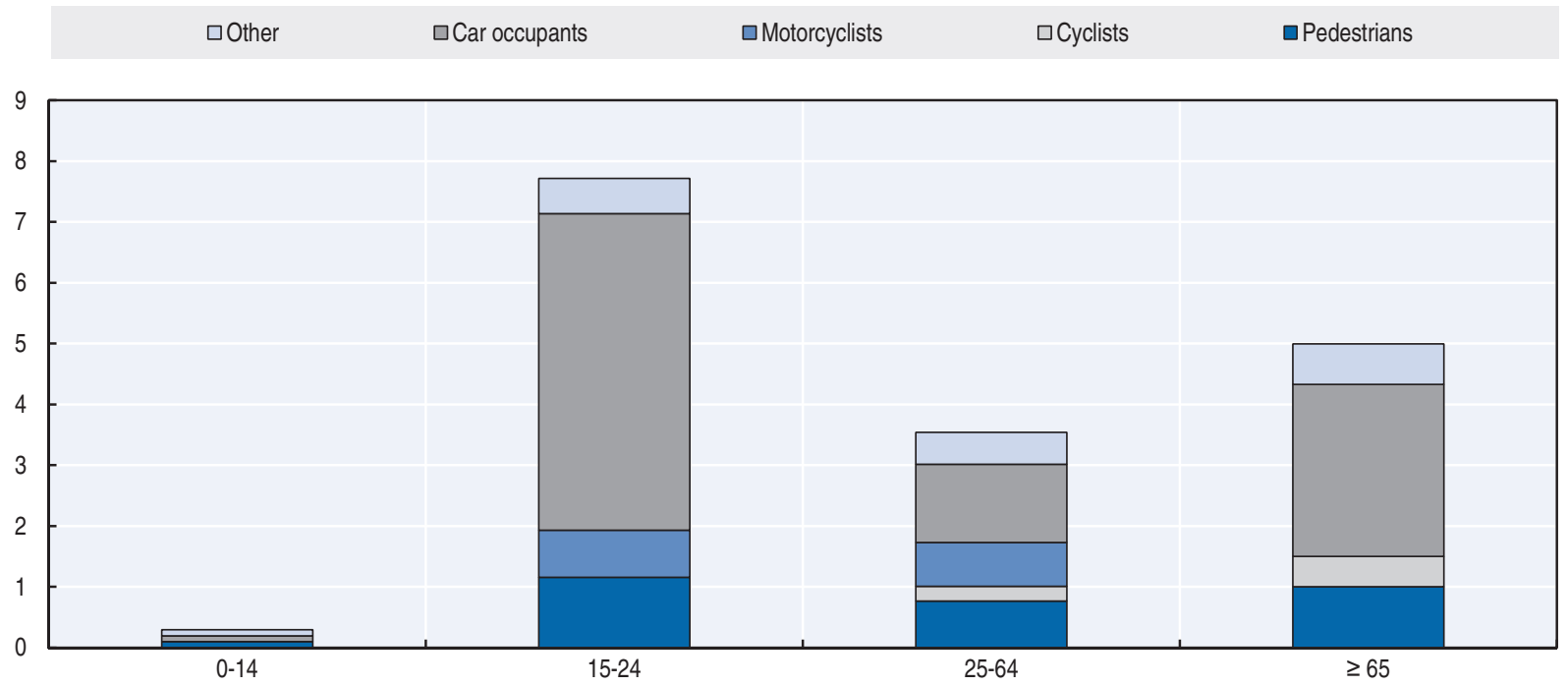

\section{Road safety by road type}

In 2015 , a large majority of fatalities (78\%) occurred on rural roads. Since 1990, urban roads have recorded the greatest reduction in fatalities (-78\%). The small number of fatalities on motorways is mostly due to the relatively low crash rates on this type of carriageway. 
Figure 17.6. Road fatalities by road type

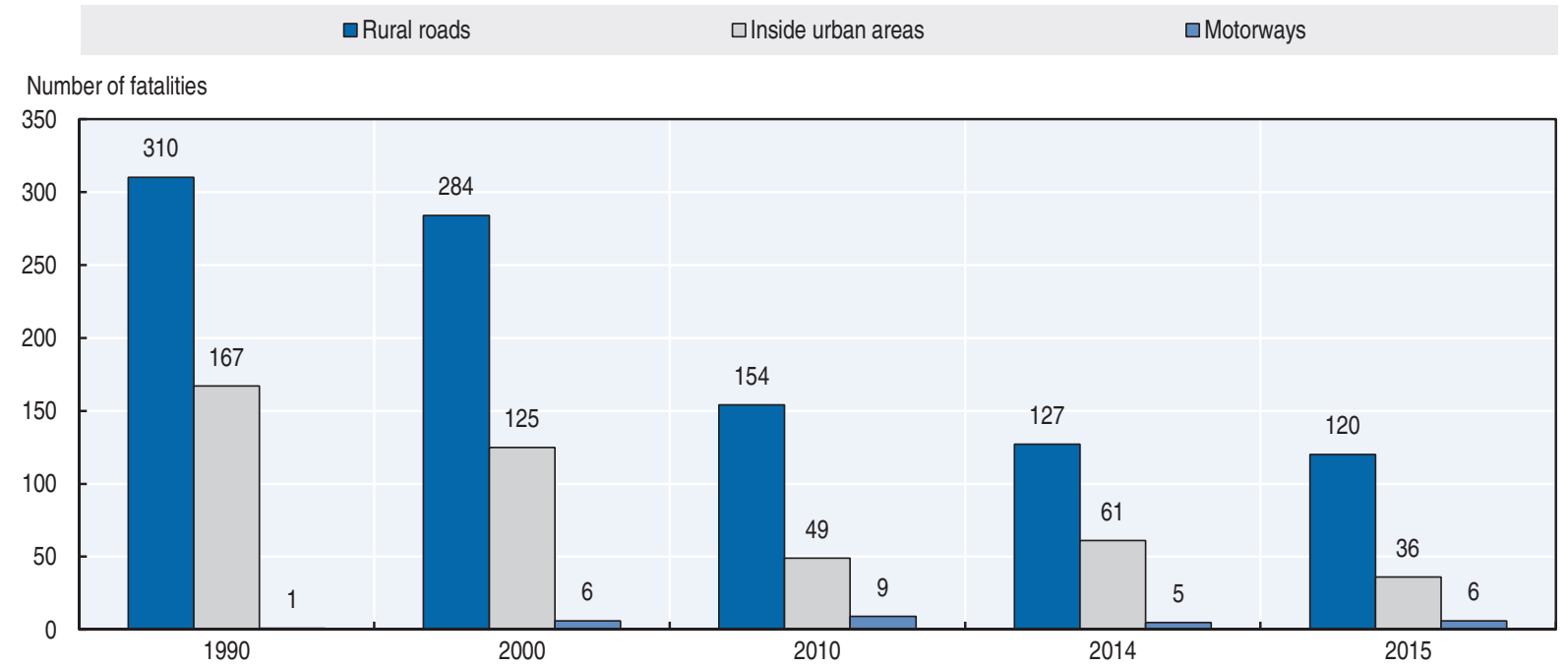

\section{Economic costs of traffic crashes}

Traffic crashes represent a significant cost for society, estimated in 2014 at around EUR 902 million or $0.47 \%$ of Ireland's GDP. The cost of collisions was provided in the Common Appraisal Framework for Transport (CAF) projects issued by the Department of Transport, Tourism, and Sport (2016). Collision values are dependent on income, therefore the change in collision values over the evaluation time horizon should follow the growth in real Gross National Product (GNP) per person employed mechanism.

Table 17.5. Costs of road crashes, 2014

\begin{tabular}{lccc}
\hline Type of collision & $\begin{array}{c}\text { Cost (EUR) inflated to 2014 } \\
\text { prices based on 2011 prices }\end{array}$ & $\begin{array}{c}\text { Number of } \\
\text { Collisions (2014) }\end{array}$ & Total \\
\hline Fatal & 2408906 & 179 & EUR 431194174 \\
Serious & 345515 & 646 & EUR 223 202 690 \\
Minor & 32425 & 4972 & EUR 161217 100 \\
Material Damage & 2606 & 33261 & EUR 86678166 \\
Total & & & EUR 902 292 130 \\
Total as \% of GDP (at constant prices & & & $0.47 \%$ \\
\hline
\end{tabular}

Source: GDP 2014 figure is from the CSO website: www.cso.ie/multiquicktables/quickTables.aspx?id=n1506.

\section{Recent trends in road user behaviour}

In 2016 the RSA published a number of pre-crash reports. The reports analysed police Fatal Collision Investigation files in order to identify the main contributory factors in collisions over the 2008-12 time period. These reports can be accessed at www.rsa.ie/RSA/ Road-Safety/Our-Research/Collision-Statistics/ (accessed 20 June 2017).The main findings indicated that:

- Excessive speed was a contributory factor in $32 \%$ of fatal collisions within the study period.

- $29 \%$ of all 867 collisions involved at least one driver or motorcyclist with a record of alcohol consumption prior to the collision. 
- $9 \%$ involved a pedestrian who had consumed alcohol.

- The condition of the tyres was cited in $8 \%$ of collisions involving a motorised vehicle as having contributed in full or part to the collision.

- Of the 93 motorcyclist collisions in the study, $49 \%$ cited speed and $29 \%$ cited alcohol as contributory factors.

\section{Speed}

Between 2008 and 2012, in total, 322 people died as a result of a collision where excessive speed was cited as a main contributory factor. Of the 867 collisions analysed, 274 (32\%) were cited as having excessive speed for the road and conditions as a contributory factor to the collision. A closer examination reveals that for $19 \%$ of the 274 fatal collisions speed was the sole contributory factor.

A survey in 2016 measured the free speed of 17 591vehicles, i.e. speed at which drivers choose to travel when unconstrained by road geometry, weather or traffic conditions. The results of the survey are summarised in the table below.

Table 17.6. Speed limits by road type, 2017

$\%$

\begin{tabular}{llll}
\hline & General speed limit & Percentage of drivers speeding (2016) & Average free speed (2016) \\
\hline Urban roads & $\leq 60 \mathrm{~km} / \mathrm{h}^{*}$ & 57 & $\begin{array}{l}65 \mathrm{~km} / \mathrm{h} \text { on urban arterial roads } \\
57 \mathrm{~km} / \mathrm{h} \text { on urban national roads }\end{array}$ \\
Rural roads & $80 \mathrm{~km} / \mathrm{h}$ or $100 \mathrm{~km} / \mathrm{h}$ & 22 on all rural roads & $96 \mathrm{~km} / \mathrm{h}$ on dual carriageways \\
& & 34 on $100 \mathrm{~km} / \mathrm{h}$ dual carriageways & (limit: $100 \mathrm{~km} / \mathrm{h})$
\end{tabular}

* Can be $60 \mathrm{~km} / \mathrm{h}$ on arterial roads or $30 \mathrm{~km} / \mathrm{h}$ in built up areas.

In the recent survey of driver attitudes and behaviours (RSA, 2015a) conducted among a sample of 1073 drivers in Ireland, 11\% of motorists admitted to being fined or otherwise for breaking the speed limit in the past three years. It was also found that between $44 \%$ and $54 \%$ of motorists consider low-level speeding broadly acceptable. In this case low-level speeding was defined as exceeding speed limits by less than $10 \mathrm{~km} / \mathrm{h}$.

\section{Drink driving}

Since 2010, the maximum authorised blood alcohol content (BAC) level is $0.5 \mathrm{~g} / \mathrm{l}(0.2 \mathrm{~g} / \mathrm{l}$ for novice drivers and professional drivers). It was $0.8 \mathrm{~g} / \mathrm{l}$ until 2009.

In the period 2008 to 2012, alcohol was cited as a contributory factor in $38 \%$ of the 867 collisions for which files were available. In $29 \%$ of fatal crashes at least one driver or motorcyclist had a record of alcohol consumption prior to the collision. This highlights the fact that a high level of drink driving is still evident in Ireland. All of these drivers were deemed culpable or part culpable for the collision through their behaviour on the road prior to the collision. A further $9 \%$ of the 867 fatal collisions were caused by a pedestrian who had consumed alcohol (Road Safety Authority, 2016b).

In the previously mentioned survey of driver attitudes and behaviours (RSA, 2015) conducted among a sample of 1073 drivers, $8 \%$ of drivers said they had driven after having at least one drink during the past 12 months. Of these, $44 \%$ said they had at least two or more drinks on that occasion. 


\section{Drugs and driving}

Following several decades of successful efforts to understand and reduce the magnitude of drink driving, driving while impaired by other psychoactive substances has emerged as its own road safety issue. A wide variety of substances, from illegal drugs to some over-the-counter preparations, can adversely affect the cognitive and behavioural skills required to operate a vehicle safely.

A study from the coroner's district in County Kildare during 1998-2009 showed that of 92 driver deaths, $9.8 \%$ had a positive toxicology for a drug. This rate undoubtedly points to the need for intoxicant impairment testing.

The police can now establish roadside Mandatory Intoxicant Checkpoints (MIT), to test drivers for the presence of both alcohol and drugs. New drug tests involve testing a sample of a driver's oral fluid (saliva) for the presence of cannabis, cocaine, opiates (e.g. heroin, morphine) and benzodiazepines (e.g. valium). The AGS also have the power, in case of suspicion, to conduct roadside impairment testing.

\section{Distraction}

Restrictions on the use of mobile phones while driving came into effect in May 2014. Legislation already in place makes it an offence to hold a mobile phone while driving.

The 2016 Mobile Phone survey found that out of the 14450 drivers observed, 878 (6\%) were observed using their mobile phone (372 using it to their ear and 506 using it in their hand).

\section{Seat belts and helmets}

\section{Seatbelts}

Seat belt use has been compulsory in front seats and rear seats since 1971. Children must be protected by a child restraint appropriate for their size and weight. The government's road safety strategy has a target of $100 \%$ compliance for seatbelt wearing rates among adults and children.

A 2016 observational survey of seat belt wearing rates on Irish roads showed that the overall seat belt wearing rate for adults (drivers, front and rear passengers) was $91 \%$. The wearing rate for drivers was $92 \%, 94 \%$ for all front seat passengers, and $74 \%$ for all rear seat adult passengers (RSA, 2016c).

A review of the 2016 fatal crashes found that $22 \%$ of vehicle occupant fatalities were not wearing a seat belt. This suggests that 27 fatalities may have been prevented had a seat belt been worn. In a significant proportion of collisions, it was not possible for the police at the scene to record whether or not a seat belt had been worn.

Table 17.7. Seat belt wearing rate by car occupancy

\begin{tabular}{lcccc}
\multicolumn{5}{c}{$\%$} \\
\hline & 2011 & 2013 & 2015 & 2016 \\
\hline Driver & 94 & 94 & 94 & 92 \\
Front passenger & 94 & 93 & 94 & 94 \\
Rear passenger & 90 & 89 & 86 & 74 \\
\hline
\end{tabular}

In the most recent survey of driver attitudes and behaviours (RSA, 2015) conducted among a sample of 1073 drivers, respondents were asked how often they wore a seat belt 
as a driver, front passenger and rear passenger. As drivers, 98\% said they always wore them; as front seat passengers, $97 \%$ said they always wore one; but as rear seat passengers, only $80 \%$ said that they always wear one. Only $77 \%$ of drivers said they always insist that seat belts are worn by those sitting in the rear of their car.

\section{Helmets}

All riders of powered two-wheelers are required to wear helmets. There is no mandatory helmet use law for cyclists. A roadside observation survey of motorcyclists in 2016 found that $99.9 \%$ wore helmets (RSA, 2016d). Of all cyclists observed 38\% wore a helmet. Further analysis was conducted based on the type of cycle being used and found that $41 \%$ of cyclists using their own bikes wore a helmet while only $22 \%$ of those using the public bike scheme wore helmets.

\section{National road safety strategies and targets Organisation of road safety}

The RSA is a state agency under the aegis of the Department of Transport, Tourism and Sport tasked with improving safety on Irish roads in order to reduce road death and injury resulting from road crashes.

The RSA co-operates and co-ordinates with stakeholders including:

- the Department of Transport, Tourism and Sport

- An Garda Síochána

- the National Roads Authority

- Medical Bureau of Road Safety

- the Department of Justice and Equality; Education and Skills; Environment, Community and Local Government; Health; Children and Youth Affairs, etc.

\section{Road safety strategy for 2013-20}

The Road Safety Authority is currently operating under the framework of the Government Road Safety Strategy 2013-20. The strategy sets out comprehensive targets and identifies 144 actions to be completed within its lifetime.

The Government Road Safety Strategy has set out a target of a reduction of road collision fatalities on Irish roads to 25 per million population (i.e., 124 fatalities or less) by 2020. This is required to close the gap between Ireland and the safest countries. To reach the target of 124 or fewer fatalities by 2020 , a $10 \%$ annual reduction in fatalities will be required from 2016 onwards. If Ireland had been on target at the end of 2016, there would be no more than 143 fatalities. Unfortunately, provisional figures for 2016 indicate that 188 people have lost their lives on Irish roads in 2016.

The monitoring system that was instrumental in the success of the previous strategy will be maintained. Annual reviews of the strategy are ongoing. Progress in implementing the strategy is reported in the context of the Road Safety Strategy Report to the Minister for Transport, Tourism and Sport. This report is informed by consultation with the major stakeholders. A mid-term evaluation of the strategy was conducted in November 2016. The RSA will be publishing a report summarising the outcomes of the Mid Term Evaluation in summer 2017. 
Figure 17.7. Trends in road fatalities towards national target

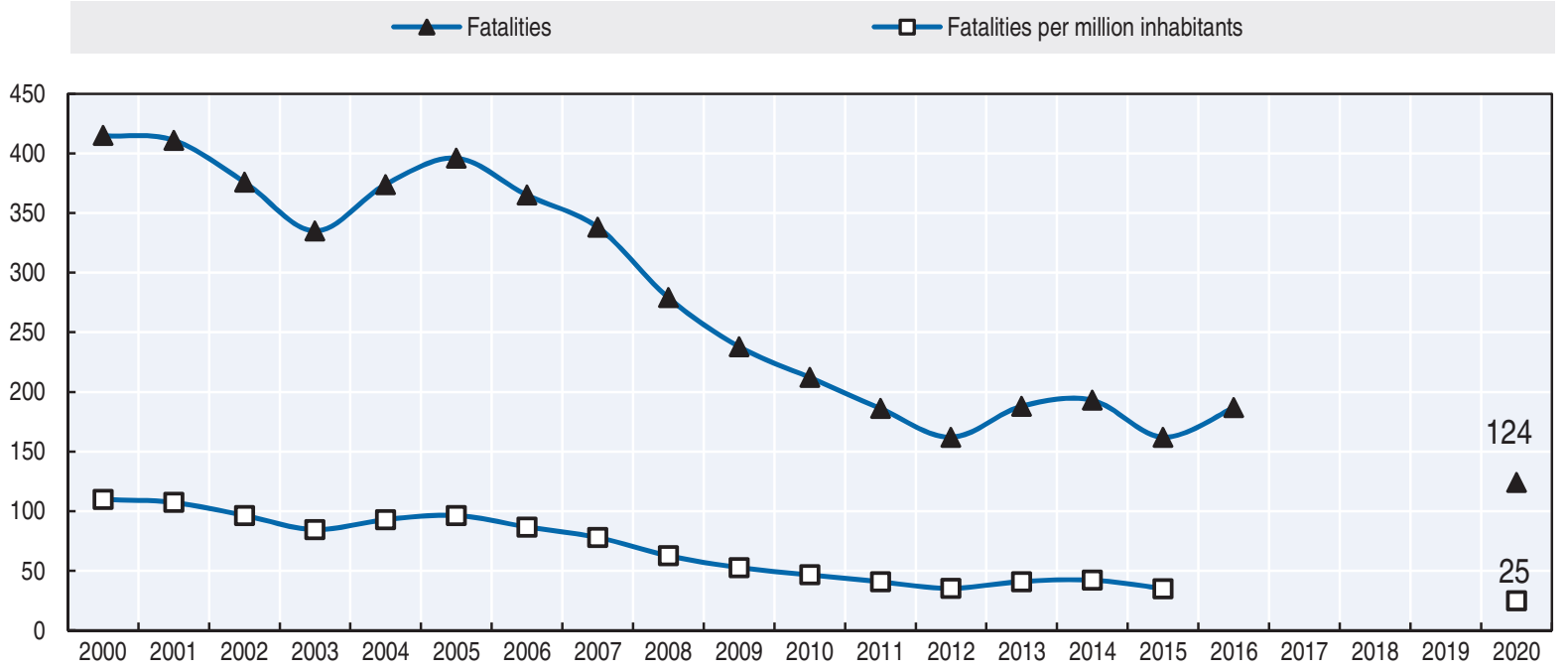

\section{Recent safety measures (2013-16)}

\section{Road safety management}

- The penalty points system has proved to have been an effective deterrent in changing road users' behaviour for the better over the past decade. The system needs to be continuously reviewed and updated to keep ahead of driver behaviour trends and actions. It will be extended over the course of the Government Road Safety Strategy 2013-20 to cover new safety related traffic offences.

- A new Fixed Charge Notice (FCN) offence for motorists who drive with defective or worn tyres on their vehicle was introduced in April 2016. Although driving a vehicle with defective or worn tyres is already an offence, there will now be a fixed charge (or fine) of EUR 80, with two penalty points endorsed, or four penalty points following conviction in court.

\section{Driving licence}

- Under the terms of the 2014 Act, the new category of novice driver came into effect from August 2014. Those drivers who receive their first full licence will be considered as novice drivers for their first two years. Novices will be required to display an N-plate during that time. Under the terms of the Act, novices will face disqualification from driving for six months if they reach seven penalty points, as opposed to 12 for those with a full licence.

- Changes to driver licence legislation now require all drivers to be qualified in the correct category of driving licence before they are permitted to tow trailers of particular weight classes.

\section{Cyclists}

- From July 2015 new fixed charge notices came into effect to promote safe cycling practices. The charge is in place for breaking a red light, failure to have a front lamp lit during lighting-up hours and cycling without reasonable consideration. 


\section{Speed management}

- The Department of Transport Tourism and Sport is actively encouraging local authorities to introduce $30 \mathrm{~km} / \mathrm{h}$ zones in residential areas and has engaged in a formal process with Local Authorities.

- Work on setting and managing speed limits has been conducted and a revised set of guidelines were issued in 2015. These guidelines include the introduction and use of new rural speed limit signs and a comprehensive review and update of all speed limits in administrative areas.

\section{Road safety campaigns}

- In 2016, the RSA ran a number of high profile campaigns aimed at targeting the main factors and at-risk groups involved in road collisions. They focused on driver distraction, driver fatigue, tyre safety, commercial vehicle safety, low level speeding and drink driving.

- Project Edward in association with TISPOL (Traffic Police network in Europe) and the AGS organised a digital and social media campaign to drive awareness of European Day without a Road Death (EDWARD).

- The "Check it Fits" Service is a free, nationwide, child car seat checking service. It aims to reassure parents, grandparents and guardians that their children are travelling safely in their child car seat and that the seat itself is securely fitted in the car. It was introduced in response to the frightening statistic that showed that as many as 4 out of 5 child car seats are incorrectly fitted. In 2016, the "Check it Fits" service checked 7137 car seats in 154 locations nationwide.

- "Streetsmart" is a road safety intervention aimed at bringing road safety to life in a fun way for young school children. It is based around a "Streetscape" map which depicts a typical street scene designed for children aged between four and eight. Children are given "walking cars" and "stand up bikes" and taught how to use the road safely. In 2016, 116 schools availed themselves of the service with 12875 children taking part.

- Use of a Rollover Simulator to encourage seat belt use. A car fitted to a hydraulic platform simulates a half or a full roll-over, demonstrating how it would feel for a driver or passenger involved in a car turning over. In 2016, 25843 people experienced the Rollover Simulator in 113 locations nationwide.

- The Road Safety Interactive Mobile Unit entitled the Shuttle provides the general public and other target audiences with the chance to interact with various road safety campaigns, including practising their driving skills on simulators, testing their hazard perception skills, using bicycle simulators, testing their brake reaction time and practising their driver theory test, etc. In 2016, approximately 70000 people visited the Shuttle.

- The RSA has trained National Road Safety Education Staff to deliver comprehensive road safety training programmes in schools, institutions, companies and community groups nationwide. Over 9000 programmes were completed in 2016.

- In 2016, the RSA distributed 3630 "Back to School Road Safety Packs" to primary schools and over 90000 high visibility vests were circulated to junior infants.

- Seatbelt Sheriff and Hi-Glo Silver packs were delivered to all primary schools in October 2016, promoting increased visibility and encouraging young children to become seatbelt sheriffs by taking a pledge to always wear their safety belt and to make sure that everyone else in the car does too. 
- In 2016, over 750000 high visibility clothing items and accessories were distributed free of charge to the public.

- The RSA provided a subvention to local authorities for cycle training. In 2016, 374 schools (16 174 children) benefitted from this training.

- The RSA assisted local authorities with the Junior School Warden Scheme, designed to provide safe crossing facilities in the vicinity of primary schools in provincial towns, villages and smaller cities.

\section{Driver education}

- Approved driving instructors (ADI's). Since 2009 driving instruction in Ireland has been a regulated industry. The regulations cover standards of instruction, driving tests and penalties. As of 31 December 2016 there were 1741 approved driving instructors working in the industry.

- Initial basic training (IBT) for motorcyclists is the mandatory 16-hour training course in four separate modules that teaches basic riding skills to learner motorcyclists. It is part of the RSA's graduated driver licence scheme.

- Essential driver training (EDT). Since its introduction almost 2.6 million EDT lessons have been provided to over 210000 learner drivers. Over 650000 lessons were completed in 2016 alone.

- Driver certificate of professional competence (driver CPC). All professional bus and truck drivers are obliged to maintain their driver CPC qualification by completing a one day refresher course each year. During 2016, 39010 individual professional drivers completed their annual periodic training and maintained their CPC qualification.

\section{Commercial vehicles}

- The RSA supported the implementation of a centralised information repository in relation to commercial vehicles, operators and drivers enabling more effective and efficient enforcement targeted at high-risk non-compliant operators and supporting compliance through minimising disruption. Enforcement is enhanced through Automatic Number Plate Recognition (ANPR).

\section{Vehicles}

- National Car Test (NCT). The NCT is a compulsory vehicle inspection programme The primary aim of this programme is to improve road safety and enhance environmental protection by reducing harmful vehicle emissions.

- The RSA has, in recent years, developed numerous recommendations and legislative amendments relating to the vehicle standards that are being applied in Ireland.

\section{Recent and ongoing research}

- The following national studies were conducted in 2016: free-speed of vehicles; seat belt use by drivers and passengers; mobile phone use by drivers; defective lights on vehicles; fog light misuse by vehicles; high-visibility and helmet wearing rates of cyclists and motorcyclists; traffic light behaviour by cyclists.

- See: www.RSA.ie/Documents/Road\%20Safety/Observational\%20Surveys/RSA\%200bservational \%20Studies.pdf (accessed 21 June 2017). 
- The Irish Longitudinal Study on Ageing (TILDA) is a large-scale, nationally representative, longitudinal study on ageing in Ireland. The Research Department of the RSA and TILDA collaborated on a study into the effects of ageing and possible implications on road user behaviour.

- Health Research Board/National Drug-Related Deaths Index study. In 2016 a continuation of the pilot study (2014) accessing coroner's data for fatal road collisions was undertaken.

- European Survey of Road Users Attitudes (ESRA). The ESRA project is a joint initiative of research organisations and road safety institutes in 17 European countries. The aim is to collect comparable (inter)national data on road users' opinions, attitudes and behaviour with respect to road traffic risks. Results from the first ESRA study were released in 2016. In total, data from more than 17000 road users was collected, including 1000 Irish road users. Results are available at: www.esranet.eu (accessed 21 June 2017).

\section{References}

CSO, (2017). Transport Omnibus 2015, www.cso.ie/en/releasesandpublications/ep/p-tranom/to2015/rt/rt/ (accessed 5 April 2017).

CSO (2016), Seasonally Adjusted Unemployment Figures, www.cso.ie/multiquicktables/quickTables.aspx? id=mum01 (accessed 5 April 2017).

Goodbody Economic Consultants (2004), Values of Time, Accident Costs and Operating Costs, Dublin.

RSA (2016a), "Provisional review of fatal collisions: January-December 2016", www.RSA.ie/Documents/ Road\%20Safety/Crash\%20Stats/RSA\%20Provisional\%20Review\%20of\%20Fatalities\%202016.pdf (accessed 21 June 2017).

RSA (2016b), "Fatal Collisions 2008-2012: Alcohol as a Contributory Factor", www.RSA.ie/Documents/Press \%200ffice/Fatal\%20Collisions\%202008-2012_Alcohol\%20as\%20a\%20Factor.pdf (accessed 18 April 2017).

RSA (2016c), Seat Belt and Mobile Phone Usage Observation Survey 2016. Unpublished data.

RSA (2016d), High Visibility and Helmet Wearing Observation Survey 2016. Unpublished data.

RSA (2015), Driver Attitudes and Behaviour Survey 2015. Unpublished data.

SEAI (2016), "Energy in Ireland 1990-2015". www.seai.ie/Publications/Statistics_Publications/Energy_in_ Ireland/Energy-in-Ireland-1990-2015.pdf, pp. 52 (accessed 5 April 2017).

World Bank (2017), “GDP (constant US\$)", World Development Indicators, http://databank.worldbank.org/ data/reports.aspx?source=world-development-indicators (accessed 23 February 2017).

\section{Websites}

- Irish Road Safety Authority (RSA) www.rsa.ie (accessed 21 June 2017).

- Road Safety Strategy 2013-20: www.rsa.ie/Documents/About\%20Us/RSA_STRATEGY_2013-2020\%20.pdf (accessed 21 June 2017).

- Penalty points: www.penaltypoints.ie (accessed 21 June 2017).

- Rules of the Road: www.rulesoftheroad.ie (accessed 21 June 2017). 


\section{Chapter 18}

\section{Israel}

This chapter presents 2015 road safety data for Israel along with provisional data from 2016. It looks at trends in traffic and road safety from the years 1990 to 2015 and road user behaviour patterns, with a special focus on the ageing population. Sections include data on speed, drink driving, drugs and driving, distracted driving, fatigue and seat belt usage. The chapter reviews Israel's road safety strategy and national targets to 2020 and the progress achieved thus far. It also provides details of recently implemented safety measures and current and ongoing research.*

* The statistical data for Israel are supplied by the relevant Israeli authorities. The use of such data by the ITF/OECD is without prejudice to the status of the Golan Heights, East Jerusalem and Israeli settlements in the West Bank under the terms of international law. All data stem from the National Road Safety Authority and IRTAD unless otherwise noted. For more information please contact: Mr. Nathaniel Sarfaty, netanelt@rsa.org.il. 
I 1 srael has seen a steady improvement in fatality rates over recent years, reaching their lowest fatality rate on record in 2014 with 3.4 deaths per 100000 inhabitants. However, 2015 saw an interruption in this trend with a total of 322 fatalities, a 15\% increase over 2014, the equivalent of 3.8 per 100000 inhabitants. Motorcyclist and cyclist fatalities both increased by $31 \%$ and $40 \%$ respectively. Provisional data from 2016 indicate a second consecutive year of increases, with fatalities rising by $4 \%$ to 335 . Pedestrians accounted for $34 \%$ of all fatalities in 2015, remaining the user group most at risk. Pedestrian safety has become a priority for Israel and a new pedestrian safety programme was launched in 2014.

\section{Road safety data collection}

\section{Definitions applied in Israel}

- Road fatality: Person killed immediately or dying within 30 days as a result of a road crash.

- Seriously injured person: A person injured in a road crash and hospitalised for a period of 24 hours or more, not for observation only. The words "not for observation only" were added by the Israel Police in December 1995 in order to obtain a clear and uniform definition. Before the second half of 1970, "seriously injured" applied only to those hospitalised for at least six days.

- Slight injury: A person injured in a road crash and hospitalised for a period of less than 24 hours.

\section{Data collection}

Police collect crash data at the scene of the crash and subsequently send them to the Central Bureau of Statistics. The Road Safety Authority (RSA) funds both the Traffic Police and the Transportation Unit at the Central Bureau of Statistics in order to manage and maintain the data system.

Police data are regularly linked with other data sources, such as hospital databases (for fatalities up to 30 days and injuries), the Trauma Registry, the Ministry of Transport (driver and vehicle registries) and Ministry of Interior (population registry). Crash data covers the entire population and the entire geographical area.

By linking hospital and police data it was seen that roughly 1500 injured persons who were recorded by the police as slightly injured are recorded in hospital data as severely injured. In addition, roughly 4000 crash survivors arrive at hospitals while they were not reported in police data. This mostly concerns single unit accidents, cyclists (including e-bikers) and motorcyclists. In addition to police data, Israel currently uses the Injury Severity Score (ISS) system to assess the severity of an injury. Police data is used as a basis for Israeli statistical publications.

In 2014, Israel collected data using the Maximum Abbreviated Injury Scale with scores of three or higher (MAIS3+) for the years 2008-14. These data will progressively be integrated in the RSA database.

It is assumed that all fatal crashes are reported to the police. 


\section{Most recent safety data}

\section{Road crashes in 2016 - provisional data}

There were 335 fatalities in 2016, representing a 4\% increase when compared to 2015. The number of injury crashes as well as the injured persons, however, slightly decreased, by $2 \%$ and $1 \%$ respectively.

In 2016 , there was an $11 \%$ decrease in pedestrian fatalities

\section{Road crashes in 2015}

In 2015, 322 persons died in road crashes in Israel. This represents a 15\% increase when compared to 2014 . The number of injury crashes increased by $3 \%$ and injured persons by $1 \%$.

\section{Trends in traffic and road safety (1990-2015)}

\section{Traffic}

Between 1990 and 2015, the number of motorised vehicles and the distance travelled almost tripled with the increase between 2014 and 2015 alone being 4\% and 4.6\% respectively.

\section{Road safety}

\section{Crashes and casualties}

The number of road fatalities peaked in 1974, with 704 road deaths. Since then, the number of fatalities has decreased by $64 \%$. Between 2000 and 2015, it decreased by $29 \%$.

\section{Rates}

Efforts at improving safety have yielded significant reductions in fatality rates, despite a certain worsening of the situation in 2015. By the end of 2015, Israel had a mortality rate of 3.8 fatalities per 100000 inhabitants and 5.9 fatalities per billion vehicle-kilometres. Both of these rates were reduced almost twofold compared to 2000 , and by $17 \%$ compared to 2010.

Table 18.1. Road safety and traffic data

\begin{tabular}{|c|c|c|c|c|c|c|c|c|c|}
\hline & \multirow{2}{*}{1990} & \multirow{2}{*}{2000} & \multirow{2}{*}{2010} & \multirow{2}{*}{2014} & \multirow{2}{*}{2015} & \multicolumn{4}{|c|}{$2015 \%$ change from } \\
\hline & & & & & & 2014 & 2010 & 2000 & 1990 \\
\hline \multicolumn{10}{|l|}{ Reported safety data } \\
\hline Fatalities & 418 & 452 & 352 & 279 & 322 & 15.4 & -8.5 & -28.8 & -23.0 \\
\hline Injury crashes & 17496 & 19925 & 14724 & 11772 & 12122 & 3.0 & -17.7 & -39.2 & -30.7 \\
\hline Injured persons hospitalised & 3965 & 2896 & 1683 & 1562 & 1796 & 15.0 & 6.7 & -38.0 & -54.7 \\
\hline Deaths per 100000 inhabitants & 8.7 & 7.1 & 4.6 & 3.4 & 3.8 & 12.0 & -17.6 & -46.4 & -56.1 \\
\hline Deaths per 10000 registered vehicles & 4.1 & 2.4 & 1.4 & 0.9 & 1.0 & 10.7 & -24.1 & -57.0 & -74.7 \\
\hline Deaths per billion vehicle kilometres & 22.4 & 12.4 & 7.1 & 5.3 & 5.9 & 10.3 & -16.8 & -52.6 & -73.8 \\
\hline \multicolumn{10}{|l|}{ Traffic data } \\
\hline Registered vehicles ${ }^{1}$ (thousands) & 1015 & 1832 & 2566 & 2966 & 3092 & 4.2 & 20.5 & 68.8 & 204.5 \\
\hline Vehicle-kilometres (millions) & 18668 & 36482 & 49870 & 52400 & 54820 & 4.6 & 9.9 & 50.3 & 193.7 \\
\hline Registered vehicles per 1000 inhabitants & 211 & 288 & 337 & 361 & 365 & 1.2 & 8.5 & 27.0 & 73.5 \\
\hline
\end{tabular}

1. Registered vehicles including mopeds. 
Figure 18.1. Road safety, traffic and GDP trends index $1990=100$

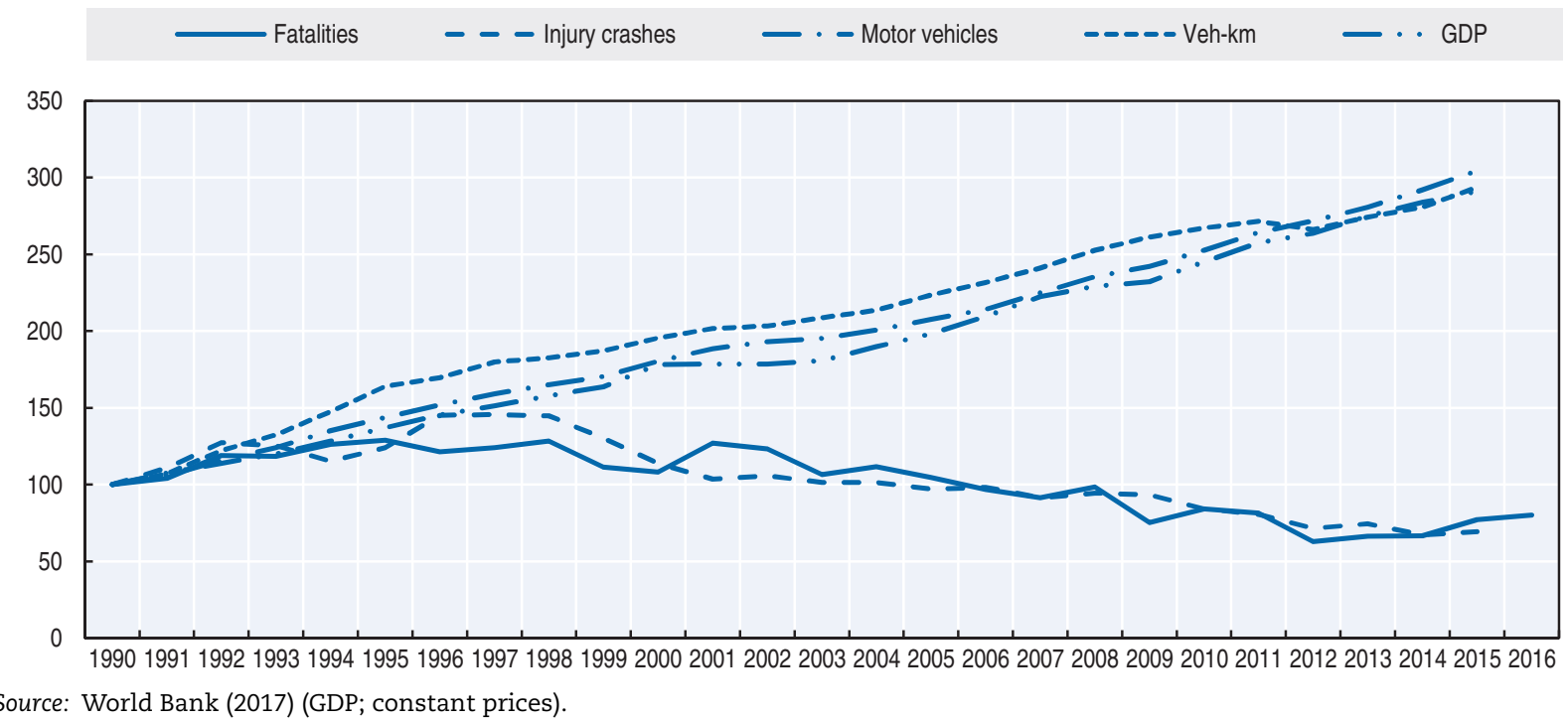

\section{Road safety by user group}

Since 2000, the situation improved for all road users, except motorcyclists. The number of motorcyclists killed increased by 10\% (38 vs. 42) since 2010 with certain fluctuations from year to year.

In 2015 there was a 31\% increase in motorcycle fatalities (42 vs. 32 in 2014) and 40\% fatality increase among cyclists (14 vs. 10 in 2014).

In recent years about one-third (34\%) of all road user fatalities in Israel were pedestrians. In 2015 , the number of pedestrians killed on the roads decreased by $7 \%$, after the significant increase from 91 in 2013 to 116 in 2014. In recent years, the authorities have looked at infrastructure solutions to improve safety at pedestrian crossings where there are no traffic lights, launching education programmes in the school system on safe road crossing and promoting public awareness of issues such as the illusion of security at pedestrian crossings, etc.

Table 18.2. Road fatalities by road user group

\begin{tabular}{lrrrr|rrr}
\hline & 2000 & 2010 & 2014 & 2015 & \multicolumn{3}{|c}{$2015 \%$ change from } \\
\cline { 6 - 8 } & & & & & 2014 & 2010 & 2000 \\
\hline Pedestrians & 169 & 119 & 116 & 108 & -6.9 & -9.2 & -36.1 \\
Cyclists & 20 & 18 & 10 & 14 & 40.0 & -22.2 & -30.0 \\
Moped riders & 7 & 3 & 4 & 4 & 0.0 & 33.3 & -42.9 \\
Motorcyclists & 38 & 40 & 32 & 42 & 31.3 & 5.0 & 10.5 \\
Car occupants & 219 & 172 & 86 & 106 & 23.3 & -38.4 & -51.6 \\
Others & 0 & 0 & 31 & 48 & 54.8 & & \\
Total & $\mathbf{4 5 2}$ & $\mathbf{3 5 2}$ & $\mathbf{2 7 9}$ & $\mathbf{3 2 2}$ & $\mathbf{1 5 . 4}$ & $\mathbf{- 8 . 5}$ & $\mathbf{- 2 8 . 8}$ \\
\hline
\end{tabular}


Figure 18.2. Road fatalities by road user group in percentage of total, 2015

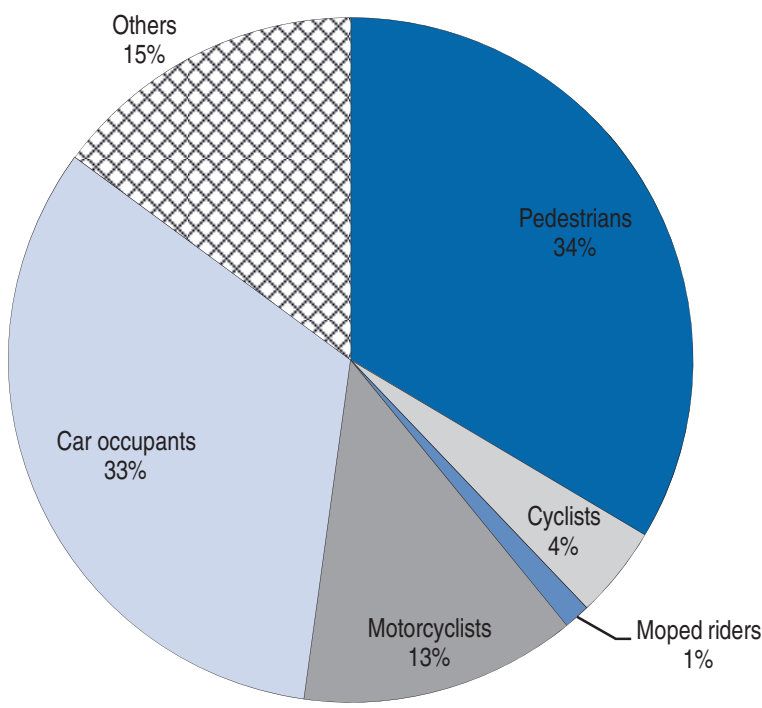

\section{Road safety by age group}

Since 2000, road safety improvements have benefited almost all age groups, with the largest decrease for the 18-20 year olds (68.8\%). The number of killed children aged 0-14 and $15-17$ decreased by $48 \%$ and $52 \%$, respectively.

In 2015, the number of road deaths decreased among the 0-14 and 18-20 year olds, but nearly doubled for the 65+ age group, with 97 fatalities in 2015 compared to 65 fatalities in 2014.

Table 18.3. Road fatalities by age group

\begin{tabular}{|c|c|c|c|c|c|c|c|}
\hline \multirow{2}{*}{ Age } & \multirow{2}{*}{2000} & \multirow{2}{*}{2010} & \multirow{2}{*}{2014} & \multirow{2}{*}{2015} & \multicolumn{3}{|c|}{$2015 \%$ change from } \\
\hline & & & & & 2014 & 2010 & 2000 \\
\hline $0-14$ & 46 & 40 & 30 & 24 & -20.0 & -40.0 & -47.8 \\
\hline $15-17$ & 23 & 13 & 5 & 11 & 120.0 & -15.4 & -52.2 \\
\hline $18-20$ & 51 & 20 & 22 & 16 & -27.3 & -20.0 & -68.6 \\
\hline $21-24$ & 43 & 40 & 25 & 25 & 0.0 & -37.5 & -41.9 \\
\hline $25-64$ & 201 & 154 & 132 & 145 & 9.8 & -5.8 & -27.9 \\
\hline $65-74$ & 36 & 30 & 28 & 48 & 71.4 & 60.0 & 33.3 \\
\hline $75-84$ & 32 & 32 & 27 & 31 & 14.8 & -3.1 & -3.1 \\
\hline$\geq 85$ & 21 & 11 & 10 & 18 & 80.0 & 63.6 & -14.3 \\
\hline Total & 452 & 352 & 279 & 322 & 15.4 & -8.5 & -28.8 \\
\hline
\end{tabular}


Figure 18.3. Road fatality rates by age group Deaths per 100000 inhabitants in a given age group, 2005-15
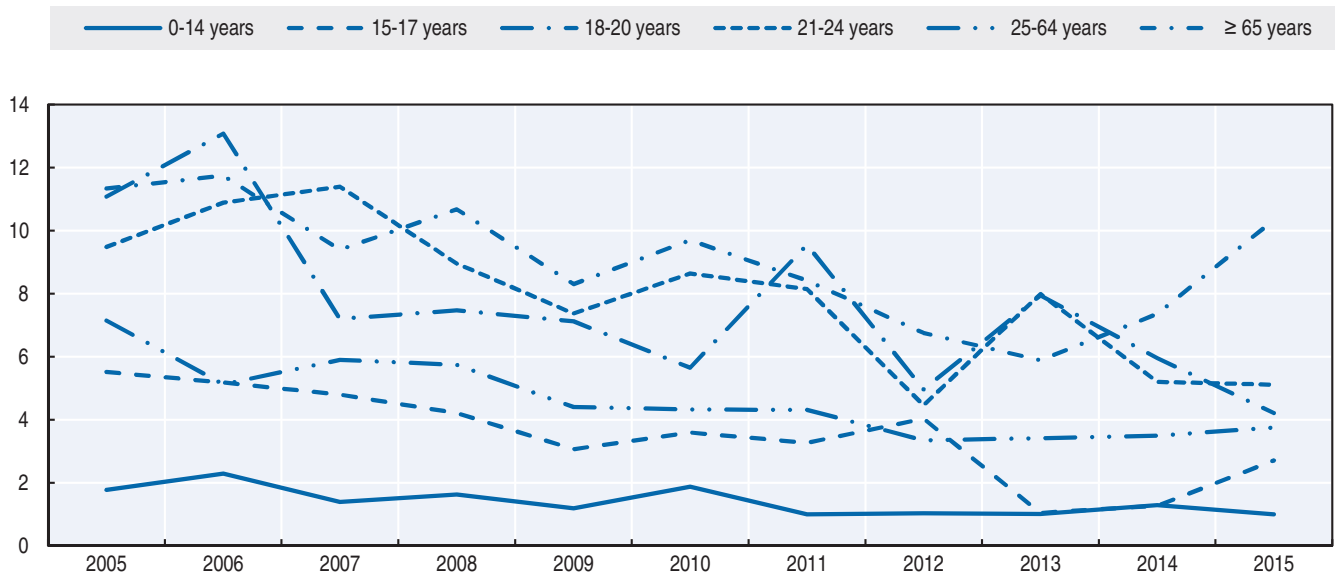

\section{Box 18.1. Road safety for an ageing population}

The population aged 65 and above represented 10\% of the population in 2015. This share should remain stable in the coming years, but according to the Central Bureau of Statistics, this share will rise to $16 \%$ by 2050 .

Table 18.4. Road fatalities among senior citizens

\begin{tabular}{|c|c|c|c|c|c|c|}
\hline & \multicolumn{2}{|c|}{$65-74$} & \multicolumn{2}{|c|}{$75-84$} & \multicolumn{2}{|c|}{$85+$} \\
\hline & 2010 & 2015 & 2010 & 2015 & 2010 & 2015 \\
\hline Pedestrians & 15 & 26 & 21 & 15 & 8 & 11 \\
\hline Cyclists & 2 & 5 & 1 & 0 & 0 & 0 \\
\hline Moped riders & 1 & 0 & 1 & 0 & 0 & 0 \\
\hline Motorcyclists & 0 & 1 & 0 & 0 & 0 & 0 \\
\hline Car occupants & 9 & 9 & 9 & 12 & 2 & 3 \\
\hline Total & 30 & 48 & 32 & 31 & 11 & 18 \\
\hline
\end{tabular}

Figure 18.4. Road fatality rates in the $65+$ age groups Deaths per 100000 inhabitants in a given age group, 2009-15

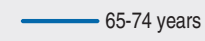

$--75-84$ years

$-\cdot 85+$ years

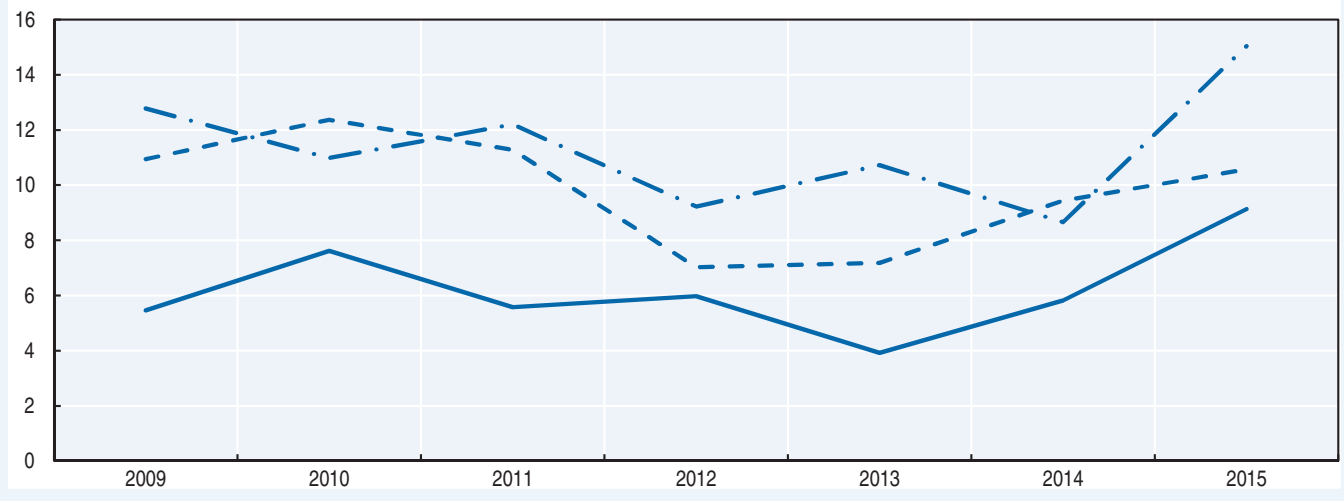




\section{Box 18.1. Road safety for an ageing population (cont.)}

The senior population is over represented in road deaths, as they account for $30 \%$ of all road deaths.

After the age of 40 , the driving licence needs to be renewed every 10 years. This renewal requires passing a sight test.

Driving instructors, heavy vehicle, bus and taxi drivers must undergo a medical examination every five years between the ages of 60 and 70, and every two years thereafter. All other drivers are required to undergo a medical examination every five years between the ages of 70 and 80, and every two years thereafter.

Figure 18.5. Road fatality rate by age and road user group Fatalities per 100000 inhabitants, 2015

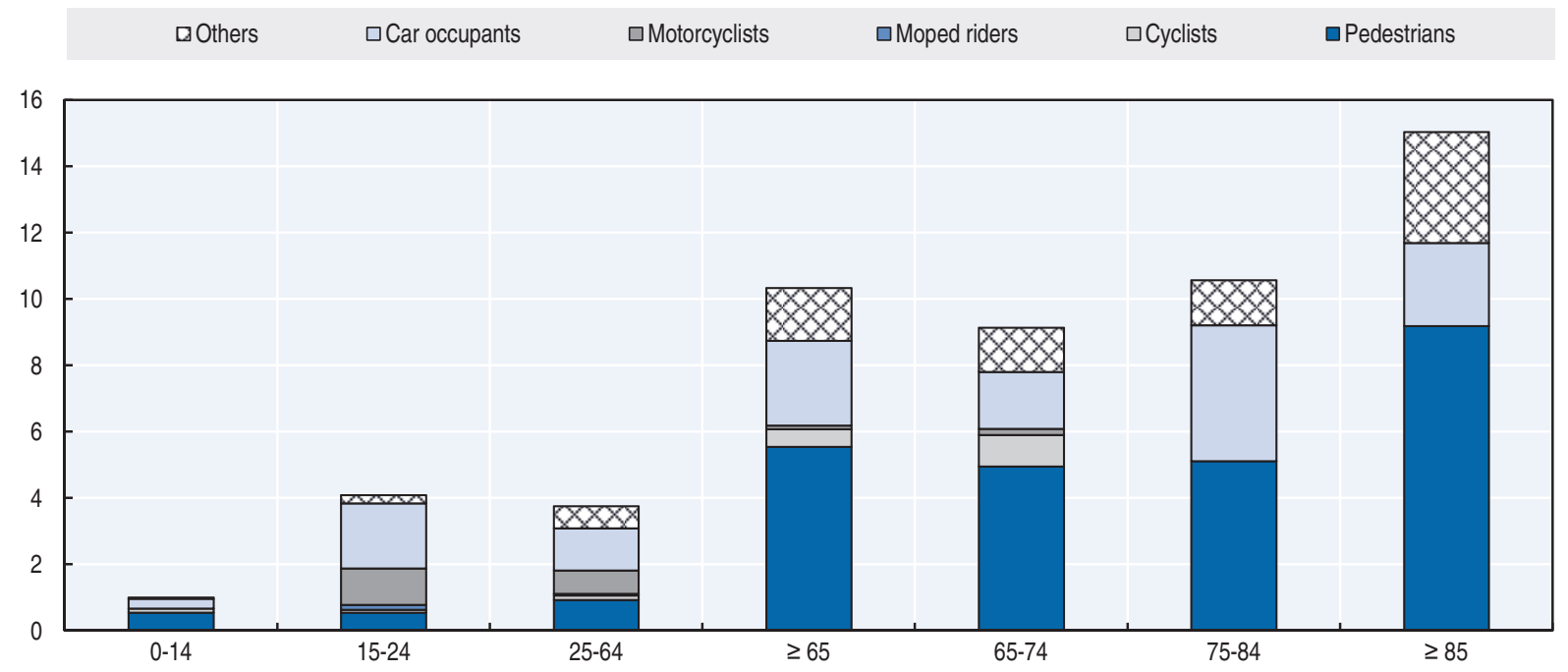

\section{Road safety by road type}

In 2015 , fatalities on roads outside urban areas rose $28 \%$ and accounted for $60 \%$ of all road fatalities. Due to the higher speed limits outside urban areas, the risk of fatalities when a crash occurs is greater.

In 2015 there was a $28 \%$ increase in fatalities on inter-urban roads.

\section{Economic costs of traffic crashes}

Traffic crashes represent a significant cost for society, estimated for the year 2014 at around ILS 9.1 billion (Israeli New Shekel).

The methodology for assessing road crash costs in Israel was developed in 2004 using a combination of all available data sources and applying a willingness-to-pay approach for the estimation of human costs (Cohen, 2004). The injury and crash cost values were recently updated (Ministry of Transport and Ministry of Finance, 2012). Calculations are based on casualty data from the National Insurance Institute and crash data from the Israel Police. Crash costs include indirect and direct costs, such as:

- medical expenses, assistance and nursing care 
Figure 18.6. Road fatalities by road type

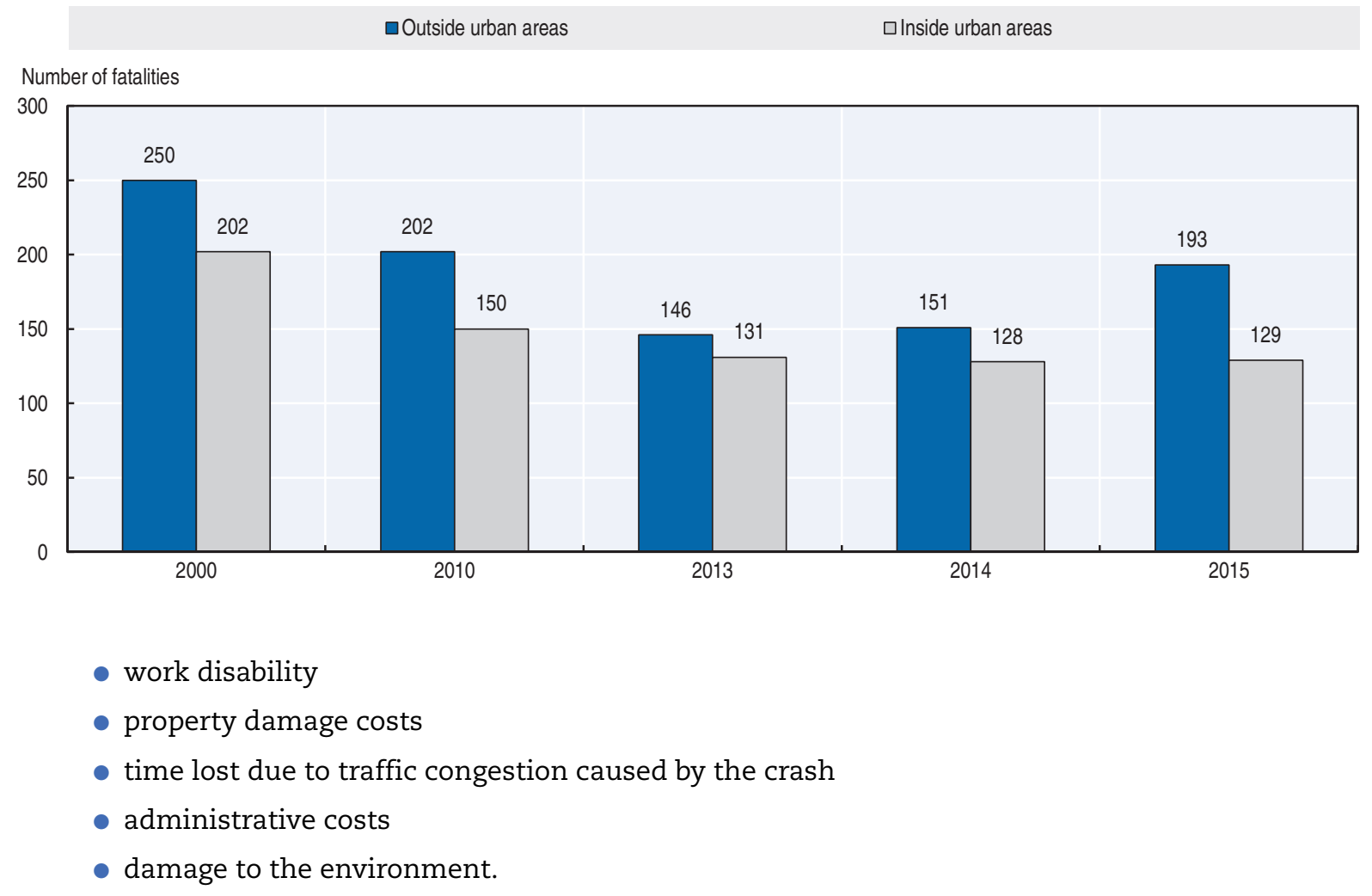

Table 18.5. Costs of road crashes, 2014

\begin{tabular}{lcc}
\hline Cost (ILS) & Unit cost & Total \\
\hline Fatalities & ILS 7 million & \\
Hospitalised persons & ILS 1.2 million & \\
Slight injuries & ILS 125000 & \\
Total & ILS 15 billion & \\
\hline
\end{tabular}

Source: Ministry of Transport and Ministry of Finance (2012).

\section{Recent trends in road user behaviour}

Speed

In $2015,11.5 \%$ of the fatal crashes were due to excessive speed. In Israel, there is a significant share of non-compliance with speed limits on all non-urban road types. It is especially serious for truck drivers on high-speed roads, where about $90 \%$ drive over the speed limit.

The table below summarises the main speed limits in Israel.

\section{Drink driving}

The maximum authorised blood alcohol content (BAC) is $0.5 \mathrm{~g} / \mathrm{l}$ and $0.1 \mathrm{~g} / \mathrm{l}$ for drivers under 24 years old, novice drivers for the first two years after receiving their license, and professional and public transport drivers. 
Table 18.6. Passenger car speed limits by road type, 2017

\begin{tabular}{lc}
\hline & General speed limit \\
\hline Motorways & $110 \mathrm{~km} / \mathrm{h}$ \\
Dual-carriageway roads without at-grade junctions & $90-100 \mathrm{~km} / \mathrm{h}$ \\
Other dual-carriageway roads & $90 \mathrm{~km} / \mathrm{h}$ \\
Single-carriageway roads & $80 \mathrm{~km} / \mathrm{h}$ \\
Local roads & $80 \mathrm{~km} / \mathrm{h}$ \\
Urban arterial roads & $70 \mathrm{~km} / \mathrm{h}$ \\
Other urban roads & $50 \mathrm{~km} / \mathrm{h}$ \\
\hline
\end{tabular}

The extent of drink driving was for a long time underestimated and not identified as a major problem, but the problem is now recognised. Police have increased roadside alcohol checks and testing for drivers involved in crashes. Conservative estimates indicate that alcohol is a contributing factor in $7-15 \%$ of fatal crashes.

In 2011, a national survey of alcohol-impaired driving was undertaken in Israel in co-operation with the Police Traffic Department. Police checked 1703 drivers on weekend nights on main arterial roads in the vicinity of pubs and nightclubs. Based on the results of the survey and additional extrapolation, it was estimated that in $2011,6.7 \%$ of drivers were suspected of drink driving, while $2.9 \%$ of drivers were actually drunk drivers.

\section{Drugs and driving}

Drivers are not routinely checked for drugs, but in the case of fatal crashes the involved parties are tested. The estimation of fatalities due to drugs and driving stands at $2 \%$ per year.

\section{Seat belts and helmets}

Seat belt use has been compulsory in front seats since 1975 and in rear seats since 1995.

Seat belts, child safety seats and booster seats are required of all relevant occupants at all times. In 2016, the usage rate was 91\% for drivers, 89\% for front seat passengers and only $70 \%$ for rear seat passengers.

Dedicated child restraint use is compulsory for children up to eight years old. By law, children in their first year must sit in a rear-facing child restraint; children aged 1-3 must sit in a forward-facing restraint; and children aged 3-8 must sit in a booster seat. The RSA has issued stricter recommendations for children up to age 2 to sit in a rear-facing child restraint; children aged 2-5 to sit in a forward-facing restraint; and children aged 5-10 to sit in a booster seat. According to a 2016 roadside survey, the overall usage rate is $87 \%$. However, only $50 \%$ of children are correctly buckled.

Similar to previous years, in 2014-15 15\% of all car occupant fatalities were not wearing seat belts when the crash occurred.

Helmet use is compulsory for all motorcycle and moped riders. The rate of use by motorcyclists is close to $100 \%$ but varies according to riding conditions (alone or in group), the age of the rider, type of site, size of town, etc.

Helmets are compulsory for child cyclists and for adults on non-urban roads. A 2013 roadside survey found that over $90 \%$ of cyclists wear helmets while riding outside urban areas. 
Table 18.7. Seat belt wearing rate by car occupancy and road type

$\%$

\begin{tabular}{lcccc}
\hline & 2003 & 2010 & 2014 & 2016 \\
\hline Front seat & & & & 97 \\
Driver & 89 & 89 & 95 & 88.7 \\
Passenger & 85 & 85 & 74 & 69.7 \\
Rear seats & 23 & 70 & 87 But an important share \\
General & & 78 & is not adequately buckled \\
Children (use of child restraint) & & & \\
& & & & 97 \\
\hline
\end{tabular}

\section{Distraction}

In Israel, it is legal to drive while operating a hands-free mobile phone, but not with a hand-held phone. The percentage of fatal and non-fatal crashes due to distraction is known to be underestimated.

\section{Sleepiness and fatigue}

Based on police reports, between 2000 and 2015 the share of fatal crashes due to fatigue was $1.2 \%$. This percentage is known to be underestimated.

\section{National road safety strategies and targets}

\section{Organisation of road safety}

The lead agency for traffic safety management is the National Road Safety Authority, which was created in 2007. The agency is charged with:

- financing and co-ordinating traffic safety activities of other government agencies such as the Public Roads Company, the National Traffic Police, the Ministry of Education, and the Ministry of Transport

- funding the analysis of national crash statistics and providing the primary resource for crash data and traffic safety knowledge and research

- creating public information campaigns and various municipal traffic safety projects

\section{Road safety strategy for 2012-20}

A five-year strategic plan for road safety was released in 2012. It includes the objectives to reduce the fatality rate to less than four fatalities per billion kilometres travelled and to position Israel among the leading five countries in road safety based on fatalities per kilometre travelled.

\section{Road safety targets}

The National Road Safety Authority set a target of no more than 240 fatalities by 2020, corresponding to a reduction of about $30 \%$ compared to the 2010 level. In addition, it established the following objectives as a series of indicators:

- increasing seat belt use to $98 \%$ for drivers, $95 \%$ for front seat passengers and $85 \%$ for rear seat passengers

- increasing the use of child restraints (ages 0-15) with the target of $70 \%$ correct usage of restraints and no more than $5 \%$ unrestrained 
- adopting of a "zero tolerance" policy towards drivers in general, and in particular the atrisk population (new and/or young drivers, drivers of public and/or heavy vehicles, drivers of vehicles carrying hazardous goods)

- increasing the number of alcohol tests performed by the police relative to the total number of drivers from $26 \%$ in 2010 to $40 \%$ in 2020

- reducing the 85 th percentile speed and the percentage of vehicles exceeding speed limits on all types of road.

Figure 18.7. Trends in road fatalities towards national target

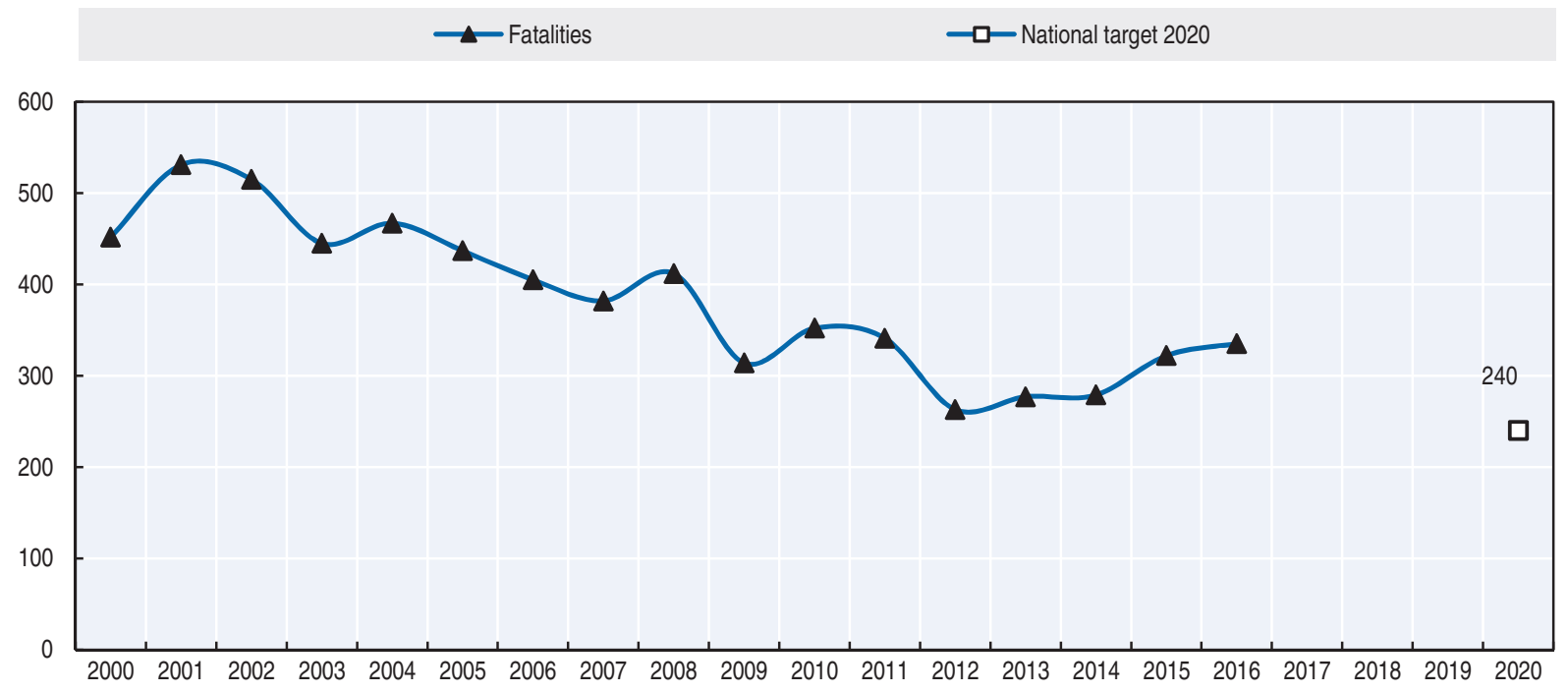

\section{Recent safety measures (2014-17)}

\section{Road safety management}

A number of updates were introduced in recent years including:

- revision of regulations concerning the use of child restraints (2014)

- equipping all seats in a car with a safety belt (2014)

- permission for cyclists to cross at pedestrian crossings providing they walk with their bicycle (2014)

- banning the use of electric scooters on non-urban roads (2014)

- making illegal having more passengers than seat belts in a car (2014)

- making illegal seating a child in a booster seat with an active air bag (2014)

- revision of regulations regarding cyclists on non-urban roads (2014)

- development of regulations ensuring the safety of electric scooter users (mostly seniors), including prohibition of driving on non-urban roads (2014)

- drivers must give the right of way to pedestrians at crossings, even if they have not yet started crossing (2015)

- drivers must stop at pedestrian crossings if the car alongside them has stopped (2015)

- development of regulations ensuring the safety of e-bike and pedelec users including age limit and licencing requirements. 


\section{Pedestrian safety}

- Improving the safety of pedestrians is a priority in Israel. A pedestrian safety programme was started in 2014, with a specific focus on elderly pedestrians. A committee was established with partners in the welfare system, the health department, the Ministry for Social Equality and NGOs to identify solutions, which include: information campaigns for the older road users and their families on the effects of ageing on the safety of pedestrians; training professionals in the health system on road safety issues; training volunteers from veteran citizens as "agents of change" to guide older ones.

- In addition, the committee has developed a partnership between the RSA and the association "Kol Shelanu" (our voice), a first project of this kind in Israel that promotes healthy, safe and cautious walking among senior citizens. The project is based on active participation and visibility of senior citizens who are encouraged to monitor and document positive and negative road and environmental factors they encounter (such as cars irregularly parked, damaged pavements, etc.).

- The RSA is promoting a multi-sectoral plan to reduce pedestrian injuries in general and elderly people in particular at crossing points, in cooperation with police, road agencies, education, local authorities and others. The plan includes, among other things, a media campaign regarding the granting of a right of way at crossings, and infrastructure treatment.

\section{Education and campaigns}

- The new "Road Guardians - Social Change on the Roads" programme is aimed to promote driving according to the law and deterring life threatening behaviour. In this programme, civilians who volunteered for this project document severe traffic violations using a phone app (in other words, civil enforcement). The programme is run by the Israel RSA with the collaboration of the police. The app was released in August 2016, and the RSA has started collecting data.

\section{Speed management}

- Automatic enforcement of speeding and red light running began in February 2012. The speed enforcement cameras incorporate automatic number plate recognition and can be used for the detection of local and average speeds. The project was accompanied by a three-year evaluation. Speed was reduced around the speed cameras $(1 \mathrm{~km}$ before and after) but there has not been a more global effect. This may be due to the low number of cameras in place (about 60) (Bar Gera et al., 2014).

\section{Vehicles}

- In order to be seen from all directions, large vehicles (longer than 20 metres or wider than three metres) must add flashing yellow lights on top of their vehicle and/or must be accompanied by an accompanying safety vehicle.

\section{Recent and ongoing research}

The Road Safety Authority has conducted the following research:

- Field study on the influence of pedestrian gestures on driver yielding at uncontrolled crosswalks. The results showed that crossing with gestures in comparison to crossing without gestures (baseline condition), significantly improved yielding rates. But not for 
older pedestrians, where a ceiling effect was observed (i.e. base line rates were high in the first place).

- Measuring Behavior of Pedestrians at Crossings (by Age Groups).

\section{References}

Bar Gera, H. et al. (2014), The effectiveness of automatic electronic enforcement systems, Road Safety Authority.

Cohen, J. (2004), Road accidents in Israel - their scope, characteristics and the estimate of associated loss for the national economy, MATAT Company, commissioned by the Ministry of Transport.

Ministry of Transport and Ministry of Finance (2012), Guidelines for assessing feasibility of transport projects.

World Bank (2017), “GDP (constant US\$)”, World Development Indicators, http://databank.worldbank.org/ data/reports.aspx? source=world-development-indicators (accessed 23 February 2017).

\section{Websites}

- National Road Safety Authority - Israel: www.rsa.gov.il/ (accessed 21 June 2017).

- Transportation Research Institute - Technion: http://techunix.technion.ac.il (accessed 21 June 2017).

- Central Bureau of Statistics - Israel: www.cbs.gov.il/ (accessed 21 June 2017).

- Or Yarok Association for Safer Driving in Israel: www.oryarok.org.il/ (accessed 21 June 2017). 



\section{Chapter 19}

\section{Italy}

This chapter presents 2015 road safety data for Italy along with provisional data from the first half of 2016. It looks at trends in traffic and road safety from the years 1990 to 2015 and road user behaviour patterns with a special focus on the ageing population. Sections include data on speed, drink driving, drugs and driving, distracted driving, fatigue and seat belt usage. The chapter reviews Italy's road safety strategy and national targets to 2020 and the progress achieved thus far. It also provides details of all recently implemented safety measures and current and ongoing research.*

* All data stem from the Italian Ministry of Infrastructure and Transport provided by the University la Sapienza, Automobile Club of Italy and IRTAD unless otherwise noted. For more information please contact: davideshingo.usami@uniroma1.it or l.pennisi@aci.it. 
In 2015, for the first time in over a decade, Italy recorded an increase in road deaths, of $1.4 \%$. The number of those seriously injured also increased by $6.4 \%$. The 3428 fatalities correspond to a fatality rate of 5.6 per 100000 inhabitants, above average for the EU28 countries. The increase seen in 2015 almost exclusively applied to motorcyclists, with 69 more fatalities than in 2014. The number of pedestrians killed also increased by $4.2 \%$.

\section{Road safety data collection}

\section{Definitions applied in Italy}

- Road fatality: Any person killed immediately or dying within 30 days as a result of a road crash.

- In crash statistics, injured persons are not differentiated by degree of severity.

Italy is following the recommendations of the International Road Traffic and Accident Database (IRTAD) and the European Union (EU) regarding the use the Maximum Abbreviated Injury Scale of 3 or more (MAIS3+) to define a serious injury. A first estimate of the number of serious injuries, based on hospital discharge data, has been calculated for the years 2013 and 2014 using a conversion table to translate data from the International Classification of Diseases (ICD-9CM). In 2015, there were 15901 seriously injured, a ratio of 4.7 to every death.

\section{Data collection}

In Italy, road crash data are collected by the National Road Police, the National Military Police (Carabinieri) and the local police. Data collection is centrally organised for the National Road Police and National Military Police, but the local police may have different crash investigation procedures.

The Italian National Institute of Statistics (ISTAT) is responsible for collecting and validating road safety statistics on all injury crashes occurring in Italy. All police forces are obliged to send ISTAT a standard crash form for each injury crash collected. ISTAT checks data consistency, both quantitatively and qualitatively, reviews any deficiencies and proceeds with data correction.

In 2013, representatives from ISTAT, the Automobile Club of Italy, the Ministry of Infrastructure and Transport, the National Road Police, the National Military Police, local police, regions, provinces and municipalities defined a new crash data collection form. The form is more comprehensive and compatible with requirements of the European accident Community database on Accidents on the Road in Europe and the Common Accident Database set (CARE/CADAS).

This process should bring a number of improvements, including a unique data collection process and a full set of information gathered for each road crash. However, the introduction of the new format requires significant changes to databases and existing programmes and for this reason the adoption of the whole new form is not realistic at the 
moment. Some small changes have been progressively introduced since 2011 to improve localisation of crashes, accident time and nationality of drivers.

Matching police and hospital data to assess underreporting of injury accidents is not carried out at a national level but occasionally at a local level.

Statistics about property damage crashes are released by the National Association of Insurance Companies (ANIA; www.ania.it) and by the National Insurance Supervisory (IVASS; www.ivass.it).

\section{Most recent safety data}

\section{Road crashes in 2016 - provisional data}

According to preliminary data for the first half of 2016, the number of injury crashes decreased by $0.8 \%$, the number of road deaths by $4.7 \%$ and the number of injured persons by $0.5 \%$, when compared to final data for the same period in 2015 .

Despite this improvement, the number of road deaths is disproportionally high and not in line to achieve the European target to half the number of road fatalities by 2020 .

In 2016, an increase in mobility was recorded. Preliminary data indicate that during the period January-June 2016, the registration of new vehicles increased by $19 \%$ and vehicle-kilometres on motorways by 3.7\% when compared to the same period in 2015.

\section{Road crashes in 2015}

In 2015, there were 174539 reported crashes, resulting in 3428 persons killed and 246920 injured persons. This corresponds to an increase of $1.4 \%$ in fatalities, despite a decrease $(-1.4 \%)$ in the number of injury crashes. The number of injured persons decreased by $1.7 \%$.

The year 2015 was the first year, since 2001, where an increase in the number of road fatalities was recorded. The number of serious injuries also increased in 2015; on the basis of hospital discharge data they were nearly 16000 compared to 15000 in 2014 (+ 6.4\%).

The increase of road fatalities was mainly due to a deterioration of road safety on motorways $(+6.3 \%$ in fatalities) and rural roads $(+2 \%$ in fatalities). While overall the number of fatalities slightly decreased on urban roads $(-0.2 \%)$, it increased markedly $(+8.6 \%)$ in the 12 main Italian cities.

The recent trend of road fatalities may be partly explained by the increased exposure in terms of distance travelled.

\section{Trends in traffic and road safety (1990-2016) Traffic}

In Italy, the majority of passenger and freight transport is by road. The car remains the preferred mean of motorised transport, representing, in 2016, 82.8\% of travel compared with 13.4\% for buses and 3.7\% for powered two-wheelers (ISFORT, 2017). However the number of trips by public transport and walking is increasing and the walking share increased from $14.3 \%$ to $17.1 \%$. The cycling share decreased from $3.6 \%$ in 2015 to $3.3 \%$ in 2016 (ISFORT, 2017).

The registration of new passenger cars increased by $15 \%$ and the national vehicle fleet started to grow again (by $+0.6 \%$ ) in 2015 , after a 4 year decreasing trend. Risk exposure on motorways grew on average by $3.6 \%$ (by $3.8 \%$ for heavy vehicles). Sales of fuel by volume also showed an increase in 2015 by 1.4\% compared to 2014, including in particular a $2 \%$ increase 
for diesel fuel and a $5 \%$ increase for LPG gas, while the sales of gasoline continued to decline by $1 \%$ in a year. Fuel pump prices decreased by $10-13 \%$ compared to the corresponding period.

Gross domestic product (GDP) at market prices showed an increase in 2015 (1.5\%). The unemployment rate decreased from $12.7 \%$ in 2014 to $11.9 \%$ in 2015.

\section{Road safety}

\section{Crashes and casualties}

The number of road fatalities peaked in 1972 with 11078 road deaths. Between 1990 and 2015 , the number of fatalities decreased by $52 \%$. Most of these improvements though fell on the years after 2000. The National Plan for Road Safety in 1999 was the first normative and legislative act with which the issue of road safety and possible solutions started to be systematically analysed in Italy.

Since 2001, several road safety measures have been implemented under the National Road Safety Plan: improvement of road traffic legislation, introduction of automatic speed control including section control, increased enforcement, improvement in road infrastructure, communication and awareness campaigns and road safety education interventions.

\section{Rates}

In the last 15 years, the mortality rate in terms of deaths per 100000 inhabitants has declined by almost 55\% and by 59\% when expressed in deaths per 10000 vehicles. Nevertheless in 2015, Italy's mortality rate of 5.6 deaths per 100000 inhabitants, was still above the average for the EU28 countries.

\section{Analysis of seriously injured data}

In 2015, there were 15901 persons seriously injured in road traffic, a ratio of 4.7 serious injured for each death. This represents an increase of $6.4 \%$ when compared to 2014 . However, the increase in number of those serious injured is probably due to better quality hospital data in reporting the road accident as the primary cause of injuries.

Table 19.1. Road safety and traffic data

\begin{tabular}{|c|c|c|c|c|c|c|c|c|c|}
\hline & \multirow{2}{*}{1990} & \multirow{2}{*}{2000} & \multirow{2}{*}{2010} & \multirow{2}{*}{2014} & \multirow{2}{*}{2015} & \multicolumn{4}{|c|}{$2015 \%$ change from } \\
\hline & & & & & & 2014 & 2010 & 2000 & 1990 \\
\hline \multicolumn{10}{|l|}{ Reported safety data } \\
\hline Fatalities & 7151 & 7061 & 4114 & 3381 & 3428 & 1.4 & -16.7 & -51.5 & -52.1 \\
\hline Injury crashes & 161782 & 256546 & 212997 & 177031 & 174539 & -1.4 & -18.1 & -32.0 & 7.9 \\
\hline Serious injuries (MAIS3+) & & & & 14943 & 15901 & 6.4 & & & \\
\hline Deaths per 100000 inhabitants & 12.6 & 12.4 & 7.0 & 5.6 & 5.6 & 1.4 & -18.9 & -54.5 & -55.3 \\
\hline Deaths per 10000 registered vehicles & 2.1 & 1.6 & 0.8 & 0.7 & 0.7 & 0.8 & -17.8 & -58.6 & -67.9 \\
\hline \multicolumn{10}{|l|}{ Traffic data } \\
\hline Registered vehicles ${ }^{1}$ (thousands) & 34729 & 44296 & 51218 & 51585 & 51910 & 0.6 & 1.4 & 17.2 & 49.5 \\
\hline Registered vehicles per 1000 inhabitants & 613 & 778 & 865 & 849 & 854 & 0.6 & -1.3 & 9.7 & 39.4 \\
\hline
\end{tabular}

1. With mopeds. 
Figure 19.1. Road safety, traffic and GDP trends index $1990=100$

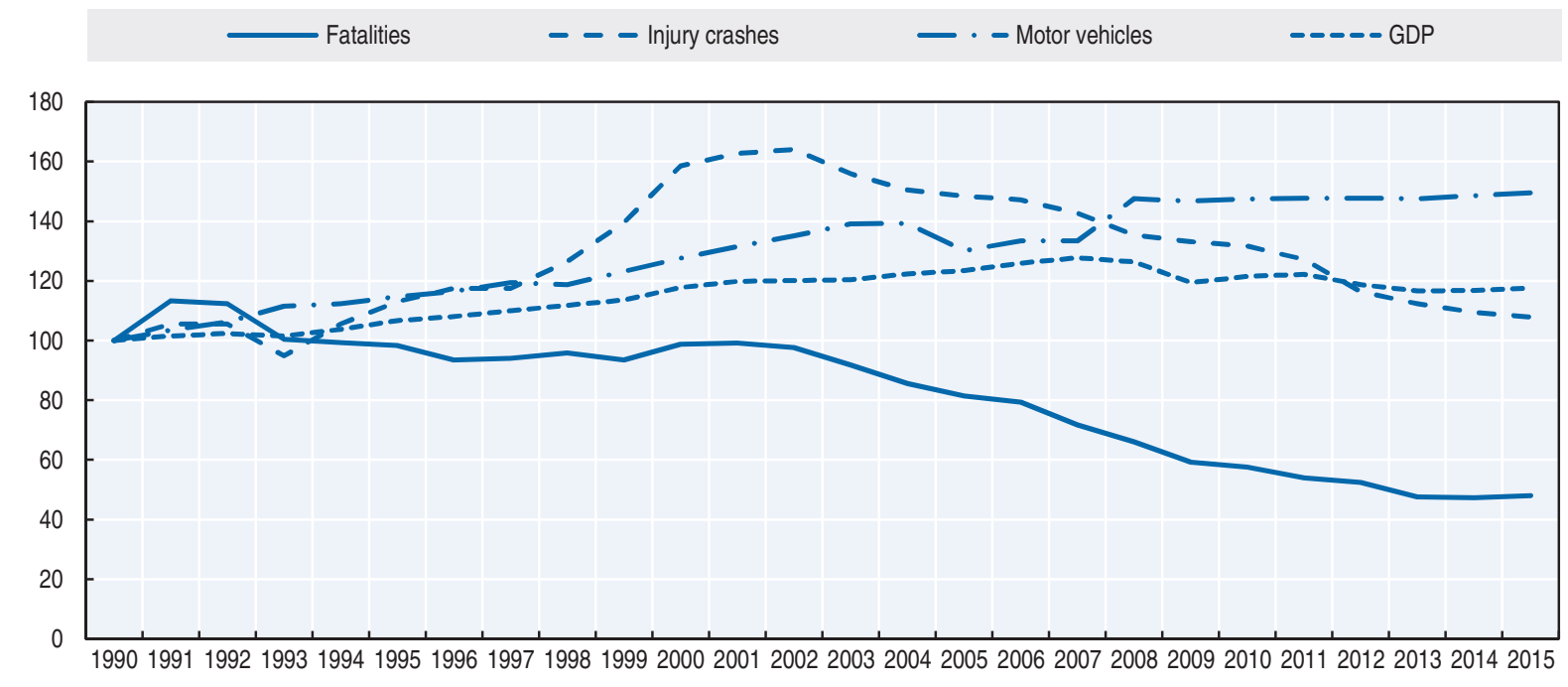

Source: World Bank (2017) (GDP; constant prices).

\section{Road safety by user group}

Since 2000, reductions have been recorded for all road user categories. The most important decrease concerned moped riders (-83.5\%). This has to be seen in the context of the introduction of the compulsory use of helmets for moped riders of all ages (from 2000) and a decreasing popularity of this means of transport.

In 2015 , road safety improved significantly for moped users $(-6.3 \%)$ and cyclists $(-8.1 \%)$. Car occupants also benefited from a reduction in fatalities (-1.5\%).

The number of pedestrians and motorcyclists killed in traffic increased respectively by $4.2 \%$ and $9.8 \%$ in 2015 compared to 2014 . The mortality index (number of fatalities per accident) for pedestrians is four times higher than that of the occupants of passenger cars (reference category), and for motorcyclists and cyclists it is more than double.

Vulnerable road users represent more than $50 \%$ of deaths.

Table 19.2. Road fatalities by road user group

\begin{tabular}{lrrrrr|rrrr}
\hline & 1990 & 2000 & 2010 & 2014 & 2015 & \multicolumn{4}{|c}{$2015 \%$ change from } \\
\cline { 7 - 10 } & & & & & & 2014 & 2010 & 2000 & 1990 \\
\hline Pedestrians & 1069 & 982 & 621 & 578 & 602 & 4.2 & -3.1 & -38.7 & -43.7 \\
Cyclists & 477 & 401 & 265 & 273 & 251 & -8.1 & -5.3 & -37.4 & -47.4 \\
Moped riders & 620 & 637 & 206 & 112 & 105 & -6.3 & -49.0 & -83.5 & -83.1 \\
Motorcyclists & 713 & 770 & 950 & 704 & 773 & 9.8 & -18.6 & 0.4 & 8.4 \\
Car occupants & 3797 & 3850 & 1822 & 1491 & 1468 & -1.5 & -19.4 & -61.9 & -61.3 \\
Others & 474 & 421 & 250 & 223 & 229 & 2.7 & -8.4 & -45.6 & -51.7 \\
Total & $\mathbf{7 1 5 1}$ & $\mathbf{7 0 6 1}$ & $\mathbf{4 1 1 4}$ & $\mathbf{3 3 8 1}$ & $\mathbf{3 4 2 8}$ & $\mathbf{1 . 4}$ & $\mathbf{- 1 6 . 7}$ & $\mathbf{- 5 1 . 5}$ & $\mathbf{- 5 2 . 1}$ \\
\hline
\end{tabular}


Figure 19.2. Road fatalities by road user group in percentage of total, 2015

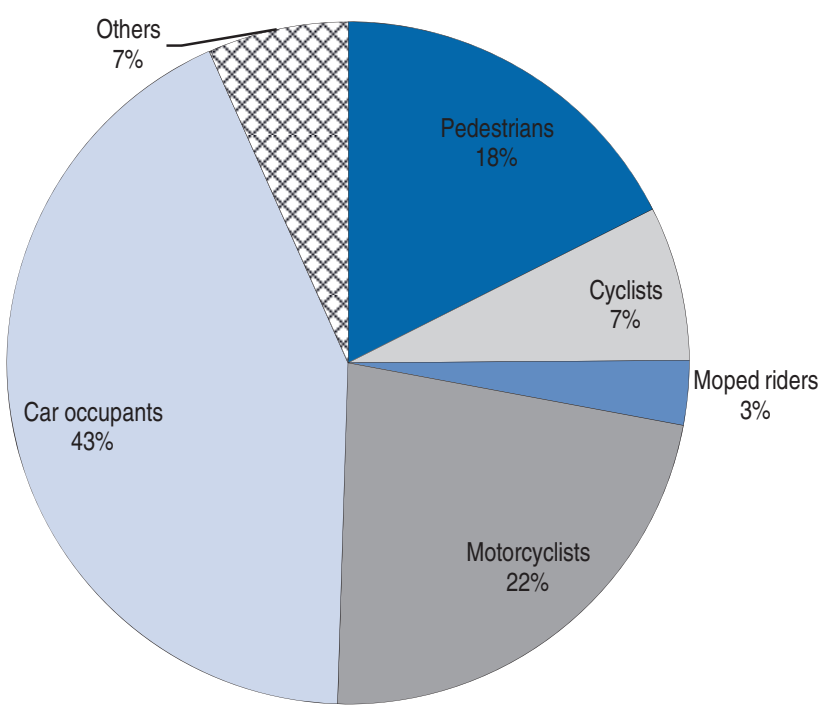

\section{Road safety by age group}

Since 1990, the reduction in fatalities benefited all age groups, in particular for those under 24 years of age. The reduction was less marked for the over 65s, in part due to the ageing of the population.

In 2015 , fatalities increased by $7.4 \%$ for the $18-20$ year age group, which along with the 21-24 year old group are the most at risk in road traffic and have a mortality rate almost twice that of the general population. Fatalities among those over 65 years of age also increased $(+3 \%)$ - primarily as pedestrians.

Table 19.3. Road fatalities by age group

\begin{tabular}{|c|c|c|c|c|c|c|c|c|c|}
\hline \multirow{2}{*}{ Age } & \multirow{2}{*}{1990} & \multirow{2}{*}{2000} & \multirow{2}{*}{2010} & \multirow{2}{*}{2014} & \multirow{2}{*}{2015} & \multicolumn{4}{|c|}{$2015 \%$ change from } \\
\hline & & & & & & 2014 & 2010 & 2000 & 1990 \\
\hline $0-14$ & 247 & 136 & 70 & 62 & 39 & -37.1 & -44.3 & -71.3 & -84.2 \\
\hline $15-17$ & 429 & 211 & 121 & 70 & 57 & -18.6 & -52.9 & -73.0 & -86.7 \\
\hline $18-20$ & 640 & 485 & 253 & 136 & 146 & 7.4 & -42.3 & -69.9 & -77.2 \\
\hline $21-24$ & 786 & 740 & 294 & 233 & 233 & 0.0 & -20.7 & -68.5 & -70.4 \\
\hline $25-64$ & 3245 & 3637 & 2218 & 1774 & 1814 & 2.3 & -18.2 & -50.1 & -44.1 \\
\hline $65-74$ & & 683 & 429 & 405 & 409 & 1.0 & -4.7 & -40.1 & \\
\hline $75-84$ & & 561 & 493 & 448 & 485 & 8.3 & -1.6 & -13.5 & \\
\hline$\geq 85$ & & 193 & 142 & 203 & 194 & -4.4 & 36.6 & 0.5 & \\
\hline Total & 7151 & 7061 & 4114 & 3381 & 3428 & 1.4 & -16.7 & -51.5 & -52.1 \\
\hline
\end{tabular}


Figure 19.3. Road fatality rates by age group Deaths per 100000 inhabitants in a given age group, 1990-2015

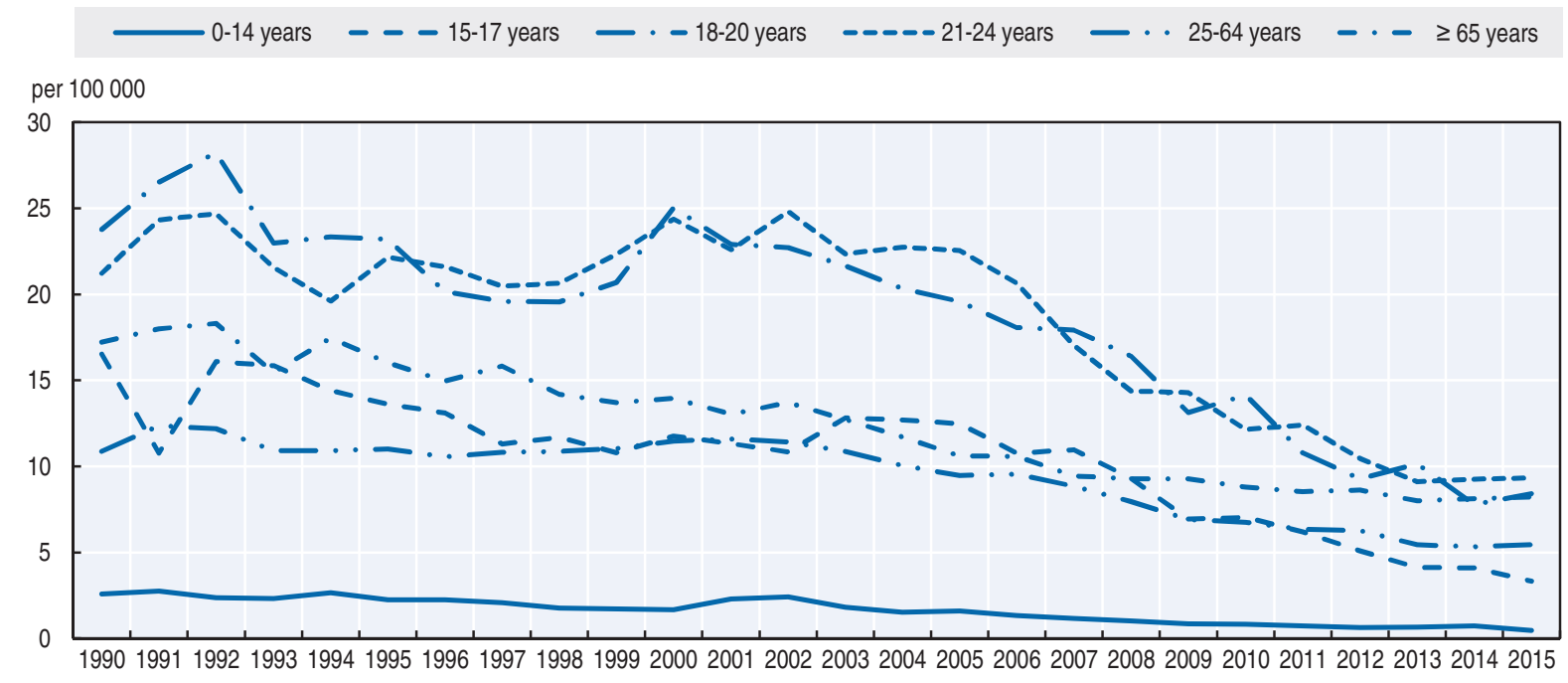

\section{Box 19.1. Road safety for an ageing population}

As in other developed countries, Italy has a highly imbalanced age structure. In 2015, those aged 65 or over represented $21.7 \%$ of the population, while the share of the $0-14$ year olds was $13.8 \%$. The number and share of senior citizens is expected to grow further. The population aging index, i.e. the ratio between those over 65 years of age and those under 14 is expected to rise from 157.7 to 257.9 between 2015 and 2065. The average age of the population will suffer a further increase, from 44.4 years in 2015 to 49.7 by 2065 .

Persons aged 65 or above accounted, in 2015, for $31.9 \%$ of road deaths. They have a much higher mortality rate of 81.4 deaths per million inhabitants, compared with an average rate of 56.4 deaths per million inhabitants for the total population. The mortality rate also increases with age: 62.5 deaths per million inhabitants for persons aged 65-74, and 99.4 deaths per million inhabitants for the over $75 \mathrm{~s}$.

Of the over 65 s killed or injured in a road crash $60.7 \%$ are men and $39.3 \%$ women.

To respond to this trend, the Ministry of Infrastructure and Transport established a special working group and the creation of an interdisciplinary project on road safety education. The project involved various national and local institutions with the aim of creating a network of trainers able to reach the population in the various territorial, social and cultural contexts; a platform to make information and tools available to promote a safe and sustainable mobility for senior citizens.

In Italy, the driving licence must be renewed every five years over the age of 50 , every three years over the age of 70 and every two years over the age of 80 , following a medical examination. The doctor performing the visit may request the assessment of psychological and physical requirements by the Local Medical Commission, which is a possibility provided for in the Highway Code for drivers of any age, whenever there is suspicion about fitness for safe driving. Certification for the driver's licence is issued by a competent doctor of public health or other authorised service. The certification must take into account previous illnesses declared by a medical certificate issued by the driver's personal doctor. 
Box 19.1. Road safety for an ageing population (cont.)

Table 19.4. Road fatalities among senior citizens

\begin{tabular}{lrrr|rrr|rrr}
\hline & \multicolumn{3}{c}{$65-74$} & \multicolumn{3}{c|}{$75-84$} & \multicolumn{3}{c}{$85+$} \\
\cline { 2 - 10 } & 2010 & 2015 & \% change & 2010 & 2015 & \% change & 2010 & 2015 & \% change \\
\hline Pedestrians & 113 & 108 & -4 & 183 & 176 & -4 & 79 & 94 & 19 \\
Cyclists & 59 & 40 & -32 & 66 & 69 & 5 & 19 & 19 & 0 \\
Moped riders & 15 & 11 & -27 & 25 & 14 & -44 & 2 & 4 & + \\
Motorcyclists & 14 & 35 & 150 & 8 & 14 & 75 & 0 & 0 & $=$ \\
Car occupants & 206 & 192 & -7 & 185 & 191 & 3 & 40 & 71 & 78 \\
Total & $\mathbf{4 2 9}$ & $\mathbf{4 0 9}$ & $\mathbf{- 5}$ & $\mathbf{4 9 3}$ & $\mathbf{4 8 5}$ & $\mathbf{- 2}$ & $\mathbf{1 4 2}$ & $\mathbf{1 9 4}$ & $\mathbf{3 7}$ \\
\hline
\end{tabular}

Figure 19.4. Road fatality rates in the $65+$ age groups Deaths per 100000 inhabitants in a given age group, 2000-15

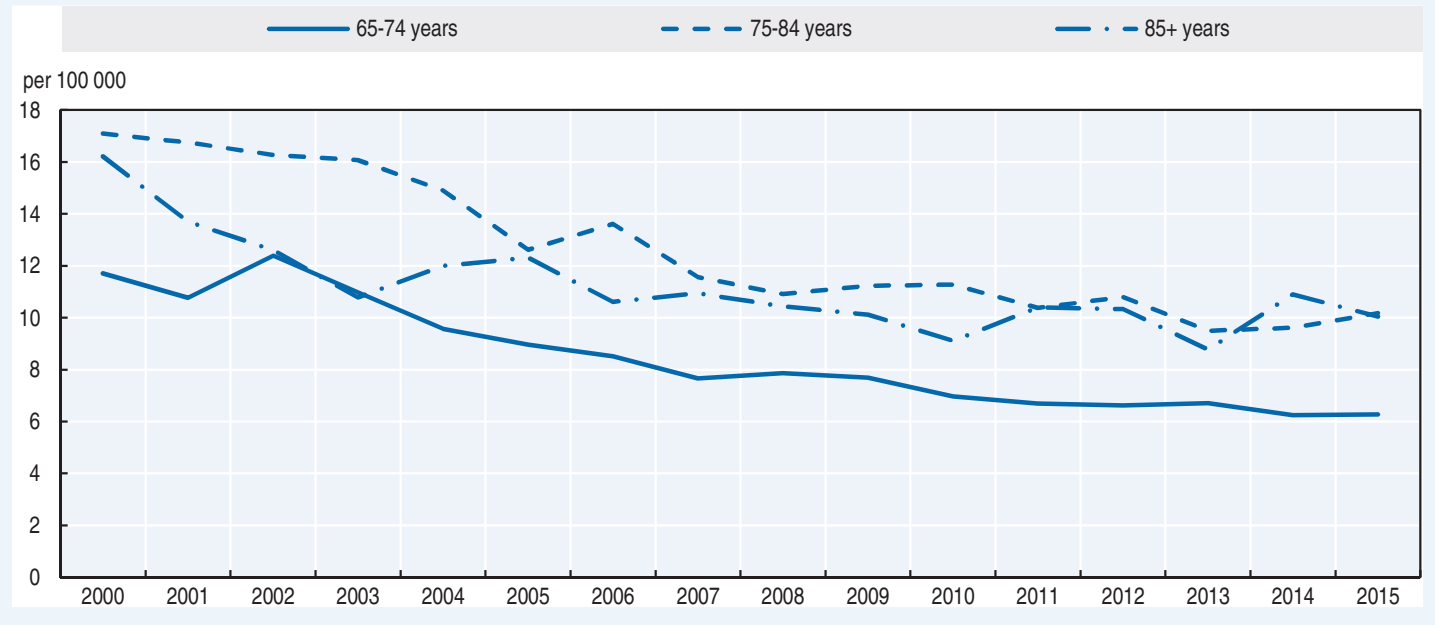

Figure 19.5. Road fatality rate by age and road user group Fatalities per 100000 inhabitants, 2015

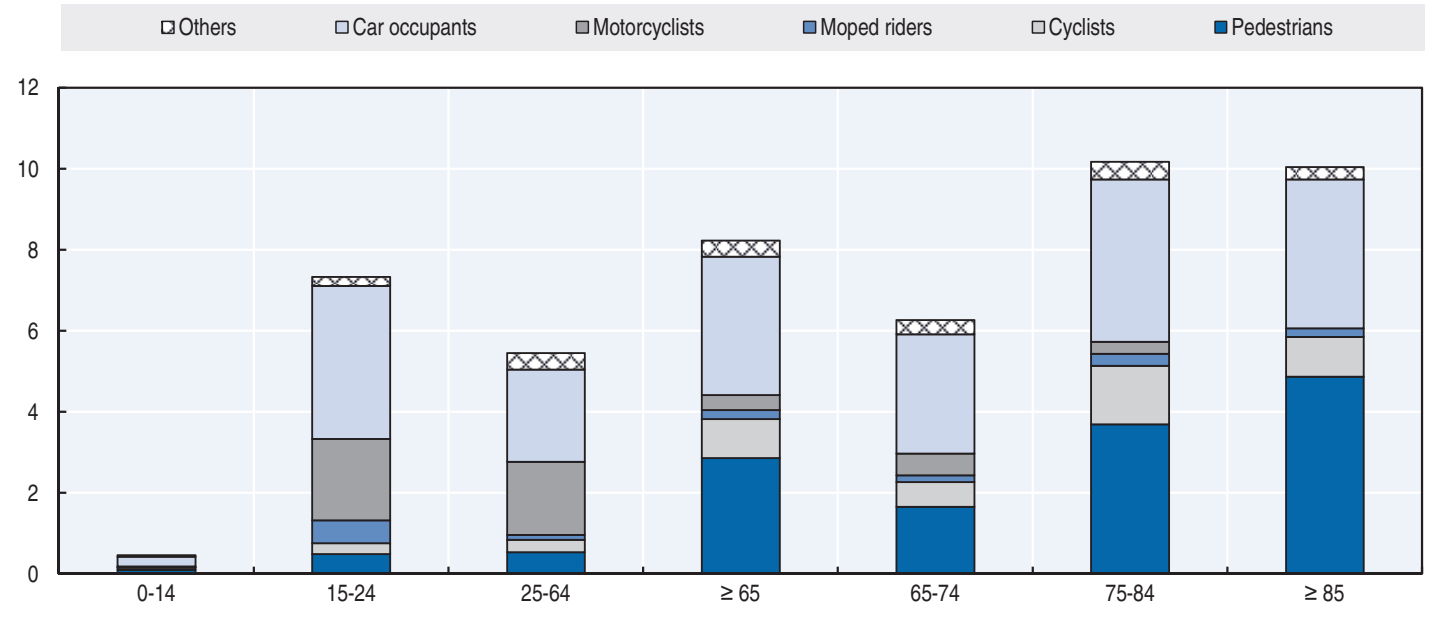




\section{Road safety by road type}

In $2015,47 \%$ of fatalities occurred on rural roads, $44 \%$ inside urban areas and $9 \%$ on motorways.

During this period, the most severe crashes occurred on rural roads, with nearly five deaths for 100 road crashes. Crashes inside urban areas are less severe (1.1 deaths per 100 crashes). For motorways, the index is 3.3 deaths per 100 crashes.

In 2015 , the biggest deterioration in fatalities was observed on motorways $(+6.3 \%)$, followed by a more moderate increase $(+2 \%)$ on rural roads. Inside urban areas, however, the number of fatalities decreased by $2 \%$ compared to 2014 .

Compared to 2010, the benchmark value for the decade 2011-20, the fatalities reduction was higher on motorways (-18.9\%), followed by rural roads $(-17.1 \%)$ and urban roads $(-15.7 \%)$. The decrease in the total number of deaths in large municipalities, compared to 2010, is approximately $16.3 \%$. The number of deaths in the 14 largest municipalities increased by $24 \%$ in 2015 compared to 2014.

In 2015, the main cause of crashes on urban roads was the failure to respect the rules of precedence or traffic signals $(27.7 \%)$, while on rural roads and motorways it was distracted driving (22.3\%) and excessive speed (17.1\%).

Figure 19.6. Road fatalities by road type

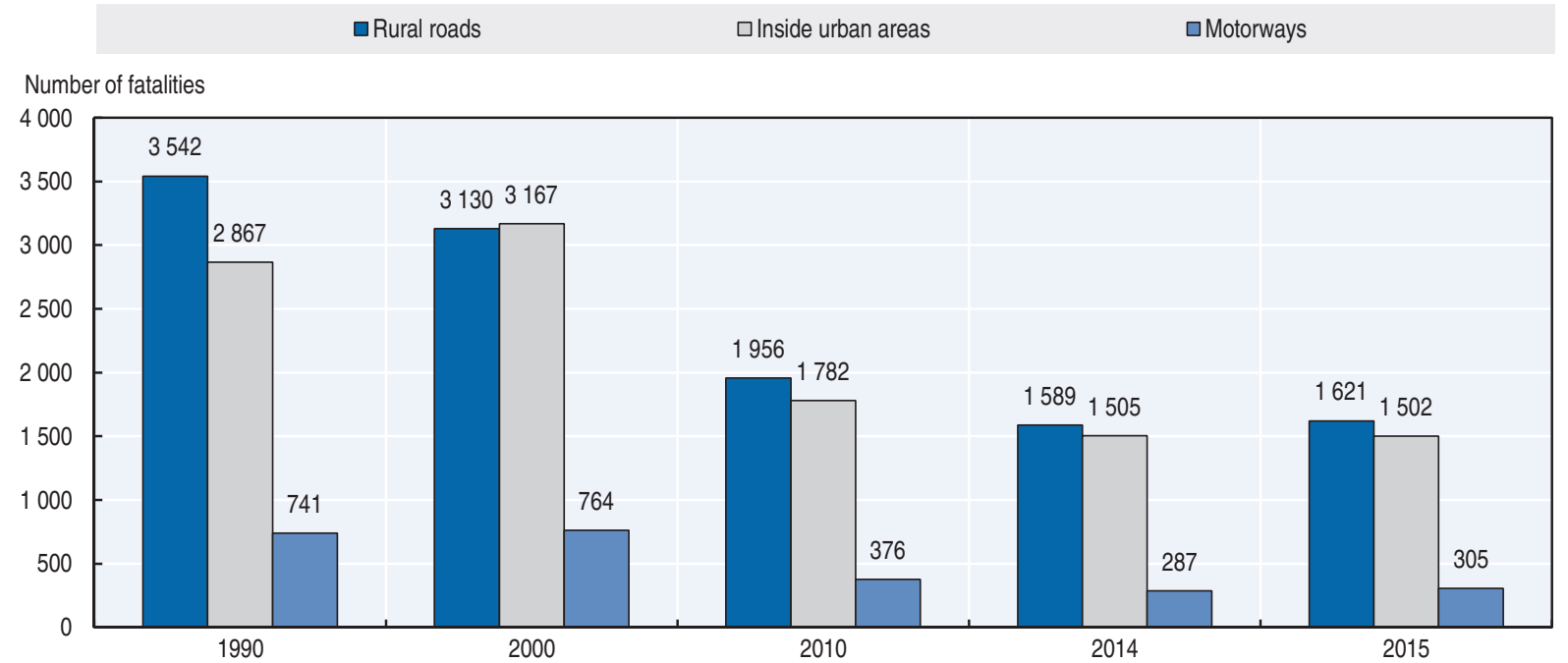

\section{Economic costs of traffic crashes}

Road crashes represent a huge cost in terms of human lives and for the national economy. According to estimates of the Ministry of Infrastructure and Transport, in 2015 the total cost for traffic crashes resulting in death or injury was estimated at around EUR 17.5 billion.

This value is based on the single social cost assessed by the Ministry in 2010 using the human capital approach. 
Table 19.5. Costs of injury road crashes, 2015

\begin{tabular}{lrc}
\hline Cost (EUR) & Unit cost & Total \\
\hline Average cost per fatality & 1504000 & 5.156 billion \\
Average cost per Injured person & 42000 & 10.420 billion \\
Average general cost per crash & 11000 & 1.917 billion \\
\hline
\end{tabular}

Note: This does not include damage-only crashes.

\section{Recent trends in road user behaviour}

Speed

In 2015 , on the basis of police data, inappropriate speeds were reported in $11.3 \%$ of injury crashes, and about $20.5 \%$ of fatalities were related to speed.

The table below summarises the main speed limits in Italy.

Table 19.6. Passenger car speed limits by road type, 2017

\begin{tabular}{lll}
\hline & General speed limit & Comments \\
\hline $\begin{array}{ll}\text { Urban roads } \\
\text { Rural roads }\end{array}$ & $50 \mathrm{~km} / \mathrm{h}$ & \\
Motorways & $90 \mathrm{~km} / \mathrm{h}$ & \\
& $130 \mathrm{~km} / \mathrm{h}$ & $\begin{array}{l}110 \mathrm{~km} / \mathrm{h} \text { in case of rain or snow } \\
100 \mathrm{~km} / \mathrm{h} \text { for novice drivers } \\
\text { In theory, the motorway operator may decide to increase the limit up to } 150 \mathrm{~km} / \mathrm{h}, \\
\end{array}$ \\
& if stringent requirements are met. \\
\hline
\end{tabular}

\section{Drink driving}

The current blood alcohol content (BAC) limit in Italy, which came into force in 2002, is $0.5 \mathrm{~g} / \mathrm{l}$. Since July 2010, there is zero tolerance for young, novice and professional drivers, for whom the BAC limit is $0.0 \mathrm{~g} / \mathrm{l}$.

Drink-driving crashes are defined in police reports as crashes in which a driver has a BAC above the legal limit.

According to data from national and local police, the number of fines given for drink driving is decreasing. In 2015, the national traffic and military police issued around 38000 fines for drunk driving and the local police about 5000.

The Carabinieri Military Police and the National Road Police, who collect about one-third of all road injury crashes, published, on a trial basis for 2015, data on driving under the influence of alcohol (ISTAT, 2017). According to these data among a total of 58981 investigated crashes, 5876 crashes (10\%) involved at least one driver who was under the influence and can be classified as "alcohol-related".

This share approximates the real extent of the drink driving issue. It must be noted that the National Police investigate mostly crashes on state highways and motorways, while the Carabinieri and National Police together collect more than $65 \%$ of accidents on rural roads and only some $20 \%$ in urban areas. As recorded by Carabinieri, it is on city streets that alcohol-related crashes occur more frequently (more than half, in 2015, compared to the total for driving under the influence of alcohol). 


\section{Drugs and driving}

Drivers under the influence of drugs can be imprisoned for a period varying from six months to one year, fined EUR 1500 to 6000 and can have their driving licence withdrawn for between one and two years, or two to four years if the vehicle does not belong to the driver.

Due to difficulties in collecting the relevant data at the scene of the crash, drug use data are probably underestimated and are not disseminated.

A pilot project to enhance the effectiveness of roadside control procedures of drivers under the influence of drugs was undertaken by the traffic police during the summer of 2015. A preliminary sample of the driver's saliva was examined through the use of drug tests capable of detecting 5 types of drugs. In the case of a positive first check, a second sample was sent to the forensic toxicology laboratory of the state police. According to the pilot results out of the 14767 drivers checked for alcohol, 930 were also tested for drugs and some 29\% were found positive for at least one type of drug during the first check. (Governo Italiano, 2016).

\section{Seat belts and helmets}

Seat belt usage has been compulsory in front seats since 1988 and rear seats since 1994. It has also been compulsory on micro cars since 2011. Children under 12 and less than $150 \mathrm{~cm}$ should be seated in a dedicated and approved child restraint system adapted to their weight and stature.

Beginning in 1986, helmet use was compulsory for motorcyclists and moped riders under 19 years old. Since 2000 helmets are required for all powered two-wheelers and for all ages.

The (self-reported) use of safety equipment has been estimated through a road user behaviour survey (PASSI) conducted from 2010-2015 by the National Institute of Health. According to this survey the use of helmets is at about $96 \%$, the use of seat-belts in front and rear seats are respectively $85 \%$ and $20 \%$.

An observational survey "Ulisse" carried out by the National Institute of Health and the Ministry of Infrastructure and Transport focused on the use of helmets, seat belts in front and rear seats, restraint systems for children and hand-held phones. Data were collected in two stages (2015 and 2016) from a sample of 28 selected urban and suburban areas throughout the country.

Results (data not published) highlight important differences with the survey based on stated behaviours. The observed use of helmets is about $98 \%$, the use of seat-belts in front

Table 19.7. Seat belt wearing rate by car occupancy and road type

\begin{tabular}{lcc}
\multicolumn{1}{c}{$\%$} & \\
\hline & 2000 & 2010 \\
\hline Front seat & & $63-16^{*}$ \\
$\quad$ Driver/Passenger (front seats) & 64 & $64-67$ \\
Urban roads (driver) & & 55 \\
Rural roads (driver) & 11 \\
Rear seats & 43 \\
General & & \\
Children (use of child restraint) & & \\
\hline
\end{tabular}

* Column indicates the value for the two-year period 2015-16, as the survey was undertaken in two steps. 
and rear seats are respectively $63 \%$ and $11 \%$. In urban roads, the use of seatbelt in front seats in city centre areas and in suburban areas are $64 \%$ and $67 \%$ respectively. In rural roads the prevalence is lower, $55 \%$. The use of child restraint systems is observed in $43 \%$ of cases.

However, it should be highlighted that these results are just preliminary estimates, final consolidated results are expected to be published in 2017.

\section{Distraction}

In 2015 , it was estimated that distraction was a contributing factor in $24.4 \%$ of injury crashes. It is the second contributing factor in fatal accidents after speed.

Since 2002, the use of hand-held mobile phones or full headsets while driving is not permitted. The use of hands-free devices, including those with a single earpiece headset, is permitted. According to the "Ulisse" monitoring system, in 2015-16 it was estimated that in Italy about $5.1 \%$ of drivers use the phone without a headset while driving.

In 2015, around 150000 fines were issued by the police forces for the use of a phone while driving, and this number is increasing.

\section{Sleepiness and fatigue}

Even if there is no evidence on the basis of police data, it is assumed that fatigue and drowsiness are a contributing factor in about 22\% of injury road crashes (Garbarino, 2010).

\section{National road safety strategies and targets \\ Organisation of road safety}

Road safety policy making is centralised in Italy. The Ministry of Infrastructure and Transport, through its Directorate for Road Safety, is responsible for national road safety plans and road safety programme. National and local road authorities are responsible for the improvement of road infrastructure.

Police forces are responsible for the enforcement of traffic law. The Italian National Institute of Statistics is responsible for collecting road safety statistics on injury crashes at the national level.

A national structure has been created for consultation with stakeholders.

\section{Road safety strategy for 2011-20}

The National Road Safety Plan, Horizon 2020 is expected to be updated with a mid-term review document and then to be approved by an inter-ministerial board in 2017 . It is in accordance with the actions and targets $(-50 \%$ fatalities) recommended by the European Commission.

The main vision of the plan is "No child should die on the road". The plan will propose a hierarchical system of objectives with two levels, allowing the monitoring of both the general road safety trend and specific targets related to road users in high risk groups such as motorcyclists, cyclists and pedestrians.

\section{Road safety targets}

The draft version of the Road Safety Plan identifies priority areas and sets specific objectives for the categories of road users showing the highest risk levels: powered-twowheelers; cyclists, pedestrians and users involved in work-related road crashes. 
Intermediate targets have been proposed for 2017, when a mid-term review of the plan is expected. They are based on an average annual reduction of fatalities by $7 \%$, corresponding to a reduction by 38\% in 2017 in comparison with 2010.

A monitoring process is being implemented in order to control the implementation of the road safety measures co-funded by the Road Safety National Plan. To reach the EU target of a $50 \%$ fatality reduction, an average annual reduction of $6.9 \%$ is required.

Figure 19.7. Trends in road fatalities towards national target

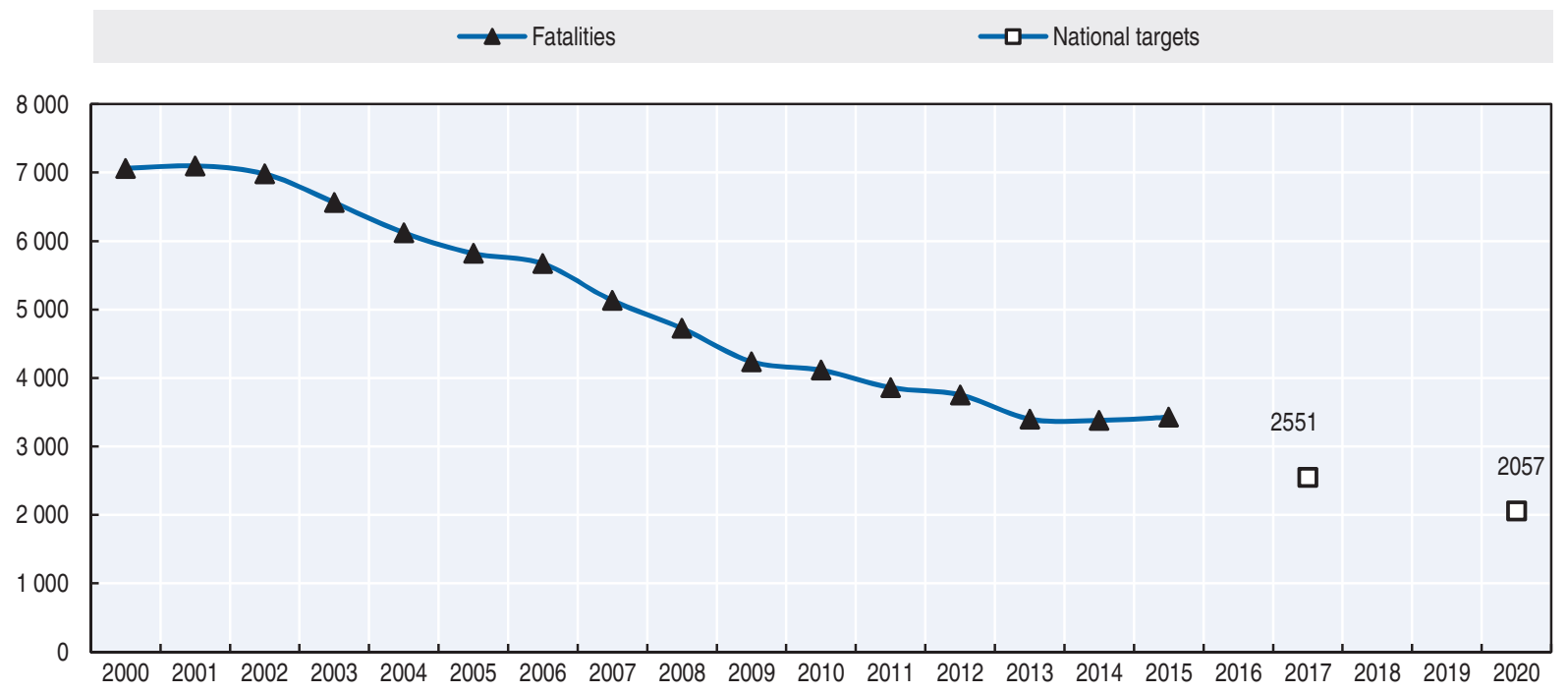

\section{Recent safety measures (2014-17)}

\section{Road safety management}

- At least twice a year the Ministry of Infrastructure and Transport convenes a technical committee, formed of representatives of regional governments responsible for road safety, to monitor the implementation of the Road Safety Plan and discuss other road safety related matters.

\section{Road users}

\section{Speed management}

- In 2006, a section system of speed control called "Tutor" was introduced to measure average speeds on sections of motorway with high crash rates. As of 2016, the system was operational on about $3035 \mathrm{~km}$ of motorways. According to a study (Montella et al., 2015) carried out on an urban motorway in Italy, the section control system results in an impressive reduction in speed variability and a reduction of excessive speeding behaviour.

- By the end of $2015,30 \mathrm{~km} / \mathrm{h}$ zones were implemented in 66 main cities with the aim of improving quality of life and quality of urban spaces, as well as reducing the risk of road accidents, especially for vulnerable road users

- "Vergilius", a system similar to "Tutor" for measuring instantaneous and average speeds on national roads, has been underway since 2012. The system is now operating on about $250 \mathrm{~km}$ of high risk portions of national roads and the A3 motorway. 


\section{Education and awareness}

- After previous campaigns in 2009, 2010 and 2013 a new national road safety campaign "On the right road" was launched in March 2016. The campaign is based on 5 messages: use of seat belts, distraction while driving, improved visibility for cyclists, speed and vulnerable road users, and children restraint systems. "Going back is impossible: stay on track" is the slogan used by the campaign. The goal is to convey a simple and effective message that road safety is the responsibility of each of us. The campaign has been broadcast on TV, radio, print, billboards, the web, etc.

\section{Infrastructure}

- A law proposed in 2015, but not yet approved, would make insurance less costly for cars equipped with an alcolock or a black box to record vehicle data in case of a crash accident. A similar proposal was made in 2012 but it failed to be adopted. Nevertheless the insurance companies' policy has been to offer large discounts to motorists who have installed the black box. According to the National Association of Insurance Companies (ANIA) it is estimated some 3 million vehicles were equipped with black boxes by the end of 2014 (www.ania.it/export/sites/default/it/pubblicazioni/Dossier-e-position-paper/Dossier-Scatole-nereItalia-leader-nel-mondo-Aggiornamento-novembre-2014-21.11.2014.pdf, (accessed 22 June 2017).

\section{Post-crash measures}

- The implementation of E-call, an automatic call to the emergency services in the case of an accident, is a shared responsibility among the Ministry of Infrastructure and Transport, the Ministry of Interior and the Ministry of Economic Development, each one with his own responsibility. The pilot project carried out in the province of Varese will be extended to all the Lombardia region and a test with cars equipped for the automatic call will be conducted on the A22 motorway.

\section{Recent and ongoing research}

- A new study on road crashes was carried out in 2015 by the Statistical Department of Transport with the cooperation of other relevant Institutions (www.mit.gov.it/ documentazione/statistiche-sulla-incidentalita-nei-trasporti-stradali-anche-con-riferimento-alla).

- Self-declared use of safety devices in cars and motorcycles from adults: www.epicentro. iss.it/passi/dati/SicurezzaStradale.asp.

- National website on road safety education (launched on Sept 2016) www.edustrada.it/

- Quality of urban environment - Transport and Mobility www.isprambiente.gou.it/it/ pubblicazioni/stato-dellambiente/xii-rapporto-qualita-dell2019ambiente-urbano-edizione-2016.

- Montella, A. et al. (2015), "Effects on speed and safety of Point-to-Point speed enforcement systems: evaluation on the urban motorway A56 Tangenziale di Napolie", Accident Analysis and Prevention 2015 Feb, Vol. 75, pp. 164-78.

- ISTAT - Road accident: innovative tools in measuring and enhancing new sources for analyzing the phenomenon www.istat.it/it/archivio/191914.

- ACI and Fondazione Caracciolo.

- "All roads lead to school" (Tutte le strade portano a scuola) www.fondazionecaracciolo.aci.it/ fileadmin/documenti/pdf/mobilita_sostenibile/Tutte_le_strade_portano_a_scuola_testo.pdf. 
- "Travelling through Rome is not for everyone" (Percorrere e attraversare Roma non è per tutti) www.fondazionecaracciolo.aci.it/fileadmin/documenti/pdf/Circolazione_stradale_e_polizie_ locali/Percorrere_e_attraversare_a_Roma_non_e_per_tutti.pdf.

\section{References}

ACI-Automobile Club of Italy (n.d.), Road Accidents Location, www.aci.it/laci/studi-e-ricerche/dati-estatistiche/incidentalita.html.

AISCAT (n.d.), Information: Annual Edition, www.aiscat.it/pubblicazioni.htm?ck=1\&nome=pubblicazioni \&idl $=4$.

Garbarino, S. (2010), Sonnolenza ed incidenti stradali: epidemiologia e strategie preventive (Sleepiness and Accidents: Epidemiology and preventative strategies), Italian Association of pulmonologists (AIPO).

Governo Italiano (2016), Executive Agreement by the Department for Antidrug Policy and the Department of Public Security of the Ministry of the Interior on contrasting accidents caused by the use of drugs and alcohol, www.politicheantidroga.it/comunicazione/comunicati/2016/siglato-l'accordo-esecutivo-per-ilcontrasto-dell'incidentalita-causata-dall'uso-di-sostanze-stupefacenti-e-dall'abuso-di-alcol.aspx.

ISFORT (2017), $14^{\circ}$ Rapporto sulla mobilità in Italia (14th Mobility Report for Italy), Istituto Superiore di Formazione e Ricerca per i Trasporti, www.isfort.it/sito/pubblicazioni/Convegni/AC_2017_19_04/ Rapporto_completo_2016.pdf.

ISTAT (2017a), Road accidents 2016 - preliminary estimates, www.istat.it/en/archive/194397.

ISTAT (2017b), Il Consumo di Alcol in Italia (Alcohol consumption in Italy), www.istat.it/it/files/2017/04/ Consumo_alcol_in_Italia_2016.pdf?title=Consumo+di+alcol++-+12\%2Fapr\%2F2017+-+Testo+integrale+e+ nota+metodologica.pdf.

ISTAT (2016a), Road accidents 2015 Final data, www.istat.it/en/archive/192246.

ISTAT (2016b), Road Accident Statistics 2015, www.istat.it/en/files/2016/07/EN_Road_accidents_2015_ provisional.pdf?title=Road+accidents+-provisional+-+19+Jul+2016+-+Full+text.pdf.

Ministero delle Infrastrutture e dei Trasporti (n.d.), Road Safety Plan - Orizzonte 2020, www.mit.gov.it/mit/ mop_all.php?p_id=17834.

Ministry of Infrastructure and Transport (2013), Studio di valutazione dei Costi Sociali dell'incidentalità stradale (Evaluation study on the social costs of road accidents), www.mit.gov.it/mit/mop_all.php? p_id=22923.

World Bank (2017), “GDP (constant US\$)”, World Development Indicators, http://databank.worldbank.org/ data/reports.aspx?source=world-development-indicators (accessed 23 February 2017).

\section{Websites (accessed 22 June 2017)}

- Ministry of Infrastructure and Transport: www.mit.gov.it.

- National Institute of Statistics: www.istat.it.

- Automobile Club of Italy: www.aci.it and www.lis.aci.it.

- Centre for Transport Logistics of the University La Sapienza: www.ctl.uniroma1.it.

- Austostrade per l'Italia (Main motorway concession company): www.autostrade.it.

- AISCAT (Association of motorway concession companies): www.aiscat.it.

- ANAS (National Road Authority) www.stradeanas.it.

- ISS (National Health Institute): www.iss.it.

- INAIL (National Institute for accident insurance at work): www.inail.it.

- ANIA (National Association of Insurance Companies): www.ania.it and www.fondazioneania.it.

- IVASS (National Authority on Insurance Companies): www.ivass.it.

- ISFORT (Transport Research Institute): www.isfort.it.

- Polizia di Stato (National Police) data: www.poliziadistato.it/pds/stradale/archivio/. 



\section{Chapter 20}

\section{Japan}

This chapter presents 2015 road safety data for Japan along with provisional data from 2016. It looks at trends in traffic and road safety from the years 1990 to 2016 and road user behaviour patterns, with a special focus on the ageing population. Sections include data on speed, drink driving and seat belt use. The chapter reviews Japan's road safety strategy and national targets to 2020 and the progress achieved thus far. It also looks at the most recently implemented safety measures. ${ }^{*}$

* All data stem from the National Police Agency and IRTAD unless otherwise noted. For more information please contact:m.ogura.3n.83@npa.go.jp. 
$\mathrm{J}$

apan's fatalities slightly increased in 2015 by $0.6 \%$, from 4838 to 4867 following their best ever year on record in 2014. The fatality rate remains stable at 3.8 deaths per 100000 inhabitants. Provisional data from 2016 indicate that a new low has once again been reached in fatalities with a total of 4682 , a $3.8 \%$ decrease over 2015 . The challenge remains protecting the most vulnerable road users as in 2015 those aged 65 and over comprised $56 \%$ of fatalities, and cyclists and pedestrians $53 \%$.

\section{Road safety data collection}

\section{Definitions applied in Japan}

- Road fatality: Person who dies within 24 hours of a crash or within 30 days of a crash. Two sets of records are kept, and the data in this report and included in the International Road Traffic and Accident Database (IRTAD) use the 30-day definition.

- Serious injury: Injury which requires medical treatment for 30 days or more.

- Slight injury: Injury which requires medical treatment for less than 30 days.

There is no plan to adopt a definition of serious injuries based on the Abbreviated Injury Scale.

\section{Data collection}

In Japan, road crash data are collected by the police. The National Police Agency has been collecting crash data since 1948. In 1966, an online database system was created and in 1993 the 30-day definition for a crash fatality was added.

Hospital data are not used to complete police data. They may be used on an ad hoc basis for research.

\section{Most recent safety data}

\section{Road crashes in 2016 - provisional data}

Based on provisional data, there were 4682 reported road fatalities in 2016, a $3.8 \%$ decrease when compared with 2015.

People aged 65 or older represented $56 \%$ of all fatalities.

\section{Road crashes in 2015}

In 2015, there were 4867 reported fatalities on Japanese roads. In comparison to 2014, fatalities increased by $0.6 \%$.

Despite a remarkable $6 \%$ drop in traffic volume, the number of road deaths did not decrease. Fatality numbers have gone up among the most vulnerable road user groups: pedestrians, cyclists and the over 65 age group. 


\section{Trends in traffic and road safety (1990-2016) Traffic}

Since 1990, the vehicle fleet has increased by $20 \%$ and the distance travelled has increased by 16\%. After reaching a peak of more than 91 million vehicles in 2007, the number of registered vehicles decreased until 2012, and then increased again slightly in recent years. In 2015 , traffic volume decreased by $6 \%$.

\section{Road safety}

\section{Crashes and casualties}

Between 1990 and 2015, the number of fatalities decreased by $67 \%$; however the number of injury crashes decreased only by $17 \%$. This discrepancy is due to the important increase in the number of vehicles and the number of licensed drivers, which has led to more crashes but, fortunately, not to more fatal crashes. Traffic deaths peaked in the late 1960s. Since then, fatalities have decreased, albeit with some fluctuations over the years. Since 2000, the number of road fatalities has decreased every year, until a small increase was observed in 2015. The improved safety record in the past decade is related to a significant increase in the seat belt wearing rate, reduction in speed and safer behaviour of pedestrians.

\section{Rates}

Since 1990, the death rate per 100000 inhabitants has decreased by $68 \%$, reaching 3.8 in 2015.

Table 20.1. Road safety and traffic data

\begin{tabular}{|c|c|c|c|c|c|c|c|c|c|}
\hline & \multirow{2}{*}{1990} & \multirow{2}{*}{2000} & \multirow{2}{*}{2010} & \multirow{2}{*}{2014} & \multirow{2}{*}{2015} & \multicolumn{4}{|c|}{$2015 \%$ change from } \\
\hline & & & & & & 2014 & 2010 & 2000 & 1990 \\
\hline \multicolumn{10}{|l|}{ Reported safety data } \\
\hline Fatalities & 14595 & 10410 & 5828 & 4838 & 4867 & 0.6 & -16.5 & -53.2 & -66.7 \\
\hline Injury crashes & 643097 & 931950 & 725924 & 573842 & 536899 & -6.4 & -26.0 & -42.4 & -16.5 \\
\hline \multicolumn{10}{|l|}{ Serious injuries (MAIS3+) } \\
\hline Deaths per 100000 inhabitants & 11.8 & 8.2 & 4.6 & 3.8 & 3.8 & 0.4 & -16.0 & -53.4 & -67.6 \\
\hline Deaths per 10000 registered vehicles & 1.9 & 1.2 & 0.6 & 0.5 & 0.5 & 0.0 & -17.4 & -54.7 & -72.3 \\
\hline Deaths per billion vehicle kilometres & 23.2 & 13.4 & 8.0 & 6.2 & 6.7 & 7.1 & -17.0 & -50.4 & -71.3 \\
\hline \multicolumn{10}{|l|}{ Traffic data } \\
\hline Registered vehicles ${ }^{1}$ (thousands) & 75960 & 88602 & 90464 & 90894 & 91316 & 0.5 & 0.9 & 3.1 & 20.2 \\
\hline Vehicle-kilometres (millions) & 628581 & 775723 & 726256 & 778335 & 730930 & -6.1 & 0.6 & -5.8 & 16.3 \\
\hline Registered vehicles per 1000 inhabitants & 615 & 698 & 706 & 715 & 718 & 0.5 & 1.7 & 2.9 & 16.9 \\
\hline
\end{tabular}

1. Including mopeds. 
Figure 20.1. Road safety, traffic and GDP trends index $1990=100$

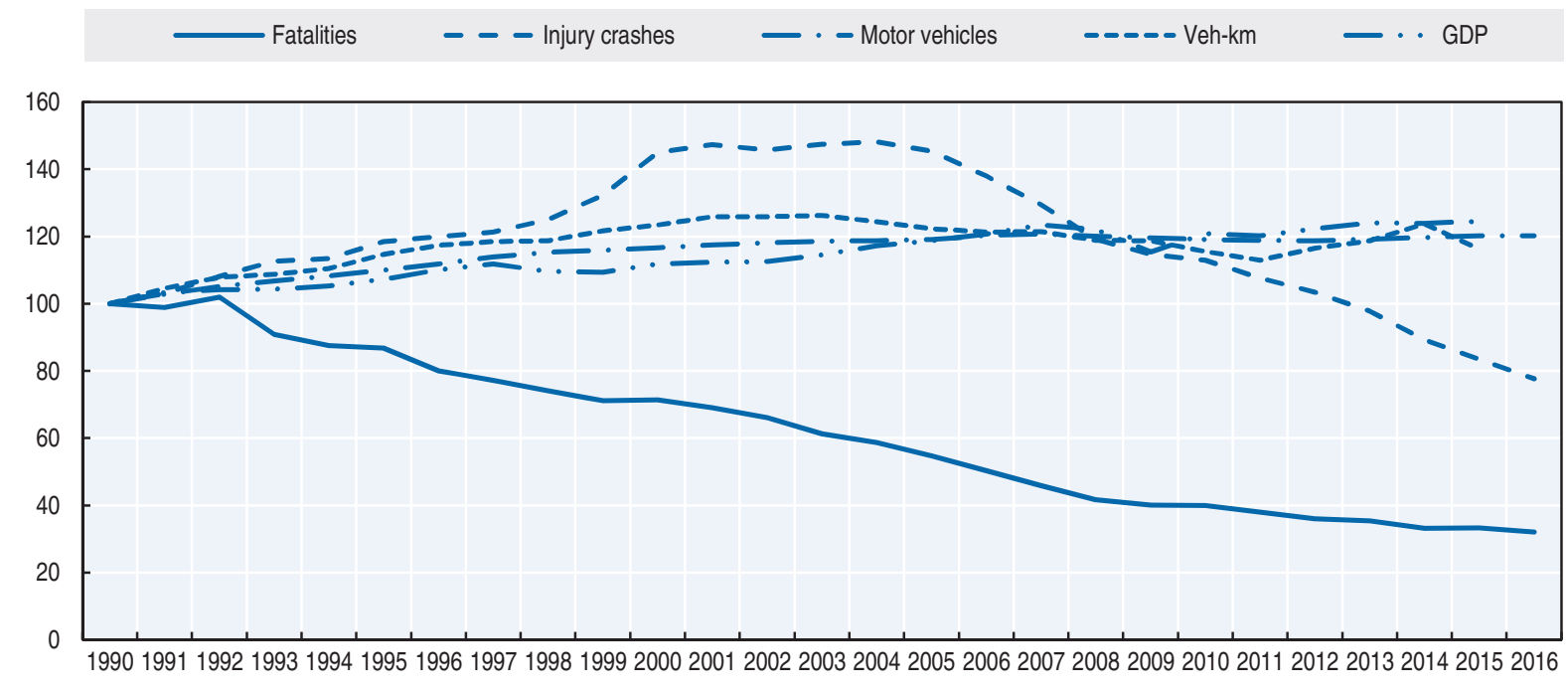

Source: World Bank (2017) (GDP; constant prices).

\section{Road safety by user group}

Since 1990, safety improvements have benefited all road users, in particular the motorised groups such as mopeds, motorcyclists, and passenger car occupants, for whom fatalities have been reduced by over $70 \%$. Factors contributing to this reduction are safer vehicles, better emergency medical care, improved road infrastructure and a change in road user behaviour. The improvement was less for vulnerable road users, in particular cyclists and pedestrians.

Pedestrians represent a very high share of total fatalities (37\% of all fatalities in 2015) in comparison with other OECD countries. In 2015, cyclists represented $16 \%$ of total fatalities. This share could rise, given the increasing popularity of cycling. Improving the safety of cyclists has become a priority.

In 2015, a 3\% increase in road fatalities was observed amongst both cyclists and pedestrians. They together make up the majority (53\%) of road fatalities in Japan.

Table 20.2. Road fatalities by road user group

\begin{tabular}{lrrrrr|rrrr}
\hline & 1990 & 2000 & 2010 & 2014 & 2015 & \multicolumn{4}{|c}{$2015 \%$ change from } \\
\cline { 7 - 10 } & & & & & & 2014 & 2010 & 2000 & 1990 \\
\hline Pedestrians & 3955 & 2955 & 2016 & 1753 & 1813 & 3.4 & -10.1 & -38.6 & -54.2 \\
Cyclists & 1509 & 1278 & 938 & 738 & 764 & 3.5 & -18.6 & -40.2 & -49.4 \\
Moped riders & 1320 & 944 & 459 & 321 & 298 & -7.2 & -35.1 & -68.4 & -77.7 \\
Motorcyclists & 1920 & 903 & 570 & 489 & 479 & -2.0 & -16.0 & -47.0 & -75.1 \\
Passenger car occupants & 3887 & 2903 & 1201 & 1053 & 1039 & -1.3 & -13.5 & -64.2 & -73.3 \\
Others & 2005 & 1427 & 644 & 484 & 474 & -2.1 & -26.4 & -66.8 & -76.4 \\
Total & $\mathbf{1 4 5 9 5}$ & $\mathbf{1 0 4 1 0}$ & $\mathbf{5 8 2 8}$ & $\mathbf{4 8 3 8}$ & 4867 & 0.6 & -16.5 & -53.2 & -66.7 \\
\hline
\end{tabular}


Figure 20.2. Road fatalities by road user group in percentage of total, 2015

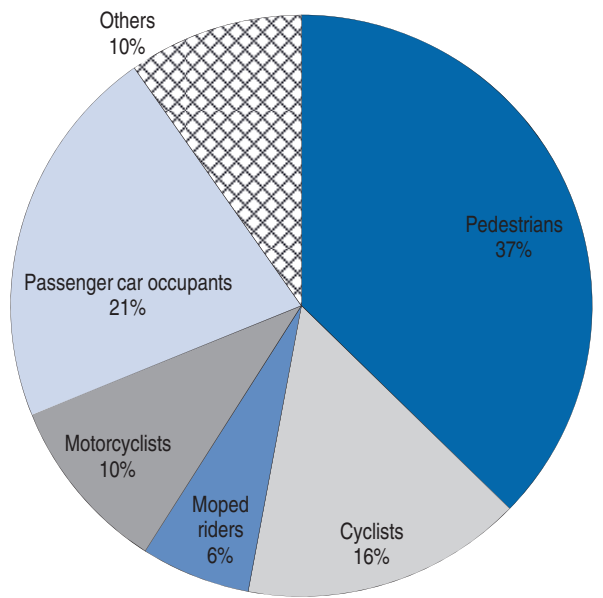

\section{Road safety by age group}

Since 1990, impressive reductions in fatalities have benefited all age groups, except for the over 65 group which has seen only a modest reduction. In 2015, this group accounted for more than half (56\%) of total fatalities.

Table 20.3. Road fatalities by age group

\begin{tabular}{|c|c|c|c|c|c|c|c|c|c|}
\hline \multirow{2}{*}{ Age } & \multirow{2}{*}{1990} & \multirow{2}{*}{2000} & \multirow{2}{*}{2010} & \multirow{2}{*}{2014} & \multirow{2}{*}{2015} & \multicolumn{4}{|c|}{$2015 \%$ change from } \\
\hline & & & & & & 2014 & 2010 & 2000 & 1990 \\
\hline $0-14$ & 653 & 239 & 124 & 97 & 86 & -11.3 & -30.6 & -64.0 & -86.8 \\
\hline $15-17$ & 1006 & 327 & 124 & 83 & 78 & -6.0 & -37.1 & -76.1 & -92.2 \\
\hline $18-20$ & 1820 & 690 & 221 & 172 & 154 & -10.5 & -30.3 & -77.7 & -91.5 \\
\hline $21-24$ & 1381 & 772 & 226 & 146 & 144 & -1.4 & -36.3 & -81.3 & -89.6 \\
\hline $25-64$ & 6261 & 4641 & 2123 & 1705 & 1678 & -1.6 & -21.0 & -63.8 & -73.2 \\
\hline $65-64$ & & 1744 & 1135 & 946 & 948 & 0.2 & -16.5 & -45.6 & \\
\hline $75-84$ & & 1575 & 1399 & 1199 & 1261 & 5.2 & -9.9 & -19.9 & \\
\hline$\geq 85$ & & 422 & 476 & 490 & 518 & 5.7 & 8.8 & 22.7 & \\
\hline Total & 14595 & 10410 & 5828 & 4838 & 4867 & 0.6 & -16.5 & -53.2 & -66.7 \\
\hline
\end{tabular}

Figure 20.3. Road fatality rates by age group Deaths per 100000 inhabitants in a given age group, 1990-2015

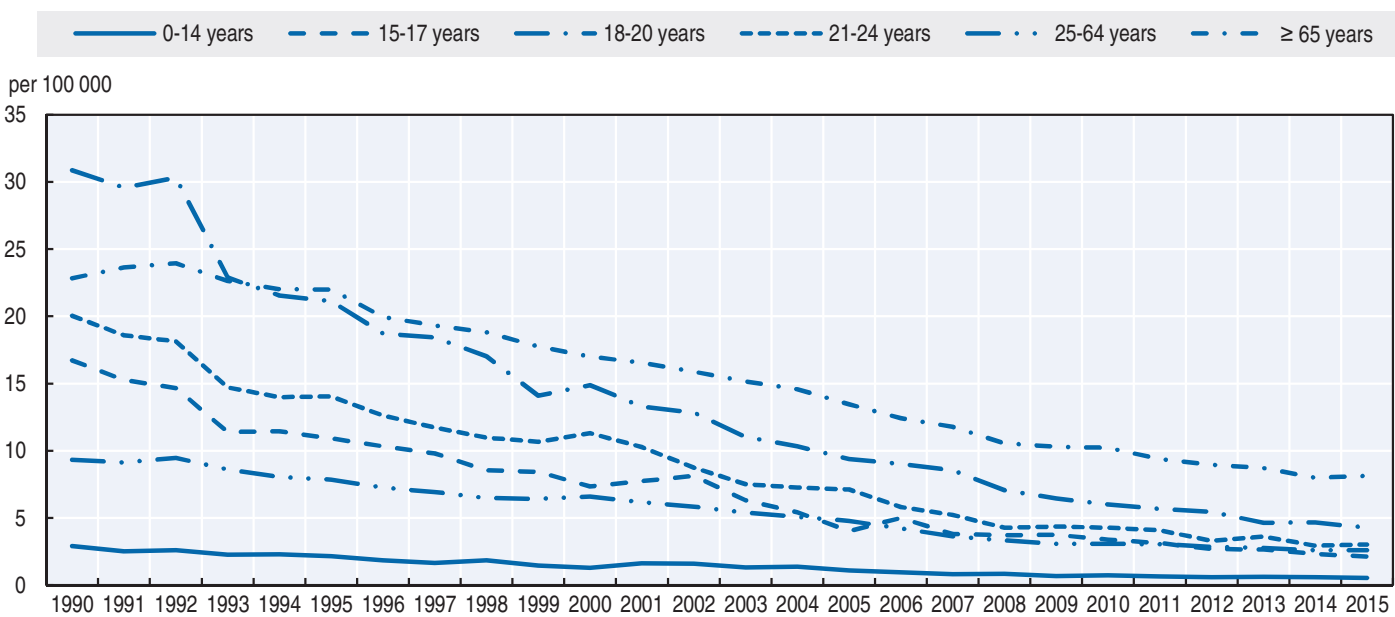




\section{Box 20.1. Road safety for an ageing population}

In 2015, those aged 65 and over represented $26 \%$ of the total population and this share is expected to reach a third by 2050.

The older population is overrepresented in traffic casualties. In 2015 , they represented $56 \%$ of all road fatalities, the highest share ever reached. Among those 65 and over killed in traffic, $47 \%$ were pedestrians, $28 \%$ car occupants and $18 \%$ cyclists.

Road safety for senior citizens is one of the top priorities of the Japanese government, who are organising a wide educational campaign on this topic.

Drivers over 71 years of age have to renew their driving licences every three years (compared to every five years for the general population). Drivers aged 70 or older at the time of renewal are required to take dedicated courses.

Since 12 March 2017, the following measures also apply:

- Drivers aged 75 or over, who would like to renew their driver's licence, are required to take cognitive impairment screening tests. Drivers whose test scores are under a certain threshold are required to have a medical examination. If dementia is diagnosed, their licences are revoked or suspended.

- Drivers aged 75 or over, who commit certain traffic violations; are required to take extraordinary cognitive impairment screening tests and go through a similar procedure.

Table 20.4. Road fatalities among senior citizens

\begin{tabular}{lrrr|rrr|rrr}
\hline & \multicolumn{3}{c|}{$65-74$} & \multicolumn{3}{c|}{$75-84$} & \multicolumn{3}{c}{$85+$} \\
\cline { 2 - 10 } & 2010 & 2015 & $\%$ change & 2010 & 2015 & $\%$ change & 2010 & 2015 & \% change \\
\hline Cyclists & 252 & 182 & -28 & 253 & 227 & -10 & 78 & 84 & 8 \\
Motorcyclists & 23 & 23 & 0 & 28 & 13 & -54 & 3 & 4 & + \\
Moped riders & 99 & 73 & -26 & 95 & 67 & -29 & 29 & 19 & -34 \\
Car Occupants & 191 & 202 & 6 & 174 & 206 & 18 & 56 & 90 & 61 \\
Pedestrians & 446 & 369 & -17 & 704 & 631 & -10 & 282 & 277 & -2 \\
Total & $\mathbf{1 1 3 5}$ & $\mathbf{9 4 8}$ & $\mathbf{- 1 6}$ & $\mathbf{1 3 9 9}$ & $\mathbf{1 2 6 1}$ & $\mathbf{- 1 0}$ & $\mathbf{4 7 6}$ & $\mathbf{5 1 8}$ & $\mathbf{9}$ \\
\hline
\end{tabular}

Figure 20.4. Road fatality rates by age group - focus on the senior population Deaths per 100000 inhabitants in a given age group, 2004-15
$65-74$ years
- - $-75-84$ years
$-\cdot-85+$ years

per 100000

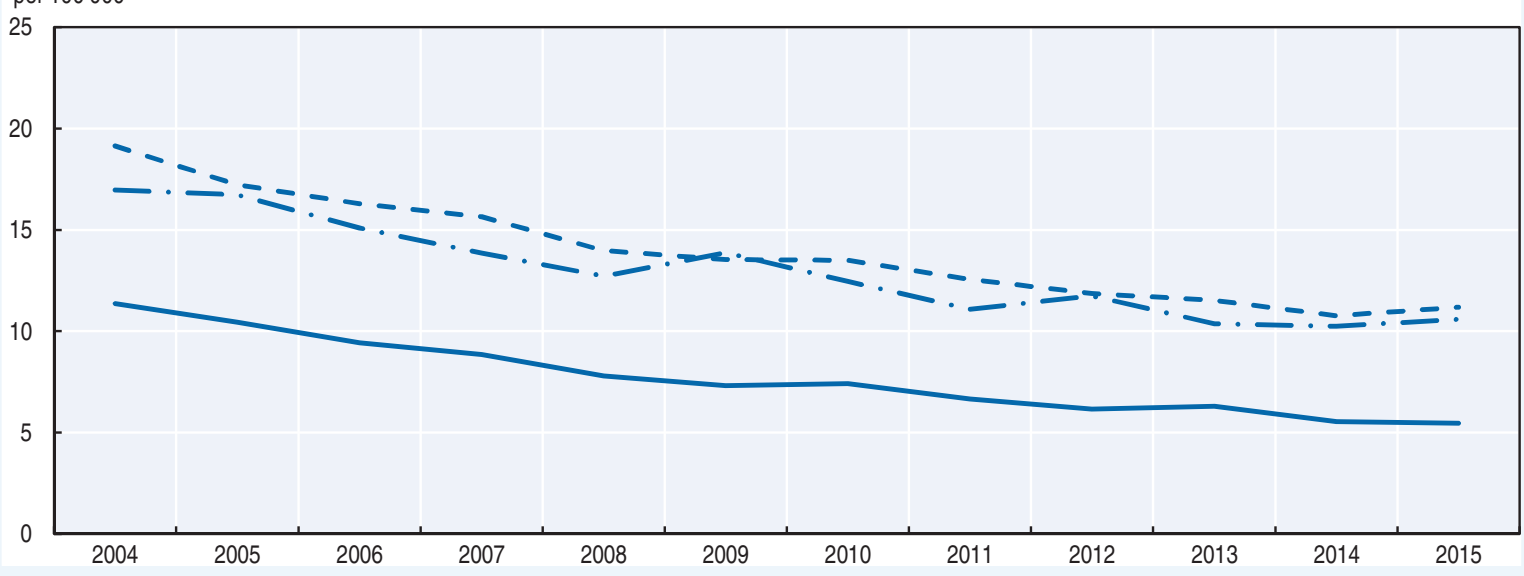


Figure 20.5. Road fatality rate by age and road user group Fatalities per 100000 inhabitants, 2015

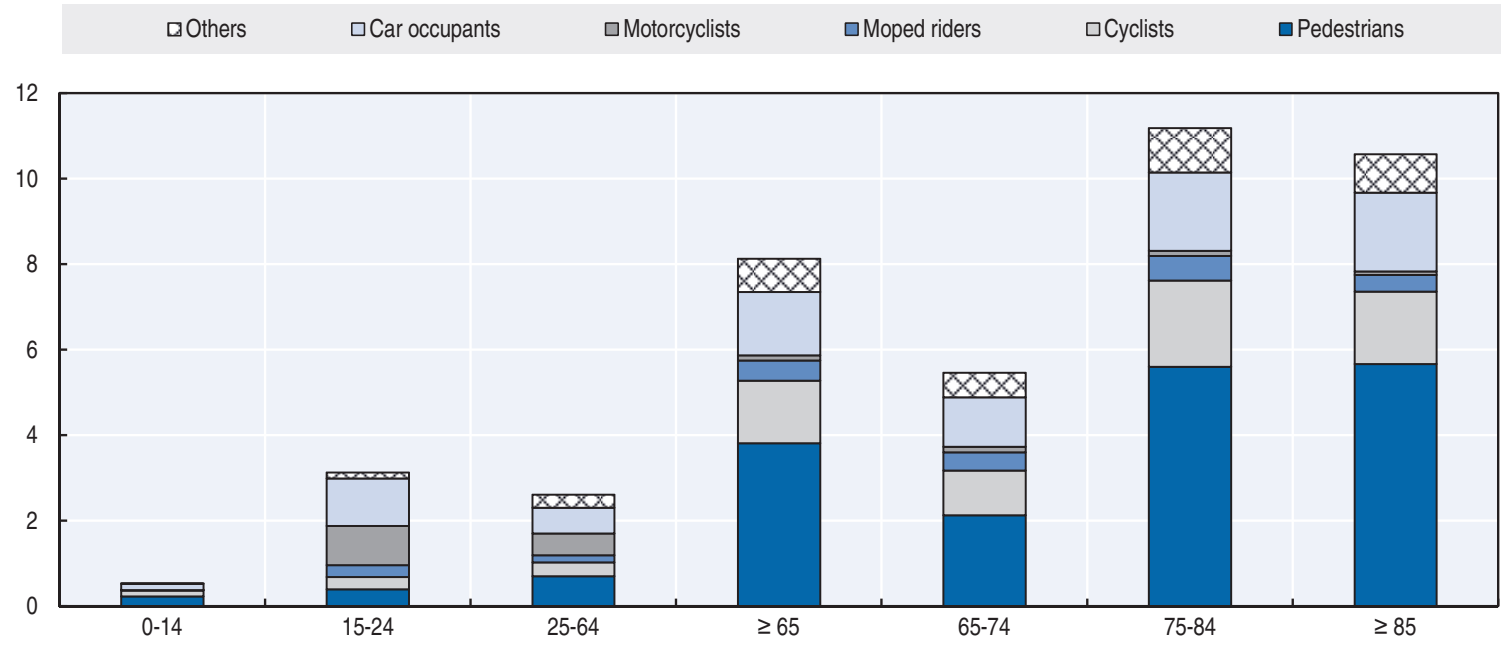

\section{Road safety by road type}

Since 1990 fatalities have decreased by $73 \%$ on rural roads, $60 \%$ inside urban areas and $65 \%$ on motorways. In general, the rate of reduction in urban areas has been slower than other road types. In 2015, fatalities inside urban areas accounted for more than half (56\%) of total fatalities.

Figure 20.6. Road fatalities by road type

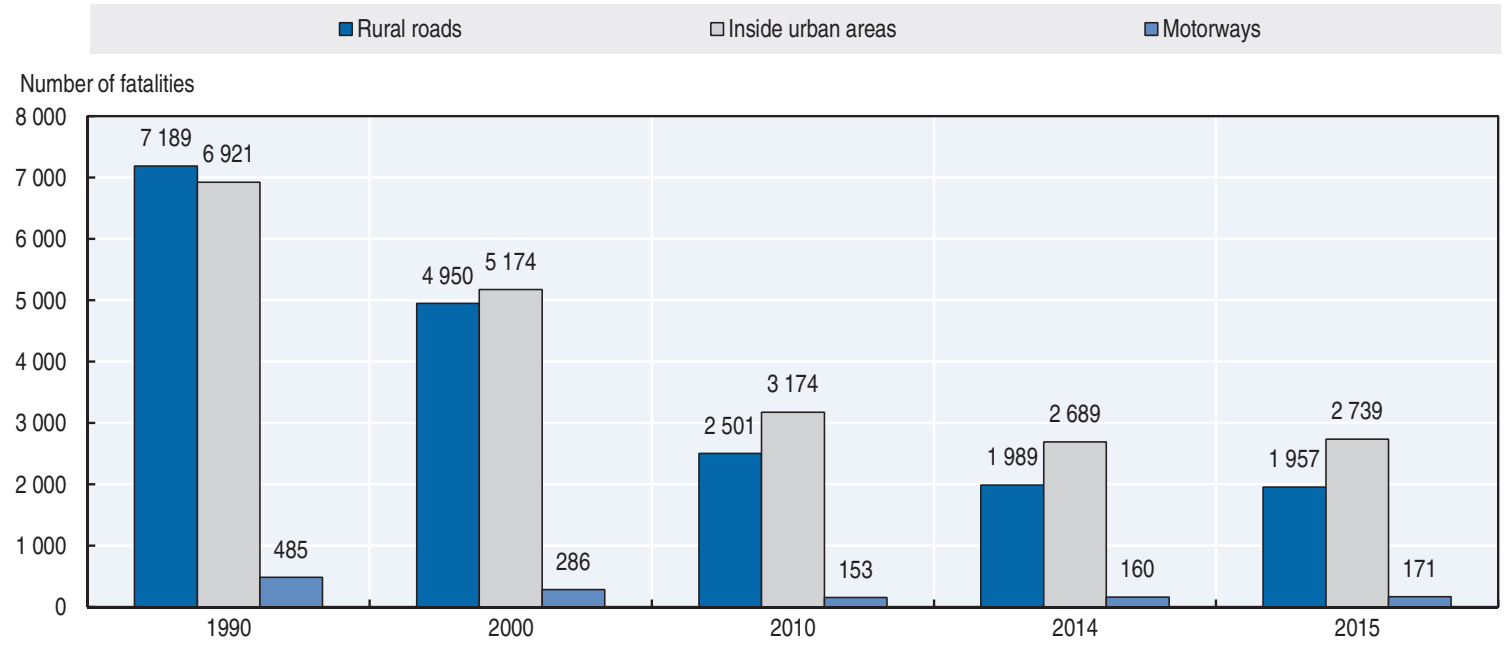

\section{Economic costs of traffic crashes}

Currently, there is no estimation of the economic cost of traffic crashes.

\section{Recent trends in road user behaviour}

\section{Speed}

The table below summarises the main speed limits in Japan. 
Table 20.5. Passenger car speed limits by road type, 2017

\begin{tabular}{lc}
\hline & General speed limit \\
\hline Urban roads & $40,50,60 \mathrm{~km} / \mathrm{h}$ \\
Rural roads & $50,60 \mathrm{~km} / \mathrm{h}$ \\
Motorways & $100 \mathrm{~km} / \mathrm{h}$ \\
\hline
\end{tabular}

\section{Drink driving}

In 2002, the maximum authorised blood alcohol content (BAC) level was lowered from $0.5 \mathrm{~g} / \mathrm{l}$ to $0.3 \mathrm{~g} / \mathrm{l}$. In 2015 , it was reported that $0.76 \%$ of all crashes were due to a driver under the influence of alcohol. The share of alcohol-related crashes has decreased in recent years, due to more severe sanctions and more frequent control.

The police regularly release information on fatalities caused by drinking driving and are conducting, with other agencies and organisations, awareness campaigns.

\section{Seat belts and helmets}

Seat belt wearing has been compulsory in front seats since 1985 and in rear seats since 2008. Children under six years old must be seated in a dedicated child restraint system.

While the seat belt wearing rate is high for front seat occupants; it is very low in rear seats. In 2016 , only $36 \%$ of rear seat passengers wore a seatbelt.

All riders of powered two-wheelers are required to wear helmets. There is no mandatory helmet use law for cyclists.

Table 20.6. Seat belt wearing rate by car occupancy and road type

\begin{tabular}{lccccc}
\multicolumn{7}{c}{$\%$} & & \\
& 2002 & 2010 & 2014 & 2015 & 2016 \\
\hline Front seat & & & & & 98.5 \\
$\quad$ Driver & 88.1 & 97.3 & 98.2 & 98.4 & 94.9 \\
$\quad$ Passenger & 75.2 & 92.2 & 93.9 & 94.6 & 99.5 \\
$\quad$ Motorways (driver) & 97.1 & 99.2 & 99.5 & 99.4 & 36.0 \\
Rear seats & & & & 35.1 & 64.2 \\
$\quad$ General & 6.7 & 33.1 & 35.1 & 62.7 & 61.9 \\
$\quad$ Children (use of child restraint) & 52.4 & 56.8 & & & \\
\hline
\end{tabular}

\section{National road safety strategies and targets Organisation of road safety}

From the first half of the 1950s to around 1970, Japan suffered from a significant increase in the number of road traffic crash casualties. As a result, traffic safety emerged as an important social issue. In June 1970, the government of Japan enacted the Traffic Safety Policies Act, with the aim of promoting traffic safety measures nationwide in a systematic manner. Under this act, the government has been working together with local governments and relevant private organisations to vigorously implement traffic safety measures.

Since 1971, the government has prepared a National Traffic Safety Programme every five years. 


\section{Road safety strategy for 2016-20}

The 10th Traffic Safety Programme was launched in March 2016 and covers the period 2016-20. It is based on two strategic objectives and eight pillars. The two strategic objectives are:

- Reducing the consequences of crashes, in particular for the senior population and children, and for pedestrians and cyclists.

- Crash prevention, through the use of new technologies, in-depth analysis of traffic and crash data and the involvement of the community

The eight pillars are:

- the maintenance of the road environment

- dissemination and reinforcement of traffic safety messages

- safe driving

- vehicle safety

- enforcement

- an improved rescue and emergency medical system

- victim support, including an appropriate damage compensation system

- research and development

\section{Road safety targets}

The current plan includes the 2020 target of fewer than 2500 deaths within 24 hours of a crash (equivalent to approximately 3000 deaths within 30 days) and fewer than 500000 casualties. The vision is to make Japan the safest country for road traffic.

The previous plan included the target for 2015 of fewer than 3000 deaths (within 24 hours). However, this target was not reached with a total of 4117 fatalities (within 24 hours) recorded for 2015.

Figure 20.7. Trends in road fatalities towards national target

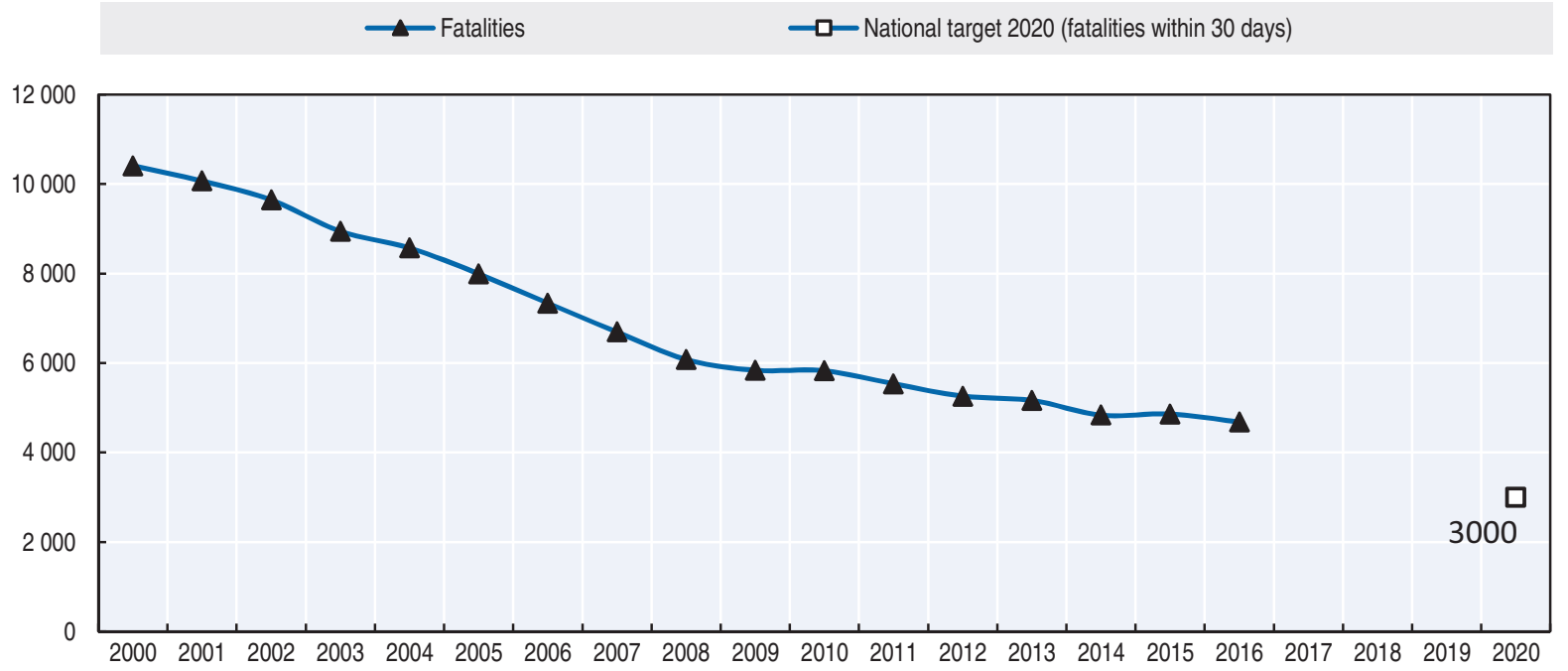




\section{Recent safety measures (2014-17)}

\section{Road safety management}

- Implementation of the 10th Traffic Safety Programme: the national government, local governments, other public organisations and private entities are co-operating to promote road traffic safety measures.

\section{Speed management}

- The police have released speed management guidelines for the attention of the general public, highlighting basic concepts regarding speed and crash risk. The police have also released speed enforcement guidelines, and identified high priority road sections for more intense enforcement.

- Expansion of the $30 \mathrm{~km} / \mathrm{h}$ zones which were introduced in 2011.

\section{Older drivers}

- Since March 2017, in order to renew their licence, drivers aged 75 and over are required to take cognitive impairment screening tests (see Box 20.1 for more information).

\section{Education and awareness}

- The police regularly organise road safety education programmes for different target groups.

- Every year, in Spring and Autumn, important national traffic safety campaigns are conducted to raise awareness for traffic safety.

\section{Infrastructure}

- Installation of new traffic signals, along with dynamic monitoring of these systems and provision of information to road users by the police.

- The police are promoting the development and implementation of the Universal Traffic Management Systems (UTMS). UTMS is designed to create a safe, comfortable and environmental-friendly motorised society, provide real time traffic information to road users and control traffic flow via infrared beacons (www.utms.or.jp/english/ [accessed 10 May 2017]).

\section{References}

World Bank (2017), “GDP (constant US\$)”, World Development Indicators, http://databank.worldbank.org/ data/reports.aspx?source=world-development-indicators (accessed 23 February 2017).

\section{Websites}

- National Police Agency: www.npa.go.jp (accessed 10 May 2017).

- Institute for Traffic Accident Research and Analysis (ITARDA): www.itarda.or.jp (accessed 10 May 2017).

- National Research Institute of Police Science (NRIPS): www.npa.go.jp/nrips/en/index.html (accessed 10 May 2017). 


\section{Chapter 21}

\section{Korea}

This chapter presents 2015 road safety data for Korea along with provisional data from 2016. It looks at trends in traffic and road safety from the years 1990 to 2016 and road user behaviour patterns, with a special focus on the ageing population. The following sections include data on speed, drink driving, drugs and driving, distracted driving, fatigue and seat belt usage. The chapter reviews Korea's road safety strategy and interim targets to 2021 and the progress achieved thus far. It also provides details of all recently implemented safety measures and current and ongoing research. ${ }^{*}$

* All data stem from the Korea Road Traffic Authority (KoROAD) unless otherwise noted. For more information please contact: dragonhwang@koroad.or.kr. 
$\mathrm{K}$

orea's ongoing positive trend continued in 2015 with a 3\% decrease in fatalities over 2014 to 4 621. Provisional data from 2016 reinforce this trend with a $7.1 \%$ decrease in fatalities compared to 2015. The road death rate per 100000 inhabitants decreased to 9.1 in 2015, and for the first time the rate per 10000 registered vehicles came in at under 2 . This is seen in the context of the rapid motorisation of Korea with a fourfold increase in the number of registered vehicles since 1990, and an ongoing annual average increase of 3\%. All user groups have benefited from reductions in fatalities, although the share of pedestrians killed remains particularly high at $39 \%$. Korea's national road safety strategy has fixed the goal of 2700 fatalities by 2021.

\section{Road safety data collection}

\section{Definitions applied in Korea}

- Road fatality: Any person killed immediately or dying within 30 days as a result of a road crash.

- Person seriously injured: Any injured person requiring medical treatment for more than three weeks.

- Person slightly injured: Any injured person requiring medical treatment for less than three weeks.

\section{Data collection}

Any road crash resulting in at least one person killed or injured must be reported to the police. The police investigate the crash, fill out a form and enter the information in the police Traffic Accident Management System database. The police refer to the medical diagnosis to classify the injuries by severity.

To complete police reported crash data, the Korea Road Traffic Authority (KoROAD) has developed an integrated road crash database, the Traffic Accident Analysis System (TAAS). This contains not only police data, but also inputs from car insurance companies and mutual aid associations. The TAAS data are collected regularly from these sources, and are refined to eliminate duplicated information.

\section{Most recent safety data}

\section{Road crashes in 2016 - provisional data}

Based on provisional data, there were 4292 road fatalities in 2016, representing a decrease of $7.1 \%$ when compared to 2015 . The number of police reported injury crashes and injured persons decreased by $5.3 \%$

The reduction in the number of casualties benefited nearly all user groups, with the exception of older drivers, for whom the number of deaths increased by $5.9 \%$. As Korea has an ageing population, the safety of this road user group is a major concern. 


\section{Road crashes in 2015}

In 2015, there were 4621 road fatalities in Korea, a decrease of 3\% compared to 2014. This was observed in the context of a rise in the number of police reported injury crashes, which increased by almost $4 \%$.

\section{Trends in traffic and road safety (1990-2016) Traffic}

Since 1990, Korea has had a very rapid increase in motorisation. Between 1990 and 2015 , the number of motorised vehicles was multiplied by more than four. Since 2000 , the increase has been more moderate. In 2013, about 200000 mopeds were registered due to moped registration becoming mandatory.

In 2015 , as in the previous year, both motorisation and traffic volume grew at a rate close to $3 \%$.

\section{Road safety}

\section{Crashes and casualties}

Fatalities peaked in 1991 at 13 429. Since then, road deaths have decreased (with some fluctuations) and were halved by 2004. In 2013, for the first time in 37 years the number of road deaths was below 5 000, and the decrease continued in 2014. Between 1990 and 2015, the number of road fatalities decreased by $67 \%$, while the number of injury crashes decreased by only $9 \%$.

This important decrease is due in part to the following measures:

- the compulsory wearing of front seat belts (1990)

- drink driving enforcement (1998)

- installation of median barriers on national roads

- speed enforcement by the police, including automatic speed camera enforcement since 2008

- lower speed limits on urban roads in residential areas (ongoing pilot project since 2014).

However, Korea still faces a number of challenges and has fatality rates above the average for countries in the Organisation for Economic Co-operation and Development (OECD). Reasons for the elevated levels of deaths and serious injuries on the roads include high alcohol consumption, wide junctions, lack of pavements on rural roads, high speed limits on urban roads (usually $60 \mathrm{~km} / \mathrm{h}$ and sometimes $80 \mathrm{~km} / \mathrm{h}$ ), a lack of road safety education in high schools and the low priority of road safety by local government. Also, Korea's older population (above 65) has a very high risk in traffic when compared to other OECD countries. This is a serious concern as the share of the senior population is increasing steadily.

\section{Rates}

From 1990 to 2015, the road death rate per 100000 inhabitants decreased by $72 \%$ to 9.1 , the death rate per 10000 registered vehicles decreased by $93 \%$ to 1.9, and the death rate per distance travelled fell to 15.5 fatalities per billion vehicle-kilometres. During the same period the number of vehicles per 1000 inhabitants, which is representative of the national level of motorisation, was multiplied by more than four. 
Table 21.1. Road safety and traffic data

\begin{tabular}{|c|c|c|c|c|c|c|c|c|c|}
\hline & \multirow{2}{*}{1990} & \multirow{2}{*}{2000} & \multirow{2}{*}{2010} & \multirow{2}{*}{2014} & \multirow{2}{*}{2015} & \multicolumn{4}{|c|}{$2015 \%$ change from } \\
\hline & & & & & & 2014 & 2010 & 2000 & 1990 \\
\hline \multicolumn{10}{|l|}{ Reported safety data } \\
\hline Fatalities & 14174 & 10236 & 5505 & 4762 & 4621 & -3.0 & -16.1 & -54.9 & -67.4 \\
\hline Injury crashes & 255303 & 290481 & 226878 & 223552 & 232035 & 3.8 & 2.3 & -20.1 & -9.1 \\
\hline Serious injuries & & 211613 & 116902 & 93047 & 92522 & -0.6 & -20.9 & -56.3 & \\
\hline Deaths per 100000 inhabitants & 33.1 & 21.8 & 11.3 & 9.4 & 9.1 & -3.3 & -18.9 & -58.1 & -72.4 \\
\hline Deaths per 10000 registered vehicles & 28.9 & 6.9 & 2.6 & 2.1 & 1.9 & -5.8 & -26.7 & -71.7 & -93.3 \\
\hline Deaths per billion vehicle kilometres & & 49.5 & 18.7 & 16.4 & 15.5 & -5.7 & -17.0 & -68.7 & \\
\hline \multicolumn{10}{|l|}{ Traffic data } \\
\hline Registered vehicles ${ }^{1}$ (thousands) & 4897 & 14928 & 20832 & 23151 & 23853 & 3.0 & 14.5 & 59.8 & 387.1 \\
\hline Vehicle-kilometres (millions) & & 206985 & 295055 & 290009 & 298323 & 2.9 & 1.1 & 44.1 & \\
\hline Registered vehicles per 1000 inhabitants & 114 & 318 & 426 & 459 & 471 & 2.6 & 10.6 & 48.2 & 313.4 \\
\hline
\end{tabular}

1. Excluding mopeds.

Figure 21.1. Road safety, traffic and GDP trends index $1990=100$

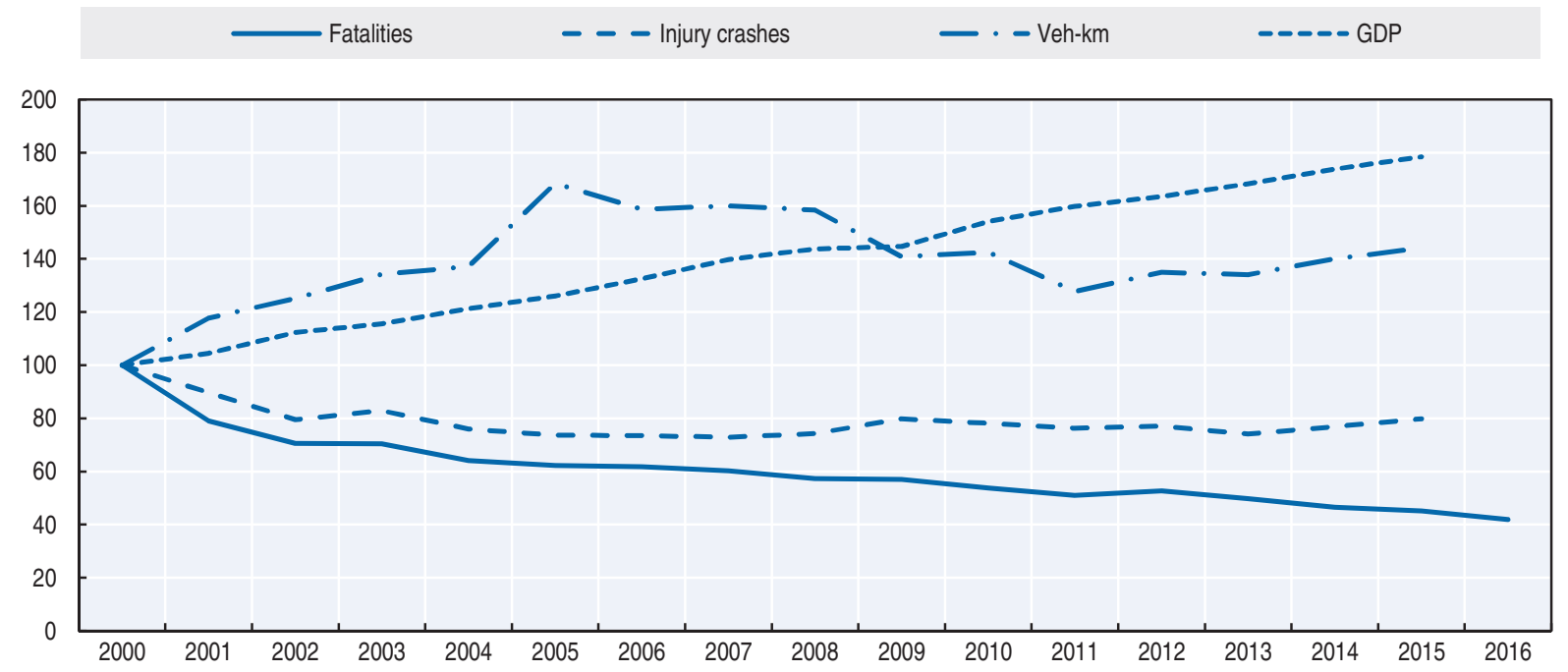

Source: World Bank (2017) (GDP; constant prices).

\section{Road safety by user group}

Since 1990, all user groups have benefited from improvements in road safety. The highest fatality decreases were observed for pedestrians (-75\%) and motorcyclists (-67\%).

Between 2000 and 2015, the number of road deaths decreased among all user groups. The greatest decrease was observed for car occupants (-65\%) and motorcycle riders (-54\%). The decrease in cyclist fatalities was more moderate (-14\%). In 2015, pedestrians accounted for $39 \%$ of all fatalities, which is very high when compared to the average for OECD countries of $20.2 \%$ (2015 data). 
Table 21.2. Road fatalities by road user group

\begin{tabular}{lrrrrr|rrrr}
\hline & 1990 & 2000 & 2010 & 2014 & 2015 & \multicolumn{4}{|c}{$2015 \%$ change from } \\
\cline { 7 - 10 } & & & & & & 2014 & 2010 & 2000 & 1990 \\
\hline Pedestrians & 7063 & 3764 & 2082 & 1910 & 1795 & -6.0 & -13.8 & -52.3 & -74.6 \\
Cyclists & 644 & 317 & 294 & 272 & 272 & 0.0 & -7.5 & -14.2 & -57.8 \\
Moped riders & & 343 & 450 & 326 & 312 & -4.3 & -30.7 & -9.0 & \\
Motorcyclists & 1674 & 1221 & 633 & 562 & 558 & -0.7 & -11.8 & -54.3 & -66.7 \\
Car occupants & 2100 & 2792 & 1228 & 998 & 989 & -0.9 & -19.5 & -64.6 & -52.9 \\
Others & 2692 & 1799 & 818 & 694 & 695 & 0.1 & -15.0 & -61.4 & -74.2 \\
Total & $\mathbf{1 4} \mathbf{1 7 4}$ & $\mathbf{1 0 2 3 6}$ & $\mathbf{5 5 0 5}$ & $\mathbf{4 7 6 2}$ & $\mathbf{4 6 2 1}$ & $\mathbf{- 3 . 0}$ & $\mathbf{- 1 6 . 1}$ & $\mathbf{- 5 4 . 9}$ & $\mathbf{- 6 7 . 4}$ \\
\hline
\end{tabular}

Figure 21.2. Road fatalities by road user group in percentage of total, 2015

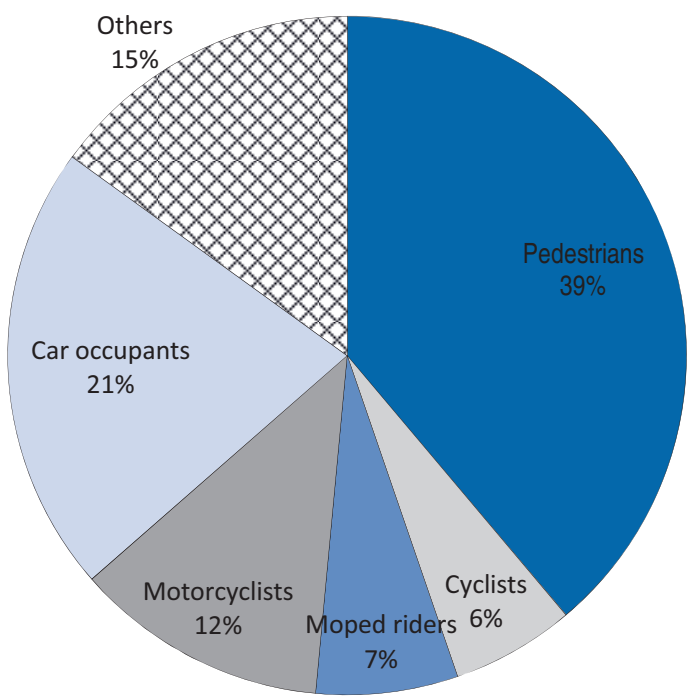

\section{Road safety by age group}

Since 2000, the reduction in road fatalities has benefited all age groups. The most impressive reduction concerned the youngest group (0-14), for which fatalities decreased by $86 \%$, from 588 in 2000 to 83 in 2015 . However, the number of road fatalities among the oldest group (65+) has hardly decreased (-2\%).

Table 21.3. Road fatalities by age group

\begin{tabular}{lrrrr|rrr}
\hline & \multirow{2}{*}{ Age } & & & & \multicolumn{3}{c}{$2015 \%$ change from } \\
\cline { 6 - 8 } & 2000 & 2010 & 2014 & 2015 & 2014 & 2010 & 2000 \\
\hline $0-14$ & 588 & 160 & 65 & 83 & 27.7 & -48.1 & -85.9 \\
$15-17$ & 263 & 139 & 104 & 64 & -38.5 & -54.0 & -75.7 \\
$18-20$ & 459 & 149 & 109 & 135 & 23.9 & -9.4 & -70.6 \\
$21-24$ & 573 & 236 & 143 & 150 & 4.9 & -36.4 & -73.8 \\
$25-64$ & 6474 & 3068 & 2526 & 2375 & -6.0 & -22.6 & -63.3 \\
$65-74$ & 1117 & 1030 & 887 & 857 & -3.4 & -16.8 & -23.3 \\
$75-84$ & 602 & 596 & 762 & 778 & 2.1 & 30.5 & 29.2 \\
$\geq 85$ & 134 & 126 & 166 & 179 & 7.8 & 42.1 & 33.6 \\
Total incl. unknown & $\mathbf{1 0} 236$ & $\mathbf{5 5 0 5}$ & $\mathbf{4 7 6 2}$ & $\mathbf{4 6 2 1}$ & $\mathbf{- 3 . 0}$ & $\mathbf{- 1 6 . 1}$ & $\mathbf{- 5 4 . 9}$ \\
\hline
\end{tabular}


Figure 21.3. Road fatality rates by age group

Deaths per 100000 inhabitants in a given age group, 1993-2015

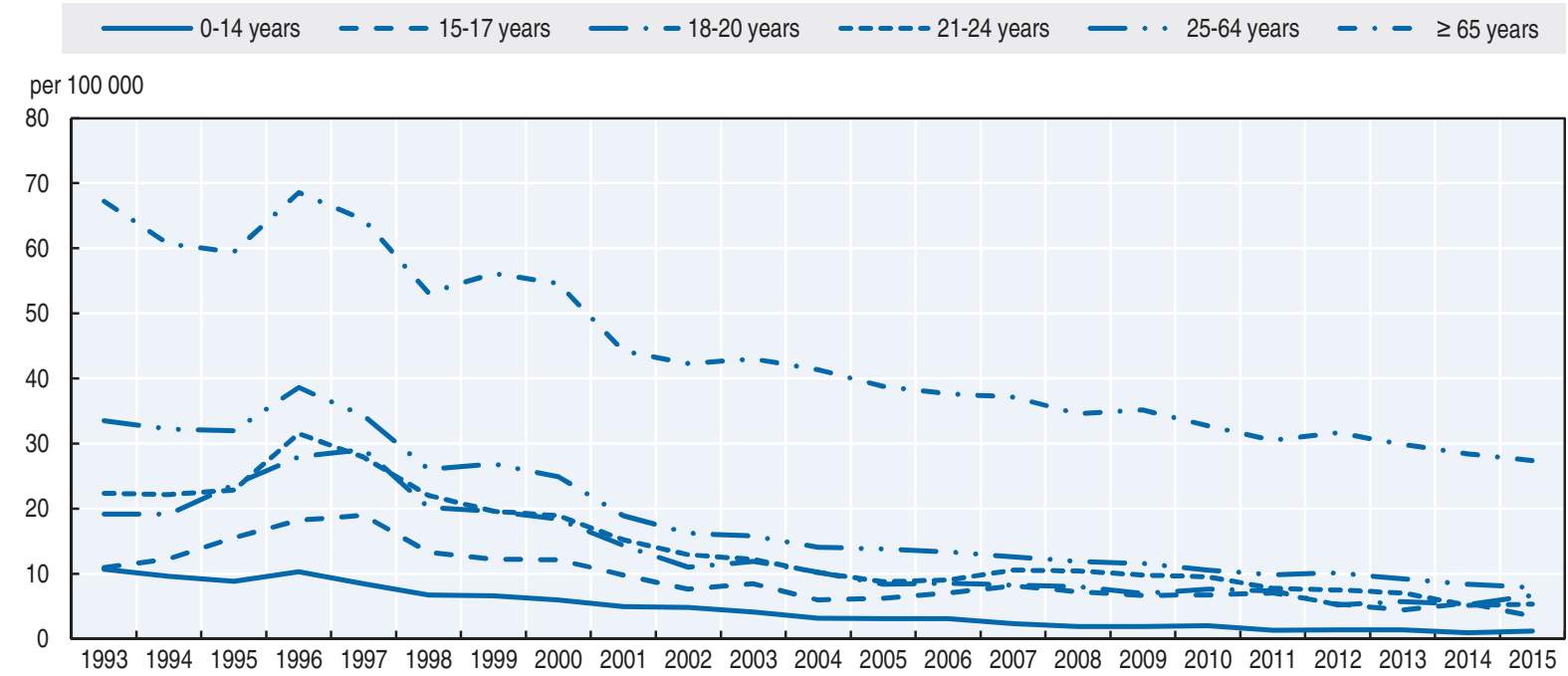

\section{Box 21.1. Road safety for an ageing population}

In 2015 , the over 65 age group represented $13 \%$ of the population. This share is expected to reach $24 \%$ in 2030 and $32 \%$ in 2040.

The older population is overrepresented in road crashes casualties. In 2015, the over 65 age group represented $38 \%$ of all fatalities. They have a much higher risk than the general population, with more than 27 deaths for 100000 inhabitants, over 3 times the risk of the average population. They also are particularly vulnerable as pedestrians, and represent nearly half of all pedestrian fatalities.

Between 2010 and 2015, the number of road fatalities decreased for the 65-74 age group, however it increased markedly for those 75 and above. In particular among the 75-84 year old group the number of road deaths doubled among motorcyclists and car occupants. For those over 85 , the situation deteriorated for the pedestrians and cyclists.

Improving the safety of the ageing population is a key priority in Korea. Recent measures include the designation of Silver Zones near facilities for the elderly. In these dedicated Silver Zones, the speed limit is $30 \mathrm{~km} / \mathrm{h}$ and crossing times at traffic signals are extended. Discussion is underway about the licence renewal process for older drivers.

Table 21.4. Road fatalities among senior citizens

\begin{tabular}{lrrr|rrr|rrr}
\hline & \multicolumn{3}{c}{$65-74$} & \multicolumn{3}{c|}{$75-84$} & \multicolumn{3}{c}{$\geq 85$} \\
\cline { 2 - 10 } & 2010 & 2015 & $\%$ change & 2010 & 2015 & $\%$ change & 2010 & 2015 & $\%$ change \\
\hline Pedestrians & 502 & 372 & -26 & 375 & 418 & 11 & 89 & 119 & 34 \\
Cyclists & 93 & 73 & -22 & 55 & 71 & 29 & 13 & 21 & 62 \\
Moped riders & 113 & 72 & -36 & 51 & 57 & 12 & 7 & 10 & + \\
Motorcyclists & 115 & 97 & -16 & 43 & 92 & 114 & 4 & 14 & + \\
Car occupants & 78 & 109 & 40 & 32 & 60 & 88 & 11 & 11 & 0 \\
Total & $\mathbf{1 0 3 0}$ & $\mathbf{8 5 7}$ & $\mathbf{- 1 7}$ & $\mathbf{5 9 6}$ & $\mathbf{7 7 8}$ & $\mathbf{3 1}$ & $\mathbf{1 2 6}$ & $\mathbf{1 7 9}$ & $\mathbf{4 2}$ \\
\hline
\end{tabular}




\section{Box 21.1. Road safety for an ageing population (cont.)}

Figure 21.4. Road fatality rates by age group - Focus on the senior population Deaths per 100000 inhabitants in a given age group, 2009-15

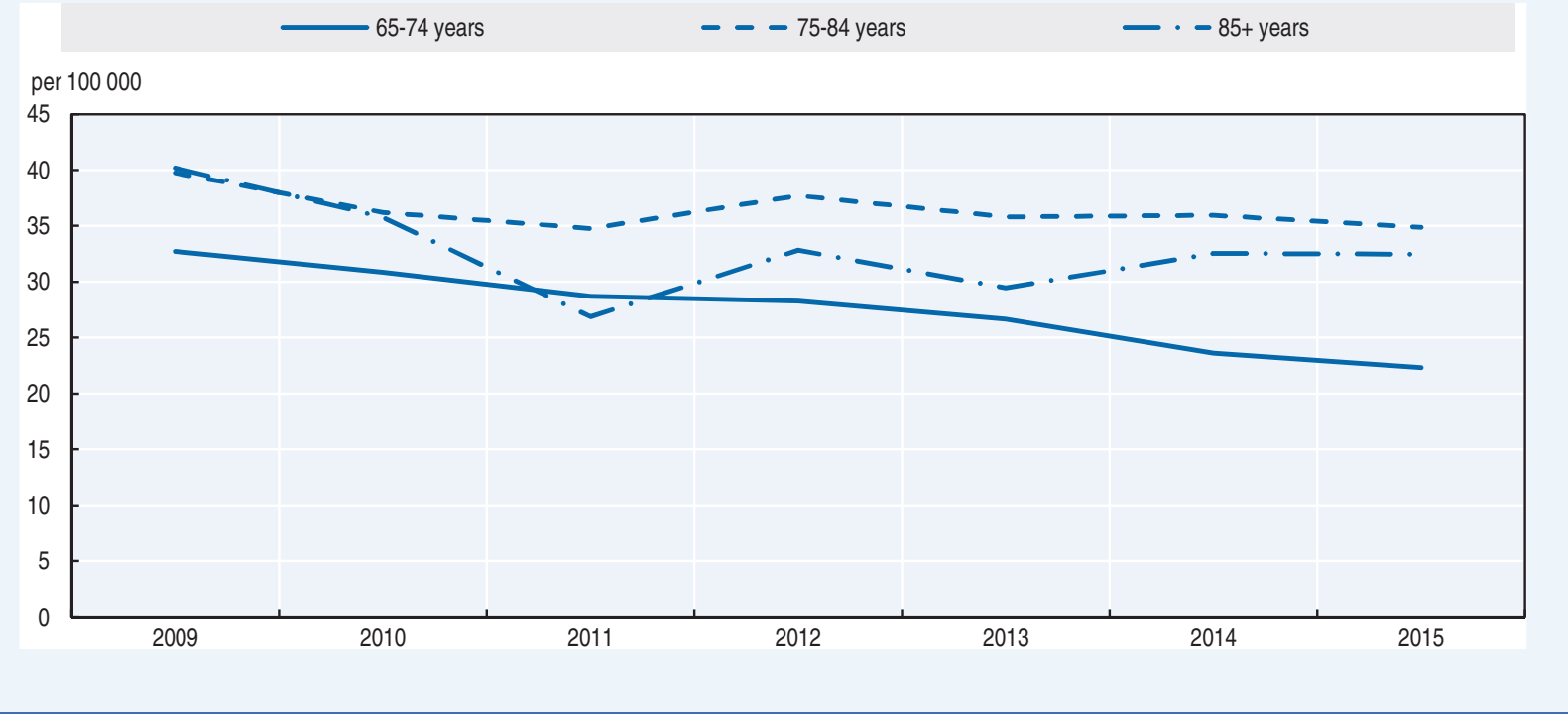

Figure 21.5. Road fatality rate by age and road user group Fatalities per 100000 inhabitants, 2015

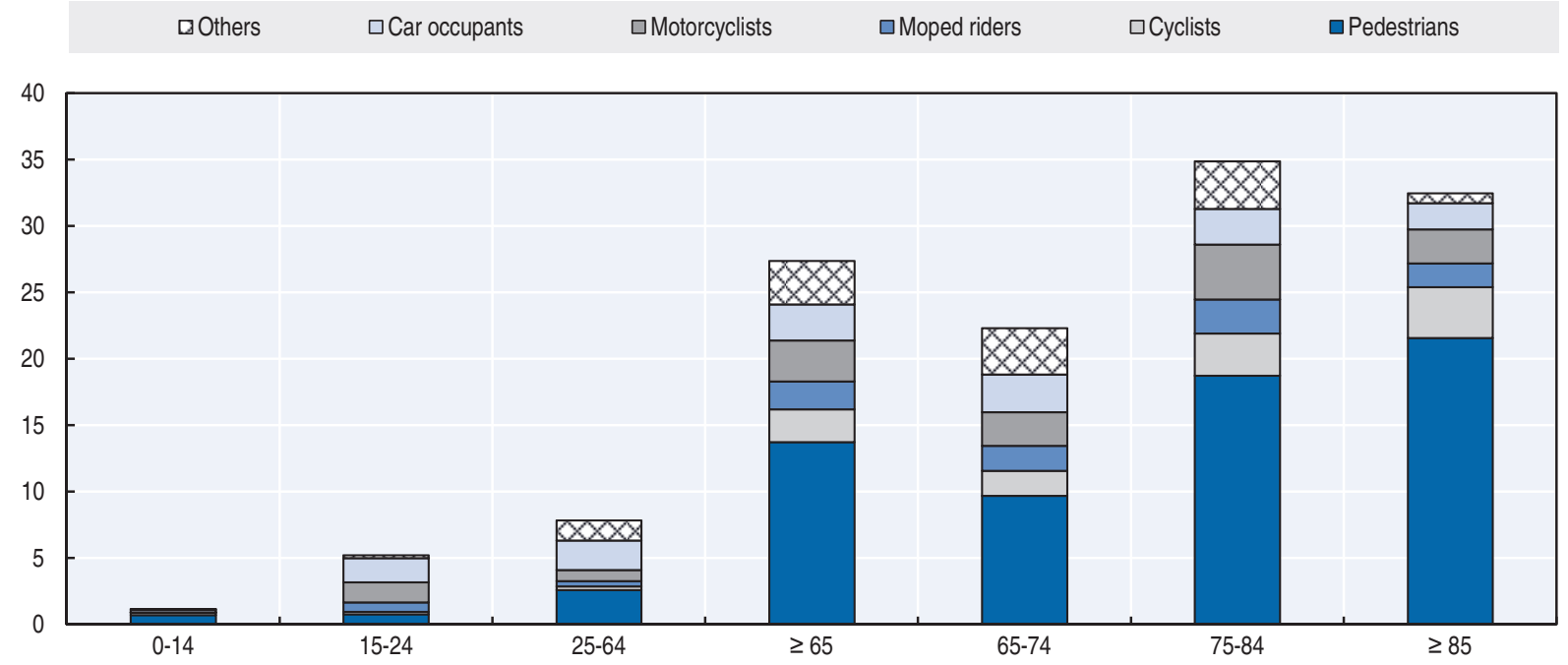

\section{Road safety by road type}

In 2015, the number of fatalities was shared equally between urban and non-urban areas, with $47 \%$ of fatalities on rural roads, $51 \%$ on urban roads and about $2 \%$ on motorways. Since 2000 , the greatest reduction has been achieved on motorways $(-86 \%)$. The good performance on motorways is explained by stronger police enforcement, treatment of black spots, construction of rumble strips, prevention campaigns on fatigue and the installation of rest areas. 
Figure 21.6. Road fatalities by road type

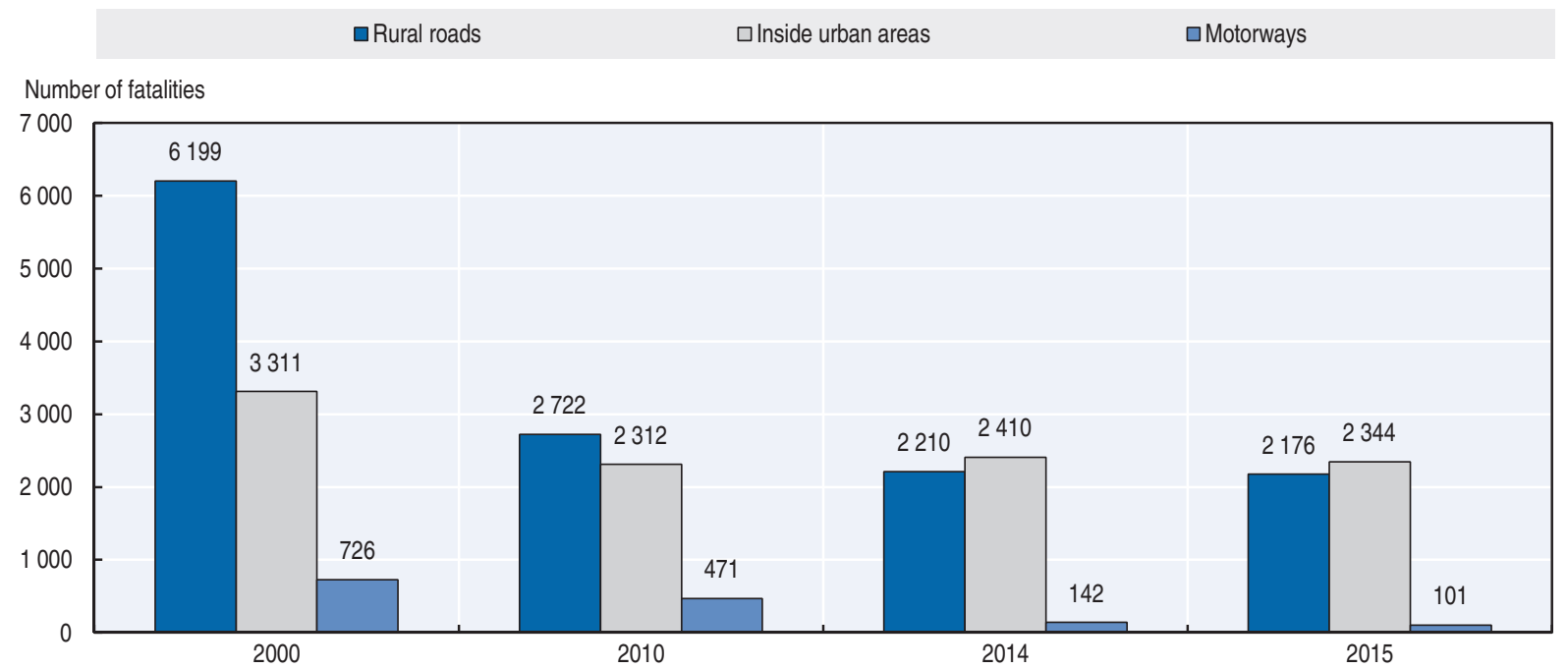

\section{Economic costs of traffic crashes}

Since 1992, KoROAD has calculated the economic cost of road crashes using the Gross Loss of Output Approach on an annual basis. The most recently published estimation of road crash cost is based on 2015 crash data (KoROAD, 2015).

The cost of crashes is calculated taking into account the direct costs such as vehicle damage, hospital and administration costs as well as the costs of future lost output. The calculation includes the following elements:

- Direct costs:

* property damaged, costs for repairs and replacement of infrastructure components and vehicle parts

* medical or funeral costs for casualties

* compensation for casualties from insurance companies.

- Indirect costs:

* administration costs for police and insurance companies

* ambulance costs

- Lost output of casualties.

Traffic crashes represent a significant cost for society, estimated in 2015 at around USD 25.2 billion, or about $1.7 \%$ of Korea's GDP. The costs are based on police crash data and information from insurance companies. These costs do not take into account the cost of suffering and pain. 
Table 21.5. Unit costs by casualty severity, 2015

\begin{tabular}{lc}
\hline Cost (KRW) & Unit cost \\
\hline Fatalities & $430964400 \mathrm{KRW}$ \\
& Approx. $380882 \mathrm{USD}$ \\
Serious injuries & $59712400 \mathrm{KRW}$ \\
& Approx $52773 \mathrm{USD}$ \\
Slight injuries & $3728100 \mathrm{KRW}$ \\
& Approx $3294 \mathrm{USD}$ \\
Injuries less than 3 days & $1749700 \mathrm{KRW}$ \\
& Approx $1546 \mathrm{USD}$ \\
\hline
\end{tabular}

Source: KoROAD (2015).

\section{Recent trends in road user behaviour} Speed

The table below summarises the main speed limits in Korea. In 2012, the speed limit in urban areas was reduced from $80 \mathrm{~km} / \mathrm{h}$ to $60 \mathrm{~km} / \mathrm{h}$ for two-lane roads. In 2015, as part of a pilot project, the speed limit was lowered from $60 \mathrm{~km} / \mathrm{h}$ to $50 \mathrm{~km} / \mathrm{h}$ or $40 \mathrm{~km} / \mathrm{h}$ in around 118 residential and shopping areas. In 2016, it was planned to lower the speed limit in additional 2000 areas.

Table 21.6. Passenger car speed limits by road type, 2017

\begin{tabular}{ll}
\hline & General speed limit \\
\hline Urban roads & $60 \mathrm{~km} / \mathrm{h}$ \\
& Pilot project underway with 50 and $40 \mathrm{~km} / \mathrm{h}$ in residential and shopping areas \\
Rural roads & One-lane roads: $60 \mathrm{~km} / \mathrm{h}$ \\
& Two or more lane roads: $80 \mathrm{~km} / \mathrm{h}$ \\
Motorways & Urban areas: $100 \mathrm{~km} / \mathrm{h}$ \\
& Outside urban areas: $110 \mathrm{~km} / \mathrm{h}$ \\
\hline
\end{tabular}

\section{Drink driving}

The maximum authorised blood alcohol content (BAC) is $0.5 \mathrm{~g} / \mathrm{l}$.

\section{Distraction}

Since 2008, the use of hand-held mobile phones is not permitted while driving. It is however a behaviour difficult to enforce, as it is strongly dependent on the driver's statement.

\section{Sleepiness and fatigue}

To prevent driver fatigue and sleepiness, the Korea Expressway Corporation installed more than 200 rest areas on the motorway network. It is planned to install 270 additional rest areas in 2017.

\section{Seat belts and helmets}

Seat belt use in front seats has been compulsory since 1990 on all roads. The use of rear seat belts on motorways was made compulsory in 2008, but it is not compulsory on other roads.

The nationwide 2016 observation survey showed that $94 \%$ of drivers, $83 \%$ of front seat passengers and $30 \%$ of rear seat passengers wear seat belts on motorways. 
Table 21.7. Seat belt wearing rate by car occupancy and road type

\begin{tabular}{lccccc}
\multicolumn{7}{c}{$\%$} \\
\hline & 2010 & 2013 & 2014 & 2015 & 2016 \\
\hline Front seat & & & & & \\
$\quad$ Driver (motorway) & 88.5 & 86.7 & 89.1 & 91.0 & 94.4 \\
$\quad$ Passenger (motorway) & 78.2 & 79.1 & 74.6 & 83.2 & 82.6 \\
Rear seats & & & & \\
$\quad$ General (motorway) & 6.3 & 9.4 & 21.8 & 27.5 & 30.2 \\
\hline
\end{tabular}

All riders of powered two-wheelers are required to wear helmets. In 2016, overall helmet use decreased from $88 \%$ to $84 \%$. The wearing rate varies markedly between cities.

There is no mandatory helmet use law for cyclists.

\section{National road safety strategies and targets Organisation of road safety}

In Korea, road safety responsibility is shared among various ministries and agencies.

- The Ministry of Land, Transportation and Infrastructure is responsible for the national trunk road network of motorways and national highways. It also manages vehicle safety and runs the New Car Assessment Program.

- The Ministry of Public Safety and Security oversees road safety particularly for local governments. It contributes to safety strategies for provincial, municipal and county roads.

- The National Police Agency is mainly responsible for traffic enforcement and crash investigation. It also operates traffic signals, crossings and speed enforcement cameras.

- The Korea Transportation Safety Authority is a government agency supporting the Ministry of Land, Transportation and Infrastructure, mainly in charge of vehicle safety.

- KoROAD is a government agency, supporting the National Police Agency, responsible for road traffic management. The agency is in charge of traffic monitoring, drivers' license examinations and management, training and education.

Road safety policy is co-ordinated by the National Transport Safety Committee, an inter-ministerial body. The committee is chaired by the Minister of Land, Transport and Infrastructure. Private professionals can participate in the committee, but in practice the committee does not convene often. The role of the committee is to review road safety policies and measures implemented by the various agencies; however, it does not have a monitoring function, nor does it have a budget or budget allocation power.

\section{Road safety strategy for 2013-17 and 2017-21}

In July 2013, the Office for Government Policy Coordination announced a comprehensive plan for reducing traffic crash casualties for the period 2013-17, including five strategic areas, each with a set of targeted measures:

- Improvement of road user behaviour

- Provision of safe transport infrastructure

- Operation of a smart transport system

- Enforcement of the safety management system

- Enhancement of the emergency response system 
In 2016, the eighth National Safety Transport Plan 2017-21 was announced.

\section{Road safety targets}

Three principal targets have been set for 2021

- Reducing the number of road fatalities to less than 2700 , with interim targets for each year from 2017-21

- Reducing the rate of fatalities per 100000 inhabitants to 5.2

- Reducing the rate of fatalities per 10000 vehicles (including mopeds) to below 1.00, in order to be ranked in the middle range of OECD member countries

Table 21.8. Targets and interim targets to 2021

\begin{tabular}{lcccccc}
\hline & 2015 & 2017 & 2018 & 2019 & 2020 & 2021 \\
\hline Fatality target & 4621 & 3976 & 3787 & 3437 & 3071 & 2700 \\
Fatalities per 100000 inhabitants & 9.1 & 7.8 & 7.4 & 6.7 & 6.0 & 5.2 \\
Fatalities per 10 000 vehicles (including mopeds) & 1.9 & 1.5 & 1.4 & 1.3 & 1.1 & 1.0 \\
\hline
\end{tabular}

Figure 21.7. Trends in road fatalities towards national target

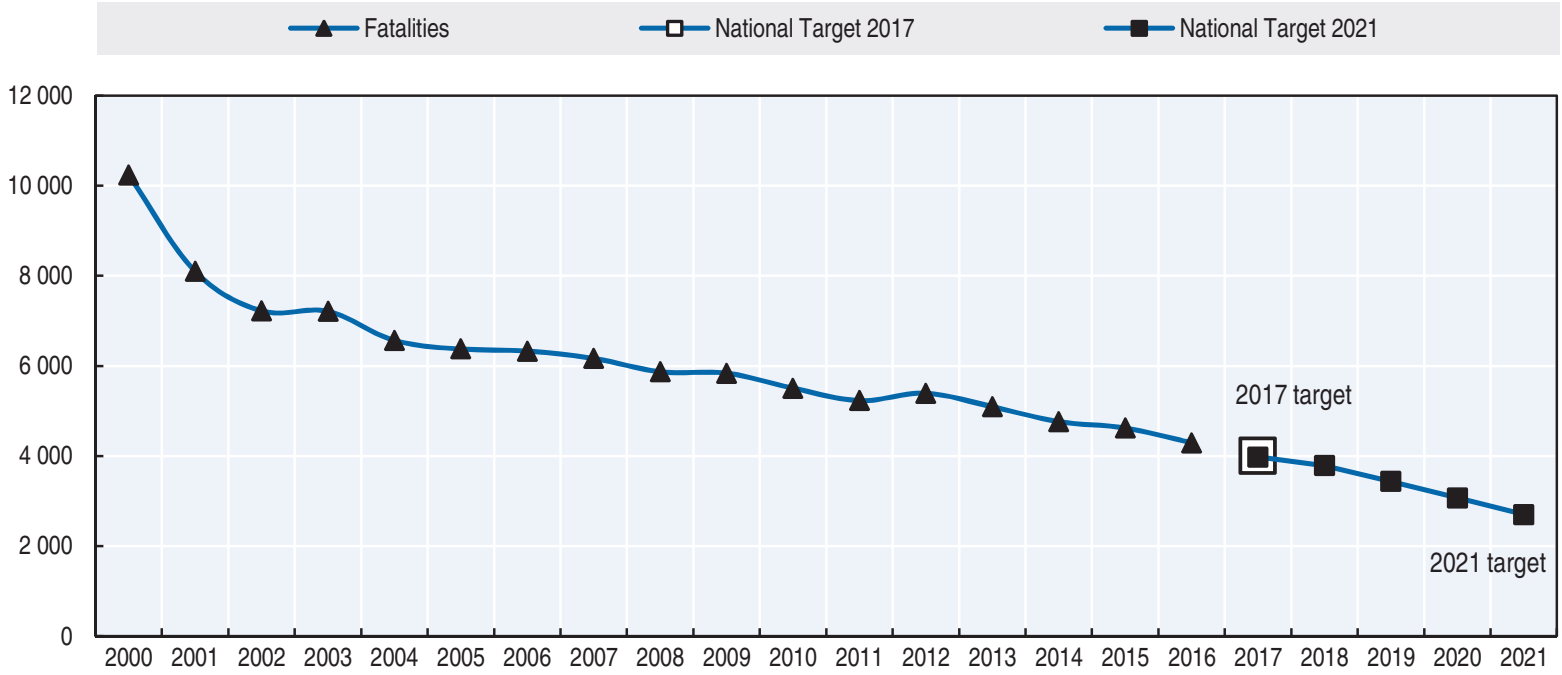

\section{Recent safety measures (2014-17)}

\section{Institutional organisation}

- The responsibility for developing road safety measures is being progressively transferred from the National Police Agency to local governments, with the creation of local autonomous police agencies. Local governments manage and promote their traffic crash-reducing measures by creating their own police organisations.

\section{Speed management}

- Speed limits have been reduced from $60 \mathrm{~km} / \mathrm{h}$ to 40 or $50 \mathrm{~km} / \mathrm{h}$ in 118 residential and shopping areas. This is being progressively extended to additional areas. In residential areas where there is dense pedestrian activity, the speed limit was reduced to $30 \mathrm{~km} / \mathrm{h}$.

- Intense speed enforcement, especially around black spot areas. 


\section{Pedestrian safety}

- In 2016, the police announced a comprehensive road safety plan for the period 2016-18 focusing on pedestrian safety.

\section{Infrastructure}

- construction of additional roundabouts (ongoing)

- designation of Silver Zones near facilities for the elderly (ongoing)

- additional designation of Pedestrian Priority Zones (ongoing)

- construction of additional rest areas along highways (ongoing)

- construction of additional pedestrian crossings to limit to less than 200 metres the distance between two crossings (2016)

- installation of safety fences to prevent jaywalking.

\section{Vehicles}

- Attachment of a safety evaluation label, to provide safety information on manufactured vehicles on a systematic basis, became obligatory in 2014 .

- The National Police Agency has access to recordings in black boxes that are currently installed in two million cars. These recordings may be used to reduce disputes over crashes.

\section{Recent and ongoing research}

Research is currently being undertaken on the following topics:

- High risk drivers (on the major causes of crashes within this group

- Older drivers (crash patterns)

- Methodologies to assess the driving ability of older drivers.

\section{References}

KoROAD (2015), The Estimation and Evaluation of Road Accidents Costs, Road Traffic Authority, Korea.

World Bank (2017), “GDP (constant US\$)”, World Development Indicators, http://databank.worldbank.org/ data/reports.aspx?source=world-development-indicators (accessed 23 February 2017).

\section{Websites}

- Ministry of Land, Infrastructure and Transport: http://english.molit.go.kr (accessed 9 May 2017).

- Road Traffic Authority: www.koroad.or.kr (accessed 9 May 2017).

- Korea Transportation Safety Authority: www.ts2020.kr (accessed 9 May 2017).

- Korea Transport Institute (KOTI): http://english.koti.re.kr/ (accessed 9 May 2017). 


\section{Chapter 22}

\section{Lithuania}

This chapter presents 2015 road safety data for Lithuania along with provisional data from 2016. It looks at trends in traffic and road safety from the years 1990 to 2015 and road user behaviour patterns with a special focus on the ageing population. Sections include data on speed, drink driving, drugs and driving, distracted driving, fatigue and seat belt usage. The chapter reviews Lithuania's road safety strategy and national targets to 2017 and the progress achieved thus far. It also provides details of all recently implemented safety measures and current and ongoing research.*

* All data stem from the Road and Transport Research Institute and IRTAD. For more information please contact m.katkus@ktti.lt. 
$\mathrm{T}$ here were 242 road fatalities reported in Lithuania in 2015, a 9.4\% decrease over 2014 and the equivalent of a fatality rate of 8.3 per 100000 . Pedestrians were the prime beneficiaries of this improvement, with a $26 \%$ decrease in fatalities in this group over the previous year. However, pedestrians remain among the most vulnerable road user group, accounting for $33 \%$ of all fatalities. Provisional data from 2016 indicate a second consecutive year with a marked improvement, recording 188 fatalities, a 22\% decrease when compared to 2015.

\section{Road safety data collection}

\section{Definitions applied in Lithuania}

- Road fatality: Any person killed in a traffic crash within 30 days of the crash (prior to 1995, the limit was 7 days).

- Injured persons: As yet, there is no official definition of slight and serious injuries. The concept of using the Maximum Abbreviated Injury Scale of three or more (MAIS3+) for a serious injury is under discussion. Nevertheless, in 2015 police reported the number of traffic injuries by severity, based on health sector definitions:

* Seriously injured: persons suffering a road injury entailing an irreversible mutilation of one part of the body or a loss of more than $30 \%$ of working capacity.

- Lightly injured: persons suffering a road injury for more than 10 days, or a loss of working capacity between 5 and 30\%.

- Slightly injured: persons suffering a road injury for less than 10 days or a loss of working capacity inferior to $5 \%$.

\section{Data collection}

Traffic police collect and manage most crash data in Lithuania. Hospitals and insurance companies also have data on some crashes.

There is no estimate of under-reporting. According to the police, nearly $100 \%$ of injury crash data are collected and recorded in the police database. The data are available to road safety experts for research. Information about the severity of an injury is defined in only $65 \%$ of injury crashes.

Road safety experts lack information to help identify the causes of crashes. Information on road user behaviour is also limited, and information on injury type is not systematically recorded.

\section{Most recent safety data}

\section{Road crashes in 2016 - provisional data}

Based on provisional data, there were 188 persons killed in road traffic in 2016, a decrease of more than $22 \%$ compared to 2015 . However, the number of injury crashes as well as the number of injured persons both increased by $8 \%$ for the same time period. 
Pedestrians and car occupants accounted for the greatest share of all fatalities (37\% and $44 \%$, respectively).

\section{Road crashes in 2015}

In 2015, 3033 injury crashes were recorded, in which 242 road users were killed. This corresponds to a $9.4 \%$ decrease in fatalities compared to 2014 , while the number of road crashes decreased by $6.8 \%$.

Pedestrians benefited the most from these improvements with an almost $26 \%$ decrease in the number of fatalities. Road fatalities increased for all other road user groups for the same time period.

\section{Trends in traffic and road safety (1990-2016) Traffic}

Between 1990 and 2015, the number of passenger cars was multiplied by 2.4. Unlike most European countries, the motorcycle fleet was more than halved. Before 1990 (when Lithuania was part of the Soviet Union), most people travelled on motorcycles, as for many this was the only affordable mode of individual motorised transport. From 1990 onward, when personal income started to grow, the vehicle market expanded and cars became affordable for many Lithuanian citizens who decided to exchange their motorcycle for a private car.

A new vehicle registration procedure was introduced in July 2014. Vehicles failing to meet the requirements of compulsory civil liability insurance and/or technical inspections were removed from the register. In practice one-third of the vehicles were removed from the register. It is therefore not possible to compare the evolution in the vehicle fleet before and after 2014.

In 2016, traffic volume (expressed in vehicle-kilometres driven) increased by $4.7 \%$ compared to 2015 .

\section{Road safety}

\section{Crashes and casualties}

The number of road fatalities peaked in 1991 with 1267 road deaths. Since then it has been divided by nearly five, while the number of motor vehicles has gradually increased.

Since 1991, road safety can be analysed for the following periods:

- 1992-96: In 1992, a significant reduction in the number of fatalities was observed, immediately after the fall of the Soviet Union. The following years saw dramatic changes politically, as well as economic austerity. Nevertheless there was a positive impact on road safety, mainly through the introduction of safer European vehicles into the market.

- 1997-2000: A slight increase was seen in the number of traffic fatalities, which reached a new peak in 1998. The number of casualties then dropped over the next two years as a result of an economic crisis in neighbouring Russia.

- 2000-07: The economic situation in Lithuania started to improve and brought a rapid increase in traffic volume, which was accompanied by a yearly increase in road traffic fatalities.

- 2008-15: An important breakthrough was achieved in 2008 with growing awareness among citizens of road safety issues and the leading role of the EU in setting a target to reduce by 50\% the number of fatalities between 2001 and 2010, which many countries 
achieved. In 2010 Lithuania reached the EU road safety target. The economic downturn in 2008-10 also probably contributed to a reduction in traffic and a decrease in the number of road fatalities.

Having successfully implemented the European target of reducing the number of deaths caused by road accidents by half in the period 2001-2010, since 2011 Lithuania have been working towards the new strategic objective defined in the National Traffic Safety Development Programme for 2011-2017. The main objectives are to rank among the 10 European Union states with the best results and to reduce the mortality rate below 60 fatalities per million inhabitants.

\section{Rates}

In 2015, the average mortality rate was of 8.4 road deaths per 100000 inhabitants, less than a third of the 1990 rate. Yet, it remains much higher than the EU27 average of 5.2 and the national target of less than 6 killed per 100000 inhabitants by 2017.

Table 22.1. Road safety and traffic data

\begin{tabular}{|c|c|c|c|c|c|c|c|c|c|}
\hline & \multirow{2}{*}{1990} & \multirow{2}{*}{2000} & \multirow{2}{*}{2010} & \multirow{2}{*}{2014} & \multirow{2}{*}{2015} & \multicolumn{4}{|c|}{$2015 \%$ change from } \\
\hline & & & & & & 2014 & 2010 & 2000 & 1990 \\
\hline \multicolumn{10}{|l|}{ Reported safety data } \\
\hline Fatalities & 1081 & 641 & 299 & 267 & 242 & -9.4 & -19.1 & -62.2 & -77.6 \\
\hline Injury crashes & 5135 & 5807 & 3530 & 3255 & 3033 & -6.8 & -14.1 & -47.8 & -40.9 \\
\hline Deaths per 100000 inhabitants & 29.3 & 18.3 & 9.5 & 9.1 & 8.4 & -8.7 & -12.9 & -54.6 & -71.7 \\
\hline Deaths per 10000 registered vehicles & 12.7 & 5.0 & 1.4 & 1.8 & 1.6 & -12.9 & 12.0 & -68.7 & -87.7 \\
\hline \multicolumn{10}{|l|}{ Traffic data } \\
\hline Registered vehicles ${ }^{1}$ (thousands) & 849 & 1286 & 2145 & 1489 & 1549 & 4.0 & -27.8 & 20.4 & 82.6 \\
\hline Vehicle-kilometres (millions) ${ }^{2}$ & & & & 1085 & 1111 & 2.3 & & & \\
\hline Registered vehicles per 1000 inhabitants & 230 & 366 & 683 & 506 & 530 & 4.8 & -22.3 & 44.8 & 130.8 \\
\hline
\end{tabular}

1. With mopeds.

2. On roads of national significance.

Figure 22.1. Road safety, traffic and GDP trends index $1995=100$

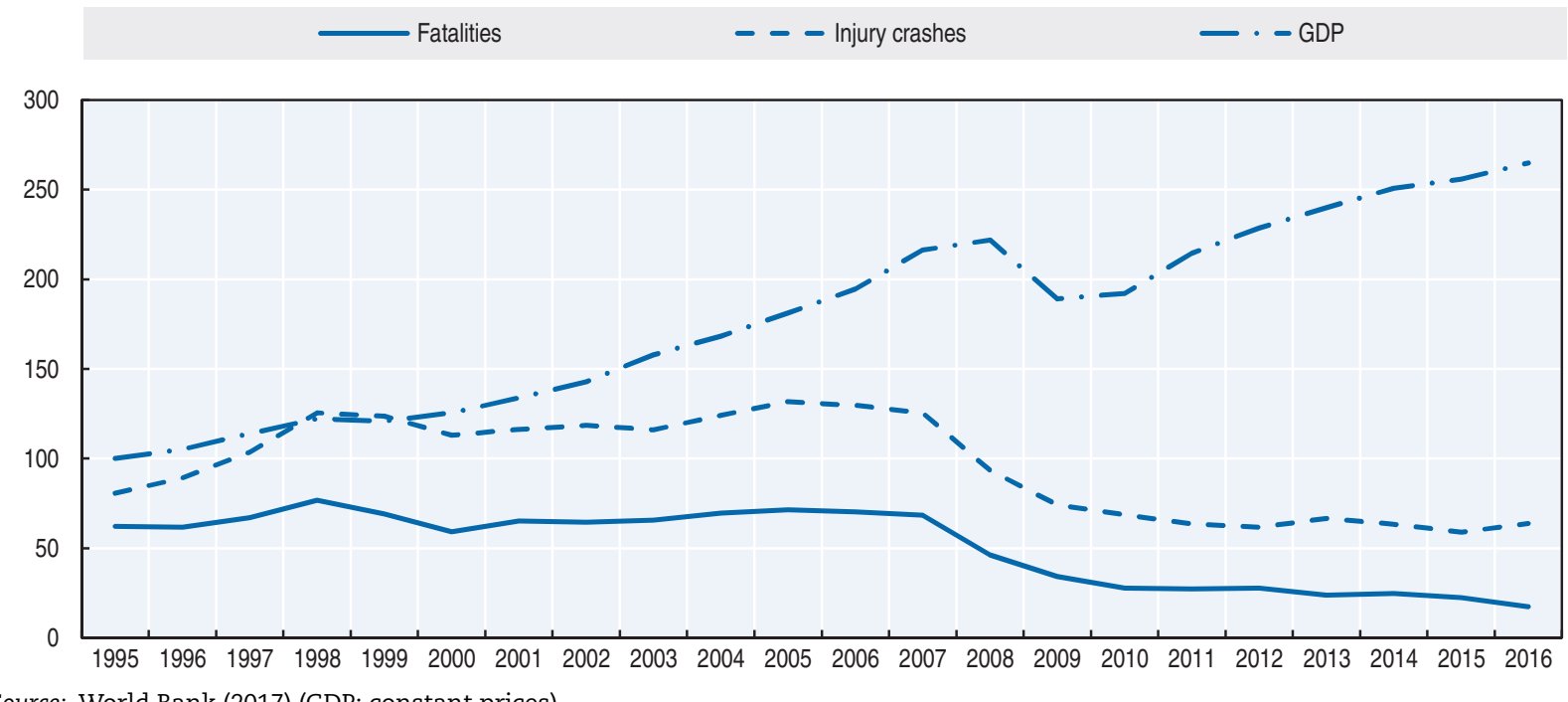

Source: World Bank (2017) (GDP; constant prices). 


\section{Road safety by user group}

Car occupants and pedestrians are the main victims of traffic crashes. Pedestrians in particular represent one-third (33\%) \% of casualties, while car occupants account for $48 \%$ of the all fatalities.

Moped riders and motorcyclists account for only $1 \%$ and $6 \%$ of the all fatalities, reflecting their modal share in overall traffic.

Table 22.2. Road fatalities by road user group

\begin{tabular}{lrrrr|rrr}
\hline & 2010 & 2013 & 2014 & 2015 & \multicolumn{3}{c}{$2015 \%$ change from } \\
\cline { 6 - 8 } & & & & & 2014 & 2013 & 2010 \\
\hline Pedestrians & 108 & 98 & 109 & 81 & -25.7 & -17.3 & -25.0 \\
Cyclists & 23 & 18 & 19 & 22 & 15.8 & 22.2 & -4.3 \\
Moped riders & 3 & 4 & 1 & 3 & & -25.0 & 0.0 \\
Motorcyclists & 15 & 16 & 14 & 14 & 0.0 & -12.5 & -6.7 \\
Car occupants & 130 & 103 & 109 & 115 & 5.5 & 11.7 & -11.5 \\
Others & 20 & 19 & 15 & 7 & -53.3 & -63.2 & -65.0 \\
Total & $\mathbf{2 9 9}$ & $\mathbf{2 5 8}$ & $\mathbf{2 6 7}$ & $\mathbf{2 4 2}$ & $\mathbf{- 9 . 4}$ & $\mathbf{- 6 . 2}$ & $\mathbf{- 1 9 . 1}$ \\
\hline
\end{tabular}

Figure 22.2. Road fatalities by road user group in percentage of total, 2015

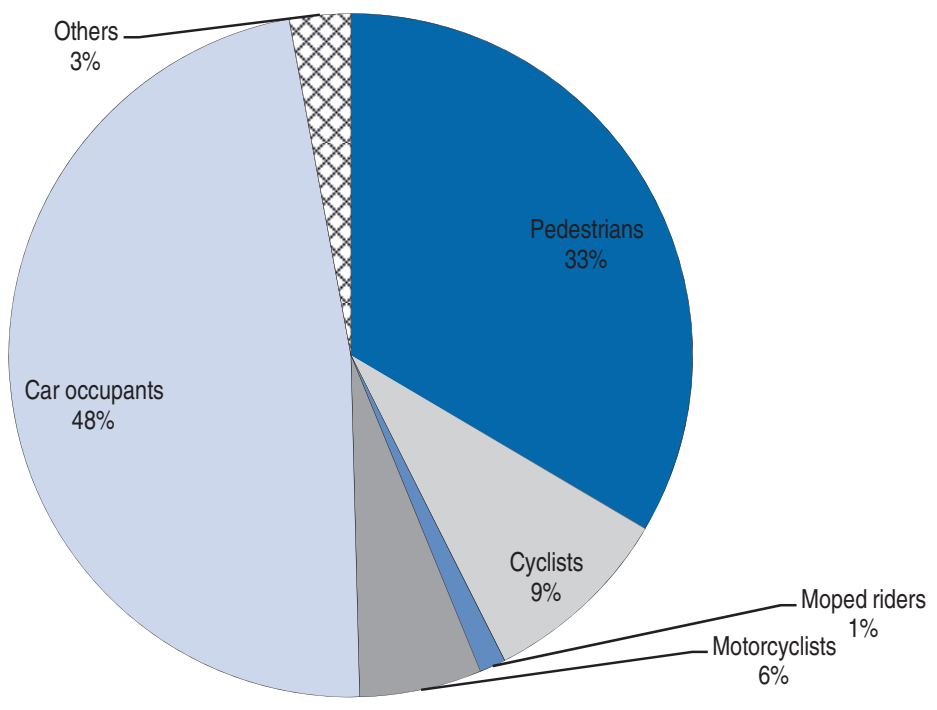

\section{Road safety by age group}

In 2015, all age groups benefitted from improvements in road safety, except the 65+ age group, for which the number of road deaths increased by nearly 35\% from 49 in 2014 to 66 in 2015.

Young people (21-24) as well as those aged 65 years and above are the age groups most at risk with a fatality rate of 12 per 100000 inhabitants. Older people are particularly vulnerable as pedestrians. 
Table 22.3. Road fatalities by age group

\begin{tabular}{|c|c|c|c|c|c|c|c|}
\hline \multirow{2}{*}{ Age } & \multirow{2}{*}{2010} & \multirow{2}{*}{2013} & \multirow{2}{*}{2014} & \multirow{2}{*}{2015} & \multicolumn{3}{|c|}{$2015 \%$ change from } \\
\hline & & & & & 2014 & 2013 & 2010 \\
\hline $0-14$ & 7 & 7 & 15 & 5 & -66.7 & -28.6 & -28.6 \\
\hline $15-17$ & 10 & 2 & 7 & 5 & -28.6 & 150.0 & -50.0 \\
\hline $18-20$ & 18 & 17 & 14 & 9 & -35.7 & -47.1 & -50.0 \\
\hline $21-24$ & 25 & 22 & 20 & 20 & 0.0 & -9.1 & -20.0 \\
\hline $25-64$ & 172 & 155 & 159 & 134 & -15.7 & -13.5 & -22.1 \\
\hline $65-74$ & 34 & 29 & 18 & 29 & 61.1 & 0,0 & $-14,7$ \\
\hline $75-84$ & 26 & 19 & 18 & 27 & 50.0 & 42,1 & 3,8 \\
\hline$\geq 85$ & 3 & 6 & 13 & 10 & -23.1 & 66,7 & 233,3 \\
\hline Total & 299 & 258 & 267 & 242 & -9.4 & -6.2 & -19.1 \\
\hline
\end{tabular}

Figure 22.3. Road fatality rates by age group Deaths per 100000 inhabitants in a given age group, 2009-15

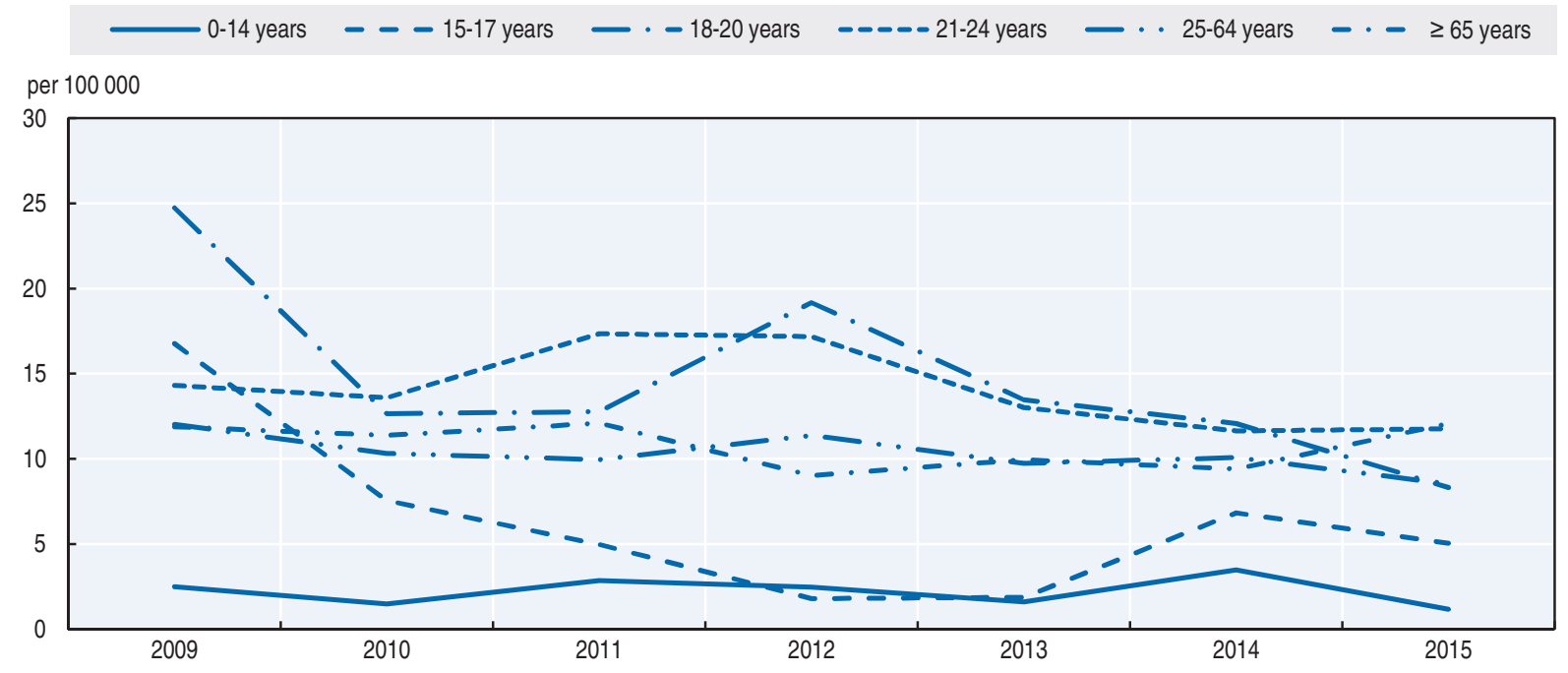

\section{Box 22.1. Road safety for an ageing population}

In Lithuania, the driving licence has to be renewed every ten years. To renew their licence, drivers (including motorcyclists and moped riders) pass a medical examination. After the age of 56, the medical examination must be taken every five years for drivers aged 56-69; every two years for drivers aged 70-79 and every year for those aged 80 and above.

\section{Table 22.4. Road fatalities among senior citizens}

\begin{tabular}{lc|c|c}
\hline & $65-74$ & $75-84$ & $85+$ \\
\cline { 2 - 4 } & 2015 & 2015 & 2015 \\
\hline Pedestrians & 13 & 14 & 7 \\
Cyclists & 6 & 1 & 1 \\
Moped riders & 0 & 0 & 0 \\
Motorcyclists & 0 & 0 & 0 \\
Car occupants & 10 & 12 & 2 \\
Total & $\mathbf{2 9}$ & $\mathbf{2 7}$ & $\mathbf{1 0}$ \\
\hline
\end{tabular}




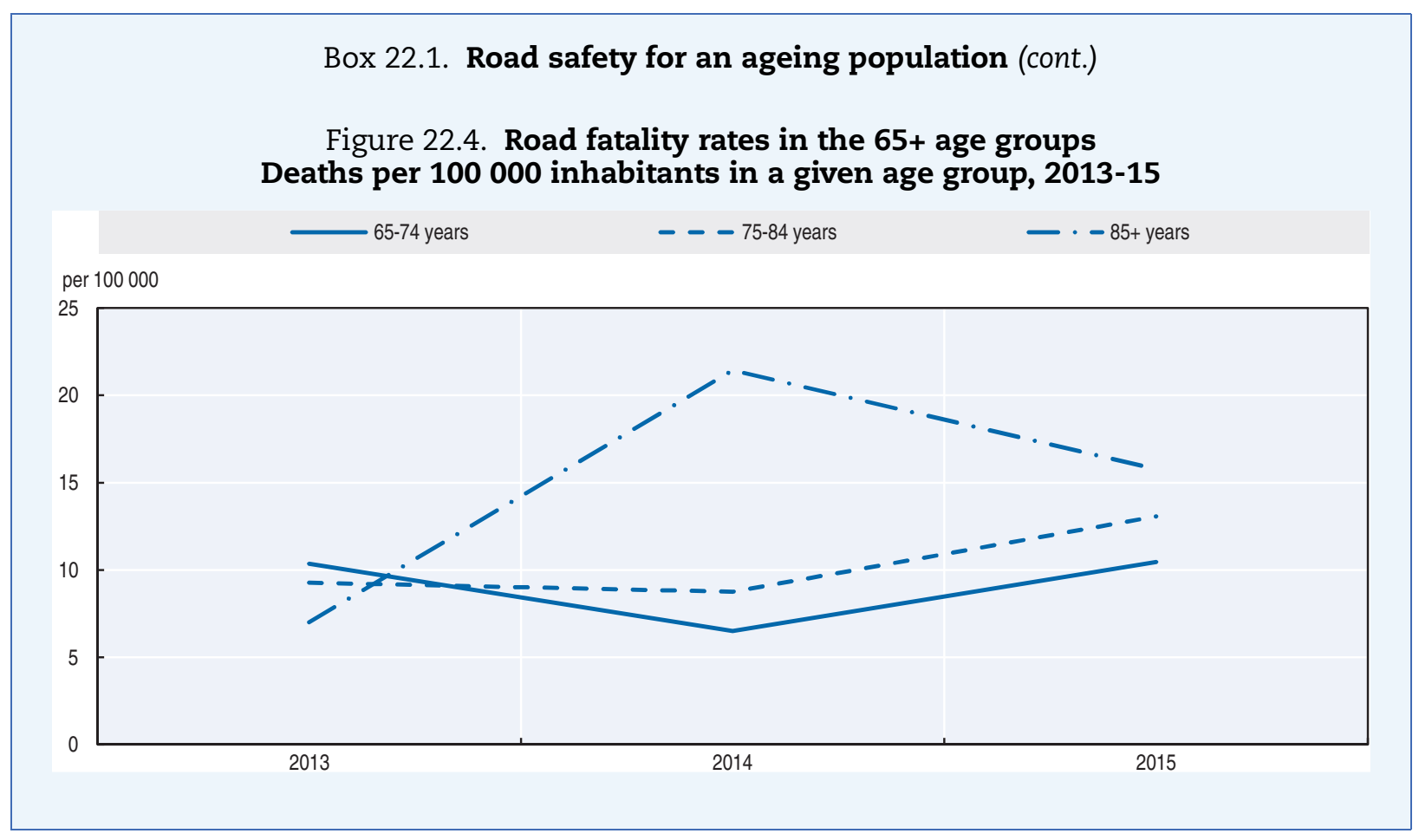

Figure 22.5. Road fatality rate by age and road user group Fatalities per 100000 inhabitants, 2015

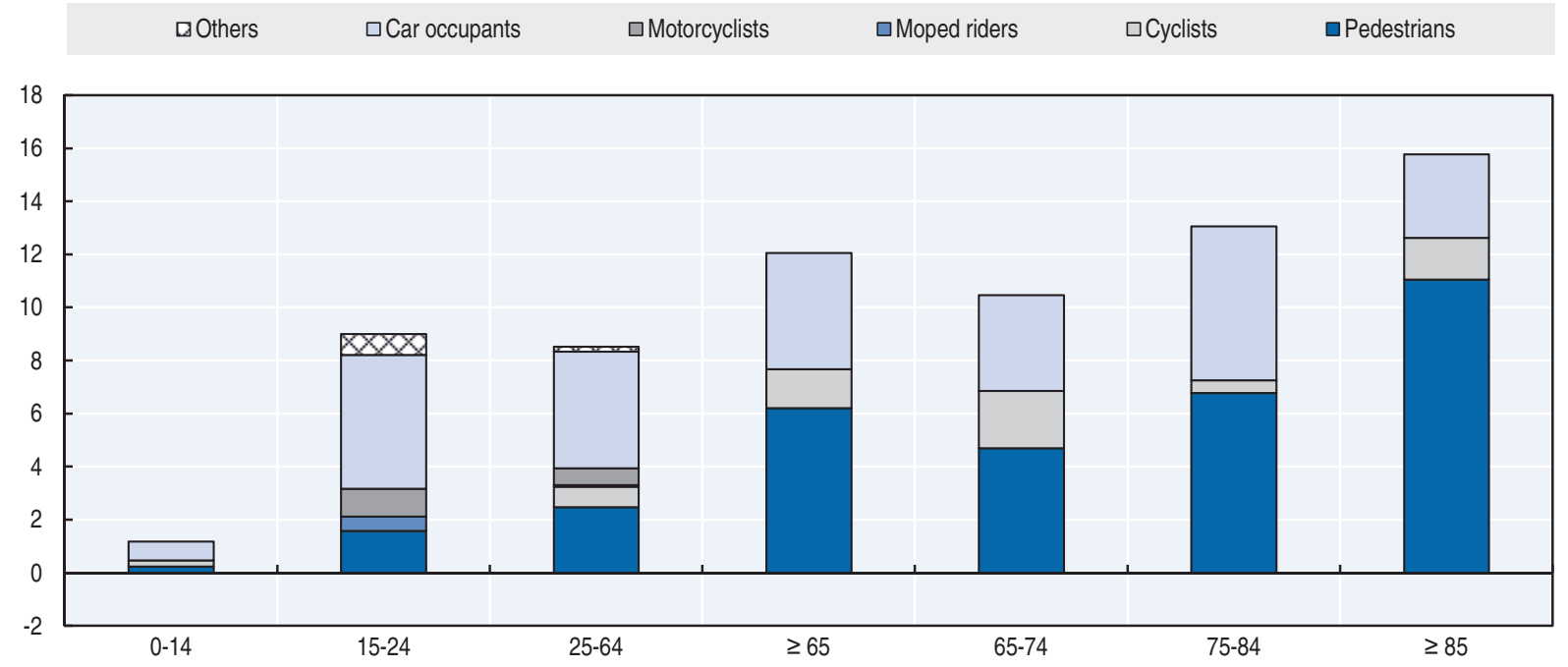

Road safety by road type

In 2015 , most road crashes (71\%) occurred on rural roads. These crashes are also more severe on these roads, as speeds are higher and infrastructure for cyclists and pedestrians less developed.

The most significant improvements achieved in 2015 were on motorways and urban roads, while fatalities on rural roads increased by more than $8 \%$. 
Figure 22.6. Road fatalities by road type

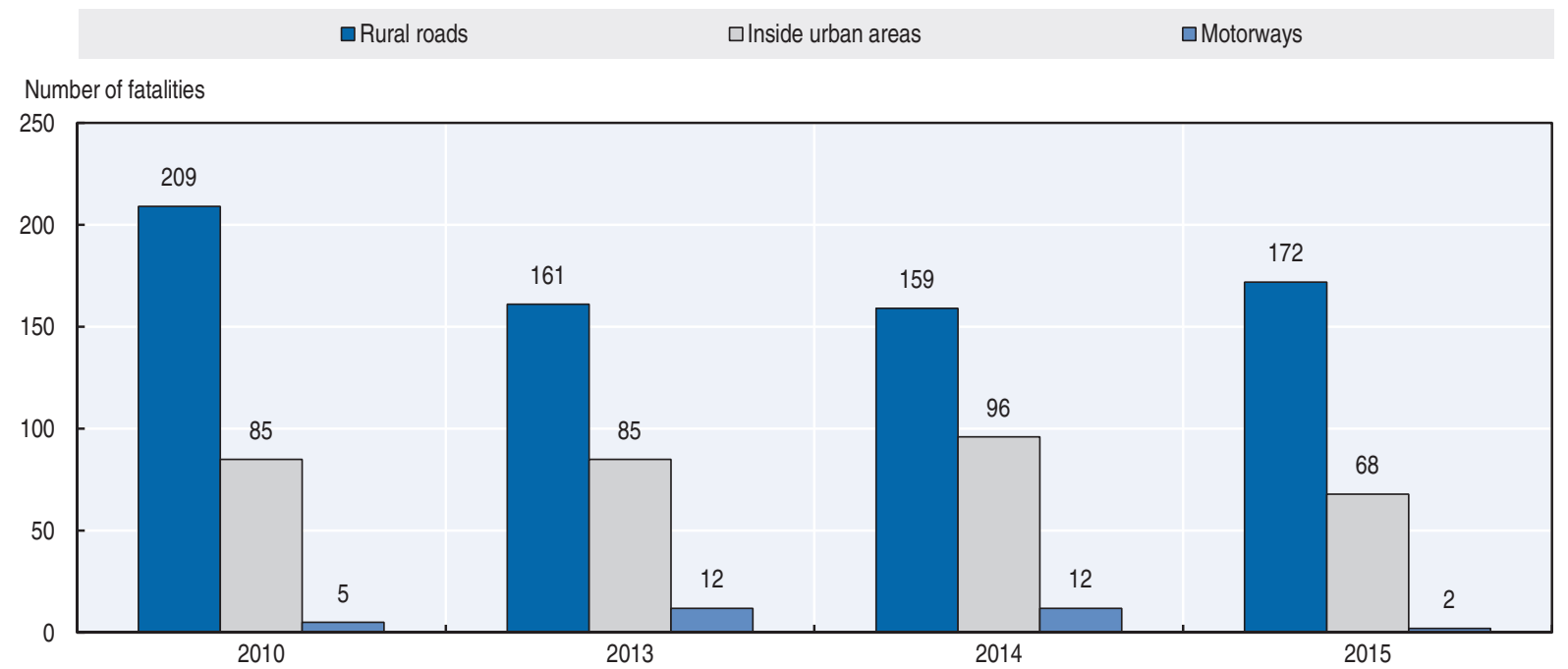

\section{Economic costs of traffic crashes}

Traffic crashes represent a significant cost for society, estimated in 2015 at around EUR 346 million, i.e. 1\% of GDP. Costs are estimated using a "capital approach" method.

Table 22.5. Costs of road crashes, 2015

\begin{tabular}{lc}
\hline Cost (EUR) & Unit cost \\
\hline Fatalities & EUR 147.4 million \\
Injured persons & EUR 198.8 million \\
Property damage costs & Not included \\
Total (EUR) & EUR 346.2 million \\
Total as \% of GDP (at constant prices) & $1 \%$ \\
\hline
\end{tabular}

\section{Recent trends in road user behaviour}

\section{Speed}

According to police data, inappropriate speed is the main cause of traffic crashes in Lithuania. Speeding at $30 \mathrm{~km} / \mathrm{h}$ above the limit is considered a serious violation, incurring severe sanctions, including immediate licence withdrawal for novice drivers.

Observations in 2015 indicate that $16 \%$ to $26 \%$ of all drivers exceed the speed limit by more than $10 \mathrm{~km} / \mathrm{h}$ on different types of state roads. In 2014 research showed that $33 \%$ of drivers exceed the speed limit by more than $10 \mathrm{~km} / \mathrm{h}$ in urban areas. The table below summarises the main speed limits in Lithuania.

Table 22.6. Passenger car speed limits by road type, 2017

\begin{tabular}{lll}
\hline \multicolumn{2}{c}{ General speed limit } & \multicolumn{1}{c}{ Comments } \\
\hline Urban roads & $50 \mathrm{~km} / \mathrm{h}$ & - \\
Rural roads & $90 \mathrm{~km} / \mathrm{h}(70 \mathrm{~km} / \mathrm{h}$ on gravel roads $)$ & $70 \mathrm{~km} / \mathrm{h}$ for novice drivers (driving experience of less than 24 months) \\
Motorways & 120 or $130 \mathrm{~km} / \mathrm{h}(110 \mathrm{~km} / \mathrm{h}$ in winter $)$ & $90 \mathrm{~km} / \mathrm{h}$ for novice drivers \\
\hline
\end{tabular}




\section{Drink driving}

The general maximum authorised blood alcohol content (BAC) in Lithuania is $0.4 \mathrm{~g} / \mathrm{l}$ and since 1 May 2015, $0.0 \mathrm{~g} / \mathrm{l}$ for novice drivers (less than 24 months driving experience), professional drivers, moped and motorcycle drivers.

Drivers that tested positive for being under the influence of alcohol have their licence withdrawn for 12-36 months and are fined EUR 150-900. The most dangerous violations (and repeat drink-driving offences) can be punished by an administrative arrest for 10-30 days. In 2015 , drink driving contributed to $8 \%$ of road crashes.

Between 2004 and 2015, the number of alcohol-related crashes was halved. However, the share of crashes due to drink driving has remained stable at about $10 \%$.

Important legislation changes entered into force in 2016. Since 1 January 2016, it is prohibited to sell alcohol in petrol stations. Since 1 April 2016, driving with a BAC of $1.5 \mathrm{~g} / \mathrm{l}$ and above is considered as a crime and subject to a sanction of up to one year imprisonment.

\section{Drugs and driving}

Drivers that test positive for driving under the influence of drugs are subject to a fine of EUR 300-900 and licence withdrawal of 12-36 months. They can also be subject to 10-30 days administrative arrest.

In 2015, it was reported that 2 injury road crashes involved drivers under the influence of drugs.

\section{Seat belts and helmets}

Seat belt wearing is compulsory in all seats. Children below $135 \mathrm{~cm}$ in height must use dedicated child restraints.

According to police data, in $2015,37 \%$ of killed car occupants and $33 \%$ of killed drivers were not wearing a seat belt when the crash occurred.

Based on a 2016 survey on roads of national significance, $98 \%$ of car drivers and $97 \%$ of front seat passengers were wearing a seatbelt, while only $26 \%$ of rear seat passengers did so.

Table 22.7. Seat belt wearing rate by car occupancy on roads of national significance

\begin{tabular}{lll}
\multicolumn{2}{c}{$\%$} & \\
\hline & 2014 & \\
\hline Front seat & & $98^{\star}$ \\
General (driver + passengers) & $96^{\star}$ & $98^{\star}$ \\
Driver & $97^{\star}$ & $97^{\star}$ \\
Passenger & $95^{\star}$ & \\
Rear seats & & $26^{\star}$ \\
General & $33^{\star}$ & n.a \\
Children (use of child restraint) & n.a & \\
\hline
\end{tabular}

All riders of powered two-wheelers are required to wear a helmet. Cyclists under 18 years old must wear a helmet. 


\section{Distraction}

It is not permitted to drive using a hand-held mobile phone. Hands-free mobile phones may be operated. There is no estimate of the number of fatal crashes due to the use of mobile phones.

\section{National road safety strategies and targets \\ Organisation of road safety}

The main stakeholder is the Ministry of Transport and Communications of the Republic of Lithuania, supported by the Lithuanian Road Administration. Police and municipalities are also agencies responsible for road safety.

Nominated by the government, the State Traffic Safety Commission comprises representatives of state and municipal administration bodies and NGOs. The commission makes recommendations on road safety policy.

\section{Road safety strategy for 2011-20}

Following the encouraging results in the past decade, Lithuania has developed a new National Traffic Safety Development Programme for 2011-17, based on the long-term vision that no one should be killed or seriously injured on Lithuanian roads.

\section{Road safety targets}

Lithuania successfully achieved the European target of reducing the number of traffic deaths by $50 \%$ in the period $2001-10$. The number of fatalities was reduced by $58 \%$, from 706 to 299.

The target of the 2011-17 programme is to reach a mortality rate of fewer than six killed per 100000 inhabitants (or 60 per million inhabitants), in order to be ranked among the best performing countries in the European Union. To achieve this objective, it is planned to improve:

- road user behaviour

- vehicle safety

Figure 22.7. Trends in road fatalities towards national target

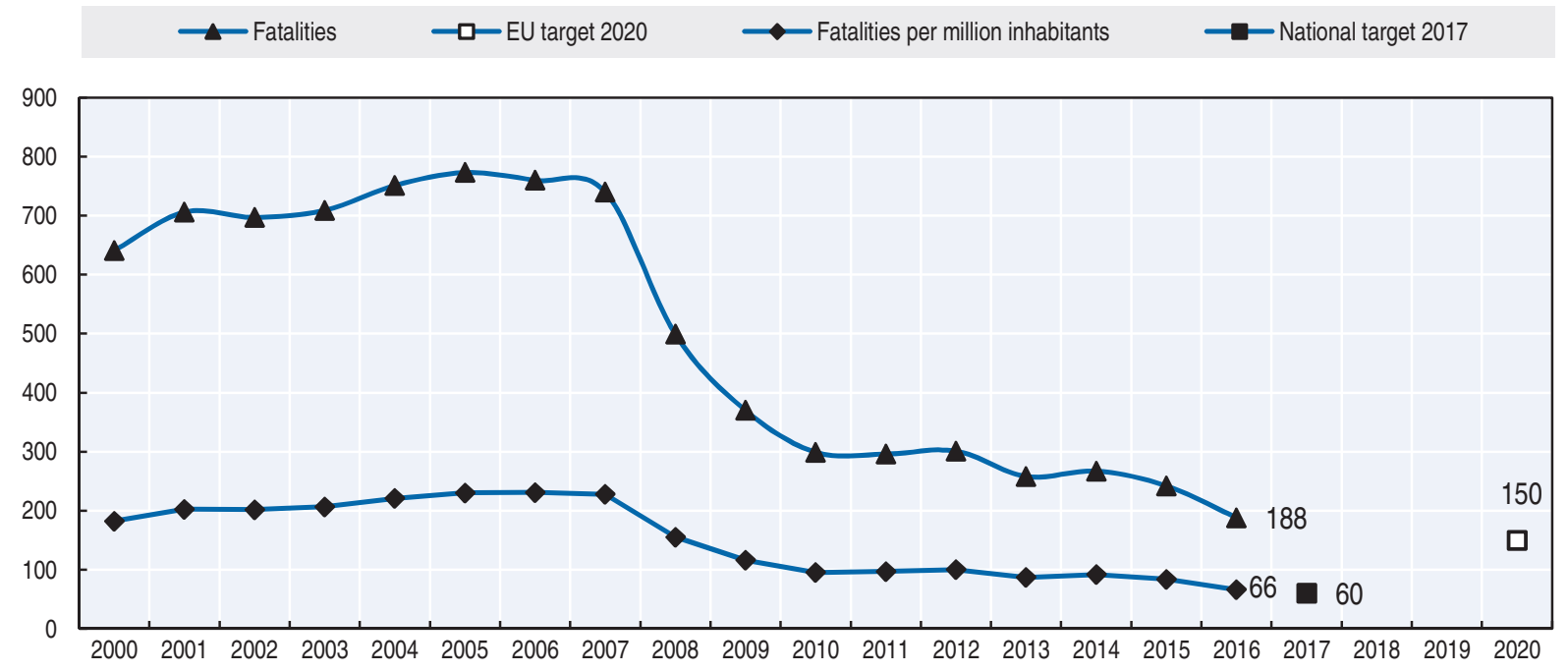


- infrastructure

- the rescue service quality

- the crash data collection system.

\section{Recent safety measures (2014-17)}

\section{Road safety management}

Recent road safety management measures focused on the following areas:

- implementation of the EU Directive 2008/96/EC on road infrastructure safety management

- implementation of road network safety management (high risk site ranking, black spot management); road safety inspections; road safety audits and road safety impact assessment.

\section{Drink driving}

- Since 1st January 2016, it is forbidden to sell alcohol in petrol stations.

- Since 1 May 2015, there is a $0.0 \mathrm{~g} / \mathrm{l}$ maximum authorised BAC level for novice drivers (less than 24 months driving experience), professional drivers, moped and motorcycle drivers.

\section{Cyclist safety}

- Since 2014, cyclists are required to wear a bright coloured and reflective vest during the day (it was already compulsory at night), or alternatively to cycle with lights on.

\section{Infrastructure}

- In 2014, a national method to manage city black spots was approved and a pilot project was implemented for the five largest cities. Every year since then Kaunas (the second largest city in Lithuania) has used this method to identify and treat black spots. See: www.kaunas.lt/transportas/juoduju-demiu-zemelapis/ (accessed 26 June 2017).

\section{Vehicles}

- In 2014, registration of modified right-hand drive vehicles was prohibited.

- Since 2014, "End of life" vehicles cannot be registered and are not allowed to circulate.

\section{References}

World Bank (2017), “GDP (constant US\$)”, World Development Indicators, http://databank.worldbank.org/ data/reports.aspx?source=world-development-indicators (accessed 23 February 2017).

\section{Websites}

- Ministry of Transport and Communications of the Republic of Lithuania: http://sumin.lru.lt/ (accessed 26 June 2017).

- Road and Transport Research Institute: www.ktti.lt (accessed 26 June 2017).

- Lithuanian Road Administration: www.lra.lt (accessed 26 June 2017).

- State Enterprise Regitra: www.regitra.lt/en/general/ (accessed 26 June 2017). 



\section{Chapter 23}

\section{Luxembourg}

This chapter presents 2015 road safety data for Luxembourg along with provisional data from 2016. It looks at trends in traffic and road safety from the years 1990 to 2015 and road user behaviour patterns. This includes data on speed, drink driving, drugs and driving, distracted driving, fatigue and seat belt usage. The chapter reviews Luxembourg's road safety strategy and national targets to 2020 and the progress achieved thus far. It also provides details of all recently implemented safety measures and current and ongoing research. ${ }^{*}$

* All data stem from STATEC unless otherwise noted. For more information please contact: MarieJo.Airoldi@statec.etat.lu. 
Luxembourg recorded one additional fatality in 2015 compared to 2014, bringing the total to 36 . The number of road crashes and those seriously injured increased to a greater degree by $8 \%$ and $30 \%$ respectively. Luxembourg is the most popular cross-border destination in Europe with $42 \%$ of the workforce commuting from Belgium, France or Germany. It also has one of the highest motorisation rates in Europe. Approximately $25 \%$ of fatalities are non-residents and 45\% are speed-related. Provisional data from 2016 show a decrease in fatalities to 32 and of serious injuries to 249 . The current fatality rate is 6.4 per 100000 inhabitants.

\section{Road safety data collection}

\section{Definitions applied in Luxembourg}

- Road fatality: Person killed in a traffic crash or who died because of an injury within 30 days of the crash.

- Serious injury: Injury causing a person to be hospitalised for at least 24 hours.

- Slight injury: Injury requiring less than 24 hours of hospitalisation.

Luxembourg is currently not using the Maximum Abbreviated Injury Scale of three or more (MAIS+3) to define serious injuries, however the Ministry of Health, the Ministry of Transport and hospitals are working towards that objective.

\section{Data collection}

Crash data are collected by the police called to the scene of crashes and consolidated at national level by the national statistical institute STATEC. STATEC also compiles a list of fatal crashes reported in general media. This list is used to double check the number of fatal crashes.

\section{Most recent safety data}

\section{Road crashes in 2016}

In 2016, the number of fatalities was 32, i.e. a decrease of four fatalities in comparison to 2015. There were 249 seriously injured persons.

\section{Road crashes in 2015}

In 2015, 36 people lost their lives on the road in Luxembourg, one fatality more than in 2014. The number of injury crashes increased for the same time period by $8 \%$ and the number of injured persons hospitalised by $30 \%$, up to 319 persons compared to 245 injured in 2014.

Speeding was the presumed contributing factor for $45 \%$ of all fatalities. Speeding is the presumed contributing factor for $38 \%$ of all fatalities and serious injuries. It is estimated that $20 \%$ of road fatalities or seriously injured casualties are due to drink driving and $15 \%$ due to drivers not respecting the priority indicators. 


\section{Trends in traffic and road safety (1990-2015) Traffic}

As Luxembourg is bordered by larger countries there is much traffic in transit (including heavy goods vehicles). In 2015, Luxembourg was the most common destination for cross-border commuters in the EU with 181000 cross-border inbound commuters from neighbouring countries, with approximately $42 \%$ of the workforce in Luxembourg commuting from Belgium, Germany and France. The high proportion of cross-border inbound commuters in Luxembourg reflects to a high degree on the traffic at rush hours.

Moreover, Luxembourg has a very high motorisation rate, among the highest of EU countries (743 cars/1 000 inhabitants).

Fuel is cheaper than in neighbouring countries, which attracts many car drivers from elsewhere to refuel in Luxembourg.

\section{Road safety}

\section{Crashes and casualties}

The peak in road fatalities in Luxembourg was in 1970 with 132 road deaths. Since then fatalities have been declining while motorisation has significantly increased.

Between 1990 and 2014, the number of fatalities has globally followed a downward trend with some fluctuations. In recent years (2000-14), the number of fatalities was halved.

Compared to 2010 , the number of fatalities increased by 4 persons and those seriously injured increased by $20 \%$ (53 persons). Two-wheelers represent one-third of serious injuries or fatalities while pedestrians account for $17 \%$. Four out of six motorcyclists lost their lives during the summer period from July to September 2015.

Analysis of road safety data for Luxembourg should take into account that the overall numbers of road crashes in Luxembourg are small. As a consequence, yearly fluctuations could be great and lead to misinterpretation.

A large share of crashes happen during the day, especially between 7 am and 8 am and then again between $2 \mathrm{pm}$ and $3 \mathrm{pm}$. The peak however is between $5 \mathrm{pm}$ and $7 \mathrm{pm}$ when commuters are on their way home from work. In $2015,73 \%$ of all fatalities or serious injured persons were residents and one fourth was foreigners.

Important measures taken include:

- the adoption of a vision zero safety strategy

- reduction of speed limits, speeding campaigns and speed cameras with the aim of reducing mean speed of traffic on potentially dangerous roads

- campaign promoting respect for all road users especially the vulnerable categories.

\section{Rates}

Since 1990, the death rate per 100000 inhabitants has decreased by more than $65 \%$, while the number of vehicles per 1000 inhabitants has increased by nearly $40 \%$.

In 2015, the fatality rate was 6.4 road deaths per 100000 inhabitants.

\section{Analysis of seriously injured data}

A downward trend has been observed since the 1970, when 1082 persons were seriously injured. In 2015, 319 persons were seriously injured in road traffic crashes, compared to 245 in 2014. 
In 2015 , close to one-third (32\%) of seriously injured persons were users of two-wheelers. Two out of five seriously injured persons were between 25 and 44 years old. Men represented $70 \%$ of all serious injuries.

Table 23.1. Road safety and traffic data

\begin{tabular}{|c|c|c|c|c|c|c|c|c|c|}
\hline & \multirow{2}{*}{1990} & \multirow{2}{*}{2000} & \multirow{2}{*}{2010} & \multirow{2}{*}{2014} & \multirow{2}{*}{2015} & \multicolumn{4}{|c|}{$2015 \%$ change from } \\
\hline & & & & & & 2014 & 2010 & 2000 & 1990 \\
\hline \multicolumn{10}{|l|}{ Reported safety data } \\
\hline Fatalities & 71 & 76 & 32 & 35 & 36 & 2.9 & 12.5 & -52.6 & -49.3 \\
\hline Injury crashes & 1216 & 901 & 876 & 908 & 983 & 8.3 & 12.2 & 9.1 & -19.2 \\
\hline Injured persons hospitalised & 556 & 400 & 266 & 245 & 319 & 30.2 & 19.9 & -20.3 & -42.6 \\
\hline Deaths per 100000 inhabitants & 18.7 & 17.5 & 6.4 & 6.4 & 6.4 & 0.4 & 0.3 & -63.5 & -65.8 \\
\hline Deaths per 10000 registered vehicles & 3.3 & 2.4 & 0.8 & 0.8 & 0.8 & 0.1 & 4.4 & -65.9 & -75.5 \\
\hline \multicolumn{10}{|l|}{ Deaths per billion vehicle kilometres } \\
\hline \multicolumn{10}{|l|}{ Traffic data } \\
\hline Registered vehicles ${ }^{1}$ (thousands) & 214 & 319 & 411 & 431 & 443 & 2.8 & 7.7 & 39.0 & 107.1 \\
\hline Registered vehicles per 1000 inhabitants & 564 & 736 & 819 & 785 & 787 & 0.4 & -3.9 & 7.1 & 39.6 \\
\hline
\end{tabular}

1. Including mopeds.

StatLink ताISt http://dx.doi.org/10.1787/888933580650

Figure 23.1. Road safety, traffic and GDP trends index $1990=100$

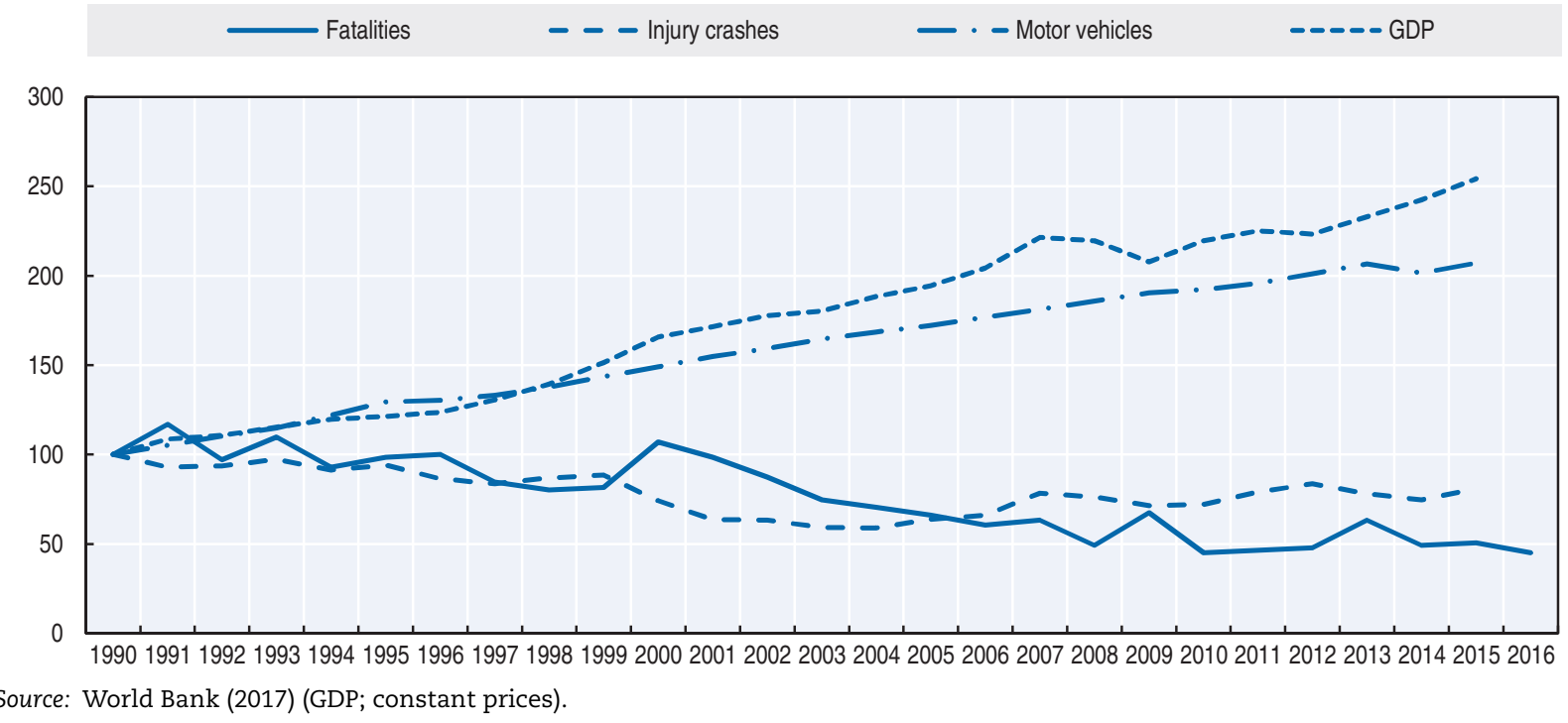

\section{Road safety by user group}

Although since 1990 the number of fatalities and serious injuries has decreased for all user groups, cyclists and motorcyclists as well as pedestrians remain the most vulnerable population. The reduction was most substantial for car occupants, with the number killed or seriously injured in road accidents reduced by nearly $38 \%$ between 2001 and 2015. For motorcyclists, however, the number of fatalities remained unchanged between 2001 and 2015 and the number of serious injuries increased by 30 persons in the same time span. 
Table 23.2. Road fatalities by road user group

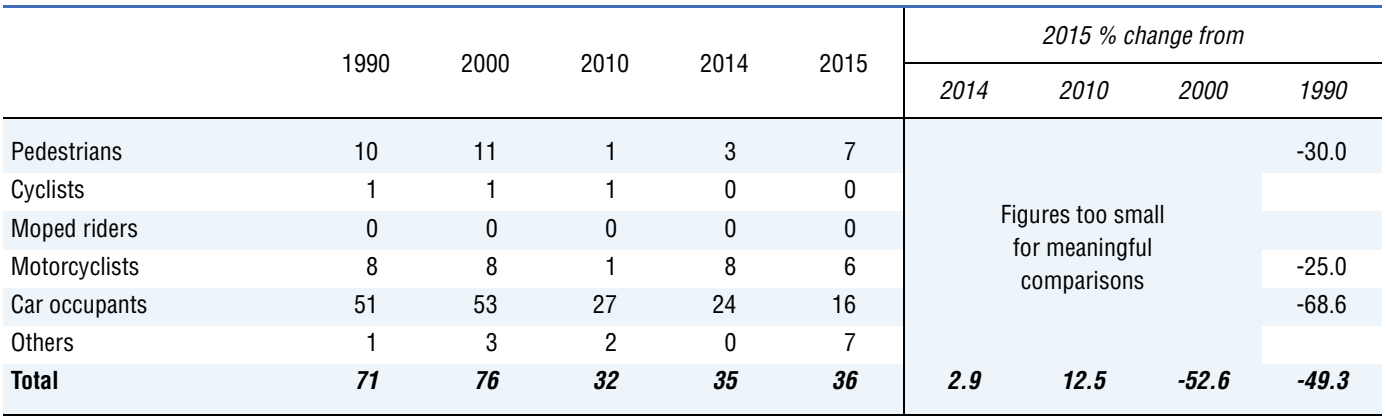

Figure 23.2. Road fatalities by road user group in percentage of total, 2015

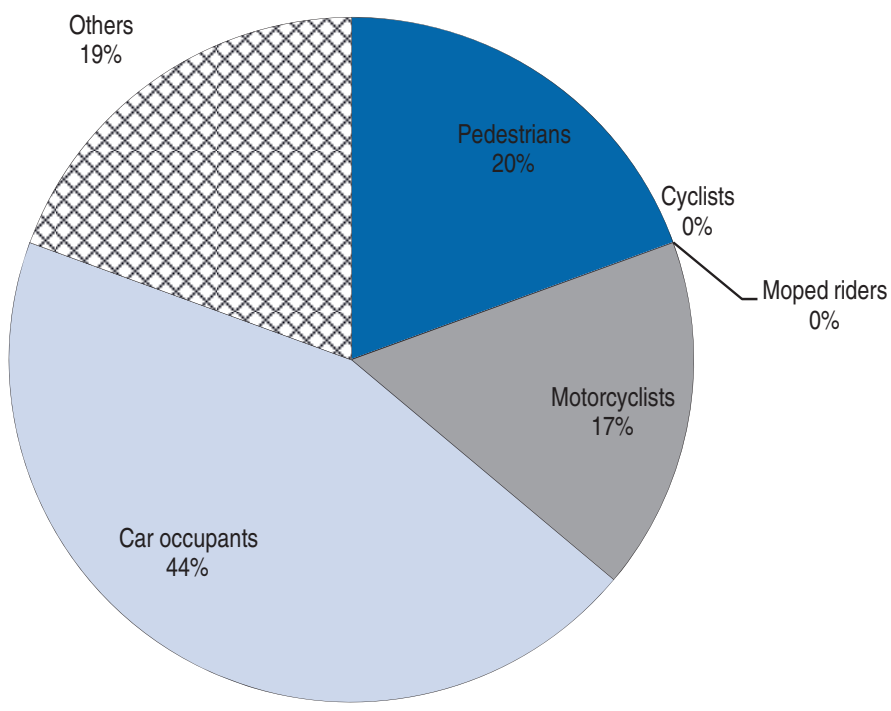

\section{Road safety by age group}

Since 1990, all age groups have benefited from the improvement in road safety.

Between 2001 and 2015, most seriously injured road users were aged between 18 and 44 years. In 2015 these age groups represented more than half of all serious injuries (57\%).

Table 23.3. Road fatalities by age group

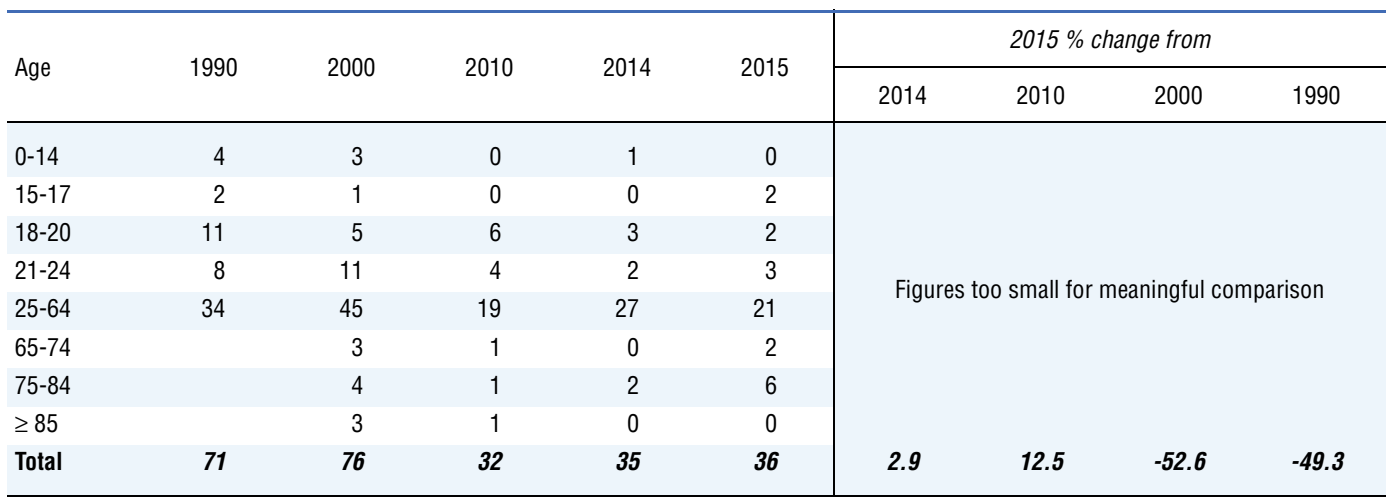




\section{Box 23.1. Road safety for an ageing population}

The number of people aged 65 and above rose by one-third between 2001 and 2016. In 2015, 8 people aged 65 and above were killed in traffic, 3 as pedestrians and 5 as car occupants.

After the age of 60 , to get an extension of their driving licence, licence holders must undergo a medical examination to assess their fitness to drive. From the age of 70 , the license can be renewed for a maximum duration of 5 years. For drivers aged 80 and above, the licence needs to be renewed every two years.

As part of the National Charter for Road Safety signed in April 2015, one of the measures to reduce the number of road crashes was the establishment of a Senior Drivers Day, on 19 June 2015. Thirteen workshops were organised around the road code and the safety behind the wheel.

\section{Road safety by road type}

In Luxembourg most fatal crashes (78\%) occur on rural roads. These crashes can be attributed, to a large extent, to high speed or drink driving.

Figure 23.3. Road fatalities by road type

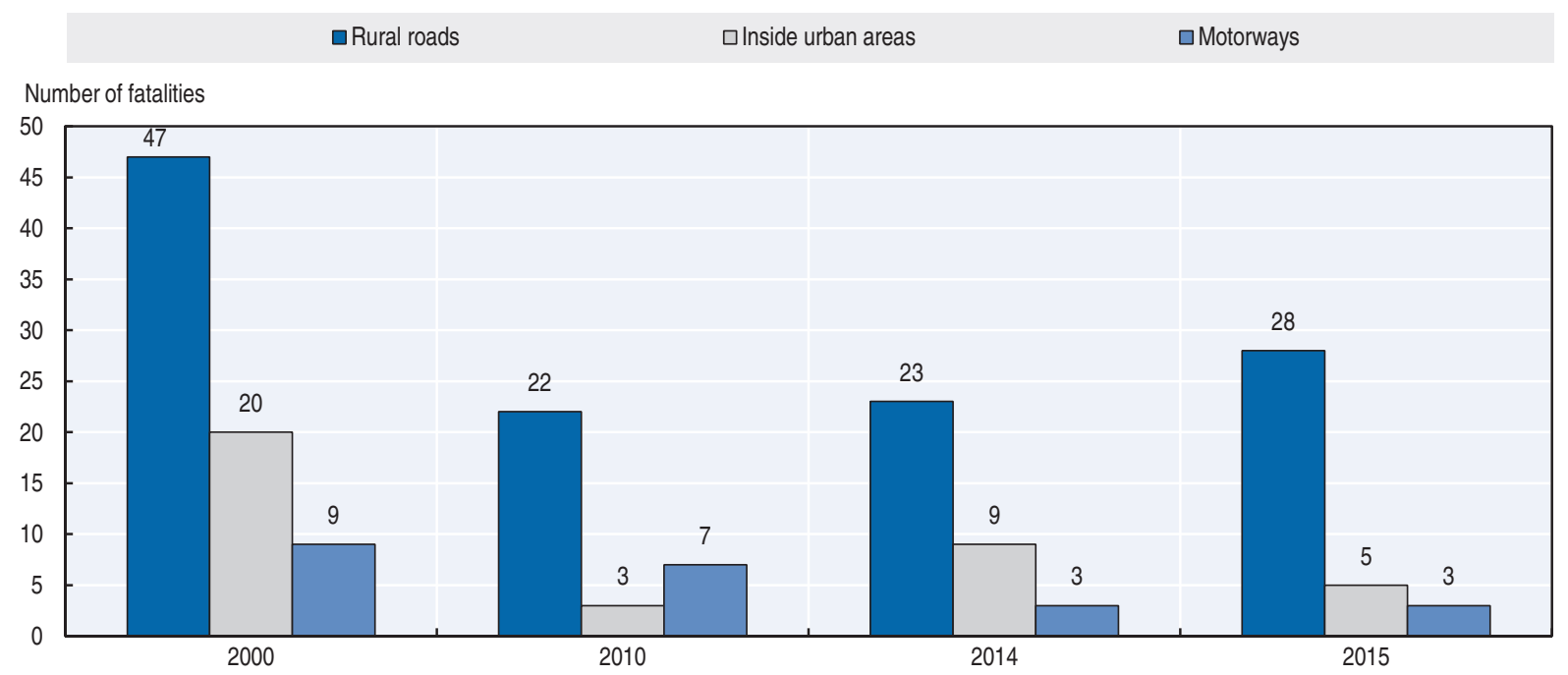

\section{Recent trends in road user behaviour}

Speed

In $2015,45 \%$ of fatal crashes and $37 \%$ of accidents resulting in serious injuries may be considered as speed-related.

The first "National Day of Road Safety" held on 26 September 2016 was dedicated to the theme of "Zones 30". The aim of that initiative was to invite the municipalities and other stakeholders to develop projects to slow down the traffic and create attractive shared space and as a result stimulate road safety.

In order to promote the creation of attractive public spaces for pedestrians and cyclists, which is often in opposition to the predominance and speed of motorised traffic on main roads, the Ministry of Transport (Ministère du Développement Durable et des Infrastructures) announced his support for encouraging the reduction of speed to $30 \mathrm{~km} / \mathrm{h}$ and, in some cases, even to $20 \mathrm{~km} / \mathrm{h}$ on public roads responding to defined criteria. 
In 2015, there were five fatal crashes and 116 serious injury crashes on roads with a speed limit of $50 \mathrm{~km} / \mathrm{h}$ and no fatal crashes and 8 serious injury crashes on roads limited to $30 \mathrm{~km} / \mathrm{h}$.

The table below summarises the main speed limits in Luxembourg.

Table 23.4. Passenger car speed limits by road type, 2017

\begin{tabular}{lc}
\hline & General speed limit \\
\hline Urban roads & $50 \mathrm{~km} / \mathrm{h}$ \\
Rural roads & $90 \mathrm{~km} / \mathrm{h}$ \\
Motorways & $130 \mathrm{~km} / \mathrm{h} 110 \mathrm{~km} / \mathrm{h}$ (in rain) \\
\hline
\end{tabular}

\section{Drink driving}

In Luxembourg, the maximum authorised blood alcohol content (BAC) is $0.5 \mathrm{~g} / \mathrm{l}$ and $0.2 \mathrm{~g} / \mathrm{l}$ for novice and professional drivers.

An alcohol-related crash is defined as an injury crash where at least one of the involved drivers or pedestrians has a BAC above $0.5 \mathrm{~g} / \mathrm{l}$.

After speed, drink driving is the second most observed contributing factor to accidents.

In 2015, 10 out of the 33 fatal crashes were classified as alcohol-related. Of the presumed responsible drivers, $21 \%$ had a BAC level of more than $0.5 \mathrm{~g} / \mathrm{l}$. Most concerned were young drivers aged $18-34$ years (18-24 years: $20 \%$ and $25-34$ years $22 \%$ with a BAC exceeding $0.5 \mathrm{~g} / \mathrm{l}$ ).

Since June 1st 2015, the point system (maximum 12 points) has been tightened. Driving with a BAC greater than $0.5 \mathrm{~g} / \mathrm{l}$ is now penalised by the withdrawal of 4 points instead of 2 points. For a BAC above $0.8 \mathrm{~g} / \mathrm{l}$, the penalty has increased from 4 to 6 points.

\section{Drugs and driving}

The maximum blood drug content authorised for the following drugs is: THC, $2 \mathrm{ng} / \mathrm{mL}$; amphetamine, $50 \mathrm{ng} / \mathrm{ml}$; methamphetamine, $50 \mathrm{ng} / \mathrm{ml}$; MDMA, $50 \mathrm{ng} / \mathrm{ml}$; MDA, $50 \mathrm{ng} / \mathrm{ml}$; morphine, $20 \mathrm{ng} / \mathrm{ml}$; cocaine, $50 \mathrm{ng} / \mathrm{ml}$; benzoylecgonine, $50 \mathrm{ng} / \mathrm{ml}$.

In 2015, two fatal crashes were classified as drug-related.

\section{Seat belts and helmets}

Seat belt use has been compulsory in front seats since 1975 and in rear seats since 1992. The use of child restraints has been compulsory since 1992. In 2015, the use of the seat belt reached $90 \%$ in the front seat of passenger cars and $76 \%$ in rear seats.

Data shows that half of killed drivers or passengers (52\%) and $75 \%$ of serious injured drivers or passengers were wearing their seatbelts.

\section{Table 23.5. Seat belt wearing rate by car occupancy and road type, $\%$}

\begin{tabular}{lc}
\hline & 2015 \\
\hline $\begin{array}{l}\text { Front seat } \\
\quad \text { General (Driver + Passenger) }\end{array}$ & 90 \\
Rear seats & \\
$\quad$ General & 76 \\
Children (use of child restraint) & n.a. \\
\hline
\end{tabular}


Helmets have been compulsory for all motorcycle and moped riders since 1976. The compliance rate is not available, but estimated to be $100 \%$.

\section{Distraction}

The use of hand-held phones while driving is forbidden. The use of hands-free devices while driving has been authorised since 2009. A new law with tougher sanctions was adopted in April 2015. It also concerns the use of laptops and tablets while driving

In 2016, according to police records, one fatal crash was due to distraction by electronic devices.

\section{Fatigue and sleepiness}

In 2016, according to police records, one fatal crash was due to fatigue.

\section{National road safety strategies and targets}

\section{Organisation of road safety}

The Department of Transport in the Ministry of Sustainable Development and Infrastructure is responsible for road safety.

\section{Road safety strategy for 2011-20}

The government of Luxembourg considers the only objective of a credible road safety policy to be a Vision Zero. With that in mind, the government of Luxembourg adopted in 2015, the "National Charter for Road Safety" with a target of zero fatalities and serious injuries on the Luxembourg road network.

Road safety is one of the priorities of the Ministry of Transport which launched, on 26 September 2016, a first National Day of Road Safety dedicated to the promotion of safety for all road users as part of the implementation of a national road safety action plan.

In 2014, a round table gathered all national road transport actors to elaborate an action plan to improve road safety. Priorities include:

- reducing speeding

- safety of vulnerable road users

- strengthening the demerit point system introduced in 2002

- road safety campaigns to raise awareness of pollution and dangerous behaviour

- implementation of automatic speed controls

- improvement in road infrastructure.

\section{Road safety targets}

Luxembourg adopted the European Union (EU) target to halve the number of fatalities by 2020. The target was defined by analysing the reasons and circumstances under which fatal and serious injury crashes occur.

To meet the EU target, there should be no more than 16 fatalities by 2020. It should be noted that in 2010 - which is the base year for the EU target - the number of road fatalities in Luxembourg was very low (32 deaths), which makes the achievement of the target even more challenging. 
Figure 23.4. Trends in road fatalities towards national target

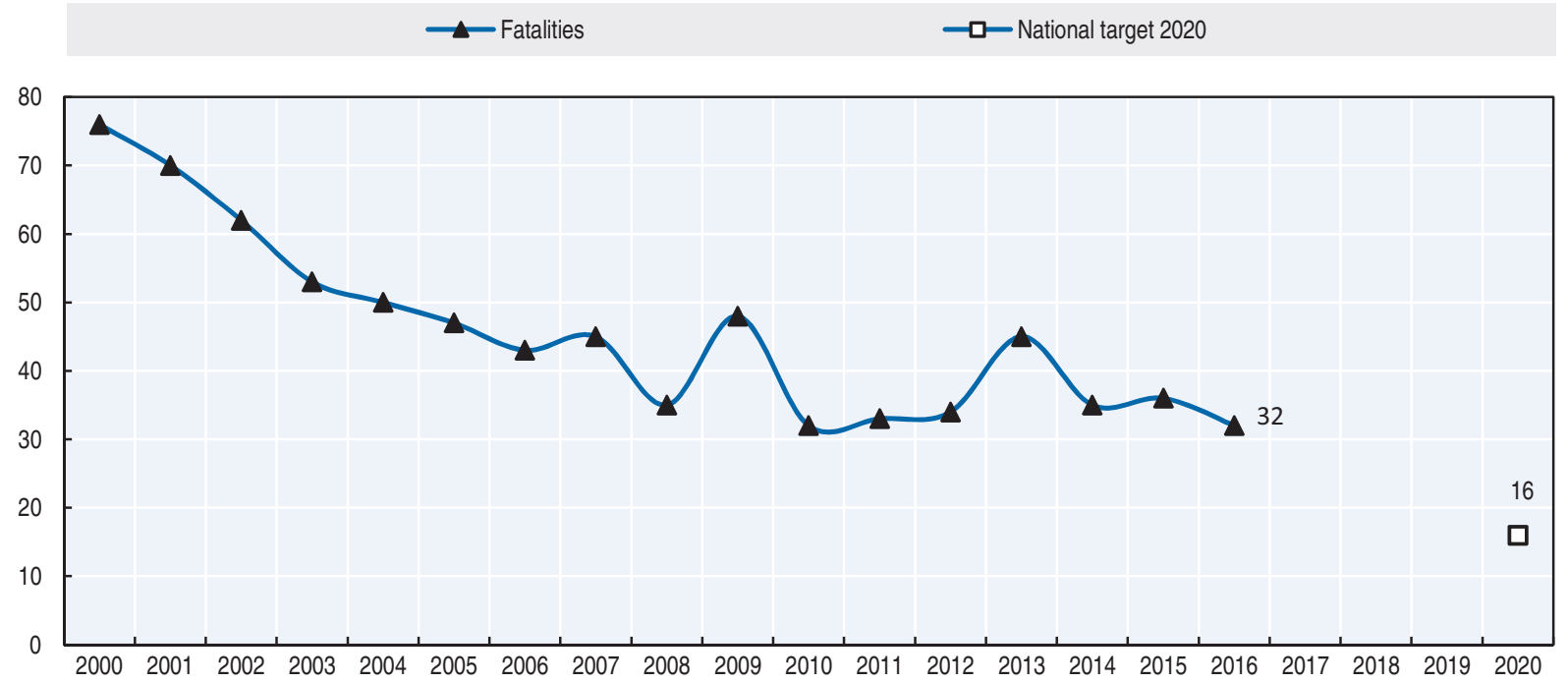

\section{Recent safety measures (2014-17)}

\section{Road safety management}

- The government signed the "National Charter for Road Safety" to increase its commitment to road safety.

\section{Speed management}

- Speed cameras and section control systems are progressively being implemented. Six fixed cameras have been operational from 16 March 2016.

- In 2014, the Ministry of Sustainable Development and Infrastructure issued guidelines on traffic calming in urban areas (www.mt.public.lu/presse/communiques/2013/05/14apais/ apais_trafic.pdf) (accessed 25 June 2017).

\section{Road users}

- More severe sanctions for traffic regulation violations have been introduced. In 2015, a sanction on using a laptop or tablet while driving was introduced.

- Parliament is considering a new law punishing impaired driving more severely (demerit point system).

- Since 2015, moped drivers must undertake practical lessons and sit a theory exam in order to obtain their licence.

\section{Infrastructure}

- A new working group to analyse and improve cycling networks was created within the Ministry of Sustainable Development and Infrastructure.

- In 2014, the Ministry of Sustainable Development and Infrastructure issued new guidelines on pedestrian crossings in urban areas www.mt.public.lu/presse/communiques/ 2014/04/22stats/CCE_pass_pietons.pdf (accessed 25 June 2017). 
- In 2015, the Ministry of Sustainable Development and Infrastructure issued guidelines on Infrastructure development on roads outside built-up areas: www.mt.public.lu/ministere/ services/direction_circulation_securite_routieres/commission_circulation_etat/Guide.pdf (accessed 25 June 2017).

\section{Recent and ongoing research}

- In 2015, STATEC published a research report on crashes involving motorcyclists www.statistiques.public.lu/fr/publications/series/regards/2015/04-15-accidents-motocyclistes/ index.html (accessed 25 June 2017).

\section{References}

World Bank (2017), “GDP (constant US\$)”, World Development Indicators, http://databank.worldbank.org/ data/reports.aspx? source=world-development-indicators (accessed 23 February 2017).

\section{Websites}

- Road Safety Luxembourg: www.securite-routiere.lu (accessed 25 June 2017).

- Ministry of Sustainable Development and Infrastructure: www.mt.public.lu (accessed 25 June 2017).

- STATEC: www.statistiques.public.lu (accessed 25 June 2017). 


\section{Chapter 24}

\section{Malaysia}

This chapter presents 2015 road safety data for Malaysia along with provisional data for 2016. It looks at trends in traffic and road safety from the years 1990 to 2015 and road user behaviour patterns. Sections include data on speed, drink driving, drugs and driving, distracted driving, fatigue and seat belt usage. The chapter reviews Malaysia's road safety strategy and national targets to 2020 along with recently implemented safety measures and current research.*

* Data included in this report are provided by the Malaysian Institute of Road Safety Research (MIROS) unless otherwise noted, and have not yet been validated by IRTAD. For more information please contact: allyana@miros.gov.my. 
$\mathrm{F}$ number of reported fatalities in 2015, bringing the total to 6706 . Motorcyclists were the most affected, representing $62.7 \%$ of all fatalities whereas car occupants accounted for $20.3 \%$. The mortality rate is high at 21.5 deaths per 100000 inhabitants; however with the rapid motorisation of Malaysia the risk in terms of deaths per vehicle registered has decreased significantly. Provisional data from 2016 indicate a further increase in reported fatalities of $6.7 \%$ to 7152 .

\section{Road safety data collection}

\section{Definitions applied in Malaysia}

- Road fatality: Death resulting from a road crash within 30 days after the crash.

- Seriously injured person: Person injured as a result of a road crash as referred to in Section 320 of the Penal Code.

- Slight injuries: Any injury not covered by the above definitions of a fatality or serious injury.

\section{Data collection}

The Royal Malaysian Police (RMP) is the agency responsible for collecting crash data. In Malaysia, all road crashes must be reported to the police. Since 1992 police have used a standardised form, POL27, to collect all relevant information for each crash. The form covers information on vehicles involved, environment, injury, location and background of the crash as well as information on the victims. Malaysia has begun work to evaluate underreporting.

In 2008, the Malaysian Institute of Road Safety Research (MIROS) developed a system called M $\neg$ ROADS to simplify data use by automating the data query request. M-ROADS serves as an intelligence system to provide road safety stakeholders with accurate, continuous and comprehensive information on road accidents. M-ROADS builds on input from existing nationwide road accident data collected by the traffic police to generate analysis and findings. A newer version of M-ROADS was recently launched in 2015 with many improvements such as a mobile application to ease data collection on site.

In addition, in 2015 the Malaysian Highway Authority (MHA), in close co-operation with MIROS, started an initiative to systematically collect all road traffic crash data that occur on main highways in Malaysia. These data only include information for main highways but nevertheless constitute an important added value to the road safety data collected in Malaysia.

\section{Most recent safety data}

\section{Road crashes in 2016 - provisional data}

Based on provisional data, there were 7152 reported road deaths in 2016 a 6.7\% increase compared to 2015. 


\section{Road crashes in 2015}

In 2015, there were 6706 reported road deaths, an increase of $0.5 \%$ when compared to 2014. Motorcyclists are the largest user group affected by road crashes.

Motorcyclists are the most affected by road crashes. In 2015, they represented $62.7 \%$ of all fatalities while car drivers and passengers represented $20.3 \%$ of fatalities.

\section{Trends in traffic and road safety (1990-2015)}

\section{Traffic}

Since 2000 the number of registered vehicles has more than doubled, with powered two-wheelers representing nearly half of the fleet. The volume of traffic has followed a similar trend with a 5\% increase for the year 2015 alone.

The motorisation rate in Malaysia is quite high with 843 registered motor vehicles per 1000 inhabitants. This includes the motorcycle fleet.

\section{Road safety \\ Crashes and casualties}

Between 2004 and 2012, fatalities increased every year. For the first time a decrease was observed in 2013 and was confirmed in 2014. However, in 2015 the number of fatalities increased, though slightly by $0.5 \%$.

\section{Rates}

The mortality rate is high (21.5 road deaths per 100000 inhabitants in 2015). However, the risk in terms of deaths per distance travelled or per registered vehicle has decreased significantly since 2000, due to the large rise in motorisation in Malaysia.

Between 2000 and 2015, the death rate in terms of deaths per 100000 inhabitants declined by $17 \%$, as a result of rapid growth in the population. Risks expressed in terms of deaths per 10000 registered vehicles decreased by $54 \%$.

Table 24.1. Road safety and traffic data

\begin{tabular}{|c|c|c|c|c|c|c|c|c|c|}
\hline & \multirow{2}{*}{1990} & \multirow{2}{*}{2000} & \multirow{2}{*}{2010} & \multirow{2}{*}{2014} & \multirow{2}{*}{2015} & \multicolumn{4}{|c|}{$2015 \%$ change from } \\
\hline & & & & & & 2014 & 2010 & 2000 & 1990 \\
\hline \multicolumn{10}{|l|}{ Reported safety data } \\
\hline Fatalities & 4048 & 6035 & 6872 & 6674 & 6706 & 0.5 & -2.4 & 11.1 & 65.7 \\
\hline Deaths per 100000 inhabitants & & 25.9 & 24.0 & 22.0 & 21.5 & -2.4 & -10.6 & -17.1 & -2.4 \\
\hline Deaths per 10000 registered vehicles & & 5.7 & 3.4 & 2.7 & 2.6 & -2.2 & -23.6 & -54.3 & -2.2 \\
\hline \multicolumn{10}{|l|}{ Traffic data } \\
\hline Registered vehicles ${ }^{1}$ (thousands) & & 10599 & 20189 & 25101 & 26302 & 4.8 & 30.3 & 148.2 & 4.8 \\
\hline Registered vehicles per 1000 inhabitants & & 456 & 706 & 828 & 843 & 1.8 & 19.4 & 85.0 & 1.8 \\
\hline
\end{tabular}

1. With mopeds. 
Figure 24.1. Road safety, traffic and GDP trends index $2000=\mathbf{1 0 0}$

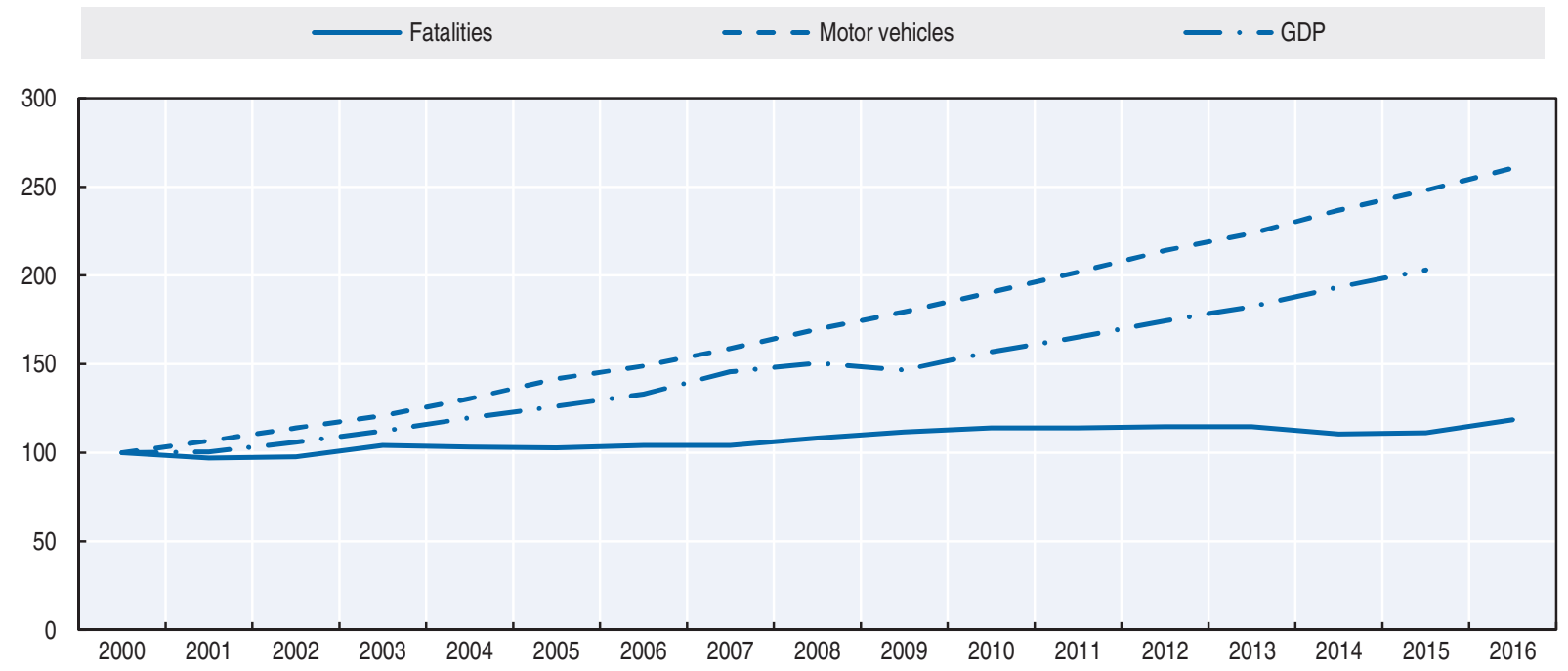

Source: World Bank (2017) (GDP; constant prices).

\section{Road safety by user group}

In 2015 , motorcycles represented $46 \%$ of the fleet but accounted for $63 \%$ of road deaths. Between 2000 and 2015 the number of motorcyclists killed increased by $19 \%$.

In 2015, the situation deteriorated for all road users except cyclists, pedestrians and bus users. The number of pedestrians and cyclists killed respectively decreased by $6.4 \%$ and $13.7 \%$ as compared to 2014 . The number of bus occupants killed decreased by $46 \%$. There was a $7 \%$ increase in the number of car occupant deaths.

Table 24.2. Road fatalities by road user group

\begin{tabular}{lrrr|rr}
\hline & 2010 & 2014 & 2015 & \multicolumn{2}{|c}{$2015 \%$ change from } \\
\cline { 5 - 6 } & & & & 2014 & 2010 \\
\hline Pedestrians & 626 & 515 & 482 & -6.4 & -23.0 \\
Cyclists & 192 & 124 & 107 & -13.7 & -44.3 \\
Motorcyclists & 4036 & 4179 & 4203 & 0.6 & 4.1 \\
Car occupants & 1421 & 1258 & 1358 & 7.9 & -4.4 \\
Others & 597 & 598 & 556 & -7.0 & -6.9 \\
Total & $\mathbf{6 8 7 2}$ & $\mathbf{6 6 7 4}$ & $\mathbf{6 7 0 6}$ & 0.5 & -2.4 \\
\hline
\end{tabular}


Figure 24.2. Road fatalities by road user group in percentage of total, 2015

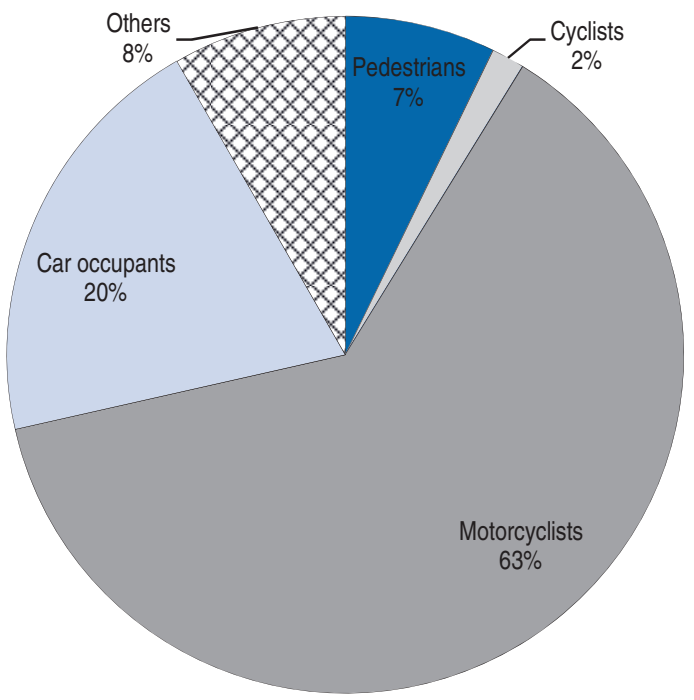

\section{Road safety by age group}

Over the past 10 years the fatalities distribution by age show the highest number of fatalities among young people aged 16 to 25 . However, in 2015, the fatalities among this age group decreased by $12.9 \%$ as compared to 2014 and 18\% as compared to 2012 .

Table 24.3. Road fatalities by age group

\begin{tabular}{lrrrr|rr}
\hline \multirow{2}{*}{ Age } & 2012 & 2013 & 2014 & 2015 & \multicolumn{2}{|c}{$2015 \%$ change from } \\
\cline { 5 - 6 } & & & & 2014 & 2012 \\
\hline $0-5$ & 24 & 59 & 75 & 73 & -2.7 & 204.2 \\
$6-10$ & 59 & $47^{*}$ & 66 & 55 & -16.7 & -6.8 \\
$11-15$ & 385 & $296^{*}$ & 326 & 366 & 12.3 & -4.9 \\
$16-20$ & 1032 & 960 & 1131 & 934 & -17.4 & -9.5 \\
$21-25$ & 1116 & 1139 & 891 & 828 & -7.1 & -25.8 \\
$26-30$ & 789 & 856 & 855 & 641 & -25.0 & -18.8 \\
$31-65$ & 2897 & 2890 & 2716 & 3162 & 16.4 & 9.1 \\
$>65$ & 615 & 668 & 614 & 647 & 5.4 & 5.2 \\
Total & $\mathbf{6 9 1 7}$ & $\mathbf{6 9 1 5}$ & $\mathbf{6 6 7 4}$ & $\mathbf{6 7 0 6}$ & 0.5 & -3.1 \\
\hline
\end{tabular}

The young (18-20) and the senior population (above 65) have the highest fatality rate, about 30 deaths per 100000 inhabitants.

\section{Road safety by road type}

In Malaysia, roads are classified into five categories: motorways, federal roads, state roads, municipal roads and others. The number of fatalities on federal roads is the highest, followed by state roads. Based on police reported data, $86 \%$ of fatalities occurred outside urban areas. 
Figure 24.3. Road fatalities by road type

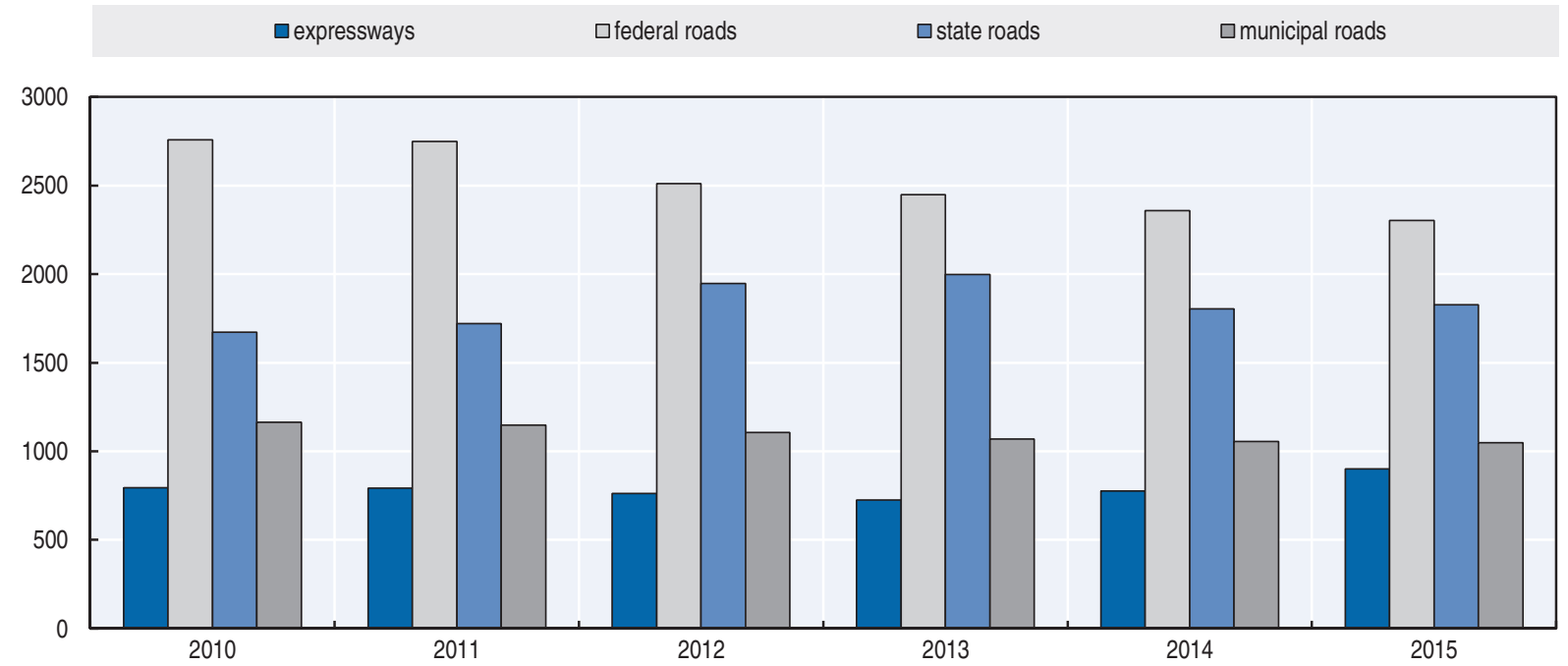

\section{Economic costs of traffic crashes}

Traffic crashes represent a significant cost for the Malaysian society. Based on a willingness-to-pay estimation, each year traffic crashes cost around 1.7\% of national GDP. The statistical value of life in Malaysia is RM 1.3 million, around EUR 330000 (Nor et al., 2003; Mohd et al., 2011).

\section{Recent trends in road user behaviour Speed}

Based on the MIROS study on contributing factors, speeding is one of the main causes of road crashes. The table below summarises the main speed limits in Malaysia.

Table 24.4. Passenger car speed limits by road type, 2017

\begin{tabular}{lr}
\hline Urban roads & $50 \mathrm{~km} / \mathrm{h}$ \\
Rural roads & $90 \mathrm{~km} / \mathrm{h}$ \\
Motorways/Expressway & $110 \mathrm{~km} / \mathrm{h}$ \\
\hline
\end{tabular}

A study undertaken in 2015 (Firdaus et al., 2015) shows that the compliance by Malaysian drivers to the $90 \mathrm{~km} / \mathrm{h}$ posted speed limit on rural roads varies from $53 \%$ to $90 \%$.

Another study in one state in Malaysia concluded that more than $50 \%$ of drivers ignored speed limits of lower than $90 \mathrm{~km} / \mathrm{h}$ especially during off-peak periods. The study also found that more than $70 \%$ of drivers complied with the speed limit of $90 \mathrm{~km} / \mathrm{h}$ or higher. Most of the non-compliant drivers were observed during the period after midnight until early morning (Othman, 2015).

\section{Drink driving and drugs and driving}

In Malaysia, according to the Road Traffic Act, it is an offence to drive a vehicle with a blood alcohol content (BAC) over the legal limit of $0.8 \mathrm{~g} / \mathrm{l}$. 
Islam is the state religion in Malaysia and around $60 \%$ of the population is Muslim. Alcohol is available at licensed outlets for the consumption of non-Muslim citizens. Policereported data indicate that drink driving is not an issue in Malaysia, with less than $0.5 \%$ of drivers in fatal crashes testing positive for blood-alcohol content.

\section{Fatigue and sleepiness}

Information on fatigue is not available from the national crash database collected by the police. A cross-sectional study conducted in urban areas of West Malaysia assessed drivers' conditions in terms of fatigue, sleep quality and risk of Obstructive Sleep Apnoea (OSA). The study revealed that out of 130 drivers, $17.7 \%$ were fatigued, $34.7 \%$ had poor sleep quality and $14.6 \%$ fell into the category of those at high risk from OSA. The study also found that use of medication and neck circumference were the most significant factors contributing to fatigue (Ilhamah et al., 2015).

\section{Seat belts and helmets}

Seat belt use has been compulsory in front seats since 1978 and in rear seats since 1 January 2009.

The compliance rates among drivers and front passengers are, respectively, about $85 \%$ and $75 \%$. Awareness of the regulation is high. The compliance rate for rear seats was $40 \%$ shortly after the law came into force in 2009 but is now declining. Following intense enforcement activities in February 2012 the seat belt wearing rate for drivers increased to $91 \%$. However, in 2015 , the seat belt wearing rate for drivers was $83 \%$, but only $10 \%$ for rear seat passengers.

In 2014, the seat belt wearing rate decreased for both drivers and passengers. The compliance rate among drivers and front seat passengers were $82 \%$ and $68 \%$ respectively, and the seat belt wearing rate for rear seats was 9\% (Wahida et al., 2015). The study also shows that women were significantly more likely to wear seat belts compared to men in front seats and that drivers in urban areas were significantly more likely to wear their seat belts than those in rural areas.

A study was conducted in 2015 during one of the main festive season to assess overall use of CRS. Before the festive season the CRS usage is 3.3\% and during the festive season it was at $7.6 \%$. CRS use is extremely low but increases during the festive season. The odds ratio of child restraint use were 2 times higher during festive season compared to before festive season $(\mathrm{OR}=2.2796 ; 95 \% \mathrm{CI}=1.3132,3.957)$. The results indicate that enforcement during festive season has an impact on CRS use even if in small numbers. (Fauziana et al., 2017).

Table 24.5. Seat belt wearing rate by car occupancy and road type \%

\begin{tabular}{lcccc}
\hline & 2009 & $\begin{array}{c}2012 \text { (intensive } \\
\text { enforcement) }\end{array}$ & 2014 & 2015 \\
\hline $\begin{array}{l}\text { Front seat } \\
\text { Drivers }\end{array}$ & 85 & & & 82 \\
$\quad$ Passengers & 75 & 81 & 68 & 74 \\
Rear seat passengers & & & & \\
$\quad$ Adults & 40 (after law came into force) & 11 & 9 & 10 \\
\hline
\end{tabular}

Helmet wearing has been compulsory for motorcycles since 1973. However, there is still an alarmingly high rate of motorcyclist fatalities due to head injuries. In general, 
helmet wearing rates are higher in urban areas than in rural areas. A nationwide study in 2015 concluded that the helmet wearing rate is high (94.40\%) and the rate of proper helmet wearing is acceptable at $77.05 \%$ (Rabihah et al., 2015).

Another study conducted during one of the major festive seasons examined helmet wearing rates. The study found that from the 1712 riders observed that wore helmets, $86.6 \%$ were properly worn and correctly fastened, $6.1 \%$ were loosely attached and $7.3 \%$ riders wore their safety helmets completely unfastened (Fauziana, L. et al., 2017).

\section{Distraction}

A cross-sectional descriptive study was conducted in 2015 to identify road users' perceptions and behaviour concerning mobile phone use while driving. It found that $61.9 \%$ of respondents used a mobile phone while stopped at red lights, about $53.6 \%$ while in a traffic jam and $43.4 \%$ while driving.

The findings show that drivers generally agreed that mobile phone use while driving can affect their driving behaviour and cause harm to themselves and others. The selfreported study also indicated that only $4 \%$ of respondents claimed to have been involved in a road crash caused by mobile phone use while driving (Aini and Sharifah, 2016)

\section{National road safety strategies and targets \\ Organisation of road safety}

The Road Safety Department of the Ministry of Transport is the lead agency for road safety in Malaysia. The Malaysian Institute of Road Safety Research (MIROS) provides support by conducting road safety research to assist in elaborating strategies to reduce road traffic deaths.

The other main stakeholders involved in road safety in Malaysia are principally the Royal Malaysian Police, the Public Works Department, the Road Transport Department, the Malaysian Highway Authority, the Ministry of Transport, the Ministry of Health, the Ministry of Education, the Land Public Transport Commission and other road-related agencies. In addition, several non-governmental organisations are actively involved in road safety in Malaysia.

\section{Road safety strategy for $2014-20$}

A new road safety plan was launched in 2014 and covers the period 2014-20. The plan is aligned with the Global Decade of Action for Road Safety and designed to:

- increase efforts to reduce the number of traffic casualties

- support the recommendations of the United Nations (UN) in the success of the Decade of Action

- gain political support and adequate resources for highway security initiatives.

It is based on the five Pillars of the UN Decade of Action Plan:

\section{Road safety targets}

The plan has adopted the target set by the Global Decade of Action for Road Safety 2011-20, to reduce the predicted number of road deaths in 2020 by $50 \%$. 
Table 24.6. Fatalities target

\begin{tabular}{lrr}
\hline & 2015 & 2020 \\
\hline Predicted number of fatalities (business as usual) & 8760 & 10716 \\
Fatality target with the implementation of the plan & 6570 & 5358 \\
\hline
\end{tabular}

\section{Monitoring}

Based on a report by MIROS, in the absence of a comprehensive road safety programme, there would be 8760 road fatalities in 2015 and 10716 in the year 2020. The target is therefore to have less than 5358 deaths by 2020. This corresponds to a reduction of $22 \%$ in the number of road deaths when compared to 2010 level.

Figure 24.4. Trends in road fatalities towards national target

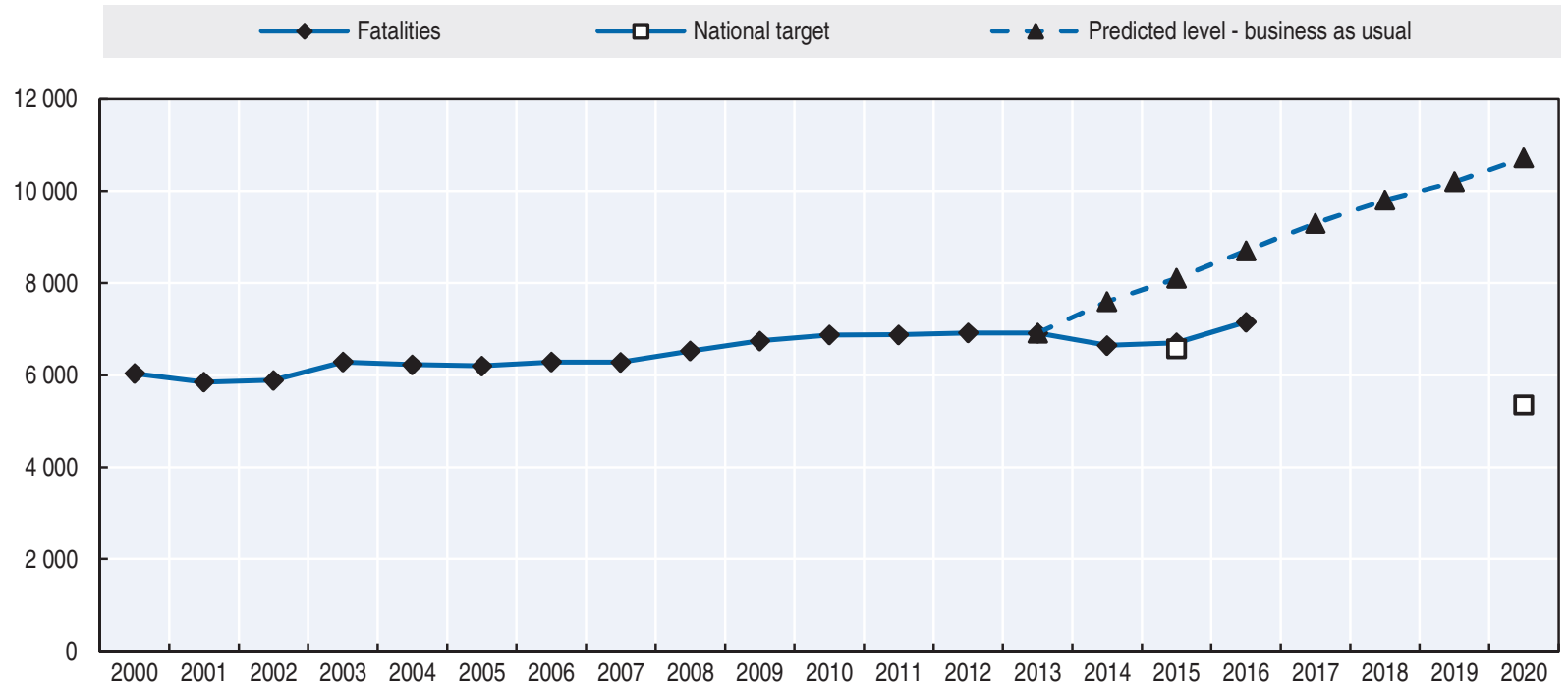

\section{Recent safety measures (2014-17)}

\section{Road users}

\section{Child Car Seat Campaign}

- The Road Transport Department (RTD) recently launched a campaign to promote the use of child car seats. The campaign is an advocacy programme for RTD to encourage the use of child restraints before making it mandatory. The Deputy Transport Minister said the government wants to educate the public to use child restraining systems (CRS) in order to reduce fatalities involving children.

\section{Vehicles}

- As of 1 July 2016, all trucks and trailers in Malaysia must be equipped with Retro-Reflective Markers (RRMs) in compliance with MS828:2011.

\section{Recent and ongoing research}

Refer to MIROS - Malaysian Institute of Road Safety Research: www.miros.gou.my (accessed 28 June 2017). 


\section{References}

Aini Abu Bakar and Sharifah Osman@ Liew Shyuan Yei (2016), Using Mobile Phones while Driving as a Contributing Factor to Road Crashes among Motorists in Klang Valley: A Self-Reported Study, MRR No201, Kuala Lumpur: Malaysian Institute of Road Safety Research.

Fauziana, L. et al. (2017), Effectiveness of OPS Selamat 7/2015, An Evaluation Study, MRR No. 211, Kuala Lumpur: Malaysian Institute of Road Safety Research.

Ilhamah, O. et al. (2015), "Driver Fatigue and Associated Factors among Commercial Truck Drivers in Malaysia", Proceeding Conference of ASEAN Road Safety, 3-6 November 2015, Kuala Lumpur.

Mohd, Y. et al. (2011), Malaysian Value of Fatal and Non-Fatal Injuries due to Road Accidents: The Willingness to Pay Using Conjoint Analysis Study, Proceedings of the Eastern Asia Society for Transportation Studies, Vol. 8.

Nor, G. and M. Faudzi (2003), "Value of Life Of Malaysian Motorists: Estimates From A Nationwide Survey", Journal of the Eastern Asia Society for Transportation Studies, Vol. 5, October.

Othman (2015), Speed limits: To what extent are they obeyed?, Proceedings from Conference of ASEAN Road Safety, 3-6 November 2015, Kuala Lumpur.

Rabihah et al. (2015), Helmet Wearing Rate: A Study in Malaysian Primary Roads, Proceedings of Conference of ASEAN Road Safety, 3-6 November 2015, Kuala Lumpur.

Wahida, A. et al. (2015), "Safety Seatbelt Wearing among Vehicle Occupants in Malaysia: Status of 5-year implementation of Rear Seatbelt Regulations", Fact sheet Vol. 1, www.miros.gov.my (accessed 28 June 2017).

World Bank (2017), "GDP (constant US\$)", World Development Indicators, http://databank.worldbank.org/ data/reports.aspx?source=world-development-indicators (accessed 23 February 2017).

\section{Websites}

- Road Safety Department: www.jkjr.gov.my (accessed 28 June 2017).

- MIROS - Malaysian Institute of Road Safety Research: www.miros.gov.my (accessed 28 June 2017).

- ASEAN New Car Assessment Program: www.aseancap.org (accessed 28 June 2017).

- Road Safety Plan Malaysia 2014-2020 (accessed 28 June 2017; in Malaysian). 


\section{Chapter 25}

\section{Mexico}

This chapter presents 2015 road safety data for Mexico along with trends in traffic and road safety from the years 1990 to 2015 and road user behaviour patterns with a special focus on the ageing population. Sections include data on speed, drink driving, drugs and driving, distracted driving, fatigue and seat belt usage. The chapter reviews Mexico's road safety strategy, recently implemented safety measures and current research.*

* The Instituto Mexicano del Transporte (IMT) joined the International Road Traffic and Accident Database (IRTAD) Group in 2016. Data included in this report have not been validated by IRTAD. All data stem from IMT and the Ministry of Health. For more information please contact: mendoza@imt.mx and laura.baas@salud.gob.mx. 
I In 2015, 16039 persons were killed on Mexican roads, a 1\% increase compared to 2014. Mexico, in 2015, had a fatality rate of 13.3 per 100000 inhabitants. Fatalities among motorcyclists increased the most in 2015 , by $13.3 \%$. Although all other user groups have experienced reductions in fatalities since 2010, the number of deaths amongst motorcyclists more than doubled in the five-year period from 2010-15, in parallel to the rapid expansion of the motorcycle fleet, which also doubled during the same period.

\section{Road safety data collection}

\section{Definitions applied in Mexico}

- Road fatality: Any person who dies following a road crash. When a person does not die at the scene of the crash, but later at hospital or during the transfer to hospital, it is reported as an "injured" person.

In this report, road fatalities are those registered in the mortality database of the National Health Information System (SINAIS), and recorded as caused by a motor vehicle traffic crash according to the codes of the International Classification of Diseases (10th Review).

- Injured person: A person suffering minor or severe injuries following a road crash.

All traffic safety related definitions are available through the national statistics agency (INEGI, 2009).

\section{Data collection}

The main sources of information for road crashes are the National Institute of Statistics and Geography (INEGI) for urban and suburban areas and the Federal Police (PF) for federal areas. Crash statistics include data on the date and time of the crash, location, type of crash, vehicle type, crash contributing factors, road user category and condition of the casualties (injured or killed). INEGI is also in charge of compiling statistics at a national level.

Crash data for urban and suburban areas are collected on a form developed by INEGI; through the state and municipal safety and traffic agencies. Crash statistics are compiled following the recommendations of the Organization of American States (OAS).

Crashes occurring on the federal road network are reported on a different form through the regional offices of the PF located in 140 areas around the country. These crash forms are then processed in the crash database for federal roads.

Currently, Mexico does not have an integrated road crash database that gathers data from INEGI and the PF. As both systems (INEGI and PF) have different variables and definitions, it is complex to have a precise count of the total number of crashes in the whole country. The most accurate source of data on road deaths and serious injuries is the health database of the Ministry of Health, which is based on health certificates and hospital discharges. Injury data are recorded based on the international classification of diseases (ICD), tenth edition. 
Efforts are underway to improve the data collection and monitoring process of road crashes. As part of the Road Safety Programme 2013-18, state observatories are being established. By 2015 observatories had been installed in 26 of the 32 federal entities. Sixteen of these report crash data on a common platform (RAVMex) through mobile and web applications, which also enable reporting on contributing factors to crashes. The registration of injury data is also being improved through multisectoral collaboration.

\section{Most recent safety data}

\section{Road crashes in 2015}

According to INEGI, 16039 persons were killed on Mexican roads in 2015, a 1\% increase compared to 2014 (INEGI, 2017b).

Since 2015 , road safety audits have been carried out, with the aim of improving road infrastructure, particularly on Federal Roads. A manual for audits is being developed and mechanisms for the certification of road safety auditors are being established. With regards to safety devices for vehicles, in 2016, NOM-194-SCFI-2015 was enacted. This stipulates the minimum safety devices required in new vehicles. Currently, the National Institute of Public Health is developing a project on helmets, cellular phones and speeding in four cities in Mexico.

\section{Trends in traffic and road safety (1990-2015) Traffic}

The motor vehicle fleet is increasing rapidly in Mexico. Between 2010 and 2015, the number of registered vehicles increased by $10.5 \%$. The number of registered motorcycles doubled from 1.15 to 2.38 million (INEGI, 2017a).

The federal highway network consists of approximately 49500 kilometres, which represent $13 \%$ of the national road network. Between 2014 and 2015, the length of the roads outside urban areas (Motorways, Federal Free Roads, State Roads, Rural Roads and Improved Dirt Roads) increased by $15 \%$ and the traffic in vehicle kilometres increased by $5 \%$. The length of roads inside urban areas increased by $17 \%$.

\section{Road safety \\ Crashes and casualties}

In the last 25 years, 15000 deaths were recorded on average every year. The number of registered fatalities peaked in 2009 at 17 820. In the last five years, a downward trend was observed. Since 2010, the number of fatalities has decreased by $3 \%$.

Almost four out of ten deaths in Mexico are vulnerable road users (pedestrians, cyclists and motorcyclists). The situation regarding motorcyclists is particularly worrying. Since 2010, the number of motorcyclists killed more than doubled.

\section{Rates}

The stabilisation in the number of road fatalities and the growth of the population led to a decrease in the fatality rate per 100000 inhabitants, from 17.2 in 1990 to 13.3 in 2015. During the same period the risk expressed in terms of deaths per 10000 registered vehicles decreased by more than $70 \%$, partly due to the large increase of the motor vehicle fleet. 


\section{Analysis of seriously injured data}

Mexico does not have an official classification of injuries. The police records the number of persons considered injured by the police au authorities at the scene of the crash, regardless of the severity of the injuries. The number of persons hospitalised are obtained from the Automated System of Hospital Exits, Ministry of Health 2010-2015.

Between 2010 and 2015 the number of injured persons hospitalised increased by 1.7\%; however the number of injured persons reported by the police at the site of the crash decreased by almost $30 \%$ in the same period of time.

Table 25.1. Road safety and traffic data

\begin{tabular}{|c|c|c|c|c|c|c|c|c|c|}
\hline & \multirow{2}{*}{1990} & \multirow{2}{*}{2000} & \multirow{2}{*}{2010} & \multirow{2}{*}{2014} & \multirow{2}{*}{2015} & \multicolumn{4}{|c|}{$2015 \%$ change over } \\
\hline & & & & & & 2014 & 2010 & 2000 & 1990 \\
\hline \multicolumn{10}{|l|}{ Reported safety data } \\
\hline Fatalities & 13974 & 14028 & 16559 & 15886 & 16039 & 1.0 & -3.1 & 14.3 & 14.8 \\
\hline Injury crashes & & 83804 & 114405 & 94423 & 86876 & -8.0 & -24.1 & 3.7 & \\
\hline Injured persons hospitalised & & & 26335 & 26389 & 26770 & 1.4 & 1.7 & & \\
\hline Deaths per 100000 population & 17.2 & 13.9 & 14.5 & 13.3 & 13.3 & -0.1 & -8.5 & -4.6 & -22.9 \\
\hline Deaths per 10000 registered vehicles & 14.2 & 9.0 & 5.2 & 4.2 & 4.6 & 9.5 & -11.5 & -48.9 & -67.5 \\
\hline \multicolumn{10}{|l|}{ Traffic data } \\
\hline Registered vehicles (thousands) & 9862 & 15612 & 31636 & 38025 & 34958 & -8.1 & 10.5 & 123.9 & 254.5 \\
\hline Registered vehicles per 1000 population & 121 & 155 & 277 & 318 & 289 & -9.1 & 4.3 & 86.5 & 138.1 \\
\hline
\end{tabular}

Figure 25.1. Road safety, traffic and GDP trends index $\mathbf{1 9 9 0}=\mathbf{1 0 0}$

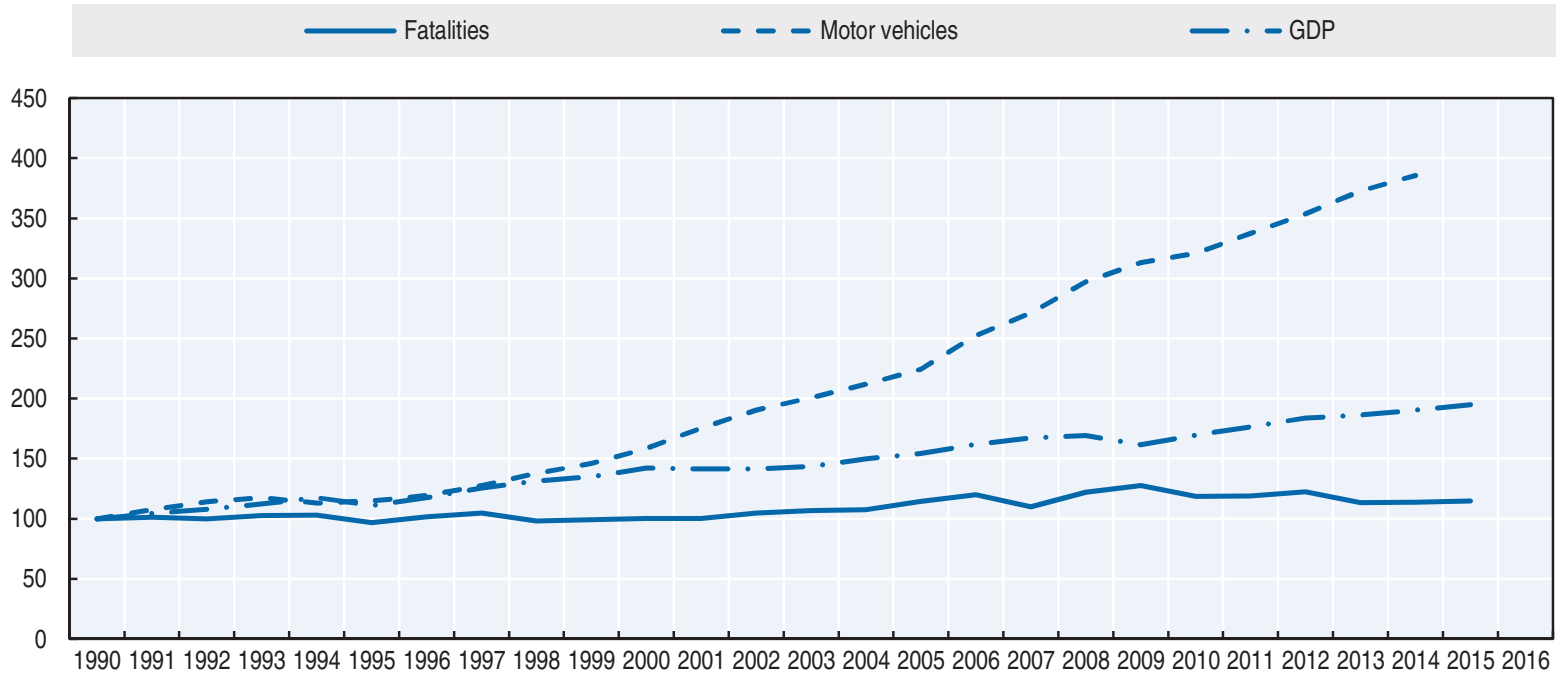

Source: World Bank (2017) (GDP; constant prices).

\section{Road safety by user group}

Since 2010, the number of people killed has decreased for all road users except motorcyclists for which the mortality more than doubled in five years. This is clearly a growing concern for Mexico, all the more as the motorcycle fleet is still relatively small and in constant expansion. 
Table 25.2. Road fatalities by road user group

\begin{tabular}{|c|c|c|c|c|c|c|c|c|c|}
\hline \multirow{2}{*}{ Road users } & \multirow{2}{*}{1990} & \multirow{2}{*}{2000} & \multirow{2}{*}{2010} & \multirow{2}{*}{2014} & \multirow{2}{*}{2015} & \multicolumn{4}{|c|}{$2015 \%$ change over } \\
\hline & & & & & & 2014 & 2010 & 2000 & 1990 \\
\hline Pedestrians & & 5509 & 4786 & 4821 & 4573 & -5.1 & -4.5 & -17.0 & \\
\hline Cyclists & & 107 & 178 & 190 & 175 & -7.9 & -1.7 & 63.6 & \\
\hline Motorcyclists & & 158 & 704 & 1360 & 1541 & 13.3 & 118.9 & 875.3 & \\
\hline Car occupants & & 2967 & 3357 & 2306 & 2439 & 5.8 & -27.3 & -17.8 & \\
\hline Others & & 5287 & 7534 & 7209 & 7311 & 1.4 & -3.0 & 38.3 & \\
\hline Total & 13974 & 14028 & 16559 & 15886 & 16039 & 1.0 & -3.1 & 14.3 & 14.8 \\
\hline
\end{tabular}

The "Others" category include the drivers and passengers of buses and goods vehicles, as well as the $40 \%$ of unknown road users.

\section{Figure 25.2. Road fatalities by road user group in percentage of total, 2015}

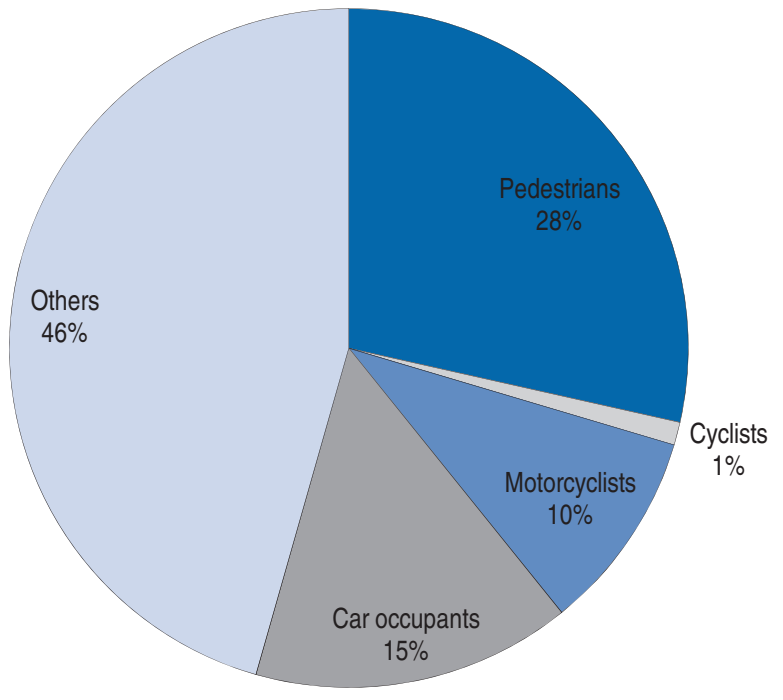

\section{Road safety by age group}

Since 2010, the number of fatalities has decreased for young people aged up to 20 and for persons over the age of 75 . It has increased by $11 \%$ for young people aged $21-24$.

The age group the most at risk in traffic are the persons over 65 years old with a fatality rate of 24 fatalities per 100000 , i.e. nearly twice that of the average population. They are particularly vulnerable as pedestrians (Secretaría de Salud, 2016). The risk increases further with age, with the 75 to 84 year old group having the highest mortality rate. 
Table 25.3. Road fatalities by age group

\begin{tabular}{lrrrr|rrrr}
\hline \multirow{2}{*}{ Age } & \multirow{2}{*}{1990} & 2000 & 2010 & 2014 & 2015 & \multicolumn{4}{|c}{$2015 \%$ change over } \\
\cline { 5 - 8 } & & & & & 2014 & 2010 & 2000 & 1990 \\
\hline $0-14$ & 1543 & 1341 & 1025 & 1021 & -0.4 & -23.9 & -33.8 \\
$15-17$ & 656 & 815 & 614 & 645 & 5.0 & -20.9 & -1.7 \\
$18-20$ & 961 & 1269 & 1167 & 1144 & -2.0 & -9.9 & 19.0 \\
$21-24$ & 1370 & 1592 & 1594 & 1763 & 10.6 & 10.7 & 28.7 \\
$25-64$ & 7699 & 9372 & 9323 & 9298 & -0.3 & -0.8 & 20.8 \\
$65-74$ & 865 & 1032 & 1015 & 1053 & 3.7 & 2.0 & 21.7 \\
\hline
\end{tabular}

Figure 25.3. Road fatality rates by age group Deaths per 100000 inhabitants in a given age group, 2010-15

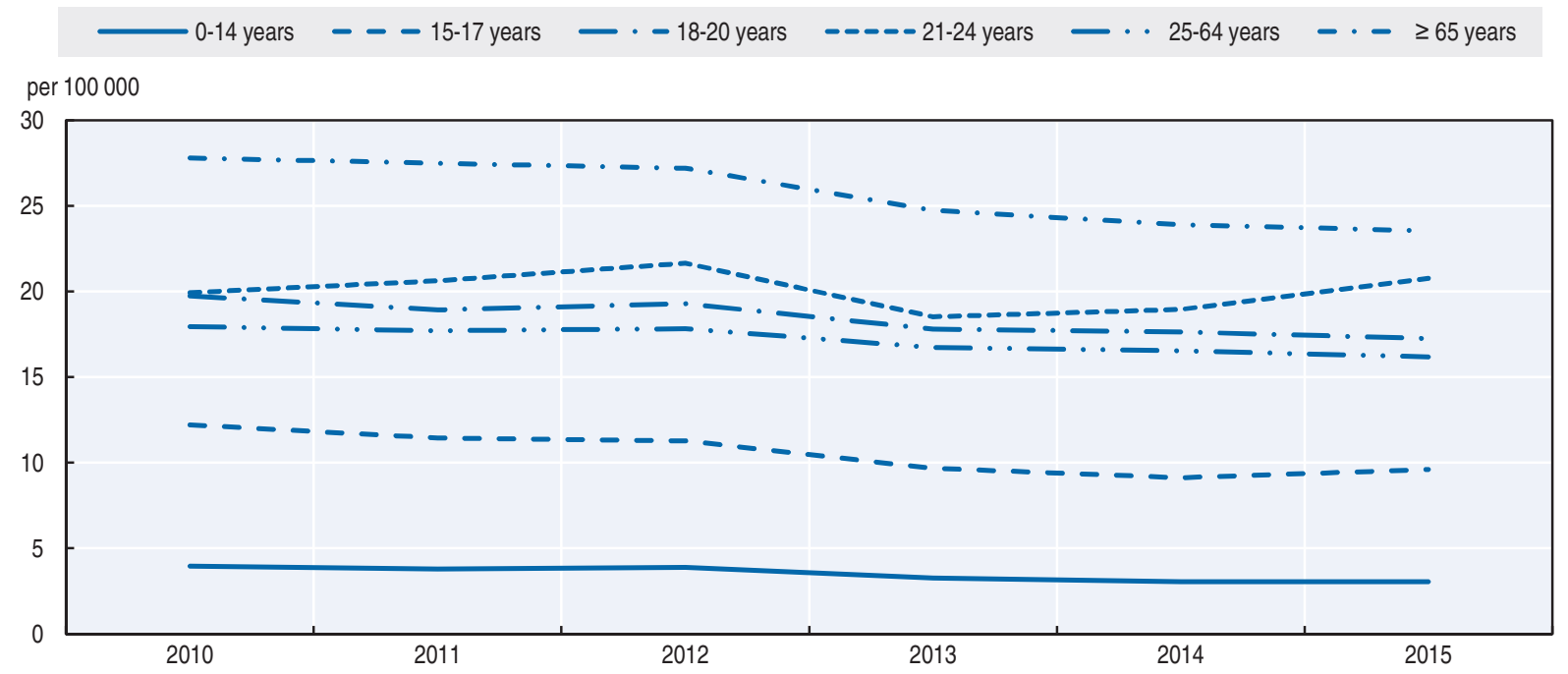

\section{Box 25.1. Road safety for an ageing population}

Currently people aged 65 and above represent $6.8 \%$ of the total population.

In 2015, this population accounted for $12 \%$ of all road traffic casualties. Between 2000 and 2015, the death toll of the senior population increased by 19\% (INEGI, 2017c).

Over half the senior citizens killed in road traffic are pedestrians.

In Mexico there is no an agency that regulates national drivers' licences. Each state has the freedom to regulate the granting of driving licences. In some states, there are driving restrictions for the elderly; in others not. For example in the State of Chihuahua, a medical examination is required, and some restrictions may apply (e.g., daytime driving or accompanied driving)

Regarding licences for the federal transport service, a medical examination is required that includes a physical examination to evaluate if the candidate is overweight, an eye examination, an evaluation of the nervous system, detection of respiratory diseases, evaluation of the endocrine, cardiovascular and hematopoietic system. Failure to pass these examinations is a reason for withdrawing or not granting a driver's licence, but there is no restriction on the maximum age to apply for a licence.

In 2016, different campaigns were carried out with television spots, aimed at senior citizens walking along and crossing roads, to encourage safe behaviour, for example right of way for pedestrians at crossings, use of a helmet for motorcyclists, respect for speed limits and non-use of distractors while driving. 
Box 25.1. Road safety for an ageing population (cont.)

Table 25.4. Road fatalities among senior citizen by user group

\begin{tabular}{|c|c|c|c|c|c|c|c|c|c|}
\hline & \multicolumn{3}{|c|}{$65-74$} & \multicolumn{3}{|c|}{$75-84$} & \multicolumn{3}{|c|}{$\geq 85$} \\
\hline & 2010 & 2015 & $\%$ change & 2010 & 2015 & $\%$ change & 2010 & 2015 & $\%$ change \\
\hline Pedestrians & 530 & 489 & -8 & 444 & 378 & -15 & 165 & 135 & -18 \\
\hline Cyclists & 19 & 18 & -5 & 12 & 10 & -17 & 2 & 1 & - \\
\hline Moped riders & 0 & 0 & $=$ & 0 & 0 & $=$ & 0 & 0 & $=$ \\
\hline Motorcyclists & 8 & 28 & 250 & 2 & 8 & + & 0 & 1 & + \\
\hline Car occupants & 167 & 129 & -23 & 76 & 86 & 13 & 25 & 23 & 18 \\
\hline Total & 1032 & 1053 & 2 & 692 & 668 & -3 & 237 & 223 & -6 \\
\hline
\end{tabular}

Figure 25.4. Road fatality rates by age group - Zoom on the senior population Deaths per 100000 inhabitants in a given age group, 2010-15

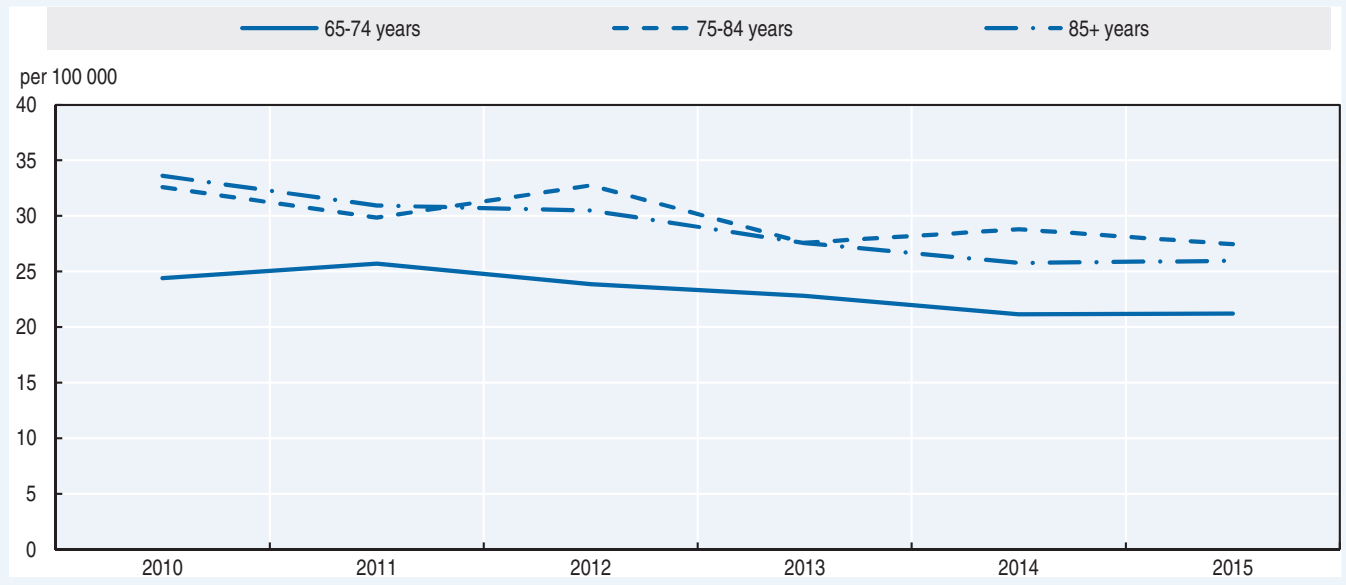

Figure 25.5. Road fatality rate by age and road user group Fatalities per 100000 inhabitants, 2015

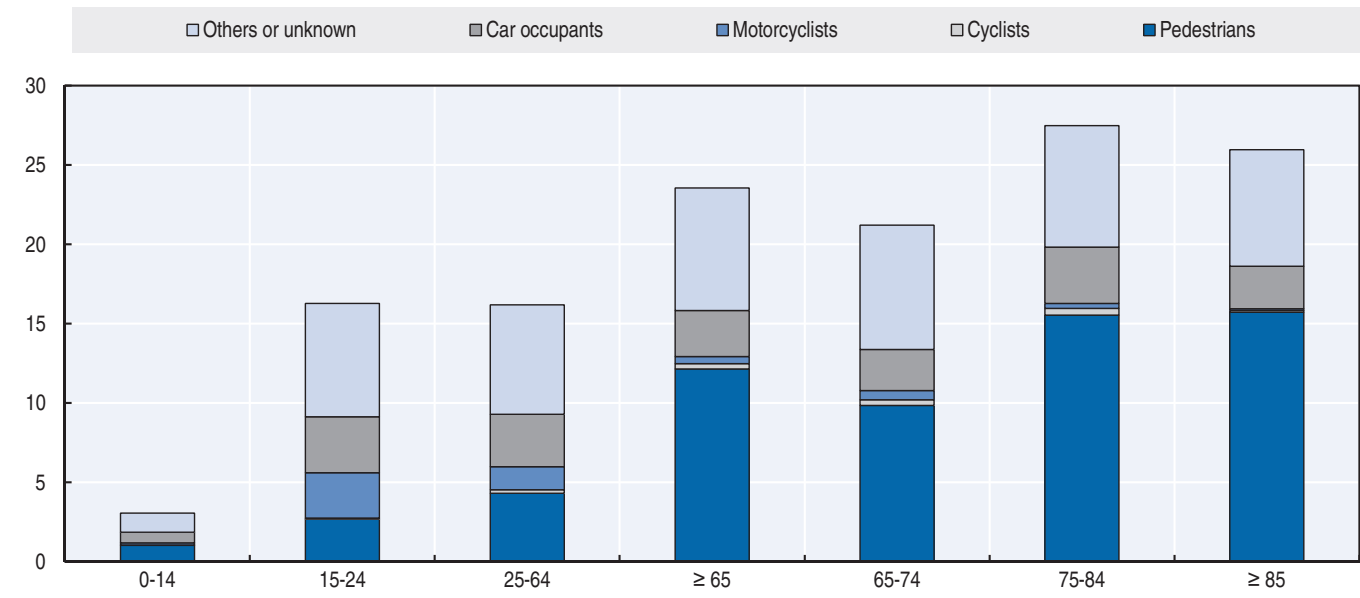




\section{Road fatalities by road type}

Between 2010 and 2015, the number of deaths recorded at the scene of the crash decreased by $25 \%$ in suburban areas and by more than $40 \%$ in urban areas. In 2015 , the number of fatalities on motorways increased by $1.1 \%$.

Figure 25.6. Road fatalities by road type

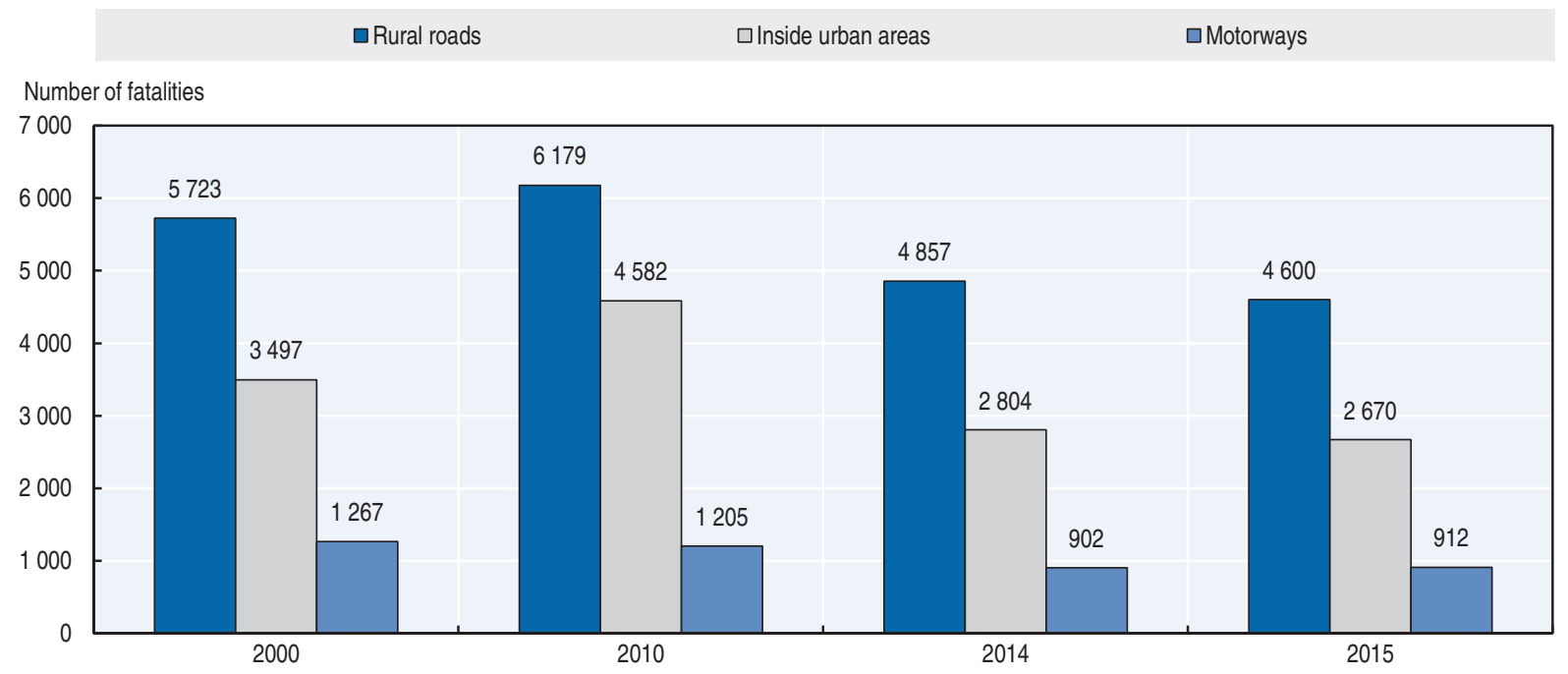

\section{Economic costs of traffic crashes}

Traffic crashes represent huge costs to society. In 2015, they were estimated at USD 18.7 billion, i.e. 1.64\% of GDP. These costs are estimated based on a human capital approach, as there are not yet any studies available on the statistical valuation of life using a willingness-to-pay approach (IMT, 2016; INEGI, 2017).

Table 25.6. Costs of road crashes, 2015

\begin{tabular}{lccc}
\hline & & Unit cost USD & Total \\
\hline Fatalities & 16039 & 400000 & 6.4 billion \\
Injuries & 122940 & 100000 & 12.3 billion \\
Total & & & $\mathbf{1 8 . 7}$ billion \\
Total as \% of GDP & & & $\mathbf{1 . 6 4 \%}$ \\
\hline
\end{tabular}

\section{Recent trends in road user behaviour}

\section{Speed}

In $2014,53 \%$ of road fatalities occurring on the federal highway network were reported by the federal police as due to excessive speed.

Speed measurement on the federal highway network conducted in 2013 revealed an average speed of $70.1 \mathrm{~km} / \mathrm{h}$ on interurban roads and $89.2 \mathrm{~km} / \mathrm{h}$ on motorways. The $85 \mathrm{th}$ percentile speeds (speed at which $85 \%$ of vehicles are not exceeding) were respectively 80.8 and $102.8 \mathrm{~km} / \mathrm{h}$.

The table below summarises the main speed limits in Mexico. 
Table 25.7. Passenger car speed limits by road type, 2017

\begin{tabular}{lc}
\hline & General speed limit \\
\hline Urban roads & $10-80 \mathrm{~km} / \mathrm{h}$ \\
Other roads & $50 \mathrm{~km} / \mathrm{h}$ \\
High speed roads & $100 \mathrm{~km} / \mathrm{h}$ \\
Motorways & $110 \mathrm{~km} / \mathrm{h}$ \\
\hline Source: Gaceta Oficial del Distrito Federal (2015) & and Diario Oficial de la \\
Federación (2012).
\end{tabular}

\section{Drink driving}

On federal roads and highways the maximum authorised blood alcohol content (BAC) is $0.8 \mathrm{~g} / \mathrm{l}$ and $0.3 \mathrm{~g} / \mathrm{l}$ for truck and coach drivers. On urban roads, the maximum BAC level differs by state.

A crash is defined as an alcohol-related crash when one of the participants (including cyclists and pedestrians) has a BAC above the legal limit.

A survey undertaken between 2010 and 2013 in 15 states revealed that 5\% of drivers were driving under the influence of alcohol.

There are several estimations of the contribution of drink driving to fatal crashes. According to the statistics office (INEGI, 2016), in 2014, on urban roads, $9 \%$ of fatalities were due to drunk drivers. However it is important to note that the BAC level of those involved in the crash was only available for $53 \%$ of the road deaths. The table below indicates the share of road fatalities due to drink driving. According to data from the Ministry of Health, drink driving was the main contributing factor for 23\% of road deaths in 2009 (Secretaría de Salud, 2010).

Table 25.6. Share of fatalities due to drinking and driving

$\%$

\begin{tabular}{lccc}
\hline & \multicolumn{3}{c}{ Alcohol test } \\
\cline { 2 - 4 } Year & Positive & Negative & No data \\
\hline $\mathbf{2 0 0 0}$ & 10.2 & 37.2 & 52.6 \\
$\mathbf{2 0 0 5}$ & 11.3 & 44.3 & 44.5 \\
$\mathbf{2 0 1 0}$ & 8.7 & 46.8 & 44.5 \\
$\mathbf{2 0 1 1}$ & 8.4 & 51.4 & 40.2 \\
$\mathbf{2 0 1 2}$ & 10.3 & 35.3 & 54.4 \\
$\mathbf{2 0 1 3}$ & 9.6 & 38.5 & 51.9 \\
$\mathbf{2 0 1 4}$ & 8.9 & 37.8 & 53.3 \\
$\mathbf{2 0 1 5}$ & 8.5 & 37.6 & 53.8 \\
\hline
\end{tabular}

Source: INEGI (2016).

\section{Drugs and driving}

A crash is defined as drug related when one of the participants (including pedestrians or cyclists) has consumed one or more psychoactive drugs.

The Mexican authorities conduct regular checks on the federal highway network to test the physical and physiological condition of professional drivers.

There is no data available to estimate deaths due to drugs and driving. 


\section{Distraction}

There is no official definition of distracted driving. In Mexico, only hands-free devices are allowed while driving. There is no data on the contribution of distracted driving to road crashes.

According to an observational study in 26 states, $55.6 \%$ of 41534 drivers are distracted while driving. Distraction means the diversion of attention away from activities critical for safe driving towards a competing activity.

\section{Sleepiness and fatigue}

There is no data on the contribution of sleepiness and fatigue to fatal crashes.

\section{Seat belts and helmets}

Seat belt wearing has been compulsory in front seats since 2012 and in rear seats since 2015.

Table 25.7. Seat belt wearing rate by car occupancy $\%$

\begin{tabular}{ll}
\hline & 2016 \\
\hline Front seat & \\
Drivers + Passengers & 54 \\
Driver & 60 \\
Passenger & 40 \\
Rear seats & \\
General & 21 \\
Children (use of child restraint) & 11 \\
\hline
\end{tabular}

Source: STCONAPRA.

The use of safety helmets is mandatory for all drivers and passengers of motorcycles, on the whole network (federal highway network; urban and suburban roads). The table below illustrates the evolution of helmet use by drivers and passengers between 2010 and 2014.

Safety helmets are not mandatory for cyclists.

Table 25.8. Evolution in the use of safety helmets, 2010-14

\begin{tabular}{llllll}
\hline \multicolumn{7}{c}{$\%$} \\
\hline Driver & 2010 & 2011 & 2012 & 2013 & 2014 \\
Passengers & 64.4 & 72.1 & 62.3 & 79.8 & 81.9 \\
\hline
\end{tabular}

Source: STCONAPRA (2014), based on an observational survey conducted in 70 municipalities from 28 states.

\section{National road safety strategies and targets}

\section{Road safety strategy for 2011-20}

To support the Decade of Action for Road Safety, Mexico launched in 2011 its National Road Safety Strategy 2011-20 (DOF, 2011). The strategy was developed jointly by the Ministry of Communications and Transport (SCT) and the Ministry of Health. Its main target is to reduce by $50 \%$ the number of fatalities and to reduce as much as possible injuries and disabilities due to road crashes. The strategy suggests the adoption of a general road safety law and the creation of a national road safety agency and a national road safety council. 
The strategy is based on the Global Plan for the Decade of Action (United Nations Road Safety Collaboration, 2011) and is organised around the following pillars:

- road safety management

- safer infrastructure

- safer vehicles

- road user behaviour

- post-crash care.

Figure 25.7. Trends in road fatalities towards national target

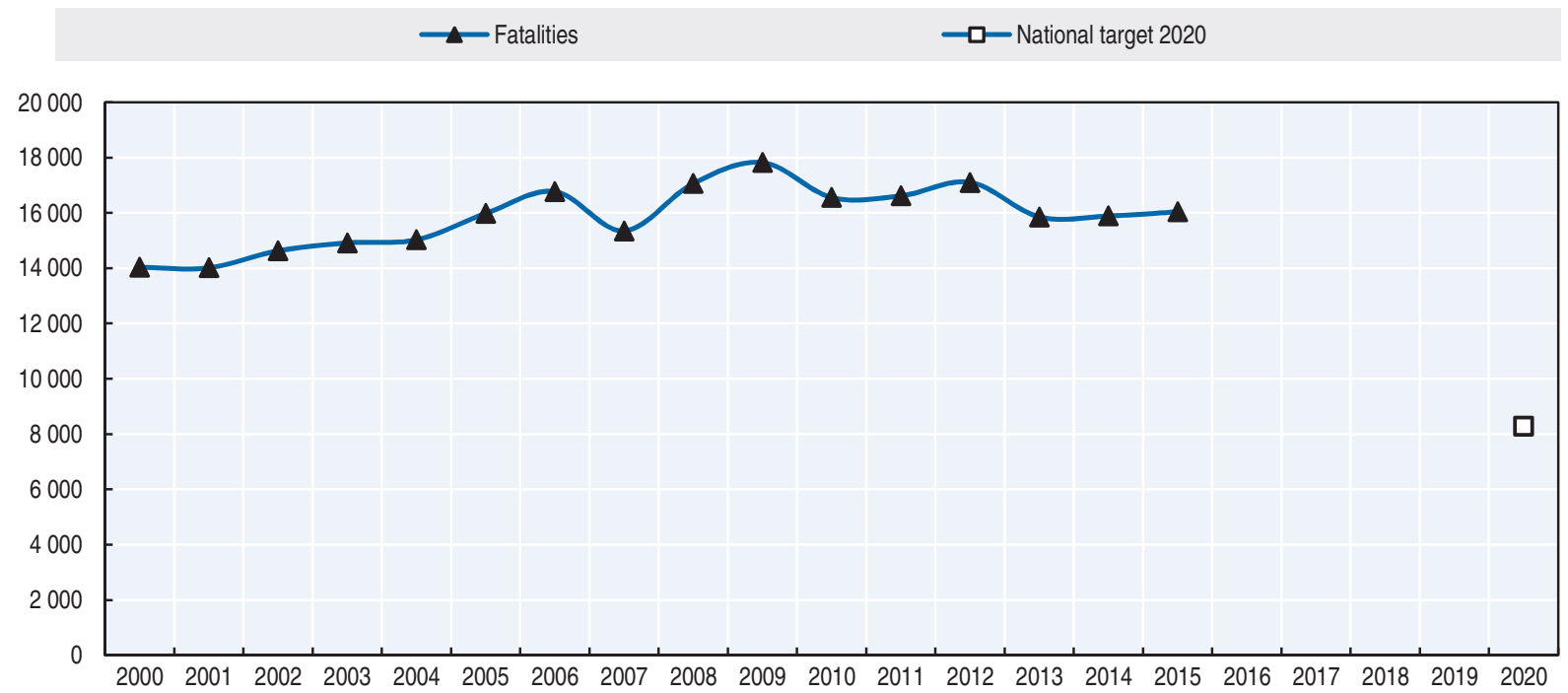

\section{Recent safety measures (2014-17) \\ Legislation}

- SCT concluded the draft of a national road safety law, including the creation of a National Road Safety Agency and a National Crash Investigation Agency, which is currently in the Chamber of Deputies for analysis and discussion.

- The National Advisory Committee on the Standardisation of Land Transport (CCNN-TT), co-ordinated by SCT, has concluded the revision and updating of several Mexican Official Standards (NOMS) and is preparing new standards:

* road signing and signalisation (concluded)

* road guardrails (concluded)

* emergency braking lanes on highways (concluded)

* maximum weight and dimension of vehicles (final stage of reviewing)

* hours of work and rest periods for professional drivers (in preparation)

- In 2016, the Ministry of Economy concluded and published the Mexican Official Standards to regulate the essential safety devices in new vehicles that are commercialised in Mexico.

- In 2017, the Ministry of Health concluded the draft of the Mexican Official Standards for motorcycle helmets, speed cameras and blood alcohol measurement. 


\section{Road safety data management}

- A task force on crash statistics and performance indicators is working towards the improvement of the national crash data system. In 2015, 26 regional road safety observatories were established. A new web-based application has been developed to link different road crash databases into a common platform (RAVMex).

\section{Road users}

- Review and update of the minimum training programme for professional drivers to obtain a federal licence.

- Ongoing project on the effective regulation of driving time.

- Since 2009, the health agency has promoted and strengthened strategic action against drunk driving. From 2016, regular alcohol checkpoints will be implemented in 158 municipalities. This is four times as many as in 2010. During 2015, more than 20000 alcohol checkpoints were set up, with 985874 breath tests conducted (13\% of them positive).

- The National Training Programme in Road Safety started in 2010. As of 2015, 1196 trainers have been trained in road safety, and 14690 promoters have given awareness talks to over 2 million citizens.

\section{Infrastructure}

- A project was conducted to assess the performance and condition of the federal highway network using the methodology of the international road assessment programme (iRAP). This has facilitated the development of an investment plan for safer roads. The iRAP Mexico project has helped address significant road safety problems and identify appropriate solutions (e.g. vertical signs and road markings).

- Several important infrastructure improvement projects are being carried out such as the installation of protective barriers, improved intersections, pedestrian bridges, bus stops, road markings, and emergency braking ramps.

- In Mexico the priority is shifting from car occupants to the most vulnerable road users. Mexico has more than 1400 road safety auditors in 30 states including 162 members of the Federal Police. Each state is required to implement at least three changes in infrastructure giving priority to pedestrians under a philosophy of Vision Zero.

\section{Recent and ongoing research}

- Dynamic Auscultation of Signs and Road Safety Devices, Case study: Route MEX-200 Manzanillo - Puerto Vallarta, Tramo Manzanillo - Melaqué; Instituto Mexicano del Transporte; Technical Publication No. 487; www.imt.mx/archivos/Publicaciones/Publicacion Tecnica/pt487.pdf (accessed 4 July 2017).

- Zero Vision in Road Safety: Some Implementation Opportunities in Mexico; Instituto Mexicano del Transporte; Technical Publication No. 466; www.imt.mx/archivos/Publicaciones/ PublicacionTecnica/pt466.pdf (accessed 4 July 2017).

- Road Safety Benefit Assessment by Modifying a Two-lane Road to a $2+1$ Configuration with Central Cable Barrier; Instituto Mexicano del Transporte; Technical Publication No. 465; www.imt.mx/archivos/Publicaciones/PublicacionTecnica/pt465.pdf (accessed 4 July 2017). 
- Casualty Analysis of Vulnerable Users on Federal Roads; Instituto Mexicano del Transporte; Technical Publication No. 453; www.imt.mx/archivos/Publicaciones/PublicacionTecnica/ pt453.pdf (accessed 4 July 2017).

- Road Safety Campaigns to Improve Human Behavior; Instituto Mexicano del Transporte; Technical Publication No. 449; www.imt.mx/archivos/Publicaciones/PublicacionTecnica/ pt449.pdf (accessed 4 July 2017).

- Safety Improvements to the Infrastructure of a Road Section based on its IRAP Evaluation. Corridor Mexico - Nuevo Laredo, Section Querétaro - San Luis Potosí; Instituto Mexicano del Transporte; Technical Publication No. 439; www.imt.mx/archivos/Publicaciones/ PublicacionTecnica/pt439.pdf (accessed 4 July 2017).

\section{References}

DOF (2011), "Acuerdo por el que se da a conocer la Estrategia Nacional de Seguridad Vial 2011-20", Diario Oficial de la Federación, Mexico.

Gaceta Oficial del Distrito Federal (2015), “Reglamento de Tránsito del Distrito Federal”, Publicado el 17 de agosto de 2015.

INEGI (2017a), "Accidentes de tránsito terrestre en zonas urbanas y suburbanas", Instituto Nacional de Estadística y Geografía, Mexico, www.inegi.org.mx/est/contenidos/proyectos/registros/economicas/ accidentes/ (accessed 4 July 2017).

INEGI (2017b), Vehículos Registrados en Circulación, Instituto Nacional de Estadística y Geografíah, Mexico, www.inegi.org.mx/est/contenidos/proyectos/registros/economicas/vehiculos/default.aspx (accessed 4 July 2017).

INEGI (2017c), Volumen y crecimiento. Población total por entidad federativa, 1895 a 2010, Instituto Nacional de Estadística y Geografía, Mexico, www.inegi.org.mx/inegi/default.aspx?s=est\&c=2343 (accessed 4 July 2017).

Secretaría de Salud (2016). Dirección General de Información en Salud. Base de datos sobre defunciones, Secretaría de Salud, Mexico.

Secretaría de Salud/STCONAPRA (2015), Informe sobre la situación de la seguridad vial en México. Primera Edición, Ciudad de México, México. http://conapra.salud.gob.mx/Interior/Documentos/Informe2015.pdf.

Secretaría de Salud (2010), Dirección General de Epidemiología, Sistema de Vigilancia Epidemiológica de las Adicciones (SISVEA), Informe 2009, Mexico.

World Bank (2017), “GDP (constant US\$)”, World Development Indicators, http://databank.worldbank.org/ data/reports.aspx?source=world-development-indicators (accessed 23 February 2017).

\section{Websites}

- Instituto Mexicano del Transporte (IMT): www.imt.mx (accessed 4 July 2017).

- Secretaría de Salud: www.gob.mx/salud/.

- Instituto Nacional de Estadística y Geografía (INEGI): www.inegi.org.mx/ (accessed 4 July 2017). 



\section{Chapter 26}

\section{Morocco}

This chapter presents 2015 road safety data for Morocco along with provisional data from 2016. It looks at trends in traffic and road safety from the years 1990 to 2015 and road user behaviour patterns. Sections include data on the ageing population, speed, drink driving, drugs and driving, distracted driving, fatigue and seat belt usage. The chapter reviews Morocco's road safety strategy 2016-25 and national targets to 2025 along with recently implemented safety measures.*

* The data in this report, unless otherwise noted, were provided by the National Committee for the Prevention of Traffic Crashes (CNPAC) and have not been validated by IRTAD. For more information please contact: boulaajoul@cnpac.gov.ma; bardan@cnpac.gov.ma. 
F roads during 2015, an $8.2 \%$ increase over 2014. Injury crashes and those seriously injured also increased. All road user groups apart from car occupants were affected, with vulnerable road users accounting for $61 \%$ of all fatalities in 2015. Morocco recorded a fatality rate of 11.1 per 100000 inhabitants in 2015. In 2015 the structure of fatalities by user groups changed as the proportion of motorcycles increased, exceeding for the first time the share of pedestrians.

\section{Road safety data collection}

\section{Definitions applied in Morocco}

- Road fatality: Any person killed immediately or dying within 30 days as a result of a road crash.

- Seriously injured person: Any person injured in a road crash requiring hospitalisation for six days or more.

- Slightly injured person: Any person injured in a road crash requiring medical treatment or hospitalisation of less than six days.

\section{Data collection}

In Morocco, crash data are collected at the scene of the crash by police: the Gendarmerie in rural areas and the national police in urban areas.

Police are expected to attend all injury or fatal crashes. Data related to accidents involving material damage only are not recorded.

Crash information is filled in on a form similar to that used in France. This form contains information on the circumstances of the crash, the location, the casualties, etc. It is planned to progressively introduce Global Information System (GIS) information into police reports.

Data are consolidated at the national level by the Roads Directorate, part of the Ministry of Equipment, Transport and Logistics, and are entered into a database administered by the same entity since the 1970s.

Police liaise with hospitals to complete their reports in case of injuries; however there is no information on the specific level of injuries such as classifications using the International Classification of Diseases 10 (ICD-10) system.

The level of underreporting is not known. In its 2015 global status report (WHO, 2015), the World Health Organization estimated that in 2013 the total number of road fatalities was between 5800 and 7000 whereas the reported number was 3832 .

\section{Most recent safety data}

\section{Road crashes in 2016 - provisional data}

The provisional data for 2016 are as follows:

- 3593 reported road deaths, a 0.8\% increase compared to the provisional figure of 2015.

- 8950 seriously injured persons, a 10.1\% decrease compared to the provisional figure of 2015. 


\section{Road crashes in 2015}

In 2015, all safety indicators recorded increases:

- The number of reported crashes increased by $14.2 \%$.

- There were 3776 reported road deaths, an increase of 8.2\% compared to 2014 .

- The number of people seriously injured increased by $4.5 \%$.

In 2015 the structure of fatalities by user groups changed as the proportion of motorcycles (28.2\%) increased, coming in just under passenger car occupants $(29.9 \%)$ and exceeding for the first time the share of pedestrians (27.3\%).

\section{Trends in traffic and road safety (1990-2015)}

\section{Traffic}

Motorisation is growing quickly in Morocco. Between 2000 and 2015, the number of motorised vehicles doubled. However, with 100 registered vehicles for 1000 inhabitants, motorisation is in its infancy, and a large increase in the vehicle fleet is expected in coming years. This will require the implementation of a wide range of road safety measures to avoid an explosion in the number of traffic crashes.

\section{Road safety}

\section{Crashes and casualties}

The number of police reported road fatalities peaked in 2011, with 4222 persons killed. In the succeeding 3 years (2012-14), there was a continuous decrease in road fatalities. However, in 2015 the number of road deaths increased by $8.2 \%$. Provisional data record a slight increase again in 2016.

Between 1990 and 2015, the number of reported road fatalities increased by $36 \%$. Following an increasing trend, the number of road fatalities recorded a noticeably lower figure in 1996 (2 807 fatalities), when compared to the five previous years. This was attributed to an important effort in enforcement and a strong mobilisation of different road safety services.

\section{Rates}

In 2015, the mortality rate was 11.1 deaths per 100000 inhabitants; while the fatality risk was 10.5 per 10000 registered vehicles. These rates are high when compared with OECD member countries.

Table 26.1. Road safety and traffic data

\begin{tabular}{|c|c|c|c|c|c|c|c|c|c|}
\hline & \multirow{2}{*}{1990} & \multirow{2}{*}{2000} & \multirow{2}{*}{2010} & \multirow{2}{*}{2014} & \multirow{2}{*}{2015} & \multicolumn{4}{|c|}{$2015 \%$ change from } \\
\hline & & & & & & 2014 & 2010 & 2000 & 1990 \\
\hline \multicolumn{10}{|l|}{ Reported safety data } \\
\hline Fatalities & 2777 & 3627 & 3778 & 3489 & 3776 & 8.2 & -0.1 & 4.1 & 36.0 \\
\hline Injury crashes & 32992 & 48350 & 65461 & 68279 & 78003 & 14.2 & 19.2 & 61.3 & 136.4 \\
\hline Deaths per 100000 inhabitants & 11,5 & 12,7 & 11,8 & 10,5 & 11,1 & 5.7 & -6.3 & -12.9 & -3.4 \\
\hline Deaths per 10000 registered vehicles & 29,0 & 21,7 & 13,5 & 10,1 & 10,5 & 4.0 & -22.2 & -51.6 & -63.8 \\
\hline \multicolumn{10}{|l|}{ Traffic data } \\
\hline Registered vehicles (thousands) & 956 & 1675 & 2791 & 3438 & 3590 & 4.4 & 28.6 & 114.3 & 275.5 \\
\hline Registered vehicles per 1000 inhabitants & 40 & 59 & 88 & 102 & 105 & 2.9 & 20.0 & 78.6 & 165.2 \\
\hline
\end{tabular}

Source: CNPAC. 
Figure 26.1. Road safety, traffic and GDP trends index $1990=100$

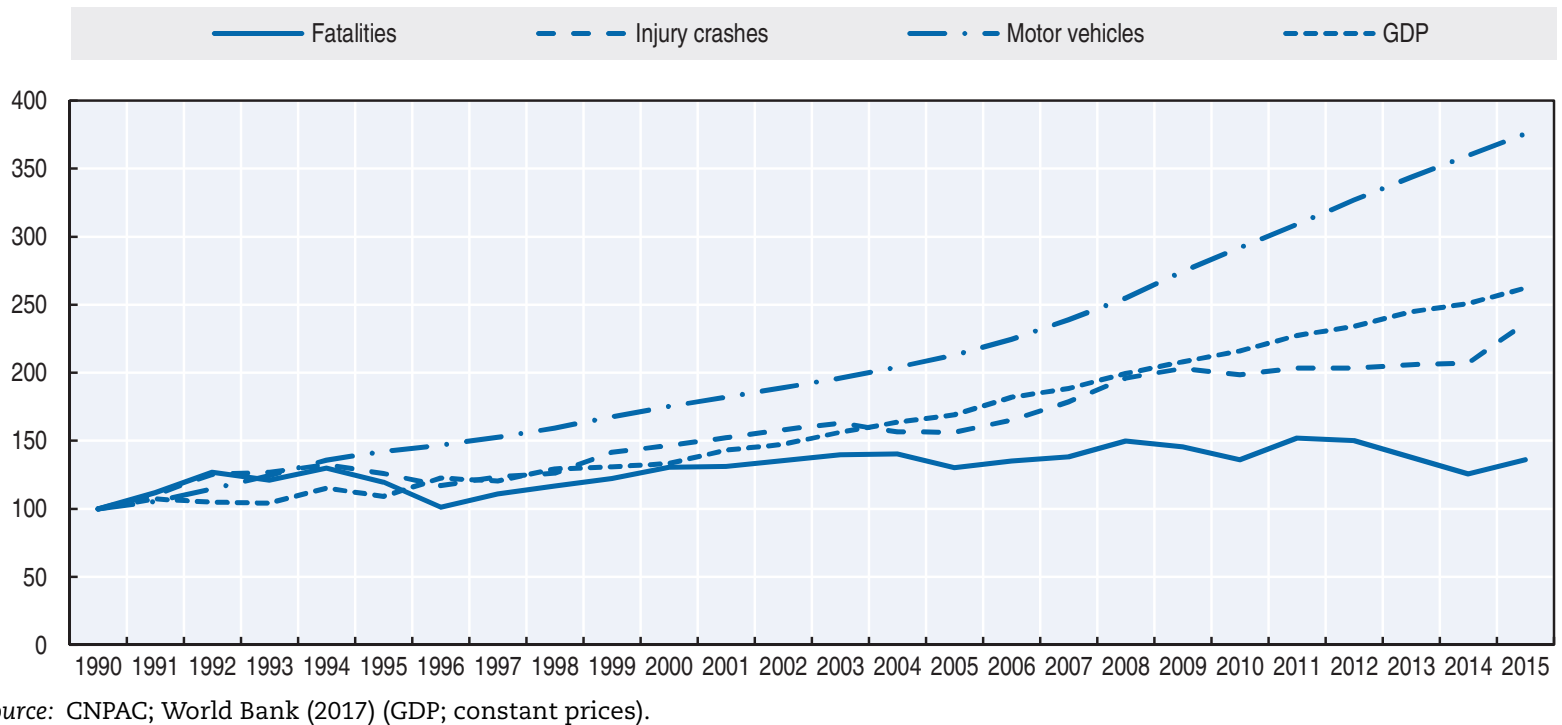

\section{Road safety by user group}

Passenger car occupants are the main victims of traffic crashes, representing $30 \%$ of all casualties, followed by motorcyclists (28\%) and pedestrians (27\%). In 2015 vulnerable road users (pedestrians, cyclists and motorcyclists) accounted for $61 \%$ of the total number of fatalities.

In 2015, the number of fatalities increased for all user groups, excepting car occupants. The highest increases were recorded for motorcyclists $(23.7 \%)$ and cyclists $(14 \%)$. Motorcyclists now represent the second user group most affected by road crashes, exceeding for the first time pedestrians.

Table 26.2. Reported road fatalities by road user group

\begin{tabular}{|c|c|c|c|c|c|c|c|c|c|}
\hline & \multirow{2}{*}{1990} & \multirow{2}{*}{2000} & \multirow{2}{*}{2010} & \multirow{2}{*}{2014} & \multirow{2}{*}{2015} & \multicolumn{4}{|c|}{$2015 \%$ change from } \\
\hline & & & & & & 2014 & 2010 & 2000 & 1990 \\
\hline Pedestrians & 987 & 1132 & 995 & 992 & 1030 & 3.8 & 3.5 & -9.0 & 4.4 \\
\hline Cyclists & 124 & 233 & 219 & 193 & 220 & 14.0 & 0.5 & -5.6 & 77.4 \\
\hline Motorcyclists & 371 & 414 & 714 & 862 & 1066 & 23.7 & 49.3 & 157.5 & 187.3 \\
\hline Passenger car occupants & 568 & 692 & 890 & 1143 & 1129 & -1.2 & 26.9 & 63.2 & 98.8 \\
\hline Others incl. unknown & 727 & 1156 & 960 & 299 & 331 & 10.7 & -65.5 & -71.4 & -54.5 \\
\hline Total & 2777 & 3627 & 3778 & 3489 & 3776 & 8.2 & -0.1 & 4.1 & 36.0 \\
\hline
\end{tabular}

Source: CNPAC. 
Figure 26.2. Road fatalities by road user group in percentage of total, 2015

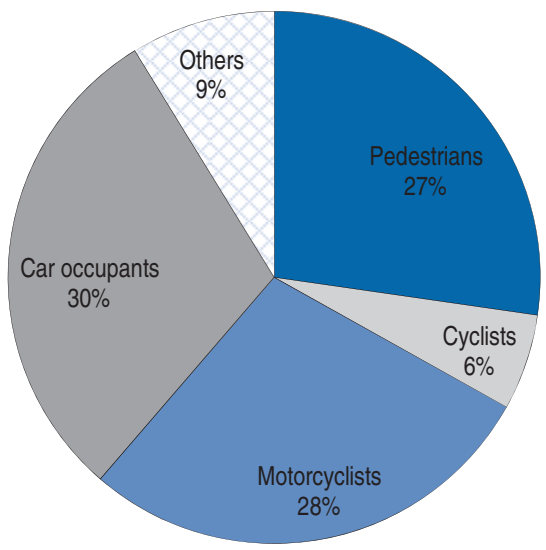

\section{Road safety by age group}

Compared to the figures for 2014, all age groups recorded increases in the number of fatalities, the highest of which were recorded among the age groups 0 -14 years $(8.7 \%), 15$-17 years $(14.7 \%)$ and 65 years and over (23.1\%).

Table 26.3. Road fatalities by age group

\begin{tabular}{lrrr|rr}
\hline \multirow{2}{*}{ Age } & 2010 & 2014 & 2015 & \multicolumn{2}{|c}{$2015 \%$ change from } \\
\cline { 4 - 5 } & & & 2014 & 2010 \\
\hline $0-14$ & 444 & 357 & 388 & 8.7 & -12.6 \\
$15-17$ & 170 & 102 & 117 & 14.7 & -31.2 \\
$18-20$ & 212 & 170 & 176 & 3.5 & -17.0 \\
$21-24$ & 362 & 325 & 329 & 1.2 & -9.1 \\
$25-64$ & 2172 & 2097 & 2249 & 7.2 & 3.5 \\
$65-74$ & & 223 & 263 & 17.9 & \\
$75-84$ & & 125 & 156 & 24.8 & \\
$\geq 85$ & 28 & 44 & 57.1 & $\mathbf{0 . 1}$ \\
Total & $\mathbf{3 7 7 8}$ & $\mathbf{3 4 8 9}$ & $\mathbf{3 7 7 6}$ & $\mathbf{8 . 2}$ & \\
\hline
\end{tabular}

Source: CNPAC.

\section{Box 26.1. Road safety for an ageing population}

In 2014, there were 2.05 million people aged 65 and above, representing $6.1 \%$ of the Moroccan population. This number is expected to double by 2050 and reach 4.36 million, when senior citizens will count for $17 \%$ of the population.

In 2015, 643 persons over the age of 65 died on Moroccan roads, which represented an increase of $25 \%$ when compared to 2010. Car occupants represented $39 \%$ of fatalities among older persons, followed by pedestrians (33\%), motorcyclists (16\%) and cyclists (5\%). Between 2010 and 2015, there was an increase in fatalities for all road users groups among senior citizens: the highest rate was recorded for motorcyclists (+55\%), followed by car occupants (+38\%), cyclists (+33\%) and pedestrians (+26\%).

In Morocco, the driving licence is renewed every 10 years and the renewal process requires taking a medical test. Drivers aged 65 and above must pass a medical test every two years to renew their licence. 


\section{Road safety by road type}

More than two-thirds of crashes occur in built up areas, but the most severe crashes occur on rural roads, where two-thirds of the fatalities are recorded. Crashes outside urban areas are more often than not related to speeding.

In 1990, the total length of motorways was less than $100 \mathrm{~km}$ and accounted for $2 \%$ of fatalities. In 2015, the total length of motorways amounted to $1499 \mathrm{~km}$ and accounted for $6.3 \%$ of fatalities. In 2015, in urban areas, pedestrians, motorcyclists and cyclists represented $85 \%$ of fatalities.

\section{Figure 26.3. Road fatalities by road type}

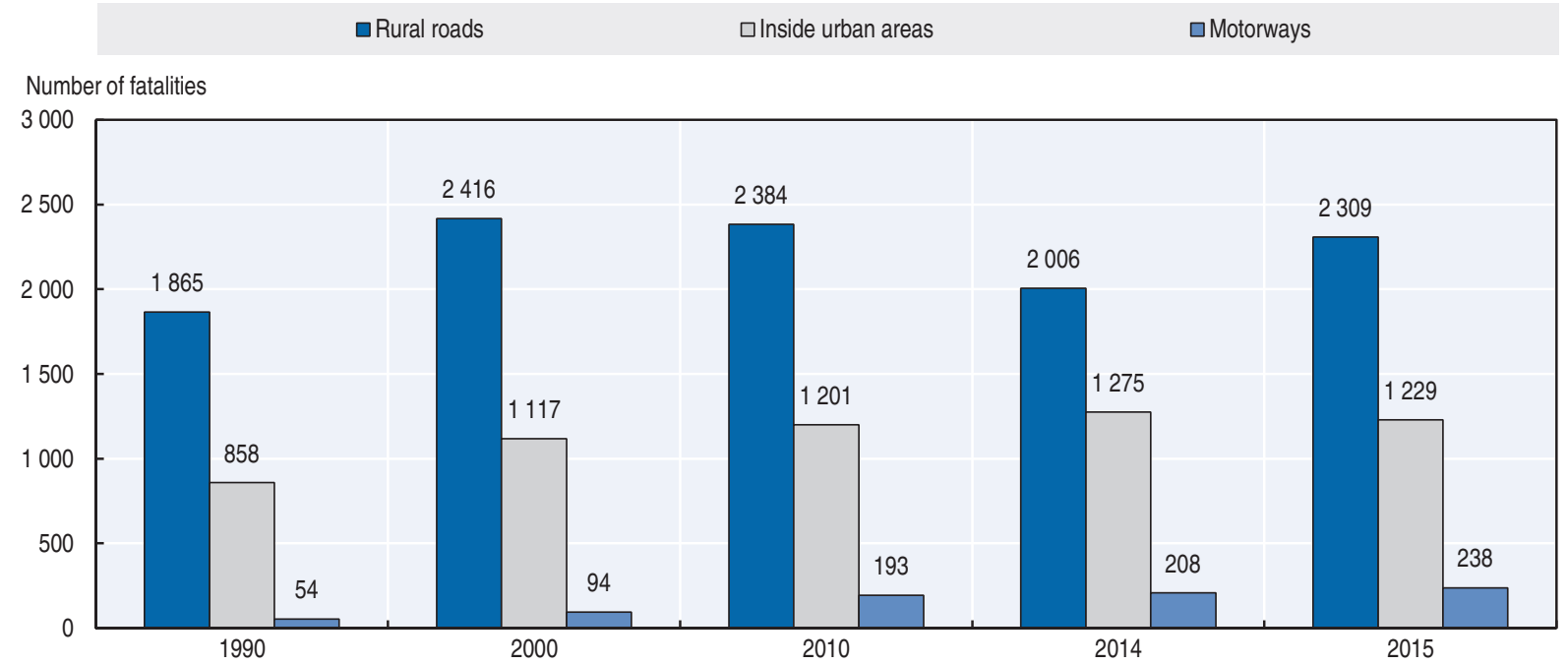

Source: CNPAC.

\section{Economic costs of traffic crashes}

Traffic crashes represent a significant cost for Moroccan society. In 2015, it was estimated that crashes cost EUR 1.8 billion. Based on estimates from the World Bank, crashes account for $2 \%$ of Morocco's GDP.

\section{Recent trends in road user behaviour}

\section{Speed}

The table below summarises the main speed limits in Morocco.

Table 26.4. Passenger car and truck speed limits by road type, 2017

\begin{tabular}{lcc}
\hline & General speed limit passenger cars & General speed limit trucks $>3.5 \mathrm{t}$ \\
\hline Urban roads & $60 \mathrm{~km} / \mathrm{h}$ & $60 \mathrm{~km} / \mathrm{h}$ \\
Rural roads & $100 \mathrm{~km} / \mathrm{h}$ & $90 \mathrm{~km} / \mathrm{h}$ \\
Motorways & $120 \mathrm{~km} / \mathrm{h}$ & $100 \mathrm{~km} / \mathrm{h}$ \\
\hline
\end{tabular}

Source: CNPAC. 


\section{Drink driving}

In 2010, Morocco enacted a law prohibiting driving under the influence of alcohol. The law fixed the maximum permissible blood alcohol content (BAC) to $0.2 \mathrm{~g} / \mathrm{l}$ when measured by blood sample and $0.1 \mathrm{mg} / \mathrm{l}$ when measured by breath testing.

In 2015 , on the basis of police data, alcohol use was cited as a contributing factor in $2.6 \%$ of all crashes.

\section{Drugs and driving}

According to the Highway Code, it is forbidden to drive under the influence of illicit drugs. This measure is not yet enforced.

\section{Distraction}

The use of hand-held phones while driving is forbidden. The use of hands-free devices while driving is authorised. In 2015 , it was estimated that $3.6 \%$ of drivers were used a mobile phone while driving.

\section{Fatigue and sleepiness}

In 2015 , on the basis of police data, it was estimated that about $1.9 \%$ of crashes were due to fatigue.

\section{Seat belts and helmets}

Seat belt use has been compulsory for front seats in rural areas since 1977, and since 2005 for front seats in urban areas and rear seats in rural areas. According to an observational study conducted in September 2016, the wearing rate in urban areas was $62 \%$ for drivers and $59 \%$ for front seat passengers. In rural areas, the wearing rate was $66 \%$ for drivers, $62.5 \%$ for front seat passengers and $25.1 \%$ for rear seat passengers.

Since 1976, all riders of powered two-wheelers (PTWs) are required to wear a helmet. In September 2016, the helmet wearing rate in urban areas was $65.1 \%$ for drivers and $34.2 \%$ for passengers.

Table 26.5. Seat belt wearing rate by car occupancy and road type

\begin{tabular}{lc}
\hline & 2016 \\
\hline Front seats & \\
Driver - urban roads & $62 \%$ \\
Passenger - urban roads & $59 \%$ \\
Driver - rural roads & $65 \%$ \\
Passenger - rural roads & $62 \%$ \\
Driver - motorways & $71 \%$ \\
Rear seats & \\
Adults & $25 \%$ \\
Children & N.A \\
\hline
\end{tabular}




\section{National road safety strategies and targets}

\section{Organisation of road safety}

The agency responsible for the management of road safety is the Directorate of Road Transport and Road Safety in the Ministry of Transport, Infrastructure and Logistics. In 2006 , several committees dedicated to road safety were created:

- The Interministerial Committee for Road Safety chaired by the Chief of the Government is responsible for the validation of national road strategies, as well as the co-ordination, monitoring and evaluation of the implementation of action plans.

- The Permanent Committee for Road Safety chaired by the Minister of Transport, Infrastructure and Logistics, which acts as the technical secretariat for the Interministerial Committee.

- Regional committees for road safety.

The Ministry of the Interior, the Ministry of Justice, the Ministry of Health, the Ministry of National Education, the Ministry of High Education and Scientific Research, the police, the Gendarmerie and the National Committee for Traffic Accidents Prevention are represented in these various committees.

The government is currently working towards the creation of a national road safety agency.

\section{Road safety strategy 2016-25}

In 2014 and 2015, the Ministry of Equipment, Transport and Logistics, with the technical assistance of the World Bank and co-operation with various stakeholders, conducted a detailed evaluation of the 2004-13 national road safety strategy and prepared the new road safety strategy for the period 2016-25.

The aim of the road safety strategy $2016-25$ is the development of responsible road behaviour and a safe road system. The strategy will focus on the following five pillars:

- pedestrians

- motorcycles

- single vehicle crashes

- children

- professional transport.

\section{Road safety targets}

The new national road safety strategy (2016-2025) has the following targets:

- Reduce the number of deaths to less than 2800 by 2020 (decrease of $20 \%$ from 2015 to 2020).

- Reduce the number of deaths to less than 1900 fatalities by 2025 (decrease of 50\% from 2015 to 2025).

\section{Recent safety measures (2016-17)}

\section{Road safety management}

- The Ministry of Transport, Infrastructure and Logistics has prepared a road safety action plan for the period 2016-25 including several measures that were already implemented in 2016. 
Figure 26.4. Trends towards national fatality target

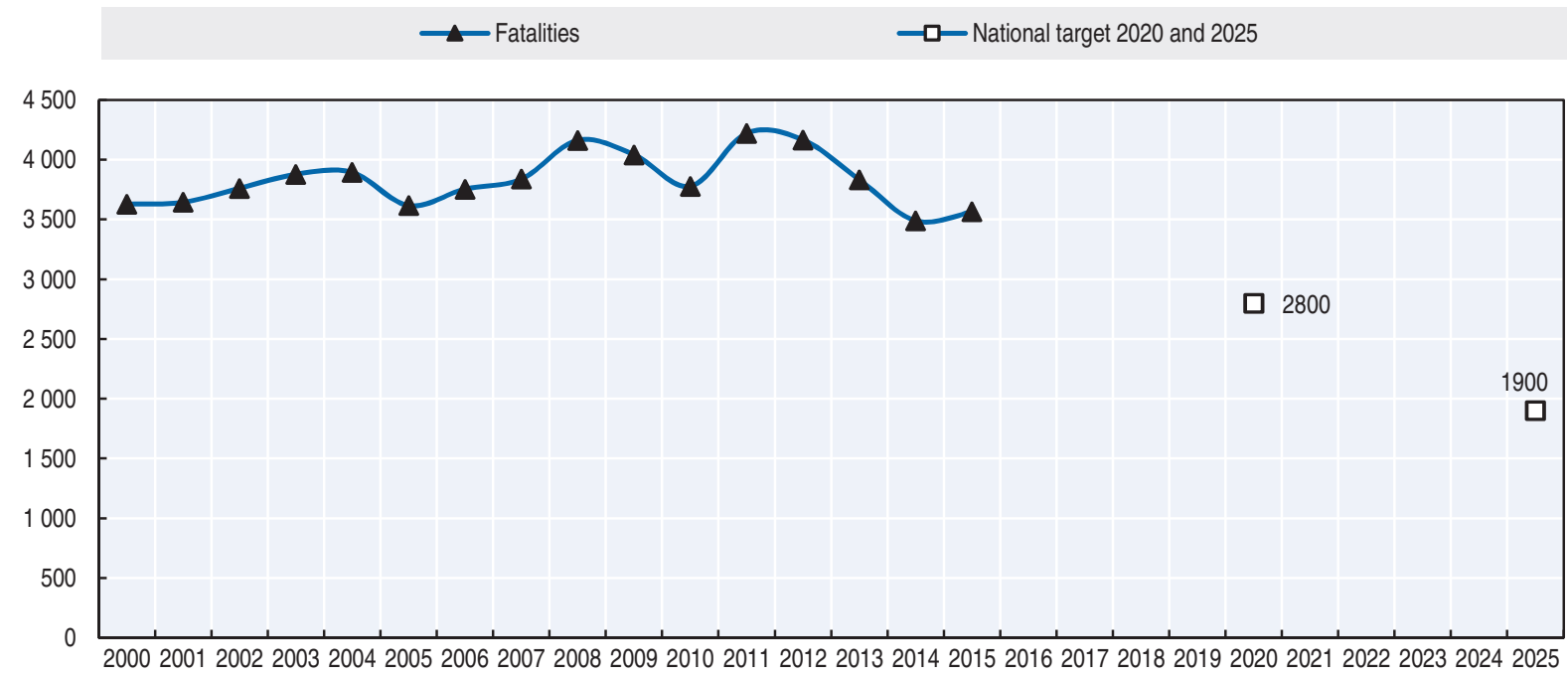

\section{Road users}

- Enhance enforcement against dangerous road user behaviour such as speed, drunk driving, mobile phone use while driving and transporting children under the age of 10 in the front seats.

- Communication campaigns are implemented on specific topics: speed, seat belts, helmet use and use of mobile phones while driving.

\section{Infrastructure}

- Construction of $35.1 \mathrm{~km}$ of cycle paths outside built up areas.

- Installation of safety measures along $351 \mathrm{~km}$ of roads outside built up areas to reduce the severity of road crashes.

- Reinforcing road signs along high crash risk sections.

- Construction of four bridges to enhance pedestrian safety. Five other bridges are under construction.

\section{Vehicles}

- Audit of technical inspection centres that are suspected of delivering counterfeit inspection certificates.

- School transport vehicles equipped with a seat and seat belt for each child.

- Public transport vehicles are required to be equipped with seatbelts for all passengers' seats.

\section{Post-crash measures}

- The ambulance fleet is being increased to enhance their presence nationwide.

- Creation of 16 proximity emergency units to complete the 80 units expected. 


\section{Recent and ongoing research}

- Road user behaviour through roadside surveys: including the use of seat belts and helmets, crossing through a red traffic light or a stop sign, etc.

\section{References}

WHO (2015), Global status report on road safety 2015, World Health Organization, Geneva.

World Bank (2017), “GDP (constant US\$)”, World Development Indicators, http://databank.worldbank.org/ data/reports.aspx? source=world-development-indicators (accessed 23 February 2017).

\section{Websites}

Comité National de Prévention des Accidents de la Circulation (CNPAC): www.cnpac.ma (accessed 3 July 2017). Ministry of Transport: www.mtpnet.gou.ma (accessed 3 July 2017). 


\section{Chapter 27}

\section{The Netherlands}

This chapter presents 2015 road safety data for the Netherlands along with fatality data from 2016. It looks at trends in traffic and road safety from the years 1990 to 2015 and road user behaviour patterns including a focus on the ageing population. Sections include data on speed, drink driving, drugs and driving, distracted driving, fatigue and seat belt usage. The chapter reviews the Dutch road safety strategy and national targets to 2020 and the progress achieved thus far. It also looks at ongoing research and recently implemented safety measures. ${ }^{*}$

* All data stem from SWOV, the Ministry of Infrastructure and the Environment and IRTAD unless otherwise noted. For more information please contact: niels.bos@swov.nl. 
I In 2015, the Netherlands recorded 621 road deaths, an increase of 9\% compared to 2014 . Cyclists accounted for $30 \%$ of all fatalities. Road users over the age of 65 are particularly affected, accounting for $40 \%$ of all fatalities and half of the number of cyclists killed. The fatality rate for 2015 was 3.7 per 100000 population. Preliminary data for 2016 indicate there were 629 road deaths, an increase of $1.3 \%$. The current Dutch road safety strategy is aimed at improved safety for cyclists and older road users.

\section{Road safety data collection}

\section{Definitions applied in the Netherlands}

- Road fatality: Death resulting from a road crash within 30 days of the crash.

- Seriously injured: Person admitted to hospital for an injury with a Maximum Abbreviated Injury Score of two or more (MAIS2+).

- Slightly injured: Other injuries, not admitted or admitted to hospital with a Maximum Abbreviated Injury Scale score of one (MAIS1).

\section{Data collection}

In the Netherlands, Statistics Netherlands (CBS) works together with the Ministry of Infrastructure and the Environment (Rijkswaterstaat) to match police-reported fatalities with other records including court files and death certificates to determine the actual number of road traffic fatalities. Both the police-reported number and the actual number have been published annually since 1996. This report uses the actual number of fatalities, unless there is a specific reference to "reported" numbers. In 2015, the percentage of police reported fatalities was $86 \%$ of the actual number (Korving et al, 2016).

Police reporting of road crashes does not meet the requirements of the Dutch Institute for Road Safety Research (SWOV) and the Ministry of Infrastructure and the Environment. A national information system for the police implemented in 2009 led to lower data quality and a smaller number of reported crashes. New procedures are intended to improve the police data in quality and quantity. So far, however, only the number of reported crashes (injury and property damage) has increased since 2014; with the quality of the characteristics reported lagging behind.

Research on serious traffic injuries shows that the number of police-reported hospitalised casualties is not a good indicator for Serious Injuries due to miscoding of injury severity, underreporting and bias. SWOV matches the Dutch police data to hospital discharge records and the MAIS score is attributed based on the ICD-derived AIS scores of patients whose injuries were coded in ICD9cm. ${ }^{*}$ The estimated actual number of serious injuries is now based on the data from both police and hospital databases, and the definition of a serious injury is based on the MAIS score, not the police report. Based on this method, the Netherlands is also able to report on MAIS2 or MAIS3+ injuries.

* International Classification of Diseases, 9th revision Clinical modification, WHO 1980. 
Ambulance data are being made available for traffic safety research (years 2009-2014). There are different reporting systems and external causes are not always recorded. Although this data source is of unknown quality, its usefulness regarding information on accident location is being considered.

In March 2016, a smartphone app was launched, enabling road crash reporting by individuals, supported and (partly) verified by police or an insurance company. Crashes can also be reported via the online tool, www.mobielschademelden.nl (accessed 4 July 2017). This source is as yet of unknown quality and quantity. Hopes are that serious crashes with bicycles and without motor vehicles involved can be reported with this app. Currently, less than $5 \%$ of these crashes are reported by the police, whereas they are the cause of more than half of all serious road injuries in the Netherlands.

\section{Most recent safety data}

\section{Road crashes in 2016 - provisional data analysis}

In 2016, there were 629 road fatalities, an increase of 1.3\% compared to 2015 (SWOV, 2017b). Over a third of traffic fatalities were car occupants and almost a third were cyclists. In 2016 about a quarter of traffic fatalities were female. Over a third of female traffic fatalities were cyclists. A relatively high number of fatalities occur among the younger population (15-29 year olds) and among senior citizens (65+).

\section{Road crashes in 2015}

In 2015 there were 621 road fatalities, an increase of 9\% compared to 2014.

More than a third of the fatalities were car occupants and almost a third were cyclists. A relatively high proportion of fatalities occurred among young people (16-24 years) and among those aged 65 and over, whereas relatively few children (0-15 years) were killed in traffic.

Mobility scooters are a growing concern in the Netherlands and many disabled and/or elderly people have been injured or even killed while using this mode of transport.

\section{Trends in traffic and road safety (1990-2015) Traffic}

Between 1990 and 2015, the number of motorised vehicles increased by 58\% and the overall vehicle distance travelled by $31 \%$. Passenger car mobility has decreased among younger drivers during recent years, levelling the rate of growth.

In 2016, the Netherlands Institute for Transport Policy Analysis (KiM) published a review of mobility patterns in the Netherlands from 2005 to 2015 (KiM, 2016). Some key facts include:

- On average, each Dutch person travels around 11000 kilometres a year within the national borders.

- Car travel as a driver, which constitutes two-thirds of total car travel in passengerkilometres, has gone up by $7 \%$ since 2005. Car travel as a passenger, which constitutes one-third of total car travel in passenger-kilometres, has gone down by $13 \%$.

- Around $10 \%$ of all kilometres are travelled by bicycle.

- Since 2005, bicycle travel (normal bicycles and e-bikes) has increased by almost $11 \%$. This increase is due to the rising number of people who cycle and to the general increase in individual travel (more frequent and longer trips). Part of the increase in bicycle use can 
be accounted for by electric bikes which, apart from being increasingly used by older people, are also being used by adults under 65 .

- From 2011 to 2015, cycling mobility in the Netherlands remained more or less stable, i.e. approximately 15 billion kilometres a year in both 2011 and 2015. (Source: CBS/BOVAG, http://bovagrai.info/tweewieler/2016/fietsen-nederland/1-16-vervoersprestatie-per-nederlanderfiets/ (accessed 16 May 2017).

Particularly relevant for road safety is that the increase in kilometres cycled is concentrated primarily among those over 50 years of age. The distance travelled by bicycle increased by almost a factor of two in this group between 1993 and 2015 and has remained constant among those under 50 years old. (source: OViN/Cognos)

There is no official data on mobility scooters or handicapped vehicles. However, their use has sharply risen in recent years which has had repercussions on the number of road deaths among this group, rising from 27 in 2014 to 41 in 2015 (Weijermars et al., 2016).

\section{Crashes and casualties}

In 1950 there were approximately 1000 road deaths, increasing to over 3000 by 1972 . Since 1973 the annual number of road deaths has gradually declined. Since 2000, the number of road deaths has decreased by $47 \%$ (actual data). However, the number of road deaths markedly increased both in 2015 and 2016.

Weijermars et al. (2014a) studied the major road safety developments in the Netherlands in the period 2000-12. On the favourable side, the number of actual fatalities in the period 2000-13 decreased from 1166 to 570. However, the number of cyclist fatalities did not decrease significantly (Schepers et al., 2016) and the number of fatalities among senior citizens decreased at a lower rate than for other age categories. In addition, the number of those seriously injured has increased. The number of casualties in crashes in which no motorised vehicles were involved more than doubled between 2000 and 2011.

The traffic system changed considerably from 2000-12. The design of the underlying road network improved and enforcement for risk-increasing behaviour (speeding, drink driving, failing to use seat belts and helmets) was intensified between 2000 and 2010 but decreased after 2010. The European New Car Assessment Programme (Euro NCAP) for passenger cars played a major role in stimulating the production of safer vehicles. Passive vehicle safety systems such as airbags and seat belts played an important role in reducing injuries, and active safety systems, car bonnets and exterior airbags help protect pedestrians and cyclists in case of a crash. Improvements in the medical care, including more regionalisation, mobile medical teams and air ambulances, have further contributed to the decrease in fatalities. The national road safety policy emphasis has shifted to vulnerable road users (Weijermars et al., 2014b).

\section{Mortality rates}

In 2015, there were 3.67 road fatalities per 100000 inhabitants and 3.8 per billion vehiclekilometres (Korving et al., 2016). Between 2000 and 2015, the mortality rate, expressed in terms of deaths per 100000 inhabitants, fell by $50 \%$. 
Table 27.1. Road safety data - Actual (real) data

\begin{tabular}{|c|c|c|c|c|c|c|c|}
\hline & \multirow{2}{*}{2000} & \multirow{2}{*}{2010} & \multirow{2}{*}{2014} & \multirow{2}{*}{2015} & \multicolumn{3}{|c|}{$2015 \%$ change from } \\
\hline & & & & & 2014 & 2010 & 2000 \\
\hline \multicolumn{8}{|l|}{ Actual safety data } \\
\hline Fatalities & 1166 & 640 & 570 & 621 & 9 & -3 & -47 \\
\hline Injured persons with score MAIS3+ & 5220 & 5700 & 7500 & 7800 & 4 & 37 & 49 \\
\hline Deaths per 100000 inhabitants & 7.3 & 3.9 & 3.4 & 3.7 & 8 & -5 & -50 \\
\hline Deaths per 10000 registered vehicles ${ }^{1}$ & 1.43 & 0.65 & 0.56 & 0.61 & 9 & -6 & -57 \\
\hline Deaths per billion vehicle kilometres & 9.2 & 5.1 & 4.5 & 4.9 & 9 & -4 & -47 \\
\hline
\end{tabular}

1. Including mopeds.

Note: Statistics in the Netherlands distinguish between reported and actual (or real) numbers of casualties. The former category covers casualties reported by the police. Actual numbers are higher, as they take into account data available from sources such as court files and death certificates. This report uses the real number of fatalities unless there is a specific reference to the "reported" numbers.

StatLink काIsL http://dx.doi.org/10.1787/888933580726

Table 27.2. Road safety and traffic data - numbers on crashes reported by the police

\begin{tabular}{|c|c|c|c|c|c|c|c|c|c|}
\hline & \multirow{2}{*}{1990} & \multirow{2}{*}{2000} & \multirow{2}{*}{2010} & \multirow{2}{*}{2014} & \multirow{2}{*}{2015} & \multicolumn{4}{|c|}{$2015 \%$ change from } \\
\hline & & & & & & 2014 & 2010 & 2000 & 1990 \\
\hline \multicolumn{10}{|l|}{ Reported safety data } \\
\hline Fatalities & 1376 & 1082 & 537 & 476 & 531 & 11.6 & -1.1 & -50.9 & -61.4 \\
\hline Deaths per 100000 inhabitants & 9.2 & 6.8 & 3.2 & 2.8 & 3.1 & 11.1 & -3.0 & -53.9 & -66.0 \\
\hline Deaths per 10000 registered vehicles & 2.15 & 1.32 & 0.55 & 0.47 & 0.52 & 11.2 & -4.0 & -60.4 & -75.6 \\
\hline Deaths per billion vehicle km & 14.2 & 8.5 & 4.3 & 3.7 & 4.2 & 11.8 & -2.0 & -51.2 & -70.6 \\
\hline Injury crashes & 44916 & 37947 & $19378^{2}$ & & & & & & \\
\hline \multicolumn{10}{|l|}{ Traffic data } \\
\hline Registered vehicles ${ }^{1}$ (thousands) & 6399 & 8174 & 9839 & 10097 & 10133 & 0.4 & 3.0 & 24.0 & 58.4 \\
\hline Distance travelled (million km) & 97077 & 126660 & 126224 & 127686 & 127351 & -0.3 & 0.9 & 0.5 & 31.2 \\
\hline Registered vehicles per 1000 inhabitants & 430 & 515 & 594 & 600 & 600 & -0.1 & 1.0 & 16.4 & 39.5 \\
\hline
\end{tabular}

1. Including mopeds.

2. Following 2009 the reporting of minor crashes sharply dropped. No information on progress in safety can be derived from the numbers.

Figure 27.1. Road safety, traffic and GDP trends index $1990=100$

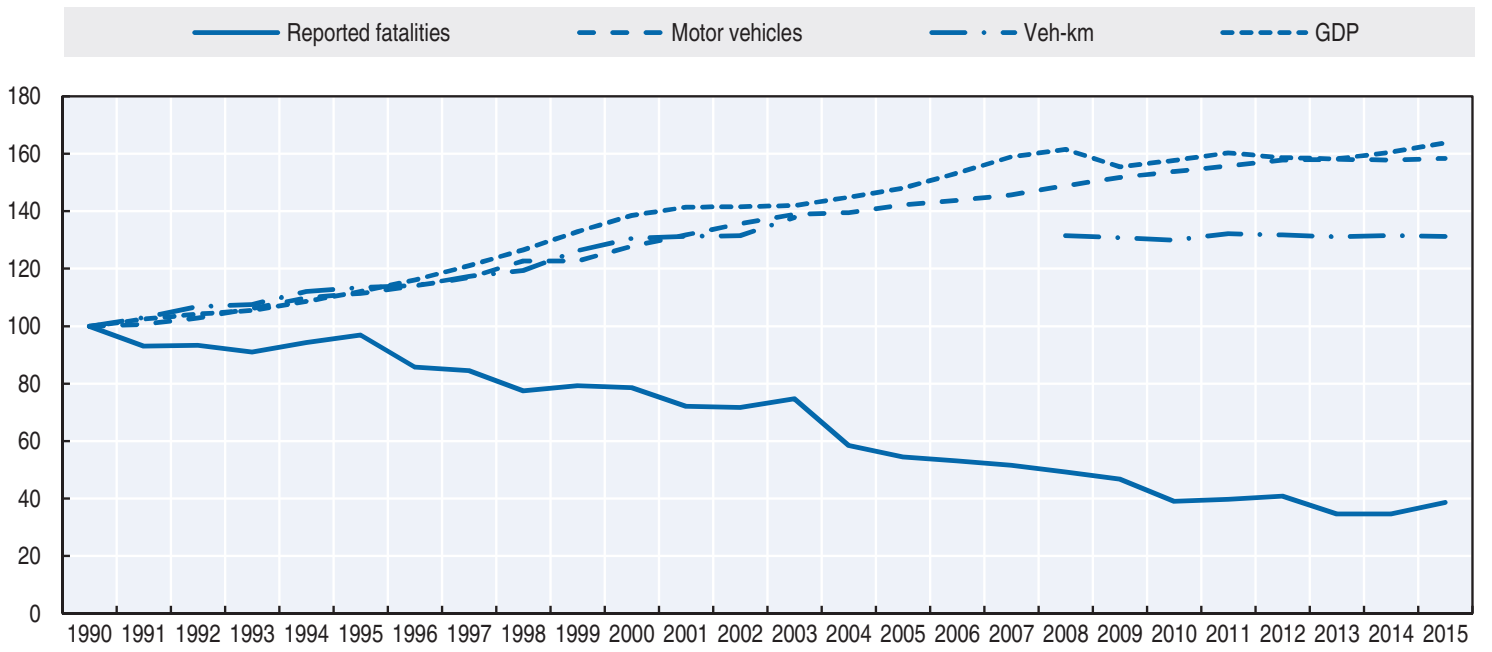

Note: Source: World Bank (2017) (GDP; constant prices). 


\section{Analysis of seriously injured data}

Many persons are injured in crashes without the involvement of a motor vehicle. While in some countries these victims are not considered as road traffic victims, their number in the Netherlands exceeds the number of those seriously injured in motor vehicle crashes.

After an initial decrease from the 1990s onward, the number of serious road injuries has been increasing since 2006. In 2015, an estimated 21300 people were seriously injured (MAIS2+) in traffic in the Netherlands, of which 7800 were MAIS3+. The number of serious road injuries has now reached the highest level since 1993, the first year they were assessed (SWOV, 2016).

Cyclists constitute almost two-thirds of the number of serious road injuries, a majority of which are injured in non-motor vehicle crashes. In proportion to the total population, many serious road injuries occur among young people (15-19 year-olds) and among road users aged 45 and older.

The number of serious road injuries among occupants of passenger cars and vans is the only group that has shown a significant decline over the last ten years. In 2009, this group still constituted about $15 \%$ of the number of serious road injuries in the hospital register. Presently, less than $10 \%$ of the serious road injuries are occupants of passenger cars or delivery vehicles.

\section{Road safety by user group}

Over the long term all user groups, but especially car occupants, have benefited from safety improvements.

In the period 2000-15, the number of road deaths among car occupants, powered twowheelers and pedestrians was reduced by more than $50 \%$. The number of cyclists killed only fell by $21 \%$.

In 2015 , the marked increase in the number of road deaths mainly affected car occupants (+19.8\% fatalities) and pedestrians $(+16.3 \%)$. The number of cyclists killed remained stable, while there was improvement for moped riders $(-4.3 \%)$ and especially motorcyclists (-14.5\%).

In 2015,57 pedestrians died in traffic, an increase of $16 \%$ compared to 2014 . By definition, pedestrian deaths that are not due to collisions with vehicles are not included in this figure. However, a significant number of pedestrian fatalities (86 in 2011) are due to falls (Methorst et al., 2017)

Table 27.3. Road fatalities by road user group - Actual data

\begin{tabular}{lrrrr|rrr}
\hline & 2000 & 2010 & 2014 & 2015 & \multicolumn{3}{c}{$2015 \%$ change from } \\
\cline { 6 - 8 } & & & & 2014 & 2010 & 2000 \\
\hline Pedestrians & 114 & & & 57 & 16.3 & -20.8 & -50.0 \\
Cyclists & 233 & 162 & 185 & 185 & 0.0 & 14.2 & -20.6 \\
Moped riders & 104 & 43 & 47 & 45 & -4.3 & 4.7 & -56.7 \\
Motorcyclists & 95 & 63 & 55 & 47 & -14.5 & -25.4 & -50.5 \\
Car occupants & 543 & 246 & 187 & 224 & 19.8 & -8.9 & -58.7 \\
Others & 77 & 54 & 47 & 63 & 34.0 & 16.7 & -18.2 \\
Total & $\mathbf{1 1 6 6}$ & $\mathbf{6 4 0}$ & $\mathbf{5 7 0}$ & $\mathbf{6 2 1}$ & $\mathbf{8 . 9}$ & $\mathbf{- 3 . 0}$ & $\mathbf{- 4 6 . 7}$ \\
\hline
\end{tabular}


Figure 27.2. Road fatalities by road user group in $\mathbf{2 0 1 5}$ - Actual data

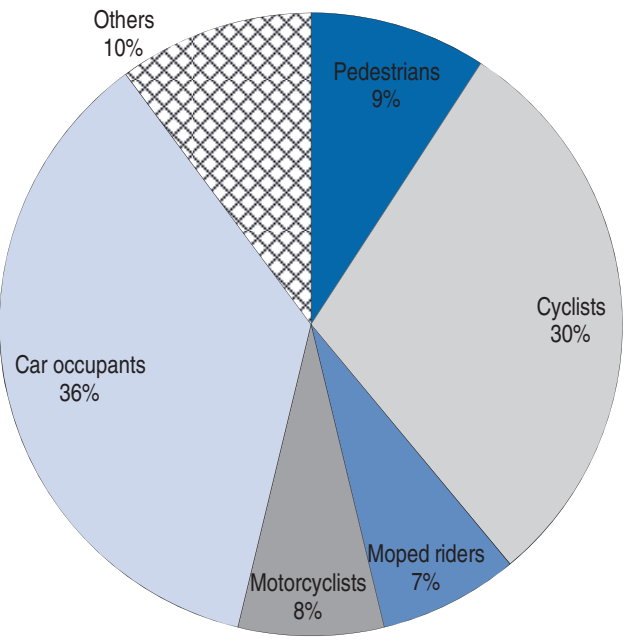

\section{Road safety by age group}

The number of fatalities varies with age. Inexperienced riders and drivers are killed more often in traffic, as are vulnerable road users. Persons aged over 65 represent another vulnerable group, especially while cycling.

Since 2000 , the reduction of nearly $50 \%$ in the number of road deaths mainly benefited the population under the age of 75. Among the 75-84 age group, the number of road deaths only decreased by $4.5 \%$, whereas they nearly doubled for those over the age of 85 .

Table 27.4. Road fatalities by age group - Actual data

\begin{tabular}{|c|c|c|c|c|c|c|c|}
\hline \multirow{2}{*}{ Age group } & \multirow{2}{*}{2000} & \multirow{2}{*}{2010} & \multirow{2}{*}{2014} & \multirow{2}{*}{2015} & \multicolumn{3}{|c|}{$2015 \%$ change from } \\
\hline & & & & & 2014 & 2010 & 2000 \\
\hline $0-14$ & 59 & 18 & 19 & 18 & -5.3 & 0.0 & -69.5 \\
\hline $15-17$ & 57 & 20 & 17 & 15 & -11.8 & -25.0 & -73.7 \\
\hline $18-20^{*}$ & 119 & 46 & 35 & 39 & 11.4 & -15.2 & -67.2 \\
\hline $21-24$ & 115 & 52 & 33 & 36 & 9.1 & -30.8 & -68.7 \\
\hline $25-64$ & 548 & 295 & 223 & 263 & 17.9 & -10.8 & -52.0 \\
\hline $65-74$ & 123 & 64 & 74 & 79 & 6.8 & 23.4 & -35.8 \\
\hline $75-84$ & 111 & 100 & 119 & 106 & -10.9 & 6.0 & -4.5 \\
\hline$\geq 85$ & 34 & 45 & 50 & 65 & 30.0 & 44.4 & 91.2 \\
\hline Total & 1166 & 640 & 570 & 621 & 8.9 & -3.0 & -46.7 \\
\hline
\end{tabular}

* Fatalities among the 5, 10+11 and 20 year olds have been estimated for the years after 2011.

\section{Box 27.1. Road safety for an ageing population}

In 2015, the Dutch population was 16.9 million with 3 million (17.7\%) aged 65 or over. It is predicted that in 2050 the population will reach 18 million, including 4.7 million (26.1\%) senior citizens (Statistics Netherlands, Population Forecast 2014-60).

Senior citizens are overrepresented in road fatalities. In 2015, 40\% of road deaths were persons aged 65 or above. Half of the senior citizens killed in traffic are cyclists. A significant increase has been seen in the number senior citizens killed on mobility scooters. The senior population is growing and they are more mobile than the previous generations. 


\section{Box 27.1. Road safety for an ageing population (cont.)}

In the Netherlands, drivers 75 years old and older have to submit a Declaration of Fitness to Drive when applying for a new driving licence (SWOV, 2015). This declaration can be obtained from the Dutch Driving Test Organisation by filling in a personal declaration with answers to ten questions about physical and mental disorders that are relevant for road safety, such as epilepsy, loss of balance, eye diseases, and use of medicines that can influence driving skills (SWOV, 2015). A medical report, filled in by a doctor, must accompany the personal declaration.

In the medical report, the doctor reports on blood pressure, visual acuity, field of vision, hearing, limitations in the use of the neck, back, and limbs, and the general physical and mental condition of the applicant. When the medical examination does not identify contraindications to driving, the applicant will receive a Declaration of Fitness to Drive that is valid for five years.

If there are doubts about future fitness, a limited validity of one to three years can be decided. In addition, limitations to the conditions under which a motor vehicle may be driven can be imposed. These can refer to requirements of the vehicle (e.g. an automatic gearbox), the driver (e.g. wearing glasses), or use of the vehicle (e.g. only during daytime). A code which is put on the driving licence indicates which restrictions apply (SWOV, 2015).

Table 27.5. Road fatalities among senior citizens - Actual data

\begin{tabular}{|c|c|c|c|c|c|c|c|c|c|c|c|c|}
\hline & \multicolumn{3}{|c|}{$65-69$} & \multicolumn{3}{|c|}{$70-79$} & \multicolumn{3}{|c|}{$80-89$} & \multicolumn{3}{|c|}{$90+$} \\
\hline & 2010 & 2015 & $\%$ change & 2010 & 2015 & $\%$ change & 2010 & 2015 & $\%$ change & 2010 & 2015 & $\%$ change \\
\hline Pedestrians & 1 & 2 & & 10 & 8 & & 15 & 9 & & 3 & 1 & \\
\hline Cyclists & 13 & 22 & & 42 & 48 & & 36 & 38 & & 2 & 13 & \\
\hline Moped riders & 6 & 4 & & 4 & 3 & & 4 & 5 & & 2 & & \\
\hline Motorcyclists & & & & 1 & & & & & & & & \\
\hline Car occupants & 8 & 8 & & 21 & 22 & & 19 & 25 & & 4 & 6 & \\
\hline Others & 4 & 2 & & 5 & 12 & & 7 & 12 & & 2 & 10 & \\
\hline Total & 32 & 38 & 19 & 83 & 93 & 12 & 81 & 89 & 10 & 13 & 30 & 131 \\
\hline
\end{tabular}

Figure 27.3. Road fatality rate by age and road user group Fatalities per 100000 inhabitants, 2015 (reported data)

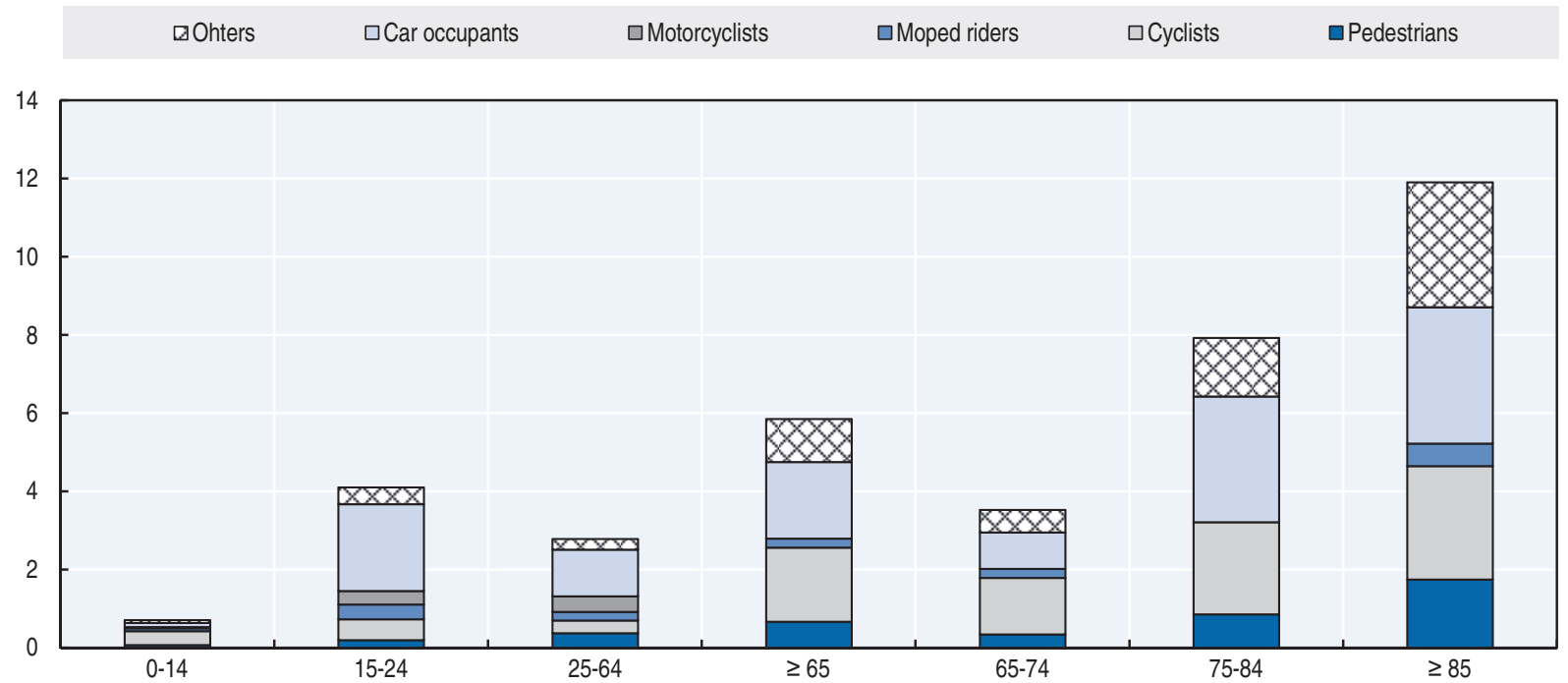




\section{Road safety by road type}

Police data are needed to classify the number of road deaths by road type. However, in addition to underreporting issues, for an increasing number of cases the road type is not recorded in police data. This means that the crash location is not known for a large share of crashes. In 2000 the crash location was unknown for $7 \%$ of road deaths but this rose to about 38\% in 2015.

\section{Figure 27.4. Road fatalities by road type}

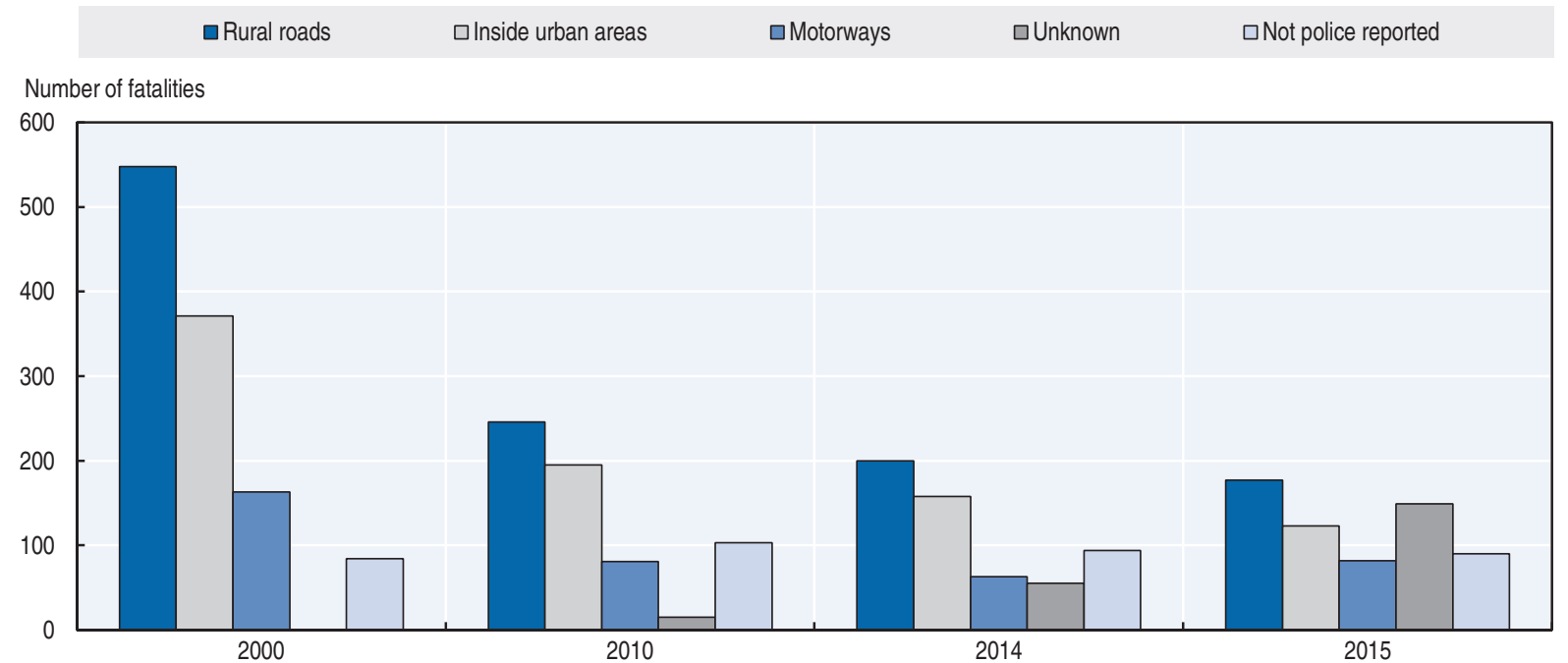

\section{Economic costs of traffic crashes}

Traffic crashes represent a significant cost for society, estimated in 2009 at around EUR 13 billion, equivalent to $2.2 \%$ of the Dutch gross domestic product (SWOV, 2014). The following six categories have been included in the estimate:

- medical costs

- production loss

- loss of quality of life (based on a willingness-to-pay method)

- property damage

- settlement costs

- congestion costs.

Table 27.6. Costs of road crashes, 2009

\begin{tabular}{lcc}
\hline & Unit & Total \\
\hline Fatalities & EUR 1.9 billion \\
Serious Injuries (MAIS2+) & EUR 5.2 billion \\
Slight injuries & EUR 2.1 billion \\
Property/damage costs & EUR 3.9 billion \\
Total & EUR $\mathbf{1 3 . 1}$ billion \\
Total as \% of GDP & $\mathbf{2 . 2 \%}$ \\
\hline
\end{tabular}




\section{Recent trends in road user behaviour}

\section{Speed}

The table below summarises the main speed limits in the Netherlands. (For an explanation on road categorisations see Advancing Sustainable Safety at www.sustainablesafety.nl, accessed 4 July 2017).

\begin{tabular}{lc} 
Table 27.7. Speed limits by road type, 2017 \\
\hline Urban access roads & $30 \mathrm{~km} / \mathrm{h}$ \\
Urban distributor roads & $50 \mathrm{~km} / \mathrm{h}$ \\
Rural access roads & $60 \mathrm{~km} / \mathrm{h}$ \\
Rural distributor roads & $80 \mathrm{~km} / \mathrm{h}$ \\
Through-roads & $100 \mathrm{~km} / \mathrm{h}$ \\
Motorways & $130 \mathrm{~km} / \mathrm{h}$ \\
\hline
\end{tabular}

\section{Drink driving}

Until 2006, the maximum authorised blood alcohol content (BAC) was $0.5 \mathrm{~g} / \mathrm{l}$ for all drivers of motor vehicles, but in 2006 a lower limit of $0.2 \mathrm{~g} / \mathrm{l}$ was applied for novice drivers during their first five years. For cyclists the legal limit is also $0.5 \mathrm{~g} / \mathrm{l}$.

Alcohol-related fatalities are defined according to the SafetyNet definition: Any death occurring within 30 days as a result of a fatal road crash in which any active participant was found with a blood alcohol level above the legal limit.

In the Netherlands, testing a deceased person for recent use of psychoactive substances is prohibited. Police reports regarding the use of psychoactive substances by seriously injured road users is not reliable.

Driving under the influence of alcohol accounts for approximately 75 to 140 (12\% to 23\%) of road deaths in the Netherlands (Goldenbeld et al, 2016). About two-thirds of all severe alcohol crashes are caused by a relatively small group of serious alcohol offenders (offenders with a blood alcohol content of $1.3 \mathrm{~g} / \mathrm{l}$ or higher). The social costs due to this group are estimated between 0.8 to 1.8 billion euros per year (Goldenbeld et al., 2016).

In the Netherlands drink driving on weekend nights decreased from $2.9 \%$ in 2006 to $1.7 \%$ in 2015 (I\&O Research, 2016). The percentage of alcohol offenders was the same in 2015 as in 2013: 1.7\%. The percentage of heavy alcohol offenders (alcohol level > $1.3 \mathrm{~g} / \mathrm{l}$ ) showed a slight increase from $0.2 \%$ in 2013 to $0.3 \%$ in 2015 .

On 3 March 2015 the Dutch judicial system determined that the use of an alcohol interlock, started in December 2011, will no longer be imposed. It was judged that this measure was in violation of the legal principle that an offender could only receive one punishment for an offence (Goldenbeld et al., 2016).

\section{Drugs and driving}

Legislation on driving under the influence of illicit drugs was expected to be introduced in 2015 but was postponed to a later date (probably 2017). This legislation entails legal limits being set for five different types of drugs. Furthermore, zero tolerance limits are proposed for combined use of drug-drug and drug-alcohol. Saliva tests and a test on physical features and behavioural characteristics will be made available to police in the Netherlands to enforce the proposed legislation. 
Results of hospital studies show that approximately $10 \%$ of the seriously injured drivers were positive for illicit drugs. As with alcohol, Dutch legislation prohibits post mortem drug testing.

\section{Distraction}

Holding a phone while driving has been illegal in the Netherlands since April 2002. Additional legislation relevant to distracted driving is applicable in cases where behaviour that explicitly endangers road safety is directly observed.

In 2015, 33000 Dutch drivers were fined for hand-held phone use (there were around 100000 in 2011). In 2015, the fine for hand-held phone use while driving was EUR 230.

An observational study, recently commissioned by the Ministry of Infrastructure and the Environment (Broeks and Bijlsma-Boxum, 2017) found that between $7 \%$ and $8 \%$ of drivers use hand-held mobile phones or hand-held smartphones while driving.

Two Dutch studies found that phone use preceded and possibly played a part in 3-4\% of bicycle injury crashes (SWOV, 2017a). Furthermore, phone use just before a crash was mentioned nearly as frequently (4.3\%) as listening to music (4.8\%). As cyclists much more frequently listen to music than use a phone, this indicates that phone use (calls and texting) is a higher risk factor for bicycle crashes than music (SWOV, 2017a). An observational study showed that $4 \%$ of cyclists text and 3\% call while cycling (Broeks and Zengerink, 2016).

\section{Sleepiness and fatigue}

A 2015 survey on fatigue among more than 1500 Dutch car drivers suggests that driver fatigue is considered a widespread problem. Nearly half of Dutch drivers (47\%) reported that sleepiness negatively affected their driving performance, $60 \%$ said they continued to drive after starting to feel sleepy and $10 \%$ continued driving even when the drive took more than one hour. Almost one-quarter took no break when they started to feel sleepy. One in ten Dutch drivers said that they were aware of an increased driving risk from their sleepiness.

\section{Seat belts and helmets}

Seat belt use has been compulsory in front seats since 1975 and in rear seats since 1992. At the last national seat belt measurement in the Netherlands in 2010, the rate of seat belt use was above $95 \%$ in front and rear seats in passenger cars. For vans (87\%) and trucks, the wearing rate was lower. No seat belt measurements have been performed since 2010.

Helmet wearing has been compulsory on motorcycles since 1972 and on mopeds (up to $50 \mathrm{cc}$, maximum speed $45 \mathrm{~km} / \mathrm{h}$ ) since 1975. A helmet is not compulsory on light mopeds (up to $50 \mathrm{cc}$, maximum speed $25 \mathrm{~km} / \mathrm{h}$ ) and bicycles. The moped category constitutes a major road safety problem, as these are regularly modified to much higher maximum speeds. There are currently about 500000 mopeds and 600000 light mopeds - which can be identical in engine volume, weight, and width to normal mopeds - in the Netherlands.

There is no recent measurement of seatbelt use or helmet wearing.

\section{National road safety strategies and targets Organisation of road safety}

In the Netherlands, the Ministry of Infrastructure and the Environment (Directorate General Mobility - Roads and Traffic Safety section) is the central agency for road safety, 
responsible for overseeing and co-ordinating all road safety activities. In particular, it is responsible for:

- Co-ordination of intergovernmental working processes and road safety decision making at the level of central government and co-ordination of national mass media campaigns. Regional and local governments have their own authority over their roads and the safety of their infrastructure. The ministry is responsible for road safety policy and together with decentralised governments they set policy targets.

- Periodic review of legislation, rules and standards against best practice; recommendations for improvement; monitoring and evaluation; establishing and supporting data systems used to monitor road safety.

- Compilation and dissemination of national statistics, co-operating with the Ministry of Infrastructure and the Environment, Statistics Netherlands and SWOV.

\section{Road safety strategy for 2008-20}

Road safety policy in the Netherlands is guided by a philosophy of sustainable road safety, based on several key concepts, including that the human being is the reference standard and prevention is preferable to a curative approach. The policy follows five safety principles: road functionality; homogeneity of mass and speed and direction; physical and social tolerance; recognition and predictability of roads and behaviour; and state of awareness.

In 2008, the Road Safety Strategic Plan 2008-2020 (SPV) was developed by the then Ministry of Transport and received support in Parliament. The SPV is based on three cornerstones: co-operation, an integral approach and sustainable safety. In 2012, the strategic plan was revised following its four-yearly evaluation conducted by SWOV. The Policy Stimulus Road Safety Initiative contains extra measures aimed at road safety improvement for cyclists, older road users, infrastructure, and road users in general.

In 2017, the Ministry started the development of a new Strategic Plan for the period of 2020-2030. Regional and local governments and other key stakeholders involved in road safety will participate in the process.

\section{Road safety targets and monitoring}

The current targets in the SPV for 2020 are a maximum of 500 road fatalities and a maximum of 10600 MAIS2+ road injuries. In 2015 SWOV predicted that if ongoing developments and efforts continued, the target for 2020 with respect to fatalities seemed feasible (Weijermars et al., 2015). However, without additional safety measures it would be near impossible to achieve the target for serious road injuries. In view of the observed increase in road fatalities in both 2015 and 2016, it is now very much doubted whether the maximum of 500 fatalities in 2020 can be achieved.

The annual assessment report on road safety developments in 2015 observes the following:

- In 2015 few new regulations and laws were implemented that were relevant for road safety.

- With regard to enforcement, the steep decline in the number of fines is particularly noticeable. It cannot be ruled out that the decline in traffic enforcement has contributed to the increase in the number of road fatalities in 2015.

- The 2015 decision to discontinue the alcohol interlock programme is a source of concern from the perspective of road safety. 
- Regarding vehicle safety, the Netherlands mainly takes up a rear-guard position in Europe. With respect to overall Euro NCAP scores, the Netherlands is in 23rd place among the 28 European countries participating.

Figure 27.5. Trends in road fatalities towards national target

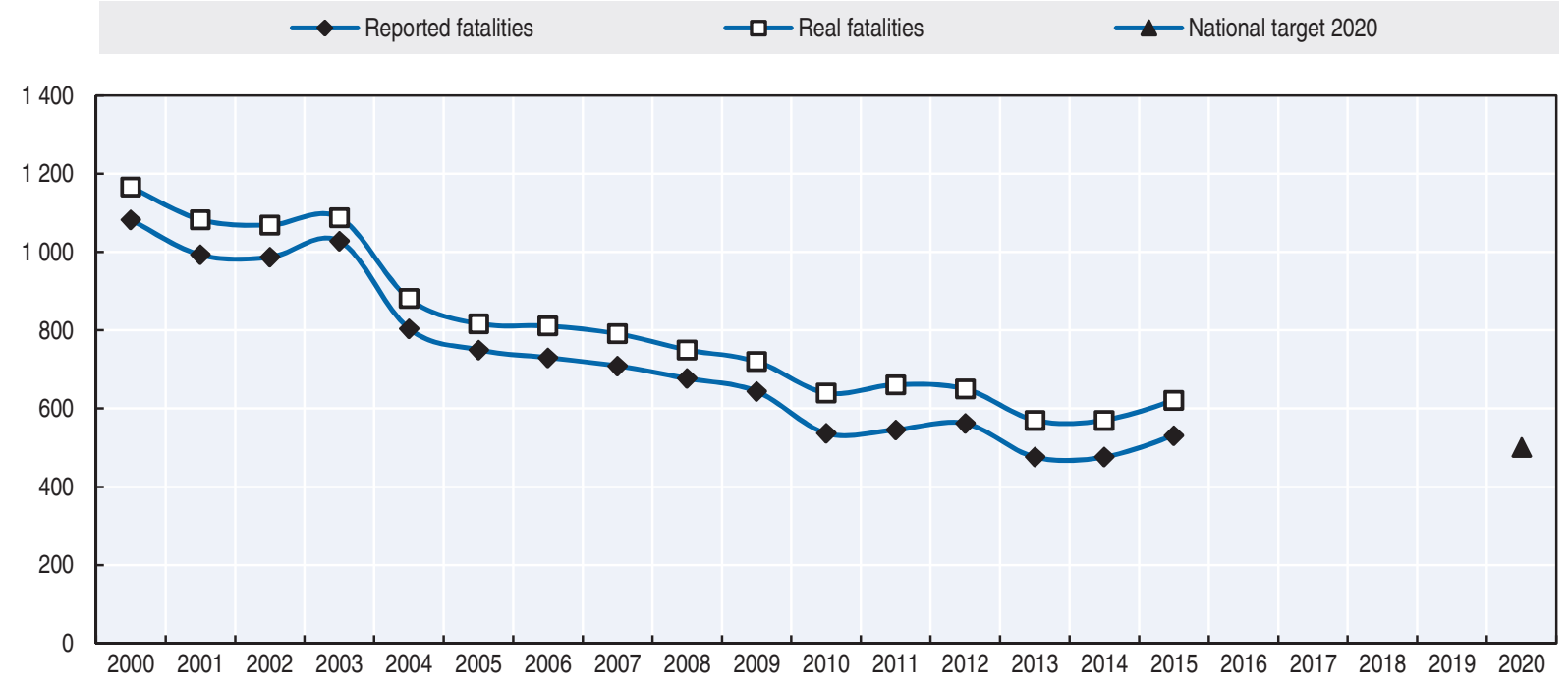

Figure 27.6. Trends in seriously injured towards national target

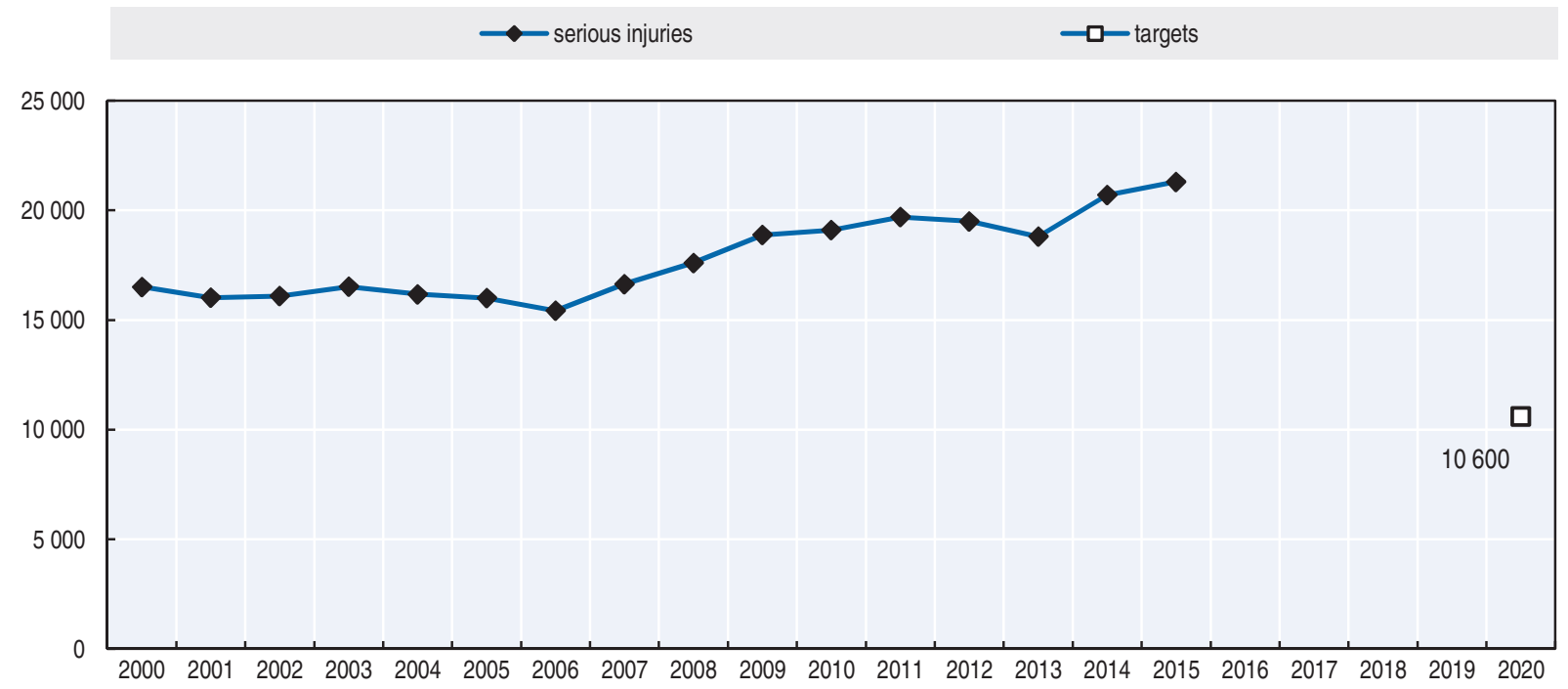

\section{Recent safety measures (2014-17)}

\section{Road safety management}

- Since March 2016, it is possible to self-report road crashes with an app (in IOS and Android). The European Damage Form is no longer required by insurers if all motor vehicles involved are Dutch. Injury crashes and crashes without motor vehicles can also be reported. The police will start to use a similar version of this app for their data entry later in 2017. 


\section{Speed management}

- The new limit of $130 \mathrm{~km} / \mathrm{h}$ on motorways was introduced in September 2012 on $60 \%$ of the motorway network. On a third of this length the limit is dynamic, with $130 \mathrm{~km} / \mathrm{h}$ permitted only between $7 \mathrm{pm}$ and $6 \mathrm{am}$. On roads with environmental or safety concerns the $120 \mathrm{~km} / \mathrm{h}$ limit or the $100 \mathrm{~km} / \mathrm{h}$ limit was maintained. Preliminary analysis in 2014 showed hardly any change in the level of safety. However in 2015 an increased number of fatalities on roads with the $130 \mathrm{~km} / \mathrm{h}$ limit was reported. More information is available at: www.swou.nl/publicatie/destijging-het-aantal-verkeersdoden-op-rijkswegen-2015 (accessed 4 July 2017).

\section{Enforcement}

- Since 1 January 2015 a new regulation has been operative for repeat traffic offenders enabling higher sanctions if the violation is repeated within a 2-year time frame. Major violations under this new regime include: driving without a licence, dangerous road behaviour, not correctly securing load, driving without a licence plate, ignoring stop signs and using the emergency lane on motorways.

- On March 3rd 2015 the Dutch judicial system determined that the installation of alcohol interlocks for recidivist drink drivers may not be imposed anymore. It was considered that this measure was in violation of the legal principle that an offender could only receive one punishment for an offence. As a consequence, heavy recidivist drink drivers are now referred to legal measures (educational measures or examination of driver competence) that are known to be less effective in reducing drinking and driving recidivism than the alcohol interlock. At the request of Parliament members in 2016, the Dutch government is studying options of reintroducing the alcohol interlock measure in a different legal format.

- The National Police have listed five priorities for traffic enforcement for the period 2016-18 (CVOM, 2015): speed, alcohol, red light running, distraction and frequent offenders. They have also determined that each motorist stopped should take an alcohol test and that their licence should be checked.

\section{Education and licensing}

- Licensing for driving tractors was changed on 1 July 2015. The category T replaces the T-certificate. Theoretical and practical examinations to obtain the T-certificate have been adapted to emphasise driving on public roads and road safety.

- In December 2016, the Dutch parliament voted against the proposal to introduce a licence plate for tractors. Also, in the proposal the introduction of licence registration was paired with an increase in speed limit from 25 to $40 \mathrm{~km} / \mathrm{h}$.

- In 2015 , the WEVER project was started aimed at establishing a valid measure of what constitutes effective traffic education (Slinger et al., 2015).

\section{Cycling safety}

- The Policy Stimulus Road Safety Initiative contains extra measures aimed at cyclists. It requires municipalities to survey road safety bottlenecks for cyclists and to make plans for improvement containing behavioural measures as well as infrastructural measures. To monitor progress in this domain all municipalities were asked to complete a survey on their cycling policies (Weijermars et al. 2014b, Duivenvoorden et al., 2015).

- A survey filled in by 288 Dutch municipalities indicated that by August 2016 nearly half of all municipalities had developed a plan to improve cycling safety (Korving et al., 2016). 
Also, $22 \%$ of municipalities were in the process of creating such a plan. A survey of what cycling safety measures have actually been implemented is lacking.

- The Royal Dutch Touring Club (ANWB) has initiated a project to improve the safety of the cycling infrastructure in the Netherlands. The objective is to develop an instrument to measure the cycling safety of a road network. The first results were reported by Wijlhuizen et al. (2016).

- National governments and regional governments have conducted a number of innovative projects to develop new measures, for instance:

* Forgiving bicycle infrastructure project.

* Edge markings along bicycle paths outside urban areas.

* 'Doortrappen' ('Keep pedalling') on new educational approaches.

* "SOFIE - Intelligent Assistive Bicycle", see www.utwente.nl/en/et/bw/research/projects/ SOFIE-website/ (accessed 4 July 2017).

\section{Mopeds}

- The proper place (cycling paths or roadways) for slow mopeds (speeds no higher than $25 \mathrm{~km} / \mathrm{h}$ ) is an issue: The ministry has now allowed municipalities to make their own choice, but it is expected that few municipalities will take up this option in the coming years.

- Since July 2014 a new rule for the confiscation of a moped licence, in the case of a tuned-up moped, has been in operation. This enables police to confiscate the licence when the measured speed of a moped is higher than permitted (Ministry of Safety and Justice, 2013).

\section{Infrastructure}

- Provincial authorities have long-range traffic, transport and mobility plans in which infrastructure measures play an important role. These include reconstruction of risky intersections, construction of roundabouts, safer roadsides, upgrading or downgrading roads to achieve more credible speed limits, more recognisable and uniform road markings, safer cycling facilities, safer cycling crossings, safer cycling paths, and better integration of maintenance and infrastructure improvement.

- In 2015, the 'Meer Veilig 3' infrastructure project, on cost-effective safety measures for motorways and through roads in the period 2015-2018, started with a budget of EUR 37 million (IenM, 2016). The aim is to bring the quality of the total network of motorways and through roads to Level 3 of road protection score stars by 2020 (Korving et al., 2016).

\section{Recent and ongoing research}

- Estimating the number of serious road injuries, by linking police and hospital data. For further details see Bos, N.M. et al. (2016), Serious road injuries 2015, Estimate of the number of serious road injuries in 2015, SWOV, The Hague, www.swov.nl/rapport/r-2016-13.pdf (accessed 4 July 2017).

- Annual monitor of the road safety situation in The Netherlands and evaluation of policies. For further details see Weijermars et al. (2016), Road Safety Monitor 2016, SWOV, The Hague, www.swou.nl/rapport/r-2016-14.pdf (accessed 4 July 2017). 
- Automated vehicles and taking back control of the vehicle. For further details see Vlakveld, W. (2015). Transition of control in highly automated vehicles, A literature review, SWOV, The Hague, www.swou.nl/rapport/r-2015-22.pdf (accessed 4 July 2017).

- Vlakveld, W., L. Vissers, K. Hulleman and N. van Nes (2015), An empirical exploration of the impact of transition of control on situation awareness for potential hazards, SWOV, The Hague, www.swov.nl/rapport/r-2015-23.pdf (accessed 4 July 2017).

- Safe interaction between cyclists, pedestrians and autonomous vehicles. For further details see Vissers, L., S. Kint, I. van der, I. Schagen, M. van and M. Hagenzieker (2016), R-2016-16, SWOV, The Hague, www.swov.nl/en/publication/safe-interaction-between-cyclists-pedestriansand-automated-vehicles (accessed 4 July 2017).

- The effect of an app on reducing smartphone use while driving a car. For further details see Groot-Mesken, J. de, W. Wijnen, A. Stelling-Konczak and J.J.F. Commandeur (2016), R-2016-3. SWOV, The Hague, www.swov.nl/en/publication/interpolis-slimopweg-programmade-automodus-app (accessed 4 July 2017).

- Influencing speed behaviour by nudging; Questionnaire study into the effect of Dick Bruna traffic signs on the estimated driving speeds in urban areas. For further details see Goldenbeld, C.H., J. de Groot-Mesken and H.A. Rijsdijk (2016), R-2016-10, SWOV, The Hague, www.swov.nl/en/ publication/beinuloeding-van-snelheidsgedrag-door-nudging (accessed 4 July 2017).

\section{References}

Broeks, J. and J. Bijlsma-Boxum (2017), Apparatuurgebruik automobilisten, Rijkswaterstaat, Utrecht.

Broeks, J. and L. Zengerink (2016), Eenmeting apparatuurgebruik fietsers, Utrecht: Rijkswaterstaat.

CVOM (2015), Leidraad Handhavingsplan Verkeer 2016-2018, Parket Centrale Verwerking Openbaar Ministerie, Afdeling Beleid \& Strategie, Openbaar Ministerie, Utrecht.

Duivenvoorden, C. et al. (2013), Evaluation of an initiative to reward correct traffic behaviour in the Province of Limburg: Study into the effects of a pilot with individual and collective town area-related rewards for speed behaviour in urban areas, SWOV, Leidschendam, www.swou.nl/rapport/r-2013-07.pdf (accessed 4 July 2017).

Goldenbeld, C., M. Blom and S. Houwing (2016), Serious alcohol offenders in traffic; Extent of the problem and characteristics of the offenders, SWOV, Den Haag, www.swov.nl/rapport/r-2016-12.pdf (accessed 4 July 2017).

IenM et al. (2016), MIRT Overzicht 2016, Ministerie van Infrastructuur en Milieu, Ministerie van Economische Zaken, Ministerie van Binnenlandse Zaken en Koninkrijksrelaties, The Hague.

I\&O Research (2016), Rijden onder invloed in Nederland in 2002-2015, Ontwikkeling van het alcoholgebruik van automobilisten in weekendnachten, Water, Verkeer en Leefomgeving WVL, Delft, www.rijksoverheid.nl/ documenten/rapporten/2016/09/22/rijden-onder-invloed-2002-2015 (accessed 4 July 2017).

KiM (2016), Mobility Report 2016, Kennisinstituut voor Mobiliteitsbeleid (KiM), The Hague, https:// english.kimnet.nl/mobility-report/publications/reports/2016/10/24/mobility-report-2016 (accessed 4 July 2017).

Korving, H. et al. (2016), Road Safety Monitor 2016 - Background information and research account., SWOV, The Hague, www.swou.nl/rapport/r-2016-14a.pdf (accessed 4 July 2017).

Methorst, R., P. Schepers, N. Christie, M. Dijst, R. Risser, D. Sauter and B. van Wee (2017), "'Pedestrian falls' as necessary addition to the current definition of traffic crashes for improved public health policies", Journal of Transport \& Health.

Ministry of Safety and Justice (2013), Toezeggingen en verzoeken verkeershandhaving, Brief aan de Tweede Kamer, 18 november 2013, Kamerstuk 29398, nr. 387. Ministerie van Veiligheid en Justitie, The Hague.

OViN/Cognos (n.d.), National Travel survey: Bicycle mobility by Age group, 1985-2015 https://cognos.swou.nl (accessed 4 July 2017).

Schepers, P., H. Stipdonk, R. Methorst and J. Olivier (2016), Bicycle fatalities: Trends in crashes with and without motor vehicles in The Netherlands, In: Transportation Research Part F, Vol. In Press, Corrected Proof, http:// dx.doi.org/10.1016/j.trf.2016.05.007. 
Slinger, W., F. Koen, J. Vissers and D. Twisk (2015), Op weg naar effectieve verkeerseducatie: Het WEVER-project. Bijdrage voor een NVVC2016. Kennissessie - 21 April 2016, Hertogenbosch - nvvc-congres.nl.

SWOV (2017a), Phone use by cyclists and pedestrians. SWOV Fact sheet, January 2017, The Hague, www.swou.nl/ en/facts-figures/factsheet/phone-use-cyclists-and-pedestrians (accessed 4 July 2017).

SWOV (2017b), Road deaths in the Netherlands. SWOV-Fact sheet, May 2017, SWOV, The Hague, www.swou.nl/ en/facts-figures/factsheet/road-deaths-netherlands (accessed 4 July 2017).

SWOV (2016), Serious road injuries in the Netherland. SWOV Fact sheet December 2016, www.swou.nl/en/ facts-figures/factsheet/serious-road-injuries-netherlands (accessed 4 July 2017).

SWOV (2015), The elderly in traffic, SWOV Fact sheet, August 2015, SWOV, The Hague, www.swou.nl/en/ facts-figures/factsheet/elderly-traffic (accessed 4 July 2017).

SWOV (2014), Road crash costs, SWOV Fact sheet, 2014, SWOV, The Hague, www.swou.nl/en/facts-figures/ factsheet/road-crash-costs (accessed 4 July 2017).

Weijermars, W. et al. (2014a), Road safety assessment 2000-2012; Causes and consequences of road unsafety, SWOV, The Hague, www.swou.nl/rapport/R-2014-24.pdf (accessed 4 July 2017).

Weijermars, W. et al. (2014b), Monitor Policy Stimulus Road Safety 2014 - Research justification, SWOV, The Hague, www.swou.nl/rapport/r-2014-36a.pdf (accessed 4 July 2017).

Weijermars, W.A.M., F.D. Bijleveld, S. Houwing, H.L. Stipdonk and A. Dijkstra (2015), Road safety forecasts for 2020 and 2030; Estimate of the expected numbers of fatalities and serious road injuries. R-2015-17A. SWOV, The Hague, www.swou.nl/rapport/r-2015-17a.pdf (accessed 4 July 2017).

Weijermars, W.A.M., H.L. Stipdonk, W. Wijnen, Ch. Goldenbeld, F.D. Bijleveld, H. Korving, J. de Bruin and N.M. Bos (2016), Increase in number of road deaths in 2015; Analysis of developments and possible causes, SWOV, The Hague, www.swou.nl/rapport/r-2016-14b.pdf (accessed 4 July 2017).

Wijlhuizen, G.J., J.W.H. van Petegem, Ch. Goldenbeld, P. van Gent, J. de Bruin, J.J.F. Commandeur and V. Kars (2016), CycleRAP instrument for proactively assessing safety level of cycling network, www.swou.nl/ rapport/r-2016-11.pdf (accessed 4 July 2017).

World Bank (2017), “GDP (constant US\$)”, World Development Indicators, http://databank.worldbank.org/ data/reports.aspx?source=world-development-indicators (accessed 23 February 2017).

\section{Websites}

- SWOV - Dutch Institute for Road Safety Research: www.swou.nl (accessed 4 July 2017).

- Ministry of Infrastructure and the Environment: www.government.nl/ministries/ministry-of-infrastructureand-the-environment (accessed 4 July 2017).

- Statistics Netherlands: www.cbs.nl (accessed 4 July 2017).

- Cycling Embassy: www.dutchcycling.nl (accessed 4 July 2017). 



\section{Chapter 28}

\section{New Zealand}

This chapter presents 2015 road safety data for New Zealand along with provisional data from 2016. It looks at trends in traffic and road safety from the years 1990 to 2015 and road user behaviour patterns with a focus on the ageing population. Sections include data on speed, drink driving, drugs and driving, distracted driving, fatigue and seat belt usage. The chapter reviews New Zealand's road safety strategy and national targets to 2020 and the progress achieved thus far. It also provides details of all recently implemented safety measures and current and ongoing research.*

* All data stem from the New Zealand Ministry of Transport and IRTAD unless otherwise noted. For more information please contact w.jones@transport.govt.nz or b.johnston@transport.govt.nz. 
Following the all-time low in fatalities achieved in 2013, New Zealand registered two consecutive years of increases, with preliminary data from 2016 indicating a continuing trend. In 2015, 319 people died on the roads in New Zealand, a 9\% increase over 2014, a fatality rate of 6.9 per 100000 inhabitants. Car occupants and motorcyclists were the groups most affected by the increases, with car occupants accounting for $69 \%$ of all fatalities.

\section{Road safety data collection}

\section{Definitions applied in New Zealand}

- Road fatality: Any person killed immediately or dying within 30 days as a result of a road crash.

- Serious injuries: Fractures, concussion, internal injuries, crushing, severe cuts and lacerations, severe general shock necessitating medical treatment, and any other injury involving removal to and detention in hospital, as recorded in police records.

- Minor injuries: Injuries such as sprains and bruises.

New Zealand does not collected data based on the Maximum Abbreviated Injury Score (MAIS).

\section{Data collection}

New Zealand's road crashes are usually attended by police officers. Police complete traffic crash reports, which are forwarded to the New Zealand Transport Agency to be coded and the information entered into the Crash Analysis System.

Fatal crashes are all reported. When a traffic crash results in injuries, the law requires that the crash be reported, but comparisons with hospital data indicate that only about two-thirds of such crashes are reported to the New Zealand Transport Agency.

Statistical linking is done to derive reporting rates needed to calculate social costs of crashes.

\section{Most recent safety data}

\section{Road crashes in 2016 - provisional data}

Based on provisional data, in 2016, 328 people lost their lives in a traffic crash, an increase of almost 3\% when compared to 2015. There were 9959 injury crashes, a $2.3 \%$ increase from 2015. Some of this increase may be due to an improvement in crash reporting by police as the result of a change from a paper traffic crash report form to an electronic form. This will be investigated as other injury data sources become available for comparison.

\section{Road crashes in 2015}

In 2015, 319 people died on New Zealand's roads. This represents a 9\% increase compared to the same period in 2014 and is the second consecutive year with a marked increase in the number of road fatalities. 
Since 2013, the number of road deaths has increased by $26 \%$. While this increase needs to be analysed in the light of the good results of 2013 (when the lowest toll since 1952 of 295 fatalities was reached), it represents nevertheless a worrying trend. Preliminary data from 2016 show a $2.8 \%$ increase when compared to the same period in 2015 . There is no immediate explanation for this increase. There have been increases in the amount of travel in the last two years but the increase in the road fatality toll is much greater.

\section{Trends in traffic and road safety (1990-2016) Traffic}

Between 1990 and 2015, the number of motorised vehicles increased by $60 \%$. Since 2000, the number of registered vehicles increased by $35 \%$ and the overall vehicle kilometres driven by $27 \%$. However, since 2007 , there has been a marked slowdown in the growth of road traffic. It started to pick up again in 2014, with an increase of $2.3 \%$ compared to 2013 , with a further increase of 3.3\% observed in 2015.

Figures for 2014 indicate that the vehicle fleet has also increased by nearly 3\% over 2013 with a further increase of 3.4\% recorded between 2014 and 2015.

\section{Road safety}

\section{Crashes and casualties}

Between 1990 and 2015, the number of fatalities decreased by 56\%. Fatalities declined by $31 \%$ between 2000 and 2015. The reported number of injury crashes has increased since 2000, which can be partly attributed to better crash reporting by the police after 2001 . However, injury crashes have decreased over the last seven years, with some year-to year fluctuations. In 2015, crash numbers were 9.6\% higher than in 2014.

New Zealand has made substantial changes to its land transport policy since 1990 to reduce road trauma. Main measures include:

- graduated driving licence system and a photo licence

- compulsory breath testing carried out through road side testing

- speed cameras

- new drug driving laws

- increased penalties for serious offences

- increased minimum driving age from 15 to 16 years

- lowered blood alcohol concentration (BAC) - to zero for drivers less than 20 years of age and to $0.5 \mathrm{~g} / \mathrm{l}$ for drivers aged 20 and over

- introduction of alcohol interlocks as part of the penalty regime

- development of a speed management programme.

The development and subsequent implementation of the "Safer Journeys" strategy adopted in 2010 and based on the Safe System approach has been a major change in the way New Zealand addresses road safety (see road safety strategy section below).

\section{Rates}

Between 1990 and 2015, the mortality rate, expressed in terms of deaths per 100000 population, decreased by nearly $68 \%$. In 2015 , it was at 6.9 . The mortality rate, in terms of deaths per 10000 registered vehicles, has halved compared to 2000 . 
Table 28.1. Road safety and traffic data

\begin{tabular}{|c|c|c|c|c|c|c|c|c|c|}
\hline & \multirow{2}{*}{1990} & \multirow{2}{*}{2000} & \multirow{2}{*}{2010} & \multirow{2}{*}{2014} & \multirow{2}{*}{2015} & \multicolumn{4}{|c|}{$2015 \%$ change from } \\
\hline & & & & & & 2014 & 2010 & 2000 & 1990 \\
\hline \multicolumn{10}{|l|}{ Reported safety data } \\
\hline Fatalities & 729 & 462 & 375 & 293 & 319 & 8.9 & -14.9 & -31.0 & -56.2 \\
\hline Injury crashes & 12818 & 7830 & 10886 & 8882 & 9737 & 9.6 & -10.6 & 24.4 & -24.0 \\
\hline Injured persons hospitalised & 5718 & 3054 & 2881 & 2672 & 2854 & 6.8 & -0.9 & -6.5 & -50.1 \\
\hline Deaths per 100000 inhabitants & 21.4 & 12.0 & 8.6 & 6.5 & 6.9 & 6.8 & -19.2 & -42.1 & -67.5 \\
\hline Deaths per 10000 registered vehicles & 3.3 & 1.8 & 1.2 & 0.9 & 0.9 & 5.3 & -21.8 & -48.9 & -72.6 \\
\hline Deaths per billion vehicle kilometres & & 13.6 & 9.4 & 7.0 & 7.4 & 5.4 & -21.1 & -45.8 & \\
\hline \multicolumn{10}{|l|}{ Traffic data } \\
\hline Registered vehicles ${ }^{1}$ (thousands) & 2198 & 2602 & 3231 & 3398 & 3515 & 3.4 & 8.8 & 35.1 & 59.9 \\
\hline Vehicle-kilometres (millions) & & 33856 & 39980 & 41714 & 43100 & 3.3 & 7.8 & 27.3 & \\
\hline Registered vehicles per 1000 inhabitants & 645 & 674 & 740 & 753 & 765 & 1.5 & 3.4 & 13.4 & 18.6 \\
\hline
\end{tabular}

1. With mopeds.

Figure 28.1. Road Safety, Traffic and GDP Trends index $1990=100$

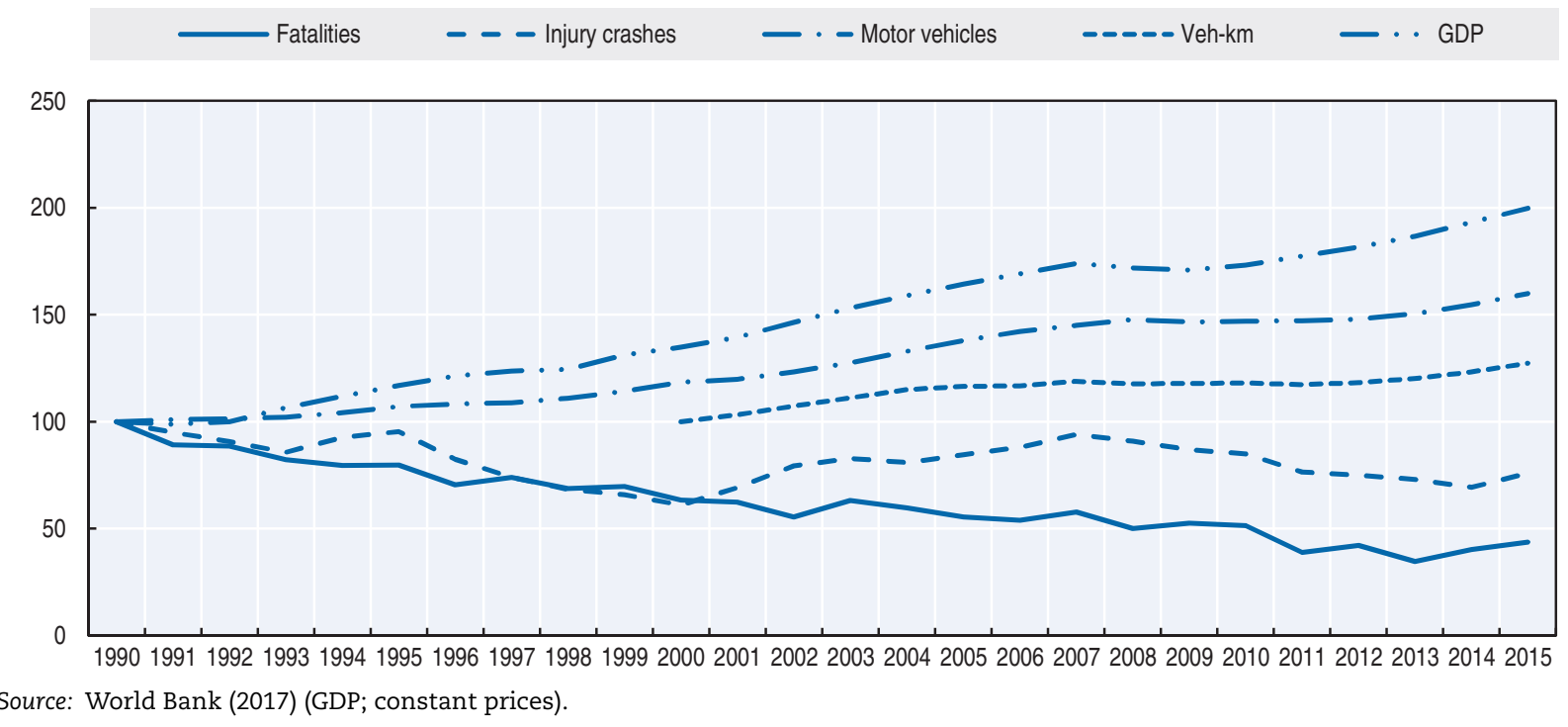

\section{Road safety by user group}

All user groups have benefited from improvement since 1990.

Since 2000, there has been a mixed picture. There has been a marked decrease in the fatalities among cyclists (-68\%) and car occupants (-38\%); improvements were less among pedestrians $(-28.6 \%)$. However the number of motorcyclists killed has increased significantly $(+77 \%)$. The increase in motorcyclists' mortality is due in part to an increase in motorcycle ownership and to the increasing power of motorcycles being purchased.

In 2015 , the situation deteriorated again for motorcyclists, with a $26 \%$ increase in fatalities, but also for car occupants. The numbers of killed vulnerable road users - pedestrians and cyclists - have decreased compared to 2014 , by $42 \%$ and $40 \%$, respectively. 
Table 28.2. Road fatalities by road user group

\begin{tabular}{lrrrrr|rrrr}
\hline & 1990 & 2000 & 2010 & 2014 & 2015 & \multicolumn{4}{c}{$2015 \%$ change from } \\
\cline { 7 - 10 } & & & & & & 2014 & 2010 & 2000 & 1990 \\
\hline Pedestrians & 104 & 35 & 35 & 43 & 25 & -41.9 & -28.6 & -28.6 & -76.0 \\
Cyclists & 27 & 19 & 10 & 10 & 6 & -40.0 & -40.0 & -68.4 & -77.8 \\
Moped riders & 0 & 1 & 0 & 1 & 1 & - & - & - & - \\
Motorcyclists & 114 & 30 & 50 & 42 & 53 & 26.2 & 6.0 & 76.7 & -53.5 \\
Car occupants & 465 & 358 & 259 & 180 & 220 & 22.2 & -15.1 & -38.5 & -52.7 \\
Others & 19 & 19 & 21 & 17 & 14 & -17.6 & -33.3 & -26.3 & -26.3 \\
Total & $\mathbf{7 2 9}$ & $\mathbf{4 6 2}$ & $\mathbf{3 7 5}$ & $\mathbf{2 9 3}$ & $\mathbf{3 1 9}$ & $\mathbf{8 . 9}$ & $\mathbf{- 1 4 . 9}$ & $\mathbf{- 3 1 . 0}$ & $\mathbf{- 5 6 . 2}$ \\
\hline
\end{tabular}

Figure 28.2. Road fatalities by road user group in percentage of total, 2015

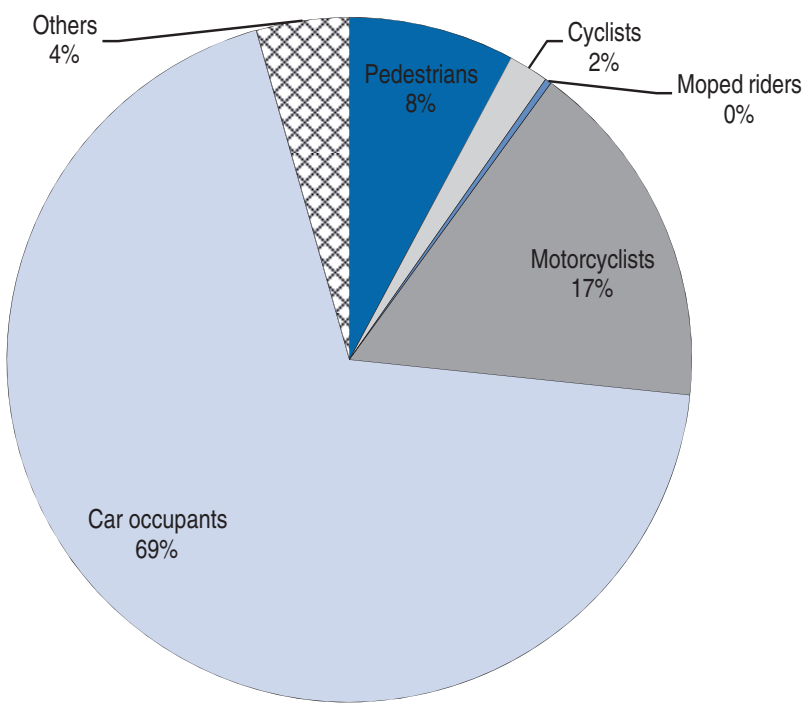

\section{Road safety by age group}

Since 1990, the reduction in fatalities has benefited all age groups; however, the improvement for senior citizens was much less than the other age groups. This is partly explained by demographic changes. Since 2000, the over 65 age group has risen from $15 \%$ to $18 \%$ of the population and from $12 \%$ to $15.5 \%$ of driver licence holders. The senior population are particularly vulnerable as pedestrians.

In 2015, the number of fatalities increased among all age groups except the 0-17 year olds.

The fatality rate of young people aged 18-24 is very high (approximately 16 deaths per 100000 inhabitants), two and half times more than the rate of the average population, despite a significant decrease for 21-24 year olds in 2012 and 2013. 
Table 28.3. Road fatalities by age group

\begin{tabular}{|c|c|c|c|c|c|c|c|c|c|}
\hline \multirow{2}{*}{ Age } & \multirow{2}{*}{1990} & \multirow{2}{*}{2000} & \multirow{2}{*}{2010} & \multirow{2}{*}{2014} & \multirow{2}{*}{2015} & \multicolumn{4}{|c|}{$2015 \%$ change from } \\
\hline & & & & & & 2014 & 2010 & 2000 & 1990 \\
\hline $0-14$ & 52 & 41 & 18 & 12 & 9 & -25.0 & -50.0 & -78.0 & -82.7 \\
\hline $15-17$ & 65 & 36 & 26 & 10 & 9 & -10.0 & -65.4 & -75.0 & -86.2 \\
\hline $18-20$ & 108 & 34 & 41 & 24 & 31 & 29.2 & -24.4 & -8.8 & -71.3 \\
\hline $21-24$ & 131 & 42 & 46 & 28 & 41 & 46.4 & -10.9 & -2.4 & -68.7 \\
\hline $25-64$ & 290 & 232 & 175 & 153 & 164 & 7.2 & -6.3 & -29.3 & -43.4 \\
\hline $65-74$ & & 43 & 36 & 28 & 30 & 7.1 & -16.7 & -30.2 & \\
\hline $75-84$ & & 28 & 18 & 20 & 19 & -5.0 & 5.6 & -32.1 & \\
\hline$\geq 85$ & & 5 & 15 & 11 & 11 & 0.0 & -26.7 & 120.0 & \\
\hline Total & 729 & 462 & 375 & 293 & 319 & 8.9 & -14.9 & -31.0 & -56.2 \\
\hline
\end{tabular}

Figure 28.3. Road fatality rates by age group Deaths per 100000 inhabitants in a given age group, 1990-2015

- $0-14$ years $\quad---15-17$ years $\quad--18-20$ years $-----21-24$ years $\quad \cdots 25-64$ years $\quad \cdots-\geq 65$ years

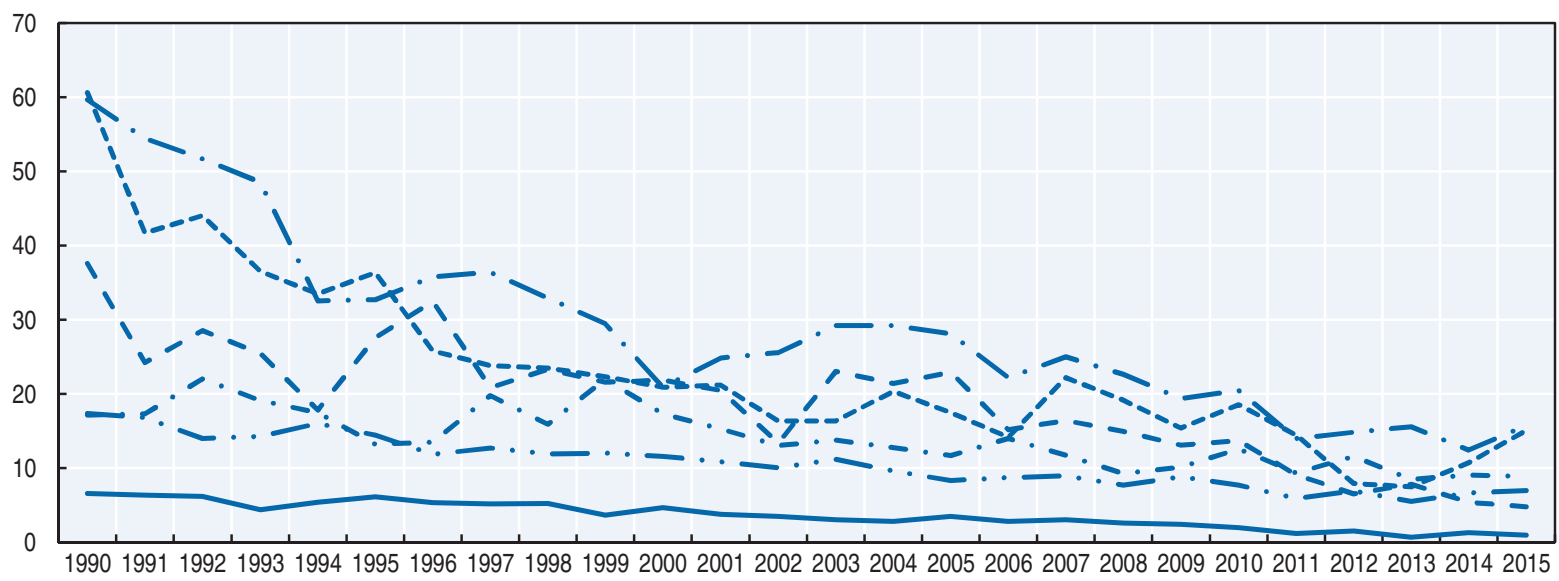

Box 28.1. Road safety for an ageing population

The population aged 65 and over is forecast to more than double by 2043 . This compares to a $27 \%$ increase for the population as a whole.

Since 1990, the reduction in fatalities among the older population was much smaller than the other age groups. This is partly explained by demographic changes. Since 2000, the over 65 age group has risen from $15 \%$ to $18 \%$ of the population and from $12 \%$ to $15.5 \%$ of driver licence holders. Senior citizens are particularly vulnerable as pedestrians.

Most driver licences are valid for 10 years, after which they must be renewed if the licence holder wishes to continue driving. All licence holders renewing their licence must apply at a driver licensing agent. The applicants are required to prove their eyesight meets the required standard (through an on-site eyesight test or a recent medical or eyesight certificate.

Senior drivers who wish to continue driving must renew their driver licence at age 75,80 and every two years thereafter. These drivers can apply to renew their licence up to six months before the expiry of their current licence. 


\section{Box 28.1. Road safety for an ageing population (cont.)}

In addition to general licence renewal requirements, senior applicants (from age 75) must present a medical certificate from their doctor that is no more than 60 days old. The medical certificate will advise if the licence holder is medically fit to drive, requires further testing to be declared fit to drive, or is fit to drive only under certain conditions (e.g. wearing corrective lenses or only during daylight hours).

Table 28.4. Road fatalities among senior citizens, 2015

\begin{tabular}{lcc|rc|rc}
\hline & \multicolumn{2}{c|}{$65-74$} & \multicolumn{2}{c|}{$75-84$} & \multicolumn{2}{c}{$85+$} \\
\cline { 2 - 7 } & 2010 & 2015 & 2010 & 2015 & 2010 & 2015 \\
\hline Pedestrians & 6 & 4 & 4 & 3 & 4 & 3 \\
Cyclists & 1 & 0 & 1 & 1 & 0 & 0 \\
Moped riders & 0 & 0 & 0 & 0 & 0 & 0 \\
Motorcyclists & 0 & 3 & 0 & 0 & 0 & 0 \\
Car occupants & 28 & 21 & 11 & 14 & 10 & 7 \\
Total & $\mathbf{3 6}$ & $\mathbf{3 0}$ & $\mathbf{1 8}$ & $\mathbf{1 9}$ & $\mathbf{1 5}$ & $\mathbf{1 1}$ \\
\hline
\end{tabular}

Figure 28.4. Road fatality rates in the 65+ age groups Deaths per 100000 inhabitants in a given age group, 2000-15

65-74 years

$--75-84$ years

$-\cdot-85+$ years

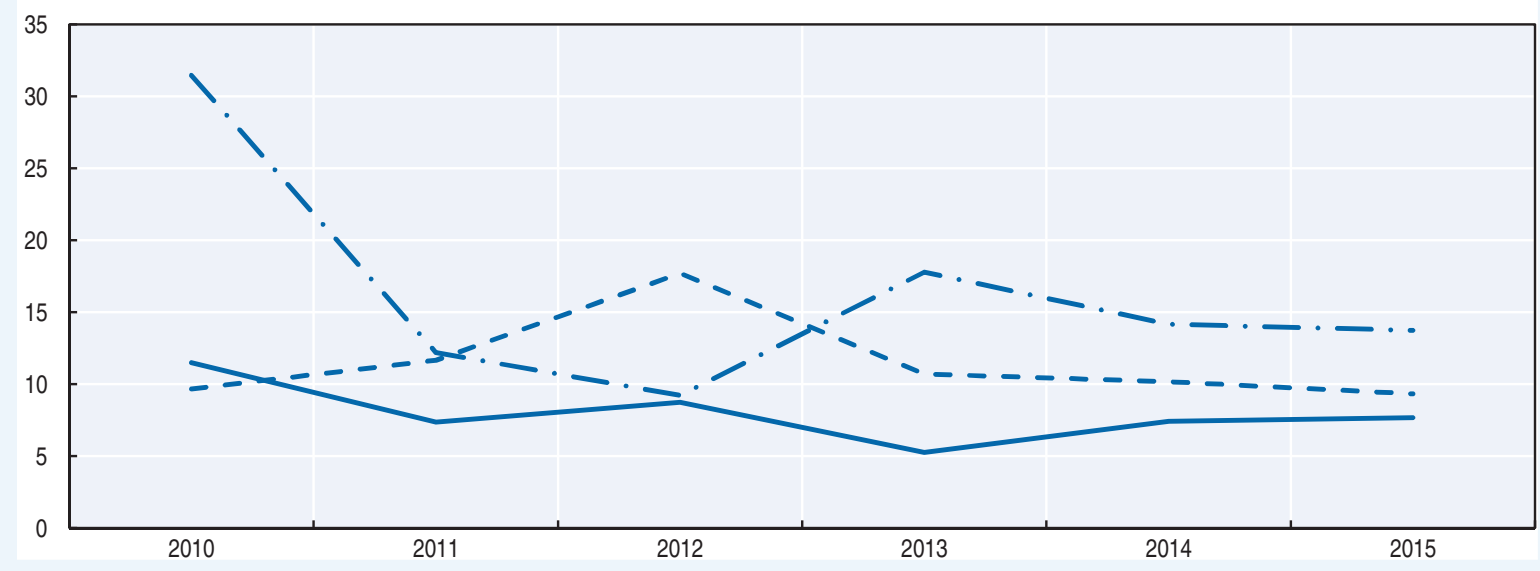


Figure 28.5. Road fatality rate by age and road user group Fatalities per 100000 inhabitants, 2015

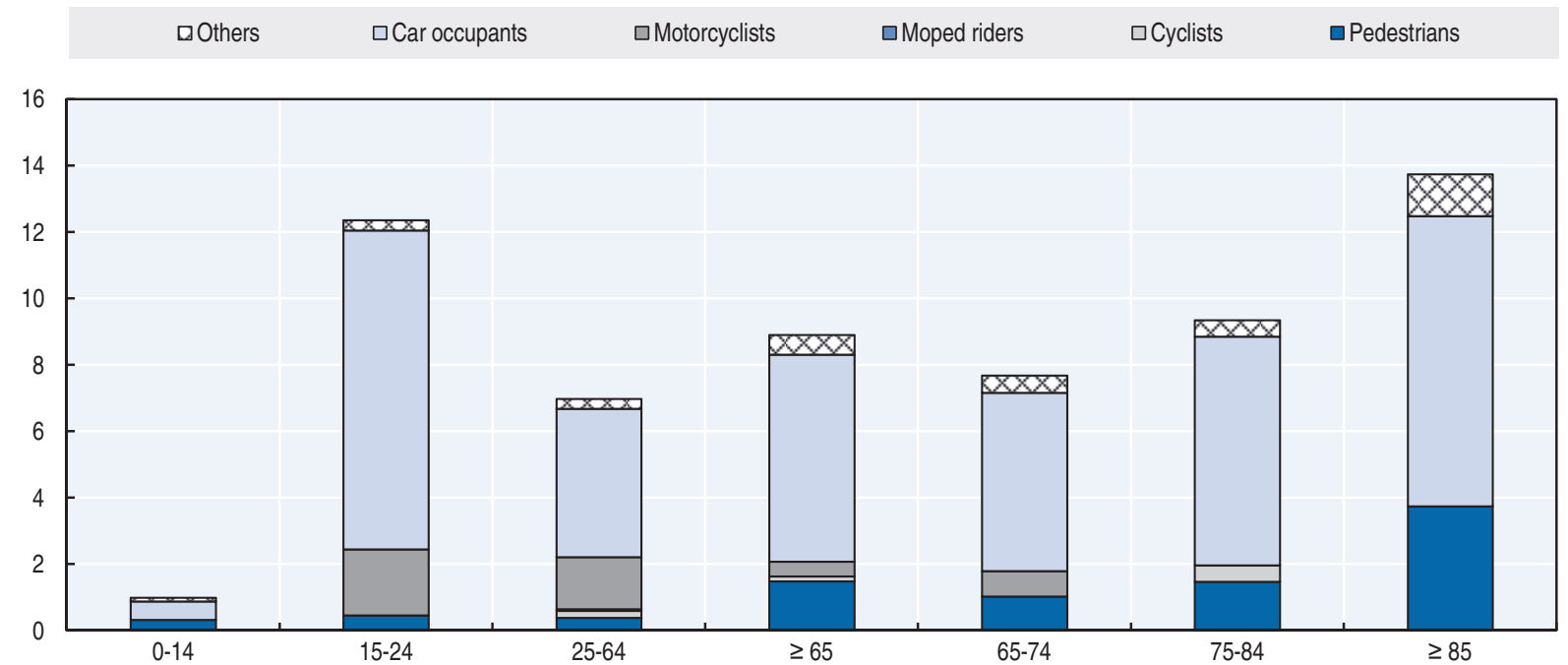

\section{Road safety by road type}

In $2015,71 \%$ of fatalities occurred on rural roads, $26 \%$ inside urban areas, while motorways accounted for only $2.5 \%$ of the road deaths.

Improvements over the last 30 years have been more rapid on urban roads and motorways.

Figure 28.6. Road fatalities by road type

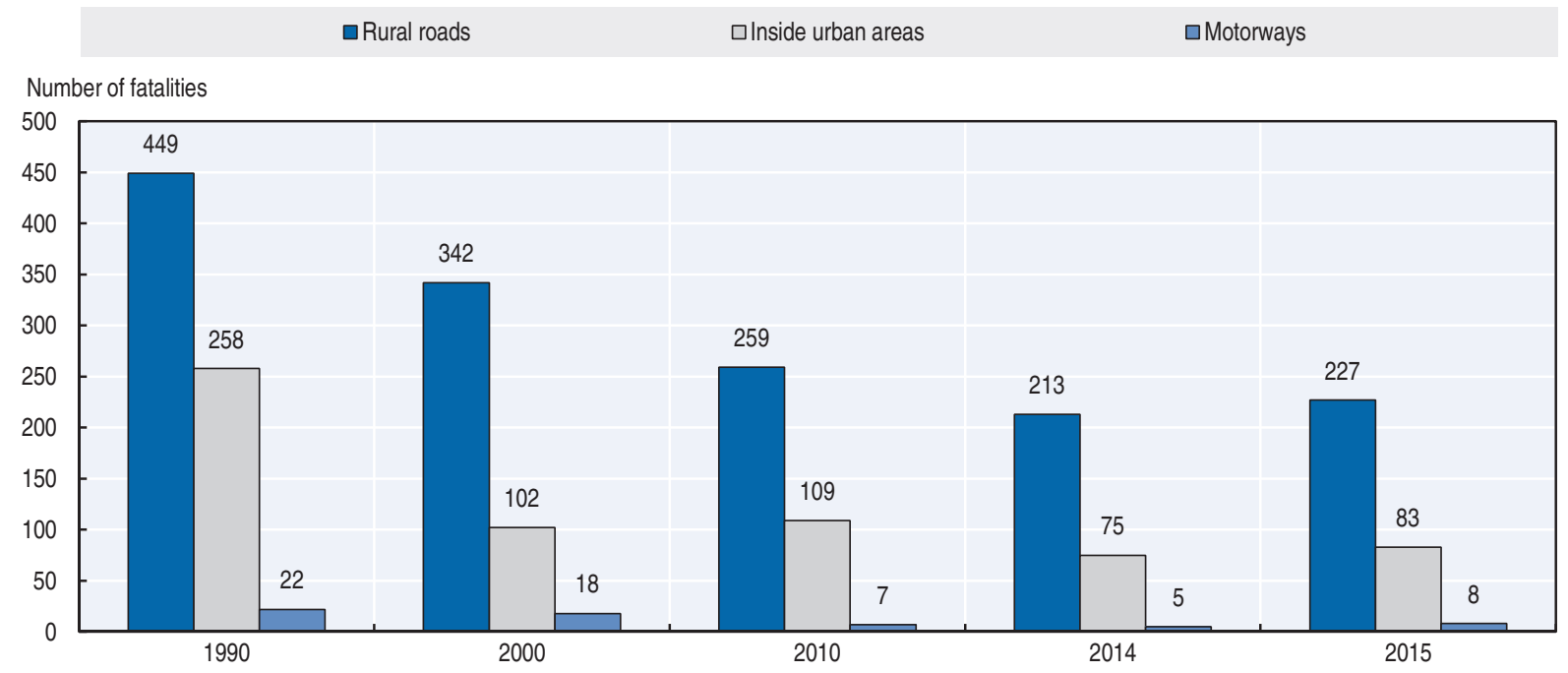

\section{Economic costs of traffic crashes}

In New Zealand, the social cost of a road crash or a road injury includes the following components:

- loss of life and life quality

- loss of output due to temporary incapacitation

- medical costs 
- legal costs

- vehicle damage costs.

Social cost components are either measurable or can be estimated in dollar terms. A "willingness-to-pay" valuation technique is used to express pain and suffering from loss of life or life quality in dollar terms. Various methodologies have been developed to estimate the value of other social cost components.

The New Zealand Ministry of Transport released its report "Social Cost of Road Crashes and Injuries 2016" in March 2017. The total social cost of motor vehicle injury crashes in 2015 is estimated at NZD 3.79 billion, at June 2016 prices. This represents an increase of $7.4 \%$ compared to the previous year.

Loss of life and/or life quality due to permanent impairment accounted for approximately $91 \%$ of the total social cost of injury crashes. Vehicle damage accounted for around 5\%, and other cost components (medical costs, legal and court costs and loss of output costs) for around $4 \%$.

Full information is provided at: www.transport.gout.nz/research/roadcrashstatistics/the socialcostofroadcrashesandinjuries/.

Published social costs take into account the estimated under reporting of crashes.

Table 28.5. Costs of road crashes, 2015

\begin{tabular}{lcc}
\hline Cost & Unit cost (NZD) & Total $^{*}(\mathrm{NZD})^{* *}$ \\
\hline Fatal crashes & 4.729 million & 1.38 billion \\
Serious injury crashes & 504500 & 1.66 billion \\
Slight injury crashes & 28600 & 0.75 billion \\
Total cost of injury crashes & 3000 & $\mathbf{3 . 7 9}$ billion \\
Property damage crashes & & 0.66 billion \\
Total & & $\mathbf{4 . 4 5}$ billion \\
\hline
\end{tabular}

* The unit costs for injury crashes includes the cost of associated property damage.

** The total cost includes an allowance for under reporting of crashes.

Table 28.6. Unit costs of road crash injuries, 2015

\begin{tabular}{lc}
\hline Cost & Unit cost (NZD)* \\
\hline Fatalities & 4.179 million \\
Serious injuries & 439100 \\
Slight injuries & 23400 \\
$*$ The unit costs for injuries includes the cost of associated property damage.
\end{tabular}

\section{Recent trends in road user behaviour}

Speed

The tables below illustrate the main speed limits in New Zealand and the percentage of drivers above the speed limit. Much progress has been accomplished since 2001 in reducing the number of violations. However, nearly half (46\%) of drivers exceed the $50 \mathrm{~km} / \mathrm{h}$ limit in urban areas, which is a cause for concern when it comes to ensuring the safety of vulnerable road users.

In 2015 , speed was a contributing factor in $32 \%$ of road fatalities. 
Table 28.7. Passenger car speed limits by road type, 2017

\begin{tabular}{lrl}
\hline & General speed limit & \multicolumn{1}{c}{ Comments } \\
\hline Urban roads & $50 \mathrm{~km} / \mathrm{h}$ & The general urban limit is $50 \mathrm{~km} / \mathrm{h}$ but specific sections may have higher or lower limits \\
Rural roads & $100 \mathrm{~km} / \mathrm{h}$ & The general open road speed limit is $100 \mathrm{~km} / \mathrm{h}$ but specific rural roads may have lower limits. \\
Motorways & $100 \mathrm{~km} / \mathrm{h}$ & \\
\hline
\end{tabular}

Table 28.8. Percentage of drivers above the posted speed limit

\begin{tabular}{lccc}
\hline Speed (survey unimpeded speeds) & 2005 & 2010 & 2015 \\
\hline$\%$ exceeding open road $100 \mathrm{~km} / \mathrm{h}$ limit & 36 & 29 & 23 \\
$\%$ exceeding urban $50 \mathrm{~km} / \mathrm{h}$ limit & 63 & 58 & 46 \\
\hline
\end{tabular}

\section{Drink driving}

In 2014, New Zealand lowered the blood alcohol content (BAC) level from $0.8 \mathrm{~g} / \mathrm{l}$ to $0.5 \mathrm{~g} / \mathrm{l}$. Drivers with a BAC over $0.8 \mathrm{~g} / \mathrm{l}$ must appear in court; a BAC between $0.5 \mathrm{~g} / \mathrm{l}$ and $0.8 \mathrm{~g} / \mathrm{l}$ results in a fine and demerit points. In 2011, a zero drink-drive limit was introduced for drivers under 20. The earlier limit was $0.3 \mathrm{~g} / \mathrm{l}$.

Alcohol-related road deaths are those in which any motor vehicle driver was found with a BAC above the legal limit, or where the reporting officer suspected alcohol was a contributing factor. Over a quarter of road fatalities are attributed to an alcohol-related crash.

\section{Drugs and driving}

Drug-related crashes include crashes where the reporting officer suspected drug use was a contributing factor based on the crash investigation. In 2015, there were 24 road deaths $(7 \%)$ for which the presence of drugs was found.

A number of recent studies have been undertaken on the issue of drugs and driving.

\section{Seat belts and helmets}

Seat belt use has been compulsory in front seats since 1972 and in rear seats since 1979.

In November 2013, the mandatory use of child restraints in vehicles was extended by two years, with all children required to be correctly secured in an approved restraint until they reach the age of seven.

Based on the most recent roadside surveys, the rate of seat belt use is about $96.5 \%$ in front seats (2016), 92\% for adults in rear seats (2014), and 93\% for children in appropriate child restraints (2016). In the three years 2013 to 2015, 34\% of vehicle occupant deaths in road crashes were not wearing a safety belt.

Helmet wearing has been compulsory on motorcycles since 1956 if travelling over $50 \mathrm{~km} / \mathrm{h}$ and since 1973 at all speeds. Compliance is virtually $100 \%$. Helmet wearing has been compulsory on mopeds (up to $50 \mathrm{cc}$, maximum speed $45 \mathrm{~km} / \mathrm{h}$ ) since 1973.

A helmet has been compulsory on bicycles since 1994. 
Table 28.9. Seat belt wearing rate by car occupancy and road type

\begin{tabular}{lllll}
\multicolumn{1}{c}{$\%$} & & & \\
\hline & 2000 & 2010 & 2014 & 2016 \\
\hline $\begin{array}{l}\text { Front seat } \\
\text { Driver }\end{array}$ & & 96 & 97 & 97 \\
$\quad$ Passenger & & 96 & 97 & 96 \\
Urban roads (driver) & 88 & 95 & 97 & 96 \\
Rural roads (driver) & 92 & 97 & 98 & 97 \\
$\quad$ Motorways (driver) & & & & \\
Rear seats & & & & \\
$\quad$ General (passengers) & & 88 & 92 & 93 \\
$\quad$ Child restraint - under 5 years & & 93 & 93 & \\
\hline
\end{tabular}

\section{Distraction}

The Land Transport Road User Rule was amended in August 2009 to include a ban on the use of hand-held mobile phones while driving. Based on police records, fatal crashes due to the use of cell phones are not frequent. Mobile phone use continues to be a problem with $60 \%$ of New Zealand drivers admitting to using their phone while driving. Publicity campaigns addressing the problem were introduced in 2015.

\section{Fatigue and sleepiness}

In 2015 fatigue was identified as a contributing factor in 43 fatal crashes, which resulted in 45 deaths (14\%).

\section{National road safety strategies and targets Organisation of road safety}

Road safety in New Zealand is managed through five transport partners. The Ministry of Transport is the government's principal transport policy adviser and has a dedicated team focused on road safety policy. The Ministry is the lead agency for road safety.

The New Zealand Transport Agency is a Crown agency responsible for the planning and funding of land transport. It produces road safety campaigns and implements road safety policy, integrating road safety aspects into road design and maintenance. It is responsible for developing, constructing, maintaining and operating the state highway network.

The New Zealand Police are responsible for road policing and enforcement. The Accident Compensation Corporation provides "no fault" cover for anyone in New Zealand who is injured in or by a motor vehicle on a public road. It has a major role in accident prevention activities.

Local government is responsible for developing, maintaining and operating the network of local roads, including setting of speed limits and delivering public transport infrastructure and services. Decisions on construction, maintenance and management of the road networks must take into account road safety.

In 1993, road safety policy development was separated from delivery with the creation of a new entity called the Land Transport Safety Authority, now called the New Zealand Transport Agency. Around the same time, traffic policing was absorbed into the New Zealand Police. 


\section{Road safety strategy for 2011-20}

"Safer Journeys" is New Zealand's Road Safety Strategy 2010-20, which was released in March 2010. The strategy's vision is a safe road system increasingly free of death and serious injury, and introduces the Safe System approach to New Zealand.

The government released a 2011-12 Action Plan outlining actions to help achieve the Safer Journeys' objectives. The action plan assigned responsibility to specific agencies, and progress was monitored by the National Road Safety Committee. A second action plan for 2013-15 was completed in 2015 and a third action plan for 2016-20 was released in May 2016. An interim evaluation was undertaken in 2015. In summary, the evaluation found that "Safer Journeys" was a professionally developed, well regarded, sound road safety strategy, supported by action plans and that it was having a significant and positive impact on wider road safety partnerships; achieving good to excellent results in its priority areas. It recommended that the next action plan focus on motorcycle safety, heavy vehicle and workplace safety, pedestrian and cyclist safety, and technology. The third action plan was informed by this evaluation.

\section{Road safety targets}

The Road Safety Strategy 2010-20 does not include a general fatality target, but has several sub-targets and performance indicators.

Crash outcomes and road user behaviour that relate to Safer Journeys' focus areas are regularly monitored. Other targeted studies are carried out for specific areas such as young driver crashes.

\section{Recent safety measures (2014-17)}

\section{Road safety management}

\section{Safe System}

A series of "signature projects" started in 2014 for challenging public and private, national and regional issues. The Safer Journeys Signature Programme was one of the key actions in the second Safer Journeys Action Plan 2013-15. The programme has a learning focus and demonstrates innovation, while applying safe system principles with the ultimate aim of reducing road casualties. There are currently three projects in the Programme, which involve a number of organisations working in partnership:

- Visiting Drivers Project - aims to improve road safety for all road users including visitors (domestic and international) while maintaining New Zealand's reputation as an attractive and safe tourist destination.

- Future Streets Project - aims to make cost effective changes to urban streets that improve road safety and make walking and cycling easier and safer.

- Behind the Wheel/Young Drivers Project - aims to support young people to become safe and fully licensed drivers.

A fourth project focused on rural road safety was formally disestablished by the National Road Safety Committee in September 2015. A review of the project identified key lessons learnt including the importance of partners reaching a shared understanding of problems and goals, the need for effective project governance and leadership, and communicating effectively with stakeholders and the wider community. 
- A Safe System film was released in November 2014 to change approaches to and understanding of road safety: www.saferjourneys.gout.nz/about-safer-journeys/the-safesystem-approach/ (accessed 4 July 2017).

Some 400 sector professionals around New Zealand have been trained in the Safe System approach to road safety.

\section{Driving licence}

- Time limits of five years were applied to learner and restricted driver licences in 2014.

- The NZ Transport Agency and the Accident Compensation Corporation collaborated to produce Drive (www.drive.gout.nz), an online learning tool to help young people become safe, skilled and capable drivers. Drive went live in June 2016. Drive was designed to support individuals on their journey through the Graduated Driver Licensing System (GDLS). There is also information and tools for parents/coaches, instructors and teachers as they are important supporters and key influencers of our young people.

- A review of the driver licensing system was undertaken in 2015-16. It found that the Driver Licensing Rule could be updated and modernised to make the driver licensing system more customer-focused and reduce compliance costs. Proposals for public consultation closed in June 2016 and law changes are expected in 2017 The proposals included:

* reductions in eyesight testing requirements to enable online licence renewals

* streamlining heavy vehicle licensing processes

* standardising rules around the operation of "special-type" vehicles, such as forklifts, and removing some endorsements

* strengthening the powers for NZTA to manage course providers.

\section{Speed management}

- A speed management programme called Safer Speeds includes a new framework to align travel speeds with road function, design, safety and use. Geospatial data provided mean speeds and traffic volumes for every public road in New Zealand, which was analysed with accident rates. The aim of Safer Speeds is to have a consistent and evidenced-based approach to speed management that is supported by community engagement and better conversations on road risk.

- One of the initiatives within Safer Speeds was the development of the Speed Management Guide. The Guide provides a national framework that helps road controlling authorities make informed, accurate and consistent speed management decisions in their communities, www.pikb.co.nz/assets/Uploads/Documents/Speed-management-guide-first-edition-Nou2016.pdf (accessed 4 July 2017).

- The full network of new generation digital static cameras is being gradually expanded. There will be a total of 56 new cameras rotated around up to 200 locations with a history of speed-related crashes.

- The Better Conversations on Road Risk programme aims to build understanding of road risk resulting in safer choices by communities and individuals. Its approach is based on evidence and focused on quality engagement with stakeholders, media and communities. The New Zealand Transport Agency works closely with Road Controlling Authorities to develop resources that help them engage with their communities, www.nzta.gout.nz/safety/speedmanagement-resources/better-conversations-on-road-risk/ (accessed 4 July 2017). 


\section{Road users}

\section{Impaired driving}

- The New Zealand government lowered the BAC for driving from $0.8 \mathrm{~g} / \mathrm{l}$ to $0.5 \mathrm{~g} / \mathrm{l}$ for drivers aged over 20 years of age on 1 December 2014.

\section{Cycling safety}

- A Cycling Safety Panel was created in response to a 2013 Coronial Inquiry, which investigated 13 cycling fatalities. The panel made 35 recommendations for central and local government. The NZ Transport Agency published a cycle safety action plan "Making cycling safer and more attractive". Highlights included the delivery of complete urban cycle networks, nationally consistent design guidance for cycle facilities, the safer speeds programme, and review of the land transport rules including an investigation into a minimum overtaking gap when passing cyclists. The delivery of the Urban Cycleways Programme is well underway in 2017, with the 4-year project ending June 2018. Many of the Programme's 54 cycleways will be underway or completed by the end of 2017.

\section{Visiting drivers}

- Over the last few years, crashes involving visiting drivers, particularly those from overseas, have gained considerable media and public attention. The Visiting Drivers Project was established with the aim of improving road safety for all road users including visitors (both domestic and international), while maintaining New Zealand's reputation as an attractive and safe tourist destination.

- A notable initiative outside of the Visiting Driver Project is the ongoing Bluetooth audio safety messaging trial, which began in June 2016. This technology can deliver audio safety messages to rental car drivers on the Christchurch to Queenstown route. Feedback from the initial research phase of the trial was positive, and transport officials are looking at the next steps for the technology, including possibilities for expanding the route network where the technology is available.

\section{Infrastructure}

- A classification system for the entire road network categorises roads according to their function and sets a consistent and predictable level of service for each category. This can help drivers understand what to expect and how to behave on different categories of road.

- Investment in operations and maintenance associated with safety improvements will be prioritised to ensure optimal road safety.

\section{Vehicles}

- Electronic Stability Control (ESC) is mandatory on all new and used imported vehicles progressively from 1 July 2015. By 2020, every light vehicle entering the New Zealand fleet will have ESC.

- The Vehicle Standards Map describes the vehicle technologies and performance standards that government transport officials believe have the greatest potential to improve the safety and resource efficiency of vehicles in New Zealand. Transport officials will use the map to help decide which vehicle features should be promoted or mandated. The map will also keep stakeholders such as road users and the vehicle industry up to date with vehicle policy developments. 
- On 1 February 2017, the new Land Transport Rule: Vehicle Dimensions and Mass 2016 (the Rule) came into force. The Rule regulates the size and weight of vehicles and loads allowed on roads with an emphasis on heavy and very large vehicles. Key changes provided by the new Rule were modest increases in allowable maximum size and weights of vehicles and some additional requirements for managing the movement of very large vehicles and loads.

- As part of the Government's Electric Vehicles Programme, the NZ Transport Agency and WorkSafe (New Zealand's work health and safety regulator) are working with local councils and the private sector to enable a network of public charging stations throughout New Zealand, and are providing information about the regulations people will need to follow if they choose to buy an electric vehicle.

\section{Recent and ongoing research}

The following are safety research projects currently active under NZTA's research programme:

- the prevalence and impairment effects of drugged driving in New Zealand

- human factor considerations for driver licensing point system

- the crash performance of seagull intersections and left turn slip lanes

- electric bicycle and low-powered vehicle standards and safety

- post impact care - the fifth pillar - how well New Zealand delivers post impact care through to hospitalisation.

Projects published in 2016 are:

- Why are some urban traffic signals much less safe than others?

- Improving safety for people who cycle on rural roads

- Quantifying the likelihood of barrier strike maintenance

- Research reports from the New Zealand Transport Agency can be downloaded at: www.nzta.gout.nz/resources/research/reports (accessed 4 July 2017).

\section{References}

World Bank (2017), “GDP (constant US\$)”, World Development Indicators, http://databank.worldbank.org/ data/reports.aspx?source=world-development-indicators (accessed 23 February 2017).

\section{Websites}

- Ministry of Transport: www.transport.gout.nz/ (accessed 4 July 2017).

- New Zealand Transport Agency (NZTA): www.nzta.gout.nz (accessed 4 July 2017).

- New Zealand's road safety strategy to 2020: www.saferjourneys.gout.nz (accessed 4 July 2017).

- New Zealand Road Assessment Programme KIWIRAP: www.kiwirap.org.nz (accessed 4 July 2017). 



\section{Chapter 29}

\section{Nigeria}

This chapter presents 2015 and 2016 road safety data from Nigeria. It looks at trends in traffic and road safety and road user behaviour patterns. This includes data on speed, drink driving, drugs and driving, distracted driving, fatigue and seat belt usage. The chapter reviews Nigeria's road safety strategy and national targets along with details of recently implemented safety measures and research undertaken. ${ }^{*}$

* The Federal Road Safety Corps (FRSC) joined the International Road Traffic and Accident Database (IRTAD) group in 2014. Data included in this report have not been validated by IRTAD. All data stem from Federal Road Safety Corps (FRSC) unless otherwise noted. For more information please contact: ACM Kayode Olagunju, ky.olagunju@frsc.gov.ng. 
F or the third consecutive year, Nigeria has reported reductions in road fatalities. In 2016, the FRSC reported 5053 fatalities, a 7.7\% reduction when compared to 2015's reported figures. However, actual figures are most likely much higher. Pedestrians are particularly vulnerable with children accounting for around $40 \%$ of all fatalities. Nigeria's road safety strategy is based on the United Nations Decade of Action for Road Safety and its five pillars.

\section{Road safety data collection}

\section{Definitions applied in Nigeria}

- Road crash: Collision involving one or more vehicles or a moving vehicle and a stationary vehicle or object or pedestrian resulting in a death, injury, damage to a vehicle or loss of physical property.

- Road fatality: Death of a person within 30 days of the crash.

- Injury crash: Crash that results in a person or persons sustaining severe or minor injuries but not leading to death.

- Serious injury: Any road traffic crash victim with open or bleeding wounds.

\section{Data collection}

Road safety data in Nigeria is collected at the scene by the road safety personnel who were on patrol or who were called to the scene via the toll-free emergency call centre or by other means. Police personnel also collect crash data during investigations.

Previously, data information officers of the Federal Road Safety Corps (FRSC) collected, collated and forwarded data to sector commands at the state level. Sector commands collected and forwarded collated data from local level to zonal headquarters. Zonal commands forwarded validated crash data to road safety headquarters for analysis.

Currently, the FRSC digitises the data collection process with computers and hand-held tablets at the scene of a crash, and data arrives directly into the FRSC data portal (www.frscrtcis.com.ng/). The portal is designed to accommodate inputs from other data collection agencies such as the Vehicle Inspection Officers, State Traffic agencies and hospitals. The portal can sieve the data to avoid multiple entries. This arrangement of data harmonisation comes under the National Committee on Crash Information System (NACRIS).

The National Crash Report Information System was inaugurated in April 2014 to harmonise all traffic crash data in Nigeria from the different agencies including the police, the Ministry of Health (hospital data), the vehicle inspection unit and state traffic agencies.

Gaps still exist in the data collection as not all crashes are recorded, especially in locations not regularly covered by the patrol teams of the FRSC and the police. The World Health Organization estimates the actual number of road fatalities could be up to 7 times higher than figures reported to FRSC (WHO, 2015).

To address this issue, data information officers regularly visit these areas and collect missing data, but this is expensive. With support from the World Bank, a new road traffic 
crash data management system is being developed in two phases: Phase 1: the design of the National Road Traffic Crash Data Management System (completed); Phase 2: the procurement and implementation of the system.

\section{Most recent safety data}

\section{Road crashes in 2016 - Final data}

Based on final data, in 2016 the FRSC reported 5053 road fatalities, a 7.7\% reduction when compared to the reported figure in 2015.

\section{Road crashes in 2015}

In 2015, FRSC reported 5440 road fatalities, a 9.3\% reduction compared to 2014.

\section{Trends in traffic and road safety (1990-2015)}

\section{Traffic}

Mobility in Nigeria is mainly by road, which has led to an over-dependence and increased pressure on the road infrastructure system. The railway system is disorganised, although rail services have improved in some parts of the network. Air travel is costly and not an option for mass transportation. The government needs to invest heavily in improving road conditions.

Vehicle ownership has increased. Powered three-wheelers are increasingly used for commercial transport, and motorcycle use is increasing.

\section{Road safety}

There is wide fluctuation in the yearly number of crashes and casualties, mainly due to a non-systematic recording of road crashes. It is expected that the efforts currently deployed to digitise the processing of crash records will contribute to a better reporting system and more accurate monitoring of road crash trends.

\section{Road safety by user group}

The increase in the motorcycle fleet has led to an increase in crashes involving motorcycles. The use of motorcycles for commercial purposes has been banned in some major cities due to the high fatality rate resulting from motorcycle crashes.

\section{Road safety by age group and gender}

Based on data reported to FRSC, nearly $80 \%$ of fatalities are male.

Children pay a very heavy price on the roads. In 2016, 1855 children were reported killed in traffic, i.e., nearly $40 \%$ of all reported fatalities.

\section{Road safety by road type}

Roads are classified as federal, state and local government roads. Urban roads occur under all three categories. Nigeria does not yet have detailed information on road crashes by road category.

There is little safety provision for pedestrians except in some major cities and pedestrians are very much at risk when walking along the roads. 


\section{Economic costs of traffic crashes}

There is no estimation of the economic costs of road crashes.

\section{Recent trends in road user behaviour Speed}

The table below summarises the main speed limits in Nigeria. In 2014, inappropriate or excessive speed was the main contributing factor in $29 \%$ of fatal crashes.

As from June 2015, all commercial vehicles must have speed limiters installed. Communication started early in 2015 and the measure has been enforced since February 2017.

Table 29.1. Speed limits by road type, 2017

\begin{tabular}{|c|c|c|}
\hline & General speed limit Passenger cars & Comment \\
\hline Urban roads & $50 \mathrm{~km} / \mathrm{h}$ & $45 \mathrm{~km} / \mathrm{h}$ for tankers/trailers and vehicles with trailers \\
\hline Rural roads & $80 \mathrm{~km} / \mathrm{h}$ & $\begin{array}{l}80 \mathrm{~km} / \mathrm{h} \text { for taxis and buses } \\
60 \mathrm{~km} / \mathrm{h} \text { for trucks } \\
50 \mathrm{~km} / \mathrm{h} \text { for motorcycles, tankers/trailers; } \\
45 \mathrm{~km} / \mathrm{h} \text { for trucks with trailer }\end{array}$ \\
\hline Motorways & $100 \mathrm{~km} / \mathrm{h}$ & $\begin{array}{l}90 \mathrm{~km} / \mathrm{h} \text { for taxis and buses } \\
70 \mathrm{~km} / \mathrm{h} \text { for trucks } \\
60 \mathrm{~km} / \mathrm{h} \text { for tankers/trailers } \\
45 \mathrm{~km} / \mathrm{h} \text { for trucks with trailers }\end{array}$ \\
\hline
\end{tabular}

\section{Drink driving}

The maximum authorised blood alcohol content (BAC) is $0.5 \mathrm{~g} / \mathrm{l}$. Based on FRSC reports, around $1 \%$ of fatal crashes are due to drink driving. The Federal Road Safety Commission Act of 2007 was amended in 2016 to further strengthen the law on drink driving. The new law includes a maximum BAC of $0.2 \mathrm{~g} / \mathrm{l}$ for novice drivers (less than one year's driving experience) and $0.0 \mathrm{~g} / \mathrm{l}$ for commercial drivers. However this law has not yet been implemented.

Patrol teams can test any driver suspected of drink driving. In 2016, a major random breath testing survey was conducted in collaboration with the Beer Sectoral Group.

\section{Drugs and driving}

It is estimated that impaired driving due to the consumption of drugs was responsible for $0.5 \%$ of fatal crashes in 2016 .

\section{Distraction}

In Nigeria, it is forbidden to drive while using a mobile phone, including hands-free devices. In 2016, it was estimated that $0.3 \%$ of fatal crashes were caused by the use of a phone while driving.

\section{Sleepiness and fatigue}

In 2016, it was estimated that fatigue was the main contributing factor in $1.3 \%$ of fatal crashes.

\section{Seat belts and helmets}

Seat belt use has been compulsory in front seats and rear seats since 1997; however, enforcement regarding seat belts in front seats only started in 2002. Enforcement regarding 
the use of seat belts in rear seats has not yet started (as the FRSC Establishment Act 2007 is still being amended). Efforts so far have focused on communication and education.

According to FRSC $80 \%$ of front seat passengers and drivers wear a seat belt; while on rear seats less than $1 \%$ of passengers are buckled up.

Table 29.2. Seat belt wearing rate by car occupancy and road type $\%$

\begin{tabular}{lcc}
\hline & 2000 & 2014 \\
\hline $\begin{array}{c}\text { Front seats } \\
\text { General }\end{array}$ & $<5$ & 80 \\
$\begin{array}{c}\text { Rear seats } \\
\text { Adults }\end{array}$ & $<1$ & $<1$ \\
\hline
\end{tabular}

All riders of powered two-wheelers (PTWs) are required to wear safety helmets. The helmet-wearing rate by riders of PTWs is estimated at $60 \%$.

There are laws making the use of helmets compulsory for all cyclists in Nigeria.

\section{National road safety strategies and targets}

\section{Organisation of road safety}

The responsibility for road safety is vested in the FRSC, the lead agency established by the federal government. The agency is a paramilitary organisation, established in February 1988 and funded through budgetary allocation. A commission supervises the corps of officers and staff that undertake day-to-day activities. The functions of the FRSC include:

- preventing and minimising road traffic crashes

- clearing obstructions on the highways

- educating drivers, motorists and other road users on the proper use of the roads

- providing attention and care to victims of road traffic crashes

- conducting research into causes of crashes and putting results of such research into use

- enforcing traffic rules

- issuing drivers licences

- managing vehicle registration

- advising the federal and state governments, including the Federal Capital Territory Administration and relevant governmental agencies, on measures to improve road safety.

\section{Road safety strategy for $2016-20$}

The Nigerian Road Safety Strategy (NRSS 2016-20) has been approved by the Federal Executive Council and endorsed by the National Economic Council which includes all the State Executives (Governors) in the Federation. It is based on the United Nations Plan for the Decade of Action for Road Safety and its five strategic pillars.

The NRSS 2016-20 sets out the road safety vision, goals, targets of the country as well as the initiatives for Road Safety in Nigeria, based on a five-year action plan towards the achievement of the targets. 


\section{Targets}

The main target is based on the target of the United Nation's Decade of Action, to reduce by half the projected number of fatalities in 2020 in comparison to the 2010 level. As of June 2016, the reported number of road deaths was below the target. These relative good results are in part due to intervention patrols carried out by the FRSC on bench marked festivities such as New Year's Day, Valentine's Day, Easter patrol, Eid el Fitril, Eid el Kabir and August Meeting in the South-Eastern part of the country.

Performance towards these main goals is regularly monitored through key performance indicators, including: number of drivers trained, number of drivers arrested for traffic law violations; number of road safety audits conducted, number of drivers tested for alcohol, number of drivers above the speed limits, etc.

In July 2015, the United Nations Economic Commission for Africa (UNECA) conducted an evaluation on the implementation of the Decade of Action on Road Safety and concluded that Nigeria was among the top three performers among 23 African countries in accomplishing the activities of the African Road Safety Action Plan (UNECA, 2015).

\section{Recent safety measures (2014-17)}

\section{Speed Management}

- Introduction of speed limiting devices on all commercial vehicles from second quarter of 2016 with enforcement from 1 February 2017.

- Nationwide education programmes on speed and the importance of installing speed limiting devices in commercial vehicles.

\section{Road safety management}

- Efforts are ongoing to harmonise road traffic crash data records through the National Committee on Crash Information System (NACRIS). The first phase of the project has been completed with implementation soon to begin.

- Continuation of the World Bank's assistance programme providing manpower and operational equipment to conduct road safety assessments on six major corridors.

- The National Road Traffic Regulations, 2012, have been amended to National Road Traffic (Amendment) Regulation 2016. The Nigeria Highway Code has also been reviewed and approved for use.

- Continued inter-agency co-operation through the Nigerian Road Safety Partnership has led to the establishment of a road safety unit within the Nigeria Defence Academy where FRSC instructors run programmes for students on road safety.

- Amended laws to strengthen road safety, such as a BAC limit $(0.2 \mathrm{~g} / \mathrm{l})$ for novice drivers and a total ban $(0 \mathrm{~g} / \mathrm{l})$ for commercial drivers.

- Increased enforcement activities, including:

- Special nationwide patrol operations targeted at such specific issues as overloading, vehicle conditions and use of phones while driving.

* Operation Zero Tolerance patrol against drunk driving carried out during Christmas/ New Year and other festive periods.

* Increased presence of FRSC patrol vehicles and motorcycles on motorways.

- Continued engagement of the individual states on the setting up of the States Motor Vehicle Administration Agency. 


\section{Road users}

- Improved regulatory and enforcement capacity by the FRSC.

- Road safety education in primary and junior secondary schools, in co-operation with Total Nigeria Plc and Shell plc.

- Road safety education on the importance of seatbelt in the rear seats of passenger cars.

\section{Vehicles}

- Implementation of inspection bays to check the road worthiness of vehicles. Every vehicle must undergo a road worthiness test before its papers are renewed.

- Free safety checks for all vehicles. Defects are identified and brought to the attention of the owners for remedial action without the issuance of tickets. More than 140000 vehicles were checked in 2016.

- Computerised vehicle inspection centres have been introduced in some states of Nigeria to check the road worthiness of vehicles. More periodic technical inspection centres are being established.

- Revival of the committee on the "Implementation of ECOWAS axle load control and harmonisation protocol" using existing weigh bridges in the country to check overloading violations by heavy duty vehicles.

- Further clarification on importation and use of the prohibited right-hand drive vehicles.

\section{Infrastructure}

- FRSC developed National Guidelines for Road Safety Audits as an effective tool for improving safety on Nigerian roads

- Consultation with stakeholders from the Federal Ministry of Works and construction companies to identify major challenges such as road signs and construction site lighting.

\section{Post-crash measures}

- Establishment of an emergency call centre with nationwide coverage. A toll-free emergency number (122) was launched in 2012 for road users to request assistance in case of an emergency.

- Establishment of emergency ambulance points (called ZEBRA) along major corridors.

- Addition of more ambulances into the operations of the FRSC.

\section{Recent and ongoing research}

- Federal Road Safety Corps in conjunction with Aromophy Ventures Ltd (2016): "The Impact of Prosecution on Road Traffic Offenders by FRSC on Road Traffic Behaviour and Road Crash Reduction in Nigeria".

- Federal Road Safety Corps in conjunction with the International Centre for Alcohol Policies (2015): Survey on breath alcohol testing of drivers across the six geological zones in Nigeria.

- Federal Road Safety Corps (2015): National survey on tyres. 


\section{References}

UNECA (2015), Status of implementation of the African road safety plan, United Nations Economic Commission for Africa, Addis Ababa.

WHO (2015), Global Status Report on Road Safety 2015, World Health Organization, Geneva.

World Bank (2017), “GDP (constant US\$)”, World Development Indicators, http://databank.worldbank.org/ data/reports.aspx?source=world-development-indicators (accessed 23 February 2017).

\section{Websites}

- Federal Road Safety Corps: www.frsc.gou.ng (accessed 5 July 2017). 


\section{Chapter 30}

\section{Norway}

This chapter presents 2015 road safety data for Norway along with provisional data from 2016. It looks at trends in traffic and road safety from the years 1990 to 2015 and road user behaviour patterns with a special focus on the ageing population. Sections include data on speed, drink driving, drugs and driving, distracted driving, fatigue and seat belt usage. The chapter reviews Norway's road safety strategy and national targets to 2029 and the progress achieved thus far. It also provides details of all recently implemented safety measures and current and ongoing research.*

* All data stem from Public Roads Administration unless otherwise noted. For more information please contact: guro.ranes@vegvesen.no. 


\section{I} 15, Norway registered 117 road deaths, the lowest number of fatalities recorded since 1945 and a $20 \%$ decrease over 2014. This equates to a fatality rate of 2.3 per 100000 inhabitants, the lowest rate among IRTAD member countries for 2015. Provisional data indicate that there were 135 road deaths in 2016, a 15\% increase over 2015's exceptional figures, but still lower than 2014 level.

\section{Road safety data collection}

\section{Definitions applied in Norway}

- Road fatality: Person killed in a traffic crash or from injuries within 30 days of the crash.

- Seriously injured: Person suffering life threatening injuries, or injuries that lead to lasting injury, or other larger injuries that are not life-threatening.

- Slightly injured: Person with minor fractures and wounds not requiring a hospital stay.

Currently in Norway the Maximum Abbreviated Injury Scale of three or more (MAIS3+) is not used to classify serious injuries, but this will hopefully be the case in the future when such injury data is provided by hospitals.

\section{Data collection}

Crash data are collected by the police and consolidated at the national level by Statistics Norway and the Public Roads Administration.

Less severe crashes and injuries are often not reported to the police, and may therefore be under-represented in the figures. This concerns in particular light injuries and single bicycle crashes. At the moment injury data is collected by police, but in 2014 and 2016 the University Hospital in Oslo collected data for bicycle accidents and accidents with pedestrians.

\section{Most recent safety data}

\section{Road crashes in 2016 - provisional data}

Based on provisional data, there were 135 road deaths in 2016, representing an increase of more than $15 \%$ compared to 2015 , which was an exceptional year as it had the lowest number of road deaths on record since 1945. When compared to 2014 the number of fatalities in 2016 was reduced by $8 \%$.

\section{Road crashes in 2015}

In 2015, there were 117 road deaths in Norway, a decrease of more than $20 \%$ when compared to 2014 and the lowest number of road deaths since 1945. In particular, there were fewer fatalities during the first semester. However, the number of people killed in the 18-20 age group was the highest since 2010. The number of deaths among those aged 65 and above was about half of the number in 2014, with a particularly low number for the over-80 age group. 


\section{Trends in traffic and road safety (1990-2016) Traffic}

In 2015, around 44250 million vehicle-kilometres were registered on Norwegian public roads. Since 1990, vehicle-kilometres have increased by almost $60 \%$ on public roads. The number of registered vehicles increased by $66 \%$ for the same time period. In the last few years, there has been an increase in cyclists in the largest cities.

\section{Road safety}

The number of road deaths peaked in 1970 with 560 fatalities. The relatively low numbers of deaths in Norway are subject to annual fluctuations. However, the long-term trend shows a steady improvement in road safety. Between 2010 and 2015, the number of road deaths decreased by nearly $44 \%$.

In 2014, the Norwegian Institute of Transport Research investigated what could explain the decline in number of traffic fatalities and serious injuries between 2010 and 2012 (TØI-report 1299/2014). The decline observed during this period was larger than in any other period of the same duration since 1970. The study indicates that the two most important factors that have contributed to the decline in the number of fatalities and serious injuries is the increasing market penetration of various safety features on cars and the tendency, seen most clearly after 2006, for the mean speed of traffic to go down. Other factors that have contributed include a change in the age distribution of riders of large motorcycles (mean age has increased), a decline in the number of young drivers involved in accidents, a decline in the number of accidents involving children as pedestrians or cyclists, a decline in the number of accidents involving young moped riders, the construction of motorways and other roads with median barriers, and increased use of speed cameras.

\section{Rates}

Norway had a fatality rate of 2.9 deaths per 100000 inhabitants in 2014 and 2.3 in 2015. This rate, as well as the rate of deaths per 10000 registered vehicles are half of the rates of 2010.

\section{Analysis of seriously injured data}

In 2015, 668 persons were seriously injured in road traffic crashes, compared to 674 in 2014. In 2015, while few fatalities were recorded for pedestrians and cyclists, they accounted for a large share of those seriously injured.

Table 30.1. Road safety and traffic data

\begin{tabular}{|c|c|c|c|c|c|c|c|c|c|}
\hline & \multirow{2}{*}{1990} & \multirow{2}{*}{2000} & \multirow{2}{*}{2010} & \multirow{2}{*}{2014} & \multirow{2}{*}{2015} & \multicolumn{4}{|c|}{$2015 \%$ change from } \\
\hline & & & & & & 2014 & 2010 & 2000 & 1990 \\
\hline \multicolumn{10}{|l|}{ Reported safety data } \\
\hline Fatalities & 332 & 341 & 208 & 147 & 117 & -20.4 & -43.8 & -65.7 & -64.8 \\
\hline Injury crashes & 8801 & 8440 & 6360 & 4972 & 4595 & -7.6 & -27.8 & -45.6 & -47.8 \\
\hline Serious injuries & & & & 674 & 668 & -0.9 & & & \\
\hline Deaths per 100000 inhabitants & 7.8 & 7.6 & 4.3 & 2.9 & 2.3 & -21.3 & -47.1 & -70.3 & -71.1 \\
\hline Deaths per 10000 registered vehicles & 1.4 & 1.2 & 0.6 & 0.4 & 0.3 & -22.1 & -49.5 & -75.5 & -78.8 \\
\hline Deaths per billion vehicle kilometres & 12.0 & 10.5 & 4.9 & 3.4 & 2.6 & -21.3 & -45.9 & -74.8 & -77.9 \\
\hline \multicolumn{10}{|l|}{ Traffic data } \\
\hline Registered vehicles ${ }^{1}$ (thousands) & 2343 & 2777 & 3495 & 3810 & 3894 & 2.2 & 11.4 & 40.2 & 66.2 \\
\hline Vehicle-kilometres (millions) & 27755 & 32547 & 42561 & 43738 & 44250 & 1.2 & 4.0 & 36.0 & 59.4 \\
\hline Registered vehicles per 1000 inhabitants & 553 & 620 & 719 & 746 & 754 & 1.1 & 4.8 & 21.6 & 36.2 \\
\hline
\end{tabular}

1. With mopeds. 
Figure 30.1. Road Safety, traffic and GDP trends index $1990=100$

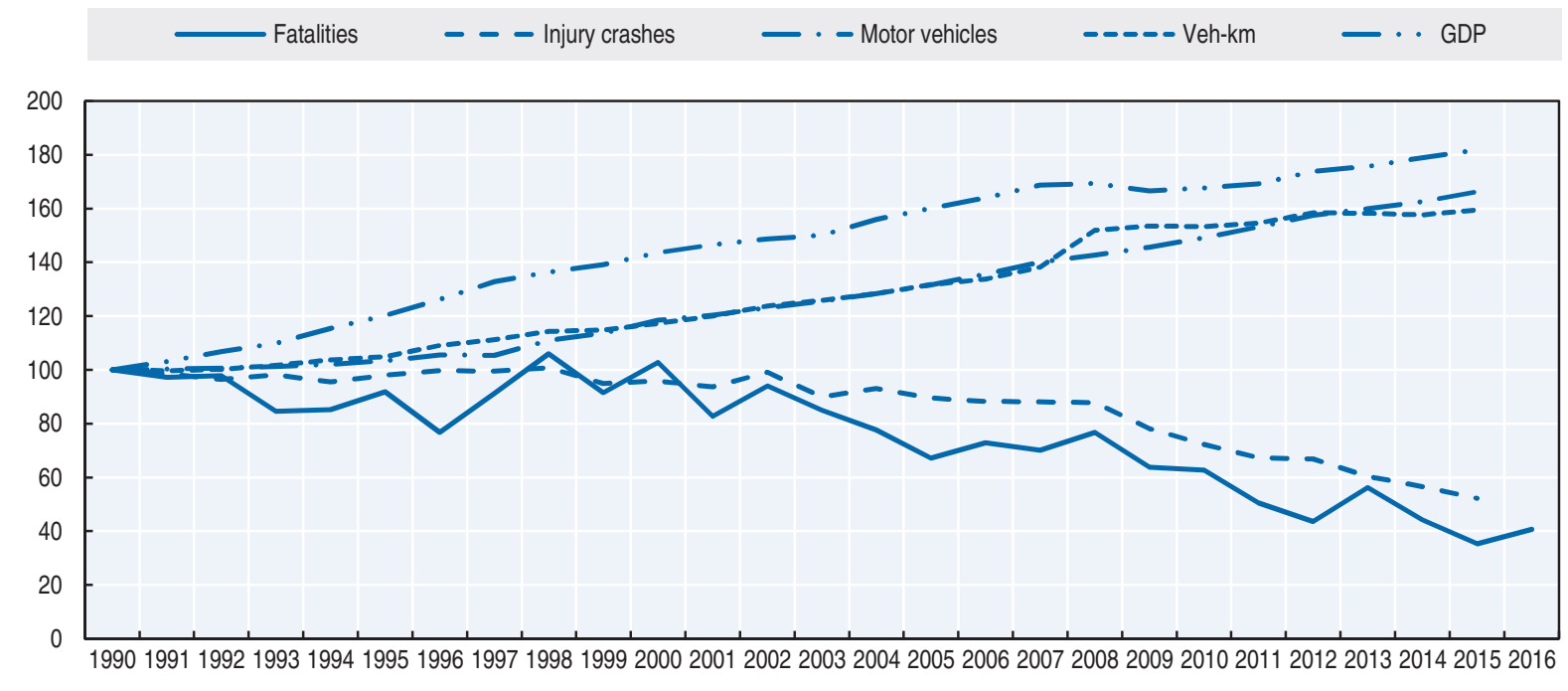

Source: World Bank (2017) (GDP; constant prices).

\section{Road safety by user group}

Since 2000, road safety improvements have benefited pedestrians and car occupants the most, while there has been less progress for cyclists and motorcyclists.

In 2015, all user groups benefited from safety improvements, except motorcyclists. The number of killed pedestrians decreased by a third, while the reduction among car occupants was less marked. The number of car drivers who lost their lives was reduced from 63 in 2014 to 58 in 2015. Their share of all fatalities, however, increased from 33\% in 2014 to $49 \%$ in 2015.

In 2014, 12 cyclists were killed, a marked increase compared to previous years. However, the number of cyclists killed dropped to five in 2015 and then increased to 12 in 2016 (preliminary number). Nevertheless, an overall increase in the number of seriously injured cyclists was observed, from 54 in 2010 to 87 in 2015 and 85 in 2016 (preliminary data).

Table 30.2. Road fatalities by road user group

\begin{tabular}{|c|c|c|c|c|c|c|c|c|c|}
\hline & \multirow{2}{*}{1990} & \multirow{2}{*}{2000} & \multirow{2}{*}{2010} & \multirow{2}{*}{2014} & \multirow{2}{*}{2015} & \multicolumn{4}{|c|}{$2015 \%$ change from } \\
\hline & & & & & & 2014 & 2010 & 2000 & 1990 \\
\hline Pedestrians & 55 & 47 & 24 & 18 & 12 & -33.3 & -50.0 & -74.5 & -78.2 \\
\hline Cyclists & 17 & 13 & 5 & 12 & 5 & -58.3 & 0.0 & -61.5 & -70.6 \\
\hline Moped riders & 14 & 6 & 0 & 2 & 1 & -50.0 & $\mathrm{Na}$ & -83.3 & -92.9 \\
\hline Motorcyclists & 25 & 40 & 26 & 20 & 20 & 0.0 & -23.1 & -50.0 & -20.0 \\
\hline Car occupants & 214 & 225 & 125 & 72 & 67 & -6.9 & -46.4 & -70.2 & -68.7 \\
\hline Others & 7 & 10 & 28 & 23 & 12 & -47.8 & -57.1 & 20.0 & 71.4 \\
\hline Total & 332 & 341 & 208 & 147 & 117 & -20.4 & -43.8 & -65.7 & -64.8 \\
\hline
\end{tabular}


Figure 30.2. Road fatalities by road user group in percentage of total, 2015

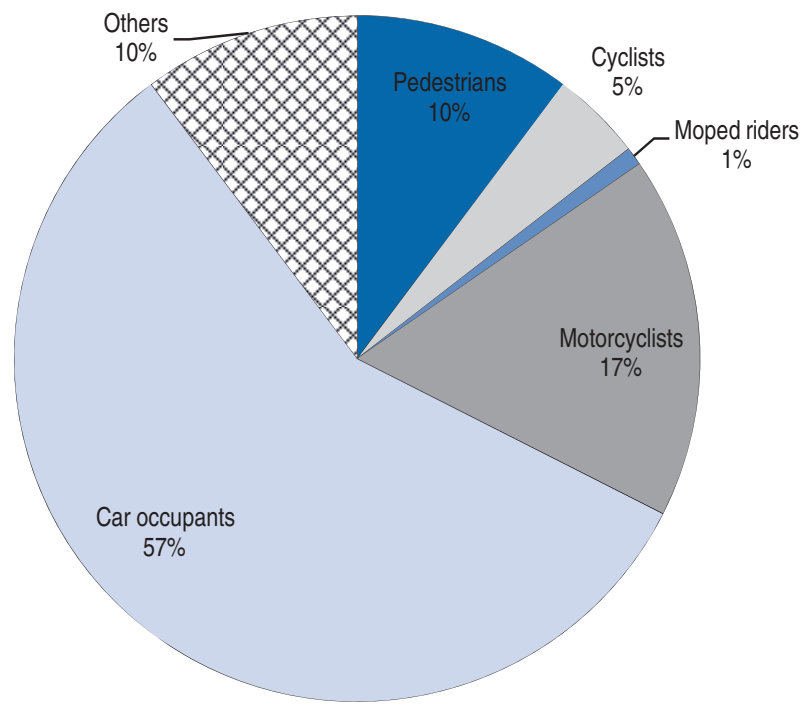

\section{Road safety by age group}

Since 1990, safety improvements have benefited all age groups, in particular children and young people.

In 2015, no children under 6 were killed in traffic, and only four young people under 18 lost their lives, compared to 9 in 2014. At the same time, in 2015 the fatality numbers as well as fatality rate increased significantly for the 18 - 20 year old group following stable year-on-year improvements since 2008.

In the 65+ age group, 24 persons were killed in road traffic crashes, accounting for $20 \%$ of all fatal crashes in 2015 . The corresponding share in 2014 was $32 \%$. The older population had in 2014 a fatality rate twice that of the average, but this rate decreased twofold in 2015.

Table 30.3. Road fatalities by age group

\begin{tabular}{|c|c|c|c|c|c|c|c|c|c|}
\hline \multirow{2}{*}{ Age } & \multirow{2}{*}{1990} & \multirow{2}{*}{2000} & \multirow{2}{*}{2010} & \multirow{2}{*}{2014} & \multirow{2}{*}{2015} & \multicolumn{4}{|c|}{$2015 \%$ change from } \\
\hline & & & & & & 2014 & 2010 & 2000 & 1990 \\
\hline $0-14$ & 18 & 18 & 4 & 4 & 2 & \multirow{2}{*}{\multicolumn{3}{|c|}{$\begin{array}{l}\text { Figures too small for meaningful } \\
\text { comparisons. }\end{array}$}} & -88.9 \\
\hline $15-17$ & 23 & 20 & 8 & 4 & 2 & & & & -91.3 \\
\hline $18-20$ & 49 & 33 & 23 & 9 & 23 & 155.6 & 0.0 & -30.3 & -53.1 \\
\hline $21-24$ & 34 & 36 & 19 & 9 & 8 & -11.1 & -57.9 & -77.8 & -76.5 \\
\hline $25-64$ & 146 & 165 & 115 & 73 & 58 & -20.5 & -49.6 & -64.8 & -60.3 \\
\hline $65-74$ & & & 14 & 26 & 14 & -46.2 & -17.6 & & \\
\hline $75-84$ & & & 16 & 14 & 7 & -50.0 & -53.3 & & \\
\hline$\geq 85$ & & & 9 & 7 & 3 & -57.1 & -70.0 & & \\
\hline Total & 332 & 341 & 208 & 147 & 117 & -20.4 & -43.8 & -65.7 & -64.8 \\
\hline
\end{tabular}


Figure 30.3. Road fatality rates by age group

Deaths per 100000 inhabitants in a given age group, 1990-2015

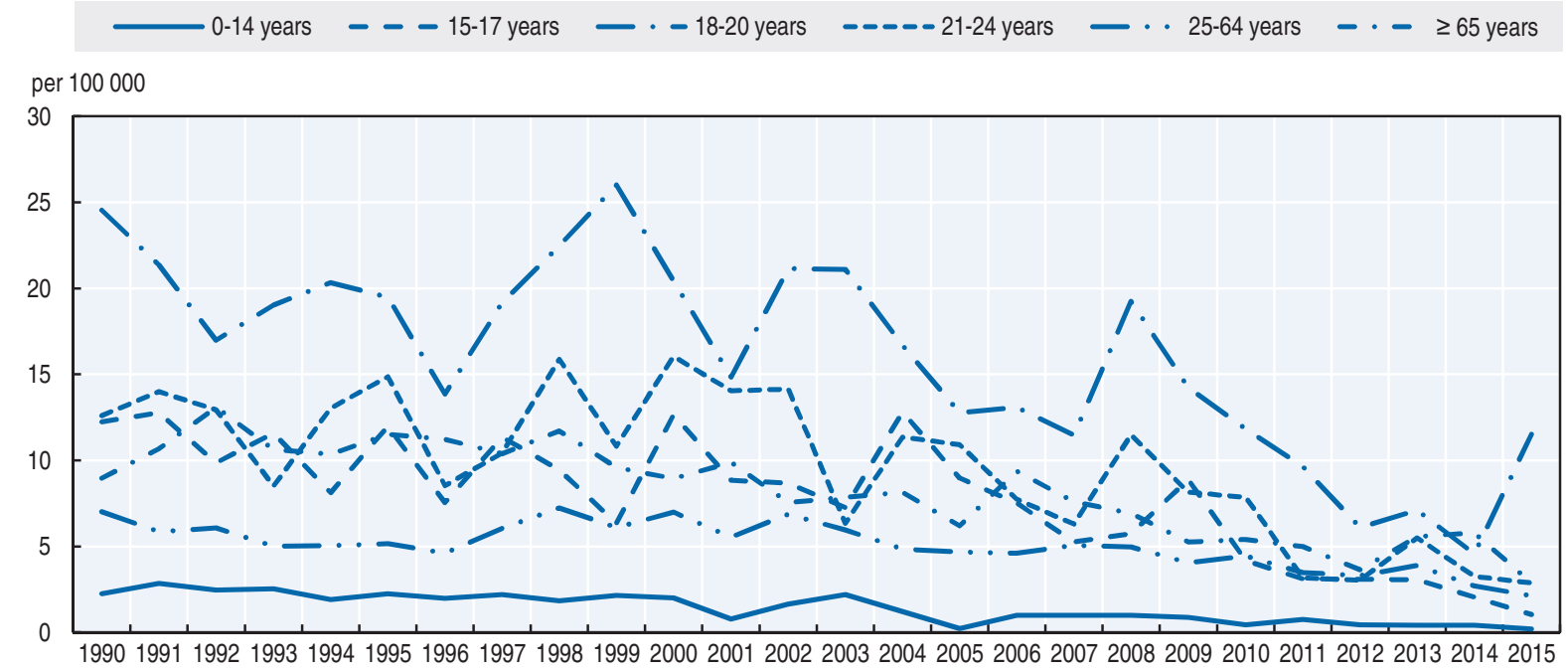

\section{Box 30.1. Road safety for an ageing population}

According to Statistics Norway, the share of people aged 75 and above will increase from $7 \%$ in 2015 to $11.5 \%$ in 2040 . This raises a number of safety challenges, as older people are more fragile and have a much higher risk in traffic especially as drivers or pedestrians.

Several steps are being taken in co-operation with a wide range of stakeholders in order to ensure safer mobility for an ageing population including a review of the licensing renewal process.

Figure 30.4. Road fatality rates in the $65+$ age groups Deaths per 100000 inhabitants in a given age group, 2004-15

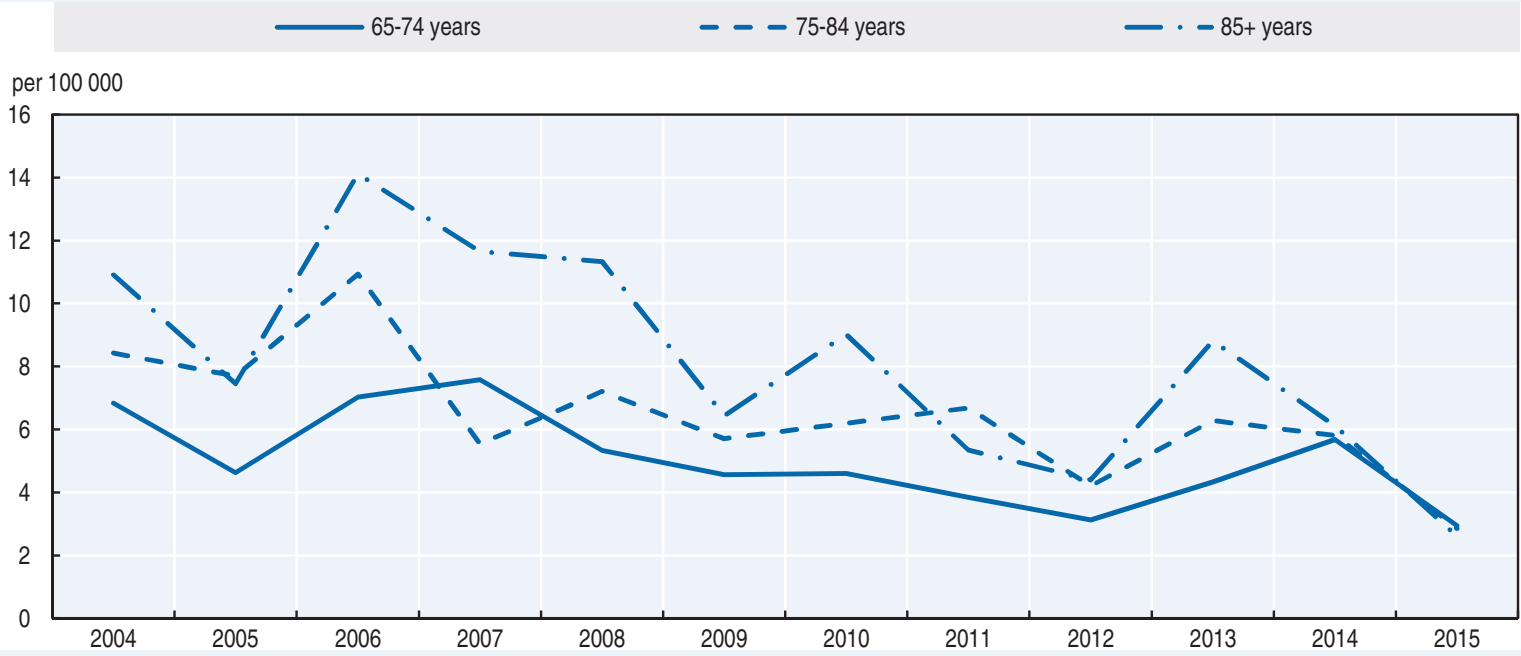




\section{Road safety by road type}

In 2015 , approximately $85 \%$ of road fatalities occurred outside densely populated areas. Of these, $52 \%$ were killed in head-on crashes or in run-off-road crashes.

During the last five years the number of killed and severely injured in head-on collisions and single vehicle crashes has decreased.

\section{Economic costs of traffic crashes}

Traffic crashes represent a significant cost for Norwegian society, estimated, in 2012, at around EUR 1.93 billion (excluding property damage costs). Costs are calculated on a willingness-to-pay approach.

\section{Recent trends in road user behaviour Speed}

Studies in Norway show that excessive speed or high speeds incompatible with road conditions like snow, ice, fog or rain are an important element in fatal crashes and their consequences.

The average speed on Norwegian roads with an $80 \mathrm{~km} / \mathrm{h}$ speed limit has decreased by about $1 \mathrm{~km} / \mathrm{h}$ during the last five years. This is partly due to an increase in the share of older drivers and the fact that older drivers drive more slowly than younger drivers. Even though the changed age composition of the driver population explains part of the speed decrease, the decrease is also due to other factors, including higher traffic volume and decreased prevalence of large speeding violations (TøI, 2016).

The table below summarises the main speed limits in Norway.

Table 30.4. Passenger car speed limits by road type, 2016

\begin{tabular}{lcc}
\hline & General speed limit & Comments \\
\hline Urban roads & $50 \mathrm{~km} / \mathrm{h}$ & Residential streets often limited to $30 \mathrm{~km} / \mathrm{h}$ \\
Rural roads & $80 \mathrm{~km} / \mathrm{h}$ & \\
Motorways & $90,100,110 \mathrm{~km} / \mathrm{h}$ & \\
\hline
\end{tabular}

\section{Drink driving}

The legal maximum blood alcohol content (BAC) is $0.2 \mathrm{~g} / \mathrm{l}$. The number of drivers impaired due to alcohol seems to be fairly stable or slightly reduced. In $2015,22 \%$ of the fatal crashes were due to drunk drivers.

\section{Drugs and driving}

The number of impaired drivers due to drugs seems to be fairly stable.

\section{Distraction}

In Norway, the law stipulates that mobile phones must be correctly attached to the instrument panel in the vehicle, as close as possible to the driver. Hands-free devices can be used. There are no good estimations on the number of fatal crashes due to the use of mobile phones, but research shows that this is a factor to be watched carefully. 


\section{Sleepiness and fatigue}

In-depth studies show that fatigue and sleepiness were the cause of $10 \%$ of all fatal crashes in Norway in 2015. Some of these crashes are also associated with illness or the consumption of alcohol or drugs.

\section{Seat belts and helmets}

Seat belt use has been compulsory in front seats of light vehicles since 1975 and in rear seats since 1985. Child restraints are compulsory for children under $135 \mathrm{~cm}$ in height. For children over $135 \mathrm{~cm}$ a child restraint should be used if available. In Norway it is recommended that children under the age of four should be seated facing backward.

The use of seat belts by drivers of light vehicles increased sharply between 2006 and 2013 as a result of enforcement and awareness campaigns. The seat belt wearing rate among drivers now stabilises at around $96-97 \%$. There is no monitoring of seat belt use in rear seats, but it is estimated to be 7-8 percentage points lower. For children aged 1-3, the use of dedicated rear facing child restraints increased from $20 \%$ in 2010 to $49 \%$ in 2015, showing wider scope for improvement. The use of seat belts by heavy vehicle drivers increased from 53\% in 2010 to $87 \%$ in 2015.

An analysis of fatal crashes in 2015 estimates that $37 \%$ of car occupants killed were not wearing a seat belt.

Table 30.5. Seat belt wearing rate by car occupancy and road type

\begin{tabular}{|c|c|c|c|c|}
\hline & 2000 & 2011 & 2015 & 2016 \\
\hline \multicolumn{5}{|l|}{ Front seat } \\
\hline Driver & & & 97 & \\
\hline Passenger & 88 & 95 & & \\
\hline Urban roads (driver) & 78 & 94 & 95 & 96 \\
\hline Rural roads (driver) & 92 & 96 & 97 & 98 \\
\hline Motorways (driver) & 91 & 96 & 97 & 98 \\
\hline \multicolumn{5}{|l|}{ Rear seats } \\
\hline General (rear seat passengers) & 84 & Not monitored & & \\
\hline Children (use of child restraint) (children aged 1 to 3 ) & & 20 (in 2010) & 49 & \\
\hline
\end{tabular}

All riders of powered two-wheelers are required to wear helmets. The helmet-wearing rate is close to $100 \%$.

There is no mandatory helmet-use law for cyclists. Helmet use by cyclists over the age of 12 in 2015 was 56\%. In 2015, 3 out of the 10 cyclists killed on the roads were not wearing a helmet.

\section{National road safety strategies and targets \\ Organisation of road safety}

Traffic safety policy is co-ordinated by the Norwegian Public Roads Administration (NPRA). In addition to the NPRA, the police, the public health and education administrations, together with leading non-governmental organisations, are the main national stakeholders. At regional and local levels, counties and municipalities play a very important role. The Norwegian road safety policy relies on this broad and collaborative approach, a common and shared strategy and co-ordination among all stakeholders. 


\section{Road safety strategy for 2018-29}

Norway's parliament adopted Vision Zero in 2001. The Norwegian Vision Zero involves all modes of transport. The main focus is to reduce crashes that can lead to fatalities and serious injuries. The highest priority is given to the reduction of head-on crashes, singlevehicle crashes and collisions with cyclists and pedestrians. Special attention is also paid to high-risk road users, such as young drivers, elderly road users and motorcyclists.

The coming National Transport Plan will cover the period 2018-29 and will include a new target of no more than 350 killed and seriously injured by 2030. The National Plan of Action for Road Traffic safety is published every four years and will soon be published for next period (2018-21). The current plan covers the period 2014-17 and is embedded into the National Transport Plan (NTP) 2014-24.

\section{Road safety targets}

The current plan includes a target of no more than 500 killed and seriously injured by 2024. The forthcoming plan includes a target of no more than 350 killed and seriously injured by 2030 .

In 2015, a research programme Better Safety in Traffic (BEST) followed up on preliminary estimates of the potential for reducing the number of killed or seriously injured road users (TØI, 2015). The results show that it is possible to reduce the number of traffic fatalities in Norway by more than $50 \%$. The number of seriously injured road users could be reduced by about $40 \%$. These reductions are possible by implementing all currently used road safety measures to the maximum conceivable extent. If measures based on new technology which are ready for large scale implementation are used in addition to the current road safety measures, fatalities could be reduced by about $60 \%$ and serious injuries by about $45 \%$.

Figure 30.5. Trends in road fatalities towards national target

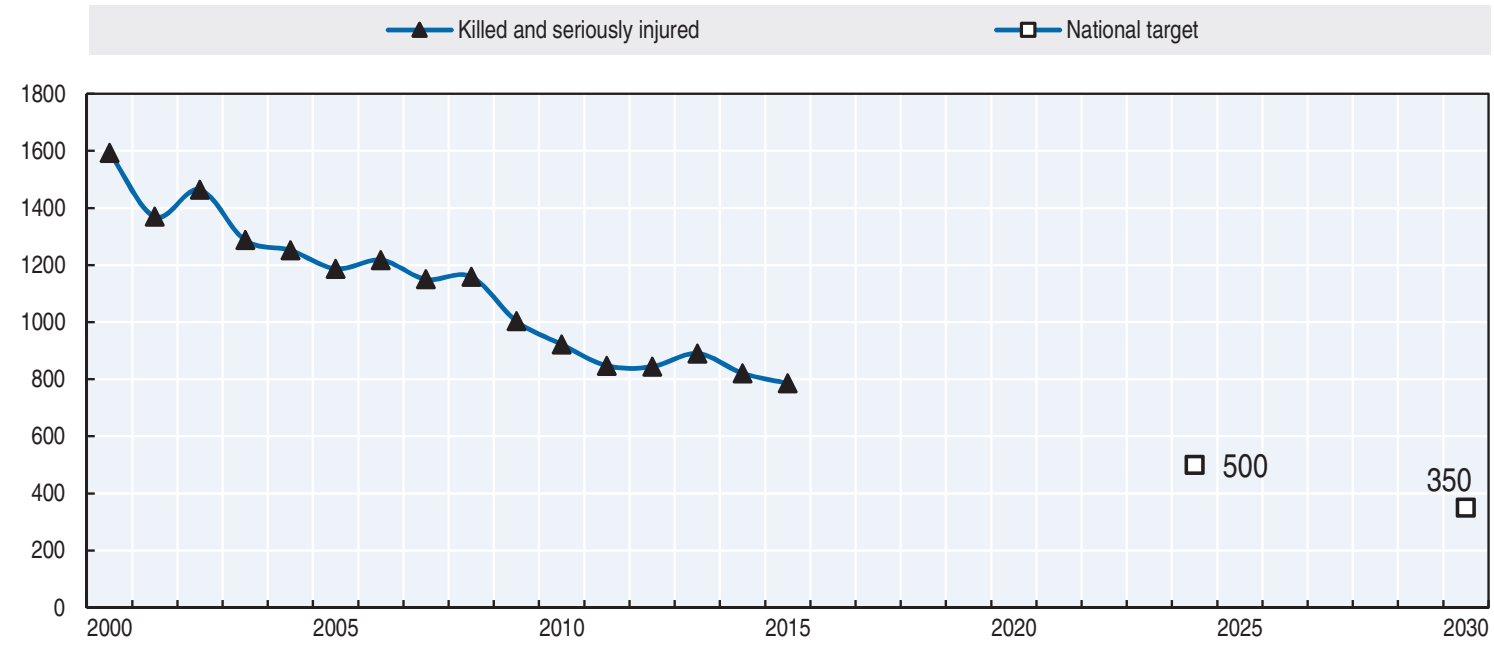

Recent safety measures (2014-17)

\section{Road safety campaigns}

- The speed campaign has been updated with a focus on young drivers. The campaign on road sharing (cyclists and cars) is ongoing and the seat belt campaign has been updated to include wearing seat belts in buses. 


\section{Vehicles}

- The NPRA uses a camera system for number plate recognition as a tool to carry out inspection tasks. The system is one of many measures adopted in order to achieve inspection objectives more efficiently. In 2015, the NPRA started a pilot project aiming to enforce compliance with the new requirement of an electronic toll payment tag for business vehicles. The requirement applies to both Norwegian and foreign vehicles on Norwegian roads.

\section{Recent and ongoing research}

- The NPRA is conducting a 5-year (2013-17) research programme Better Safety in Traffic (BEST). The purpose of the programme is to assess the potential for reducing the numbers of fatalities and seriously injuries and identify areas where the greatest returns can be made in the coming years. In 2015 and 2016, there was specific research and analysis on all cyclist and pedestrians accidents registered by the emergency centre of Oslo.

- The Institute of Transport Economics published, in 2017, a compendium of road safety measures, which summarises state-of-the-art knowledge on the effects of 34 types of road safety measures on fatalities and injuries (TøI report 1556/2017). www.toi.no/getfile.php/ Publikasjoner/T\%C3\%981\%20rapporter/2017/1556-2017/1556-2017-\%20sum.pdf (accessed 3 July 2017).

- The Institute of Transport Economics published, in 2016, a study on speed and age which analyses the extent to which the increased share of older drivers has contributed to the recent decrease in average speeds (TØI report 1462/2016). www.toi.no/getfile.php/Publikasjoner/ T\%C3\%981\%20rapporter/2016/1462-2016/1462-2016-sum.pdf (accessed 3 July 2017).

- The Institute of Transport Economics published, in 2016, a study entitled "Safety in numbers: Uncovering the mechanisms of interplay in urban transport", which assessed the impact on safety of an increased number of cyclists on the road (TØI report 1466/20164).

- See more TØI reports at: www.toi.no (accessed 3 July 2017).

\section{References}

TOI (2015), "The potential for reducing the number of killed or seriously injured road users: Preliminary estimates", ТØI Report 1417/2015, Report with summary in English, www.toi.no/getfile.php/ Publikasjoner/T\%C3\%98I\%20rapporter/2015/1417-2015/1417-2015-sum.pdf (accessed 3 July 2017).

TØI (2016), "Speed and age: Changes in speed level on Norwegian roads with $80 \mathrm{~km} / \mathrm{h}$ limit", TOI report 1462/2016 TOI Institute of Transport Economics, Oslo, www.toi.no/getfile.php/Publikasjoner/T\%C3 \%98I\%20rapporter/2016/1462-2016/1462-2016-sum.pdf (accessed 3 July 2017).

World Bank (2017), “GDP (constant US\$)”, World Development Indicators, http://databank.worldbank.org/ data/reports.aspx? source=world-development-indicators (accessed 23 February 2017).

\section{Websites}

- Public Road Administration: www.veguesen.no, National Road Safety Plan: www.veguesen.no/en/Traffic/ Road+safety/Road+safety (accessed 3 July 2017).

- TØI - Research Institute for Transport Economics: www.toi.no (accessed 3 July 2017).

- International Research Institute: www.iris.no (accessed 3 July 2017).

- SINTEF: www.sintef.no (accessed 3 July 2017).

- Norwegian Institute of Public Health: www.fhi.no (accessed 3 July 2017).

- COWI: www.cowi.no (accessed 3 July 2017). 


\section{Chapter 31}

\section{Poland}

This chapter presents 2015 road safety data for Poland along with provisional data from 2016. It looks at trends in traffic and road safety from the years 1990 to 2015 and road user behaviour patterns with a focus on the ageing population. Sections include data on speed, drink driving, drugs and driving, distracted driving, fatigue and seat belt usage. The chapter reviews Poland's road safety strategy and national targets to 2020 and the progress achieved thus far. It also provides details of all recently implemented safety measures and current and ongoing research.*

* All data stem from the Motor Transport Institute and IRTAD unless otherwise noted. For more information, please contact: justyna.wacowska-slezak@its.waw.pl. 
$\mathrm{P}$ of $8.2 \%$ compared to 2014 . This is the fourth consecutive year of decreases, with all road user groups benefitting except cyclists. A significant reduction of $18 \%$ in the number of pedestrian fatalities was recorded although they continue to account for a large proportion of total road deaths (31\%), well above the EU average. The fatality rate in 2015 was 7.7 per 100000 inhabitants. Provisional data from 2016 indicate a levelling off in the number of road deaths, with 8 more estimated fatalities than in 2015.

\section{Road safety data collection}

\section{Definitions applied in Poland}

- Road fatality: Death caused by a road crash within 30 days of the crash.

- Seriously injured: A person who sustains a serious disability, an incurable disease or a chronic life threatening disease, a permanent mental disorder, complete or substantial permanent incapacity to work in their current occupation, or permanent or substantial scarring or disfiguration of the body. The definition also includes persons who suffer other injuries that incapacitate them or cause health problems for longer than seven days.

- Slightly injured: Person who experiences a loss of health at a lesser level than in the case of serious injuries and that continues for less than seven days.

- Injury crash: Crash resulting in at least one injured or killed person.

Poland does not yet rate serious injuries as having a score of three or more on the Maximum Abbreviated Injury Scale (MAIS3+). However, as the International Road Traffic and Accident Database (IRTAD) and the European Commission recommend the system, MAIS3+ are progressively been estimated. Following agreements between the National Road Safety Council, the Ministry of Infrastructure and Development and the Ministry of Health, the National Institute of Public Health is in charge of introducing MAIS 3+, starting with the conversion of the International Classification of Diseases (ICD10) codes into Abbreviated Injury Scale codes on the basis of hospital discharge data. This conversion process started in 2015 based on the mapping table developed by the Association for the Advancement of Automotive Medicine (AAAM) and provided by the European Commission. MAIS 3+ data are not yet published.

A pilot conversion was undertaken and showed that the results are not reliable and are subject to further verification due to difficulties in the comparability of the AAAM tables and ICD-10 scale used in Poland. Many hospital records were not considered in the pilot conversion process since they lacked information about the cause of the hospital admission or the hospitals did not provide the patient documentation.

\section{Data collection}

The basic source of road crash data is the police database, which was set up in 1975 under the responsibility of the police's Department of Road Traffic.

Information is gathered by police officers according to categories included in the Road Accident Card (such as the description of the crash site, circumstances of the crash, 
behaviour of participants, type of injuries, etc.). Guidelines and definitions are described in the Head Chief of Police Regulation No. 123 of 31 May 2012.

In 2012, the Motor Transport Institute reviewed the police crash database and compared data from the years 2008-10 with public statistics from national health services and the national statistics office. The result was that the number of people killed in road crashes could be 3\%-25\% higher than official police data. This pilot study showed the need for further investigation.

\section{Most recent safety data}

\section{Road crashes in 2016 - provisional data}

Based on provisional data, it is estimated that in 2016, the number of those killed on the roads has stagnated at 2015 levels, with 2946 road fatalities (with a minor increase of 0.27\%). This follows the significant 8.2\% decrease recorded in 2015 when compared to 2014.

The number of injury crashes, as well as injured persons increased for the same time period by almost $2 \%$.

\section{Road crashes in 2015}

In 2015, 2938 people were killed on the road, a decrease of $8.2 \%$ compared to 2014 . The number of injury crashes decreased by $5.7 \%$.

The improvements concerned mostly pedestrians (-18\%), motorcyclists $(-13.4 \%)$ and moped riders (-7.1\%). However, the number of fatalities among cyclists increased by almost $5 \%$ during the same time period.

\section{Trends in traffic and road safety (1990-2016) \\ Traffic}

Since 1990, the number of motorised vehicles has multiplied by more than 2.5. In recent years, the increase in the number of motor vehicles has stabilised at about $3 \%$ annually, after a more rigorous increase in the 1990s and 2000s, and a slight drop in the number of vehicles in 2009 compared to 2008 , following the economic crisis.

\section{Road safety}

\section{Crashes and casualties}

A peak in the number of fatalities was reached in 1991, with 7901 deaths. In recent years (2000-15) the upward trend has broken, and compared to 1990, the number of fatalities has declined by nearly $60 \%$ and injury crashes by $35 \%$.

Since 1991, the following legislation and policies have been implemented in Poland:

- compulsory seat belt wearing for all car occupants

- appointment of National Road Safety Council

- national Road Safety Programme GAMBIT

- demerit point system

- compulsory use of child restraints

- severe penalties for drunk driving

- speed enforcement (including automatic speed enforcement)

- increased severity of penalties for speeding 
- $50 \mathrm{~km} / \mathrm{h}$ speed limit in built-up areas

- daytime running lights

- changes in the driver education system

- implementation of a new law for cyclists

- implementation of the European Union (EU) directive on road safety management

- development of the National Road Safety Programme 2013-20.

Rates

In 2015, Poland had a fatality rate, expressed in terms of deaths per 100000 inhabitants, of 7.7. The fatality rate has been constantly decreasing since the 1990s and was reduced more than two-fold between 2000 and 2015.

Fatalities per 10000 vehicles have also decreased noticeably from 4.5 in 2000 to 1.1 in 2015.

Table 31.1. Road safety and traffic data

\begin{tabular}{|c|c|c|c|c|c|c|c|c|c|}
\hline & \multirow{2}{*}{1990} & \multirow{2}{*}{2000} & \multirow{2}{*}{2010} & \multirow{2}{*}{2014} & \multirow{2}{*}{2015} & \multicolumn{4}{|c|}{$2015 \%$ change from } \\
\hline & & & & & & 2014 & 2010 & 2000 & 1990 \\
\hline \multicolumn{10}{|l|}{ Reported safety data } \\
\hline Fatalities & 7333 & 6294 & 3908 & 3202 & 2938 & -8.2 & -24.8 & -53.3 & -59.9 \\
\hline Injury crashes & 50532 & 57331 & 38832 & 34970 & 32967 & -5.7 & -15.1 & -42.5 & -34.8 \\
\hline \multicolumn{10}{|l|}{ Serious injuries (MAIS3+) } \\
\hline Deaths per 100000 inhabitants & 19.3 & 16.4 & 10.2 & 8.4 & 7.7 & -8.2 & -24.5 & -53.0 & -59.9 \\
\hline Deaths per 10000 registered vehicles & 8.1 & 4.5 & 1.8 & 1.3 & 1.1 & -11.4 & -36.4 & -74.8 & -86.1 \\
\hline \multicolumn{10}{|l|}{ Deaths per billion vehicle kilometres } \\
\hline \multicolumn{10}{|l|}{ Traffic data } \\
\hline Registered vehicles ${ }^{1}$ (thousands) & 9041 & 14106 & 22115 & 25255 & 26150 & 3.5 & 18.2 & 85.4 & 189.2 \\
\hline \multicolumn{10}{|l|}{ Vehicle-kilometres (millions) } \\
\hline Registered vehicles per 1000 inhabitants & 238 & 369 & 579 & 664 & 688 & 3.6 & 18.7 & 86.6 & 189.5 \\
\hline
\end{tabular}

1. Registered vehicles excluding mopeds.

StatLink AाISL $h$ ttp://dx.doi.org/10.1787/888933580783

Figure 31.1. Road safety, traffic and GDP trends index $1990=100$

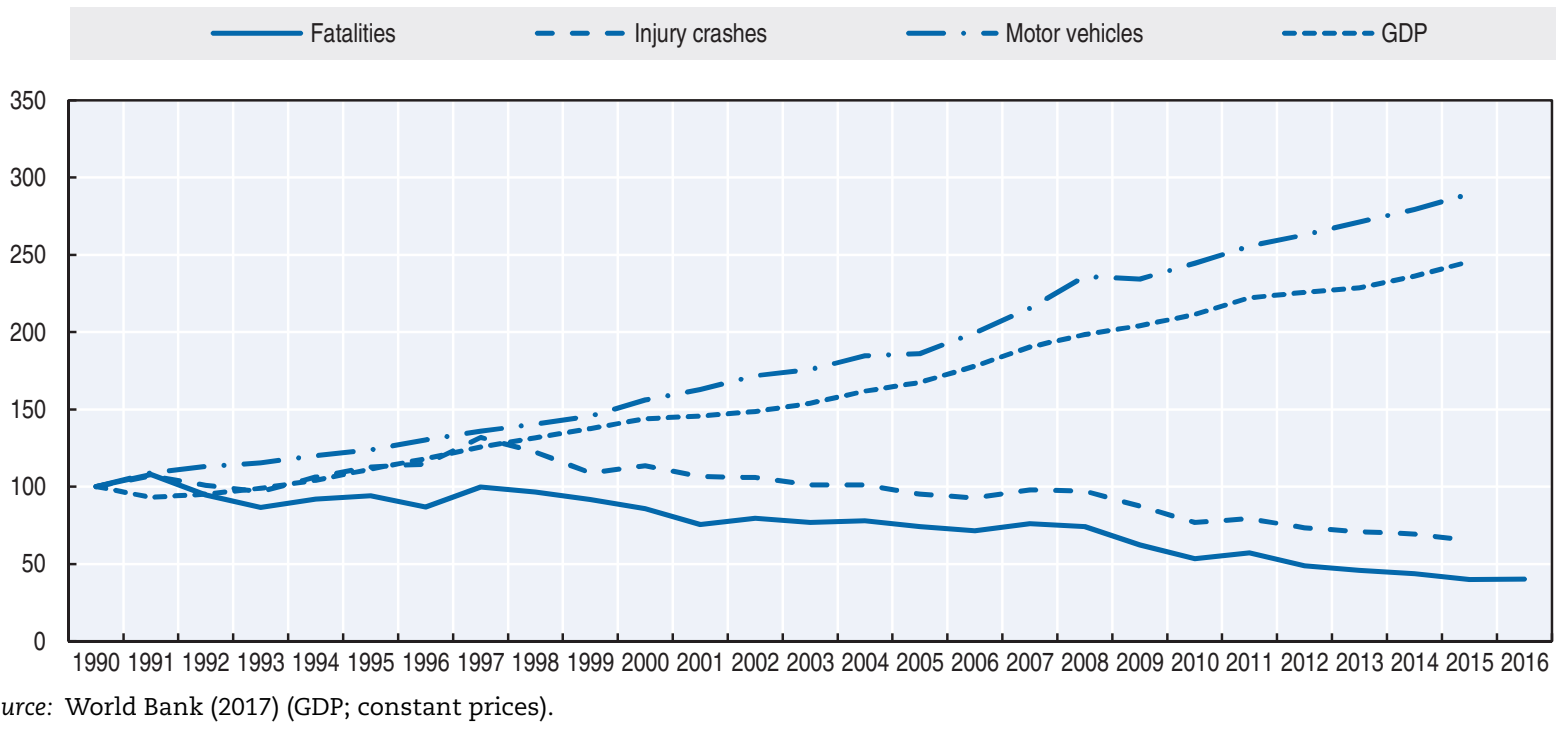




\section{Road safety by user group}

Since 2000, all user groups except motorcyclists have benefited from a decrease in the number of fatalities. The number of motorcyclists killed has increased by nearly $16 \%$.

There was a sharp decrease in the number of killed motorcyclists and moped riders between 1990's and 2000's, followed by the consecutive year-to-year increases until 2011, however the situation started improving from 2012 again. The growth in fatalities was due to a significant increase in the number of motorcycles and their high presence on roads. Since then a number of social awareness campaigns have been introduced as well as new regulations (based on EU directives). There is a similar increase in the popularity of cycling. Half of the road fatalities in Poland are vulnerable road users. Pedestrians make up $31 \%$ of all fatalities (in the European Union the share is $21 \%$ ).

In 2015, the most significant reduction in the number of fatalities was observed among pedestrians $(-18 \%)$. The number of motorcyclists and moped riders killed decreased by more than $13 \%$ and $7 \%$ respectively while the number of cyclists killed increased by almost 5\%.

Table 31.2. Road fatalities by road user group

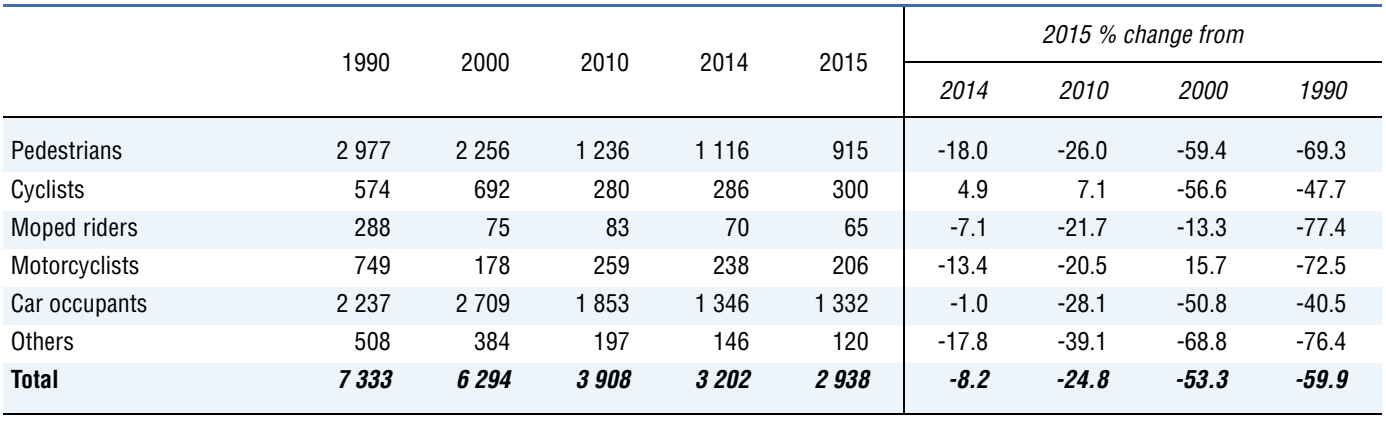

Figure 31.2. Road fatalities by road user group in percentage of total, 2015

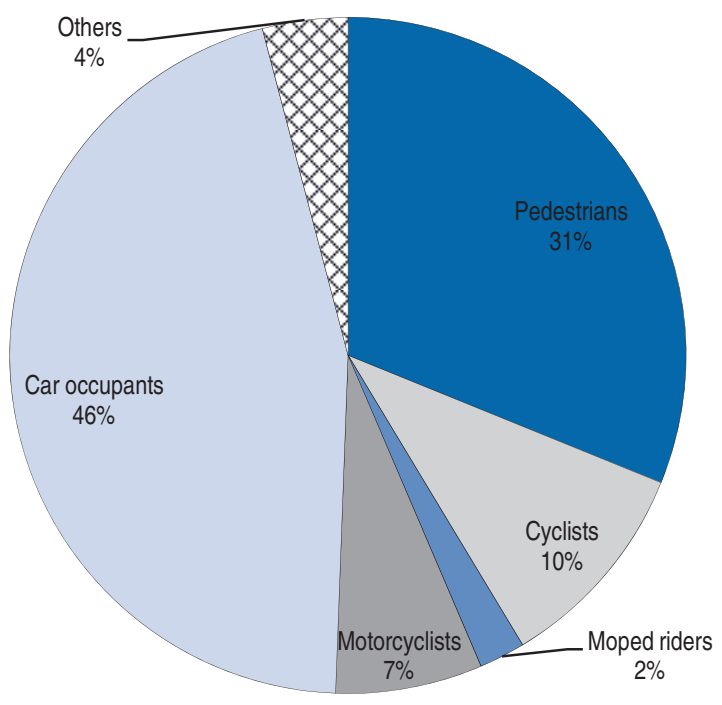




\section{Road safety by age group}

Since 1990, the reduction in fatalities has benefited all age groups. The highest reduction concerns the youngest age groups (0-14), for which fatalities fell from 471 in 1990, to 62 in 2015, a decrease of nearly $87 \%$.

On the other hand, fatalities among the over-65s have decreased at a much lower pace. This is in part due to demographic changes and the ageing of the population. This group has the second highest fatality risk, after young people aged 18-24. They are especially vulnerable as pedestrians, particularly persons aged 85 and above. For this latter group safety has decreased compared to 2010 and 2014, by almost $41 \%$ and $9 \%$, respectively.

Young people aged 18-24 have a fatality risk nearly twice as high as the general population.

Table 31.3. Road fatalities by age group

\begin{tabular}{|c|c|c|c|c|c|c|c|c|c|}
\hline \multirow{2}{*}{ Age } & \multirow{2}{*}{1990} & \multirow{2}{*}{2000} & \multirow{2}{*}{2010} & \multirow{2}{*}{2014} & \multirow{2}{*}{2015} & \multicolumn{4}{|c|}{$2015 \%$ change from } \\
\hline & & & & & & 2014 & 2010 & 2000 & 1990 \\
\hline $0-14$ & 471 & 267 & 112 & 80 & 62 & -22.5 & -44.6 & -76.8 & -86.8 \\
\hline $15-17$ & 223 & 245 & 122 & 71 & 63 & -11.3 & -48.4 & -74.3 & -71.7 \\
\hline $18-20$ & 455 & 443 & 280 & 199 & 178 & -10.6 & -36.4 & -59.8 & -60.9 \\
\hline $21-24$ & 636 & 583 & 392 & 300 & 252 & -16.0 & -35.7 & -56.8 & -60.4 \\
\hline $25-64$ & 4493 & 3751 & 2293 & 1852 & 1743 & -5.9 & -24.0 & -53.5 & -61.2 \\
\hline $65-74$ & & 575 & 330 & 326 & 281 & -13.8 & -14.8 & -51.1 & \\
\hline $75-84$ & & 329 & 285 & 290 & 255 & -12.1 & -10.5 & -22.5 & \\
\hline$\geq 85$ & & 91 & 59 & 76 & 83 & 9.2 & 40.7 & -8.8 & \\
\hline Total & 7333 & 6294 & 3908 & 3202 & 2938 & -8.2 & -24.8 & -53.3 & -59.9 \\
\hline
\end{tabular}

Figure 31.3. Road fatality rates by age group Deaths per 100000 inhabitants in a given age group, 1990-2015

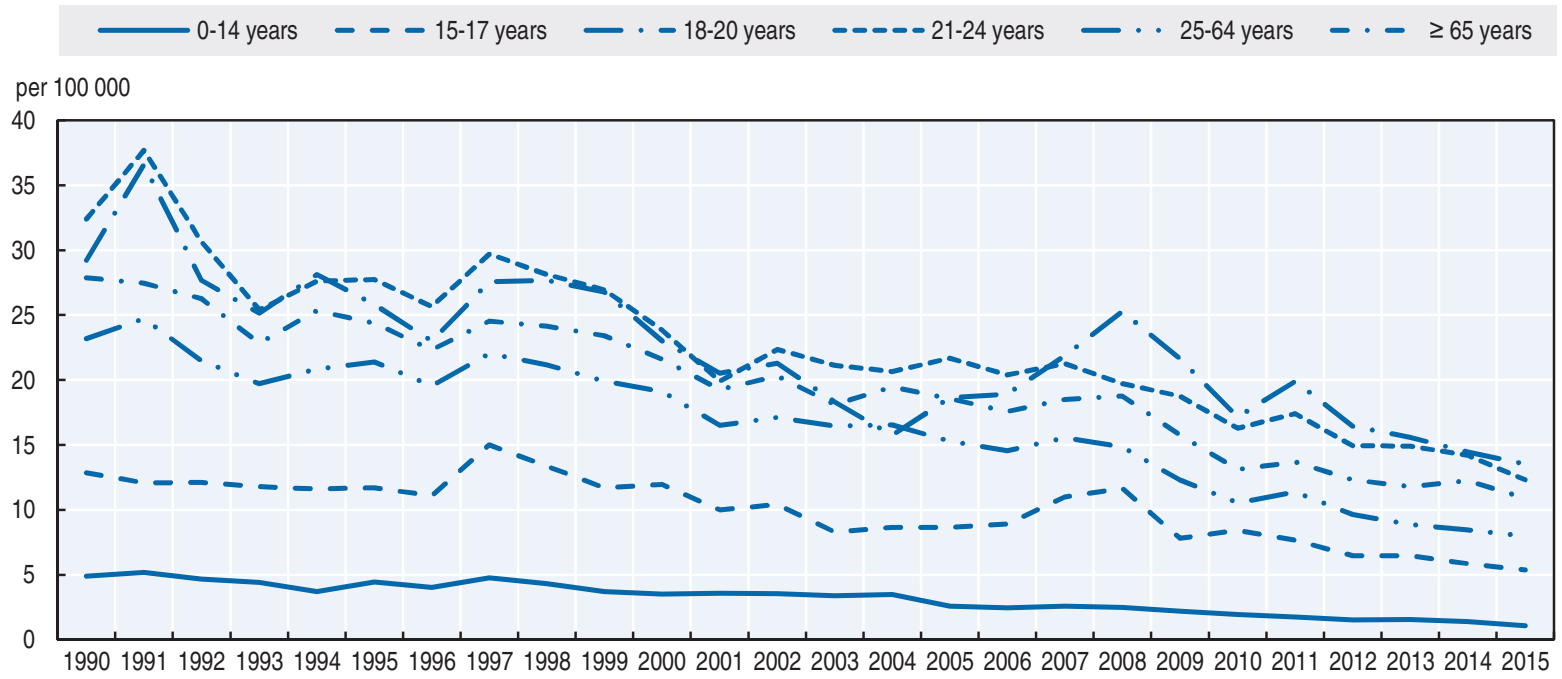




\section{Box 31.2. Road safety for an ageing population}

In the coming years there will be a drastic demographic evolution in Poland. The population will decrease by 2050 in comparison with 2015 by 12\% in almost all age groups. The biggest decline will be observed among young people aged 18-24. The only increase will be noted in 65+ age group, by more than $80 \%$.

Figure 31.4. Population projection - Poland, 2015-50

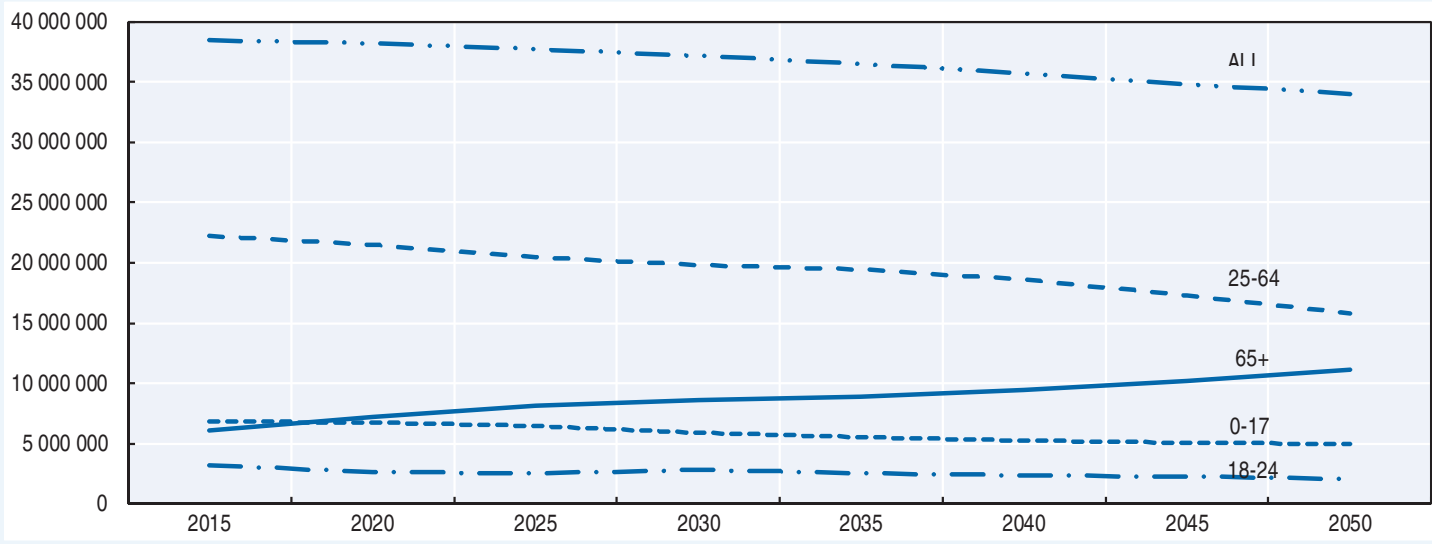

Table 31.4. Road fatalities among senior citizens

\begin{tabular}{lrr|rr|rr}
\hline & \multicolumn{2}{c|}{$65-74$} & \multicolumn{2}{c|}{$75-84$} & \multicolumn{2}{c}{$85+$} \\
\cline { 2 - 7 } & 2010 & 2015 & 2010 & 2015 & 2010 & 2015 \\
\hline Pedestrians & 147 & 134 & 180 & 140 & 45 & 51 \\
Cyclists & 57 & 49 & 43 & 45 & 7 & 15 \\
Moped riders & 9 & 8 & 3 & 6 & 0 & 0 \\
Motorcyclists & 5 & 1 & 0 & 2 & 0 & 1 \\
Car occupants & 93 & 85 & 58 & 58 & 5 & 16 \\
Total & $\mathbf{3 3 0}$ & $\mathbf{2 8 1}$ & $\mathbf{2 8 5}$ & $\mathbf{2 5 5}$ & $\mathbf{5 9}$ & $\mathbf{8 3}$ \\
\hline
\end{tabular}

Figure 31.5. Road fatality rates by age group - focus on the senior population Deaths per 100000 inhabitants in a given age group, 2000-15

$65-74$ years

- - - 75-84 years

$-\cdot-85+$ years

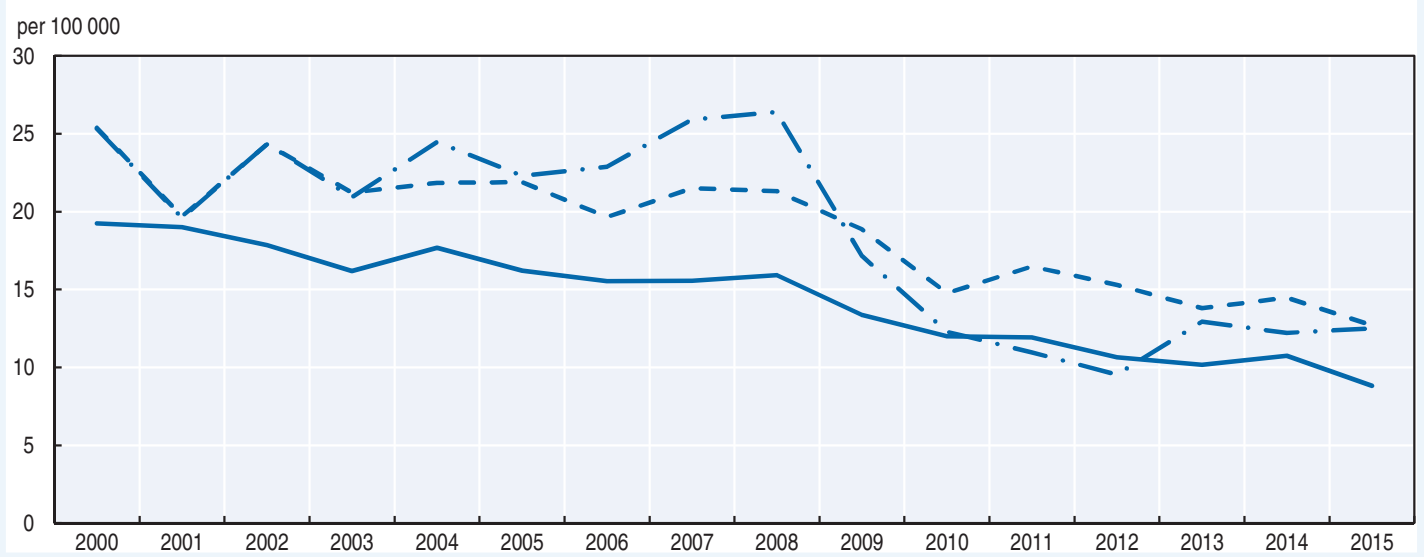




\section{Box 31.2. Road safety for an ageing population (cont.)}

Senior citizens have a higher fatality and injury risk. Although the total number of fatalities and injuries are decreasing, the number of killed and injured within the 60+ age group has dropped at a much slower rate over the past ten years.

Most often seniors are killed on roads as pedestrians, in passenger cars and as cyclists.

In Poland there is no procedure for driving licence renewal. Generally the driving licence B is issued for a lifetime. However the driver has to renew the document every 15 years (without any test, except when a driving licence has been issued with some medical restrictions).

Figure 31.6. Road fatality rates by age and road user group Fatalities per 100000 inhabitants, 2015

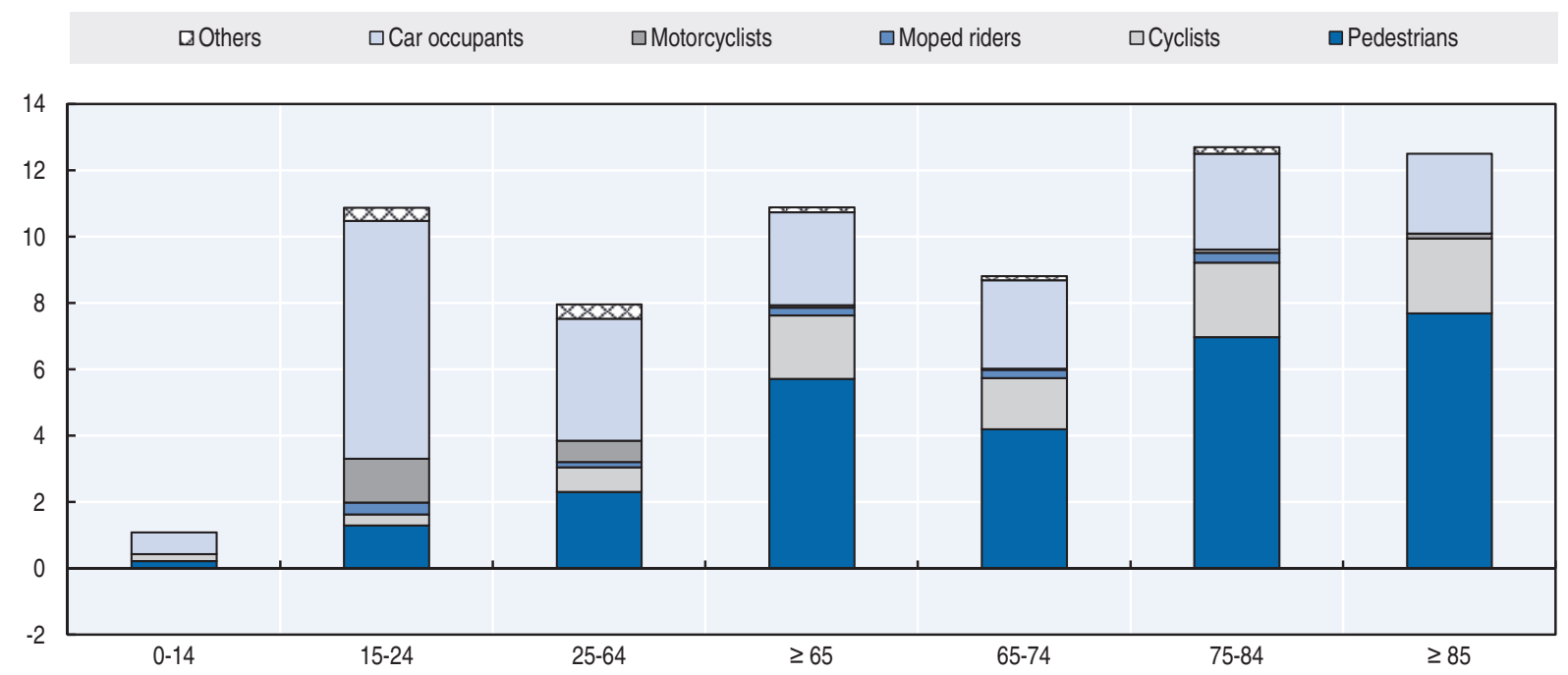

\section{Road safety by road type}

The decrease in fatalities over the last 25 years has been achieved mainly through the improvement of road safety inside urban areas $(-71 \%)$. On rural roads significant improvements were achieved also, in particular since to $2000(-52 \%)$.

The motorway network has been significantly developed over the last few years. Motorways totalled $1560 \mathrm{~km}$ in 2015 , only $0.5 \%$ of the whole road network, but they account for $2 \%$ of total fatalities, with the fatality numbers growing over the same time period.

\section{Economic costs of traffic crashes}

Costs of traffic crashes are calculated based on the capital approach. Traffic crashes represent a significant cost for society, estimated at around PLN 33.5 billion (around EUR 7,8 billion), or $2 \%$ of GDP. They account for more than the budget deficit in Poland (KRBRD, 2016). 
Figure 31.7. Road fatalities by road type

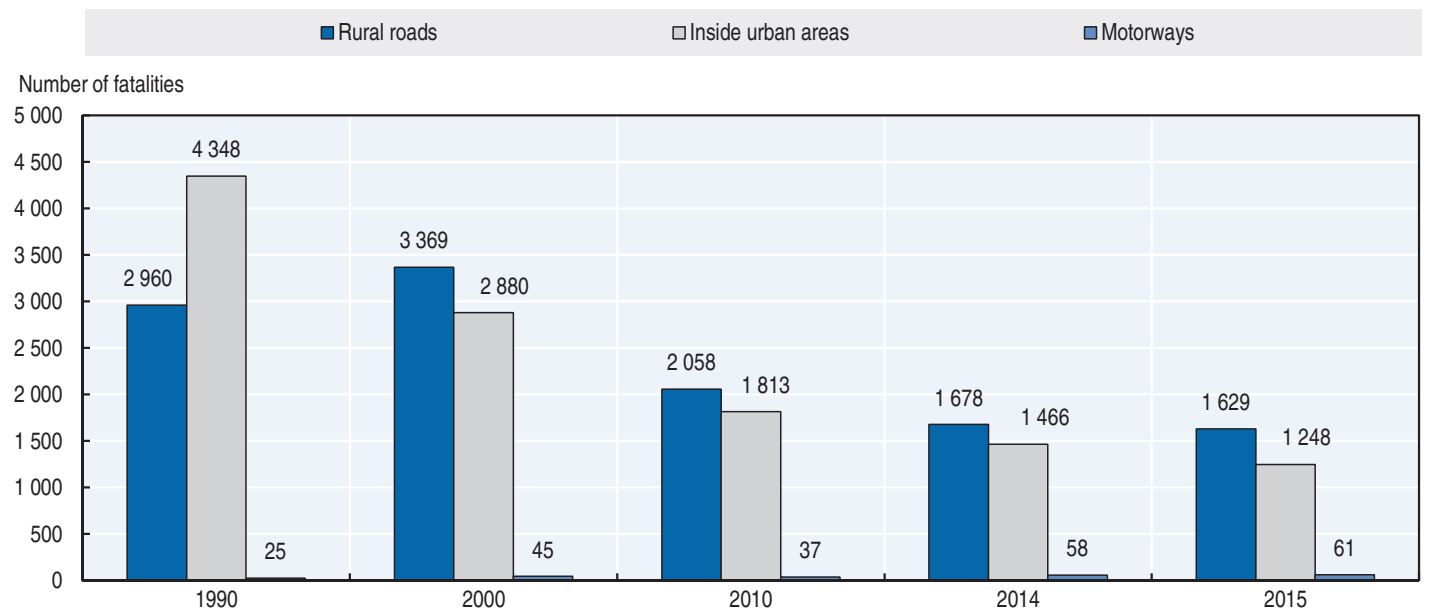

Table 31.5. Costs of road crashes, 2015

\begin{tabular}{lcc}
\hline Cost (EUR) & Unit cost & Total \\
\hline Fatalities & PLN 2.05 million & PLN 6.03 billion \\
injured & & PLN 26.79 billion \\
Serious injuries & PLN 2.32 million & \\
Slight injuries & PLN 26860 & \\
Property damage costs & PLN 40458 & PLN 0.75 billion \\
Total & & PLN $\mathbf{3 3 . 4}$ billion \\
Total as \% of GDP & & $\mathbf{2 . 0 \%}$ \\
\hline
\end{tabular}

PLN $1.00=$ EUR 0.23 on 11 April 2017

Source: KRBRD (2016).

\section{Recent trends in road user behaviour}

Speed

In the last ten years, the number of fatal crashes involving speeding has decreased by $50 \%$; however, speed remains one of the main causes of crashes in Poland and is a contributing factor in around 30\% of fatal crashes. Speed enforcement efforts are constantly increasing. New regulations regarding automatic speed enforcement are being introduced into Polish law. In addition, new legislation was brought into Polish law in 2015. Drivers who exceed the speed limit by $50 \mathrm{~km} / \mathrm{h}$ in a built-up area have their driving licence automatically withdrawn for three months. The table below summarises the main speed limits in Poland.

Table 31.6. Passenger car speed limits by road type, 2017

\begin{tabular}{lc}
\hline & General speed limit \\
\hline Urban roads & $50 \mathrm{~km} / \mathrm{h}$ between $5: 00$ and 23:00 \\
& $60 \mathrm{~km} / \mathrm{h}$ between, 23::00 and 5:00 \\
Rural roads & $90 \mathrm{~km} / \mathrm{h}$ \\
2-carriage expressway & $120 \mathrm{~km} / \mathrm{h}$ \\
Single-carriage express roads and dual-carriage roads & $100 \mathrm{~km} / \mathrm{h}$ \\
with at least two lanes in each direction & $140 \mathrm{~km} / \mathrm{h}$ \\
Motorways & \\
\hline
\end{tabular}




\section{Drink driving}

The maximum authorised blood alcohol content (BAC) in Poland is $0.2 \mathrm{~g} / \mathrm{l}$ for all drivers. Crashes are classified "alcohol related" if one of the crash participants has a BAC of $0.2 \mathrm{~g} / \mathrm{l}$ or more.

Over the last 10 years, the number of crashes caused by drivers under the influence of alcohol has decreased by 40\%. According to police data, $9 \%$ of traffic fatalities are alcohol related. In 2015, the number of alcohol-related crashes decreased by $11.2 \%$ over 2014 .

\section{Drugs and driving}

In Poland, driving under the influence of alcohol and other psychoactive substances is forbidden.

According to the European DRUID (Driving under the Influence of Drugs, Alcohol and Medicines) research project, the prevalence of alcohol in the driving population of Poland, $1.9 \%$, is lower than the EU average of $3.5 \%$. The research indicated that the prevalence of illegal drugs in the EU is $1.9 \%$, while in Poland it is $0.7 \%$.

\section{Seat belts and helmets}

Seat belt use has been compulsory in front seats since 1983 and rear seats since 1991.

Since 1997, children of 0-12 years old and below $150 \mathrm{~cm}$ in height have to be seated in a child restraint system adapted to their height and weight. This applies to all motor vehicles. Rear-facing child restraint systems in front seats protected by an airbag are prohibited. The child restraint wearing rate was 93.2\% in 2016.

Table 31.7. Seat belt wearing rate by car occupancy and road type

\begin{tabular}{|c|c|c|c|}
\hline & 2014 & 2015 & 2016 \\
\hline \multicolumn{4}{|l|}{ Front seat } \\
\hline Driver & 93 & 95 & 93 \\
\hline Passenger & 94 & 96 & 95 \\
\hline Urban roads (driver) & 92 & & \\
\hline Rural roads (driver) & 92 & & \\
\hline Motorways (driver) & 96 & & \\
\hline \multicolumn{4}{|l|}{ Rear seats } \\
\hline General & 71 & 76 & 83 \\
\hline Children (use of child restraint) & 89 & 94 & 93 \\
\hline
\end{tabular}

Source: Motor Transport Institute.

Helmet wearing has been compulsory on motorcycles and mopeds since 1997. The helmet wearing rate by riders of powered two-wheelers is nearly $100 \%$.

Helmet use is not compulsory for bicycles.

\section{Distraction}

The use of hand-held mobile phones while driving is forbidden in Poland, the use of hands-free phones is allowed. According to a national survey from 2015 around 3.1\% of drivers in passenger cars use hand-held mobile phones. 


\section{Sleepiness and fatigue}

There is no information available on the impact of sleepiness and fatigue on road crashes in Poland

\section{National road safety strategies and targets \\ Organisation of road safety}

The National Road Safety Council (NRSC; Krajowa Rada Bezpiecze?stwa Ruchu Drogowego) was established on 1 January 2002 under the Act of Road Traffic Law as an auxiliary interministerial body for the Polish Council of Ministers for road safety issues. The NRSC is chaired by the minister responsible for transport. The members of the NRSC are high-level representatives of several ministries and governmental institutions. The executive unit is the NRSC Secretariat, based in the Ministry of Infrastructure and Development. The NRSC establishes targets and co-ordinates the activities of government administrations in the area of road safety.

NRSC activities include:

- guiding state policy

- developing and appraising road safety programmes

- initiating research, legislation, international agreements and staff training programmes

- international co-operation

- working closely with social institutions and NGOs

- instigating road safety education, publicity and promotional campaigns

- monitoring and evaluating road safety activities

- implementing new laws for cyclists.

\section{Road safety strategy for 2011-20}

The NRSC adopted in January 2013 a National Road Safety Programme for the period 2013-20, developed by the NRSC Secretariat and experts from government bodies. It is based on the Vision Zero approach.

\section{Road safety targets}

The 2013-20 programme targets include a 50\% reduction in road deaths and a $40 \%$ reduction in people seriously injured by 2020, in comparison to 2010 levels.

The National Road Safety Council is in charge of monitoring road safety performance.

At the beginning of 2016 a provisional interim report was published. It was based on the survey of NRSC members as well as advisors. It is estimated that Poland is on track to reach its fatality target but not the injury target. Achieving this target would require the adoption and implementation of new and effective measures. The main conclusions of the report are:

- the vision and targets remain the same

- there is a need of dedicated funds for road safety activities

- there is a need to intensify road safety actions in order to meet the targets. 
Figure 31.8. Trends in road fatalities and seriously injured* toward national targets

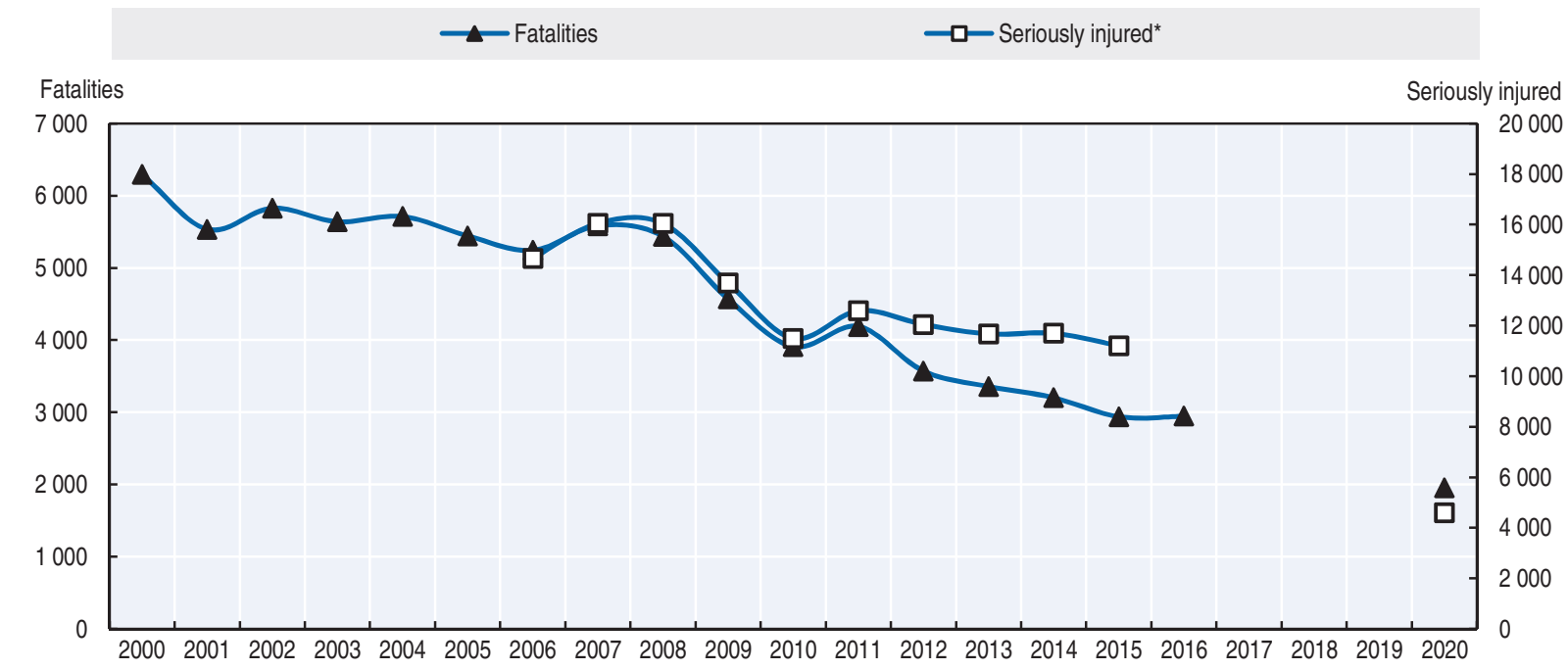

* According to national seriously injured definition.

\section{Recent safety measures (2014-17)}

\section{Road safety management}

- Implementation of the EU Directive 2008/96/EC on Road Safety Management.

- Creation of the National Road Safety Observatory (2014).

\section{Road users}

\section{Speed management}

- In May 2015, the penalties for exceeding the speed limit in built-up areas by more than $50 \mathrm{~km} / \mathrm{h}$ were amended and provide for licence withdrawal for three months.

\section{Impaired driving}

- Penalties for driving under the influence of alcohol increased in 2015. In addition to possible imprisonment or lifelong driving licence withdrawal, the courts can now request drivers at fault to pay PLN 5000 to a victims aid fund (PLN 10000 for recidivists) or PLN 10000 directly to the victim. In addition, the act introduces the obligation of installing alcohol interlocks in the vehicles of drink driving offenders.

\section{Education and awareness}

- Regular awareness campaigns are conducted on the use of seat belts and child restraint systems, young drivers as well as on speed, driving under influence of alcohol and pedestrian safety.

\section{Infrastructure}

- A Road Safety Audit is obligatory for all road designs within the Trans-European Transport Network, based on Directive 2008/96/EC, and a training programme for auditors has been prepared in Poland. 


\section{Vehicles}

- Coaches and buses used for the transport of children during holiday periods are subject to special inspections.

\section{Recent and ongoing research}

- In 2015, the Motor Transport Institute joined the European two-year research project "SaferWheels" to investigate motorcycle crashes. Results are expected in 2017.

\section{References}

ITS (2016), "Stosowanie urządzeń zabezpieczających dzieci w Polsce w 2016 roku".

ITS (2016), "Stosowanie pasów bezpieczeństwa w Polsce w 2016 roku".

KGP/ITS (2016), "Wypadki drogowe w Polsce w 2015 r", http://statystyka.policja.pl/download/20/192140/ Wypadki2015.pdf (accessed 10 July 2017).

KRBRD (2016), “Wycena kosztów wypadków i kolizji drogowych na sieci dróg w Polsce na koniec roku 2015, z wyodrębnieniem średnich kosztów społeczno-ekonomicznych wypadków na transeuropejskiej sieci transportowej", National Road Safety Council, http://krbrd.gov.pl/pl/koszty-zdarzen-drogowych.html (accessed 10 July 2017).

KRBRD (2015), "Korzystanie z telefonów komórkowych przez kierujących pojazdami w Polsce w 2015 roku”, National Road Safety Council, http://krbrd.gou.pl/pl/monitoring-zachowan.html (accessed 10 July 2017).

World Bank (2017), “GDP (constant US\$)”, World Development Indicators, http://databank.worldbank.org/ data/reports.aspx?source=world-development-indicators (accessed 23 February 2017).

\section{Websites}

- Ministry of Infrastructure and Construction: http://mib.gou.pl/ (accessed 10 July 2017).

- National Road Safety Council (KRBRD): www.krbrd.gov.pl (accessed 10 July 2017).

- National Road Safety Programme for the years 2013-2020: www.krbrd.gou.pl/files/file/Programy/KRBRDProgram-P1a-20140422-S2-K3d-EN.pdf (accessed 10 July 2017).

- Motor Transport Institute: www.its.waw.pl (accessed 10 July 2017).

- Polish Road Safety Observatory: www.obserwatoriumbrd.pl (accessed 10 July 2017). 



\section{Chapter 32}

\section{Portugal}

This chapter presents 2015 road safety data for Portugal along with provisional data from 2016. It looks at trends in traffic and road safety from the years 1990 to 2015 and road user behaviour patterns with a special focus on the ageing population. Sections include data on speed, drink driving, drugs and driving, distracted driving, fatigue and seat belt usage. The chapter reviews Portugal's road safety strategy and national targets to 2020 and the progress achieved thus far. It also provides details of all recently implemented safety measures and current and ongoing research.*

* All data stem from the National Authority for Road Safety (ANSR) unless otherwise noted. For more information please contact transito@ansr.pt. 
$\mathrm{P}$ fatalities of 7\% recorded since 2010. Fatalities dropped from 638 in 2014 to 593 in 2015, a reduction of $7 \%$. However, injury crashes increased by $4.4 \%$. In 2015 , Portugal's fatality rate decreased to 5.7 deaths per 100000 inhabitants, well below its interim target of 6.2.

\section{Road safety data collection}

\section{Definitions applied in Portugal}

- Road fatality: A person who died immediately following the crash or within the next 30 days. Until 2010, only fatalities within 24 hours of the crash were recorded. A correction factor of 1.26 was applied in the IRTAD database to match the 30 days definition.

- Seriously injured person: A person hospitalised as a result of the crash for a period of 24 hours or more who did not die within 30 days of the crash.

- Slightly injured person: A person injured as a result of the crash who was not hospitalised or was hospitalised for less than 24 hours and who did not die within 30 days of the crash.

Since 2010, Portugal has started estimating serious injury data according to the new European Union definition (MAIS3+). The method used is based only on hospital data. The Central Administration of the Health System (ACSS) applies the AAAM converter provided by the EU Commission to the ICD9-CM codes (International Classification of Diseases, 9th revision Clinical Modification) to obtain the number of MAIS3+ injuries. MAIS3+ data are available for the years 2010 to 2015.

\section{Data collection}

In Portugal, the authorities responsible for reporting road crashes are the:

- Public Security Police (PSP) inside urban areas

- National Republican Guard (GNR) outside urban areas.

When police officers attend a crash they must fill in the standard "BEAV" road crash form. Statistics cover only crashes reported to the police.

The BEAV registration forms are sent to the National Authority for Road Safety (ANSR, Autoridade Nacional Segurança Rodoviária), which is responsible for controlling the quality of data and inserting it into the national road accident database. Controls consist of checking for duplications, incoherent data or other errors.

In Portugal, the severity of an injury is registered by police on the BEAV form. The national road traffic injury database uses only police reports and the number of seriously and slightly injured persons reported by police is not cross-checked with the medical services.

In 2015, a working group with representatives of the ANSR, the General Health Directorate, the National Institute for Medical Emergency, the National Statistical Institute, the Central Administration of the Health System and the PSP and GNR developed a methodology based on national hospital discharge database to assess the number of serious injuries using the Maximum Abbreviated Injury Scale of three or more (MAIS3+) - the 
Central Administration of the Health System (ACSS) applies the AAAM converter provided by the EU Commission to the ICD9-CM codes and then calculates the MAIS score.

\section{Most recent safety data}

\section{Road crashes in 2016 - provisional data}

Based on provisional data, there were 563 road fatalities registered in 2016, representing a decrease of $5.1 \%$ compared to the same period in 2015.

\section{Road crashes in 2015}

In 2015, the number of fatalities significantly decreased. There were 593 road deaths in Portugal, representing a reduction of over $7 \%$ compared to 2014 . However, numbers of injury crashes and injured persons hospitalised increased by $4.4 \%$ and $7 \%$ respectively.

All user groups benefited from safety improvements, except pedestrians. The number of killed pedestrians in 2015 increased by $0.7 \%$ compared to 2014 .

\section{Trends in traffic and road safety (1990-2016) \\ Traffic}

In Portugal no estimate is available for the evolution of traffic volume.

Between 1990 and 2015, the number of motorised vehicles more than doubled, rising from about 2.2 million vehicles in 1990 to 5.8 million in 2015 (+163\%).

\section{Road safety}

\section{Crashes and casualties}

Since 1990, the number of road fatalities has decreased by $80 \%$ and the number of injury crashes by $29 \%$.

- Between 1970 and 1989, there was an average annual increase in road deaths of 3.5\% and injury crashes of 3.9\%. The number of fatalities reached a peak in 1975, with 3372 persons killed.

- Between 1990 and 2000 there was a steady decrease in the number of fatalities and injury crashes. On a yearly average, the number of fatalities fell by $3.2 \%$.

- Since 2000 , the rate of decline has accelerated, with an average annual decrease of $7 \%$ between 2000 and 2015.

Although it is not possible to provide a full explanation, several measures contributed to this significant decrease in the number of traffic casualties, including:

- successive road safety plans and respective targets and actions

- treatment and reduction of black spots, implementation of traffic calming measures and construction of new roads, in particular motorways

- highway code update (revised 2014) taking into account new traffic rules and penalties

- regular awareness campaigns on television, radio and press, focused on specific targets and issues

- increased enforcement, particularly focused on speeding, drink driving, use of seat belts especially on rear seats and child restraint systems

- improved passive safety features of vehicles

- advances in post-impact care. 
The economic recession that hit the country has also probably contributed to the important reduction in the number of road deaths since 2008.

\section{Rates}

In 2015, Portugal had a mortality rate, expressed in terms of road deaths per 100000 inhabitants, of 5.7, less than one-third of what it was in 2000 and closer to the EU average of 5.2 .

The fatality risk, expressed as the number of fatalities per 10000 motorised vehicles, has also improved substantially, from 13.4 in 1990 to 1.0 in 2015.

\section{Analysis of seriously injured data}

The number of people seriously injured decreased by 69\% between 2000 and 2015 . However, in 2015 the number of serious injuries increased by $7 \%$ compared to the previous year.

Table 32.1. Road safety and traffic data

\begin{tabular}{|c|c|c|c|c|c|c|c|c|c|}
\hline & \multirow{2}{*}{1990} & \multirow{2}{*}{2000} & \multirow{2}{*}{2010} & \multirow{2}{*}{2014} & \multirow{2}{*}{2015} & \multicolumn{4}{|c|}{$2015 \%$ change from } \\
\hline & & & & & & 2014 & 2010 & 2000 & 1990 \\
\hline \multicolumn{10}{|l|}{ Reported safety data } \\
\hline Fatalities & 2924 & 2053 & 937 & 638 & 593 & -7.1 & -36.7 & -71.1 & -79.7 \\
\hline Injury crashes & 45110 & 44159 & 35426 & 30604 & 31953 & 4.4 & -9.8 & -27.6 & -29.2 \\
\hline Injured persons hospitalised & 12165 & 6918 & 2475 & 2010 & 2148 & 6.9 & -13.2 & -69.0 & -82.3 \\
\hline Serious injuries (MAIS3+) & & & 2290 & 2055 & 2171 & 5,6 & $-5,2$ & & \\
\hline Deaths per 100000 inhabitants & 29.3 & 20.0 & 8.9 & 6.1 & 5.7 & -6.6 & -35.5 & -71.5 & -80.5 \\
\hline Deaths per 10000 registered vehicles & 13.4 & 4.3 & 1.6 & 1.1 & 1.0 & $-10,3$ & $-38,2$ & $-76,9$ & $-92,5$ \\
\hline \multicolumn{10}{|l|}{ Traffic data } \\
\hline Registered vehicles ${ }^{1}$ (thousands) & 2188 & 4743 & 5795 & 5721 & 5762 & 0,7 & $-0,6$ & 21,5 & 163,3 \\
\hline \multicolumn{10}{|l|}{ Vehicle-kilometres (millions) } \\
\hline Registered vehicles per 1000 inhabitants & 219 & 463 & 548 & 549 & 557 & 1,5 & 1,6 & 20,4 & 154,5 \\
\hline
\end{tabular}

1. Registered vehicles excluding mopeds.

StatLink AाIsय http://dx.doi.org/10.1787/888933580802

\section{Road safety by user group}

Since 1990, all user groups benefited from the improvements in road safety. Pedestrians and moped users were the groups with the highest reduction in fatalities, by $80.3 \%$ and $94.7 \%$ respectively. However, the reduction in moped user fatalities can also be explained by the decrease in the number of these vehicles during this period.

Numbers of killed cyclists were also reduced by more than $79 \%$ for the same time period.

The progress was less significant among motorcyclists: between 1990 and 2015 fatalities for this group only decreased by $31.1 \%$.

In 2015, fatalities decreased, when compared to 2014, for all road user groups except pedestrians. The number of killed pedestrians remained at 2014 level, while the highest reduction of road user fatalities was among cyclists (-24\%). 
Figure 32.1. Road safety, traffic and GDP trends index $1990=100$

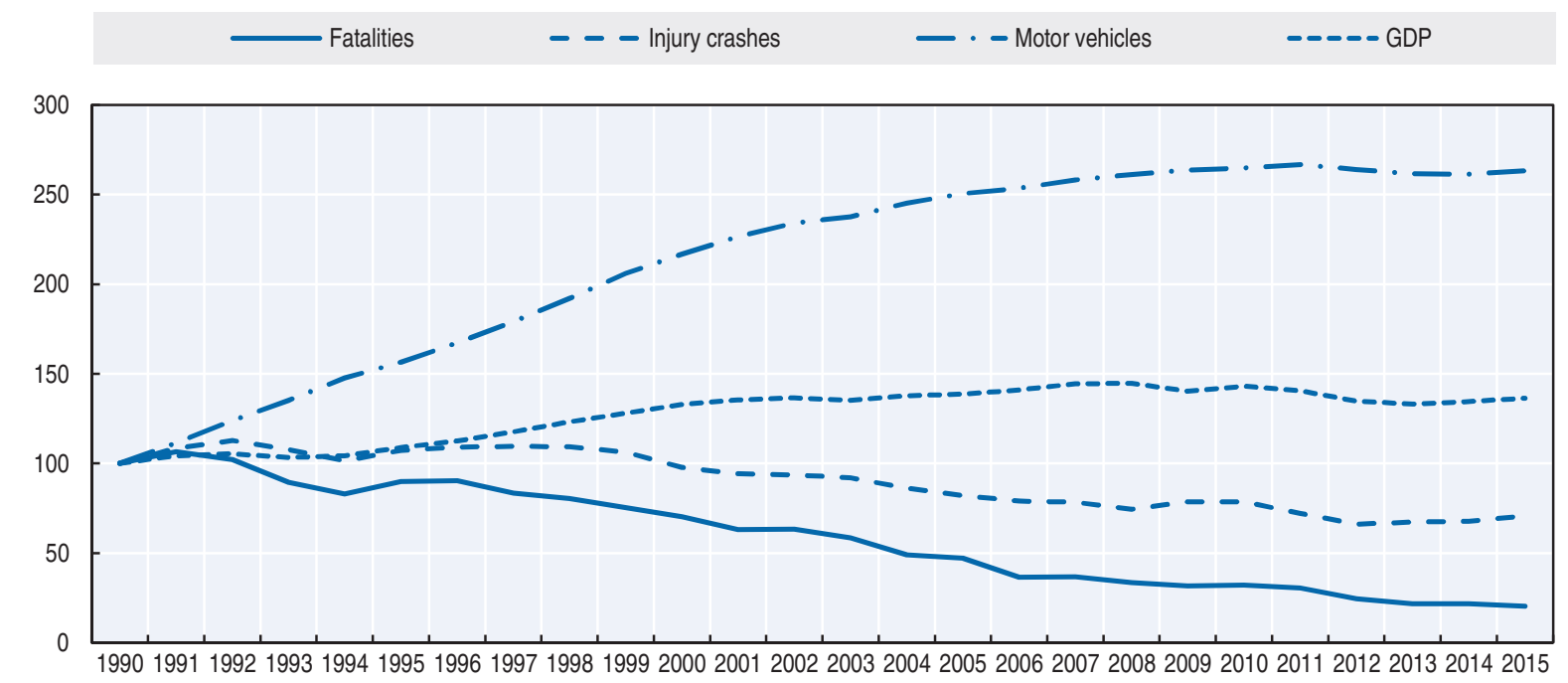
Source: World Bank (2017) (GDP; constant prices).

Table 32.2. Road fatalities by road user group

\begin{tabular}{lrrrrr|rrrr}
\hline & 1990 & 2000 & 2010 & 2014 & 2015 & \multicolumn{4}{c}{$2015 \%$ change from } \\
\cline { 7 - 10 } & & & & & & 2014 & 2010 & 2000 & 1990 \\
\hline Pedestrians & 742 & 425 & 195 & 145 & 146 & 0.7 & -25.1 & -65.6 & -80.3 \\
Cyclists & 120 & 62 & 31 & 33 & 25 & $-24,2$ & $-19,4$ & $-59,7$ & $-79,2$ \\
Moped users & 786 & 248 & 77 & 43 & 42 & -2.3 & -45.5 & -83.1 & -94.7 \\
Motorcyclists & 106 & 234 & 128 & 91 & 73 & -19.8 & -43.0 & -68.8 & -31.1 \\
Car occupants & 898 & 809 & 367 & 223 & 214 & -4.0 & -41.7 & -73.5 & -76.2 \\
Others & 272 & 275 & 139 & 103 & 93 & $-9,7$ & $-33,1$ & $-66,2$ & $-65,8$ \\
Total & $\mathbf{9 2 4}$ & $\mathbf{2 0 5 3}$ & $\mathbf{9 3 7}$ & $\mathbf{6 3 8}$ & $\mathbf{5 9 3}$ & $\mathbf{- 7 . 1}$ & $\mathbf{- 3 6 . 7}$ & $\mathbf{- 7 1 . 1}$ & $\mathbf{- 7 9 . 7}$ \\
\hline
\end{tabular}

Figure 32.2. Road fatalities by road user group in percentage of total, 2015

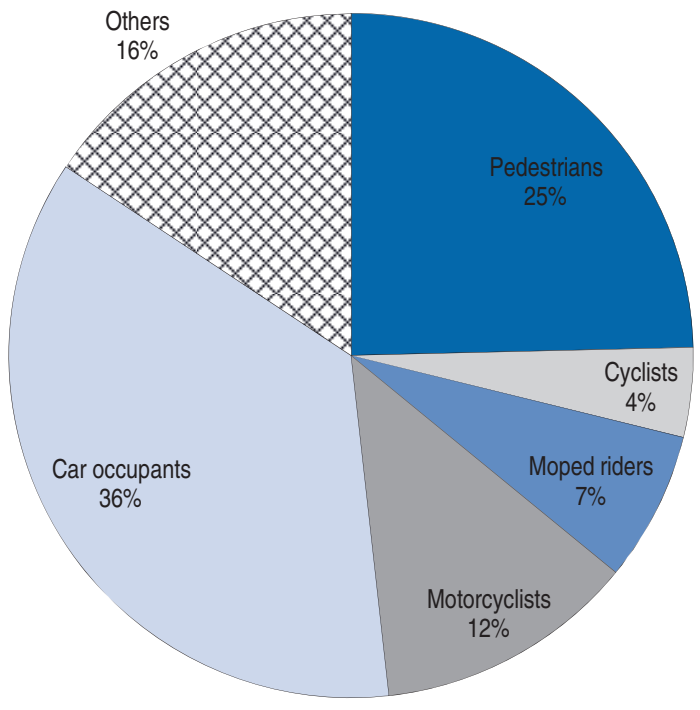




\section{Road safety by age group}

Between 1990 and 2015, all age groups benefited from safety improvements, with fatality reductions above $91 \%$ for the youngest and young people age groups (0-20 and 21-24 year olds).

From 2000 to 2015, the highest reductions in the number of deaths were also observed among the youngest and young people groups while the older age group (65+) has shown a slower decrease, due to demographic change and the ageing of the population. However, comparing 2015 with the previous year, fatalities increased for the age groups 0-14, 18-20 and 65-74 years old.

In 2015, the older age group (65+) and young people aged 18-20 had the highest death rates.

Table 32.3. Road fatalities by age group

\begin{tabular}{|c|c|c|c|c|c|c|c|c|c|}
\hline \multirow{2}{*}{ Age } & \multirow{2}{*}{1990} & \multirow{2}{*}{2000} & \multirow{2}{*}{2010} & \multirow{2}{*}{2014} & \multirow{2}{*}{2015} & \multicolumn{4}{|c|}{$2015 \%$ change from } \\
\hline & & & & & & 2014 & 2010 & 2000 & 1990 \\
\hline $0-14$ & 180 & 83 & 18 & 8 & 13 & 62.5 & -27.8 & -84.3 & -92.8 \\
\hline $15-17$ & 152 & 60 & 8 & 11 & 8 & -27.3 & 0.0 & -86.7 & -94.7 \\
\hline $18-20$ & 282 & 171 & 31 & 22 & 25 & 13.6 & -19.4 & -85.4 & -91.1 \\
\hline $21-24$ & 333 & 221 & 60 & 30 & 23 & -23.3 & -61.7 & -89.6 & -93.1 \\
\hline $25-64$ & 1411 & 1120 & 549 & 360 & 345 & -4.2 & -37.2 & -69.2 & -75.5 \\
\hline $65-74$ & & 246 & 127 & 71 & 77 & 8,5 & $-39,4$ & $-68,7$ & \\
\hline $75-84$ & & 105 & 118 & 106 & 76 & $-28,3$ & $-35,6$ & $-27,6$ & \\
\hline$\geq 85$ & & 28 & 25 & 29 & 24 & -17.2 & -4.0 & -14.3 & \\
\hline Total incl. unknown & 2924 & 2053 & 937 & 638 & 593 & -7.1 & -36.7 & -71.1 & -79.7 \\
\hline
\end{tabular}

Figure 32.3. Road fatality rates by age group Deaths per 100000 inhabitants in a given age group, 1990-2015

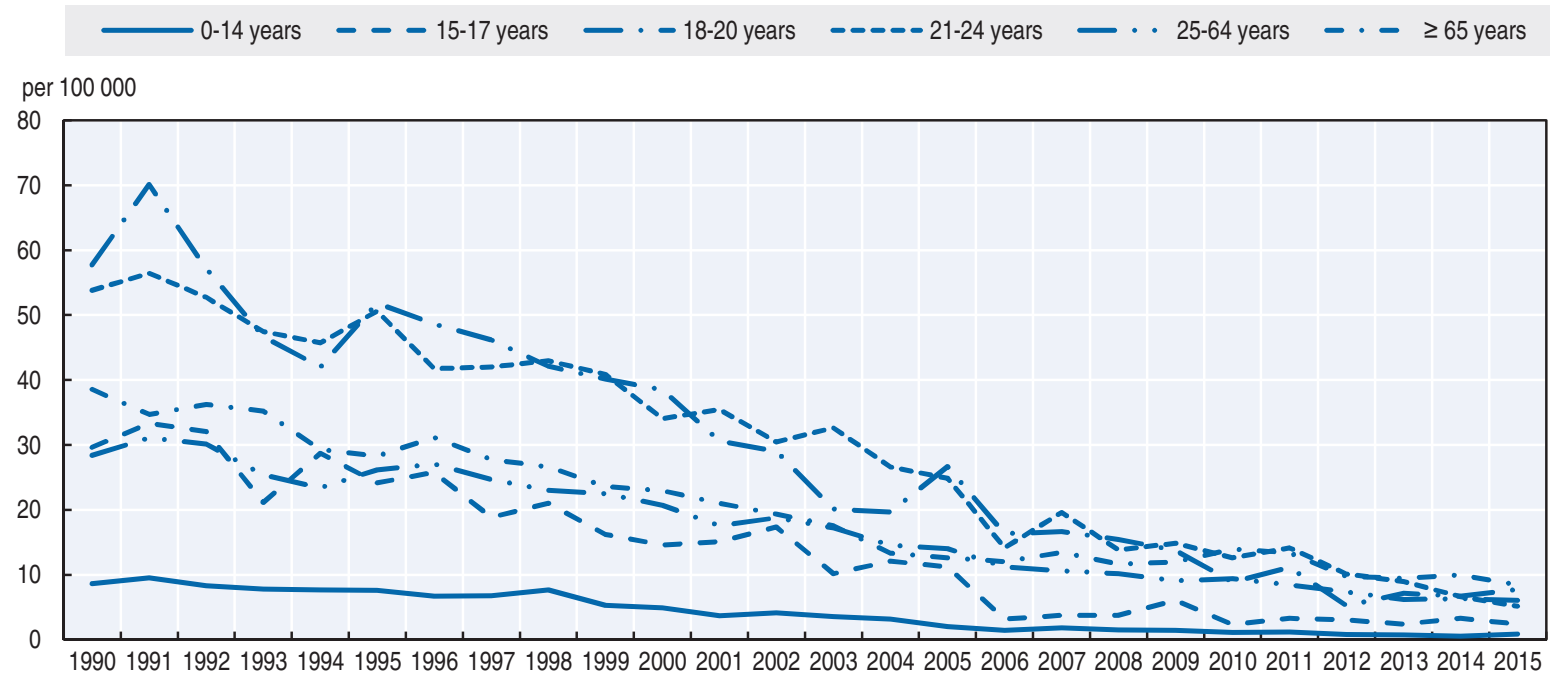




\section{Box 32.1. Road safety for an ageing population}

According to Statistics Portugal (INE), the proportion of the population aged 65 or over is projected to rise from $20.7 \%$ in 2015 to $35.6 \%$ in 2050 . The rate of increase projected for the age groups $65-74,75-84$ and $85+$ years old in this period is, respectively, $+20 \%,+64 \%$ and $+148 \%$.

Regarding the evolution in the number of fatalities by age group within the senior population $(\geq 65)$, there was a decrease for the $65-74(-39 \%)$ and $75-84(-36 \%)$ age groups from 2010 to 2015 , whereas the number of deaths among the age group $85+$ remained constant.

In 2015, the highest number of fatalities per 100000 inhabitants was recorded for persons 75-74 years old (10), followed by the $85+$ years old group (9).

The distribution of fatalities by road user type depends on the age group: while people aged 65 to 74 years old killed in injury accidents were predominantly car occupants (44\%) and pedestrians (36\%), for the 75-84 age group most of the deaths were pedestrians $(46 \%)$, followed by car occupants $(22 \%)$, and persons 85 years old and over were mostly pedestrians $(75 \%)$.

The probability of men of 65 years old and over being killed in a road accident is greater than that of the women regardless the age group.

In Portugal, driving licences must be renewed at 60, 65 and 70 years of age, and every two years thereafter. To renew the driving licence a medical certificate of fitness to drive is required.

Table 32.4. Road fatalities among senior citizens

\begin{tabular}{lrr|rr|rc}
\hline & \multicolumn{2}{c|}{$65-74$} & \multicolumn{2}{c|}{$75-84$} & \multicolumn{2}{c}{$85+$} \\
\cline { 2 - 7 } & 2010 & 2015 & 2010 & 2015 & 2010 & 2015 \\
\hline Pedestrians & 42 & 28 & 48 & 35 & 17 & 18 \\
Cyclists & 6 & 3 & 9 & 4 & 0 & 0 \\
Moped users & 15 & 4 & 8 & 8 & 2 & 1 \\
Motorcyclists & 4 & 1 & 4 & 1 & 0 & 0 \\
Car occupants & 39 & 34 & 35 & 17 & 5 & 4 \\
Total (incl. other road users) & $\mathbf{1 2 7}$ & $\mathbf{7 7}$ & $\mathbf{1 1 8}$ & $\mathbf{7 6}$ & $\mathbf{2 4}$ & $\mathbf{2 4}$ \\
\hline
\end{tabular}

Figure 32.4. Road fatality rates by age group - focus on the senior population Deaths per 100000 inhabitants in a given age group, 2000-15

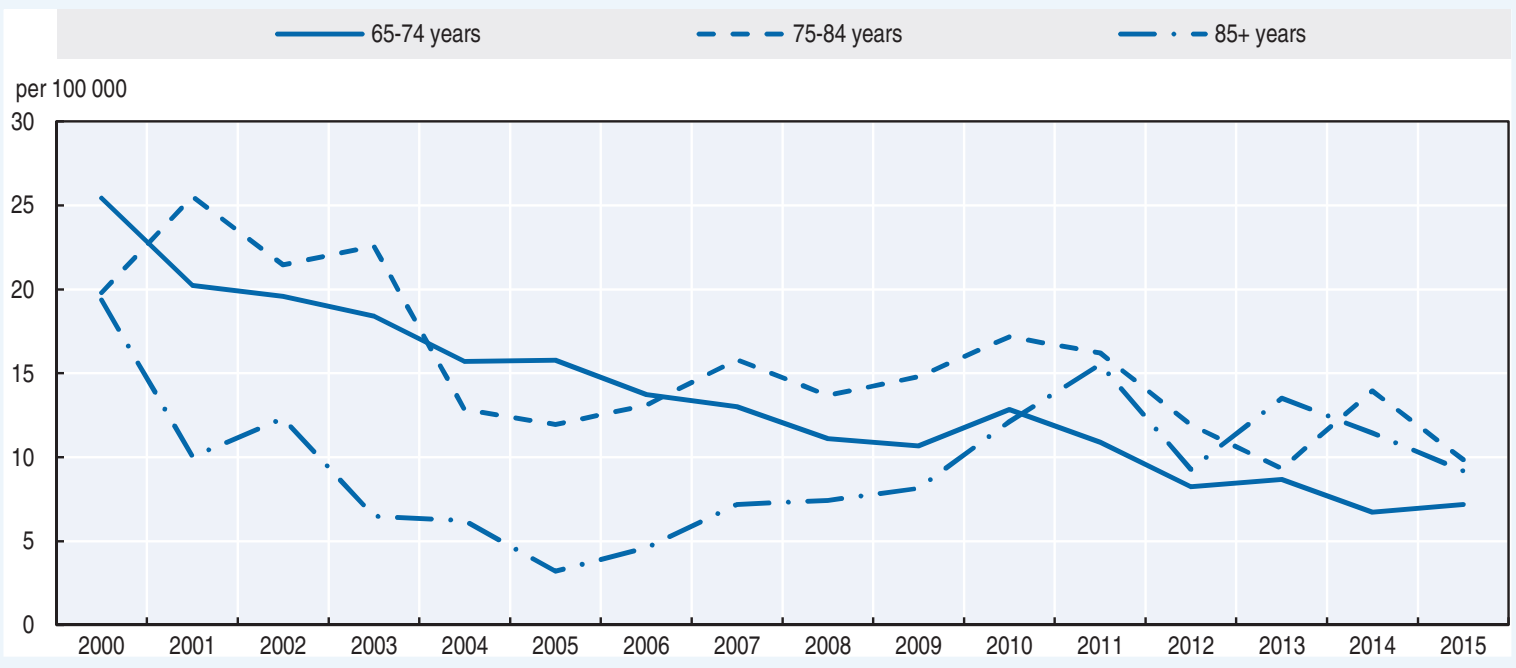


Figure 32.5. Road fatality rate by age and road user group Fatalities per 100000 inhabitants, 2015

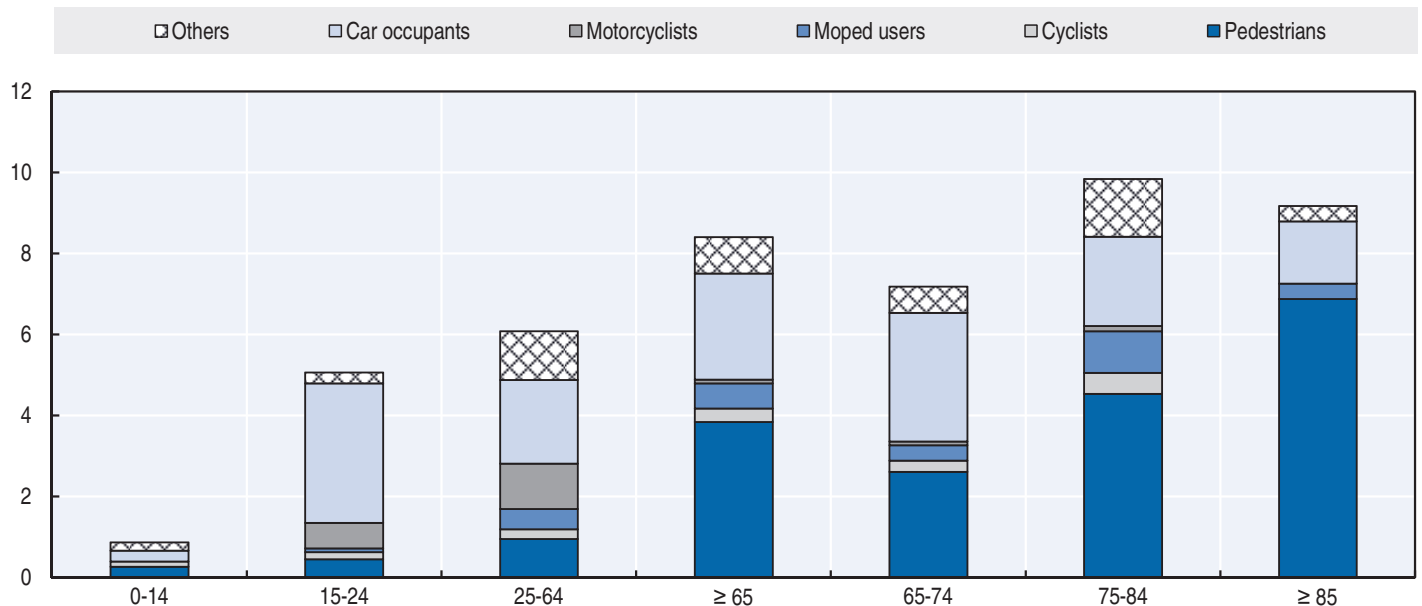

\section{Road safety by road type}

In 2015 , there were more fatalities in urban areas (51.3\%) than outside urban areas (38.4\%). Since 1990 there have been more improvements in the reduction of road deaths on rural roads. This is mainly related to an overall improvement in rural road safety, with important financial investments. There was also an improvement in rural infrastructure management.

Urban area fatalities and serious injuries are a major concern and urban road safety remains a priority objective of the National Road Safety Strategy.

Compared to 2010, the number of road fatalities on motorways decreased almost by $45 \%$, notwithstanding certain increases during the last two years. The economic crisis in Portugal led to an important reduction in motorway traffic along with an overall speed reduction. The increase of speed enforcement also contributed to the decrease of road fatalities on motorways. On the other hand, the introduction of tolling on some free motorways led to an increase in traffic on alternative roads, possibly affecting the number of crashes on those roads.

Figure 32.6. Road fatalities by road type

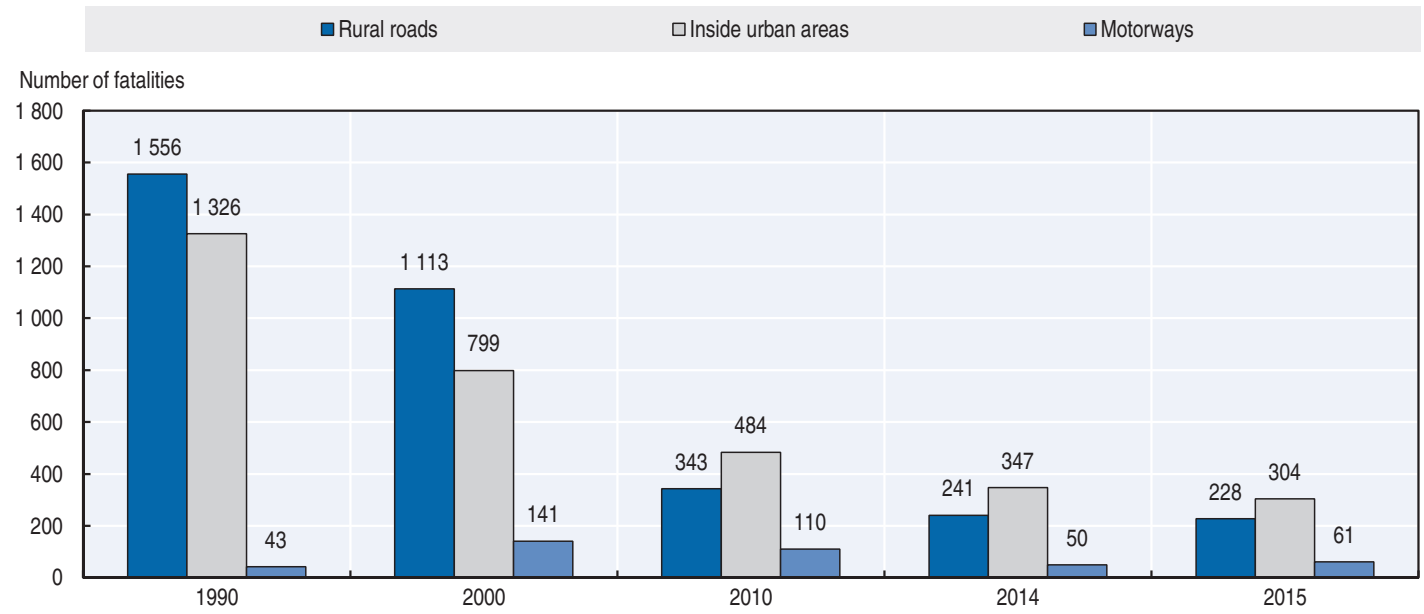




\section{Economic costs of traffic crashes}

The ANSR and the University of Lisbon (Universidade Autónoma de Lisboa) conducted a study in 2011 to estimate the national costs of traffic crashes.

This study used the methodology of human capital, based on data from several public institutions for a period of 15 years (1996-2010). This method relies mainly on historical data and tends to estimate a value lower than the willingness-to-pay approach. Therefore, the costs presented in this study should be viewed as minimum estimates.

Table 32.5. Costs of road crashes, 2015

\begin{tabular}{lcc}
\hline Cost (EUR) & Unit cost & Total \\
\hline Fatalities & EUR 625000 & EUR 0.37 billion \\
Hospitalised persons / Serious injuries & EUR 102000 & EUR 1.24 billion \\
Slight injuries & EUR 26000 & \\
Property damage costs & & \\
Total & & EUR $\mathbf{1 . 6 1}$ billion \\
Total as \% of GDP & & $\mathbf{1 . 2 \%}$ \\
\hline
\end{tabular}

Source: ANSR, University of Lisbon.

\section{Recent trends in road user behaviour Speed}

The table below summarises the main speed limits in Portugal. The revised Highway Code introduced the concept of "coexistence zones" where pedestrians may make use of the road over its entire width and drivers should not put pedestrians at risk nor behave in an obstructive manner. In these areas the speed limit is $20 \mathrm{~km} / \mathrm{h}$.

\section{Table 32.6. Passenger car speed limits by road type, 2017}

\begin{tabular}{lc}
\hline & General speed limit \\
\hline Urban roads & $50 \mathrm{~km} / \mathrm{h}$ \\
Rural roads & $90 \mathrm{~km} / \mathrm{h}$ \\
Motorways & $120 \mathrm{~km} / \mathrm{h}$ \\
\hline
\end{tabular}

\section{Drink driving}

Until 2013, the maximum authorised blood alcohol content (BAC) in Portugal was $0.5 \mathrm{~g} / \mathrm{l}$ for all drivers. Following the revision of the Highway Code that entered into force on the 1 January 2014, a limit of $0.2 \mathrm{~g} / \mathrm{l}$ applies for novice drivers during the probation period and professional drivers of emergency/medical service vehicles, taxis, school buses, heavy goods vehicles and dangerous goods transport vehicles.

A drink driving crash is defined as a crash where at least one of the drivers involved is over the legal BAC limit. It is estimated that $30 \%$ of all road fatalities occur in drink driving crashes.

According to the Toxicological Department of the National Institute for Legal Medicine and Forensic Sciences, 31.8\% of drivers killed in road crashes in 2015 were found with a BAC above the legal limit.

Between 2006 and 2015 the number of killed drivers in road crashes with a BAC above the legal limit decreased by $48 \%$. 


\section{Drugs and driving}

It is forbidden to drive under the influence of drugs. Every driver and pedestrian involved in a fatal or serious injury crash is tested for drug consumption, and the application of roadside drug tests is permitted when there is a suspicion of drug abuse.

According to the Toxicological Department of the National Institute for Legal Medicine and Forensic Sciences, 9\% of killed drivers in 2015 tested positive for drugs.

\section{Seat belts and helmets}

Seat belt use has been compulsory in front seats since 1978 and in rear seats since 1994. The seat belt wearing rate in cars is $96 \%$ for drivers and front seat passengers and $77 \%$ for rear seat passengers. The front seat rate is relatively higher on motorways than on other roads.

The use of child restraint systems is compulsory until the age of 12 or for children under $135 \mathrm{~cm}$ tall. In 2013, 98\% of children traveling in front seats and $94 \%$ in rear seats were using a child restraint system.

Table 32.7. Seat belt wearing rate by car occupancy and road type

\begin{tabular}{|c|c|}
\hline & 2013 \\
\hline \multicolumn{2}{|l|}{ Front seat } \\
\hline General (driver + passengers) & 96 \\
\hline \multicolumn{2}{|l|}{ Rear seats } \\
\hline General & 77 \\
\hline Children (use of child restraint) & 94 \\
\hline
\end{tabular}

All riders of powered two-wheelers are required to wear helmets. The use of a helmet it is not mandatory for cyclists.

\section{Distraction and fatigue}

Portuguese law allows the use of hands-free mobile phones while driving.

The use of mobile phones and fatigue are part of a new operational objective defined in the review of the National Road Safety Strategy, which aims to better understand the influence of these issues on road crashes.

\section{National road safety strategies and targets Organisation of road safety}

The ANSR is a government agency within the Ministry of Internal Affairs which has the mission of planning and co-ordinating road safety policies in Portugal through the development of national road safety strategies and targets.

Directly dependent on the ANSR, the Road Safety Council is an advisory body chaired by the ANSR president. The council ensures the strategic management and co-ordination of organisations involved in road safety. Members are representatives of PSP and GNR, the Mobility and Transport Institute and the Directorate of Health. The Road Safety Council can also invite other public or private institutions to take part in its meetings.

Although the ANSR defines the medium and long-term road safety targets with the support of external expertise, local authorities are invited to participate in the process of elaboration of programmes. 
The main stakeholders within the road safety sector are:

- other ministries, such as the Ministry of Education, the Ministry of Economy and the Ministry of Justice

- universities, insurance companies, concession companies

- non-governmental organisations and associations, such as automobile associations, the Portuguese Road Accident Prevention, the Auto-mobilized Citizens Association, the Children Safety Promotion, etc.

\section{Road safety strategy for 2016-20}

The road safety programme for the period 2008-15 has ended and the Council of Ministries approved on 20 April 2017 a new National Road Safety Strategy for the years 2016-20 (“PENSE 2020").

\section{Road safety targets}

Portugal exceeded the target defined for the year 2015 (6.2 fatalities per 100000 inhabitants), with a death rate 6.1 fatalities per 100000 inhabitants in 2013 and 2014, with further improvement in 2015 to a fatality rate of 5.7, well below the set target.

PENSE 2020 establishes the following targets for 2020:

- A maximum of 41 deaths per million inhabitants by 2020 , representing a reduction of $56 \%$ compared to 2010 level.

- A maximum of 178 serious injuries MAIS3+ per million inhabitants by 2020, representing a reduction of $22 \%$ compared to 2010 level.

The National Authority for Road Safety (ANSR) has also defined new strategic targets, following the five pillars of the "Decade of Action for Road Safety" plan, 13 operational objectives and an action plan, including 107 measures. All the targets and respective actions and measures should be evaluated.

Figure 32.7. Trends in road fatalities towards national target

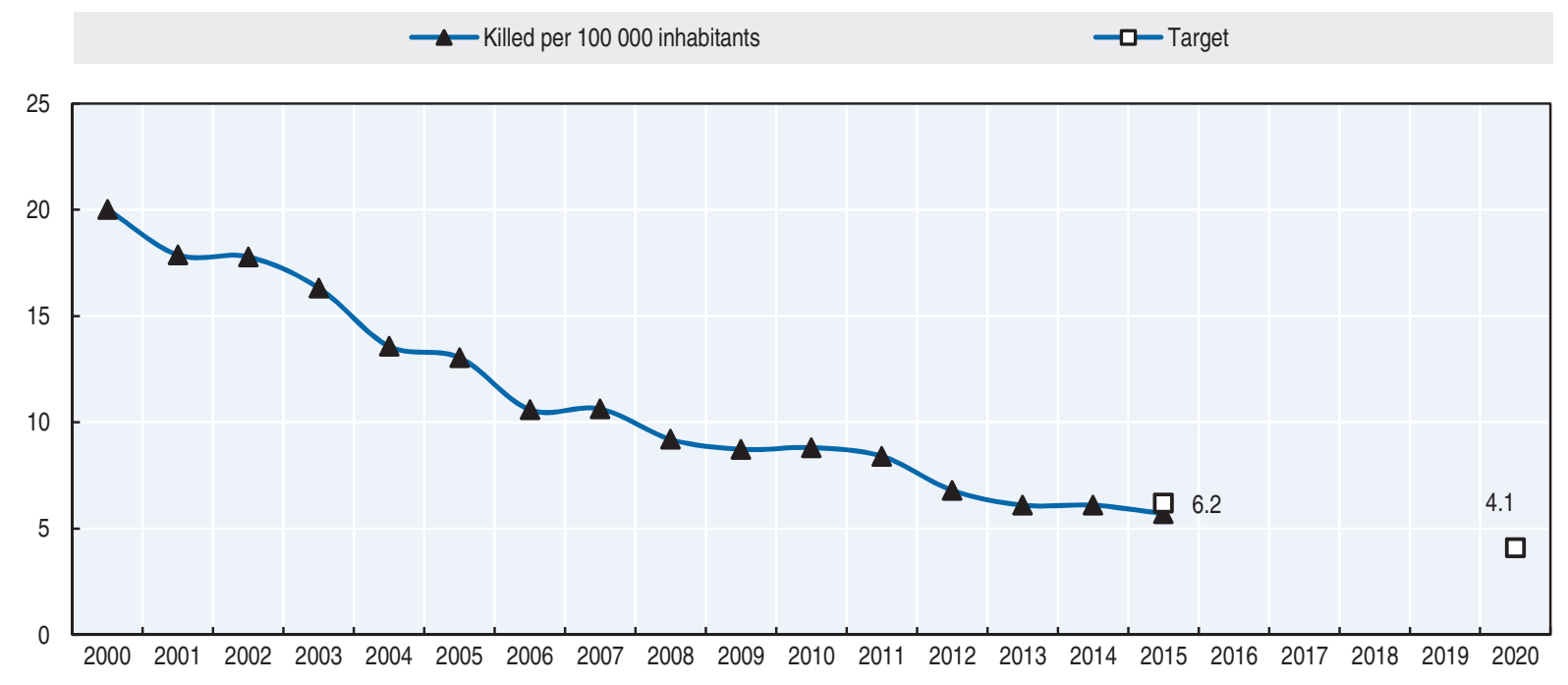




\section{Recent safety measures (2014-17)}

\section{Road safety management}

- From 1 January 2016 road accident data are electronically collected by the National Republican Guard (GNR). Data are transferred to the National Authority for Road Safety (ANSR) that carries out some corrections and inserts the deaths occurring within 30 days that are communicated by both policy authorities (GNR and PSP) into the national database.

- The ANSR promoted a Star Rating and investment plan for the national road n 118 (EN118), according to EuroRap Methodology.

\section{Road users}

\section{Speed management}

- The SINCRO project (installation of automatic speed cameras) will begin to operate in the second half of 2017.

\section{Education and awareness}

- As in previous years, in 2015 and 2016 the ANSR undertook annual road safety campaigns, namely at Easter, during the summer and the Christmas/New Year holiday period, which were related to fatigue, alcohol and speed, and during the months of May and October for "The pilgrimage to Fatima".

\section{References}

World Bank (2017), “GDP (constant US\$)”, World Development Indicators, http://databank.worldbank.org/ data/reports.aspx?source=world-development-indicators (accessed 23 February 2017).

\section{Websites (all accessed 22 May 2017)}

- National Authority for Road Safety (ANSR; Autoridade Nacional de Segurança Rodoviária): www.ansr.pt.

- Mobility and Transport Institute (IMT; Instituto Mobilidade e Transportes): www.imt-ip.pt.

- Public Security Police (PSP; Polícia Segurança Pública): www.psp.pt.

- National Republican Guard (GNR; Guarda Nacional Republicana) ): www.gnr.pt. 


\section{Chapter 33}

\section{Serbia}

This chapter presents 2015 road safety data for Serbia along with preliminary data from 2016. It looks at trends in traffic and road safety from the years 1990 to 2015 and road user behaviour patterns with a special focus on the ageing population. Sections include data on speed, drink driving, drugs and driving, distracted driving, fatigue and seat belt use. The chapter reviews Serbia's road safety strategy and national targets to 2020 and the progress achieved thus far. It also provides details of all recently implemented safety measures and current and ongoing research.*

* The Republic of Serbia joined the International Road Traffic and Accident Database (IRTAD) group in 2013. Data and information provided in this report stem from the Road Traffic Safety Agency (RTSA) unless otherwise noted and have not been validated by IRTAD. For more information contact: andrijana.pesic@abs.gov.rs or jovica.vasiljevic@abs.gov.rs. 
Following serbia's lowest year on record in 2014, fatalities increased by $12 \%$ in 2015 with 599 deaths on the roads. Preliminary data from 2016 indicate a similar trend with a small increase to 607 fatalities. Overall, Serbia has seen a decrease in fatalities of $42 \%$ since 2000 and around 9\% since 2010. The fatality rate was 8.4 for 100000 inhabitants in 2015. In 2015, there was a marked reduction of $32.6 \%$ in motorcyclist fatalities. Conversely, cyclist fatalities increased by $36 \%$.

A new integrated road safety database was completed in 2016 contributing to more detailed and accurate data on accidents.

\section{Road safety data collection}

\section{Definitions applied in Serbia}

- Road fatality: Any person who died immediately or within 30 days as a result of a road crash.

- Serious injury: Serbia has not yet adopted a definition for serious injury in police records.

- Slight injury: Serbia has not adopted a definition for slight injury in police records.

Although there are no national definitions for serious or slight injuries, certain criteria exist for both categories enabling doctors to determine the degree of injury of a person involved in a road accident. During 2017, Serbia will look at implementing MAIS3+ criteria and the necessary requirements (resources, stakeholders). Later in 2017, the Road Traffic Safety Agency (RTSA) will launch a programme with all involved stakeholders to improve the way road accident injury data is collected, including changes in database, training courses, etc.

\section{Data collection}

Data on road deaths have been available since 1981. More detailed information on road crashes is available from 1996 onward and is included in the police crash database established in 1996. The latest major revision of the road accident database was conducted in 2015 and 2016. Following these revisions, the road accident database is now completely harmonised with the European Commission Common Accident Data Set (CADaS) requirements and since 1 January 2016, traffic police have been collecting data on road crashes in accordance with the CADaS recommendations. Around 400 police officers have received training to improve the data collection process during a crash scene investigation.

Traffic police must attend the scene of all fatal and injury road crashes and crashes with important material damage (above RSD 200000 [EUR 2 000]). They are responsible for securing the site, organising relief and collecting data. For other crashes, participants are allowed to fill in a special form, without calling traffic police. However, if one of the participants requests the presence of the police, they are required to attend the crash scene. Data on crashes not covered by the traffic police are collected by insurance companies.

Information on injury severity is recorded by the traffic police based on information from hospitals. Hospitals are obliged to inform the police of every person admitted to hospital claiming to have been involved in a road crash. There is no information on the level of underreporting. 
A project entitled "New Road Crash Database", funded by the World Bank, was finalised in 2016. The main aim of the project is to connect all relevant road safety data holders into an integrated database managed by the RTSA. The crucial data stakeholders are the Ministry of the Interior (Traffic Police Directorate), the RTSA and the public enterprise "Roads of Serbia". Data exchange between institutions has been improved and there are also additional datasets publicly available. Another significant improvement is the public availability of the location of road crashes, as the main prerequisite for the spatial analysis of road accidents.

This integrated road safety database (operated by the RTSA) has already been publicly available since June 2015 via a WEB GIS application, which has also recently been improved through the same project financed by the World Bank (http://en.abs.gou.rs/database (English); http://abs.gou.rs/gis-baza (Serbian).

The development of this integrated road safety database is not yet complete, with improvement in data accuracy and the inclusion of additional datasets related to road safety yet to come.

\section{Most recent safety data}

\section{Road crashes in 2016 (preliminary data)}

In 2016, there were 607 reported road fatalities in the Republic of Serbia. This closely corresponds to the fatality numbers observed in 2015 (599). The number of slight injuries also increased in 2016 (17 278). However, the number of seriously injured persons in road accidents decreased (3 363).

Increases in the number of injured persons were observed for all road user groups during 2016 (in comparison with 2015), except for moped riders and passengers, and drivers and passengers of heavy goods vehicles. In terms of age, there was an increase in the number of all injured persons for all three vulnerable age groups: children, young people and those above 65 years of age.

However, although the total number of fatalities increased in 2016, the number of fatalities among the 65+ population decreased (146 in 2016 compared to 176 in 2015, a decrease of about 17\%). A decrease in the number of fatalities among pedestrians and cyclists was also recorded.

\section{Road crashes in 2015}

In 2015, there were 599 reported road deaths, i.e., an almost $12 \%$ increase compared to 2014 (536 in 2014), which was the best year in terms of road fatalities since 1981.

The number of fatalities increased for all user groups, except motorcyclists and moped riders. The number of killed motorcyclists was reduced by $32.6 \%$ in 2015 , while the number of moped riders killed remained at the 2014 level. The number of injured persons and injury crashes in 2015 increased by $7.5 \%$ and 5\%, respectively.

\section{Trends in traffic and road safety (1990-2016) Traffic}

Between 2001 and 2015, the number of registered motorised vehicles increased by almost 28\%. Between 2010 and 2015, there was continued growth in the number of registered vehicles reaching an overall increase of $18.9 \%$. 


\section{Road safety}

\section{Crashes and casualties}

The number of fatalities in 2016 is almost $42 \%$ lower than in 2000 and almost $70 \%$ lower than 1990. The number of injury accidents, however, is characterised by yearly fluctuations. There was improvement between 1997 and 2005, but injury accidents started increasing again from 2005, reaching a peak in 2008 with 16672 injury road accidents. Since 2008, injury crashes decreased each year (except 2013), but started to increase again in 2015. The number of injury road accidents in 2016 was almost at the same level as 1997 and 1998.

A number of important measures have been implemented since the adoption of the Law on Road Traffic Safety in 2009, including:

- establishment of institutions such as the national Road Traffic Safety Coordination Body, Road Traffic Safety Agency, etc.

- introduction of a penalty point system

- introduction a graduated licensing system (in 2012)

- reduction of the maximum legal blood alcohol content (BAC) to $0.3 \mathrm{~g} / \mathrm{l}$

- introduction of a $50 \mathrm{~km} / \mathrm{h}$ speed limit in urban areas

- compulsory seat belt wearing for rear seats.

It is expected that the Republic of Serbia will adopt amendments and additions to the Law on Road Traffic Safety by the end of 2017. The main improvements expected are the introduction of procedures such as road safety inspections, road safety audits and black spot identification. In addition, regulations for novice drivers and those related to child restraint systems will be improved.

\section{Rates}

Fatality rates in 2015, measured per 100000 population and per 10000 registered vehicles decreased compared to 2010 by $7 \%$ and $24 \%$, respectively. In 2015 , the reported death rate per 100000 inhabitants was 8.4 , which is about $12 \%$ higher compared to rate of 7.5 recorded in 2014. Almost 486 persons were seriously injured per 100000 population during 2015. This was also an increase in comparison with 2014 (459 injured persons per 100000 population).

Table 33.1. Road safety and traffic data

\begin{tabular}{|c|c|c|c|c|c|c|c|}
\hline & \multirow{2}{*}{2000} & \multirow{2}{*}{2010} & \multirow{2}{*}{2014} & \multirow{2}{*}{2015} & \multicolumn{3}{|c|}{$2015 \%$ change from } \\
\hline & & & & & 2014 & 2010 & 2000 \\
\hline \multicolumn{8}{|l|}{ Reported safety data } \\
\hline Fatalities & 1048 & 660 & 536 & 599 & 11.8 & -9.2 & -42.8 \\
\hline Injury crashes & 12749 & 14197 & 13044 & 13654 & 4.7 & -3.8 & 7.1 \\
\hline Deaths per 100000 inhabitants & 13.9 & 9.0 & 7.5 & 8.4 & 12.3 & -6.8 & -39.5 \\
\hline Deaths per 10000 registered vehicles & & 3.6 & 2.6 & 2.8 & 8.3 & -23.7 & \\
\hline \multicolumn{8}{|l|}{ Traffic data } \\
\hline Registered vehicles ${ }^{1}$ (thousands) & & 1810 & 2085 & 2152 & 3.2 & 18.9 & \\
\hline Registered vehicles per 1000 inhabitants & & 248 & 292 & 302 & 3.7 & 22.1 & \\
\hline
\end{tabular}

1. Registered vehicles including mopeds. 
Figure 33.1. Road safety, traffic and GDP trends index $1990=100$

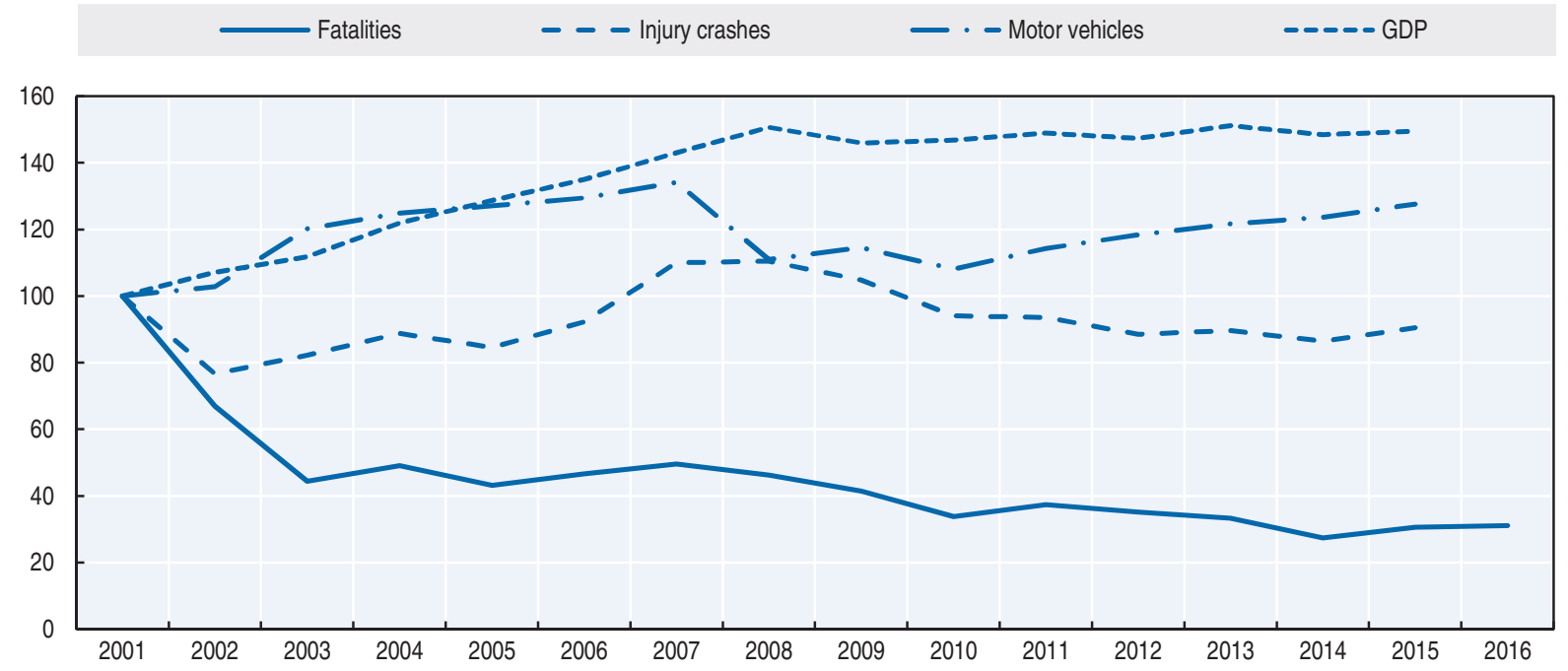

Source: World Bank (2017) (GDP; constant prices).

\section{Road safety by user group}

In 2015 , passenger car occupants represented $45 \%$ of traffic fatalities, pedestrians $27 \%$ and powered two-wheelers $7 \%$.

The number of motorcyclist fatalities increased significantly between 2000 and 2008, when it reached its highest value. Since 2009, the number of motorcyclist fatalities has decreased overall, with fluctuations from year to year, with a marked reduction of $32.6 \%$ in 2015.

Since 2010, the situation has improved for all road users, except cyclists. In 2015 in particular, the number of cyclists killed increased by $36 \%$. Increases in fatalities were also observed in 2015 among pedestrians (+23.4\%) and car occupants (+10.2\%). The situation for moped riders for the same time period remained unchanged.

Table 33.2. Road fatalities by road user group

\begin{tabular}{lrrrrr|rrrr}
\hline & 2000 & 2010 & 2013 & 2014 & 2015 & \multicolumn{4}{c}{$2015 \%$ change from } \\
\cline { 7 - 10 } & & & & & & 2014 & 2013 & 2010 & 2000 \\
\hline Pedestrians & 315 & 172 & 175 & 128 & 158 & 23.4 & -9.7 & -8.1 & -49.8 \\
Cyclists & 129 & 65 & 59 & 50 & 68 & 36.0 & 15.3 & 4.6 & -47.3 \\
Moped riders & 40 & 20 & 19 & 13 & 13 & 0.0 & -31.6 & -35.0 & -67.5 \\
Motorcyclists & 29 & 48 & 37 & 43 & 29 & -32.6 & -21.6 & -39.6 & 0.0 \\
Car occupants & 424 & 282 & 300 & 244 & 269 & 10.2 & -10.3 & -4.6 & -36.6 \\
Others & 111 & 73 & 60 & 58 & 62 & 6.9 & 3.3 & -15.1 & -44.1 \\
Total & $\mathbf{1 0 4 8}$ & $\mathbf{6 6 0}$ & $\mathbf{6 5 0}$ & $\mathbf{5 3 6}$ & $\mathbf{5 9 9}$ & $\mathbf{1 1 . 8}$ & $\mathbf{- 7 . 8}$ & $\mathbf{- 9 . 2}$ & $\mathbf{- 4 2 . 8}$ \\
\hline
\end{tabular}


Figure 33.2. Road fatalities by road user group in percentage of total, 2015

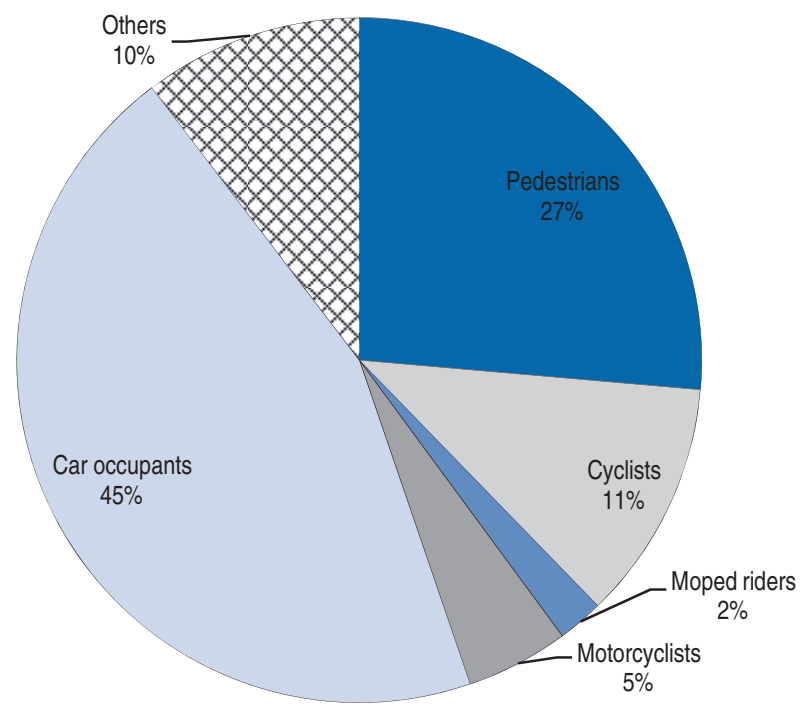

\section{Road safety by age group}

Since 2000, children under 14 have mostly benefited from road safety improvements. The situation was much improved for young people aged 15-17 and 18-20, with fatality reductions of $57 \%$ and $62 \%$, respectively. During 2000 , almost $60 \%$ of all children with serious injuries from road accidents were pedestrians, while during 2015 about $40 \%$ were pedestrians and $40 \%$ were passengers. Children are becoming more vulnerable as car passengers than as pedestrians.

Older people are particularly vulnerable, with a fatality rate (for $65+$ persons) of more than 14 per 100000 inhabitants of the 65 and over age group, which is almost twice the average rate. Half of the pedestrians killed in road traffic during 2015 were aged 65 and over. During whole period from 2010 to 2015, almost 50\% of all pedestrians killed in road accidents were aged 65 and over. While overall the situation for the persons aged 65+ improved between 2000 and 2015, with the reduction of $50 \%$ in the number of fatalities, the trend is still not stable (fatalities increased in 2015, but decreased in 2016).

Table 33.3. Road fatalities by age group

\begin{tabular}{lrrrrr|rrrr}
\hline \multirow{2}{*}{ Age } & 2000 & 2010 & 2013 & 2014 & 2015 & \multicolumn{4}{|c}{$2015 \%$ change from } \\
\cline { 7 - 10 } & & & & & & 2014 & 2013 & 2010 & 2000 \\
\hline $0-14$ & 43 & 24 & 11 & 10 & 14 & 40.0 & 27.3 & -41.7 & -67.4 \\
$15-17$ & 21 & 8 & 11 & 13 & 9 & -30.8 & -18.2 & 12.5 & -57.1 \\
$18-20$ & 50 & 31 & 34 & 31 & 19 & -38.7 & -44.1 & -38.7 & -62.0 \\
$21-24$ & 89 & 50 & 45 & 46 & 46 & 0.0 & 2.2 & -8.0 & -48.3 \\
$25-64$ & 587 & 389 & 377 & 306 & 335 & 9.5 & -11.1 & -13.9 & -42.9 \\
$65-74$ & 181 & 64 & 85 & 48 & 92 & 91.7 & 8.2 & 43.8 & -49.2 \\
$75-84$ & 67 & 76 & 74 & 63 & 75 & 19.0 & 1.4 & -1.3 & 11.9 \\
$\geq 85$ & 9 & 14 & 11 & 19 & 9 & -52.6 & -18.2 & -35.7 & 0.0 \\
Total & $\mathbf{1 0 4 8}$ & $\mathbf{6 6 0}$ & $\mathbf{6 6 0}$ & $\mathbf{5 3 6}$ & $\mathbf{5 9 9}$ & $\mathbf{1 1 . 8}$ & $\mathbf{- 9 . 2}$ & $\mathbf{- 9 . 2}$ & $\mathbf{- 4 2 . 8}$ \\
\hline
\end{tabular}


Figure 33.3. Road fatality rates by age group Deaths per 100000 inhabitants in a given age group, 2000-15

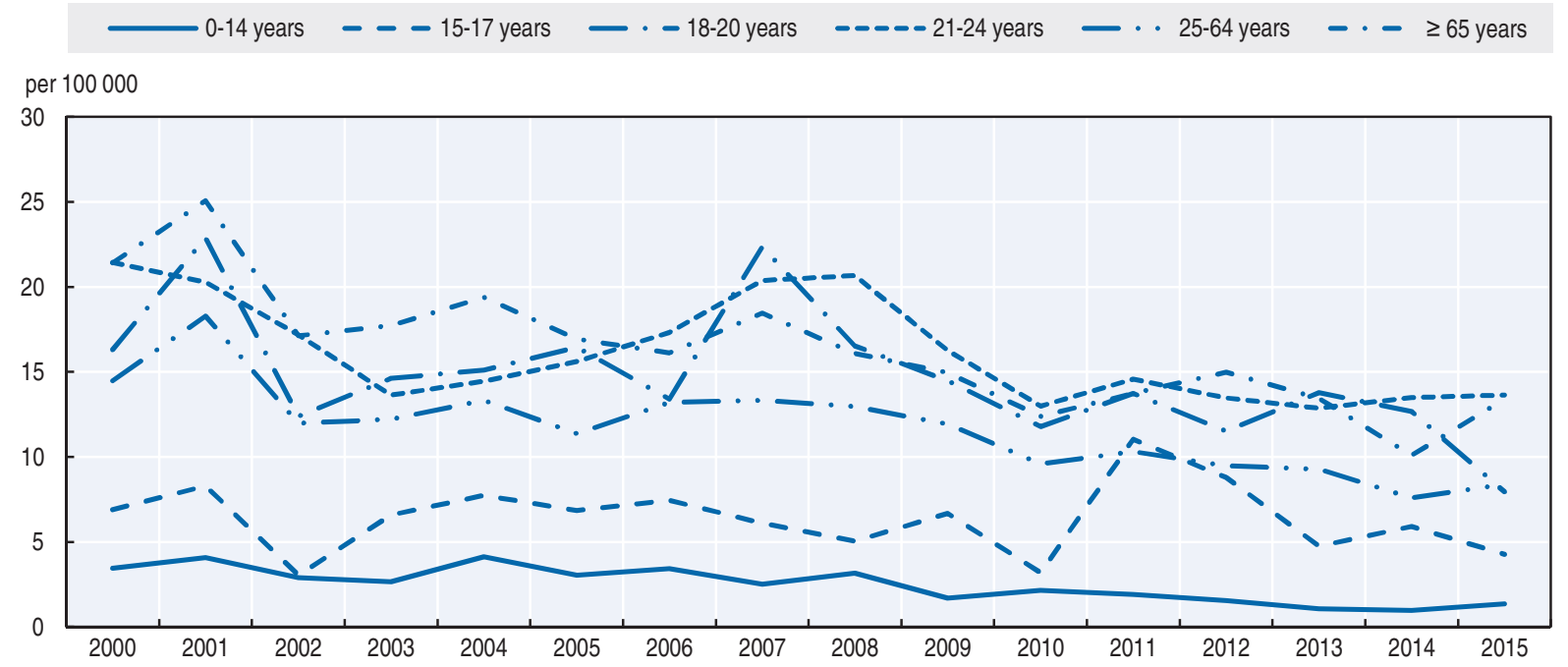

\section{Box 33.1. Road safety for an ageing population}

According to the latest population census from 2011 in the Republic of Serbia, there are about 1.2 million persons older than 65 which represents about $17 \%$ of the total population. It is expected that the number of persons aged over 65 will reach 1.6 million in 2030 (23.6\% of total population). The average age of the population is also increasing ( 40.2 was the average population age in 2002, while it was at 42.7 in 2015).

In 2015, 176 people of 65 and above were killed in traffic crashes, representing 30\% of all road deaths. Almost half of them were pedestrians. It is also characteristic that approximately $50 \%$ of all pedestrians killed are persons older than 64 .

Driving licences for persons over 65 are issued for a maximum of 5 years (compared to 10 years for drivers under 65). A medical certificate is necessary to obtain the driving licence. The medical examinations required depend on the driving licence category.

Table 33.4. Road fatalities among senior citizens

\begin{tabular}{lrr|rr|rc}
\hline & \multicolumn{2}{c|}{$65-74$} & \multicolumn{2}{c|}{$75-84$} & \multicolumn{2}{c}{$85+$} \\
\cline { 2 - 7 } & 2010 & 2015 & 2010 & 2015 & 2010 & 2015 \\
\hline Pedestrians & 22 & 37 & 46 & 35 & 10 & 6 \\
Cyclists & 17 & 19 & 9 & 15 & 2 & 1 \\
Moped riders & 1 & 4 & 2 & 0 & 0 & 0 \\
Motorcyclists & 0 & 0 & 0 & 0 & 0 & 0 \\
Car occupants & 13 & 24 & 11 & 16 & 1 & 2 \\
Total & $\mathbf{6 4}$ & $\mathbf{9 2}$ & $\mathbf{7 6}$ & $\mathbf{7 5}$ & $\mathbf{1 4}$ & $\mathbf{9}$ \\
\hline
\end{tabular}




\section{Box 33.1. Road safety for an ageing population (cont.)}

Figure 33.4. Road fatality rates by age group - focus on the senior population Deaths per 100000 inhabitants in a given age group, 2000-15

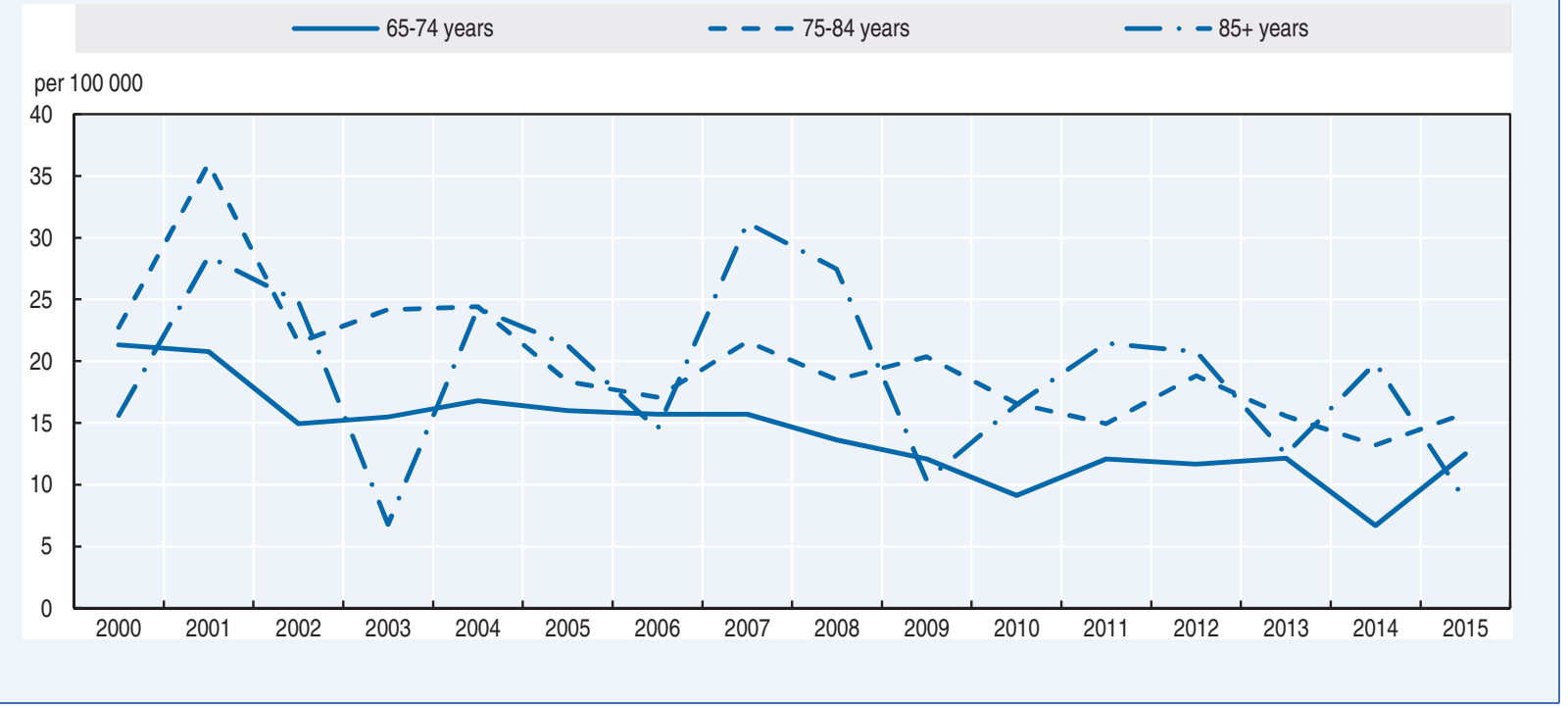

Figure 33.5. Road fatality rate by age and road user group Fatalities per 100000 inhabitants, 2015

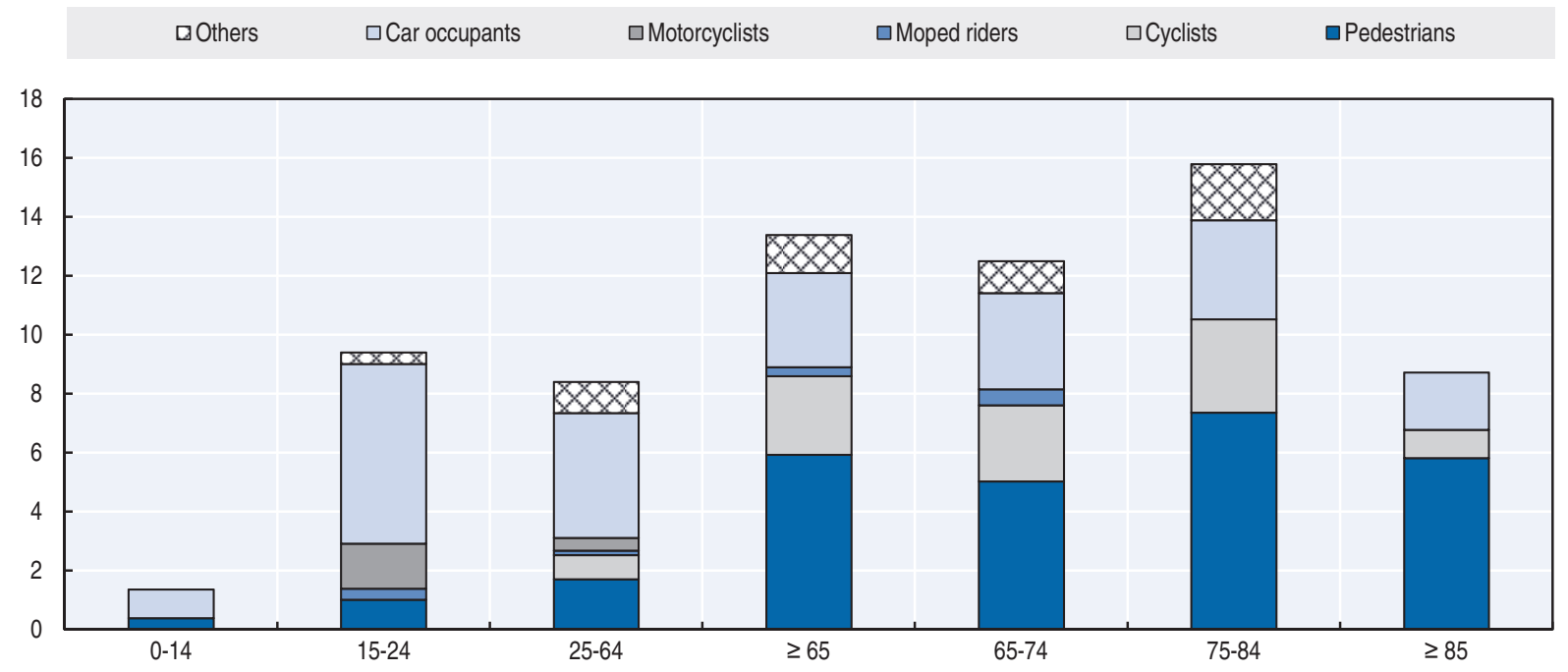

\section{Road safety by road type}

Unlike most other IRTAD countries, the majority of fatalities occur inside built-up areas. In $2015,62.6 \%$ of fatalities occurred inside urban areas, $27.5 \%$ on rural roads and $9.8 \%$ on motorways. In 2015 , fatalities were reduced only in the urban areas (-14\%). Significantly higher numbers of persons were killed in road accidents both on rural roads and motorways in 2015 compared to 2014. 
The most common problems in built-up areas are the following:

- main state roads pass through built-up areas

- local roads and street networks lack adequate features to protect vulnerable road users, especially pedestrians and cyclists.

In 2016 , almost $12 \%$ of all injury crashes were influenced by the road type. Improvements in the data collection process for road accidents should improve awareness on the influence of road design on accidents and the level of injuries.

Figure 33.6. Road fatalities by road type

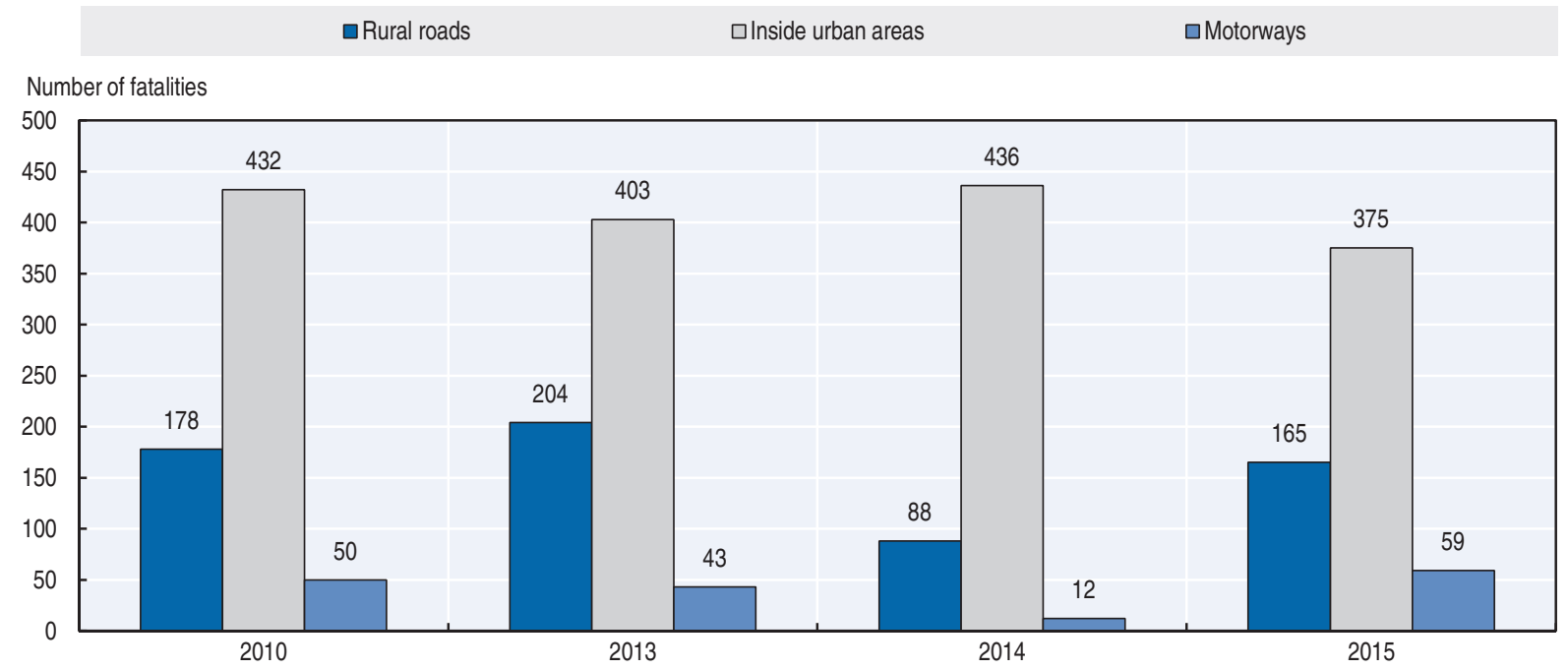

\section{Economic costs of traffic crashes}

Based on a recent study (Ross et al., 2012), in 2012 road crashes represented a total cost of about EUR 321.3 million. This estimate was used to guide development of Serbia's road traffic safety strategy for 2015-20.

\section{Recent trends in road user behaviour \\ Speed}

Speeding is determined as the most frequent cause of road crashes in Serbia. In 2015, excessive or inappropriate speed was identified as a factor in $53 \%$ of fatal road crashes, with preliminary data from 2016 indicating that this has increased to $56 \%$. The improvement in the road accident data collection process from January 2016 will enable a more precise analysis of crash contribution factors, including the contribution of excessive speed for various types of crashes.

Speed measurement conducted in 2016 showed that 54\% of passenger car drivers exceeded the speed limit in urban areas (51\% in 2015). This share is $37 \%$ on motorways and $34 \%$ on all other roads outside urban areas.

The table below summarises the main speed limits in Serbia. 
Table 33.5. Passenger car speed limits by road type

\begin{tabular}{lcc}
\hline & General speed limit & Comments \\
\hline Urban roads & $50 \mathrm{~km} / \mathrm{h}$ & $\begin{array}{c}\text { Speed limits for novice drivers are } 90 \% \\
\text { of the defined speed limits on certain roads. }\end{array}$ \\
Rural roads & $80 / 100^{*} \mathrm{~km} / \mathrm{h}$ & \\
Motorways & $120 \mathrm{~km} / \mathrm{h}$ & \\
\hline
\end{tabular}

* Speed limit on roads (usually called "motor roads") dedicated only to motorcyclists, passenger cars, cargo vehicles and buses, with or without trailers, marked by a special traffic sign.

\section{Drink driving}

In Serbia, the maximum authorised blood alcohol content (BAC) is $0.3 \mathrm{~g} / \mathrm{l}$. The limit of $0.0 \mathrm{~g} / \mathrm{l}$ is applied to the following categories of road users:

- drivers of motor vehicles registered for the transport of more than 8 passengers (not including driver)

- drivers of vehicles with a maximum allowed weight over than 3.5 tonnes

- drivers of motor vehicles for the public transport of people or goods

- drivers of vehicles for special transport or the transport of dangerous goods

- drivers of motorcycles, mopeds, light tricycles and quadricycles

- driving instructors and examiners

- novice drivers and persons who supervise novice drivers

- drivers of vehicles with priority right of way or vehicles in a police escort.

Over the past 10 years (2005-15), about $8 \%$ of fatal crashes were attributed to drink driving. However, measurement of causal factors for each road accident (collected by trained police officers and available only from 2016), has changed that proportion. About $17 \%$ fatal road crashes were related to driving under the influence of alcohol during 2016.

\section{Drugs and driving}

The Law on Road Traffic Safety forbids driving under the influence of illicit drugs. Driving under the influence of drugs or forbidden medications was detected as a factor in only 4 road accidents with fatalities and in 6 road accidents with injuries during 2016. Improvement in data related to driving under the influence of drugs is needed to fully recognise the scale of the problem.

\section{Seat belts and helmets}

Seat belt use has been compulsory for front seats since 1982 and for rear seats since 2009. Child restraints have been compulsory since 2009 for children up to 3 years old. Amendments and additions to the Law on Road Traffic Safety will include new requirements, in particular dedicated child seats for all children between under 12 years of age and below $135 \mathrm{~cm}$ in height.

A roadside survey undertaken in 2016 indicated that the seat belt wearing rate is $77 \%$ for front-seat occupants and $10.1 \%$ for rear-seat occupants. Child restraint use is $40.2 \%$ for children up to 3 years old and only 17.2\% for children between 4 and 12 years old.

All riders of powered two-wheelers must wear a protective helmet. In 2016, the helmet-wearing rate was $80 \%$ for moped riders and $91 \%$ for motorcyclists. 
Table 33.6. Seat belt wearing rate by car occupancy and road type

\begin{tabular}{|c|c|c|c|c|}
\hline & 2013 & 2014 & 2015 & 2016 \\
\hline \multicolumn{5}{|l|}{ Front seat } \\
\hline Driver & 70 & 72 & 74 & 77 \\
\hline Passenger & 68 & 70 & 73 & 73 \\
\hline Urban roads (driver) & 65 & 66 & 70 & 74 \\
\hline Rural roads (driver) & 72 & 73 & 78 & 77 \\
\hline Motorways (driver) & 81 & 84 & 83 & 85 \\
\hline \multicolumn{5}{|l|}{ Rear seats } \\
\hline General & 3 & 4 & 7 & 10 \\
\hline \multirow[t]{2}{*}{ Children (use of child restraint) } & $32(0-3)$ & $36(0-3)$ & $44(0-3)$ & $40(0-3)$ \\
\hline & $7(4-12)$ & $9(4-12)$ & $15(4-12)$ & $17(4-12)$ \\
\hline
\end{tabular}

There is no mandatory helmet law for cyclists.

A brochure about road safety performance indicators measurement results in 2016 is available at the following link: http://en.abs.gou.rs/download/1046 (English, accessed 22 May 2017).

\section{Distraction}

Distracted driving is recognised as a growing problem in Serbia. However there are no adequate surveys to assess the extent of the phenomenon. Mobile phone use by the driver was reported as a factor in only 15 injury road accidents during 2016 (out of 14404 injury road accidents). Additional methods for adequate evaluation of the extent of the problem are needed.

Since 2009, it is illegal to use a hand-held mobile phone or similar device while driving (hands-free devices are allowed). The penalty for this is about EUR 50. It is also illegal for a pedestrian to use a mobile phone or headset while crossing a street.

\section{Fatigue and sleepiness}

In 2016, fatigue was reported as the contributing factor in 247 injury road crashes (almost $2 \%$ of total injury road accidents). However, fatigue has been reported as a factor in about $4.3 \%$ all fatal road accidents in 2016.

\section{National road safety strategies and targets Organisation of road safety}

In Serbia, the leading agency for road safety is the Ministry of Transport with support from the Road Traffic Safety Agency (RTSA). The national Road Traffic Safety Co-ordination Body is composed of ministers in charge of traffic issues, interior affairs, health, labour, justice, education, and trade and services, with the main aim being to establish co-operation and harmonise efforts to improve road safety.

The government established the RTSA to manage legal and technical issues in the field of road traffic safety. The agency also co-operates with regional and local bodies for road traffic safety.

\section{Road safety strategy for 2015-20}

In June 2015, the Republic of Serbia adopted the National Strategy for Road Traffic Safety for the period 2015-20. 


\section{Road safety targets and monitoring}

The strategy 2015-20 includes several targets:

- No children killed in traffic by 2020.

- Reduce the number of road deaths and those seriously injured by 50\% between 2011 and 2020.

- To halve, between 2011 and 2020, the total annual social-economic costs of road crashes.

To guide actions towards the achievement of these goals, a set of performance indicators has been established based on recommendations from the European SafetyNet project.

Table 33.7. European SafetyNet recommended road safety targets

\begin{tabular}{|c|c|c|}
\hline Performance indicators & 2016 level & Target 2020 \\
\hline \multicolumn{3}{|l|}{ Indicators on the use of protective equipment } \\
\hline Wearing rate of safety belts on front seats in passenger cars & 77.0 & 95 \\
\hline Wearing rate of safety belts on rear seats in passenger cars & 10.1 & 85 \\
\hline Percentage of the usage of dedicated child restraint system for children under the age of 3 & 40.2 & 96 \\
\hline Wearing rate of protective helmets by riders of motorcycles & 90.6 & 99 \\
\hline Wearing rate of protective helmets by riders of mopeds & 80.2 & 99 \\
\hline \multicolumn{3}{|l|}{ Indicators related to speeding } \\
\hline Percentage of drivers over the speed limit in daylight conditions in urban areas & 53.8 & 19 \\
\hline Percentage of drivers over the speed limit in daylight conditions outside urban areas & 34.2 & 19 \\
\hline Percentage of drivers over the speed limit in daylight conditions on motorways & 36.9 & 19 \\
\hline Percentage of drivers $10 \mathrm{~km} / \mathrm{h}$ or more above the speed limit in daylight conditions in urban areas & 17.9 & 4.9 \\
\hline Percentage of drivers $10 \mathrm{~km} / \mathrm{h}$ or more above the speed limit in daylight conditions outside urban areas & 11.5 & 4.9 \\
\hline Percentage of drivers $10 \mathrm{~km} / \mathrm{h}$ or more above the speed limit in daylight conditions on motorways & 18.5 & 9.9 \\
\hline \multicolumn{3}{|l|}{ Indicator related to drink driving } \\
\hline Percentage of drivers under the influence of alcohol & 0.71 & 0.1 \\
\hline \multicolumn{3}{|l|}{ Indicator related to the use of daytime running lights } \\
\hline Percentage of usage of daytime running lights by passenger cars & $97(2015)$ & 99 \\
\hline
\end{tabular}

Figure 33.7. Trends in road fatalities towards national target

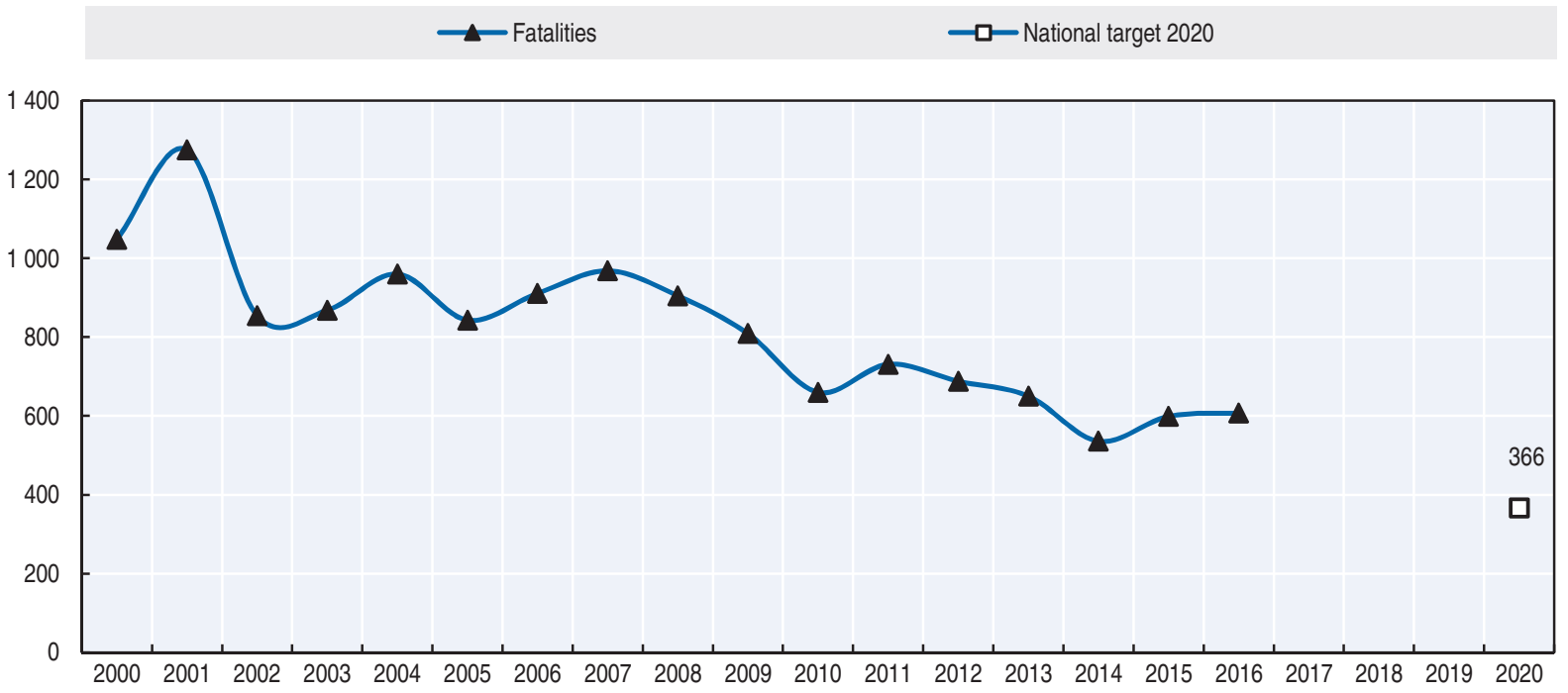




\section{Recent safety measures (2014-17)}

\section{Road safety management}

- During 2016, the RTSA continued its safety analysis of each local community in Serbia (161 local communities). Safety analysis is based on road crash data, injuries and safety performance indicators. The objective is to provide all local communities with a basic and common review so that they can quickly create measures based on the data. Specific short reports on road safety have been prepared for each local community and are available to the public at $h$ ttp://abs.gou.rs/statistika-lokalne-samouprave (Serbian only; accessed 22 May 2017).

\section{Safety data management}

- Preparation for use of MAIS 3+ scale for injuries has been planned for 2017. Collection of data on road accidents has been fully based on CADaS protocol from the beginning of 2016. The RTSA is working together with the Ministry of the Interior (Road Traffic Police Department) on improving the precision of collected data (improvement of database).

- In 2015, Serbia completed training of the traffic police to collect data on road accidents according to the CADaS recommendations by the European Commission.

- Since 2015, the Road Safety Database is publicly available through the Web GIS Application (http://en.abs.gov.rs/database). The application was updated during 2016 (project financed by the World Bank). Users are able to choose filters and columns for data exporting and can easily obtain a wide range of analyses.

\section{Road users}

\section{Awareness campaigns}

- The RTSA conducts several road safety campaigns each year. During 2016 emphasis was on motorcycle safety, restraint system usage, driving under the influence of alcohol, 65+ participants in traffic and the campaign "My personal story" for those with disabilities. As each local community has its own fund for road safety improvement, they can organise individual activities in the field of human behaviour and infrastructure development.

\section{Education, training and enforcement}

- The RTSA manages two important educational projects. The first is peer education for future drivers in high schools. The second is called "I'm still driving", in which paraplegics injured in a road crash present the importance of safe behaviour in road traffic through their own experience. The RTSA also regularly conducts education for children in elementary schools through a mascot who knows all the road traffic rules and behaves safely in traffic.

- The RTSA has also introduced seminars for lecturers in pre-schools, primary and secondary schools. The seminar is free of charge and lecturers receive points needed for their professional improvement process. The aim of this seminar is to improve the professional competencies of lecturers on road safety. Lecturers are in contact with pupils, and that potential may be used to increase of road safety awareness.

\section{Infrastructure}

- The Republic of Serbia is in the process of adopting amendments and additions to the Law on Road Traffic Safety. These amendments will introduce a road safety inspection and audit process, and describe in detail the responsibilities and organisation of these activities. 


\section{Recent and ongoing research}

Five important research projects were completed in 2016:

- Guide for road safety improvement. Consists of 48 different measures for road safety improvement. Guide to be used by local road safety authorities.

- Methodology for black spot identification. Government proposal for a new national definition for potential black spots based on road accident locations information from police records (road accident coordinates are being collected from 2015).

- Benchmarking of road safety for closed systems. Methodology and case study (three companies) for benchmarking of road safety in different closed systems (for example, transport companies).

- Benchmarking of road safety at national level. Results provided guidelines for each institution at national level whose work is related to road safety (guidelines are based on good practice in EU countries that have a long and successful tradition in terms of road safety management).

- Measurement of road safety performance indicators (SPIs) in 2016. The RTSA continued its ongoing research on SPIs (started in 2013). Research in 2016 also included a pilot project on SPIs related to pedestrian behaviour.

More information can be found at: http://en.abs.gou.rs/brochures (accessed 22 May 2017).

\section{References}

Ross et al. (2012), Costs of road accidents, The Republika Srpska, Banja Luka.

World Bank (2017), “GDP (constant US\$)”, World Development Indicators, http://databank.worldbank.org/ data/reports.aspx?source=world-development-indicators (accessed 23 February 2017).

\section{Websites}

- Road Traffic Safety Agency of Serbia: www.abs.gou.rs (accessed 22 May 2017). 


\section{Chapter 34}

\section{Slovenia}

This chapter presents 2015 road safety data for Slovenia along with provisional data from 2016. It looks at trends in traffic and road safety from the years 1990 to 2015 and road user behaviour patterns with a special focus on the ageing population. Sections include data on speed, drink driving, drugs and driving, distracted driving, fatigue and seat belt use. The chapter reviews Slovenia's road safety strategy and national targets to 2022 and the progress achieved thus far. It also provides details of all recently implemented safety measures and current and ongoing research.*

\footnotetext{
* All data stem from the Slovenian Traffic Safety Agency and IRTAD unless otherwise noted. For more information please contact: andraz.murkovic@avp-rs.si.
} 
Slovenia recorded an 11\% increase in fatalities in 2015, with provisional data for 2016 indicating a further increase of $8 \%$ from 120 deaths to 130 . The fatality rate was at 5.8 per 100000 inhabitants in 2015.Vulnerable road users accounted for $47 \%$ of fatalities, the highest share in five years. The over 65 age group are most at risk in traffic, and comprised $24 \%$ of all fatalities in 2015. Slovenia did not reach its 2015 interim target of 115 fatalities; although progress has been made with an overall decrease, since 2010 , of $13 \%$ in the number of fatalities and injury crashes.

\section{Road safety data collection}

\section{Definitions applied in Slovenia}

- Road fatality: Any person killed immediately or dying within 30 days as a result of a road crash.

- Seriously injured person: Any person who sustains injuries from a road traffic crash entailing temporary or permanent health damage or temporary or permanent reduced ability to work.

- Slightly injured person: Any person injured excluding persons seriously injured.

\section{Data collection}

In Slovenia, crash data are collected by the police, who are the main source of information for road fatalities and injuries. The police confirm information on the severity of injuries with the hospitals. But there is not as yet any procedure in place for linking data.

With support from the Institute of Public Health, the Traffic Safety Agency has started work on estimating the number of persons injured with a Maximum Abbreviated Injury Scale of 3 or more (MAIS3+), using the conversion tables provided by the European Commission to convert injury information based on the 10th revision of the International Statistical Classification of Diseases and Related Health Problems (ICD-10) into MAIS3+ data. Further work is still needed before Slovenia can publish official MAIS3+ data.

\section{Most recent safety data}

\section{Road crashes in 2016 - provisional data}

In 2016, there were 125 fatal crashes and 130 persons were killed, 10 more than in 2015 (an increase of $8 \%$ ). The number of people severely injured decreased by $8 \%$, to 850 .

The highest increase in fatalities was recorded among pedestrians $+38 \%$ (22 killed in 2016, 16 in 2015) and passenger car drivers $+11 \%$ (61 killed in 2016, 55 in 2015). The number of motorcyclists killed decreased by 11\% (22 killed in 2016, 25 in 2015), and the number of cyclists killed decreased by 7\% (13 killed in 2016, 14 in 2015).

The year 2016 was the second consecutive year showing an increase in fatalities. Several factors explain this negative trend, including a higher interaction between unprotected users and motorised road users in cities. 
In 2016, Slovenia saw an increase in driving under the influence of alcohol, which is partly attributable to weaker enforcement by police due to a strike in the first half of the year. The number of fatalities on motorways doubled compared to 2015. The increasing traffic (vehicle kilometres) on national motorways could have contributed to this result. The increase in fatalities was especially marked in the first half of 2016, while in the period between September and November a significant improvement was recorded - overall numbers of fatalities for those months were at a record low compared to the same period over the previous 25 years.

\section{Road crashes in 2015}

In 2015 , there were 120 fatalities on Slovenian roads, an $11 \%$ increase over 2014. The number of persons severely injured increased by $13 \%$ and slightly injured by $5 \%$ for the same time period.

Vulnerable road users (pedestrians, cyclists, powered two-wheeler riders) accounted for $47 \%$ of all fatalities in 2015 . This is the highest share of vulnerable road users killed in the last five year period. There were 55 car occupants killed (46\% of all fatalities), 25 motorcyclists (21\%), 16 pedestrians (13\%), 14 cyclists (12\%) and 10 fatalities among the other user group.

The largest share of fatalities in 2015 was in the over 65 age group (29 fatalities or 24\%) and those between 45 and 54 years old (22 fatalities or $20 \%$ ). The lowest share - $6 \%$ of the total, or 7 fatalities was for children and young people under the age of 18 .

The number of fatalities was above the declared goal of 115 fatalities or less for year 2015, which was adopted in the Resolution on the National Road Safety Programme for the period 2013-22.

In 2015, Slovenia recorded a higher level of fatalities than in 2014, but this number remains lower overall than in previous years and, on a multi-annual level, road safety is still improving. Overall road safety performance in 2015 was affected in part due to an exceptionally bad month in July 2015 (with 26 fatalities, 19 more than 2014). Following the end of the summer months a marked improvement was seen in road safety, with a low number of fatalities reported from September to December.

\section{Trends in traffic and road safety (1990-2016) Traffic}

Since 1990, traffic (in vehicle-kilometres) has more than doubled and the vehicle fleet has increased by more than $80 \%$. In the last eight years, the number of registered motorcycles increased by $65 \%$.

\section{Road safety}

\section{Crashes and casualties}

Fatalities peaked in 1979, when 735 people died on the roads. Since then the number of road deaths has steadily decreased, with a period of relative stagnation between 2002 and 2007. Fatalities declined noticeably from 2007 to 2010, most likely due to the new motorway toll system, regular media campaigns promoting road safety and the Road Safety Act that came into force in 2008. From 2010 to 2014, the number of road fatalities decreased by $22 \%$, from 138 to 108 . 
In 2013, Slovenia launched a new National Road Safety Programme 2013-22 with the goal of reducing the number of fatalities and severely injured by 50\% compared to 2011 (2011 was the last year of the National Road Safety Programme 2007-11). However, a negative trend emerged in 2015 and 2016, with an average 10\% year-on-year increase in the number of road deaths.

\section{Rates}

Between 1990 and 2015, the mortality rate, expressed in terms of deaths per 100000 inhabitants, was reduced by almost $80 \%$. The fatality risk expressed in terms of deaths per billion vehicle-kilometres was reduced by $90 \%$. In 2015 , Slovenia had a mortality rate of 5.8 deaths per 100000 inhabitants and a fatality risk of 6.7 deaths per billion vehiclekilometres.

Table 34.1. Road safety and traffic data

\begin{tabular}{|c|c|c|c|c|c|c|c|c|c|}
\hline & \multirow{2}{*}{1990} & \multirow{2}{*}{2000} & \multirow{2}{*}{2010} & \multirow{2}{*}{2014} & \multirow{2}{*}{2015} & \multicolumn{4}{|c|}{$2015 \%$ change from } \\
\hline & & & & & & 2014 & 2010 & 2000 & 1990 \\
\hline \multicolumn{10}{|l|}{ Reported safety data } \\
\hline Fatalities & 517 & 314 & 138 & 108 & 120 & 11.1 & -13.0 & -61.8 & -76.8 \\
\hline Injury crashes & & 8951 & 7596 & 6264 & 6585 & 5.1 & -13.3 & -26.4 & \\
\hline Deaths per 100000 inhabitants & 25.9 & 15.8 & 6.7 & 5.2 & 5.8 & 11.0 & -13.7 & -63.2 & -77.5 \\
\hline Deaths per 10000 registered vehicles & 6.9 & 3.2 & 1.0 & 0.8 & 0.9 & 9.3 & -17.0 & -73.2 & -87.5 \\
\hline Deaths per billion vehicle kilometres & 65.1 & 26.7 & 7.7 & 6.1 & 6.7 & 8.5 & -13.9 & -75.0 & -89.8 \\
\hline \multicolumn{10}{|l|}{ Traffic data } \\
\hline Registered vehicles ${ }^{1}$ (thousands) & & & 1332 & 1373 & 1395 & 1.6 & 4.8 & & \\
\hline Vehicle-kilometres (millions) & 7945 & 11759 & 17826 & 17578 & 18006 & 2.4 & 1.0 & 53.1 & 126.6 \\
\hline Registered vehicles per 1000 inhabitants & & & 651 & 666 & 676 & 1.5 & 4.0 & & \\
\hline
\end{tabular}

1. Registered vehicles including mopeds.

Figure 34.1. Road safety, traffic and GDP trends index $1995=100$

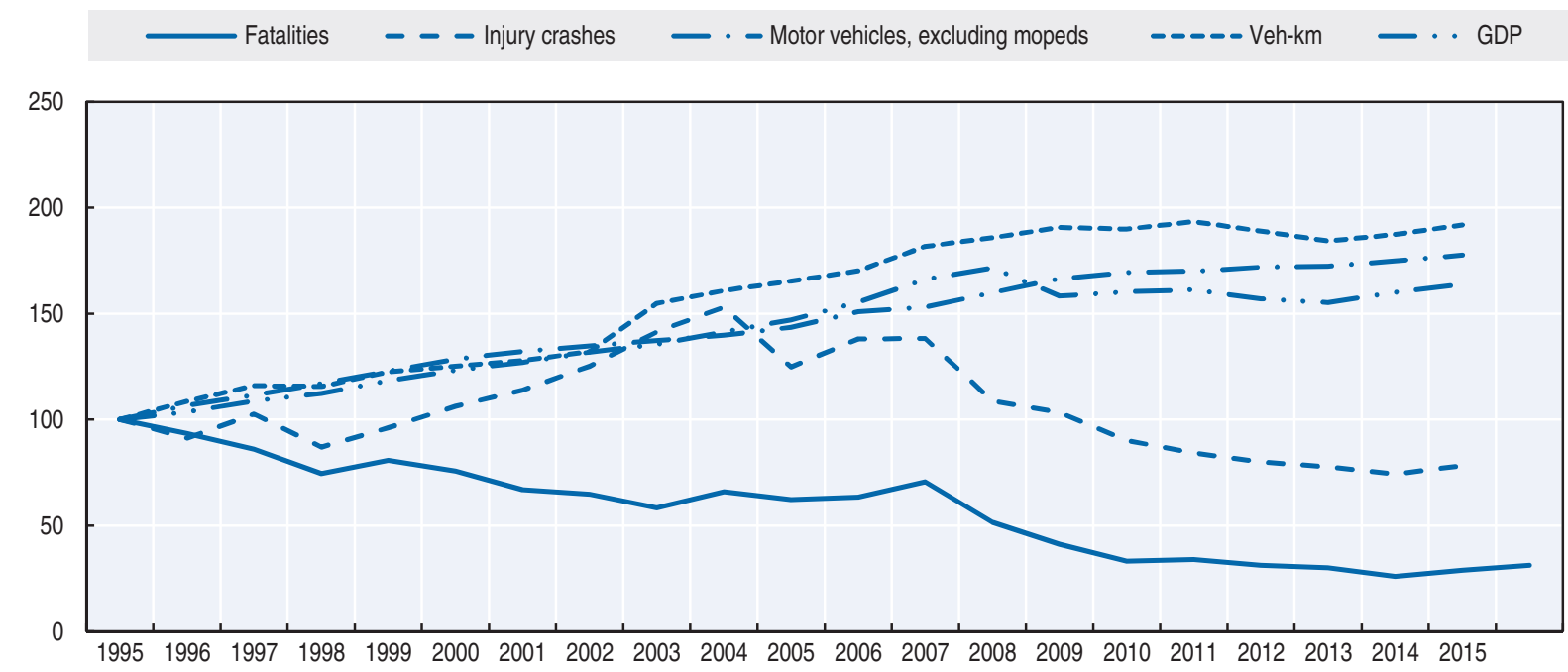

Source: World Bank (2017) (GDP; constant prices). 


\section{Road safety by user group}

Since 2000, all user groups have benefited from improved safety, with the exception of motorcyclists. Fatality numbers for both pedestrians and car occupants, compared to 2000 , has decreased by approximately $70 \%$, with the largest reduction in fatalities observed among moped riders. The situation for motorcyclists deteriorated markedly in 2015 as the number of motorcyclists killed increased from 15 to 25 .

Table 34.2. Road fatalities by road user group

\begin{tabular}{lrrrr|rrr}
\hline & 2000 & 2010 & 2014 & 2015 & \multicolumn{3}{c}{$2015 \%$ change from } \\
\cline { 6 - 8 } & & & & 2014 & 2010 & 2000 \\
\hline Pedestrians & 60 & 26 & 14 & 16 & 14.3 & -38.5 & -73.3 \\
Cyclists & 26 & 16 & 13 & 14 & 7.7 & -12.5 & -46.2 \\
Moped riders & 21 & 6 & 2 & 1 & -50.0 & -83.3 & -95.2 \\
Motorcyclists & 19 & 17 & 15 & 25 & 66.7 & 47.1 & 31.6 \\
Car occupants & 179 & 68 & 59 & 55 & -6.8 & -19.1 & -69.3 \\
Others & 9 & 5 & 5 & 9 & - & - & 0.0 \\
Total & $\mathbf{3 1 4}$ & $\mathbf{1 3 8}$ & $\mathbf{1 0 8}$ & $\mathbf{1 2 0}$ & $\mathbf{1 1 . 1}$ & $\mathbf{- 1 3 . 0}$ & $\mathbf{- 6 1 . 8}$ \\
\hline
\end{tabular}

Figure 34.2. Road fatalities by road user group in percentage of total, 2015

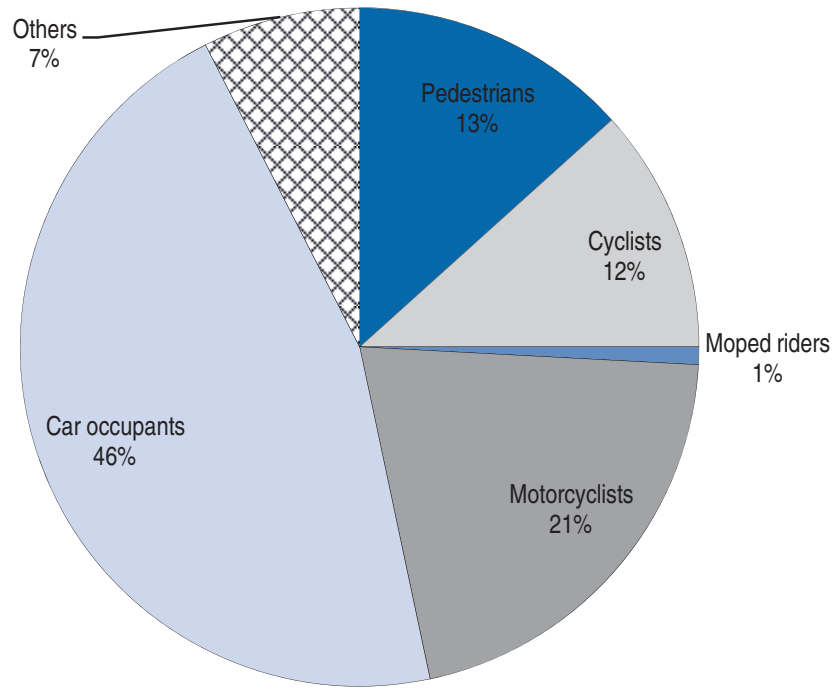

\section{Road safety by age group}

Since 2000 , all age groups have benefited from the improvements in road safety, with the best results for young people (15-24). For the age group 25-64 fatalities have decreased by more than $62 \%$.

The largest share of fatalities in 2015 was in the over 65 age group (29 fatalities or $24 \%$ ) and the 45-54 year old group (22 fatalities or $20 \%$ ). The lowest share was among children and young people (under 18) $-6 \%$ or 7 fatalities.

Senior citizens are now the age group the most at risk in traffic. They are particularly vulnerable as pedestrians. 
Table 34.3. Road fatalities by age group

\begin{tabular}{|c|c|c|c|c|c|c|c|}
\hline \multirow{2}{*}{ Age } & \multirow{2}{*}{2000} & \multirow{2}{*}{2010} & \multirow{2}{*}{2014} & \multirow{2}{*}{2015} & \multicolumn{3}{|c|}{$2015 \%$ change from } \\
\hline & & & & & 2014 & 2010 & 2000 \\
\hline $0-14$ & 8 & 2 & 2 & 3 & \multirow{3}{*}{\multicolumn{2}{|c|}{$\begin{array}{l}\text { Numbers too small for } \\
\text { meaningful comparison }\end{array}$}} & -62.5 \\
\hline $15-17$ & 18 & 4 & 1 & 4 & & & -77.8 \\
\hline $18-20$ & 23 & 3 & 2 & 7 & & & -69.6 \\
\hline $21-24$ & 28 & 16 & 7 & 9 & 28.6 & -43.8 & -67.9 \\
\hline $25-64$ & 181 & 82 & 70 & 68 & -2.9 & -17.1 & -62.4 \\
\hline $65-74$ & 34 & 12 & 9 & 17 & 88.9 & 41.7 & -50.0 \\
\hline $75-84$ & 15 & 12 & 14 & 9 & -35.7 & -25.0 & -40.0 \\
\hline$\geq 85$ & 7 & 6 & 3 & 3 & 0.0 & -50.0 & -57.1 \\
\hline Total & 314 & 138 & 108 & 120 & 11.1 & -13.0 & -61.8 \\
\hline
\end{tabular}

Figure 34.3. Road fatality rates by age group Deaths per 100000 inhabitants in a given age group, 1994-2015

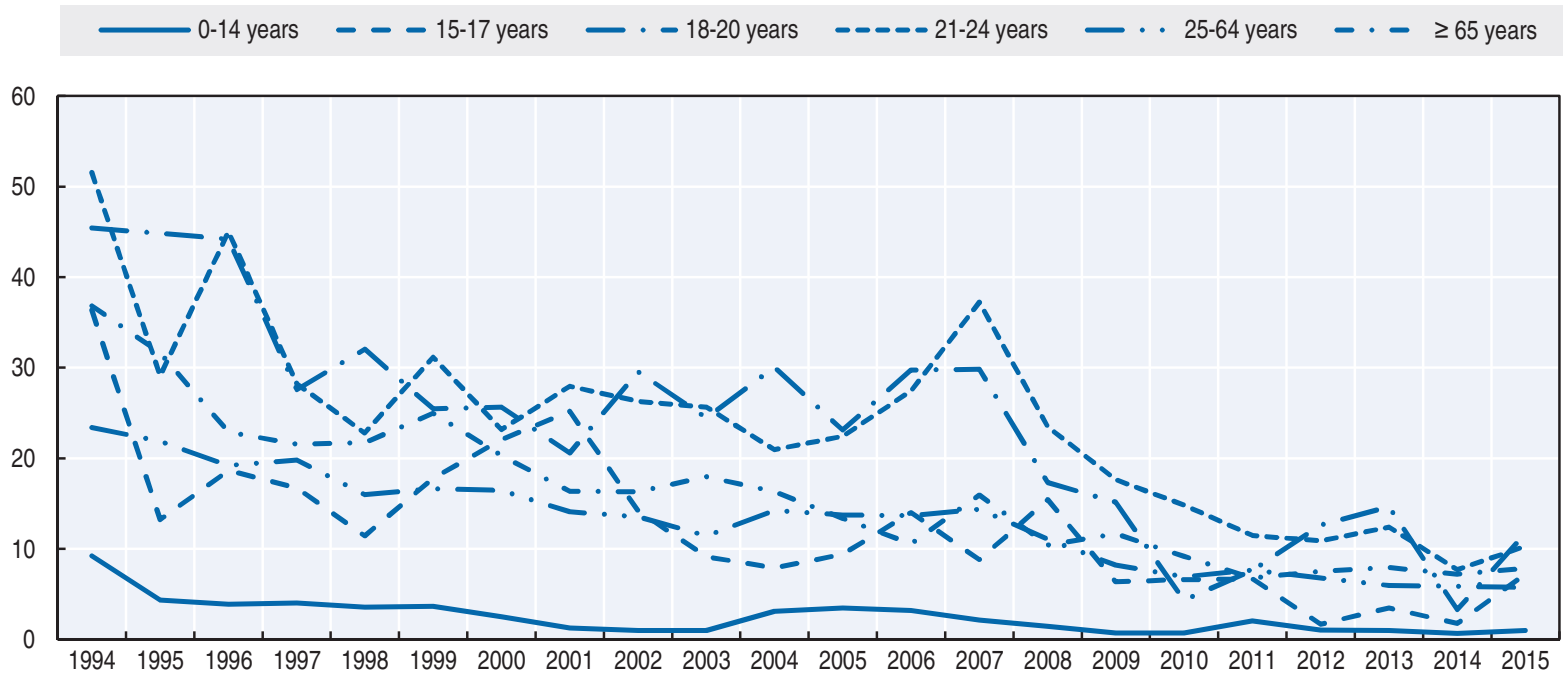

\section{Box 34.1. Road safety for an ageing population}

In 2015 , senior citizens aged 65 and above represented $18 \%$ of the population and accounted for $24 \%$ of total fatalities.

The number of traffic crashes involving senior drivers has been on the increase in recent years. In 2016, the share of traffic accidents with drivers in the over 65 age group was $15 \%$, as compared to $12.8 \%$ in 2012 . The share of older drivers at the cause of an accident is also increasing (10.5\% in 2016, 8.8\% in 2012).

Driving licences are issued up until the age of 80 to all persons who have passed a driving test or extended their licence prior to 19 January 2013. A driving licence can be extended over 80 years of age, if a medical certificate is submitted. Persons who passed a driving test after 19 January 2013 received a driving licence valid until the age of 70, or 65 for professional categories. A person who has a valid driving licence must undergo a medical examination if ordered so by a personal doctor or specialist. After 70 or 80 years of age medical certificates are issued for a period up to three years.

Since 2015, the Slovenian authorities have organised one day road safety workshops for older road users. 
Box 34.1. Road safety for an ageing population (cont.)

Table 34.4. Road fatalities among senior citizens

\begin{tabular}{|c|c|c|c|c|c|c|}
\hline & \multicolumn{2}{|c|}{$65-74$} & \multicolumn{2}{|c|}{$75-84$} & \multicolumn{2}{|c|}{$85+$} \\
\hline & 2010 & 2015 & 2010 & 2015 & 2010 & 2015 \\
\hline Pedestrians & 4 & 6 & 7 & 2 & 0 & 2 \\
\hline Cyclists & 2 & 3 & 0 & 2 & 3 & 0 \\
\hline Moped riders & 0 & 1 & 0 & 0 & 0 & 0 \\
\hline Motorcyclists & 0 & 2 & 0 & 0 & 0 & 0 \\
\hline Car occupants & 4 & 3 & 3 & 1 & 1 & 0 \\
\hline Total & 12 & 17 & 12 & $g$ & 6 & 3 \\
\hline
\end{tabular}

Figure 34.4. Road fatality rates by age group - focus on the senior population Deaths per 100000 inhabitants in a given age group, 2000-15
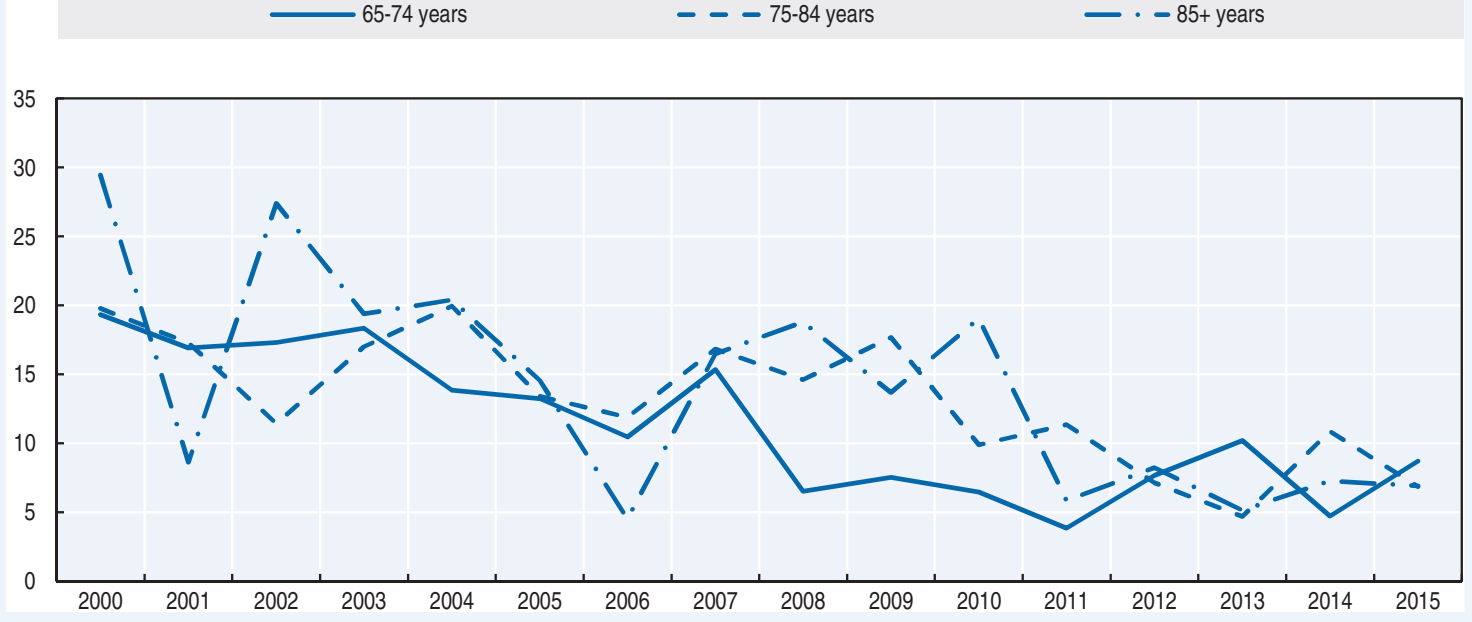

Figure 34.5. Road fatality rate by age and road user group Fatalities per 100000 inhabitants, 2015

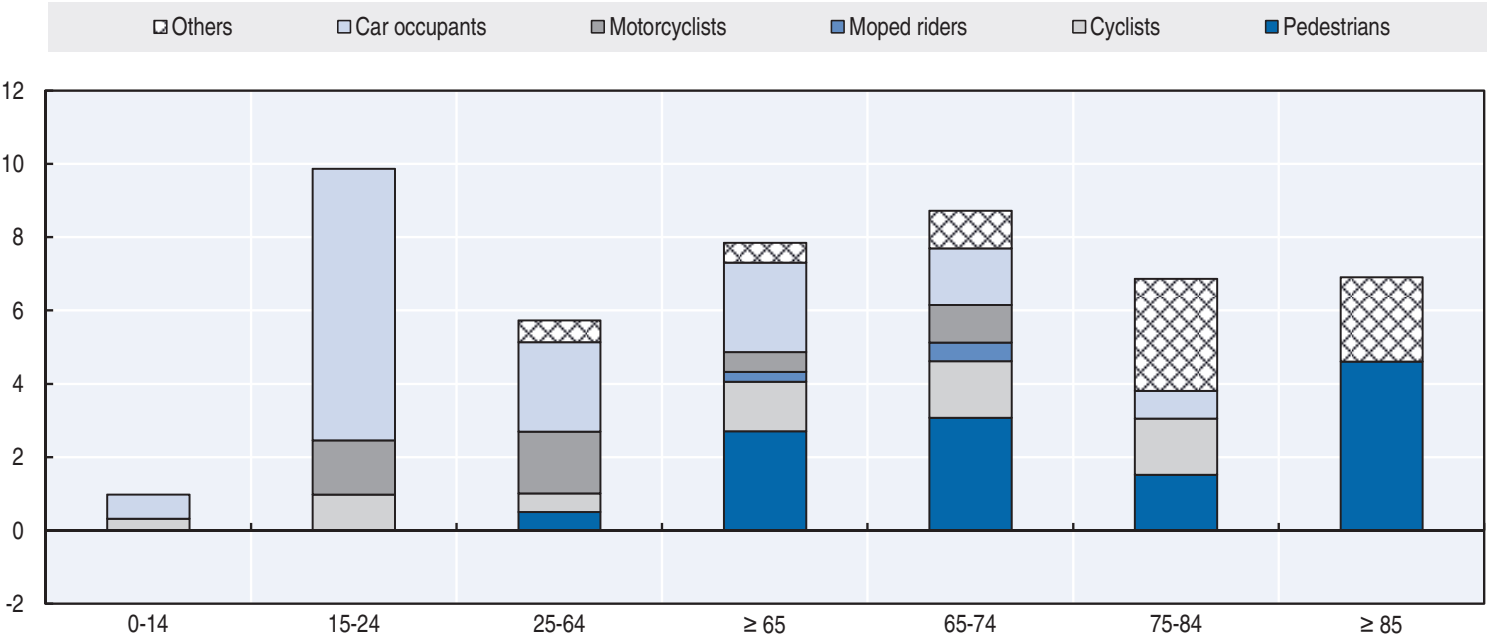




\section{Road safety by road type}

In 2015 , more than half (55\%) of fatalities occurred on rural roads, $32.5 \%$ occurred on urban roads and $12.5 \%$ on motorways. Since 2000 , the number of fatalities decreased more rapidly on the rural network, followed by a significant decrease in urban areas.

Figure 34.6. Road fatalities by road type

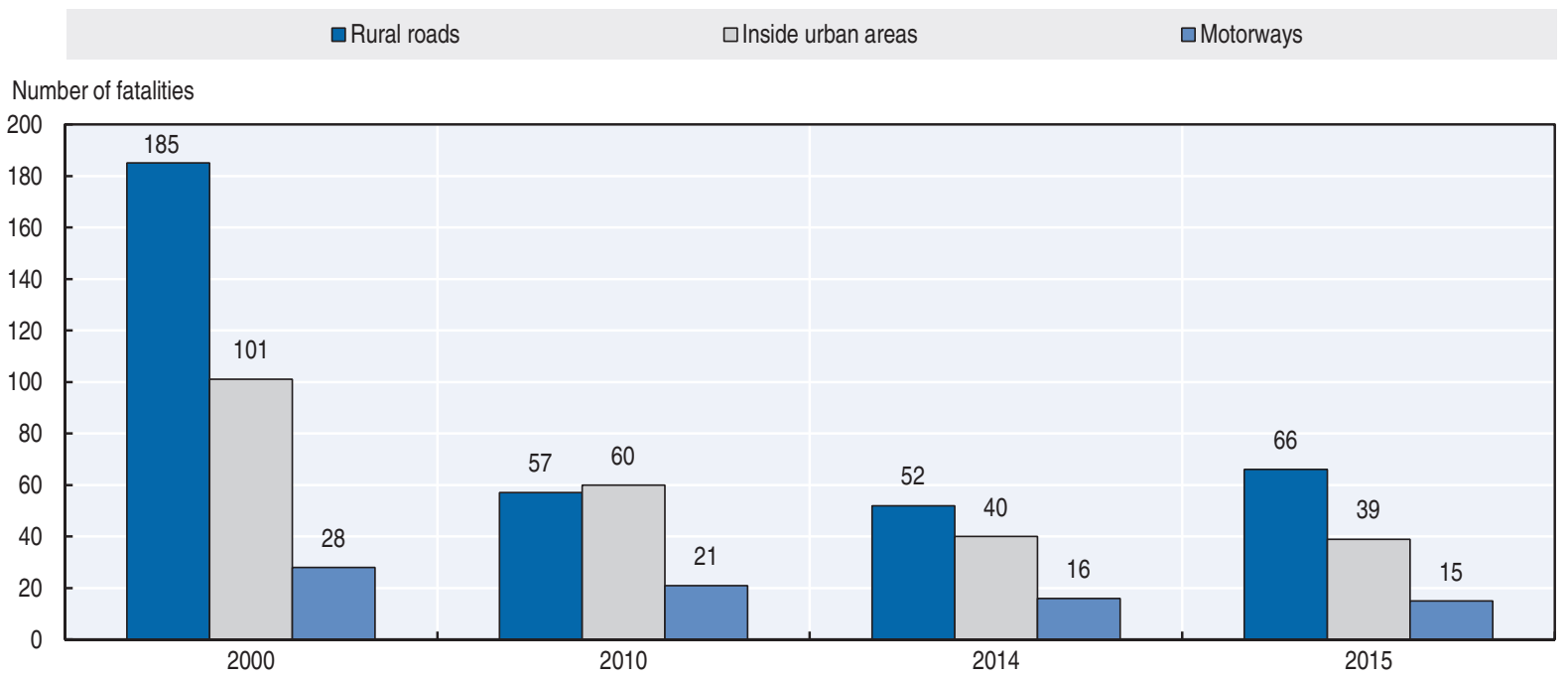

\section{Economic costs of traffic crashes}

Traffic crashes represent a significant cost for society, estimated in 2015 at around EUR 1.08 billion, or $2.8 \%$ of GDP. The figure is based on the number of reported crashes and an estimate of non-reported crashes, using the methodology Harmonised European Approaches for Transport Costing and Project Assessment (HEATCO), adapted to the specific conditions of Slovenia.

Table 34.5. Costs of road crashes, 2015

\begin{tabular}{lcc}
\hline Cost (EUR) & Unit cost & Total \\
\hline Fatalities & EUR 1678382 & EUR 209.13 million \\
Serious injuries & EUR 194958 & EUR 240.11 million \\
Slight injuries & EUR 19226 & EUR 408.22 million \\
Property damage costs & & EUR 223.61 million \\
Total (EUR) & & EUR $\mathbf{1 0 8 1 . 0 8}$ million \\
& & $\mathbf{2 . 8 0} \%$
\end{tabular}

\section{Recent trends in road user behaviour Speed}

Speeding is a major cause of traffic crashes in Slovenia. In 2015, 17.5\% of traffic accidents were caused by speeding. This figure is similar to the one in 2014, but the consequences were greater with an increase in the number of road users killed by speeding of $44 \%$.

In 2015, the average day time speed was: on highways $114 \mathrm{~km} / \mathrm{h}$ (V85 $120 \mathrm{~km} / \mathrm{h})$, urban roads $55 \mathrm{~km} / \mathrm{h}$ (V85 $59 \mathrm{~km} / \mathrm{h}$ ) and rural roads $66 \mathrm{~km} / \mathrm{h}$ (V85 $71 \mathrm{~km} / \mathrm{h})$. 
Speeding is an important issue particularly in urban areas, where the average speed is well above the $50 \mathrm{~km} / \mathrm{h}$ speed limit.

The table below summarises the main speed limits in Slovenia.

Table 34.6. Passenger car speed limits by road type, 2016

\begin{tabular}{|c|c|c|}
\hline & General speed limit & Comments \\
\hline Urban roads & $50 \mathrm{~km} / \mathrm{h}$ & $\begin{array}{l}\text { Average day time speed: } 55 \mathrm{~km} / \mathrm{h} \\
\text { V85*: } 67 \mathrm{~km} / \mathrm{h}\end{array}$ \\
\hline Rural roads & $90 \mathrm{~km} / \mathrm{h}$ & $\begin{array}{l}\text { Average day time speed: } 65 \mathrm{~km} / \\
\text { V85*: } 80 \mathrm{~km} / \mathrm{h}\end{array}$ \\
\hline Expressway & $\begin{array}{c}110 \mathrm{~km} / \mathrm{h} \\
\text { (it was } 100 \mathrm{~km} / \mathrm{h} \text { until 2011) }\end{array}$ & \\
\hline Motorways & $130 \mathrm{~km} / \mathrm{h}$ & $\begin{array}{c}\text { Average day time speed: } 110 \mathrm{~km} / \mathrm{h} \\
\qquad 85^{\star}: 131 \mathrm{~km} / \mathrm{h}\end{array}$ \\
\hline
\end{tabular}

\section{Drink driving}

The maximum permissible blood alcohol content (BAC) is $0.5 \mathrm{~g} / \mathrm{l}$ for most drivers and $0.0 \mathrm{~g} / \mathrm{l}$ for professional drivers and drivers who have had their licence for less than three years. Driving under the influence of alcohol is a major safety issue in Slovenia and is responsible for about one-third of serious injury crashes.

A crash is defined as an alcohol-related crash when one of the active participants has a blood alcohol content above the limit.

In 2015 , the number of road accidents caused by drink driving was reduced by $1 \%$ compared to 2014. The number of road users killed due to drink driving increased by $48 \%$, while the number of severely injured was reduced by $3 \%$. The average BAC of drivers involved in a fatal crash decreased to $1.44 \mathrm{~g} / \mathrm{l}$ compared to $1.45 \mathrm{~g} / \mathrm{l}$ in 2014.

\section{Drugs and driving}

A crash is defined as a drug-related crash when one of the participants tests positive for drugs (via a blood test).

In 2015 , official data attributed around $0.4 \%$ of traffic crashes to drivers under the influence of drugs. However it should be noted that police officers very rarely check if the driver is under influence of drugs.

A police officer has the right to administer an on-the-spot drug test in the case of suspicion. If the driver refuses this test the police can insist on a more complete medical examination.

In 2016, the Slovenian Traffic Safety Agency addressed the problem of driving under the influence of drugs. It implemented an online questionnaire about the use of drugs while driving. More than 3000 respondents completed the questionnaire. The analysis showed that $8 \%$ of drivers occasionally drive under the influence of drugs (most commonly cannabis, followed by cocaine and amphetamines).

\section{Seat belts and helmets}

Seat belt use has been compulsory in front seats since 1977 and in rear seats since 1998. 
Dedicated child restraints are compulsory for children under $150 \mathrm{~cm}$. Child restraint use for rear seats is $93 \%$ for children under 8 years old and seat belt use is $88 \%$ for children 8-14 (2016 data).

In 2015, 6 of the 38 drivers killed in traffic accidents were not wearing a seat belt.

Table 34.7. Seat belt wearing rate by car occupancy and road type

\begin{tabular}{lllll}
\hline \multicolumn{1}{c}{$\%$} & & \\
\hline & 2000 & 2010 & 2011 & 2016 \\
\hline Front seat & & & & \\
$\quad$ Driver & & 92 & 93 & 90 \\
$\quad$ Passenger & & 93 & 95 & 92 \\
Urban roads (driver) & 90 & 87 & 89 & 88 \\
Rural roads (driver) & 94 & 93 & 95 & 92 \\
$\quad$ Motorways (driver) & 94 & 96 & 97 & 93 \\
Rear seats & & 69 & 66 & 69 \\
$\quad$ General & & & 94 & 93 \\
Children 0-7 (use of child restraint) & & & 87 & 88 \\
Children 8-14 & & &
\end{tabular}

A helmet is compulsory for riders and passengers of motorcycles and mopeds. Helmets are also compulsory for cyclists under 15 years.

There is no data available on the helmet-wearing rate for motorcycle and moped riders. A survey conducted in 2011 in Ljubljana and Maribor - the two largest cities in Slovenia - showed that only $5 \%$ of cyclists wore a helmet.

During the summer of 2016, the Slovenian Traffic Safety Agency studied the behaviour of cyclists and the use of safety helmets. The results showed that violation of regulations and traffic rules among cyclists is very frequent: $23 \%$ of cyclists violated traffic rules, most of the offenders being male. The average rate of helmet use was $13 \%$ among observed cyclists, and was significantly higher in men $(17 \%)$ than women $(8 \%)$. The rate of cycle helmet use among children is $67 \%$ (for children up to 14 years old a protective helmet is obligatory). Only $3.8 \%$ of adolescents used a helmet.

\section{Distraction}

The use of hand-held mobile phones while driving is not allowed in Slovenia. The use of hands- free devices is tolerated. There is no statistical data available on the effect of mobile phone use on Slovenian traffic crashes.

\section{Sleepiness and fatigue}

There is no data available on the influence of fatigue on crashes.

\section{National road safety strategies and targets Organisation of road safety}

The Slovenian Traffic Safety Agency was created in 2010, in accordance with the Road Traffic Safety Act of 1 September 2010. It is an independent agency financially linked to the Ministry of Infrastructure.

The agency is the main national traffic safety organisation, bringing together expertise in the road safety field. The agency's mission covers research and analysis, preventive and 
educational programmes, support for development of programmes for national road safety, drivers, vehicles and driver rehabilitation. The agency will also take over the independent investigation of fatal crashes.

\section{Road safety strategy for 2013-22}

The Slovenian National Road Safety Programme 2013-22 was adopted by the government in March 2013. The programme is based on Vision Zero, aiming at no fatalities or seriously injured persons on Slovenian roads. Priorities addressed in the national road safety programme are:

- driver education and training

- preventative action and media campaigns for vulnerable road users such as pedestrians, children, the elderly and cyclists

- measures against the main killers on the roads: speed and alcohol.

Implementation of the National Road Safety Programme has been established at three levels:

- Political level: The parliament reviews the programme annually.

- Strategic level: A board of directors, nominated by the government, prepares the strategy, defines the main measures and assigns responsibilities for them. It also provides financial and other resources and monitors the programme.

- Professional level: An inter-ministerial working group was established to monitor and implement the programme, bringing together individual experts, organisations and nongovernmental organisations in the field of road safety. Local councils, civil society and some companies are also involved.

In the framework of the 2013-22 strategy, biennial action plans are elaborated. The current action plan covers the years 2017 and 2018.

\section{Road safety targets}

The main target is, by 2022, to halve (compared to 2011) the number of fatalities and those seriously injured, attaining a fatality rate below 3.5 fatalities per 100000 inhabitants and fewer than 230 seriously injured per million inhabitants.

A board of directors regularly monitors the implementation of the National Road Safety Programme. It provides strategic guidelines towards the achievement of national road safety targets. In 2016, the board of directors made an in-depth evaluation of the 2015 action plan and submitted their recommendations to parliament.

As of 2014, with 108 road deaths, Slovenia seemed on track to reach its 2022 target. However, in 2015 Slovenia recorded more fatalities that in 2014, but this is still less than in previous years. Comparatively on the multi-annual level road safety is still improving. Slovenia did not reach the interim target for 2015 set by the National Road Safety Programme (no more than 115 fatalities in 2015).

An average annual reduction of 4-5\% should be sustained to reach the 2022 target. 
Figure 34.7. Trends in road fatalities towards national target

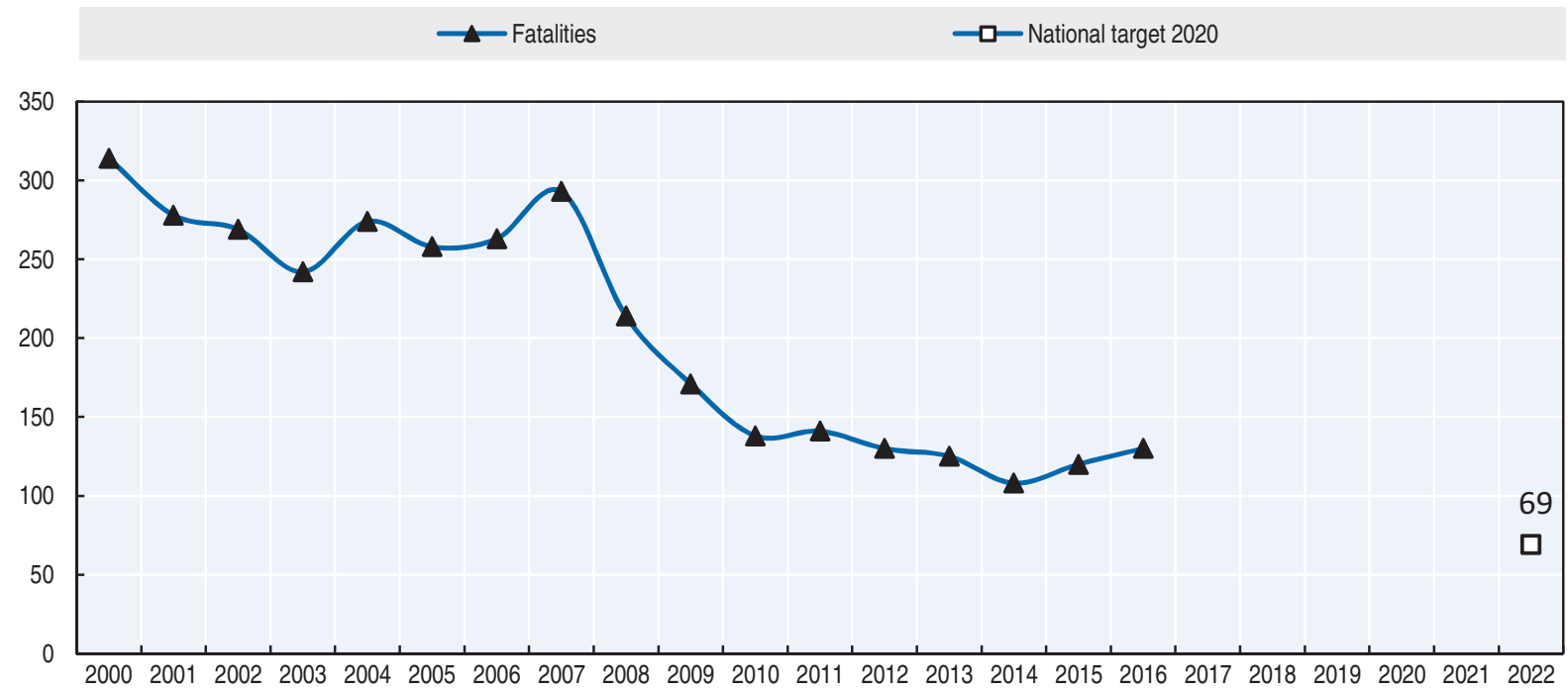

\section{Recent safety measures (2014-17)}

\section{Road safety management}

- In 2013, the government established a board of directors to monitor, lead and supervise the implementation of the National Road Safety Programme and report to the National assembly.

- An interim action plan for 2017 and 2018 has been prepared by the interdepartmental working group (established in 2013, in order to monitor and execute the programme), which, though not adopted officially, is being implemented in practice.

\section{Road users}

\section{Driving licence}

- In 2014, Slovenia introduced an electronic test for the theory section of the driving test.

\section{Cycling}

- Safe cycling: The Slovenian Traffic Safety Agency launched (in 2014) a pilot project focusing on the promotion of safe cycling in the wider context of mobility, sustainable transport, health and congestion policies. Within this project, a new measure, "sharrow", has been implemented in Maribor, Slovenia's second largest city. Sharrow is shared-lane marking to indicate a shared space for cyclists and drivers. A symbol placed in the centre of a lane indicates that a bicyclist may use the full lane. Cyclist counters are being introduced in the capital Ljubljana to record cyclist activity. The cyclist counter is devoted to promoting and increasing bicycle use. The Slovenian Traffic Safety Agency is conducting before/after analysis on the two implemented measures and is organising other activities to promote safe cycling.

- In May 2015 a preventive campaign was co-ordinated by the Slovenian Traffic Safety Agency to increase responsible behaviour among cyclists and other road users. The focus was on the benefits of safety helmets. 


\section{Pedestrian safety}

- In March 2015, a new initiative, "a safe and friendly community for pedestrians", was implemented to promote good practice and effective safety measures for pedestrians. Municipalities achieving a safe and friendly community for pedestrians are rewarded.

\section{Education and awareness}

- Road safety campaigns are regularly conducted focusing on the main road safety topics (speeding, drink driving, seatbelt use, etc.). Campaigns and road education programmes implemented from September 2015 till October 2016 include:

- February - March 2016: "40 days without alcohol"

- April, June, July and August 2016: "Speed - drive carefully"

- March and September 2016: "Has the seat belt clicked? Clicking a seat belt can save your life!"

- September 2016: "European Mobility Week"

- March and April 2016: "Safety of Motorcyclists";

- May 2016: preventive campaign "Cyclists"

- October 2015 and 2016: "Pedestrians, be careful - be seen" - Promoting the use of reflective vests for pedestrians.

- February 2016: "Stop, because the train can't" - This preventive campaign was the successor of the 2010 campaign, launched to improve safety at railway crossings in the context of the resolution on the national programme for road safety.

- A campaign "Improving road safety of elderly road users" was launched in March 2015 and continued throughout 2016. It included refreshment classes on traffic regulations, sessions on safe motorway driving, practical advice on health criteria, driving with a driving instructor, test driving simulator etc. Preventive events are organised in different municipalities all over Slovenia.

- February, July and October 2016: "Safety of heavy vehicles and buses": 30000 leaflets were prepared and distributed for drivers of heavy vehicles and buses, focusing mainly on topics such as: road accident statistics, safety distance, speed and proper cargo fixing

- November and December 2015 and June, November and December 2016: "0.0 driver sober decision" - Preventive campaign managed and coordinated by the Ministry of Health and Slovenian Traffic Safety Agency.

- In August and September 2015 and 2016 campaigns: "Preventive action: Beginning of the school year" focused on safe routes to schools. Activities included the review of school paths, a review and update of the school path maps, meetings with school teachers and parents, and the priority of pedestrians at pedestrian crossings in urban areas.

- In 2016 the Slovenian Traffic Safety Agency organised workshops in high schools for young people (16-18 year olds), who listen to and debate on different road safety topics such as how to get driver's licence, key risk factors for traffic accidents, a policeman's experience of tragic accidents on the road, life-saving techniques etc. In 2016, 15 high schools were visited with 1200 participants. 


\section{Infrastructure}

- The road network is regularly audited, with identification and treatment of high risk sections.

- In March, September and October 2016, the Slovenian Traffic Safety Agency organised initial and periodic trainings for road safety auditors, bringing the number of road safety auditors in the country to 34 . The sessions involved local and foreign experts, who presented innovations in the field of road safety auditing and inspection.

- In February 2016, the Slovenian Traffic Safety Agency issued the "Guidelines for School Paths". The guidelines help schools and local communities to produce effective plans for comprehensive review, safety improvement and unified labelling of school routes.

- Rules on Traffic Signs and Traffic equipment on the roads were updated in 2016, to harmonise with European Standards.

- In 2015, a set of measures was implemented to prevent "wrong way" driving on the motorway network, including the installation of new traffic signs and equipment on public roads.

\section{Recent and ongoing research}

The following recent research projects have been undertaken:

- 2014 and 2015: Speed indicators on state roads; average speeds

- 2016: Seat belt use while driving a passenger vehicle

- 2016: Mobile phone use while driving

- 2016: Driving under the influence of drugs and alcohol

- Measures and analysis to reduce incorrect directional driving on Slovenian highways and motorway networks

- EuroRAP risk map for road infrastructure (highways, motorways and state roads)

- Contribution to the ongoing European project Road User's Attitudes in Europe (ESRA) ESRA survey of Slovenia.

\section{References}

World Bank (2017), “GDP (constant US\$)”, World Development Indicators, http://databank.worldbank.org/ data/reports.aspx? source=world-development-indicators (accessed 23 February 2017).

\section{Websites}

- Slovenia Traffic Safety Agency: www.aup-rs.si (accessed 17 May 2017).

- Slovenian Infrastructure Agency: www.di.gov.si/en/ (accessed 17 May 2017).

- Slovenian Traffic Statistics: www.policija.si/eng/index.php/statistics (accessed 17 May 2017). 


\section{Chapter 35}

\section{South Africa}

This chapter presents 2015 and 2016 road safety data for South Africa. It looks at trends in traffic and road safety from the years 1990 to 2015 and road user behaviour patterns. This includes regulations on speed, drink driving, drugs and driving, distracted driving, fatigue and seat belt usage. The chapter reviews South Africa's road safety strategy and national targets, along with recently implemented safety measures and current research projects. ${ }^{*}$

* The Road Traffic Management Corporation (RTMC) joined the International Road Traffic and Accident Database group in 2016. Data included in this report have not been validated by IRTAD. All data stem from RTMC. For more information please contact: MagadiG@rtmc.co.za. 
South Africa has made strides in reducing road crash fatalities since their peak in 2006. However, numbers still remain high and recent years have seen an increasing trend once again. In 2015, there were 12944 reported road fatalities, a 2\% increase over 2014. In 2016, a total of 14071 deaths were reported, an increase of $9 \%$ over 2015. South Africa's fatality rate in 2016 was at 25.2 per 100000 inhabitants. Pedestrians accounted for $38 \%$ of the fatalities in 2016, with children being particularly affected.

\section{Road safety data collection}

\section{Definitions applied in South Africa}

- Road fatality: Any person killed during or immediately after a crash, or death directly attributable to a crash within 30 days of such a crash.

- Seriously injured: Any person sustaining injuries to such an extent that hospitalisation is required. Serious injuries include fractures, concussion, internal injuries, severe cuts and lacerations, severe shock, etc. which require medical treatment, hospitalisation and/or confinement to a bed.

- Slightly injured: Any person sustaining minor cuts and bruises, sprains and light shock which may be treated at the scene of the crash or at home.

\section{Data collection}

In South Africa, the police and traffic authorities collect motor vehicle crash data using Accident Report (AR) forms. The data collection procedure is conducted on behalf of the Road Traffic Management Corporation (RTMC), which has a legislative responsibility to report on the information.

Data is then sent to RTMC which generates, consolidates, interprets, analyses and compiles State of Road Safety reports. Fatal crashes are reported within 24 hours using quick response forms. South Africa records fatalities in accordance with the 30 day international standard.

The Culpable Homicide Crash Observation Report (CHoCOR) forms are used to collect fatal crash data on a daily basis. The South African Police Service (SAPS) is the primary source of the fatal crash data. RTMC receives a list of all recorded fatal crashes from SAPS as well as the CHoCOR forms from the various police stations. RTMC then captures, processes and verifies the data in order to compile a consolidated report. There are continuous engagements with provinces to validate the integrity of the submitted information.

The management of road traffic information across the local, provincial and national authorities continues to be ineffective. Police records alone are usually inadequate to carry out an analysis on the nature and consequences of serious injuries and other risk factors associated with crashes. To address this, initiatives are being undertaken to strengthen cooperation between the bodies involved in road traffic data. In an effort to move towards an integrated road traffic information management, a new database is being developed in 
collaboration with the Council for Scientific and Industrial Research (CSIR) in partnership with Statistics South Africa (STATS SA).

There is currently a process underway to expand the data sources by obtaining road crash information from other stakeholders.

Information included in this report corresponds to the consolidated set of the SAPS data.

\section{Most recent safety data}

\section{Road crashes in 2016 - Provisional data}

In 2016, 14071 road fatalities were reported by RTMC, a 9\% increase compared to 2015.

Most road crashes were recorded during the months of April, July, September, October and December with more than 1000 per month. This is linked to school and work recess periods whereby there is significant amount of travelling.

The main highlights of 2016 in terms of traffic safety are as follows:

- Approval of the national road safety strategy by the National Assembly.

- Establishment of a review committee for road traffic law enforcement to harmonise law enforcement in the country.

- Launch of road safety drama series on a public broadcaster. The drama series was aimed at educating and creating awareness on road safety matters.

- The 3rd National Road Safety Summit (21-22 November 2016).The National Department of Transport, its Road Traffic Entities and public and private stakeholders held a summit which placed emphasis on monitoring mechanisms that will ensure efforts towards reduction of road injuries and fatalities are implemented.

- National Road Traffic Indaba (national conference) in December 2016. The Indaba focused on the following key areas: improved and integrated law enforcement; best practices in the law enforcement fraternity; economic impact of road crashes; norms and standards of law enforcement; new technologies to improve efficiency in law enforcement; improved working conditions for traffic law enforcement officers.

\section{Road crashes in 2015}

In 2015, 12944 road fatalities were reported by RTMC, a 2\% increase compared to 2014.

\section{Trends in traffic and road safety (1990-2016) Registered vehicles}

The number of registered vehicles increased by 2.2\% in 2016 when compared to 2015. Passenger cars represent $58 \%$ of the motorised fleet, light duty vehicles $20 \%$; trucks $3 \%$, motorcycles $3 \%$ and buses and minibuses $3 \%$.

\section{Road safety}

\section{Crashes and casualties}

Between 1990 and 2000, the reported number of road fatalities fluctuated around 9500 per annum. After 2000, the number increased significantly and reached a peak in 2006 with more than 15000 reported road deaths. The country has since implemented a wide range of interventions which have produced positive results and a steady decline in fatal crashes between 2006 and 2014. However, the number of reported road deaths increased again in 2015 and 2016. 
Aware of the current road safety challenges, the Department of Transport aims, through its road agencies, to:

- make roads and roadsides safer

- strengthen traffic law enforcement

- set safer speed limits

- promote the development of safer vehicles

- encourage people to behave more safely on the roads.

The support of all stakeholders, communities and individuals is needed for a successful implementation of these measures.

\section{Rates}

In 2016, there were 25 road deaths per 100000 inhabitants. There has been gradual improvement since 1990, when the rate was of 30 fatalities per 100000 population.

The fatality risk expressed in terms of road deaths per 10000 registered vehicles was at 9.8 in 2016. The rate has nearly halved since 1990 mainly due to the strong increase in the vehicle fleet.

Table 35.1. Road safety and traffic data

\begin{tabular}{|c|c|c|c|c|c|c|c|c|c|}
\hline & \multirow{2}{*}{1990} & \multirow{2}{*}{2000} & \multirow{2}{*}{2010} & \multirow{2}{*}{2015} & \multirow{2}{*}{2016} & \multicolumn{4}{|c|}{$2016 \%$ change over } \\
\hline & & & & & & 2015 & 2010 & 2000 & 1990 \\
\hline \multicolumn{10}{|l|}{ Reported safety data } \\
\hline Fatalities & 11157 & 8494 & 13967 & 12944 & 14071 & 8.7 & 0.7 & 65.7 & 26.1 \\
\hline Fatal crashes & 9174 & 6679 & 10837 & 10613 & 11676 & 10.0 & 7.7 & 74.8 & 27.3 \\
\hline Deaths per 100000 population & 30.3 & 19.0 & 27.4 & 23.6 & 25.2 & 7.0 & -8.2 & 32.8 & -16.9 \\
\hline Deaths per 10000 registered vehicles & 24.2 & 14.0 & 15.3 & 11.1 & 9.8 & -11.3 & -35.9 & -29.9 & -59.5 \\
\hline \multicolumn{10}{|l|}{ Traffic data } \\
\hline Registered vehicles (thousands) & 4616 & 6074 & 9134 & 11710 & 11964 & 2.2 & 31.0 & 97.0 & 159.2 \\
\hline Registered vehicles per 1000 population & 125 & 136 & 179 & 213 & 214 & 0.4 & 19.2 & 57.7 & 70.6 \\
\hline
\end{tabular}

Figure 35.1. Road safety, traffic and GDP trends index $1990=100$

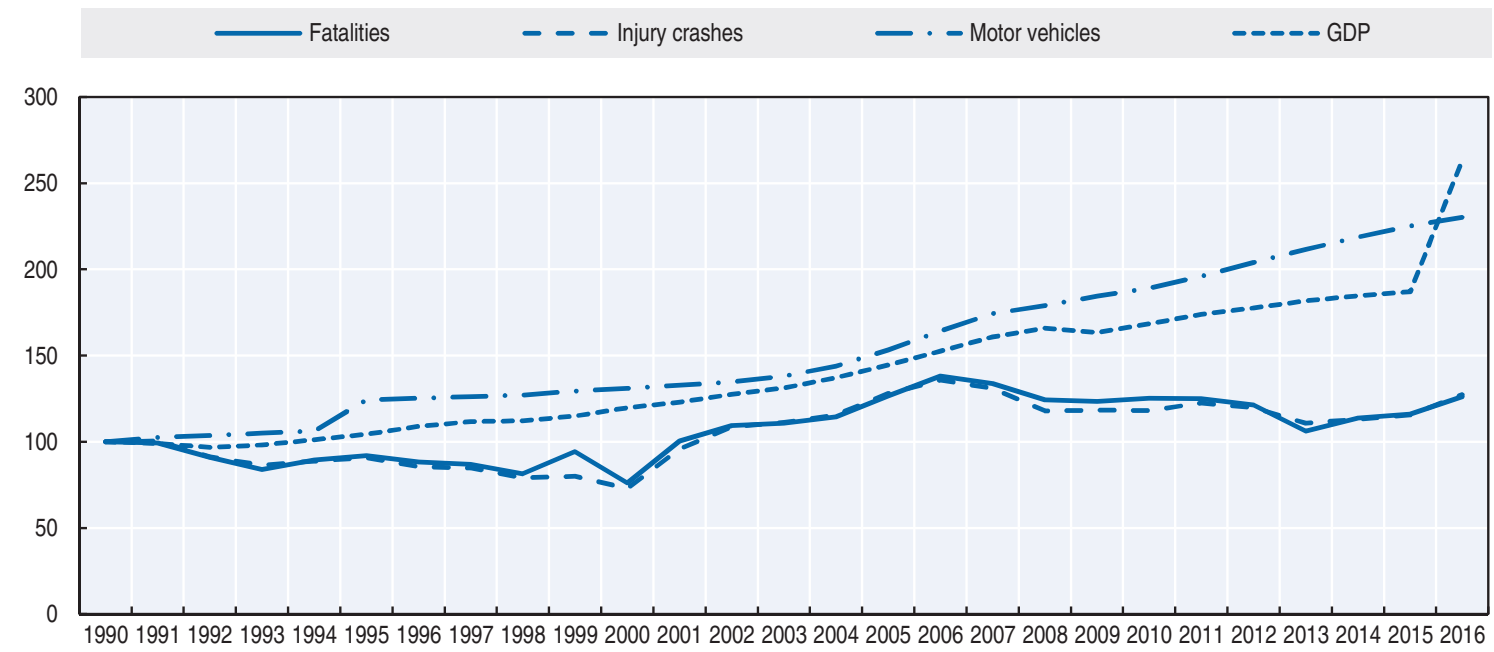

Source: World Bank (2017) (GDP; constant prices). 


\section{Road safety by user group}

In 2016, pedestrians alone accounted for $38 \%$ of reported fatalities, motorised vehicle passengers accounted for $33 \%$ and motorised vehicle drivers for $26 \%$.

\section{Road safety by age group}

Children are very much affected by road crashes in South Africa and are particularly vulnerable as pedestrians.

\section{Economic costs of traffic crashes}

The high number of road traffic crashes and their associated consequences have a significant impact on the South African society, which in turn continues to hamper socioeconomic development and impacts on the well-being of all South Africans. This impact is measured in terms of human lives lost, 'pain, grief and suffering', as well as an increasing cost to the economy.

The total cost of road crashes in 2015 amounted to an estimated ZAR 142.95 billion, or $3.4 \%$ of GDP.

\section{Recent trends in road user behaviour Speed}

The table below summarises the main speed limits in South Africa.

Table 35.2. Passenger car speed limits by road type, 2017

\begin{tabular}{lll}
\hline & & General speed limit \\
\hline Urban roads & $60 \mathrm{~km} / \mathrm{h}$ & \\
Rural roads & $100 \mathrm{~km} / \mathrm{h}$ & \\
Motorways & $120 \mathrm{~km} / \mathrm{h}$ & \\
\hline
\end{tabular}

\section{Drink driving}

In South Africa, the maximum authorised blood alcohol content (BAC) is $0.5 \mathrm{~g} / \mathrm{l}$. There is a lower limit of $0.2 \mathrm{~g} / \mathrm{l}$ for professional drivers of public transport and heavy goods vehicles.

A crash is defined as alcohol-related when one of the participants has a BAC above the legal limit.

Based on crash reports from 2015, 5.5\% of fatalities involved a driver with a BAC above the legal limit, and 1.8\% involved a pedestrian with a BAC above the legal limit.

\section{Drugs and driving}

Driving while under the influence of intoxicating liquor or drugs having a narcotic effect, or with an excessive amount of alcohol in the blood or breath is prohibited. Drug driving measures are not yet enforced.

\section{Distraction}

The National Road Traffic Act states that no person shall drive a vehicle on a public road holding a cellular or a mobile telephone or any other communication device in one or both hands or with any other part of the body. 
In 2016, the RTMC published a research report on distracted driving. It shows that drivers frequently engage in secondary activities while driving. Passenger-related distractions (i.e., looking at, talking to or listening to a passenger) constitute the most common distraction. Other secondary distractions include using electronic devices, grooming, eating and person or object-related distractions. The important question to answer is what constitutes normal driving and is it possible that distracted driving has become the norm rather than the exception.

\section{Sleepiness and fatigue}

The estimation of fatalities due to sleepiness and fatigue is still a challenge in South Africa.

\section{Seat belts and helmets}

All new motor vehicles must be fitted with seat belts for all passengers. Since 2005, seatbelt use is compulsory for drivers and all passengers of cars and minibuses registered after 1 January 2006. The driver is responsible for ensuring that infants are seated with an appropriate child restraint. The seat belt wearing rate is very low, estimated in 2010 at $4.5 \%$ for the drivers and $5 \%$ for front seat passengers. There has not been any more recent survey on the use of seatbelts.

The wearing of a protective helmet on a motorcycle, motor tricycle, a motor quadricycle, and passenger in the side-car attached to a motorcycle or pedal cycle is compulsory for both the driver and the passenger.

Helmets are compulsory for cyclists. In practice, it is not enforced.

Table 35.3. Seat belt wearing rate

\begin{tabular}{lc} 
& $\%$ \\
\hline & 2010 \\
\hline Front seat & \\
$\quad$ Driver & 4.5 \\
Passenger & 5 \\
\hline
\end{tabular}

\section{National road safety strategies and targets Organisation of road safety}

The RTMC, established in April 2005, is the lead agency for Road Safety in South Africa. It reports to the Department of Transport. Other major road agencies that also have a responsibility to contribute towards road safety are:

- Road Accident Fund (RAF)

- Road Traffic Infringements Agency (RTIA)

- South African National Roads Agency (SOC; Limited) (SANRAL)

- Cross-Border Roads Transport Agency (CBRTA).

In addition, the Department of Health, the Department of Justice and Constitutional Development, the Department of Roads and Public Works, the Department of Safety and Security, the Provincial Traffic Authorities, Statistics South Africa, and the emergency medical services are important stakeholders. 
The RTMC's shareholders are composed of provincial representatives from each of the nine provinces. The shareholder group also comprises a representative from the South African Local Government Authority (SALGA) with the Minister being the Chairperson.

The RTMC is responsible for:

- enhancing the overall quality of road traffic service provision, in particular to ensure safety, security, order, discipline and mobility on the roads

- protecting road infrastructure and the environment through the adoption of innovative practices and implementation of innovative technology

- introducing commercial management principles to inform and guide road traffic governance and decision making in the interests of enhanced service provision

- optimising the utilisation of public funds

- regulating, strengthening and monitoring intergovernmental contact and cooperation in road traffic matters

- improving the exchange and dissemination of information on road traffic matters

- stimulating research in road traffic matters and effectively using the resources of existing institutes and research bodies

- developing human resources in the public and private sectors that are involved in road traffic.

The Road Safety Advisory Council was established in 2014, with the main objective to provide strategic advice to the Minister of Transport. It is composed of representatives of different sectors (automotive industry, road engineering, NGOs, transport companies, motor insurance companies, civil society organisations, etc.).

\section{Road safety strategy 2016-30}

In 2015, the Department of Transport and its other road agencies, began developing the National Road Safety Strategy 2016-30 which is aligned with the United Nations Decade of Action pillars. The objective is to reduce fatalities and injuries by $50 \%$ from the 2010 base by 2030. The National Road Safety Strategy was approved by the National Assembly. It places emphasis on the following priority areas:

- road safety in schools

- drink driving

- safety of young people

A strategic plan for the period $2015-20$ has been developed. The main measures are summarised in the table below.

Table 35.4. Measures and objectives of the 2015-20 strategic road safety plan

\begin{tabular}{ll}
\hline \multicolumn{1}{c}{ Key measures of the 2015-2020 Strategic Plan } & \multicolumn{1}{c}{ Main objective } \\
\hline $\begin{array}{l}\text { Development of the National Road Safety Strategy } \\
\text { Implement measures targeting young people }\end{array}$ & $\begin{array}{l}\text { Provide a uniform approach in achieving the UN goal to halve fatalities and injuries by 2020 } \\
\text { Curb the impact of road fatalities on the youth. } \\
\text { introduce best road user behaviour at a young age }\end{array}$ \\
$\begin{array}{l}\text { Eevelopment of the national road traffic information } \\
\text { database }\end{array}$ & $\begin{array}{l}\text { Increase the accuracy, reliability and availability of information for all stakeholders } \\
\text { Publication of road safety status reports }\end{array}$ \\
$\begin{array}{l}\text { Monitoring of drink driving and speeding offences } \\
\text { Anti-engaud and corruption awareness programmes } \\
\text { Investment in road safety research and development }\end{array}$ & $\begin{array}{l}\text { Monitor the impact of speeding and drink driving and identify measures to combat these behaviours. } \\
\text { Increase compliance with traffic rules }\end{array}$ \\
\hline
\end{tabular}




\section{Road safety targets}

The main target of the 2016-30 strategy is to reduce the number of fatalities by $50 \%$ by 2030 from 2010 level.

Quarterly monitoring reports, including transversal indicators implemented by provinces, are sent to provincial representatives (Members of the Executive Council [MECs]).

Figure 35.2. Trends in road fatalities towards national target

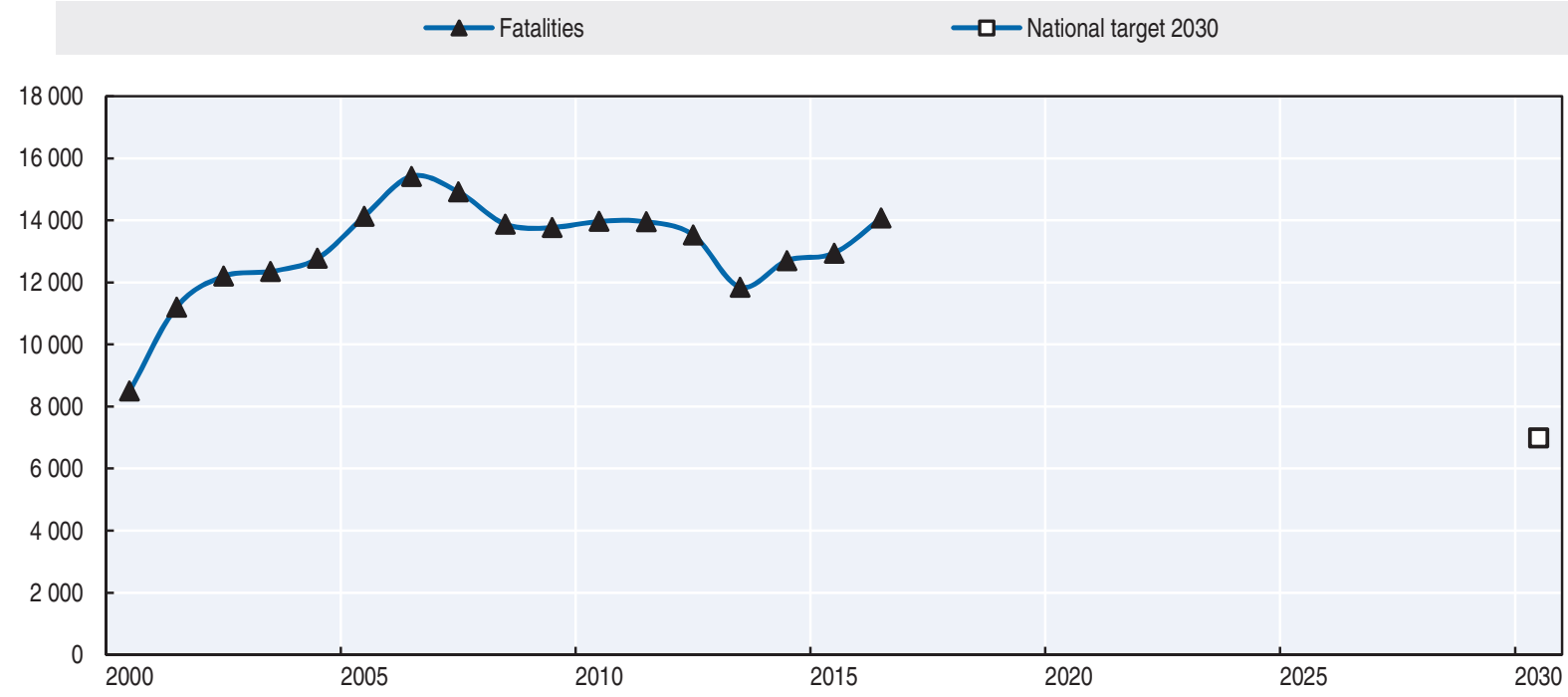

\section{Recent safety measures (2014-17)}

\section{Road safety management}

- Development of the national crash database (ongoing)

- Establishment of an improved single centralised national data management system (ongoing).

\section{Road users}

- The RTMC has been engaging with the Department of Education on integrating road safety education into the lower grade curriculum.

- In April 2015, the Minister of Transport approved the amendments to the Act and its Regulations which made it compulsory for children three years of age (or less) to be seated in a child seat when travelling in passenger cars.

- The amendment to the regulations of the National Land Transport Act, 2009 prohibit the transportation of school children for reward in the goods compartment of a vehicle.

\section{Recent and ongoing research}

- South African Road Assessment Programme (SARAP)

- Reclassification of serious road traffic offences on the Criminal Procedure Act (CPA)

- Impact of alcohol consumption on road crashes

- Review of the South African Road Safety Audit Manual (SARSAM) 


\section{References}

World Bank (2017), “GDP (constant US\$)”, World Development Indicators, http://databank.worldbank.org/ data/reports.aspx? source=world-development-indicators (accessed 23 February 2017).

\section{Websites}

- Road Traffic Management Corporation: www.rtmc.co.za (accessed 10 July 2017).

- Department of Transport: www.transport.gou.za/ (accessed 10 July 2017). 



\section{Chapter 36}

\section{Spain}

This chapter presents 2015 road safety data for Spain along with provisional fatality data from 2016. It looks at trends in traffic and road safety from the years 1990 to 2015 and road user behaviour patterns with a special focus on the ageing population. Sections include data on speed, drink driving, drugs and driving, distracted driving, fatigue and seat belt usage. The chapter reviews Spain's road safety strategy and national targets to 2020 and the progress achieved thus far. It also provides details of all recently implemented safety measures and current and ongoing research.*

* All data stem from the Directorate General for Traffic (DGT) and IRTAD unless otherwise noted. For more information please contact: analisis.estadistica@dgt.es. 


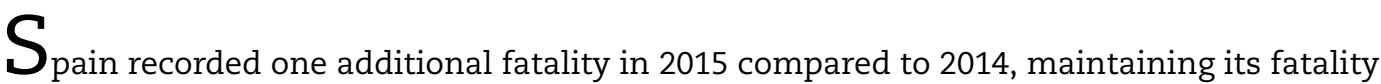
rate of 3.6 per 100000 inhabitants. Injury crashes have continued to rise over recent years, partly due to improved reporting by local police. Cyclists and car occupants benefitted the most from a reduction in fatalities in 2015, whereas the older population (over 65) are most at risk and comprised $30 \%$ of those killed. Spain has already achieved its fatality target for 2020 and is on track to achieve additional targets and indicators adopted as part of their road safety strategy.

\section{Road safety data collection}

\section{Definitions applied in Spain}

- Road fatality: Person killed immediately or dying within 30 days as a result of a road crash.

- Seriously injured: Any injured person hospitalised for more than 24 hours as a result of a road crash.

- Slightly injured: Any injured person who was not hospitalised for more than 24 hours as a result of a road crash.

- A MAIS 3+ injured person: Any person with road crash injuries for which the score on the Maximum Abbreviated Injury Scale is 3 or more.

\section{Data collection}

In Spain, there are several sources of information for traffic injury data. The police collect detailed information and data on the circumstances of the crashes using a dedicated form. Traffic police monitor the condition of those injured for 24 hours after the crash to classify the person as killed, seriously injured or slightly injured.

From 1993 to 2010, the procedure to estimate the number of people killed within 30 days among those initially recorded as seriously injured was based on adjusting the number statistically, after monitoring during 30 days a representative sample of seriously injured people. From 2011, the number of fatalities has been determined by linking the register of crashes reported by the police and the national deaths register, which includes the total number of deaths registered throughout the national territory.

Information on road crashes from hospital discharges and health sources and information reported by the police revealed important differences in 2014:

- Figures from police records show that for each person killed there are 6 seriously injured and 69 slightly injured.

- Figures from health sources show that for each fatality there are 11 people hospitalised and 282 slightly injured.

Since 2011 Spain has reported the number of MAIS injured based on hospital data. The methodology has recently been revised, in the framework of the work that European Member States are conducting with the aim of having harmonised data in the CARE database. Now the search for specific traumatic injury codes is performed not only among 
main diagnoses, but among the 14 diagnoses that may be recorded for each patient. As a result of that, whereas the overall number of crash-related inpatients has barely been altered, the number of identified MAIS3+ cases increased by $23 \%$.

The procedure to obtain MAIS3+ consists of several steps:

- A number of selection criteria are applied to hospital discharge data to obtain the records of those injured due to road traffic crashes.

- International Classification of Diseases (ICD) codes, 9th revision, are converted into AIS codes using an algorithm provided by the European Commission.

- Finally, the MAIS score is calculated.

\section{Most recent safety data}

\section{Road crashes in 2016 - provisional data}

Based on provisional data, the overall number of road fatalities within 24 hours outside and inside urban areas - increased in 2016 by 3.8\%. Figures of fatalities within 30 days are not yet available.

\section{Road crashes in 2015}

In 2015 , the number of fatalities was 1689 , one more than in 2014 . The police reported number of injured persons hospitalised decreased by $1 \%$, and the reported number of nonhospitalised injured persons increased by $7 \%$, partly as a result of better reporting by local police forces.

The number of reported injury crashes increased for the third consecutive year. In 2015 they were $6.8 \%$ higher as compared to 2104 and $14.3 \%$ higher as compared to 2010 . The variation since 2010 depends on the type of road: $-11.8 \%$ outside urban areas and $+36.4 \%$ inside urban areas, suggesting again that the increase in the overall figure could be partly related to the improvement in crash reporting in urban areas.

Between 1990 and 2015 the number of fatalities and hospitalised injured fell by 81\% and the number of non-hospitalised injured increased by $14 \%$. Limiting the analysis to the period between 2000 and 2015, the number of fatalities fell by $71 \%$ and the number of hospitalised injured by $66 \%$; the number of non-hospitalised injured increased by $2 \%$.

Comparing 2015 to 2014, the biggest increases in the number of fatalities are observed in motorcyclists (15\%), pedestrians (9\%) and users with ages between 25 and 34 , and between 75 and 84 years (increase of $12 \%$ in both groups).

\section{Trends in traffic and road safety (1990-2015) Traffic}

Between 1990 and 2015, vehicle-kilometres increased by more than $80 \%$ on the Spanish State Road Network, which carries more than $50 \%$ of the overall traffic volume outside urban areas.

Overall, between 2000 and 2015, traffic volume outside urban areas increased by 11\%. However, while the traffic volume effectively increased (by 23\%) between 2000 and 2007, it decreased by 14\% between 2007 and 2013 due to the economic downturn. In 2015, there was an almost $4 \%$ increase as compared to 2014 . This is the second consecutive year showing an increase in traffic volume. GDP growth was 1.1\% and 3.7\% in 2014 and 2015, respectively. 
The vehicle fleet nearly doubled between 1990 and 2011. In 2012 and 2013, the number of both new registered vehicles and the vehicle fleet slightly decreased. In 2015 and in 2014 there was an increase in the total number of vehicles as compared to the previous year.

In 2015, the progressive ageing of the vehicle fleet over recent years continued. The median age of the fleet was 11.5 years.

\section{Road safety}

\section{Crashes and casualties}

Since 1990, the number of road fatalities has decreased by more than $80 \%$. Road fatalities peaked in 1989 with 9344 deaths; since then they have decreased steadily and in 2013 they reached its lowest level. Since 2010, the number of fatalities has decreased by $32 \%$; which is among the highest reductions among IRTAD countries.

In the past 15 years, improvements have been introduced in all elements of the road traffic system. Safety performance indicators related to drivers' behaviour show that the incidence of speeding, drink driving and non-wearing of seat belts has been significantly reduced. This is probably related to improvements in education and training, increased enforcement, the penalty point system and the reform of the Crime Code.

The length of motorways and dual carriageways increased from 4693 kilometres in 1990 to 15336 kilometres in 2015. It is estimated that the fatality risk per unit exposure on these types of roads is about $25 \%$ of the corresponding value for rural roads. There have also been improvements in the system of traffic management, with the generalisation of traffic cameras, vehicle detectors and variable message signs. This has contributed not only to improvements in safety but also to reductions in congestion and travel times.

As for the vehicle fleet, important actions in the field of roadworthiness inspections and renewal schemes have been implemented. To collect exposure data, a new project on the development of national exposure indicators for each vehicle type (average and total kilometres driven), based on odometer readings from roadworthiness tests, has been implemented. Preliminary findings include the distribution of total vehicle-kilometres by type of vehicle (2014 data); passenger cars $(71 \%)$, heavy goods vehicles $(17 \%)$ and vans $(8 \%)$ account for $96 \%$ of total vehicle-kilometres.

\section{Rates}

In 2015 , the fatality rate per 100000 inhabitants was at 3.6 and the fatality rate per 10000 registered vehicles at 0.5 . Since 1990, the risk of being killed on a Spanish road has been reduced by a factor of 7 to 11, depending on the indicator chosen.

There is no estimation of the total number of vehicle-kilometres on the entire network. It is therefore not possible to calculate the fatality risk expressed in terms of deaths per billion vehicle-kilometres.

\section{Analysis of seriously injured data}

In 2014, 19507 people with road traffic injuries were discharged from Spanish private and public hospitals - including those who died in hospital.

When considering the number of people injured with a Maximum Abbreviated Injury Score of 3 or more (MAIS3+) in 2014 there were 6343 people seriously injured, 4\% less than the 6613 seriously injured registered in 2013. 
By age, the over 84 group suffered from more serious injuries, $51 \%$ of them showed MAIS3+ in 2014, followed by those aged 75-84 years, with 43\%, and the 65-74 year age group at $41 \%$.

Table 36.1. Road safety and traffic data

\begin{tabular}{|c|c|c|c|c|c|c|c|c|c|}
\hline & \multirow{2}{*}{1990} & \multirow{2}{*}{2000} & \multirow{2}{*}{2010} & \multirow{2}{*}{2014} & \multirow{2}{*}{2015} & \multicolumn{4}{|c|}{$2015 \%$ change from } \\
\hline & & & & & & 2014 & 2010 & 2000 & 1990 \\
\hline \multicolumn{10}{|l|}{ Reported safety data } \\
\hline Fatalities & 9032 & 5776 & 2478 & 1688 & 1689 & 0.1 & -31.8 & -70.8 & -81.3 \\
\hline Injury crashes & 101507 & 101729 & 85503 & 91570 & 97756 & 6.8 & 14.3 & -3.9 & -3.7 \\
\hline Injured persons hospitalised & 50301 & 27764 & 11995 & 9574 & 9495 & -0.8 & -20.8 & -65.8 & -81.1 \\
\hline Serious injuries (MAIS3+) & & 12766 & 7331 & 6343 & na & & & & \\
\hline Deaths per 100000 inhabitants & 23.3 & 14.4 & 5.3 & 3.6 & 3.6 & 0.2 & -31.8 & -74.8 & -84.4 \\
\hline Deaths per 10000 registered vehicles & 5.1 & 2.2 & 0.7 & 0.5 & 0.5 & -1.1 & -31.9 & -77.5 & -90.1 \\
\hline \multicolumn{10}{|l|}{ Traffic data } \\
\hline Registered vehicles ${ }^{1}$ (thousands) & 17615 & 25715 & 33375 & 33037 & 33413 & 1.1 & 0.1 & 29.9 & 89.7 \\
\hline Vehicle-kilometres $^{2}$ (millions) & & 208508 & 241131 & 222689 & 230840 & 3.7 & -4.3 & 10.7 & \\
\hline Registered vehicles per 1000 inhabitants & 454 & 642 & 718 & 710 & 719 & 1.3 & 0.2 & 12.0 & 58.6 \\
\hline
\end{tabular}

1. Including mopeds.

2. Outside urban areas.

Figure 36.1. Road safety, traffic and GDP trends index $1990=100$

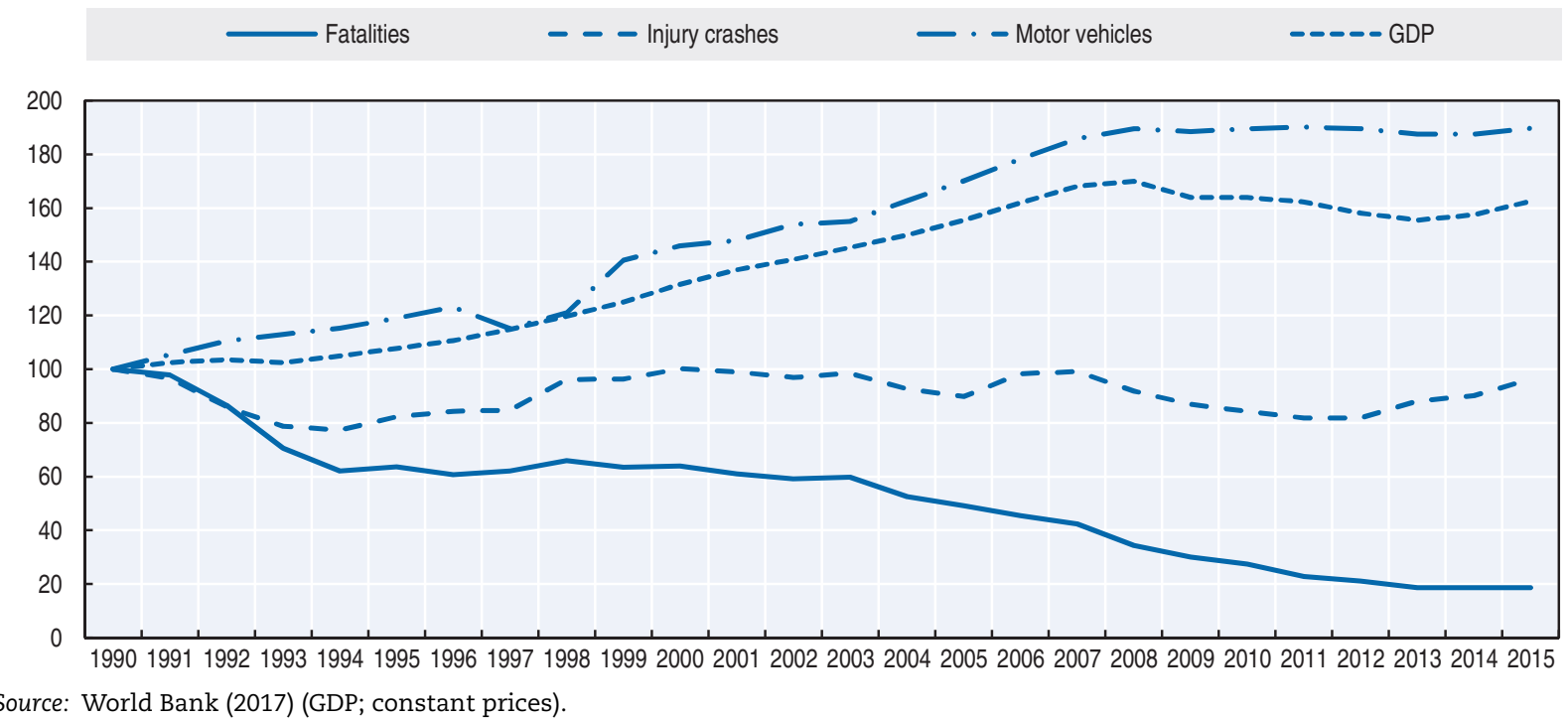

\section{Road safety by user group}

Since 1990, all user groups, but especially car occupants and moped riders, have benefited from improvements in road safety. The decrease in fatalities among moped riders is partly explained by the decrease in the number of sales (98\% between 2000 and 2015).

Between 2003 and 2007, there was a very sharp increase $(+72 \%)$ in the number of motorcyclists killed; this trend was broken in the following years, with reductions almost every year since. Between 2007 and 2015, the number of motorcyclists killed was reduced by $48 \%$. 
Since 2010, there has been improvement for all road user groups. In 2015, fatalities increased among pedestrians, moped riders and motorcyclists, and decreased among cyclists and car occupants.

Table 36.2. Road fatalities by road user group

\begin{tabular}{|c|c|c|c|c|c|c|c|c|c|}
\hline & \multirow{2}{*}{1990} & \multirow{2}{*}{2000} & \multirow{2}{*}{2010} & \multirow{2}{*}{2014} & \multirow{2}{*}{2015} & \multicolumn{4}{|c|}{$2015 \%$ change from } \\
\hline & & & & & & 2014 & 2010 & 2000 & 1990 \\
\hline Pedestrians & 1542 & 898 & 471 & 336 & 367 & 9.2 & -22.1 & -59.1 & -76.2 \\
\hline Cyclists & 160 & 84 & 67 & 75 & 58 & -22.7 & -13.4 & -31.0 & -63.8 \\
\hline Moped riders & 683 & 474 & 100 & 53 & 56 & 5.7 & -44.0 & -88.2 & -91.8 \\
\hline Motorcyclists & 792 & 392 & 386 & 287 & 329 & 14.6 & -14.8 & -16.1 & -58.5 \\
\hline Car occupants & 5034 & 3289 & 1197 & 722 & 693 & -4.0 & -42.1 & -78.9 & -86.2 \\
\hline Others & 823 & 639 & 257 & 215 & 186 & -13.5 & -27.6 & -70.9 & -77.4 \\
\hline Total & 9032 & 5776 & 2478 & 1688 & 1689 & 0.1 & -31.8 & -70.8 & -81.3 \\
\hline
\end{tabular}

Figure 36.2. Road fatalities by road user group in percentage of total, 2015

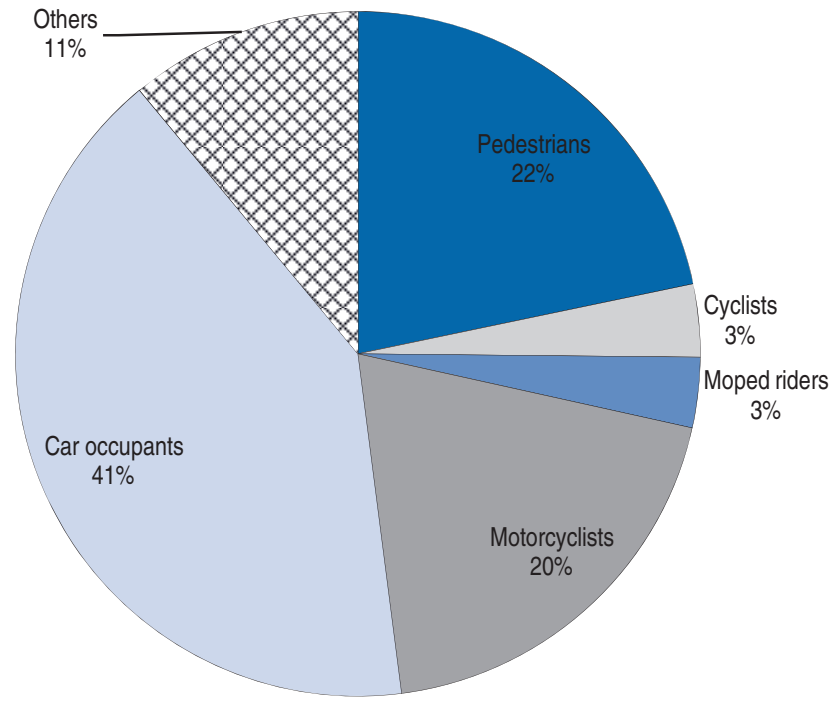

\section{Road safety by age group}

Since 1990, the reduction in fatalities has benefited all age groups, with the highest reduction of more than $92 \%$ for children and young people, while the reduction was much less remarkable for the over 65 age group (-55.5\%).

In 2015 , the over 65 s accounted for $30 \%$ of fatalities. They are the age group most at risk in traffic, with a fatality rate above the average. Older people are particularly vulnerable as pedestrians.

In terms of the mortality rate per 100000 inhabitants, progress has been most remarkable for young people aged 18-20, for which the rate has been divided by four since 2007. They now have a fatality rate similar to that of the general population. 
Table 36.3. Road fatalities by age group

\begin{tabular}{|c|c|c|c|c|c|c|c|c|c|}
\hline \multirow{2}{*}{ Age } & \multirow{2}{*}{1990} & \multirow{2}{*}{2000} & \multirow{2}{*}{2010} & \multirow{2}{*}{2014} & \multirow{2}{*}{2015} & \multicolumn{4}{|c|}{2015 \% change from } \\
\hline & & & & & & 2014 & 2010 & 2000 & 1990 \\
\hline $0-14$ & 400 & 181 & 79 & 37 & 25 & -32.4 & -68.4 & -86.2 & -93.8 \\
\hline $15-17$ & 417 & 223 & 50 & 24 & 27 & 12.5 & -46.0 & -87.9 & -93.5 \\
\hline $18-20$ & 902 & 422 & 139 & 46 & 47 & 2.2 & -66.2 & -88.9 & -94.8 \\
\hline $21-24$ & 1266 & 661 & 174 & 84 & 96 & 14.3 & -44.8 & -85.5 & -92.4 \\
\hline $25-64$ & 4759 & 3267 & 1489 & 1002 & 979 & -2.3 & -34.3 & -70.0 & -79.4 \\
\hline $65-74$ & & 488 & 240 & 188 & 202 & 7.4 & -15.8 & -58.6 & \\
\hline $75-84$ & & 287 & 209 & 204 & 229 & 12.3 & 9.6 & -20.2 & \\
\hline$\geq 85$ & & 68 & 80 & 85 & 74 & -12.9 & -7.5 & 8.8 & \\
\hline Total & 9032 & 5776 & 2478 & 1688 & 1689 & 0.1 & -31.8 & -70.8 & -81.3 \\
\hline
\end{tabular}

Figure 36.3. Road fatality rates by age group Deaths per 100000 inhabitants in a given age group, 1990-2015

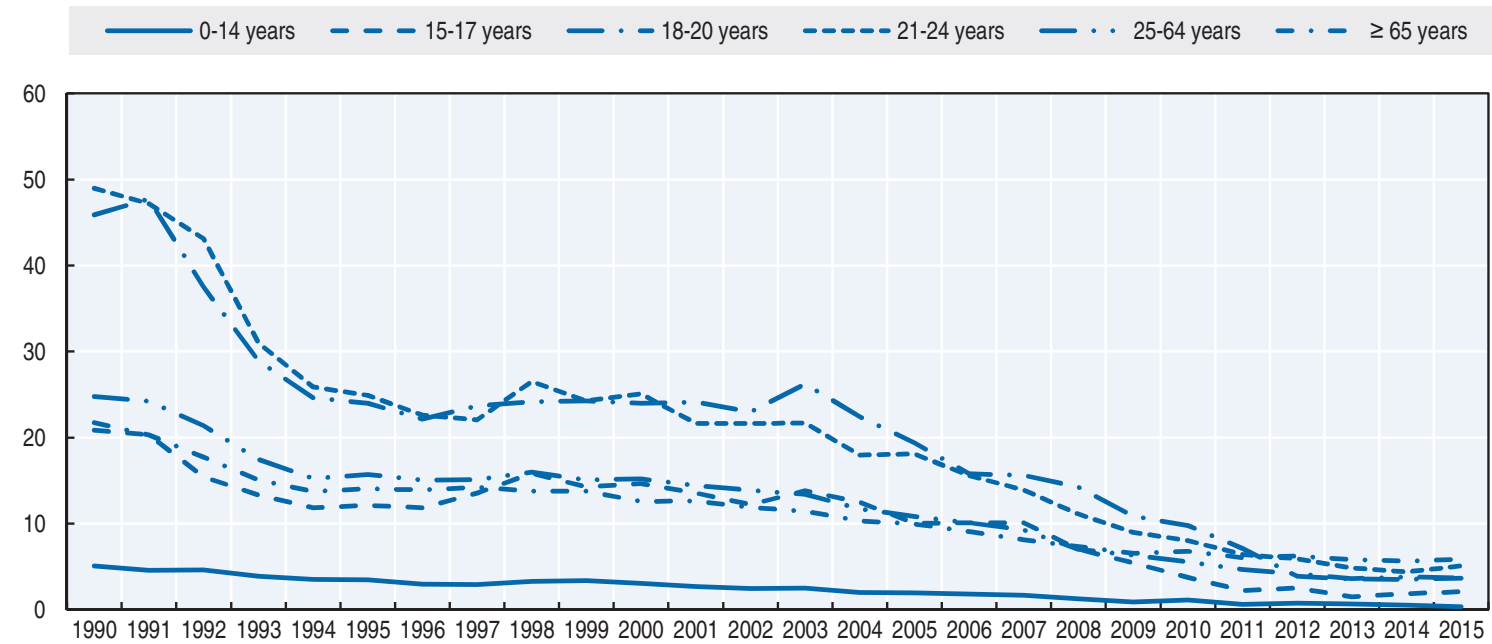

\section{Box 36.1. Road safety for an ageing population}

The senior population has steadily been increasing in Spain. The share of persons aged 65 or over increased from $16.6 \%$ in 2010 to $18.5 \%$ in 2015. It is projected that this share will further increase to more than $32 \%$ by 2050 (Eurostat http://ec.europa.eu/eurostat/web/main/home).

In 2015 , senior citizens represented $30 \%$ of fatalities and $17 \%$ of seriously injured. The absolute number of fatalities among senior persons decreased from 529 in 2010 to 505 in 2015. This reduction of 5\% is the lowest among all of the age groups; the overall reduction in fatalities for the whole population was $32 \%$ in the same period. The evolution within the groups of the senior population has not been homogenous: there were reductions of $16 \%$ in the group of $65-74$ years and $8 \%$ in the group of more than 84 years, as opposed to an increase of $10 \%$ in the group of $75-84$ years.

In a similar manner, the number of seriously injured among those aged 65 or over decreased by $1 \%$ in 2010-2015, as compared to a $21 \%$ reduction for the whole population.

Differences in reduction rates between fatalities within senior and general populations are reduced when we take into account the growth of the total number of senior inhabitants. Per million inhabitants, the number of senior persons killed decreased by $13 \%$ and the number of seriously injured by $10 \%$; the rates for the general population were $32 \%$ and $21 \%$, respectively. 


\section{Box 36.1. Road safety for an ageing population (cont.)}

The distribution of fatalities among the over $65 \mathrm{~s}$ by user type shows only slight variations over recent years. About $40 \%$ of them are pedestrians and another $40 \%$ are car occupants. Changes are more visible when looking at the share of senior citizens in the general population of killed drivers and pedestrians. In 2015, senior citizens represented 19\% of killed drivers - in 2010 the figure was 15\% - and 57\% of killed pedestrians $-45 \%$ in 2010 .

Males represent $65 \%$ of fatalities and $55 \%$ of seriously injured senior persons.

In Spain, driving licences have an administrative validity of 10 years for drivers under the age of 65, and five years for drivers aged 65 or over. In the case of licences for heavy goods vehicles and buses, the validity is of five years for drivers under 65, and three years for older drivers. Shorter validity periods may apply if the driver suffers from conditions or deficiencies that, while not preventing them from driving, may worsen over time.

A mandatory medical check is required for renewing the driving licence. Minimum standards of physical and mental fitness from the European Directive 2006/126/EC apply. If, anytime between legal renewals, the road traffic authority has evidence that a driver no longer meets any of the requirements concerning physical and mental fitness, the driving licence shall be revoked.

Senior people are one of the target groups of the Spanish Road Safety Strategy 2011-20. Measures to improve their safety include information and awareness campaigns, improvement of medical checks, obtaining risk exposure data and promoting technical recommendations on safe urban design, including $30 \mathrm{~km} / \mathrm{h}$ zones.

Table 36.4. Road fatalities among senior citizens

\begin{tabular}{lrr|rr|rc}
\hline & \multicolumn{2}{c|}{$65-74$} & \multicolumn{2}{c|}{$75-84$} & \multicolumn{2}{c}{$85+$} \\
\cline { 2 - 7 } & 2010 & 2015 & 2010 & 2015 & 2010 & 2015 \\
\hline Pedestrians & 70 & 66 & 91 & 101 & 51 & 42 \\
Cyclists & 8 & 6 & 4 & 9 & 3 & 1 \\
Moped riders & 12 & 7 & 6 & 5 & 1 & 1 \\
Motorcyclists & 6 & 13 & 0 & 4 & 0 & 0 \\
Car occupants & 127 & 88 & 88 & 91 & 19 & 27 \\
Total & $\mathbf{2 4 0}$ & $\mathbf{2 0 2}$ & $\mathbf{2 0 9}$ & $\mathbf{2 2 9}$ & $\mathbf{8 0}$ & $\mathbf{7 4}$ \\
\hline
\end{tabular}

Figure 36.4. Road fatality rates by age group - focus on the senior population Deaths per 100000 inhabitants in a given age group, 2000-15
65-74 years
$--75-84$ years
$-\cdot-85+$ years

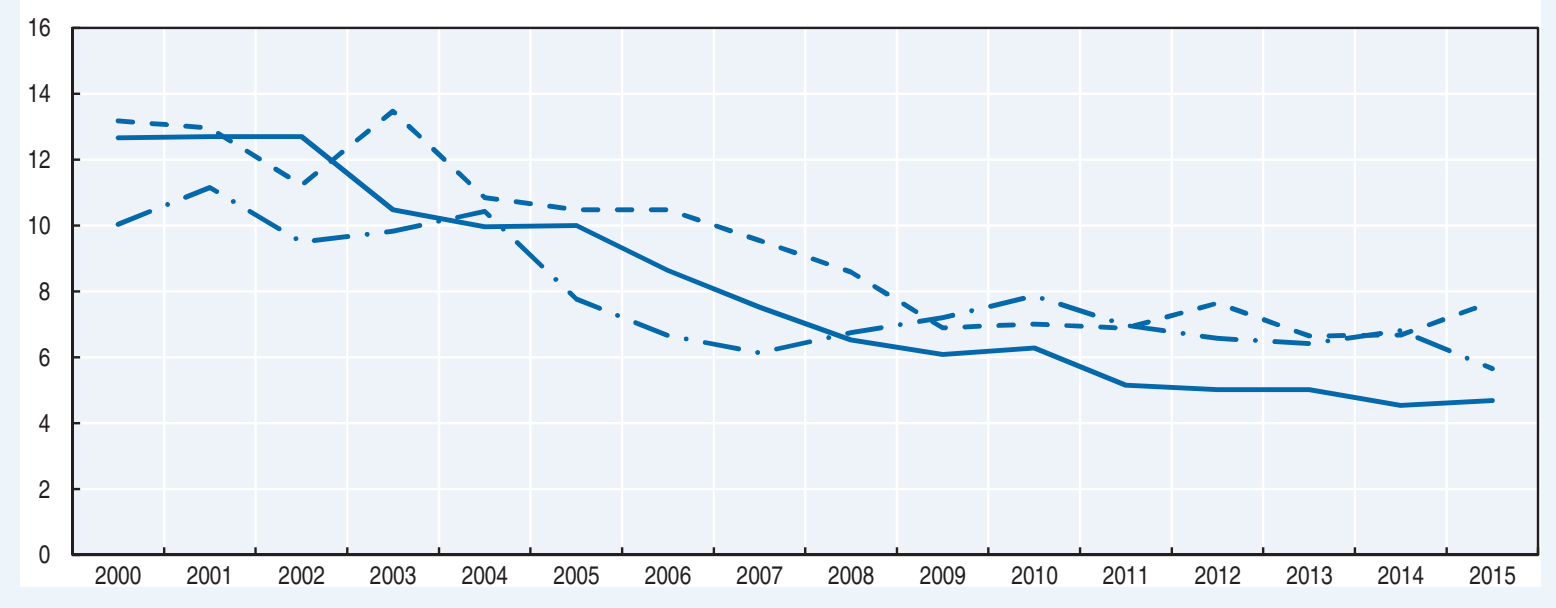


Figure 36.5. Road fatality rate by age and road user group Fatalities per 100000 inhabitants, 2015

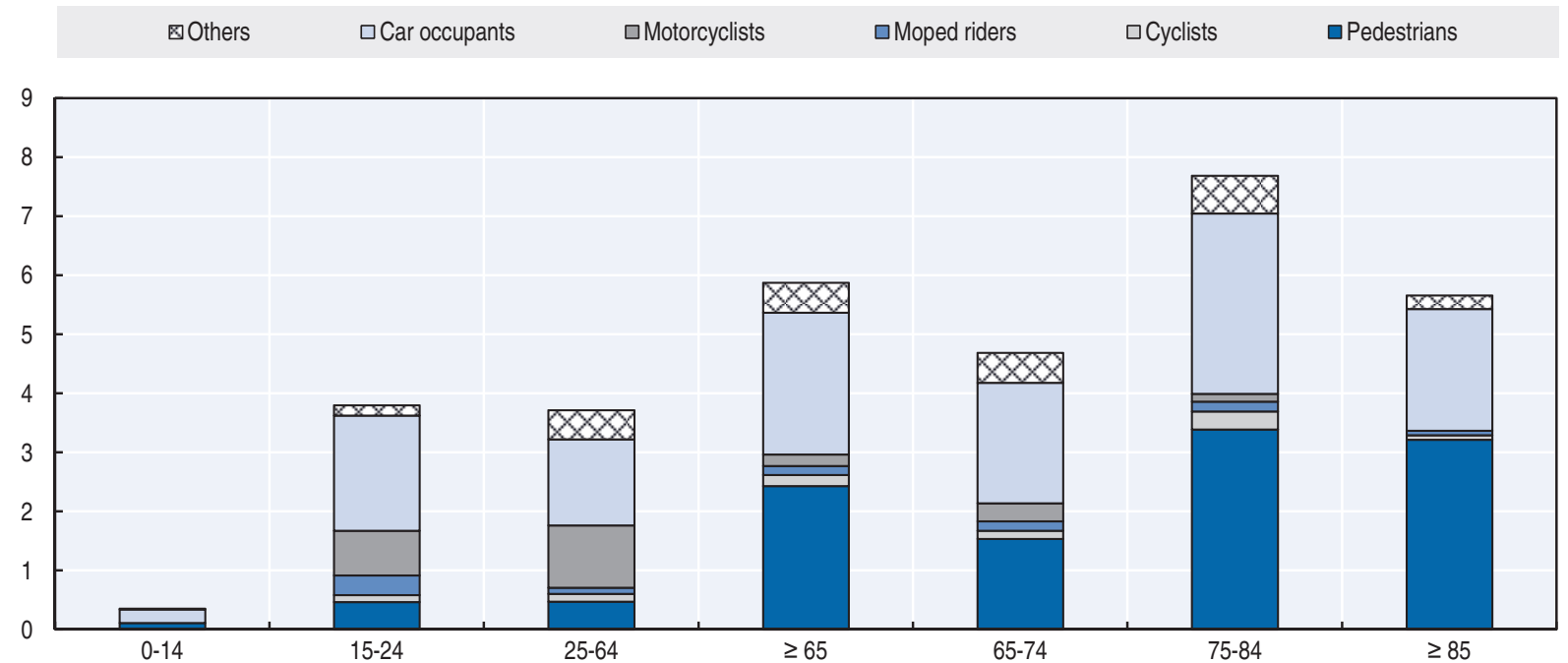

\section{Road safety by road type}

In $2015,69 \%$ of fatalities occurred on roads outside urban areas. Approximately $30 \%$ of fatal crashes are run-off road crashes, typically on rural roads. Since 2000, while the whole road network benefited from significant improvements, the smallest progress was achieved on urban roads.

Risk exposure data is only available for roads outside urban areas. The number of vehicle-kilometres travelled on those roads decreased by $4 \%$, while the number of fatalities decreased by $35 \%$.

Figure 36.6. Road fatalities by road type

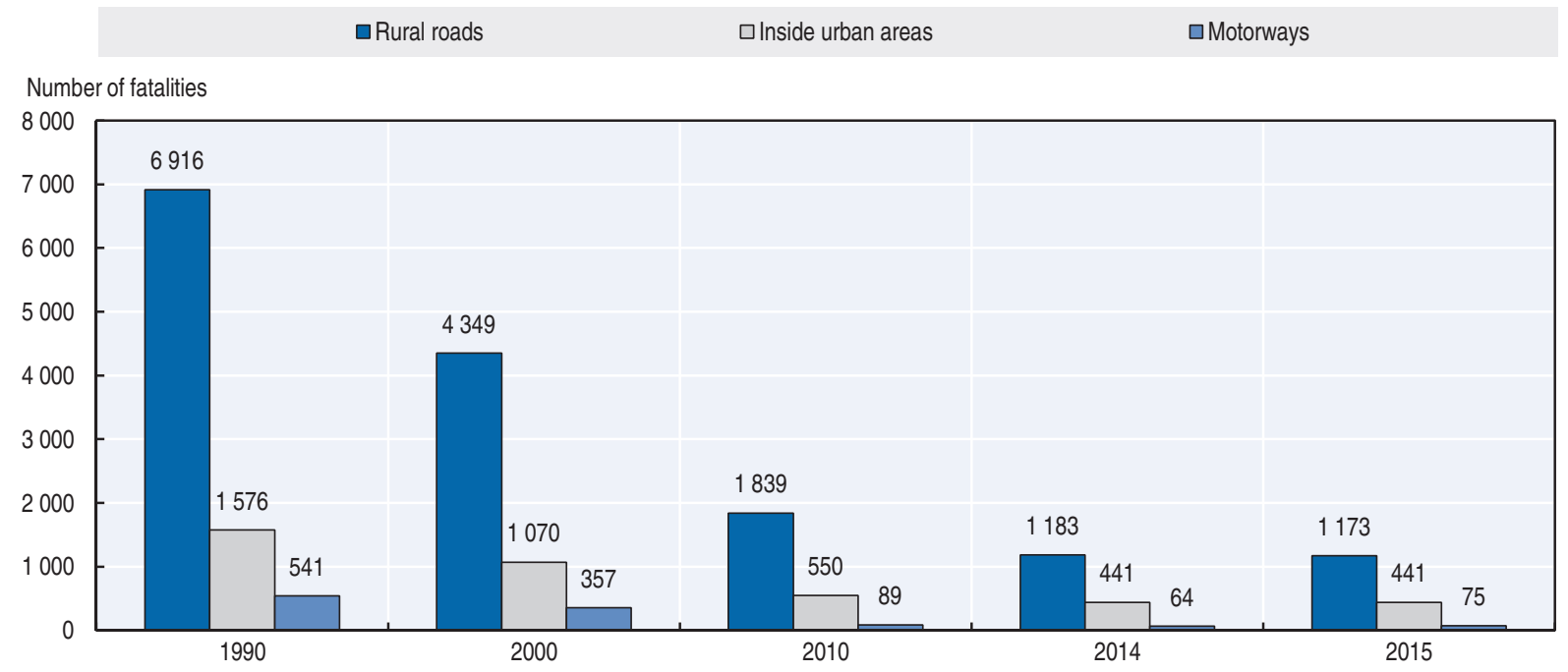




\section{Economic costs of traffic crashes}

Traffic crashes represent a significant cost for society, estimated at around EUR 5.1 billion (i.e. $0.5 \%$ of GDP), according to police-reported data. However, when the health system data are included, economic costs rise to EUR 9.3 billion (i.e. 1\% of GDP). These estimates do not include property damage and administrative costs.

Costs are based on the calculation of a monetary value of statistical life, based on a willingness-to-pay approach (DGT, 2011). A value of preventing life of EUR 1.37 million (2015 prices) is used to compute the social costs of fatal road crashes in Spain (Abellan et al., 2011). Likewise, it is used to assess the benefits of road safety measures in terms of saved lives, making possible the economic evaluation of Spanish transport policies.

Table 36.5. Costs of road crashes, 2015

\begin{tabular}{lccc}
\hline & Unit cost & Total based on police reported data & Total when health data are included \\
\hline Fatalities & EUR 1.37 million & EUR 2.31 billion & EUR 2.31 billion \\
Hospitalised persons & EUR 213992 & EUR 2.03 billion & EUR 4.10 billion \\
Slight injuries & EUR 5961 & EUR 0.74 billion & EUR 2.84 billion \\
Property damage costs & & not included & not included \\
Total (EUR) & 5.09 billion & 9.25 billion \\
Total as $\%$ of GDP (at constant prices) & & $0.50 \%$ & $1.00 \%$ \\
\hline
\end{tabular}

\section{Recent trends in road user behaviour}

\section{Speed}

In 2015, inappropriate speed was reported as a contributing factor in $9 \%$ of injury crashes and $20 \%$ of fatal crashes.

In 2015, 26.6 million vehicles were checked for speed (mobile checks), and 4.6\% were driving above the limit (this proportion was $4.0 \%$ in 2014 and 6.5\% in 2013).

The table below summarises the main speed limits in Spain.

Table 36.6. Passenger car speed limits by road type, 2017

\begin{tabular}{lcl}
\hline & General speed limit & \multicolumn{1}{c}{ Comments } \\
\hline Urban roads & $50 \mathrm{~km} / \mathrm{h}$ & \\
Rural roads & $90 / 100 \mathrm{~km} / \mathrm{h}$ & $\begin{array}{l}90 \mathrm{~km} / \mathrm{h} \text { (roads with no hard shoulder or with one of less than } 1.5 \mathrm{~m} \text {. width) } \\
100 \mathrm{~km} / \mathrm{h} \text { (roads with hard shoulder, at least } 1.5 \mathrm{~m} \text {. wide or with two lanes or more } \\
\text { in each direction) }\end{array}$ \\
Motorways & $120 \mathrm{~km} / \mathrm{h}$ & \\
\hline
\end{tabular}

\section{Drink driving}

In Spain, the blood alcohol content (BAC) limit is $0.5 \mathrm{~g} / \mathrm{l}$ for general drivers and $0.3 \mathrm{~g} / \mathrm{l}$ for novice and professional drivers.

Between 2001 and 2015, random preventive alcohol tests have been tripled and the positive tests have been reduced by almost a third. In 2001, the Traffic Division of the Civil Guard carried out 1.6 million preventive tests, and 5\% of them tested positive. In 2015, 5.0 million preventive tests were carried out and $1.4 \%$ tested positive.

According to the National Institute of Toxicology, in 2015 the percentage of drivers killed who tested positive for the presence of alcohol was about $29 \%$. 


\section{Drugs and driving}

The Traffic Division of the Civil Guard carried out 76040 saliva drug tests in 2015, as compared to 29643 in 2014. Nearly 70000 of the tests were preventive, with a rate of positives of $33 \%$.

According to the National Institute of Toxicology, in 2015 the percentage of drivers killed who tested positive for the presence of drugs other than alcohol was about $14 \%$.

\section{Seat belts and helmets}

Seat belt use has been compulsory in front seats outside urban areas since 1974 and in front seats inside urban areas and rear seats since 1992.

Children with a height of less than $135 \mathrm{~cm}$ must be seated on rear seats and use a dedicated child restraint system (CRS). In 2015, five of the 13 children (under 12) killed in road traffic as car occupants were not using a CRS or seat belt.

Table 36.7. Seat belt wearing rate by car occupancy and road type

$\%$

\begin{tabular}{lcc}
\hline & 2010 & 2012 \\
\hline Front seat & & \\
$\quad$ Driver & 89 & 90 \\
Passenger & 88 & 91 \\
Urban roads (driver) & 83 & 86 \\
Rural roads (driver) & 93 & 93 \\
$\quad$ Motorways (driver) & 96 & 96 \\
Rear seats & & \\
$\quad$ General & 76 & 81 \\
Children (use of child restraint) & n.a. & n.a. \\
\hline
\end{tabular}

Helmet use is compulsory for riders of all powered two-wheelers. The helmet wearing rate is nearly $100 \%$. Nevertheless, in $2015,5 \%$ of motorcycle users killed outside urban areas were not wearing a helmet, and in urban areas $10 \%$ did not use a helmet. As for moped riders, among the 28 fatalities outside urban areas, four were not wearing a helmet. On urban roads, three out of 28 killed moped riders were not wearing a helmet.

\section{Distraction}

Distraction is a concurrent factor in $29 \%$ of injury crashes. It is a more prevalent issue outside urban areas ( $36 \%$ of injury crashes) than inside urban areas ( $25 \%$ of injury crashes). Factors that may affect attention are the use of mobile telephones, radios, DVDs, witnessing a previous crash, looking at the environment, absent-mindedness, and sudden illness or indisposition.

One of the main reasons for distraction is the use of the mobile phone while driving. In 2015, the Traffic Division of the Guardia Civil issued 94986 tickets for the use of a mobile telephone while driving, which represented a decrease of $18 \%$ as compared to 2014 .

Since 2002, the use of hand-held mobile phones while driving is forbidden. Only hands-free phones are permitted. As of 1 July 2006, driving while using hand-held mobile phones, GPS or other communication devices entails the loss of three points from the driving licence. 


\section{Sleepiness and fatigue}

There is no estimate of crashes due to fatigue.

\section{National road safety strategies and targets}

\section{Organisation of road safety}

The agency that centralises most aspects of road safety is the Directorate-General for Traffic, which belongs to the Ministry of the Interior. The core responsibilities of the DGT are at a national level on all interurban roads, except for the Basque Country, Catalonia and part of Navarre. Key missions of the DGT include:

- Issuing and renewing driving licences and vehicle authorisations, regulating and licensing private driving training schools, and supervising the Roadworthiness Inspection System.

- Registering vehicles, drivers and traffic offences.

- Controlling traffic and enforcing traffic law on all interurban roads.

- Managing the Traffic Division of the Civil Guard (the police body in charge of traffic control and traffic law enforcement), with around 10000 officers.

- Centralising road traffic statistics and co-ordinating crash investigations.

- Developing road safety strategies, plans and policies, in coordination with other relevant ministries or public bodies.

- Supervising driving information and road safety education campaigns.

\section{Road safety strategy for 2011-20}

The Spanish Road Safety Plan 2011-20 was adopted by the Council of Ministers on 25 February 2011.

\section{Road safety targets}

The main objective of the Spanish Road Safety Strategy is to reduce by 2020 the rate of road fatalities to below 37 per million inhabitants. This target is aligned with the European objective of halving the number of people killed by 2020. A mid-term review of the strategy is currently being conducted. This review includes an evaluation of the measures taken in the first half of the decade and a proposal for revised targets.

In the framework of the Road Safety Strategy, a number of indicators and targets were adopted. These are being monitored annually.

Table 36.8. Targets and performance indicators of the 2011-20 road safety plan

\begin{tabular}{lccc}
\hline Indicators & Reference figures in 2009 & Figures in 2015 & Target figures 2020 \\
\hline Reach a fatality rate of 37 deaths per million inhabitants & 59 & 36 & $<37$ \\
Reduce by $35 \%$ the number of serious injuries & 13923 & 9495 & 9050 \\
No child (<12) killed without a child restraint system & 12 & 5 & 0 \\
$25 \%$ fewer drivers between the ages of 18 and 24 & 730 & 353 & 548 \\
killed or seriously injured at weekends & 203 & 200 & 183 \\
$10 \%$ fewer drivers killed above the age of 64 & 459 & 306 & 321 \\
$30 \%$ fewer deaths due to being run over & 1.2 cyclists killed/ & 1.2 cyclists killed/ & 1.2 cyclists killed / \\
1 million more cyclists without their death rate going up & 100000 population & 100 population & 100000 population \\
& 101 & 61 & 0 \\
Zero deaths in cars in urban areas & 3473 & 2928 & 2778 \\
$20 \%$ fewer deaths and serious injuries amongst motorcyclists & 520 & 285 & 364 \\
$30 \%$ fewer deaths due to having come off a single carriageway & &
\end{tabular}


Table 36.8. Targets and performance indicators of the 2011-20 road safety plan (cont.)

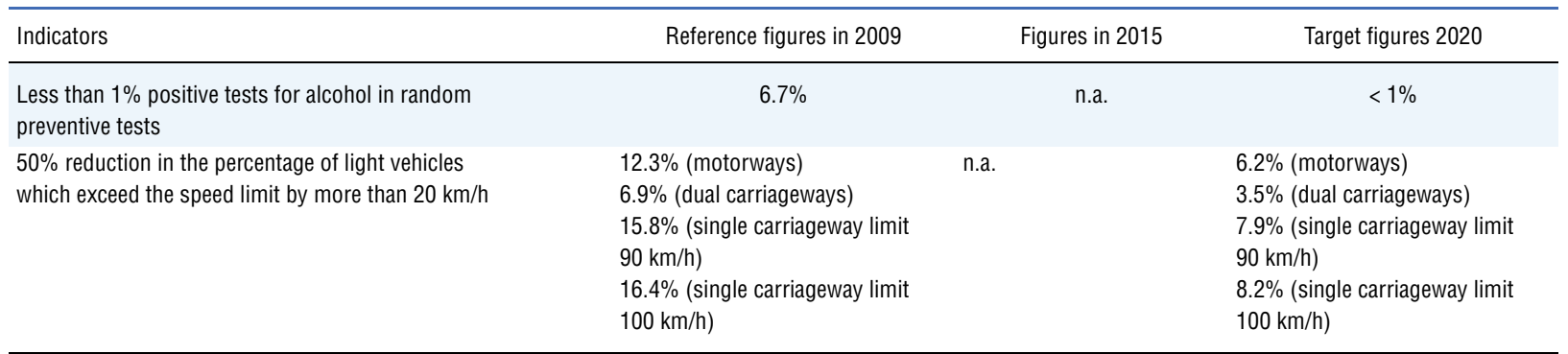

Figure 36.7. Trends in road fatalities towards national target

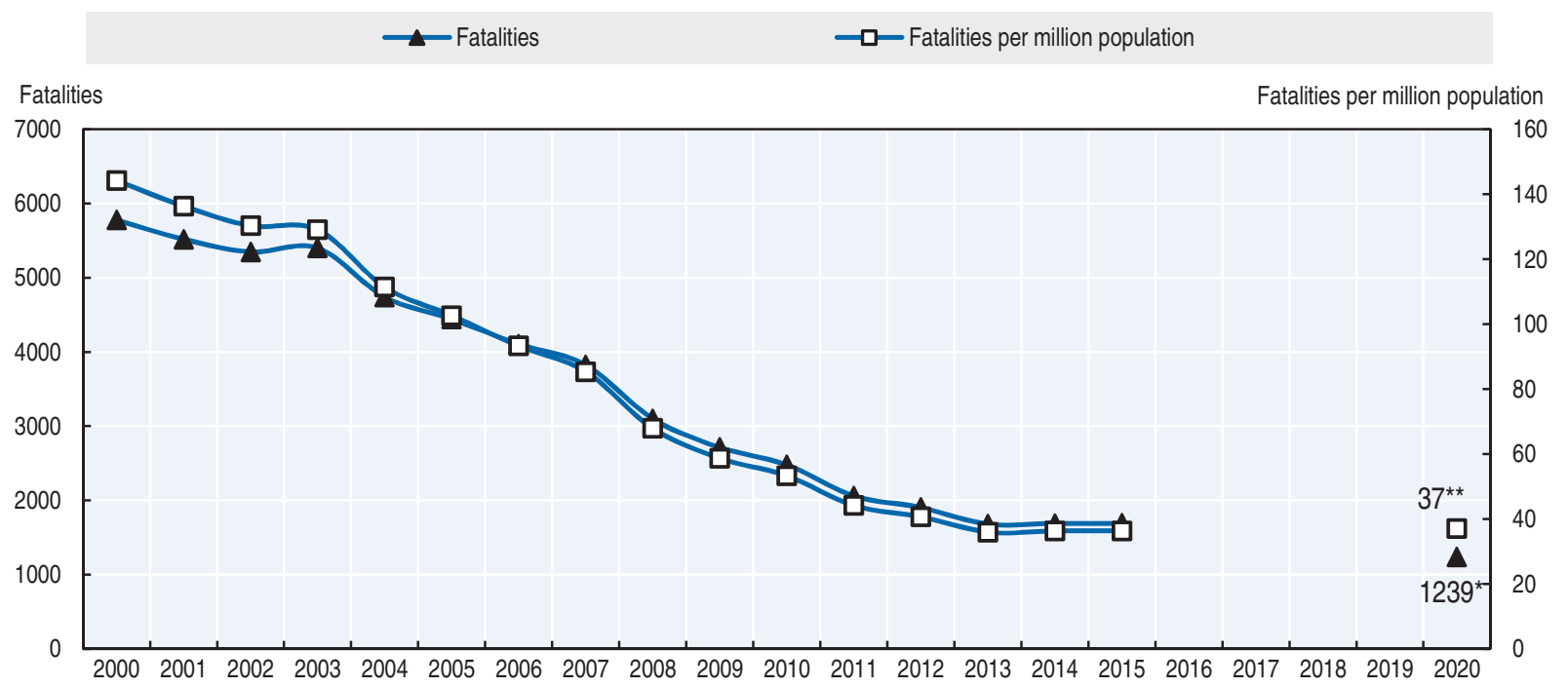

* National target to reduce by 2020 the rate of road fatalities to below 37 per million inhabitants.

* EU target of halving the number of people killed by 2020.

\section{Recent safety measures (2014-17)}

\section{Road safety management}

- The licensing system is being reviewed regarding both theoretical and practical tests with more focus on safe and responsible driving.

- DGT is improving its crash data information systems with the progressive inclusion of new parameters, such as risk exposure, descriptive analysis and time trends. Specific measures include: adoption, collection and dissemination of MAIS3+ indicators; collaboration with regional governments in order to link police and hospital registers; collaboration with the Ministry of Justice to collect data from post-mortem analyses; collection of exposure indicators based on odometer readings and mobility surveys.

- In 2014, the following changes to the Law on Road Safety were approved:

* zero tolerance for alcohol, drugs and medicines at non-therapeutic doses

* immobilisation of the vehicle if a child restraint system appropriate for the minor passenger is not used

* prohibition of the use of radar detectors 
* introduction of procedures to facilitate cross-border exchange of information on road safety related traffic offences, following EU Directive 2011/82.

- In 2014, a new code was passed regulating the communication of road crash data to the National Register of Victims of Road Crashes. It entered into force on 1 January 2015. This new rule was accompanied by the establishment of a new crash form to be used by traffic police officers at the scene of the crash.

- In the area of criminal offenses related to road safety, a protocol was signed between the Ministries of Interior and Justice for the notification by electronic means of information on penalties and security and precautionary measures. This protocol will improve the enforcement of penalties implying the deprivation of the right to drive motor vehicles and mopeds.

- Regarding sustainable mobility and the protection of vulnerable users, the DGT signed with the Network of Walking Cities an agreement for the development of joint activities to improve road safety, in particular relating to pedestrian safety. The agreement aims to coordinate the actions of the Directorate General for Traffic and the Network of Walking Cities in activities designed to promote pedestrian mobility through the exchange of information, experiences and knowledge, and technical advice and participation in conferences and other public events organized by both entities.

\section{Road users}

\section{Speed management}

- In 2015, new measures for speed management were implemented. The operational margin of speed cameras was set at $7 \mathrm{~km} / \mathrm{h}$ for speed limits up to $100 \mathrm{~km} / \mathrm{h}$, and $7 \%$ for higher speed limits.

- Sections of rural roads with intensified enforcement through mobile speed cameras are now published on the website of the Directorate General for Traffic. Sections are selected on the basis of their actual speeds and crash records. The list is updated twice a year.

- Computational methods are now applied to speed cameras, so that different types of vehicles can be distinguished, particularly heavy vehicles. This will allow the application of differential speed limits in order to identify speed violations.

- New average speed controls have been put in place, particularly in rural roads.

- In 2013, the Pegasus radar system was installed in one helicopter owned by the DGT, in order to monitor and enforce traffic on secondary roads. Four additional helicopters in 2014 and two in 2015 have been equipped with the Pegasus system.

\section{Alcohol and drugs}

- There are strengthened controls for drink driving on rural roads.

- Comprehensive checks are undertaken on rural roads to detect multiple offenders, i.e. drivers that commit more than one traffic violation at the same time.

- Strengthened checks for drug driving. In 2015, almost 70000 preventive tests were carried out by the Civil Guard outside urban areas, as compared to about 30000 in 2014. Furthermore, the DGT provides local authorities with drug kits, and assists in the training of local police officers. This intervention is part of the Spanish strategy of zero tolerance for drugs and alcohol. 


\section{Seat belts}

- In 2017, 225 cameras were installed on roads outside urban areas for the automated enforcement of seat belt use.

\section{Education and awareness}

- Week-long campaigns conducted in 2014, 2015 and 2016 with the Traffic Division of the Civil Guard and local police forces included: trucks and vans, school transport, speed enforcement, motorcycles and bicycles, use of mobile phones while driving, alcohol and drugs, helmets, seat belts and child restraint systems, rural roads, vehicle conditions and roadworthiness tests.

- Letters sent to traffic offenders to inform them about their penalties are now accompanied by information about the risks associated with the traffic violations they committed.

- Measures have also been developed in the field of mobile applications. The DGT launched an app called Comobity, which collaboratively connects road users among them and with their environment, in order to offer protection through advanced safety services and connected mobility. The app allows drivers, cyclists and pedestrians to inform other users of their presence, in order to take the necessary actions for safe driving.

\section{Infrastructure}

- Heavy goods vehicles are being diverted from rural road sections, with a high risk of crashes involving this type of traffic, to high capacity roads.

- A number of measures have been recently announced to improve safety on rural roads, including: improvement of safety on sections with high risk of overtaking related crashes, actuated junctions, implementation of panels informing drivers of their current speed, a new methodology for the identification of high risk sites, revision of criteria for the location of fixed speed cameras, signalling of sections with high cyclist exposure, installation of road stripes in sections with high risk of run-off crashes.

\section{Vehicles}

- The content in the national vehicle register was expanded in 2014 to include more technical data and information relating to technological safety elements, interventions carried out at garages, changes to the vehicle and kilometres driven, the rescue sheet, active safety elements and the rating stars awarded at the European New Car Assessment Programme (EuroNCAP).

- Regarding child safety, the Road Traffic Code was amended, so that all children under $135 \mathrm{~cm}$ tall must be seated in the rear of vehicles, and be using the appropriate child restraint system for their size and weight.

\section{Post-crash measures}

- Implementation of the Road Traffic Accident Victims Unit in 2013 to support traffic casualties and their relatives and inform them about available private and public services.

\section{Recent and ongoing research}

With regard to road safety research, in 2015, 2016 and 2017 the second, third and fourth calls for proposals in the areas of traffic, mobility and road safety were made, under the Research Plan on Road Safety and Mobility. Some of the main areas of research are: 
measurement of exposure, effects of psychoactive substances on morbidity, rehabilitation programmes for repeated offenders in driving under the influence of psychoactive substances, the interaction of the road environment and the vehicle on driver behaviour, the applicability of new technologies or post-accident response, among others.

Below are some relevant research results published in 2015 and 2016 (all websites accessed 16 May 2017).

- Abellán López et al. (2016), New motorcyclists protection system made in recycled rubber. (www.dynapubli.com/busqueda/nuevo-sistema-de-proteccion-de-motociclistas-fabricado-encaucho-reciclado).

- Alonso et al. (2015), Driving under the influence of alcohol: frequency, reasons, perceived risk and punishment.

- Barrio et al. (2015), An example of the usefulness of joinpoint trend analysis for assessing changes in traffic safety policies (www.sciencedirect.com/science/article/pii/S0001457514003893).

- Basagana et al. (2015), High Ambient Temperatures and Risk of Motor Vehicle Crashes in Catalonia, Spain (2000-2011): A Time-Series Analysis (http://ehp.niehs.nih.gov/1409223/).

- Castillo-Manzano et al. (2015), Are traffic violators criminals? Searching for answers in the experiences of European countries (www.sciencedirect.com/science/article/pii/ S0967070X14002510).

- Castillo-Manzano et al. (2015), Can cars and trucks coexist peacefully on highways? Analyzing the effectiveness of road safety policies in Europe (www.sciencedirect.com/ science/article/pii/S0001457515000214).

- Castillo-Manzano et al. (2016), Exploring the relationship between truck load capacity and traffic accidents in the European Union. (www.sciencedirect.com/science/article/pii/ S1366554516000223).

- Dadashova et al. (2016), Methodological development for selection of significant predictors explaining fatal road accidents (www.sciencedirect.com/science/article/pii/S0001457516300288).

- Herrero-Fernández (2016), The relationship between driving anger and risk could be nonlinear. Towards a circumplex model of anger and risk on the road. (www.tandfonline.com/ doi/abs/10.1080/02134748.2016.1143180).

- Herrero-Fernández et al. (2016), Risky behavior in young adult pedestrians: Personality determinants, correlates with risk perception, and gender differences. (www.sciencedirect. com/science/article/pii/S1369847815001886).

- Jiménez et al. (2015), Autonomous collision avoidance system based on accurate knowledge of the vehicle surroundings (www.crossref.org/iPage?doi=10.1049\%2Fiet-its.2013.0118).

- Jiménez-Mejías et al. (2016), Pedestrian- and driver-related factors associated with the risk of causing collisions involving pedestrians in Spain (www.sciencedirect.com/science/ article/pii/S0001457516300926).

- Ledesma et al. (2015), Measuring Individual Differences in Driver Inattention: Further Validation of the Attention-Related Driving Errors Scale (http://hfs.sagepub.com/content/ 57/2/193.long).

- Machado-León et al. (2016), Socio-economic and driving experience factors affecting drivers' perceptions of traffic crash risk (www.sciencedirect.com/science/article/pii/S136984781500203X). 
- Martínez Ruiz et al. (2015), Contribution of exposure, risk of crash and fatality to explain ageand sex-related differences in traffic-related cyclist mortality rates (www.sciencedirect. com/science/article/pii/S0001457515000196).

- Martínez Ruiz et al. (2015), Factores asociados al riesgo de provocar una colision entre un ciclista y un peaton en Espana, 1993-2011 (www.gacetasanitaria.org/es/factores-asociadosal-riesgo-provocar/articulo/S0213911115000710/).

- Melchor et al. (2015), Trends in mortality due to motor vehicle traffic accident injuries between 1987 and 2011 in a Spanish region (Comunitat Valenciana). (www.sciencedirect. com/science/article/pii/S0001457515000342).

- Mueller et al. (2015), Health impact assessment of active transportation: A systematic review (www.clinicalkey.com/\#!/content/playContent/1-s2.0-S0091743515001164? returnurl= http:\%2F\%2Flinkinghub.elsevier.com\%2Fretrieve\%2Fpii\%2FS0091743515001164\%3Fshowall\%3 Dtrue\&referrer $=$ ).

- Olabaria et al (2015) Effect of neighbourhood motorization rates on walking levels. (http:// eurpub.oxfordjournals.org/content/25/4/740)

- Olabarria et al. (2015), Head-on crashes on two-way interurban roads: a public health concern in road safety (www.gacetasanitaria.org/en/head-on-crashes-on-two-way-interurban/ articulo/S0213911115000618/).

- Pérez et al. (2015), Road traffic injuries: An example of public health (www.gacetasanitaria. org/es/lesiones-por-trafico-un-ejemplo/articulo/S0213911115001946/).

- Pulido et al. (2016), The role of exposure on differences in driver death rates by gender and age: Results of a quasi-induced method on crash data in Spain. (www.sciencedirect. com/science/article/pii/S0001457516301749).

- Rangel et al. (2015), Modeling the effect of contractual incentives on road safety performance (www.sciencedirect.com/science/article/pii/S0967070X15000360).

\section{References}

Abellan et al. (2011), "El valor monetario de una vida estadística en España Estimación en el contexto de los accidentes de tráfico", DGT, Spain.

DGT (2016), "Main figures in road safety data, Spain 2015".

World Bank (2017), "GDP (constant US\$)", World Development Indicators, http://databank.worldbank.org/ data/reports.aspx?source=world-development-indicators (accessed 23 February 2017).

\section{Websites}

- General Traffic Directorate: www.dgt.es (accessed 16 May 2017). 



\section{Chapter 37}

\section{Sweden}

This chapter presents 2015 road safety data for Sweden along with the most recent data from 2016. It looks at trends in traffic and road safety from the years 1990 to 2015 and road user behaviour patterns with a special focus on the ageing population. Sections include data on speed, drink driving, drugs and driving, distracted driving, fatigue and seat belt usage. The chapter reviews Sweden's road safety strategy and national targets to 2020 and the progress achieved thus far. It also provides details of all recently implemented safety measures and current and ongoing research.*

* All data stem from the Swedish Transport Administration, Swedish Transport Agency and IRTAD unless otherwise noted. For more information please contact: karin.bengtsson@transportstyrelsen.se; anna.vadeby@vti.se. 
W ith its rate of 2.7 fatalities per 100000 inhabitants, Sweden remains one of the top performers in road safety. However, 2016 saw 11 more fatalities than in 2015, an increase of $4 \%$, bringing it back to the same level as 2014. In general, since 2010 the rate of reduction in fatalities and injury crashes has levelled off. Car occupants continue to make up the majority of fatalities (56\%) although cyclists made up the greater percentage of those seriously injured in 2016 (46\%). Sweden's focus is now shared between ensuring a safer environment for vulnerable users and reducing the number of fatalities amongst car occupants, in particular on roads of $80 \mathrm{~km} / \mathrm{h}$ where the majority of fatalities are recorded. Sweden remains on track to reach its 2020 target of less than 220 fatalities on the roads.

\section{Road safety data collection}

\section{Definitions applied in Sweden}

- Road fatality: Person killed in a traffic crash or within 30 days of the crash. Suicides have been excluded from official statistics since 2010.

- Slightly injured person: Persons slightly injured in road traffic crashes reported by the police.

- Serious injury: Two definitions are used

* Road traffic accidents with fatal and severe personal injury reported by the police are still used as official statistics.

* Another definition is used in the preventive road safety work. This definition is based on health loss following a traffic injury in which the previous health condition is not recovered within a reasonable amount of time. A person with any percentage of medical impairment, who has not recovered their previous physical health condition, is defined as seriously injured.

Medical impairment is a concept for evaluating various functional impairments, regardless of the reason. The disability scale is based on the level of functional impairment: For example, total paralysis is regarded as $100 \%$ impairment, the loss of one hand as $50-65 \%$, and the loss of the outer joint of the ring finger as $2 \%$. A person with any percentage of medical disability who has not recovered their previous physical health condition is therefore defined as seriously injured. Today, the medical impairment cut-off is $1 \%$ but discussions are ongoing on adding a complementary category of $10 \%$ or higher.

Sweden is therefore not using the score of three or more on the Maximum Abbreviated Injury Scale (MAIS3+) as a formal measure of a seriously injured person. MAIS3+ is, however, used to calculate the number of persons seriously injured and is therefore an important part of the Swedish efforts to increase the level of road safety.

\section{Data collection}

Sweden's safety data system integrates police and health data. This system, called STRADA, is composed of two parts: 
- STRADA police: Based on crash reports by the police, which include detailed information on crashes.

- STRADA hospital: Based on medical information and includes information of the crash from the patient.

The system is based on a systematic link between police and health data and allows accurate information on the severity and consequences of crashes to be obtained.

STRADA, however, only provides information on seriously injured people and acquires medical information about injured persons visiting the emergency department of a hospital following the crash. The number of people less seriously injured is likely to be underreported. As an example, people suffering from a minor injury requiring only primary care, without being further directed to a hospital, are not recorded in STRADA. However, slightly injured persons known by the police are reported into STRADA.

\section{Most recent safety data}

\section{Road crashes in 2016}

In 2016, 270 persons were killed in road crashes. This is 11 more than in 2015, representing a $4 \%$ increase. After several years of decreasing fatalities, recent years have seen a stagnation in the figures, most notably among car occupants on roads with speed limits $70-90 \mathrm{~km} / \mathrm{h}$. This group made up approximately $40 \%$ of all fatalities in 2016 .

The number of those seriously injured, defined as the number of persons calculated to have a medical impairment of at least 1\% (see above), rose in 2016 over the previous year to approximately 4600 . The numbers of those seriously injured has also levelled off in recent years as with fatalities. Cyclists constituted $46 \%$ of all those seriously injured in Sweden in 2016 , and car occupants 33\%. The number of seriously injured car occupants steadily decreased until 2015 but rose slightly in 2016. Cyclists are more likely to be seriously injured in single crashes in urban areas, while car occupants are more likely to be seriously injured outside urban areas.

\section{Road crashes in 2015}

In 2015, 259 persons were killed in road crashes, 11 less than in 2014 representing a $4 \%$ decrease. The steep reduction in the number of fatalities among protected road users drivers and passengers of cars, buses and trucks - has levelled out for the first time since 2003. Unprotected road users such as pedestrians, cyclists and motorcyclists have seen gradual progress. Compared to 2014, the number of fatalities amongst cyclists, pedestrians and moped riders decreased. Despite the slowing down in the reductions among protected road users, the safety issues in Sweden appear to be switching from protected road users outside cities to vulnerable road users within urban areas. However, a close focus on progress regarding protected road users is still needed and efforts to continuing reducing the number of fatalities in this group are important.

\section{Trends in traffic and road safety (1990-2016) Traffic}

Between 1990 and 2015, the number of motorised vehicles increased by 35\% and the overall vehicle kilometres driven by $25.5 \%$. Passenger cars account for about $82 \%$ of traffic volume (vehicle kilometres) on Swedish roads. Buses and motorcycles account for just over 
$1 \%$ each, light trucks for $11 \%$ and heavy trucks for $6 \%$. Light trucks are the type of vehicle showing the most rapid increase, both in terms of numbers of vehicles and traffic volume.

In 2015 , the total traffic volume increased by $1.9 \%$ compared to 2014 . It increased by slightly more than $2 \%$ for passenger cars and light trucks. Traffic volume decreased by $0.5 \%$ for heavy goods vehicles above 3.5 tonnes and motorcycle traffic volume also decreased slightly $(-0.3 \%)$ compared to 2014.

\section{Road safety}

The number of road fatalities reached a peak in 1965 and 1966, with 1313 road deaths each year, and since then road deaths have decreased by almost $80 \%$.

Between 1990 and 2016, the number of road fatalities decreased by $65 \%$, while the number of injury crashes (as reported by the police) between 1990 and 2016 was reduced by only $17 \%$. This variation is explained by a much better reporting of injury crashes in recent years and by a strong focus on reducing the most severe crashes.

The overall positive trend can partly be explained by gradual improvements in infrastructure, vehicle fleet, an increased focus on injury prevention and reduced speeds. Both the safe national road indicators and safe vehicle indicators are improving, and road design has long embraced greater safety.

Sweden has experienced a substantial drop in injured occupants of passenger cars since 2003. For the seriously injured the drop is so radical that since 2011 more cyclists than car occupants have been seriously injured. This is mainly due to safer cars, lower speeds and the introduction of median barriers.

\section{Rates}

Since 1990, the death rate per 100000 inhabitants has decreased by more than $70 \%$, and the death rate per 10000 registered vehicles dropped by 75\%, while the number of vehicles per 1000 inhabitants has increased by more than $18 \%$. The rate reached a record low of 2.7 in 2013, slightly increased to 2.8 in 2014, then dropped to 2.7 again in 2015 and 2016.

\section{Analysis of seriously injured data}

In 2015, 906 persons suffered MAIS 3+ injuries in Sweden, 38\% were cyclists and 28\% were in passenger cars. In 2016, there were 987 persons suffering MAIS 3+ injuries, $40 \%$ as cyclists and $30 \%$ as passenger car occupants. This represents an overall $16 \%$ decrease when 2016 is compared to 2014. Since 2007 the number of persons suffering MAIS 3+injuries has decreased by $29 \%$, but this differs for different road users. While the number of injured persons in passenger cars has decreased, the number of injured cyclists is slightly higher than in 2007.

\section{Road safety by user group}

Since 1990, all user groups have benefited from improvements in road safety. However, the reduction in fatalities was much smaller for motorcyclists than for other road users.

This relative lack of progress is partly explained by the doubling of the motorcycle fleet between 1996 and 2013. To respond to this trend, in April 2010, the Swedish Transport Administration presented a new national strategy on motorcycle and moped safety. The main result was to focus on Anti-lock Braking Systems (ABS), increased speed compliance by motorcyclists and proper helmet use for moped riders. In 2013, 40 motorcyclists died in 
Table 37.1. Road safety and traffic data

\begin{tabular}{|c|c|c|c|c|c|c|c|c|c|}
\hline & \multirow{2}{*}{1990} & \multirow{2}{*}{2000} & \multirow{2}{*}{2010} & \multirow{2}{*}{2014} & \multirow{2}{*}{2015} & \multicolumn{4}{|c|}{$2015 \%$ change from } \\
\hline & & & & & & 2014 & 2010 & 2000 & 1990 \\
\hline \multicolumn{10}{|l|}{ Reported safety data } \\
\hline Fatalities & 772 & 591 & 266 & 270 & 259 & -4.1 & -2.6 & -56.2 & -66.5 \\
\hline Injury crashes & 16975 & 15770 & 16255 & 12926 & 14667 & 13.5 & -9.8 & -7.0 & -13.6 \\
\hline Serious injuries (MAIS3+) & & & 1217 & 1173 & 906 & -22.8 & -25.6 & & \\
\hline Deaths per 100000 inhabitants & 9.1 & 6.7 & 2.8 & 2.8 & 2.7 & -5.1 & -6.7 & -60.2 & -70.7 \\
\hline Deaths per 10000 registered vehicles & 1.7 & 1.2 & 0.5 & 0.5 & 0.4 & -5.6 & -8.6 & -64.8 & -75.1 \\
\hline Deaths per billion vehicle kilometres & 12.0 & 8.5 & 3.5 & 3.4 & 3.2 & -5.8 & -7.4 & -62.4 & -73.3 \\
\hline \multicolumn{10}{|l|}{ Traffic data } \\
\hline Registered vehicles ${ }^{1}$ (thousands) & 4461 & 4842 & 5654 & 5923 & 6021 & 1.7 & 6.5 & 24.3 & 35.0 \\
\hline Vehicle-kilometres (millions) & 64310 & 69267 & 76731 & 79221 & 80714 & 1.9 & 5.2 & 16.5 & 25.5 \\
\hline Registered vehicles per 1000 inhabitants & 523 & 546 & 605 & 614 & 618 & 0.6 & 2.0 & 13.0 & 18.1 \\
\hline
\end{tabular}

1. Includes mopeds.

StatLink तiाst http://dx.doi.org/10.1787/888933580897

Figure 37.1. Road safety, traffic and GDP trends index $1990=100$

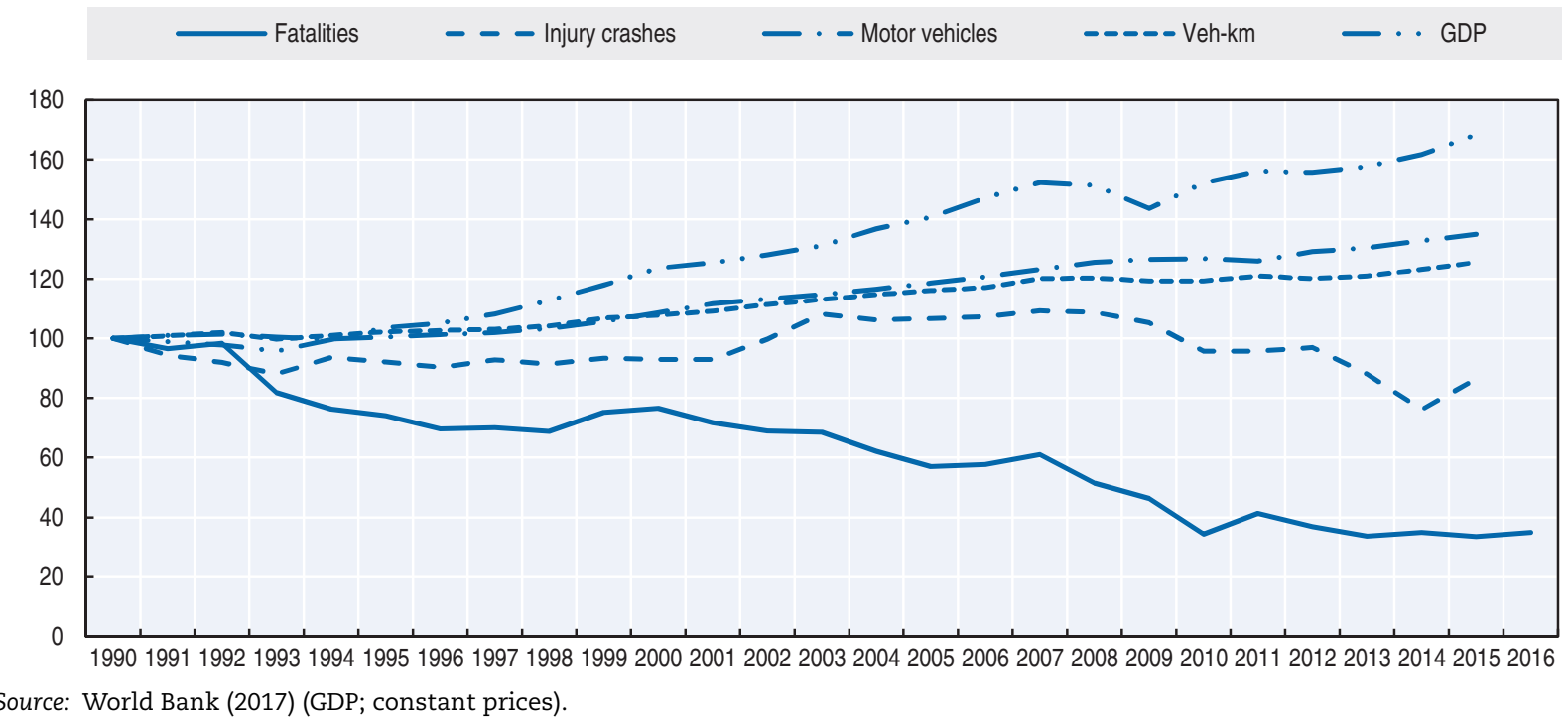

road traffic crashes, a $29 \%$ increase compared to 2012. In 2014 the number of killed motorcyclists decreased to 31, increased again to 44 in 2015 and then decreased again to 36 in 2016.

The decrease in the number of deaths in 2015 concerned primarily pedestrians, cyclists and, to some extent, moped riders; whereas the number of fatalities increased for other categories of road users. In 2016, the increase in fatalities was, in contrast to 2015, seen primarily amongst pedestrians and cyclists.

Seventeen cyclists were killed in 2015, 16 less than in 2014. In 2016, this rose by 5 to 22 cyclist fatalities. For moped riders and pedestrians, the number of fatalities decreased respectively, from 8 to 5 and 52 to 28 between 2014 and 2015. However, in 2016 there were 8 moped riders and 42 pedestrians killed.

In summary, the stagnation among fatalities that has been seen from 2010 onward is present in all user groups, with yearly deviations within each group. 
Table 37.2. Road fatalities by road user group

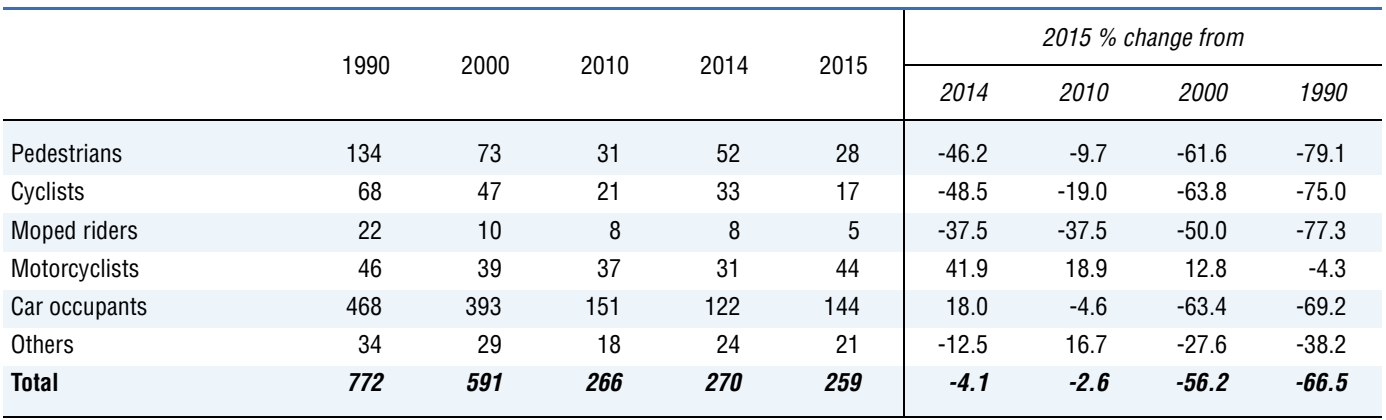

Figure 37.2. Road fatalities by road user group in percentage of total, 2015

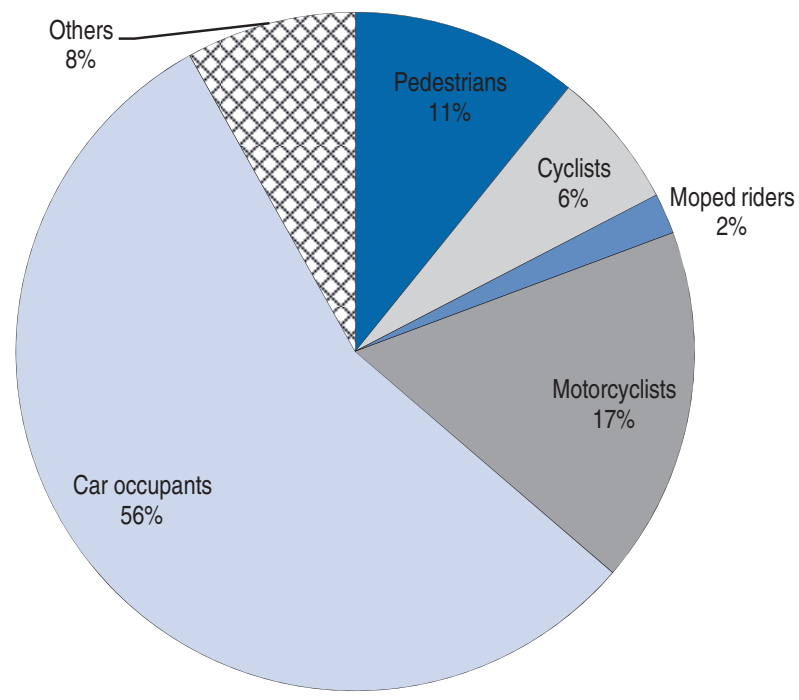

\section{Road safety by age group}

Since 1990, the reduction in fatalities has benefited all age groups, but the highest reduction concerns the younger age groups. Child fatalities (0-14) have been reduced nearly threefold since 2000, partly due to the legislation on child-restraint systems, but also to efforts to separate traffic modes in urban areas.

Table 37.3. Road fatalities by age group

\begin{tabular}{|c|c|c|c|c|c|c|c|c|c|}
\hline \multirow{2}{*}{ Age } & \multirow{2}{*}{1990} & \multirow{2}{*}{2000} & \multirow{2}{*}{2010} & \multirow{2}{*}{2014} & \multirow{2}{*}{2015} & \multicolumn{4}{|c|}{$2015 \%$ change from } \\
\hline & & & & & & 2014 & 2010 & 2000 & 1990 \\
\hline $0-14$ & 35 & 19 & 10 & 7 & 7 & 0.0 & -30.0 & -63.2 & -80.0 \\
\hline $15-17$ & 34 & 16 & 9 & 7 & 9 & 28.6 & 0.0 & -43.8 & -73.5 \\
\hline $18-20$ & 88 & 53 & 20 & 14 & 20 & 42.9 & 0.0 & -62.3 & -77.3 \\
\hline $21-24$ & 66 & 49 & 26 & 11 & 15 & 36.4 & -42.3 & -69.4 & -77.3 \\
\hline $25-64$ & 357 & 300 & 137 & 132 & 138 & 4.5 & 0.7 & -54.0 & -61.3 \\
\hline $65-74$ & & 50 & 28 & 37 & 35 & -5.4 & 25.0 & -30.0 & \\
\hline $75-84$ & & 85 & 22 & 41 & 25 & -39.0 & 13.6 & -70.6 & \\
\hline$\geq 85$ & & 19 & 14 & 21 & 10 & -52.4 & -28.6 & -47.4 & \\
\hline Total & 772 & 591 & 266 & 270 & 259 & -4.1 & -2.6 & -56.2 & -66.5 \\
\hline
\end{tabular}


Compared to 2010 , there has been an increase by nearly $40 \%$ in the number of older people (65+) killed in traffic in 2014. However, in 2015, this number dropped again to 2010 level. Sweden has an ageing population which is still very active in the road transport system. Therefore there are more vulnerable persons exposed to injury risk.

Figure 37.3 . Road fatality rates by age group Deaths per 100000 inhabitants in a given age group, 1990-2015

$-0-14$ years $\quad-\quad-15-17$ years $\quad \cdots-18-20$ years $\quad----21-24$ years $\quad \cdots 25-64$ years $-\cdots-65$ years

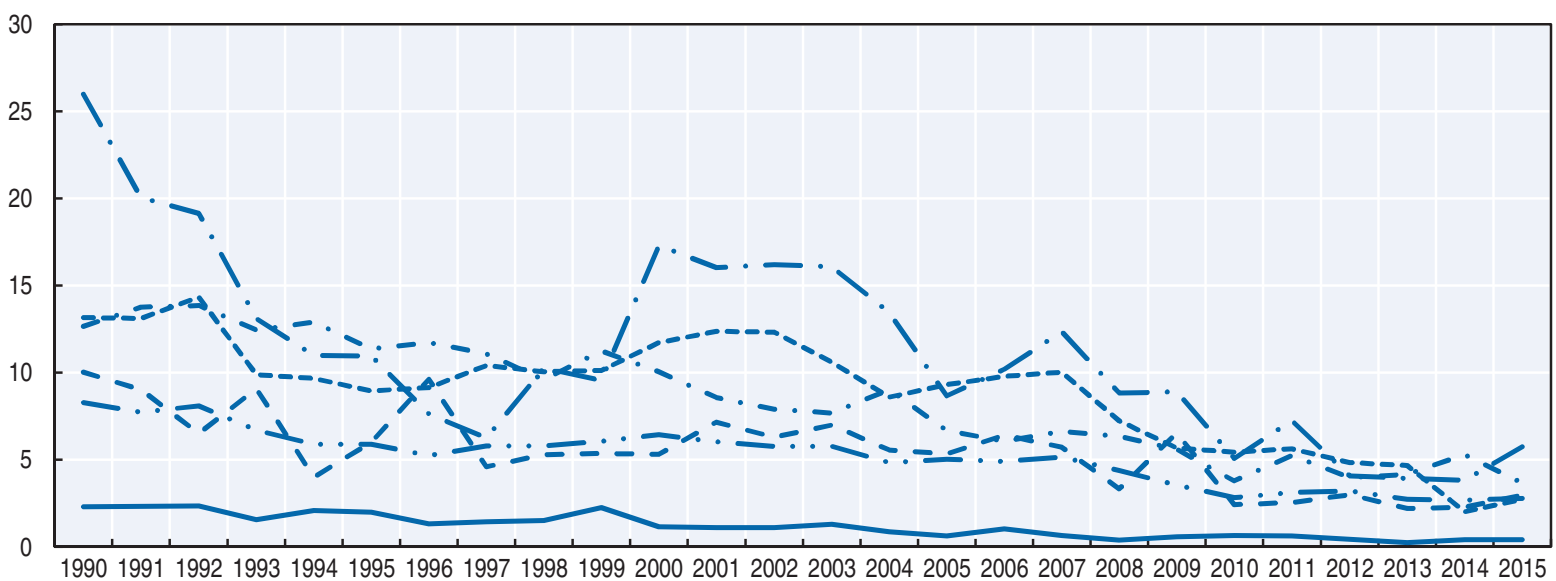

\section{Box 37.1. Road safety for an ageing population}

In 2016, 1977000 out of almost 10000000 people in Sweden were aged 65 or older. The population in Sweden is ageing due to the fact that people live longer and have fewer children. A forecast made by Statistics Sweden predicts an increase in the share of the senior population by $30 \%$ between 2010 and 2050, meaning that a quarter of the Swedish population is expected to be 65 years or older by 2050 .

The overall number of fatalities has fallen by $45 \%$ when comparing 2016 to 2005 , looking at a three-year moving average. The best development has been seen in the younger age groups, where fatalities of those under 24 years of age decreased by approximately $60 \%$. The older age groups have not had the same positive development; fatalities for the $65+$ age group only decreased by $28 \%$ in the same period. Slightly more than half of this group who died in traffic in recent years were as car occupants and $25 \%$ as pedestrians. The proportion of vulnerable road users who lost their lives in traffic was higher 2016 than $2005,48 \%$ compared to $40 \%$.

When looking at fatalities among people aged 65 years and older, there is less difference between genders. Overall, approximately $75 \%$ of all road fatalities are men, but among the older population, this number is $64 \%$ and among killed pedestrians, the gender distribution is split equally at $50 \%$. The decrease in fatalities among the over 65 age group from 2005 to 2016 has also been greater among men than women, $30 \%$ and $24 \%$ respectively.

In the renewed commitment to Vision Zero presented by the Swedish Government in 2016, road safety for vulnerable road users is highlighted as an important aspect that should receive greater attention. Continued transport safety work focused on vulnerable road users should more closely monitor the development of transport safety among different transport user groups, e.g. older road users, and be open to taking measures adapted accordingly. 


\section{Box 37.1. Road safety for an ageing population (cont.)}

Sweden has no statutory health checks/medical examinations for older drivers who have group 1 licenses (AM, A1, A2, A, B, BE and tractor). A person who has groups 2 and 3 licenses (C1, C1E, C, CE, D1, D1E, $D, D E)$ should renew their licence every five years. From the age of 45 , the person must send in a medical certificate to the Swedish Transport Agency that shows that he/she is medically fit to drive.

In Sweden the physician must report medically inappropriate drivers to the Swedish Transport Agency. All doctors are obliged to notify a person who is medically unsuitable to have a driving license. The medical requirements are regulated by the Transport Agency's regulations and general advice on medical requirements for driving licenses.

The Swedish Transport Agency has also developed a brochure, Older and Car Driving - information and guidance for related parties. The brochure refers to the person who is related to an elderly person and wants to know more about the continued fitness of driving.

Table 37.4. Road fatalities among senior citizens

\begin{tabular}{lcc|cc|cc}
\hline & \multicolumn{2}{c|}{$65-74$} & \multicolumn{2}{c|}{$75-84$} & \multicolumn{2}{c}{$85+$} \\
\cline { 2 - 7 } & 2010 & 2015 & 2010 & 2015 & 2010 & 2015 \\
\hline Pedestrians & 5 & 4 & 8 & 5 & 7 & 4 \\
Cyclists & 2 & 5 & 4 & 2 & 3 & 1 \\
Moped riders & 2 & 0 & 0 & 0 & 1 & 0 \\
Motorcyclists & 4 & 3 & 0 & 1 & 0 & 1 \\
Car occupants & 19 & 23 & 10 & 17 & 4 & 4 \\
Total & $\mathbf{3 3}$ & 35 & $\mathbf{2 3}$ & $\mathbf{2 5}$ & $\mathbf{1 5}$ & $\mathbf{1 0}$ \\
\hline
\end{tabular}

Figure 37.4. Road fatality rates by age group - focus on the senior population Deaths per 100000 inhabitants in a given age group, 2000-15
65-74 years
$--75-84$ years
$-\cdot-85+$ years

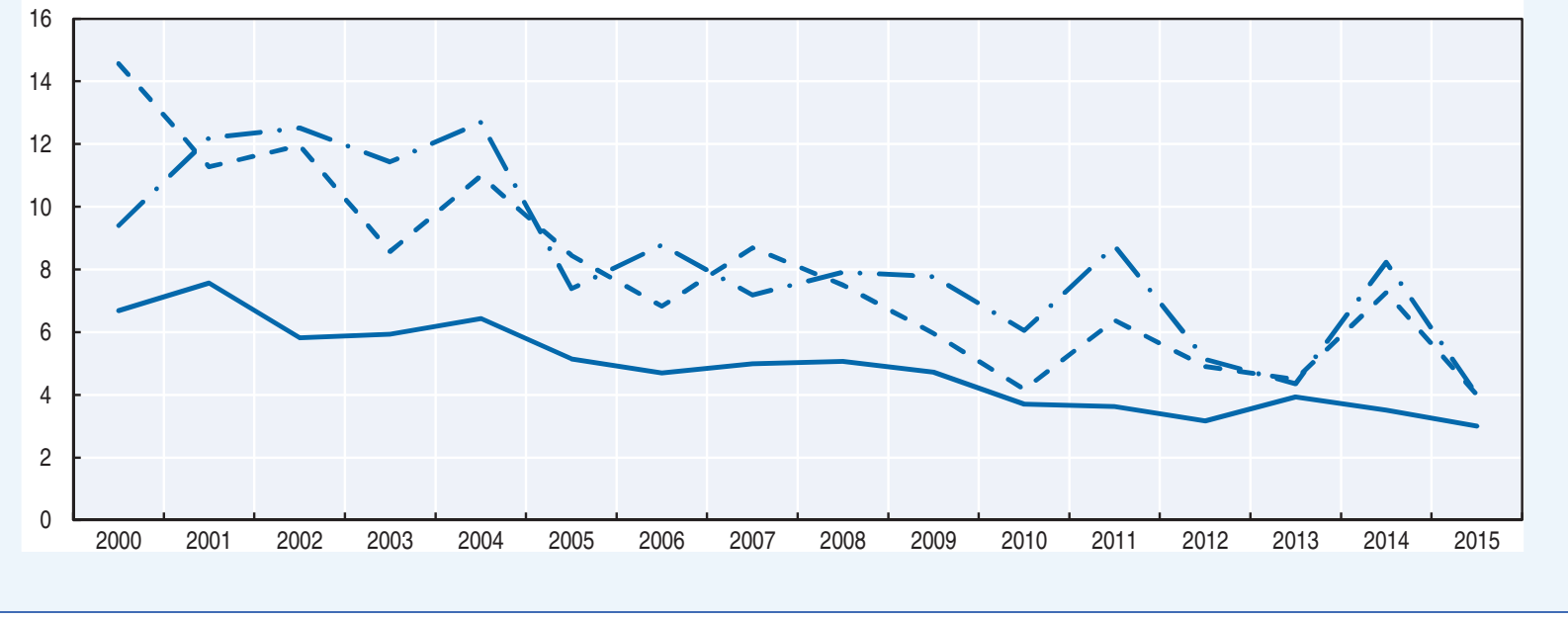


Figure 37.5. Road fatality rate by age and road user group Fatalities per 100000 inhabitants, 2015

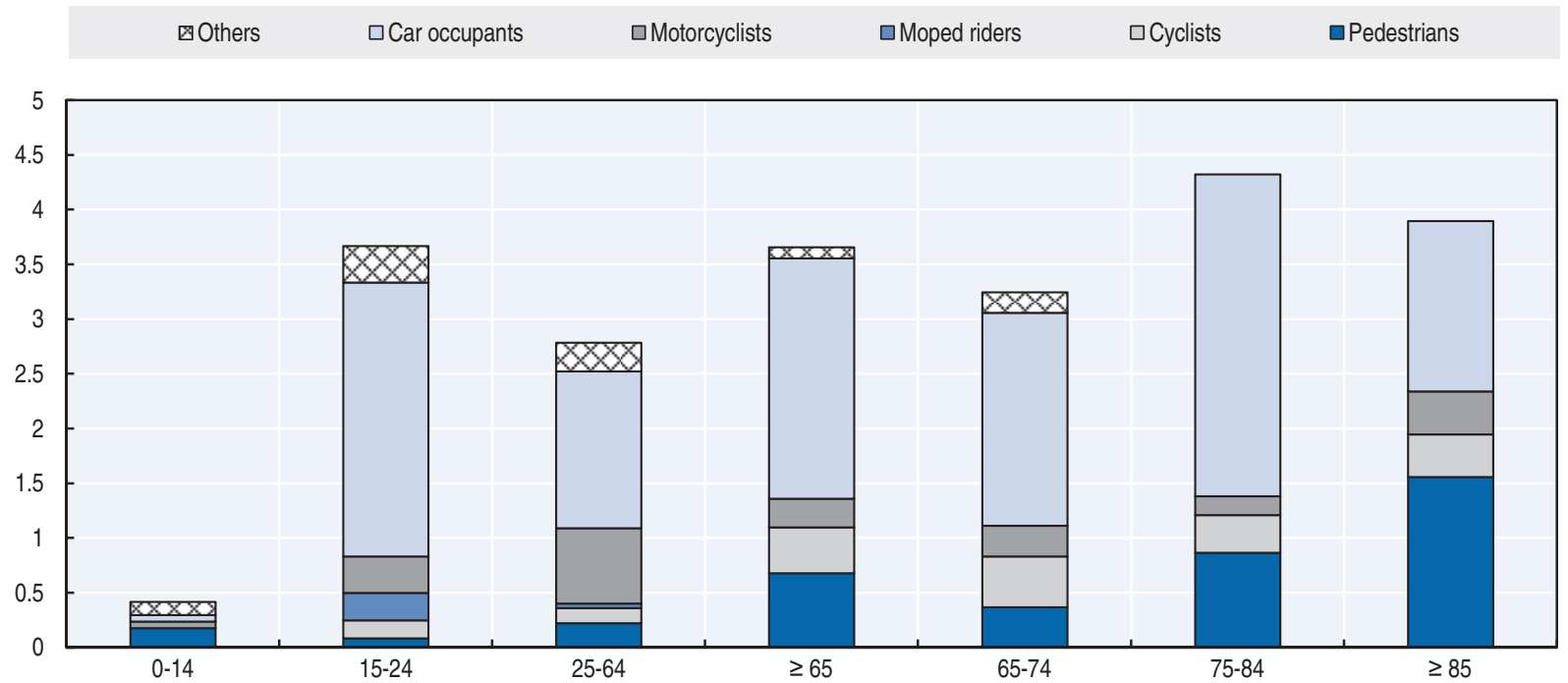

\section{Road safety by road type}

In 2015 , more than $70 \%$ of fatalities occurred on rural roads, $24 \%$ on urban roads and $6 \%$ on motorways.

Over the past 20 years, there has been a major improvement over the whole network.

The urban road environment was improved through the construction of mini roundabouts, cycle lanes and other infrastructure measures. As there has been less positive development recently in the safety of vulnerable roads users, future efforts will focus on safer municipal passages for pedestrians, cyclists and moped riders.

On rural roads, improvements in road safety since 2000 are in part due to the implementation of speed cameras and the generalisation of the " $2+1$ " roads (i.e. the transformation of traditional two wide lane roads into three narrow lane roads with a median barrier). The central lane alternates between traffic directions at regular intervals to provide ample passing opportunities. After years of discussion and debate, the first $2+1$ road was built, and it has been very cost effective by reducing head-on collisions on rural roads. The consistent trend towards safer vehicles and an increased focus on injury prevention has also supported road safety.

The decrease in the number of fatalities among car occupants on roads with the speed limit 70-90 km/h up until 2010 was partly due to efforts made to reduce collisions which had been the dominant cause of accidents on this type of road. Single crashes have not benefited in the same way and in recent years become as common as collisions among fatalities on this type of road. 
Figure 37.6. Road fatalities by road type

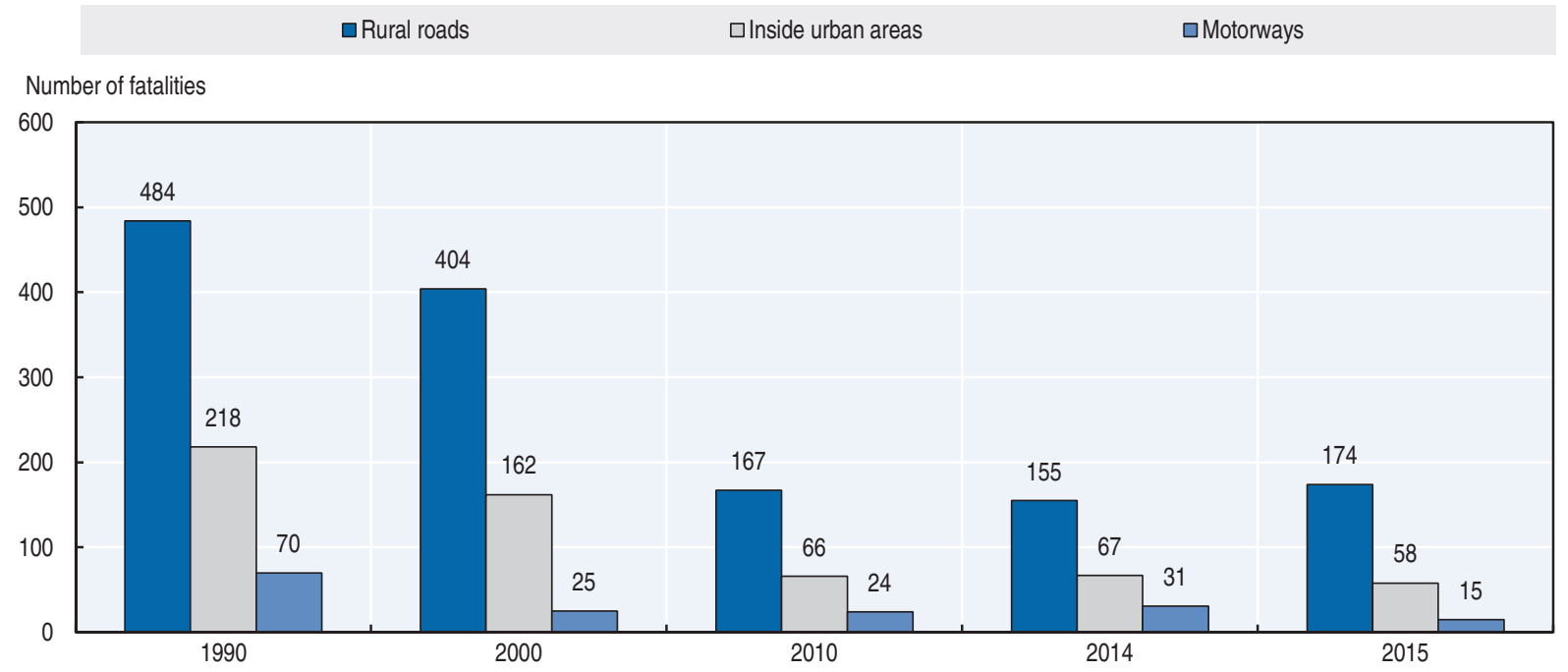

\section{Economic costs of traffic crashes}

Traffic crashes represent a significant cost for society, estimated in 2011 at around EUR 5.2 billion, or 1.3\% of GDP. The cost of road crashes was first evaluated in 1990 by the ASEK Group, on the basis of a willingness-to-pay approach to assess the unit cost of a fatality, a hospitalised person, a slightly injured person and a property-damage-only crash. Since then, these unit costs are regularly re-evaluated taking into account the evolution of GDP and of the Consumer Price Index.

Table 37.5. Costs of road crashes, 2011

\begin{tabular}{lcc}
\hline \multicolumn{1}{c}{ Cost (EUR) } & Unit cost & Total \\
\hline Fatalities & EUR 900 million \\
Serious injuries & EUR 2700 million \\
Slight injuries & EUR 800 million \\
Property damage costs & EUR 800 million \\
Total (EUR) & EUR $\mathbf{5 . 2}$ billion \\
Total as \% of GDP (at constant prices) & $\mathbf{1 . 3 \%}$ \\
\hline
\end{tabular}

\section{Recent trends in road user behaviour}

Speed

The reduction in the number of fatalities since 2007 is mainly explained by ongoing improvements to the vehicle fleet and infrastructure, and not least by reduced speeds. However, speeding remains a major problem in Sweden. The percentage of drivers exceeding the speed limit increased at the beginning of the century. This was followed by several years where compliance with speed limits improved slightly. However, data from 2016 show that the number of drivers exceeding speed limits has increased again.

The average speed on the national road network is estimated to have increased from 2013 to 2014, decreased in 2015, and increased again in 2016 to $79 \mathrm{~km} / \mathrm{h}$ (target: $77 \mathrm{~km} / \mathrm{h}$ ). Compliance with speed limits remains at an unacceptably low level. In 2014, the share of 
traffic volume within speed limits was estimated at $47 \%$ (target: $80 \%$ ) on national roads and 63\% (target: 80\%) on urban roads. Data for 2016 show that compliance has decreased for national roads $(44 \%)$, but increased slightly on urban roads $(67 \%)$.

Sweden has adopted tighter speed limits and introduced new limits in $10 \mathrm{~km} / \mathrm{h}$ steps, ranging from $30 \mathrm{~km} / \mathrm{h}$ to $120 \mathrm{~km} / \mathrm{h}$. In some specific areas, speed limits of 5, 10 and $20 \mathrm{~km} / \mathrm{h}$ are also used.

The table below summarises the main speed limits in Sweden.

Table 37.6. Passenger car speed limits by road type, 2017

\begin{tabular}{lc}
\hline & General speed limit \\
\hline Urban roads & $30-50 \mathrm{~km} / \mathrm{h}$ \\
Rural roads & $60-100 \mathrm{~km} / \mathrm{h}$ \\
Motorways & $110 \mathrm{~km} / \mathrm{h}$ or $120 \mathrm{~km} / \mathrm{h}$ \\
\hline
\end{tabular}

\section{Drink driving}

In Sweden, the legal blood alcohol content (BAC) limit is $0.2 \mathrm{~g} / \mathrm{l}$. A crash is defined as alcohol-related if a BAC level of above $0.2 \mathrm{~g} / \mathrm{l}$ can be proven in the driver, rider, pedestrian or cyclist involved. Even if only $0.23 \%$ of all drivers in random tests are above the legal limit, in 2015, 61 out of the 259 fatalities (or 24\%) involved a driver, rider, pedestrian or cyclist under the influence of alcohol. The corresponding number for 2016 is 67 (or 25\%) out of 270 fatalities.

The goal for Sweden is that, by 2020, at least $99.9 \%$ of drivers should be under the legal BAC limit of $0.2 \mathrm{~g} / \mathrm{l}$. The police's sobriety checks, which have decreased in number in recent years, represent an important measure for improving this indicator. An important role in future efforts to prevent drunk driving will also be played by quick and reliable breath tests.

In the long term, there is great potential in new technology to combat drink driving. In the short term, police surveillance plays an important part in reducing drink driving, as well as improved measures in reducing reoffending. "Alco-Gates" automate part of the sobriety check systems at ports and the government is currently considering installing the equipment in three to five additional ports.

\section{Drugs and driving}

A drug related crash is defined as any crash where one of the persons involved has any trace of an illegal drug in the body.

It is forbidden to drive a motor vehicle under the influence of illegal drugs. A driver who is under suspicion of driving after taking illegal drugs must leave a sample of blood or saliva to be analysed. It is up to the driver to decide whether to drive when using medication. If the medication has a negative effect on driving, the person is not allowed to drive. In 2015, 21 fatalities involved a driver under the influence of illegal drugs; amphetamines being the substance most commonly found, with some overlap on alcohol-related fatalities where a driver has been under the influence of both alcohol and drugs. In total, 75 persons died in alcohol and/or drug related accidents in 2015 which is $29 \%$ of all fatalities.

In 2016, 35 fatalities were drug related which is a 67\% increase from 2015. The overlap of drugs/alcohol was also greater in 2016 with in total, 83 persons dying in alcohol and/or drug related accidents. 


\section{Seat belts and helmets}

Seat belt use has been compulsory for front seats since 1975, rear seats since 1986 and it has been compulsory for children under $135 \mathrm{~cm}$ to use a child-restraint system since 1988. The medical recommendation is that a booster seat or similar device be used up to the age of 12 .

There has been a long-term upward trend in the use of seat belts. This trend will probably continue due to the increasing percentage of cars with seat belt reminder or warning functions.

The driver's use of seat belts in passenger cars was at 98\% during 2016. The proportion of car drivers killed who were unrestrained has decreased since 2001 and was at $38 \%$ in 2015 and 32\% in 2016.

In rear seats, children have always had a much higher rate of belt use than adults. In 2015, 98\% of children in the rear seat were belted. This is an increase compared with 2014 and seat belt use among children in rear seats is now on a par with that of front seats.

\section{Table 37.7. Seat belt wearing rate by car occupancy and road type}

\section{$\%$}

\begin{tabular}{lllll}
\hline & 2000 & 2014 & 2015 & 2016 \\
\hline $\begin{array}{l}\text { Front seat } \\
\text { Driver }\end{array}$ & 90 & 98 & 98 & 98 \\
$\quad$ Passenger & 92 & 96 & 97 & 96 \\
Urban roads (driver) & 87 & & \\
$\quad$ Rural roads (driver) & 89 & & \\
$\quad$ Motorways (driver) & 98 & & 93 \\
Rear seats & 81 & 89 & 98 \\
$\quad$ General & 89 & 95 & \\
$\quad$ Children (use of child restraint) & & & \\
\hline
\end{tabular}

All riders of powered two-wheelers (PTWs) are required to wear a helmet. The helmet wearing rate by riders of PTWs is high, at $96-99 \%$. In Sweden, it is mandatory for children under 15 years of age to use a helmet while cycling, and $60-70 \%$ of children comply. About $30 \%$ of adults use helmets, but it varies greatly by city.

\section{Distraction}

The Swedish Road Traffic Ordinance requires drivers to pay sufficient attention to driving. To avoid crashes, road users shall "observe the care and attention that the circumstances demand". However, from 2013, the government has strengthened this by-law, forbidding the use of communications devices when driving if "the use influences the driving in an unfavourable way".

In 2015, the government decided to undertake an assessment of the safety effect of the new by-law. The Swedish Transport Agency carried out an evaluation and the result showed a need for further research along with investment in technological developments that discourage use of hand held phones while driving. A proposal has also been made that hand held mobile phone use while driving should be prohibited. 


\section{Sleepiness and fatigue}

Fatigue may be a stronger cause of road crashes than alcohol, as it interacts with alcohol and drugs in a dramatic way. Sweden has no clear facts on the magnitude of the problem, but it is estimated that $10-20 \%$ of all crashes are caused by fatigue. Fatigue mostly concerns single-car crashes.

\section{National road safety strategies and targets Organisation of road safety}

Several agencies in Sweden support the government in the field of road safety. Authorities co-operate with each other but have specific tasks within the road transport system. The three main governmental agencies are:

- Transportstyrelsen, the Swedish Transport Agency, whose goal is to offer good accessibility and high-quality, secure and environmentally friendly rail, air, sea and road transport. The Agency has overall responsibility for drawing up regulations and ensuring that authorities, companies, organisations and citizens comply with them.

- Trafikverket, the Swedish Transport Administration, is responsible for long-term planning of the transport system for all types of traffic, as well as for building, operating and maintaining public roads and railways. The Swedish Transport Administration is also responsible for administering the theoretical and practical driving tests needed for a driving licence for both professional and private drivers.

- Trafikanalys, Transport Analysis, which reviews the bases for decisions, assesses measures and is responsible for statistics.

Sweden is divided into 290 municipalities and 20 county councils. These municipalities and counties have responsibility for local road safety. Local government has a long tradition in Sweden. The country's municipalities, county councils and regions are responsible for providing a significant proportion of all public services, including road safety. They have a considerable degree of autonomy, as well as independent powers of taxation. Local self-government and the right to levy taxes are stipulated in the Instrument of Government, one of the four pillars of the Swedish Constitution.

\section{Road safety strategy for 2011-20}

The basis of Swedish road safety work is Vision Zero, a strategic approach towards a safe system, whereby no one is at risk of being fatally or severely injured while using road transport. There is no safety plan in a traditional sense.

During 2015 and 2016, the Ministry of Enterprise relaunched Vision Zero. An extensive review of traffic safety work was done in collaboration with relevant parties and in September 2016, three new assignments were presented:

- The Swedish Transport Administration will lead the national collaboration for increased traffic safety. Results will be reported annually, in May, starting in 2017.

- An investigation of a new default speed limit of $40 \mathrm{~km} / \mathrm{h}$ in urban areas will be undertaken by Trafikanalys. Results will be presented in October 2017 .

- An investigation of traffic safety goals and performance indicators after 2020 will be undertaken Trafikanalys. Results will be presented in May 2017. 


\section{Road safety targets}

The current interim targets were adopted by the Swedish Parliament in 2009 and specify that the number of road fatalities should be halved between 2007 and 2020. That translates into a maximum of 220 road deaths in 2020. The number of seriously injured on the roads is to be reduced by a quarter. In addition to the current national target, there is an interim target at the EU level, for halving the number of road deaths between 2010 and 2020. This corresponds to a more stringent interim target of a maximum of 133 road deaths in 2020. No decision has been made to adjust the Swedish target to this level, and so the interim target of no more than 220 road deaths remains.

To achieve the road safety targets, road safety work is managed by objectives and targets have also been set for a number of performance indicators.

The target level and monitoring process for reaching this target have been revised during 2015-16. It concluded that the safety performance indicators used today are relevant in general, but that some of the indicators need to be revised. An example of this is that an indicator that measured use of ABS brakes on motorcycles will be removed because so many new motorcyclists have ABS brakes and the indicator therefore loses some of its driving force. A new indicator focusing on the compliance with traffic laws among motorcyclists is suggested.

An annual report is presented in April each year where progress toward the 2020 targets for fatalities and those seriously injured are analysed as well as the development of the 10 traffic safety performance indicators. The report presented in 2017 revealed that it will be difficult to reach the target both for fatalities and seriously injured if no measures beyond those already planned are being implemented. Compliance with speed limits needs to be improved and drink driving needs to decrease. It is also important that the infrastructure is more adequately adapted to vulnerable road users and maintenance of pavements and cycle paths is of good quality.

Figure 37.7. Trends in road fatalities towards national target

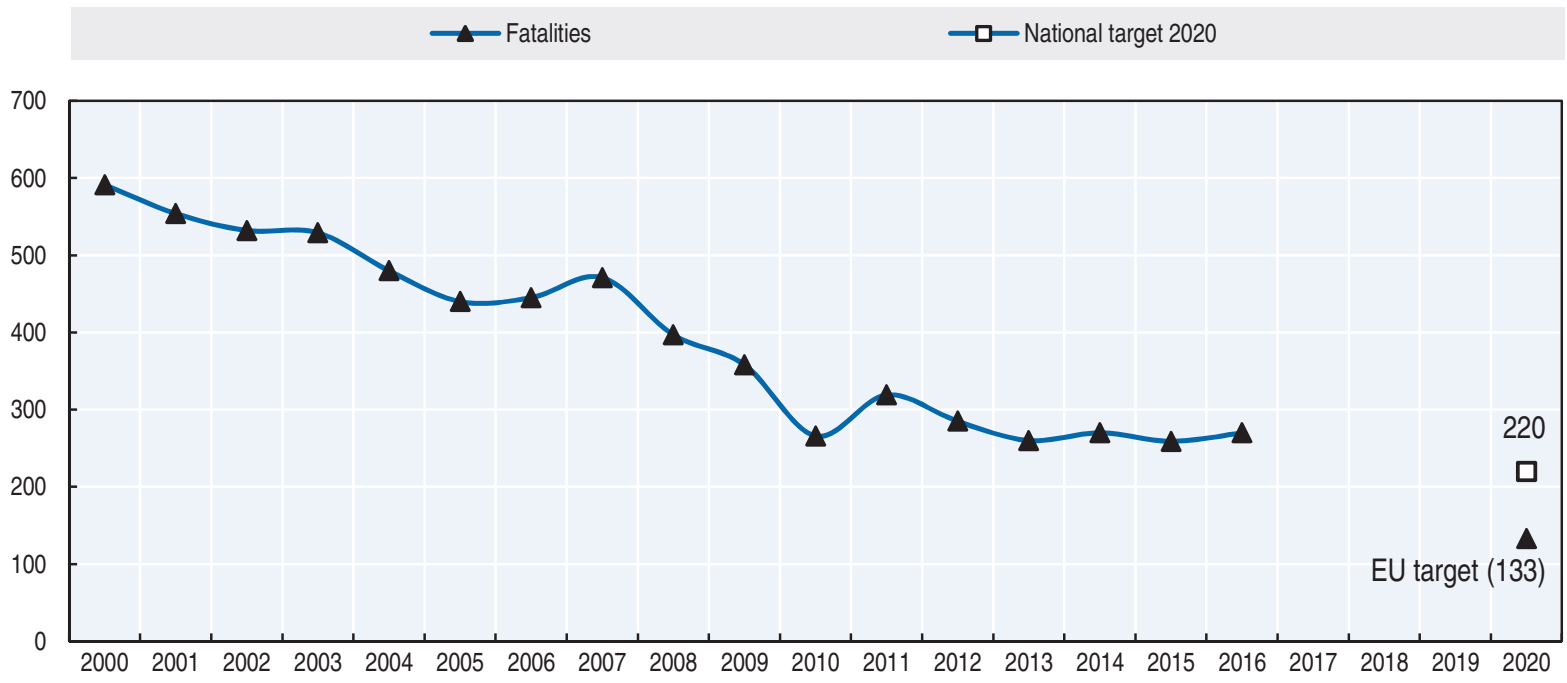




\section{Recent safety measures (2014-17)}

\section{Road safety management}

Renewed commitment to Vision Zero, presented in 2016, aims at intensifying transport safety work in Sweden due to the stagnation seen since 2010. Future safety work should more clearly take into account vulnerable road users with infrastructure design and maintenance tailored to their needs.

The Swedish government presented a national strategy for cycling in April 2017 which is intended to function as a platform for future safety work. Five areas of action were highlighted:

- higher priority for cyclists in social planning

- higher focus on different groups of cyclists

- promote a more functional and user-friendly infrastructure

- promote a safer environment for cyclists

- research and innovation.

\section{Road users}

\section{Speed management}

- At the end of 2016 there were around 1500 speed cameras on the rural network in Sweden. For the period 2017-20, yearly additions of about 200 new cameras are planned. Additional use of speed cameras is especially important on roads with speed limits of $80 \mathrm{~km} / \mathrm{h}$ since these roads usually do not have median barriers and speed compliance is low.

\section{Infrastructure}

- The goal for 2025 is that all rural roads with an average annual daily traffic (AADT above 2000 vehicles/day should have a median barrier or a speed limit at or below $80 \mathrm{~km} / \mathrm{h}$.

\section{Vehicles}

- The development of ABS as standard equipment on motorcycles has moved quickly over the last three years. From being standard with only one manufacturer and an expensive option with the others, ABS has become a natural piece of standard equipment on the majority of the major motorcycle models. The percentage of motorcycles by traffic volume fitted with ABS increased from 9\% in 2007 to $44 \%$ in 2015.

\section{Recent and ongoing research}

Some research projects are presented below.

- Berg, H.-Y., J. Ifver and M. Hasselberg (2016), "Public health consequences of road traffic injuries - Estimation of seriously injured persons based on risk for permanent medical impairment", Transportation Research Part F, Vol. 38, pp. 1-6.

- Sternlund, S., J. Strandroth, M. Rizzi, A. Lie, C. Tingvall (2016), "The effectiveness of lane departure warning systems - a reduction in real-world passenger car injury crashes", Traffic Injury Prevention, http://dx.doi.org/10.1080/15389588.2016.1230672 (accessed 16 May 2017).

- Vadeby, A. (2016), "Traffic safety effects of narrow 2+1 roads with median barrier in Sweden", in Proceedings of the 17th International Conference on Road Safety on Five Continents, Rio de Janeiro, Brazil, 17-19 May, 2016. 
- Vadeby, A. and Å. Forsman (2016), "Traffic safety effects of new speed limits in Sweden, in Proceedings of the 17th International Conference on Road Safety on Five Continents, Rio de Janeiro, Brazil, 17-19 May, 2016.

- Eriksson, J. and G. Sörensen (2015), "Winter weathers' impact on injuries in singlepedestrian accidents", VTI report 868 - 2015, VTI. Linköping. In Swedish, summary in English.

- Forsman, Å. (2015), “Alcohol, drugs and medicines among killed drivers of passenger cars Year 2005-2013", VTI-notat 11-2015, VTI, Linköping. In Swedish, summary in English.

- Gregersen, N.P. et al. (2015), "Accident involvement of young moped riders - Causes and consequences", VTI Report 856 - 2015, VTI. Linköping. In Swedish, summary in English.

- Vadeby, A. and U. Björketun (2016), "Safe accessibility - traffic safety evaluation 2013 and 2014", VTI-notat 7-2016, VTI, Linköping. In Swedish, summary in English.

- Vadeby, A. and U. Björketun (2015), "New speed limits in Sweden - long term traffic safety effects”, VTI Report 860 - 2015, VTI. Linköping. In Swedish, summary in English.

\section{References}

The Swedish Transport Administration (2015), Analysis of road safety trends 2014, Management by objectives for road safety work towards the 2020 interim targets, http://online4.ineko.se/trafikverket/ Product/Detail/50450 (accessed 16 May 2017).

World Bank (2017), “GDP (constant US\$)”, World Development Indicators, http://databank.worldbank.org/ data/reports.aspx? source=world-development-indicators (accessed 23 February 2017).

\section{Websites}

- Swedish Transport Administration: www.trafikuerket.se (accessed 16 May 2017).

- Swedish Transport Agency: www.transportstyrelsen.se/en/ (accessed 16 May 2017).

- Swedish National Road and Transport Research Institute VTI: www.vti.se/en/ (accessed 16 May 2017).

- Transport Analysis: www.trafa.se (accessed 16 May 2017).

- Chalmers University: www.chalmers.se (accessed 16 May 2017). 


\section{Chapter 38}

\section{Switzerland}

This chapter presents 2015 road safety data for Switzerland along with fatality data from 2016. It looks at trends in traffic and road safety from the years 1990 to 2015 and road user behaviour patterns, with a special focus on the ageing population. Sections include data on speed, drink driving, drugs and driving, distracted driving, fatigue and seat belt usage. The chapter reviews Switzerland's road safety strategy with recently implemented safety measures and current and ongoing research.*

* All data stem from Federal Roads Office (FEDRO), Swiss Council for Accident Prevention (bfu) and IRTAD unless otherwise noted. For more information please contact: philippe.bapst@astra.admin.ch or s.niemann@bfu.ch. 
Following a small increase in fatalities in 2015, data from 2016 indicate a significant decrease of $15 \%$ down to 216 fatalities, the lowest number in over 70 years of record keeping. The number of injury crashes decreased by $1 \%$. As the reduction is in most amongst motorcyclists and cyclists, it is likely that the poor weather conditions in the first part of 2016 contributed to this positive development. In 2015, car occupants in particular benefited from a reduction of $22.7 \%$ in the number of fatalities, comprising $30 \%$ of the total fatalities. The over 65 age group remain the most vulnerable as pedestrians, comprising $60 \%$ of pedestrian fatalities overall since 2012 .

\section{Road safety data collection}

\section{Definitions applied in Switzerland}

- Road fatality: Death which occurred within 30 days of the road crash.

- Seriously injured person: Since January 2015 hospitalisation for at least 24 hours is the minimum precondition for classification as a serious injury. To enable standardisation the severity scale was linked to the codes of the National Advisory Committee for Aeronautics, used by all emergency services in Switzerland. A serious injury is either a significant (NACA Codes 3 and 4) or a life-threatening injury (NACA Codes 5 and 6).

- Slight injury: Minor injury such as superficial skin injury. The casualty can leave the crash site unaided. An outpatient treatment in a hospital or by physicians may still be required.

- Injury crash: Crash resulting in at least one injured or killed person.

In Switzerland, injury severity is assessed by police present at the scene. Following the new definition on serious injury, in force since January 2015, police officers are trained to record injury severity based on the new classification.

\section{Data collection}

Since January 2011, the Federal Roads Office (FEDRO) is responsible for all Swiss road crash data. A new reporting form was introduced to all cantonal police forces and a new platform for data entry and data analysis (statistical and geographical) is available online.

To estimate the real extent of road traffic injuries, police-reported data is compared to insurance data. Factors are then calculated to correct the number of unreported cases by road use and age group.

To have a better understanding of the consequences of road crashes, the Swiss Federal Roads Office carried out a research project to link police-reported data of a given year with other data sources, including hospital data. This has enabled coding of the recommended maximum Abbreviated Injury Scale score based on the International Classification of Diseases (ICD-10). A yearly data linkage procedure is implemented. The availability of data for several years will facilitate future research. 


\section{Most recent safety data}

\section{Road crashes in 2016}

In 2016, with 216 fatalities, Switzerland achieved its best road safety result in over 70 years of record keeping. Compared to 2015, the number of fatalities decreased by $15 \%$. The number of those seriously injured for the same time period decreased by only $1 \%$, from 3830 in 2015 to 3785 in 2016.

However, the reduction in fatalities and those seriously injured was exclusively achieved in the first half of 2016 and most notably for motorcycles and bicycles. The most likely explanation for the reduction is, once again, the bad weather conditions in spring 2016. The second half of 2016 is comparable to previous years.

Recent accident data show that cyclists, pedestrians and motorcyclists will be the focus of future prevention.

\section{Road crashes in 2015}

In 2015, there were 253 road fatalities in Switzerland, a 4\% increase from 243 in 2014. However, this figure does not bring into question the overall decreasing trend. The number of fatalities in 2015 is below the average of the previous four years. The number of injury crashes over the same time period decreased by $6 \%$.

While 14 electric bicycle (e-Bike) riders were killed in 2015, 9 more than in 2014, the fatalities for traditional bicycles decreased by $14 \%$. There were 66 fatally injured motorcycle riders, a $25 \%$ increase compared to 2014 , probably due to the mild weather in the summer of 2015.

As mentioned above, a new and tightened definition of "serious injury" was introduced in 2015. This led to a decrease in the number of seriously injured road users while slightly injured road users increased compared to the previous year.

\section{Trends in traffic and road safety (1990-2016) Traffic}

Since 1990, the distance travelled (vehicle-kilometres) increased by $28.5 \%$ and the number of motorised vehicles increased by $42.5 \%$.

Total vehicle-kilometres travelled in 2015 showed an increase of 1.5\% compared with the previous year. Provisional figures for 2016 indicate that the overall traffic volume rose again (1.5\%).

Constant population growth and the ever-increasing trend of mobility has lead to increasing traffic volume for both individual and public transport. An important characteristic of road traffic in Switzerland is the transport of freight through the Alps. In recent years there has been a decrease in transalpine road freight traffic. However, in 2015 more than 1 million HGVs crossed the Alps, of which 70\% were foreign vehicles.

\section{Road safety}

\section{Crashes and casualties}

Road fatalities peaked in 1971, when 1720 people died on the roads. Between 1971 and 1996, the number of fatalities significantly diminished. The average annual reduction from 1971 to 1976 was 7.5\%, and then 3\%, until 1996. Between 1997 and 2000, the number of 
casualties stabilised at around 600 per year. In 2004-06, the rate of decrease significantly accelerated. Recent figures show a downward trend in the numbers of those seriously injured, following years of little change.

Over the last 15 years several important safety measures have been implemented in Switzerland, including:

- 2005: The legal blood alcohol content (BAC) limit was lowered to $0.5 \mathrm{~g} / \mathrm{l}$. At the same time police were authorised to check for alcohol without suspicion.

- 2005: Jurisdiction for licence withdrawal was strengthened and a new, two-stage drivers' training was introduced.

- 2013-15: The first measures of the road safety programme "Via Sicura" came into force, including mandatory daytime running lights, a zero blood alcohol limit for novice, bus and truck drivers, and tightened sanctions for excessive speeding up to lifelong licence withdrawal, seizure and exploitation of motor vehicles.

- The following measures are planned for implementation from 2019:

*xcessive drink-driving offenders must equip their car with an Alcolock.

*xcessive speed offenders will get their licence back when their car is equipped with a data recorder for five years.

\section{Rates}

In 2015, the mortality rate expressed in terms of deaths per 100000 inhabitants was 3.1 , a $63 \%$ decrease compared to 2000 . Similarly, the mortality risks, expressed in terms of deaths per distance travelled, have decreased by two-thirds since 2000.

Table 38.1. Road safety and traffic data

\begin{tabular}{|c|c|c|c|c|c|c|c|c|c|}
\hline & \multirow{2}{*}{1990} & \multirow{2}{*}{2000} & \multirow{2}{*}{2010} & \multirow{2}{*}{2014} & \multirow{2}{*}{2015} & \multicolumn{4}{|c|}{$2015 \%$ change from } \\
\hline & & & & & & 2014 & 2010 & 2000 & 1990 \\
\hline \multicolumn{10}{|l|}{ Reported safety data } \\
\hline Fatalities & 925 & 592 & 327 & 243 & 253 & 4.1 & -22.6 & -57.3 & -72.6 \\
\hline Injury crashes & 23834 & 23737 & 19609 & 17803 & 17736 & -0.4 & -9.6 & -25.3 & -25.6 \\
\hline Serious injuries (national definition) & 11182 & 6191 & 4458 & 4043 & 3830 & -5.3 & -14.1 & -38.1 & -65.7 \\
\hline Deaths per 100000 inhabitants & 13.9 & 8.3 & 4.2 & 3.0 & 3.1 & 2.9 & -26.9 & -62.8 & -77.8 \\
\hline Deaths per 10000 registered vehicles & 2.2 & 1.2 & 0.6 & 0.4 & 0.4 & 2.3 & -29.3 & -65.9 & -80.8 \\
\hline Deaths per billion vehicle kilometres & 18.6 & 10.6 & 5.2 & 3.9 & 4.0 & 2.9 & -24.4 & -62.7 & -78.7 \\
\hline \multicolumn{10}{|l|}{ Traffic data } \\
\hline Registered vehicles ${ }^{1}$ (thousands) & 4242 & 4822 & 5525 & 5937 & 6046 & 1.8 & 9.4 & 25.4 & 42.5 \\
\hline Vehicle-kilometres (millions) & 49624 & 55686 & 62339 & 62994 & 63761 & 1.2 & 2.3 & 14.5 & 28.5 \\
\hline Registered vehicles per 1000 inhabitants & 636 & 673 & 710 & 729 & 734 & 0.6 & 3.4 & 9.0 & 15.5 \\
\hline
\end{tabular}

1. Including mopeds. 
Figure 38.1. Road safety, traffic and GDP trends index $1990=100$

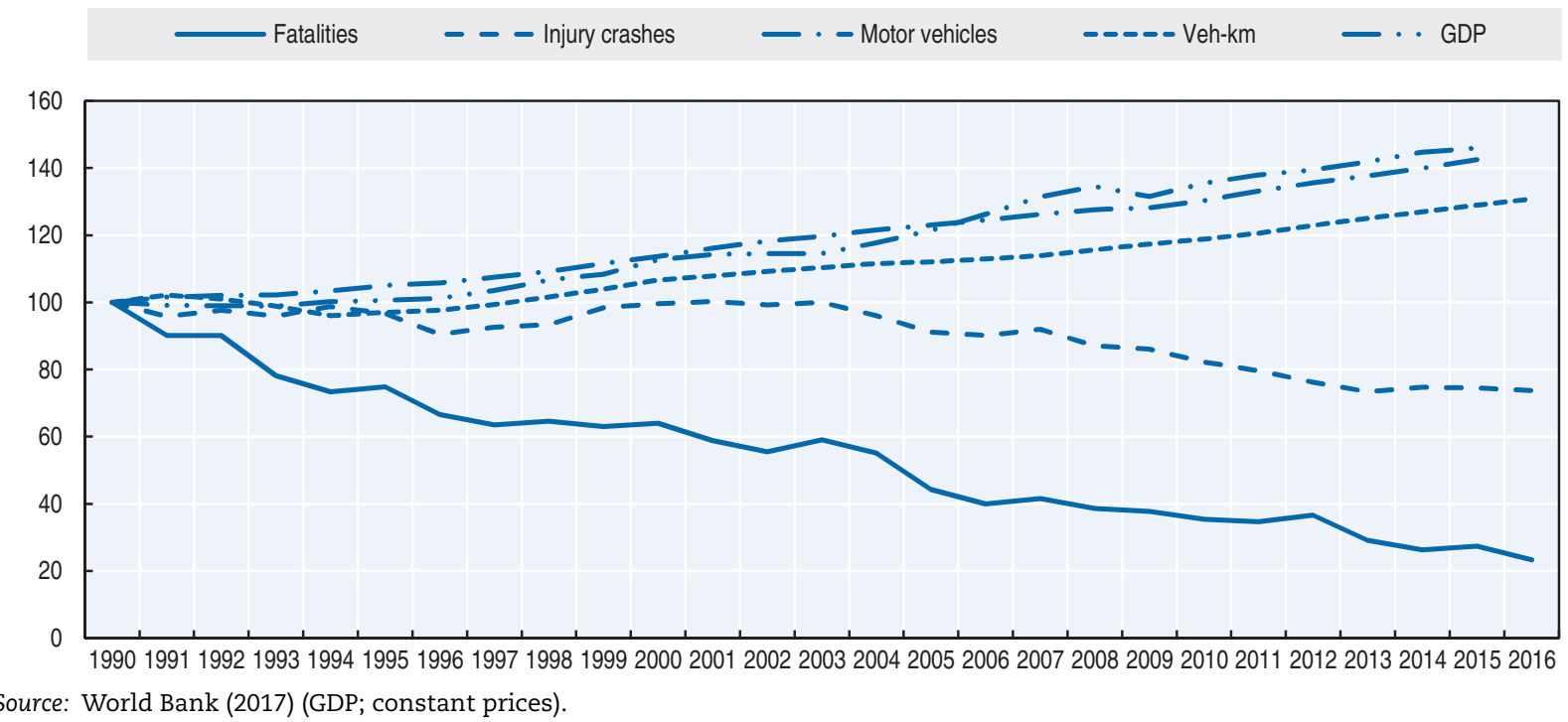

\section{Road safety by user group}

All user groups have benefited from the improvement in road safety since 1990. A sharp decrease is observed for moped riders (-94\%) mainly due to a large reduction in moped distance travelled in recent years.

Since 2000, car occupant safety has improved substantially (-72.5\%). The penetration of safer vehicles into the fleet partly explains these good results.

Since 2011, e-Bikes constitute a new category of vehicle in police records. From 2011 to 2015 serious or fatal crashes involving these vehicles increased in proportion to the sales figures. In 2016, 9 fatal and 201 seriously injured e-Bike riders were registered by the police. From 2011 to 2015, 3 in 4 fatally injured e-Bike riders were aged 65 or older.

In the last few years, on average 60 pedestrians were killed each year. The figure for 2014, with 43 pedestrians killed, was a statistical outlier downwards. In 2015, the number of killed pedestrians increased again to 58 .

Table 38.2. Road fatalities by road user group

\begin{tabular}{lrrrrr|rrrr}
\hline & 1990 & 2000 & 2010 & 2014 & 2015 & \multicolumn{4}{|c}{$2015 \%$ change from } \\
\cline { 7 - 10 } & & & & & & 2014 & 2010 & 2000 & 1990 \\
\hline Pedestrians & 167 & 130 & 75 & 43 & 58 & 34.9 & -22.7 & -55.4 & -65.3 \\
Cyclists & 58 & 48 & 34 & 34 & 39 & 14.7 & 14.7 & -18.8 & -32.8 \\
Moped riders & 49 & 19 & 4 & 1 & 3 & -- & -- & -84.2 & -93.9 \\
Motorcyclists & 155 & 92 & 67 & 53 & 66 & 24.5 & -1.5 & -28.3 & -57.4 \\
Car occupants & 455 & 273 & 129 & 97 & 75 & -22.7 & -41.9 & -72.5 & -83.5 \\
Others & 41 & 30 & 18 & 15 & 12 & -20.0 & -33.3 & -60.0 & -70.7 \\
Total & $\mathbf{9 2 5}$ & $\mathbf{5 9 2}$ & $\mathbf{3 2 7}$ & $\mathbf{2 4 3}$ & $\mathbf{2 5 3}$ & $\mathbf{4 . 1}$ & $\mathbf{- 2 2 . 6}$ & $\mathbf{- 5 7 . 3}$ & $\mathbf{- 7 2 . 6}$ \\
\hline
\end{tabular}


Figure 38.2. Road fatalities by road user group in percentage of total, 2015

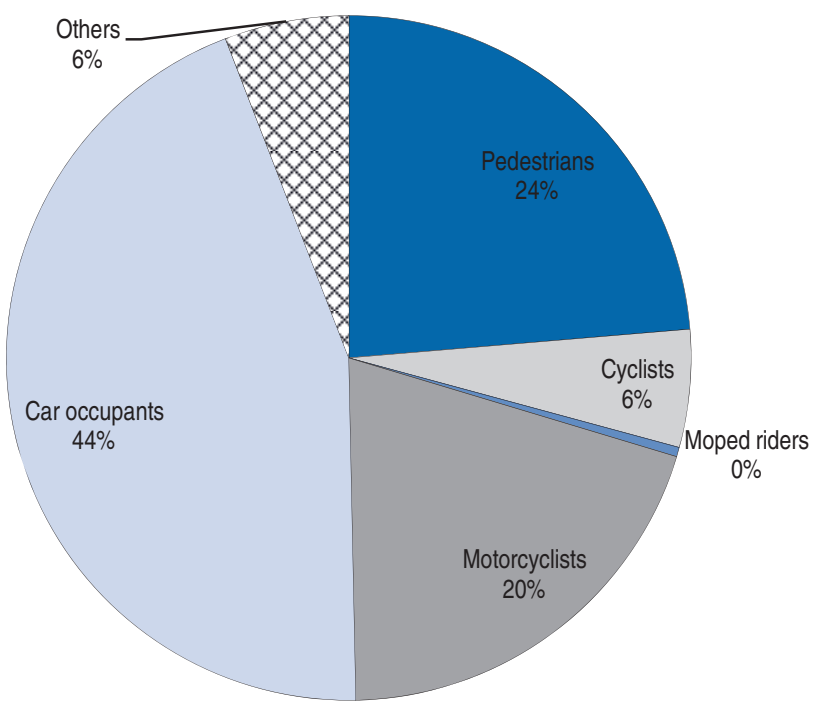

\section{Road safety by age group}

Since 1990, a reduction in fatalities has been observed in all age groups, with a greater than average reduction for teenagers and young people. The trend for older road users is less positive than for other age groups. They are particularly vulnerable as pedestrians. In the period $2012-16,60 \%$ of all pedestrian fatalities were aged 65 or over.

The mortality rate of young people (18-20) has decreased substantially since 2004. This is partly explained by reduced exposure, as the mean age for obtaining a driving licence is increasing. Another explanation is the introduction in 2005 of the two-phase licensing scheme, with a three-year probationary licence.

Table 38.3. Road fatalities by age group

\begin{tabular}{|c|c|c|c|c|c|c|c|c|c|}
\hline \multirow{2}{*}{ Age } & \multirow{2}{*}{1990} & \multirow{2}{*}{2000} & \multirow{2}{*}{2010} & \multirow{2}{*}{2014} & \multirow{2}{*}{2015} & \multicolumn{4}{|c|}{$2015 \%$ change from } \\
\hline & & & & & & 2014 & 2010 & 2000 & 1990 \\
\hline $0-14$ & 47 & 28 & 8 & 9 & 7 & -22.2 & -12.5 & -75.0 & -85.1 \\
\hline $15-17$ & 28 & 26 & 12 & 2 & 4 & --50 & -66.7 & -84.6 & -85.7 \\
\hline $18-20$ & 93 & 42 & 21 & 18 & 15 & -16.7 & -28.6 & -64.3 & -83.9 \\
\hline $21-24$ & 121 & 49 & 15 & 20 & 20 & -- & 33.3 & -59.2 & -83.5 \\
\hline $25-64$ & 438 & 285 & 170 & 108 & 110 & 1.9 & -35.3 & -61.4 & -74.9 \\
\hline $65-74$ & 66 & 56 & 38 & 27 & 44 & 63.0 & 15.8 & -21.4 & -33.3 \\
\hline $75-84$ & 104 & 73 & 42 & 43 & 31 & -27.9 & -26.2 & -57.5 & -70.2 \\
\hline$\geq 85$ & 28 & 32 & 21 & 16 & 22 & 37.5 & 4.8 & -31.3 & -21.4 \\
\hline Total & 925 & 592 & 327 & 243 & 253 & 4.1 & -22.6 & -57.3 & -72.6 \\
\hline
\end{tabular}


Figure 38.3. Road fatality rates by age group Deaths per 100000 inhabitants in a given age group, 1990-2015

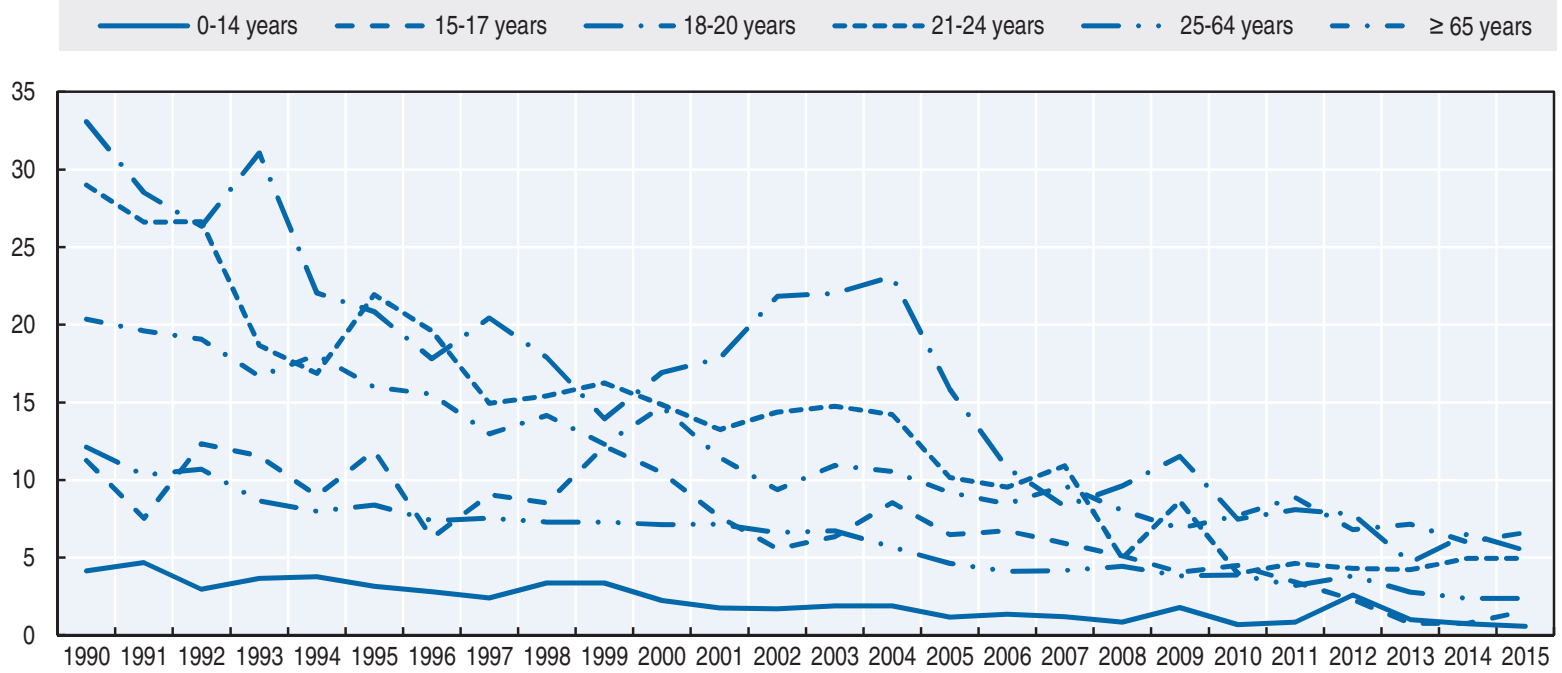

\section{Box 38.1. Road safety for an ageing population}

The Swiss Statistical Office published different models to forecast the demographic evolution up to 2045. The population is expected to grow by $30 \%$ - from 8.5 million to 11 million. In the same period the population aged 65 or older will rise by more than $80 \%$, from 1.5 to 2.8 million.

In 2015, there were 97 persons of 65 years and over killed in road traffic (38\% of all road deaths). Of those, $38 \%$ were pedestrians, $23 \%$ car occupants, $18 \%$ cyclists and $14 \%$ motorcyclists. The proportion of the senior population in the total number of fatalities has been increasing (21 \% in 1990, 27\% in 2000,31\% in 2010), reflecting to a certain extent a general trend of population aging.

In Switzerland, medical examinations are mandatory from 70 years of age. They focus on vision, hearing, skin, mental health, the nervous system, cardiovascular system, lungs, abdominal organs and movement. Tests include the Trail-Making Test Part A and B, Mini Mental Status Test, and the clock test (all related to dementia).

From 1 July 2016, the mandatory medical examination from age 70 has been modified, in particular with regard to mental health. In that year, the number of licence withdrawals among that age group increased by more than $20 \%$. On the other hand, there have been political moves to increase the age of the first medical examination from 70 to 75 (similar to the Netherlands and Denmark).

Table 38.4. Road fatalities among senior citizens

\begin{tabular}{lrr|rr|rr}
\hline & \multicolumn{2}{c|}{$65-74$} & \multicolumn{2}{c|}{$75-84$} & \multicolumn{2}{c}{$85+$} \\
\cline { 2 - 7 } & 2010 & 2015 & 2010 & 2015 & 2010 & 2015 \\
\hline Pedestrians & 7 & 8 & 15 & 15 & 12 & 14 \\
Cyclists & 5 & 9 & 7 & 6 & 3 & 2 \\
Moped riders & 2 & 1 & 0 & 0 & 0 & 1 \\
Motorcyclists & 3 & 14 & 3 & 0 & 0 & 0 \\
Car occupants & 18 & 12 & 17 & 6 & 5 & 4 \\
Total & $\mathbf{3 8}$ & $\mathbf{4 4}$ & $\mathbf{4 2}$ & $\mathbf{3 1}$ & $\mathbf{2 1}$ & $\mathbf{2 2}$ \\
\hline
\end{tabular}




\section{Box 38.1. Road safety for an ageing population (cont.)}

Another aspect is to do with the self-assessment instruments. The bfu is planning to introduce a German, French and Italian version of the Driving Decisions Workbook (Eby et al., 2000). The implementation will begin in 2018 and should be finished by 2020.

Specific measures are required to improve pedestrian and e-cycling safety. These may include more pedestrian crossings with middle isles and courses for beginner e-cyclists. The usefulness of the medical examination should also be analysed and consequences drawn.

Figure 38.4. Road fatality rates by age group - focus on the senior population Deaths per 100000 inhabitants in a given age group, 1990-2015
- $65-74$ years
- - $-75-84$ years
$-\cdot-85+$ years

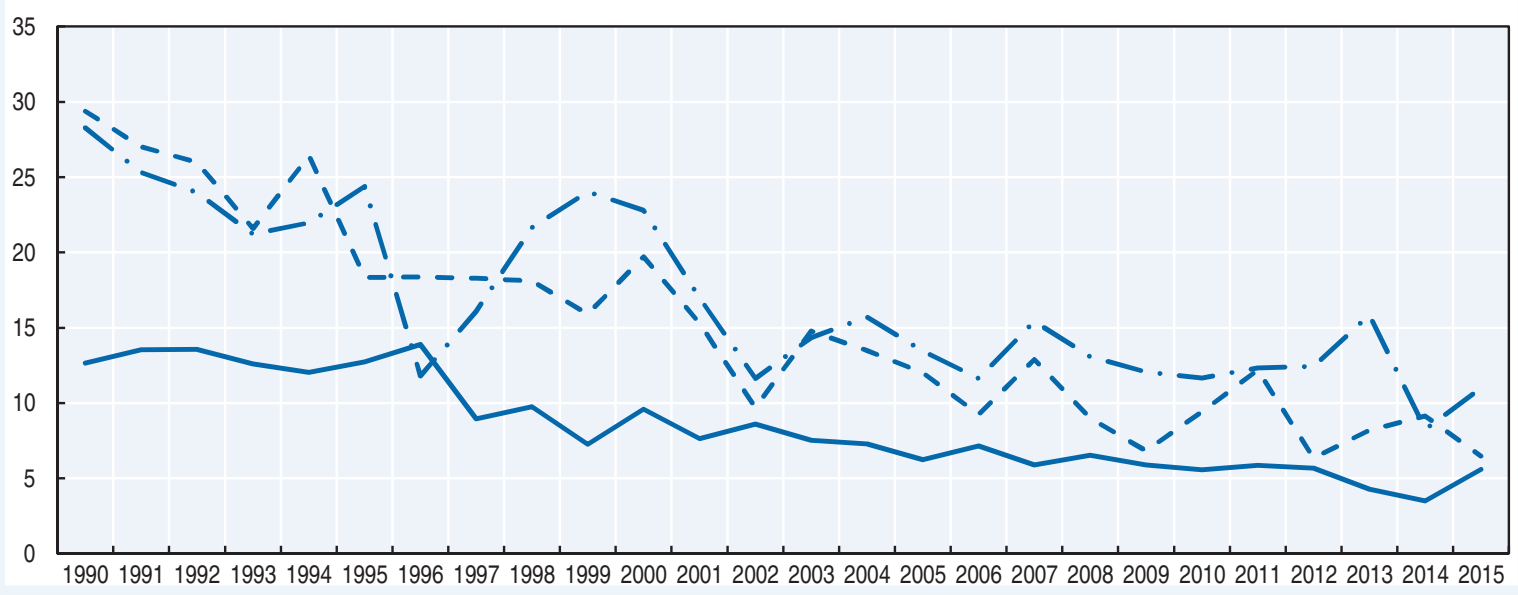

Figure 38.5. Road fatality rate by age and road user group Fatalities per 100000 inhabitants, 2015

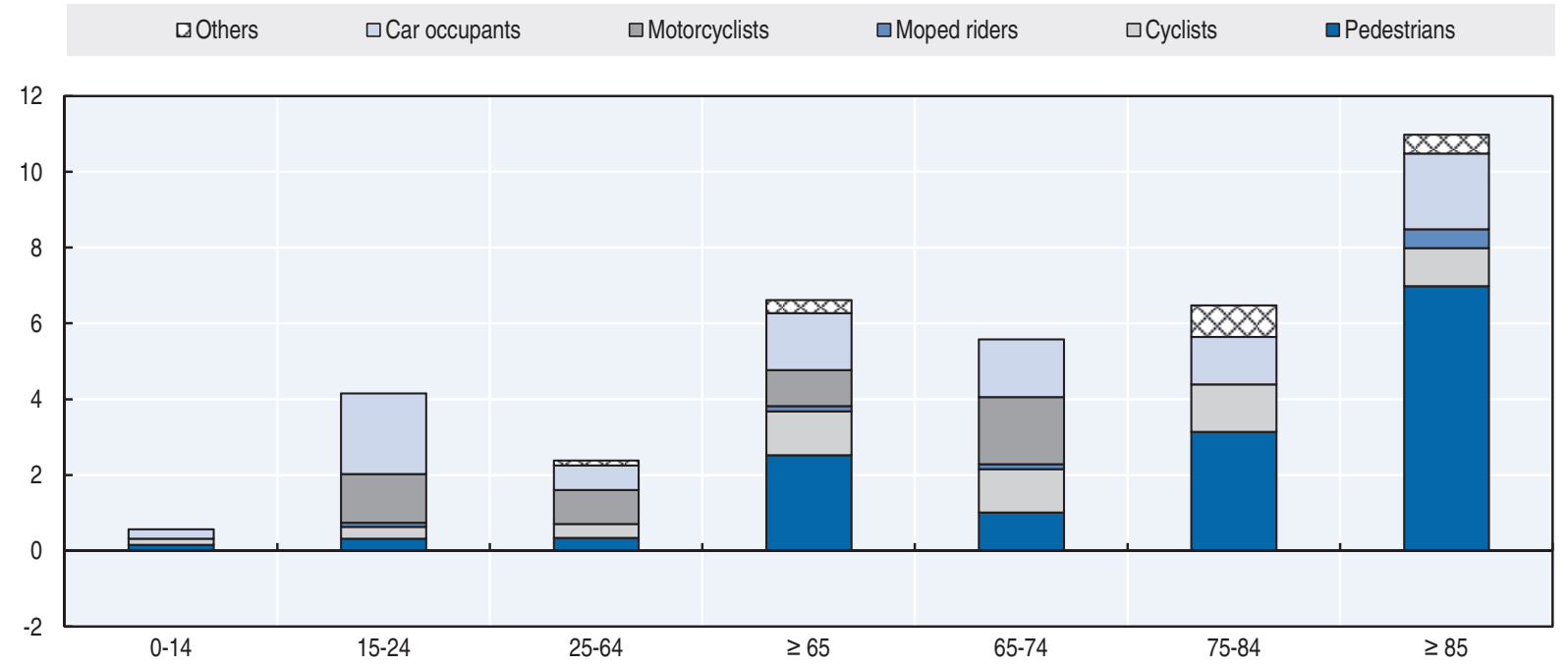




\section{Road safety by road type}

In the last 25 years fatalities in urban areas decreased by more than $65 \%$, on rural roads by $78 \%$ and $71 \%$ on motorways. Motorways, already the safest roads, have become even safer.

In 2015, for the first time, more road users were killed on urban roads than on rural roads (119 vs. 113). On motorways there were 21 fatalities, 9 more than 2014 but still few compared to other road types.

In 2016, there were again more fatalities on rural roads compared to other road types.

Figure 38.6. Road fatalities by road type

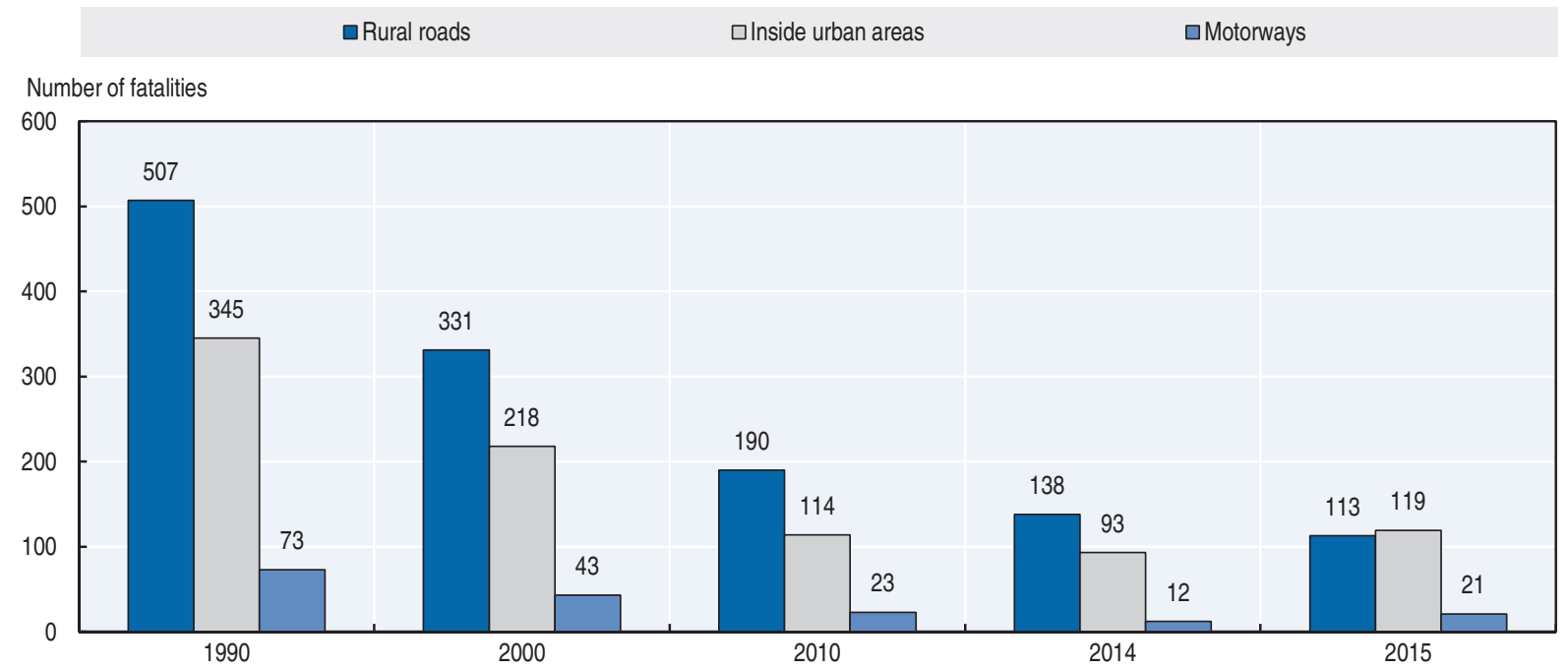

\section{Economic costs of traffic crashes}

In 2013, the cost of road crashes was CHF 8.8 billion. This estimate of the total economic burden is based on a willingness-to-pay approach (Niemann et al., 2015). The estimate includes non-reported crashes.

Table 38.5. Cost of road crashes, 2013

\begin{tabular}{lcc}
\hline Cost (EUR) & Unit cost (CHF) & Total \\
\hline Fatalities & 2.53 million & 0.6 billion \\
Serious injuries & 0.35 million & 4.9 billion \\
Slight injuries & 0.02 million & 1.0 billion \\
Property damage costs & & 2.3 billion \\
Total & & CHF 8.8 billion \\
\hline
\end{tabular}

\section{Recent trends in road user behaviour \\ Speed}

In 2015 , speed was a contributing factor in about $27 \%$ of fatal crashes. In most cases, inappropriate speed is to blame rather than excessive speed. In 2010, the proportion of drivers above the speed limit was $23 \%$ on urban roads, $31 \%$ on rural roads and $18 \%$ on motorways. The survey on actual speeds was stopped in 2010.

The table below summarises the main speed limits in Switzerland. 
Table 38.6. Passenger car speed limits by road type, 2017

\begin{tabular}{lc}
\hline & General speed limit \\
\hline Urban roads & $50 \mathrm{~km} / \mathrm{h}$ \\
Rural roads & $80 \mathrm{~km} / \mathrm{h}$ \\
Motorways & $120 \mathrm{~km}$ \\
\hline
\end{tabular}

\section{Drink driving}

An alcohol crash is defined as any fatal crash, in which any active participant (driver, pedestrian, cyclist, etc.) has a blood alcohol level (BAC) above the legal limit.

In 2005 , the maximum legal BAC was reduced from $0.8 \mathrm{~g} / 1$ to $0.5 \mathrm{~g} / \mathrm{l}$ and random breath testing was introduced. As of 1 January 2014, novice drivers are subject to a zero alcohol limit for their first three years behind the wheel. The same restriction applies to all professional drivers.

In the last few years the share of alcohol crashes in all fatalities declined. In 2016, 16\% of fatal crashes involved an intoxicated driver and was thus higher than in the previous 2 years. While the share of drivers under influence of alcohol is not known, research results show that the acceptance of drink driving in the population is decreasing.

Since 1 October 2016 a breath alcohol test can also be used as evidence for a higher alcohol concentration than $0.8 \mathrm{~g} / \mathrm{l}$. Until then a blood sample was required.

\section{Drugs and driving}

In 2016, 20 road fatalities (10\%) were explicitly due to a road user impaired by drugs, legal or otherwise. However, in official statistics, the consumption of drugs is probably underreported.

In Switzerland the limit for drugs is set at zero ("zero tolerance"). The road traffic law specifies that driving ability must be ensured. The use of any drugs which reduce driving ability is prohibited. In the case of some drugs, like THC or amphetamine, a positive test is proof of reduced driving ability and considered an offence. In the case of other drugs or medical substances a "three-pillar system" is used: driving impairment is judged by police, physicians and blood tests.

\section{Distraction}

Distraction, or lack of attention, is cited in $28 \%$ of fatal crashes in 2016. Distraction or lack of attention is judged by the police at scene and includes distraction by passengers, animals, mobile phone use, handling car equipment like air conditioning or a navigation system.

The use of mobile phones without a hands-free set or for texting is subject to a fine of CHF 100. Although using mobile phones with hands-free sets is not prohibited, in several cases the Swiss Federal Court has qualified such use as a situation that leads to impaired driving.

\section{Sleepiness and fatigue}

According to police reporting, 5\% of all fatal crashes in 2016 were due to fatigue. The real number is expected to be much higher. 


\section{Seat belts and helmets}

Seat belt use has been compulsory in front seats since 1981 and in rear seats since 1994. Since 2002, dedicated child-restraint systems have been mandatory for all children below the age of seven. Since April 2010, new regulations have been applied for the transport of children in cars: Children aged between 7 and 12 and less than $150 \mathrm{~cm}$ must be restrained with a certified child-restraint system.

In 2016, seat belt wearing rates among car drivers and front-seat passengers remained stable, with figures of $94 \%$ each. For back seats the highest rate observed was $86 \%$. The rates by location and language regions did not significantly change in 2016 . One special group are delivery trucks, box-type vans, and vehicles with a truck bed - mostly tradespeople and delivery services, where just $80 \%$ of drivers and $77 \%$ of passengers buckle up while transporting goods. Passenger transport journeys on the other hand report a wearing rate of $96 \%$ and $97 \%$ respectively.

In the past three years, $41 \%$ of killed car occupants were not wearing a seat belt. Considering the actual wearing rate and a $50 \%$ protective effect of the seat belt on front seats and $25 \%$ on rear seats, it is estimated a $100 \%$ wearing rate in front and rear seats would have saved four lives in 2016.

\section{Table 38.7. Seat belt wearing rate by car occupancy and road type}

\begin{tabular}{lcccc}
\hline \multicolumn{5}{c}{$\%$} \\
\hline & 2000 & 2010 & 2015 & 2016 \\
\hline Front seat & & & & \\
$\quad$ Driver & 77 & 88 & 93 & 94 \\
Passenger & na & 89 & 92 & 94 \\
Urban roads (driver) & 66 & 83 & 92 & 93 \\
Rural roads (driver) & 76 & 88 & 93 & 94 \\
$\quad$ Motorways (driver) & 89 & 93 & 96 & 97 \\
Rear seats & & & & \\
$\quad$ General (passengers) & 32 & 74 & 76 & 86 \\
$\quad$ Children (use of child restraint) & $85(2002)$ & $94(2007)$ & $93(2012)$ & na \\
\hline
\end{tabular}

Helmet wearing has been compulsory on motorcycles since 1981 and on mopeds (up to $50 \mathrm{cc}$, maximum speed $45 \mathrm{~km} / \mathrm{h}$ ) since 1990 . Observation indicates a compliance rate of almost $100 \%$.

Since 2012 bicycle helmets are required on e-Bikes above $25 \mathrm{~km} / \mathrm{h}$ with pedal assistance.

\section{National road safety strategies and targets Organisation of road safety}

Due to Swiss federalism, many organisations are involved in and responsible for road safety, including local and cantonal authorities, special interest groups and insurance companies. The leading roles in road safety are taken mainly by the three organisations: The Fund for Road Safety, the Swiss Council for Accident Prevention (bfu) and the Federal Roads Office (FEDRO). The Swiss Federal Council regulates the national road safety policy and is responsible for the "Via Sicura" road safety programme. 


\section{Road safety strategy for 2011-20}

On 15 June 2012, the Swiss Federal Council adopted the road safety programme "Via Sicura", almost 10 years after the first proposal. A range of safety measures is being progressively implemented (see details in section below).

\section{Road safety targets}

No quantitative target was set under the "Via Sicura" programme.

An evaluation of the Swiss road safety programme "Via Sicura" started in 2016. First results are expected mid-2017.

Bfu regularly publishes safety performance indicators, including daytime running lights, seat belt use and bicycle helmet use.

\section{Recent safety measures (2014-17)}

Since January 2013, a number of measures of the Swiss road safety programme "Via Sicura" came into force.

\section{Road users}

\section{Speed management}

- A driver's licence is revoked for a minimum of two years in cases of excessive speeding and for 10 years to life in the case of repeated offences.

\section{Drink driving}

- As of 1 January 2014, novice drivers are subject to a zero alcohol limit for their first three years behind the wheel. The same restriction applies to all professional drivers.

- A test on fitness to drive is mandatory for those convicted of offences such as driving under the influence of drugs.

- From 1 October 2016 a breath alcohol test can be used as evidence in court. A blood sample is no longer necessary, even at high alcohol concentrations.

\section{Infrastructure}

- A new norm "Single Accident Site Management" was published in 2015.

- A new online database was activated in 2016 for an evaluation of infrastructural road safety measures. On http://bfumevasi.bfu.ch/mevasi/ (accessed 15 May 2017) local authorities record infrastructural measures (currently they can choose between 23 measures such as roundabouts, traffic lights or zebra crossings) in a GIS-based system. Accident data was linked to more than 1100 measures and a statistical analysis on the safety effect of measures is undergoing. The first results will be published in summer 2017.

\section{Vehicles}

- As of January 2014, daytime running lights are mandatory for all motorised vehicles. The bfu survey on daytime running lights was conducted in July 2014. Six months after daytime running lights became mandatory, $94 \%$ of vehicles were in compliance with the new regulation (compared to 68\% in 2013). With 95\% in 2015 and in 2016, the rate remained stable. 


\section{Recent and ongoing research}

- A study on the safety effects of accident recorders was published. (www.bfu.ch/de/bestellen/ alles\#k=2.274, accessed 15 May 2017).

- A report on road safety of children will be published in May 2017.

- A study on single vehicle crashes of e-Bikes is underway.

\section{References}

Bfu (2015), SINUS 2016 Annual report, Swiss Council for Accident Prevention.

Bfu: Results of the safety performance indicators:

Bicycle helmet: www.bfu.ch/sites/assets/Shop/bfu_2.999.08_bfu\%20survey\%202016\%20-\%20Helmet\%20 wearing\%20reates\%20among\%20cyclists\%20in\%20road\%20traffic.pdf (accessed 15 May 2017).

Seat belt: www.bfu.ch/sites/assets/Shop/bfu_2.999.08_bfu\%20survey\%202016\%20-\%20Seat\%20belt\%20use \%20in\%20Switzerland.pdf (accessed 15 May 2017).

Daytime running lights: www.bfu.ch/sites/assets/Shop/bfu_2.999.08_bfu\%20survey\%202016\%20-\%20 Daytime\%20running-light\%20usage\%20rates.pdf (accessed 15 May 2017).

Niemann, S., C. Lieb and H. Sommer (2015), Nichtberufsunfälle in der Schweiz: Aktualisierte Hochrechnung und Kostenberechnung, bfu-Report 71, Bern, bfu - Beratungsstelle für Unfallverhütung.

World Bank (2017), “GDP (constant US\$)", World Development Indicators, http://databank.worldbank.org/ data/reports.aspx?source=world-development-indicators (accessed 23 February 2017).

\section{Websites}

- Federal Roads Office (FEDRO/ASTRA): www.astra.admin.ch (accessed 15 May 2017).

- Swiss Council for Accident Prevention (bfu): www.bfu.ch (accessed 15 May 2017).

- STATUS 2016: statistics on non-occupational accidents and the level of safety in Switzerland www.bfu.ch/sites/assets/Shop/bfu_2.265.08_STATUS\%202015\%20\%e2\%80\%93\%20Statistics\%20on\%20nonoccupational\%20accidents\%20and\%20the\%20level\%20of\%20safety\%20in\%20Switzerland.pdf (accessed 15 May 2017).

- Road accident data

* Statistics: www.unfalldaten.ch (accessed 15 May 2017).

* Geospatial data: $h$ tttps://map.geo.admin.ch/?topic=vu\&lang=de\&bgLayer=ch.swisstopo.pixelkarte-grau\&layers= ch.astra.unfaelle-personenschaeden_alle\&layers_timestamp=\&catalogNodes=1318 (accessed 15 May 2017). 



\section{Chapter 39}

\section{United Kingdom}

This chapter presents 2015 road safety data for the United Kingdom along with provisional data from 2016. It looks at trends in traffic and road safety from the years 1990 to 2015 and road user behaviour patterns, with a special focus on the ageing population. Sections include data on speed, drink driving, drugs and driving, distracted driving, fatigue and seat belt usage. The chapter reviews UK's road safety strategy and national targets to 2020 and the progress achieved thus far. It also provides details of all recently implemented safety measures and current and ongoing research. ${ }^{*}$

* Information and data presented in this report from the Department for Transport concern the United Kingdom (i.e. Great Britain + Northern Ireland). Where comparable information is not available for Northern Ireland, data are provided for Great Britain only, which accounts for $97 \%$ of UK fatalities. All data stem from the Department for Transport and IRTAD unless otherwise noted. For more information please contact: ROADACC.STATS@dft.gsi.gov.uk. 
Since 2011, the United Kingdom has seen road fatalities stabilise at a record low level with small annual variations. There were 1804 fatalities in 2015, the second lowest year on record after 2013, maintaining the rate of 2.8 fatalities per 100000 and its position as one of the better performing countries for road safety. Provisional data from 2016 indicate a similar result to 2015 with 1810 road deaths recorded.

\section{Road safety data collection}

\section{Definitions applied in the United Kingdom}

- Road fatality: Human casualties whose injuries resulted in death within 30 days of a road accident. Confirmed suicides are excluded.

- Serious injury: An injury for which a person is detained in hospital as an "in-patient", or any of the following injuries whether or not they are detained in hospital: fractures, concussion, internal injuries, crushings, burns (excluding friction burns), severe cuts, severe general shock requiring medical treatment and injuries causing death 30 or more days after the accident. Casualties are recorded as seriously or slightly injured by police on the basis of information available within a short time of the accident. This generally will not reflect the results of a medical examination, but may be influenced according to whether the casualty is hospitalised or not.

- Slight injury: An injury of a minor character such as a sprain (including neck whiplash injury), bruise or cut which are not judged to be severe, or slight shock requiring roadside attention. This definition includes injuries not requiring medical treatment.

- Injury accident: An accident in which at least one person is injured or killed.

\section{Data collection}

There are three main sources of safety information in the United Kingdom:

- The national road accident reporting system, STATS19, which is based upon police reports.

- Information from coroners (in England and Wales) and procurators fiscal (in Scotland) on the levels of alcohol in the blood of people killed in road traffic accidents.

- Hospital episode statistics (HES).

Most of the data in this report, which is also included in the IRTAD database, come from STATS19.

While all fatal crashes are reported by the police, data from hospitals, surveys and compensation claims indicate that a considerable proportion of non-fatal casualties are not known to the police. The best current estimate derived primarily from the National Travel Survey data and produced in 2016, is that the total number of road casualties in Great Britain each year, including those not reported to the police, is within the range 630000 to 800000 with a central estimate of 710000 (DfT, 2016a). 
Linking HES data from hospitals and police data for England gives a better understanding of injury severity and outcomes. Around $47 \%$ of the police-reported seriously injured casualties for England alone are matched to the hospital records. As part of this linkage, the Department for Transport has been working with the Maximum Abbreviated Injury Scale (MAIS) to rate the severity of injury crashes.

\section{Most recent safety data}

\section{Road crashes in 2016 - provisional data to year ending September 2016}

Provisional data for Great Britain indicates that there were 1810 road deaths in the year ending September 2016, which is not statistically different from the year ending September 2015 (DfT 2017a).

The main findings in this provisional data (in the 12 months to end-September 2016) indicate that:

- A total of 25160 people were killed or seriously injured (KSI casualties) in the year ending September 2016, up by $6 \%$ from the previous year.

- There were 182560 casualties of all severities in the year ending September 2016, down by $4 \%$ from the previous year.

- Motor traffic levels rose by 1.4\% compared with the year ending September 2015.

- The overall casualty rate per vehicle mile decreased by $5 \%$ over the same period.

\section{Road crashes in 2015}

A total of 1804 people were killed in reported road traffic accidents in the United Kingdom in 2015. Although this represents a decrease of 50 fatalities (or 2.7\%) from 2014, it is likely that natural variation in the figures explains the change. It is the second lowest year on record after 2013. However, in statistical terms the number of fatalities has remained unchanged since 2011. There were 45\% fewer fatalities in 2015 than a decade earlier in 2006 and $4 \%$ fewer than the 2010-14 average.

There has been no clear trend in the number of fatalities since around 2011. Prior to that, and particularly during 2006 to 2010, the general trend was for fatalities to fall. Since that point, though, most of the year on year changes are either explained by one-off effects (for instance, the snow in 2010) or natural variation. The evidence points towards the UK being in a period where the fatality numbers are fairly stable and most of the changes relate to random variations.

In 2015, there were 22144 seriously injured casualties in reported road traffic accidents. This is the second lowest year behind 2013 and 2.9\% lower than the 22807 serious injuries in 2014. This decrease is statistically significant, so it is more likely than not that the drop reflects genuine changes on British roads.

By the provisional estimates, in 2015 there were 4860 MAIS3+ injuries, 4\% less compared to 2014 level.

A total of 146203 personal-injury road traffic accidents were reported to the police in 2015. Of these accidents, 1616 resulted in at least one fatality. 


\section{Trends in traffic and road safety (1990-2016) Traffic}

Motor vehicle traffic in Great Britain peaked in 2007 and decreased consecutively each year to 2010. From 2010 to 2013, traffic volumes remained broadly stable and in 2013 overall motor vehicle traffic volume levels were similar to levels seen in 2003.

In 2015, traffic on Great Britain's roads was about 1\% above the previous high in 2007. It is estimated that between 2014 and 2015 all motor traffic increased by about 1.6\%. The largest increase was for light goods vehicles which increased by over 4\% compared to 2014 .

\section{Road safety}

\section{Crashes and casualties}

Road fatalities reached a peak in 1941 of just over 9000 in Great Britain. Since then it has decreased by more than 80\% reaching 1730 in 2015. This was the second lowest year on record, after 2013.

The number of fatalities in the United Kingdom decreased by 66.6\% from 1990 to 2015, and by almost $50 \%$ between 2000 and 2014 . Various factors may have contributed to the recent large reductions in fatalities in addition to the longer-term trends in improved vehicle safety, road engineering, trauma care and education. The recession and economic downturn led to falling traffic levels and the continued reduction in average speeds will have played a significant part. Similarly large falls in fatalities were seen in the recession in the early 1990 s.

Over more recent years, though, traffic levels have risen again, now exceeding the prerecession levels. This might be one key reason why casualty levels have, at best, plateaued and might start to increase again.

A statistical weather model for Great Britain has been used to assess the impact of weather on the number of road casualties reported in 2015. The model indicates that for most months of the year the weather had little net effect, so the weather adjusted figures for 2015 differ little from the actual reported figures.

\section{Rates}

Fatality rates have generally been on a downward trend since 1973, with some intermittent periods where small increases were observed. In 2015, the UK had a fatality rate of 2.8 deaths per 100000 inhabitants.

Fatality rate per billion vehicle kilometres in 2015 was 3.4, less than a half compared to 2010; death rates per 10000 vehicles also decreased by more than $50 \%$ for the same time period.

\section{Road safety by user group}

Since 1990, the reduction in mortality has benefited all road users. Of all the user groups with significantly large numbers, the greatest reduction has been for pedestrians over the long term.

In 2015 , car occupants accounted for $44 \%$ of road deaths, pedestrians for $24 \%$, motorcyclists for $20 \%$, and cyclists for $6 \%$. Motorcyclists were the only significant road user group where fatalities increased during 2015. The number of motorcycle fatalities is roughly similar to the figure in 2011 , but still at a historically low level. 
Table 39.1. Road safety and traffic data

\begin{tabular}{|c|c|c|c|c|c|c|c|c|c|}
\hline & \multirow{2}{*}{1990} & \multirow{2}{*}{2000} & \multirow{2}{*}{2010} & \multirow{2}{*}{2014} & \multirow{2}{*}{2015} & \multicolumn{4}{|c|}{$2015 \%$ change from } \\
\hline & & & & & & 2014 & 2010 & 2000 & 1990 \\
\hline \multicolumn{10}{|l|}{ Reported safety data } \\
\hline Fatalities & 5402 & 3580 & 1905 & 1854 & 1804 & -2.7 & -5.3 & -49.6 & -66.6 \\
\hline Injury crashes & 265600 & 242117 & 160080 & 152407 & 146203 & -4.1 & -8.7 & -39.6 & -45.0 \\
\hline Serious injuries (MAIS3+) ${ }^{\star}$ & & 4728 & 4741 & 5070 & 4860 & -4.2 & 2.5 & 2.8 & \\
\hline Deaths per 100000 inhabitants & 9.4 & 6.1 & 3.0 & 2.9 & 2.8 & -3.5 & -8.7 & -54.4 & -70.6 \\
\hline Deaths per 10000 registered vehicles & 2.1 & 1.2 & 0.5 & 0.5 & 0.5 & -4.9 & -11.4 & -60.3 & -77.6 \\
\hline Deaths per billion vehicle kilometres & 12.8 & 7.4 & 3.8 & 3.6 & 3.4 & -4.2 & -9.2 & -54.0 & -73.3 \\
\hline \multicolumn{10}{|l|}{ Traffic data } \\
\hline Registered vehicles ${ }^{1}$ (thousands) & 25191 & 29629 & 35170 & 36715 & 37571 & 2.3 & 6.8 & 26.8 & 49.1 \\
\hline Vehicle-kilometres (millions) & 422840 & 482951 & 507814 & $521310^{\star *}$ & $529508^{\star *}$ & 1.6 & 4.3 & 9.6 & 25.2 \\
\hline Registered vehicles per 1000 inhabitants & 440 & 503 & 560 & 568 & 577 & 1.5 & 3.0 & 14.7 & 31.1 \\
\hline
\end{tabular}

1. Including mopeds.

* Estimation.

** Estimation

Figure 39.1. Road safety, traffic and GDP trends index $1990=100$

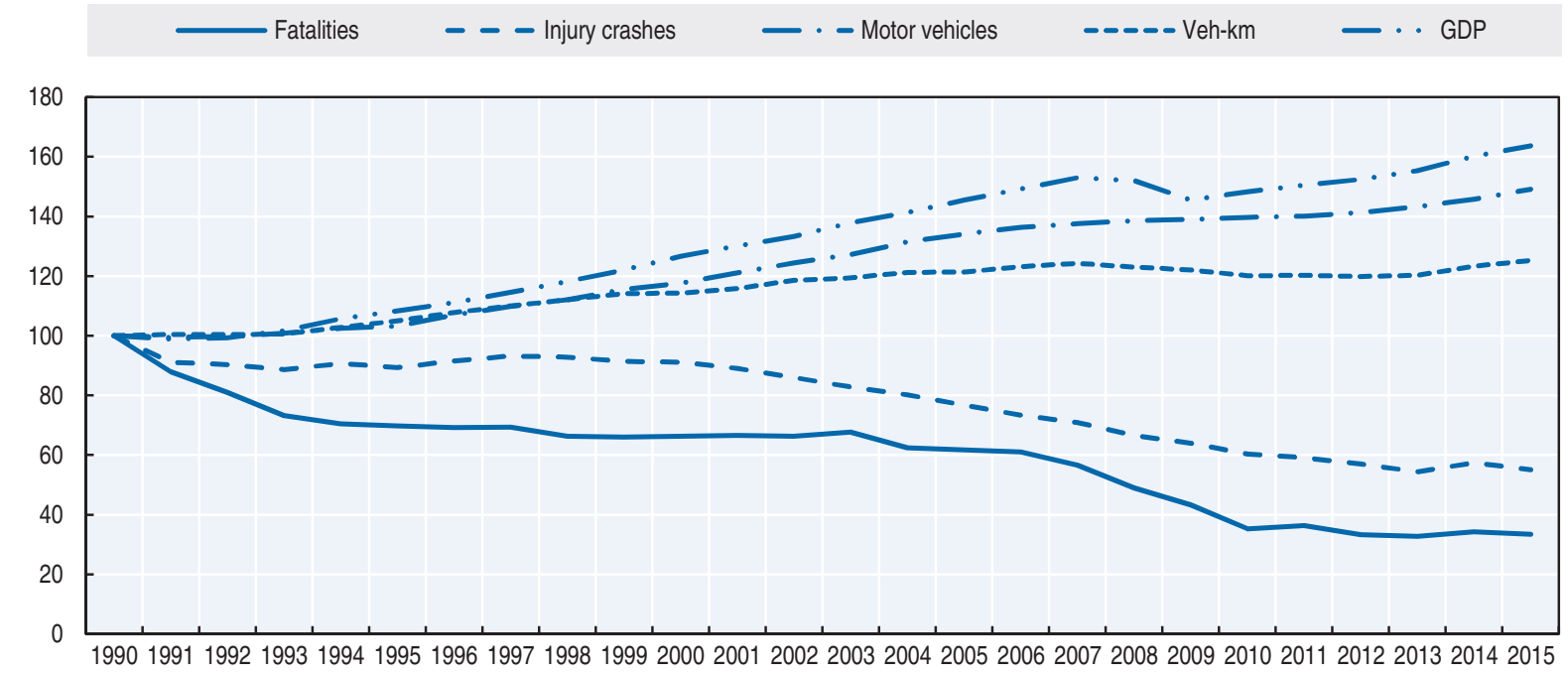

Source: World Bank (2017) (GDP; constant prices).

Table 39.2. Road fatalities by road user group

\begin{tabular}{lrrrrr|rrrr}
\hline & 1990 & 2000 & 2010 & 2014 & 2015 & \multicolumn{3}{c}{$2015 \%$ change from } \\
\cline { 7 - 10 } & & & & & & 2014 & 2010 & 2000 & 1990 \\
\hline Pedestrians & 1754 & 889 & 415 & 464 & 427 & -8.0 & 2.9 & -52.0 & -75.7 \\
Cyclists & 267 & 131 & 111 & 116 & 100 & -13.8 & -9.9 & -23.7 & -62.5 \\
Moped riders & 37 & 15 & 10 & 6 & 8 & 33.3 & -20.0 & -46.7 & -78.4 \\
Motorcyclists & 634 & 597 & 403 & 347 & 361 & 4.0 & -10.4 & -39.5 & -43.1 \\
Car occupants & 2462 & 1784 & 867 & 839 & 802 & -4.4 & -7.5 & -55.0 & -67.4 \\
Others & 248 & 164 & 99 & 82 & 106 & 29.3 & 7.1 & -35.4 & -57.3 \\
Total & $\mathbf{5 0 2}$ & $\mathbf{3 5 8 0}$ & $\mathbf{1 9 0 5}$ & $\mathbf{1 8 5 4}$ & $\mathbf{1 8 0 4}$ & $-\mathbf{2 . 7}$ & $\mathbf{- 5 . 3}$ & $\mathbf{- 4 9 . 6}$ & $\mathbf{- 6 6 . 6}$ \\
\hline
\end{tabular}


Figure 39.2. Road fatalities by road user group in percentage of total, 2015

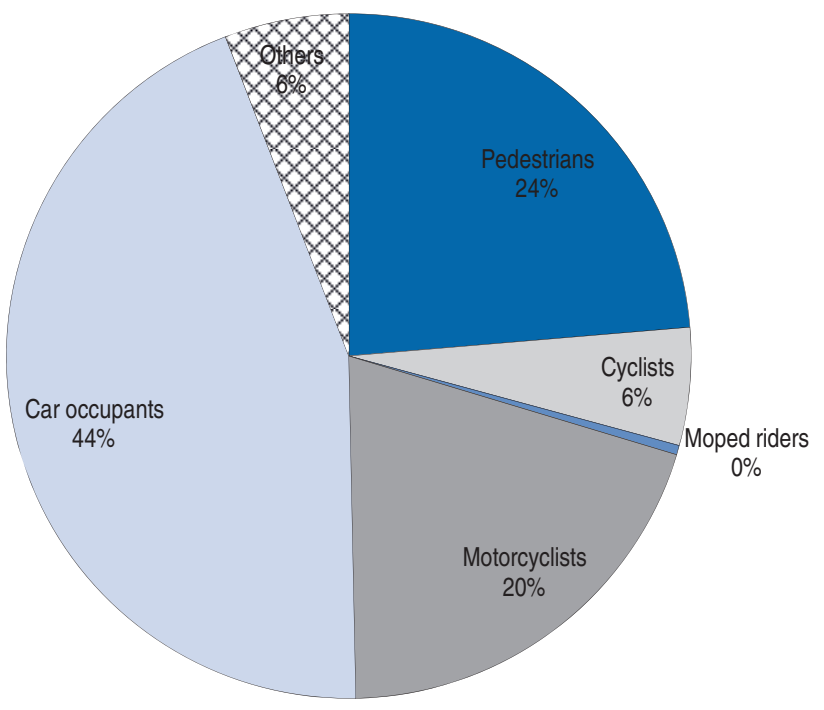

\section{Road safety by age group}

Since 2000, the reduction in fatalities has benefited all age groups, with the highest reduction for the youngest groups (0-14 and 15-17). For 15-17 year olds fatalities decreased by $72 \%$, from 169 in 2000, to 48 in 2015: for the 0-14 age group the fatalities decreased by $70 \%$ for the same time period.

The elderly (over 65) have not benefited at the same rate as the average population from the improvement in road safety. Between 2000 and 2015 fatalities decreased by 50\% for the general population but the $65+$ age group only experienced a $35 \%$ reduction in fatalities.

In 2015 , the $18-20$ group has the highest risk, with a fatality rate per 100000 inhabitants twice that of the general population.

Table 39.3. Road fatalities by age group

\begin{tabular}{|c|c|c|c|c|c|c|c|c|c|}
\hline \multirow{2}{*}{ Age } & \multirow{2}{*}{1990} & \multirow{2}{*}{2000} & \multirow{2}{*}{2010} & \multirow{2}{*}{2014} & \multirow{2}{*}{2015} & \multicolumn{4}{|c|}{$2015 \%$ change from } \\
\hline & & & & & & 2014 & 2010 & 2000 & 1990 \\
\hline $0-14$ & 394 & 171 & 42 & 50 & 52 & 4.0 & 23.8 & -69.6 & -86.8 \\
\hline $15-17$ & 335 & 169 & 93 & 38 & 48 & 26.3 & -48.4 & -71.6 & -85.7 \\
\hline $18-20$ & 558 & 342 & 206 & 148 & 127 & -14.2 & -38.3 & -62.9 & -77.2 \\
\hline $21-24$ & 616 & 304 & 156 & 187 & 182 & -2.7 & 16.7 & -40.1 & -70.5 \\
\hline $25-64$ & 2223 & 1908 & 1031 & 957 & 951 & -0.6 & -7.8 & -50.2 & -57.2 \\
\hline $65-74$ & & 272 & 126 & 176 & 162 & -8.0 & 28.6 & -40.4 & \\
\hline $75-84$ & & 267 & 164 & 192 & 185 & -3.6 & 12.8 & -30.7 & \\
\hline$\geq 85$ & & 140 & 87 & 106 & 97 & -8.5 & 11.5 & -30.7 & \\
\hline Total & 5402 & 3580 & 1905 & 1854 & 1804 & -2.7 & -5.3 & -49.6 & -66.6 \\
\hline
\end{tabular}


Figure 39.3. Road fatality rates by age group Deaths per 100000 inhabitants in a given age group, 1990-2015

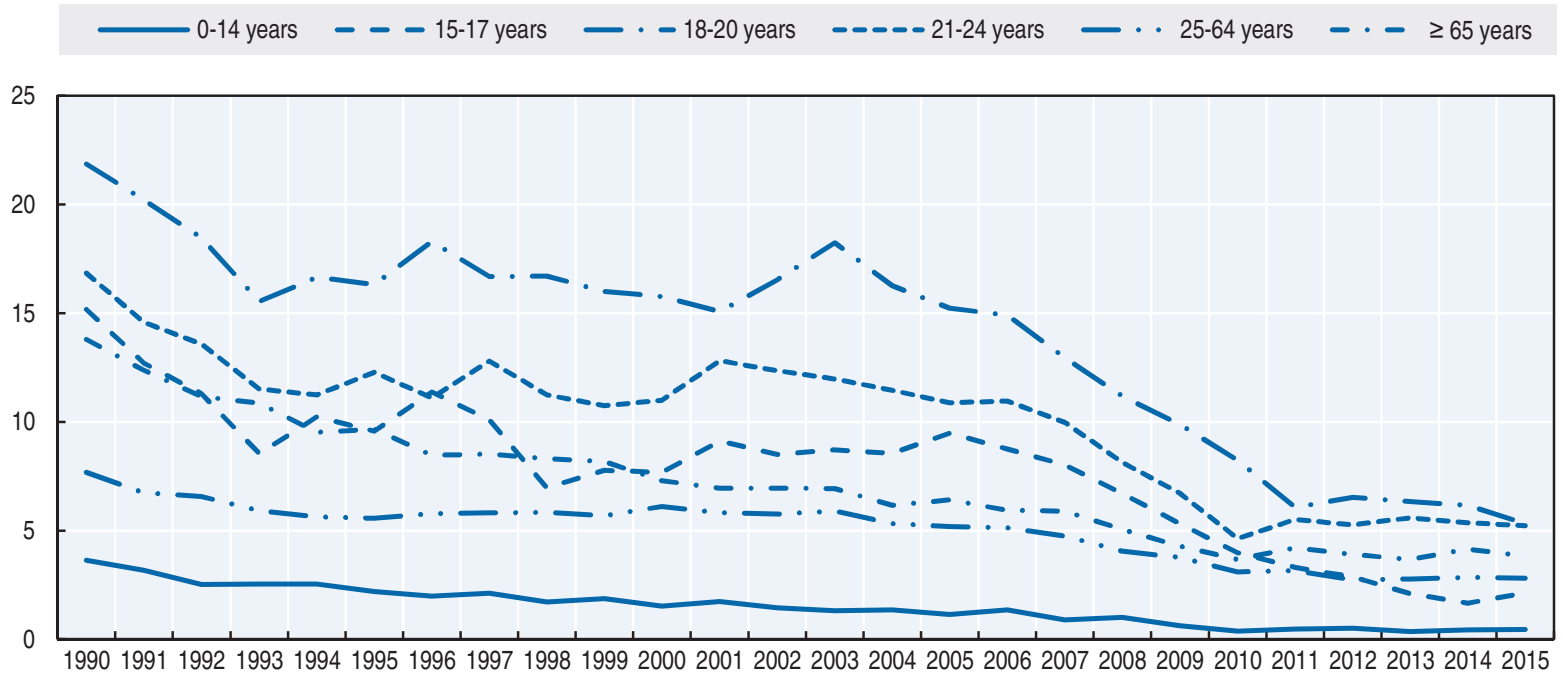

\section{Box 39.1. Road safety for an ageing population}

The UK has an ageing population; currently around one in six people are aged 65 or over, and it is predicted that by 2050 this will increase to one in four people (Cracknell, 2010).

As the proportion of the population in older age groups increases, the number of people holding a driving licence over the age of 70 also increases. In 1975, only one in three men and one in twenty women over 70 held a driving licence; by 2014 four out of five men and one in two women over 70 were licensed to drive. In the UK driver licences have to be renewed at the age of 70 and every three years thereafter.

The proportion of those aged 70 or over on average sustaining a road injury per year has remained approximately the same over the last ten years while other age groups have had a decline. The rapidly increasing population and increased likelihood of this age group to drive and be more active than they were previously may be leading to the slower decline in the casualty figures for this age group compared with the others. Frailty is another factor that could slow reductions. Older people are more vulnerable and may suffer a more serious injury than a younger person in a similar crash.

Older drivers are over represented in multiple vehicle accidents. These collisions typically occur at intersections, particularly where the older driver is turning against oncoming traffic that has right of way on a main road. Drivers over 70 are less likely to be involved in accidents involving speed, loss of control or alcohol as a cause.

Although there are some signs of increases in older casualties between 2010 and 2015, probably relating to a relatively rapidly growing population in that age group, any large increases observed are a most likely to be the result of chance or natural variation rather than any specific mechanism.

Further information about older casualties in Great Britain can be found at the following sites:

www.pacts.org.uk/2016/07/making-older-drivers-safer-for-longer/ (accessed 28 June 2017).

www.roadsafetyobservatory.com/KeyFacts/drivers/older (accessed 28 June 2017). 
Box 39.1. Road safety for an ageing population (cont.)

Table 39.4. Road fatalities among senior citizens

\begin{tabular}{lrr|rr|rr}
\hline & \multicolumn{2}{c|}{$65-74$} & \multicolumn{2}{c|}{$75-84$} & \multicolumn{2}{c}{$85+$} \\
\cline { 2 - 7 } & 2010 & 2015 & 2010 & 2015 & 2010 & 2015 \\
\hline Pedestrians & 41 & 54 & 57 & 65 & 40 & 41 \\
Cyclists & 10 & 12 & 6 & 7 & 4 & 0 \\
Moped riders & 0 & 0 & 0 & 0 & 0 & 0 \\
Motorcyclists & 10 & 16 & 4 & 3 & 0 & 1 \\
Car occupants & 61 & 70 & 89 & 101 & 39 & 48 \\
Total & $\mathbf{1 2 6}$ & $\mathbf{1 6 2}$ & $\mathbf{1 6 4}$ & $\mathbf{1 8 5}$ & $\mathbf{8 7}$ & $\mathbf{9 7}$ \\
\hline
\end{tabular}

Figure 39.4. Road fatality rates in the $65+$ age groups Deaths per 100000 inhabitants in a given age group, 2000-15

- $65-74$ years

$--75-84$ years

$-\cdot-85+$ years

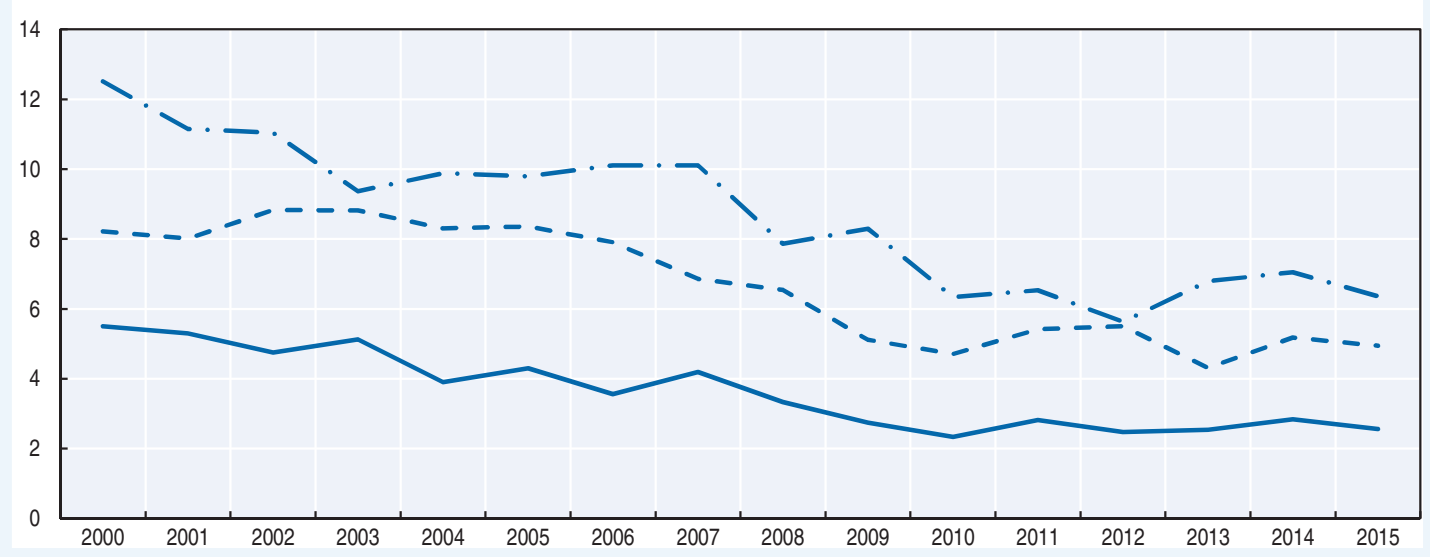

Figure 39.5. Road fatality rate by age and road user group Fatalities per 100000 inhabitants, 2015

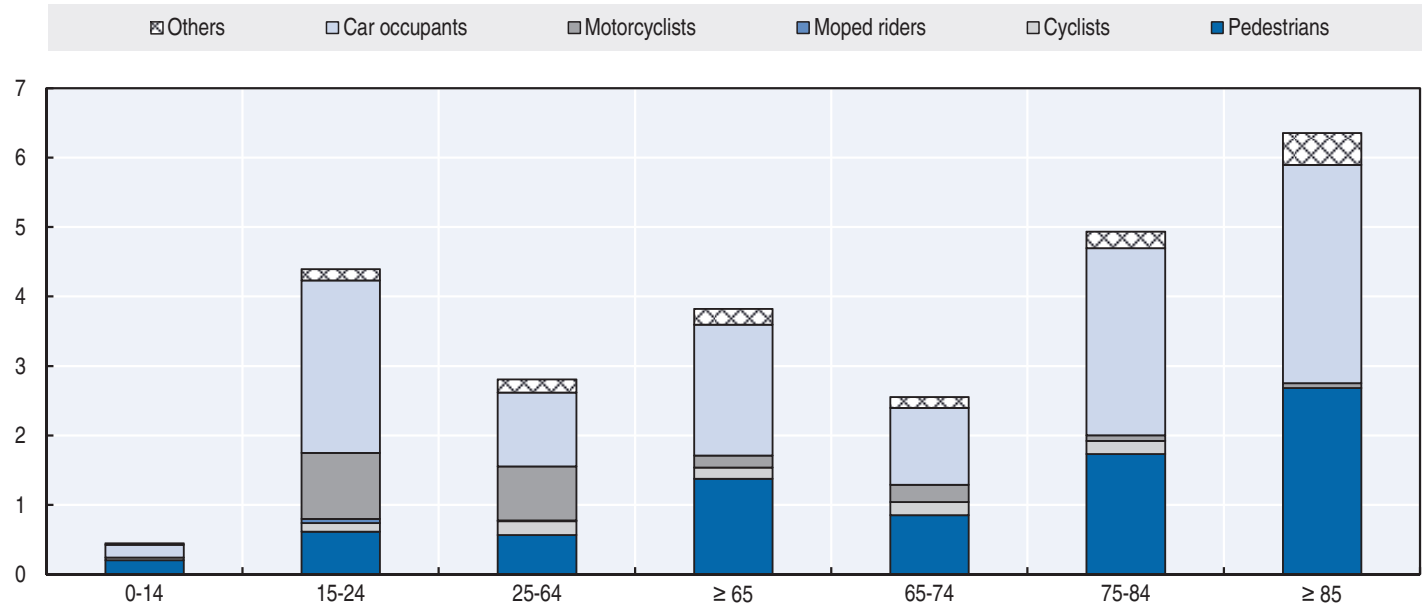




\section{Road safety by road type}

In 2015 , most fatalities (59\%) occurred on rural roads. This is considerably higher than the $43 \%$ of traffic on these roads. Traffic on urban roads usually travels at lower speeds; as a result injuries from collisions involving just cars, buses and goods vehicles tend to be less serious. The higher average speeds on rural roads more frequently result in more serious injuries and deaths. Since 1990, the largest improvement was made on urban roads, possibly as a result of improved secondary safety and highway engineering.

Motorways accounted only for $6 \%$ of fatalities in 2015; yet the number of people killed on motorways increased in 2015 by more than 15\% compared to 2014.

Figure 39.6. Road fatalities by road type

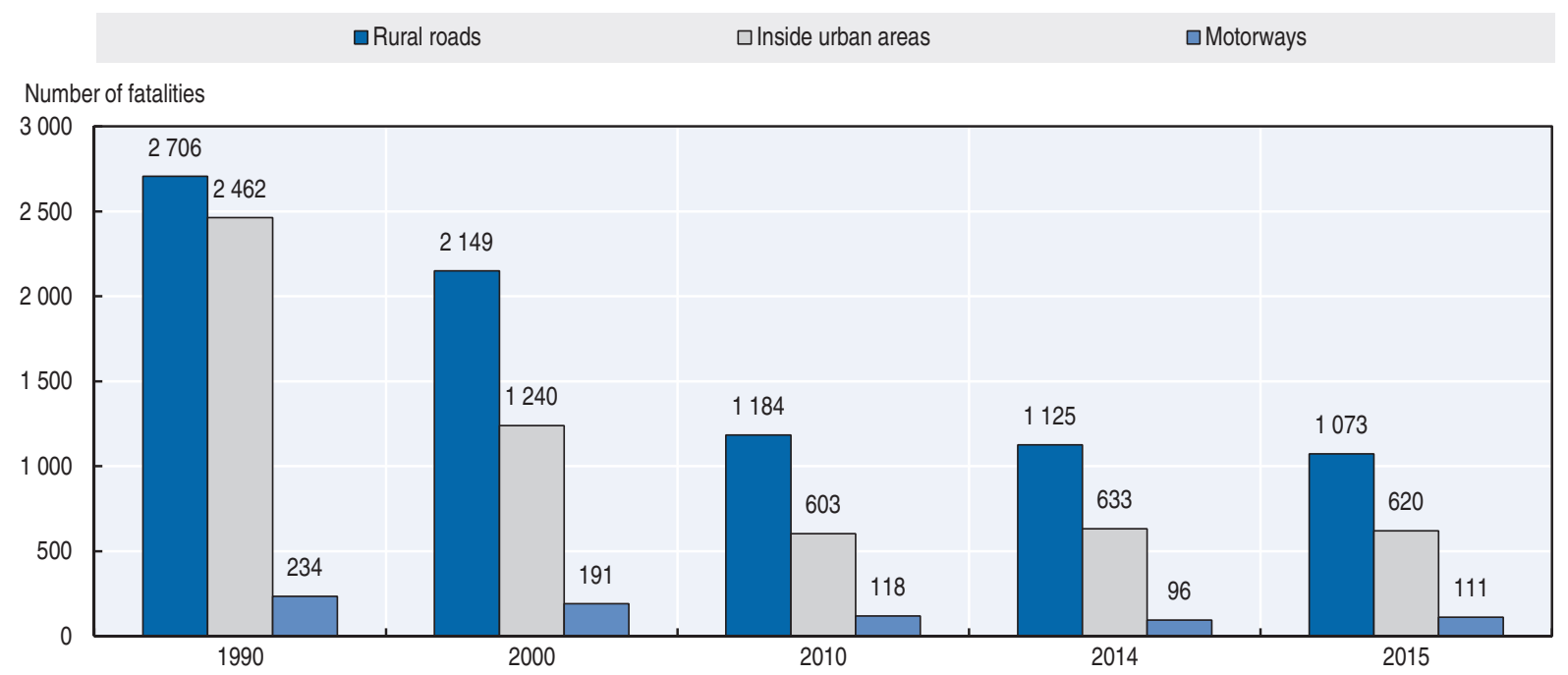

\section{Economic costs of traffic crashes in Great Britain}

For the first time in 2015 unreported injuries have been included in the "value of prevention of accidents". The estimated total value of prevention of unreported accidents is around GBP 20 billion a year, higher than the value of reported injury accidents. This raises the total estimate for all reported and unreported accidents to around GBP 35.5 billion a year (DfT, 2016).

Table 39.5. Costs of road crashes, 2015 (Great Britain)

\begin{tabular}{lcc}
\hline & Unit cost & Total \\
\hline Fatalities & GBP 2.057 million & GPB 3 241 million \\
Hospitalised persons & GBP 0.230 million & GBP 4 604 million \\
Slight injuries & GBP 0.024 million & GPB 2 865 million \\
Damage-only crashes (including property damage, & GBP 0.002 million & GBP 4577 million \\
police costs, and insurance/administration costs) & & \\
Non-fatal accidents not reported to police & & GBP 20 263 million \\
Total & & GBP 35 550 million \\
\hline
\end{tabular}




\section{Recent trends in road user behaviour}

\section{Speed}

Exceeding the speed limit was reported as a factor in $5 \%$ of all crashes in Great Britain in 2015. These crashes accounted for $15 \%$ of fatalities.

The table below summarises the main speed limits in the United Kingdom.

Table 39.6. Passenger car speed limits by road type, 2017

\begin{tabular}{lll}
\hline & \multicolumn{1}{c}{ General speed limit } & \multicolumn{1}{c}{ Comments } \\
\hline Urban roads & $30 \mathrm{mph}$ & \\
Rural roads & Single carriageway: $60 \mathrm{mph}$ & Dual carriageway : $70 \mathrm{mph}$ \\
Motorways & $70 \mathrm{mph}$ & \\
\hline
\end{tabular}

\section{Drink driving}

In England and Wales the maximum authorised blood alcohol content (BAC) is $0.8 \mathrm{~g} / \mathrm{l}$. In Scotland the maximum limit was reduced to $0.5 \mathrm{~g} / \mathrm{l}$ in December 2014. Northern Ireland will lower the limit to $0.5 \mathrm{~g} / \mathrm{l}$ from 2018.

For statistical purposes, a drink drive accident is defined as an incident on a public road in which someone is killed or injured and where at least one of the motor vehicle drivers or riders involved met one of the following criteria:

- Refused to give a breath test specimen when requested by police (other than when incapable of doing so for medical reasons)

- failed a roadside breath test by registering over 35 micrograms of alcohol per 100 millilitres of breath in England and Wales (or 22 micrograms of alcohol per 100 millilitres of breath in Scotland).

- died and was subsequently found to have more than the authorised BAC.

Drink drive casualties are defined as all road users killed or injured in a drink drive accident.

In 2015 , about $13 \%$ of all road deaths involved a driver with an illegal alcohol level. Between 180 and 250 people were killed in accidents in Great Britain where at least 1 driver was over the drink drive limit in 2015, with a central estimate of 220 deaths. Although the central estimate for 2015 is lower than the final figure for 2014, the difference is not statistically significant and continues a period of stability recorded since 2010 .

The provisional total number of casualties of all types in drink drive accidents is 8480 , up $3 \%$ on the 2014 figure. This total is slightly lower than was previously reported in 2015 for the initial estimate so it is possible that it could reduce again once final figures are available. The total number of drink drive accidents of all severities rose by 2\% to 5740 in 2015 (DfT, 2017b).

In a survey on drink driving in England and Wales undertaken in 2015-16, around 8\% of drivers said that they had driven at least once or twice within the previous 12 months when they thought they were over the legal alcohol limit (DfT, 2016). This proportion has remained broadly unchanged since 2012/13.

\section{Drugs and driving}

In 2015-16 in England and Wales, $0.6 \%$ of drivers said they had driven under the influence of illegal drugs at least once in the previous year. This is not significantly 
different from earlier years. Both drink and drug driving are more prevalent amongst males and younger drivers. More detailed results on self-reported drink and drug drinking are published at: www.gov.uk/government/statistical-data-sets/ras51-reported-drinking-and-driving (accessed 28 June 2017).

The UK introduced new legislation on 2 March 2015 on driving with a specified controlled drug in the body above a specified limit. The previous legislation required the police to demonstrate that driving was impaired by drugs in order to prosecute. For more information see www.gov.uk/government/news/drug-drive-legislation-am-i-fit-to-drive (accessed 28 June 2017).

This new legislation was supported by a campaign to inform the public of this change, with three key objectives:

- raise awareness of the new drug driving legislation and build knowledge and understanding of what it means for drivers

- increase awareness and salience of the consequences of a drug driving conviction

- increase the belief that drivers are likely to be caught and convicted if they drug drive.

The evaluation of this campaign is available at: www.gou.uk/government/publications/ think-drug-driving-evaluation-2015 (accessed 28 June 2017).

\section{Seat belts and helmets}

Seat belt use is compulsory for all seats:

- Front seat belt wearing regulations for drivers and passengers (both adult and children) came into force on 31 January 1983.

- Seat belt wearing regulations for children in rear seats came into force on 1 September 1989.

- Seat belt wearing regulations for adults in rear seats came into force on 1 July 1991.

The most recent survey of seat belt use, carried out in 2014, provided estimates that $98 \%$ of car drivers, $96 \%$ of front-seat passengers and $87 \%$ of rear-seat car occupants in England wore seat belts (DfT, 2015a). These rates are slightly higher than earlier in the decade. The Department for Transport is expecting to repeat this survey in 2017.

Children are required to be restrained by a suitable combination of car seats and belts, depending on age. The level of children in restraints in the rear seat of cars fell from $96 \%$ in 2009 to $91 \%$ in 2014 .

Table 39.7. Seat belt wearing rate by car occupants: England

$\%$

\begin{tabular}{lcc}
\hline & 2009 & 2014 \\
\hline Driver & 95 & 97.9 \\
Front seat passenger & 95 & 96 \\
Rear seat passenger & 89 & 87.1 \\
Child rear seat passenger (aged $<14$ ) & 96 & 90.7 \\
Adult rear seat passenger (aged 14 and over) & 79 & 81.1 \\
\hline
\end{tabular}

Results are available at: www.gou.uk/government/statistics/seatbelt-and-mobile-phone-usesurveys-2014 (accessed 28 June 2017). 
Helmet wearing has been compulsory on motorcycles since 1973 and on mopeds (up to $50 \mathrm{cc}$, maximum speed $45 \mathrm{~km} / \mathrm{h}$ ) since 1977. A helmet is not compulsory on bicycles.

\section{Distraction}

An observational survey held in 2014 (DfT 2015a) in England and Scotland showed the proportion of drivers using hand-held mobile phones while driving was $1.6 \%$ overall: $1.4 \%$ for car drivers, $2.7 \%$ for van drivers, and $1.2 \%$ for truck drivers. Results are available at: www.gou.uk/ government/statistics/seatbelt-and-mobile-phone-use-surveys-2014 (accessed 28 June 2017).

A follow-up survey is scheduled to be undertaken in 2017.

In March 2017 new penalties were introduced. Motorists using a phone while driving will now receive 6 points on their licence and a GBP 200 fine - up from the previous 3 points and GBP 100 penalty. Motorists caught using their mobile twice or accruing 12 points on their licence will face magistrates' court, being disqualified and fines of up to GPB 1000 . New drivers, within 2 years of passing their test, risk having their licence revoked and lorry or bus drivers can be suspended if caught.

\section{Sleepiness and fatigue}

In Great Britain "fatigue" was assigned as a contributory factor in $2 \%$ of all reported accidents and 4\% of fatal injury crashes in 2015 (DfT 2016).

\section{National road safety strategies and targets Organisation of road safety}

The Department for Transport sets overall road safety strategy in Great Britain. This includes decisions about road safety targets and legislating on key safety issues. Transport Scotland has certain powers in respect of road safety in Scotland, for example it can vary the drink driving limit; and the Welsh Assembly has set a Welsh road safety target. Local highway authorities are responsible for safety on their roads and can use engineering measures as well as local education campaigns to improve safety. Road safety in Northern Ireland is the responsibility of the Department of the Environment in Northern Ireland.

For latest information see: www.gov.uk/government/policies/road-safety (accessed 28 June 2017).

\section{Road safety strategy for 2011-20}

The Department published a Road Safety Statement in December 2015. It provides a road safety strategy for the immediate future. The strategy sets out the context of road safety in Britain today and the overarching scope of road safety activity for the government. It will be followed by consultations on specific issues as options are developed. The statement covers road safety policy within Britain as governed by the Department for Transport (DfT). The governments and administrations of Scotland, Wales and Northern Ireland will seek to produce their own policies and strategic documents on devolved matters (DfT, 2015b).

For more information see: www.gov.uk/government/publications/road-safety-statementworking-together-to-build-a-safer-road-system (accessed 28 June 2017).

The key priorities for road safety include:

- Adopting the Safe System approach. This is clear in the framework set with Highways England and which it is now implementing. It is also a theme that runs throughout this statement. 
- Protecting vulnerable road users, including pedestrians, cyclists, motor cyclists and horse riders, through infrastructure and vehicle improvements, promotion of safer behaviour and equipment and ensuring other road users are aware of the risks posed to these groups and adapt accordingly.

- Taking tough action against those who speed, exceed the drink-driving limit, take drugs or use their mobile phone while on the road.

- Ensuring that the driver testing and training regime prepares new drivers for a wide range of real life driving conditions and situations.

- Working with the insurance industry to incentivise safer behaviour and to reward the uptake of new technologies and opportunities to improve skills that are proven to reduce collisions.

- Helping employers to reduce road related collisions at work, including through improved heavy goods vehicle (HGV) safety.

- Encouraging the faster uptake of safer vehicles via the promotion of clear consumer information and the procurement of safer vehicles.

- Promoting the development and adoption of connected and autonomous vehicle technologies in a way that maximises safety benefits.

- Continuing the THINK! campaign to provide road user education and influence behaviour in a targeted and engaging way.

- Enabling the police to use modern enforcement technologies, while protecting the privacy of law-abiding people.

- Supporting Highways England and local authorities in improving the safety standards of the UK roads.

- Reviewing the nation's road safety management capacity, to identify opportunities for strengthening joint working, local innovation and efficiency.

- Supporting further devolution of road safety policy, in a way that meets the needs of the nation as a whole.

- Underpinning policy decisions with robust evidence, research and evaluation.

- Working in partnership with public and private sector bodies and civil society organisations to save lives.

\section{Road safety targets}

The government has a manifesto commitment to reduce the number of cyclists and other road users killed or seriously injured on the roads every year. However, there is no specific target associated with this commitment.

\section{Recent safety measures (2014-17)}

\section{Road users}

\section{Protective equipment for motorcyclists}

- Motorcyclist safety has been a longstanding priority for the Government's THINK! road safety campaign. Previous campaigns have included 'THINK! BIKER', which encourages drivers to look out for bikes at junctions. THINK! also manage a THINK! BIKER Facebook channel, offering safety tips and extra training advice. This now has a following of over 77000 motorcyclists. 
- This year, THINK! are running a social media led motorcycle safety campaign encouraging riders to undertake further training, wear protective clothing and reduce their speed on rural roads. This is being complemented by wider social media activity, encouraging drivers to look out for bikes.

\section{Education and awareness}

- A new section offence of driving over specified limits for specified drugs came into force on 2 March 2015. See link for more information: www.gov.uk/government/news/drug-drivelegislation-am-i-fit-to-drive (accessed 28 June 2017).

- The Scottish Government reduced the drink driving blood alcohol content limit from $0.8 \mathrm{~g} / \mathrm{l}$ to $0.5 \mathrm{~g} / \mathrm{l}$. The change came into force in December 2014. The limit in Northern Ireland will also be lowered to $0.5 \mathrm{~g} / \mathrm{l}$ from 2018.

- DfT conducted a drug drive campaign in 2015. An evaluation study is available at: www.gov. uk/government/publications/think-drug-driving-evaluation-2015 (accessed 28 June 2017).

\section{Vehicles}

- The car tax disc was abolished in 2014 after 93 years. This was a paper disc issued by the licensing authorities to show that vehicle excise duty had been paid for the vehicle. This has now been replaced by a purely electronic system.

\section{Recent and ongoing research}

Some research projects are presented below.

- "Modelling the impact of the weather on road casualty statistics". The study analyses the relationship between casualties and weather events such as rain or sub-zero temperatures. Further details see article in: www.gov.uk/government/statistics/reported-road-casualties-greatbritain-annual-report-2014 (accessed 28 June 2017).

- Driving test changes: plans to improve road safety www.gov.uk/government/news/drivingtest-changes-plans-revealed-to-improve-road-safety (accessed 28 June 2017).

- Driving test changes in 2017: www.gov.uk/government/collections/new-driving-test-trial (accessed 28 June 2017).

- The Department for Transport has published MASI3+ estimates for the UK for the first time. These figures and background information are available at www.gov.uk/government/ statistics/reported-road-casualties-great-britain-annual-report-2015 (accessed 28 June 2017).

\section{References}

Cracknell, R. (2010), The ageing population. In: House of Commons Library Research, 2010. Key Issues for the New Parliament 2010, www.parliament.uk/documents/commons/lib/research/key_issues/Key-Issues-Theageing-population2007.pdf (accessed 28 June 2017).

DfT (2017a), Reported Road casualties in great Britain: quarterly provisional estimates year ending September 2016, Department for Transport, London, www.gov.uk/government/statistics/reported-road-casualtiesgreat-britain-provisional-estimates-july-to-september-2016 (accessed 28 June 2017).

DfT (2017b), Reported road casualties in Great Britain, estimates involving illegal alcohol levels: 2015 (second provisional), Department for Transport, London, www.gou.uk/government/statistics/reported-roadcasualties-in-great-britain-accidents-involving-illegal-alcohol-levels-2015-second-provisional (accessed 28 June 2017). 
DfT (2016a), Report Road Casualties in Great Britain: 2015 Annual Report, Department for Transport, London, www.gov.uk/government/uploads/system/uploads/attachment_data/file/568484/rrcgb-2015.pdf (accessed 28 June 2017).

DfT (2016b) National Travel Survey: 2015 Report, Department for Transport, London, www.gov.uk/ government/statistics/national-travel-survey-2015 (accessed 28 June 2017).

DfT (2015a), Seatbelt and mobile phone use surveys: 2014. Department for Transport, London, www.gov.uk/ government/statistics/seatbelt-and-mobile-phone-use-surveys-2014 (accessed 28 June 2017).

DfT (2015b), Working together to build a safer road system: British road safety statement, Department for Transport, London, www.gov.uk/government/publications/road-safety-statement-working-together-tobuild-a-safer-road-system (accessed 28 June 2017).

World Bank (2017), “GDP (constant US\$)”, World Development Indicators, http://databank.worldbank.org/ data/reports.aspx? source=world-development-indicators (accessed 23 February 2017).

\section{Websites}

- UK Department for Transport - Road Safety policy: www.gov.uk/government/policies/making-roads-safer (accessed 28 June 2017).

- UK Department for Transport - Road Safety Statistics: www.gov.uk/government/collections/road-accidentsand-safety-statistics (accessed 28 June 2017).

- UK Road safety observatory: Key facts and summaries of research on road safety topics: www.road safetyobservatory.com (accessed 28 June 2017). 



\section{Chapter 40}

\section{United States}

This chapter presents 2015 road safety data for the United States along with provisional data from 2016. It looks at trends in traffic and road safety from the years 1990 to 2015 and road user behaviour patterns with a special focus on the ageing of the population. Sections include data on speed, drink driving, drugs and driving, distracted driving, fatigue and seat belt usage. The chapter reviews the United States' road safety strategy and looks at recently implemented safety measures and research.*

* All data stem from the National Highway Traffic Safety Administration (NHTSA) and IRTAD unless otherwise noted. For more information please contact: terry.shelton@dot.gov. 
I In 2015, there were 35092 road fatalities, a 7.2\% increase over 2014. This increase is the largest percentage increase recorded in nearly 50 years. The number of injury crashes and those seriously injured also increased substantially. Pedestrian and cyclists fatalities increased to a level not seen in 20 years and motorcyclist deaths increased by over $8 \%$. Almost half of passenger vehicle occupants killed were not wearing seat belts. The fatality rate in 2015 was 10.9 per 100000 inhabitants. Provisional data from the first 9 months of 2016 indicate an additional 8\% increase in fatalities over the same period in 2015.

\section{Road safety data collection}

\section{Definitions applied in the United States}

- Road fatality: A fatality that occurs within 30 days of a crash involving a motor vehicle travelling on a traffic way customarily open to the public.

- Serious injuries: Incapacitating injuries, defined as severe lacerations, broken or distorted extremities, crush injuries, internal skull/chest/abdominal injuries, significant burns, unconsciousness and paralysis.

For general crash-related injury figures, the National Highway Traffic Safety Administration (NHTSA) does not differentiate between seriously and slightly-injured people. A crash is considered an injury crash if there were no fatalities, but someone involved in the crash - occupant or non-occupant - was reported as injured.

\section{Data collection}

State Police collect data on motor vehicle traffic crashes on specific roadways in each of the 50 states DC and Puerto Rico. Each state also has local police jurisdictions within counties, cities and towns that collect data on motor vehicle traffic crashes on the roadways not covered by the State Police.

The Fatality Analysis Reporting System (FARS) is a nationwide census providing the NHTSA, Congress and the American public yearly data regarding fatal injuries suffered in motor vehicle traffic crashes.

The National Automotive Sampling System (NASS) provides the NHTSA an efficient and reusable resource with which to conduct data collection representing a broad spectrum of American society. Using a core set of crash data components, the NASS has proven a reliable resource for a variety of agency sponsored electronic data collection efforts over the past 10 years.

The NASS is composed of two systems - the Crashworthiness Data System (CDS) and the General Estimates System (GES). These are based on cases selected from a sample of police crash reports. CDS data focus on passenger vehicle crashes, and are used to investigate injury mechanisms to identify potential improvements in vehicle design. GES data focus on the bigger overall crash picture, and are used for problem size assessments and tracking trends. 
A challenge of collecting data at the federal level is obtaining and maintaining cooperation with state and local police jurisdictions.

\section{Data Modernisation Project}

In 2012, United States Congress appropriated USD 25 million to NHTSA to modernise NASS. The project "DataMod" was launched in January 2012 for implementation in January 2016. The goal of DataMod is to affirm NHTSA's position as the leader in motor vehicle crash data collection and analysis, by collecting quality data to keep pace with emerging technologies and policy needs.

NASS was designed in the 1970s, and this 30-year old system needs to be updated to meet the data needs of the transport community that have increased and significantly changed over the last three decades. Congress was specific in their request and NHTSA is looking into the following items:

- expanding the current sample size

- expanding the scope of its data collection to possibly include large trucks, motorcycles, and pedestrians

- assessing the need for more data from the pre-crash, crash, and post-crash phases

- reviewing the crash data elements to be collected

- soliciting input from interested parties, including suppliers, automakers, safety advocates, the medical community and research organisations.

\section{Most recent safety data}

\section{Road crashes in 2016 - provisional data}

A statistical projection of traffic fatalities for the first 9 months of 2016 shows that an estimated 27875 people died in motor vehicle traffic crashes. This represents an increase of about $8 \%$ as compared to the first 9 months of 2015.

\section{Road crashes in 2015}

In 2015, there were 35092 road fatalities, ending a five-decade trend of declining fatalities with a $7.2 \%$ increase in deaths over 2014 . The $7.2 \%$ increase is the largest percentage increase in nearly 50 years (NHTSA, 2016a).

Pedestrian and cyclists fatalities increased to a level not seen in 20 years. Motorcyclist deaths increased over $8 \%$. Almost half of passenger vehicle occupants killed were not wearing seat belts. One in three fatalities involved drunk drivers or speeding. One in 10 fatalities involved distraction.

The estimated number of injured people experienced a statistically significant increase. In 2015 there was an increase of 105000 people injured in motor vehicle crashes over 2014.

According to NHTSA, job growth and low fuel prices are two factors that led to increased driving, including increased leisure driving and driving by young people, partly explaining the higher fatality rates. In response to the increase, the United States' Department of Transportation (USDOT), the National Highway Traffic Safety Administration and the White House issued an unprecedented call to action to involve a wide range of stakeholders in helping determine the causes of the increase. In addition to the call to action on understanding the increase in deaths, USDOT held a special session at its Safer 
People, Safer Streets Summit on September 16th, 2016 to discuss the pedestrian and bicycle fatality increase with city leaders taking part in the Mayor's Challenge.

\section{Trends in traffic and road safety (1990-2016)}

\section{Traffic}

Since 1990, the number of registered vehicles grew steadily reaching over 259 million in 2008. Even though the number of registered vehicles declined for the years 2009 and 2010, the number began rising again and the 281 million registered vehicles in 2015 has well surpassed the 2008 high. Vehicle ownership exceeds 860 vehicles per 1000 inhabitants.

Between 1990 and 2007, vehicle-miles travelled (VMT) had grown at an annual average compound growth rate of about 1\%. VMT declined in 2008 and reached in 2011, its lowest level since 2003. In 2015, VMT increased 2.3\% over 2014, the largest increase in 15 years.

\section{Road safety}

\section{Crashes and casualties}

In the first decade of the 21st century, the United States averaged more than 40000 deaths and more than 2500000 injuries on the roads each year. Road crashes generally are the leading cause of death for Americans aged 3 to 34. However, there has been some change with certain age groups from year to year more recently.

Over the past decade there has been a general downward trend in traffic fatalities, with a slight increase in 2012. Ten years ago in 2006, there were 42708 people killed in traffic crashes. Safety programmes such as those that have resulted in increased belt use and reduced impaired driving have worked to substantially lower the number of traffic fatalities over the years. Vehicle improvements including technologies such as air bags and electronic stability control have also contributed greatly to reduce traffic deaths. However, with the large increase in fatalities in 2015, that decade-long downward trend of almost $25 \%$ has been reduced by almost one-third.

\section{Rates}

In 2014, the fatality rate per 100 million VMT fell to 1.08, the lowest since NHTSA began collecting fatality data through the Fatality Analysis Reporting System in 1975. However, following the sharp increase in fatalities in 2015 , the fatality rate increased to 1.13 . In terms of population, the death rate in 2015 was 10.9 road fatalities per 100000 inhabitants, a $6.3 \%$

Table 40.1. Road safety and traffic data

\begin{tabular}{|c|c|c|c|c|c|c|c|c|c|}
\hline & \multirow{2}{*}{1990} & \multirow{2}{*}{2000} & \multirow{2}{*}{2010} & \multirow{2}{*}{2014} & \multirow{2}{*}{2015} & \multicolumn{4}{|c|}{$2015 \%$ change from } \\
\hline & & & & & & 2014 & 2010 & 2000 & 1990 \\
\hline \multicolumn{10}{|l|}{ Reported safety data } \\
\hline Fatalities & 44599 & 41945 & 32999 & 32744 & 35092 & 7.2 & 6.3 & -16.3 & -21.3 \\
\hline Injury crashes & 2161757 & 2107431 & 1572400 & 1677782 & 1747560 & 4.2 & 11.1 & -17.1 & -19.2 \\
\hline Deaths per 100000 inhabitants & 17.9 & 14.9 & 10.7 & 10.3 & 10.9 & 6.3 & 2.3 & -26.6 & -38.9 \\
\hline Deaths per 10000 registered vehicles & 2.4 & 1.9 & 1.3 & 1.2 & 1.2 & 4.7 & -2.7 & -35.5 & -48.5 \\
\hline Deaths per billion vehicle kilometres & 12.9 & 9.5 & 6.9 & 6.7 & 7.0 & 4.8 & 1.9 & -25.8 & -45.5 \\
\hline \multicolumn{10}{|l|}{ Traffic data } \\
\hline Registered vehicles (thousands) & 184275 & 217028 & 257312 & 274805 & 281312 & 2.4 & 9.3 & 29.6 & 52.7 \\
\hline Vehicle kilometres (millions) & 3451016 & 4420747 & 4775352 & 4869321 & 4981520 & 2.3 & 4.3 & 12.7 & 44.3 \\
\hline Registered vehicles per 1000 inhabitants & 739 & 769 & 832 & 862 & 875 & 1.6 & 5.2 & 13.8 & 18.5 \\
\hline
\end{tabular}


Figure 40.1. Road safety, traffic and GDP trends index $1990=100$

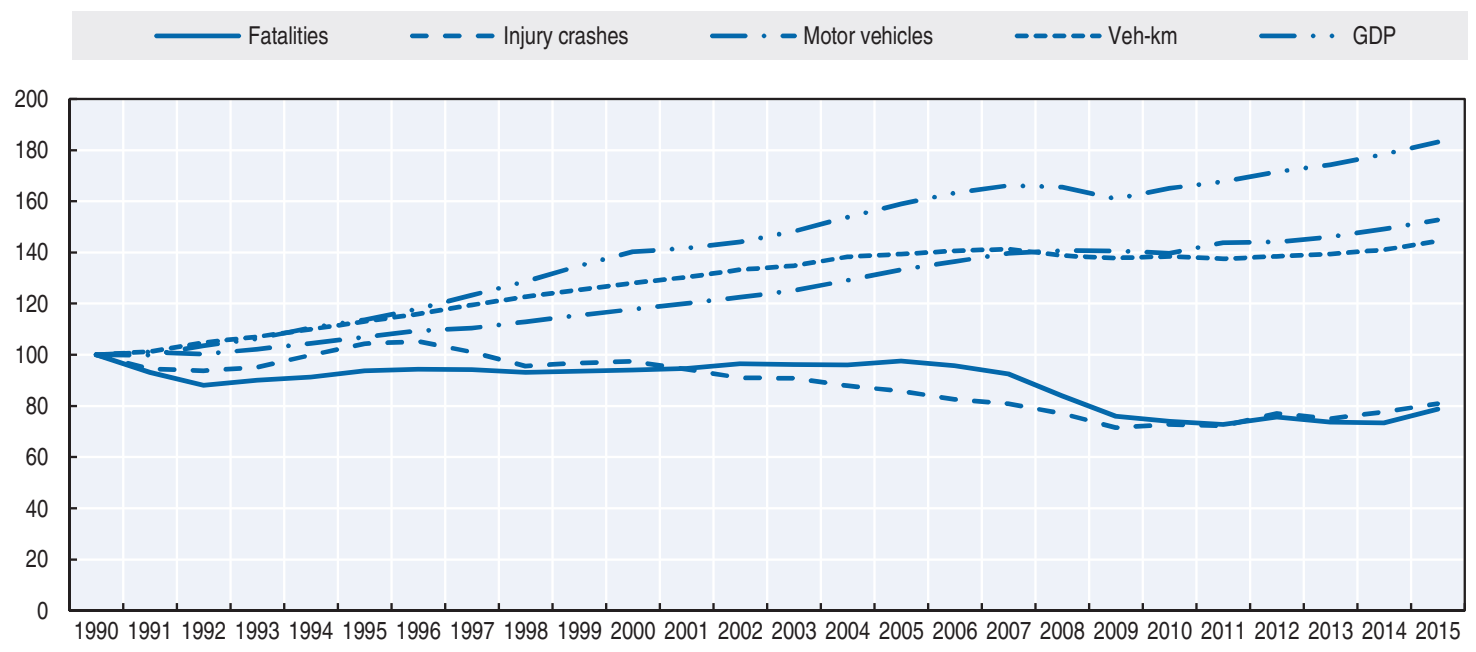

Source: World Bank (2017) (GDP; constant prices).

increase from 2014. Between 1990 and 2015, the death rate expressed in terms of deaths per 100000 inhabitants, decreased by $39 \%$, and the risk in terms of deaths per billion vehiclekilometres declined by $46 \%$.

\section{Road safety by user group}

Since 1990, all road users except powered two-wheeler riders have benefited from the improvement in road safety. Motorcycle rider fatalities increased by $51 \%$ between 1990 and 2015 and moped rider fatalities by $237 \%$ (it should however be noted that the moped fleet is quite small in the United States).

In 2015, all road users, except moped riders, were affected by the deterioration of road safety. Cyclist, pedestrian, motorcyclist, SUV, and van occupant fatalities increased at a rate higher than the overall increase of $7.2 \%$. The motorcyclist fatalities increased by 389 , a $9 \%$ increase. The 2015 motorcyclist fatality count (4 811) is the highest number since 2012. Pedestrian fatalities increased by 466, a $9.5 \%$ increase. The 2015 pedestrian fatality count (5 376) is the highest number since 1996. Cyclists fatalities increased by 89 , a $12 \%$ increase. The 2015 cyclist fatality count (818) is the highest number since 1995. The number of passenger vehicle occupant fatalities increased by 1391 , a $7 \%$ increase, which accounted for $59 \%$ of the overall increase in fatalities. The 2015 passenger vehicle fatality count $(22441)$ is the highest number since 2009. Passenger vehicles include passenger cars and light trucks.

Table 40.2. Road fatalities by road user group

\begin{tabular}{lrrrrr|rrrr}
\hline & 1990 & 2000 & 2010 & 2014 & 2015 & \multicolumn{4}{|c}{$2015 \%$ change from } \\
\cline { 7 - 10 } & & & & & & 2014 & 2010 & 2000 & 1990 \\
\hline Pedestrians & 6482 & 4763 & 4302 & 4910 & 5376 & 9.5 & 25.0 & 12.9 & -17.1 \\
Cyclists & 859 & 693 & 623 & 729 & 818 & 12.2 & 31.3 & 18.0 & -4.8 \\
Moped riders & 49 & 29 & 113 & 172 & 165 & -4.1 & 46.0 & 469.0 & 236.7 \\
Motorcyclists & 3195 & 2868 & 4405 & 4422 & 4811 & 8.8 & 9.2 & 67.7 & 50.6 \\
Car occupants & 24092 & 20699 & 12491 & 11947 & 12628 & 5.7 & 1.1 & -39.0 & -47.6 \\
Others including SUVs & 9922 & 12893 & 11065 & 10564 & 11294 & 6.9 & 2.1 & -12.4 & 13.8 \\
Total & $\mathbf{4 4 5 9 9}$ & $\mathbf{4 1 9 4 5}$ & $\mathbf{3 2 ~ 9 9 9}$ & $\mathbf{3 2 ~ 7 4 4}$ & $\mathbf{3 5 0 9 2}$ & $\mathbf{7 . 2}$ & $\mathbf{6 . 3}$ & $\mathbf{- 1 6 . 3}$ & $\mathbf{- 2 1 . 3}$ \\
\hline
\end{tabular}


Figure 40.2. Road fatalities by road user group in percentage of total, 2015

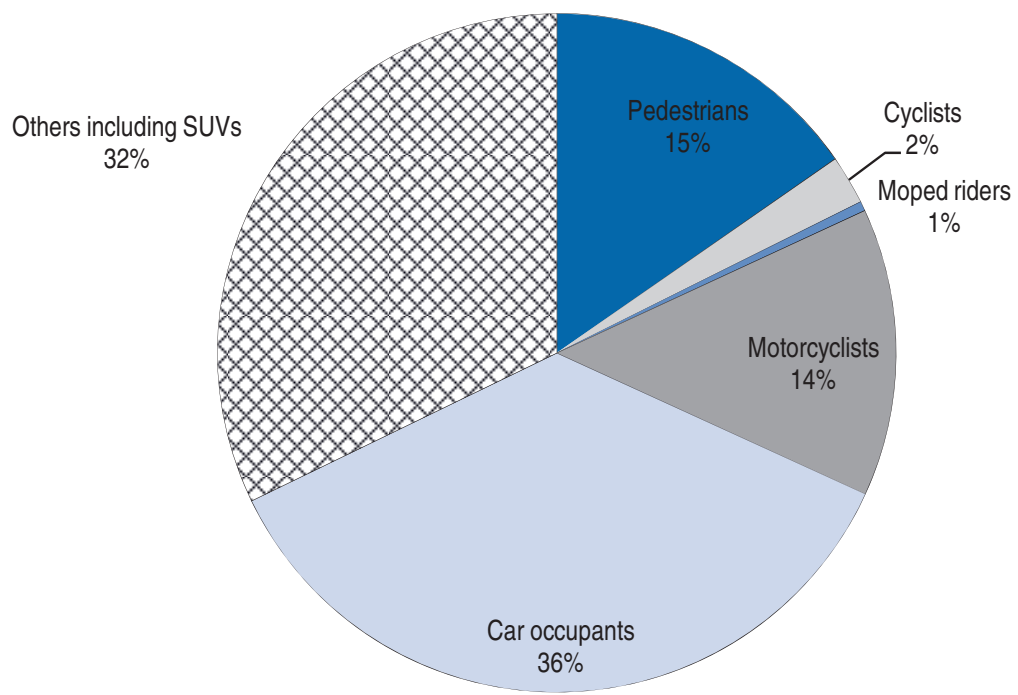

\section{Road safety by age group}

Since 1990, safety improvements have benefited all age groups, but the improvement was more marked for young people up to the age of 20 than for older age groups. The Department of Transportation has been working diligently to address the safety risk of young drivers. This group, lacking experience that is acquired only over time, often poses a greater safety risk on the road. However, over the years, with the attention to young drivers and the introduction of graduated driver licensing, fatalities associated with young drivers have decreased.

In 2015 the increase in fatalities affected nearly all age groups. Only in the 75-84 age group did the number of fatalities remain stable. The largest increase was observed in the 65-74 age group. Since 2010, the number of road fatalities in this group increased by $30 \%$, partly explained by the demographic evolution

Table 40.3. Road fatalities by age group

\begin{tabular}{|c|c|c|c|c|c|c|c|c|c|}
\hline \multirow{2}{*}{ Age } & \multirow{2}{*}{1990} & \multirow{2}{*}{2000} & \multirow{2}{*}{2010} & \multirow{2}{*}{2014} & \multirow{2}{*}{2015} & \multicolumn{4}{|c|}{$2015 \%$ change from } \\
\hline & & & & & & 2014 & 2010 & 2000 & 1990 \\
\hline $0-14$ & 2878 & 2363 & 1211 & 1073 & 1132 & 5.5 & -6.5 & -52.1 & -60.7 \\
\hline $15-17$ & 2744 & 2467 & 1216 & 986 & 1060 & 7.5 & -12.8 & -57.0 & -61.4 \\
\hline $18-20$ & 4564 & 3967 & 2449 & 2204 & 2251 & 2.1 & -8.1 & -43.3 & -50.7 \\
\hline $21-24$ & 5049 & 4061 & 3340 & 3297 & 3415 & 3.6 & 2.2 & -15.9 & -32.4 \\
\hline $25-64$ & 22812 & 22267 & 19213 & 19377 & 20976 & 8.3 & 9.2 & -5.8 & -8.0 \\
\hline $65-74$ & & 2809 & 2396 & 2750 & 3115 & 13.3 & 30.0 & 10.9 & \\
\hline $75-84$ & & 2829 & 2086 & 1986 & 1985 & -0.1 & -4.8 & -29.8 & \\
\hline$\geq 85$ & & 1063 & 1042 & 990 & 1065 & 7.6 & 2.2 & 0.2 & \\
\hline Total & 44599 & 41945 & 32999 & 32744 & 35092 & 7.2 & 6.3 & -16.3 & -21.3 \\
\hline
\end{tabular}


Figure 40.3. Road fatality rates by age group

\section{Deaths per 100000 inhabitants in a given age group, 1990-2015}

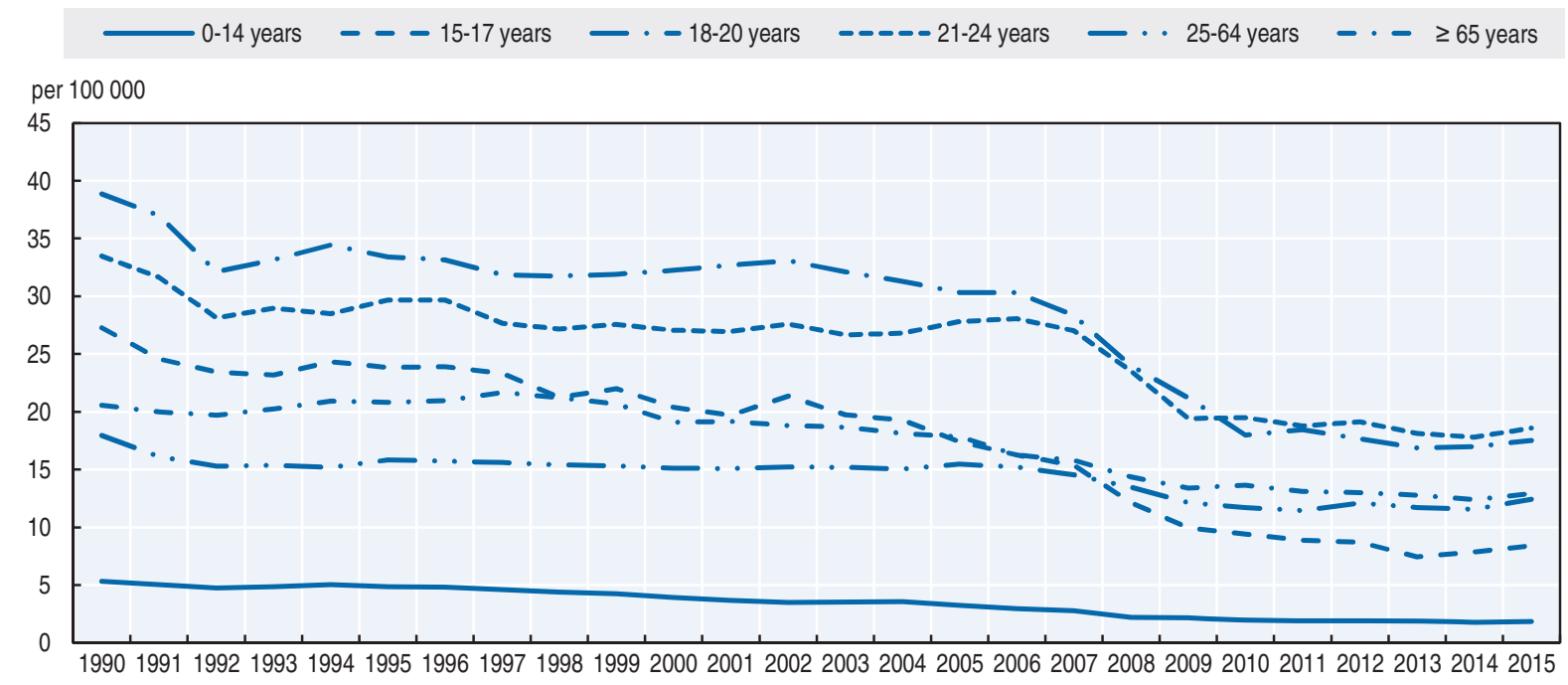

\section{Box 40.1. Road safety for an ageing population}

The 65 and over age group made up 15\% of the population in 2015. Between 2006 and 2015 the number of older people in the U.S. increased by $29 \%$, while the total population increased by $8 \%$. Thus, a larger percentage of the population is in this age group than a decade ago (12\% in 2006 to $15 \%$ in 2015). There were 40.1 million licensed older drivers in 2015, a 33\% increase from 10 years earlier (2006). In contrast, the total number of licensed drivers in the United States increased by $8 \%$ from 2006 to 2015 . Older drivers made up $18 \%$ of all licensed drivers in 2015, compared to $15 \%$ in 2006.

Over the past 10 years $4 \%$ more people were killed in crashes involving older drivers - from 6334 in 2006 to 6608 in 2015. While the annual numbers of people killed in these crashes over the last 10 years has varied, there was an increase of $9 \%$ between 2014 and 2015. This increase in one year accounts for a large portion of the increases over the last decade. Motorcyclist fatalities, though a relatively small number, increased by $142 \%$.

Among drivers involved in fatal crashes in 2015, drivers 65 and older had a lower involvement rate per 100000 licensed drivers than any other age group.

In 2015 among the older population the fatality rate for the 85 and older age group was 16.94 per 100000 population, which was higher than any other older age group.

The elderly are particularly vulnerable as vehicle occupants, and not so much as pedestrians, reflecting the fact that older people walk less than in other countries.

More information can be found in NHTSA Traffic safety facts on the Older Population (NHTSA, 2017): https://crashstats.nhtsa.dot.gov/Api/Public/ViewPublication/812372 (accessed 27 June 2017).

Due to increased physical impairments that many drivers face as they age, most states have enacted legislation that places additional restrictions or requirements on older drivers. These laws include license renewal requirements, accelerated license renewal terms, and testing mandates. Medical Advisory Boards are addressed, as well. Detailed information can be found at www.nhtsa.gov/road-safety/older-drivers (accessed 30 June 2017). 
Box 40.1. Road safety for an ageing population (cont.)

Table 40.4. Road fatalities among senior citizens

\begin{tabular}{lrrr|rrr|rrr}
\hline & \multicolumn{3}{c}{$65-74$} & \multicolumn{3}{c|}{$75-84$} & \multicolumn{3}{c}{$85+$} \\
\cline { 2 - 9 } & 2010 & 2015 & \% change & 2010 & 2015 & $\%$ change & 2010 & 2015 & $\%$ change \\
\hline Pedestrians & 368 & 520 & 41 & 327 & 312 & -5 & 139 & 170 & 22 \\
Cyclists & 44 & 76 & 73 & 21 & 21 & 0 & 2 & 5 & + \\
Moped riders & 11 & 13 & 18 & 2 & 4 & + & 0 & 3 & + \\
Motorcyclists & 213 & 344 & 62 & 49 & 45 & -8 & 6 & 7 & + \\
Car occupants & 891 & 1015 & 14 & 1079 & 904 & -16 & 690 & 607 & -12 \\
Total & $\mathbf{2 3 9 6}$ & $\mathbf{3 1 1 5}$ & $\mathbf{3 0}$ & $\mathbf{2 0 8 6}$ & $\mathbf{1 9 8 5}$ & $\mathbf{- 5}$ & $\mathbf{1 0 4 2}$ & $\mathbf{1 0 6 5}$ & $\mathbf{2}$ \\
\hline
\end{tabular}

Figure 40.4. Road fatality rates in the $65+$ age groups Deaths per 100000 inhabitants in a given age group, 2000-15

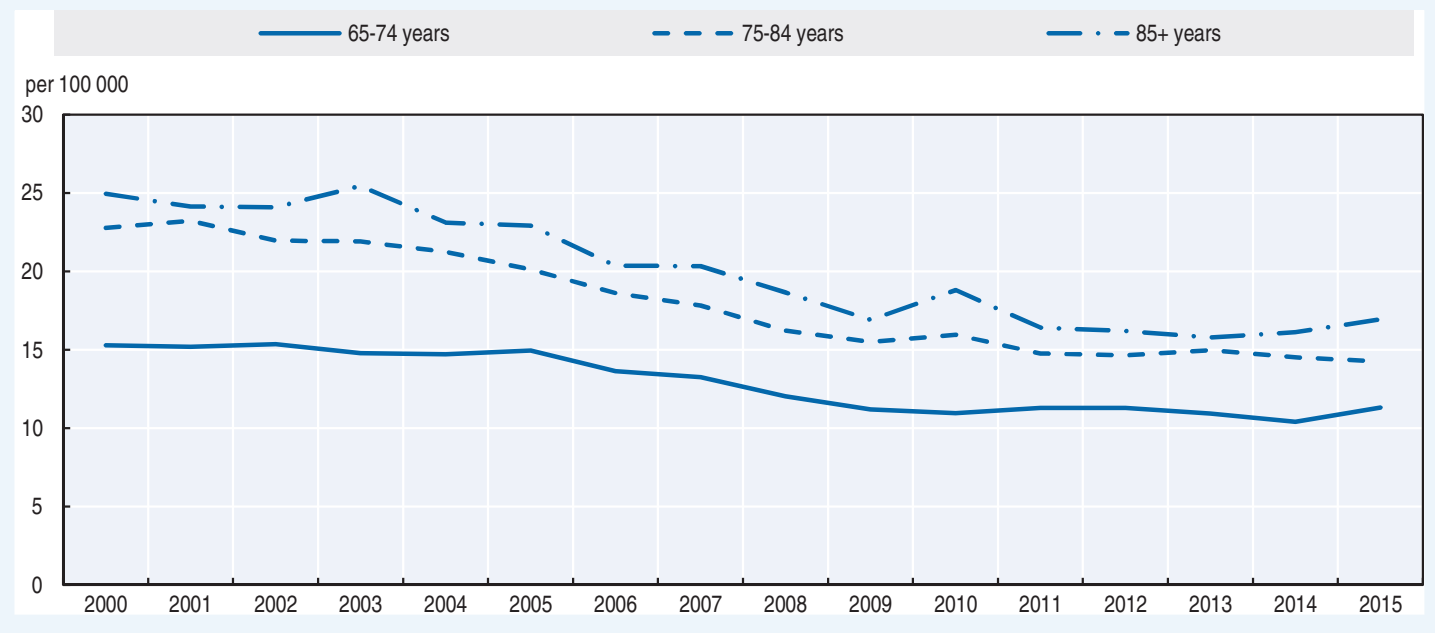

Figure 40.5. Road fatality rate by age and road user group Fatalities per 100000 inhabitants, 2015

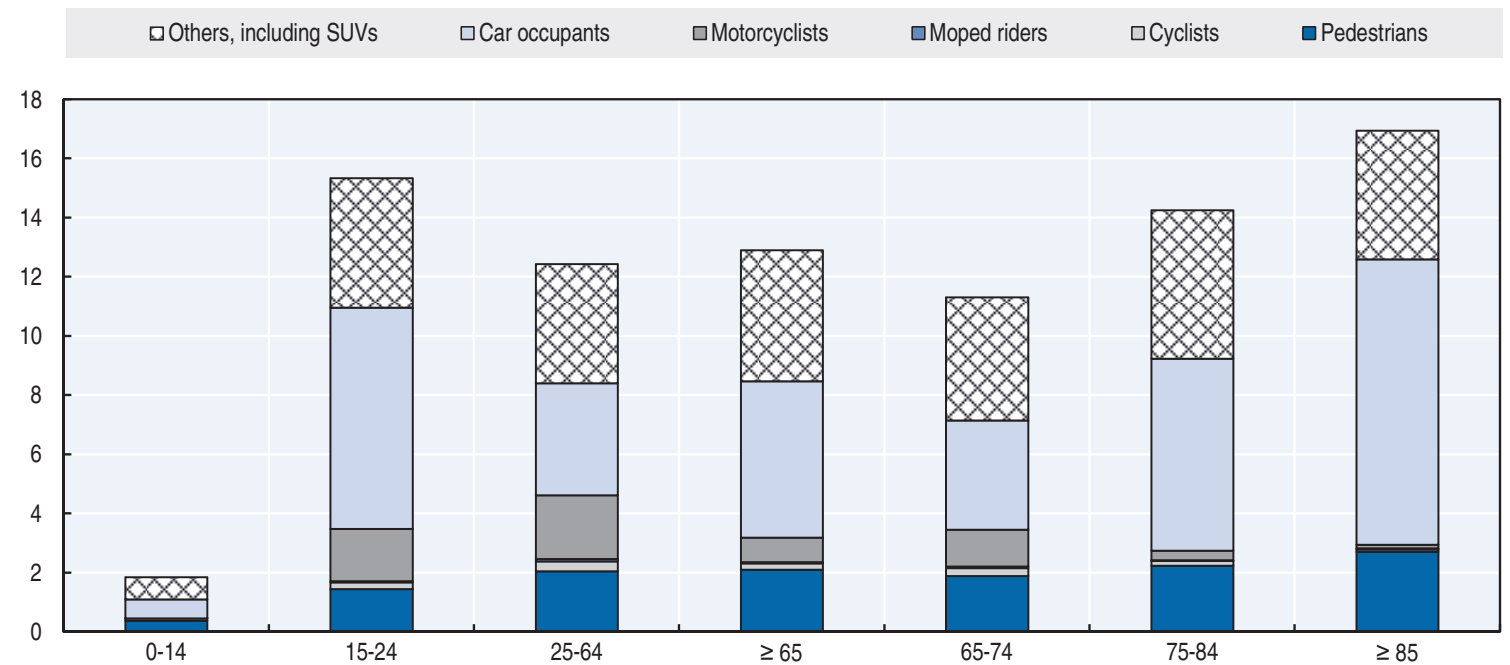




\section{Road safety by road type}

In 2015 , less than half of fatalities occurred on rural roads. The number of fatalities on rural roads decreased from 14886 in 2014 to 14241 in 2015. There were 4342 fatalities on motorways in the United States in 2015. This percentage has not changed from 2014 (12\%).

Figure 40.6. Road fatalities by road type

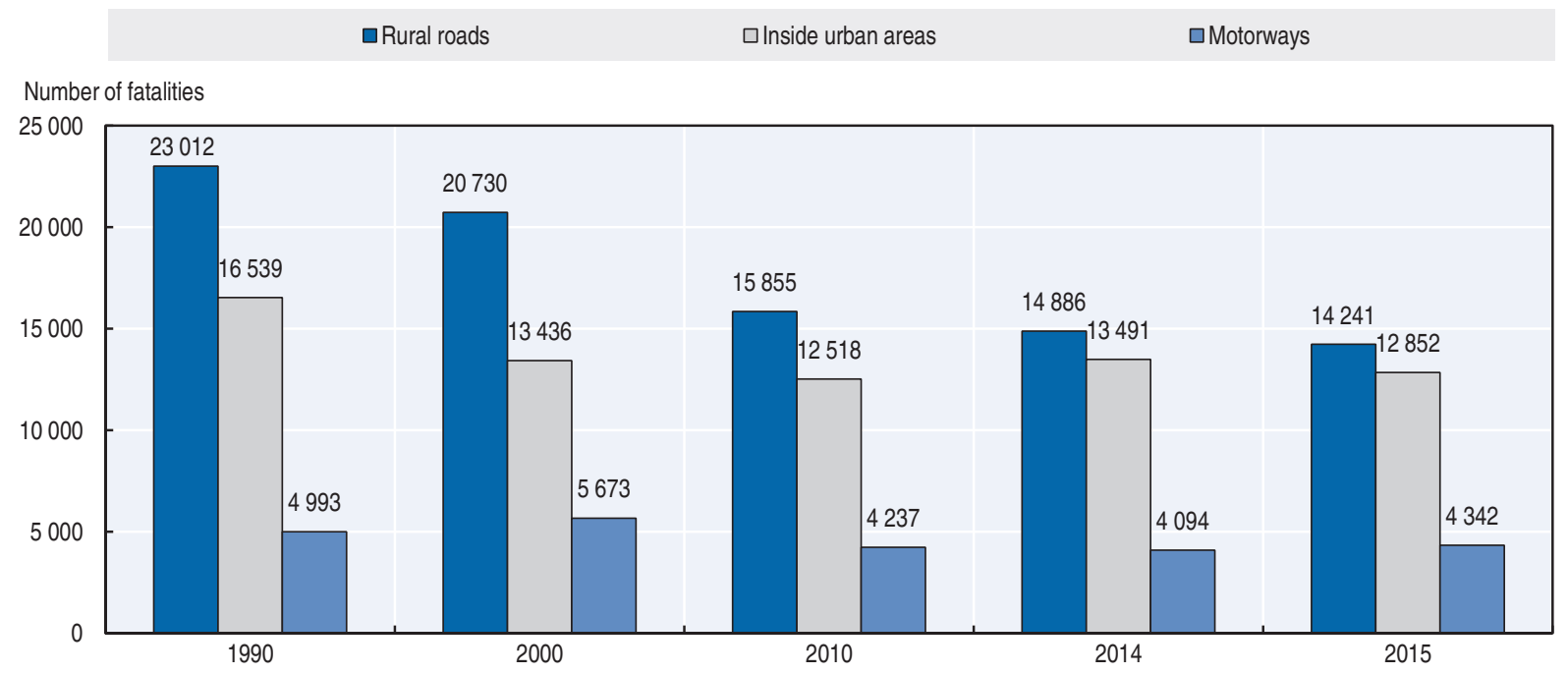

\section{Economic costs of traffic crashes}

Based on a recent study published in 2014 (NHTSA, 2014), the economic costs of traffic crashes totalled USD 242 billion in 2010, representing 1.6\% of the GDP of the United States. This represents the value of lifetime economic costs for 32999 fatalities, 3.9 million non-fatal injuries, and 24 million damaged vehicles. This figure includes both police-reported and unreported crashes. When quality of life valuations are considered, the total value of societal harm from motor vehicle crashes in 2010 was USD 836 billion, nearly $6 \%$ of GDP.

Cost components include productivity losses, property damage, medical costs, rehabilitation costs, congestion costs, legal and court costs, emergency services such as medical, police, and fire services, insurance administration costs, and costs to employers.

Table 40.5. Costs of road crashes, $\mathbf{2 0 1 0}$

\begin{tabular}{lcc}
\hline Type of crashes & Economic cost & Comprehensive cost \\
\hline Total & USD 242.0 billion & USD 835.8 billion \\
Alcohol impaired & USD 44.0 billion & USD 201.1 billion \\
Speeding & USD 52.0 billion & USD203.2 billion \\
Motorcycle crashes & USD 12.9 billion & USD 65.7 billion \\
Helmet non-use & USD 1.2 billion & USD $\$ 7.6$ billion \\
Seat belt non-use & USD 10.4 billion & USD 68.6 billion \\
Pedestrian crashes & USD 11.5 billion & USD 65.0 billion \\
Cyclist crashes & USD 4.4 billion & USD 21.7 billion \\
\hline
\end{tabular}




\section{Recent trends in road user behaviour}

\section{Speed}

NHTSA considers a crash to be speed-related if the driver was charged with a speedrelated offense, or if an officer indicated that racing, driving too fast for conditions, or exceeding the posted speed limit was a contributing factor in the crash.

Speeding is one of the most prevalent factors contributing to traffic crashes. In 2015, speed was a contributing factor in $27 \%$ of all fatal crashes. Fatalities in speed-related crashes increased by 3\%, from 9283 to 9557.

Speed limits in the United States are set by each state. The table below summarises speed limit ranges in the United States.

Table 40.6. Passenger car speed limits by road type, 2017

\begin{tabular}{lcl}
\hline & General speed limit & \multicolumn{1}{c}{ Comments } \\
\hline Urban roads & $25 \mathrm{mph}$ & $\begin{array}{l}\text { Speed limits depend on the use of the road } \\
\text { and the size of the road as well as state discretion. }\end{array}$ \\
Rural roads & $25-55 \mathrm{mph}$ & \\
Motorways & $55-80 \mathrm{mph}$ & \\
\hline
\end{tabular}

\section{Drink driving}

All 50 states, the District of Columbia (D.C.) and Puerto Rico have enacted $0.8 \mathrm{~g} / 1$ blood alcohol content (BAC) laws that make it a criminal offence to drive with that level of alcohol. All 50 states have enacted zero tolerance laws (primarily laws at $0.2 \mathrm{~g} / \mathrm{l}$ or lower) that make it illegal for drivers under the age of 21 to have any detectable alcohol in their bodies.

An alcohol-impaired driving fatality is defined as a fatality in a crash involving a driver or motorcycle rider (operator) with a BAC of $0.8 \mathrm{~g} / \mathrm{dl}$ or greater. In 2015 , the number of fatalities in crashes involving an alcohol-impaired driver increased by 3.2\%, from 9943 to 10265 and accounted for $30 \%$ of 2015 overall fatalities. Light-truck van drivers showed the greatest percentage decrease in alcohol-impaired drivers involved in fatal crashes from 2014 to 2015, dropping 13\%. Passenger car drivers involved in alcohol-impaired driving crashes had the largest increase with 193 drivers (a 5\% increase), followed by SUV drivers (35 or $2.3 \%)$.

\section{Drugs and driving}

There is no federal law regarding driving under the influence of drugs. Drug laws are generally written to forbid driving with certain drugs in the system. However, not all states have drug laws. Given the differences in state collection and reporting of drug data, and the large amounts of missing data, NHTSA's data on drugs and crashes should be considered with care. Of those drivers involved in fatal crashes in 2015 (48 613 drivers), 36\% were tested for drugs and of those, $39 \%$ were reported as having drugs in their system at the time of the fatal crash.

\section{Distraction}

Distracted driving laws focus on the use of mobile electronic devices while driving. Each state sets its own laws regarding distracted driving. As of June 2017, 14 states and D.C. 
prohibit drivers from using hand-held mobile phones while driving. In 38 states and D.C., all mobile phone use is banned for novice drivers, and 47 states and D.C. ban text messaging for all drivers.

In 2015, fatalities in distraction affected crashes increased from 3197 to 3477 , representing $9.9 \%$ of all road fatalities.

The percentage of passenger vehicle drivers text messaging or visibly manipulating hand-held devices remained constant at 2.2\% in 2015 (NHTSA, 2016e). The percentage of drivers holding mobile phones to their ears while driving decreased from $4.3 \%$ in 2014 to $3.8 \%$ in 2015

\section{Sleepiness and fatigue}

For NHTSA, drowsy driving crashes are those in which the driver was reported, on official crash documents, as drowsy, sleepy, asleep or fatigued. NHTSA recognises the difficulty in collecting data regarding fatigue in crashes and offers these figures as the only known crash data regarding fatigue.

In 2015, 824 people lost their lives in crashes in which a driver was reported as drowsy at the time of the crash. This represents $2.3 \%$ of the fatalities in the year. This proportion has remained relatively consistent over time. In addition to those killed, an estimated 41000 people were injured in crashes involving a drowsy driver in 2015. A total of 90000 police-reported crashes throughout the year were estimated to be considered drowsy driving crashes.

\section{Seat belts and helmets}

Seat belt laws are divided into two categories: primary and secondary. Primary seat belt laws allow law enforcement officers to ticket a driver or passenger for not wearing a seat belt, without any other traffic offense taking place. Secondary seat belt laws state that law enforcement officers may issue a ticket for not wearing a seat belt only when there is another citable traffic infraction. As of May 2017, the seat belt law situation was as follow:

- 34 states, D.C., American Samoa, Guam, the Northern Mariana Islands, Puerto Rico and the Virgin Islands have primary seat belt laws for front seat occupants.

- 15 states have secondary laws. Secondary seat belt laws state that law enforcement officers may issue a ticket for not wearing a seat belt only when there is another citable traffic infraction. In many of these states, the law is primary for younger drivers and/or passengers.

- New Hampshire has enacted neither a primary nor a secondary seat belt law for adults, although the state does have a primary child passenger safety law that covers all drivers and passengers under 18.

- Rear seats: 28 states, D.C., Guam and the Northern Mariana Islands, have laws requiring belt use for all rear seat passengers. In 18 of these states, D.C. and 2 territories, the law is primary.

In 2016, seat belt use reached 90.1\% up from 88.5\% in 2015 (NHTSA, 2016b). Seat belt use has shown an increasing trend since 2000 , accompanied by a steady decline in the percentage of unrestrained passenger vehicle occupants killed during the daytime. Seat belt use continued to be higher in the states in which vehicle occupants can be pulled over solely for not using seat belts. 
For more information on seatbelt laws: www.ghsa.org/state-laws/issues/Seat-Belts (accessed 30 June 2017).

Child passenger restraint laws vary based on age, weight and height. Most laws use restrictions in stages, starting with infants in rear facing seats, moving to toddlers in forward facing child seats, and then older children using booster seats until they reach a size or age for using an adult belt. All 50 states and D.C. require child safety seats for infants and children fitting specific criteria, and all but two states require booster seats or other appropriate devices for children who have outgrown a child safety seat but are still too small to use an adult seat belt safely.

For more information on child restraint law: www.ghsa.org/state-laws/issues/ChildPassenger-Safety (accessed 30 June 2017).

Booster seat use among 4-7 year-old children was 44.5\% in 2015 (NHTSA, 2016d),

Table 40.7. Seat belt wearing rate by car occupancy and road type

$\%$

\begin{tabular}{lcccc}
\hline & 2000 & 2010 & 2015 & 2016 \\
\hline All occupants & & 85 & 88.5 & 90.1 \\
Front seat & & & & \\
$\quad$ General (driver + passengers) & 71 & 85 & 88.5 & 90.1 \\
$\quad$ Driver & 72 & 86 & 88.9 & 90.5 \\
$\quad$ Passenger & 68 & 83 & 86.8 & 88.6 \\
Rear seats & & & & \\
$\quad$ General & $\mathrm{n} / \mathrm{a}$ & $74 \%$ & $\mathrm{n} / \mathrm{a}$ & \\
\hline
\end{tabular}

Currently, about half the states require helmets for all motorcyclists. Most other states require helmets for certain riders, and a few have no helmet law. The Global Health Security Agenda (GHSA) urges all states to adopt a universal motorcycle helmet law and vigorously enforce existing laws. As of May 2017, the situation regarding motorcycle helmet law was as follow:

- 47 states, D.C., Guam, the Northern Mariana Islands, Puerto Rico and the U.S. Virgin Islands have a helmet law for motorcyclists.

- 19 states, D.C., the Northern Mariana Islands, Puerto Rico and the U.S. Virgin Islands have a universal helmet law, requiring helmets for all riders.

- The remaining 28 states and Guam require helmets for specific riders.

- 3 states (Illinois, Iowa and New Hampshire) do not have a motorcycle helmet law.

For more information on helmet laws: www.ghsa.org/state-laws/issues/motorcyclists (accessed 30 June 2017).

In 2016, the average wearing rate of a DOT-compliant motorcycle helmet meeting DOT safety standard FMVSS218 was $65.3 \%$. Use of non-compliant helmets was $8.6 \%$ (a decrease when compared to 2015) and $26.1 \%$ had no helmet. Among states with universal helmet laws, $79.6 \%$ were wearing DOT-compliant helmets with an additional $14.9 \%$ wearing non-DOT-compliant helmets. In states without universal helmet laws, 53.5\% were wearing DOT-compliant helmets and an additional 3.5\% were wearing non-compliant helmets (NHTSA, 2016c).

Overall the helmet usage in the United States is much lower than in most other OECD countries. 


\section{National road safety strategies and targets \\ Organisation of road safety}

The United States uses a "federalism" approach that divides the powers of government between the national (federal) government and state and local governments. Under federalism, each level of government has sovereignty in some areas and shares power in others. At the national level, Congress passes the laws and assigns the funding that provides the overall structure for the DOT to carry out its safety mission. However, most traffic safety laws and policies are enacted and developed at the state level. For example, each of the 50 states, D.C. and Puerto Rico have the authority to set their own speed limits, distracted driving rules, or seat belt use law.

Congress can influence the states by providing incentive grants if they enact certain laws that have been proven effective or penalties if they do not. It can also use performance results as eligibility criteria for grants in some cases. The DOT implements the grant programmes and provides guidance to the states on developing effective strategies that address their particular traffic safety challenges.

Within DOT, NHTSA has the lead role in reducing traffic crashes and fatalities.

In 2010, DOT designated reducing roadway fatalities as one of its high-priority performance goals. Three agencies, the NHTSA, the Federal Highway Administration (FHWA), and the Federal Motor Carrier Safety Administration (FMCSA), work together to address multiple dimensions of roadway safety.

\section{Road safety strategy for 2011-20}

The number one priority of DOT remains safety.

To align the programme and policy actions, DOT has established four fatality sub measures: passenger vehicles, non-occupants, motorcycle riders, and heavy goods vehicle or bus-related fatalities. The purpose of this approach is to more closely examine fatality rates of the different segments of highway users, focus the energy and resources involved and develop new strategies to reduce fatalities in each of the four areas.

\section{Road safety targets}

The DOT currently has performance targets to 2016 for the overall fatality rate and NHTSA and FMCSA have performance targets for each of the four sub measures. For 2016, DOT's overall motor vehicle crash fatality rate target is 1.02 fatalities per 100 million VMT. The sub-measure targets for 2016 are 0.15 fatalities per 100 million VMT for the nonoccupant fatality rate, 62 fatalities per 100000 registrations for the motorcyclist fatality rate, 0.82 fatalities per 100 million VMT for the passenger vehicle fatality rate, and the large vehicle and bus fatality rate for 2016 is 0.114 fatalities per 100 million VMT.

The fatality rates are forecast through statistical methods for a number of years into the future in order to guide a plan of action for safety countermeasures. These forecasts use historical data combined with an evaluation of the existing countermeasures, trend data, and other societal factors that may affect fatality rates in the future.

Starting in 2016, NHTSA changed its non-occupant fatality measure (pedestrians and cyclists) from a rate of fatalities per 100 million vehicle miles travelled (VMT) to per 100000 population.

The fatality rate per 100 million VMT increased from 1.08 in 2014 to 1.13 in 2015. 
Figure 40.7. Trends in road fatalities towards national target

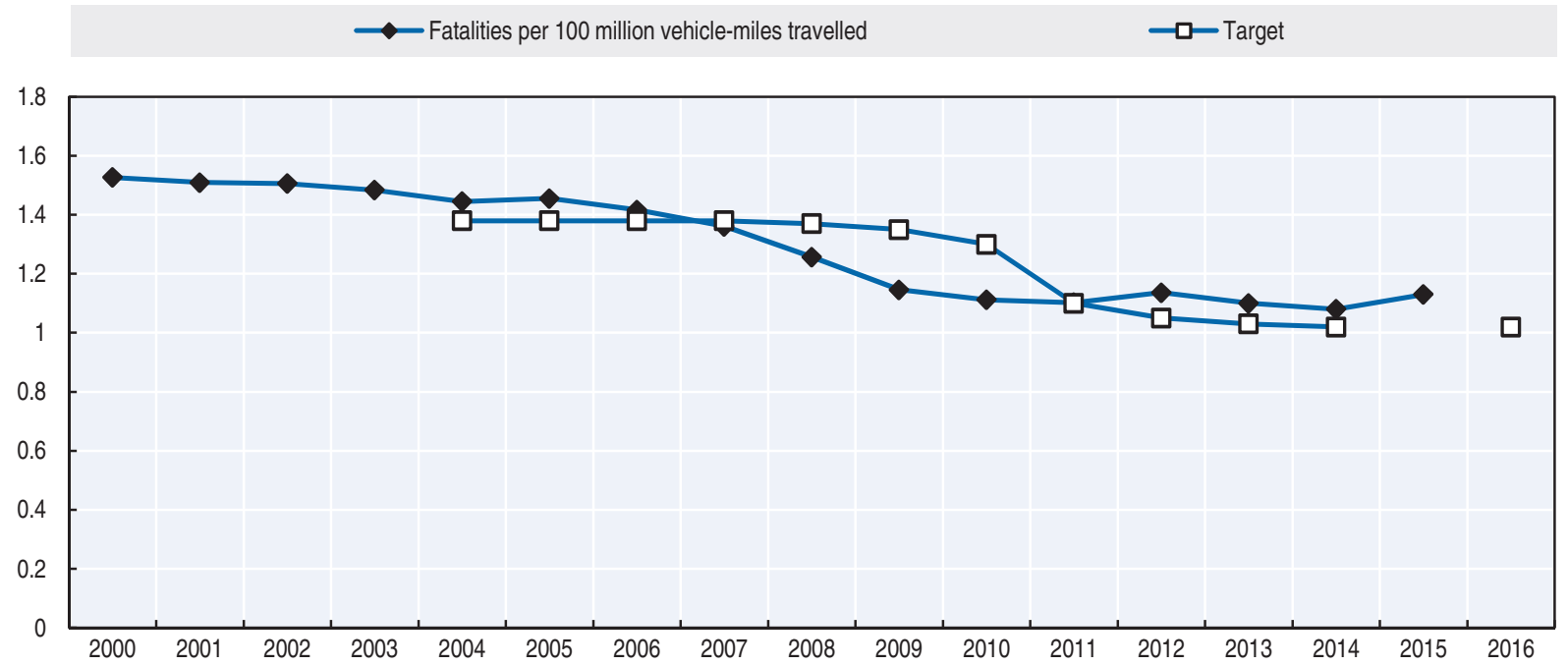

\section{Recent safety measures (2014-17)}

\section{Road safety management}

- In 2016, NHTSA focused its efforts in three major areas this year: proactive vehicle safety, automated vehicle technology and long-term planning for the road to zero fatalities. Diversified public outreach was an integral part of these initiatives. NHTSA held public hearings and forums around the nation in an effort to engage traditional and nontraditional stakeholders to make innovative changes to highway safety: two public hearings on proposed enhancements to the 5-Star Safety Rating programme, two public meetings on the development of federal automated vehicle policies, a forum on drowsy driving, a cybersecurity roundtable, and six regional forums on behavioural safety.

- The behavioural safety events culminated with a final summit in October 2016 to lay out a roadmap on the road toward zero fatalities over the next 30 years.

- The USDOT has pledged up to USD 40 million to one city to help it define what it means to be a "Smart City" and become the country's first city to fully integrate innovative technologies - self-driving cars, connected vehicles, and smart sensors - into their transportation network. See more at: www.transportation.gov/smartcity (accessed 30 June 2017).

- The USDOT has launched the Department's Safer People, Safer Streets Initiative. Over the course of the next year and a half, the Department will be doing more to address non-motorised safety issues and help communities create safer, better connected cycling and walking networks. See more at: www.transportation.gov/safer-people-saferstreets (accessed 30 June 2017)

\section{Road users}

\section{Human behaviour}

- NHTSA released a Drowsy Driving Research and Program Plan in 2016. See: www.nhtsa. gov/sites/nhtsa.dot.gou/files/drowsydriving_strategicplan_030316.pdf (accessed 30 June 2017). "ChORUS" - A Clearinghouse for Older Road Users, is a comprehensive and dynamic 
source of information on traffic safety for older drivers, pedestrians, and cyclists which was also developed. See: www.roadsafeseniors.org/ (accessed 30 June 2017). The agency also held an expert panel meeting in partnership with Harvard's School of Public Health to explore the feasibility of research projects focusing on the role situational awareness in crashes.

\section{Vehicles}

- Advances in automated vehicle technology continue to accelerate at an astounding pace. In September 2016, NHTSA released a major new policy on automated vehicles that sets the framework and pathway for the safe testing and deployment of these new technologies that have enormous potential for improving safety and mobility. NHTSA also secured a groundbreaking commitment from 20 automakers in March 2016 to make automatic emergency braking (AEB) technology a standard feature on new vehicles by 2022, and on heavier trucks by 2025.

- NHTSA finalised new motor vehicle standards for medium and heavy-duty vehicles to improve fuel efficiency. The agency proposed equipping large commercial vehicles with speed limiters, a safety measure that could save lives and more than USD 1 billion in fuel costs each year. NHTSA also announced a new direction on school bus safety supporting the installation of three-point seat belts on school buses.

- NHTSA launched a first ever national recall campaign, Safe Cars Save Lives, to provide consumers with information on vehicle safety helping them make more informed purchasing decisions and to improve recall completion rates. The campaign includes online advertising that directs consumers to a dedicated web site that makes it easy for them to check their vehicle for recalls. While NHTSA will continue to hold manufacturers accountable for identifying and addressing defects in a timely manner (the agency imposed more than USD 450 million in penalties on vehicle and equipment makers in 2016), the agency recognises that real safety is identifying risks and providing remedies before a tragedy occurs in the first place.

- Toward that end, NHTSA developed the Proactive Safety Principles in 2016. This historic agreement between USDOT and 18 automakers includes a set of principles that provide a framework to help the industry build a culture of proactive safety, improve data analysis, maximise safety recall participation rates and enhance cybersecurity, while working in a collaborative manner. Complementing the Principles, NHTSA organised a Safety Stand-down Day, a unique one-day forum that gathered leaders from the Federal Aviation Administration (FAA), which is a sister agency of NHTSA, and the aviation and auto industries to discuss how safety lessons learned from aviation could be applied to the auto industry to encourage collaboration on safety.

- Vehicle safety: NHTSA released a proposal to strengthen its 5-Star Safety Ratings programme by adding an additional crash test that measures how well a vehicle protects occupants in an angled frontal crash, and by developing new crash test dummies. The changes will also encompass rating vehicles on new crash-avoidance advanced technologies, and how well vehicles protect pedestrians in a crash: www.safercar.gov/ 5Stars (accessed 30 June 2017).

- NHTSA and the Insurance Institute for Highway Safety (IIHS) announced on 17 March 2016 a historic commitment by 20 car manufacturers representing more than $99 \%$ of the US car market to make automatic emergency braking (AEB) a standard feature on 
virtually all new cars no later than 2022. NHTSA estimates that the agreement will make AEB standard on new cars three years faster than could be achieved through the formal regulatory process. During those three years, according to IIHS estimates, the commitment will prevent 28000 crashes and 12000 injuries.

\section{Roadway and infrastructure}

- Infrastructure safety: FHWA expanded its "Road Diet" technical assistance resources and workshops to States. The primary benefits of a Road Diet include enhanced safety, mobility and access for all road users and a "complete streets" environment to better accommodate a variety of transportation modes: http://safety.fhwa.dot.gov/road_diets/ (accessed 30 June 2017).

USDOT's Federal Highway Administration has several programmes to address safety on different road types as well as intersection, pedestrian and cyclist safety. Some of the programmes are:

- Highway Safety Improvement Program: http://safety.fhwa.dot.gov/hsip/ (accessed 30 June 2017).

- Intersection Safety: http://safety.fhwa.dot.gou/intersection/ (accessed 30 June 2017).

- Roadway Departure Safety: http://safety.fhwa.dot.gov/roadway_dept/ (accessed 30 June 2017).

- Pedestrian and Bicycle Safety: http://safety.fhwa.dot.gov/ped_bike/ (accessed 30 June 2017).

- Local and Rural Road Safety Program: http://safety.fhwa.dot.gov/local_rural/ (accessed 30 June 2017).

\section{Recent and ongoing research}

- NHTSA released a Drowsy Driving Research and Program Plan in 2016. See: www.nhtsa. gov/staticfiles/nti/pdf/DrowsyDriving_StrategicPlan_030316.pdf (accessed 30 June 2017).

- "ChORUS" - A Clearinghouse for Older Road Users: a comprehensive and dynamic source of information on traffic safety for older drivers, pedestrians, and cyclists www.roadsafe seniors.org/ (accessed 30 June 2017).

\section{References}

NHTSA (2016a), 2015 Motor Vehicle Crashes: Overview, NHTSA, Washington, DC, https://crashstats.nhtsa. dot.gov/Api/Public/ViewPublication/812318 (accessed 30 June 2017).

NHTSA (2016b), Seat Belt Use in 2016 - Overall Results, NHTSA, Washington, DC, https://crashstats.nhtsa. dot.gov/Api/Public/ViewPublication/812351?_ga=1.130211079.923985568.1492078308 (accessed 30 June 2017).

NHTSA (2016c), Motorcycle Helmet Use in 2015 - Overall Results, NHTSA, Washington, DC, https://crashstats. nhtsa.dot.gov/Api/Public/ViewPublication/812275 (accessed 30 June 2017).

NHTSA (2016d), The 2015 National Survey of the Use of Booster Seats, NHTSA, Washington, DC, https:// crashstats.nhtsa.dot.gov/Api/Public/ViewPublication/812309 (accessed 30 June 2017).

NHTSA (2016e), Driver Electronic Device Use in 2015, NHTSA, Washington DC, https://crashstats.nhtsa.dot. gou/Api/Public/ViewPublication/812326 (accessed 30 June 2017).

NHTSA (2015), Lives saved by vehicle safety and associated Federal Motor Vehicle Safety Standards, 1960 to 2012, Department of Transportation, Washington, DC, www-nrd.nhtsa.dot.gov/Pubs/812069.pdf (accessed 30 June 2017).

NHTSA (2014), The Economic and Societal Impact of Motor Vehicle Crashes, 2010, NHTSA, Washington, DC, www-nrd.nhtsa.dot.gov/pubs/812013.pdf (accessed 30 June 2017). 
World Bank (2017), “GDP (constant US\$)”, World Development Indicators, http://databank.worldbank.org/ data/reports.aspx?source=world-development-indicators (accessed 23 February 2017).

\section{Websites}

- National Highway Traffic Safety Administration: www.nhtsa.gov (accessed 30 June 2017).

- NHTSA Office of Vehicle Safety Research: www.nhtsa.gov/Research (accessed 30 June 2017). 



\section{Chapter 41}

\section{Uruguay}

This chapter presents 2015 and 2016 road safety data for Uruguay. It looks at trends in traffic and road safety from the years 1990 to 2015 and road user behaviour patterns with a special focus on the ageing population. Sections include data on speed, drink driving, drugs and driving, distracted driving, fatigue and seat belt usage. The chapter reviews Uruguay's road safety strategy and national targets to 2020 and the progress achieved thus far. It also provides details of all recently implemented safety measures and current and ongoing research. ${ }^{*}$

* All data stem from UNASEV. Data have not been validated by IRTAD. For more information please contact: rcaudullo@presidencia.gub.uy. 
$\mathrm{U}$ ruguay, with its population of 3.4 million, has seen a steady decreasing trend in road deaths since 2011, reaching a new low in 2016 of 446 fatalities, a reduction of 11.8\% over 2015. Approximately half of all fatalities are motorcyclists, partly explained by constant expansion of the vehicle fleet, in particular powered two-wheelers which account for $53 \%$ of registered vehicles. Uruguay had a fatality rate of 12.8 per 100000 inhabitants in 2016 and since 2011 has adopted a new road safety strategy in line with the UN Decade of Action for Road Safety.

\section{Road safety data collection}

\section{Definitions applied in Uruguay}

- Road fatality: Person who died immediately or dying within 30 days as a result of a road crash.

- Serious injury: There is no definition for a serious or slight injury. The severity of an injury is determined based on primary information collected at the scene of the crash by the medical doctor who classifies the injury as "severe" or "not severe".

Uruguay does not use the Maximum Abbreviated Injury Scale to classify injuries.

\section{Data collection}

SINATRAN is the National Traffic Information System in use since 2011.

Information on crash data comes from the Public Security Management System of the Ministry of the Interior and is transmitted to SINATRAN for analysis.

Information covers all injury crashes that have occurred on the national territory since 2011 and is available within 24 hours after the crash, with its geolocation.

The national registry of road crash injuries (LESITRAN) is currently under development. It will provide more details on the injuries. Unlike police reports, LESITRAN will collect data from ambulances sent to the scene of a crash.

\section{Most recent safety data}

\section{Road crashes in 2016}

In 2016, there were 446 reported road deaths representing a reduction of $11.8 \%$ compared to 2015 . The mortality rate was 12.8 road deaths per 100000 inhabitants representing a $12.3 \%$ decrease compared to 2015. Some key findings include:

- $70 \%$ of all road deaths were male.

- $46 \%$ of road fatalities were motorcyclists.

- $43 \%$ of road deaths were young and aged between 15 and 39 years. Almost half of the motorcyclists killed were young people between 15 and 29 years old.

\section{Road crashes in 2015}

In 2015, there were 506 road deaths representing a reduction of $5.9 \%$ when compared to 2014. The mortality rate was 14.6 road deaths per 100000 inhabitants. Some key findings include: 
- $80 \%$ of all road deaths were male.

- 256 motorcyclists killed, i.e., more than half of all road deaths.

- The share of older people killed in traffic increased from 12.3\% in 2014 to 15\% in 2015.

- $44 \%$ of people killed were young people aged between 15 and 39 years.

\section{Trends in traffic and road safety (2011-16)}

\section{Traffic}

The vehicle fleet in Uruguay has been in constant expansion since 2000. In 2016, there were 2.3 million registered motor vehicles, an increase of 157\% when compared with 2000 . In 2016, registered vehicles included motorcycles (53\%), light vehicles (43\%) and trucks and buses (3\%).

The motorcycle fleet is growing particularly fast. It represented $38 \%$ of the fleet in 2000 and $53 \%$ in 2016.

\section{Road safety}

\section{Crashes and casualties}

When SINATRAN was established in 2011, the number of road deaths peaked at 572. It has since followed a decreasing trend until 2016 when it reached its lowest level of 446, a reduction of $22 \%$ over the five-year period.

The first national traffic and safety law was enacted in 2007. The purpose of this law was to regulate the movement of pedestrians and vehicles, as well as road safety. The law focused on general traffic regulations, standards for traffic signs, active and passive safety equipment, the technical conditions of the vehicles, the administrative system to regulate the circulation of vehicles, the definition of traffic offences and of their penalties. As a result, important road safety measures were implemented.

In 2011, Uruguay adopted a new road safety strategy (2011-20), adhering to the UN Decade of Action for Road Safety.

\section{Rates}

In 2016, the mortality rate expressed in terms of deaths per 100000 inhabitants was of 12.8, the fatality risk expressed in terms of deaths per 10000 vehicles was 1.9.

Table 41.1. Road safety and traffic data

\begin{tabular}{|c|c|c|c|c|c|c|c|c|c|}
\hline & \multirow{2}{*}{1990} & \multirow{2}{*}{2000} & \multirow{2}{*}{2010} & \multirow{2}{*}{2014} & \multirow{2}{*}{2015} & \multirow{2}{*}{2016} & \multicolumn{3}{|c|}{$2016 \%$ change from } \\
\hline & & & & & & & 2015 & 2010 & 2000 \\
\hline \multicolumn{10}{|l|}{ Reported safety data } \\
\hline Fatalities & 475 & 542 & 556 & 538 & 506 & 446 & -5.9 & -9.0 & -17.7 \\
\hline Injury crashes & & & 23924 & 23422 & 23267 & 21243 & -0.7 & -2.7 & \\
\hline Injured persons hospitalised & & & & 4074 & 3657 & & -10.2 & & \\
\hline Deaths per 100000 inhabitants & & & 16.6 & 15.6 & 14.6 & 12.8 & -6.3 & -12.0 & \\
\hline Deaths per 10000 registered vehicles & & & 3.4 & 2.6 & 2.2 & 1.9 & -12.9 & -34.8 & \\
\hline \multicolumn{10}{|l|}{ Traffic data } \\
\hline Registered vehicles ${ }^{1}$ (thousands) & & & 1616 & 2088 & 2255 & 2342 & 3.9 & 44.9 & \\
\hline Registered vehicles per 1000 inhabitants & & & 482 & 605 & 650 & & & & \\
\hline
\end{tabular}

StatLink तiाsस $h$ ttp://dx.doi.org/10.1787/888933580973 
Figure 41.1. Road safety, traffic and GDP trends index $2011=100$

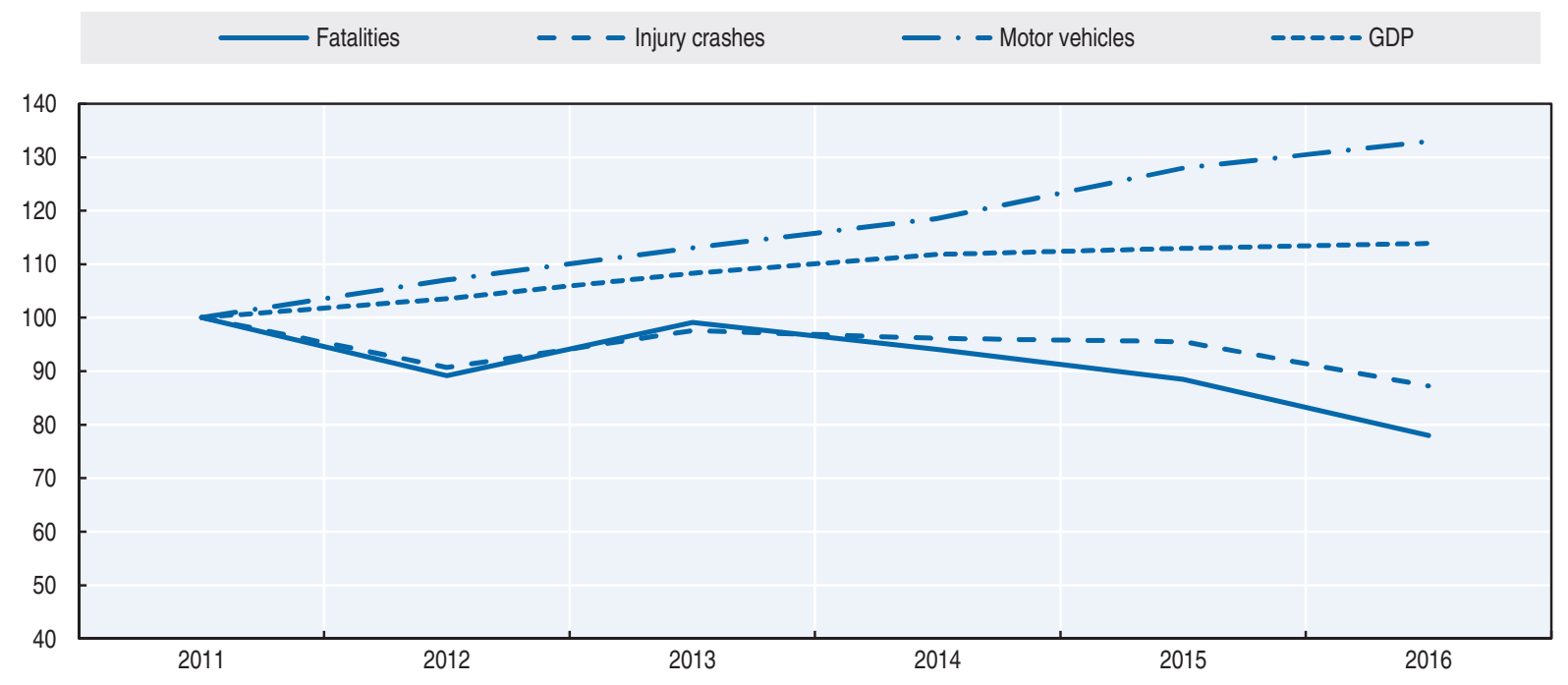

Source: World Bank (2017) (GDP; constant prices).

\section{Road safety by user group}

In 2015, motorcyclists represented 51\% of all road deaths. Almost 6 out of 10 motorcyclists who died in 2015 were under the age of 40, with a particular incidence for the age group 15 to 29 years old, who accounted for $21 \%$ of all road deaths.

Passenger car occupants are the second at-risk group and represented $25 \%$ of all road deaths in 2015.

There were 83 pedestrian deaths, with the over 60 age group representing nearly half of all pedestrians killed and a very high incidence for those over 70 years of age.

Since 2013, the reduction in the number of road deaths has benefited all users, except cyclists. The number of cyclists killed doubled between 2013 and 2015, partly reflecting an increase in the number of cyclists on the road. The increasing popularity of cycling is explained by multiple factors, among them: economic factors, healthy living and environmental protection.

Table 41.2. Road fatalities by road user group

\begin{tabular}{lrrr|rr}
\hline & 2013 & 2014 & 2015 & \multicolumn{2}{|c}{$2015 \%$ change from } \\
\cline { 4 - 5 } & & & 2014 & 2013 \\
\hline Pedestrians & 90 & 93 & 83 & -10.8 & -7.8 \\
Cyclists & 16 & 23 & 31 & 34.8 & 93.8 \\
Motorised two-wheelers & 299 & 275 & 256 & -6.9 & -14.4 \\
Car occupants & 147 & 137 & 124 & -9.5 & -15.6 \\
Others & 15 & 10 & 12 & 20.0 & -20.0 \\
Total & $\mathbf{5 6 7}$ & $\mathbf{5 3 8}$ & $\mathbf{5 0 6}$ & $\mathbf{- 5 . 9}$ & -10.8 \\
\hline
\end{tabular}


Figure 41.2. Road fatalities by road user group in percentage of total, 2015

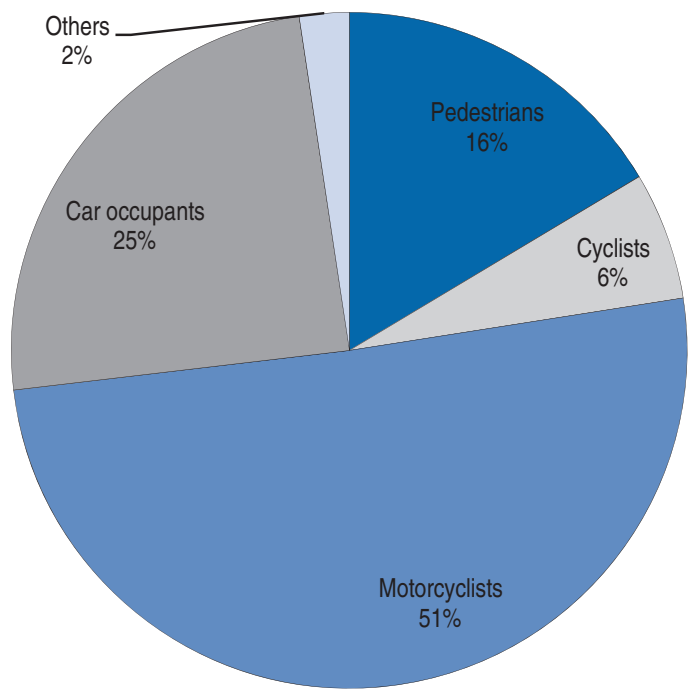

\section{Road safety by age group}

Young people are overrepresented in road crashes in Uruguay. In $2015,44 \%$ of road fatalities and $60 \%$ of casualties were young people aged between 15 and 39 years of age, while they represented $37 \%$ of the total population.

The 21-24 age group and those aged 70 and above have the highest risk in traffic with a mortality rate, respectively, of 26.0 and 25.0 road deaths per 100000 inhabitants, i.e. more than twice the risk of the average population.

Table 41.3. Road fatalities by age group

\begin{tabular}{lrrr|rr}
\hline \multirow{2}{*}{ Age } & 2013 & 2014 & 2015 & \multicolumn{2}{|c}{$2015 \%$ change from } \\
\cline { 4 - 5 } & & & 2014 & 2013 \\
\hline $0-14$ & 26 & 15 & 20 & 33.3 & -23.1 \\
$15-17$ & 22 & 21 & 11 & -47.6 & -50.0 \\
$18-20$ & 66 & 44 & 38 & -13.6 & -42.4 \\
$21-24$ & 35 & 49 & 54 & 10.2 & 54.3 \\
$25-64$ & 314 & 310 & 277 & -10.6 & -11.8 \\
$65-74$ & & 49 & & \\
$75-84$ & & 35 & & \\
$\geq 85$ & & 16 & & \\
Total & & 506 & & \\
\hline
\end{tabular}

\section{Road safety by road type}

In Uruguay, roads are classified as either "national routes" or "city and departmental roads".

Most of fatalities occur in urban and departmental roads. The proportion of deaths in traffic crashes in cities and on departmental roads has increased consecutively in the last 5 years, from $53 \%$ in 2011 to $62 \%$ in 2015 . 
Figure 41.3. Road fatality rates by age group

Deaths per 100000 inhabitants in a given age group, 2013-15

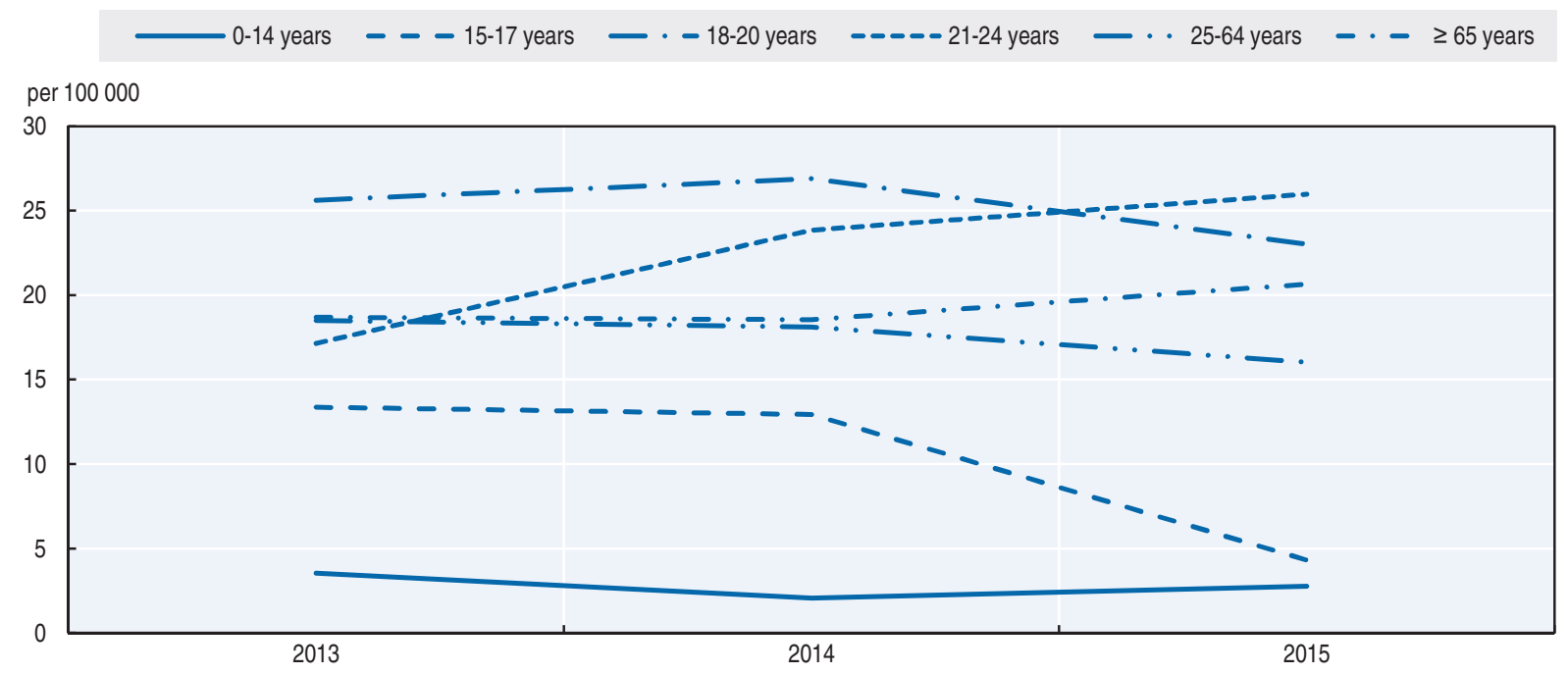

\section{Box 41.1. Road safety for an ageing population}

The number of people aged 65 and above is growing fast and is expected to increase by $70 \%$ between 2015 and 2050.

Senior citizens are particularly vulnerable as pedestrians. In 2015, persons aged 65 and above represented nearly half $(46 \%)$ of all pedestrians killed with a very high incidence for those over 70 years old, who represented one-third of all pedestrian fatalities.

The mortality rate increases with age, it is at 19.1, 21.4 and 25.0 deaths per 100000 inhabitants respectively for the age groups $65-74,75-84$ and 85 and above.

Table 41.4. Road fatalities among senior citizens 2015

\begin{tabular}{lccc}
\hline & $65-74$ & $75-84$ & $85+$ \\
\hline Pedestrians & 11 & 14 & 13 \\
Cyclists & 2 & 6 & 1 \\
Moped riders & & & \\
Motorcyclists & 18 & 4 & 1 \\
Car occupants & 17 & 11 & 1 \\
Total & $\mathbf{4 8}$ & $\mathbf{3 5}$ & $\mathbf{1 6}$ \\
\hline
\end{tabular}




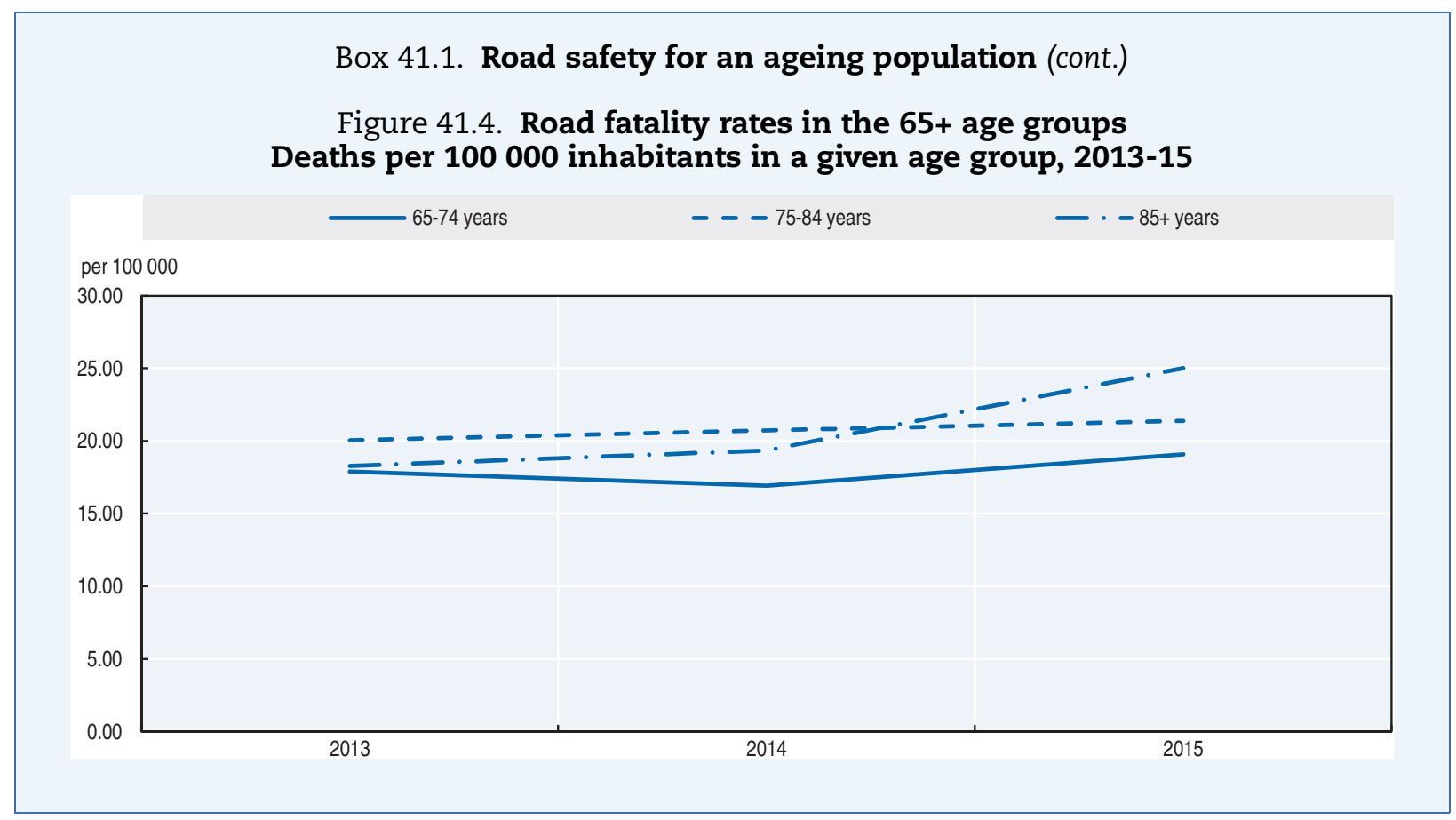

Figure 41.5. Road fatality rate by age and road user group Fatalities per 100000 inhabitants, 2015

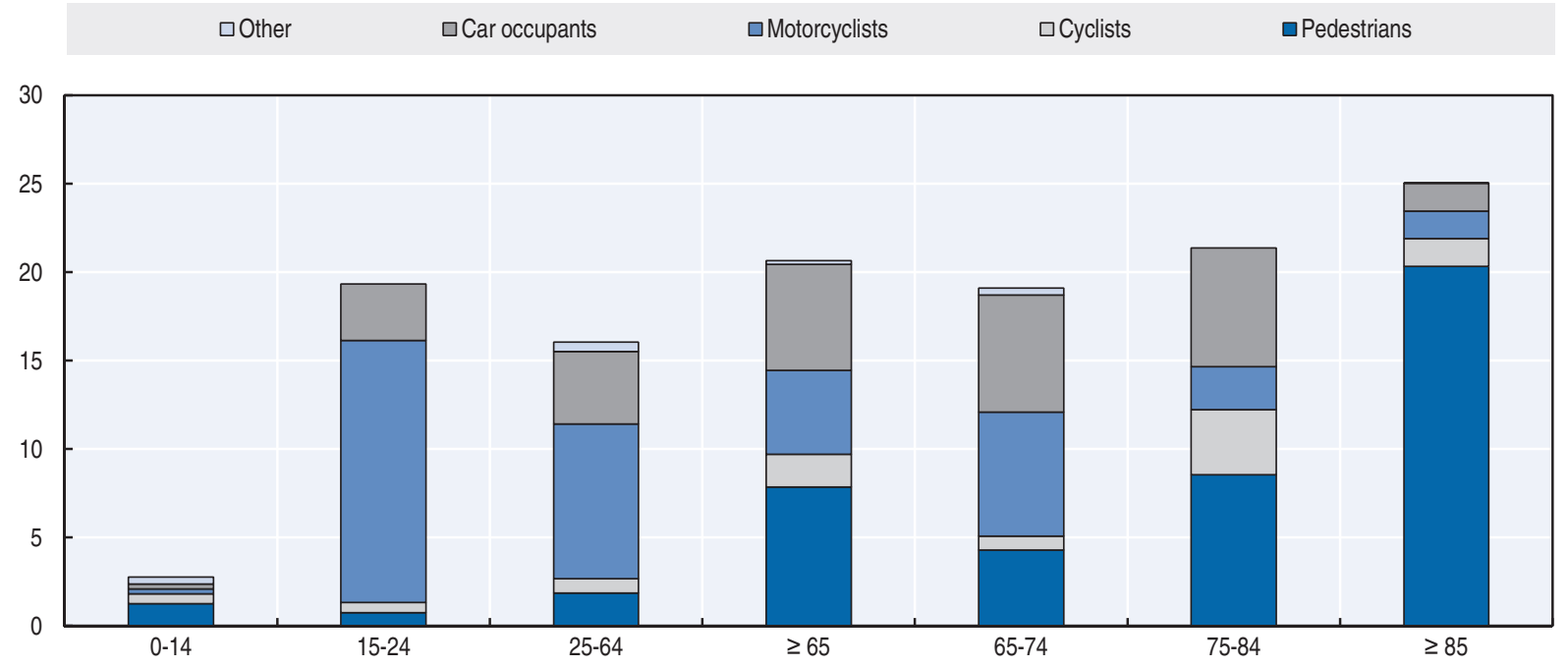

\section{Economic costs of traffic crashes}

As yet, there is no estimation for the economic costs of road crashes. A methodology to undertake this estimation is under development.

\section{Recent trends in road user behaviour}

Speed

The speed limits in Uruguay are summarised in the table below. 
Table 41.5. Passenger car speed limits by road type, 2017

\begin{tabular}{lc}
\hline & General speed limit \\
\hline Urban roads & $45 \mathrm{~km} / \mathrm{h}$ \\
Rural roads & $90 \mathrm{~km} / \mathrm{h}$ \\
Motorways & There are no motorways in Uruguay \\
\hline
\end{tabular}

Several initiatives are being undertaken to manage traffic and speed, in particular through the adoption of automatic speed control (see details in the section on recent measures).

\section{Drink driving}

Since January 2016, there had been a zero tolerance policy for drink driving in Uruguay. The maximum permissible blood alcohol content (BAC) is $0.0 \mathrm{~g} / \mathrm{l}$ for all drivers. The population is very much aware of the high risk of drinking and driving. A recent survey among 131500 persons revealed that $90 \%$ of the population is favourable of a zero tolerance policy for drink driving

A crash is classified as alcohol-related when any involved driver has a BAC above zero.

\section{Drugs and driving}

According to the law enacted in 2014, "every driver will be considered unfit to drive when the concentration of tetrahydrocannabinol (THC) in the body is above the permitted amount in accordance with the issued regulations".

\section{Seat belts and helmets}

Seat belt use has been compulsory since 2007.

Children under 12 are not allowed to be seated in the front seat, and a dedicated child restraint system is compulsory for children up to $150 \mathrm{~cm}$ and $36 \mathrm{~kg}$.

According to an observational study conducted in 2016 (UNASEV, 2016), the use of seat belts in the front seats of cars and vans was of $62.8 \%$ in 2016 , but only $33 \%$ in rear seats. At a country level, the use of dedicated child restraint systems is at $23 \%$ for children under 12 .

\section{Table 41.6. Seat belt wearing rate by car occupancy and road type}

\begin{tabular}{lcc}
\multicolumn{2}{c}{$\%$} & 2016 \\
\hline Front seat & 2013 & \\
General & 56.3 & 62.8 \\
Driver & 62.4 & 69.1 \\
Passenger & 56.2 & 62.8 \\
Rear seats & & 33 \\
General & 31.4 & 23 \\
Children (use of child restraint) & - & \\
\hline
\end{tabular}

The use of helmets is compulsory for all moped and motorcycle riders and passengers. In $2016,79 \%$ of motorcyclists involved in a traffic crash used a helmet.

Since 2013, all cyclists must wear a helmet. 


\section{Daytime running lights}

Daytime running lights are mandatory for all motor vehicles. The 2016 observational study revealed that their use increased from 58.4\% in 2013 to $71.3 \%$ in 2016 (UNASEV, 2016).

\section{Distraction}

Since 2013, it is not permitted to drive with a hand-held mobile phone.

The use of the cell phone while driving decreases from 6.2\% in 2013 to $3.4 \%$ in 2016.

\section{National road safety strategies and targets Organisation of road safety}

At a national level, road safety is the responsibility of the National Road Safety Agency, UNASEV, together with the Ministry of the Interior, the Ministry of Transport and Public Works and the Municipal Intendancies.

UNASEV was created in 2007 as a state agency exclusively dedicated to road safety. It answers directly to the President of the Republic. Its mission is to regulate, implement and monitor road safety activities throughout the country. It is also responsible for the development of the national road safety policy. Its objective is to generate a "road safety culture" and encourage social responsibility in both the public and private sectors.

Uruguay has 19 provinces. In these departments, road safety is the responsibility of interdependencies (local agencies) who work closely with national agencies.

Traffic control is the responsibility of the National Traffic Police for national roads working in coordination with the Municipal Transit Police of each municipality for city and departmental roads.

\section{Road safety strategy for 2011-20}

In 2011, Uruguay adopted a new road safety strategy (2011-20), adhering to the UN Decade of Action for Road Safety. It is based on the five pillars of the Action Plan of the UN Decade of action:

- strengthening road safety management

- safer infrastructure

- safer vehicles

- road user behaviour

- post-crash care.

\section{Road safety targets}

The 2011-20 strategy includes as a main objective, a reduction of $50 \%$ in the number of deaths between 2010 and 2020 .

With the collaboration of the 19 departments (intendencies), UNASEV has developed the Action Plan for Road Safety (POSEVI), which is a guide to support the planning and implementation of concrete actions to achieve the 2020 target. This action plan is based on three pillars:

- communication and education

- enforcement of traffic rules

- co-operation with the health sector on preventive measures and post-crash care response. 
Other priority actions include:

- the mandatory installation of advanced braking systems (ABS) on new motorcycles sold

- mandatory electronic stability control (ESC) and ABS on cars and vans.

Figure 41.6. Trends in road fatalities towards national target

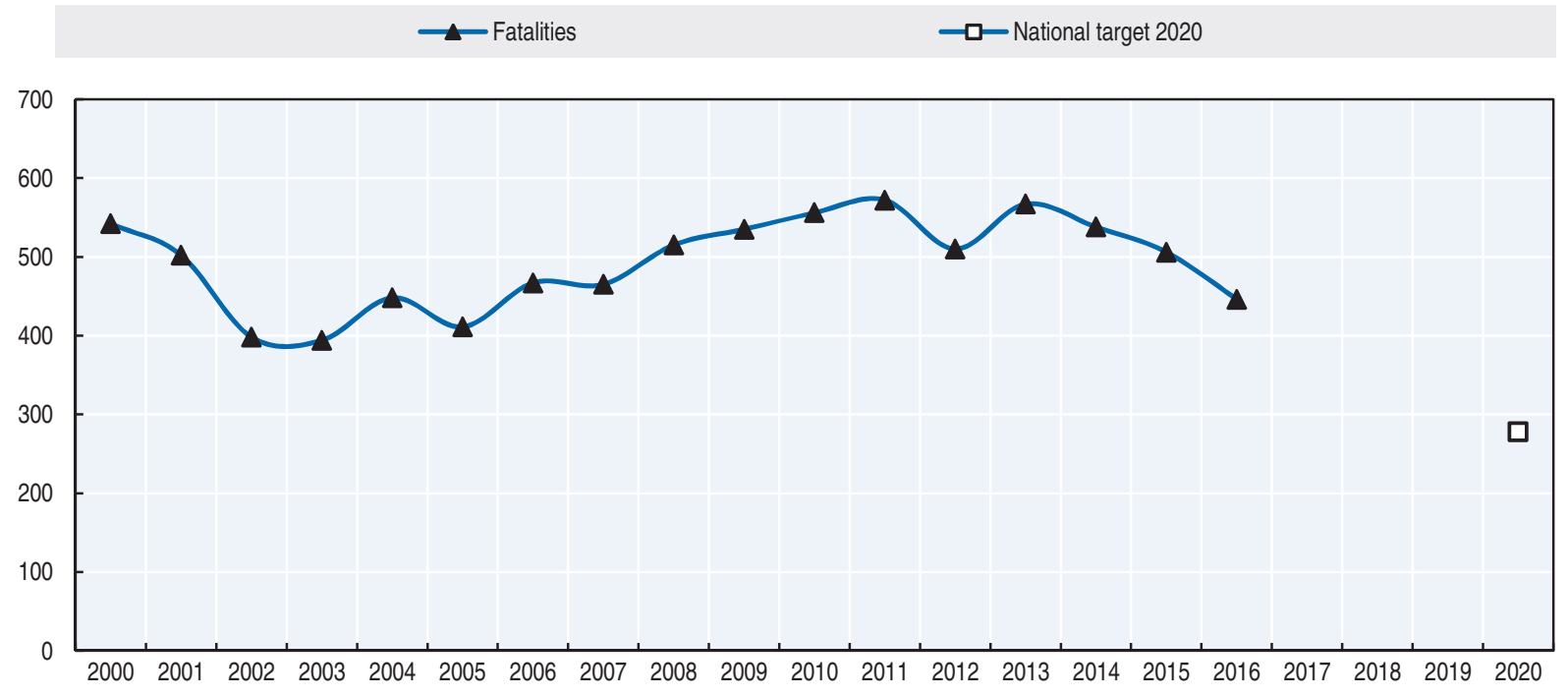

\section{Recent safety measures (2014-17)}

\section{Road safety management}

- 2015: Creation of the National Road Safety Board composed of the undersecretaries of the Ministry of Education and Culture, Ministry of the Interior, Ministry of Transport and Public Works, Ministry of Health, Congress of Intendants and UNASEV, to foster co-ordination and co-operation between the various governmental agencies.

- 2016: Creation of the National Traffic Police.

\section{Speed and traffic management}

- 2016: Launch of the Traffic Management Centre was launched. This includes the implementation of several Intelligent Transportation Systems to manage and monitor traffic in real time in the city of Montevideo. This will allow improvements in traffic dynamics and new information and communication systems for citizens. The system comprises:

* 170 centralised traffic lights

* 160 cameras for vehicle counting

* 49 cameras for traffic monitoring

* 31 speed and red light control points

* 4 variable messaging panels

* 35 wireless sensors for counting.

\section{Drink driving}

- 2015: Adoption of the Zero Alcohol law, which came into force in January 2016. 


\section{Motorcycle safety}

- In the year 2016 UNASEV launched an interinstitutional group to regulate motorcycle deliveries. The result of this joint work is reflected in decree No. 119/2017 dated May 2017, which requires compulsory training for workers on motorcycles, including a certificate of professional training by the competent authority.

\section{Vehicles}

- 2014: All four-wheeled or more motor-powered vehicles that are marketed in the country are required to have ABS brakes, head restraints on all seats, safety belts and front airbags in the front seats.

\section{Recent and ongoing research}

- Observational study on road behaviour in Uruguay in 2016. The UNASEV/OISEVI study conducted by FACTUM monitored the use of safety belts and helmets as well as distracting factors in urban areas. More information is available at: http://unasev.gub.uy/inicio/ sinatran/estudios_observacion/ (accessed 30 June 2017).

- 2016 Barometer Survey: This study consists of a national survey on habits, behaviour and perception regarding traffic and its different components in daily life. The execution of the survey and the subsequent processing of data were carried out by the company RADAR. More information is available at: http://unasev.gub.uy/inicio/sinatran/encuestas_opinion/ (accessed 30 June 2017).

\section{References}

UNASEV (2016), Estudio de comportamiento observacional en Seguridad Vial en Uruguay 2016, http:// unasev.gub.uy/inicio/sinatran/estudios_observacion/ (accessed 30 June 2017).

World Bank (2017), “GDP (constant US\$)”, World Development Indicators, http://databank.worldbank.org/ data/reports.aspx? source=world-development-indicators (accessed 23 February 2017).

\section{Websites}

- National road safety agency, UNASEV: http://unasev.gub.uy/ (accessed 30 June 2017). 



\section{List of members and observers}

\section{Chair: Mr Fred Wegman (Netherlands)}

\begin{tabular}{|c|c|c|}
\hline Argentina & National Road Safety Agency (ANSV) & $\begin{array}{l}\text { Ms Veronica HELER } \\
\text { Ms Eugenia KELLER }\end{array}$ \\
\hline \multirow[t]{2}{*}{ Australia } & Department of Infrastructure and Regional Development & $\begin{array}{l}\text { Mr Tim RISBEY } \\
\text { Ms Katrina CRISTOFANI }\end{array}$ \\
\hline & Australian Road Research Board & Mr Blair TURNER \\
\hline \multirow[t]{2}{*}{ Austria } & Austrian Road Safety Board (KFV) & $\begin{array}{l}\text { Mr Robert BAUER } \\
\text { Mr Klaus MACHATA }\end{array}$ \\
\hline & Austrian Institute of Technology (AIT) & $\begin{array}{l}\text { Mr Peter SALEH } \\
\text { Mr Christian STEFAN }\end{array}$ \\
\hline Belgium & Belgian Road Safety Institute (BIVV - IBSR) & $\begin{array}{l}\text { Ms Nathalie FOCANT } \\
\text { Mr Jean Francois GAILLET } \\
\text { Ms Heike MARTENSEN } \\
\text { Mr Wouter VAN DEN BERGHE }\end{array}$ \\
\hline Cambodia & National Road Safety Committee & $\begin{array}{l}\text { Mr Sattya BORAN } \\
\text { Mr Voun CHHOUN } \\
\text { Mr Davann YUN }\end{array}$ \\
\hline Canada & Transport Canada & $\begin{array}{l}\text { Ms Kim BENJAMIN } \\
\text { Ms Ibrahima SOW } \\
\text { Mr Michael MARTH }\end{array}$ \\
\hline Chile & Comisión Nacional de Seguridad de Tránsito (CONASET) & Ms Carla MEDINA ARAOS \\
\hline Czech Republic & CDV - Transport Research Centre & Mr Jan TECL \\
\hline \multirow[t]{4}{*}{ Denmark } & Road Directorate & Mr Stig HEMDORFF \\
\hline & Danish National Police & Ms Tove HELS \\
\hline & University of Alborg & Ms Camilla SLOTH ANDERSEN \\
\hline & Technical University of Denmark (DTU) & Ms Kira HYLDEKÆER JANSTRUP \\
\hline Finland & Finnish Transport Safety Agency (TraFi) & Ms Riikka RAJAMÄKI \\
\hline \multirow[t]{2}{*}{ France } & Observatoire National Interministériel pour la Sécurité Routière & $\begin{array}{l}\text { Ms Mélanie d'AURIA } \\
\text { Mr Francis BESNARD } \\
\text { Ms Camille PAINBLANC } \\
\text { Mr Thierry ROUSSEAU } \\
\text { Ms Manuelle SALATHE }\end{array}$ \\
\hline & Cerema & $\begin{array}{l}\text { Ms Ruth BERGEL-HAYAT } \\
\text { Mr Laurent CARNIS } \\
\text { Mr Sylvain LASSARRE } \\
\text { Mr Jean-Louis MARTIN } \\
\text { Mr Dominique MIGNOT } \\
\text { Mr Gilles DUCHAMP }\end{array}$ \\
\hline \multirow[t]{4}{*}{ Germany } & Bundesanstalt für Straßenwesen (BASt) & $\begin{array}{l}\text { Mr Andreas SCHEPERS } \\
\text { Ms Susanne SCHOENEBECK }\end{array}$ \\
\hline & German Road Safety Council & Ms Jacqueline LACROIX \\
\hline & German Insurance Association - German Insurers Accident Research & Mr Jean Emmanuel BAKABA \\
\hline & $\begin{array}{l}\text { ADAC } \\
\text { Traffic Accident Research Institute at University of Technology Dresden }\end{array}$ & $\begin{array}{l}\text { Mr Wolfgang STEICHELE } \\
\text { Mr Henrik LIERS }\end{array}$ \\
\hline Greece & National Technical University of Athens (NTUA) & Mr George YANNIS \\
\hline Hungary & KTI Institute for Transport Science & Mr Peter HOLLO \\
\hline Iceland & Icelandic Road and Coastal Administration & Ms Audur Thora ARNADOTTIR \\
\hline
\end{tabular}




\begin{tabular}{|c|c|c|}
\hline Ireland & Road Safety Authority & $\begin{array}{l}\text { Ms Velma BURNS } \\
\text { Ms Sharon HEFFERNAN }\end{array}$ \\
\hline Israel & National Road Safety Authority & $\begin{array}{l}\text { Ms Adina MARCIANO } \\
\text { Mr Assaf SHARON }\end{array}$ \\
\hline \multirow[t]{2}{*}{ Italy } & University La Sapienza & $\begin{array}{l}\text { Mr Luca PERSIA } \\
\text { Mr Davide Shingo USAMI }\end{array}$ \\
\hline & Automobile Club d'Italia (ACI) & Ms Lucia PENNISI \\
\hline Jamaica & Ministry of Transport, Works and Housing & Mr Kenute HARE \\
\hline \multirow[t]{4}{*}{ Japan } & National Police Agency & Mr Masaki OGURA \\
\hline & National Research Institute of Police Science (NRIPS) & $\begin{array}{l}\text { Mr Goro FUJITA } \\
\text { Mr Kenji HAGITA } \\
\text { Ms Kazuko OKAMURA }\end{array}$ \\
\hline & Institute for Traffic Accident Research and Data Analysis (ITARDA) & $\begin{array}{l}\text { Ms Satoko ITO } \\
\text { Mr Toru KIUCHI }\end{array}$ \\
\hline & Kansai University & Mr Mitsuhiro YAMAMOTO \\
\hline \multirow[t]{3}{*}{ Korea } & Korean Road Traffic Authority (KoROAD) & $\begin{array}{l}\text { Ms Hyoung Eun CHO } \\
\text { Mr Daegon HWANG } \\
\text { Mr Euiyong LEE }\end{array}$ \\
\hline & Korean Transportation Safety Authority (TS) & $\begin{array}{l}\text { Mr Byongho CHOE } \\
\text { Mr Minwoo KIM } \\
\text { Mr Sungmin HONG }\end{array}$ \\
\hline & Korea Expressway Corporation & Mr Sun Woong MIN \\
\hline Lithuania & Transport and Road Research Institute & $\begin{array}{l}\text { Mr Mindaugas KATKUS } \\
\text { Ms Natalija GARNELE }\end{array}$ \\
\hline Luxembourg & STATEC & Ms Marie Jo AIROLDI \\
\hline Malaysia & Malaysian Institute of Road Safety Research (MIROS) & $\begin{array}{l}\text { Ms Sharifah Allyana SYED RAHIM } \\
\text { Mr Shaw Voon WONG }\end{array}$ \\
\hline Mexico & $\begin{array}{l}\text { Mexican Transportation Institute } \\
\text { Ministry of Health }\end{array}$ & $\begin{array}{l}\text { Mr Alberto MENDOZA } \\
\text { Ms Laura BAAS }\end{array}$ \\
\hline Morocco & Comité National de Prévention des Accidents de la Circulation (CNPAC) & $\begin{array}{l}\text { Mr Ahmed BARDAN } \\
\text { Mr Benacer BOULAAJOUL }\end{array}$ \\
\hline Netherlands & $\begin{array}{l}\text { Ministry of Infrastructure and the Environment } \\
\text { SWOV Institute for Road Safety Research }\end{array}$ & $\begin{array}{l}\text { Mr Peter MAK } \\
\text { Mr Niels BOS }\end{array}$ \\
\hline New Zealand & Ministry of Transport & Mr Wayne JONES \\
\hline Nigeria & Federal Road Safety Corps & $\begin{array}{l}\text { Mr Kayode OLAGUNJU } \\
\text { Mr Boboye OYEYEMI }\end{array}$ \\
\hline Norway & Norwegian Public Roads Administration & $\begin{array}{l}\text { Ms Guro RANES } \\
\text { Ms Marianne Stølan ROSTOFT }\end{array}$ \\
\hline Poland & Motor Transport Institute & Ms Justyna WACOWSKA-SLEZAK \\
\hline Portugal & $\begin{array}{l}\text { Autoridade Nacional SegurancaRodoviara } \\
\text { APEC Associação portuguesa escolas condução }\end{array}$ & $\begin{array}{l}\text { Mr Helder BATISTA } \\
\text { Mr. Silva ILIDIO }\end{array}$ \\
\hline \multirow[t]{2}{*}{ Serbia } & Road Traffic Safety Agency & $\begin{array}{l}\text { Ms Andrijana PEŠIĆ } \\
\text { Mr Miroslav ROSIC } \\
\text { Mr Jovica VASILJEVIĆ }\end{array}$ \\
\hline & AMSS-CMV Ltd & Mr Dragoslav KUKIC \\
\hline Slovenia & Slovenian Traffic Safety Agency & Mr Andraz MURKOVIC \\
\hline South Africa & Road Traffic Management Corporation & Ms Magadi GAINEWE \\
\hline Spain & $\begin{array}{l}\text { Dirección General de Tráfico (DGT) } \\
\text { RACC Automóvil Club }\end{array}$ & $\begin{array}{l}\text { Mr Gerard AZOR MARTINEZ } \\
\text { Mr Miquel NADAL }\end{array}$ \\
\hline Sweden & $\begin{array}{l}\text { Swedish Transport Agency } \\
\text { Swedish Transport Administration } \\
\text { VTI } \\
\text { Chalmers University of Technology }\end{array}$ & $\begin{array}{l}\text { Ms Karin BENGTSSON } \\
\text { Mr Simon STERNLUND } \\
\text { Ms Anna VADEBY } \\
\text { Ms Helen FAGERLIND }\end{array}$ \\
\hline \multirow[t]{2}{*}{ Switzerland } & Federal Roads Office (ASTRA) & $\begin{array}{l}\text { Mr Philippe BAPST } \\
\text { Ms Iris OBERAUNER }\end{array}$ \\
\hline & Swiss Council for Accident Prevention (bfu) & Mr Steffen NIEMANN \\
\hline
\end{tabular}




\begin{tabular}{lll}
\hline United Kingdom & Department for Transport & $\begin{array}{l}\text { Mr Anil BHAGAT } \\
\text { Mr Stephen REYNOLDS } \\
\text { Ms Elizabeth WLOCH }\end{array}$ \\
& & Mr John FLETCHER \\
& Transport Research Laboratory (TRL) & Ms Terry SHELTON \\
\hline United States & National Highway Traffic Safety Administration (NHTSA) & Mr Umesh SHANKAR \\
& & Ms Carol FLANNAGAN \\
& University of Michigan & Ms Lidia UZIEL \\
Uruguay & Harvard University & Mr Adrian BRINGA \\
European Commission & UNASEV & Ms Maria Teresa SANZ VILLEGAS \\
OISEVI & DG MOVE & Ms Roy ROJAS \\
The World Bank & The Ibero American Road Safety Observatory & Ms Véronica RAFFO \\
& Global Road Safety Facility & Mr Marc SHOTTEN \\
\hline
\end{tabular}

Industry and international non-governmental organisations

\begin{tabular}{ll} 
ACEA - European Automobile Manufacturers Association & Mr Gianfranco BURZIO \\
ACEM - European Motorcycle Manufacturers Association & Ms Veneta VASSILEVA \\
Daimler AG & Mr Jorg BAKKER \\
DEKRA Automobile GmbH & Mr Walter NIEWOEHNER \\
European Transport Safety Council (ETSC) & Ms Graziella JOST \\
FIA & Ms Dovile ADMINAITE \\
FIA Foundation for the automobile and society & Mr Luca PASCOTTO \\
Ford & Ms Rita CUYPERS \\
IMMA - International Motorcycle Manufacturer's Association & Mr Roland SCHAEFER \\
Global NCAP & Mr Edwin BASTIAENSEN \\
Renault & Mr David WARD \\
LAB PSA Renault & Mr Yves PAGE \\
Robert Bosch Gmbh & Mr Nicolas BERTHOLON \\
Together for Safer Roads Coalition & Mr Thomas LICH \\
Volkswagen AG & Mr David BRAUNSTEIN \\
& Ms Stefanie ACHMUS \\
\hline
\end{tabular}

The following national institutes also provide information and data to IRTAD:

\begin{tabular}{lll}
\hline Israel & Central Bureau of Statistics & Ms Tehila KLEIN \\
& & Mrs. Orit YALON-SHUQRUN \\
Finland & Statistics Finland & Mr Matti KOKKONEN \\
Greece & EL.STAT. & Ms Effrosyni CHANTSOULI \\
Iceland & Icelandic Transport Authority (ICETRA) & Mr Gunnar Geir GUNNARSSON \\
Italy & ISTAT & Ms Silvia BRUZZONE \\
\hline
\end{tabular}

\section{ITF-OECD/IRTAD Secretariat}

Ms Véronique FEYPELL-DE LA BEAUMELLE

Mr Stephen PERKINS

Ms Rachele POGGI

Mr Alexandre SANTACREU

Ms Elene SHATBERASHVILI 



\section{ORGANISATION FOR ECONOMIC CO-OPERATION AND DEVELOPMENT}

The OECD is a unique forum where governments work together to address the economic, social and environmental challenges of globalisation. The OECD is also at the forefront of efforts to understand and to help governments respond to new developments and concerns, such as corporate governance, the information economy and the challenges of an ageing population. The Organisation provides a setting where governments can compare policy experiences, seek answers to common problems, identify good practice and work to co-ordinate domestic and international policies.

The OECD member countries are: Australia, Austria, Belgium, Canada, Chile, the Czech Republic, Denmark, Estonia, Finland, France, Germany, Greece, Hungary, Iceland, Ireland, Israel, Italy, Japan, Korea, Latvia, Luxembourg, Mexico, the Netherlands, New Zealand, Norway, Poland, Portugal, the Slovak Republic, Slovenia, Spain, Sweden, Switzerland, Turkey, the United Kingdom and the United States. The European Union takes part in the work of the OECD.

OECD Publishing disseminates widely the results of the Organisation's statistics gathering and research on economic, social and environmental issues, as well as the conventions, guidelines and standards agreed by its members. 


\section{Road Safety Annual Report 2017}

\section{IRTAD: An International Expert Network and Database on Road Safety Data}

The International Traffic Safety Data and Analysis Group (IRTAD) is a permanent working group of the International Transport Forum at the OECD. It is composed of road safety experts and statisticians from renowned safety research institutes, national road and transport administrations, international organisations, universities, automobile associations, the automobile industry, and others from OECD and non-OECD countries. IRTAD's Road Safety Annual Report series provides a yearly overview of road safety performance in member and observer countries. It presents a synthesis of the latest trends in member countries as well as detailed reports for each country, outlining the crash data collection process, the road safety strategies and targets in place. It also provides detailed safety data by road user, location and age together with information on recent trends in speeding, drink-driving and other aspects of road user behaviour.

The IRTAD Road Safety Annual Report 2017 provides an overview of road safety performance for 2015 in 40 countries, with preliminary data for 2016, and detailed reports for each country. It includes tables with cross country comparisons on key safety indicators.

The report outlines the most recent safety data in IRTAD countries, including detailed analysis by road user, age group and type of road. It describes the crash data collection process in IRTAD countries, the road safety strategies and targets in place, and information on recent trends in speeding, drink-driving and other aspects of road user behaviour. The 2017 edition of the IRTAD Road Safety Annual Report puts special emphasis on road safety for an ageing population, which represents a growing concern in many countries.

Consult this publication on line at $h t t p: / / d x . d o i . o r g / 10.1787 / i r t a d-2017-e n$.

This work is published on the OECD iLibrary, which gathers all OECD books, periodicals and statistical databases. Visit www.oecd-ilibrary.org for more information. www.oecd.org/publishing
ISBN 978-92-82-10819-2

752017011 P 